DOE/OR/01-1252\&D2

\title{
Characterization Plan for the Oak Ridge National Laboratory Area-Wide Groundwater Program, Oak Ridge, Tennessee
}

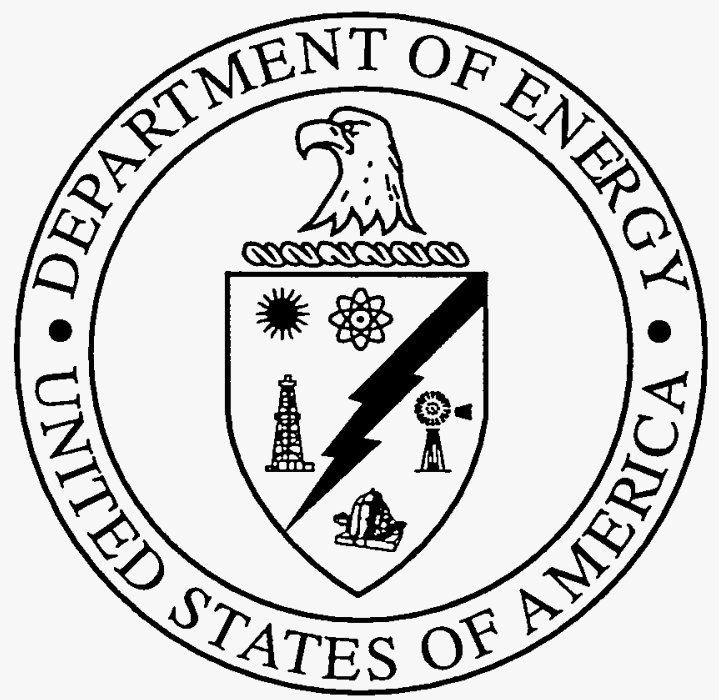


Science Applications International Corporation

contributed to the preparation of this document and should not be considered an eligible contractor for its review. 


\section{DISCLAIMER}

Portions of this document may be illegible in electronic image products. Images are produced from the best available original document. 


\section{RESPONSES TO EPA AND TDEC COMMENTS ${ }^{1}$ OF THE \\ REMEDIAL INVESTIGATION WORK-PLAN FOR THE \\ GROUNDWATER OPERABLE UNIT AT \\ OAK RIDGE NATIONAL LABORATORY}

\section{EPA Comments and Responses}

\section{General Comment, Paragraph 1}

This document represents a strategy for investigations of the overall groundwater system within Melton and Bethel Valleys affected by ORNL and its waste disposal operations. This document is not a remedial investigation work plan and there is no true groundwater operable unit at this time.

The revised document will be submitted as the Characterization Plan for the ORNL Area-Wide Groundwater Program. The ORNL Groundwater OU was established in order to manage and prioritize site-wide groundwater actions.

\section{General Comment, Paragraph 2}

It is useful to refer to the groundwater as a separate unit since ORNL has been partitioned into units (i.e., WAGs) for the purpose of investigations. However, as data is developed for the groundwater system, discrete groundwater actions will be implemented and result in discrete groundwater operable units.

Agree. This document is a plan to guide investigations toward determining specific CERCLA actions for groundwater throughout the ORNL site in a risk-prioritized sequence. Initial characterization work is intended to define discrete areas within the ORNL area-wide GWOU where CERCLA activities will be implemented leading to remediation of groundwater contamination.

\section{General Comment, Paragraph 3}

The site wide data gaps (i.e. exit pathways, deep flow pathway) need to be filled. However, there should be a balance between wide scale investigations and remediation of known contaminant discharges and contaminant plumes. Information gathered as a result of investigations presented in this document should support focused RI work plans to investigate specific releases for remedial action. However, this should not preclude groundwater investigations and remediation for currently known releases.

Agree. The response to the previous comment identifies the strategy for groundwater CERCLA actions.

\section{General Comment, Paragraph 4}

General data needs consistent with the requirements of DOE's internal groundwater monitoring orders should be addressed and funded through other means such as DOE's comprehensive groundwater monitoring program.

The ORNL Office of Environmental Compliance and Documentation (OECD) is charged with the responsibility for monitoring activities required and recommended under DOE Orders. Groundwater data and surface water data collected by the Office of Environmental Compliance and Documentation have

\footnotetext{
${ }^{1}$ Comments are keyed exactly as shown on original documents from EPA and TDEC.
} 
been used extensively in the planning process for the Characterization Plan for the ORNL Area-Wide Groundwater Program as well as in other Environmental Restoration Program activities. The ORNL OECD presently fulfills all agreed requirements included in the Environmental Monitoring Plan for the Oak Ridge Reservation (DOE/OR-1066). Additional characterization investigations proposed in the Characterization Plan for the ORNL Area-Wide Groundwater Program are designed to complement the monitoring activities of OECD and enable management and remediation of contaminated groundwater at ORNL.

\section{Document Disclaimer}

The disclaimer used in this document is inappropriate. The second and fourth sentences must be deleted. The information must be accurate, complete, useful, and must reflect the views and opinions of DOE.

The wording for this standard DOE disclaimer currently is being reviewed; in the meantime, the disclaimer will be omitted from this document.

\section{Executive Summary}

EPA agrees with DOE that this document reflects an overall groundwater strategy document for understanding broad issues relating to groundwater rather than a remedial investigation work plan. However, the investigation of the broad issues should occur through DOE's comprehensive groundwater monitoring program which is required under DOE Orders and the Tennessee Oversight Agreement. These broad issues should have already been addressed or have had investigations started under the comprehensive groundwater monitoring program rather than a remedial program that should be focused on remedial activities.

EPA and TDEC should have some level of involvement in formulating objectives for the comprehensive program that would be directly related to the DOE Environmental Restoration Program. However, ER funds should be used to support remedial investigations that will lead to specific remedial actions. DOE has identified a number of areas at ORNL with known groundwater contamination with levels exceeding $M C L G s, M C L s$, or other ARARs. All of these areas may potentially require remediation. Additional emphasis needs to be placed on implementing groundwater remedial action, either through interim or final RODs.

Please see response to EPA General Comment (Paragraph 2) regarding DOE's site-wide GWOU characterization strategy that will lead to implementation of CERCLA actions on discrete groundwater management units.

The ORNL OECD performs environmental monitoring under the framework of the Environmental Monitoring Plan for the Oak Ridge Reservation. EPA and TDEC review and comment on that monitoring plan annually. Monitoring activities performed by ORNL are those identified in the preparation of the Environmental Monitoring Plan. (Also please see response to EPA's General Comment, Paragraph 4.)

Please see response to EPA comment (Chapter 2, Page 2-26, Bullet Items) regarding WAG 3 and WAG 4 investigation activities directed at facilitating remedial action(s) within these areas. 


\section{Chapter 1, Page 1-7, Last Paragraph}

How do DOE's internal orders requiring comprehensive groundwater monitoring relate to the stated goal of a "site-wide appraisal of the groundwater flow and contaminant transport conditions throughout the extent of the ORNL GWOU."

The ORNL Office of Compliance and Documentation performs monitoring in accordance with the agreed upon scope in the Environmental Monitoring Plan for the Oak Ridge Reservation (DOE/OR1066), which is reviewed annually by DOE, EPA, and TDEC.

\section{Page 1-13, Figure 1.4}

As remedial decisions are made for specific operable units, wherever possible, those decisions will be final for that unit, not interim. By properly scoping and defining the operable unit and its relationship to the site, final decisions may be made for each operable unit prior to completing an assessment of every potential unit.

The boxes in the diagram that refer to interim RODs for individual sites will be changed to final RODs. This is a flow diagram, not a time diagram. Source OU activities are programmed in a staggered fashion. The figure caption will be changed to say, "Flow diagram showing ...."

\section{Page 1-14, Section 1.10.1}

Decisions documented in proposed plans and RODs will address the levels of remedial action or risk management required. The RI and FS should present unbiased factual statements regarding the nature and extent of contamination found, the results of the baseline risk assessment, and potential remedial alternatives. The RI and FS should not mix risk management decisions with their analysis of site conditions and what would be required for remediation (alternatives) if site risks exceed the target risk range. It is already known that many contaminants within the groundwater at ORNL exceed established standards such as non-zero MCLGs or MCLs.

The groundwater need not reach "off-site" receptors to require remediation. The decision for remediation does not revolve around selecting the "most cost effective engineering controls, "but an evaluation of alternatives against all of the nine criteria for remedy selection. The threshold criteria, protection of human health and the environment and compliance with ARARs, must be met. Cost is not a threshold criteria.

Text has been revised as follows: "It is expected that a number of groundwater management unit investigations will be conducted that will constitute the ORNL GWOU RI. The scope of this investigation will result directly from the characterization strategy outlined in this document (e.g., see Fig. 1.4). Existing information and data derived during characterization studies will facilitate decisions regarding which discrete groundwater management units pose a potential threat to human health or the environment. Data derived during the subsequent remedial investigation will more fully describe the nature and extent of groundwater contamination at ORNL and from the basis for making risk management decisions and for taking further CERCLA actions."

\section{Page 1-16, 3rd Bullet}

At this point, a ROD has not been issued that established controlled areas where risks would be managed by institutional controls at ORNL.

The phrase "when established" will be added to the end of the 3rd bullet. 
Page 1-18, 1st Bullet

If a contaminated groundwater discharge contributes a significant amount of the contaminant flux at WOD, that discharge should be considered for an expedited response action such as a time-critical removal action or interim remedial action.

This bullet will be rewritten to indicate that if a groundwater discharge contributes $10 \%$ or more risk based on strontium-90 flux (1993 monitoring data) at WOD, that discharge will be considered for an expedited response action such as a time-critical removal action or interim removal action.

\section{Page 1-18, 3rd Bullet}

The BRA and FS must address all groundwaters where non-zero MCLGs, MCLs, ARARs, or other health based standards are exceeded. Risk assessment and alternatives development are done in the RI/BRA/FS. Risk management is done through the proposed plan and ROD.

Agree.

\section{Chapter 2, Page 2-26, Bullet Items}

A non-time critical removal action is being prepared to address the continuing release of Sr-90 into First Creek. It appears that there are other areas, such as WAG 3, where expedited response actions could be implemented. What steps are being taken or are planned to mitigate ongoing releases from WAG 3 as well as other releases not mentioned here.

Additional data are being collected to quantify releases from WAG 3 in order to determine if expedited action is required. Investigations are underway at WAG 4 to determine the feasibility of controlling discrete contaminant sources.

\section{Page 2-29, Paragraph 3}

It is stated that the groundwater velocities "cannot adequately be explained at present". Based on the discussion here and on the preceding page under Sec. 2.3.3.7, with "fractured" aquifers, is it really possible to model the groundwater with 3-D models, for example, as outlined in later sections.

Also, later in this paragraph, it is "hypothesized" about the major groundwater flow that is suspected. With all of this uncertainty, and based on all the studies of the Oak Ridge hydrogeology over the last 3 decades, can we really expect to achieve more definitive, quantitative results with the proposed future modeling of the fate and transport of contaminants? Can you provide discussion on the uncertainty of the groundwater flow and transport that is anticipated to remain after the modeling effort has been completed?

The information in this paragraph is needlessly complicated and tends to detract from the objective of the document, which is to present a general strategy for characterizing contaminant migration via groundwater at ORNL. Therefore, this paragraph will be deleted from the revised document.

\section{Page 2-33, Section 2.3.5, Paragraph 3}

Have any evaluations of the water balance for WOC been conducted since 1988 to verify the losing stream analysis?

No detailed water budget analysis has been performed since 1988. However, surface water flow data are reviewed and reported in the annual hydrologic summary report (i.e., Borders et al. 1993. 
Hydrologic Data Summary for the White Oak Creek Watershed at Oak Ridge National Laboratory, Oak Ridge, Tennessee, ORNL/ER-166). Under low-flow conditions, surface water data show a discrepancy in flow between the 7500 bridge site and the White Oak Creek station at the confluence with Melton Branch. The cause of this apparent loss in flow volume is still unknown.

\section{Chapter 3, Page 3-57, Section 3.8.1.8}

No date was given for when these leaks occurred or remediated. This also applies to Sections 3.8.1.9 and 3.8.1.10.

Information presented in Sections 3.8.1.8, 3.8.1.9, and 3.8.1.10 was derived from the Preliminary Geohydrologic Site Characterization and Proposed Water Quality Well Locations for WAG 7, WAG 8, and WAG 9 (ORNL/RAP/Sub-86/72139/2), which was the only available source of information about the leak sites described in these sections. This reference did not contain any information concerning the times when the described leaks occurred, or the types of remedial actions implemented.

\section{Page 3-58, Section 3.8.1.11}

It is stated that the blasting sand located outside of the building has a on contact exposure rate of $2 \mathrm{mR} / \mathrm{hr}$. When was this site in use and how long has this contaminated blasting sand been exposed to the open environment? What steps have been taken to minimize the potential for spreading of this contaminated material.

Information in Section 3.8.1.11 was derived from the Preliminary Geohydrologic Site Characterization and Proposed Water Quality Well Locations for WAG 7, WAG 8, and WAG 9 (ORNL/RAP/Sub-86/72139/2), which was the only available source of information about the Building 7819 facility described in this section. This reference did not contain any information concerning the time period over which the blasting sand was exposed in the open environment, or actions taken to contain the contaminated material. Further record checks would be required in order to determine dates and durations.

\section{Page 3-79. Section 3.11.1.2}

Did the basic composition of the waste change between the time injections were conducted at the Old and New Hydrofracture facilities? OHF waste was primarily Cs-137 (609,000 Ci) while NHF was primarily Sr-90 (644,000 Ci).

Waste injected at the OHF was evaporator-concentrated LLW from the Bethel Valley waste storage tanks that contained a higher activity of Cs-137 $(609,000 \mathrm{Ci})$ compared to $\mathrm{Sr}-90(40,000 \mathrm{Ci})$. Waste injected at the NHF was concentrated LLW and sludge removed from the gunite tanks in the South Tank Farm that contained a higher activity of Sr-90 (644,000 Ci) compared to Cs-137 (83,800 Ci).

\section{Page 3-83, Section 3.13.2.2}

VOC concentrations well above MCLs have been found in groundwater at this WAG. This WAG is located apart from the main cluster of waste sites at ORNL. What efforts have been made to identify the scope and magnitude of this release? What would be the expected flow pathway and discharge point for groundwater in this area?

Information presented in Section 3.13.2.2 was derived from the Preliminary Geohydrologic Site Characterization and Proposed Water Quality Well Locations for WAG 17 and Lower WAG 2 (ORNL/RAP/Sub-86/189/1). This reference did not contain any information concerning the extent of contamination detected in monitoring wells located within the area. Presently, there are no ongoing 
monitoring activities at WAG 17 other than routine well sampling. Although contaminant transport occurring in bedrock along strike-oriented solution channels may be occurring at WAG 17 as observed at WAGs 1 and 3, additional investigation is required to confirm the nature, extent, and transport mechanisms for contamination present at WAG 17.

\section{Chapter 4, General}

The need for acquiring information necessary for fate and transport models needs to be balanced with selecting and implementing response actions as soon as sufficient information is available. This site has been studied for many years and there still are, and probably always will be, data needs and uncertainties. However, there are also many sites where areas of groundwater contamination are documented and may require remediation. A balanced approach must be taken to resolve larger questions, such as a deep flow pathway, and institute response actions for known contamination as soon as practical.

We agree that needs must be balanced. Fate and transport modeling will be conducted in support of RI/FS activities to estimate the effectiveness of particular remedial actions. These modeling efforts, however, will not preclude remediation of known regions of contaminated groundwater. Contingencies for prompt response actions are built into this document. Additionally, the level of effort for acquiring information necessary for fate and transport models is minimal.

Page 4-1. Last Bullet

The "uncertainties inherent" should include the fractured geology. Long-term migration prediction for ORNL may be impossible. This should be discussed.

The bullet is written in the context of attempting to quantify uncertainties. Text will be added at the end of the bullet to say, "... and to quantify the uncertainties in such model predictions."

\section{Pages 4-5 and 4-6. Sections 4.1.1 and 4.1.2}

The FRAC3D model is very new, and assumed to be untested. Will this model be compared against other fracture flow models or non-fracture flow models, when running the two test cases?

The results of FRAC3D will be compared with those of non-fracture flow models such as FEMWATER, MOC, or MODFLOW to verify the mass balance of the model.

\section{Chapter 5, Page 5-1, Section 5.1}

The guidance provided in OSWER Directive \#9283.1-06 regarding "Considerations in Groundwater Remediation at Superfund and RCRA Facilities" (May 27, 1992) should also be an aspect of the overall strategy for groundwater at ORNL.

While some relatively small areas of groundwater contamination (i.e. WAG 17, WAG 3) may not be as significant as ORNL's major sites (i.e., WAG 1, WAG 5), that should not automatically prevent implementing response actions at those sites. Sites have been prioritized by the criteria cited in this section. However, one key to the groundwater strategy should be to contain plumes early. This may mean that a lower priority site gets remediated while a higher priority site is being studied. This may only be appropriate in certain cases. However, the ability to implement quick actions (i.e. WAG 11, WAG 13) for specific goals, needs to be balanced with the needs of the higher profile sites (i.e., gunite tanks, WAG 5) that may take many years and hundreds of millions of dollars to complete.

Agreed. The fourth bullet will read: "identify source control action that results in a significant reduction of risks or contaminant flux, or may prevent the spread of contamination that could lead to significant future risk." 
Page 5-2, Section 5.2.2

The risk assessment must support the decision making process for remedial action. If groundwater discharges to a surface stream within the currently controlled area and results in unacceptable risk from ingestion or contact with that surface stream, would that be covered in the GW risk assessment? This may be a future exposure scenario that may be partially covered if ingestion of the groundwater is considered.

The second paragraph accurately describes the desired approach for evaluating current and future potential risk. However, in all cases a determination must be made if unrestricted access and unlimited exposure is allowable for a site. This is necessary to assess the five-year ROD review requirement.

The information produced by the groundwater and surface water programs is important from both a risk management and assessment perspective. Therefore, any risk information that is identified by decision-makers as necessary to support the remedial decision-making process will be provided. Annual risk assessments will be conducted based on data collected for the surface water and groundwater programs, the results subsequently will be communicated to decision-makers. Risk information based on surface water concentrations mentioned in this comment will be (and is) available as part of the WAG 2 and surface water programs.

In addition, predictive modeling results generated by the groundwater program will be used as concentration terms for groundwater and surface water risk assessments to determine the significance of plumes that are identified. The groundwater risk assessment will treat these plumes as a "source" of contamination. If it is determined that the plume would likely move to surface water, transport to surface water and ingestion of surface water would be evaluated as one of the future risk pathways.

The unrestricted access/unlimited exposure scenario will always be part of the data assessment process. We agree that at any given time in the decision-making process over time at ORNL, it will be important to reevaluate and reiterate the need to prevent high risk exposures.

\section{Page 5-3, Section 5.2.3}

Why is this section titled current COPC's? Will these COPCs address the future potential exposure scenarios? Why was the screening limited to oral carcinogens? Noncarcinogens and pathways other than oral exposure should be considered, as appropriate.

The text in this section has been rewritten to incorporate the comment. This section is titled "current" because the groundwater monitoring at ORNL is a long-term program and delineation of contaminants of concern will be an iterative process that responds to changes in contaminant concentrations in monitored wells over time. Also, as the support that the Groundwater Program provides to the source areas' changes (as represented by near-term support, mid-phase support, and final-phase support), the screening criteria used to determine priority contaminants and areas will change (from prioritization and screening to baseline risk assessment considerations). The "current" COPCs do address future potential exposure. The screening is limited to oral carcinogens at this time because background data for the metals are not currently available. Without the background data, the screen could incorrectly focus efforts on contaminants that are present at naturally occurring levels. Noncarcinogens and pathways other than oral exposure are being considered in new efforts. Dermal contact and inhalation pathways are included in the revised risk tables; the text has been changed accordingly. 
Page 5-4, Paragraphs 2 and 3

Non-detects should not be used in determining average concentrations for data summary tables. Nondetects are considered when calculating exposure point concentrations for the exposure assessment. In exposure assessments, non-detects are considered to be either $1 / 2$ the detection limit or equal to the detection limit.

For screening level assessments, the maximum detected or modeled concentration should be used as the exposure concentration.

For risk assessments the 95 percent upper confidence limit on the arithmetic average is used as the exposure concentration unless that value exceeds the maximum detected value. In that case, the maximum detected or modeled value would be used.

The text in this section has been rewritten to incorporate this and the previous comment. It is standard practice to include non-detects in an evaluation of a statistical distribution and calculation of mean for any reason-whether it be to represent "averages" or estimated exposure point concentrations (which should be based on the same approach). For a normal distribution, the average and the midpoint value (the 50th percentile of the data set) should be similar. If non-detects are not accounted for, the average value would be greater-and in some cases much greater than the midpoint. If the belowdetection-limit data were ignored in the assessment, the average would be biased high. Over the years, numerous checks have been run to show that for a normal distribution of data, use of one-half of the detection limits gives a good approximation of the distribution of data below the detection limit, and therefore leads to a good estimate of the average.

The statistical treatment of the exposure concentration in the revised tables is based on baseline risk assessment considerations rather than the previous comparative screening emphasis (using the average). EPA guidance (RAGS 1989) recommends using either one-half of the detection limit or the detection limit as the proxy value for non-detects. The revised tables presented in this final version of the characterization plan use the detection limit as the proxy value.

For the revised tables, after non-detects are assigned the detection limit value, a test for normality and log-normality is performed using the Kolmogorov-Smirnov Test. If a normal distribution provides the better fit based on this test, then the upper $95 \%$ confidence limit on the mean is calculated based on a normal distribution (EPA Supplemental Guidance). If the underlying distribution is not normal, as represented here for when a log-normal distribution provides a better fit based on the test, then replacing censored observations by proxy values is an inefficient method that can produce biased estimates. In this case the log-normal distribution is estimated through a maximum likelihood procedure that finds the mean and standard deviation of the distribution by methods in Beauchamp (et al. 1992) to reduce the bias in proxy methods for the mean for small sample sizes. The upper $95 \%$ confidence limit on the mean is then calculated based on this estimated log-normal distribution (EPA Supplemental Guidance). The minimum of the upper $95 \%$ confidence limit and the maximum detected concentration are used as the exposure concentration.

\section{Page 5-4, Last Paragraph}

10E-04 was used as the criteria for the target risk. EPA uses a target risk range of IOE-06 to 10E-04. At the screening stage a risk level of 10E-06 should be used.

The baseline risk assessment will use $1 \times 10^{-6}$ as a screening level. For purposes of strategy development, $1 \times 10^{-4}$ was used to focus on the primary contaminants and locations that may necessitate 
a risk-based early cleanup and to support the goals of the near-term and mid-phase risk support. The use of $1 \times 10^{-6}$ does not provide a focus for identifying action sites and contaminants at this time.

\section{Page 5-5. Table 5.1}

This table does not appear to be complete. For example, VOC's detected at WAG 17 at levels well above the MCL are not included in the table.

This table should also include background concentrations for the COPCs and frequency of detection.

All tables presented in Chapter 5 have been revised to reflect the incorporation of site-wide data.

\section{Page 5-6, Table 5.2}

This table does not show which chemical is responsible for the majority of the risk associated with each well as stated on page 5-4.

The text in Sect. 5.2.3 has been revised and new tables were added. Table 5.4 presents the chemicals responsible for the majority of the risk.

\section{Appendix A}

This analysis used the average concentration for the concentration-toxicity screening. The maximum detected value for each chemical should be used instead of the average concentration. (See Page 5-24 of "Risk Assessment Guidance for Superfund: Volume 1 Human Health Evaluation Manual (Part A)") The frequency of detection for individual wells shows inconsistency in results, especially for beryllium. If data from different sampling dates were combined, contaminant migration should be considered. If this is the case, it is especially important not to screen by average concentrations in the concentration-toxicity screening phase.

Specify units for the PRGs (which should equate to a 10E-06 risk) and for concentrations (which should be the maximum value detected).

The concentration results over time indicate that a number of constituents (e.g., beryllium) had their maximum detection early in the RCRA compliance program. More recent sampling for these constituents indicate lower concentrations or non-detects. Identification of these trends in discrete areas is one of the goals for continued work in the Area-wide Groundwater Program. No clear quantitative guidance is currently available from EPA on how to handle significant changes in the concentration over time. Near-term efforts will focus on identifying contaminant trends within wells and within identified plumes so that significant changes in concentration will serve as a justification for truncating the number of observations or the amount of time that is used to determine the exposure concentration. The revised tables in Appendix A use all of the currently available data to calculate the concentration term.

\section{Page 5-8, Paragraph 3}

It should also be noted that, as shown in Figure 5.1, every WAG exceeds the screening risk level of IE-06 and the upper bound of the target risk range, $1 E-04$, based upon the methodology used. If similar results occur at the end of the baseline risk assessment, the baseline risk assessment would indicate that every WAG would require remedial action to address risks associated with the groundwater.

The risk screening was performed to identify the most problematic areas of the site, using risk as the only criteria. Because the screening attempts to identify which wells (and areas of wells) are potentially risky relative to other wells, the only criteria for selecting the land use and exposure 
assumptions are that the same assumptions be used for every well. The only decision being made with these results is "which areas are the most risky relative to other-areas." The comment is correct, if this exercise was used to identify the need for remediation, every WAG would fall at least within the $10^{-6}$ to $10^{-4}$ risk range-the target range for CERCLA actions. However, risk assessment to support the need for action (e.g., the baseline risk assessment) would not necessarily use the same assumptions as used for the risk screen.

For example, the risk screen assumed a receptor would drink 2 liters of water/day from a well. One big issue facing the ORNL Groundwater baseline risk assessment is how to assess the risk from wells and geologic formations that have low water yield rates. The yields are so low in some areas and some depths, wells could not be relied on as a potable water source.

Another major assumption is that the receptor is currently on site. Some of the high risk estimates using this assumption are associated with exposure to volatile organics. The RI could indicate that once the source of the volatiles is controlled, the volatiles in the groundwater will naturally dissipate because of biological degradation or the air-stripping-like action that may be occurring when the shallow groundwater resurfaces in the watershed.

When the baseline risk assessment is performed to identify the potential need for remediation and, more importantly, when the risk evaluation of remedial alternatives is combined with other CERCLA decision criteria to select alternatives, the risk management decision may not identify the need for remediation at every WAG.

\section{Page 5-8, Section 5.2.4}

Do the shallow or deep aquifers underlying ORNL meet the definitions of an actual or potential drinking water source as defined by EPA or TN?

The State of Tennessee has recently issued a proposed definition for aquifer classification under Chapter 1200-4-3-.04 of TDEC regulations. The proposed regulations received extensive comments and are currently being revised. Frequent discussions with the State indicate that the groundwater underlying ORNL will likely be classified as a Class B aquifer-a "potential" drinking water source that cannot be used for drinking water because of contamination. As stated in Sect. 5.6, the ORNL GWOU has not been given an EPA classification.

\section{Page 5-10, Section 5.3}

In general these assumptions are acceptable as a strategy to evaluate risk and prioritize activities without duplication of effort. However, it should also be noted that the lack of a "current risk issue to address" (assumption 4) does not mean the lack of a need for emphasis on remedial action as discussed in the last paragraph on page 1-2. As shown in figure 5.1 all WAGs exhibit unacceptable risk levels.

Based on contaminant concentrations and fluxes to surface water systems, the ORNL area groundwater presently has a lower priority than either source WAGs or associated seeps. Prioritization will focus RI/FS activities on groundwater plumes that pose the greatest risk. 


\section{Page 5-11, Figure 5.2}

The institutional control scenario with receptors outside of the current DOE boundaries would essentially sacrifice the areas groundwater resources to potential beneficial uses. As discussed in the Preamble to the NCP, EPA expects to return groundwaters to their beneficial uses. The use of institutional controls shall not substitute for active response measures as the sole remedy unless such active measures are determined not to be practical, based on the balancing of trade-offs among alternatives that is conducted during selection of remedy. $(\$ 300.430(a)(1)(i i)(D))$

Agree. Over the long term, returning water to its beneficial use is the goal of the ORNL Areawide Groundwater Program. However, further policy decisions and site characterization work are necessary to determine what that beneficial use is. In the near term, resources should be directed to actions that will ensure protection of human health and the environment, including actions that could stop the spread of contamination that could move off site. When pertinent RIs and FSs have been completed and RODs issued, it will be determined whether groundwater remediation is technically practical on a case-by-case basis and, at that time, institutional controls may be implemented where appropriate.

\section{Page 5-12, Section 5.4, Paragraph 1}

EPA totally agrees with this paragraph. TDEC will also be involved in the policy decisions along with $D O E, E P A$, and the public.

Inadvertent omission. "TDEC" will be added to the text.

\section{Page 5-12, 1st Bullet}

The criteria specified in the NCP for determining the need for a removal action $(\$ 300.415(b))$ should be used in this determination. Exceeding a PRG alone does not trigger the need for a CERCLA removal action.

Agree. The bullet will be revised to read: "provide risk assessment input into the decision for the need for a CERCLA removal action according to the criteria described in the National Oil and Hazardous Substances Pollution Contingency Plan, §300.415."

\section{Page 5-15, Section 5.4.3, Paragraph 2}

Any residuals present in "no action" areas should be included, along with remediation residuals, in evaluating risk. The "no action" source WAGs are not likely to be at "zero risk" either.

Agree. The text will be revised to read: "This risk assessment must compile a post-remediation report of residual risk associated with "no action" sources and post-remediation residual risks remaining after engineering controls have been implemented." 
Page 5-18, Table 5.4

Is Co- $\underline{61}$ is the correct radioisotope? Strontium isotopes should be listed separately. Were all previous strontium data analyzed as total? Is there any way to differentiate Sr-90, -89, etc.?

The proposed MCLs for radionuclides (FR 7/18/91) should be listed here. The 4 mremlyr limit is as footnote " $c$ " indicates, but it is a little misleading when one radionuclide MCL is listed and the others aren't. Since the anticipated date for the final rule is April, 1995, it would be prudent to list the proposed MCL levels specifically:

$\begin{array}{lll}\text { Co-60 } & - & 218 \mathrm{pCi} / \mathrm{l} \\ \mathrm{Sr}-89 & - & 599 \mathrm{pCi} / \mathrm{l} \\ \mathrm{Sr}-90 & - & 42 \mathrm{pCi} / \mathrm{l} \\ \mathrm{H}-3 & - & 60,900 \mathrm{pCi} / \mathrm{l} \text { (this may have been changed to } 69,000) \\ U-234 & - & 13.9 \mathrm{pCi} / \mathrm{l}\end{array}$

Reference to Co-61 is typographical error that has been removed from the document. The specific isotopes of strontium that are COPCs for the OU are not known, although they are assumed to be $\mathrm{Sr}-90$ and $\mathrm{Sr}-89$.

The MCL for radionuclides is a dose-based MCL, not a concentration-based MCL. Various assumptions must be used to convert the total dose into isotope-specific concentrations. This also involves understanding how many different radionuclides are present and may contribute to the total dose limit. At this point in the ORNL Area-wide Groundwater Program characterization process, we believe it is more prudent to list the ARAR as it stands in the regulations, not an interpretation of the ARAR.

\section{Chapter 6, Section 6.2}

In Section 6.2 different methods of evaluating aquifer parameters or hydraulic connections within an aquifer or between aquifers are discussed. Section 6.2.4 proposes to use pulse tests to evaluate hydraulic connections during this investigation. Otherwise, Section 6.2 does not propose to use any specific method or combination of methods to evaluate aquifer parameters. Despite the statement in the introductory part of Section 6.2 that the section summarizes the data gaps concerning hydrologic properties of the various formations of concern, the text does not mention the existing hydraulic parameter database, which is no doubt extensive. In is unclear from this discussion what is needed overall to close data gaps at ORNL. Another statement should be added that hydrologic parameter studies in specific areas will be tailored to address specific data gaps at each specific area of investigation. The use of pulse tests has the drawback of potentially driving groundwater contaminants further away from source areas. While this situation would probably be insignificant at this site, the proposal for this pulse test procedure in Section 6.2.4 is very open ended, and the magnitude of such tests is unspecified. More information about the magnitude and potential adverse effects of the pulse tests should be provided.

This section is designed to list the types of test methods that will be used to address data gaps that were identified in Section 2.4.6.2; it is not intended to be a sampling and analysis plan. As the reviewer states, the methods used to evaluate aquifer parameters or hydraulic connections will be tailored to address the specific data gaps at each specific area of investigation.

Any aquifer test has the potential to move contaminants in the subsurface depending on local aquifer properties, volume of water moved, and duration of the test. Pumping tests of long duration have the potential to move contaminated groundwater further than short duration pressure pulse tests, which could be useful in defining the zone of influence of a groundwater extraction project. 


\section{Page 6-19}

The plan states that the geochemical monitoring is to be based upon the COPC list. Full TAL/TCL analyses should be conducted on a portion of the sample locations for groundwater, surface water, seeps, and spring samples.

Agree. The text will be changed to indicate that at least $10 \%$ of all samples collected for geochemical analysis will be analyzed for contaminants that will require the full TAL/TCL.

\section{Chapter 7, Page 7-1, Section 7.1}

Many, if not all, of the nonintrusive activities should have been conducted as part of the preparation of the groundwater work plan. The three parties of the FFA have generally agreed that nonintrusive activities do not need specific approval from TDEC or EPA.

Considering the number of years that this site has been studied, the first 18 months of the investigation should consist of more than historical data review, on-going monitoring of existing wells, seep sampling, and geophysical investigations. Areas that may be appropriate for interim or final remedial actions should be highlighted and investigated to proceed to remedy selection.

Agree. It is true that a number of studies have been conducted previously at ORNL. However, in order for potential RI activities to occur effectively and efficiently, it will be necessary to compile data from these many disparate sources and collect new data to fill data gaps. One purpose of the initial characterization efforts will be to highlight areas that are appropriate for interim or final remedial actions. As these areas are identified, DOE will make recommendations for CERCLA actions and begin formal interaction with EPA and TDEC to prioritize investigations.

\section{Page 7-14, Section 7.5.5}

It is good that this area is highlighted due to the possibility for off-site transport of contaminants. $A$ primary goal should be establishing an understanding of the nature and extent of contamination to support alternatives development.

We agree that establishing an understanding of the nature and extent of contamination at WAG 3 should be a primary goal. Section 7.5.5 was written with the intent of establishing such an understanding. The text will be revised to clarify DOE's intent.

\section{Chapter 8, Page 8-15, Section 8.3.6}

Blanks should be made of organic free water, not distilled or deionized water. Preservative blanks should be collected for $Q A / Q C$ purposes.

Agree. Text will be revised to indicate that blanks will be made of organic free water. Certificates of analysis are obtained for the preservatives that are used. 


\section{TDEC Comments and Responses}

\section{General Comment}

This document describes site investigations within the Groundwater Operable Unit which will enhance DOE's ability to initiate a CERCLA action. However, it does not seem to provide the normal amount of $R I$ data necessary to support a feasibility study. The State concedes that site wide data gaps, such as exit pathways, need to be filled, and information gathered as a result of this document should support focused $R I$ work plans. However, because it will not supply enough data to support a feasibility study, this document should not be presented as a RIWP at this time.

The revised document will be submitted as the Characterization Plan for the ORNL Area-Wide Groundwater Program. The ORNL ER Program has established a groundwater OU for managing and prioritizing site-wide groundwater actions.

\section{Document Disclaimer}

The disclaimer used in this document is inappropriate. The second and fourth sentences should be deleted. The information must be accurate, complete, useful, and must reflect the views and opinions of DOE.

The wording for this standard DOE disclaimer currently is being reviewed; in the meantime, the disclaimer will be omitted from this document.

\section{Executive Summary, Page xvii}

The first paragraph states that a review of historical data will take place during the first 18 months of $R I$ work. The review of historical data should take place before the development of the RI Work Plan in order to maximize the efficiency and effectiveness of the RI.

Under DOE's current strategy for characterization of the ORNL GWOU, review of historical data will be conducted in conjunction with characterization work and will precede any RI work.

\section{Section 1.3, Lines 3 and 4}

The presumption that the groundwater divide is the same as the surface water divide is a questionable assumption based upon information being gathered from Well 883 and the Corehole 8 investigation.

The presumption is presented here as an introductory comment. It is explicitly stated in Section 2.4.3.1 that this presumption will be tested during characterization of the divide.

\section{Section 1.3, Paragraph 1}

The Fleenor formation of the Chickamauga Group has been designated as a member of the Lincolnshire formation and the spelling disagrees with the spelling in other areas in the document (page 2-10)? Is the correct spelling Fleenor or Fleanor, and is it a member of that formation?

The Fleanor is a member of the Lincolnshire Formation and the text in Section 1.3 will be changed to reflect this. The discussion of the Chickamauga Group in Section 2.2.2.4 correctly identifies the Fleanor as a member of the Lincolnshire Formation. 
According to Hatcher et al. (1992), the correct spelling is Fleanor and all references to it will be spelled as such.

Page 1-10, Section 1.9

The anticipated year of completion of this GWOU remedial investigation is 2008. How was this date determined, and does DOE expect to proceed with a feasibility study at the completion of the RI?

At the time that the GWOU RI Plan was prepared (Winter 1993), the anticipated year of completion for the GWOU RI (2008) was set to coincide with the projected year of completion for the WAG 2 RI. This was based on a general strategy of dealing with contaminant source areas prior to focused activities on the integrator OUs at ORNL (i.e., WAG 2 and the GWOU). As discussed at the June 1994 regulatory working group meeting, the revised approach for the GWOU investigation will involve conducting initial area-wide characterization/scoping studies. As data are developed through these general studies, discrete groundwater management units will be identified. CERCLA-based actions (RI, FS, PP, ROD, RA) will then be initiated on those discrete management units as necessary. Uncertainties regarding the extent of existing groundwater contamination, contaminant sources, contaminant transport, and exit pathways make it difficult to provide a firm schedule at this time for the GWOU area-wide characterization and subsequent discrete actions. It is very likely that some form of an FS will follow.

Page 2-1, Sections 2.1 and 2.1.1

It is stated in Section 2.1 that hydrologic properties of the Knox Group make it an effective barrier to groundwater. Section 2.1.1 then states that because of the Knox Group's susceptibility to chemical weathering, it often exhibits Karstic features. These two statements are inconsistent, please explain.

Knox Group outcrop areas on Chestnut Ridge and Copper Ridge are groundwater recharge areas and occur at elevated topographic positions relative to ORNL contaminant sources. The conceptual model for groundwater movement beneath Chestnut Ridge includes recharge via infiltration through the soil mass and directly into karst features with subsequent flow through karst hydrologic features to discharge at springs located near the Knox/Chickamauga contact at the northwestern edge of Bethel Valley and/or flow along strike within the Knox to discharge via streams or submerged springs to the Clinch River. This conceptual model of hydrogeology for Chestnut Ridge and Bethel Valley suggests that the Knox aquifer northwest of and beneath Bethel Valley should be under elevated head pressure relative to the region in Bethel Valley where ORNL contaminant sources lie, therefore minimizing the likelihood that groundwater from Bethel Valley could flow into the Knox aquifer. The conceptual model for groundwater flow in the Knox beneath Copper Ridge includes recharge via infiltration through soil and karst features into the Knox/Maynardville aquifer with flow via karst hydrologic features to streams and springs discharging to White Oak Creek and the Clinch River. Some groundwater discharges into Melton Valley via spring discharges near the base of the Maynardville Limestone (possibly because of the lower permeability of the underlying Nolichucky Shale); however, most of the recharge on Copper Ridge apparently flows down dip and along strike to discharge into Melton Hill Reservoir or into the Clinch River. Again, the elevated topographic position of the Knox on Copper Ridge relative to Melton Valley is assumed to prevent groundwater from flowing out of Melton Valley into the Knox aquifer to the southeast of the ORNL GWOU.

\section{Section 2.2.2.1. Lines 6-10}

In reference to the soluble bed(s) in the Rome Formation as referenced in Section 2.2.2.1 and earlier in Section 2.1.3, is the implication that this unit serves as a pressure barrier between valleys based on modeling or is it an assumption?

This is a conclusion based on observation of three multi-zoned, hydraulic-head monitoring stations. 
Section 2.2.2.4, Page 2-10

Is the correct spelling of "Edison" as shown in the text or "Eidson" as shown on page 2-11?

The correct spelling is Eidson and will be spelled as such in all appropriate places.

\section{Section 2.2.5}

$12 \%$ of wells intersecting cavities having a mean dimension of $1.8 \mathrm{ft}$. should be considered to be quite significant. This number is large compared to the predicted percentage of .04\% for conduit intersection in Karst terrains given by Quinlan and Ewers, 1985 (in Groundwater Flow in Limestone, 5th National Symposium Aquifer Restoration and Groundwater Monitoring, pp. 197-234).

Agree. Solution cavities in karst comprise a significant factor in groundwater flow in the ORR. Language in the text will be revised to indicate its importance.

\section{Page 2-20, Section 2.3.3.1}

Further explanation should be given to explain how "opposite changes in hydraulic gradient and saturated thickness" occur from one topographic location to another.

The text will be clarified by stating, "compensating changes in hydraulic gradient ... to another in order to conserve mass in the aquifer."

Page 2-23, Section 2.3.3.2

The dip section shows no fractures normal to bedding - is this an accurate representation?

As stated in the figure caption, the figure is a hypothetical, conceptual representation of fracture density. A statement to this effect will be added to the text.

\section{Page 2-26, Section 2.3.3.4}

Should "biothermal origin" actually be "biohermal origin". If currently correct, please explain the meaning of this term.

The term should read biohermal and the text will be changed accordingly.

\section{Section 2.3.3.7}

The final paragraph of this section implies the absence of rapid groundwater movement except at the base of the Knox (presumably the Maynardville-Copper Ridge contact?). The only evidence in support of this shows flow hypothesis comes from hydraulic conductivity values obtained through conventional borehole tests. It has often been demonstrated that such methods are inadequate to characterize flow in carbonate aquifers (see Quinlan, et. al., II. of Hydraulic Engineering, volume 119, number I2, pp. 1436-1441).

The information in this paragraph is needlessly complicated and tends to detract from the objective of the document, which is to present a general strategy for characterizing contaminant migration via groundwater at ORNL. Therefore, this paragraph will be deleted from the revised document. 


\section{Page 2-43, Section 2.4.6.2. Paragraph 3}

Has there been any attempt to verify the zero natural flow conditions reported by Moore in 1988? If so, please briefly discuss.

No detailed water budget analysis has been performed since 1988. However, surface water flow data are reviewed and reported in the annual hydrologic summary report (i.e., Borders et al. 1993. Hydrologic Data Summary for the White Oak Creek Watershed at Oak Ridge National Laboratory, Oak Ridge, Tennessee, ORNL/ER-166). Under low-flow conditions, surface water data show a discrepancy in flow between the 7500 bridge site and the White Oak Creek station at the confluence with Melton Branch. The cause of this apparent loss in flow volume is still unknown.

\section{Chapter 3}

There are several instances where areas of concern are mentioned without reference to a drawing. Such areas should be referenced in drawings to allow better understanding of the material.

The intent of Chap. 3 is to provide summaries of the results of contaminant source WAG investigations and historical data. Maps presented in Chap. 3 are either reproductions of maps provided in reference documents for this chapter or are maps generated from information contained in the ORNL map data base. The specific areas that are presented on the maps in Chap. 3 are therefore limited to those areas available from these two sources of information.

\section{Page 3-48, Section 3.7.1.1}

Is the use of the term "fissile" meant to describe material which is fissionable or that which is easily split into thin layers?

The term "fissile" as used throughout Chapter 3 describes materials that are fissionable.

\section{Page $3-59$, Section 3.8 .1 .13}

What was the final disposition of the "corehole located 60 meters north of the injection well"?

The well still exists and is listed as inactive in the ORNL data base.

\section{Chapter 4}

The discussion in Section 2.3.3.4 makes a convincing argument that groundwater contaminant pathways may be strata bound or follow structurally related preferential flow paths. Modeling efforts that do not attempt to account for these preferential pathways are likely to provide little information that could be used in a defensible risk assessment or in the choice or design of a remedial action. Verifiable quantitative modeling of this groundwater system may require such extensive data inputs that time constraints or financial resources would make such an effort impossible. For risk assessment purposes, modeling might be most useful as a means of better understanding the range of uncertainty inherent in predicting groundwater pathway future risks.

Agree. The document lays out plans to gather critical information to feed site-specific models that address the dominant flowpaths in order to strengthen remedial designs. 


\section{Page 4-3, Section 4.1.1.1, Part 4}

The conceptual model description does not include mention of conduit flow. Is this concept not considered appropriate for the site?

Testing the site conceptual model will involve investigations of many hydrogeologic heterogeneities that include, but are not limited to, local conductivity contrasts, cavities, and conduit flow. Conduit flow will be added to this section as an important component of the site conceptual model.

\section{Section 7.3.1.1, Last Sentence}

Section 8.5 includes no discussion of other deep wells to be used. Please clarify.

Reference to Section 8.5 is an error. It should be Section 7.5 and the text will be changed accordingly. 
Previously issued as Remedial Investigation Work Plan for the Groundwater Operable Unit at Oak Ridge National Laboratory, Oak Ridge, Tennessee, DOE/OR/01-1252\&D1, ORNL/ER-221\&D1, March 1994

Energy Systems Environmental Restoration Program

ORNL Environmental Restoration Program

\section{Characterization Plan for the Oak Ridge National Laboratory Area-Wide Groundwater Program, Oak Ridge, Tennessee}

Date Issued-August 1994

Prepared by

Science Applications International Corporation

Oak Ridge, Tennessee under contract 95B-99069C-X01-106

Prepared for

U.S. Department of Energy

Office of Environmental Restoration and Waste Management

under budget and reporting code EW 20

OAK RIDGE NATIONAL LABORATORY

Oak Ridge, Tennessee 37831-6285

managed by

MARTIN MARIETTA ENERGY SYSTEMS, INC.

for the

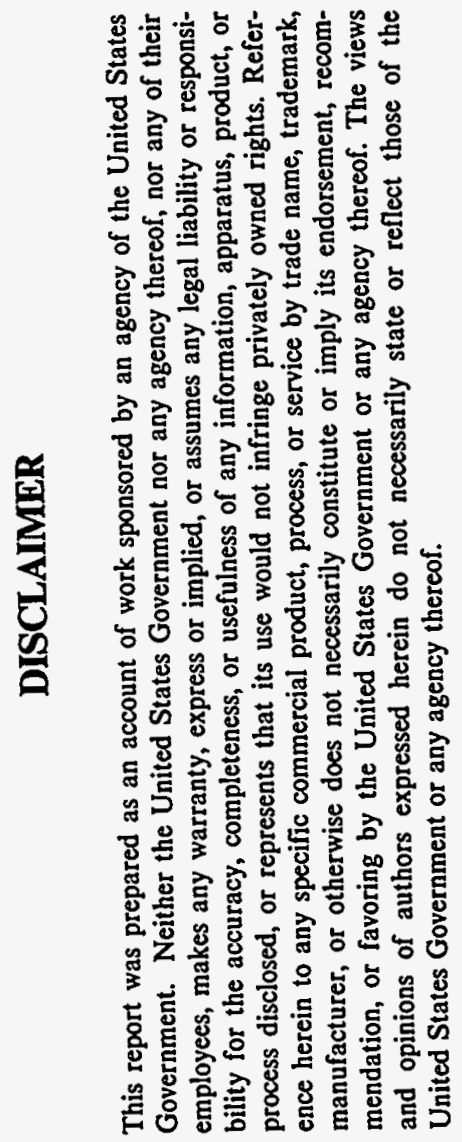

U.S. DEPARTMENT OF ENERGY

under contract DE-AC05-84OR21400 
: $, \cdots, \ldots, \cdots, \ldots, \ldots+\infty$ 


\section{CONTENTS}

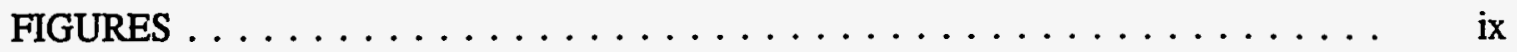

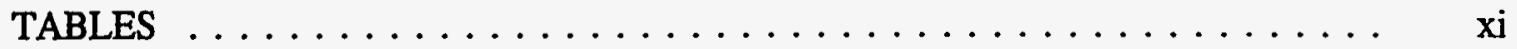

ACRONYMS $\ldots \ldots \ldots \ldots \ldots \ldots \ldots \ldots \ldots \ldots \ldots \ldots \ldots \ldots \ldots \ldots \ldots \ldots \ldots \ldots \ldots$

EXECUTTVE SUMMARY $\ldots \ldots \ldots \ldots \ldots \ldots \ldots \ldots \ldots \ldots \ldots \ldots \ldots$

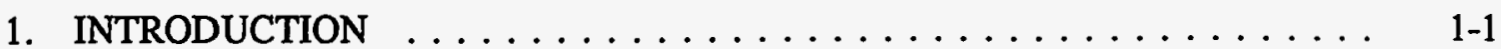

1.1 REGULATORY INITIATIVE . . . . . . . . . . . . . . . 1 1-1

1.2 ORR ENVIRONMENTAL RESTORATION PROGRAM $\ldots \ldots \ldots \ldots .1-2$

1.3 ORNL GROUNDWATER OPERABLE UNIT $\ldots \ldots \ldots \ldots \ldots \ldots \ldots$

1.4 PURPOSE AND SCOPE OF THE ORNL GROUNDWATER

CHARACTERIZATION PLAN . . . . . . . . . . . . . . . 1-4

1.5 RI IMPLEMENTATION STRATEGY $\ldots \ldots \ldots \ldots \ldots \ldots \ldots \ldots \ldots$. $\ldots \ldots$

1.6 RELATIONSHIP OF GWOU TO CONTAMINANT SOURCE

WAG ACTIVITIES . . . . . . . . . . . . . . . . . . 1-8

1.7 IDENTIFICATION OF POTENTIAL CLASSES OF REMEDIAL

TECHNOLOGIES . . . . . . . . . . . . . . . . . . $1-9$

1.8 RISK ASSESSMENT FOR THE GWOU . . . . . . . . . . . . . . . . . 1-11

1.9 PROJECT SCHEDULE . . . . . . . . . . . . . . . . 1 1-11

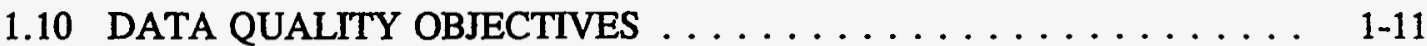

1.10.1 Decisions To Be Made . . . . . . . . . . . . . . . . 1-13

1.10 .2 Inputs to the Decision . . . . . . . . . . . . . . 1-15

1.10 .3 Decision Rule . . . . . . . . . . . . . . . . . . . 1-17

1.10 .4 Uncertainty Constraints . . . . . . . . . . . . . . . . . . 1-19

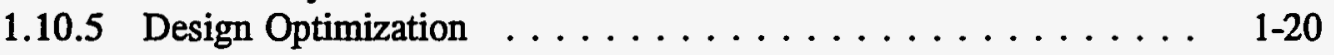

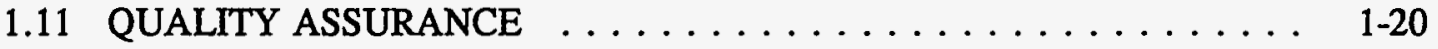

1.11.1 Program Planning and Implementation $\ldots \ldots \ldots \ldots \ldots$ 1-20

1.11 .2 Project-specific Planning . . . . . . . . . . . . 1-21

2. ORNL GWOU SITE CONCEPTUAL MODEL . . . . . . . . . . . 2-1

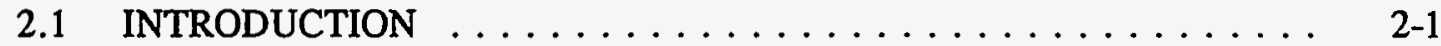

2.1.1 Geological Setting of the GWOU ............. 2-1

2.1.2 GWOU Hydrological Conceptual Model ............ 2-2

2.1.3 GWOU Boundaries and Pathways ............ 2-2

2.2 GEOLOGICAL SETTING .................. $2-3$

2.2.1 Location and Physiography ............... 2-3

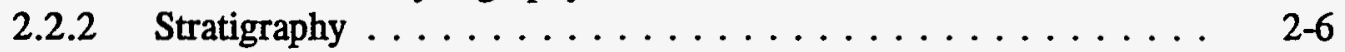

2.2 .3 Structural Geology .................... 2-13

2.2 .4 Fractures ......................... 2-13

2.2.5 Cavities and Solution Openings . . . . . . . . . . 2-15

2.3. . GWOU.HYDROLOGICAL CONCEPTUAL MODEL . . . . . . . . . 2 2-16

2.3.1 Stormflow Zone . . . . . . . . . . . . . . . 2-18

2.3 .2 Vadose Zone ...................... 2-18

2.3.3 Groundwater Zone .................... 2-20

2.3.4 Groundwater Geochemistry ............... 2-30

2.3.5 Surface Water ..................... 2-34 
2.4 GWOU BOUNDARIES AND PATHWAYS $\ldots \ldots \ldots \ldots \ldots \ldots 2-35$

2.4.1 North and South Boundaries . . . . . . . . . . 2-37

2.4 .2 Medial Boundary . . . . . . . . . . . . . . . . .

2.4 .3 West Boundary . . . . . . . . . . . . . . 2-40

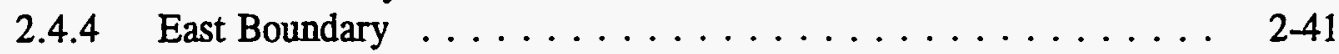

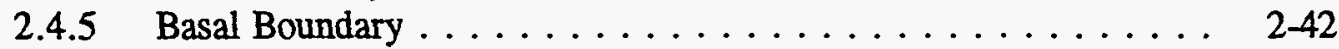

2.4.6 Flow Systems and Exit Pathways $\ldots \ldots \ldots \ldots \ldots \ldots .2-43$

3. NATURE AND EXTENT OF GROUNDWATER CONTAMINATION . . . . . 3-1

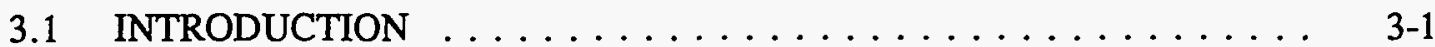

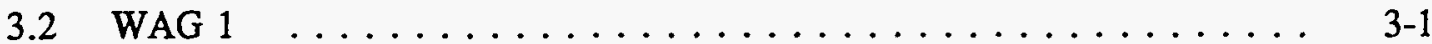

3.2.1 Site Location, Description, and Background . . . . . . . . 3-1

3.2.2 Characterization of Groundwater Contamination ........ 3-5

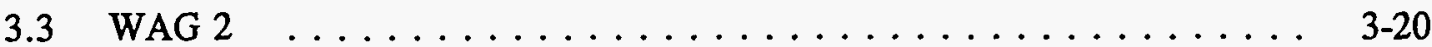

3.3.1 Site Location, Description, and Background . . . . . . . 3-20

3.3.2 Characterization of Groundwater Contamination (Upper WAG 2) 3-23

3.3.3 Characterization of Groundwater Contamination (Lower WAG 2) 3-27

3.4 WAG $3 \quad \ldots \ldots \ldots \ldots \ldots \ldots \ldots \ldots \ldots \ldots \ldots . \ldots \ldots$. $3-29$

3.4.1 Site Location, Description, and Background . . . . . . . . 3-29

3.4.2 Characterization of Groundwater Contamination ........ 3-32

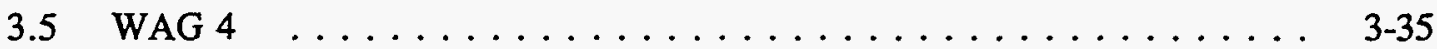

3.5.1 Site Location, Description, and Background ........ 3-35

3.5.2 Characterization of Groundwater Contamination . . . . . . . 3-37

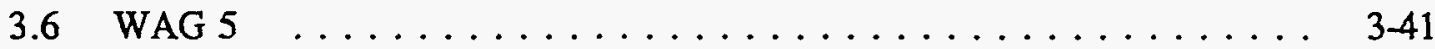

3.6.1 Site Location, Description, and Background ......... 3-41

3.6.2 Characterization of Groundwater Contamination ........ . 3-44

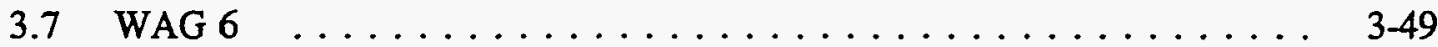

3.7.1 Site Location, Description, and Background . . . . . . . . . 3-49

3.7.2 Characterization of Groundwater Contamination ......... 3-51

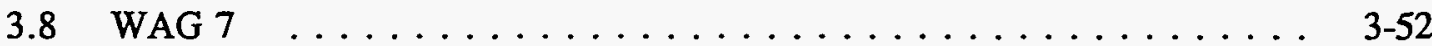

3.8.1 Site Location, Description, and Background . . . . . . . 3-52

3.8.2 Characterization of Groundwater Contamination . . . . . . 3-60

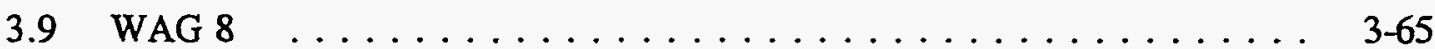

3.9.1 Site Location, Description, and Background . . . . . . . . . 3-65

3.9.2 Characterization of Groundwater Contamination ... . . . . 3-71

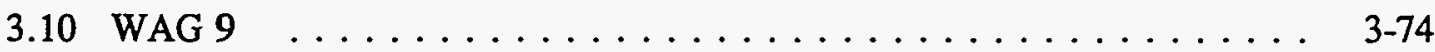

3.10.1 Site Location, Description, and Background . . . . . . . . 3-74

3.10.2 Characterization of Groundwater Contamination $\ldots \ldots \ldots \ldots$ 3-76

3.11 WAG $10 \ldots \ldots \ldots \ldots \ldots \ldots \ldots \ldots \ldots \ldots \ldots \ldots \ldots \ldots \ldots$ 3-77

3.11.1 Site Location, Description, and Background . . . . . . . . 3-77

3.11.2 Characterization of Groundwater Contamination ....... . 3-80

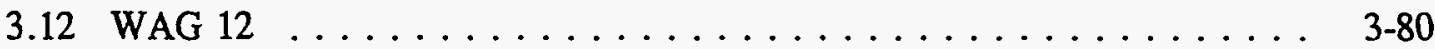

3.12.1 Site.Location, Description, and Background . . . . . . . 3-80

3.12.2 Characterization of Groundwater Contamination $\ldots \ldots \ldots \ldots$ 3-81

3.13 WAG $17 \ldots \ldots \ldots \ldots \ldots \ldots \ldots \ldots \ldots \ldots \ldots \ldots \ldots . \ldots \ldots$ 3-81

3.13.1 Site Location, Description, and Background . . . . . . . . . 3-81

3.13.2 Characterization of Groundwater Contamination . . . . . . . 3-83

3.14 WAG $19 \ldots \ldots \ldots \ldots \ldots \ldots \ldots \ldots \ldots \ldots \ldots . \ldots \ldots$ 3-84

3.14.1 Site Location, Description, and Background . . . . . . . . . 3 3-84

3.14.2 Characterization of Groundwater Contamination . . . . . . . 3-86 
4. GROUNDWATER MODELING, AND CONTAMINANT FATE AND

TRANSPORT INVESTIGATIONS

4.1 GROUNDWATER FLOW AND CONTAMINANT TRANSPORT

MODELING

4.1.1 Regional Models .................. 4-2

4.1 .2 Local Models $\ldots \ldots \ldots \ldots \ldots \ldots \ldots \ldots \ldots \ldots$ 4.5

4.1.3 Resources . . . . . . . . . . . . . . .

4.2 CONTAMINANT FATE AND TRANSPORT

INVESTIGATIONS $\ldots \ldots \ldots \ldots \ldots \ldots \ldots \ldots \ldots \ldots \ldots \ldots$

4.2.1 Introduction $\ldots \ldots \ldots \ldots \ldots \ldots \ldots \ldots \ldots \ldots \ldots$ 4-9

4.2.2 Contaminant Source Concentration $\ldots \ldots \ldots \ldots \ldots \ldots$ 4-11

4.2.3 Retardation Mechanism Definition ............ 4-11

4.2.4 Soil and Bedrock Porosity Determinations . . . . . . . . . 4-12

4.2.5 Mineralogic Characterization $\ldots \ldots \ldots \ldots \ldots \ldots \ldots \ldots$ 4-12

5. RISK ASSESSMENT $\ldots \ldots \ldots \ldots \ldots \ldots \ldots \ldots \ldots \ldots \ldots \ldots \ldots \ldots \ldots$ 5-1

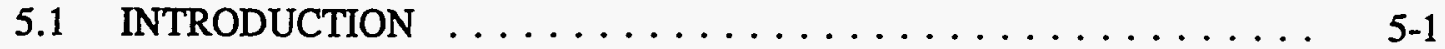

5.2 CONCEPTUAL RISK MODEL $\ldots \ldots \ldots \ldots \ldots \ldots \ldots \ldots$ 5-2

5.2.1 Fate and Transport $\ldots \ldots \ldots \ldots \ldots \ldots \ldots \ldots \ldots$ 5-2

5.2.2 Exposure Model $\ldots \ldots \ldots \ldots \ldots \ldots \ldots \ldots \ldots$ 5-2

5.2.3 Current COPCs and Associated Risk ........... 5-3

5.2.4 Uncertainties in the Conceptual Risk Model . . . . . . . . 5-10

5.3 RISK ASSESSMENT STRATEGY FOR THE GWOU $\ldots \ldots \ldots \ldots$ 5-14

5.4 RISK ASSESSMENT ACTIVITIES AND METHODS $\ldots \ldots \ldots \ldots .5-16$

5.4.1 Near-Term Support . . . . . . . . . . . . . . . 5-16

5.4.2 Mid-Phase Support $\ldots \ldots \ldots \ldots \ldots \ldots \ldots \ldots \ldots$ 5-18

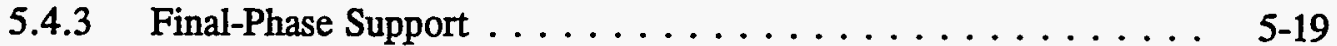

5.5 RISK MANAGEMENT SUPPORT $\ldots \ldots \ldots \ldots \ldots \ldots \ldots \ldots$ 5-20

5.6 IDENTIFICATION OF CHEMICAL-SPECIFIC ARARS . . . . . $5-20$

6. GWOU TEST METHODS $\ldots \ldots \ldots \ldots \ldots \ldots \ldots \ldots \ldots \ldots \ldots$ 6 1

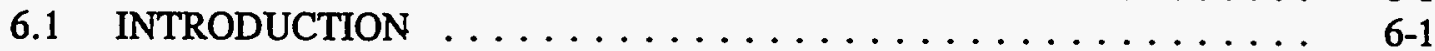

6.2 AQUIFER PARAMETERS $\ldots \ldots \ldots \ldots \ldots \ldots \ldots \ldots \ldots \ldots$ 6-1

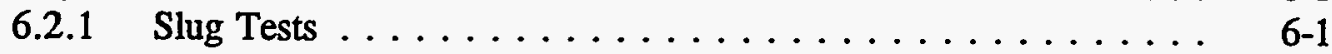

6.2.2 Pumping Tests $\ldots \ldots \ldots \ldots \ldots \ldots \ldots \ldots \ldots$ 6-1

6.2.3 Tracer Tests ............ 6-2

6.2.4 Pulse Train Tests $\ldots \ldots \ldots \ldots \ldots \ldots \ldots \ldots$ 6-3

6.2.5 TVA Electromagnetic Borehole Flowmeter Tests . . . . . . 6 6-3

6.2.6 Rock and Soil Parameters .................. 6.4

6.3 GROUNDWATER FLOW SYSTEM DEFINITION $\ldots \ldots \ldots \ldots \ldots$ 6-9

6.3.1 Seep and Spring Monitoring $\ldots \ldots \ldots \ldots \ldots \ldots \ldots$ 6-11

6.3.2 Stream Flow Monitoring $\ldots \ldots \ldots \ldots \ldots \ldots \ldots$ 6-13

6.3.3 ... Piezometric Head Measurements . . . . . . . . . . . 6-13

6.3.4 Geochemical Monitoring . . . . . . . . . . . . . 6-21

6.4 SUBSURFACE CHARACTERIZATION $\ldots \ldots \ldots \ldots \ldots \ldots \ldots, 6-22$

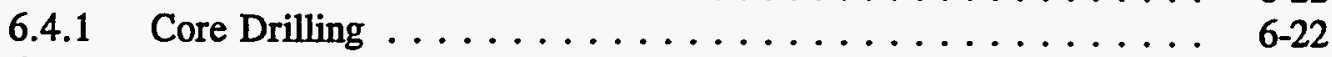

6.4.2 Geophysical Borehole Logs . . . . . . . . . . . . 6-23

6.4.3 Surface Geophysical Investigations . . . . . . . . . 6-27 
7. FIELD SAMPLING/SURVEY PLAN $\ldots \ldots \ldots \ldots \ldots \ldots \ldots \ldots \ldots$ 7-1

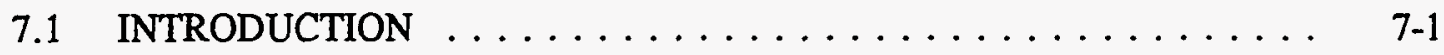

7.2 OBSERVATIONAL APPROACH $\ldots \ldots \ldots \ldots \ldots \ldots \ldots \ldots \ldots$ 7-1

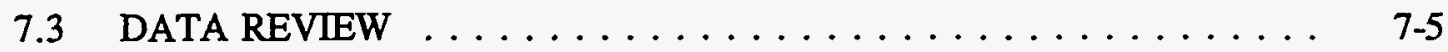

7.3.1 Groundwater Well Review . . . . . . . . . . . . .

7.3.2 Seeps and Springs Review . . . . . . . . . . . 7-6

7.4 SAMPLING AND SURVEY APPROACH AND RATIONALE . . . . . $7-6$

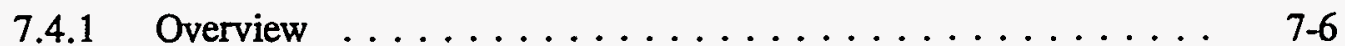

7.4.2 Clinch River Thermal Mapping $\ldots \ldots \ldots \ldots \ldots \ldots$ 7-7

7.4.3 Geophysical Investigations . . . . . . . . . . . . 7-7

7.4.4 Piezometric Measurements and Well Sampling . . . . . . 7-10

7.4.5 Seep and Spring Sampling $\ldots \ldots \ldots \ldots \ldots \ldots \ldots \ldots$ 7-11

7.5 FIELD SAMPLING/SURVEY PLAN $\ldots \ldots \ldots \ldots \ldots \ldots \ldots 7-11$

7.5.1 Clinch River Thermal Mapping $\ldots \ldots \ldots \ldots \ldots \ldots$ 7-12

7.5.2 Raccoon Creek and Bearden Creek Monitoring/Sampling .... 7-12

7.5.3 Haw Ridge Dolostone Mapping . . . . . . . . . . . 7-13

7.5 .4 GWOU Water Level Monitoring $\ldots \ldots \ldots \ldots \ldots \ldots \ldots \ldots \ldots \ldots$

7.5.5 WAG 3 Water Level Monitoring ............ 7-15

7.5.6 WAG 1 Pressure Monitoring and Well Sampling ....... 7-16

7.5.7 WAG 5 Westbay Monitoring and Sampling ......... 7-17

7.5.8 Hydrofracture Pressure Monitoring and Sampling . . . . . . 7-17

7.5.9 HHMS Pressure Monitoring and Sampling $\ldots \ldots \ldots \ldots$ 7-18

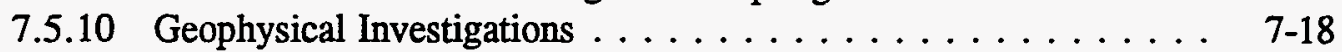

8. QUALITY ASSURANCE PROJECT PLAN $\ldots \ldots \ldots \ldots \ldots \ldots \ldots$ 8-1

8.1 QUALITY ASSURANCE OVERVIEW $\ldots \ldots \ldots \ldots \ldots \ldots \ldots$ 8-1

8.1 Project Description $\ldots \ldots \ldots \ldots \ldots \ldots \ldots \ldots \ldots$ 8-1

8.1 .2 Modular Profile . . . . . . . . . . . . . . . 8

8.1 .3 Exclusion Rationale $\ldots \ldots \ldots \ldots \ldots \ldots \ldots \ldots \ldots$. 8 .5

8.2 PROJECT ORGANIZATION $\ldots \ldots \ldots \ldots \ldots \ldots \ldots \ldots \ldots \ldots$ 8-5

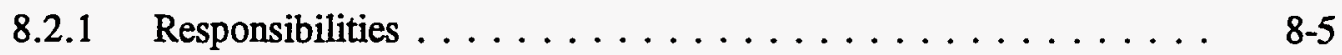

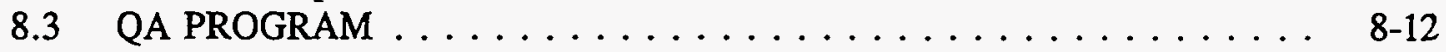

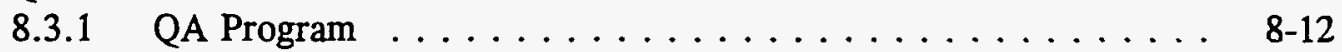

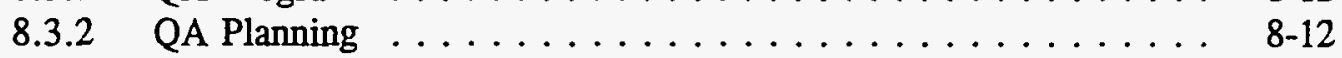

8.3 .3 DQOs $\ldots \ldots \ldots \ldots \ldots \ldots \ldots \ldots \ldots \ldots \ldots \ldots$ 8 8 .12

8.3.4 QA Program Status Reporting $\ldots \ldots \ldots \ldots \ldots \ldots \ldots$ 8-14

8.3.5 QA Training and Awareness $\ldots \ldots \ldots \ldots \ldots \ldots \ldots$ 8-14

8.3.6 QC Samples .................... 8

8.4 PROCUREMENT DOCUMENT CONTROL $\ldots \ldots \ldots \ldots \ldots \ldots$ 8-16

8.5 INSTRUCTIONS, PROCEDURES, AND DRAWINGS $\ldots \ldots \ldots \ldots \quad 8$.16

8.5.1 Responsibilities . . . . . . . . . . . . . . . . 8-16

8.5.2 Standard Operating Procedures and Instructions $\ldots \ldots \ldots \ldots \quad 8-20$

8.6 DOCUMENT CONTROL $\ldots \ldots \ldots \ldots \ldots \ldots \ldots \ldots \ldots \ldots \ldots$

8.6 .1 Responsibilities $\ldots \ldots \ldots \ldots \ldots \ldots \ldots \ldots \ldots \ldots$ 8-20

8.6 .2 Procedures . . . . . . . . . . . . . . . 8-22

8.7 CONTROL OF PURCHASED ITEMS AND SERVICES $\ldots \ldots \ldots \ldots 8-22$

8.7 .1 Responsibilities $\ldots \ldots \ldots \ldots \ldots \ldots \ldots \ldots \ldots \ldots$ 8-22

8.7 .2 Procedures $\ldots \ldots \ldots \ldots \ldots \ldots \ldots \ldots \ldots \ldots \ldots \ldots$ 8-22

8.8 IDENTIFICATION AND CONTROL OF ITEMS $\ldots \ldots \ldots \ldots \ldots \ldots 8$

8.8 .1 Responsibilities . . . . . . . . . . . . . . $8-25$ 


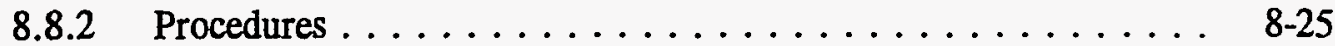

8.9 CONTROL OF PROCESSES $\ldots \ldots \ldots \ldots \ldots \ldots \ldots \ldots \ldots \ldots$

8.9.1 Responsibilities . . . . . . . . . . . . . . . 8-26

8.9.2 Procedures $\ldots \ldots \ldots \ldots \ldots \ldots \ldots \ldots \ldots \ldots \ldots$ 8-26

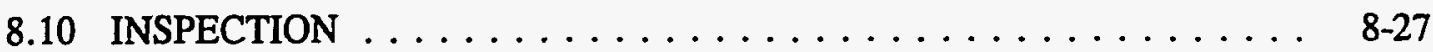

8.10.1 Responsibilities of the Project Manager ........... 8-27

8.10.2 Responsibilities of the QA/QC Coordinator ......... $8-27$

8.11 TEST CONTROL $\ldots \ldots \ldots \ldots \ldots \ldots \ldots \ldots \ldots \ldots \ldots . \ldots \ldots$

8.11.1 Data Summarization, Validation, and Reporting ........ 8-27

8.11.2 Field Data Reduction and Evaluation $\ldots \ldots \ldots \ldots \ldots .8$ 8-28

8.11.3 Analytical Laboratory Data Reduction and Evaluation . . . . . . 8-28

8.12 CONTROL OF MEASURING- AND TESTING- EQUIPMENT

CALIBRATION . . . . . . . . . . . . . . . . . . . .

8.12 .1 Responsibilities . . . . . . . . . . . . . . . . . 8-29

8.12.2 Procedures . . . . . . . . . . . . . . . . . . . . 8 8-29

8.13 HANDLING, STORAGE, AND SHIPPING $\ldots \ldots \ldots \ldots \ldots \ldots .8 .29$

8.13.1 Responsibilities . . . . . . . . . . . . . . . . . 8-29

8.13.2 Procedures . . . . . . . . . . . . . . . . . . 8-29

8.14 INSPECTION, TESTING, AND OPERATING STATUS . . . . . . 8-29

8.15 NONCONFORMANCE $\ldots \ldots \ldots \ldots \ldots \ldots \ldots \ldots \ldots \ldots . .6 \ldots \ldots$

8.15 .1 Responsibilities . . . . . . . . . . . . . . 8-30

8.15 .2 Procedures $\ldots \ldots \ldots \ldots \ldots \ldots \ldots \ldots \ldots \ldots \ldots, 8.30$

8.16 CORRECTIVE ACTIONS $\ldots \ldots \ldots \ldots \ldots \ldots \ldots \ldots \ldots, 8-31$

8.17 QA RECORDS $\ldots \ldots \ldots \ldots \ldots \ldots \ldots \ldots \ldots \ldots \ldots \ldots . \ldots \ldots$

8.18 AUDITS $\ldots \ldots \ldots \ldots \ldots \ldots \ldots \ldots \ldots \ldots \ldots \ldots \ldots . \ldots \ldots$ 8-32

8.18.1 Responsibilities of the QA/QC Coordinator . . . . . . 8 $8-32$

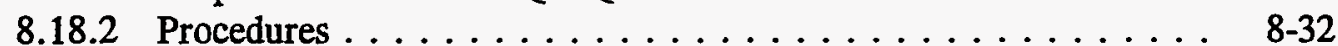

8.19 SOFTWARE QA $\ldots \ldots \ldots \ldots \ldots \ldots \ldots \ldots \ldots \ldots . \ldots \ldots$

8.19.1 Responsibilities of the Project manager $\ldots \ldots \ldots \ldots \ldots$ 8-34

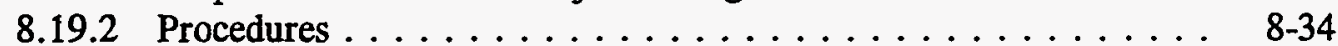

8.20 TECHNICAL AND PEER REVIEWS $\ldots \ldots \ldots \ldots \ldots \ldots \ldots .8 .6 .34$

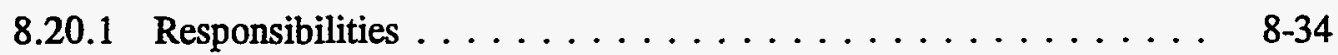

8.20 .2 Procedures $\ldots \ldots \ldots \ldots \ldots \ldots \ldots \ldots \ldots \ldots \ldots .8 \ldots \ldots$

9. HEALTH AND SAFETY PLAN $\ldots \ldots \ldots \ldots \ldots \ldots \ldots \ldots \ldots$ 9-1

9.1 INTRODUCTION $\ldots \ldots \ldots \ldots \ldots \ldots \ldots \ldots \ldots \ldots \ldots$ 9-1

9.2 PROPOSED PLAN $\ldots \ldots \ldots \ldots \ldots \ldots \ldots \ldots \ldots \ldots \ldots \ldots$ 9-1

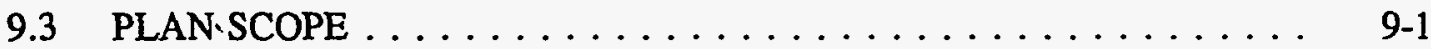

10. WASTE MANAGEMENT PLAN $\ldots \ldots \ldots \ldots \ldots \ldots \ldots \ldots \ldots \ldots$ 10-1

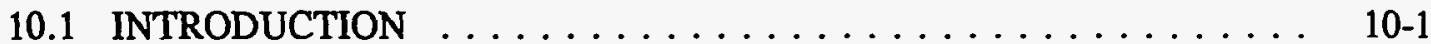

10.2 GENERAL SITE INFORMATION $\ldots \ldots \ldots \ldots \ldots \ldots \ldots \ldots$ 10-1

.10 .3 ..GENERAL PROJECT DESCRIPTION $\ldots \ldots \ldots \ldots \ldots \ldots \ldots$. . . . . .

10.4 ORGANIZATIONAL STRUCTURE AND RESPONSIBILITY . . . . . 10-1

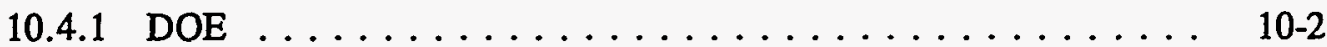

10.4.2 Energy Systems . . . . . . . . . . . . . . . 10-2

10.4.3 Ebasco Services, Inc. . . . . . . . . . . . . . 10-2

10.4.4 M-K Ferguson . . . . . . . . . . . . . . 10-2

10.4.5 Service Contractor or Fixed Price Subcontractors . . . . . . 10-3

10.4.6 Generator Certification Official $\ldots \ldots \ldots \ldots \ldots \ldots \ldots$ 10-3 
10.4.7 Laboratory Certification Official . . . . . . . . . . . . . . 10-5

10.4 .8 Generator-Packager . . . . . . . . . . . . . . . . . . . . . . . . . . . . . .

10.5 WASTE GENERATION . . . . . . . . . . . . . . . . . 10-10

10.5.1 Waste-Generating Activities ................ 10 . . . . . . . . .

10.5.2 Possible Wastes Generated . . . . . . . . . . . . . . . . . . 10-10

10.6 WASTE PACKAGING AND HANDLING . . . . . . . . . . . . . 10-12

10.6.1 Generating . . . . . . . . . . . . . . . . . . . . . 10-12

10.6.2 Segregating ....................... 10-12

10.6.3 Packaging and Handling $\ldots \ldots \ldots \ldots \ldots \ldots$ 10-12

10.6.4 Equipment Decontamination . . . . . . . . . . . . . 10 . 13

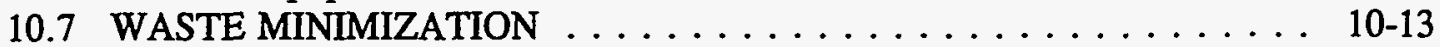

10.8 CONTROL PROGRAMS . . . . . . . . . . . . . . . . . 10-14

$10.8 .1 \mathrm{HP} / \mathrm{IH}$ Surveys $\ldots \ldots \ldots \ldots \ldots \ldots . \ldots \ldots$. . . . . . . . . . . . . . . . . . . . . . . . . . . .

10.8.2 Controls . . . . . . . . . . . . . . . . . . . . 10 10-14

10.8.3 Personnel Exposure Control . . . . . . . . . . . . . . . . . . 10-14

10.8 .4 Training . . . . . . . . . . . . . . . . . 10-14

10.8.5 QA Requirements . . . . . . . . . . . . . . . 10-15

10.8.6 Spill Control . . . . . . . . . . . . . . . . . 10-15

10.9 TEMPORARY STORAGE OF WASTE $\ldots \ldots \ldots \ldots \ldots \ldots$ 10-15

11. DATA MANAGEMENT PLAN ................... 11-1

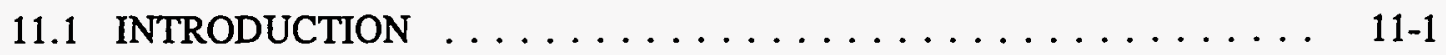

11.2 PURPOSE AND GOAL . . . . . . . . . . . . . . . $11-1$

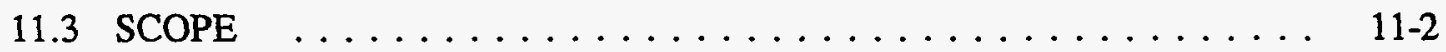

11.4 FUNCTIONAL RESPONSIBILITIES . . . . . . . . . . . . . . . 11-2

11.5 DATA MANAGEMENT ACTIVITIES AND RESPONSIBILITIES . . . 11-11

11.5.1 Phase 1: Planning . . . . . . . . . . . . . . . 11-11

11.5.2 Phase 2: Field Preparation and Sampling . . . . . . . . . 11-14

11.5.3 Phase 3: Data Verification and Validation . . . . . . . . . . 11-17

11.5.4 Phase 4: Data Analysis and Presentation . . . . . . . . . 11-22

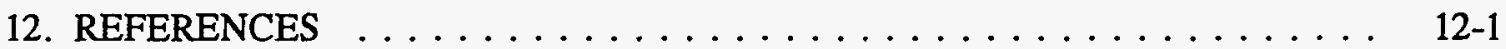

APPENDIX A SUMMARY OF RISK RESULTS FOR COMPLIANCE WELLS AND GROUNDWATER DATA COLLECTED FOR REMEDIAL

INVESTIGATIONS AT WAGS 1,5 , AND $6 \ldots \ldots$ A-1 


\section{FIGURES}

$1.1 \quad$ Boundaries of ORNL WAGs $\ldots \ldots \ldots \ldots \ldots \ldots \ldots \ldots \ldots$ 1-5

1.2 Schematic model of the relationship between the source WAGs and the integrator GWOU $\ldots \ldots \ldots \ldots \ldots \ldots \ldots \ldots \ldots \ldots$

1.3 The DQO development process $\ldots \ldots \ldots \ldots \ldots \ldots \ldots \ldots \ldots$ 1-12

1.4 Flow diagram showing the integrator-source OU investigation process $\ldots \ldots \quad 1-14$

2.1 Location map showing the relationship of ORNL to the physiographic

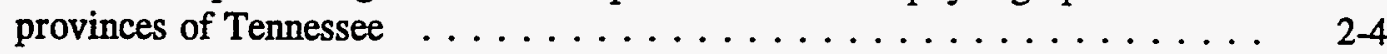

2.2 Generalized geologic map of the vicinity around ORNL . . . . . . 2-5

2.3 Correlation of Stockdale's (1951) unit designations with formal formation names for Chickamauga Group rocks $\ldots \ldots \ldots \ldots \ldots$ 2-11

2.4 Schematic geologic cross section in the vicinity of the GWOU ....... 2-14

2.5 Generalized map of ORR showing surface distribution of the Knox aquifer and the $\mathrm{ORR}$ aquitards $\ldots \ldots \ldots \ldots \ldots \ldots \ldots \ldots \ldots \ldots \ldots$ 2-17

2.6 A schematic drawing showing conceptual groundwater flow at ORNL $\ldots . .2$ 2-19

2.7 Cumulative probability graph of transmissivity data for water-producing intervals and matrix fractures .

2.8 Sections showing hypothetical differences in trends and densities of fractures near ORNL ................... 2-24

2.9 Location map and sections showing specific conductance of water along lines of paired shallow and deeper wells $\ldots \ldots \ldots \ldots \ldots \ldots$ 2-32

2.10 Schematic representation of the GWOU at ORNL showing its boundaries, major surface features, and major subsurface geological features $\ldots \ldots \ldots \quad 2-36$

3.1 Location of WAGs at ORNL $\ldots \ldots \ldots \ldots \ldots \ldots \ldots \ldots \ldots \ldots \ldots \ldots, 3-2$

3.2 Location of WAG 1 at ORNL $\ldots \ldots \ldots \ldots \ldots \ldots \ldots$ 3-3

3.3 Overview of radiological contamination in groundwater at WAG $1 \ldots \ldots$ 3-7

3.4 Distribution of TCE and degradation products in groundwater at WAG $1 \ldots$ 3-9

3.5 Cadmium detected in unfiltered groundwater samples exceeding $5 \mu \mathrm{g} / \mathrm{L}$ during low base flow conditions at WAG $1 \ldots \ldots \ldots \ldots \ldots \ldots$ 3-11

3.6 Locations of buildings or other facilities associated with groundwater contamination within WAG $1 \ldots \ldots \ldots \ldots \ldots \ldots \ldots$ 3-13

3.7 Locations of monitoring wells, piezometers, and coreholes associated with groundwater contamination within WAG $1 \ldots \ldots \ldots \ldots \ldots$

3.8 Locations of contamination in the western portion of WAG 1 and interpreted plume configuration $\ldots \ldots \ldots \ldots \ldots \ldots \ldots$ 3-17

3.9 Location of WAG 2 at ORNL $\ldots \ldots \ldots \ldots \ldots \ldots \ldots \ldots \ldots . \ldots \ldots$ 3-21

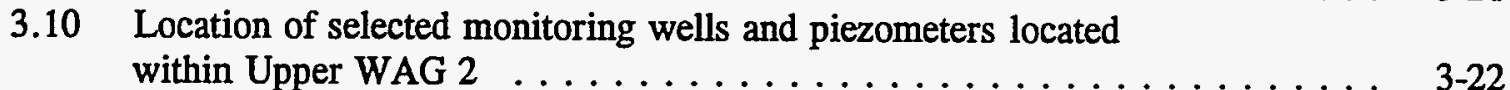

3.11 Location of selected monitoring wells and piezometers located

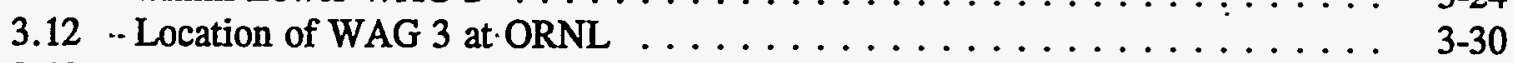

3.13 Location of selected monitoring wells within WAG $3 \ldots \ldots \ldots \ldots \ldots$ 3-33

3.14 Location of WAG 4 at ORNL $\ldots \ldots \ldots \ldots \ldots \ldots \ldots \ldots \ldots \ldots$

3.15 Location of selected monitoring wells within WAG $4 \ldots \ldots \ldots \ldots \ldots \ldots$ 3-39

3.16 Location of WAG 5 at ORNL $\ldots \ldots \ldots \ldots \ldots \ldots \ldots \ldots \ldots \ldots \ldots$

3.17 Location of selected monitoring wells within WAG $5 \ldots \ldots \ldots \ldots \ldots 3-46$

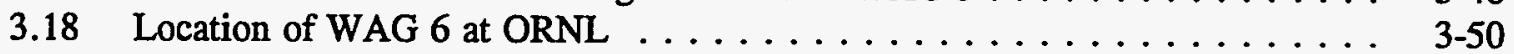

3.19 Location of selected monitoring wells within WAG $6 \ldots \ldots \ldots \ldots$ 3-53 
3.20 Location of WAG 7 at ORNL . . . . . . . . . . . . . 3-55

3.21 Location of selected monitoring wells within WAG $7 \ldots \ldots \ldots$ 3-61

3.22 Location of WAG 8 at ORNL . . . . . . . . . . . . . . . 3-66

3.23 Location of selected monitoring wells within WAG $8 \ldots \ldots \ldots \ldots \ldots$ 3-72

3.24 Location of WAG 9 at ORNL . . . . . . . . . . . . . 3-75

3.25 Location of selected monitoring wells within WAG $9 \ldots \ldots \ldots \ldots$ 3-78

3.26 Location of WAG 17 at ORNL . . . . . . . . . . . . . . 3-82

3.27 Location of selected monitoring wells within WAG $17 \ldots \ldots \ldots \ldots$. . . . . . . .

4.1 Conceptual flow chart for conducting fate and transport modeling . . . . . . 4-10

5.1 WAG contributions to risk in the GWOU . . . . . . . . . . . . 5-13

5.2 Major decisions and likely receptor locations for risk assessment support . . . 5-15

6.1 Known locations of GWOU seeps and springs . . . . . . . . . . . 6-12

6.2 ORNL surface water monitoring stations $\ldots \ldots \ldots \ldots \ldots \ldots \ldots$ 6-14

6.3 Location of wells included in routine water level measurement programs at ORNL . . . . . . . . . . . . . . . . . . . . 6-16

6.4 Westbay Multiport (MP) system showing packer/backfill and port setup . . . 6 6-18

6.5 Multiport pressure probe operation ................ 6-19

6.6 Example of actual MP installation using 19 measurement port couplings isolated by 22 water inflated packers . . . . . . . . . . . . 6-20

6.7 Example of six different geophysical logs of a well in the upper Brazos River Basin . . . . . . . . . . . . . . . . . 6-25

7.1 Timeline for proposed activities during the first 18 months of GWOU . . . . 7-2

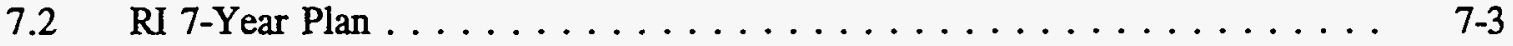

7.3 Areas of investigation for GWOU . . . . . . . . . . . . . . $7-4$

10.1 Container Packing List form (TX-5749 V1.0) . . . . . . . . . . . . $10-4$

10.2 Waste Pickup Request form (TX-5753 V1.0) . . . . . . . . . . . . . . 10-6

10.3 Environmental Restoration Waste Management Program Total Generated Waste form (UCN-1911) . . . . . . . . . . . . . . . . . . . . 10-7

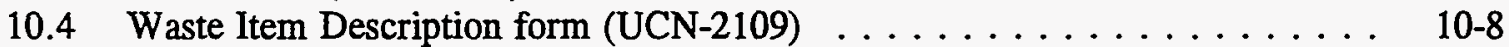

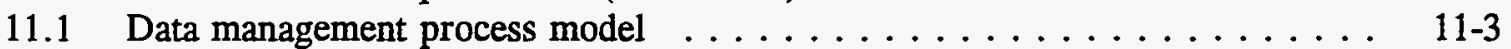




\section{TABLES}

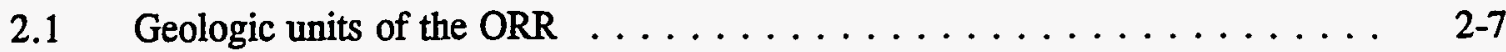

2.2 Number of cavities in wells by geologic unit $\ldots \ldots \ldots \ldots \ldots \ldots .2-16$

3.1 Summary of Upper WAG 2 groundwater monitoring system wells and piezometers $\ldots \ldots \ldots \ldots \ldots \ldots \ldots \ldots \ldots \ldots \ldots \ldots \ldots \ldots$ 3-25

3.2 Summary of Lower WAG 2 groundwater monitoring system wells and piezometers $\ldots \ldots \ldots \ldots \ldots \ldots \ldots \ldots \ldots \ldots \ldots \ldots \ldots \ldots \ldots \ldots, 3-28$

3.3 Summary of WAG 3 groundwater monitoring system wells $\ldots \ldots \ldots$ 3-34

3.4 Summary of WAG 4 groundwater monitoring system wells $\ldots \ldots \ldots, 3-40$

3.5 Summary of WAG 5 groundwater monitoring system wells $\ldots \ldots \ldots .3-47$

3.6 Summary of WAG 6 groundwater monitoring system wells $\ldots \ldots \ldots$ 3-54

3.7 Summary of WAG 7 groundwater monitoring system wells $\ldots \ldots \ldots, 3-62$

3.8 Summary of WAG 8 groundwater monitoring system wells $\ldots \ldots \ldots \ldots$ 3-73

3.9 Summary of WAG 9 groundwater monitoring system wells $\ldots \ldots \ldots \ldots$ 3-79

3.10 Summary of WAG 17 groundwater monitoring system wells $\ldots \ldots \ldots$ 3-86

5.1 Residential parameters for the drinking water pathway ......... 5-5

5.2 Residential parameters for dermal contact with groundwater $\ldots \ldots \ldots$ 5-6

5.3 Residential parameters for indoor inhalation pathway ........... 5-7

5.4 Chemicals of concern in ORNL perimeter groundwater wells with risks $>1 \times 10^{-4} \ldots \ldots \ldots \ldots \ldots \ldots \ldots \ldots . \ldots \ldots$. $5-8$

5.5 GWOU wells ranked by total risk with quality of aquifer denotations . . . . . 5-11

5.6 Tiered approach for estimating plume water flow volumes $\ldots \ldots \ldots \ldots$ 5-18

5.7. Safe Drinking Water Act maximum contaminant levels . . . . . . . . . 5-21

6.1 Borehole geophysical methods applicable for ORNL OU groundwater

8.1 Modular profile for the GWOU project $\ldots \ldots \ldots \ldots \ldots \ldots \ldots \ldots$ 8-2

8.2 GWOU project document summary $\ldots \ldots \ldots \ldots \ldots \ldots \ldots \ldots . \ldots \ldots$

8.3 Surveillance activities $\ldots \ldots \ldots \ldots \ldots \ldots \ldots \ldots \ldots$ 8-21

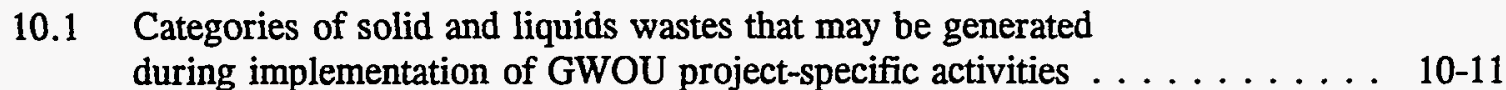

11.1 Mapping of data management activities to proposed set of data management procedures and suggested interim guidance documents $\ldots \ldots \ldots \ldots \ldots$ 11-4 


\section{ACRONYMS}

ADP

ANSI/ASME

ARARs

ASTM

CCS

CERCLA

CLP

COC

COPC

DAF

DC

DMC

DMP

DOE

DOE-ORO

DQO

EM

Energy Systems

EPA

ER

ESD

FFA

FM

FS

FS/SP

GPR

GWOU

H\&S

HFIR

HHMS

HP

HPCC

HRE

HRT

ID

IDW

IH

ILLW

IP

LLLW

LLW

MCL

MP

NCP

NEPA automated data processing

American National Standards Institute/American Society of Mechanical Engineers

applicable or relevant and appropriate requirements

American Society for Testing and Materials

Contract Compliance Screening

Comprehensive Environmental Response, Compensation, and Liability Act of 1980

Contract Laboratory Program

chain of custody

contaminant of potential concern

dilution/attenuation factor

direct control

Document Management Center

Data Management Plan

U.S. Department of Energy

DOE-Oak Ridge Operations

data quality objective

electromagnetic

Martin Marietta Energy Systems, Inc.

U.S. Environmental Protection Agency

Environmental Restoration

Environmental Sciences Division

Federal Facility Agreement

Facility Manager

Feasibility Study

Field Sampling/Survey Plan

ground-penetrating radar

Groundwater Operable Unit

health and safety

High Flux Isotope Reactor

hydrologic head monitoring station

Health Physics

High Performance Computing Center

Homogeneous Reactor Experiment

Homogeneous Reactor Test

inside diameter

investigation-derived waste

Industrial Hygiene

intermediate-level liquid waste

integration point

low-level liquid waste

low-level waste

maximum contaminant limit

multiport

National Contingency Plan

National Environmental Policy Act of 1969 


\begin{tabular}{|c|c|}
\hline NPDES & National Pollutant Discharge Elimination System \\
\hline NRWTP & Non-Radiological Wastewater Treatment Plant \\
\hline NSPP & Nuclear Safety Pilot Plant \\
\hline OREIS & Oak Ridge Environmental Information System \\
\hline ORNL & Oak Ridge National Laboratory \\
\hline ORR & Oak Ridge Reservation \\
\hline ORRHAGS & ORR Hydrologic and Geologic Studies \\
\hline OSHA & Occupational Safety and Health Act \\
\hline OU & operable unit \\
\hline PARCC & precision, accuracy, representativeness, completeness, and comparability \\
\hline PPE & personal protective equipment \\
\hline PRG & preliminary remediation goal \\
\hline PVC & polyvinyl chloride \\
\hline PWTP & Process Waste Treatment Plant \\
\hline QA & quality assurance \\
\hline QAPjP & Quality Assurance Project Plan \\
\hline $\mathrm{QC}$ & quality control \\
\hline RAP & Remedial Action Program \\
\hline RCRA & Resource Conservation and Recovery Act of 1976 \\
\hline RFI & RCRA Facility Investigation \\
\hline RI & Remedial Investigation \\
\hline ROD & Record of Decision \\
\hline SAIC & Science Applications International Corporation \\
\hline SAP & sampling and analysis plan \\
\hline SLLW & solid low-level waste \\
\hline SOP & standard operating procedure \\
\hline SOW & statement of work \\
\hline SP & spontaneous or self potential \\
\hline SPARCC & $\begin{array}{l}\text { sensitivity, precision, accuracy, representativeness, completeness, and } \\
\text { comparability }\end{array}$ \\
\hline SSHEA & Site Specific Hazard Evaluation Addendum \\
\hline SWMU & Solid Waste Management Unit \\
\hline SWSA & Solid Waste Storage Area \\
\hline TDEC & Tennessee Department of Environment and Conservation \\
\hline TDS & total dissolved solids \\
\hline TEM & time-domain or transient electromagnetic \\
\hline TRU & transuranic \\
\hline TURF & Thorium-Uranium Facility \\
\hline VLA & very low activity \\
\hline WAC & waste acceptance criteria \\
\hline WAG & waste area grouping \\
\hline WMP & Waste Management Plan \\
\hline WMRAD & Waste Management and Remedial Action Division \\
\hline
\end{tabular}




\section{EXECUTIVE SUMMARY}

\section{INTRODUCTION}

This characterization plan has been developed as part of the U.S. Department of Energy's (DOE's) investigation of the Groundwater Operable Unit (GWOU) at Oak Ridge National Laboratory (ORNL) located near Oak Ridge, Tennessee. The first iteration of the characterization plan is intended to serve as a strategy document to guide subsequent GWOU remedial investigations. The plan provides a rationale and organization for groundwater data acquisition, monitoring, and remedial actions to be performed during implementation of environmental restoration activities associated with the ORNL GWOU. It is important to note that the characterization plan for the ORNL GWOU is not a prototypical work plan. As such, remedial investigations will be conducted using anmual work plans to manage the work activities, and task reports will be used to document the results of the investigations. Sampling and analysis results will be compiled and reported annually with a review of data relative to risk (screening level risk assessment review) for groundwater. This characterization plan outlines the overall strategy for the remedial investigations and defines tasks that are to be conducted during the initial phase of investigation. This plan is presented with the understanding that more specific addenda to the plan will follow.

\section{GWOU BOUNDARIES}

The ORNL GWOU encompasses all of Bethel Valley, Melton Valley, and Haw Ridge between Bearden Creek as the eastern boundary to the Clinch River as the western boundary. The geographic boundary formed by Haw Ridge separates the Bethel Valley and Melton Valley portions of the ORNL GWOU. The southern boundary of the GWOU is the geologic contact between the Nolichucky shale and the Maynardville limestone of the Conasauga Group; the northern boundary is the base of the Fleanor formation of the Chickamauga Group. The base of the GWOU is considered to be the lowest depth where groundwater contains $10,000 \mathrm{mg} / \mathrm{L}$ of total dissolved solids. The depth of this fresh-brine water interface varies throughout the GWOU. Movement of underlying saline water is extremely slow; therefore, contaminants contained in such water are unlikely to reach distant receptors.

\section{GWOU INVESTIGATION GOALS}

The ORNL GWOU investigation is a multi-year program investigating many aspects of groundwater flow (e.g., defining the nature and extent of groundwater contamination at the site, assessing potential risks to human health from groundwater discharge or use as a water supply, identifying groundwater contaminant problems that require early action to reduce risks to human health and the environment, and performing those actions). The goals of these investigations are to

- develop the environmental data needed to define the nature and extent of groundwater contamination;

- identify and respond to critical contaminant discharge situations through early actions; 
- quantify the uncertainties in prediction of contaminant migration;

- monitor and document changes in contaminant concentrations and locations;

- support remedial investigations and activities at the contaminant source OUs through interpretation of groundwater data and modeling results;

- assess potential risks to human health and the environment from long-term migration of contaminated groundwater; and

- develop feasible remedial action alternatives for controlling those groundwater contaminants that may pose an unacceptable risk to human health or the environment.

\section{GWOU INVESTIGATION APPROACH}

Within this plan, data gaps were defined to guide the GWOU investigation and can be categorized into those needed to determine the nature and extent of contamination in groundwater and those needed to refine and test the conceptual model. Data in the former category are needed to define contaminant flow pathways from contaminant source Waste Area Groupings (WAGs) to the GWOU discharge boundary; gaps in these data are applicable to (1) contaminant source WAGs located in Bethel Valley (such as WAGs 1 and 3) and (2) those source WAGs in Meiton Valley (such as 4, 5, and 7). The main component of the conceptual model that requires confirmation is the integrity of the GWOU boundaries and the assumption that nearly all of the precipitation that reaches the water table exits GWOU as surface flow over White Oak Dam. Each data acquisition activity will provide data pertaining to the nature and extent of contamination and the site conceptual model.

A preliminary screening of risks using existing data has identified strontium and tritium as the primary radiological contaminants of potential concern (COPCs) in groundwater. Some volatile organic contaminants were detected in isolated instances, mainly in the perimeter wells along the WAG boundaries. Beryllium also has been noted as a contaminant contributing to significant risk because of its high slope factor. Further study of background levels must be conducted before a definitive set of COPCs can be determined.

Groundwater flow and contaminant transport modeling is expected to play a key role in the GWOU investigation. Model results will help investigators further understand the site hydrologic regime and may be used to guide subsequent remedial investigation activities. The models will be used to address the following overall objectives:

- determine the base of the active flow system and assess the potential for the off-site transport of contaminants via the deep system;

- assess the impact of the regional flow system on local flow regimes to guide the choice of appropriate boundary conditions in local models;

- provide a means for testing scale differences through comparison with local scale models;

- test and refine the site conceptual model; and 
- provide a front-end model to incorporate into cost-benefit decision analysis for optimizing monitoring and remedial activities.

The Field Sampling/Survey Plan contained within this characterization plan outlines the approach for the first 18 months of work necessary to meet the objectives outlined in this document. During this period, the investigation will focus mainly on nonintrusive activities. A review of historical data will be conducted to optimize available resources and direct efforts in subsequent stages of the investigation. These data will be evaluated for their quality and applicability to attaining the goals of the characterization plan. Data collection during this 18-month period will involve field activities such as piezometric head measurements in existing wells, and seep and spring monitoring and analysis. Additionally, in preparation for subsequent data collection activities, existing well bores will be retrofitted during this time period for vertical head measurements and discrete zone sampling, and geophysical methods will be developed for karst delineation and subsurface structure interpretation.

\section{CHARACTERIZATION PLAN ORGANIZATION}

While major elements common to most work plans are contained within this document, the role of the GWOU as an integrator operable unit requires a slightly different approach. The GWOU Characterization Plan is organized as follows:

Chap. 1, "Introduction," describes the regulatory setting and remedial investigation approach;

Chap. 2, "ORNL GWOU Site Conceptual Model," characterizes the geologic and hydrologic setting of the ORNL site;

Chap. 3, "Nature and Extent of Groundwater Contamination," describes the results of source WAG investigations and historical data;

Chap. 4, "Groundwater Modeling, and Contaminant Fate and Transport Investigation," discusses the use of numerical modeling to gain an understanding of the site hydrologic regime and to assess contaminant transport;

Chap. 5, "Risk Assessment," lays out the site-wide strategy for addressing environmental risk issues;

Chap. 6, "GWOU Test Methods," identifies a number of methods for gathering information related to data gaps;

Chap. 7, "Field Sampling/Survey Plan," outlines the approach for the initial 18 months of . the investigation;

Chap. 8, "Quality Assurance Project Plan," provides guidance to ensure that data are of sufficient quality for their intended purposes;

Chap. 9, "Health and Safety Plan," indicates that a comprehensive programmatic Health and Safety Plan will cover all activities related to the investigation; 
Chap. 10, "Waste Management Plan," identifies wastes management practices that will be used for the investigation; and

Chap. 11, "Data Management Plan," provides a system for maintaining technically and legally defensible data. 


\section{INTRODUCTION}

\subsection{REGULATORY INITIATIVE}

The framework for remedial action on the Oak Ridge Reservation (ORR) is provided by the ORR Federal Facility Agreement (FFA). The U.S. Department of Energy (DOE), the U.S. Environmental Protection Agency (EPA), and the Tennessee Department of Environment and Conservation (TDEC) entered into this Agreement to comply with the Comprehensive Environmental Response, Compensation, and Liability Act of 1980 (CERCLA) and coordinate remediation activities undertaken on the ORR pursuant to CERCLA, the Resource Conservation and Recovery Act of 1976 (RCRA), and the National Environmental Policy Act of 1969 (NEPA).

The general purposes of the FFA are to:

- ensure that the environmental impacts associated with past and present activities at the site are thoroughly investigated and that appropriate remedial action is taken as necessary to protect the public's health and welfare and the environment;

- establish a procedural framework and schedule for developing, implementing, and monitoring appropriate response actions at the site in accordance with CERCLA, the National Contingency Plan (NCP), RCRA, NEPA, appropriate guidance and policy, and Tennessee State law;

- prevent, mitigate, or abate releases or threatened releases of hazardous substances from lowlevel radioactive waste tank systems under this Agreement prior to final remedial action at the site;

- facilitate cooperation, exchange of information, and participation of the Parties;

- minimize the duplication of investigative and analytical work and documentation and ensure the quality of data management;

- ensure that remedial action(s) at the site will be in compliance with applicable or relevant and appropriate requirements (ARARs);

- expedite response actions with a minimum of delay;

- establish a basis for a determination that DOE has completed the Remedial Investigation/ Feasibility Study (RI/FS), remedial designs, and remedial actions at the site pursuant to CERCLA and applicable Tennessee State laws;

- coordinate (1) response actions under CERCLA and this Agreement with RCRA Facility Investigations (RFI) and (2) corrective measures now being conducted under RCRA and applicable State laws; and

- ensure that all releases of CERCLA hazardous substances, pollutants, or contaminants and RCRA hazardous wastes or hazardous constituents are addressed so that a comprehensive remediation of the site is achieved. 


\subsection{ORR ENVIRONMENTAL RESTORATION PROGRAM}

To address contamination of the ORR as a whole, the ORR has been partitioned into waste area groupings (WAGs) and operable units (OUs), which can be prioritized to achieve the most effective and rapid investigation and cleanup possible. An OU is defined as a discrete action that constitutes an incremental step toward comprehensively addressing site problems. This discreet portion of a remedial response manages migration or eliminates or mitigates a release, threat of release, or pathway of exposure. The cleanup of a site can be divided into a number of OUs, depending on the complexity of the problems associated with the site. OUs may address geographic portions of a site, specific site problems, or initial phases of an action, or may consist of any set of actions performed over time or any actions that are concurrent but located in different parts of a site. OUs will not impede the implementation of subsequent actions, including final action at the site. OUs may be redefined and work schedules adjusted as investigations progress and new data become available.

A WAG is defined as a group of solid waste management units (SWMUs) and/or other areas of contamination that are geographically contiguous or are located within defined hydrologic units. DOE may consolidate SWMUs, WAGs, and/or other areas into single groupings to conduct work under the FFA.

An SWMU is defined as a unit subject to applicable RCRA corrective action requirements, identified by EPA and TDEC as requiring further investigation, and specifically identified as an SWMU in the FFA.

The following guidelines are basic to Environmental Restoration (ER) Program planning and implementation:

- Emphasis is placed on integrating ongoing activities and historical information into the overall effort.

- Considerable attention and importance has been paid to coordinating relevant activities of other major programs with the ER Program to ensure that adequate resources are available, data are provided in a consistent format to satisfy multi-program needs, and technical issues and remediation technologies are communicated throughout the ER Program so that consistent approaches are applied.

- Remedial action schedules for the OUs are dynamic and can be revised per appropriate public involvement and the mutual agreement of DOE, EPA, and TDEC.

- OUs may be redefined or reprioritized as the investigation progresses per appropriate public involvement and the mutual agreement of DOE, EPA, and TDEC.

- Work at the OUs will be managed to minimize waste and to prevent the recontamination of previously remediated OUs.

A fundamental goal of cooperative efforts among DOE, EPA, and TDEC is that remedial action be emphasized. This goal recognizes that no reasonable amount of investigation can resolve all uncertainty and that once remedial actions are initiated they must be able to 
accommodate divergence from original hypotheses. This approach promotes earlier remedy selection, flexibility for remedial action, and contingencies to react to new information discovered during investigations.

The ORR remedial actions will be conducted using a "lead agency" strategy to minimize duplication of effort and maximize oversight productivity. The lead agency is designated as the responsible agency for overseeing and coordinating the activities in accordance with the Agreement. The regulators will provide support within the oversight role to the lead agency.

DOE-Oak Ridge Operations (DOE-ORO), as the lead agency for the ORR, provides the onscene coordination to plan and implement response action under the NCP. Lead agency duties include:

- overseeing and managing ORR remedial activities pursuant to the FFA and the site management plan and

- serving as primary contact and coordinator with the regulators to implement the Agreement.

EPA and TDEC are participating in the Agreement as working partners in initiating the remedial action work at Oak Ridge and in a regulatory oversight role. In this capacity, they provide regulatory opinions and counsel to the lead agency. The regulators assist the lead agency by attending working meetings, providing timely response to action items, and providing timely review and concurrence, where applicable, of ORR remedial documentation and/or activities. EPA, DOE, and TDEC will each designate project managers to coordinate the implementation of the Agreement and the ongoing regulatory oversight duties and shall notify each other in writing of the designation.

The Oak Ridge National Laboratory (ORNL) site was established in 1943, and 47 years of operations have produced a diverse legacy of contaminated inactive facilities, research areas, and waste disposal areas that are potential candidates for remedial action. ORNL initially developed a site-specific Remedial Action Program (RAP) that represents a comprehensive effort to meet new regulatory requirements at about 250 sites. The RAP has been superseded by the ER Program through Martin Marietta Energy Systems, Inc. (Energy Systems).

Because of the large number of sites and the hydrologic complexity of ORNL, the strategy developed in response to regulatory requirements has been oriented toward WAGs rather than individual sites. The WAGs are generally defined by watersheds that contain contiguous and similar remedial action sites. In some cases, there have been hydrologic interaction among the sites within a WAG, making individual sites hydrologically inseparable. The use of groups provides perimeter monitoring of both groundwater and surface water and the development of a response that is protective of human health and environment. Of the 20 WAGs identified at ORNL, 13 are definite candidates for further action.

The ORNL ER Program was established to coordinate DOE's response obligations to the CERCLA and RCRA and other relevant regulations. The program manages remedial efforts to achieve comprehensive remediation of releases and threatened releases of hazardous substances, hazardous wastes, pollutants, or contaminants at or from ORNL. The ORNL ER Program follows a structured path of site characterization, site maintenance and surveillance, interim 
corrective action, alternate assessment, technology development, engineering design, and eventual site closure or remediation.

\subsection{ORNL GROUNDWATER OPERABLE UNIT}

The ORNL Groundwater Operable Unit (GWOU) encompasses all of Bethel Valley, Melton Valley, and Haw Ridge between Bearden Creek as the eastern boundary to the Clinch River as the western boundary (Fig. 1.1). The obvious geographic boundary formed by Haw Ridge separates the Bethel Valley and Melton Valley portions of the ORNL GWOU. The southern boundary of the GWOU is the geologic contact between the Nolichucky shale and the Maynardville limestone of the Conasauga Group, and the northern boundary is the base of the Fleanor member of the Lincolnshire Formation of the Chickamauga Group. The base of the GWOU is considered to be the deepest limit of potable groundwater $(<10,000 \mathrm{mg} / \mathrm{L}$ total dissolved solids). Highly saline groundwater occurs primarily in low permeability bedrock environments, and movement of such highly saline water is extremely slow; therefore, any contaminants contained in such water move slowly toward distant receptors.

Physical boundaries have been established in the conceptual model (see Chap. 2) to define the horizontal and vertical extent of the GWOU. The GWOU is defined in terms of stratigraphy and structure for the northern and southern boundaries, on the presumption that the groundwater divide mimics the surface water divide for the east and west boundaries, and on the presence of brine exceeding $10,000 \mathrm{mg} / \mathrm{L}$, at depth, for the basal boundary. Surface water is not considered in the context of this characterization plan; however, it cannot be omitted from GWOU investigations because of the need to develop a water budget for the GWOU. Shallow groundwater will be investigated in terms of contaminant transport away from source units.

Additional boundary conditions established for this investigation are the selection of contaminants of potential concern (COPCs) derived from source unit investigations (mostly radiological contaminants) and analytical methods used to provide exposure point concentrations for risk assessment purposes.

Primary emphasis will be placed on the shallow $(<30 \mathrm{~m})$ to intermediate groundwater zones ( 30 to $100 \mathrm{~m}$ ), because this is the zone of potential future groundwater use and is the depth of potential contaminant migration. The major effort will entail the identification of any potential exit pathways for the intermediate zone and the demonstration that saline-freshwater interface is stable, supporting the contention of no deep zone flow out of the GWOU.

\subsection{PURPOSE AND SCOPE OF THE ORNL GROUNDWATER CHARACTERIZATION PLAN}

Conceptually, the RIs resulting from the Characterization Plan for the ORNL Area-Wide Groundwater Program will be planned and implemented in the same manner as the ongoing remedial investigation of WAG 2 at ORNL; i.e. a general plan for each RI will be prepared and submitted to EPA and TDEC for review and approval followed by more specific addenda to the general plan. 


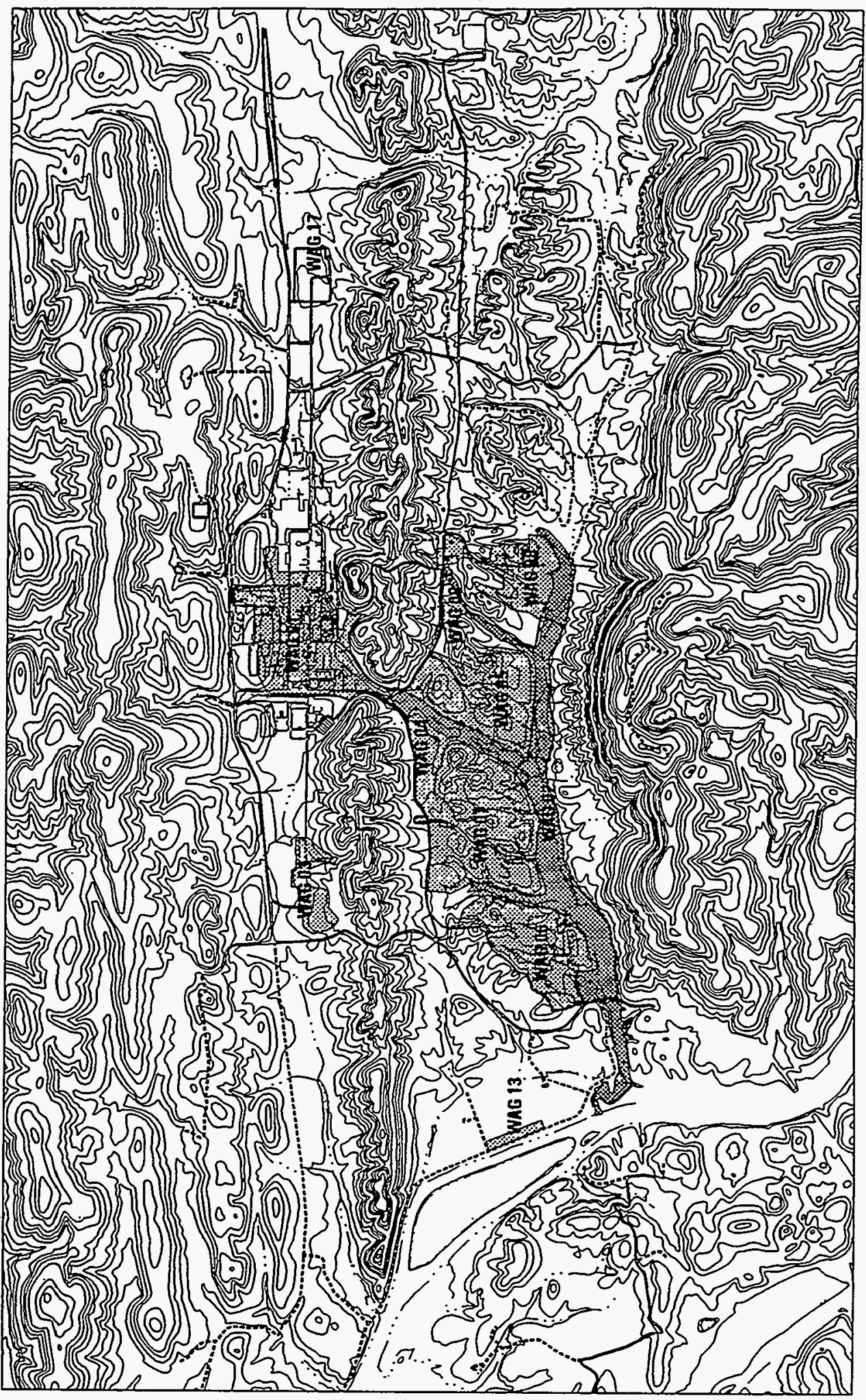


The Characterization Plan for the ORNL Area-Wide Groundwater Program is intended to serve as a strategy document for performing the ORNL GWOU Remedial Investigations. The purpose of this document is to provide a rationale and organization for groundwater data acquisition, monitoring, and remedial actions performed during implementation of environmental restoration activities associated with the ORNL GWOU. Data acquisition is expected to improve our understanding of the nature, extent, and fate and transport of groundwater contamination. This understanding will subsequently improve our ability to select and implement appropriate and effective groundwater remedial actions.

It is important to note that this characterization plan for the ORNL GWOU is not a prototypic RI Work Plan. This plan is presented with the understanding that RI work plans and more specific addenda to it will follow; it outlines the strategy and overall activities of the ensuing RIs and defines tasks that are included in the initial phase of investigation. The ensuing RIs will be conducted using annual work plans to manage the work activities, and task reports will be used to document the results of the investigations. Sampling and analysis results will be compiled and reported annually with a review of data relative to risk (screening level risk assessment review) for groundwater.

The ORNL GWOU Remedial Investigations will be part of a multi-year program addressing many aspects of groundwater flow, defining the nature and extent of groundwater contamination at the site, assessing potential risks to human health through groundwater discharge or use as a water supply, and identifying groundwater contaminant problems that require early action to reduce risks to human health and the environment, and performing those early actions. The goals of this remedial investigation are to:

- develop the data to define the nature and extent of groundwater contamination;

- identify and respond to critical contaminant-discharge situations through early actions;

- address the uncertainties in prediction of contaminant migration;

- monitor and document changes in contaminant concentrations and locations;

- support remedial investigations and activities at the contaminant source OUs through interpretation of groundwater data and modeling results;

- assess potential risks to human health and the environment from long-term migration of contaminated groundwater; and

- develop feasible remedial action alternatives for control of those groundwater contaminants that may pose an unacceptable risk to human health or the environment.

The hydrogeologic complexity of the ORNL GWOU (described in Chap. 2) combined with the numerous contaminant sources and variable natures of contaminants of concern (described in Chap. 3) raise several key technical issues that must be addressed in the process of the remedial investigation: 
- resolving the nature and extent of groundwater contamination;

- defining the uncertainties in delineation of groundwater contaminant transport pathways; and

- quantifying the uncertainties in predictions of future contaminant concentrations and locations for reliable risk assessment.

To meet these goals and address the key issues associated with the long-term risk assessment and groundwater contaminant remediation, a variety of investigations, each of which responds to one or more data needs, will be conducted for the GWOU.

\subsection{RI IMPLEMENTATION STRATEGY}

As described in Sect. 1.4, the GWOU remedial investigations will be conducted throughout a period of several years, using an observational approach that is responsive to issues that must be addressed in determining appropriate groundwater contaminant migration control and remediation. The project goals outlined in Sect. 1.4 serve as a general scope of the long-term investigation. Implementation planning will address the details of tasks in a prioritized fashion. This characterization plan explains long-term project goals and identifies the tasks to be performed in the first phase of investigation.

Existing information has been examined sufficiently to identify data gaps of initial concern with regard to the GWOU-wide groundwater flow system and nature and extent of groundwater contamination (Chap. 3). These data gaps serve as the starting point for the remedial investigation activities. In summary, these data gaps include:

- refinement of the conceptual model of groundwater flow and contaminant migration;

- establishment of appropriate exit-pathway and hydrofracture-area monitoring;

- identification of the OU groundwater flow boundaries and determination whether underflow of watershed boundaries occurs;

- identification of contaminant migration pathways, including characterization of the karst flow systems and risk-based prioritization of contaminant discharge control actions;

- definition of the nature and extent of groundwater contamination between and beneath contaminant source OUs;

- quantification of hydrogeologic parameters and contaminant retardation mechanisms that control long-term contaminant migration; and

- development of site models appropriate for both investigation planning and remedial alternative cost-benefit analysis, long-term groundwater risk assessment, and uncertainty analysis. 


\section{$1-8$}

Initial GWOU remedial investigation activities include performing investigations that will define an appropriate flow system boundary and exit pathway monitoring system; upgrading and instrumenting existing deep borings that are appropriate for multi-zone head pressure and water quality sampling to add to the three-dimensional monitoring network; establishing an ongoing water-level monitoring network; establishing seep and spring monitoring related to karstic groundwater flow conditions within the GWOU; establishing and calibrating comparable threedimensional groundwater models for Bethel Valley and Melton Valley (a Melton Valley model is in calibration at the time of characterization plan development); compiling, managing, and interpreting data on geology, groundwater, and contaminants throughout the GWOU area; and supporting the ongoing environmental restoration activities in contaminant source OUs through modeling, data interpretation, and technical support (Chap. 7).

The basis for starting with the investigations described in Chap. 7 is that these are the tasks that must be performed to initiate a site-wide appraisal of the groundwater flow and contaminant transport conditions throughout the extent of the ORNL GWOU.

In the performance of the GWOU investigations, each issue under investigation will be evaluated through the data quality objective process. This evaluation will document conditions expected to be encountered in the area, identify alternative conditions, factor these alternatives into the area conceptual model, and use a carefully targeted subsurface investigation to resolve the issue under investigation. Tracking the results of these targeted investigations will be the basis for confirmation or modification of the conceptual model of groundwater flow and contaminant transport within the GWOU. This conceptual model is of key importance because it forms the basis of all assumptions used in the long-term groundwater-flow and contaminanttransport models used in risk assessment.

As mentioned above, one component of the characterization plan will be to develop and refine groundwater models for the GWOU area and for local areas of concern. These models will assist in the planning of intrusive investigations, data collection, and performance of cost-benefit evaluations on proposed remedial actions in support of contaminant source OUs as well as the GWOU. Chapter 4 describes groundwater modeling activities planned to support the GWOU and other ORNL ER Program activities. As the remedial investigation progresses, model evaluations of existing data and the need for additional data will be considered in investigation planning. A portion of the remedial investigation work will collect data that quantify the mechanisms that attenuate groundwater contamination and control the ability to remove contaminants from the subsurface. These retardation mechanisms ultimately control the fate and transport of contaminants and control the effectiveness of some remedial alternatives.

The initial and subsequent RIs will collect and utilize geophysical data where appropriate and feasible to identify locations where intrusive investigations are judged to be most informative in addressing issues or data gaps. Geophysical investigations that may be used in the $\mathrm{RI}$ are discussed in Chap. 6.

\subsection{RELATIONSHIP OF GWOU TO CONTAMINANT SOURCE WAG ACTIVITIES}

The ORNL GWOU encompasses the subsurface environment beneath and between all the ORNL facilities, contaminant source OUs, and WAG 2 in Bethel Valley and Melton Valley 
(Fig. 1.2). Lateral GWOU boundaries are described in Sect. 1.3. The base of the GWOU is taken as the elevation where groundwater salinity reaches $10,000 \mathrm{mg} / \mathrm{L}$ total dissolved solids. The hydrofracture injection zones (WAG 10) for HF-2, HF-3, and HF-4 beneath Melton Valley lie beneath the GWOU because, at the injection depths in these wells, the groundwater consists of highly saline brine. The hydrofracture 1 experimental site lies within the depth region encompassed by the GWOU.

Because the GWOU serves as this integrator for groundwater, remedial investigation activities associated with the GWOU include investigation of contaminant plumes that extend beyond the contaminant source WAG boundaries or extend significantly below local stream base levels. The source WAG remedial actions must include detailed assessments of groundwater both as a contaminated media to be assessed as well as a site physical constraint to source remediation. At the ORNL site (Fig. 1.2), most contaminant sources are located above the floodplain elevations of the local surface water drainage system. The depth to which contaminant source groundwater OUs have concern and responsibility for groundwater conditions is approximately the stream base elevation within the respective WAG boundary. At depths greater than the stream base, the site-wide GWOU has primary responsibility for assessing groundwater contaminant movement because deeper flow paths suggest longer distance and longer duration migration pathways.

In addition to collection of groundwater-related data in areas outside the contaminant source WAGs, the GWOU uses the groundwater data obtained through the source WAG investigations in assembly of the site-wide geologic and groundwater flow conceptual and computational models. The GWOU provides technical support to the source WAG investigators in the forms of modeling support, technical recommendations on the tests and investigations to perform, recommendations on groundwater contaminant control measures implemented either as early actions or as remedial actions, and data sharing.

\subsection{IDENTIFICATION OF POTENTIAL CLASSES OF REMEDIAL TECHNOLOGIES}

As stated in Sect. 1.4, one objective of the Characterization Plan for the ORNL Area-Wide Groundwater Program is to identify the need for and implement early action to control the off-site migration of contaminants in groundwater. Remedial technologies that may be used to accomplish this goal include interception and treatment using trenches and subsurface drains to intercept contaminated groundwater; installation and operation of pumping wells to contain contaminant plumes; and in-situ zeolite treatment. Any groundwater intercepted and/or pumped from wells would be treated in the Process Waste Treatment Plant (PWTP) and/or the Waste Evaporator.

An alternative to groundwater collection in areas where groundwater and secondary contaminant sources are commingled is hydrologic isolation of the secondary contamination and associated groundwater. Technologies that may be used to accomplish this goal are pumping of contaminated groundwater in source areas, in-situ vitrification of contaminated soils, cryogenic freezing of contaminated areas, hydraulic isolation of contaminated areas (e.g., by installation of grout curtains or sheet pilings), and excavation of contaminated soils that may be serving as secondary sources of groundwater contamination. 


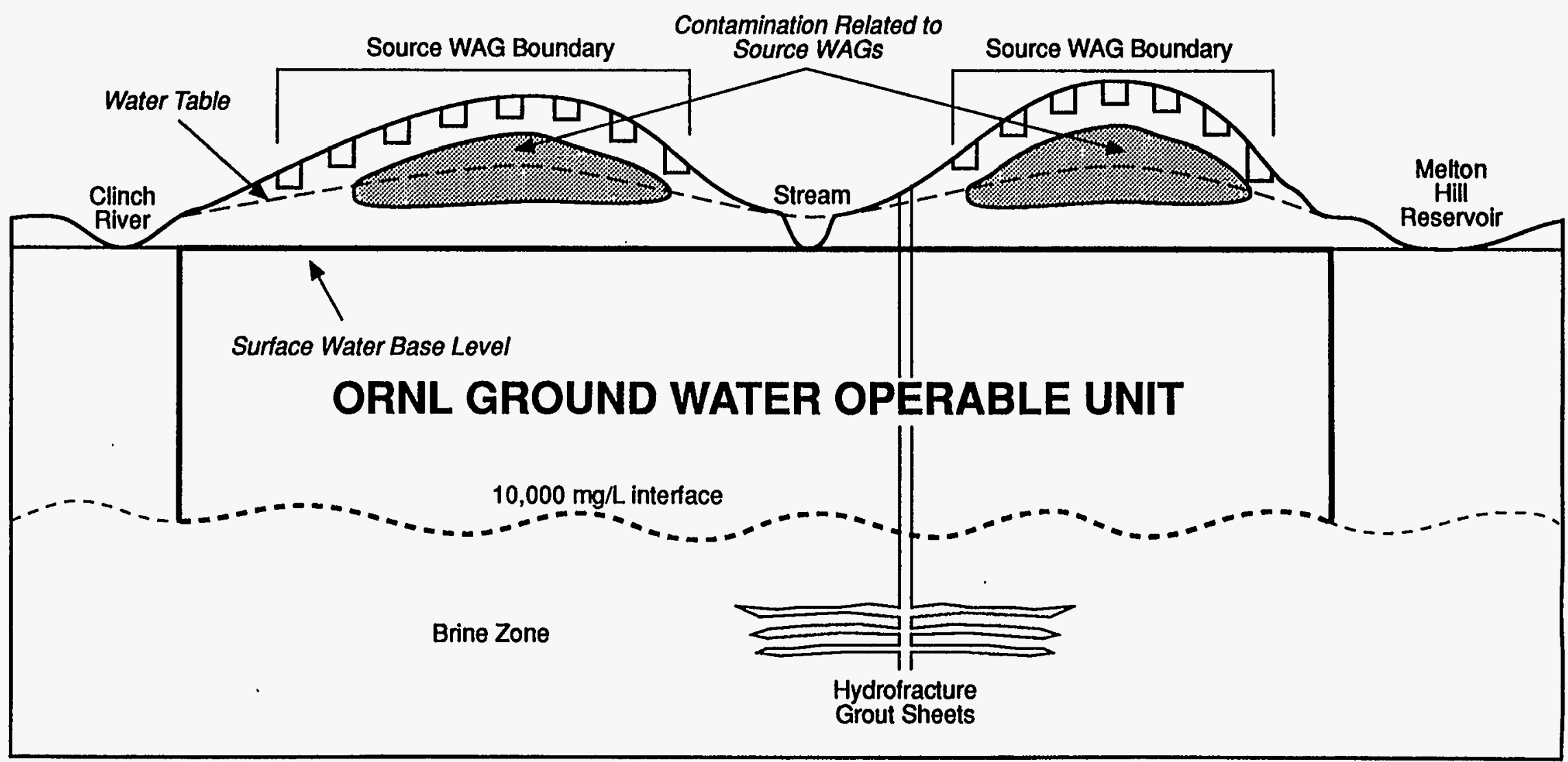

Fig. 1.2. Schematic model of the relationship between the source WAGs and the integrator GWOU. 
Data needs for evaluating these alternatives are (1) the locations of sources and pathways; (2) the levels of contamination in source areas and contaminant plumes; (3) the areal extent of source areas and contaminant plumes; (4) the isotopic composition of the contamination; and (5) the relative contribution of the contaminant discharges to off-site risk.

\subsection{RISK ASSESSMENT FOR THE GWOU}

A baseline risk assessment will be prepared in combination with the final RI report for the GWOU. Screening level risk assessments with analysis of the trends of groundwater contaminant concentrations will be performed annually using data collected by the GWOU, contaminant source WAG monitoring, and ORNL Compliance Division data obtained from WAG perimeter monitoring wells.

\subsection{PROJECT SCHEDULE}

The schedule for completion of the GWOU remedial investigation is dovetailed with the schedule for completion of the WAG 2 Remedial Investigation; 2008 is the anticipated year of completion. The project will be managed through preparation of annual sampling and analysis plans, with annual reports issued at the end of each fiscal year.

The Annual Sampling and Analysis Plans (SAPs) will be issued as addendums to a general work plan, and work will proceed as planned and described therein unless comments are received from regulatory agencies, or clarification is needed. The Annual SAPs will be an informal mechanism for presenting planned GWOU characterization activities on a timely basis by avoiding formal documentation and lengthy reviews. The Annual Reports will document the activities and findings of the ORNL GWOU RI and will update the scope and strategy for future GWOU-related efforts.

\subsection{DATA QUALITY OBJECTIVES}

Data quality objectives (DQOs) are qualitative and quantitative statements that specify the quality of the data required to support decisions during remedial response activities. The DQO process follows the "observational approach," which is aimed at characterizing the site, interpreting and predicting expected conditions and deviations from expected conditions, and formulating decision rule statements to guide site activities. The process sequentially develops the consideration of relevant issues such as the definition of the problem, decision points, participants, and uncertainties. The process flow is depicted in Fig. 1.3.

DQOs are determined on the basis of the end uses of the data to be collected. For example, sufficient data may have to be collected to characterize the site, evaluate remedial alternatives, determine design criteria, perform the baseline risk assessment, or monitor site conditions or remedial action effectiveness. DQOs apply to all types of data collected, not just to the analytical data from a laboratory. The level of detail and data quality needed varies on the basis of intended uses of the data. The variability of site characteristics makes it impossible to apply a generic set of DQOs to all CERCLA activities. 


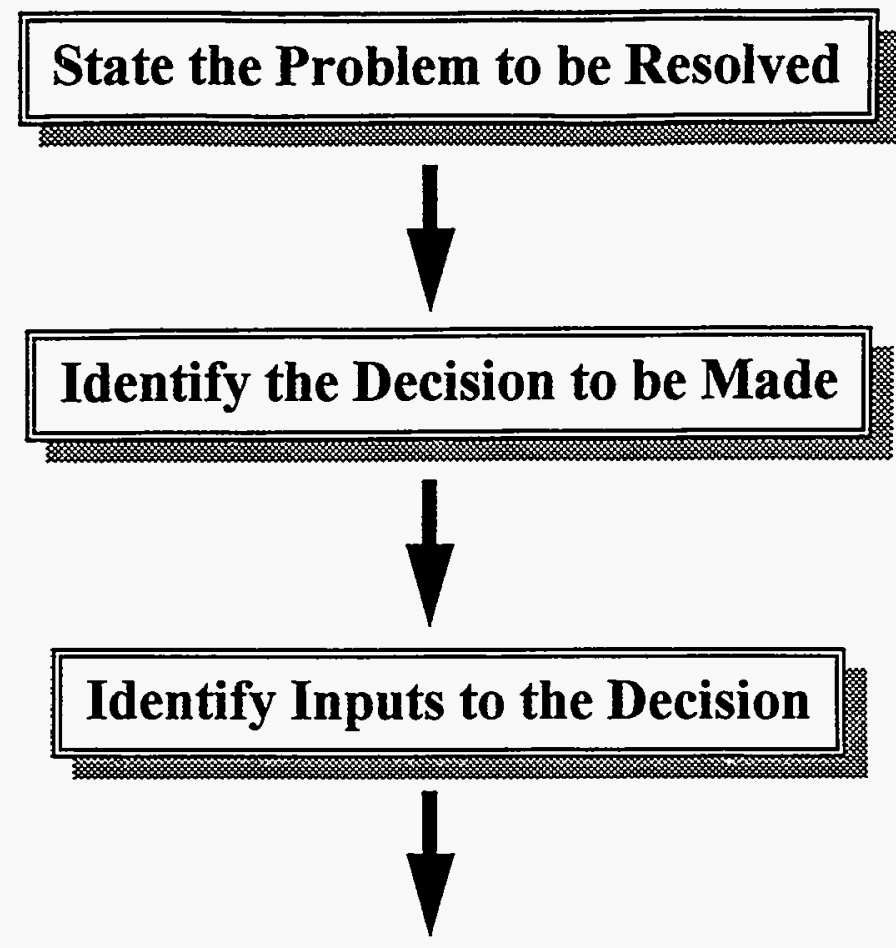

\section{Define the Study Boundaries}
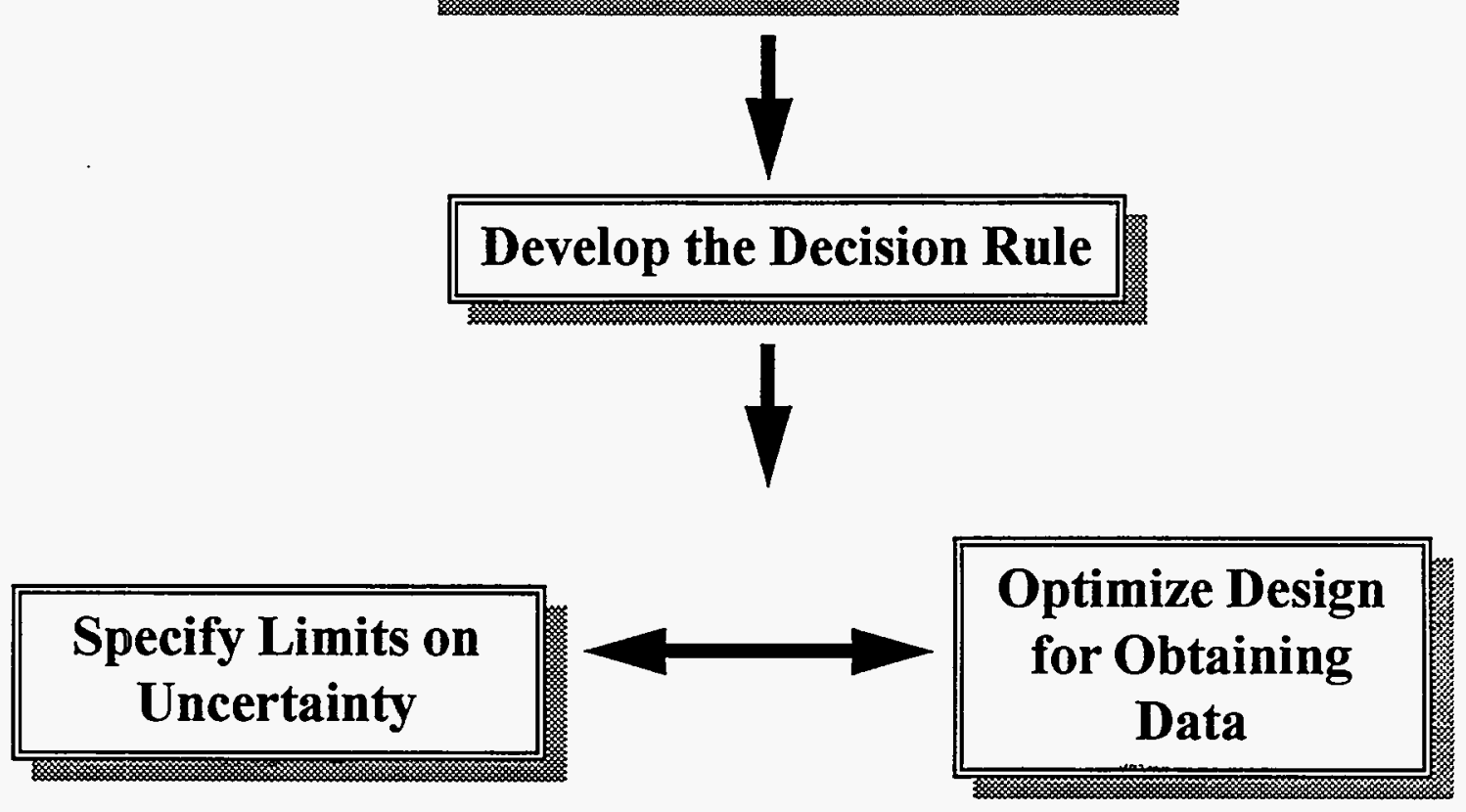

Fig. 1.3. The DQO development process. 
Because of the complex nature of groundwater flow at ORNL, this document will provide the conceptual plan for a staged investigation in which the direction of later phases will be contingent on the results from initial stages. Establishing DQOs will, therefore, be an evolving process. This investigation, more than most, will incorporate a wide range of data types with varying degrees of precision and accuracy. Much of the data will be used to validate the conceptual model and therefore will be interpretative in nature. Because interpretations made from these data may not have a unique solution, the establishment of specific criteria against which to judge data quality may not be possible (or at least may not be possible on a programwide basis).

The investigation will be staged over several years to resolve data gaps listed in Chap. 2 . To encourage optimum data usage, a substantial effort during the early stages of the investigation will be directed toward critical review of existing data and data gathering using existing boreholes, stream monitoring locations, and nonintrusive surface techniques. Figure 1.4 shows how review of existing data fits into the overall strategy of data acquisition. An important part of the investigation will be the geophysical method development and site-specific testing of several geophysical techniques to be used in the delineation of the saline-fresh water interface, strata-bound karst identification, and geologic structure. Computerized modeling will be used to identify key data gaps in the existing data base.

The encompassing problems to be addressed during the GWOU investigation will be to assess the integrity of the vertical and horizontal OU boundaries, to identify and evaluate preferential contaminant transporting flow zones, including conduits that act as preferred exit pathways, and to quantify the contaminant attenuation mechanisms that control the mobility of contaminants in the subsurface. A conceptual model has been developed to assist in establishing DQOs for this assessment. This model incorporates the current knowledge of the bedrock geology and hydrogeology to identify data gaps related to the stratigraphy (including karst features), structure, and shallow/deep groundwater flow paths. COPCs related to the source OUs, migration of the COPCs within the GWOU, and the surface-groundwater relationship will be considered during this investigation. The investigation will also assist with the quantification of groundwater flow by providing input into fate and transport modeling. This input will consist of determining groundwater and aquifer parameters for key areas of the GWOU. Chapter 2 describes a conceptual model of groundwater flow and transport developed for the ORNL GWOU on the basis of a review of operational history and existing environmental samples and their analyses.

\subsubsection{Decisions To Be Made}

It is expected that a number of groundwater management unit investigations will be conducted that will constitute the ORNL GWOU RI. The scope of this investigation will result directly from the characterization strategy outlined in this document (e.g., see Fig. 1.4). Existing information and data derived during characterization studies will facilitate decisions regarding which discrete groundwater management units pose a potential threat to human health or the environment. Data derived during the subsequent remedial investigation will more fully describe the nature and extent of groundwater contamination at ORNL and form the basis for making risk management decisions and for taking further CERCLA actions. 
Integrator $\mathrm{OU}$
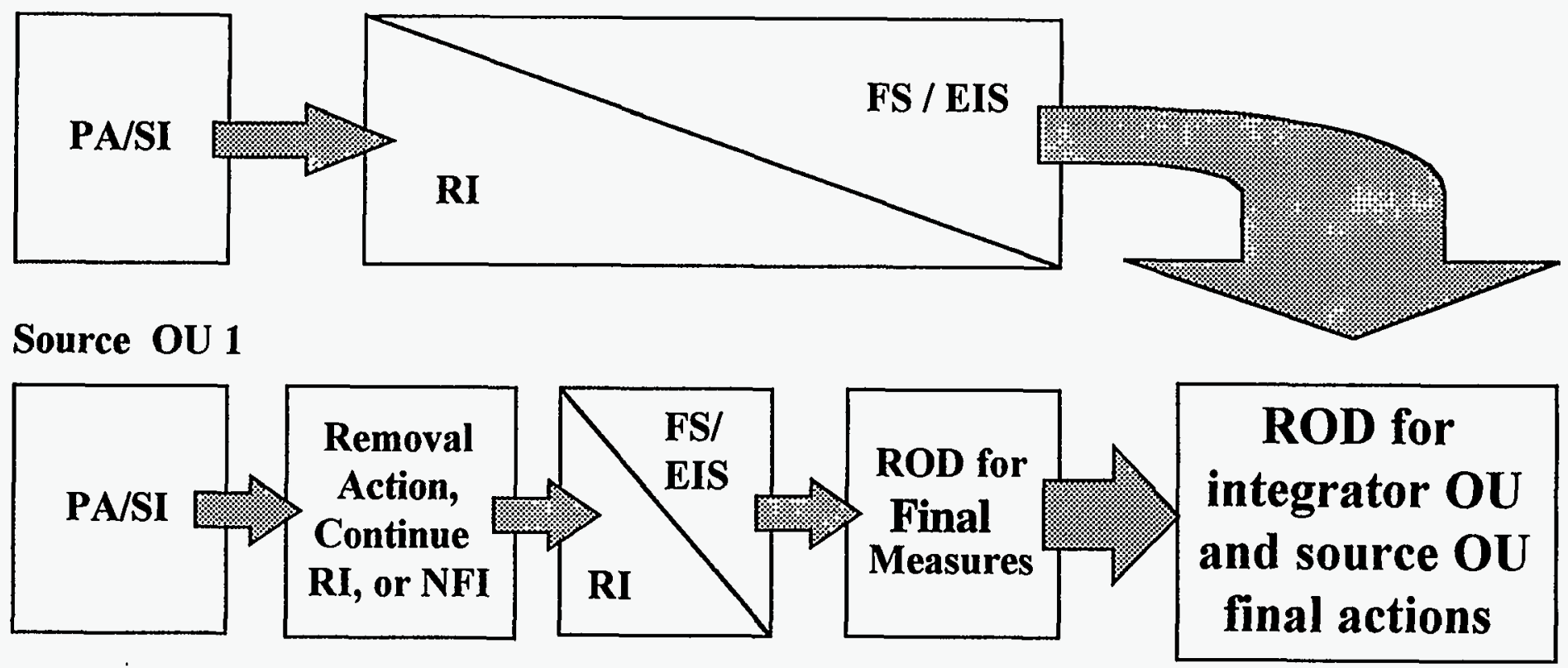

Source OU n

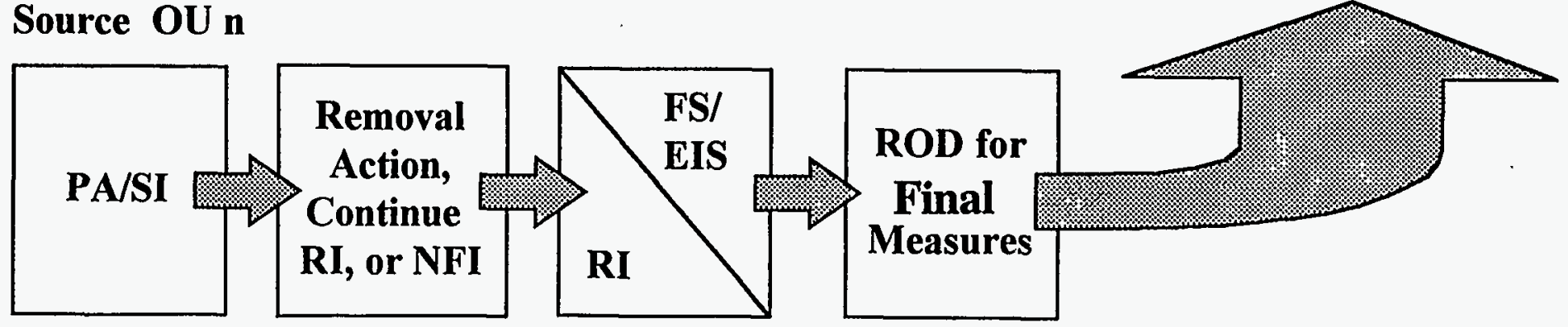

Fig. 1.4. Flow diagram showing the integrator-source $O U$ investigation process. 


\subsubsection{Inputs to the Decision}

Inputs to a decision should be derived from two broad questions: Who are the users of the data obtained during the course of the RI, and what are the actual uses of the data?

\subsubsection{Data users}

An RI conducted under CERCLA is designed to fill data gaps, allowing subsequent participants in the process to accomplish their tasks. For instance, risk assessors will use data on the contaminant concentrations to calculate the toxicity and the risk of excessive lifetime cancers under defined exposure assumptions. Planners and engineers will use the data to screen remedial alternatives in the FS and to make recommendations regarding cleanup and mitigation options.

The following is a description of the data users and their responsibilities for the ORNL GWOU:

RI Contractor(s)-the ORNL ER Program, ORNL Environmental Science Division, and Science Applications International Corporation (SAIC) solicit input and concurrence from the other participants for data needs; design an investigation to obtain the data; and evaluate the data to ascertain the nature and extent of contamination at each site as well as the potential risks to human and environmental receptors.

FS Contractor-the ORNL ER Program, ORNL Engineering Division, and Jacobs Engineering use the results of the RI to assess the magnitude of the cleanup task; to screen the remedial alternatives in a systematic manner; and to make recommendations for the Record of Decision (ROD).

Integrating Contractor-Energy Systems organizes the overall approach to the RI/FS and evaluates the results and conclusions for the RI, FS, engineering design, and construction management tasks.

Lead Agency - the Environmental Restoration Division of DOE-ORO has primary responsibility for the success of the environmental restoration program, initiates and oversees the entire process, provides budget and schedule constraints, and closely coordinates input and approval from the other FFA participants.

FFA Participants-DOE, EPA, and TDEC have the ultimate decision-making authority on any recommendations or initiatives; have regulatory and lead agency oversight on the approach, schedule, and budget for the environmental program; respond to public needs; and ensure public health and safety.

The General Public and Public Interest Groups-The public as a whole, and specific groups within the public, participate in policy decisions by providing input to basic considerations such as the definition of acceptable risk and what constitutes a worthwhile benefit. 


\subsubsection{Data uses}

Data uses are defined as those data applications that help resolve the project issues and data gaps. Data from the investigation will be used by hydrogeologists to validate the conceptual model or construct an alternative to the existing model. Data will also be incorporated into numerical models to: (1) describe fate and transport of contaminants, (2) complete a risk assessment to determine the impact to human health and the environment, and (3) permit the selection of remedial technologies to mitigate contaminant releases.

Identifying data uses and needs follows the development of the objectives and conceptual model developed for the site and involves

- identifying data uses, types, quality needs, and quantity needs;

- evaluating sampling and analysis options;

- reviewing precision, accuracy, representativeness, completeness, and comparability (PARCC) parameter information; and

- applying PARCC parameter information.

Data uses for the GWOU remedial investigation must be defined in both the short term and the long term, because the investigation will take place over several years. Anticipated uses for the data during these time intervals are:

\section{Short term}

- select locations that require early actions to interrupt or control contaminated groundwater migration and

- develop technical options for early actions identified above and support the screening of alternative;

\section{Long term}

- determine the remedial actions required for contaminated groundwater based on the estimate of risk,

- propose technical alternatives to clean up contaminated groundwater for zones that may require remedial actions, and

- determine the extent of long-term monitoring required to verify that acceptable levels of risk exist at boundaries of controlled areas when established.

Identifying Data Types. Several types of data are required for the GWOU RIs, including historical data on water levels, water quality, and hydrogeologic parameters; geophysical measurements; data to quantify the fate and transport behavior of COPCs in the groundwater 
system; data that define the location of contaminant transporting zones; and concentration trends of contaminants in plumes.

Identifying Data Quality Needs. Data quality needs vary with the types of data to be collected. Quality control (QC) is least strict for historical records and most strict for laboratory analyses. Other data types with QC include observations by the field sampling and analysis team, geophysical measurements taken in area surveys, and geohydrologic measurements. Detailed data quality and QC measures for specific investigation tasks are included in the detailed task plans and in the Field and Laboratory Quality Assurance Project Plans (QAPjPs).

Identifying Data Quantity Needs. Data quantity needs for the GWOU RI vary by issue and geographic location within the GWOU area. Data quantity is determined in application of the decision rules described in Sect. 1.10.3 to each issue or data gap in the RI with consideration of PARCC requirements. Data quantity for individual RI tasks will be addressed in the detailed task plans.

Evaluating Sampling and Analysis Options. Sampling and analysis options to meet data requirements must be evaluated for technical and economic feasibility. This will be done for each of the data types required to meet the objectives for this project. Laboratory quality assurance (QA) is the responsibility of the laboratory, as delineated in the Laboratory Quality Assurance Plan approved by the Analytical Project Office.

Reviewing and Utilizing PARCC Parameter Information. The PARCC of all data proposed must be accounted for in the final data evaluation effort. This includes operational histories, field observations, and laboratory analyses. The sampling program was designed so that data of sufficient quantity would enable a reasonable, accurate evaluation of the nature and extent of contamination and its fate in the environment. If all data are not received as requested, accuracy of the evaluation is jeopardized. The QA documentation required to verify that all data can be accounted for will be described in the Field and Laboratory QAPjPs.

\subsubsection{Decision Rule}

At the project level in the CERCLA process, the decision rule is a statement regarding the choice of alternatives based on the results of the investigation. Because the purpose of the GWOU investigation is to ascertain whether groundwater is migrating off site and whether human or ecological receptors will suffer unacceptable impacts, the decision will be whether to effect remedial actions. The range of remedial actions will be determined by the rate, volume, and concentration of contaminant migration as well as by feasible technologies available to mitigate any potential exposure.

The CERCLA process incorporates the decision rule in the following manner:

- Upon completion of the RI, a limited number of alternatives will be developed in the FS for remediation of the groundwater to ensure long-term protection. A focused-alternatives analysis will then be performed using the nine criteria established by CERCLA. 
- On the basis of the analysis of all alternatives studied in the FS and the evaluation of the alternatives against the nine criteria, DOE will recommend preferred alternatives for cleanup, as outlined in an Interim Proposed Plan submitted to state and federal regulators.

- After the regulators review and comment on the plan and the comments have been addressed and resolved, the plan will be made available for public comment. Comments will be addressed and incorporated into an ROD, followed by remedial design/remedial action.

In addition to this project-level decision rule for the ORNL GWOU remedial investigation, a set of decision rules will be prepared for use in directing subsurface investigations. Each issue or data gap related to the nature and extent of groundwater contamination or groundwater flow under investigation will be evaluated with respect to existing data, expected groundwater conditions in the area of the data gap based on the conceptual model, alternative conditions or deviations, and model uncertainty in the area of question prior to initiation of an intrusive investigation. Intrusive investigations must resolve the data gaps and either confirm or refine the conceptual model in the area of the test(s) and reduce overall model uncertainty with the most cost-effective level of investigation. This approach is consistent with the overall objectives of the program and, near the end of site investigations, should provide reasonable predictive capabilities for the behavior of contaminant flow pathways with bounds on uncertainty in model predictions.

Two classes of decisions must be made during the course of any investigation: near term and long term. The following is an initial presentation of the decisions and decision rules:

Near-term decisions:

- Is the contamination detected in the shallow groundwater exiting to surface water via a seep? If so, does this groundwater contamination contribute significantly (e.g., 10\%) to the total risk at White Oak Dam?

- Do new data indicate that potential plumes or groundwater exit pathways need to be further investigated? Do new data suggest contaminants in shallow groundwater are migrating to deep groundwater at rates and concentrations greater than those suggested by currently available information?

- Are removal actions proposed by other WAGs (e.g., WAG 5) technically feasible (e.g., does the proposed action address or affect groundwater and thus require decision-making support from the groundwater $\mathrm{OU})$ ?

Near-term decision rules:

- If groundwater contamination that directly seeps into surface water in White Oak Creek watershed contributes to $\sim 10 \%$ or more of the total ${ }^{\text {'0 }} \mathrm{Sr}$ flux (relative to 1993 monitoring data), that discharge will be considered for an expedited response action such as a time-critical or interim removal action.

- If new data indicate that the migration of contaminants from shallow to deep groundwater is more prevalent than currently thought (e.g., new contaminant hits or high concentrations), 
the following annual scheme will accommodate additional investigations of the deep groundwater to address concerns raised by the new data.

\section{Long-term decisions:}

- What constitutes a shallow or deep groundwater plume that would need to be addressed by a Baseline Risk Assessment and a Feasibility Study detailed analysis of alternatives? What constitutes a plume for which groundwater flow and transport modeling may be required?

- What are the primary deep groundwater exit pathways that could result in long-term off-site exposures to the public?

- What are the exposure point concentrations associated with a plume to which future on-site residents could be exposed?

\section{Long-term decision rules:}

- Not available at this time.

The primary decision makers in the DQO process must concur, amend, and supplement these decisions. It should be noted, however, that at this point in the process long-term decision rules cannot be established.

\subsubsection{Uncertainty Constraints}

Uncertainty constraints are efforts to control decision errors based on environmental data, which always involve some degree of uncertainty. Both administrative and method-specific constraints can be incorporated into data collection activities to minimize uncertainty. While much of the data to be generated during this investigation will be used to validate or revise the conceptual model and is interpretive in nature, other activities lend themselves to quantitative limits on the acceptable error.

Any data derived from the groundwater sampling and analysis described in this plan or detailed task plans will be collected and documented in such a manner as to be technically and legally defensible. Specific methods to provide defensible quality will be outlined in an accompanying GWOU QAPjP. In general, however, sampling will be performed according to a set of approved procedures and documented with field logbooks and chain-of-custody records. The sampling design will be set forth to determine the nature and extent of contamination in potential groundwater plumes and will characterize the statistical population distribution of the contaminants. Some analyses and data-gathering activities may be proposed to acquire data for screening level assessments and will be subject to sufficient scrutiny and quality controls to ensure a useable data base. For other activities, laboratory methods will be performed according to the EPA Contract Laboratory Program (CLP) Statement of Work (SOW) or an analogous statement of work/method for radiochemical analyses that identifies acceptable internal QC limits, calibration frequencies, etc. Laboratory and field data will be validated to ensure that they provide a technically defensible basis for the resultant decisions. The data will be used principally to support risk-based decisions for remedial actions and to establish appropriate action levels. Because of the diverse type of activities to be conducted during the GWOU RI, data 
validation criteria and QA limits will be established on a project-specific basis in a DQO workshop, which will be held early in the RI process. The purpose of the workshop, which will be attended by the primary data users, is to ensure that the data derived from the investigation are precise, accurate, and representative enough for their intended uses. The outcome of the workshop will be to define the uncertainty constraints as a set of DQOs for each task.

\subsubsection{Design Optimization}

The Characterization Plan for the ORNL Area-Wide Groundwater Program has developed its testing and sampling design by outlining a series of known data gaps that must be resolved to confirm/revise the conceptual model. These data gaps have been formulated in relation to specific areas of the GWOU and in the vicinity of certain WAGs within the OU to locate proposed tests. Conducting individual tests at specific sites will allow the investigation to focus on defined questions and observations related to locations rather than testing general concepts throughout the GWOU. Moreover, the investigation is planned to economize resources by testing several data gaps (i.e., depth to salinity, vertical head distribution, and strata-bound karst development from a single borehole) with one activity. In addition, the development of low-cost and nonintrusive geophysical techniques will be promoted to answer many of the questions that might otherwise require expensive drilling and coring operations. The techniques will, at a minimum, assist in optimizing the location of the tests.

The RI is initiated with the first stage of the DQO process. This stage should be repeated whenever (1) new data on either the operational history or the site environment are received by the primary data users or (2) the objectives or the requirements of the investigation are redefined. This stage comprises the following tasks: identifying and involving data users, evaluating available information, developing a conceptual model, and specifying objectives and decision rules.

\subsection{QUALITY ASSURANCE}

\subsubsection{Program Planning and Implementation}

The overall planning and implementation of QA and QC activities of this project are governed by the Environmental Restoration Quality Program Plan [ES/ER/TM-4/R3 (Energy Systems 1993d)], which addresses the guidance in EPA's Interim Guidelines and Specifications for Preparing Quality Assurance Project Plans [EPA-600/4-83-004 (QAMS-005/80)] (EPA 1983a) and the specifications of the Energy Systems Quality Procedures Manual, the American Society of Mechanical Engineers document Quality Assurance Program Requirements for Nuclear Facilities [ASME NQA-1 (ANSI/ASME 1989)], and applicable DOE orders. 


\subsubsection{Project-Specific Planning}

The ER Quality Program Plan [ES/ER/TM-4/R3 (Energy Systems 1993d)] will be supplemented by the Field QAPjP and the Laboratory QAPjP. The format and requirements of these project-specific QAPjPs are based on the elements of QAMS-005/80 and will integrate other elements of the ER Quality Program Plan as needed. 


\section{ORNL GWOU SITE CONCEPTUAL MODEL}

\subsection{INTRODUCTION}

This section presents a conceptual model for subsurface flow and contaminant transport at ORNL and identifies data needs for accurate characterization of the potential for off-site contaminant migration. The conceptual model represents an integration of data, information, and interpretations from many technical studies. The model is intended to describe the concepts of groundwater flow in the GWOU and the physical factors that define those concepts. This characterization plan identifies as data gaps those parts of the model that are limited by data availability and those parts that are challenged by observations made subsequent to formulation of the concepts. These data gaps will be the data needs for the RIs that follow from this characterization plan. Because the focus of the RIs will be to ensure that contaminants do not migrate outside of the GWOU boundaries, a primary emphasis of the RIs will be placed on evaluating the integrity of the GWOU conceptual boundaries and characterizing GWOU exit pathways.

The conceptual model is described in three component sections. The first of these is the Geological Setting (Sect. 2.2), which describes the GWOU in terms of its underlying lithologic and structural characteristics. The second section is the GWOU Hydrological Conceptual Model (Sect. 2.3), which describes the behavior of subsurface water and the strong stratigraphic and structural controls on groundwater flow in the GWOU. The third section is the GWOU Boundaries and Pathways (Sect. 2.4). This section describes the GWOU conceptual boundaries and summarizes the essential information, including data gaps, for understanding the potential for contaminant transport outside of the GWOU. These three sections emphasize the hydrogeology of the GWOU, but utilize information related to any rock unit within the ORR when appropriate. In particular, considerable attention is paid to the Knox Group and to the Knox aquifer whose rocks bound the GWOU but lie outside of its boundaries. The hydrologic properties of these rocks, however, make them effective barriers to groundwater in the GWOU and therefore they play an important role in boundary considerations.

The site conceptual model is presented here beginning with Sects. 2.1.1 through 2.1.3 that outline the fundamental points of the three parts of the site conceptual model. Sections 2.2 through 2.4 then provide details on each of these components.

\subsubsection{Geological Setting of the GWOU}

- The geology of the GWOU displays a layer-cake-style stratigraphy that is observed on a regional scale where limestone- and dolomite-dominated rock groups are interbedded with dominantly clastic groups. This style is repeated on the outcrop scale where clastic beds are interlayered with limestone/dolomite beds.

- Because of their susceptibility to chemical weathering, limestone/dolomite beds often exhibit karstic features. This is most apparent in the Knox Group rocks, but is also present to a more limited extent in the Chickamauga Group. 
- Knox Group and Rome Formation rocks represent the competent units that supported the folding and low-angle thrust faulting associated with the Alleghenian orogeny, and as a result, today constitute ridge-forming units in the GWOU.

- Residuum (weathered bedrock) covers most of the GWOU to variable thickness. It is thicker on ridges, thins in the valleys, and nearly disappears in stream channels.

- The rocks of the GWOU are extensively fractured.

- Fracture density and aperture width decrease with depth. Apertures are greatest near the residuum/bedrock interface, probably as a result of weathering.

\subsubsection{GWOU Hydrological Conceptual Model}

- The rocks in and around the GWOU can be broadly characterized in terms of their hydrologic properties as: (1) the Knox aquifer, composed of rocks of the Knox Group and the Maynardville Limestone of the Conasauga Group; and (2) aquitards, the bulk of the rocks inside the GWOU.

- In general, groundwater is recharged on ridges and is discharged into lakes, streams, springs, and seeps entirely within the boundaries of the GWOU.

- The subsurface flow system can be divided into three distinct parts: the stormflow zone; the vadose zone; and the groundwater zone that is subdivided into the water table interval, the intermediate interval, the deep interval, and the aquiclude.

- Subsurface flow occurs predominantly within the stormflow flow zone, the vadose zone, and the water table interval of the groundwater zone. Therefore, subsurface flow is relatively shallow.

- Subsurface flow occurs mainly through fractures and fracture systems that are sometimes enlarged by solutioning.

- Within the aquifer units, a large portion of subsurface flow occurs within solution cavities.

\subsubsection{GWOU Boundaries and Pathways}

- Because groundwater is recharged on ridges in the GWOU and because groundwater elevations roughly mimic topography in the GWOU, the boundaries of the GWOU are largely defined by ridges and other topographic highs and lows.

- The boundaries of the GWOU are located along Chestnut Ridge to the north, Copper Ridge to the south, the Clinch River and the Bearden Creek watershed to the east, the Clinch River to the west, and the saline/freshwater interface at its base. Additionally, Haw Ridge represents a medial boundary that separates the two valleys of the GWOU. 
- Chestnut Ridge and Copper Ridge are held up by the Knox aquifer, which lies outside of the GWOU. The high hydrostatic pressure of the Knox constitutes an effective pressure barrier that confines GWOU groundwater.

- The Rome formation, predominantly an aquitard, holds up Haw Ridge and contains a dolostone unit with high hydraulic head that serves a pressure barrier, which separates the groundwater of Bethel Valley from the groundwater of Melton Valley.

- Nearly all subsurface flow in the GWOU is discharged to White Oak Creek and its tributaries and exits the GWOU via the White Oak Lake outfall.

\subsection{GEOLOGICAL SETTING}

The physical geology and the geological controls on groundwater flow and occurrence on the ORR have been the subject of considerable study over the past few years. One of the goals of these studies has been to establish correlations between fracture systems and associated subsurface fluid flow, thereby formulating a structural-hydrologic model that enables interpretation of the behavior of groundwater and other subsurface fluids on the ORR. Understanding the structural setting and its controls on fluid flow is essential to developing a model for groundwater movement in this area. Descriptions of the results of work carried out to date and of the site conceptual model that has been developed are contained in Hatcher et al. (1992) and Solomon et al. (1992).

\subsubsection{Location and Physiography}

The 35-mile ${ }^{2}$ ORR is located on the western side of the Valley and Ridge physiographic province, $-32 \mathrm{~km}$ (20 miles) west of Knoxville, Tennessee (Fig. 2.1). The general features that distinguish this province are: (1) parallel ridges and valleys typically oriented from northeast to southwest, (2) topography influenced by alternating weak and strong strata exposed to erosion through a relatively great amount of folding and faulting, (3) a few major transverse streams with subsequent streams forming a trellis-like drainage pattern, (4) many ridges with accordant summit levels suggesting former erosion surfaces (peneplantation), and (5) many water and wind gaps through resistant ridges. The scarp (northwest-facing) slopes of these ridges are relatively short, steep, and smooth. The dip (southeast-facing) slopes are longer, shallower, and hummocky to dissected. Elevations range from 225 to $410 \mathrm{~m}$ ( 738 to $1345 \mathrm{ft}$ ) above sea level. Surface slopes average $\sim 0.075$ and generally have a range of 0.03 to 0.3 . However, the steepest part of a scarp slope may be $<0.5$, whereas slopes on the floodplain of the Clinch River are $\sim 0.015$. Drainage patterns have a dendritic shape in headwater areas and a trellis shape farther downstream.

The surface boundaries of the GWOU, as they are known to exist today, are shown in Fig. 2.2. The northern boundary is located on Chestnut Ridge at the contact of the Knox Group, which lies outside the GWOU, with the underlying Chickamauga Group. The southern boundary is located along Copper Ridge where the Knox Group, again outside the GWOU, contacts the underlying Conasauga Group. The eastern boundary is defined by the Clinch River at Melton Valley and the Bearden Creek watershed in Bethel Valley, both of which are topographically higher than the Clinch River to the west that defines the western boundary. Haw Ridge, which 


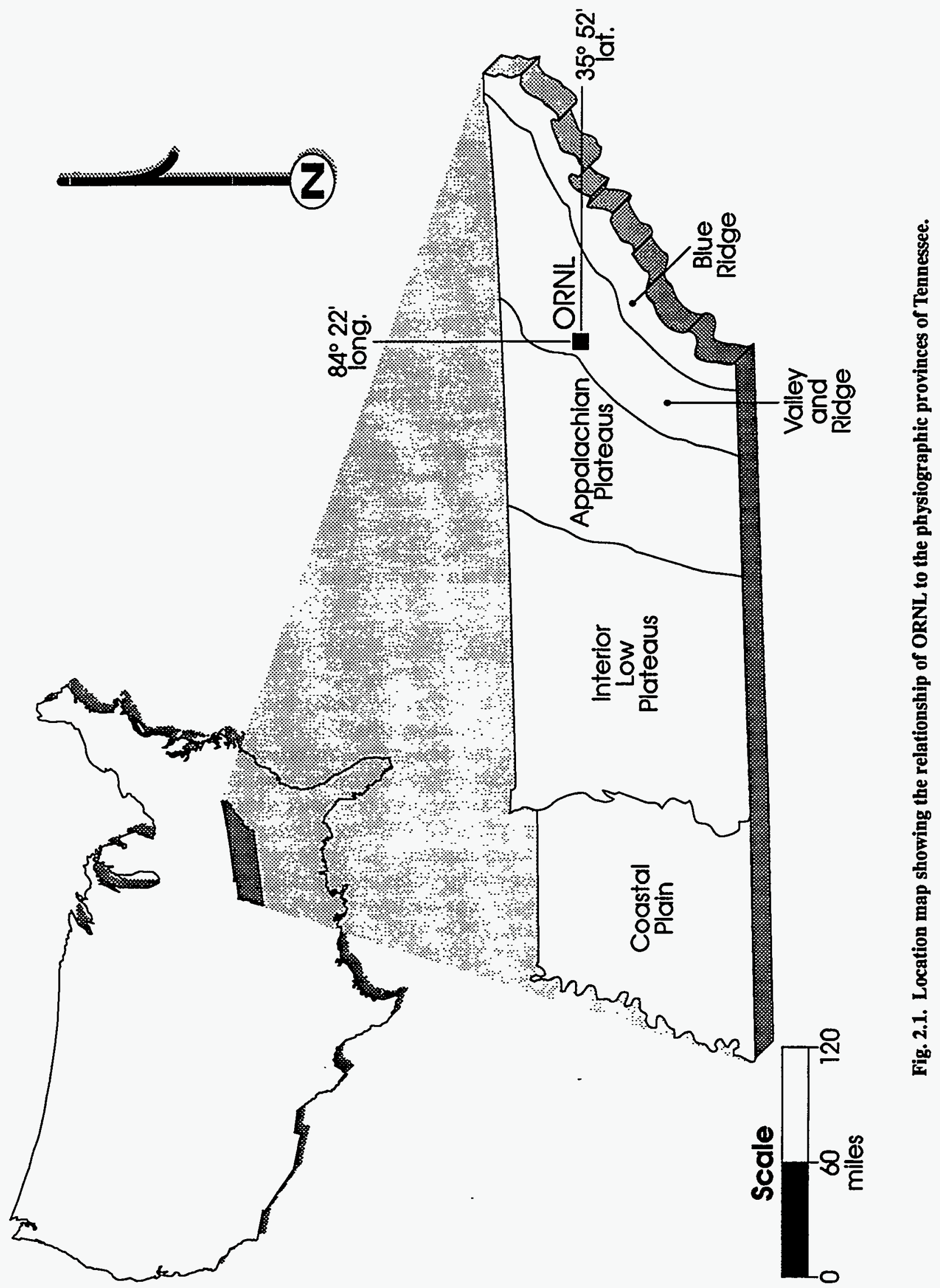



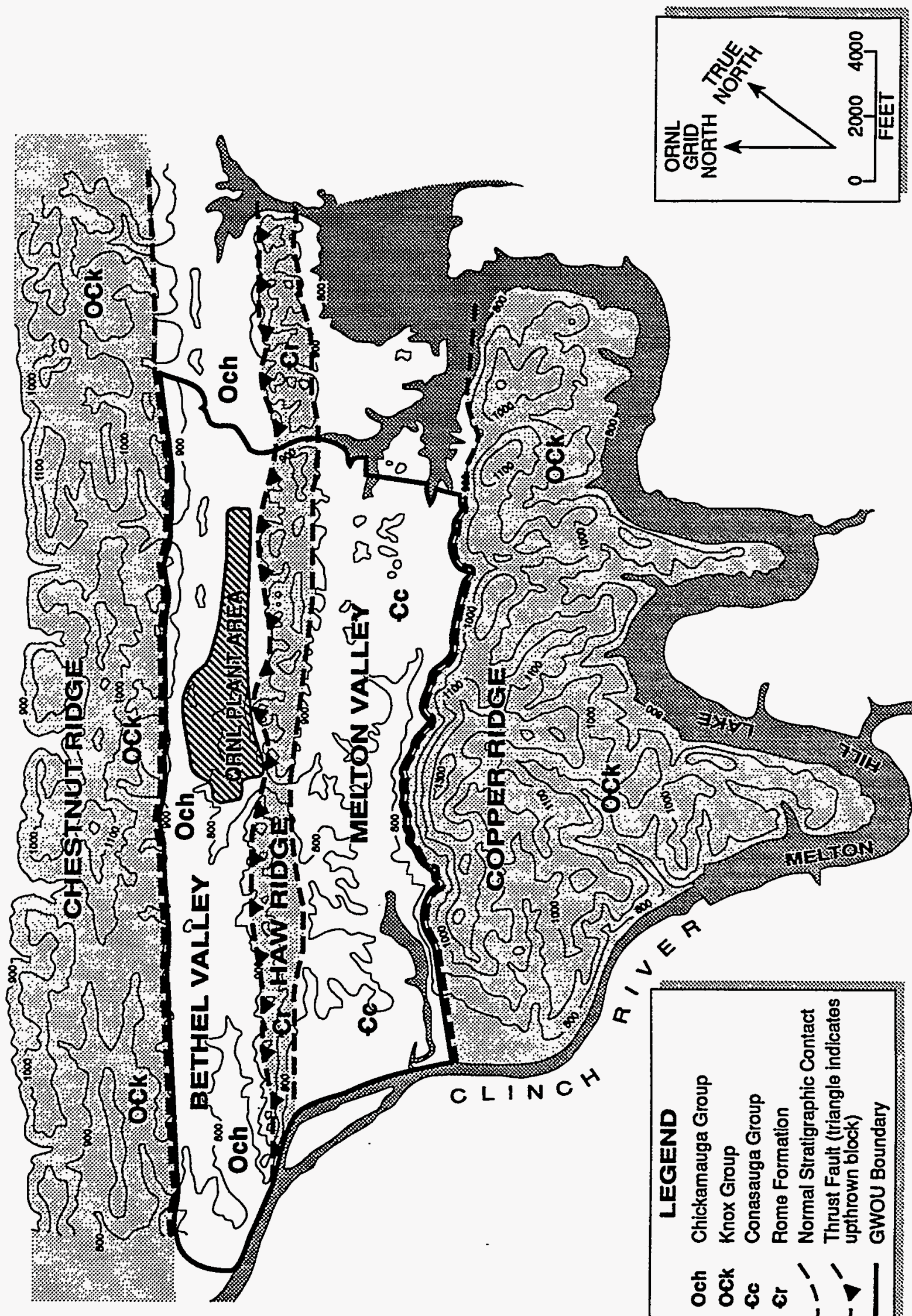
separates Bethel Valley and Melton Valley, also separates the valleys' groundwater, and therefore is considered to be a medial boundary within the OU. An additional subsurface boundary, not depicted in Fig. 2.2, exists within the deep groundwater system where salinity exceeds $10,000 \mathrm{mg} / \mathrm{L}$.

\subsubsection{Stratigraphy}

Rock units of the stratigraphic section in the ORR range in age from Early Cambrian to Silurian (Table 2.1). The stratigraphic units comprise a complex assemblage of lithologies, with representatives from the entire Cambrian and Ordovician section. The total thickness of section in the ORR is $-2.5 \mathrm{~km}$ ( 1.6 miles).

In general, the Cambro-Ordovician Knox Group and part of the overlying Chickamauga Group form the competent units within the major thrust sheets in this area. Each major stratigraphic unit (and formations within those units), because of compositional and textural properties, possesses unique mechanical characteristics that respond differently to the strain fields affecting these rocks through time. Therefore, each may have experienced a slightly different scheme of brittle deformation that subsequently may affect the transmission of fluids through them.

For general descriptions of the stratigraphy of geological units in the ORR, see Hatcher et al. (1992) for an overview of the ORR geology; Haase et al. (1985) for the Conasauga Group and Rome Formation; Lee and Ketelle (1987) for the Knox Group; and Lee and Ketelle (1988) for the Chickamauga Group.

The following is a brief description of the formations in the vicinity of ORNL and their relative importance with respect to groundwater occurrence and groundwater flow.

\subsubsection{Rome Formation}

The Rome Formation outcrops at ORNL on Haw Ridge and dips beneath Melton Valley. It is the oldest rock unit exposed in the ORR. In the Copper Creek Thrust Sheet, this formation is 122 to $183 \mathrm{~m}$ (400 to $600 \mathrm{ft}$ ) thick. Maroon, green, and/or yellow brown micaceous shale is the most common lithology in the Rome Formation. Siltstone, sandstone, dolomitic sandstone, and dolomite are interbedded with shale. Some dolomite and dolomitic sandstone beds in the upper Rome Formation are laterally continuous in the Copper Creek thrust sheet. It is the massive dolomite and the dolomitic sandstone beds that provide the best potential pathways for groundwater flow (in the Rome Formation), especially where these beds have developed karst. In one instance, sinkholes occur on Haw Ridge at the Rome Formation outcrop. These sinkholes are indicative of karst formation in the Rome Formation that may represent a layer with good permeability.

\subsubsection{Conasauga Group}

The Conasauga Group outcrops above the Rome Formation on the Southern flank of Haw Ridge and in the central axis of Melton Valley. The average thickness of the Conasauga Group in Melton Valley is $567 \mathrm{~m}$ (1860 ft). The Group is traditionally subdivided in central East Tennessee into the Middle Cambrian Pumpkin Valley Shale, Rutledge Limestone, Rogersville 
Table 2.1. Geologic units of the $\operatorname{ORR}^{a}$

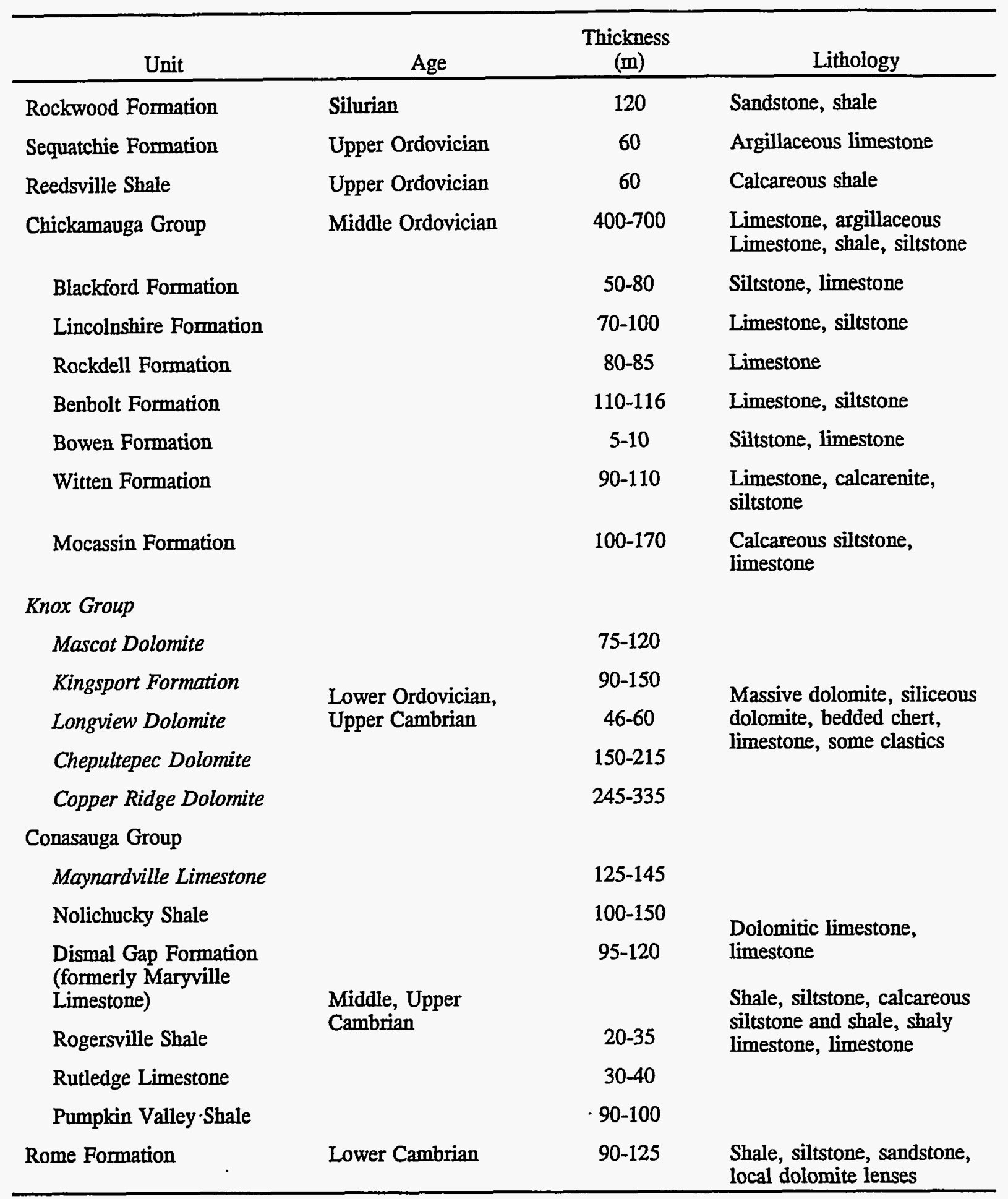

${ }^{a}$ Names in italic are units that make up the Knox aquifer. Other units form the ORR aquitards. 
Shale, and Maryville Limestone (the Dismal Gap Formation in Hatcher et al. 1992), and the Upper Cambrian Nolichucky Shale and Maynardville Limestone.

With the exception of the Maynardville Limestone, the Conasauga is a monotonous sequence of shale, siltstone, and thin-bedded limestone and is considered a regional aquitard. Some formations, however, include laterally continuous limestone beds that can be several meters thick and, where karstification has enlarged fractures in limestone beds, strata-bound high permeability zones may exist. The Maynardville, the uppermost member of the Conasauga Group, is a massively bedded limestone and dolomite with extreme karstification.

Because of the many years of extensive waste disposal activities in Melton and Bear Creek valleys, the Conasauga Group is the most thoroughly studied rock unit in the ORR. The main WAGs in Melton Valley, including the Hydrofracture, are located on the Conasauga Group outcrop.

The following are brief descriptions of the six formations in this group.

Pumpkin Valley Shale. Oldest of the Conasauga Group formations, the Pumpkin Valley Shale crops out along the southeastern edges of ridges formed on the Rome Formation. Predominantly an olive and maroon, massive clay shale with thin beds of siltstone and sandstone, the Pumpkin Valley Shale is gradational with the underlying Rome Formation but lacks the sandstone that is characteristic of the Rome Formation. Two members of the Pumpkin Valley Shale have been identified (Law Engineering 1975), the upper one being more shale rich than the lower one. The lower member exhibits units that are commonly bioturbated or have wavy parallel stratification. The Pumpkin Valley Shale is a very tight formation that is considered one of the poorest aquifers in East Tennessee (DuBuchananne and Richardson 1956). The lack of continuous limestone beds also precludes the possibility of extensive karst formation in this formation. In the vicinity of ORNL, the formation is $\sim 94$ to $109 \mathrm{~m}$ (308 to $358 \mathrm{ft}$ ) thick (Hatcher et al. 1992).

Friendship Formation (formerly referred to as the Rutledge Limestone). In the vicinity of ORNL, the Friendship Formation ranges in thickness from 31 to $45 \mathrm{~m}$ (102 to $148 \mathrm{ft}$ ). The formation is predominantly clastic ( $75 \%$ shale) with some limestone. Light grey to white, medium to thinly bedded limestones and micritic limestones are interbedded with mudstones and shales that become more calcareous higher in the succession. Some limestone beds are persistent and serve as marker beds within the lower Conasauga Group. Increased amounts of limestone distinguish the Friendship Formation from the overlying and underlying formations. Although limestone is a minor lithology in this formation, laterally continuous beds, which in one case form a sequence $6 \mathrm{~m}$ (19.6 ft) thick, may provide groundwater flow paths where karst has formed.

Rogersville Shale. In the vicinity of ORNL, the Rogersville Shale is $-36 \mathrm{~m}$ (118 ft) thick. This formation is composed of massive to medium-bedded, noncalcareous mudstones, interbedded with brown shales. The shales and mudstones contain subordinate units of glauconitic and/or calcareous siltstones. In the Copper Creek thrust sheet, a limestone-rich interval known as the Craig Limestone Member, which outcrops throughout much of eastern Tennessee, occurs in the upper portion of the Rogersville Shale. Clastic sediments dominate the Rogersville Shale, and karst formation is probably not common with the exception of the Craig Limestone Member. 
Dismal Gap Formation (formerly referred to as the Maryville Limestone). In the vicinity of ORNL, the Dismal Gap Formation ranges in thickness from 47 to $85 \mathrm{~m}$ (154 to $279 \mathrm{ft}$ ). The formation consists of calcareous shales and shaley-siltstones ( $\sim 60$ to $70 \%$ ) interbedded with light to dark grey, fine to coarsely crystalline limestone ( -30 to $40 \%)$. The Dismal Gap Formation is informally divided into two members (Haase et al. 1985). The lower member consists of medium to thinly bedded calcareous mudstone interbedded with pelloidal or oolitic calcareous siltstones. Limestones appear as discrete beds, 5 to $20 \mathrm{~cm}$ (2 to 8 in.) thick in coarsening upward cycles. Several relatively limestone-rich horizons ranging from 6 to $12 \mathrm{~m}$ (20 to $39 \mathrm{ft}$ ) thick occur throughout the lower member and are characteristic of the Dismal Gap Formation. The upper member of the Dismal Gap Formation is characterized by the presence of distinctive flat limestone-pebble conglomerates. In places, the intraclastic limestones are glauconitic or ooliterich. The limestone units in this formation offer the potential for karst formation. Bedding in the clastic units is commonly wavy, which may result in poor development of bedding parallel fractures.

Nolichucky Shale (Foreman et al. 1991; Rothschild et al. 1984). In the vicinity of ORNL, the Nolichucky Shale is $-190 \mathrm{~m}(620 \mathrm{ft})$ thick. Shale interbedded with intraclastic limestone, thick fossiliferous limestone, and oolitic limestone are characteristic of the Nolichucky Shale in the White Oak Mountain thrust sheet. Shale is the dominant lithology and occurs in 2.5 to $3 \mathrm{~m}$ ( 8 to $10 \mathrm{ft}$ ) thick beds that are laterally continuous. The shale has good fissility, and horizontal laminae are well preserved.

Maynardville Limestone (Shevenell et al. 1992). The Maynardville Limestone is the youngest formation of the Conasauga Group and consists primarily of light-gray to tan, massive to thinly bedded limestone with subordinate amounts of dolostone. Data obtained from the ongoing Maynardville Exit Pathway Monitoring Program at the Y-12 Plant in Bear Creek Valley demonstrate that on the ORR, the Maynardville is more uniformly dolomitic and exhibits more subtle vertical lithologic differentiation than that described in the type section. At ORNL, the Maynardville Limestone is $\sim 80 \mathrm{~m}(260 \mathrm{ft})$ thick. The Exit Pathway Monitoring Program in Bear Creek has subdivided the Maynardville into seven different informal lithologic zones (Zones 1-7). The zones were divided based on the gamma log signatures of the individual zones, and may also be present in the Maynardville at ORNL.

\subsubsection{Knox Group}

The Knox Group underlies and forms Copper Ridge and Chestnut Ridge in the vicinity of ORNL and dips southward underneath Bethel Valley. The upper contact of the Knox Group with the Chickamauga Group on Chestnut Ridge and the lower contact of the Knox in the Copper Creek thrust sheet with the Conasauga Group on Copper Ridge, and the extension of these contacts down dip are the proposed boundaries of the GWOU at ORNL. On the ORR the Knox Group is divided into five separate units: the Copper Ridge Dolomite, the Chepultepec Dolomite, the Longview Dolomite, the Kingsport Formation, and the Mascot Dolomite. Total thickness of the Knox Group ranges between 600 and $900 \mathrm{~m}$ (1970 and $2950 \mathrm{ft}$ ), with the Copper Ridge Dolomite making up roughly one-third of the total. This formation forms the principal strong unit to support the folding and low-angle thrust faulting that occurs throughout the Valley and Ridge Province in East Tennessee. 
The Knox Group is composed of a series of medium to thickly bedded, massive, grey, green, and pink dolomite. The Copper Ridge and Longview Formation dolomites are siliceous and these formations tend to be ridge formers. All formations within the group contain subordinate amounts of chert, some in nodular form that characteristically remains in the soils after weathering of the dolomite matrix. The Knox Group, along with the Maynardville Limestone from the Conasauga Group, forms the regionally important Knox aquifer. Although the dolomite lithologies have little matrix porosity, extensive karst formation in the Knox Group formations has resulted in substantial secondary porosity and high permeability. Sinkholes are common at outcrop, and springs and seeps are common features at the upper and lower geologic contacts.

\subsubsection{Chickamauga Group}

At ORNL the Chickamauga Group underlies Bethel Valley. The lower contact with the Knox Group outcrops on the south face of Chestnut Ridge and the upper contact is faulted against the Rome Formation by the Copper Creek Fault on the north face of Haw Ridge. All the WAGs in Bethel Valley (WAGs 1, 3, and 17) are located on Chickamauga Group formations.

The Chickamauga Group represents deposition on a regionally extensive disconformity on the top of the Knox Group. Relief on this surface accounts for variable stratigraphic thicknesses in the lower Chickamauga unit. The Group consists primarily of calcareous shale interbedded with shaley to silty limestone and is considered a regional aquitard. In Bethel Valley, where the section is incomplete, the Chickamauga Group consists of more than $400 \mathrm{~m}(1312 \mathrm{ft}$ ) of variable thick maroon shale-dominated units separated by gray limestones. Some formations include laterally continuous limestone beds that can be several meters thick. Where karstification has enlarged fractures in limestone beds, strata-bound high permeability zones may exist. Below are descriptions of the seven formations that make up the Chickamauga Group. A different terminology for Chickamauga lithologies at ORNL was used by Stockdale (1951) and Lee and Ketelle (1988). Figure 2.3 correlates Stockdale's (1951) terminology with the formal stratigraphic nomenclature used below.

Blackford Formation. The bulk of the Blackford Formation consists of massive- to thickbedded purplish to dark maroon and olive-gray calcareous siltstone interbedded with subordinate amounts of dark- and light-gray calcarenite. This is overlain by a thin bed of pale-olive limestone and a very thin [1 m (3.3 ft) thick] purplish-maroon dolomitic limestone. The siltstones contain small, angular dolomitic intraclasts, presumably derived from the underlying Knox Group. Total formation thickness ranges from 70 to $80 \mathrm{~m}$ (230 to $260 \mathrm{ft})$.

Lincolnshire Formation. On the ORR, the Lincolnshire Formation is divided into two members. The Eidson Member of the Lincolnshire Formation is a relatively minor limestone unit in the ORR with limited outcrop exposure, but it provides a sharp contrast to the maroon siltstones of the underlying Blackford Formation. In core, the Eidson Member is $20 \mathrm{~m}(65 \mathrm{ft})$ thick, but its thickness may vary laterally on the ORR. It consists of massive to nodular limestone with bedded and nodular chert near the top. The Fleanor Member of the Lincolnshire Formation is a thick accumulation [75 to $80 \mathrm{~m}$ (246 to $260 \mathrm{ft}$ )] of maroon, calcareous, and shaly siltstone with numerous light-gray limestone beds. Vertical burrows and general bioturbation are common. The lowermost and uppermost portions of the Fleanor consist of thick, olive-gray calcareous siltstone that characterizes the unit. 


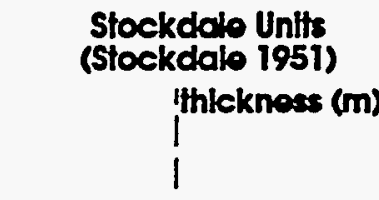

H $\quad 91$
Told Soction $=529 \mathrm{M}$

Coppor Crook Foult

-

$\frac{-1-1-1}{-1}$

$\overline{I-1-1}$

$1-1-1$

IIII

$\overline{I-I-T}$

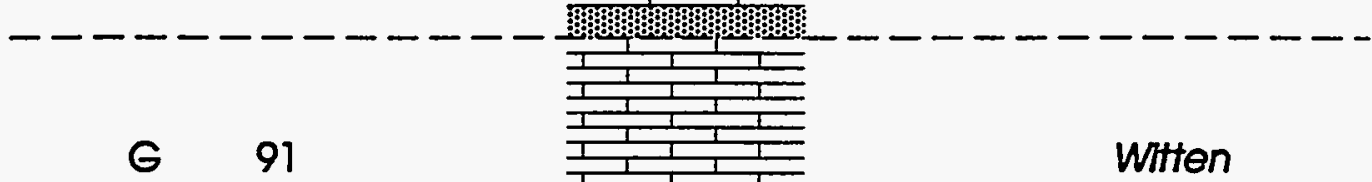

Formation Namos

Moccasin

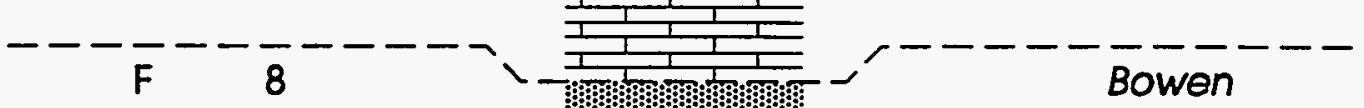

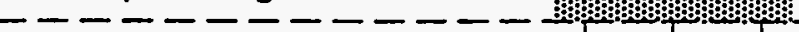

E $\quad 116$

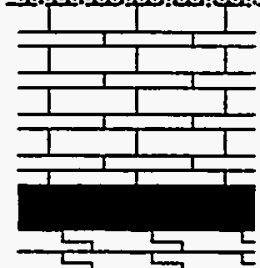

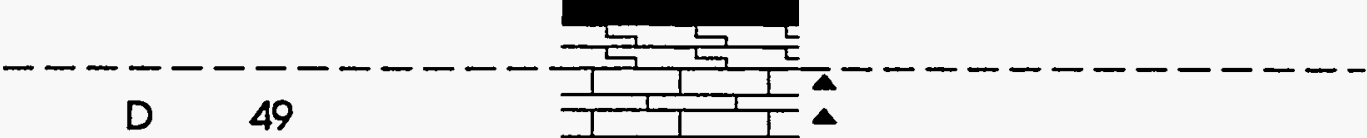

Rockdell

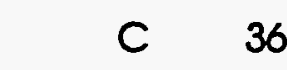

B 66

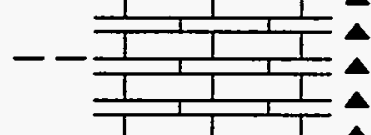

Benbolt

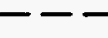

36

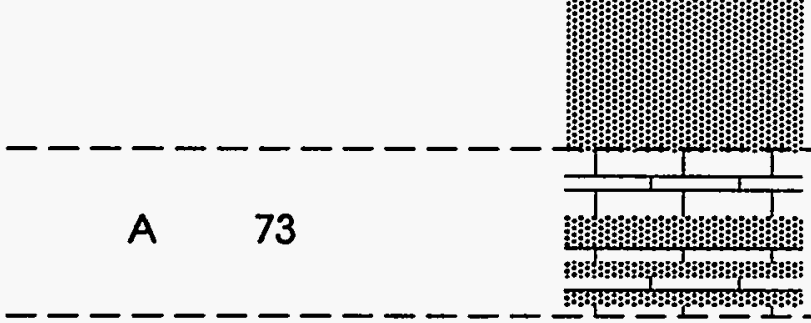

Fleanor

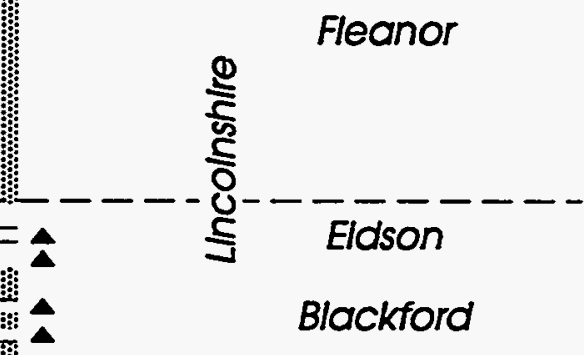

\section{Knox Group}
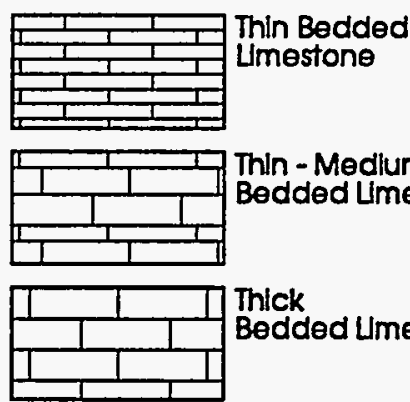

Thin - Medlum - Thlck Bedded Limestone

Thick

Bedded Umestone

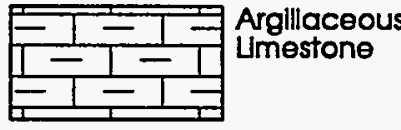

Nodular
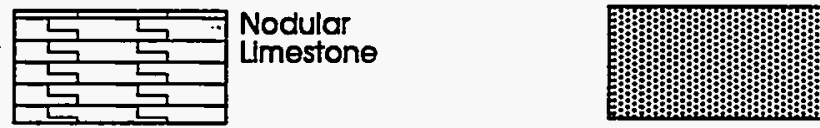

Siltstone

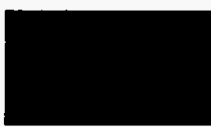

Fig. 2.3. Correlation of Stockdale's (1951) unit designations with formal formation names for Chickamauga Group rocks. Source: Adapted from Hatcher et al. 1992. 
Rockdell Formation. A thick section of limestone, the Rockdell Formation, overlies the Fleanor Member of the Lincolnshire Formation. The Rockdell is 80 to $85 \mathrm{~m}$ (260 to $280 \mathrm{ft}$ ) thick and underlies the continuous low ridge near the middle of Bethel Valley. The lower portion of the Rockdell contains light-gray calcarenite, dark-gray calcareous siltstone, fossiliferous nodular limestone, and birdseye micritic limestone. Small chert nodules are common and evidence of vertical burrowing has been observed. This lower lithology grades upward to dense calcarenite, which contains subordinate amounts of birdseye micrite and nodular limestone. The common occurrence of bedded and nodular chert is distinctive of the upper portion of the Rockdell. The lower and upper lithologies are of nearly equal thickness.

Benbolt Formation. The Benbolt Formation is a relatively heterogeneous formation that is 110 to $115 \mathrm{~m}$ (360 to $380 \mathrm{ft}$ ) thick. The Benbolt consists of thick interbeds of fossiliferous nodular limestone; unfossiliferous, amorphous micrite within a dark-gray siltstone matrix; darkgray siltstone; and unfossiliferous calcarenite. A pale buff color is characteristic of weathered Benbolt rock fragments that are seen in vegetatively barren areas. Rockcore and geophysical logs show that limestone content increases in the upper $23 \mathrm{~m}(75 \mathrm{ft})$.

Bowen Formation. The Bowen Formation is a maroon unit that overlies the lower thick limestone of the Benbolt and is a reliable marker for field and subsurface correlations. The Bowen is 5 to $10 \mathrm{~m}$ ( 16 to $33 \mathrm{ft}$ ) thick and consists of maroon calcareous and shaly siltstone with thin beds of light-gray to olive-gray limestone and argillaceous limestone. Vertical and horizontal burrows are prevalent throughout the unit.

Witten Formation. The uppermost limestone-dominated unit in the Chickamauga Group in Bethel Valley is the Witten Formation which is 105 to $110 \mathrm{~m}$ (344 to $360 \mathrm{ft}$ ) thick. The Witten consists of interbedded nodular limestone; calcarenite; amorphous, thin-bedded limestone and siltstone; and wavy limestone. Extensively bioturbated beds and beds with numerous bryozoa are distinctive of the upper part of the Witten Formation. The predominance of limestone in this unit makes it a likely stratigraphic horizon for strata-bound flow paths resulting from karstification.

Moccasin Formation. Because it was largely removed by the Copper Creek Fault, the Moccasin Formation (Cooper 1956) is not fully represented on the ORR. For the same reason, its thickness varies from 100 to $170 \mathrm{~m}$ (330 to $560 \mathrm{ft}$ ). The Moccasin is recognized as olive- to light-gray and pale-maroon calcareous siltstone interbedded with light-gray, fine-grained limestone.

\subsubsection{Unconsolidated materials}

Unconsolidated material overlying bedrock in the ORNL consists of weathered bedrock (referred to as residuum), human-made fill, alluvium, and colluvium. Residuum comprises a majority of the unconsolidated material in this area. The depths to unweathered bedrock differ throughout the ORR because of the different thicknesses of fill and alluvium and the particular weathering characteristics of the bedrock units. The total thickness of these materials typically ranges from 3 to $15 \mathrm{~m}$ (10 to $50 \mathrm{ft}$ ) (Hoos and Bailey 1986). 
Residuum overlies bedrock throughout the ORR except in scattered outcrop areas and ranges from silty to sandy clay overlying shale units to a slightly sandy clay overlying limestone units; predominant colors are shades of brown, orange, and grey. With increasing depth, the colors darken and the clay grades to weathered rock that has retained its structural characteristics (saprolite). Bedding planes and joint surfaces in the weathered bedrock commonly are marked by dark reddish-brown and yellow-brown oxide coloration, indicative of a high degree of weathering by circulating groundwater. Most groundwater flow through residuum is by way of matrix flow. Hydraulic conductivities are generally low and range from $1 \times 10^{-4}$ to $1.7 \times 10^{-7}$ $\mathrm{cm} / \mathrm{s}$. Conduits may exist in the residuum where major flow paths emerge from the underlying bedrock (Moore 1988).

\subsubsection{Structural Geology}

The Oak Ridge area is underlain by two major northeast/southwest trending thrust faults that dip to the southeast and define thrust sheets, the White Oak Mountain and the Copper Creek Fault (Hatcher et. al. 1992) (Fig. 2.4). Chestnut Ridge and Bethel Valley are underlain by the White Oak Mountain thrust sheet, which is soled by the White Oak Mountain fault. Haw Ridge, Melton Valley, and Copper Ridge are underlain by the Copper Creek thrust sheet, which is soled by the Copper Creek thrust fault. Both thrusts are regional thrust faults of the Valley and Ridge, which demonstrate at least several kilometers of translation. The faults formed during the Permian-Pennsylvanian age Alleghenian Orogeny and have not been historically active. At the ORR, both faults trend parallel to regional strike (N55E) and dip steeply $\left(45^{\circ}\right)$ to the southeast (King and Haase 1987). Bedding plane dip values measured in outcrops cluster around $45^{\circ}$ but may steepen to vertical as a result of localized small-scale folding or faulting.

The ORR contains a variety of geologic structures on several scales. The map-scale structure is dominated by southeast-dipping beds interrupted by the two major thrust faults and the locally overturned East Fork Ridge and Pilot Knob synclines (McMaster 1962). Overall, the faults and stratigraphy strike northeast and dip to the southeast, except in the synclines where dips swing to the northwest. Outcrop-scale structures include minor folds, faults, and fractures. The formation of most of these structures is closely related to map-scale structures. Most minor folds and faults observed occur in either the Rome Formation or Conasauga Group, a function of lithology, stratigraphy, and proximity to map-scale faults and folds.

\subsubsection{Fractures}

Because of the large-scale faulting, all geologic units in the ORR are highly fractured. The most pervasive structural features are extensional, hybrid, and shear fractures, which are important factors in groundwater flow in this region. A majority of fractures constitute a single cubic system (three orthogonal sets) of extension fractures (Dreier et al. 1987a; Sledz and Huff 1981). One fracture set is formed by bedding planes, which have an average strike of $\sim \mathrm{N} 55^{\circ} \mathrm{E}$; the dip is variable, but commonly is -30 to $40^{\circ} \mathrm{SE}$ (Stockdale 1951). Two other joint sets are approximately strike parallel and dip parallel; at shallow depths, these sets are commonly angled $\sim 50$ to $60^{\circ}$ below horizon. These three fracture sets may occur in any locality, and other extension and shear fractures may also be present. The parallel bedding fractures are mainly release joints, and recent studies elsewhere in the Appalachians suggest that release joints can form at depths up to a kilometer (Engelder 1985). 


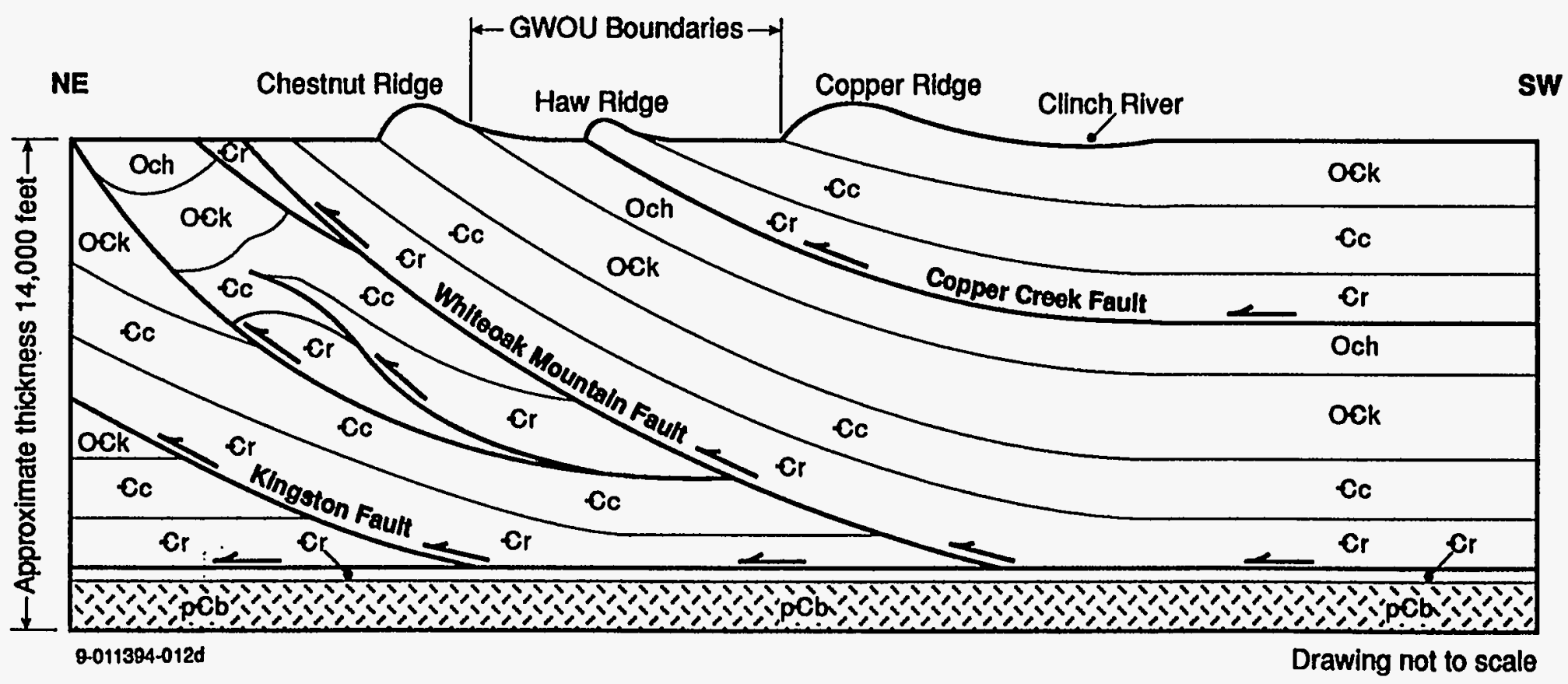

Fig. 2.4. Schematic geologic cross section in the vicinity of the GWOU. Surface features associated with the GWOU are highly exaggerated. Source: Adapted from Hatcher et al. 1992. 
Fractures are abundant on rock outcrops, in saprolite, and at shallow depths in fresh bedrock. Dreier et al. (1987a) measured an average fracture density of $\sim 200 / \mathrm{m}(60 / \mathrm{ft})$ in saprolite of the Maryville Limestone and Nolichucky Shale at WAG 6 near ORNL. At the other extreme, Sledz and Huff (1981) measured a minimum fracture density of $5 / \mathrm{m}(1.5 / \mathrm{ft})$ in fresh rock. Fewer open fractures occur at deeper levels. As described by Haase et al. (1985), fracture frequency is variable, but most fractures observed in cores occur within limestone or sandstone layers $>0.5 \mathrm{~m}(1.6 \mathrm{ft})$ thick, and many fractures are filled or partly filled with secondary minerals.

Most fractures are short, a few centimeters to $\sim 1 \mathrm{~m}(3.3 \mathrm{ft})$ in length (longest dimension). Sledz and Huff (1981) found a relatively uniform fracture length of $-12 \mathrm{~cm}(5 \mathrm{in}$.) in shale but a fracture length that increases with bed thickness in siltstone. Haase et al. (1985) observed numerous fractures $\sim 0.1$ to $1.5 \mathrm{~m}(0.3$ to $5 \mathrm{ft})$ long within limestone and sandstone units of the Conasauga Group and the Rome Formation. Groundwater flow occurs only through networks of pervious, connected fractures. In limestone, typical fracture spacings range from $<5 \mathrm{~cm}$ ( 2 in.) for very thin beds to $>3 \mathrm{~m}(10 \mathrm{ft}$ ) for very thick to massive beds. The areal extent of fractures may be only a few square meters for thin to very thin beds, but pervious bedding-plane fractures may be $10^{3}$ to $10^{6} \mathrm{~m}^{2}$ for medium to massive beds (Ford and Williams 1989). Also, many pervious fractures cross one to several rock layers but terminate at the connections with other fractures (Ford and Williams 1989).

\subsubsection{Cavities and Solution Openings}

In the Knox Group and, to a much more limited extent, in other carbonate rocks of the ORR, fractures are enlarged by solution. As solution progresses in an upgradient direction of the water table, some conduits, as they intercept smaller cavities, become dominant flow channels, in a way somewhat analogous to the development of a surface drainage system. It is only in the Knox Group and the adjacent Maynardville Limestone (together in this report called the Knox aquifer) that cavity systems are highly developed and are extensive; however, many of the smaller limestone or dolomite beds within the aquitards exhibit solution openings and cavities at shallow depth. Solution cavities probably comprise a significant factor in groundwater flow in the ORR.

Cavities in the Chickamauga Group were first described by Stockdale (1951, p. 41). Since then, cavities have been reported in all other rock units with limey layers. A general principle of cavity occurrence is that the largest cavities are found in the purest and most massively bedded limestones. Cavities in the Conasauga Group have been reported only in the Maryville Limestone (now Dismal Gap Formation), Nolichucky Shale, and Maynardville Limestone. All three of these formations contain limestone layers, and cavities are presumed to occur in these layers. Similarly, cavities in Rome Formation bedrock may occur in dolostone layers, which have been described in the upper part of this formation (Stockdale 1951, p. 17).

A few cavities in the study area have been reported as zones of high water velocity (which washed away sandpack material) in regolith, just above top of bedrock. Apparently this is a form of piping which occasionally occurs in unconsolidated sediments near a point of groundwater discharge. Two cavities in the Rome Formation and three cavities in the Conasauga Group are of this type. The piping at the base of the regolith may occur along upward extensions of enlarged fractures in the bedrock. 
The records of 802 wells in the study area show that only 97 wells (12\%) intercept a cavity and most of these intercept only one cavity. However, there are some distinctive differences in cavity occurrence among the geologic units (Table 2.2). None of the wells in the Rome Formation and only one ( $8 \%)$ in the Chickamauga Group intercept more than one cavity. In the Conasauga Group, 27 wells (46\%) intercept more than one cavity, but only 11 wells (19\%) intercept more than two cavities, and none intercept more than four cavities. More Knox wells (48\%) intercept two cavities than one or any larger number. A total of ten cavities were reported in one Knox well, but only four wells (19\%) intercept more than three cavities. Thus, multiple cavities are rare except in the Conasauga Group and the Knox Group, and more than three cavities are uncommon in these units.

Table 2.2. Number of cavities in wells by geologic unit

\begin{tabular}{|c|c|c|c|c|c|c|}
\hline \multirow[b]{2}{*}{ Geologic unit } & \multirow[b]{2}{*}{$\begin{array}{l}\text { Number } \\
\text { of wells }\end{array}$} & \multicolumn{5}{|c|}{ Number of wells with one or more cavities } \\
\hline & & $\begin{array}{c}\text { One } \\
\text { cavity }\end{array}$ & $\begin{array}{l}\text { Two } \\
\text { cavities }\end{array}$ & $\begin{array}{l}\text { Three } \\
\text { cavities }\end{array}$ & $\begin{array}{l}\text { Four } \\
\text { cavities }\end{array}$ & $\begin{array}{c}\text { Five or more } \\
\text { cavities }\end{array}$ \\
\hline Chickamauga Group & 13 & 12 & 1 & 0 & 0 & 0 \\
\hline Knox Group & 21 & 5 & 10 & 2 & 3 & 1 \\
\hline Conasauga Group & 59 & 32 & 16 & 9 & 2 & 0 \\
\hline Rome Formation & 4 & 4 & 0 & 0 & 0 & 0 \\
\hline Total population & 97 & 53 & 27 & 11 & 5 & 1 \\
\hline
\end{tabular}

There is also a correlation between formations and the cavity geometry. The average cavity height (vertical dimension of a cavity in a boring) at ORNL in the 97 occurrences is $0.59 \mathrm{~m}$ $(1.8 \mathrm{ft})$. The largest cavities are generally found in the Knox Group [mean $=1.0 \mathrm{~m}(3.3 \mathrm{ft})$ ] and although large cavities were found in the Conasauga Group, the average height of cavities in the Knox Group is almost twice as large as that in the Conasauga Group [mean $=0.16 \mathrm{~m}(0.5 \mathrm{ft})$ ].

An analysis of cavity depths by geologic unit shows that the geometric mean depth of cavities in the Knox Group [mean = $34 \mathrm{~m}(112 \mathrm{ft})$ ] is much larger than those in the Rome Formation [mean $=12 \mathrm{~m}(39 \mathrm{ft})$ ], the Conasauga Group [mean $=8.3 \mathrm{~m}(27 \mathrm{ft})$ ], and the Chickamauga Group [mean $=9.7 \mathrm{~m}(31.8 \mathrm{ft})$ ]. This result was expected because of the larger regolith thickness in the outcrop area of the Knox Group.

\subsection{GWOU HYDROLOGICAL CONCEPTUAL MODEL}

Two broad hydrologic units are identified in the ORR, each having fundamentally different hydrologic characteristics. The Knox Group and the Maynardville Limestone of the Conasauga Group constitute the Knox aquifer, in which flow is dominated by solution conduits formed along fractures and bedding planes. The remaining geologic units constitute the ORR aquitards, in which flow is dominated by fractures. The generalized map in Fig. 2.5 shows surface distribution of the Knox aquifer and the ORR aquitards. 


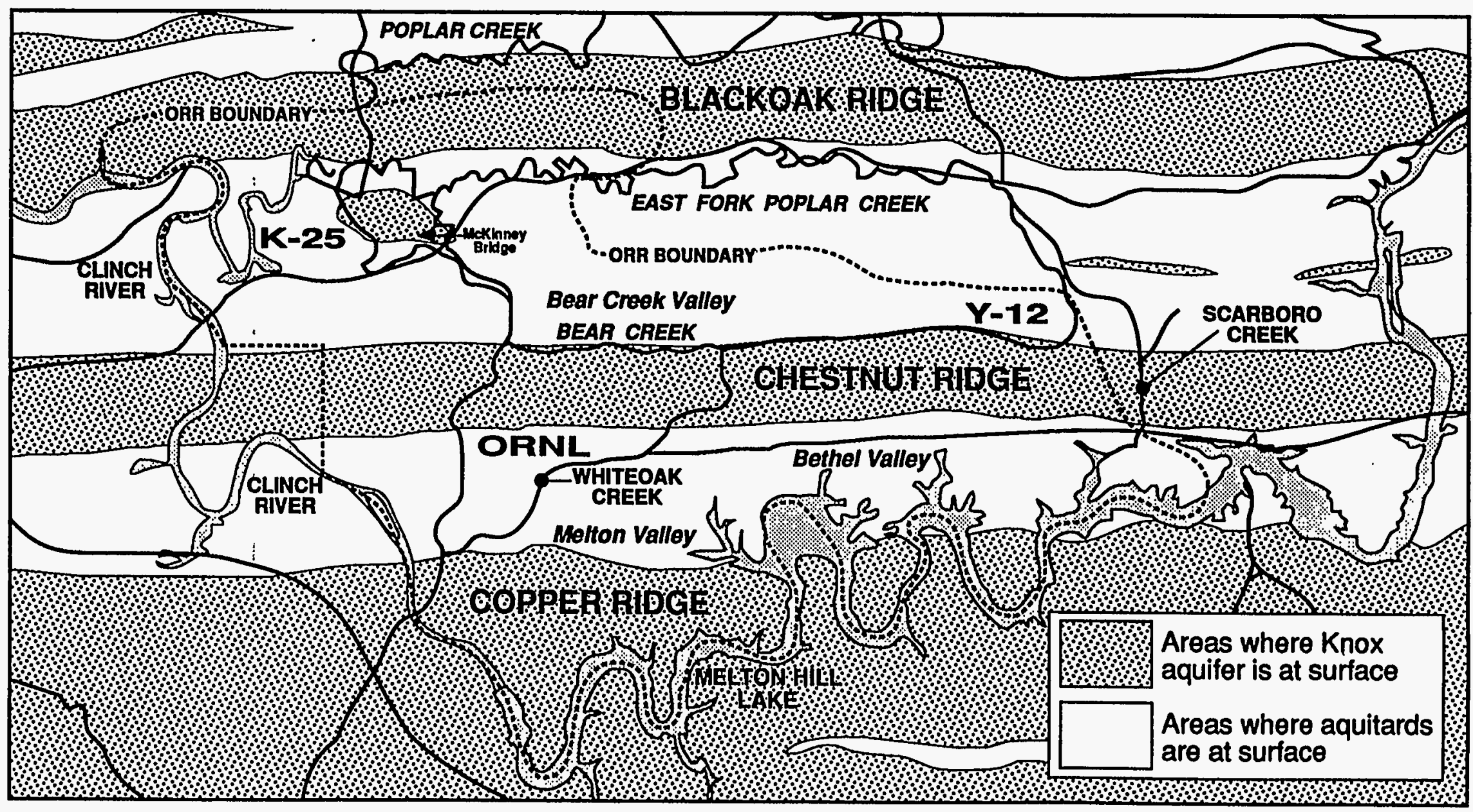

Fig. 2.5. Generalized map of ORR showing surface distribution of the Knox aquifer and the ORR aquitards. Source: Adapted from Solomon et al. 1992. 
For hydrological purposes the Cambro-Ordovician Knox Group and the uppermost member of the Cambrian Conasauga Group (Maynardville Limestone) comprise the Knox aquifer, an aquifer that is of regional importance. The remaining formations are considered aquitards on the ORR. Subsurface flow in both the Knox aquifer and in the ORR aquitards is recharged mainly on ridges and discharged into lakes, streams, springs, and seeps (Fig. 2.6). The subsurface flow system can be divided as follows: the stormflow zone; the vadose zone; the groundwater zone, which is subdivided into the water table interval, the intermediate interval, and the deep interval; and the aquiclude. Although many factors influence groundwater flow on the ORR, topography, surface cover, geologic structure, and lithology exhibit strong influence on the hydrogeology. Variations in these features result in water flux variations.

The groundwater zone of the hydrologic conceptual model is of primary interest to GWOU investigations. Contamination affecting groundwater moving through the stormflow and vadose zones is considered in the RIs for each source unit. The following are descriptions of the subsections of the hydrological conceptual model with emphasis placed on the groundwater subsection. Thorough discussions of the hydrological conceptual model can be found in Moore (1988), Solomon et al. (1992), and Moore and Toran (1992), from which the following is summarized.

\subsubsection{Stormflow Zone}

Detailed water budgets indicate that $\sim 90 \%$ of active subsurface flow occurs through the 1- to 2-m-(3.3- to 6.6-ft-) deep stormflow zone (Moore 1988; Solomon et al. 1992). Natural areas of the ORR are heavily vegetated, and the stormflow zone corresponds approximately to the root zone. Infiltration tests indicate that this zone is as much as 1000 times more permeable than the underlying vadose zone. According to this conceptual model, during rain events, the stormflow zone partially or completely saturates and then transmits water laterally to the surfacewater system. When the stormflow zone becomes completely saturated, overland flow occurs.

Between rain events, as the stormflow zone drains, flow rates decrease dramatically and flow becomes nearly vertical toward the underlying vadose zone. The transmissive capability of the stormflow zone is created primarily by root channels, worm holes, clay aggregation, fractures, etc., collectively referred to as large pores. Although highly transmissive, large pores comprise only $-0.2 \%$ of the total void volume of the stormflow zone. Because most of the water mass resides within less transmissive small pores, advective-diffusive exchange between large and small pores substantially reduces contaminant migration rates relative to fluid velocities in large pores (Solomon et al. 1992).

\subsubsection{Vadose Zone}

A vadose zone exists throughout the $\mathrm{ORR}$ except where the water table is at land surface, such as along perennial stream channels. The thickness of the vadose zone is greatest beneath ridges and thins towards valley floors. Beneath ridges underlain by the Knox aquifer (Copper Ridge, Chestnut Ridge, McKinney Ridge, and Blackoak Ridge), the vadose zone commonly is as much as $50 \mathrm{~m}(160 \mathrm{ft}$ ) thick, whereas beneath ridges underlain by the Rome Formation (Haw Ridge and Pine Ridge) the vadose zone is typically $<20 \mathrm{~m}(65 \mathrm{ft})$ thick. In lowland areas near streams, a permanent vadose zone does not exist because the stormflow zone intersects the water 


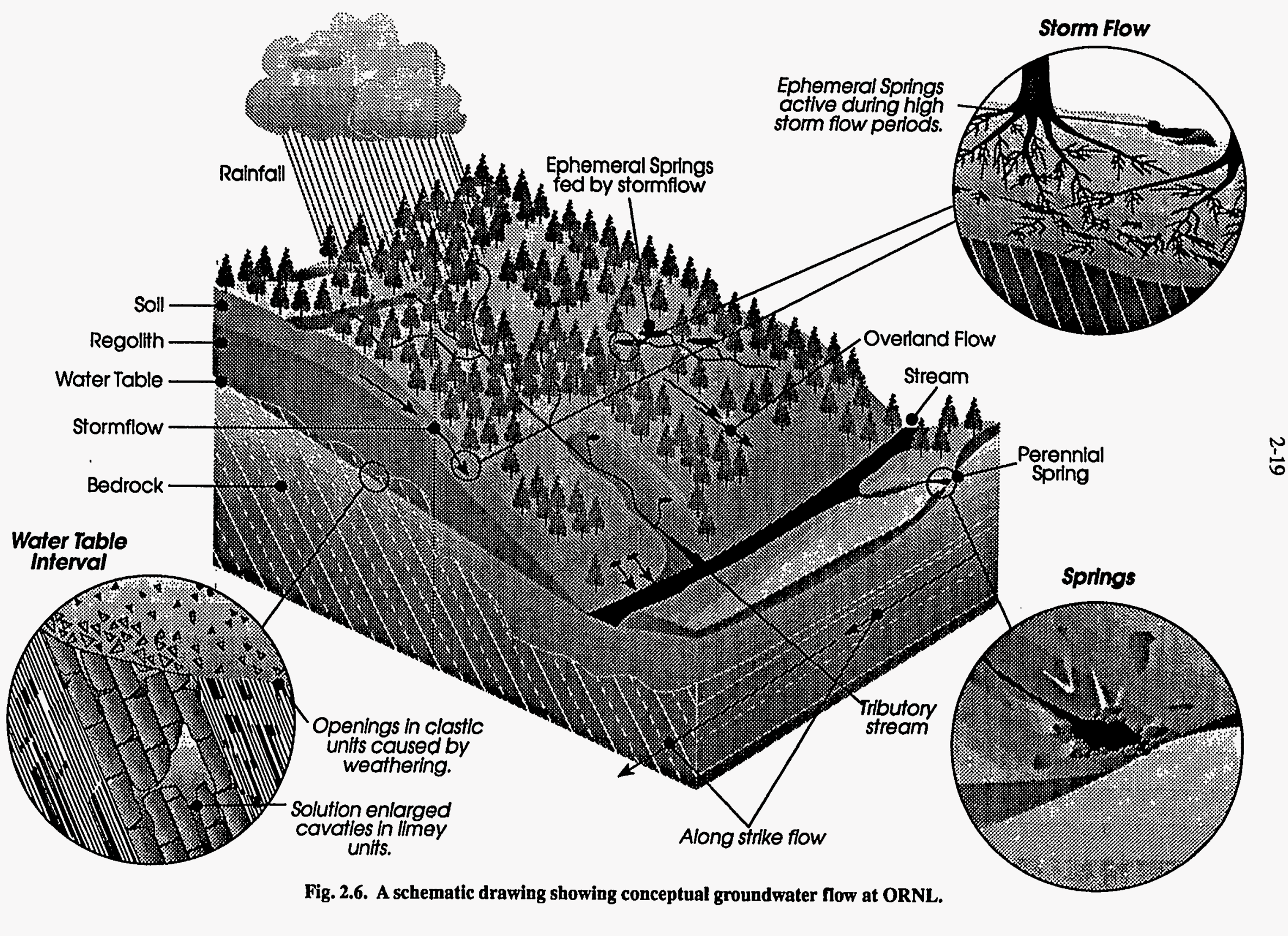


table. The vadose zone consists of regolith composed mostly of clay and silt, most of which is derived from the weathering of bedrock materials, and which has significant water storage capacity. Most recharge through the vadose zone is episodic and occurs along discrete permeable features that may become saturated during rain events, even though surrounding micropores remain unsaturated and contain trapped air. During recharge events, flow paths in the vadose zone are complex, controlled by the orientation of structures of the materials, such as relict fractures. Between recharge events, flow rates decrease dramatically, and flow paths are toward the groundwater zone.

\subsubsection{Groundwater Zone}

The permanent water table typically is near the transition from regolith to bedrock at depths of $<1$ to $5 \mathrm{~m}$ ( 3.3 to $16 \mathrm{ft}$ ). Changes in hydraulic parameters and changes in major ion chemistry with depth suggest vertical subdivision of the groundwater zone into three intervals: (1) a water table interval, (2) an intermediate interval, and (3) a deep interval. The depth and thickness of these intervals vary, especially between the ORR aquitards and the Knox aquifer.

A thin ( $\sim 1$ to $3 \mathrm{~m}$ thick) permeable interval may be present near the water table. Spatial and temporal differences in the saturated thickness and transmissivity of this interval explain both the configuration of the water table and most of the fluctuations in groundwater discharge to streams. The water table is near the contact between regolith and weathered bedrock because a large flux has formed regolith at shallower levels by solution of the rock cement; fresh bedrock at deeper levels indicates a smaller water flux. Seasonal declines in water table elevation can nearly drain this interval. The resulting changes in transmissivity explain an order-of-magnitude fluctuation in groundwater discharge rates even though contours of water table elevation at the times of annual high and low water levels show little change in hydraulic gradients.

Changes in saturated thickness with the inverse of hydraulic gradient from one topographic location to another explain the common observation that the water table is a subdued replica of land surface, because the product of transmissivity and hydraulic gradient is nearly constant at all locations along any flow path. The concept of a thin water table interval is new and detailed studies designed to directly define this interval have not been conducted. Groundwater movement below the water table interval is dominated by flow through fractures which can be separated into the larger and well connected water producing fractures, and those smaller ones that make up the matrix.

More than 600 values of transmissivity have been measured by slug tests (primarily) and other tests in the study area. A cumulative probability graph (Fig. 2.7) of transmissivity data from both water-producing openings and matrix fractures shows two slopes, thereby indicating two different populations. The upper population represents water-producing intervals in the shallow groundwater zone, and the geometric mean of transmissivity is $0.23 \mathrm{~m}^{2} / \mathrm{d}\left(0.27 \mathrm{yd}^{2} / \mathrm{d}\right)$. The minimum transmissivity value in the upper population is the same as the maximum transmissivity in the lower population and is $0.0055 \mathrm{~m}^{2} / \mathrm{d}\left(0.0065 \mathrm{yd}^{2} / \mathrm{d}\right)$. The lower population represents the matrix intervals, and the geometric mean of transmissivity is $0.0011 \mathrm{~m}^{2} / \mathrm{d}$ $\left(0.0013 \mathrm{yd}^{2} / \mathrm{d}\right)$ (Solomon et al 1992).

The deeper groundwater zone occurs below any water-producing intervals and generally has the same hydrologic characteristics as matrix intervals within the shallow groundwater zone. The 


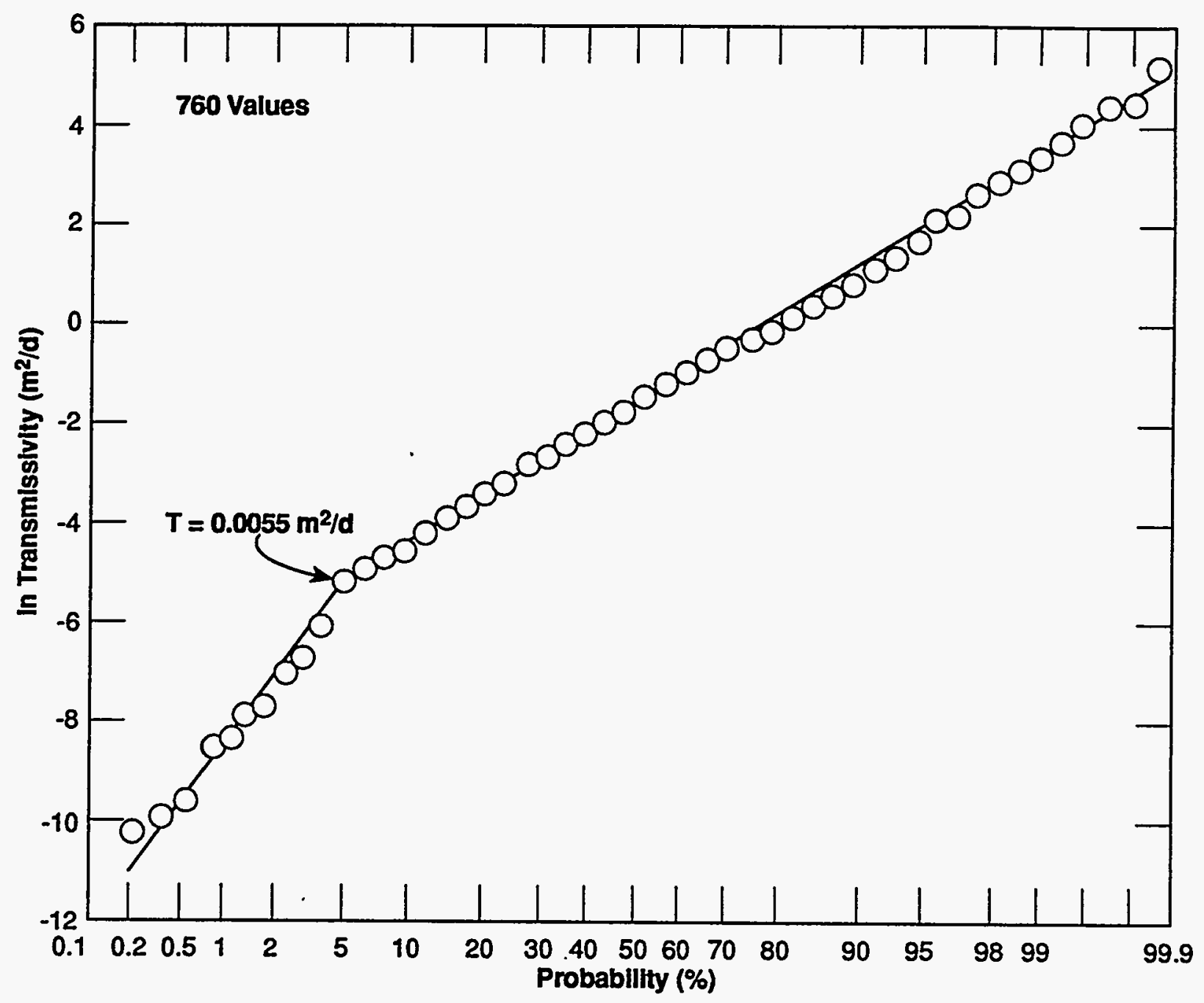

Fig. 2.7. Cumulative probability graph of transmissivity data for water-producing intervals and matrix fractures. Source: Adapted from Solomon et al. 1992. 
fracture porosity of the deeper groundwater zone has not been determined but probably is smaller than water-producing intervals of the shallow groundwater zone. There is a smaller spatial frequency of open fractures at depth, and average aperture is smaller because of a larger overburden pressure. A typical effective porosity in the deeper groundwater zone might be in the range of $1 \times 10^{-5}$ to $1 \times 10^{-4}$ and the geometric mean of transmissivity in the deeper groundwater zone is $0.00044 \mathrm{~m} / \mathrm{d}(0.00143 \mathrm{ft} / \mathrm{d})$.

The small geometric mean of transmissivity in the deeper groundwater zone, as compared to water-producing intervals in the shallow groundwater zone, indicates that rates and quantities of groundwater flow are much smaller than in the shallow groundwater zone. Transmissivity has not been measured in the brine section of the groundwater zone; however, it is probably very low.

\subsubsection{Flow at the soil/bedrock interface}

A convergence of evidence indicates that most water in the groundwater zone of the aquitards is transmitted through a layer, $\sim 1$ to $5 \mathrm{~m} \mathrm{(3} \mathrm{to} 15 \mathrm{ft}$ ) thick, of closely spaced, connected fractures near the water table. Many open fractures, which extend only a short distance into the rock, can be seen on outcrops, and the near correspondence of the water table with the top of weathered bedrock in the ORR is probably not coincidental. Regolith above this level has been formed by a large water flux, and the presence of unweathered bedrock at deeper levels apparently indicates a smaller water flux. Cyclic variations in water table elevation change the saturated thickness of the permeable layer. The resulting changes in transmissivity explain an order-of-magnitude fluctuation in groundwater discharge rates even though (1) contours of annual high and low water table elevations show little change in hydraulic gradient and (2) seasonal changes of water level in most wells are small compared with height of the water level above stream level. Compensating changes in hydraulic gradient and saturated thickness occur from one topographic location to another in order to conserve mass in the aquifer. The product of transmissivity and hydraulic gradient is constant (or increases with recharge) along each flow path.

The range of seasonal fluctuations in depth to the water table and in rates of groundwater flow vary significantly across the reservation. In the areas of the Knox aquifer, seasonal fluctuations in water levels average $5 \mathrm{~m}(16 \mathrm{ft})$, and the specific discharge through the active groundwater zone is typically $9 \mathrm{~m} /$ year (30 ft/year). In the aquitards of Bear Creek Valley, Melton Valley, East Fork Valley, and Bethel Valley, seasonal fluctuations in water levels average

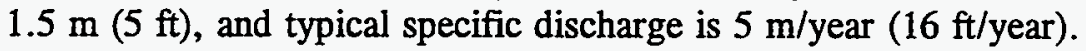

As in the stormflow zone, the bulk of water mass in the water table interval resides within porous matrix blocks between fractures, and diffusive exchange between matrix and fractures reduces contaminant migration rates relative to fracture fluid velocities. For example, the leading edge of a geochemically nonreactive contaminant plume migrates along fractures at a typical rate of $1 \mathrm{~m} / \mathrm{d}(3 \mathrm{ft} / \mathrm{d})$; however, the center of mass of a contaminant plume typically migrates at only $0.05 \mathrm{~m} / \mathrm{d}(0.16 \mathrm{ft} / \mathrm{d})$.

The concept of the thin, transmissive water table interval is relatively new and few data exist that can define it. The vertical distribution of hydraulic conductivity at the residuum/bedrock interface needs to be defined as well as the extent to which this zone acts as a conduit to 
groundwater flow before this hypothesis can be included in the site conceptual model. Another important aspect of this hypothesis is to define how the nature of this zone varies relative to the underlying geology.

\subsubsection{Fracture control of flow paths}

Below the water table interval, fracture control becomes dominant in flow path directing, particularly in the aquitards. The base of the water table interval corresponds to the zone of transition from regolith to bedrock. In the intermediate interval of the groundwater zone, groundwater movement occurs primarily in permeable fractures (Sledz and Huff 1981; Smith and Vaughan 1985; Dreier et al. 1987a; Moore 1988).

Rocks in the ORR have little intergranular porosity and permeability, but fractures, both parallel to bedding planes and cross-cutting, are present throughout the area. Flow through fractures, therefore, dominates the movement of groundwater on the ORR. The cube law (doubling a fracture's aperture increases the rate of flow through that fracture by 8 times) results in groundwater flow being dominated by the few fractures that have the largest apertures (Domenico and Schwartz 1990). Key parameters that determine if fracture systems result in good hydraulic permeability relative to their orientation are the connectivity of fractures and lateral continuity of the individual fractures. Fracture systems that tend to contain laterally continuous fractures or that contain numerous small fractures that are well connected to each other (such as anastomosing fracture patterns) will tend to form higher permeability.

Both fracture density and average aperture are probably larger in water-producing intervals than in matrix intervals. Dreier et al. (1987a, pp. 54-55) measured a fracture density of $200 / \mathrm{m}$ in saprolite of the WAG 6 area, but fewer fractures occur in rock that is less weathered. Sledz and Huff (1981, pp. 44-51) measured a minimum fracture density of $5 / \mathrm{m}$ in fresh rock. It may be reasonable to assume that average fracture density is 50 to $100 / \mathrm{m}$ in water-producing zones and 5 to $10 / \mathrm{m}$ in matrix zones. Moore (1988) calculated that the average aperture in waterproducing zones is 0.019 to $0.025 \mathrm{~m}(0.062$ to $0.082 \mathrm{ft})$, and that fracture porosity is 0.001 to 0.002 . Similarly, he calculated that the average aperture in matrix zones is 0.009 to $0.011 \mathrm{~mm}$ ( 0.0003 to 0.0004 in.), and fracture porosity is $6 \times 10^{-5}$ to $9 \times 10^{-5}$. The calculated porosity for water-producing zones is only slightly smaller than the average previously determined by hydrograph analysis (0.0042).

Within a fracture, groundwater can flow downdip, laterally, or in both directions. Changes in flow direction, as well as splits and joins of flow paths, may occur at fracture intersections, and groundwater flow paths may locally resemble stairsteps in both plan and section views. Tracer tests, however, show that most groundwater flow is nearly parallel to the water table. A typical fracture system in the GWOU (shown hypothetically in Fig. 2.8) is confined to discrete strata with the dominant fracture orientation parallel to the bedding planes and little connectivity between fracture systems across bedding planes. Because of the apparent lithological controls on fracture development, these fracture systems tend to form more densely at certain stratigraphic intervals. Thus, along-valley flow paths are almost entirely along strike and within waterproducing intervals toward cross-cutting, tributary valleys and streams. Cross-valley flow paths occur partly in water-producing intervals but also cross matrix intervals toward main-valley streams. 


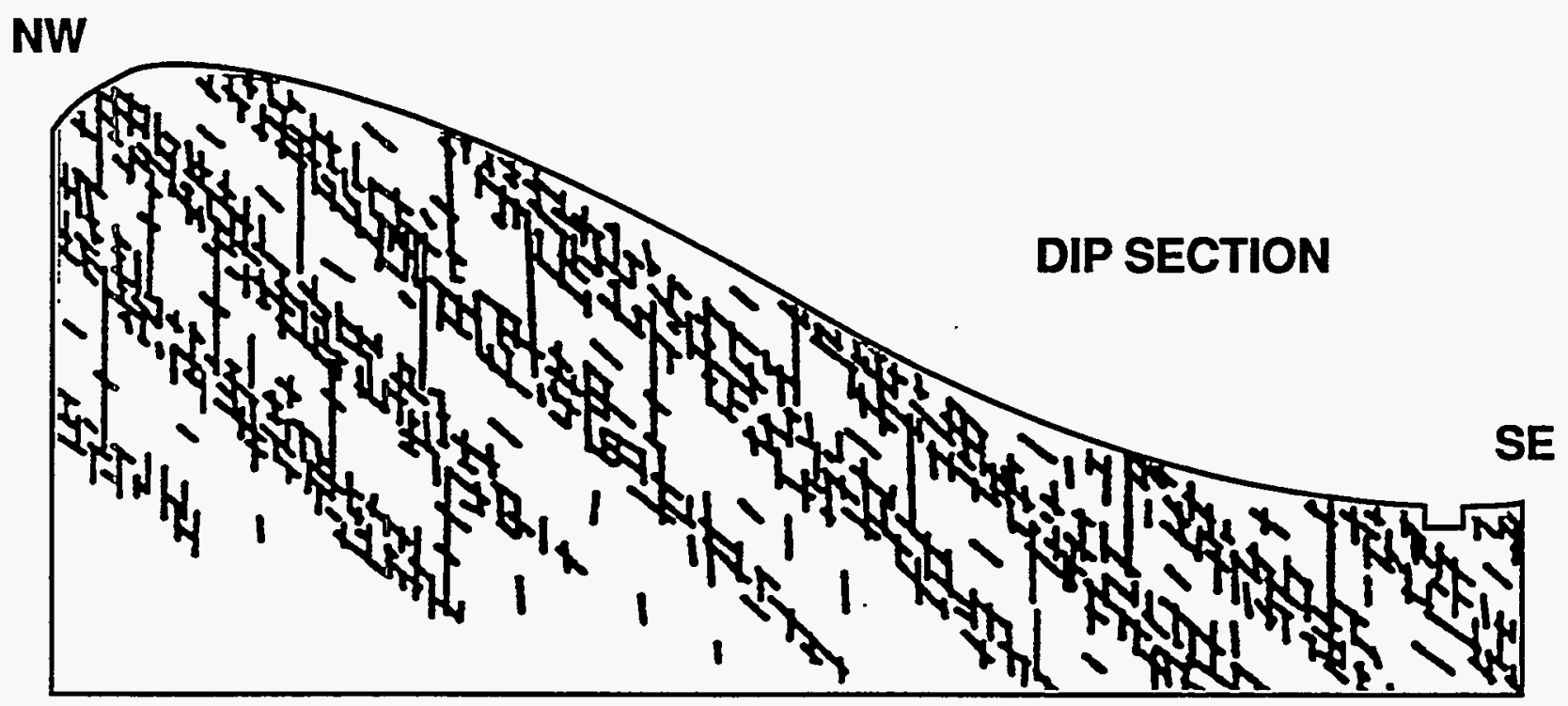

SW

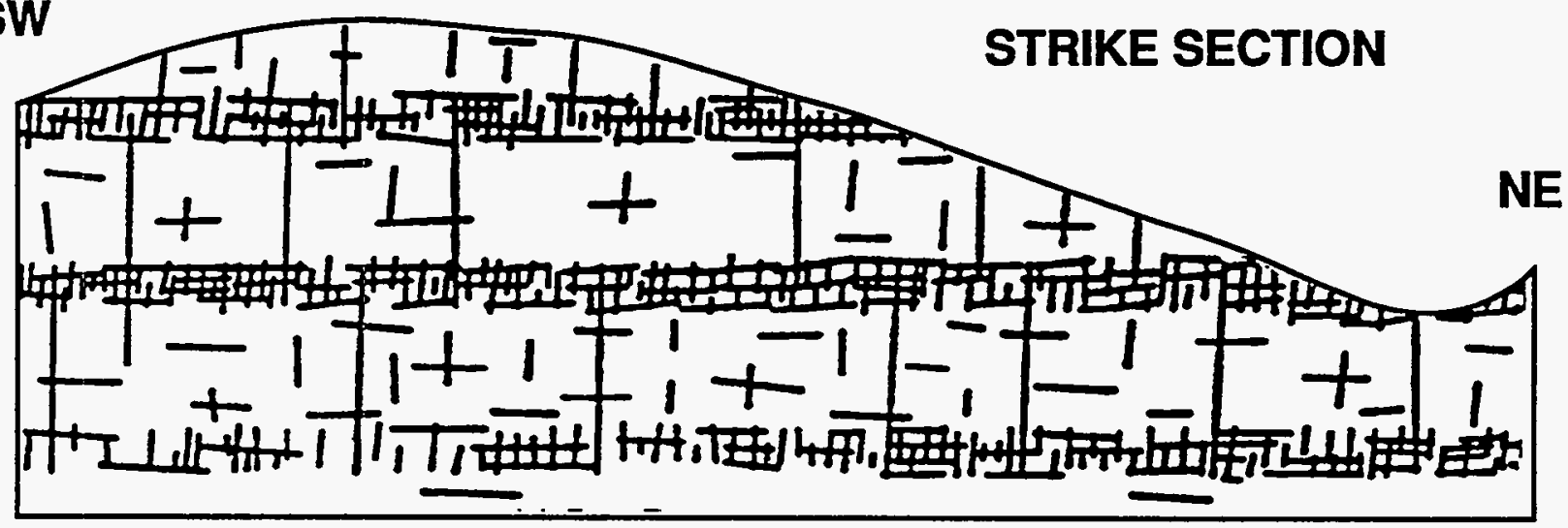

Not To Scale

Fig. 2.8. Sections showing hypothetical differences in trends and densities of fractures near ORNL. Source: Adapted from Moore and Toran 1992. 
Below the intermediate interval, small quantities of water are transmitted through discrete fractures. Other than this, little is known about the deep interval. The hydrologically active fractures in the deep interval are thought to be significantly fewer in number and shorter in length than in the other intervals, and the spacing is thought to be greater, partly because of less dissolution of fracture fillings. Fracture orientations are thought to be similar to those described earlier for the water table interval.

\subsubsection{Karst control of flow paths}

Karst is a type of topography that forms over gypsum, limestone, and dolomite bedrock as a result of both surface and subsurface dissolution of the bedrock. Because it is directly related to subsurface activity, karst also refers to all of the features that arise as a result of dissolution, including subsurface cavities. Karst occurs worldwide. It is actively developing today and has developed in the past to become a part of today's rock record (paleokarst). In the case of ORNL, karst involves dissolution of carbonate rocks, i.e., limestone and dolomite, which occurs in response to complex chemical equilibria between atmospheric $\mathrm{CO}_{2}$, groundwater, and the carbonate rock. Dissolution occurs more readily at low $\mathrm{pH}$ but, as a chemical reaction, it is also highly dependent upon other parameters such as groundwater composition.

Karst-related features have great potential for enhancing a rock's ability to transmit groundwater and for directing its flow. Cavities are the most obvious example in this regard. Open cavity systems that are well-connected to exit points are highly transmissive; cavities that are poorly connected or filled with detritus can be less transmissive. Less obvious karstic feature for transmitting groundwater are topographic irregularities, such as solution valleys, that formed on paleosurfaces and today provide preferred groundwater pathways along bedding planes.

Cavities have been identified in many drill holes in the ORR. In most instances, they appear to have formed along existing fractures by solution enlargement of voids. However, Moore (1988) presented arguments that many cavities may have formed in the geologic past. For example, many cavities are filled with terrace gravels that developed on paleosurfaces and Moore (1988) argues that the cavities which contain the gravels must have formed contemporaneously with the gravels. These cavities may represent ancient flow paths that are active today. The likelihood of ancient cavities in the rocks of the ORR imply the possibility of other paleokarst features, such as solution valleys, which today may serve as conduits for groundwater. Solution valleys and other paleokarst, surficial features are today more occult than cavities. Whereas cavities are readily apparent when intercepted during drilling, the surficial features are camouflaged along bedding planes. However, likely locations for paleokarst topographic conduits are at unconformities where the stratigraphically lower bed is composed of carbonate rock.

Solution cavities in the ORR are not well characterized. As a result, our understanding of their origin and abundance is lacking, and the data for comparing the transmissive quality of cavities to that of fractured rock is inconclusive. The reason for the poor characterization of cavities is that they tend to occur only in the purest, most massively-bedded carbonate rocks. In the whole ORR, this type of rock is dominated by the Knox aquifer which, because it occurs along ridges, is apparently unimportant for contaminant transport and has not been extensively studied as rocks occurring in ORR valleys. In the GWOU, massively-bedded, pure carbonates are relatively sparse. They occur mainly in the Rockdell and Witten formations in Bethel Valley, in a dolostone unit in the Rome formation on Haw Ridge, and in the Maynardville Limestone of 
the Conasauga Group along the GWOU southern boundary in Melton Valley. Transmissivity data for cavities, including those in the Knox aquifer, show them to be, on average, twice as transmissive as fractures $(0.085 \mathrm{~m} / \mathrm{d}$ vs. $0.041 \mathrm{~m} / \mathrm{d}$, respectively) (Moore 1988). However, the difference between the averages is not statistically significant (Moore 1988). Apparently, this is a result of the relatively few data for cavities (25) compared to the total number of data points (407), and the fact that the transmissivity data for cavities constitute both the highest and the lowest values of the data set with few values for cavities in between. This latter point probably arises because active, cavity-dominated flow systems are highly transmissive but, apparently, some of the fossil cavity flow paths are no longer active.

Although it lies outside the GWOU boundaries, the Knox aquifer has important effects on containing GWOU groundwater. Also, because it is the dominant, massively-bedded, carbonate unit in the ORR, it provides a good analog for similar type rocks in the GWOU. Groundwater flow in the Knox aquifer is dominated by a few cavity systems. Two wells on the southeast side of Bear Creek Valley are reported to produce $>60 \mathrm{~L} / \mathrm{s}$ of water, and about a dozen large springs discharge water near the base of ridges underlaid by the Knox aquifer. Also, a tracer test in the Knox aquifer showed a fluid velocity of 200 to $300 \mathrm{~m} / \mathrm{d}(656$ to $984 \mathrm{ft} / \mathrm{d})$ between a swallow hole and a resurgent spring farther downstream (Ketelle and Huff 1984). However, most existing wells in the Knox aquifer yield small quantities of water $(<1 \mathrm{~L} / \mathrm{min})$ and do not represent conditions in the most permeable regions. A statistical analysis of transmissivity data shows a geometric mean value of $2.3 \times 10^{-3} \mathrm{~cm}^{2} / \mathrm{s}$ with a mean minus one standard deviation of $3 \times 10^{-4}$ $\mathrm{cm}^{2} / \mathrm{s}$ and a mean plus one standard deviation of $2.2 \times 10^{-2} \mathrm{~cm}^{2} / \mathrm{s}$. The available data suggest that the bulk permeability in the Knox is ten times greater than the ORR aquitards and, in some places, the Knox is very permeable and is capable of transmitting large quantities of water.

The velocity of groundwater in cavities is at present poorly defined as a result of the contradictory evidence from tracer tests and groundwater hydraulic gradients. The velocity of flow in the main conduits is an important parameter in predicting the rate of migration of contaminants in the subsurface. The stratigraphic location and depth of cavities in the aquitard formations are needed to better define flow paths.

\subsubsection{Strata-bound flow paths}

Groundwater flow near valley floors within the GWOU is often confined within discrete beds where movement occurs preferentially along strike toward cross-cutting drainageways. This type of flow is called strata-bound flow. Elongated cones of depression during pumping tests and first arrivals of tracers in wells located along geologic strike from the point of injection have been interpreted in some previous studies as indicating anisotropic flow and rock masses that are more permeable in the along-valley direction than in the cross-valley direction. Instead, these observations and measurements are best explained by strata-bound flow that results from the occurrence of solution cavities within only the purest and most massively bedded carbonate units, and by the development of fracture networks within discrete beds where flow paths within networks have a much larger average permeability than do flow paths across matrix intervals from one fracture network to another. 
Examples of strata-bound flow at ORNL have been identified from the distribution of contaminants in plumes and from groundwater elevation measurements. The following are presently-known examples of preferred flow paths at the ORNL site:

- A plume of radiologically contaminated groundwater has been identified at WAG 1 (Ketelle and Lee 1992). In this situation, radiologic contamination identified in Well 4005 at WAG 1 led to the development of a hypothesis for strata-bound contaminant migration in the Witten Formation. A 18-m (36-ft) thick limestone bed of apparent biothermal origin contained the highest levels of contamination in Well $4005(487,093 \mathrm{pCi} / \mathrm{L}$ and $585,497 \mathrm{pCi} / \mathrm{L}$ gross beta/gamma). The subsurface extent of this bed was mapped using key stratigraphic indicators. Then using the hypothesis for strata-bound flow paths, the discharge points to storm drains and First Creek were predicted for this flow path. The predicted outfalls were subsequently tested by analyzing historical data for surface water and groundwater quality and the hypothesis was confirmed.

- Groundwater contamination has been identified at WAG 3 in Bethel Valley in monitoring wells and in surface water bodies that drain the site. Contamination in surface water appears in two distinct areas, one in the northwest tributary of White Oak Creek and a second in an unnamed tributary to Raccoon Creek. Studies of these tributaries have identified specific reaches that appear to be the sources of each stream's contamination. The hypothesis that strata-bound flow in the Witten Formation is controlling the distribution of contamination at WAG 3 comes from the observation that a line drawn between the seeps along each stream runs approximately parallel to strike and passed through SWSA 3, the expected main contributor to groundwater contamination in WAG 3. The distribution of contaminants in monitoring wells at this site is difficult to explain. The hypothesis for preferential flow needs to be further developed and tested for this site.

- At WAG 7 in Melton Valley where liquid radioactive wastes were disposed of in open trenches, radionuclide migration away from the trenches has been identified (Olsen et al. 1983, 1986). Groundwater contamination at this site varies seasonally, being low in the fall and winter and increasing with a rise in groundwater levels in the spring. Transport pathways in shallow groundwater at this site appear to be influenced by two faults and the limbs of a plunging anticline. High radionuclide concentrations occur where the water table intersects specific bedding planes, faults, and folds which probably served as preferential pathways during liquid disposal.

- Well 0883 is a $15-\mathrm{m}$ (49-ft) open hole with a $.3-\mathrm{m}$ (1-ft) cavity at the bottom. The well is located in WAG 1 on the south side of the impoundments near White Oak Creek. Water

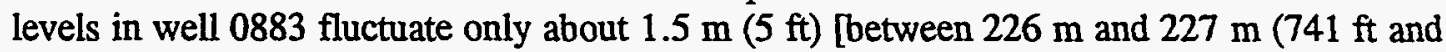
$746 \mathrm{ft}$ ) above mean sea level], even during heavy rains, which is relatively little compared to other wells in the ORR. Additionally, these water levels are some 8 to $9 \mathrm{~m}$ ( 25 to $30 \mathrm{ft}$ ) below the water level of White Oak Creek and more in line with the elevation of the Clinch River on the west end of the GWOU. These observations imply that the stratum into which well 0883 penetrates contains a well-connected, cavity-dominated exit pathway whose water level is controlled by the level of the Clinch River.

The physical and stratigraphical locations of the strata-bound flow paths underlying Melton Valley and Bethel Valley need to be cataloged. A better understanding of the mechanisms that 
result in strata-bound fracture systems, and the relationships between fracture formation and parameters such as bed thickness and lithology, will provide a basis for identifying and prioritizing likely zones and areas where strata-bound flow conduits exist. When identified, the depth of those conduits and the nature of flow at deeper intervals will need to be determined. Also important will be the nature and direction of flow in conduit systems close to discharge points at the surface such as springs, seeps, and stream channels, and near groundwater divides.

\subsubsection{Flow in alluvium deposits}

Three piezometer wells near WAG 13 show that recent alluvium along the floodplain of

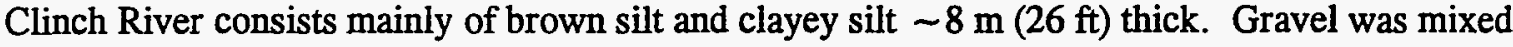
with the silt in samples from one well. Along White Oak Creek and Melton Branch, alluvium

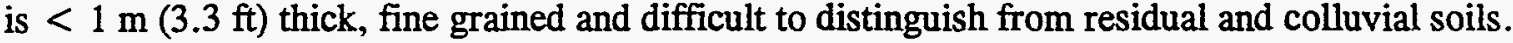
Subangular to rounded terrace gravels have been commonly described as mixed with clay and silt in near-surface samples from many wells. At one location, near Well 270 in WAG 6, a terrace deposit $\sim 5 \mathrm{~m}(16 \mathrm{ft})$ thick was found to consist of "well-rounded pebbles and cobbles of quartzite and other resistant materials along with sand, silt, and clay . . . . The pebbles and cobbles, which are not representative of the surrounding bedrock, are thought to be remnants of an ancient floodplain of the nearby Clinch River" (Lomenick and Wyrick 1965, p. 5).

Hydrologically, the floodplain and terrace materials are considered to be a part of the regolith for the purpose of this report. However, rounded gravel, pebbles, and cobbles are also reported as fill material in many bedrock cavities.

Groundwater flow through alluvium deposits is probably locally important. These materials are usually porous and have high transmissivities. Most streams are probably hydraulically connected to the alluvium which may effectively act as a porous liner for the stream channels.

Alluvium may provide an alternative down valley flow path for water in streams. This has important ramifications for analyzing surface water hydrographs and measuring flow in streams. Stream flow may be matched by a similar flux in the stream alluvium and the flux in a stream channel at any one point may not represent the total along channel flux. Another possibility is that the stream alluvium provides a buffer to high flow stages by providing bank storage.

\subsubsection{Depth of flow and brine interaction}

Wells finished in the deep interval of the ORR aquitards typically yield $<0.1 \mathrm{~L} / \mathrm{min}$ and thus have no potential for water supply. The specific storage of the bedrock aquitard is small and, as a result, some hydraulic heads in the deep interval respond to precipitation events, even though the associated water flux is small. The chemical characteristics of groundwater in the deep interval are different from those of the water table interval and probably reflect longer water residence times. Although diffusive transfer between fractures and matrix blocks is an important process in the deep interval, the total matrix porosity is less than that of the water table interval, the vadose zone, or the stormflow zone, thereby reducing the retarding effect on contaminant migration rates relative to more shallow zones.

Identification of a deep groundwater interval is based on limited hydraulic and geochemical data from borehole depths ranging from 30 to $300 \mathrm{~m}$ (98 to $984 \mathrm{ft}$ ). Hydraulic conductivity data 
come primarily from straddle packer tests (King and Haase 1987) and are supplemented by siug tests and slow-recovery analysis (Dreier and Toran 1989). In general, the intermediate groundwater interval shows hydraulic conductivities that are $>10^{-6} \mathrm{~cm} / \mathrm{s}$. The deep groundwater interval shows conductivities that are as high as in the intermediate range; however, measured conductivities in this interval are also as low as $10^{-9} \mathrm{~cm} / \mathrm{s}$. The low conductivities may be the result of either reduced matrix permeability or increased fracture spacing. The high conductivities presumably occur when the test interval intersects a permeable fracture.

The extent to which deep brines interact with water in the intermediate flow paths at the ORR is not known; however, some wells in Melton Valley that are screened at intermediate depths [(30 to $61 \mathrm{~m}$ (98 to $200 \mathrm{ft}$ )] show anomalously high sodium concentrations (60 to $300 \mathrm{mg} / \mathrm{L}$ ). This suggests that the deep brine aquifer is not completely isolated from flow paths in the intermediate and shallow level.

In the deep aquifer, hydraulic conduits are probably few and therefore are more important for identifying preferred flow paths. Determining the location of flow paths in the deep aquifer will be important to addressing long-term contaminant migration in the deep aquifer.

\subsubsection{Rate of flow}

For porous media, advective groundwater flow is in the direction of the maximum hydraulic gradient. In fractured rock, however, groundwater flow occurs in all directions where there are open fractures and a hydraulic gradient. Folds, faults, sealed fractures, and water table rises are common barriers to lateral flow in a fracture system, but in the absence of such barriers, advective flow from one point in one fracture may eventually occupy a semicylindrical volume of the aquifer. Splits and joins of the flow paths have considerable importance for the spread of pollutants from a source near the water table, and various amounts of longitudinal dispersivity may occur along all branches of the flow paths.

Calculations of hydraulic gradient assume linear flow paths between the points where potentiometric heads are measured. In fractured rocks, the path length between two points may be nearly the same as map distance in the directions of the fracture sets. In other directions, the length of a stairstep path is up to 1.4 times longer than the map distance in a two-dimensional view and up to 1.7 times longer in three dimensions. Path length corrections are generally unnecessary for calculations of hydraulic gradient because map distance errors are small and because both permeability and porosity are spatially variable.

Measurements of hydraulic grading indicate a range of 0.01 to 0.1 for cross-valley hydraulic gradient; the average gradient near the water table is $\sim 0.05$. In the along-valley direction, the hydraulic gradient has a range of 0.001 to 0.01 and the average may be $\sim 0.005$. A hydraulic gradient in the range for cross-valley flow may also occur along strike on the slopes of tributary valleys. Gradients near the lower ends of these ranges occur in relatively flat areas and gradients closer to the upper ends occur on steeper slopes. However, any apparent hydraulic gradient larger than $\sim 0.06$ may represent a cascade, a different flow path, or other discontinuity in flow and should be considered suspect. Smaller hydraulic gradients would be expected at deeper levels in the aquifer, but at depths of $\sim 20 \mathrm{~m}$ (65 ft), gradients are not greatly different than those near the water table in the Conasauga Group and the Chickamauga Group. Smaller hydraulic 
gradients are shown at depths of 30 to $70 \mathrm{~m}$ (98 to $229 \mathrm{ft}$ ) on sections of Melton Valley by Webster and Bradley (1987, pp. 82, 89), but are based on sparse data.

The best approach to calculation of average groundwater flow rate in the shallow aquifer is uncertain because of (1) truncated populations of hydraulic conductivity values for waterproducing intervals and matrix fractures and (2) large flow rates in a small percentage of fractures with large apertures. In calculating representative groundwater flow rates, Moore (1989) assumed that flow towards the center of valleys from ridges is by way of matrix fractions and that flow along strike in valleys is mainly by way of water-producing fractures. Using cumulative probability graphs for conductivity derived from aquifer tests in the ORR, Moore (1989) determined that flow rates in a tube $1 \mathrm{~m}(3.3 \mathrm{ft})$ wide is $>10.3 \mathrm{~m}^{3} /$ year for cross-valley but $<15 \mathrm{~m}^{3} /$ year $\left(19.6 \mathrm{yd}^{3} /\right.$ year $)$. The average flow rate for a tube $1 \mathrm{~m}(3.3 \mathrm{ft})$ wide and $30 \mathrm{~m}(98$ $\mathrm{ft}$ ) high was $12.5 \mathrm{~m}^{3} /$ year $\left(16.3 \mathrm{yd}^{3} /\right.$ year $)$.

The water table is deeper beneath ridges in areas of the Knox aquifer, and the average hydraulic gradient toward nearby streams is $\sim 0.01$ to 0.03 . Assuming an average hydraulic conductivity that is ten times greater than the ORR aquitards, the average specific discharge in the Knox aquifer is $\sim 45 \mathrm{~m} /$ year $(147 \mathrm{ft} /$ year).

The coarse detrital material reported as fill in some cavities and the reported washing away of sand during construction of a few wells suggest large groundwater velocities in at least a few cavities. A velocity of $-40 \mathrm{~cm} / \mathrm{s}(3.5 \mathrm{~km} / \mathrm{d})$ is required to move sand with a particle diameter of 0.2 to $1 \mathrm{~mm}(0.007$ to $0.39 \mathrm{in}$.) (Gregory and Walling 1973, pp. 238-239). One tracer test in the Knox Group showed a water velocity of $\sim 200$ to $300 \mathrm{~m} / \mathrm{d}(656$ to $984 \mathrm{ft} / \mathrm{d})$ between a swallow hole and a discharge point farther downstream (Ketelle and Huff 1984). Another tracer test in the Chickamauga Group showed a groundwater velocity of $\sim 20$ to $80 \mathrm{~m} / \mathrm{d}$ (65 to $260 \mathrm{ft} / \mathrm{d}$ ) between an excavated cavity in limestone and a sump in a reactor building at ORNL. In contrast, low water velocities are indicated by the range of hydraulic conductivity values and by the hydraulic gradients that have been measured in the shallow aquifers. Typical lateral gradients in the study area are 0.005 to 0.05 following Darcy's law; if the gradient is 0.05 , groundwater velocity near the cavity well that has the largest hydraulic conductivity $[7.6 \mathrm{~m} / \mathrm{d}(25 \mathrm{ft} / \mathrm{d})]$ is only $0.38 \mathrm{~m} / \mathrm{d}(1.24 \mathrm{ft} / \mathrm{d})$.

\subsubsection{Groundwater Geochemistry}

\subsubsection{Geochemistry}

The composition of groundwater is controlled by many factors, including the chemical content of recharge waters, interactions with regolith and bedrock, residence times, and mixtures or dilutions with waters from other flow paths. These factors and the complexity of flow paths below the water table commonly result in large differences in the concentrations of dissolved constituents in nearby wells. Also, the concentration of the constituents in water at some wells is not constant but varies throughout the year.

\section{Stormflow Geochemistry}

Only a few incomplete chemical analyses are available for water from the stormflow zone. Davis et al. (1984, p. 46) showed analyses of chemical extracts from soils in WAG 6 and 
described the material as highly leached and strongly acidic; except for one sample, the range in $\mathrm{pH}$ was 4.0 to 4.7 . A water sample from well T6-7 in WAG 7 was reported to contain $3.4 \mathrm{mg} / \mathrm{L}$ of $\mathrm{Ca}, 2.7 \mathrm{mg} / \mathrm{L}$ of $\mathrm{Na}$, and $1.2 \mathrm{mg} / \mathrm{L}$ of $\mathrm{Mg}$. Another shallow well (1062) in lower WAG 2 has shown a range of in-situ measurements for specific conductance of 35 to 56 micromhos $/ \mathrm{cm}$ at $25^{\circ} \mathrm{C}\left(77^{\circ} \mathrm{F}\right)$ over a period of 6 months. Samples of surface water collected at a flume in WAG 6 (Davis et al. 1984, p. 157) may include some water from the shallow aquifer but show a mean specific conductance of 120 micromhos $/ \mathrm{cm}$, a mean alkalinity $\left(\right.$ as $\mathrm{HCO}_{3}$ ) of $120 \mathrm{mg} / \mathrm{L}$, a mean $\mathrm{Ca}$ concentration of $46 \mathrm{mg} / \mathrm{L}$, and a mean $\mathrm{SO}_{4}$ concentration of $13 \mathrm{mg} / \mathrm{L}$. According to these data, water in the stormflow zone is acidic to nearly neutral; the water apparently is a calcium bicarbonate type, but other important ions are $\mathrm{Mg}, \mathrm{Na}$, and $\mathrm{SO}_{4}$. Total dissolved solids are probably $<100 \mathrm{mg} / \mathrm{L}$.

\section{Conductor Geochemistry}

In general, the chemical characteristics of groundwater change from a mixed-cation- $\mathrm{HCO}_{3}$ water type to an $\mathrm{Na}-\mathrm{HCO}_{3}$ type in the ORR aquitards at depths ranging from 30 to $50 \mathrm{~m}$ (98 to $164 \mathrm{ft}$ ). Although the geochemical mechanism responsible for this change in water types is not entirely quantified, it probably is related to water residence time. The transition from $\mathrm{Ca}-\mathrm{HCO}_{3}$ to $\mathrm{Na}-\mathrm{HCO}_{3}$ serves as a useful marker and is used in this report to distinguish the intermediate groundwater interval from the deep interval, a transition which is not marked by a distinct change in rock properties.

The properties and concentrations of chemical constituents in water from the shallow aquifer are not constant and may show relatively large changes through time and space. Davis et al. (1984) noted changes in specific conductance of up to $50 \%$ and on temperature of several degrees centigrade in well pickets in Melton Valley.

An example of spatial variability of specific conductance in Melton Valley is shown on Fig. 2.9 (Moore 1988). In this figure, the sections show location and length of each well screen and the specific conductance [micromhos $/ \mathrm{cm}$ at $25^{\circ} \mathrm{C}\left(77^{\circ} \mathrm{F}\right)$ ] of water at the center of each screen. Groundwater in this area probably flows laterally across the valleys and upward to discharge into White Oak Creek. However, there is no apparent relationship between well screen locations and amounts of specific conductance. This result apparently indicates nearly unique conditions along each of many groundwater flow paths and suggests that the interpretation of other data obtained by water quality monitoring will be complex.

A distinctly different groundwater geochemistry is reported by Webster and Bradley (1987, Table 10) from six wells in the Conasauga Group of Melton Valley that range from 30 to $61 \mathrm{~m}$ (98 to $200 \mathrm{ft}$ ) deep. This is a sodium carbonate or sodium bicarbonate type with a $\mathrm{pH}$ of 8.5 to 10.5 , a sodium content of 60 to $300 \mathrm{mg} / \mathrm{L}$, and a calcium plus magnesium concentration of $<12 \mathrm{mg} / \mathrm{L}$. These characteristics apparently result from ion exchange (calcium and magnesium for sodium) along deeper flow paths. -Total dissolved-solids are $<500 \mathrm{mg} / \mathrm{L}$ according to these few data. Other water types may also occur in the deeper aquifer, but available data are inadequate for characterization.

A much higher concentration of dissolved salts is found in water from wells in Melton Valley that are 150 to $450 \mathrm{~m}$ (492 to $1476 \mathrm{ft}$ ) deep. Total dissolved solids contents as high as $300,000 \mathrm{mg} / \mathrm{L}$ have been reported. This water is acidic and has (1) a high percentage weight of 

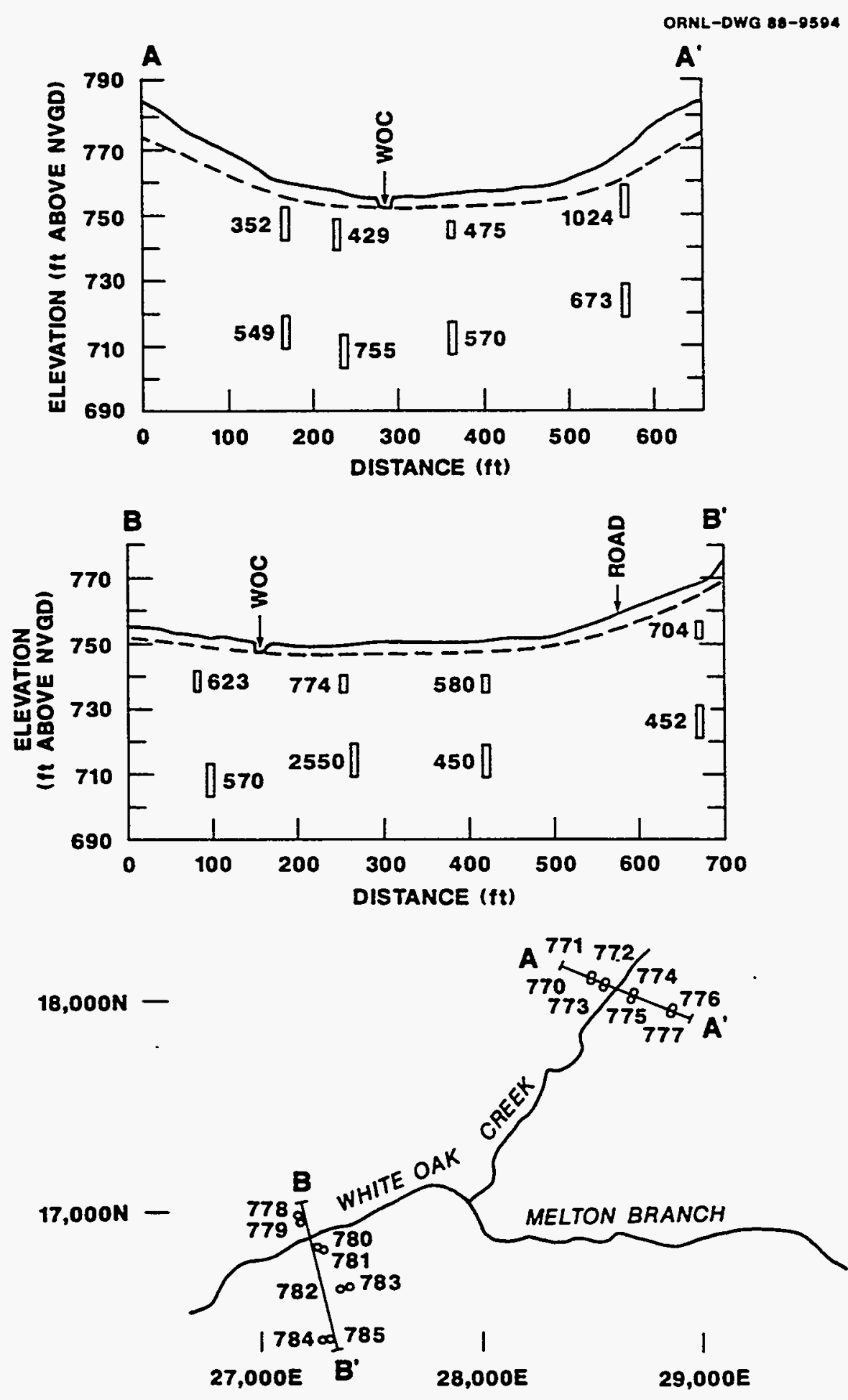

Fig. 2.9. Location map and sections showing specific conductance of water along lines of paired shallow and deeper wells. Source: Moore 1988. 
chloride; (2) an equivalent weight of sodium less than that of chloride; (3) enriched calcium, magnesium, strontium, and bromide contents; and (4) relatively low concentrations of bicarbonate, sulfate, and nitrogen. In terms of membrane-filtration theory, these waters are membrane concentrated and connate.

Saline water, having total dissolved solids ranging from 2000 to $275,000 \mathrm{mg} / \mathrm{L}$, lies beneath the deep interval of the groundwater zone, delineating an aquiclude. Chemically, this water resembles brines associated with major sedimentary basins, but its origin and rate of movement are not known. The depth to the aquiclude is $\sim 180$ to $240 \mathrm{~m}$ (590 to $787 \mathrm{ft}$ ) in Melton and Bethel Valleys and is believed to be $>300 \mathrm{~m}$ ( $984 \mathrm{ft}$ ) in portions of Bear Creek Valley. Depth to the aquiclude in areas of the Knox aquifer is not known but is believed to be $>350 \mathrm{~m}$ (1148 ft).

\subsubsection{Contaminant fate and transport}

Subsurface contamination may occur by spills and leaching at land surface; by leakage from pipes, drains, buried tanks, and sumps; and by the leaching of buried materials, including wastes. Contaminants may thus be introduced into the stormflow zone, the vadose zone, or the shallow aquifer. Soluble and liquid constituents (and probably colloidal particles) are entrained in groundwater in the source areas and generally move toward points of discharge at springs and streams. Contaminant transport occurs along preferred flow paths that connect the sources to discharge areas.

The exposed surface available to geochemical reactions with bedrock is substantially less when considering flow through fractures versus porous media flow. Thus contaminants are less likely to be retarded by sorption or filtration, and this is especially true for the larger fractures with the highest flow rates. Overall, fracture flow allows contaminants to migrate more rapidly and with less reduction in concentration to exit points than would be the case if flow was by way of a porous medium.

In many instances on the ORR, groundwater sampled in monitoring wells has been highly contaminated, whereas closeby surface water bodies do not show the same level of contamination. This has lead to the hypothesis of Matrix Diffusion, where much of the currently identified groundwater contamination is located in the matrix of the bedrock and is not connected to the preferred flow paths. Migration in the matrix is much slower and hydraulic conductivities are much lower. Movement of contaminants is by way of limited mixing of matrix and flow path waters, or by diffusion of dissolved contaminants from the high concentrations in the matrix to lower concentrations in the flow paths. In this way, the majority of groundwater contamination is held in a reservoir of contaminants below the main waste areas that is slowly released to the active flow network.

Lateral flow in the shallow groundwater zone is relatively slow, an average of $1 \mathrm{~m} / \mathrm{d}$ $(3.3 \mathrm{ft} / \mathrm{d})$, and only 5 to $10 \%$ of all streamflow moves through this zone to discharge locations. However, the complex flow paths mean that any contaminant introduced at a point would soon occupy all fractures within a semicylindrical volume of the aquifer and that pollution in upland areas would continue to spread both radially and vertically. In valleys, on the other hand, the convergence of lateral and vertical flow paths toward discharge locations would tend to localize a pollution plume toward exit points. 


\section{2-34}

Only $\sim 1 \%$ of all groundwater follows flow paths through the deeper groundwater zone. This water comes from the shallow groundwater zone and eventually may flow upward, back into the shallow groundwater zone. Fractures in the deeper groundwater zone are tightly compressed; filtration and sorption may be somewhat more effective than in the enlarged fractures and cavities of the shallow groundwater zone. Webster and Bradley $(1987, \mathrm{pp} .34,59,75-78)$ detected little radionuclide contamination below a depth of $30 \mathrm{~m}(98 \mathrm{ft})$ in Melton Valley. Well yields are very low in the deeper groundwater zone, and large volumes of rock could be dewatered at an average pumping rate of $0.2 \mathrm{~L} / \mathrm{min}$ for each well.

\subsubsection{Surface Water}

The two valleys that comprise the GWOU are connected by the same surface water drainage system. Melton Valley is drained by two main channels, Melton Branch and White Oak Creek, which merge and flow into White Oak Lake. From there, surface water drains directly into the Clinch River. In Bethel Valley, the sole main drainage is White Oak Creek, which passes through the water gap into Melton Valley. A topographic divide on the western end of Bethel Valley causes surface water on the eastern side of the divide to flow into White Oak Creek and exit through the water gap while surface water on the western side of the divide flows into the Clinch River through Raccoon Creek. Additionally, the area around Bearden Creek on the eastern boundary of Bethel Valley constitutes a topographic divide. Thus, except for the water gap in Haw Ridge, Bethel Valley is a closed basin in terms of its surface water.

There is an important relationship between groundwater and surface water in the GWOU in that nearly all streamflow is discharged groundwater (Moore 1988). According to the groundwater model of Solomon et al. (1992), fully $90 \%$ of all subsurface flow occurs within the stormflow zone and this discharges immediately into streams. Even water that percolates through the stormflow and vadose zones into the water table interval of the groundwater zone mostly is discharged into surface streams. This relationship between groundwater and surface water in the GWOU results in numerous seeps and springs that occur on the ridges and the valley floors. Some seeps and springs are ephemeral, arising in response to heavy or prolonged precipitation. Others are permanent. For instance, many of the springs on Chestnut Ridge are fed by the Knox aquifer and probably arise where solution cavities and preferred flow paths meet the surface, creating the perennial creeks that flow into Bethel Valley. Other springs and seeps occur on ridges and valley floors where the water table intersects the surface.

Surface water data are important input parameters for understanding groundwater in the GWOU. For example, according to Moore (1988), monitoring of White Oak Creek below its confluence with Melton Branch in Melton Valley showed natural streamflow (i.e., streamflow minus input from water imported for ORNL activities) in late June 1988 to be near zero. An important inference that can be made from Moore's (1988) observation is that White Oak Creek is losing water. A continual supply of surface water reaches Bethel Valley from the perennial springs that flow from the Knox aquifer at Chestnut Ridge. Thus, only loss of surface water can account for Moore's (1988) observation. A probable mechanism for water loss is groundwater recharge along the course of White Oak Creek, an idea that challenges the accepted notion of recharge being restricted to ridges in the GWOU. 


\subsubsection{Surface water contamination}

The surface water system-seeps, springs, and streams-constitute the primary exit pathway for most water in the groundwater system at ORNL. The nature and extent of contamination in surface water is, therefore, indicative of the nature and extent of contamination in groundwater. This is an important concept as, in general, monitoring surface water is more cost effective than monitoring groundwater. At the same time, surface water discharge points are located at the end of groundwater flow pathways and are representative of the active flow systems, whereas groundwater wells do not necessarily intersect groundwater pathways.

Groundwater and surface water contamination at WAG 3 serves as an example of how identification of surface water contamination can lead to a better understanding of the nature of groundwater contamination and provide information on the flow paths in groundwater. WAG 3 straddles the surface water divide between White Oak Creek and Raccoon Creek in Bethel Valley and straddles the apparent shallow groundwater divide between these two drainage systems. Groundwater quality data for this area are sporadic and analysis of groundwater at three wells in the vicinity of the WAG has identified the main contaminant in groundwater as ${ }^{90} \mathrm{Sr}$, with one analysis of $\mathrm{Cd}$ above maximum contaminant levels (MCLs).

Contamination with ${ }^{90} \mathrm{Sr}$ has been identified in the northwest tributary of White Oak Creek and in Raccoon Creek. A $30.5 \mathrm{~m}$ (100-ft) reach of the northwest tributary of White Oak Creek and a similar reach in an unnamed tributary at the headwaters of Raccoon Creek have been reported as the primary sources of this contamination. A line drawn connecting these discharge points is parallel to geologic strike and passes through SWSA 3, the primary source of this contaminant.

Using this preliminary evidence derived from limited groundwater data and stream data, it is possible to infer that the primary groundwater and contaminant flow paths from WAG 3 are strata-bound and discharge to the surface water where the flow paths intersect the stream valleys. This will allow the investigation at WAG 3 to be more focused.

\subsection{GWOU BOUNDARIES AND PATHWAYS}

Establishing verifiable boundaries for the GWOU is the principal goal of this characterization plan. The present boundary condition hypothesis is that contaminants residing within the GWOU do not migrate outside of the conceptual boundaries. As described in Sect. 2.1, the primary emphasis of the initial investigations will be to test this working hypothesis by evaluating the integrity of the GWOU conceptual boundaries. If the results of these initial investigations invalidate any of the conceptual boundary conditions, then steps will be taken to characterize contaminant transport within the GWOU that leads to off-site migration.

The conceptual boundaries of the GWOU (Fig. 2.10) are defined by presumed groundwater divides that define the hydrologic regimes of Bethel Valley, Melton Valley, and Raccoon Creek. Three of these boundaries parallel the regional strike: Chestnut Ridge to the north, Copper Ridge to the south, and Haw Ridge, a medial groundwater boundary that acts as a divide between Bethel and Melton Valleys. All three ridges constitute surface water divides and, for reasons explained 


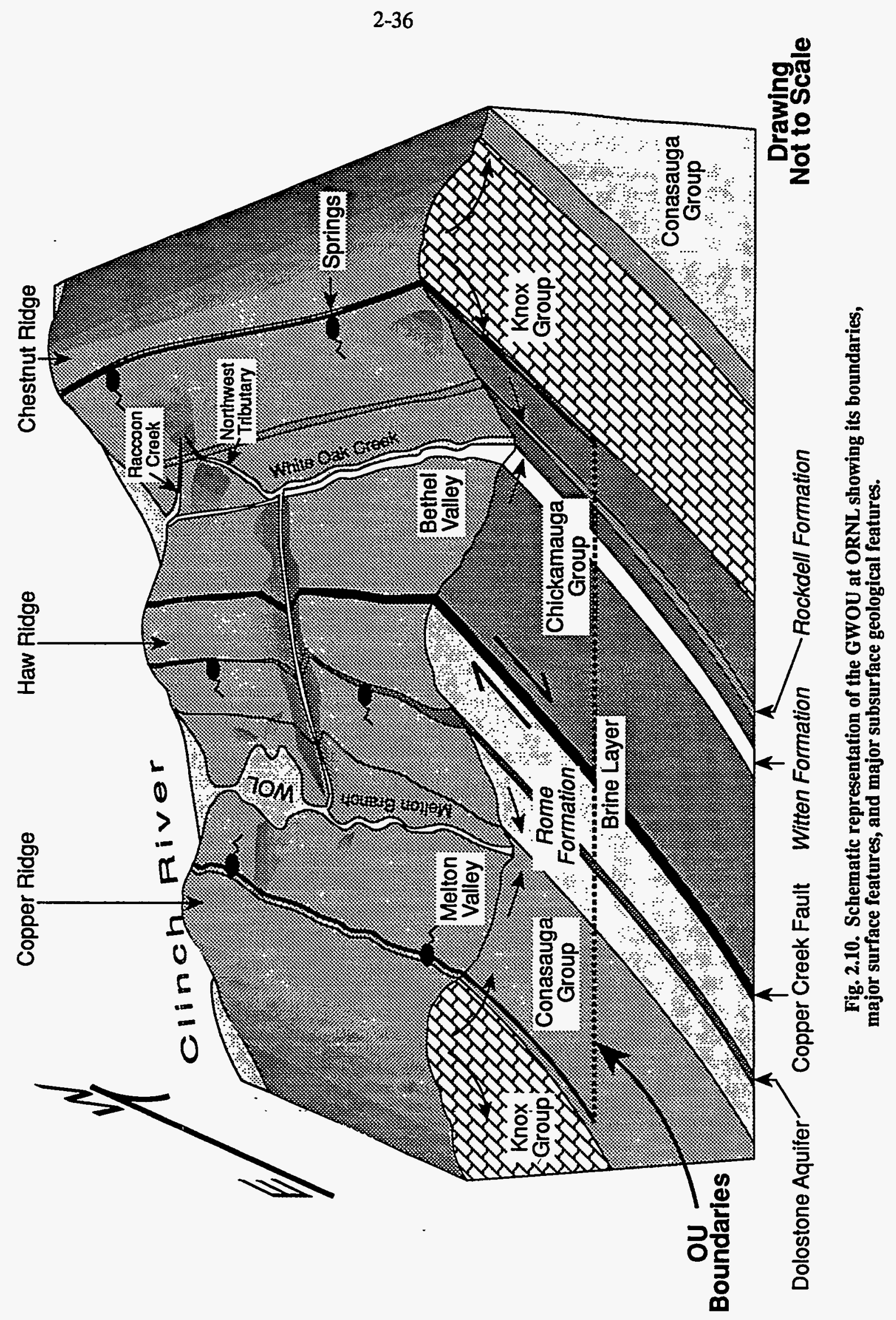


below, are assumed to constitute groundwater divides. The remaining boundaries are the east, west, and a basal boundary.

\subsubsection{North and South Boundaries}

\subsubsection{Description}

The northern groundwater conceptual boundary of the GWOU is the contact between the Knox Group and the overlying Chickamauga Group near the base of Chestnut Ridge (Fig. 2.9). Because of repetitions of surface rock units that result from the compressional tectonics that formed the geology of East Tennessee, the Knox Group is also an important component of the southern boundary. This boundary is marked by the contact of the Knox Group with the underlying Conasauga Group at Copper Ridge (Fig. 2.10). Because of the importance of the Knox Group at both boundaries, the two are considered together here.

The Knox aquifer, at Chestnut Ridge, is confined between aquitards. As a result, it is believed that the hydraulic head on the Knox aquifer exceeds that in the rocks surrounding it and this pressure difference acts as a divide, effectively separating the groundwater of Bethel Valley from that in Bear Creek Valley to the north. Visual evidence of the confined head lies in numerous springs, seeps, and perennial creeks that arise from the Knox along Chestnut Ridge. Solomon et al. (1992) estimated an average specific discharge in the Knox aquifer of $\sim 45 \mathrm{~m} /$ year (147 ft/year), compared to $\sim 11 \mathrm{~m} /$ year (36 ft/year) for more permeable intervals of the aquitards. However, though on average the Knox aquifer is more permeable and transmissive than the aquitards, it is heterogeneous with respect to its hydrologic properties. For example, two creeks arising from the Knox on Chestnut Ridge that are marked as perennial creeks on USGS topographic sheets are, in fact, ephemeral creeks that flow only during and immediately after heavy rains. This heterogeneity probably results from the distribution and connectedness of solution cavities in the Knox.

The Knox aquifer along the southern boundary of the GWOU holds up Copper Ridge. Similar hydrologic conditions are thought to exist at the southern boundary as exist at the northern boundary, but little or no data are available to support this assumption.

Hydrologic isolation of the GWOU along its north and south boundaries is dependent on the ability of the Knox Formation to prevent groundwater from escaping the GWOU. Most of the present understanding of the hydrologic character of the Knox in the GWOU comes from studies conducted along Chestnut Ridge. For the most part, these indicate a closed boundary with the possible exception of the heterogeneous distribution of permeability. Little if any work has been conducted on the Knox along Copper Ridge and it is not known if these rocks exhibit similar characteristics to those along the northern boundary.

\subsubsection{Data gaps and needs}

Data gaps associated with the north and south boundaries are strongly tied to the Knox aquifer even though the rocks that make up the aquifer lie outside the OU boundaries. The reason for this is that within the conceptual model the Knox aquifer effectively acts as a hydrostatic pressure seal to flow across the geologic contacts at the north and south boundaries. 
Thus, the data gaps that arise concerning the Knox seek boundary condition confirmation. The concept of the Knox aquifer as a hydrostatic pressure seal arises from the following observations:

- The Knox aquifer has higher transmissivity to depth than the aquicludes as a result of the extensive cavities in the formations that constitute the aquifer. Therefore, water can be transmitted to depth in the Knox aquifer more easily than in the aquitards, and hydraulic gradients in the aquifer will be generally lower than those in the aquitards.

- The formations of the Knox aquifer generally make up ridges in the ORR; therefore, recharge at the ridges can maintain a higher hydrostatic head.

- Cross strata transmissivity in the aquitards and between the aquitards and the Knox aquifer is relatively poor compared to transmissivity within strata.

The difference between recharge rates and the poor transmissivity across strata can maintain a higher hydraulic head in the Knox aquifer than in the aquicludes. However, in locations where the Knox aquifer is well connected to a pathway to the Clinch River, the hydrostatic level of the Watts Bar Lake will exert a strong influence on the head in the Knox, resulting in lower heads. This concept needs to be tested for both the north and south boundaries because no wells penetrate the Knox/aquiclude contact such that pressures on either side of that boundary can be measured.

North Boundary. At the north boundary, the high hydraulic head in the Knox aquifer results in perennial spring and stream discharge at the contact with the Chickamauga Group along most of Chestnut Ridge. In one area, north of WAG 3, ephemeral creeks that flow down Chestnut Ridge raise doubts as to the effectiveness of the aquifer as a pressure barrier along the north boundary of GWOU at this point.

If hydraulic head in parts of the Knox is less than that in the overlying Chickamauga Group, the Knox may become an exit pathway for contaminants in Bethel Valley. Variable hydraulic head in the Knox could signify discrete cavity systems, each with its own characteristic hydraulic head. In this case, regions of the Knox with low head could be the result of either direct connection to an exit pathway or relaxation of confining pressure that causes upward flow into the Chickamauga Group. Either case raises the possibility that the Knox Group rocks may be acting as conduits for transporting contaminants either along strike into the Clinch River or into deeper groundwater by means of longer flow paths away from the ORR.

The enhanced permeability of the Knox, relative to other rocks of GWOU, is the result of pervasive solution cavities. These could be relatively modern features, in which case they will be more concentrated at the relative near surface (e.g., at outcrop along Chestnut and Copper Ridge). However, the Knox Group at Chestnut Ridge sits beneath a major disconformity, and variable thickness of the Mascot Dolomite at the top of the Knox Group indicates that the rocks were exposed and eroded during the early to middle Ordovician (Hatcher et al. 1992). Today, the Knox may possess paleokarst features, including remnant cavern systems, that developed when the Knox was subaerially exposed. Subsequent to its exposure at the surface, the Knox would have been buried, then exhumed during or after the Appalachian orogeny. Diagenesis during burial has the potential to anneal paleosolution features, but the extent of diagenesis of the Knox during burial has not been characterized. If annealing were relatively minor, the Knox 
could have been left with significant permeability that exists today deep beneath the GWOU. In addition, a potential result of a paleokarst topography is that, today, the topographic irregularities on the paleosurface of the Knox could provide preferred pathways for groundwater flow along the unconformity with the overlying Chickamauga Group. The distribution of solution features in Knox Group rocks and the degree to which they are connected are important parameters for understanding the role of these rocks as a pressure barrier to the groundwater at the north boundary of the GWOU.

South Boundary. Investigations of the Knox aquifer under Copper Ridge and its contact with the underlying Nolichucky Shale are particularly important for understanding the south boundary of GWOU. Most of our information regarding the behavior of the Knox aquifer at ORNL comes from investigations conducted along the northern boundary of GWOU, Chestnut Ridge. Characteristics of the Knox aquifer along the southern boundary are inferred from this information. On Copper Ridge, the lower boundary of the Knox aquifer is the contact between the Nolichucky Shale and the Maynardville Limestone, both in the Conasauga Group. Elsewhere in the ORR, the Maynardville Limestone contains extensive solution cavities; this feature may also be present in this formation below Copper Ridge. The conceptual site model hypothesizes that more rapid recharge to the Knox aquifer on Copper Ridge maintains a higher hydraulic head than is maintained in the underlying Nolichucky Shale. The southern boundary is therefore thought to be a pressure boundary over which any flow is directed into the GWOU from the Knox.

Supporting the hypothesis that greater head is maintained in the Knox aquifer below Copper Ridge is a line of perennial springs that occurs approximately at the Maynardville/Nolichucky contact along the base of Copper Ridge. Monitoring wells into the Nolichucky in Melton Valley confirm that head in this formation is below that of the springs, suggesting that the springs discharge from the Knox aquifer.

\subsubsection{Medial Boundary}

\subsubsection{Description}

The assumed boundary for groundwater between Bethel Valley and Melton Valley is the Rome Formation which holds up Haw Ridge (Fig. 2.10). Four factors contribute to this boundary. First, the Rome Formation is one of the aquitard units in the ORR. Second, Haw Ridge is a topographic high and, because groundwater flow is thought to be relatively shallow in the GWOU, the ridge prevents groundwater from crossing valleys. Third, a karstified dolomite unit within the Rome Formation exhibited artesian water pressure when intercepted during drilling on Haw Ridge. This dolostone may act as a pressure barrier between any deep groundwater within Bethel Valley and Melton Valley. Fourth, the Copper Creek Fault, which lies beneath the Rome Formation on Haw Ridge, has traditionally been interpreted to be impermeable to groundwater (de Laguna et al. 1968).

\subsubsection{Data gaps and needs}

The validity of the model for Haw Ridge as a divide between the groundwater units of Bethel and Melton Valleys rests on four mechanisms: (1) low permeability of the Rome Formation, (2) shallow groundwater flow in GWOU, (3) high piezometric head in a dolostone unit of the 
Rome Formation creating a pressure divide, and (4) low permeability of the Copper Creek fault zone.

Two geological features specific to Haw Ridge can be potential conduits for deep groundwater flow. The first feature is the Copper Creek Fault, which is exposed along higher elevations on Haw Ridge and intersects the valley floor in the White Oak Creek water gap (Fig. 2.10). The fault zone rocks have been thought to be impermeable to groundwater flow (deLaguna et al. 1968), but recently, Nativ and Hunley (1993) cited evidence for permeable regions within the fault zone. Because the water gap is an important funnel for surface water from Bethel Valley to Melton Valley, fault zone regions of high permeability in the water gap could become conduits for deep groundwater flow and contaminant transport beneath Melton Valley.

The second geological feature specific to Haw Ridge is the morphology of the water gap, which suggests structural control of its position and could also result in a permeable groundwater pathway. The water gap is a steep-sided feature through Haw Ridge created by a relatively small creek. Its form is not the typical V-shaped notch expected of an antecedent stream. In addition, the two segments of the ridge on either side of the water gap do not constitute a continuous, linear feature. The northeast segment of the ridge is offset to the southeast relative to the other ridge segment. Dreier et al. (1987b) mapped the water gap as the location of a tear fault associated with the Copper Creek thrust fault. If the position of the water gap is controlled by a plane of weakness in Haw Ridge, such as a major fault, the structure could act as a groundwater recharge conduit leading to deep flow in Melton Valley. The abilities of this possible structure and of the Copper Creek fault zone to transmit groundwater are enhanced where the two structures intersect.

Characterizing the hydrologic properties of the Rome Formation is also important to understanding the effectiveness of the medial boundary as a hydrologic barrier. Two points need to be tested: (1) the relative impermeability of the bulk of the Rome Formation, and (2) the effectiveness of the dolostone interval as a pressure barrier. However, regardless of the natures of these rocks, if they are cut by permeable structures, such as those suggested above, they will not be able to prevent groundwater exchange between the two valleys.

\subsubsection{West Boundary}

\subsubsection{Description}

The boundary west of the GWOU is the Clinch River (Fig. 2.10). Piezometric measurements indicate that, in general, the hydraulic gradient throughout the GWOU is from east to west, and present understanding is that the bulk of the groundwater within the GWOU is intercepted by surface streams and exits the GWOU as surface water (Solomon et al. 1992). Melton Valley surface water drains to the west into the Clinch River via White Oak Creek and White Oak Lake. In Bethel Valley, westward surface drainage directly into the Clinch River is interrupted by a topographic divide. All of the water in Bethel Valley to the east of this divide drains through the water gap in Haw Ridge into White Oak Lake and ultimately into the Clinch River (Fig. 2.10). The water to the west of the divide drains to the west by means of Raccoon Creek into the Clinch River (Fig. 2.10). Additionally, the Clinch River is assumed to be the local base level for the GWOU groundwater system. Therefore, it is currently thought that any 
groundwater within the GWOU that is not intercepted by surface streams within the GWOU boundaries ultimately is intercepted by the Clinch River.

A major question regarding the west boundary of the GWOU is the topographic divide that separates Bethel Valley from the Clinch River. It is not known whether the divide also constitutes a groundwater divide or if groundwater from Bethel Valley underflows it into Raccoon Creek. This question holds important implications for contaminant transport, especially from WAG 3, and therefore for a mass balance of contaminants that flow out of Bethel Valley via the water gap.

\subsubsection{Data gaps and needs}

White Oak Lake as the west boundary of the GWOU along Melton Valley is fairly clear cut. Only deep groundwater that would underflow the lake and empty directly into, or underflow, the Clinch River would violate this boundary. The site conceptual model says that all groundwater in Melton Valley resurfaces before leaving the GWOU. However, as pointed out in this section and by Nativ and Hunley (1993), deep flow could occur along deep solution features or fractures. Additionally, the rocks beneath Melton Valley are known to contain various structures, such as those in the Maryville Limestone, that could act as groundwater conduits. Of additional importance to Melton Valley are deep contaminants released to the aquiclude by the hydrofracture experiments.

According to the site conceptual model, the west boundary at Bethel Valley is also the Clinch River. However, the bulk of Bethel Valley is separated from the Clinch River by a topographic divide that is marked roughly by the location of State Highway 95. It is not clear to what extent this surface water divide is also a groundwater divide. Monitoring indicates that contaminants from Bethel Valley (apparently derived from WAG 3, which straddles the divide) are entering Raccoon Creek on the west side of the divide. Whether the groundwater passing under the divide represents flow from the bulk of Bethel Valley or whether it is only locally derived from WAG 3 is not known. Quantifying this variable is crucial to other boundary problems in the GWOU. For instance, water balance is important to understanding the medial boundary. To calculate an accurate water balance, it is necessary to know the proportion of Bethel Valley groundwater that exits through the water gap in Haw Ridge and the proportion that exits Bethel Valley at the west boundary. Underflow of this western boundary at any point could end up at springs in the bed of the Clinch River. It is assumed that all local deep flow paths at ORNL will exit at, or before, the Clinch River.

The hydrologic characteristics of the extensive Clinch River alluvial deposits west of Melton Valley are unknown. WAG 13 is located on these deposits and is a likely contributor to groundwater contamination. Additionally, White Oak Lake and Raccoon Creek drain into these deposits, and underflow of the western boundaries of the GWOU can also potentially transport contaminants into them.

\subsubsection{East Boundary}

\subsubsection{Description}

The boundary of the GWOU to the east is taken to be Bearden Creek at Bethel Valley and 
the Clinch River at Melton Valley. Bearden Creek represents a surface water divide and is the deepest incision of eastern Bethel Valley tributaries to the Clinch River. Piezometric measurements throughout Bethel Valley indicate that the hydraulic gradient decreases from the valley's eastern end to its western end. Due to Melton Lake Dam, the Clinch River at Melton Valley's eastern end is some $15 \mathrm{~m} \mathrm{(50} \mathrm{ft)} \mathrm{higher} \mathrm{than} \mathrm{at} \mathrm{its} \mathrm{western} \mathrm{end.} \mathrm{This} \mathrm{implies} \mathrm{a} \mathrm{higher}$ head in the east and, combined with piezometric measurements, indicates groundwater flow is to the west.

\subsubsection{Data gaps and needs}

Very few data exist that support the placement of the eastern boundary of GWOU. The location of this boundary is determined largely by the following: (1) GWOU-wide hydraulic gradient generally decreases toward the west, (2) the Bearden Creek watershed marks a topographic high along the eastern part of Bethel Valley, and (3) the Clinch River is $15 \mathrm{~m}(50 \mathrm{ft})$ higher in elevation along the east boundary than along the west boundary. Local perturbations of the general GWOU-wide hydraulic gradient could result in underflow of the eastern boundary, particularly at Bearden Creek. Water balances and hydraulic head measurements would provide necessary information for verifying the location of this boundary.

\subsubsection{Basal Boundary}

\subsubsection{Description}

The base of the GWOU at ORNL is taken to be the top of the aquiclude of the subsurface flow system within the ORR (Fig. 2.10) (i.e., the contact between freshwater and brine) (Solomon et al. 1992). For the purposes of this investigation, brine is defined as water with salinity that exceeds $10,000 \mathrm{mg} / \mathrm{L}$. Core hole measurements have shown that the elevation of the aquiclude is variable throughout the GWOU. For example, brine is encountered in aquitard rock units of Melton Valley at depths ranging between 180 and $240 \mathrm{~m}$ (590 and $787 \mathrm{ft}$ ) (Haase et al. 1987; Switek et al. 1987). Brine has not been encountered within the Knox aquifer but is believed to be $>350 \mathrm{~m}$ (1148 ft) deep (Hatcher et al. 1992).

The aquiclude marks the base of the GWOU because it is thought to have negligible flow owing to diminishing permeability in the rocks of the GWOU with depth. As a direct result, contaminant transport into the brine should also be negligible. Evidence for the presumed rate

of flow comes from evidence for long residence times of water in the aquiclude. The origin of the brine is unknown but its composition is consistent with one that would develop from formation waters during long term water-rock interaction or dissolution of evaporites (Solomon et al. 1992). Brine composition and temperature are spatially and temporally variable, observations that Nativ and Hunley (1993) interpreted to indicate communication with overlying freshwater. Additional evidence for communication with the overlying freshwater through mixing and/or chemical diffusion lies in the presence of brackish water at intermediate depths above the aquiclude.

The assumed unimportance of deep groundwater flow is key to placement of the basal boundary of the GWOU. It implies that the probability of contaminants reaching the aquiclude is small and, if they were to reach the aquiclude, the likelihood that they would be transported out of the GWOU is even smaller. However, little is known about the hydrologic properties of 
the rocks at the depths of the aquiclude and a number of observations begin to raise questions about assumptions regarding these properties. For example, variable depth, variable composition, and variable temperature of the deep brine all hint at non-uniform physical and chemical conditions in the aquiclude that could arise from greater than expected communication with overlying, shallower groundwater. This, in turn, could mean greater than expected flow into and within the aquiclude.

\subsubsection{Data gaps and needs}

There are two main questions regarding the basal boundary of the GWOU: (1) Is there significant deep groundwater flow so that contaminants are being transported to the brine? and (2) Is there sufficient flow within the brine to transport the contaminants outside the bounds of the GWOU? The very presence of brine at depth and questions of its origin imply that if this water is moving, the flow rate is very slow, and flow paths may take hundreds of thousands of years to complete. In addition, at present, no identifiable outfall for a deep brine flowpath exists in the vicinity of the ORR or in east Tennessee.

The current model for groundwater flow in the GWOU (Solomon et al. 1992) says that deep groundwater flow is unimportant because groundwater flow within the GWOU is controlled by fractures and because fracture density and apertures decrease with depth, groundwater flow in GWOU should be restricted to relatively shallow intervals. However, little empirical evidence exists to support this conclusion. The majority of drill hole observations are for relatively shallow depths [e.g., $<100 \mathrm{~m}(328 \mathrm{ft})$ ]; none of the deeper observations are from the Knox aquifer, the rocks in which deep flow is most likely to occur because of solution activity. For instance, the aquiclude within aquitard rocks lies at depths of 180 to $240 \mathrm{~m}$ ( 590 to $787 \mathrm{ft}$ ), but the aquiclude has not been observed in the Knox and is believed to reside at depths $>350 \mathrm{~m}$ $(1148 \mathrm{ft})$. If this is the case, is it a higher head being transmitted through the more impermeable depths of the Knox that holds the aquiclude boundary twice as deep as in the aquitards, or is there substantial freshwater flow down to depths of $350 \mathrm{~m}(1148 \mathrm{ft})$ that keeps the aquitard that deep? If there is substantially deep groundwater flow in the Knox, it is important to know if the flow is sustained within the aquiclude because this might be a mechanism for large-scale migration of contaminants out of GWOU.

Nativ and Hunley (1993) cited a number of observations as evidence for greater-thanexpected communication between the brine and the overlying freshwater. Among these observations were fluctuations in head measurements in deep holes, variable depth to the brine, variable composition of the brine, and variable temperature of the brine. They suggested locally high concentrations of fractures in deep rock as a mechanism for this larger-than-expected interaction. Nativ and Hunley (1993) also suggested that communication between brine and freshwater is facilitated by enhanced permeability among karst-affected rocks.

\subsubsection{Flow Systems and Exit Pathways}

\subsubsection{Description}

A key component of the GWOU groundwater model is shallow groundwater flow. Fully $90 \%$ of all subsurface water is thought to flow through the stormflow zone to be quickly discharged into the White Oak Creek drainage system. The stormflow zone resides mainly in the 
regolith of the GWOU and is therefore relatively shallow. Beneath the regolith is bedrock that is dominated by carbonates and shales, rocks with little porosity and low permeability. The permanent groundwater zone exists within fractures in the bedrock, but because fracture apertures and density are thought to decrease with depth, the groundwater zone is relatively shallow and meets the surface in stream beds where the regolith has been eroded and washed away exposing the underlying bedrock. As a result of shallow flow, $99 \%$ or more of all subsurface water in the GWOU is modeled as being discharged into the White Oak Creek drainage system where it ultimately exits the GWOU over White Oak Dam.

Understanding groundwater flow systems and exit pathways is key to modeling contaminant fluxes and pathways. The current model for groundwater flow in the GWOU implies that subsurface contamination will follow shallow pathways and ultimately be discharged from the subsurface into the White Oak Creek drainage system. Discharge from the subsurface flow system into the surface water system of the GWOU occurs through seeps and springs. Within Bethel and Melton Valley, these are the discharge points for contaminants carried in the subsurface flow system, therefore flow measurements and contaminant concentrations at these points are crucial to characterizing contaminant fluxes. However, many perennial seeps and springs that contribute surface water to the GWOU occur on ridges both inside and outside the GWOU boundaries. For example, seeps and springs along Chestnut Ridge and Copper Ridge arise from groundwater flow in solution cavities in the Knox aquifer; others occur along Haw Ridge and arise from the dolostone aquifer in the Rome formation. These springs and seeps are not contaminant discharge points because they are recharged on ridges, and contaminant sources reside solely in the valleys. However, because they are important contributors to the surface water of the GWOU, characterizing their flow is vital to quantifying contaminant fluxes within the GWOU and to understanding the dynamical behavior of water as it changes back and forth between surface and groundwater.

\subsubsection{Data gaps and needs}

A number of important data gaps and needs can be identified in the current understanding of GWOU flow systems and exit pathways. Many of these arise from observations that challenge the current understanding. For example, strata-bound flow in WAGs 1 and 3 and constant water levels in well 0883 demonstrate, at least, the local importance of cavities to the subsurface flow system and to deep flow in the GWOU, and also, the possible existence of subsurface exit pathways directly out of the GWOU. The extent and depth of karstification and solution activity in carbonate units have not been quantified. Deep karst features have the potential to create a deep subsurface flow system that could bypass the surface exit pathways that are presently part of the groundwater model. The same holds true for deep fracture flow systems. The importance of shallow groundwater flow in the GWOU is based upon modelled diminishing fracture apertures and density with depth, phenomena for which little empirical evidence exists. Deep flow could create exit pathways that lead directly to the Clinch River or even underflow the Clinch River.

The data gaps and needs just described are related mainly to observations that indicate deep groundwater flow in the GWOU; deep flow challenges the shallow-flow model for the ORR. However, the concept of shallow groundwater flow is new, and data are needed for its accurate characterization. The concept arises from the fact that groundwater in the GWOU flows through fractures in relatively impermeable rock and that fracture flow is dominated by a few large fractures and fracture networks. An important contaminant retardation mechanism that results 
from fracture flow is Matrix Diffusion in which contaminants come to reside in groundwatersaturated fractures that are not part of the preferred fracture flowpath. Therefore, detailed characterization of the shallow, fracture-dominated flow concept will result in a better understanding of contaminant transport in the GWOU.

Important information for understanding GWOU flow systems and exit pathways is surface water volumes entering and exiting the GWOU, including water imported into the GWOU. An implication from this type of information is that any water entering the GWOU that does not exit by surface pathways must contribute to recharge of the deep groundwater system. A program for identifying and monitoring seeps and springs has been ongoing within the GWOU. These data need to be assessed for value to the GWOU Work Plan and, where the data are deficient, new measurements must be made. The water gap in Haw Ridge and the topographic divide at the west end of Bethel Valley are specific locations in the GWOU for which surface water balances are important. As described previously, the water gap is potentially important as a location for the convergence of two structures that could provide a conduit for surface water into deeper levels of the groundwater system. Groundwater recharge in the valleys of the GWOU is contrary to the groundwater model, but observations such as zero natural flow in White Oak Creek in Melton Valley (Moore 1988) challenge this part of the model. A water balance at the topographic divide at the west end of Bethel Valley will be necessary to characterize the degree of underflow of the divide. In addition to the water balance approach, direct observation and monitoring of seeps and springs along or outside of the GWOU boundaries will help characterize flow systems and exit pathways. In particular, it is important to identify seeps and springs in the Raccoon Creek drainage basin to the west of Bethel Valley and in the Clinch River itself. 


\section{NATURE AND EXTENT OF GROUNDWATER CONTAMINATION}

\subsection{INTRODUCTION}

This section presents a general overview of the nature and extent of groundwater contamination documented at the 13 WAGs that are located within the boundaries of the GWOU. Those WAGs that have been identified at ORNL but are located outside the operable unit, and thus are not addressed herein, are WAGs $11,13,14,15,16,18$, and 20. The locations of these WAGs at ORNL are presented in Fig. 3.1.

Information presented for the subject WAGs includes a general description of each WAG and its associated SWMUs, the types of wastes disposed of or stored at the SWMUs, monitoring wells and piezometers that are part of the groundwater monitoring system for each WAG and for which data were evaluated, and a summary of major sampling events and their results.

Several references have been used as sources for site location, description, and background information for all of the subject WAGs. References used for all WAGs except WAGs 1 and 6 included the Preliminary Geohydrologic Site Characterization and Proposed Water Quality Well Location reports (Energy Systems 1987a, 1987b, 1988a, and 1988b), the RCRA Facilities Assessment for Oak Ridge National Laboratory (Energy Systems 1987c), and the Remedial Action Plan for ORNL Hydrofracture Operations (Myrick and Stow 1987). Description and background information for WAG 1 was derived from the Phase II Remedial Investigation Work Plan for Groundwater at WAG 1 at ORNL (Energy Systems 1993a); information for WAG 6 was derived from the ORNL WAG 6 Site Characterization Summary (Energy Systems 1990) and the RCRA Facility Investigation Report for WAG 6 at ORNL (Energy Systems 1991a). Additional references regarding the nature and extent of groundwater contamination are cited as necessary throughout this chapter. Although all of these references represent only a small percentage of all documentation developed for the subject WAGs, the intent of this section is to provide a general overview of the types of wastes present at the WAGs and the nature and extent of groundwater contamination.

\subsection{WAG 1}

\subsubsection{Site Location, Description, and Background}

WAG 1 is located in Bethel Valley within the main plant area of ORNL (Fig. 3.2). The site is bounded on the north by Bethel Valley Road, on the south by White Oak Creek, and on the west by First Creek. The eastern boundary follows Fifth Creek but extends east to include Solid Waste Storage Area (SWSA) 2 and Buildings 4501 and 4508.. A total of 167 SWMUs have been identified within WAG 1. Pursuant to a RCRA permit issued prior to the initiation of the WAG 1 Remedial Investigation, 27 SWMUs were classified as requiring no further investigation. Fourteen additional SWMUs were listed for decommissioning and demolition under the DOE surplus facilities program. The remaining $126 \mathrm{SWMUs}$ include inactive underground storage tanks, waste burial grounds, surface impoundments, waste transfer lines and leak sites, active underground waste storage tanks, and mercury spill sites. Most of the SWMUs are related to 


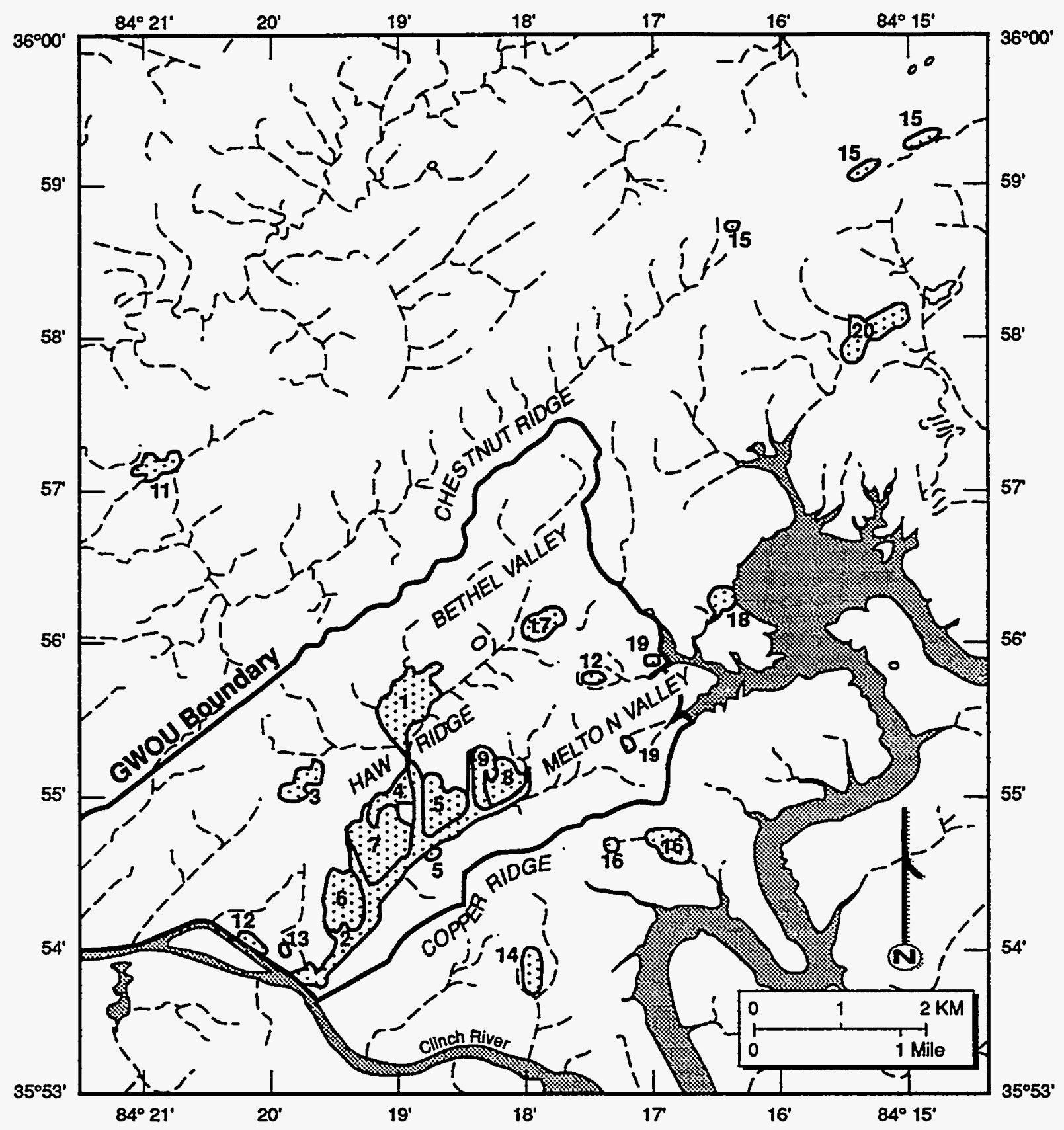

Fig. 3.1. Location of WAGs at ORNL. Source: Energy Systems 1992b. 


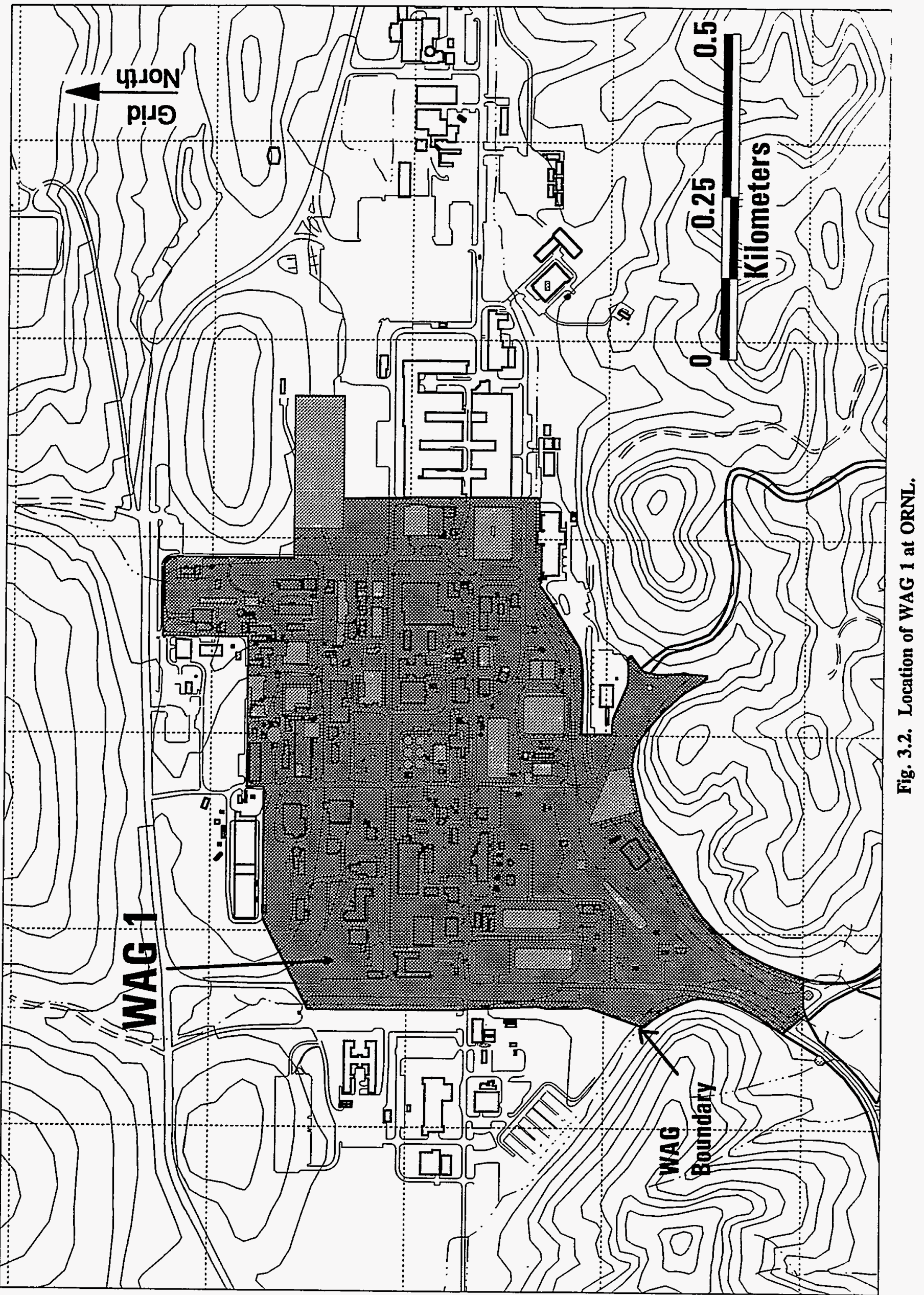


current or past liquid and solid radioactive waste management operations conducted within the main plant area of ORNL.

The ORNL main plant site initially included a nuclear reactor, a chemical separations plant, a number of large underground tanks, and a variety of support facilities. The nuclear reactor (Building 3001), referred to as the "Graphite Reactor" was air cooled and was the first nuclear reactor with production capacity. The Radiochemical Processing Pilot Plant (Building 3019), referred to as the "Hot Pilot Plant," was constructed to dissolve the irradiated fuel elements from the Graphite Reactor. The Isotopes Area, located in the east-central portion of WAG 1, was among the earliest radioisotope production area at ORNL. Facilities in this area prepared radioisotopes from the late 1940s and early 1950s until production activities were ceased in the early $1990 \mathrm{~s}$. Limited documentation is available concerning the activities performed in this area and the wastes generated in the associated facilities, and most of the information which does exist is anecdotal.

From the beginning, the management of radioactive waste required classification of the waste into categories. Despite changes over time in the names used for a category of waste and the divisions between categories, the early categories are generally recognizable and can be related to current categories. Initially, liquid wastes were divided into three main categories: metal wastes, radiochemical wastes, and process wastes. Metal wastes contained primarily uranium with small quantities of plutonium or thorium. Radiochemical wastes contained primarily fission product radionuclides that have half-lives significantly shorter than the metal wastes. Radionuclides associated with this category of waste include ${ }^{137} \mathrm{Cs},{ }^{90} \mathrm{Sr},{ }^{131} \mathrm{I},{ }^{141} \mathrm{Ce},{ }^{143} \mathrm{Ce},{ }^{103} \mathrm{Ru}$, ${ }^{140} \mathrm{Ba}$, and ${ }^{140} \mathrm{La}$. Process waste was theoretically nonradioactive or had very low activity. A fourth category of waste referred to as "warm waste" was in use during early operations. Warm waste was moderately radioactive and represented a transition between process waste and radiochemical waste.

An extensive system of underground utilities has been constructed and modified over the history of the main plant area. This system includes low-level liquid waste (LLLW) and process waste transfer lines whose purpose was to transport wastes from their generation points to treatment, storage, and disposal facilities within the main plant area and in Melton Valley. Numerous underground tanks have also been installed during the operational history of the facility. The purpose of these tanks was to store wastes generated during site activities. The system includes six 643,450-L (170,000-gal) Gunite tanks in the South Tank Farm, Gunite and stainless steel tanks in the North Tank Farm, and other waste collection and storage tanks located adjacent to waste-generating facilities within WAG 1.

The Gunite tanks were originally constructed to store all of the radioactive liquid (radiochemical and metal) wastes generated by ORNL site operations. However, because of expanding requirements for managing radioactive liquid wastes, the capacity of these tanks was inadequate for permanent storage, and it became necessary to implement various waste management approaches. The first approach was to separate the different waste streams and to concentrate the radioactive components in the liquids by precipitation. The large Gunite tanks in the South Tank Farm were used for the precipitation process, while the smaller Gunite tanks in the North Tank Farm were used for either storage of metal waste or collection of waste for characterization prior to transfer. The precipitation step formed a sludge at the bottom of the tanks, and the supernatant was discharged to a 5,677,500-L (1,500,000-gal) settling basin where 
the supernatant was diluted with large volumes of process waste before being discharged into White Oak Creek. In 1945, the precipitation of radiochemical waste was discontinued.

Starting in 1949 , the radiochemical waste stream was treated by concentration using a pot-type evaporator. This operation was conducted in the Waste Evaporator Facility (Building 3506), which was constructed on the western side of the South Tank Farm. This facility operated from 1949 until 1954. In 1950, further expansion of ORNL required additional modifications to the waste management system in order to handle increased waste volumes and levels of radioactivity. Underground stainless steel tanks were installed near each building or area that was a source of radiochemical or metal waste. Four additional tanks were also installed within the North Tank Farm.

In 1952, some radiochemical waste was discharged directly into the ground using a series of pits and trenches located within Melton Valley. The use of the Waste Evaporator Facility was discontinued in 1954 in favor of the pits and trenches disposal practice. Gunite tanks in the South Tank Farm were used to hold radiochemical waste prior to pumping of these wastes to the pits and trenches for disposal. Disposal of waste within pits and trenches was continued until 1966, when routine disposal of the waste was initiated using a hydrofracture technique. The technique involved the mixing of the waste with cement grout, which was then injected into subsurface shale at a depth of $\sim 305 \mathrm{~m}(1000 \mathrm{ft})$.

Continuous improvements and modifications to the ORNL waste management system eventually eliminated the need for most of the older tanks. Tanks in the North Tank Farm were removed from service in the late 1950s or early 1960s. The liquid waste in these tanks was removed, and any sludge, as well as a small volume of residual liquid, remained in the tanks. The large Gunite tanks in the South Tank Farm were removed from service in the late 1970s. Accumulated sludge precipitated from solution, as well as residual solutions, remained in these tanks until they were cleaned in 1982 and 1983. However, some residual liquid and sludge remain within these tanks.

\subsubsection{Characterization of Groundwater Contamination}

\subsubsection{Overview of contamination}

Three principal source documents were used to develop an understanding of groundwater contamination within WAG 1. These documents were the Site Characterization Summary Report for WAG 1 at ORNL (Energy Systems 1992a), the Phase II Remedial Investigation Work Plan for Groundwater at WAG 1 at ORNL (Energy Systems 1993a), and the report concerning Migration of a Groundwater Contaminant Plume by Stratabound Flow in WAG 1 at ORNL (Ketelle and Lee 1992). The Site Characterization Summary Report for WAG 1 at ORNL detailed interpretations regarding the nature and extent of groundwater contamination at WAG 1 that were based on samples collected from 109 wells and piezometers during the Phase I RI/FS studies. Four separate sampling events were conducted, though not all wells and piezometers were sampled during each event.

The first event involved sampling 77 wells and piezometers during low base groundwater flow conditions in September and October of 1990. The second included 18 wells and piezometers sampled during a prolonged storm and high base groundwater flow conditions in 
February of 1991 . The third event involved 82 wells and piezometers sampled during normal (nonstorm) high base groundwater flow conditions in March and April of 1991. The fourth sampling event was conducted in response to the addition of 33 SWMUs in 1991 to the scope of the Phase I investigation, and the discovery of radioactive contaminants in well 4005 (CH008). This event entailed sampling 14 piezometers in the vicinity of the newly added SWMUs and CH008 during the period July through October of 1991. In addition to the four noted sampling events, samples were also collected from 25 wells installed as part of a groundwater quality monitoring well installation program at ORNL. These wells were sampled during both low base and high base (nonstorm) groundwater flow conditions.

Several general areas of contamination were identified based on the results of the groundwater sampling conducted at WAG 1. Both radiological and chemical contaminants were identified in groundwater at this site (Figs. 3.3 and 3.4). The primary radionuclides found in groundwater were strontium and tritium. Radionuclides found less frequently included ${ }^{226} \mathrm{Ra}$, ${ }^{228} \mathrm{Ra},{ }^{99} \mathrm{Tc},{ }^{234} \mathrm{U},{ }^{238} \mathrm{U},{ }^{228} \mathrm{Th},{ }^{230} \mathrm{Th},{ }^{232} \mathrm{Th},{ }^{238} \mathrm{Pu},{ }^{239} \mathrm{Pu},{ }^{240} \mathrm{Pu},{ }^{241} \mathrm{Am},{ }^{60} \mathrm{Co},{ }^{63} \mathrm{Ni},{ }^{55} \mathrm{Fe}$, and ${ }^{137} \mathrm{Cs}$. There is evidence that ${ }^{90} \mathrm{Sr}$ is migrating from WAG 1 and seeping into First Creek. There is also limited evidence that some of this plume may be underflowing First Creek and migrating westward. Other locations where groundwater contamination may be affecting surface water quality are near the surface impoundments and near SWSA 1.

The most widespread organic compounds found in groundwater at WAG 1 are trichloroethene and its degradation products 1,2-dichloroethene and vinyl chloride. Benzene, toluene, xylene, and ethylbenzene were found associated with an underground petroleum storage tank previously located near the steam plant facility (Building 2519). Silver, cadmium, chromium, lead, and mercury (one sample) were detected at concentrations exceeding the MCLs in samples from wells within and outside WAG 1. Cadmium, chromium, and lead were generally found to occur in the same wells. The most widespread metal detected at elevated concentrations was cadmium, which exceeded the MCL at the largest number of locations throughout WAG 1 (Fig. 3.5).

\subsubsection{Specific area contamination}

Building 3001/3019 Area. Indicator radiological data from groundwater and soil samples collected from the Building 3001/3019 area (Fig. 3.6) indicate that three areas of contamination exist: (1) site of a past pipeline leak southwest of Building 3019, (2) site of a past pipeline leak north of Building 3019, and (3) the 3019 Hot Bank. The pipeline network at 3001/3019 is believed to have a large impact on the transport of contaminated groundwater. A large, complex array of buried pipelines extends from the area to much of WAG 1, including areas south of 3001/3019 (e.g., the corehole CH008 area, North Tank Farm, and the Isotopes Area), First Creek, and Fifth Creek. As a result, the pipeline system may conceivably transport contaminants from the 3001/3019 area to virtually any other part of WAG 1 .

North Tank Farm. Groundwater data are available only from the periphery of the tank farm and are probably not representative of groundwater data within the site or the excavations immediately around the tanks. Despite the absence of groundwater data from the North Tank Farm, its history of operation and proximity along geologic strike to corehole CH008 has made it a candidate source area for the $\mathrm{CH} 008$ plume. Alternatively, leaks from low-level waste (LLW) or process waste pipelines from the Building 3019 area could be sources. Based on 


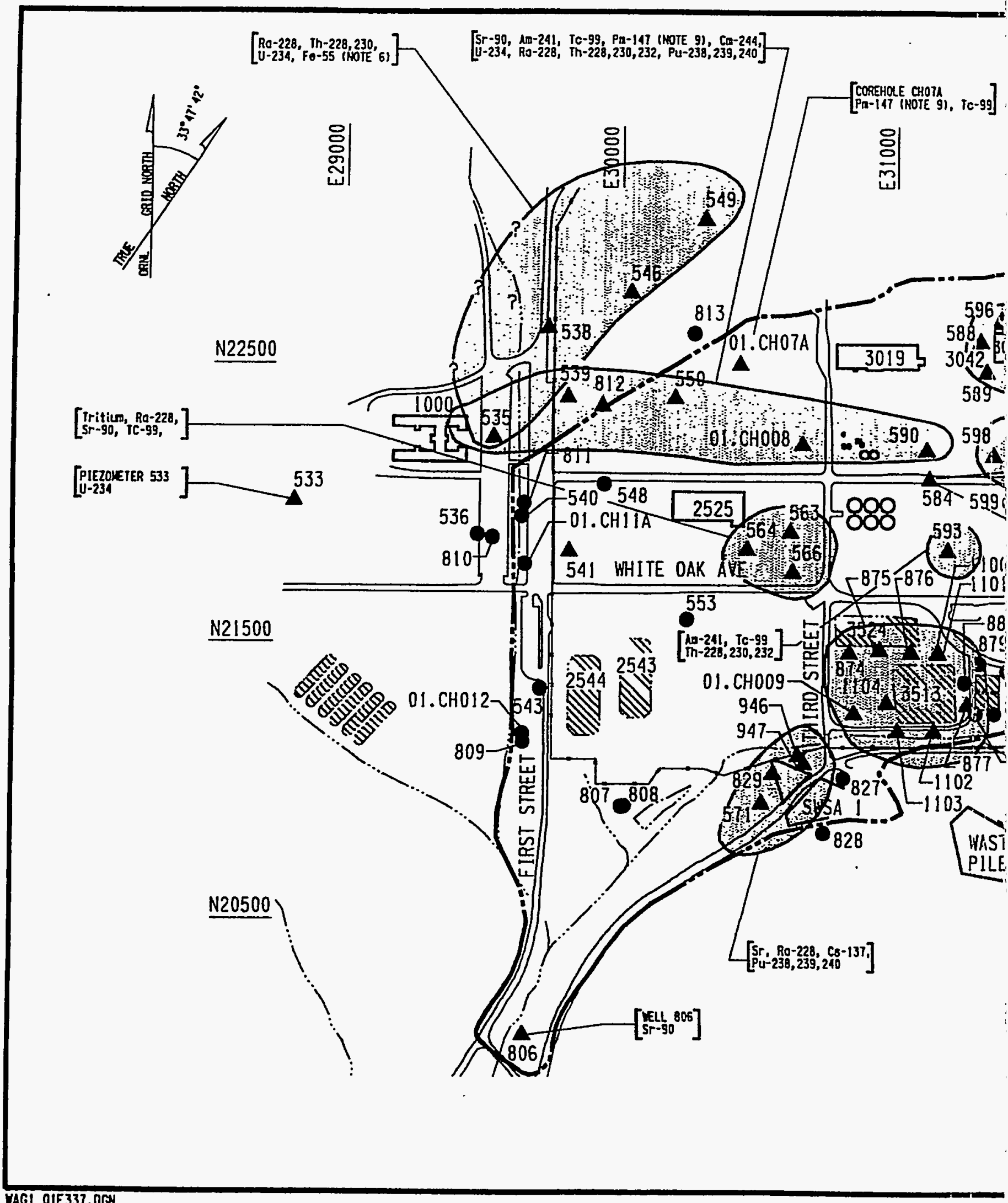

Fig. 3.3. Overview of radiological contamination it 


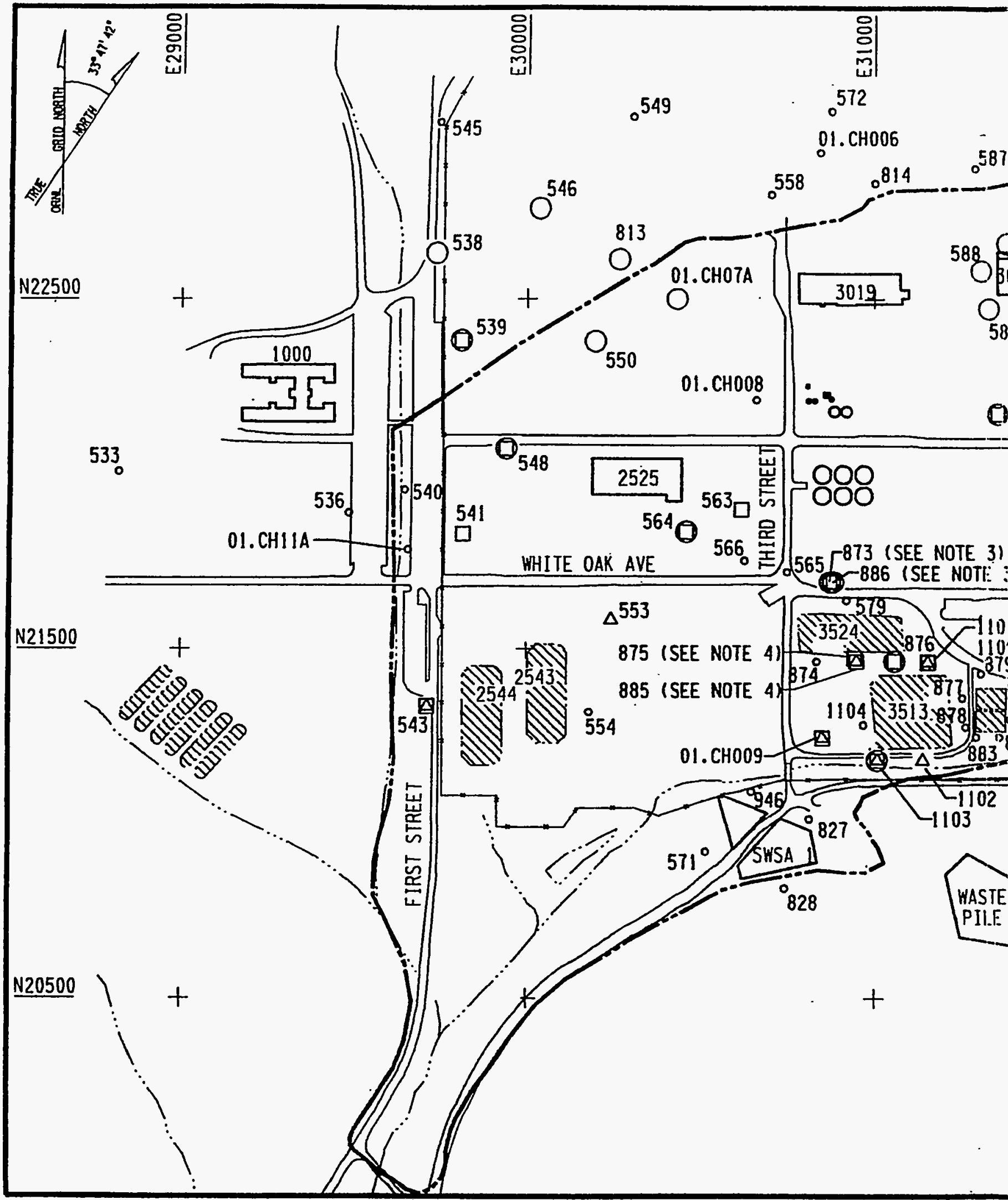

Fig. 3.4. Distribution of TCE and degradation pro 


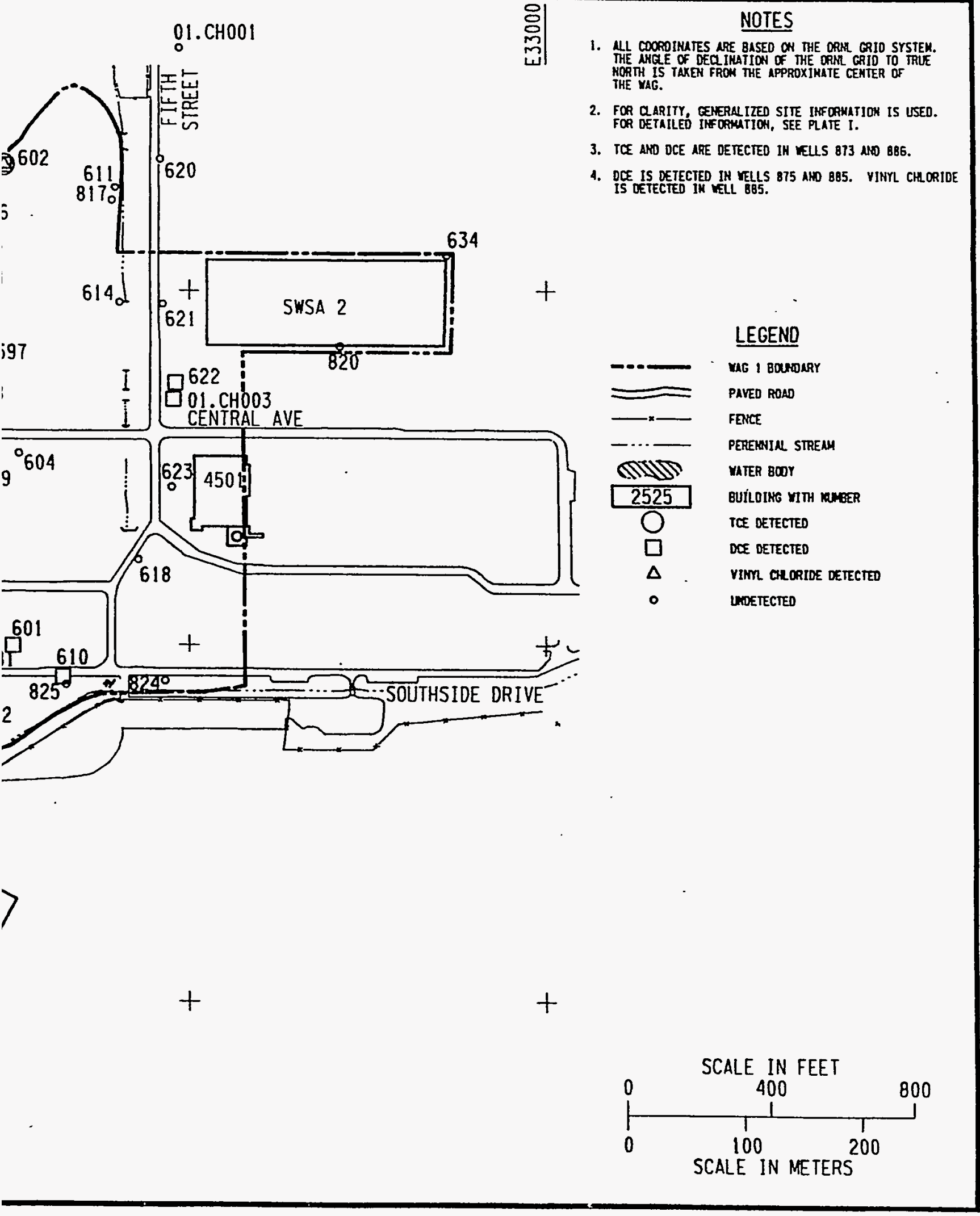

ts in groundwater at WAG 1. Source: Energy Systems 1992a. 


\section{3-11}

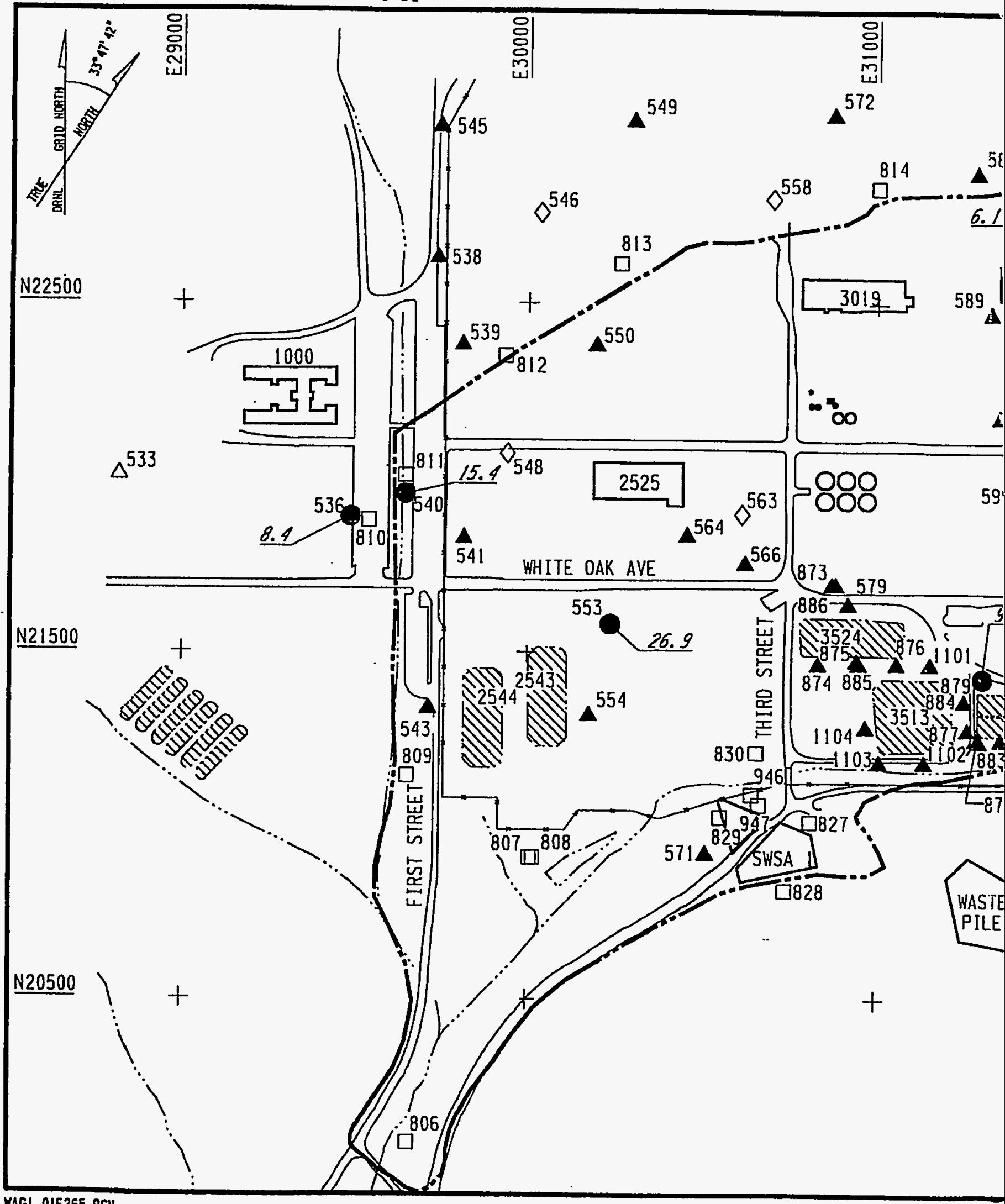

Fig. 3.5. Cadmium detected in unfiltered groundwater samples exceeding s 


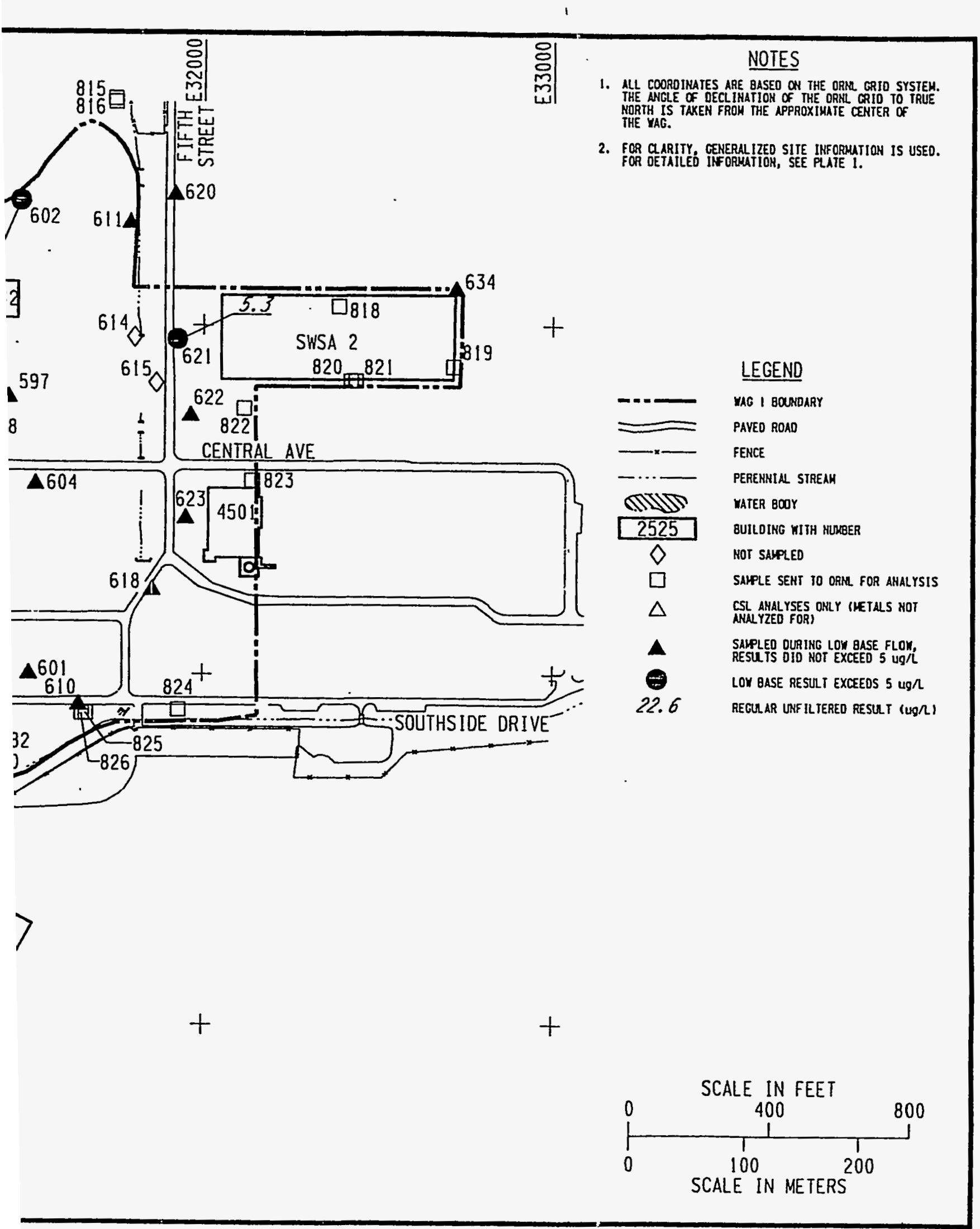

L during low base flow conditions at WAG 1. Source: Energy Systems 1992a. 


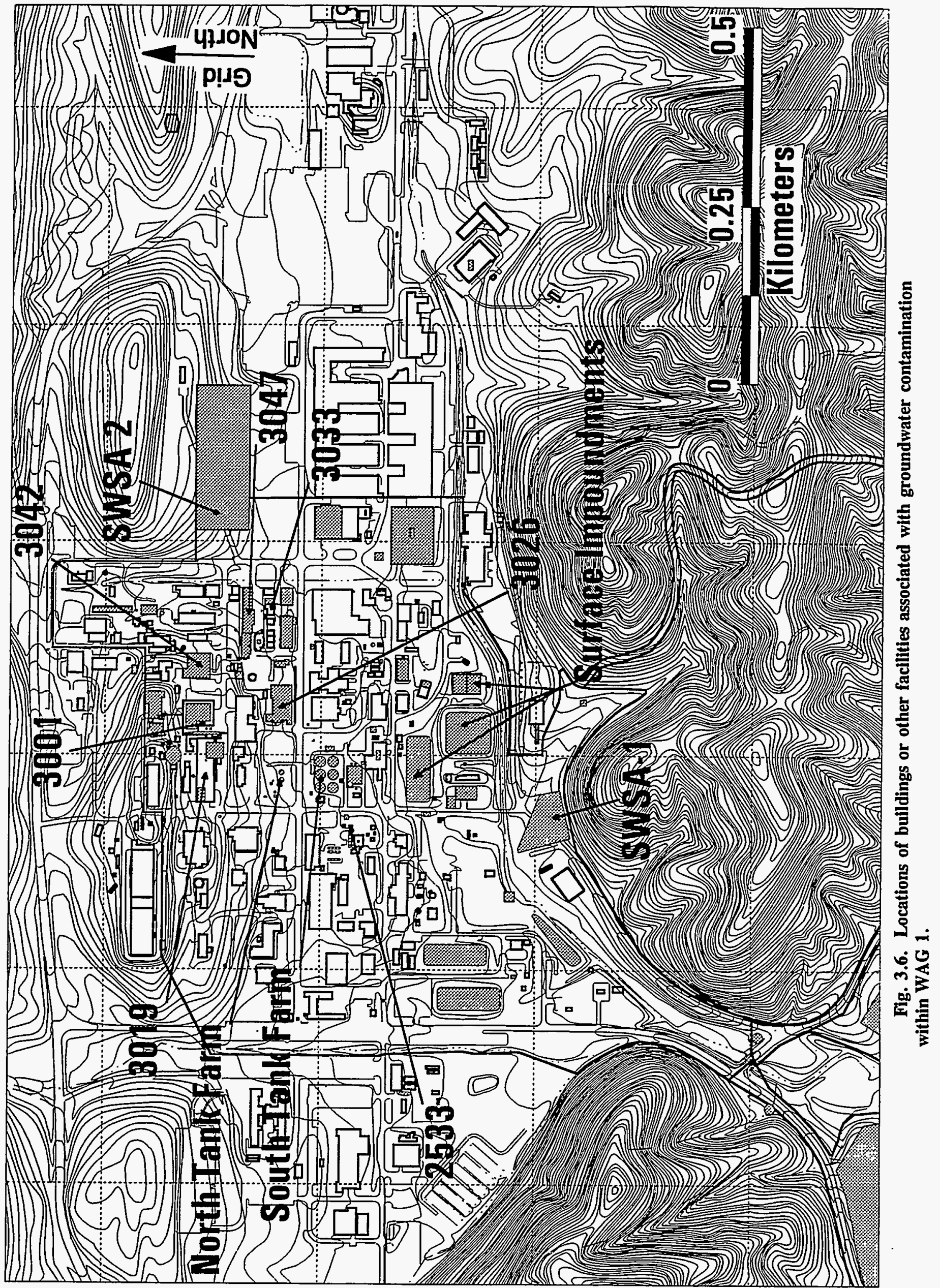


assumptions concerning groundwater elevation in the vicinity of the North Tank Farm, it is not considered to be a likely source area for the CH008 plume. However, this assumption is not confirmed, and essentially no data are available to describe the potential migration of North Tank Farm contaminants either through pipeline trenches or the groundwater flow system to the west or south.

South Tank Farm. Data collected at the South Tank Farm indicate that significant amounts of contamination exist in shallow soil at the site. However, information about the nature of the tank/groundwater interactions is not known. Groundwater contamination at the South Tank Farm may have resulted from historical leaks in pipelines, or from contaminants migrating along pipeline trenches. The tank farm is contained within a pit that was excavated into bedrock, and the major factor affecting groundwater is probably the tank sump system. Depending on the effectiveness of the dry well and sump system, some contaminated groundwater may be able to migrate out of the tank farm through pipeline trenches or within the groundwater flow system. Data regarding hydrogeological conditions within the tank farm are needed to evaluate these scenarios and to evaluate the effectiveness of the dry well system.

Isotopes Area. During the production of radioisotopes over the years, numerous spills and pipeline leaks of radioactive and nonradioactive contaminants have occurred in the Isotopes Area. Contamination that is, at least partly, discharging into the process waste pipeline network in the area is known to occur beneath Building 3047. Elevated levels of gross alpha, gross beta, and tritium have been detected in groundwater samples from Isotopes Area wells and sumps. Levels of these contaminants, including the highest tritium activity detected in WAG 1, which were from two to four orders of magnitude higher than those detected in Isotopes Area wells, were found in a water sample collected from the Building 3033 sump.

Possible sources of the radiological contamination of groundwater within the Building 3033 sump, and in the area process system, could be located uphill in the 3019 or 3042 areas. Contaminants could be transported down-dip with groundwater in Unit D, discharge upward to Unit $\mathrm{E}$, and move along strike to the east in a mirror image of the corehole CH008 plume. Alternatively, there could be a source to the west in the Building 3026 area, a localized pipeline leak, or a combination of sources. This contamination could ultimately be intercepted by the process system and be treated in the PWTP, move off-WAG in permeable pipeline trench backfill, and/or underflow Fifth Creek.

Corehole CH008. As part of the Phase I studies in WAG 1, rock core drilling was conducted to accurately describe subsurface geologic conditions and to permit the performance of subsurface hydrologic tests. In June 1991, rock core drilling of corehole CH008 (Fig. 3.7) revealed radiologically contaminated conditions in the uppermost portions of the bedrock. The corehole was drilled to a depth of $16.3 \mathrm{~m}(53.5 \mathrm{ft})$ below ground level and was outfitted with a Westbay multilevel groundwater sampling device. Sampling results indicated that the highest levels of gross beta/gamma contamination occurred from 6.1 to $9.2 \mathrm{~m}$ ( 20 to $30 \mathrm{ft}$ ) below the bedrock/water table interface.

The discovery of groundwater contamination at $\mathrm{CHOO8}$ prompted a detailed investigation to identify the contaminant plume. Using a working hypothesis of stratabound groundwater flow and contaminant transport, investigators analyzed existing subsurface geologic data to predict the contaminant plume discharge location in First Creek and the locations of contaminated 


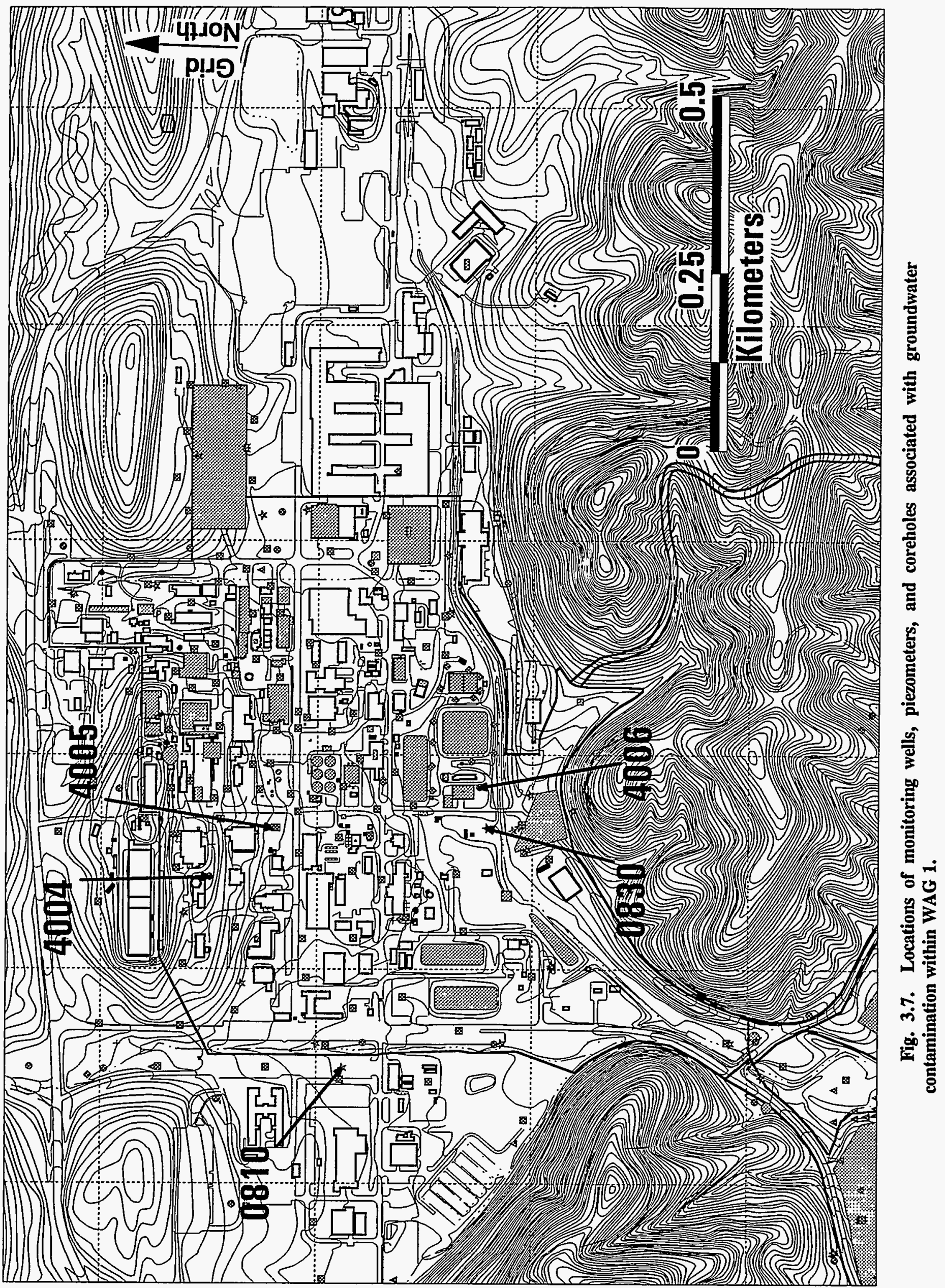


groundwater seepage into storm drains. This hypothesis stated that differential lithologic/fracture conditions lead to the development of preferred flow and transport pathways, of discrete vertical extent, which may not be coincident with the local hydraulic gradient. Results of the analysis indicated that application of the hypothesis accurately predicted the CHOO8 plume discharge in First Creek, which migrated to the discharge point parallel to geologic strike and $\sim 65^{\circ}$ oblique to the local hydraulic gradient (Fig. 3.8).

Oak Ridge Research Reactor (Building 3042) Area. Groundwater samples collected from the Oak Ridge Research Reactor (Building 3042) area wells detected activities of gross alpha, gross beta, and tritium above reference levels. Higher levels of radiological contamination than were found in the Building 3042 area wells were observed in a water sample collected from the Building 3042 sump. Results of a dye test indicated that groundwater was flowing eastward, along geologic strike, to the Building 3042 sump from the area of a LLLW line break that occurred between Buildings 3019 and 3074 . A cavity in the limestone bedrock was observed in the excavation dug for the line break. Fluorescein dye that was injected into this cavity was observed in the inner (upper) Building 3042 sump within $48 \mathrm{~h}$. The hydraulic gradient calculated from the dye test is produced by pumping water, which maintains a groundwater depression in the vicinity of the sump. Therefore, radiological contamination detected in samples from the Building 3042 sump may be moving from the Buildings 3001/3019 area along cavities and solution features in Unit D. Contaminants may also be collected in the sump from leaks in nearby underground lines.

Surface Impoundments (3524, 3513, 3539, and 3540). Activities of gross alpha, gross beta, and tritium were detected above reference levels in groundwater samples collected from the Surface Impoundments area wells. In general, significant radiological contamination was found downgradient (south) of the unlined waste detention basin 3513 and equalization basin 3524 , but was not found in the 3539/3540 area. The highest levels of contamination occurred in samples collected during high base storm conditions. This contamination consisted primarily of high levels of tritium, moderately high levels of gross beta (predominantly ${ }^{90} \mathrm{Sr}$ and ${ }^{228} \mathrm{Ra}$ ), and moderately low levels of gross alpha.

Seepage of contaminated water from the detention basin and equalization basin impoundments is apparently a major source of tritium, ${ }^{90} \mathrm{Sr}$, and ${ }^{228} \mathrm{Ra}$ contamination of groundwater within WAG 1 . Video inspection of a 61-cm (24-in.) storm sewer west of the equalization basin revealed numerous inleaking joints, particularly in that portion of the sewer on the northwest side of this basin. Because most of the leaks were from the equalization basin side (east) of the pipeline, and a head potential exists from the equalization basin to the pipeline, it is reasonable to assume that the pipeline inleakage is derived at least partly from seepage from the equalization basin. Contaminants should move southward (downgradient in the overburden and down-dip in bedrock) and eventually discharge to White Oak Creek. Contaminants may also be migrating in pipeline trench backfill materials. Given the relatively short half-life and slow transport velocity in groundwater of ${ }^{228} \mathrm{Ra}$, tritium and ${ }^{20} \mathrm{Sr}$ are the primary contaminants that could reach White Oak Creek and be transported off-WAG.

SWSAs 1 and 2. The relatively complete set of historical data for many wells located in SWSA 1 indicates generally stable contaminant concentrations over time and between high and low base flow groundwater conditions. Gross alpha and beta concentrations were found to be generally below reference levels, and tritium values ranged between -37 and $92 \mathrm{~Bq} / \mathrm{L}$. The 


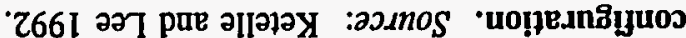

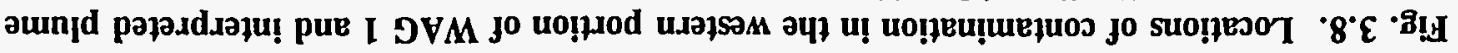

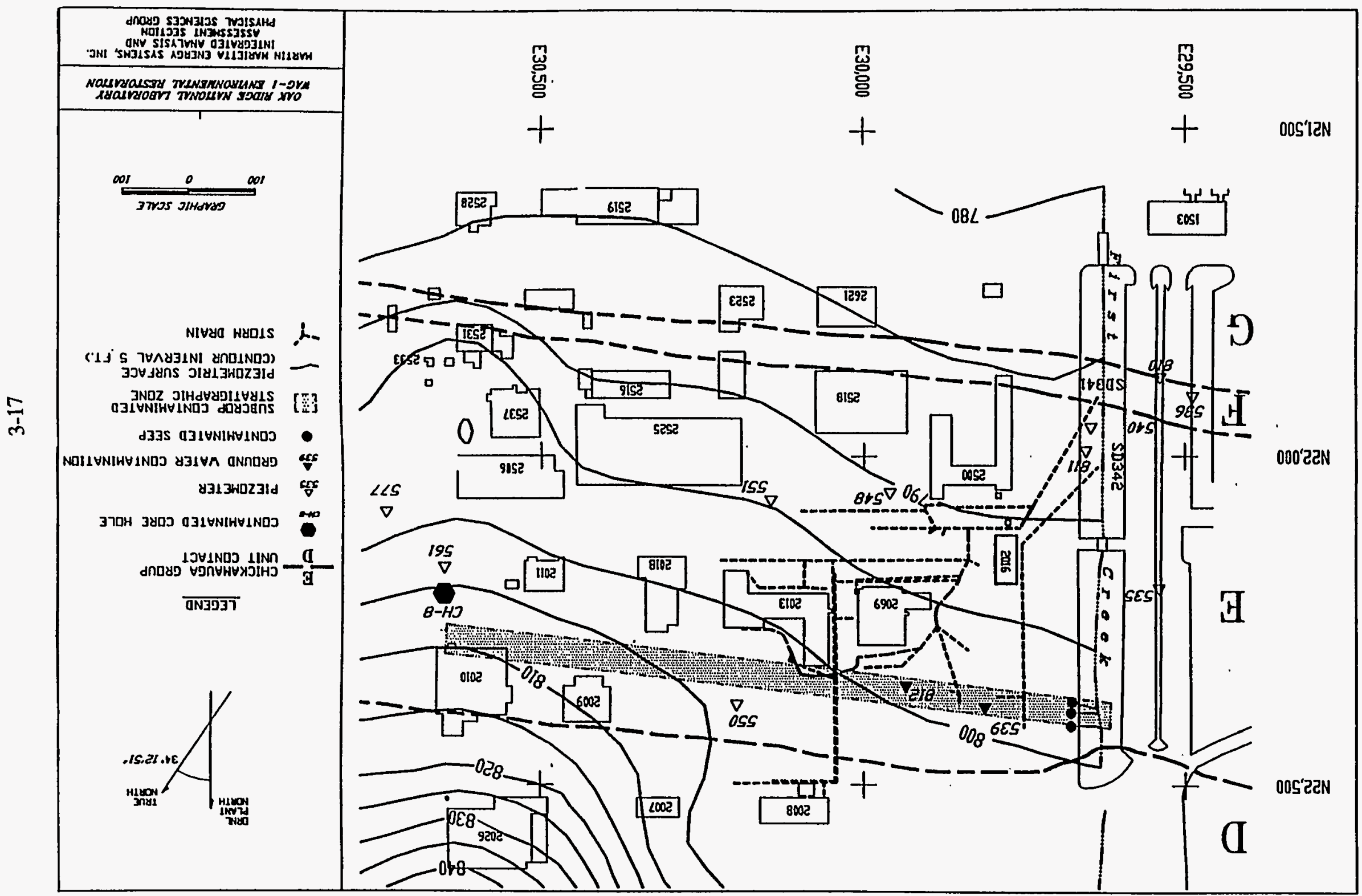


higher tritium activities in bedrock wells suggest the possibility of flow paths below the water table surface. In addition, several radionuclides $\left({ }^{39} \mathrm{Pu},{ }^{240} \mathrm{Pu}\right.$, and $\left.{ }^{228} \mathrm{Ra}\right)$ detected in a piezometer may suggest westward migration of contaminants from SWSA 1.

Groundwater samples collected from wells in SWSA 2 indicate that tritium contamination is prevalent throughout much of the area, with the highest concentrations occurring within and southwest of SWSA 2. This finding suggests that contamination may be migrating southwestward from SWSA 2. Slightly higher gross alpha and beta detected in a downgradient piezometer also suggests minor migration of these contaminants. This is corroborated by the presence of radiological contamination in Fifth Creek outfall 165, which serves a small segment of a storm sewer from Fifth Street. Because no other source for the outfall 165 contamination is apparent, it is presumed to be coming from discharging groundwater from SWSA 2. Data from an adjacent pair of bedrock wells drilled to depths of 6.1 and $24.4 \mathrm{~m}(20$ and $80 \mathrm{ft}$ ) indicate that contamination decreases with depth.

Pipelines. Because pipelines, particularly process waste pipelines, are known to collect significant amounts of contaminated groundwater, available flow and radiological data from process waste manholes monitored monthly were analyzed. Correlation between manhole contaminant flux and precipitation and/or groundwater elevation supports the concept that contaminant mobilization occurs principally during periods of elevated water table despite apparently lower concentrations due to dilution. It also suggests that contaminants residing in groundwater, or in the vadose zone immediately above the water table, are mobilized above the bedrock weathering interface in response to elevation of the water table. Compared to contaminant concentrations in underground tank dry wells, the level of contamination in pipeline trenches is comparatively small. However, although tank dry wells tend to capture contaminated groundwater, pipeline trenches tend to distribute contamination.

With the exception of the limited data pertaining to contaminant migration in pipeline trenches within WAG 1, further resolution of migration pathways within WAG 1 is considered to be exceedingly difficult. Pipeline routes and system interconnections are only generally known, and the map atlas for the system is more than 10 years old. Rather than attempting to unravel WAG interior pathways, sampling of trench backfill near pipeline discharge locations at surface water bodies is the preferred approach for delineation. Identified excursions can then be traced back on a case-by-case basis using atlas information and/or camera examination to locate individual sources.

Unit F. Because strike-parallel flow and contaminant transport in Unit F has been described from SWSA 3 (WAG 3), consideration is given to similar type flow in WAG 1. Three areas of contamination in or immediately outside of WAG 1 could be related to strike-parallel flow within Unit F.

The first of these areas is located in the vicinity of Piezometer 0536 and Well 0810, which are located immediately west of First Creek near the intersection of First Street and Central Avenue. Data indicate the absence of either a hydraulic or concentration gradient from piezometers or wells in WAG 1 toward Piezometer 0536 or Well 0810 . Very close control on the elevation of First Creek in the vicinity of Unit F indicates a reverse hydraulic potential from the creek to Well 0810 . These data essentially preclude WAG 1 as a source of the detected contamination. Rather, hydraulic and concentration gradients do exist from Piezometer 0533 
toward Piezometer 0536 and Well 0810 , indicating an eastward migrating plume. Because strike-parallel flow has been documented within Unit F at SWSA 3, the most logical explanation for the source of contamination near WAG 1 is migration from SWSA 3. If this is the case, it suggests that the Northwest Tributary is an incomplete groundwater discharge surface water body, and that First Creek is the ultimate discharge location for eastward migrating groundwater.

The second area is located in the vicinity of the Building 2533 sump. Indicator radiological data for piezometers and sumps appear to describe another contaminant plume associated with Unit F. The data indicate the presence of a plume originating in the vicinity of the Building 2533 sump and migrating in a southwesterly direction. The plume exhibits highly elevated concentrations of tritium and gross beta contamination; nearly $75 \%$ of the gross beta activity in the Building 2533 sump occurs as ${ }^{137} \mathrm{Cs}$. The plume appears to terminate in Unit F, and a piezometer located south of Unit $\mathrm{F}$ in the apparent plume migration direction does not exhibit radiological contamination. Radiological contamination slightly above background levels in a piezometer located $198 \mathrm{~m}$ (650 ft) west in Unit F may represent strike-parallel migration since no other apparent source for that contamination (especially ${ }^{137} \mathrm{Cs}$ ) is in the area. However, current data are insufficient to substantiate the occurrence of such migration.

The third area is located in the vicinity of corehole CH009. Sampling conducted in two straddle packer test intervals in this corehole [ 96 to $100 \mathrm{~m}$ and 38 to $42 \mathrm{~m} \mathrm{(314} \mathrm{to} 327 \mathrm{ft}$ and 126 to $138 \mathrm{ft}$ )] revealed the presence of ${ }^{137} \mathrm{Cs}$ and tritium. One explanation for the contamination detected in CH009 is down-dip migration within Unit F. Such migration is potentially significant because, contrary to the current conceptual model of the flow field, it would indicate the presence of long, deep flow paths actively involved in contaminant migration. The lower CH009 contaminated interval is within Unit F, and the upper contaminated interval is within Unit G. Flow meter testing in the corehole determined that water entered the hole in the vicinity of $103 \mathrm{~m}$ (338 ft) and exited the hole at $41 \mathrm{~m}$ (135 ft). Geochemical sampling of the contaminated intervals indicated that the waters are of the sodium chloride type which has been interpreted to represent deep and older water. Mixing between the time the hole was drilled and straddle packer testing may render results questionable for the upper interval. These data suggest that the upper interval contaminants are derived from the lower interval. However, the presence of significantly higher tritium concentrations in the upper interval is inconsistent with interpretation of upward migration of tritium within the corehole.

Localized Areas of Contamination. Several localized areas of groundwater contamination have been identified within WAG 1. Contamination detected at Well 0830 and Piezometers 0584, 0590,0593 , and 0601 is believed to be associated with various pipeline, sump, or tank leaks in the vicinity of these installations. Possible sources of contamination detected in Piezometer 0553 include fallout from atmospheric emissions from coal combustion at the site steam plant and a release from the nearby diesel underground storage tank.

Well 4004 (CH 7A) is located in the northwestern part of WAG 1, north of Building 2009. It was drilled to a total depth of $56.3 \mathrm{~m}(184.6 \mathrm{ft})$ and penetrated Chickamauga Unit $\mathrm{D}$ at $8.5 \mathrm{~m}$ $(28 \mathrm{ft})$ and Chickamauga Unit $\mathrm{C}$ at $45.0 \mathrm{~m}(147.6 \mathrm{ft})$. Geophysical, temperature, and hydrological testing, as well as groundwater sampling, were performed within the Unit D interval of the borehole. The results of this testing indicated the presence of a cavity, active groundwater flow, detection of low levels of contamination, and a low head, which imply that this interval may include a significant groundwater discharge zone in Unit D. 
An area comprising the northern 2000 part of ORNL is located northwest of the WAG 1 boundary. Elevated gross alpha, gross beta, and tritium activities were detected in low base and high base groundwater samples collected from wells in this area. Radionuclides detected above reference levels were ${ }^{228} \mathrm{Th},{ }^{230} \mathrm{Th},{ }^{232} \mathrm{Th},{ }^{234} \mathrm{U},{ }^{238} \mathrm{U},{ }^{226} \mathrm{Ra},{ }^{228} \mathrm{Ra}$, and total strontium. In general, activities of these radionuclides were higher in the high base flow samples than in low base flow samples.

\subsection{WAG 2}

\subsubsection{Site Location, Description, and Background}

WAG 2 is located in Melton Valley and consists of two SWMUs: (1) White Oak Lake and the embayment below White Oak Dam above the Clinch River, and (2) White Oak Creek and its tributaries and their respective floodplains. These surface water bodies constitute the major drainage system for ORNL and its outlying support facilities. To better manage data, produce usable graphics, and present concise descriptive information, WAG 2 has been divided into upper and lower sections (Fig. 3.9).

\subsubsection{Upper section of WAG 2}

The upper section of WAG 2 is composed of portions of White Oak Creek, Melton Branch, two Melton Branch tributaries, and the floodplains surrounding these water bodies (Fig. 3.10). The White Oak Creek portion of the site begins at the confluence of White Oak Creek and Melton Branch and extends $1.00 \mathrm{~km}$ (0.62 miles) upstream to the 7500 bridge. The Melton Branch portion of the site also begins at the confluence of White Oak Creek and Melton Branch and extends upstream and to the east about $1.42 \mathrm{~km}(0.88$ miles). The Western and Eastern tributaries of Melton Branch that are included in the upper section of WAG 2 are 0.61 and $0.27 \mathrm{~km}$ ( 0.38 and 0.17 miles) in length, respectively.

Upper WAG 2 shares common boundaries with adjacent WAGs 1, 4, 5, 7, and 8. The site receives drainage from these WAGs and from WAG 9. Each of these adjacent WAGs contains multiple SWMUs that have operating histories spanning as many as 40 years. During this extended period, surface runoff and groundwater transport of contaminants from the adjoining WAGs have occurred. Many of these contaminants have accumulated within the floodplains and streambeds of upper WAG 2. In addition to serving as a collection point for the more mobile contaminants, upper WAG 2 contains two ORNL support facilities, one inactive and one active. The inactive facility is the remnant of a diked area and the bottom of a former impoundment. The impoundment was located on the White Oak Creek floodplain south of the 7500 bridge and served as an intermediate settling basin for ORNL plant discharges from 1943 to 1944. Late in 1944, the dike failed and the impoundment was drained, but many of the contaminated sediments remain. The active ORNL support facility is a short section of Intermediate Level Liquid Waste (ILLW) line located about $91.5 \mathrm{~m}$ (300 ft) east of the confluence of White Oak Creek and Melton Branch. This section of ILLW line is constructed of double-wall pipe and is used to transfer ILLW to storage tanks at the hydrofracture facility. 


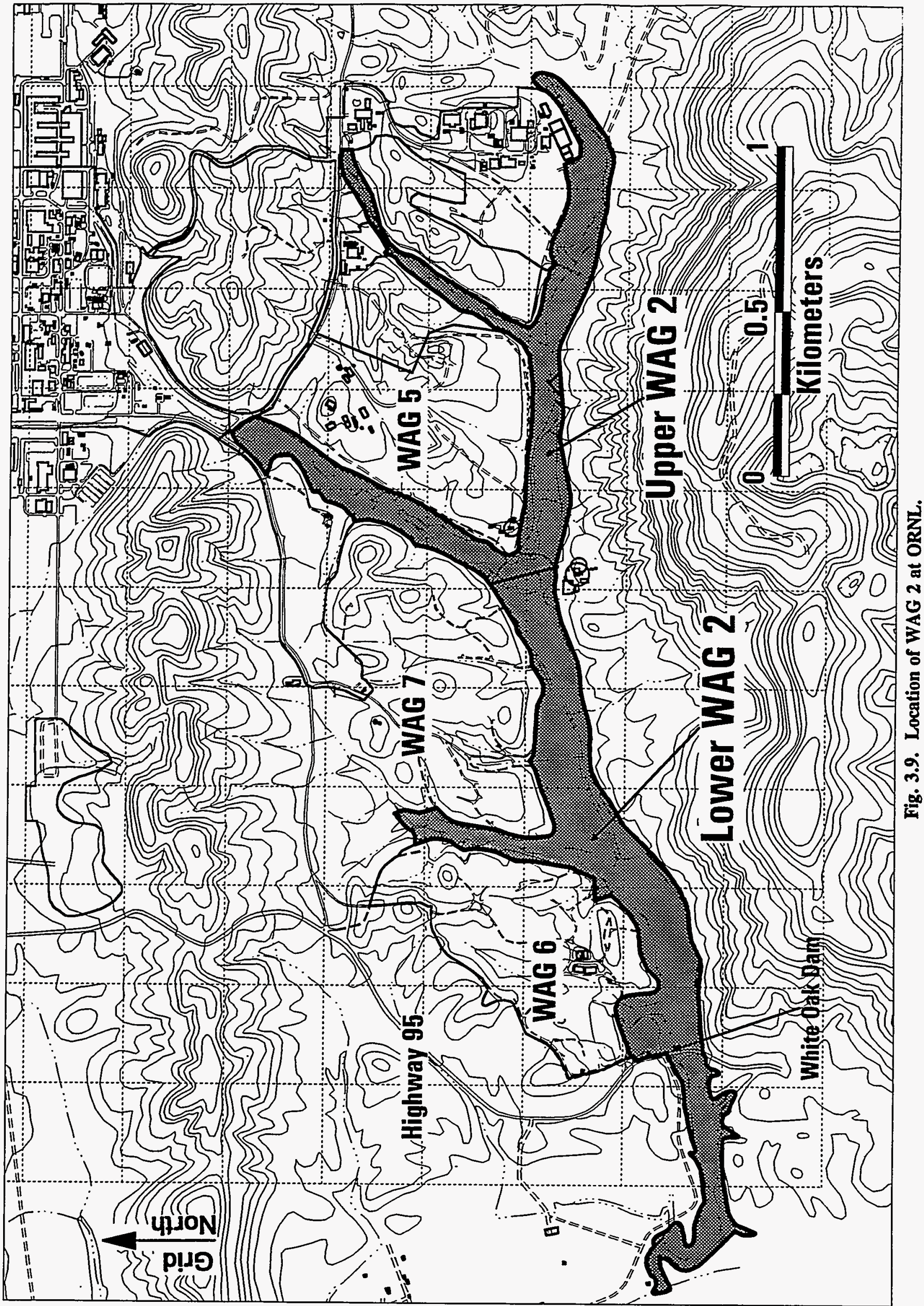




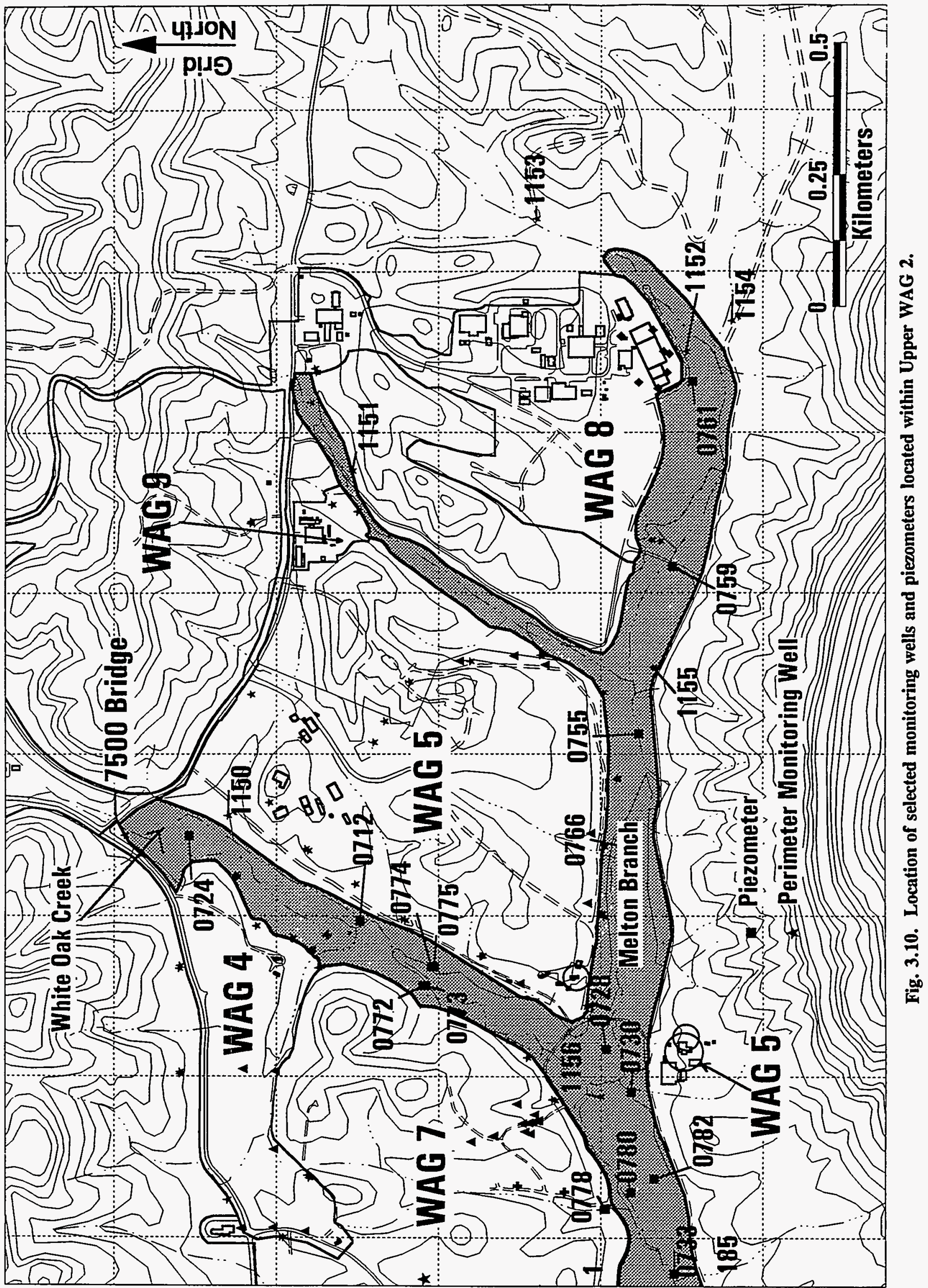


Overall, the contamination in upper WAG 2 is thought to be derived primarily from non-point sources in adjoining WAGs. As a result, the distribution of contaminants in upper WAG 2 is believed to be diffuse, with locally elevated zones of contamination at the principal discharge points for surface water and groundwater from the adjoining WAGs.

\subsubsection{Lower section of WAG 2}

The lower section of WAG 2 is composed of White Oak Creek, White Oak Lake and one of its feeder streams, and the embayment below White Oak Dam and its floodplain (Fig. 3.11). The upper reach of the site begins at the confluence of White Oak Creek and Melton Branch and extends $\sim 1.4 \mathrm{~km}(0.9$ miles) downstream to White Oak Dam. From there, the site continues $\sim 1.0 \mathrm{~km}$ ( 0.6 miles) through the embayment below the dam to its outfall into the Clinch River.

Lower WAG 2 shares common boundaries with adjacent WAGs 6 and 7 and a portion of WAG 5. The site receives drainage from these WAGs, as well as from upper WAG 2 and its tributaries. Each of these adjacent WAGs contains multiple SWMUs that have operating histories spanning as many as 40 years. During this extended period, surface runoff and groundwater transport of contaminants from the adjoining WAGs has occurred. Many of these contaminants have accumulated within the lakebed, streambed, and floodplain sediments of lower WAG 2. The one man-made feature with the most significant environmental impact in lower WAG 2 is the White Oak Dam. This feature is an earthfill and rock structure, which is crossed by Tennessee Highway 95 (Fig. 3.11). The dam is described as a low-head structure since at its normal pond

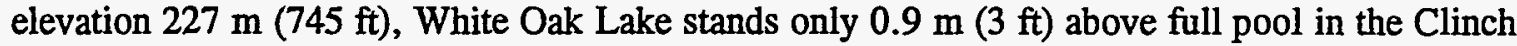
River $226 \mathrm{~m}$ ( $742 \mathrm{ft}$ ). The lake covers an area of 10.1 ha ( 25 acres) extending due east from the dam and has a maximum depth of 1.5 to $1.8 \mathrm{~m} \mathrm{(5} \mathrm{to} 6 \mathrm{ft}$ ). White Oak Lake and its associated creek drain an area of $15.5 \mathrm{~km}^{2}\left(6 \mathrm{mi}^{2}\right)$, which includes the 1175-ha (2900-acre) ORNL site.

\subsubsection{Characterization of Groundwater Contamination (Upper WAG 2)}

\subsubsection{Groundwater monitoring system .}

The groundwater monitoring system in upper WAG 2 includes 33 monitoring wells installed in 1974, 25 piezometers installed between 1986 and 1987, and 7 additional monitoring wells installed in 1989. The 33 older monitoring wells were installed as part of the pre-RAP and were constructed with perforated steel casing running the entire length of the borehole. The piezometers were constructed of $5-\mathrm{cm}$ or 10 -cm (2-in. or 4-in.) inside diameter (ID) polyvinyl chloride (PVC) or stainless steel casing and screens. Sandpack was placed around the screens, and a bentonite seal was placed above the sandpack. The remaining annulus was grouted and each piezometer was completed with a cap and protective cover.

The seven additional wells in upper WAG 2 were installed as part of a groundwater quality monitoring well installation program at ORNL. These wells were constructed of 5-cm (2-in.) ID stainless steel casing and screens. The remainder of the well construction was the same as described for the piezometers. Each well was completed with a steel protective casing, locking cap, steel guardposts, and a concrete pad. The locations of the monitoring wells or piezometers within upper WAG 2 for which groundwater quality data were evaluated for this summary are presented in Fig. 3.10, and a summary of the total depths for these installations is presented in Table 3.1 . 


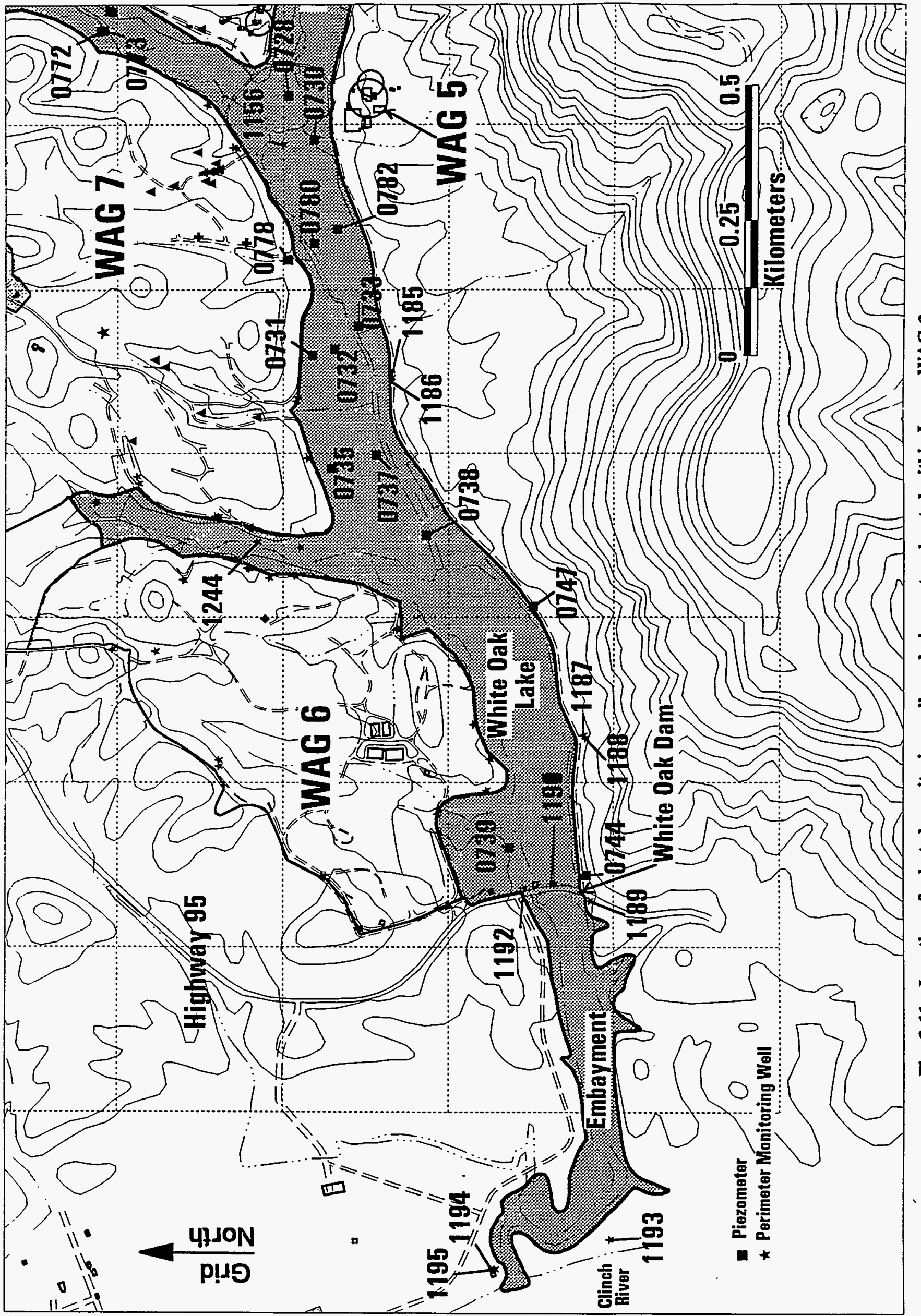


Table 3.1. Summary of Upper WAG 2 groundwater monitoring system wells and piezometers

\begin{tabular}{|c|c|}
\hline Well no. & Total depth (ft) \\
\hline \multicolumn{2}{|c|}{ Piezometers } \\
\hline 0712 & 9.30 \\
\hline 0724 & 8.00 \\
\hline 0728 & 11.00 \\
\hline 0755 & 6.00 \\
\hline 0759 & 21.00 \\
\hline 0761 & 7.00 \\
\hline 0766 & 13.50 \\
\hline 0772 & 16.00 \\
\hline 0773 & 51.00 \\
\hline 0774 & 12.00 \\
\hline 0775 & 47.00 \\
\hline \multicolumn{2}{|c|}{ Groundwater quality wells } \\
\hline 1150 & 16.30 \\
\hline 1151 & 20.30 \\
\hline 1152 & 15.00 \\
\hline 1153 & 18.00 \\
\hline 1154 & 15.70 \\
\hline 1155 & 23.00 \\
\hline 1156 & 21.40 \\
\hline
\end{tabular}




\subsubsection{Contamination nature and extent}

Two principal source documents were used to develop an understanding of groundwater contamination within upper WAG 2. These documents were the Preliminary Geohydrologic Site Characterization and Proposed Water Quality Well Locations for WAG 11 and Upper WAG 2 (Energy Systems 1988a), and the Oak Ridge Reservation Environmental Report for 1991 (Energy Systems 1992b). The Preliminary Geohydrologic Site Characterization report summarized results for groundwater samples collected from 11 of the piezometers located in upper WAG 2, 6 along the White Oak Creek reach, and 5 along the Melton Branch reach (Fig 3.10).

Samples from Piezometer 0724 indicated the presence of ${ }^{90} \mathrm{Sr},{ }^{137} \mathrm{Cs}$, and tritium contamination, as well as elevated gross alpha and beta activity, and chromium concentrations slightly above MCLs. The detected contamination at this piezometer may have been derived from either the main plant area or WAG 4, which is a known source of ${ }^{90} \mathrm{Sr}$. Samples from Piezometer 0712 , located $\sim 350 \mathrm{~m}(1150 \mathrm{ft})$ downstream of 0724 , contained the same radiological contaminants as those found at Piezometer 0724. The most significant increase in contamination between the two piezometers was in the detected activity of tritium, which increased from $100 \mathrm{~Bq} / \mathrm{L}$ at 0724 to $6600 \mathrm{~Bq} / \mathrm{L}$ at 0712 . Samples from Piezometers 0772 and 0774 , located $-176 \mathrm{~m}(580 \mathrm{ft})$ downstream of 0712 , contained tritium and gross beta contamination. Piezometer 0774 also contained ${ }^{90} \mathrm{Sr}$ contamination, which was detected at levels less than those found upstream. Tritium activities detected in Piezometers 0772 and 0774 were $120 \mathrm{~Bq} / \mathrm{L}$ and $160 \mathrm{~Bq} / \mathrm{L}$, respectively.

Samples from Piezometers 0761 and 0759 located in the eastern reach of Melton Branch indicated the presence of gross alpha and beta, tritium, ${ }^{90} \mathrm{Sr}$, and ${ }^{137} \mathrm{Cs}$ contamination. At the intersection of the western tributary of Melton Branch, samples from Piezometer 0755 indicated significant increase in tritium and ${ }^{90} \mathrm{Sr}$ contamination. Tritium increased from $95 \mathrm{~Bq} / \mathrm{L}$ upstream to $120,000 \mathrm{~Bq} / \mathrm{L}$ at 0755 , and ${ }^{90} \mathrm{Sr}$ increased from $0.21 \mathrm{~Bq} / \mathrm{L}$ upstream to $7.5 \mathrm{~Bq} / \mathrm{L}$ at 0755 . From Piezometer 0755 downstream, all detected contaminants decreased in activity with the exception of tritium. The trend of contamination along the Meiton Branch reach of upper WAG 2 suggests that the western tributary of Melton Branch may be a source of both tritium and ${ }^{90} \mathrm{Sr}$. Another source area of the tritium contamination may be the trench disposal area and associated seeps in WAG 5.

The Oak Ridge Reservation Environmental Report for 1991 (Energy Systems 1992b) summarized results for groundwater samples collected during June of 1991 from the seven groundwater quality wells located throughout upper WAG 2. Well 1153 was found to have a total strontium activity of $0.35 \mathrm{~Bq} / \mathrm{L}$. Wells 1152 and 1156 were found to have tritium activities of $9999 \mathrm{~Bq} / \mathrm{L}$ and $4699 \mathrm{~Bq} / \mathrm{L}$, respectively. Subsequent sampling of these wells in June 1992 and January 1993 indicated similar levels of tritium contamination in Wells 1152 and 1156. However, during these two sampling events, total strontium was not detected above the MCL in Well 1153. Total strontium $(0.31 \mathrm{~Bq} / \mathrm{L})$ and cadmium $(10 \mu \mathrm{g} / \mathrm{L})$ were detected in Well 1151 during the June 1992 sampling.

A significant finding of the environmental report and subsequent sampling was the tritium contamination in Well 1152. This finding suggests that there may be an additional tritium source in or around WAG 8 contributing contamination to upper WAG 2. The observation that relatively minor concentrations of tritium were detected in Piezometers 0761 and 0759, and none 
above MCL in Well 1155, suggests that this additional flux may be new to the upper WAG 2 area; or that the tritium may be migrating in bedrock along strike-oriented solution channels not previously encountered until the drilling of Well 1152.

\subsubsection{Characterization of Groundwater Contamination (Lower WAG 2)}

\subsubsection{Groundwater monitoring system}

The groundwater monitoring system in lower WAG 2 includes 31 monitoring wells installed between 1964 and 1977, 48 piezometers installed between 1986 and 1987, and 12 additional monitoring wells installed between 1989 and 1990. The 31 older monitoring wells were installed as part of the pre-RAP and were constructed as open boreholes or were stabilized with perforated steel casing running the entire length of the borehole. The piezometers were constructed of 5-cm or 10-cm (2-in. or 4-in.) ID PVC or stainless steel casing and screens. Sandpack was placed around the screens and a bentonite seal was placed above the sandpack. The remaining annulus was grouted and each piezometer was completed with a cap and protective cover.

The 12 additional wells in lower WAG 2 were installed as part of a groundwater quality monitoring well installation program at ORNL. These wells were constructed of $5-\mathrm{cm}$ or $10-\mathrm{cm}$ (2-in. or 4-in.) ID stainless steel casing and screens. The remainder of the well construction was the same as described for the piezometers. Each well was completed with a steel protective casing, locking cap, steel guardposts, and a concrete pad. The locations of the monitoring wells or piezometers within lower WAG 2 for which groundwater quality data was evaluated for this summary are presented in Fig. 3.11, and a summary of the total depths for these installations is presented in Table 3.2.

\subsubsection{Contamination nature and extent}

Two principal source documents were used to develop an understanding of groundwater contamination within lower WAG 2. These documents were the Preliminary Geohydrologic Site Characterization and Proposed Water Quality Well Locations for WAG 17 and Lower WAG 2 (Energy Systems 1988b), and the Oak Ridge Reservation Environmental Report for 1991 (Energy Systems 1992b). The Preliminary Geohydrologic Site Characterization report summarized results for groundwater samples collected from 14 of the piezometers located in lower WAG 2 along White Oak Creek and White Oak Lake (Fig 3.11).

Five of the piezometers located along the White Oak Creek reach of lower WAG 2 (0728, 0730, 0780, 0731, and 0733) contained contamination above MCLs. Samples from Piezometer 0728 located near the eastern boundary of the WAG were found to contain tritium $(150,000 \mathrm{~Bq} / \mathrm{L})$ and chromium contamination. Activities and concentrations of both these contaminants were found to be significantly reduced in samples from Piezometer 0730. The only contaminant detected in the Piezometer 0780 samples was ${ }^{90} \mathrm{Sr}$. Samples from Piezometer 0731 exhibited increased chromium concentrations, and those from Piezometer 0733 were found to contain significantly elevated activities of ${ }^{90} \mathrm{Sr}(21 \mathrm{~Bq} / \mathrm{L})$, tritium $(1200 \mathrm{~Bq} / \mathrm{L})$, and gross alpha.

Three of the piezometers located along the White Oak Lake section of lower WAG 2 (0737, 0738, and 0739) also contained contamination above MCLs. Samples from Piezometers 0737 and 0738 located at the eastern end of the lake indicated a progressive decrease in ${ }^{90} \mathrm{Sr}$ activities. 
Table 3.2 Summary of Lower WAG 2 groundwater monitoring system wells and piezometers

\begin{tabular}{|c|c|}
\hline Well no. & Total depth (ft) \\
\hline \multicolumn{2}{|c|}{ Piezometers } \\
\hline 0728 & 11.00 \\
\hline 0730 & 25.00 \\
\hline 0731 & 12.00 \\
\hline 0732 & 5.50 \\
\hline 0733 & 8.00 \\
\hline 0735 & 10.00 \\
\hline 0737 & 8.50 \\
\hline 0738 & 8.50 \\
\hline 0739 & 33.00 \\
\hline 0744 & 33.50 \\
\hline 0747 & 22.50 \\
\hline 0778 & 15.00 \\
\hline 0780 & 12.50 \\
\hline 0782 & 14.50 \\
\hline \multicolumn{2}{|c|}{ Groundwater quality wells } \\
\hline 1185 & 27.50 \\
\hline 1186 & 68.30 \\
\hline 1187 & 85.00 \\
\hline 1188 & 27.50 \\
\hline 1189 & 27.50 \\
\hline 1190 & 47.40 \\
\hline 1191 & 26.20 \\
\hline 1192 & 18.80 \\
\hline 1193 & 85.00 \\
\hline 1194 & 97.50 \\
\hline 1195 & 32.00 \\
\hline 1244 & 24.99 \\
\hline
\end{tabular}


However, at Piezometer 0738 concentrations of tritium (4200 Bq/L) and chromium $(690 \mu \mathrm{g} / \mathrm{L})$ were found to increase compared to upstream values. Piezometer 0739, located at the western end of the lake, was found to contain elevated gross alpha activity.

The Oak Ridge Reservation Environmental Report for 1991 (Energy Systems 1992b) summarized results for groundwater samples collected during June of 1991 from the 12 groundwater quality wells located throughout lower WAG 2. Samples collected from Well 1185 located at the eastern end of White Oak Lake were found to be contaminated by $1,1,2,2$-tetrachloroethene at a concentration of $1.0 \mu \mathrm{g} / \mathrm{L}$. Subsequent samples from this well collected during June/July 1992 and February 1993 were absent of this contaminant. Wells 1190 and 1191, located near White Oak Dam, contained tritium contamination at activities of $2100 \mathrm{~Bq} / \mathrm{L}$ and $6500 \mathrm{~Bq} / \mathrm{L}$, respectively. Well 1191 was also found to be contaminated by total strontium, and Well 1192 (same vicinity) contained nickel contamination at $183 \mu \mathrm{g} / \mathrm{L}$. Subsequent sampling during the periods noted above indicated the presence of several volatile organic contaminants at Well 1190 and chromium contamination $(998 \mu \mathrm{g} / \mathrm{L})$ at Well 1192 . No contamination above MCLs was detected at Wells 1193 and 1195, located at the western end of lower WAG 2. However, subsequent sampling of these wells indicated the presence of arsenic at levels ranging from $84 \mu \mathrm{g} / \mathrm{L}$ to $280 \mu \mathrm{g} / \mathrm{L}$. Well 1244 , located along a tributary entering White Oak Lake, was sampled for the first time in July 1992 and was found to be contaminated with tritium $(1200 \mathrm{~Bq} / \mathrm{L})$.

Based on the data evaluated for lower WAG 2, strontium activity appears to peak in the White Oak Creek section of the WAG and then decrease in the direction of White Oak Lake. Tritium activities decrease from the eastern boundary of the WAG to the area around Piezometer 0733. However, the activities then appear to increase from the eastern end of White Oak Lake to White Oak Dam. This observation may be an effect of White Oak Lake rather than an indicator of upgradient contamination. However, results obtained from Well 1244 suggest that the tributary in which it is located may be contributing tritium to White Oak Lake from an upgradient source (probably WAG 6). Metal and volatile organic contaminants were detected at various sites within lower WAG 2; however, no trend is readily apparent.

\subsection{WAG 3}

\subsubsection{Site Location, Description, and Background}

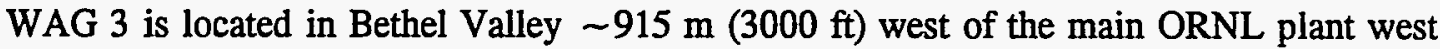
gate and is composed of an estimated 8.9 ha (22 acres) (Fig. 3.12). This WAG contains 3 SWMUs: (1) the Contractors' Landfill, which is presently in operation; (2) the Closed Scrap Metal Area; and (3) SWSA 3, which is not currently in use.

\subsubsection{Contractors' Landfill}

The Contractors' Landfill is located $\sim 40 \mathrm{~m}$ (130 ft) west of SWSA 3 and is composed of $-2.8 \mathrm{ha}$ ( 7 acres). The operating conditions of the landfill permit for this SWMU restrict the types of waste that may be disposed of here to concrete block, masonry, roofing, plastic, fly ash, pasteboard, plaster, paper and wood wastes, noncontaminated soil, electrical wiring, and piping. Prior to permitting, it is believed that similar materials were disposed of in the landfill; however, 


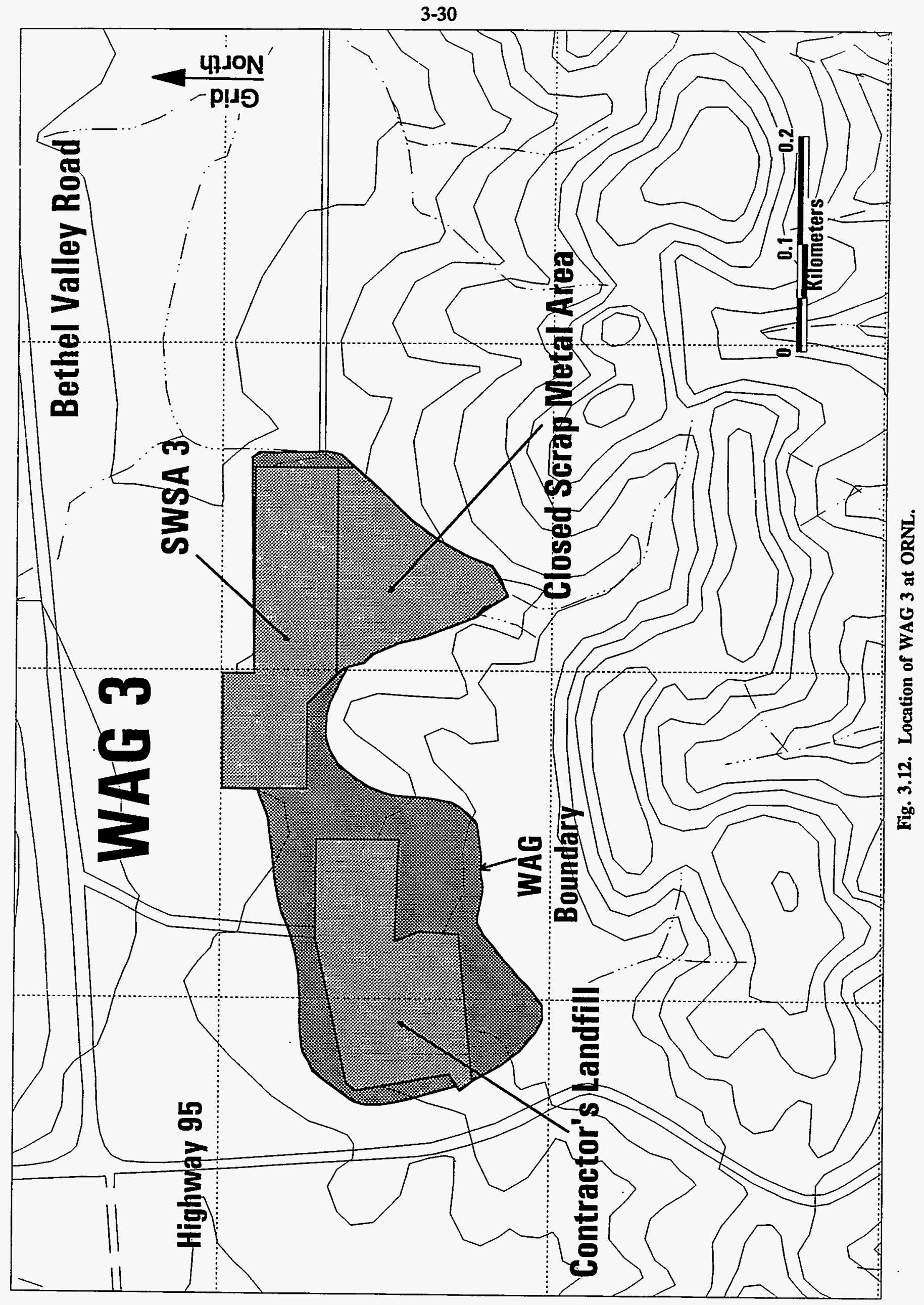


there is no documentation to support this assumption. It is possible that contaminated soil from construction activities in the main plant area was disposed of at the site. A beta-gamma survey of the area identified two small areas of contamination where the principal contaminants were determined to be ${ }^{90} \mathrm{Sr}$ and ${ }^{137} \mathrm{Cs}$ with lesser amounts of ${ }^{60} \mathrm{Co}$.

\subsubsection{Closed Scrap Metal Area}

The Closed Scrap Metal Area consists of an estimated 1.6 ha (4 acres) of graded fill maintained in grass. Its general location is adjacent to and southeast of SWSA 3; however, its exact boundaries are not known. This SWMU was operated as a contractors' landfill for an estimated 15 years. After reaching its capacity, the fill area was reportedly used for storage of scrap metal, the nature and origin of which are not documented. Ultimately, this area was closed and much of the scrap material is believed to have been buried on site. Because the nature of the wastes disposed of in this area were not well known, health physics surveys of the site were conducted. The surveys indicated activity levels above background in the section where the scrap metal area adjoins SWSA 3. Details on the level and exact location of activity are sketchy, though there is some information suggesting that the contaminated area(s) may have been related to a scrapped and buried storage tank and/or runoff from SWSA 3.

The health physics survey also included soil, vegetation, and biological sampling. Of all the samples collected, only one soil sample taken near the SWSA 3 fenceline showed significant activity of ${ }^{137} \mathrm{Cs}$ at a depth of $20 \mathrm{~cm}(8 \mathrm{in})$. The general conclusion of the health physics survey was that contamination levels in the buried scrap metal were low, if present at all. It was inferred that the contaminated areas in the Closed Scrap Metal Area adjacent to SWSA 3 are probably related to sources within SWSA 3, with the possible exception of the buried storage tank/contaminated metal.

\subsubsection{SWSA 3}

SWSA 3 is composed of $\sim 2.8$ ha ( 7 acres), appearing in plan view as two offset rectangles with a triangular protrusion on the southeastern side. This SWMU is located northeast of the Closed Scrap Metal Area and is presently planted in grass and enclosed by a chain link fence. SWSA 3 was used for the disposal of contaminated trash and laboratory equipment; however, it also received some waste transplanted from the closure of SWSA 2. The area was operational from 1946 to 1951; although several months prior to opening for routine burial, it is reported to have received "special hot materials" from off site.

Initially, a trench was excavated at the site's northeastern end and lined with concrete. Alpha wastes in containers were placed in the lined trench and then entombed with additional concrete. The subsequent burial procedures for alpha wastes changed; additional materials of this type were placed in unlined trenches and then capped with concrete. Beta and gamma wastes were also disposed of in unlined trenches covered with soil. The exact location and orientation of the trenches is unknown; however, they were reportedly oriented parallel to one another with their long axis spanning the width of SWSA 3. The trenches were reportedly excavated to a depth of $\sim 4.6 \mathrm{~m}$ (15 ft) and were not free-draining. Water was reported to accumulate within the confines of the trenches; however, it is not clear whether this was surface water or an influx of groundwater. The site was subsequently closed and after closure was used for aboveground 
storage of contaminated equipment. Between 1978 and 1979, all of the above-ground stored material was removed from the site.

\subsubsection{Characterization of Groundwater Contamination}

\subsubsection{Groundwater monitoring system}

The groundwater monitoring system in and around WAG 3 includes 19 monitoring wells installed in 1950 or 1964, 21 piezometers installed in 1986, and 26 additional monitoring wells installed between 1987 and 1990 . The 19 older monitoring wells were installed as part of the pre-RAP and were constructed as open boreholes or were stabilized with perforated steel casing running the entire length of the borehole. The piezometers were constructed of 5-cm or $10-\mathrm{cm}$ (2-in. or 4-in.) ID PVC casing and screens. Sandpack was placed around the screens, and a bentonite seal was placed above the sandpack. The remaining annulus was grouted, and each piezometer was completed with a cap and protective cover.

The 26 additional wells at WAG 3 were installed as part of a groundwater quality monitoring well installation program at ORNL. These wells were constructed of $5-\mathrm{cm}$ or $10-\mathrm{cm}(2-\mathrm{in}$. or 4-in.) ID stainless steel casing and screens. The remainder of the well construction was the same as described for the piezometers. Each well was completed with a steel protective casing, locking cap, steel guardposts, and a concrete pad. The locations of the monitoring wells or piezometers within WAG 3 for which groundwater quality data were evaluated for this summary are presented in Fig. 3.13, and a summary of the total depths for these installations is presented in Table 3.3.

\subsubsection{Contamination nature and extent}

Two principal source documents were used to develop an understanding of groundwater contamination at WAG 3. These documents were the Preliminary Geohydrologic Site Characterization and Proposed Water Quality Well Locations for WAGs 4, 5, and 3, and SWSA 1 (Energy Systems 1987a) and the Oak Ridge Reservation Environmental Report for 1991 (Energy Systems 1992b). The Preliminary Geohydrologic Site Characterization report summarized results from two previous studies regarding groundwater contamination at WAG 3. The first study reported results for groundwater samples collected from monitoring wells 0301, 0302, and 0303 located in SWSA 3. Analyses indicated that all three wells contained ${ }^{90} \mathrm{Sr}$ contamination, but the parameters ${ }^{137} \mathrm{Cs},{ }^{60} \mathrm{Co},{ }^{125} \mathrm{Sb}$, and tritium were below detection limits. Only one occurrence of metals contamination was indicated (Well $0303-0.012$ ppm cadmium) above MCLs.

The second study reported results for water samples collected from two distinct areas of ${ }^{90} \mathrm{Sr}$ contamination. The first area was associated with the northwest tributary of White Oak Creek where a $30.5-\mathrm{m}(100-\mathrm{ft})$ reach located $-350 \mathrm{~m}(1150 \mathrm{ft})$ northeast of SWSA 3 was identified as the principal source of contamination. The second area was associated with an unnamed tributary of Raccoon Creek where a seep and a 10-m (33-ft) reach adjacent to the seep located $\sim 640 \mathrm{~m}$ ( $2100 \mathrm{ft}$ ) southwest of SWSA 3 were identified as the principal source of contamination. Activity levels of ${ }^{90} \mathrm{Sr}$ averaged about $6.4 \mathrm{mCi}$ per month at the White Oak Creek site and $0.5 \mathrm{mCi}$ per month at the Raccoon Creek site. The study concluded that both streams appeared to be receiving contaminated groundwater in the form of base flow and that the contamination may be related to leaching of waste from either SWSA 3 or the Contractors' Landfill with subsequent transport occurring in bedrock along strike-oriented solution channels. 


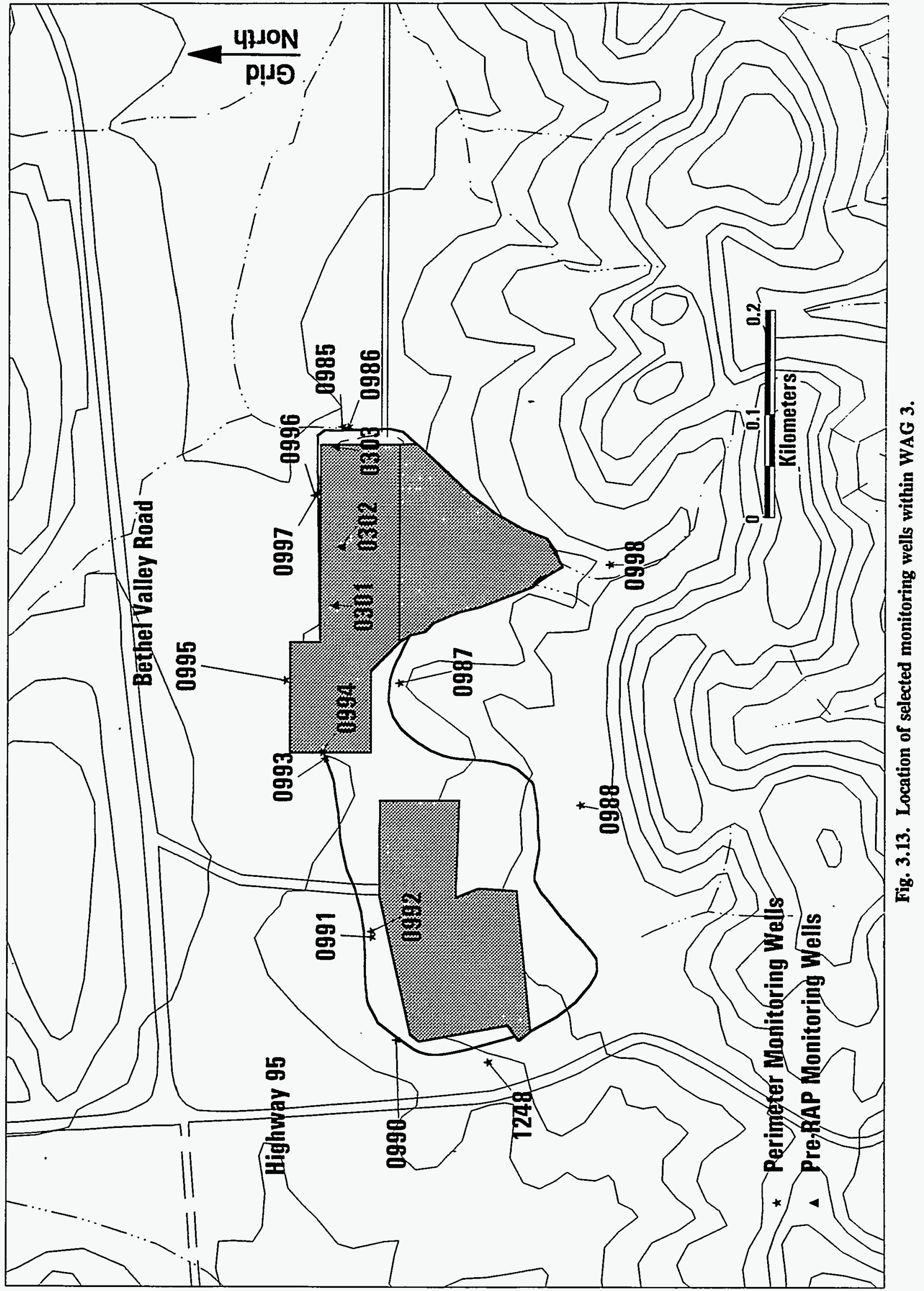


Table 3.3. Summary of WAG 3 groundwater monitoring system wells

\begin{tabular}{|c|c|}
\hline Well no. & Total depth (ft) \\
\hline \multicolumn{2}{|c|}{ Pre-RAP wells } \\
\hline 0301 & 14.00 \\
\hline 0302 & 6.00 \\
\hline 0303 & 6.00 \\
\hline \multicolumn{2}{|c|}{ Groundwater quality wells } \\
\hline 0985 & 35.00 \\
\hline 0986 & 82.50 \\
\hline 0987 & 48.20 \\
\hline 0988 & 46.00 \\
\hline 0990 & 40.80 \\
\hline 0991 & 85.00 \\
\hline 0992 & 53.50 \\
\hline 0993 & 45.00 \\
\hline 0994 & 80.50 \\
\hline 0995 & 48.50 \\
\hline 0996 & 62.50 \\
\hline 0997 & 33.50 \\
\hline 0998 & 20.70 \\
\hline 1248 & 72.50 \\
\hline
\end{tabular}


The Oak Ridge Reservation Environmental Report for 1991 (Energy Systems 1992b) summarized results for groundwater samples collected during August of 1991 from 15 of the groundwater quality wells at WAG 3 . Well 1247 was dry during the sampling period and thus results for only 14 wells were reported. Four of the perimeter wells were found to have total strontium activities in excess of MCLs: Wells $0992(5.3 \mathrm{~Bq} / \mathrm{L}), 0993(5.5 \mathrm{~Bq} / \mathrm{L})$, and 0994 $(24 \mathrm{~Bq} / \mathrm{L})$ located along the northwest perimeter of the WAG, and Well $0997(3.8 \mathrm{~Bq} / \mathrm{L} \mathrm{pCi} / \mathrm{L})$ located near the northeast corner of SWSA 3. Well 0994 also contained tritium at an activity of $1199 \mathrm{~Bq} / \mathrm{L}$. Well 0985 was found to contain trichloroethene $(18.0 \mu \mathrm{g} / \mathrm{L})$ and Well 0998 tetrachloroethene $(15 \mu \mathrm{g} / \mathrm{L})$ in excess of MCLs. Subsequent sampling of these wells in August and September of 1992 indicated the presence of similar concentrations of the noted contaminants, with the exceptions that no tetrachloroethene was detected in Well 0998, and a total strontium concentration of $0.8 \mathrm{~Bq} / \mathrm{L}$ was detected in Well 1248. The irregular occurrences of strontium contamination [between $\sim 10$ and $24 \mathrm{~m}$ (33 and $80 \mathrm{ft}$ ) below ground level] within the various perimeter wells at WAG 3 suggest that multiple contamination sources may be present at the site; or that contamination is migrating along preferential flow pathways, which may include strike-oriented solution channels.

\subsection{WAG 4}

\subsubsection{Site Location, Description, and Background}

WAG 4 is located in Melton Valley and consists of $\sim 10.9$ ha (27 acres) (Fig. 3.14). This WAG is also located $\sim 824 \mathrm{~m}(2700 \mathrm{ft})$ southwest of the main ORNL plant area. WAG 4 contains three SWMUs: (1) the abandoned ILLW Transfer Line, (2) the Experimental Pilot Pit Area, and (3) SWSA 4, which is the largest unit in the WAG and the primary unit of interest.

\subsubsection{ILLW Transfer Line}

The ILLW transfer lines were used to transport fission waste products from the main plant area to the disposal pits and trenches located in WAG 7. The lines were constructed of $5-\mathrm{cm}$ (2-in.) cast iron pipe and were buried about $0.9 \mathrm{~m}(3 \mathrm{ft})$ below ground level. The lines were decommissioned over a 2-year period beginning in 1981. A section of abandoned ILLW transfer line is located along the northwestern boundary of WAG 4 . Surface radiation surveys along the route of this line in WAG 4 did not locate any areas of contamination, suggesting that this SWMU should not be a significant source of groundwater contaminants.

\subsubsection{Experimental Pilot Pit Area}

The Experimental Pilot Pit Area contains two pits whose exact locations are not precisely known. The pits were to be used in studying a means of fixing radioactive wastes. However, only one experiment involving radiation was conducted before termination of the project. Contaminated materials were removed from the site, and the only remaining radioactivity at the site was reported to be in the form of rock core samples from a 1960s Clinch River study.

\subsubsection{SWSA 4}

SWSA 4 is an elongated, irregularly shaped tract that trends from northeast to southwest within WAG 4. It is bounded by White Oak Creek to the east, Lagoon Road to the northwest, 


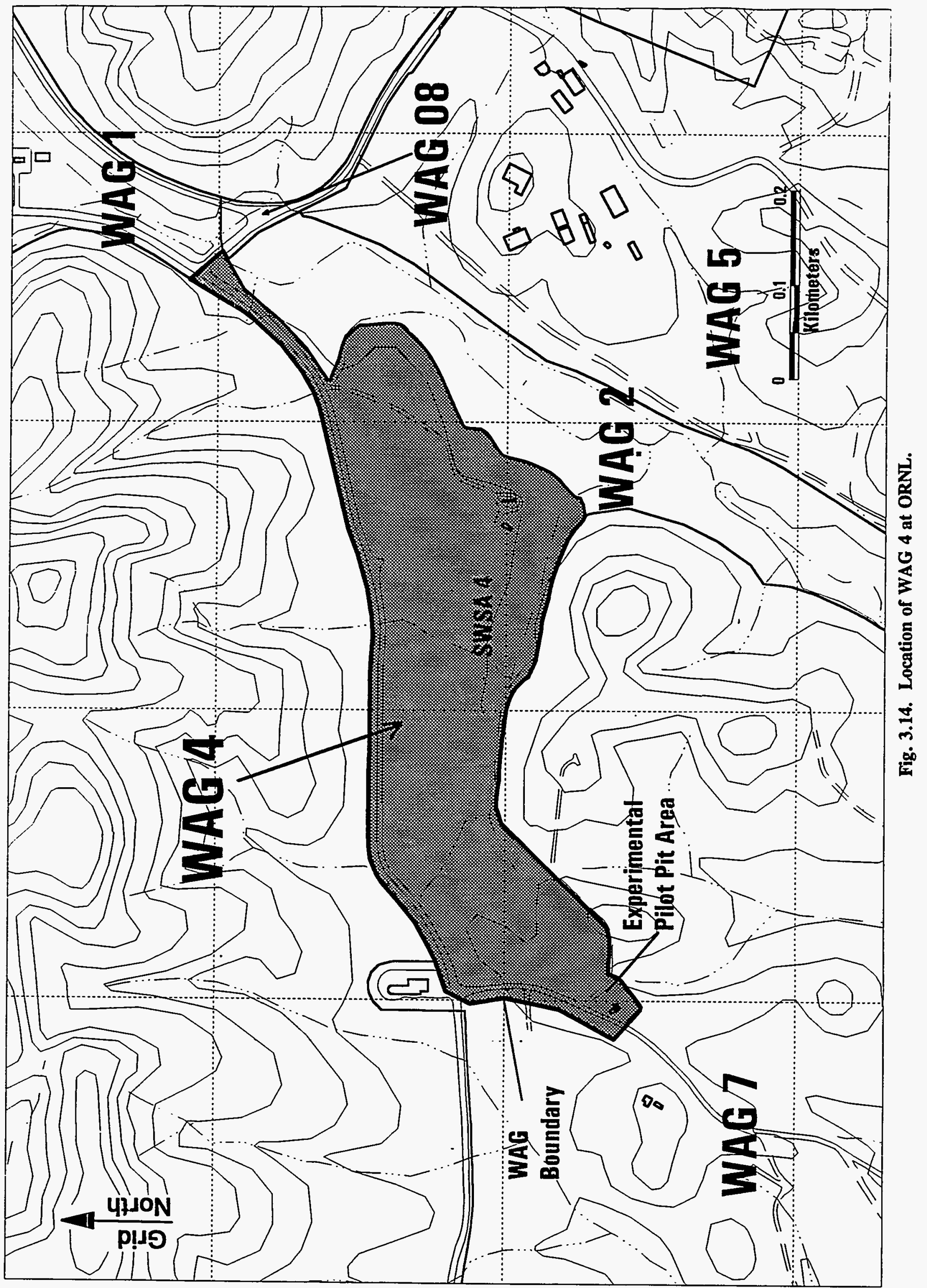


a reservation access road to the west, and an unnamed tributary of White Oak Creek to the southwest. The site was used for waste disposal beginning in 1951 and received a variety of wastes from the main plant area including glassware, scrap metal, paper, dirt, filter media, oils, depleted uranium, animal carcasses, and contaminated equipment. During the period from 1955 to 1959 , SWSA 4 also received a variety of poorly characterized wastes from off-site sources within the nuclear research industry, which eventually contributed as much as $50 \%$ of the total volume of the waste disposed of at SWSA 4. These additional wastes can generally be characterized as low-level solid wastes; however, most of the operating records for SWSA 4 were destroyed, and it is assumed that some of the materials would have been classified as hazardous by present standards.

Wastes at SWSA 4 were disposed of in both auger holes and trenches excavated in the soil and weathered shale underlying the site. The auger holes are located along the northern border of the site and were $\sim 4.3 \mathrm{~m}(14 \mathrm{ft})$ in depth and $\sim 0.9 \mathrm{~m}(3 \mathrm{ft})$ in diameter. The holes were reportedly lined with concrete and then used for containment of higher activity or "special wastes." The trenches are located throughout the site and occur as parallel sets of $\sim 2$ to 20 trenches. The orientation of the trench sets varies across the site. Most waste was placed in trenches whose dimensions reportedly varied from 15.3 to $125 \mathrm{~m} \mathrm{(50} \mathrm{to} 410 \mathrm{ft}$ ) in length, 2.4 to $9.2 \mathrm{~m}(8$ to $30 \mathrm{ft}$ ) in width, and 2.4 to $4.6 \mathrm{~m}$ (8 to $15 \mathrm{ft}$ ) in depth. Observations made during the operation of this site and during subsequent studies indicated that some of the trenches, particularly those in the lower eastern portion of the SWSA, intercepted the water table. Trenches containing alpha wastes were capped with $45.7 \mathrm{~cm}$ (18 in.) of concrete; those containing beta-gamma wastes were backfilled with native soils.

SWSA 4 stopped receiving general nuclear industry wastes in 1959 but continued to receive uncontaminated construction debris, which was used as a surface cap, until 1973. By virtue of the fill's higher permeability, its presence at the site probably set the stage for increased infiltration of surface water into the underlying wastes. SWSA 4 has been identified as the single largest non-point source contributor of ${ }^{90} \mathrm{Sr}$ to the White Oak Creek watershed. The principal contributing factors causing this condition have been described as surface run-on and infiltration of vadose water into the disposal trenches. Waste constituents are subsequently transported by surface water in the form of seeps, and by groundwater in the form of base flow to White Oak Creek and its tributary. In an effort to reduce contaminant migration, two surface water diversion projects have been completed along the site's northern border and across the site proper. Grass cover is also maintained over the site to minimize erosion.

\subsubsection{Characterization of Groundwater Contamination}

\subsubsection{Groundwater monitoring system}

The groundwater monitoring system at WAG 4 includes 66 monitoring wells installed between 1959 and 1974, 13 piezometers installed in 1986 or 1987, and 15 additional monitoring wells installed between 1987 and 1990 . The 66 older monitoring wells were installed as part of the pre-RAP and were constructed with perforated corrugated metal casing running the entire length of the borehole; others are of unknown construction. The piezometers were constructed of 5-cm (2-in.) ID PVC casing and screens. Sandpack was placed around the screens, and a bentonite seal was placed above the sandpack. The remaining annulus was grouted, and each piezometer was completed with a cap and protective cover. 
The 15 additional wells at WAG 4 were installed as part of a groundwater quality monitoring well installation program at ORNL. These wells were constructed of 5-cm or 10-cm (2-in. or 4-in.) ID stainless steel casing and screens. The remainder of the well construction was the same as described for the piezometers. Each well was completed with a steel protective casing, locking cap, steel guardposts, and a concrete pad. The locations of the monitoring wells or piezometers within WAG 4 for which groundwater quality data were evaluated for this summary are presented in Fig. 3.15, and a summary of the total depths for these installations is presented in Table 3.4.

\subsubsection{Contamination nature and extent}

Two principal source documents were used to develop an understanding of groundwater contamination at WAG 4. These documents were the Preliminary Geohydrologic Site Characterization and Proposed Water Quality Well Locations for WAGs 4, 5, and 3, and SWSA 1 (Energy Systems 1987a), and the Oak Ridge Reservation Environmental Report for 1991 (Energy Systems 1992b). The Preliminary Geohydrologic Site Characterization report summarized results for samples collected from seven of the pre-RAP wells in SWSA $4(0180,0181,0182,0186$, 0190,0191 , and 0195) and three undesignated seeps located in proximity to each other along the southern boundary of SWSA 4. All of the well and seep samples were found to be contaminated with ${ }^{90} \mathrm{Sr}$ ranging in activity from 0.89 to $1000 \mathrm{~Bq} / \mathrm{L}$ in the wells and from 42 to $800 \mathrm{~Bq} / \mathrm{L}$ in the seeps. The highest activity of ${ }^{90} \mathrm{Sr}$ was detected in Well 0191 , which is located in proximity to the seeps. Wells 0186 and 0191 also were found to be contaminated with ${ }^{137} \mathrm{Cs}$ at pre-purging activities of 0.31 and $0.21 \mathrm{~Bq} / \mathrm{L}$, respectively.

The Oak Ridge Reservation Environmental Report for 1991 (Energy Systems 1992b) summarized results for groundwater samples collected during March and April of 1991 from the 15 groundwater quality wells at WAG 4 . Six of these wells located along the southeast boundary of WAG 4 (0954, 0955, 0956, 0957, 0958, and 0960) were found to contain tritium contamination ranging from 2500 to $400,000 \mathrm{~Bq} / \mathrm{L}$. The four southeast boundary wells exhibiting the highest tritium activities also were found to be contaminated by nickel at concentrations ranging from 120 to $170 \mu \mathrm{g} / \mathrm{L}$. Three wells located along the north and southeast boundaries of the WAG $(0951,0953$, and 0956) contained total strontium contamination ranging from 0.31 to $20 \mathrm{~Bq} / \mathrm{L}$. Finally, four wells located along the west and southeast boundaries $(0949,0954,0955$, and 0958) were found to be contaminated by one or more of the following volatile organics at concentrations ranging from 7.0 to $200 \mu \mathrm{g} / \mathrm{L}$ : 1,2-dichloroethane, 1,1-dichloroethene, trichloroethane, and vinyl chloride.

Subsequent sampling of the wells in November and December of 1991 and October and November of 1992 indicated the presence of similar activities and concentrations of the noted contaminants. However, total strontium was observed to be below the MCL in Wells 0951 and 0953 during the later sampling events and was detected above MCLs in Wells 0955 and 0962. Also, nickel was observed to be below the MCL in Well 0957 during the later sampling events. Based on the data evaluated for WAG 4 , contaminated groundwater containing ${ }^{137} \mathrm{Cs}$, ${ }^{90} \mathrm{Sr}$, and tritium derived from the disposal trenches and/or auger holes appears to have migrated downgradient from the south and southeast boundaries of WAG 4 . In addition, nickel contamination in groundwater also appears to be migrating beyond the southeast boundary of the WAG. Several source areas within WAG 4 also appear to be contributing minor amounts of volatile organic contaminants to groundwater. 


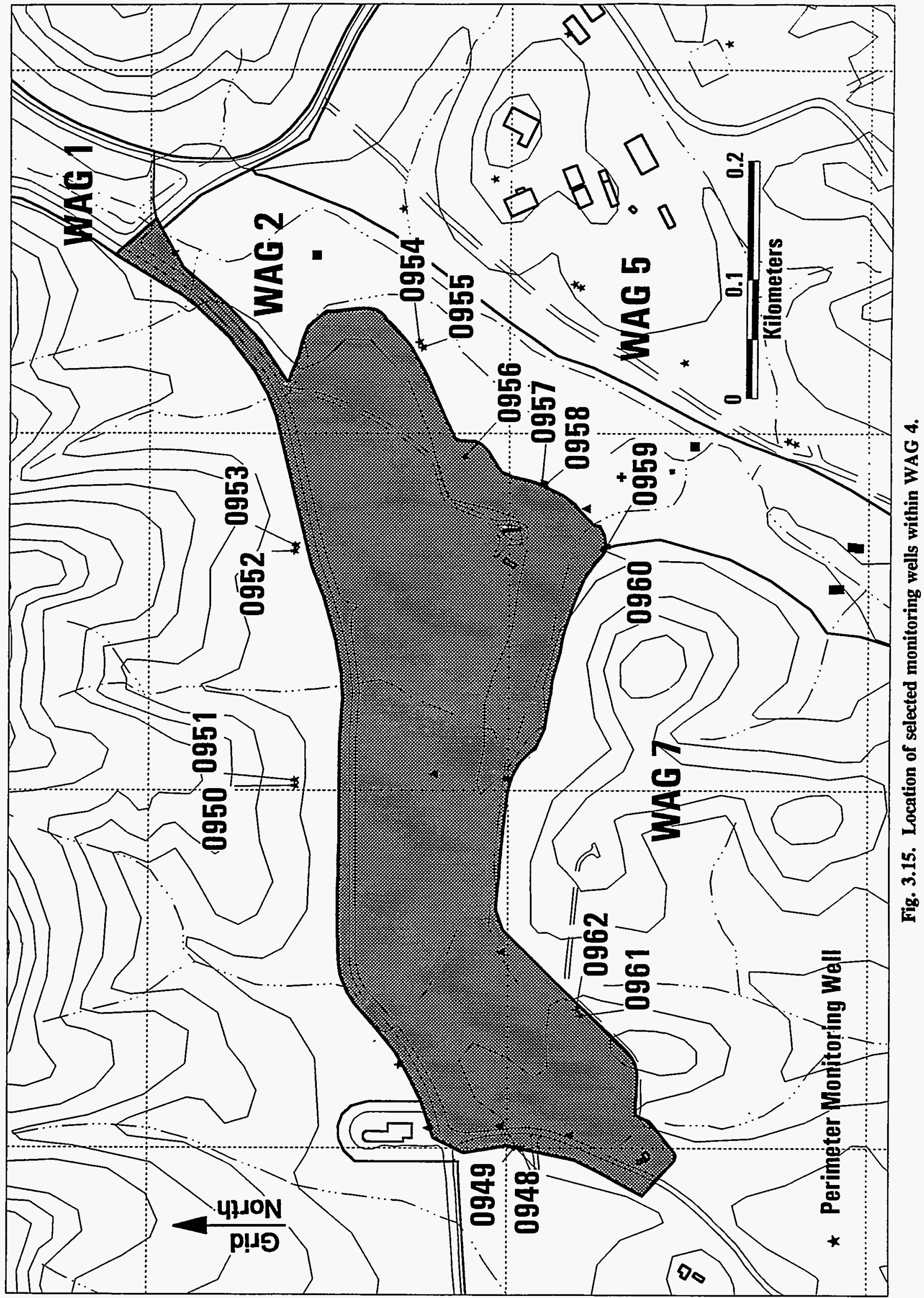


Table 3.4. Summary of WAG 4 groundwater monitoring system wells

\begin{tabular}{|c|c|}
\hline Well no. & Total depth (ft) \\
\hline \multicolumn{2}{|c|}{ Pre-RAP wells } \\
\hline 0180 & 18.00 \\
\hline 0181 & 14.00 \\
\hline 0182 & 20.00 \\
\hline 0186 & 6.00 \\
\hline 0190 & 15.00 \\
\hline 0191 & 7.00 \\
\hline 0195 & 7.00 \\
\hline \multicolumn{2}{|c|}{ Groundwater quality wells } \\
\hline 0948 & 83.00 \\
\hline 0949 & 33.40 \\
\hline 0950 & 49.50 \\
\hline 0951 & 70.30 \\
\hline 0952 & 30.50 \\
\hline 0953 & 70.50 \\
\hline 0954 & 62.50 \\
\hline 0955 & 22.50 \\
\hline 0956 & 22.50 \\
\hline 0957 & 82.50 \\
\hline 0958 & 27.50 \\
\hline 0959 & 72.50 \\
\hline 0960 & 32.50 \\
\hline 0961 & 80.30 \\
\hline 0962 & 38.00 \\
\hline
\end{tabular}




\subsection{WAG 5}

\subsubsection{Site Location, Description, and Background}

WAG 5 is located in Melton Valley and consists of $\sim 20.3$ ha (50 acres), which are divided into two separate areas: a main tract and an outlying area (Fig. 3.16). The main tract of the WAG is bounded to the southwest by the floodplain of White Oak Creek and to the southeast by the floodplain of Melton Branch. The outlying area of the WAG lies $\sim 153 \mathrm{~m}(500 \mathrm{ft}$ ) southeast of the confluence between White Oak Creek and Melton Branch.

The main tract of WAG 5 contains seven SWMUs, which are divided into the following two groups: (1) the Old Hydrofracture Facility and (2) SWSA 5 Area. The Old Hydrofracture Facility category of SWMUs includes the Site Surface Facilities, Facility Pond, Waste Pit/Spill Site, and the Waste Storage Tanks. The SWSA 5 Area category of SWMUs includes the SWSA 5 Burial Ground, Transuranic Waste Storage Area, and the Process Waste Sludge Basin. The outlying area of WAG 5 contains three SWMUs associated with the New Hydrofracture Facility: (1) the Site Surface Facilities, (2) Radioactively Contaminated Waste Oil Storage Tank, and (3) the LLW Tank Storage System.

\subsubsection{Old Hydrofracture Site Surface Facilities}

The Old Hydrofracture Surface Facilities operational history and physical characteristics are of limited interest because they have minimal potential for interaction with groundwater. The operating histories of the three remaining SWMUs at this site suggest the possibility for interaction with groundwater and are therefore described below.

\subsubsection{Old Hydrofracture Facility Pond}

The Old Hydrofracture Facility Pond is located in the southwestern corner of the main tract of WAG 5. The pond is about $30.5 \mathrm{~m} \mathrm{(100} \mathrm{ft)} \mathrm{in} \mathrm{length,} 6.1 \mathrm{~m}(20 \mathrm{ft})$ in width, and ranges from 0.9 to $1.8 \mathrm{~m}$ ( 3 to $6 \mathrm{ft}$ ) in depth. It was excavated into the residuum of the Conasauga Group and was originally designed with an asphalt liner, although the presence of the liner has not been confirmed. This impoundment is inactive but once served as an emergency containment basin for spilled grout and operational washdown from the old hydrofracture facility. The pond is exposed to the elements and continues to receive rainfall and some surface runoff. Based upon estimated differences between mean annual precipitation and mean annual evaporation, it is estimated that $\sim 132,475 \mathrm{~L} /$ year $(35,000 \mathrm{gal} /$ year) infiltrate into the subsurface from the pond. Samples from the pond indicated that it is primarily contaminated with ${ }^{137} \mathrm{Cs}$ and ${ }^{90} \mathrm{Sr}$, although it also contains ${ }^{60} \mathrm{Co},{ }^{134} \mathrm{Cs}$, and alpha-emitting transuranic wastes. Toxicity testing of the pond's bottom sediment indicated that it was below characteristic waste standards.

\subsubsection{Old Hydrofracture Facility Waste Pit/Spill Site}

Little information is available regarding the spill at the Old Hydrofracture Waste Pit. The spill reportedly was the result of a valve failure that occurred during the injection process in June of 1977 . The waste pit, which was designed for this type of situation, received $\sim 8705 \mathrm{~L}$ ( $2300 \mathrm{gal}$ ) of waste slurry. Later, the waste was removed from the pit and reintroduced into the injection line for disposal. 


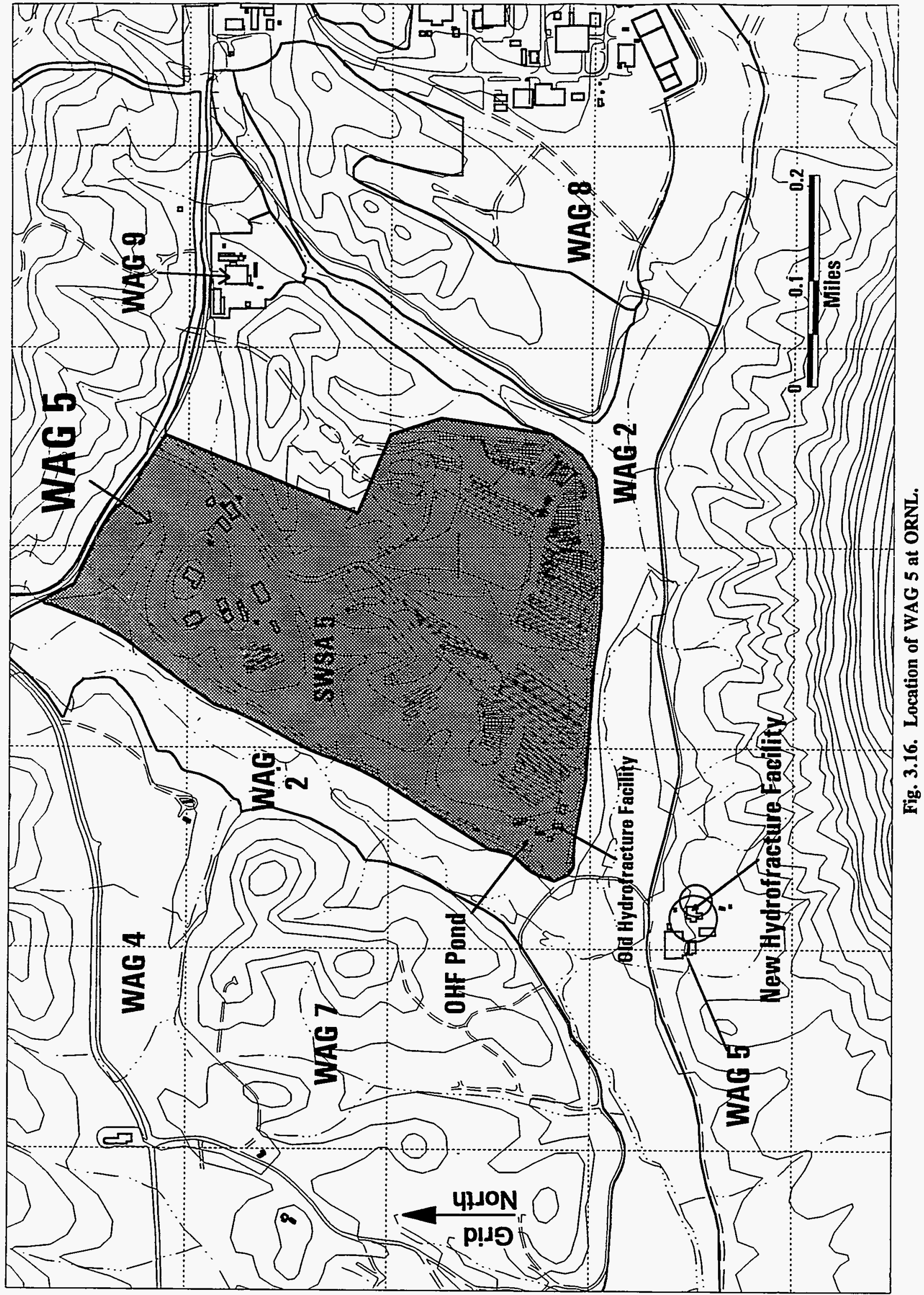




\subsubsection{Old Hydrofracture Facility Storage Tanks}

The Old Hydrofracture Storage Tanks were used as holding vessels prior to preparation of wastes for subsurface injection. There are five of these tanks, which have the following capacities: T-1 and T-2 [58,668 L (15,500 gal) each], T-3 and T-4 [109,765 L (29,000 gal) each], and T-9 [43,906 L (11,600 gal)]. The tanks are constructed of carbon steel and were placed on concrete pads in open trenches with concrete dividing walls separating the tanks. There is now a 1.2-m (4-ft) soil cover over all of the tanks. The contents of these tanks are believed to include ${ }^{137} \mathrm{Cs},{ }^{90} \mathrm{Sr},{ }^{60} \mathrm{Co}$, and transuranic type wastes.

\subsubsection{SWSA 5 Burial Ground}

The SWSA 5 Burial Ground began operation in 1958 and, like SWSA 4, was used for burial of various types of low-level radioactive wastes. In addition to low-level material disposal, the northern portion of SWSA 5 has been, and continues to be, used for retrievable storage of transuranic wastes. Low-level wastes were disposed of in trenches located in the southern portion of the site. Auger holes were also used for disposal of low-level waste in this portion of SWSA 5, but they also received higher activity wastes and fissile materials. The locations for many of the trenches and auger holes are known; however, due to a loss of records there is an area where trench orientations are unknown. The undefined area was reportedly used for disposal of alpha-contaminated materials. There is also a "dump area" for which no records exist.

Records for the remainder of the site indicate that the trench dimensions were $3.7 \mathrm{~m}(12 \mathrm{ft})$

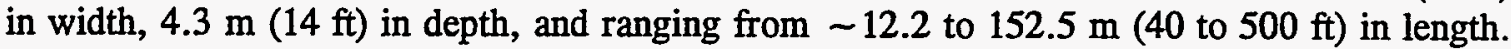
The trenches occur as relatively parallel sets numbering from $\sim 5$ to 25 trenches and were excavated roughly perpendicular to geologic strike with their long axis parallel to topographic slope. Several contaminated seeps have been documented at the base of the fill area, and it has been suggested that the orientation of the trenches promotes downgradient seepage. Remedial measures were taken to reduce seepage from SWSA 5 in 1975. Two underground barriers were constructed to impede shallow subsurface water flow. Four trenches were also stripped of their overburden and covered with a PVC membrane. The overburden was then replaced, and vegetation was established in an effort to reduce infiltration of meteoric water. The site was terraced, and several concrete diversion ditches were constructed to control surface runoff and reduce erosion.

\subsubsection{Transuranic Waste Storage Area}

Transuranic wastes are currently stored in the northern portion of SWSA 5. Low-level wastes are placed in stainless steel drums and then held temporarily in Building 7823 until they are transported for storage in Buildings 7826 and 7834. Hot cell wastes are placed in concrete casks and then stored in Building 7855. High beta-gamma activity waste is placed in stainless steel containers and held in storage wells in Buildings 7827 and 7829 . In the past, some hot cell wastes were sealed in concrete casks and buried in trenches in the northern part of SWSA 5 for potential retrieval. Additionally, certain transuranic wastes that were difficult to manage because of their bulk or physical character were buried in trenches on the hillside southwest of Building 7824 and west of Buildings 7820 and 7804. Certain preventive measures were initiated in the transuranic waste trench area in an effort to reduce surface water infiltration in 14 of the 
trenches. This work consisted of constructing a subsurface seal using a mixture of bentonite and shale.

\subsubsection{Process Waste Sludge Basin}

The Process Waste Sludge Basin consists of a basin $-24 \times 24 \mathrm{~m}(80 \times 80 \mathrm{ft})$ with a maximum depth of $\sim 2.4 \mathrm{~m}(8 \mathrm{ft})$. The basin was constructed with a compacted clay base and was lined with a PVC membrane. The basin is currently inactive; however, between 1976 and 1980 , it received sludge from the process waste treatment plant's water softening processes. The sludge constituents are primarily ferrous sulfate and ferrous hydroxide, but the basin also contains some fission products.

\subsubsection{New Hydrofracture Site Surface Facilities}

The New Hydrofracture Surface Facilities' operational history and physical characteristics are of limited interest because they have minimal potential for interaction with groundwater. The operating histories of the two remaining SWMUs at this site suggest the possibility for interaction with groundwater and, therefore, are described below.

\subsubsection{Radioactively Contaminated Waste Oil Storage Tank}

This storage tank was constructed of mild steel and installed below ground level near Building 7860 in 1981 or 1982 . Documentation of the tank's exact location is not available; however, a verbal communication indicated that the tank was installed beneath the southeastern slopes of the New Hydrofracture Facility behind Building 7860. The tank contains radioactive contaminated oils and water, which are estimated to occupy about one half of the tank's 17,032-L (4500-gal) capacity. No indication that leakage has occurred from the tank exists at this time.

\subsubsection{LLW Tank Storage System}

The LLW Tank Storage System is an eight-component tank system used for storage of concentrate from the LLW evaporator. The tanks are located at Building 7830 and are designated as follows: W-24, W-25, W-26, W-27, W-28, W-29, W-30, and W-31. No groundwater monitoring has been proposed because these tanks are double-contained.

\subsubsection{Characterization of Groundwater Contamination}

\subsubsection{Groundwater monitoring system}

The groundwater monitoring system at WAG 5 includes 93 monitoring wells installed between 1958 and 1977, 7 piezometers installed in 1986 or 1987, and 22 additional monitoring wells installed in 1987. The 93 older monitoring wells were installed as part of the pre-RAP, and many were constructed with perforated corrugated metal casing running the entire length of the borehole. However, 29 of these wells installed between 1976 and 1977 were constructed of plastic casing with discrete screened intervals. The piezometers were constructed of 5-cm (2-in.) ID PVC casing and screens. Sandpack was placed around the screens, and a bentonite seal was placed above the sandpack. The remaining annulus was grouted, and each piezometer was completed with a cap and protective cover. 
The 22 additional wells at WAG 5 were installed as part of a groundwater quality monitoring well installation program at ORNL. These wells were constructed of $5-\mathrm{cm}$ or $10-\mathrm{cm}$ (2-in. or 4-in.) ID stainless steel casing and screens. The remainder of the well construction was the same as described for the piezometers. Each well was completed with a steel protective casing, locking cap, steel guardposts, and a concrete pad. In addition to the monitoring system elements noted above, four monitoring wells constructed of fiberglass casing and screens are also located around the perimeter of the Old Hydrofracture Facility Pond. The locations of the monitoring wells or piezometers within WAG 5 for which groundwater quality data were evaluated for this summary are presented in Fig. 3.17, and a summary of the total depths for these installations is presented in Table 3.5.

\subsubsection{Contamination nature and extent}

Two principal source documents were used to develop an understanding of groundwater contamination at WAG 5. These documents were the Preliminary Geohydrologic Site Characterization and Proposed Water Quality Well Locations for WAGs 4, 5, and 3, and SWSA 1 (Energy Systems 1987a), and the Oak Ridge Reservation Environmental Report for 1991 (Energy Systems 1992b). The Preliminary Geohydrologic Site Characterization report summarized results from three previous studies regarding groundwater contamination at WAG 5 . The first study reported results for groundwater samples collected from the four monitoring wells located around the perimeter of the Old Hydrofracture Facility Pond. Analyses indicated that all four wells contained ${ }^{90} \mathrm{Sr},{ }^{137} \mathrm{Cs}$, and tritium contamination and that the concentration of tritium in the single upgradient well (MW-1) was higher than in the three downgradient wells. This occurrence suggests that the source of tritium is upgradient of the pond and that the pond may act as a recharge zone, thereby diluting the concentration of tritium downgradient.

The second study reported results from six monitoring wells $(1767,0159,0161,0436,0454$, and 0456) and one undesignated seep located around the southern boundaries of WAG 5. Analyses indicated that all six wells were contaminated with ${ }^{90} \mathrm{Sr}$ ranging from 8.2 to $520 \mathrm{~Bq} / \mathrm{L}$ and with ${ }^{137} \mathrm{Cs}$ ranging from 0.13 to $5.8 \mathrm{~Bq} / \mathrm{L}$. The undesignated seep was found to be contaminated with ${ }^{90} \mathrm{Sr}$ at an activity of $13,000 \mathrm{~Bq} / \mathrm{L}$. Two of the wells were also found to be contaminated with the following metals: 1767 (cadmium and lead) and 0454 (barium, lead, and selenium). The third study reported results for groundwater samples collected along the southern perimeter of SWSA 5 from temporary boreholes. Results of this study indicated seven distinct areas of ${ }^{90} \mathrm{Sr}$ contamination; however, the locations of these areas were not presented in the Preliminary Geohydrologic Site Characterization report.

The Oak Ridge Reservation Environmental Report for 1991 (Energy Systems 1992b) summarized results for groundwater samples collected during June and July of 1991 from the 22 groundwater quality wells at WAG 5. A majority of these wells located around the southeast, south, and southwest boundaries of the WAG were found to be contaminated with total strontium ranging from 0.34 to $19 \mathrm{~Bq} / \mathrm{L}$ and tritium ranging from 770 to $9,500,000 \mathrm{~Bq} / \mathrm{L}$. Four of the wells located along the perimeter of WAG $5(0969,0973,0975,0978$, and 0981) were found to be contaminated by one or more of the following volatile organics at concentrations ranging from 10 to $4700 \mu \mathrm{g} / \mathrm{L}$ : trichloroethene, benzene, and vinyl chloride. Subsequent sampling of the wells in September and October 1992 and April 1993 indicated the presence of similar activities and concentrations of the noted contaminants. However, total strontium was observed to be below the MCL in Well 0972 during the later sampling events and was detected above the MCL in 


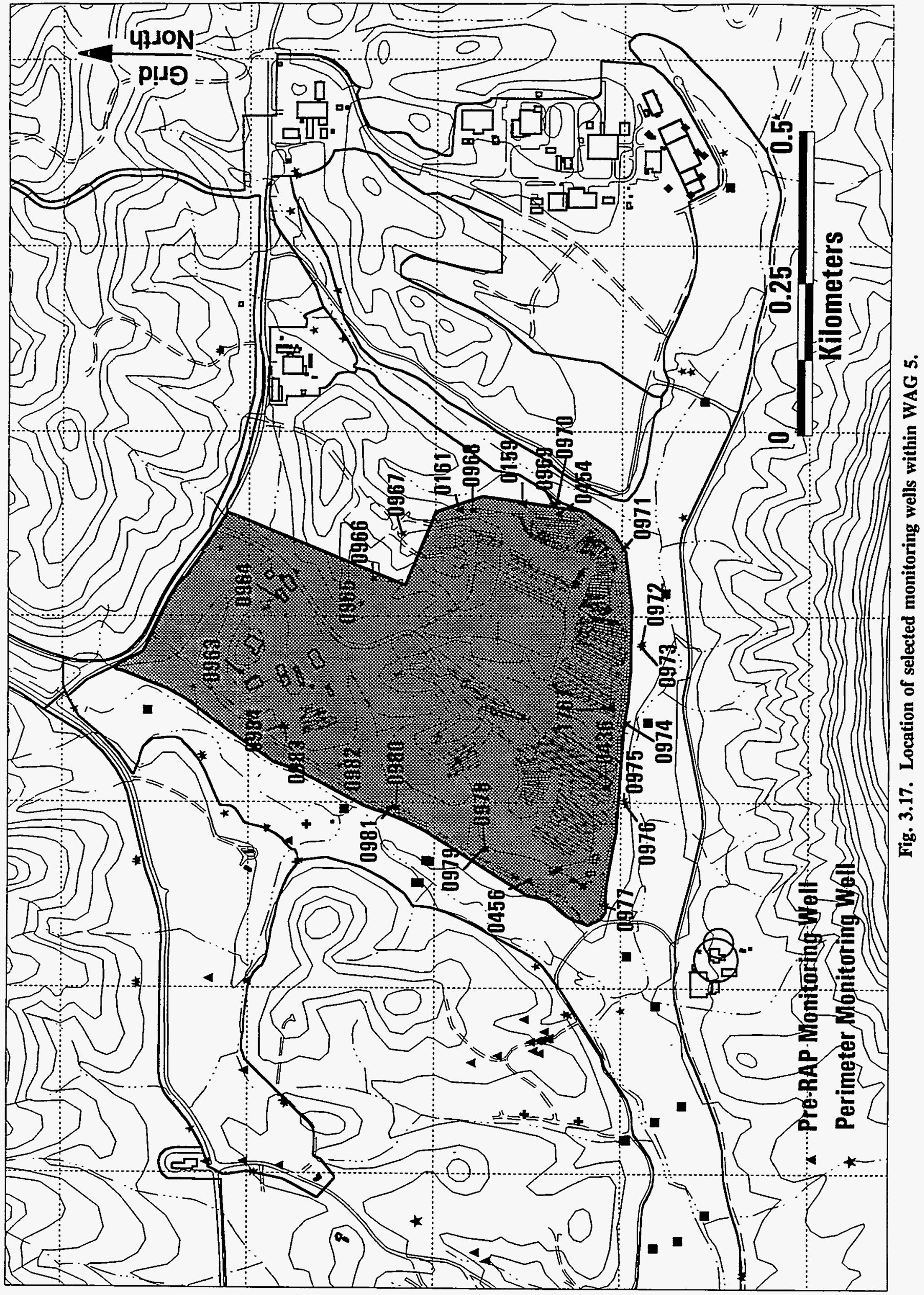


Table 3.5. Summary of WAG 5 groundwater monitoring system wells

\begin{tabular}{|c|c|}
\hline Well no. & Total depth (ft) \\
\hline \multicolumn{2}{|c|}{ Pre-RAP wells } \\
\hline MW-1 & No Data \\
\hline$M W-2$ & No Data \\
\hline$M W-3$ & No Data \\
\hline$M W-4$ & No Data \\
\hline $1767(T 64-1)^{a}$ & 15.00 \\
\hline 0159 & 6.00 \\
\hline 0161 & 8.00 \\
\hline 0436 & 31.00 \\
\hline 0454 & 22.00 \\
\hline 0456 & 11.00 \\
\hline \multicolumn{2}{|c|}{ Groundwater quality wells } \\
\hline 0963 & 95.00 \\
\hline 0964 & 49.20 \\
\hline 0965 & 28.50 \\
\hline 0966 & 24.40 \\
\hline 0967 & 60.00 \\
\hline 0968 & 20.40 \\
\hline 0969 & 15.60 \\
\hline 0970 & 75.00 \\
\hline 0971 & 14.90 \\
\hline 0972 & 75.00 \\
\hline 0973 & 15.50 \\
\hline 0974 & 22.30 \\
\hline 0975 & 28.30 \\
\hline 0976 & 84.20 \\
\hline 0977 & 19.80 \\
\hline 0978 & 20.00 \\
\hline 0979 & 49.60 \\
\hline 0980 & 50.00 \\
\hline
\end{tabular}


$3-48$

Table 3.5 (continued)

\begin{tabular}{cc}
\hline Well no. & Total depth $(\mathrm{ft})$ \\
\hline 0981 & 20.00 \\
0982 & 16.40 \\
0983 & 25.00 \\
0984 & 80.00 \\
\hline
\end{tabular}

"well alias in parenthesis 
Well 0977. Also, tritium and thallium were detected above MCLs in Wells 0968 and 0974, respectively, during the later sampling events.

Based on the data evaluated for WAG 5 , contaminated groundwater containing ${ }^{137} \mathrm{Cs},{ }^{90} \mathrm{Sr}$, and tritium (probably derived from wastes in SWSA 5) appears to have migrated beyond the southern boundaries of WAG 5 . In addition, metal and volatile organic contaminants in groundwater also appear to be migrating beyond the southern WAG boundaries. However, these contaminants do not appear to be as widespread within the local groundwater system as are the radioactive contaminants.

\subsection{WAG 6}

\subsubsection{Site Location, Description, and Background}

WAG 6 is located in Melton Valley and consists of $\sim 27.5$ ha (68 acres) (Fig. 3.18). The site is bounded to the south by White Oak Lake (WAG 2), to the east by an unnamed tributary of White Oak Creek (WAG 2), and to the west by State Highway 95. The topography of the site is gently to moderately sloping and drains to White Oak Lake on the south and to the unnamed tributary of White Oak Creek on the east. WAG 6 contains three SWMUs: SWSA 6, the Emergency Waste Basin, and the Explosives Detonation Trench.

\subsubsection{SWSA 6}

SWSA 6 was opened for limited disposal operations in 1969 and began full-scale operations in 1973. This site received both radioactive and chemical wastes from the ORNL plant site, including solvents, scintillation liquids, laboratory glassware and equipment, protective clothing, mechanical equipment, construction materials, asbestos, filter media and resins, animal remains, and contaminated earth. Currently, only LLW is disposed of at SWSA 6. Disposal of chemical wastes was halted at the site in 1986. Prior to 1986, packaging of wastes was highly variable, ranging from plastic bags and stainless steel drums to no containerization. Previous waste disposal at SWSA 6 occurred in more than 510 trenches and 490 auger holes.

Dimensions of trenches used at SWSA 6 were highly variable depending on the topography and trench type. In general, they were $15.3 \mathrm{~m}$ (50 ft) in length, $3 \mathrm{~m} \mathrm{(10} \mathrm{ft)} \mathrm{in} \mathrm{width,} \mathrm{and}$ ranging from 4 to $6 \mathrm{~m}$ (13 to $20 \mathrm{ft}$ ) in depth. The trenches are classified into the following categories based on the form of waste disposed: high activity (unlined), low activity (unlined), biological, asbestos, baled, fissile, high-activity concrete lined, and low-activity concrete lined. The inventory of radiological contamination within the SWSA 6 trenches is estimated to be $19,054 \mathrm{Ci}$.

Auger holes within SWSA 6 were generally located in the higher elevations of the site. Diameters of the holes ranged from 0.3 to $1.2 \mathrm{~m}$ ( 1 to $4 \mathrm{ft})$, with depths to $6.1 \mathrm{~m}(20 \mathrm{ft})$. The auger holes are classified into the following categories based on the form of waste disposed: high-activity, fissile, and solvent. Fissile auger holes received wastes containing ${ }^{235} U$, which was possibly mixed with other radionuclides including ${ }^{137} \mathrm{Cs},{ }^{238} \mathrm{U}$, and ${ }^{90} \mathrm{Sr}$. Solvent auger holes were used for disposal of a variety of chemical wastes, some of which were radioactively contaminated. These wastes included oils, cleaning solutions, alcohols, paint thinners, kerosene, 


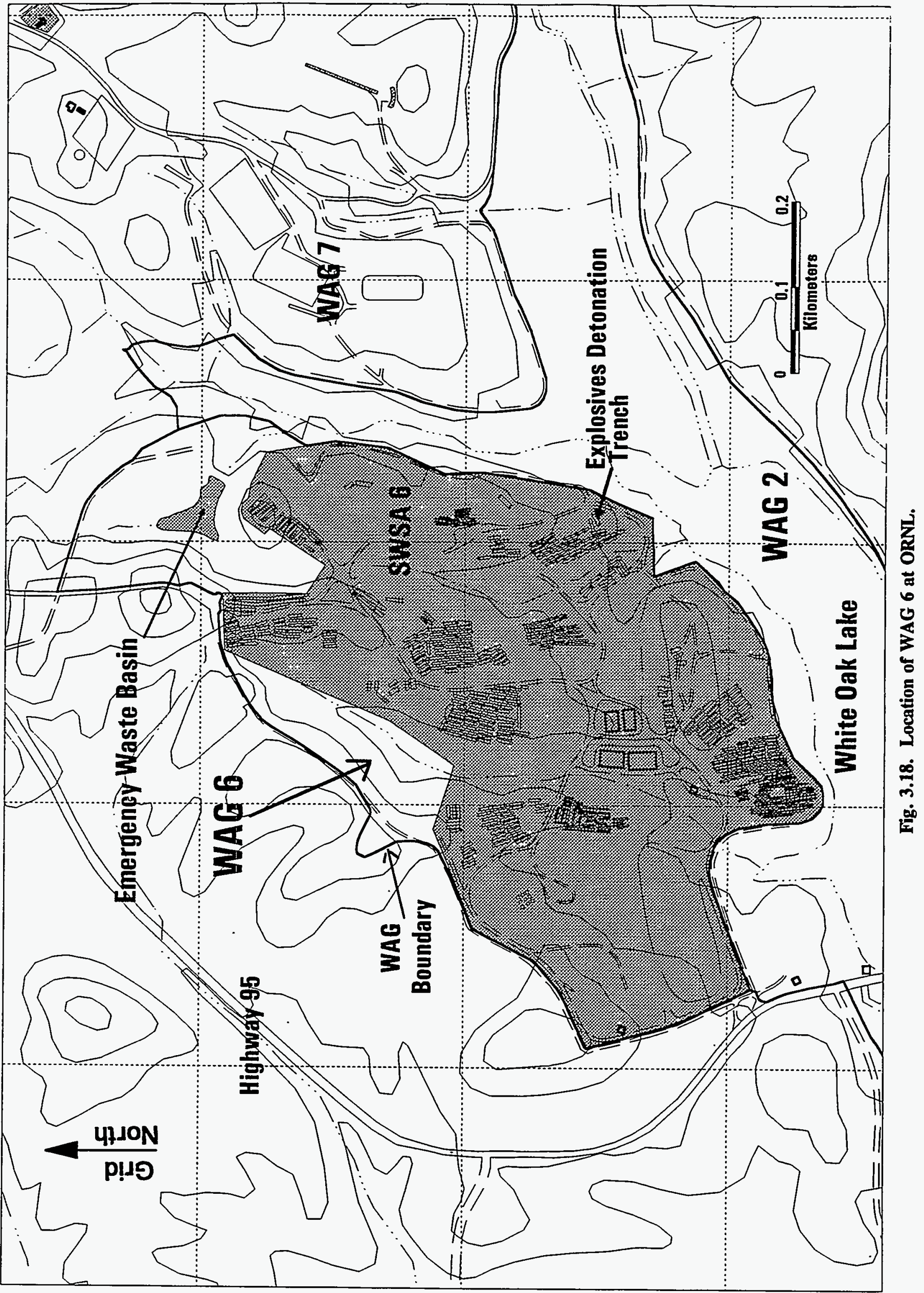


jet fuel, acids, and sodium. The inventory of radiological contamination within the SWSA 6 auger holes is estimated to be $208,660 \mathrm{Ci}$.

The demolition landfill, used for disposal of suspected low-hazard waste, is also located within SWSA 6. This landfill occupies $\sim 2$ ha (5 acres) and is located in the northeastern portion of SWSA 6. Waste is shredded to reduce volume, placed into the landfill, and finally covered with soil. As noted previously, LLW is currently disposed of at SWSA 6. This waste is placed into Greater Confinement Disposal silos, which are cylindrical concrete silos constructed of 15-cm (6-in.)-thick concrete walls with 20-cm (8-in.)-thick steel-reinforced concrete top and bottom caps. A majority of the silos are equipped with PVC monitoring wells on the inner wall of the silo for detection and sampling of waste leachate. The silos are buried below grade in a vertical orientation. The Greater Confinement Disposal silos are located in three groups: two groups of low-activity silos, and one group of high-activity silos. Approximately 100 silos currently are located within SWSA 6.

\subsubsection{Emergency Waste Basin}

The Emergency Waste Basin was constructed between 1961 and 1962 to serve as an emergency holding basin for LLW or process wastes. It was to be used if ORNL was unable to release wastes to White Oak Creek. The basin, which encompasses -0.8 ha ( 2 acres) and has a potential storage volume of 56.8 million L ( 15 million gal), was reportedly never used.

\subsubsection{Explosives Detonation Trench}

The Explosives Detonation Trench is no longer used and has been backfilled. It was located in the southeastern portion of SWSA 6 . The trench measured $\sim 4.6 \mathrm{~m}(15 \mathrm{ft})$ in length, $1.5 \mathrm{~m}$

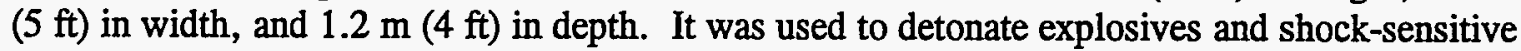
chemicals such as picric acid, phosphorus, and ammonium nitrate. During operations, wastes were placed in the bottom of the trench and detonated with small plastic charges. Debris from the explosions generally remained in the trench.

\subsubsection{Characterization of Groundwater Contamination}

Two principal source documents were used to develop an understanding of groundwater contamination within WAG 6 . These documents were the ORNL WAG 6 Site Characterization Summary (Energy Systems 1990), and the Oak Ridge Reservation Environmental Report for 1991 (Energy Systems 1992b). The Site Characterization Summary document detailed interpretations regarding the nature and extent of groundwater contamination at WAG 6 based on Phase 1 Activity 1 RFI activities, which included a well evaluation, surface water investigation, review of ORNL groundwater data quality, monitoring of well installations, and a groundwater investigation.

Based on the results of these investigations, the primary radiological groundwater contaminants detected at WAG 6 were tritium and ${ }^{90} \mathrm{Sr}$. Other radionuclides found to be present in groundwater at the site included ${ }^{60} \mathrm{Co},{ }^{137} \mathrm{Cs},{ }^{40} \mathrm{~K}$, and several transuranics $\left({ }^{238} \mathrm{Pu},{ }^{239} \mathrm{Pu},{ }^{240} \mathrm{Pu}\right.$, and ${ }^{241} \mathrm{Am}$ ). Activities of tritium and ${ }^{90} \mathrm{Sr}$ were found to range from 0.03 to $159,988 \mathrm{~Bq} / \mathrm{L}$ and from 0.001 to $111 \mathrm{~Bq} / \mathrm{L}$, respectively. Several areas in WAG 6 appear to be sources of the detected radiological contamination: (1) the 17-Trench area (tritium); (2) East Waste Disposal 
Area: Northwest auger hole area (tritium); (3) Central Waste Disposal Area: high-activity trenches, 49-Trench area, and low-activity trenches northeast of 49-Trench area (tritium and ${ }^{90} \mathrm{Sr}$ ); (4) West Waste Disposal Area: low-activity trenches (tritium and ${ }^{90} \mathrm{Sr}$ ) and biological trenches (tritium); and (5) the South Waste Disposal Area (tritium).

The primary organic chemical groundwater contaminants detected at WAG 6 were trichloroethene and its degradation products, fuel-related volatiles (benzene, ethylbenzene, toluene, and xylene), and bis(2-ethylhexyl) phthalate. Concentrations of these compounds were found to range from nondetectable to $6800 \mu \mathrm{g} / \mathrm{L}$. Several areas in WAG 6 appear to be sources of the detected organic chemical contamination: (1) 17-Trench area; (2) East Waste Disposal Area: Northwest auger hole area; (3) Central Waste Disposal Area: high-activity trenches, solvent auger hole area between low-activity and high-activity silo areas, solvent auger hole area on east side area, 49-Trench area, low activity trenches northeast of 49-Trench area, and the biological trench area; and (4) the West Waste Disposal Area, biological trench area.

The Oak Ridge Reservation Environmental Report for 1991 (Energy Systems 1992b) summarized results for groundwater samples collected during February, September, and December of 1991 from 26 perimeter groundwater quality wells at WAG 6 (Fig. 3.19 and Table 3.6). The 10 monitoring wells of major concern are located on the northeast perimeter of WAG 6 , or east of SWSA 6 within WAG 2. Volatile organic compound contamination is apparently isolated in the area around Wells 0842 and 0841 . Trichloroethene was detected in both wells at concentrations up to $330 \mu \mathrm{g} / \mathrm{L}$. Well 0842 was also found to contain 1,2-dichloroethene and carbon tetrachloride ranging from 11 to $19 \mu \mathrm{g} / \mathrm{L}$ and from 40 to $65 \mu \mathrm{g} / \mathrm{L}$, respectively. Elevated levels of tritium were found along the eastern and southern boundaries of WAG 6 ranging up to $4440 \mathrm{~Bq} / \mathrm{L}$ at Well 0842 within SWSA 6, and up to $77,700 \mathrm{~Bq} / \mathrm{L}$ at Well 1243 east of SWSA 6. Total strontium and ${ }^{60} \mathrm{Co}$ were also detected in the wells of concern. Total strontium was detected up to $1.9 \mathrm{~Bq} / \mathrm{L}$ at Well 0841 and ${ }^{60} \mathrm{Co}$ up to $35.8 \mathrm{~Bq} / \mathrm{L}$ at Well 1243.

\subsection{WAG 7}

\subsubsection{Site Location, Description, and Background}

WAG 7 is located in Melton Valley and consists of $\sim 47$ ha (116 acres), which are predominantly woodiand (Fig. 3.20). The site is irregulariy shaped and is bounded to the south, southwest, and southeast by White Oak Lake and the floodplain of White Oak Creek (WAG 2). To the east the site is bordered by uplands that drain toward White Oak Creek, and to the northeast by SWSA 4, which adjoins the site. Lagoon Road parallels the northern limit of the site which lies on the footslope of Haw Ridge. On its western flank the site is adjoined by WAG 2 and the head of a north-south draw which drains toward White Oak Lake.

WAG 7 contains 14 SWMUs, which are divided into the following three groups: (1) Pits and Trenches, (2) ILLW Lines and Leak Sites, and (3) Other Inactive Facilities. The Pits and Trenches category of SWMUs includes Pits 1, 2, 3, and 4 and Trenches 5, 6, and 7. The ILLW Lines and Leak Sites category of SWMUs includes the ILLW Line Leak Site, Leak Site southeast of Trench 6, and the Access Road Leak Site at the end of Trench 7. The Other Inactive Facilities category of SWMUs includes the Building 7819 Decontamination Facility, Homogeneous Reactor 


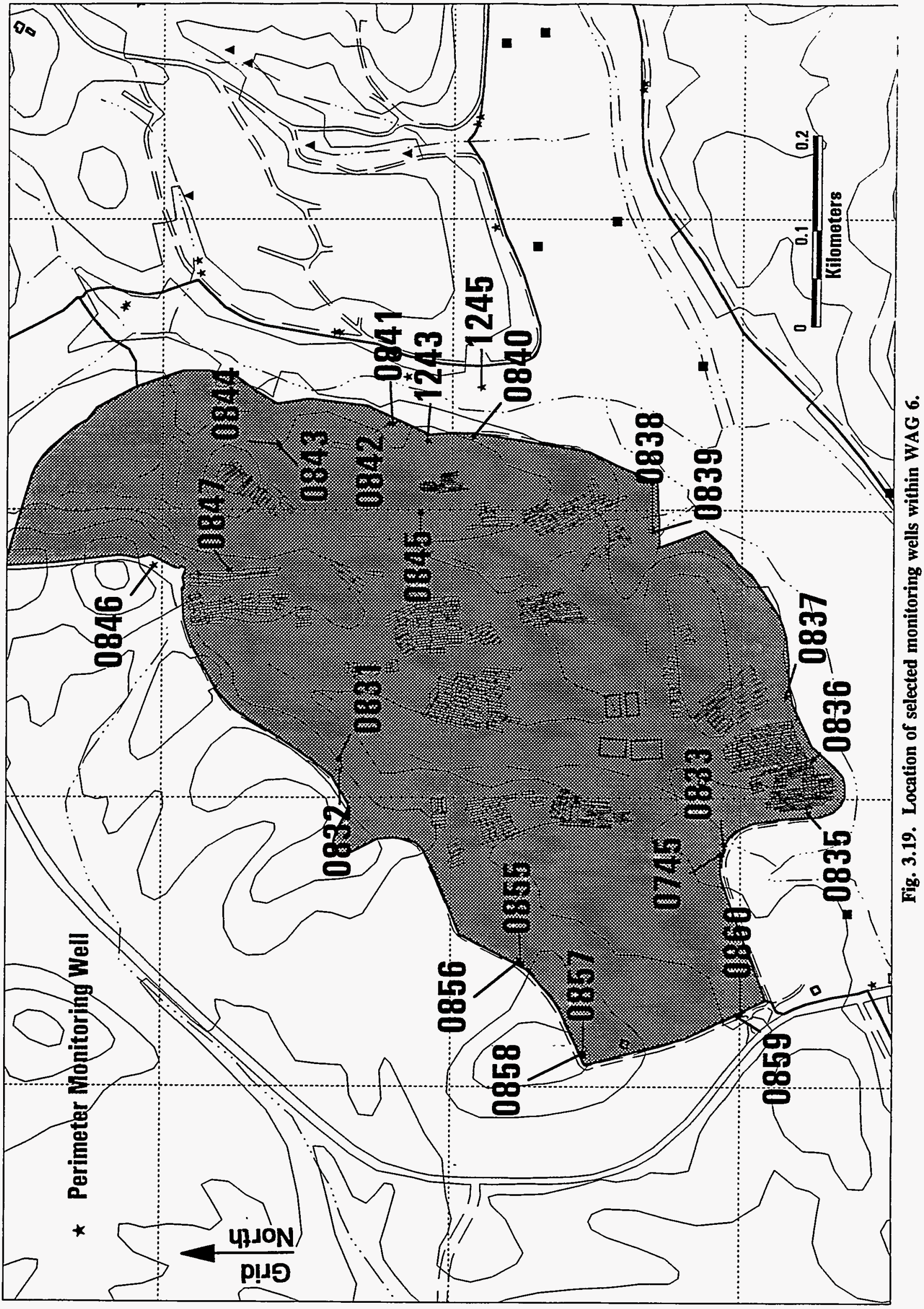


3-54

Table 3.6. Summary of WAG 6 groundwater monitoring system wells

\begin{tabular}{|c|c|}
\hline Well no. & Total depth (ft) \\
\hline \multicolumn{2}{|c|}{ Groundwater quality wells } \\
\hline 0745 & 60.20 \\
\hline 0831 & 50.70 \\
\hline 0832 & 85.90 \\
\hline 0833 & 31.00 \\
\hline 0835 & 27.50 \\
\hline 0836 & 28.50 \\
\hline 0837 & 31.60 \\
\hline 0838 & 22.80 \\
\hline 0839 & 56.00 \\
\hline 0840 & 26.90 \\
\hline 0841 & 56.50 \\
\hline 0842 & 26.80 \\
\hline 0843 & 21.00 \\
\hline 0844 & 52.00 \\
\hline 0845 & 41.00 \\
\hline 0846 & 81.00 \\
\hline 0847 & 67.00 \\
\hline 0855 & 52.00 \\
\hline 0856 & 82.00 \\
\hline 0857 & 70.00 \\
\hline 0858 & 106.40 \\
\hline 0859 & 26.50 \\
\hline 0860 & 61.80 \\
\hline 1243 & 27.91 \\
\hline 1244 & 24.99 \\
\hline 1245 & 58.06 \\
\hline
\end{tabular}




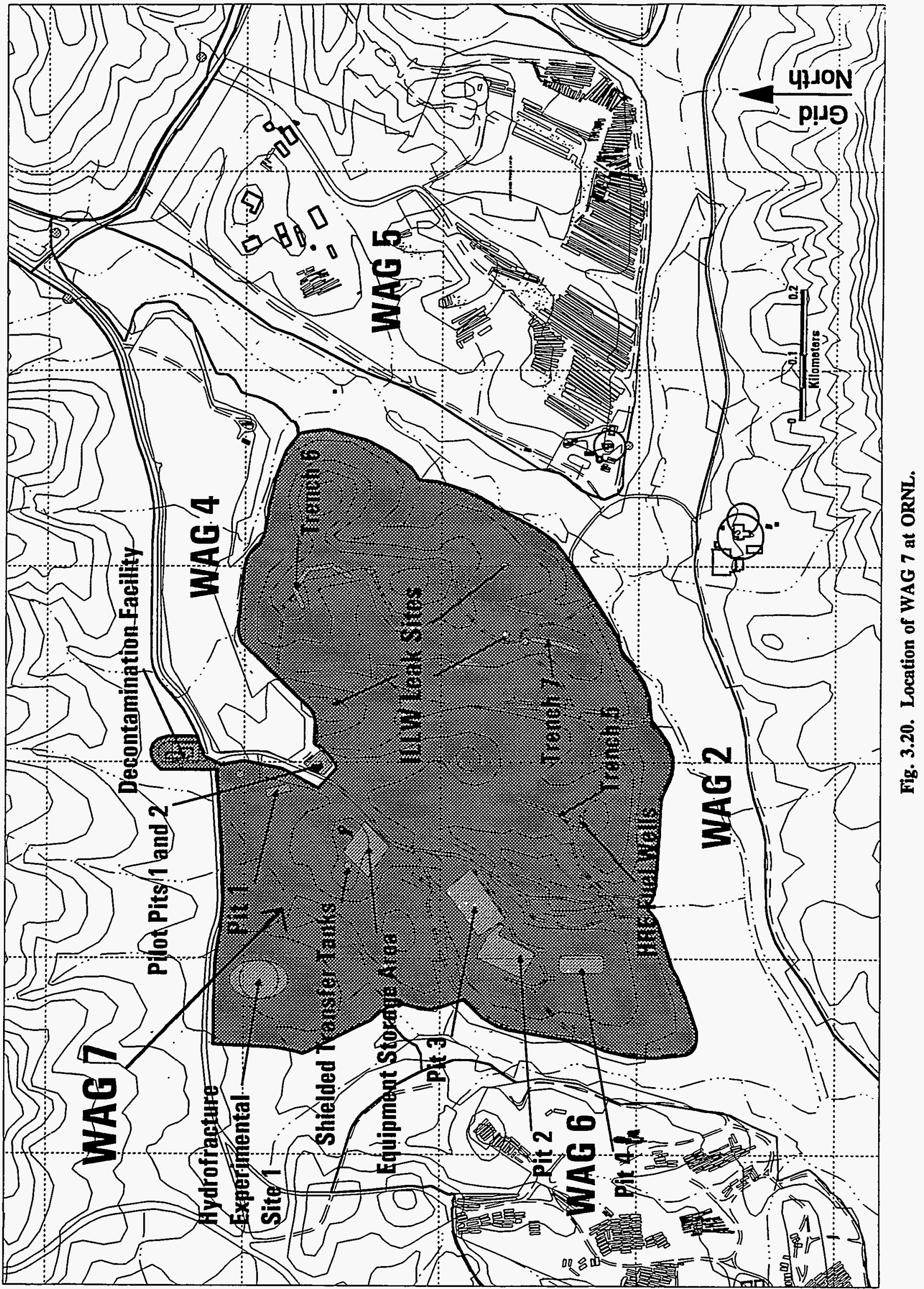


Experiment Fuel Wells, soil contamination at the Hydrofracture Experimental Site 1, and the Shielded Transfer Tanks.

During the period from 1951 through 1966, ORNL disposed of ILLW by means of shallow seepage pits and trenches. The liquid wastes were generated as part of routine plant operations and were stored and treated with a caustic precipitant in gunite tanks located in the main plant area. These wastes initially were hauled from the gunite tanks to the pits in a tank truck but later were piped to the pits and trenches after construction of the ILLW lines in 1954. The pits were open-topped earthen impoundments; the trenches were long, narrow trackhoe excavations that were backfilled with crushed stone and covered with an earthen cap.

The liquid waste system at ORNL was formerly called the ILLW system but is now referred to as the LLW system because the waste stream has been reclassified. However, the pipe network and leak sites related to WAG 7 were active or occurred prior to the reclassification; thus, the waste stream is referred to herein as ILLW. The ILLW system's components include: collection tanks in the main plant area and in Melton Valley, an evaporator in the main plant area, and a piping network used to transfer waste within the main plant area and to the disposal sites in Melton Valley. The first section of the ILLW line was constructed in June of 1954. The line was fabricated of 5-cm (2-in.) cast iron pipe and ran underground from the main plant area through the gap in Haw Ridge to its discharge point at Pit 2 in Melton Valley. The line was extended to Trench 5 in 1960, with additional extensions to Trenches 6 and 7 in 1961 and 1962, respectively. In 1966, the first hydrofracture facility became operational, and the ILLW line was extended southeastward from Trench 7 to this facility. This extension was also constructed of cast iron but was replaced with stainless steel in 1971.

\subsubsection{Pit 1}

Pit 1 was constructed just west of SWSA 4 and south of Lagoon Road in July of 1951 . The pit was $\sim 30.5 \mathrm{~m}(100 \mathrm{ft})$ long by $6.1 \mathrm{~m}(20 \mathrm{ft})$ wide by $4.6 \mathrm{~m}(15 \mathrm{ft})$ deep and had a capacity of $681,300 \mathrm{~L}(180,000 \mathrm{gal})$. About $465,555 \mathrm{~L}(123,000 \mathrm{gal})$ of liquid waste were placed in the pit during its period of operation. The waste reportedly had a $\mathrm{pH}$ of about 12.5 and was principally contaminated with ${ }^{137} \mathrm{Cs}$ and ${ }^{106} \mathrm{Ru}$, although operating records indicate that $196 \mathrm{~kg}$ of uranium and $266 \mathrm{mg}$ of plutonium were also disposed of in Pit 1. In October 1951, the pit was closed to ILLW disposal after a ruthenium-contaminated seep was discovered. However, Pit 1 received additional waste in the form of drain discharge from Decontamination Building 7819 , which began in 1962 and continued until at least 1964 but may have continued until as recently as 1981 . The nature and duration of discharges from the decontamination building are not clearly documented, but the total amount of activity from this source is thought to have been low. Pit 1 was filled with shale and covered with a sloping asphalt cap in 1981.

\subsubsection{Pit 2}

Pit 2 is located on a hill $\sim 427 \mathrm{~m}$ (1400 ft) south of Pit 1 and was constructed in 1952 . The pit was $\sim 61 \mathrm{~m}(200 \mathrm{ft})$ long by $30.5 \mathrm{~m}(100 \mathrm{ft})$ wide by $4.6 \mathrm{~m}(15 \mathrm{ft})$ deep, had sloping sides

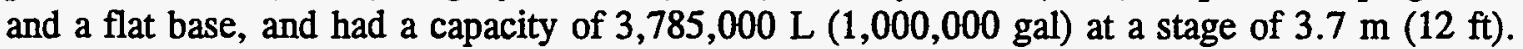
The pit received ILLW via tank trucks until completion of the ILLW pipeline; however, tank trucks continued to transport inactive chemical wastes composed primarily of aluminum and ammonium nitrates to Pit 2 for disposal. The amount of active waste disposed of in Pit 2 is 
difficult to assess because overflow from Pit 2 was routed to Pits 3 and 4 . Therefore, the relative distribution of ILLW among these three pits is not known, but the total quantity for all three is estimated at $79,485,000 \mathrm{~L}(21,000,000 \mathrm{gal})$.

The principal waste constituents disposed of in the three pits were ${ }^{137} \mathrm{Cs},{ }^{100} \mathrm{Ru}$, ${ }^{90} \mathrm{Sr}$, and the trivalent rare earths. During the years 1959 and 1961 , considerable amounts of ${ }^{106} \mathrm{Ru}$ were discharged to the pits and a seep contaminated with ${ }^{106} \mathrm{Ru}$ was discovered on the west side of Pit 2. A trench was excavated at this location to intercept and collect the seep discharge, which was then pumped back into Pit 2. Sodium sulfide was added to Pit 2 in an effort to reduce the flux of ${ }^{106} \mathrm{Ru}$, but this was ineffective, and subsequently the leveis of ruthenium discharged to the pit were decreased. Pit 2 was closed by backfilling with soil as it continued to drain over a period from 1962 to 1963 . Final grading was completed in late 1963, and a sloping asphalt cap was placed over the pit in 1970 .

\subsubsection{Pit 3}

Pit 3 is located on the same hill as Pit 2 and is immediately northeast and upslope of Pit 2. This pit was constructed in January of 1955 and had the same dimensions and holding capacity as Pit 2. Pit 3 became the initial discharge point for the ILLW pipeline and was designed to overflow through a pipe into Pit 2 . The principal radionuclides disposed of in Pit 3 were ${ }^{137} \mathrm{Cs}$, ${ }^{106} \mathrm{Ru}$, and the trivalent rare earths, as well as sodium and nitrate from the treatment process in the main plant gunite tanks. Other radionuclides disposed of in lesser amounts in Pit 3 included ${ }^{89} \mathrm{Sr},{ }^{90} \mathrm{Sr},{ }^{60} \mathrm{Co}$, and ${ }^{125} \mathrm{Sb}$. Seepage from Pit 3 was observed on its eastern side, but the flow was relatively small compared to that at Pit 2 ; therefore, no corrective measures were taken. Pit 3 was closed in September of 1961 in the same general manner as Pit 2.

\subsubsection{Pit 4}

Pit 4 is located immediately south and downslope of Pit 3. This pit had the same dimensions and holding capacity as Pits 2 and 3 and went into operation in April 1956, when it began to receive ILLW overflow piped in from Pit 2. Pit 4 proved to be more permeable than its predecessors, and an increase in ruthenium discharges to the pits in 1959 apparently resulted in a contaminated seep on the eastern side of the pit. An interception/collection trench measuring $3 \mathrm{~m}(10 \mathrm{ft})$ deep and $53 \mathrm{~m}$ (175 ft) long was excavated along the eastern side of Pit 4 and used to pump accumulated liquid back into the pit. Copper compounds were also placed into the pit in the hope of immobilizing the ruthenium. Ultimately, discharges to the pits were discontinued, but it took some time for the seepage to abate. During this period, another interception/collection trench was excavated on the west side of Pit 4, and 10 tons of sodium sulfide were added to the pits to reduce ruthenium mobility. Beginning in 1976, Pit 4 was gradually backfilled and was capped with asphalt in 1980.

\subsubsection{Trench 5}

Trench 5 is located on a hill $-223 \mathrm{~m}$ (730 ft) east of Pit 4 and was constructed in May of 1960. The design of this trench was markedly different from that of the WAG 7 pits in that it was intended to minimize worker exposure and reduce the amount of meteoric water collected. The design also called for the trench to be oriented perpendicular to geologic strike which would enhance its seepage capacity since most of the seepage was believed to occur along strike via 


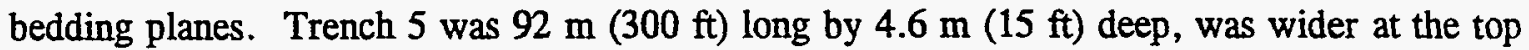
than at the base, and was calculated to have a seepage rate of $\sim 15,140 \mathrm{~L} / \mathrm{d}(4000 \mathrm{gal} / \mathrm{d})$. Prior to operation, the trench was treated with $\sim 817 \mathrm{~kg}(1800 \mathrm{lb})$ of copper sulfate and $\sim 454 \mathrm{~kg}$ $(1000 \mathrm{lb})$ of sodium sulfide to reduce the mobility of ruthenium. Trench 5 operated near its seepage capacity for a period of $\sim 6$ years and ultimately received $\sim 36,000,000 \mathrm{~L}$ $\left(9,500,000\right.$ gal) of waste contaminated with ${ }^{89} \mathrm{Sr},{ }^{90} \mathrm{Sr},{ }^{137} \mathrm{Cs}$, ${ }^{106} \mathrm{Ru}$, and ${ }^{80} \mathrm{Co}$. The trench stopped receiving ILLW in 1966 and was asphalt-capped in 1970.

\subsubsection{Trench 6}

Trench 6 is located $\sim 458 \mathrm{~m}(1500 \mathrm{ft})$ north of Trench 5 on a hillcrest above a draw and was constructed in 1961. Contrary to the intended design criteria for the WAG 7 trenches, Trench 6 was excavated in a U-shaped configuration and thus portions of it were probably normal to geologic strike while other portions were perpendicular to strike. This trench was also treated with copper sulfate prior to operation to reduce ruthenium mobility. However, $\sim 1$ month after becoming operational, Trench 6 was removed from service because of seepage outbreaks contaminated with ${ }^{90} \mathrm{Sr}$ and ${ }^{137} \mathrm{Cs}$. Only $\sim 492,050 \mathrm{~L}$ (130,000 gal) of ILLW discharge contaminated with ${ }^{90} \mathrm{Sr},{ }^{137} \mathrm{Cs},{ }^{106} \mathrm{Ru}$, and ${ }^{60} \mathrm{Co}$ were disposed of in the trench. In 1981, Trench 6 was capped with asphalt.

\subsubsection{Trench 7}

Trench 7 is located $\sim 244 \mathrm{~m}(800 \mathrm{ft}$ ) east of Trench 5 and was completed in August of 1962. This trench was designed with three separate segments, only two of which were built because shallow groundwater was discovered beneath the site of the proposed third segment. Trench 7 was oriented perpendicular to geologic strike and consisted of two segments $30.5 \mathrm{~m}(100 \mathrm{ft})$ long and $\sim 4.6 \mathrm{~m}$ (15 ft) deep. Prior to operation, the trench was treated with $189,250 \mathrm{~L}(50,000 \mathrm{gal})$ of $4 \%$ sodium hydroxide. This trench operated until 1966 during which time it received $\sim 36,000,000 \mathrm{~L}(9,500,000 \mathrm{gal})$ of ILLW discharge contaminated with ${ }^{90} \mathrm{Sr},{ }^{137} \mathrm{Cs},{ }^{106} \mathrm{Ru}$, and ${ }^{60} \mathrm{Co}$. Only one documented seep containing relatively low levels of ruthenium occurred on the eastern side of the trench, and no remedial measures were taken. In 1970, Trench 7 was capped with asphalt, which was expanded in 1985 to enhance runoff and decrease surface water infiltration. In 1985 and 1986, a grout curtain was installed at varying depths on the northern and eastern sides of the trench; the grout curtain was not intended to completely seal off lateral groundwater movement, but rather was designed to plug preferred migration routes.

\subsubsection{ILLW Line Leak Site}

This leak site resulted from waste seepage from a coupling in the ILLW line. The waste was reported to have spread laterally over a small area, but a radiometric survey of the area indicated the presence of contaminated sediment extending all the way to White Oak Creek. The principal contaminants associated with the leak were ${ }^{90} \mathrm{Sr},{ }^{137} \mathrm{Cs}$, and ${ }^{244} \mathrm{Cm}$, with minor activity attributed to ${ }^{241} \mathrm{Am},{ }^{238} \mathrm{Pu}$, and ${ }^{239} \mathrm{Pu}$. Monitoring wells installed at the leak site indicated contamination; thus, $278 \mathrm{~m}^{3}\left(364 \mathrm{yd}^{3}\right)$ of contaminated soil were removed. Subsequent groundwater monitoring showed significant decreases in radiologic activity, but a surface survey indicated the persistence of contamination, leaving some question about the effectiveness of the remediation and the integrity of the ILLW line. 


\subsubsection{Leak Site southeast of Trench 6}

This leak site is located $\sim(150 \mathrm{ft})$ south of Trench 6 , and contamination was documented by two radiometric surveys of the ILLW line. The surveys indicated that contamination has spread downslope of the site to the southwest and was present over several feet of soil. The principal contaminants identified were ${ }^{137} \mathrm{Cs},{ }^{90} \mathrm{Sr},{ }^{244} \mathrm{Cm},{ }^{241} \mathrm{Am},{ }^{238} \mathrm{Pu}$, and ${ }^{239} \mathrm{Pu}$, and soil samples indicated beta-gamma activity ranging from 0.01 to $50 \mu \mathrm{Ci} / \mathrm{g}$ and alpha activity of about $1.0 \mu \mathrm{Ci} / \mathrm{g}$. The leak site was cleared of vegetation, and both contaminated soil $\left[\sim 76.5 \mathrm{~m}^{3}\right.$ $\left.\left(100 \mathrm{yd}^{3}\right)\right]$ and the ILLW were removed. Clean fill mixed with bentonite was placed over the spill area and graded. Finally, $15 \mathrm{~cm}$ ( $6 \mathrm{in}$.) of crushed stone were applied to the area, and it was capped with asphalt.

\subsubsection{Access Road Leak Site at the end of Trench 7}

No detailed information is available for this leak site which involved the rupture of a plastic pipeline releasing about $11,355 \mathrm{~L}$ ( $3000 \mathrm{gal})$ of ILLW. The incident was documented in a waste disposal operations report and occurred just north of Trench 7. The principal contaminants released were cesium, cerium, and strontium. Remediation of this leak site consisted of applying $1.5 \mathrm{~m}(5 \mathrm{ft})$ of graded clay cover.

\subsubsection{Building 7819 Decontamination Facility}

This facility is located on the north side of Lagoon Road near the western corner of SWSA 4. It was used for unshielded decontamination operations, which included acid baths, sandblasting, and other unspecified procedures. The residual contamination on the site includes portions of the building, equipment within the building, and blasting sand located $\sim 30.5 \mathrm{~m}$ $(100 \mathrm{ft})$ north of the building. The blasting sand located outside the building has a maximum exposure rate of $2.0 \mathrm{mR} / \mathrm{h}$.

\subsubsection{Homogeneous Reactor Experiment Fuel Wells}

There are reportedly seven Homogeneous Reactor Experiment (HRE) fuel wells (identified as S-1 through S-7) located just south of Trench 5, although field reconnaissance of the area in April of 1987 could only confirm the location of four of these wells. The wells were used to dispose of the HRE liquid fuel; they were actually auger holes $30.5 \mathrm{~cm}$ (12 in.) in diameter and were reported to be $5.2 \mathrm{~m}(17 \mathrm{ft})$ deep and $-3 \mathrm{~m}(10 \mathrm{ft})$ apart. The liquid fuel consisted of uranium in solution with $4.0 \mathrm{M}$ sulfuric acid. Some fission products were also associated with the waste, predominantly strontium and ruthenium. Laboratory correspondence documented the disposal of $367 \mathrm{~L}$ ( $97 \mathrm{gal}$ ) of fuel solution distributed between Wells S-3 through S-7 during the period from March to April of 1964. Disposal of the solution was accomplished through a plastic transfer line, which was run to the bottom of the auger holes. Afterwards, the plastic line was lowered into the hole, and the well was backfilled with earth.

\subsubsection{Soil contamination at the Hydrofracture Experimental Site 1}

The Hydrofracture Experimental Site 1 is located near the northwestern corner of WAG 7, just southwest of Lagoon Road. In October of 1959, the first hydrofracture experiment was conducted to determine the orientation of hydraulically initiated fractures. The experiment was 


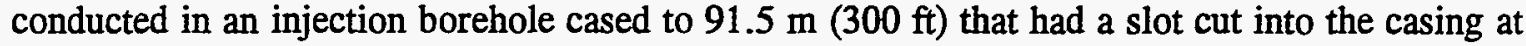
$88.5 \mathrm{~m}$ (290 ft). A fracture was created in a subsurface shale bed and $102,195 \mathrm{~L}(27,000 \mathrm{gal})$ of water, cement, diatomaceous earth, and a fluid loss additive were pumped into the fracture. The grout mixture was tagged with $35 \mathrm{Ci}$ of ${ }^{137} \mathrm{Cs}$ and $8.7 \mathrm{Ci}$ of ${ }^{144} \mathrm{Ce}$. The grout sheet created during the experiment extends $\sim 122 \mathrm{~m}(400 \mathrm{ft})$ north-northeast from the injection well location.

After the grout was pumped into the shale, the injection well was flushed with water. Toward the end of the flushing operation, grout was observed flowing out of a 7.6-cm (3-in.) diameter corehole located $60 \mathrm{~m}$ (199 ft) north of the injection well. Pumping was stopped, but grout continued to flow for a period of several hours, followed by clear water, which continued to flow from the corehole for $\sim 2$ months. The grout and adjoining soil were excavated after the grout had cured and were disposed of in SWSA 5.

\subsubsection{Shielded Transfer Tanks}

There are five heavily shielded transfer tanks (designated ST1 through ST5) located above ground in a storage area $\sim 153 \mathrm{~m}(500 \mathrm{ft})$ north of Pit 3 . These tanks were originally used in the late 1950s to transfer low concentrations of aqueous cesium and strontium waste from Arco, Idaho, to ORNL. During the 1960 s, the tanks were used for the transfer of cesium-loaded ion exchange resins from Hanford, Washington, to ORNL. In 1967, all but one of the tanks were taken out of service. The single active tank was used at ORNL in 1970 and 1971 for the transfer of a caustic solution contaminated with high-level fission product waste. All of the tanks are now inactive but contain residual contamination, principally ${ }^{137} \mathrm{Cs}$. At present, none of the tanks is known to be leaking.

\subsubsection{Characterization of Groundwater Contamination}

\subsubsection{Groundwater monitoring system}

The groundwater monitoring system within WAG 7 includes 63 monitoring wells installed prior to 1980,8 piezometers installed in 1986 or 1987 , and 16 additional monitoring wells installed between 1989 and 1990. The 63 older monitoring wells installed as part of the pre-RAP were constructed as open boreholes or were stabilized with perforated steel casing running the entire length of the borehole. The piezometers were constructed of 5-cm (2-in.) ID PVC casing and screens. Sandpack was placed around the screens, and a bentonite seal was placed above the sandpack. The remaining annulus was grouted, and each piezometer was completed with a cap and protective cover.

The 16 additional monitoring wells at WAG 7 were installed as part of a groundwater quality monitoring well installation program at ORNL. These wells were constructed of $5-\mathrm{cm}$ or $10-\mathrm{cm}$ (2-in. or 4-in.) ID stainless steel casing and screens. The remainder of the well construction was the same as described for the piezometers. Each well was completed with a steel protective casing, locking cap, steel guardposts, and a concrete pad. The locations of the monitoring wells or piezometers within WAG 7 for which groundwater quality data were evaluated for this summary are presented in Fig. 3.21, and a summary of the total depths for these installations is presented in Table 3.7. 


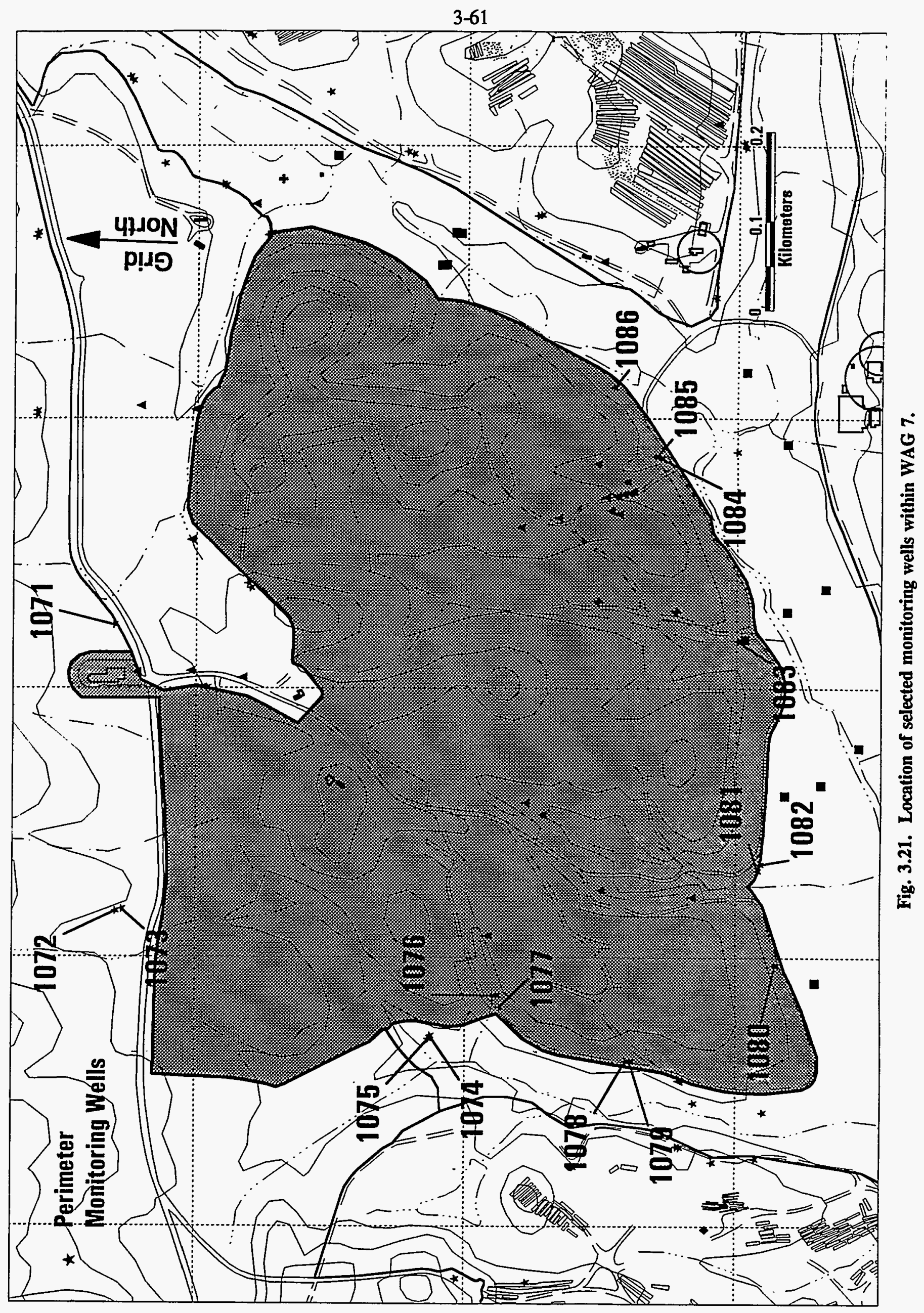


Table 3.7. Summary of WAG 7 groundwater monitoring system wells

\begin{tabular}{|c|c|}
\hline Well no. & Total depth (ft) \\
\hline \multicolumn{2}{|c|}{ Pre-RAP wells } \\
\hline 0084 & No Data \\
\hline 0095 & No Data \\
\hline 0096 & No Data \\
\hline 0098 & No Data \\
\hline 0099 & No Data \\
\hline 0124 & No Data \\
\hline $1820\left(\right.$ WT7-3) ${ }^{a}$ & No Data \\
\hline 1826 (WT7-7) & No Data \\
\hline 1764 (T6-7) & No Data \\
\hline $1776(\mathrm{~T} 7-2)$ & No Data \\
\hline $2324(T 7-3)$ & No Data \\
\hline $1770(T 7-10)$ & No Data \\
\hline $1817(\mathrm{~T} 7-13)$ & No Data \\
\hline $1772(\mathrm{~T} 7-15)$ & No Data \\
\hline $1777(T 7-20)$ & No Data \\
\hline $1778(\mathrm{~T} 7-21)$ & No Data \\
\hline $1779(\mathrm{~T} 7-22)$ & No Data \\
\hline $1780(\mathrm{~T} 7-23)$ & No Data \\
\hline $1781(T 7-24)$ & No Data \\
\hline $1782(T 7-25)$ & No Data \\
\hline $1783(T 7-26)$ & No Data \\
\hline \multicolumn{2}{|c|}{ Groundwater quality wells } \\
\hline 1071 & 25.00 \\
\hline 1072 & 70.00 \\
\hline-1073 & 25.60 \\
\hline 1074 & 30.00 \\
\hline 1075 & 73.00 \\
\hline 1076 & 20.00 \\
\hline 1077 & 82.60 \\
\hline
\end{tabular}


Table 3.7 (continued)

\begin{tabular}{cc}
\hline Well no. & Total depth $(\mathrm{ft})$ \\
\hline 1078 & 20.00 \\
1079 & 70.00 \\
1080 & 20.00 \\
1081 & 73.50 \\
1082 & 15.00 \\
1083 & 15.00 \\
1084 & 15.00 \\
1085 & 72.80 \\
1086 & 14.75 \\
\hline
\end{tabular}

awell alias in parentheses 


\subsubsection{Contamination nature and extent}

Two principal source documents were used to develop an understanding of groundwater contamination within WAG 7. These documents were the Preliminary Geohydrologic Site Characterization and Proposed Water Quality Well Locations for WAGs 7, 8, and 9 (Energy Systems 1987b), and the Oak Ridge Reservation Environmental Report for 1991 (Energy Systems 1992b). The Preliminary Geohydrologic Site Characterization report summarized results from two previous studies regarding groundwater contamination at WAG 7.

The first study reported results for groundwater samples collected from nine of the pre-RAP monitoring wells located in the vicinity of Pits 2, 3, and 4, and Trenches 6 and 7 . Six monitoring wells located around the perimeter of Pits 2, 3, and $4(0124,0099,0098,0096,0095$, and 0084) were sampled. Results from this sampling indicated the presence of ${ }^{60} \mathrm{Co}$ and ${ }^{90} \mathrm{Sr}$ contamination in all of the wells with the exception of Well 0096, which only contained ${ }^{60} \mathrm{Co}$ contamination. Activities of ${ }^{60} \mathrm{Co}$ and ${ }^{90} \mathrm{Sr}$, respectively, ranged from 0.83 to $4.4 \mathrm{~Bq} / \mathrm{L}$ and 0.34 to $1.4 \mathrm{~Bq} / \mathrm{L}$ in the northern half of the pits area and from 23 to $120 \mathrm{~Bq} / \mathrm{L}$ and 0.36 to $3.2 \mathrm{~Bq} / \mathrm{L}$ in the southern half of the area. Results from two monitoring wells sampled west of Trench 7 (1820 and 1826) indicated the presence of ${ }^{60} \mathrm{Co}$ and ${ }^{90} \mathrm{Sr}$ contamination averaging $0.3 \mathrm{~Bq} / \mathrm{L}$ for both contaminants. Samples from Well 1764 located in the vicinity of Trench 6 indicated the presence of ${ }^{60} \mathrm{Co},{ }^{90} \mathrm{Sr}$, and ${ }^{137} \mathrm{Cs}$ at activities of $2.7,54$, and $180 \mathrm{~Bq} / \mathrm{L}$, respectively. Tritium was not detected above detection limits at any of the sampling locations.

The second study reported results for groundwater samples collected from 12 of the pre-RAP monitoring wells $(1776,1787,1770,1771,1772$, and 1777 through 1783), one soil boring (SB-1), and one seep located near Trench 7. All of the sampling locations were found to be contaminated by tritium and ${ }^{\infty} \mathrm{Sr}$, with activities ranging from 85 to $27,300 \mathrm{~Bq} / \mathrm{L}$ for tritium and from 0.3 to $2350 \mathrm{~Bq} / \mathrm{L}$ for ${ }^{90} \mathrm{Sr}$. A majority of the sampling locations were also found to be contaminated by ${ }^{60} \mathrm{Co}$ and ${ }^{233} \mathrm{U}$, with activities ranging from 14 to $2040 \mathrm{~Bq} / \mathrm{L}$ for ${ }^{60} \mathrm{Co}$ and from 0.13 to $12.9 \mathrm{~Bq} / \mathrm{L}$ for ${ }^{233} \mathrm{U}$.

The Oak Ridge Reservation Environmental Report for 1991 (Energy Systems 1992b) summarized results for groundwater samples collected during April and May of 1991 from the 16 groundwater quality wells at WAG 7. Five of the perimeter wells, four located along the southwest boundary of WAG $7(1076,1978,1079$, and 1082) and one along the southeast boundary (1084), were found to be contaminated with tritium. Activities of tritium in the southwest perimeter wells ranged from 760 to $38,000 \mathrm{~Bq} / \mathrm{L}$; the activity within Well 1084 was $4500 \mathrm{~Bq} / \mathrm{L}$. Wells 1079 and 1085 were found to contain nickel contamination above the MCL at concentrations of $370 \mu \mathrm{g} / \mathrm{L}$ and $146 \mu \mathrm{g} / \mathrm{L}$, respectively. Subsequent sampling of the wells in April and May of 1992 indicated the presence of similar activities and concentrations of the noted contaminants, with the exceptions that no tritium was detected in Well 1082 and no nickel was detected in Well 1085.

Based on the data evaluated for WAG 7 , contaminated groundwater containing ${ }^{60} \mathrm{Co},{ }^{90} \mathrm{Sr}$, and tritium derived from one or more of the disposal pits and/or trenches appears to have migrated downgradient to the southern boundaries of WAG 7. Trench 7 also appears to be a possible source of ${ }^{233} \mathrm{U}$ contamination; Trench 6 may be a possible source of ${ }^{137} \mathrm{Cs}$. The absence of tritium contamination in the pre-RAP wells sampled around Pits 2, 3, and 4 does not correlate with later detection of this contaminant in the groundwater quality perimeter wells. This 
observation may be attributed to different well depths, resulting in the sampling of two different groundwater horizons, or may be attributed to arrival of tritium contamination in this area of the WAG between the two sampling events. Regardless of the explanation, the detection of tritium in Wells 1076 and 1078 suggests that one or both of the upgradient disposal sites (Pit 1 or Trench 6 ) in WAG 7 , or possibly WAG 4 , are sources of tritium contamination.

\subsection{WAG 8}

\subsubsection{Site Location, Description, and Background}

WAG 8 is located mainly in Melton Valley and consists of $\sim 13.8$ ha (34 acres) (Fig. 3.22). The site is irregularly shaped and has two sinuous extensions from its northern end that contain the LLW transfer lines. One of these lines extends northwest and crosses Haw Ridge; the other runs parallel to Melton Valley Drive up to its juncture with another line at Lagoon Road. To the east, the site is bordered by two draws that contain tributaries of Melton Branch. The floodplain of Melton Branch borders the site to the south. The noted tributaries and floodplain constitute the upper reaches of WAG 2. On its western side, WAG 8 is flanked by a low southwesterlytrending knoll.

WAG 8 contains 20 SWMUs, which are divided into the following four groups: (1) Waste Collection Basins, (2) LLW Line Leak Sites, (3) Active LLW Tanks, and (4) Other Facilities. The Waste Collection Basins category of SWMUs includes Basins 7905, 7906, 7907, and 7908. The LLW Line Leak Sites category includes the Melton Valley Transfer Line, Melton Valley Drive Leak Site, Melton Valley Drive and SWSA 5 Access Road Leak Site, 7500 Area Leak Site, Leak Site West of Melton Valley Pumping Station, Building 7920 and Melton Valley Pumping Station Leak Site, and the Building 7920 Ditch Line Leak Site. The Active LLW Tanks category of SWMUs includes WC-20, HFIR, T-1, and T-2 Active LLW Collection/Storage Tanks. The Other Facilities category includes Soil Contamination at Hydrofracture Experimental Site 2, 7507 Hazardous Waste Storage Facility, 7507W Mixed Waste Storage Pad, Sewage Treatment Plant, and Silver Recovery Process.

Four surface impoundments are located south of the High Flux Isotope Reactor (HFIR) facility in WAG 8. Impoundments 7905 and 7906 receive process waste streams from the HFIR facility. Impoundments 7907 and 7908 receive process waste streams from the Thorium-Uranium Facility (TURF) and the Transuranic (TRU) Processing Facility. Based on topography, it appears that all four basins were constructed by excavation and that some of the excavated material was used to construct berms around the basins. All of the basins are lined with an estimated ( $2 \mathrm{ft}$ ) of rock rip-rap on their interior slopes.

Six of the seven leak sites included in WAG 8 occurred along the sections of pipeline that transferred waste from the -HFIR facility, TURF, and TRU processing facility to the Melton Valley pumping station and then to the South Tank Farm in Bethel Valley. The one leak site that did not occur along this section of line is believed to have taken place along the original transfer line that ran from the South Tank Farm to the pits and trenches in WAG 7. Both sections of these lines are presently inactive. The information available for the leak sites varies from detailed written accounts to oral accounts recalled from 17 to 27 years ago. Therefore, the level of detail 
3-66

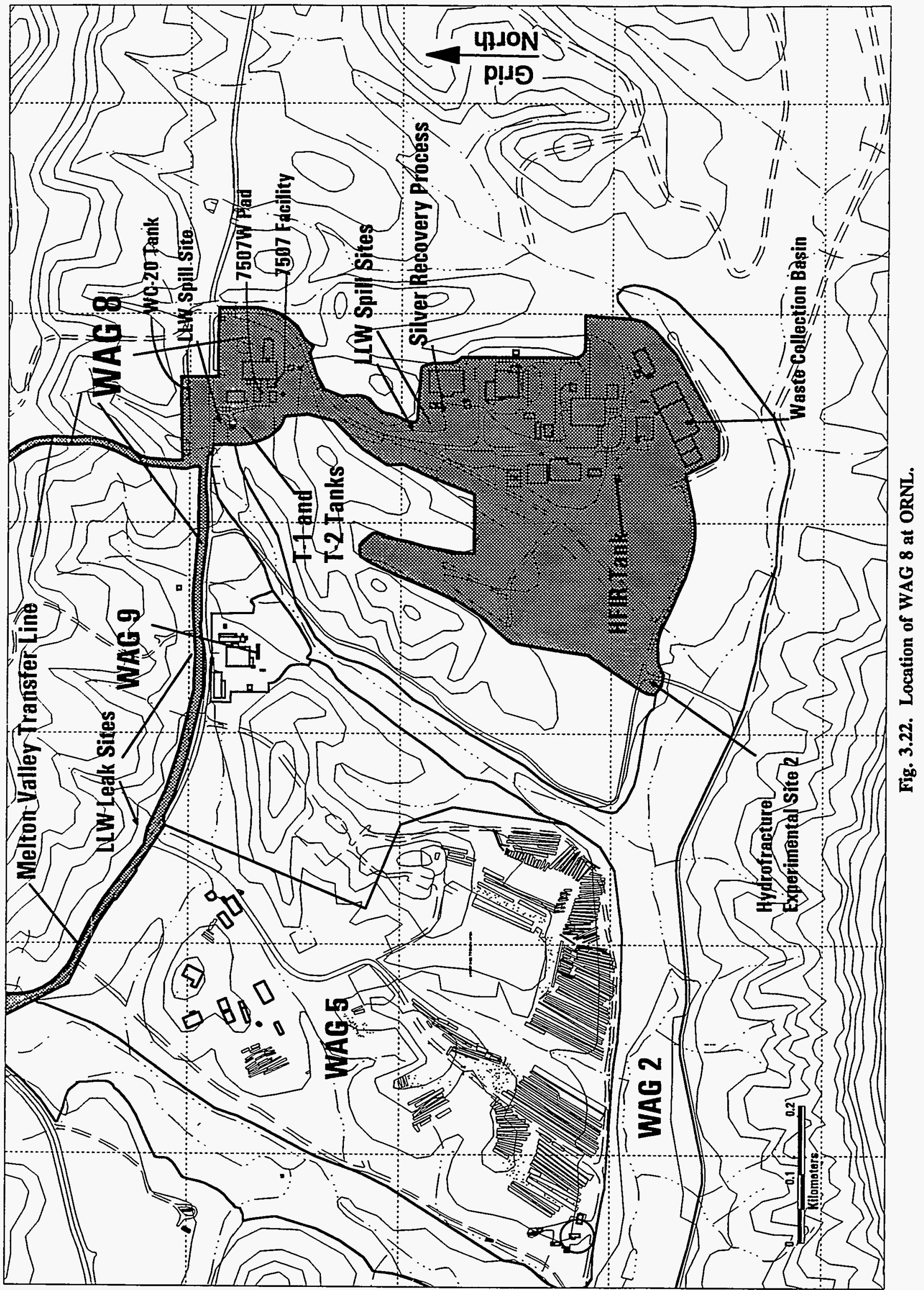


regarding individual leaks varies, and in some instances accounts of a given leak event could not be positively matched to documented leak locations.

There are four underground tanks, which are used to collect low-level wastes in Melton Valley. Three of the tanks (T-1, T-2, and the HFIR tank) are singly contained units that rest on concrete pads fitted with a sump. These tanks are surrounded by gravel backfill and covered with earth. The fourth tank (WC-20) is double-contained.

\subsubsection{7905 Waste Collection Basin}

The 7905 Basin began operation in 1965 and has a design capacity of $\sim 908,400 \mathrm{~L}$ (240,000 gal). Process wastes discharged to this basin from the HFIR facility include floor drains, laboratory drains, steam condensate, and process vessel cooling water. Additionally, the basin receives radioactive contaminated blowdown water from the cooling tower in Building 7902. Discharge from the basin is released to Melton Branch if not contaminated, or is routed to Basin 3524 in the main plant area for further treatment. Approximately $30.5 \mathrm{~cm}$ (12 in.) of sediment have accumulated on the base of this impoundment; however, analyses indicate that the sediment does not exceed characteristic waste standards. The principal radionuclide contaminant associated with waste streams directed to Basin 7905 is ${ }^{60} \mathrm{Co}$.

\subsubsection{7906 Waste Collection Basin}

The 7906 Basin began operation in 1965 and has a design capacity of $\sim 1,892,500 \mathrm{~L}$ $(500,000 \mathrm{gal})$. Process wastes are discharged to this basin from the HFIR facility, but it can also receive waste streams diverted from the TURF and TRU processing facility. Discharge from the basin is released in the same manner as described for Basin 7905. Approximately $20 \mathrm{~cm}$ (8 in.) of sediment have accumulated on the base of this impoundment; however, analyses indicate that the sediment does not exceed characteristic waste standards. The principal radionuclide contaminants associated with waste streams directed to Basin 7906 are ${ }^{60} \mathrm{Co}$ and plutonium and its daughter products.

\subsubsection{7907 Waste Collection Basin}

The 7907 Basin began operation in 1965 and has a design capacity of $\sim 189,250 \mathrm{~L}$ $(50,000 \mathrm{gal})$. Process wastes are discharged to this basin from the TURF and TRU processing facility. Discharge from the basin is released in the same manner as described for Basin 7905 . Approximately $6.1 \mathrm{~cm}$ (2.4 in.) of sediment have accumulated on the base of this impoundment; however, analyses indicate that the sediment does not exceed characteristic waste standards. The principal radionuclide contaminant associated with waste streams directed to Basin 7907 is ${ }^{244} \mathrm{Cm}$.

\subsubsection{7908 Waste Collection Basin}

The 7908 Basin shares the same dimensions, waste streams, and operating history as Basin 7907, except that it is filled and emptied alternately with its sister basin. Sediments that have accumulated on the base of this impoundment do not exceed characteristic waste standards. The principal radionuclide contaminant associated with waste streams directed to Basin 7908 is also ${ }^{244} \mathrm{Cm}$. 


\subsubsection{Melton Valley Transfer Line}

The older section of the Melton Valley LLW transfer line ran from the Melton Valley pumping station along Melton Valley Drive crossing White Oak Creek and Lagoon Road to its junction with the original transfer line that ran between the main plant and the WAG 7 disposal pits and trenches. The line was constructed of 5-cm (2-in.) mild steel with mechanical joints and was routed underground. This section of line was reportedly replaced in 1973 with cathodically protected 5-cm (2-in.) stainless steel line, portions of which are double-contained. The original sections of piping from the HFIR and TRU processing facilities that carried waste to the collection tanks were 7.6-cm and 5-cm (3-in. and 2-in.) lines, respectively.

\subsubsection{Melton Valley Drive Leak Site}

This incident presumably occurred during the April-June timeframe of 1960 . The incident was actually a line break, not a leak, and probably involved the original 5-cm (2-in.) transfer line that led to the WAG 7 pits and trenches rather than the line that connected the Melton Valley pumping station to the main plant area. The incident occurred near the 7500 bridge where the line crosses White Oak Creek; however, no wastes were being transferred at the time of the line damage. Documentation noted that an inspection of the line at this location indicated that there may have been other potential leaks in the line. Aside from repairing the line, there is no record of any remedial measures taken at this location.

\subsubsection{Melton Valley Drive and SWSA 5 Access Road Leak Site}

This leak occurred on July 9, 1970, during a transfer of waste from Melton Valley to the tank farm. The leak site is located south of Melton Valley Drive just west of the entrance to the SWSA 5 access road. The leak was described as liquid coming out of the ground and running west along the shoulder of the road and southwest into the grass. Approximately $18.6 \mathrm{~m}^{3}$ $\left(200 \mathrm{ft}^{3}\right)$ of contaminated pavement and soil were excavated and disposed of by burial. A neoprene gasketed pipe joint was determined to have been the source of the leak, which was subsequently repaired. Another leak site in the same general area was indicated in a report issued

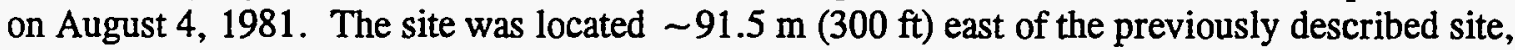
along the northern side of Melton Valley Drive. Written documentation for the leak at this site was not found during a literature search. Other undocumented leaks may have occurred in this area at mechanical joints in the transfer line during the late 1960s and early 1970s. These leaks frequently occurred during LLW transfer and were identified by observation of liquid at the ground surface or by volume discrepancies. Typically, the waste and some contaminated earth were remediated by excavation.

\subsubsection{7500 Area Leak Site}

On July 21, 1969, a leak-was discovered in the ILLW-transfer line that served the Melton Valley area. The leak was located between Buildings 7500 and 7503 alongside the ditch immediately on the north side of Melton Valley Drive. Analysis of the liquid waste showed alpha, beta, and gamma contamination identified as predominantly ${ }^{244} \mathrm{Cm}$ and fission products. The total volume of the leak was estimated to be $7948 \mathrm{~L}$ ( 2100 gal $)$. Remedial actions at the site involved removal of the high-level contaminated earth and repair of the line. Some low-level contamination remains in the wet area on the south side of Melton Valley Drive. 


\subsubsection{Leak Site west of Melton Valley Pumping Station}

On January 15,1971 , a leak developed while waste was being transferred from Melton Valley to the tank farm. Approximately $9.3 \mathrm{~m}^{3}\left(100 \mathrm{ft}^{3}\right)$ of earth located west of the pumping station was remediated by excavation. A report of the incident indicated that there was no spread of contamination outside the immediate area of the leak.

\subsubsection{Building 7920 and Melton Valley Pumping Station/Building 7920 Ditch Line Leak Sites}

These two leak sites are probably the same event, although an early inventory of leak sites identified them as separate incidents. The assertion that the two sites are actually the same incident is supported by the similarity of the written descriptions for the leak. On July 31, 1970, visible quantities of liquid were observed on the soil surface and in a drainage ditch near the roadway west of Building 7920. Analysis of the liquid in the ditch showed alpha contamination (identified as ${ }^{244} \mathrm{Cm}$ ), and beta-gamma contamination (identified as ${ }^{106} \mathrm{Ru}$ ). The ditch was filled with crusher-run stone to absorb and immobilize the liquid. All contaminated areas and the rock fill surface were then sprayed with asphalt to prevent weathering. Final remediation restored all accessible areas to an uncontaminated status except for the interior of a culvert under the road between Buildings 7920 and 7930 .

\subsubsection{WC-20 LLW Collection/Storage Tank}

The WC-20 Tank is located $-76 \mathrm{~m}$ (250 ft) northwest of Building 7503 on the northern side of Melton Valley Drive. The top of the tank is buried $-2.3 \mathrm{~m}(7.5 \mathrm{ft})$ below ground level, is doubly contained within a concrete vault, and has a capacity of $37,850 \mathrm{~L}(10,000 \mathrm{gal})$. This tank receives wastes from Building 7920 and discharges the wastes to Building 7567, where they are pumped to the South Tank Farm in Bethel Valley.

\subsubsection{HFIR LLW Collection/Storage Tank}

The HFIR Tank is located $\sim 48.8 \mathrm{~m}(160 \mathrm{ft})$ southeast of Building 7900 . The top of the tank is buried $\sim 5.8 \mathrm{~m}$ (19 ft) below ground level, and has a capacity of 49,205 L (13,000 gal). This tank collects LLW from Building 7900 through a $15-\mathrm{cm}$ (6-in.) stainless steel line and discharges to Tanks T-1 and T-2 through a 7.6-cm (3-in.) cast iron mechanically jointed line.

\subsubsection{T-1 and T-2 LLW Collection/Storage Tanks}

The T-1 and T-2 Tanks are located southwest of Building 7567. The tops of the tanks are buried $\sim 2 \mathrm{~m}(6.5 \mathrm{ft})$ below ground level and have a capacity of $56,775 \mathrm{~L}(15,000 \mathrm{gal})$ each. The tanks are operated alternately to collect wastes from Buildings $7500,7502,7503$, and the HFIR Tank via 7.6-cm (3-in.) cast iron mechanically jointed lines. The wastes are discharged to the central pumping station, from which they are pumped to the south tank farm in Bethel Valley. 


\subsubsection{Soil contamination at Hydrofracture Experimental Site 2}

The Hydrofracture Experimental Site 2 is located near the southwestern corner of WAG 8. In September of 1960, the second hydrofracture experiment was conducted to determine such factors as pressures achieved in the fracture zone, the effects of friction losses on pumping efficiencies, the feasibility of multiple injection zones, and extent of surface uplift and the orientation of the grout sheets. The experiment was conducted in an injection well drilled to a depth of $320 \mathrm{~m}$ (1050 ft), which had a slot cut into the casing at $285 \mathrm{~m}(934 \mathrm{ft})$. A nearby observation well was drilled near the injection well and was cased and grouted to a depth of $\sim 271 \mathrm{~m}$ (890 ft), below which a small-diameter perforated pipe string was set to a depth of $320 \mathrm{~m}(1050 \mathrm{ft})$.

A total of $346,581 \mathrm{~L}(91,567 \mathrm{gal})$ of water, cement, and bentonite grout tagged with $25 \mathrm{Ci}$ of ${ }^{137} \mathrm{Cs}$ was injected into the fracture zone, and the injection well was plugged to a depth of $214 \mathrm{~m}$ (700 ft) with cement. A second slot was then cut in the injection well casing at $212 \mathrm{~m}$ $(694 \mathrm{ft})$ and $502,270 \mathrm{~L}(132,700 \mathrm{gal})$ of additional grout, also tagged with ${ }^{137} \mathrm{Cs}$, was pumped into a second fracture zone. The lower grout sheet created during the experiment extends $\sim 91.5 \mathrm{~m}$ (300 ft) north from the injection well location; the upper grout sheet extends $-153 \mathrm{~m}(500 \mathrm{ft})$ northeast from the injection well location. No documentation regarding surface soil contamination was found for the second hydrofracture experiment. A written account of the experiment did indicate that a corehole drilled into the subsurface grout sheet flowed water slowly for an extended period. However, the description did not indicate whether the water was contaminated or if any remedial activities were conducted.

\subsubsection{7507 Hazardous Waste Storage Facility}

This building is located south of Melton Valley Drive just west of Building 7503. The structure was erected in the 1950 s and was converted to a hazardous waste storage facility in the early 1980s. The conversion included construction of a 15-cm (6-in.) concrete dike to contain seepage in the event of a container leak. Building 7507 stores a variety of hazardous wastes segregated into storage bays by hazardous characteristic (e.g., oxidizer, poison, corrosive). No releases from this facility have been documented.

\subsubsection{7507W Mixed Waste Storage Pad}

The Mixed Waste Storage Pad is located just west of Building 7507 and is a concrete pad $\sim 12.2 \times 12.2 \mathrm{~m}(40 \times 40 \mathrm{ft})$ surrounded by a concrete dike. A sump with an estimated 227-L (60-gal) capacity at the center of the pad area catches rainfall and potential leakage from waste containers. The facility receives ORNL mixed wastes, which are contained in 208-L (55-gal) drums. No releases from this facility have been documented.

\subsubsection{7- Silver Recovery Process}

The Silver Recovery Process is located in Building 7934 just west of the TURF. The recovery process treats $\sim 1515 \mathrm{~L} /$ week ( $400 \mathrm{gal} /$ week) of photographic waste generated by the ORNL, Y-12, and K-25 facilities. The facility recovers silver from waste solutions by a batch-type chemical process involving the use of sodium hydrosulfite and sodium hydroxide. Silver precipitated by the process is dewatered by centrifuge and sold for further reclamation and 
resale. Supernatant from the process is transferred from a pH adjustment tank to the main wastewater treatment plant. No releases from this facility have been documented.

\subsubsection{Characterization of Groundwater Contamination}

\subsubsection{Groundwater monitoring system}

The groundwater monitoring system in WAG 8 includes 8 water quality wells installed in 1985, 13 piezometers installed in 1986 or 1987, and 9 additional monitoring wells installed between 1989 and 1990. The eight water quality wells were installed around the HFIR facility, and no information concerning their construction is available. The piezometers were constructed of 5-cm (2-in.) ID PVC casing and screens. Sandpack was placed around the screens, and a bentonite seal was placed above the sandpack. The remaining annulus was grouted, and each piezometer was completed with a cap and protective cover.

The nine additional monitoring wells at WAG 8 were installed as part of a groundwater quality monitoring well installation program at ORNL. These wells were constructed of 5-cm or 10-cm (2-in. or 4-in.) ID stainless steel casing and screens. The remainder of the well construction was the same as described for the piezometers. Each well was completed with a steel protective casing, locking cap, steel guardposts, and a concrete pad. The locations of the monitoring wells or piezometers within WAG 8 for which groundwater quality data were evaluated for this summary are presented in Fig. 3.23, and a summary of the total depths for these installations is presented in Table 3.8.

\subsubsection{Contamination nature and extent}

Two principal source documents were used to develop an understanding of groundwater contamination within WAG 8. These documents were the Preliminary Geohydrologic Site Characterization and Proposed Water Quality Well Locations for WAGs 7, 8, and 9 (Energy Systems 1987b), and the Oak Ridge Reservation Environmental Report for 1991 (Energy Systems 1992b). The Preliminary Geohydrologic Site Characterization report summarized results for samples collected in June of 1986 from seven of the eight water quality wells at the HFIR facility. Two of the wells located downgradient of the facility (0893 and 0894) were found to contain gross alpha contamination at levels of 0.66 and $2.08 \mathrm{~Bq} / \mathrm{L}$, respectively. Well 0894 also contained radium contamination at $1.5 \mathrm{~Bq} / \mathrm{L}$. Five of the wells located both upgradient and downgradient of the facility contained gross beta contamination ranging from 0.34 to $37.0 \mathrm{~Bq} / \mathrm{L}$. The occurrence of contamination in the upgradient wells suggests that a beta-emitting source area, possibly one of the LLW line leak sites, is present upgradient from the HFIR facility.

The Oak Ridge Reservation Environmental Report for 1991 (Energy Systems 1992b) summarized results for groundwater samples collected during May and June of 1991 from the 9 groundwater quality wells at WAG 8. Two of the wells (Wells 1087 and 1090) located along the western sinuous extension of WAG 8 were found to be contaminated with total strontium at activities of $25 \mathrm{~Bq} / \mathrm{L}$ and $0.34 \mathrm{~Bq} / \mathrm{L}$, respectively. Another well (Well 1088) located between these two wells along the same extension contained tritium contamination at $2500 \mathrm{~Bq} / \mathrm{L}$. Subsequent sampling of the wells in May and June of 1992 indicated the presence of similar activities and concentrations of the noted contaminants, with the exceptions that no total strontium was detected in Well 1090, and thallium was detected at $5.1 \mu \mathrm{g} / \mathrm{L}$ in Well 1092 located at the 


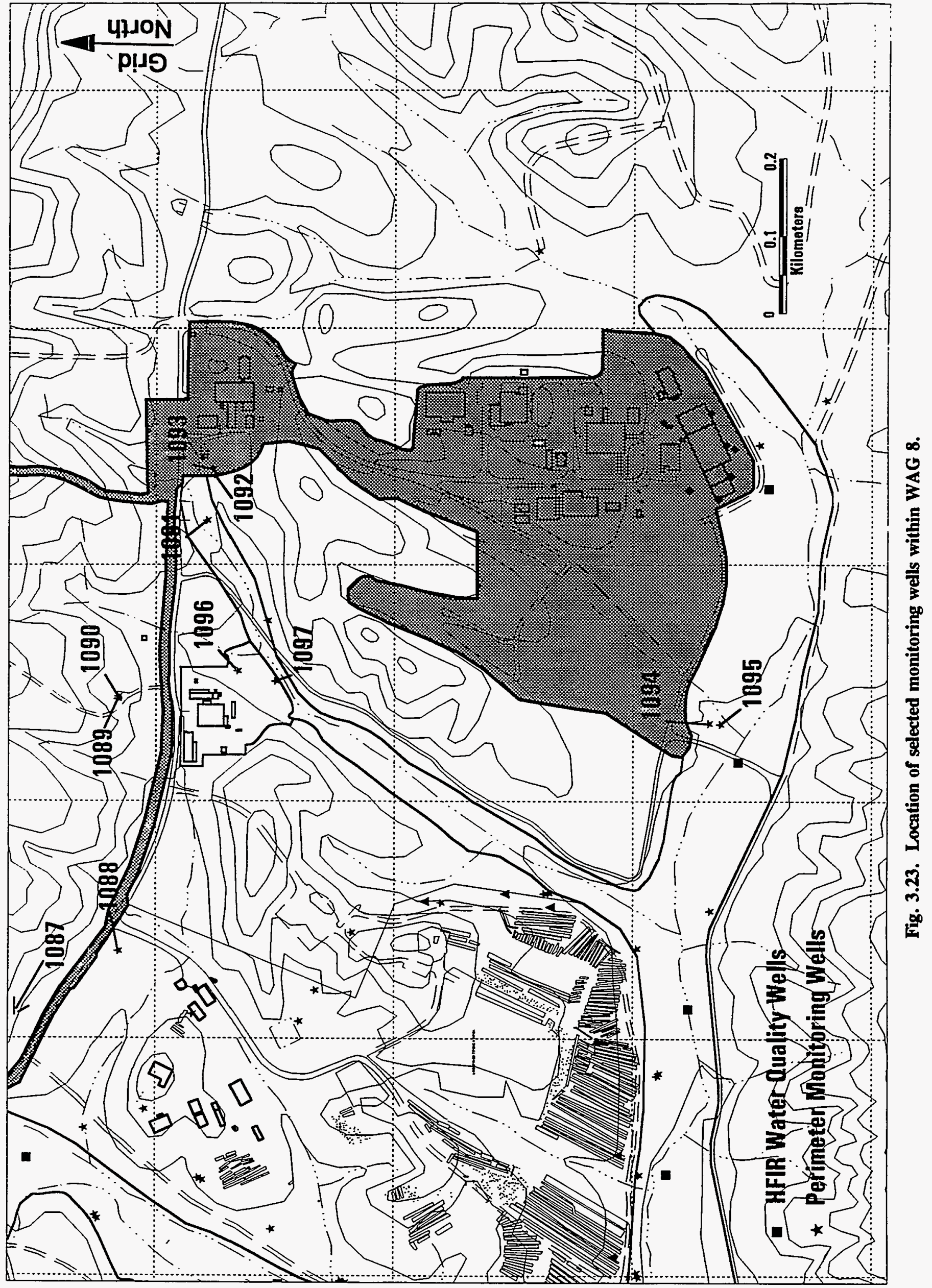


Table 3.8. Summary of WAG 8 groundwater monitoring system wells

\begin{tabular}{cc}
\hline Well no. & Total depth (ft) \\
\hline $0877(32-001)^{a}$ & No Data \\
$0888(32-002)$ & No Dater quality wells \\
$0889(32-003)$ & No Data \\
$0890(32-004)$ & No Data \\
$0891(32-005)$ & No Data \\
$0892(33-001)$ & No Data \\
$0893(33-002)$ & No Data \\
$0894(33-003)$ & No Data \\
& Groundwater quality wells \\
1087 & 23.00 \\
1088 & 35.00 \\
1089 & 30.18 \\
1090 & 73.10 \\
1091 & 22.65 \\
1092 & 87.50 \\
1093 & 48.25 \\
1094 & 70.30 \\
1095 & 23.10 \\
1096 & 23.20 \\
1097 & 17.80 \\
\hline & \\
\hline &
\end{tabular}

awell alias in parentheses. 
northeast corner of WAG 8. Based upon the irregular occurrences of contaminants within WAG 8 at the few locations sampled, no patterns regarding the overall extent of contamination at this site are apparent.

\subsection{WAG 9}

\subsubsection{Site Location, Description, and Background}

WAG 9 is located in Melton Valley and consists of $\sim 1.2$ ha ( 3 acres) (Fig. 3.24). This WAG is located west of the main portion of WAG 8 and south of Melton Valley Drive. WAG 9 was the site of HRE 1 and later the Homogeneous Reactor Test (HRT), which is sometimes referred to as HRE 2. HRE 1 operated intermittently from 1951 through 1954 and was subsequently decommissioned and decontaminated. Following this, construction was begun on a new containment cell for the HRT, which operated from 1957 until 1961. After the HRT was shut down, some of the facilities were converted for use by the Nuclear Safety Pilot Plant (NSPP), which continues to operate today.

WAG 9 contains four SWMUs: (1) the HRT Pond, (2) 7560 LLW Collection/Storage Tank, (3) $7562 \mathrm{LLW}$ Collection/Storage Tank, and (4) the NSPP Septic. There are several additional potential environmental influences in WAG 9 that are not presently identified as SWMUs. The first of these was a reported release of purge water from the hot storage pool in Building 7500 . Neither the volume nor the radioactive content of this release are known; however, based on a description, it is presumed that the release was to the tributary in the drainageway east of Building 7500.

The second potential environmental influence is the presence of seven buried 208-L (55-gal) stainless steel drums, which are thought to be located in a north-south line along the western edge of the HRT Pond's asphalt cap. The tops of these drums are thought to be buried flush with the ground surface and are believed to contain contaminated valves, pump heads, and other components from the HRE. The third potential environmental influence is the discharge from sumps in the lower sub-level of Building 7500. The sumps were designed to eliminate any water that might accumulate on the floor of the sub-level. During operation of the HRT, the sump lines discharged to the HRT Pond; but after operation of the NSPP began, the sump piping was rerouted to an unspecified location. Several inactive underground lines and equipment pits located at the WAG 9 facilities also may be potential environmental influences.

\subsubsection{Homogeneous Reactor Test Pond}

The HRT Pond is located on a hillside $\sim 24 \mathrm{~m} \mathrm{(80} \mathrm{ft)} \mathrm{south} \mathrm{of} \mathrm{Building} 7500$. It was constructed in 1955 by excavation and forming of an embankment with the soils, and had a capacity of $\sim 1,135,500 \mathrm{~L}(300,000 \mathrm{gal})$. Inlet piping from the HRT entered the pond at its northwestern corner; the outlet piping was located at the southeastern corner. The outlet piping led to a weir box located $\sim 12 \mathrm{~m}(40 \mathrm{ft}$ ) from the pond, where discharges were released to a nearby but unspecified creek. The pond served as a retention/settling basin for liquid radioactive wastes from the HRT from 1958 through 1961. 


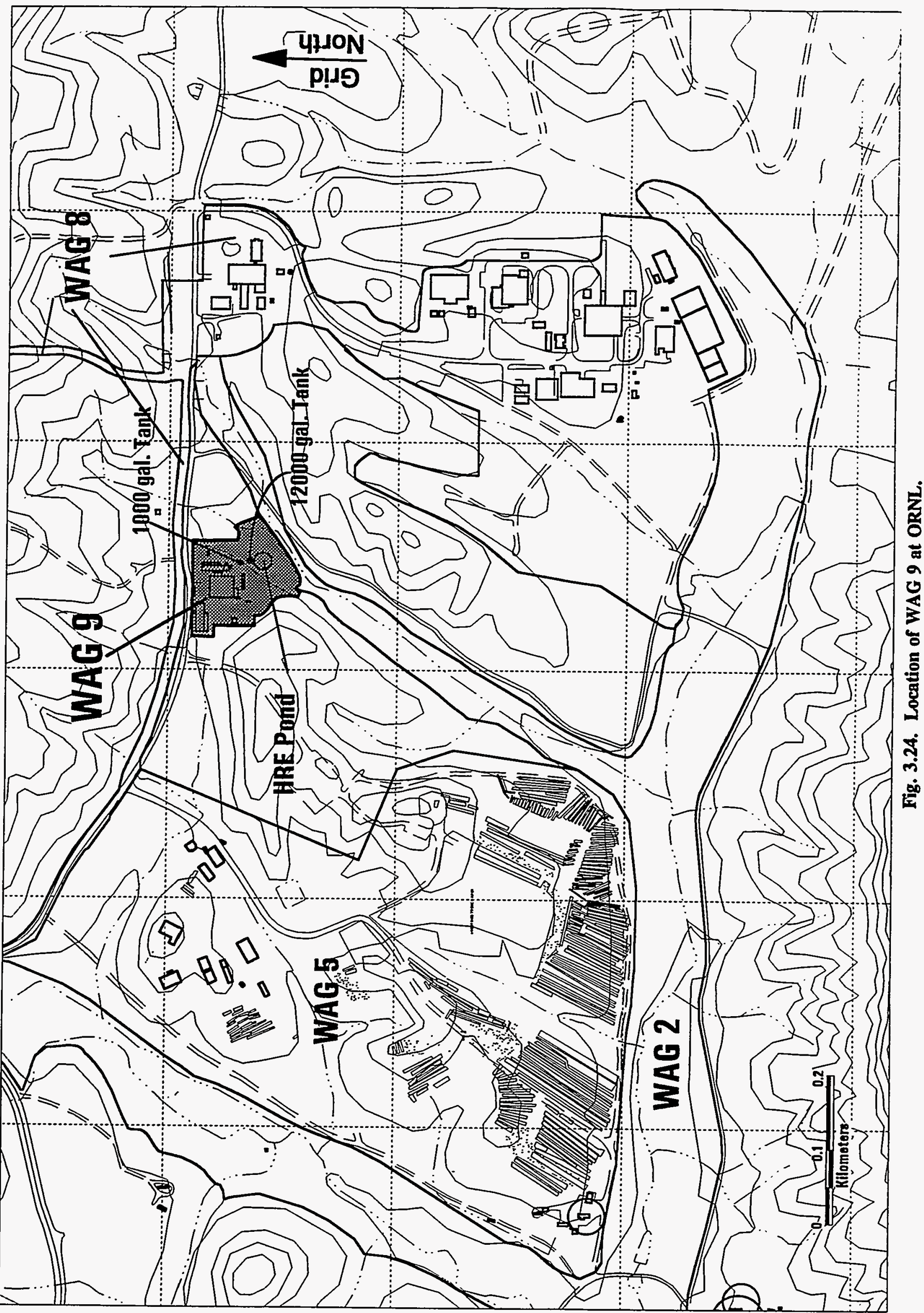


Contaminants from these waste streams were flocculated in the pond, and the treated water was discharged to the weir box. The principal contaminants associated with the wastes were ${ }^{137} \mathrm{Cs}$ and ${ }^{90} \mathrm{Sr}$, with trace amounts of ${ }^{238} \mathrm{Pu},{ }^{239} \mathrm{Pu},{ }^{241} \mathrm{Am}$, and ${ }^{244} \mathrm{Cm}$. In 1970 , the pond was closed by backfilling with soil and shale. At this time, the pond was observed to be approximately halffilled with sludge and clay; the clay was presumed to have eroded and slumped from the pond's banks. After the backfilling was complete, $500 \mathrm{~kg}(1100 \mathrm{lb})$ of sodium borate were added along with $20 \mathrm{~cm}$ (8 in.) of crushed stone. The closure was completed by applying a 3.8-cm (1.5-in.) asphaltic concrete cap over the site.

\subsubsection{7560 and 7562 LLW Collection/Storage Tanks}

The 7560 and 7562 LLW Collection/Storage Tanks are buried tanks that were used in the HRT waste processing system. Both tanks have identification numbers; however, records do not indicate which tank was assigned which number. One of the tanks has a 3785-L (1000-gal) capacity; the other has a 45,420-L (12,000-gal) capacity. The 3785-L (1000-gal) tank is located south of Building 7502 and was constructed of stainless steel. Conflicting reports indicate that this tank is buried either 1.5 or $6.1 \mathrm{~m}$ ( 4.9 or $20 \mathrm{ft}$ ) below ground level. The 3785-L (1000-gal) tank was used from 1957 to 1961 to collect condensate from the HRT waste evaporator cell in Building 7502. The tank's contents were sampled periodically; depending on the level of radioactivity, the waste was either discharged to the HRT Pond or transferred to the 45,420-L (12,000-gal) tank for recycling. The 3785-L (1000-gal) tank was removed from service in 1961, and no releases from this unit are known to have occurred.

The 45,420-L (12,000-gal) tank is located $\sim 4.6 \mathrm{~m}(15 \mathrm{ft})$ north of the HRT Pond's cap and

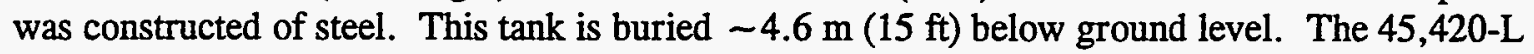
$(12,000$-gal) tank was originally used to store high-level HRT waste prior to shipment to the evaporator loading pit. After the HRT was decommissioned, the NSPP used the 45,420-L $(12,000-\mathrm{gal})$ tank for disposal of depleted uranium. The principal contaminants associated with wastes stored in this tank are believed to be ${ }^{90} \mathrm{Sr},{ }^{137} \mathrm{Cs}$, and transuranics, with lesser amounts of uranium and plutonium isotopes combined with various short half-life radionuclides. A spill was reported to have occurred at the $45,420-\mathrm{L}(12,000$-gal) tank site during a transfer of LLW. Soil samples in the vicinity indicated the presence of ${ }^{90} \mathrm{Sr}$ and ${ }^{137} \mathrm{Cs}$ contamination. The $45,420-\mathrm{L}$ $(12,000$-gal) tank was removed from service in 1986.

\subsubsection{Characterization of Groundwater Contamination}

\subsubsection{Groundwater monitoring system}

The groundwater monitoring system in WAG 9 includes nine water quality wells installed around 1970, four monitoring wells installed in 1985, seven piezometers installed in 1987, and two additional monitoring wells installed in 1990. The nine water quality wells were installed around the perimeter of or through the asphalt cap of the HRT Pond and were constructed of perforated well casings fitted with pointed drive shoes. The four monitoring wells were also installed around the perimeter of the HRT Pond and were constructed of 7.6-cm (3-in.) ID fiberglass casing and screens. Sandpack was placed around the screens, and a bentonite seal was placed above the sandpack. The remaining annulus was grouted, and each well was completed with a protective casing set around the well riser pipe. The piezometers were constructed of 5-cm 
(2-in.) ID PVC casing and screens and were constructed in the same manner as described for the fiberglass wells.

The two additional monitoring wells at WAG 9 were installed as part of a groundwater quality monitoring well installation program at ORNL. These wells were constructed of 5-cm (2-in.) ID stainless steel casing and screens. The remainder of the well construction was the same as described for the piezometers and fiberglass wells. Each well was completed with a steel protective casing, locking cap, steel guardposts, and a concrete pad. The locations of the monitoring wells or piezometers within WAG 9 for which groundwater quality data were evaluated for this summary are presented in Fig. 3.25, and a summary of the total depths for these installations is presented in Table 3.9.

\subsubsection{Contamination nature and extent}

Two principal source documents were used to develop an understanding of groundwater contamination within WAG 9. These documents were the Preliminary Geohydrologic Site Characterization and Proposed Water Quality Well Locations for WAGs 7, 8, and 9 (Energy Systems 1987b), and the Oak Ridge Reservation Environmental Report for 1991 (Energy Systems 1992b). The Preliminary Geohydrologic Site Characterization report summarized results for samples collected in May of 1985 from the four monitoring wells installed around the perimeter of the HRT Pond. The principal groundwater contaminants detected in all four wells were ${ }^{90} \mathrm{Sr}$, tritium, gross alpha, and gross beta. Activities of these contaminants were found to range from 0.26 to $540 \mathrm{~Bq} / \mathrm{L}$ for ${ }^{90} \mathrm{Sr}, 20$ to $370 \mathrm{~Bq} / \mathrm{L}$ for tritium, 0.10 to $5.6 \mathrm{~Bq} / \mathrm{L}$ for gross alpha, and 3.5 to $950 \mathrm{~Bq} / \mathrm{L}$ for gross beta. Chromium was also detected in MW-4 at a concentration of $59.1 \mu \mathrm{g} / \mathrm{L}$. The most significant finding of the sampling was the occurrence of radionuclide contamination in MW-1 located upgradient of the HRT Pond, which suggested that contaminants from other facilities or sources within or upgradient of WAG 9 may have migrated to this sampling point.

The Oak Ridge Reservation Environmental Report for 1991 (Energy Systems 1992b) summarized results for groundwater samples collected during June of 1991 from the two groundwater quality wells at WAG 9. Well 1096 is located along the eastern boundary of WAG 9 and was found to be contaminated by total strontium and trichloroethene at concentrations of $26 \mathrm{~Bq} / \mathrm{L}$ and $6 \mu \mathrm{g} / \mathrm{L}$, respectively. Well 1097 is located near the southeast boundary of WAG 9 and was found to be contaminated by total strontium at a concentration of $24 \mathrm{~Bq} / \mathrm{L}$. Based on the data evaluated for WAG 9, strontium appears to be migrating across the site and exiting at least along the east-southeast boundaries. The source of this strontium would be presumed to be the HRT Pond area. However, WAG 9 also appears to be a source of tritium groundwater contamination, and possibly trichloroethene, which may or may not have migrated beyond the WAG boundaries.

\subsection{WAG 10}

\subsubsection{Site Location, Description, and Background}

WAG 10 is located in Melton Valley and consists of four SWMUs associated with the hydrofracture waste injection activities previously conducted at ORNL. Each of the SWMUs in 


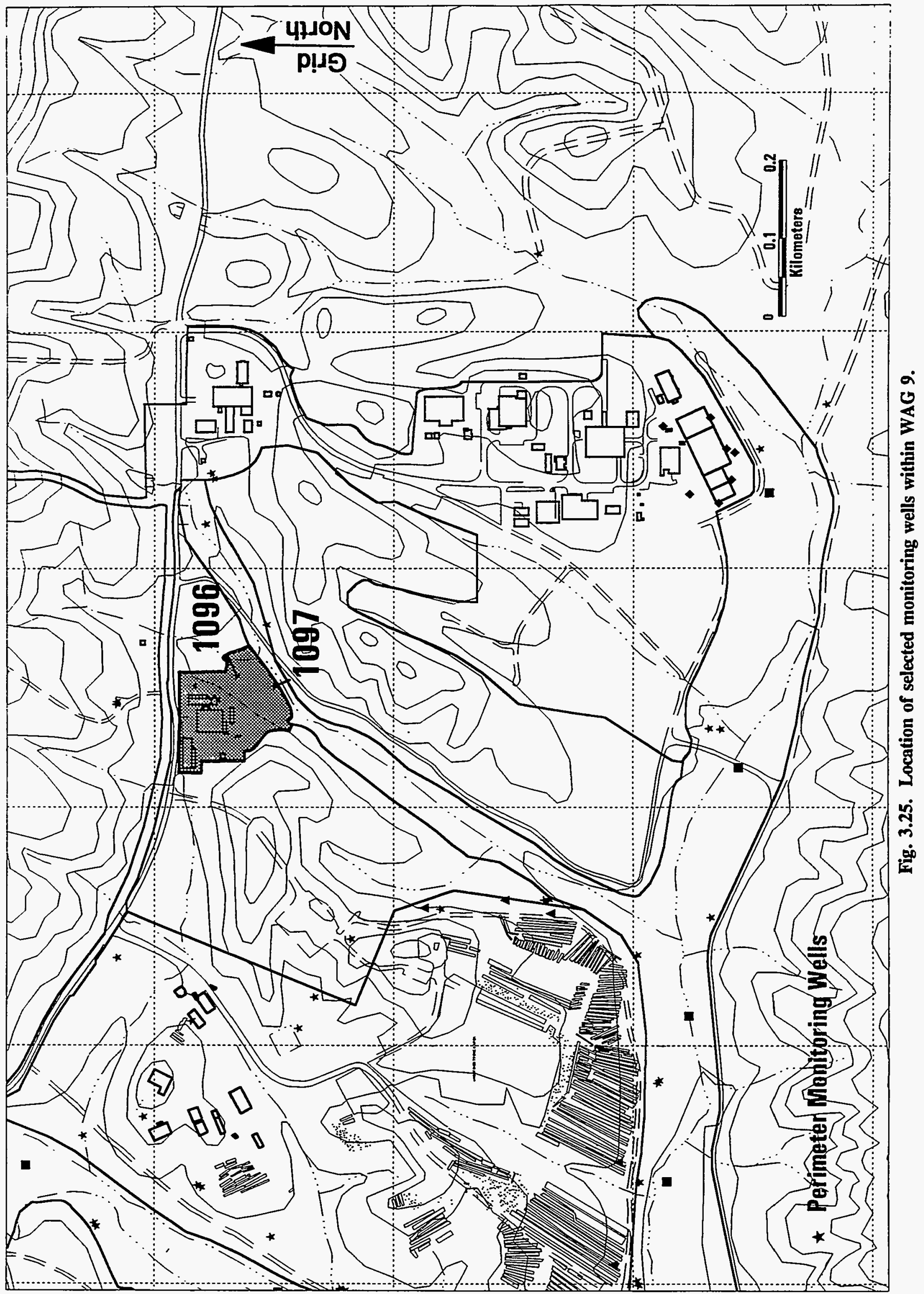


Table 3.9. Summary of WAG 9 groundwater monitoring system wells

\begin{tabular}{cc}
\hline Well no. & Total depth (ft) \\
\hline & HRT pond wells \\
1109 (HRE-1) ${ }^{a}$ & 29.70 \\
$1110(\mathrm{HRE}-2)$ & 24.90 \\
1111 (HRE-3) & 24.70 \\
$1112(\mathrm{HRE}-4)$ & 24.70 \\
\multicolumn{2}{c}{ Groundwater quality wells } \\
$1096 \quad 23.20$ \\
1097 & 17.80 \\
\hline awell alias in parentheses.
\end{tabular}

WAG 10 consists of the injection well and subsurface grout sheets at the following locations: the Hydrofracture Experimental Site 1, the Hydrofracture Experimental Site 2, the Old Hydrofracture Facility, and the New Hydrofracture Facility. Details concerning the activities conducted at the Hydrofracture Experiment Sites 1 and 2 were previously discussed in Sect. 3.8.1.13 and Sect. 3.9.1.14, respectively.

WAG 10 is significantly different from the other subject WAGs in that the grout sheets are located at depths of between 91.5 and $305 \mathrm{~m}$ (300 and $1000 \mathrm{ft}$ ) below the ground surface. These grout sheet are thin [2.5 cm (1-in.)] layers of solidified, cement-based LLW slurry that was injected into subsurface fractures. The geologic formation used for the injections at all four hydrofracture locations was the Pumpkin Valley Shale, which is the lowest formation in the Conasauga Group. The slurry constituents were selected and formulated to produce a solid product that would retain the radionuclides in the LLW. Using this technique, it was believed that the radionuclides would be retained in the grout and would not be subject to groundwater transport.

\subsubsection{Old Hydrofracture Facility}

The Old Hydrofracture Facility was commissioned in 1963 and was removed from service in 1980. This facility served as a pilot plant to demonstrate the feasibility of permanent disposal of LLW in impermeable shale formations using hydrofracture methods. The waste injection well at this site was installed within a borehole drilled to a depth of $320 \mathrm{~m}(1050 \mathrm{ft})$ below the ground surface. Injections of grout and water were made at intervals from 239 to $301 \mathrm{~m}$ (782 to $988 \mathrm{ft}$ ). Waste injected at this facility was evaporator-concentrated LLW transferred from the Bethel Valley waste storage tanks. During the operation of this facility, 7 experimental injections and 22 operational injections were conducted. Following each waste injection, the cased observation wells surrounding the facility were logged to determine the extent and orientation of the grout sheets. The sheets formed in different directions along bedding planes; however, there was no evidence that any of the sheets extended more than $183 \mathrm{~m}(600 \mathrm{ft})$ from the injection well location. 
The volume of grout injected totaled $8,705,500 \mathrm{~L}(2,300,000 \mathrm{gal})$, which contained $40,000 \mathrm{Ci}$ of ${ }^{90} \mathrm{Sr}$; $609,000 \mathrm{Ci}$ of ${ }^{137} \mathrm{Cs} ; 233 \mathrm{Ci}$ of ${ }^{244} \mathrm{Cm} ; 5.8 \mathrm{Ci}$ of transuranics; and other unidentified radionuclides. No reported surface releases of grout occurred at the facility with the exception of an incident in which it was necessary to divert grout to the Old Hydrofracture Facility Waste Pit until it could be retrieved and pumped down the injection well. Additional information concerning this incident was previously discussed in Sect. 3.6.1.3.

\subsubsection{New Hydrofracture Facility}

The New Hydrofracture Facility was commissioned in 1982 and was removed from service in 1985. This facility was constructed to replace the Old Hydrofracture Facility and served as the operational LLW waste disposal system for ORNL. The waste injection well at this site was installed within a borehole drilled to a depth of $338 \mathrm{~m}(1107 \mathrm{ft})$ below the ground surface. Injections of grout were made at intervals from 302 to $326 \mathrm{~m}$ (990 to $1069 \mathrm{ft})$. Waste injected at this facility was concentrated LLW and sludge removed from the gunite tanks in the South Tank Farm. During the operation of this facility, 1 experimental injection and 13 operational injections were conducted. The volume of grout injected totaled 10,976,500 L (2,900,000 gal), which contained $644,000 \mathrm{Ci}$ of ${ }^{90} \mathrm{Sr}, 83,800 \mathrm{Ci}$ of ${ }^{137} \mathrm{Cs}, 7500 \mathrm{Ci}$ of ${ }^{244} \mathrm{Cm}, 2100 \mathrm{Ci}$ of transuranics, and $13,300 \mathrm{Ci}$ of other radionuclides. No reported surface releases of grout occurred at the facility.

\subsubsection{Characterization of Groundwater Contamination}

The primary reference used to obtain information concerning groundwater contamination related to WAG 10 was the RCRA Facilities Assessment for Oak Ridge National Laboratory (Energy Systems 1987c). This document indicated that three deep monitoring wells were installed at the New Hydrofracture Facility in 1984. Two of these wells were found to be contaminated with radiological constituents ranging from 94,000 to $400,000 \mathrm{~Bq} / \mathrm{L}$ at approximately the same depths at which some of the New Hydrofracture Facility grout sheets are located. The document also noted that there is no information to suggest that the radiological contamination detected in the monitoring wells has migrated from the grout sheets to surface streams within the ORNL area.

\subsection{WAG 12}

\subsubsection{Site Location, Description, and Background}

WAG 12 is located in Melton Valley and is the location of the Closed Contractors' Landfill, which is the only SWMU located at this site (Fig. 3.1). WAG 12 is located $\sim 2.3 \mathrm{~km}$ (1.4 miles) east-southeast of the main ORNL plant site and is $\sim 1.2$ ha (2.9 acres) in size. The landfill functioned as the disposal point for ORNL contractors' construction and demolition waste from 1950 until 1975, when disposal was stopped and the site was graded level and seeded. Estimates

of the amount of material buried at the site range from $-765,000$ to $1,300,500 \mathrm{~m}^{3}(1,000,000$ to $\left.1,700,000 \mathrm{ft}^{3}\right)$. However, no waste-specific records were kept on the landfill operation, and no administrative controls were maintained on the nature of the waste being buried. As a result, construction waste sent to the landfill probably included such items as empty paint cans and other similar debris that could have included small amounts of hazardous waste. 
None of the existing documentation indicates that WAG 12 represents a release source of either radioactive or hazardous materials. Aerial radiation surveys and walkover radiation surveys have not detected radiation levels above background. Also, no visible leakage or seeps have been observed or documented.

\subsubsection{Characterization of Groundwater Contamination}

None of the available reference documents reviewed contained information concerning investigation of groundwater contamination related to WAG 12.

\subsection{WAG 17}

\subsubsection{Site Location, Description, and Background}

WAG 17 is located in Bethel Valley $\sim 945 \mathrm{~m} \mathrm{(3100} \mathrm{ft)} \mathrm{east} \mathrm{of} \mathrm{the} \mathrm{main} \mathrm{ORNL} \mathrm{plant} \mathrm{area}$ and is composed of $\sim 9.3$ ha (23 acres) (Fig. 3.26). The facilities in this WAG constitute the ORNL Services Area and include the shipping and receiving departments, machine shops, carpenter shops, paint shops, lead burning facilities, garage facilities, welding facilities, tritium facility, and the materials storage area. This area contains eight SWMUs; the Septic Tank for Building 7000, Waste Oil Storage Tanks at 7002W, 7009E, 7075, 7021, and 7030E, and Photographic Reproduction Waste Storage Tanks at 7075A and 7075B. WAG 17 also contains one documented leak site involving the release of gasoline at an underground tank.

\subsubsection{Septic Tank for Building 7000}

This below-grade concrete tank is located west of Building 7000 and has a capacity of $147,615 \mathrm{~L}(39,000 \mathrm{gal})$. The tank was formerly used as a septic tank, but is now used as a collection vessel for the pumping station that pumps waste to the Bethel Valley treatment system. The tank has operated from 1959 to the present with no history of leaks or releases and reportedly receives only domestic sewage.

\subsubsection{7002W Waste Oil Storage Tank}

This tank is located above ground and is west of Building 7002. It is constructed of steel with a capacity of $9463 \mathrm{~L}(2500 \mathrm{gal})$ and has operated from 1984 to the present for waste oil storage. There are no records indicating that the tank has been used to store hazardous materials or radionuclides; however, the contents of the tank have not been analyzed. To date, there have been no documented releases from this unit.

\subsubsection{7009E Waste Oil Storage Tank}

This tank is located below ground and is west of Building 7033. It has a capacity of $18,925 \mathrm{~L}(5000 \mathrm{gal})$ and has operated from 1975 to the present for waste oil storage. There are no records indicating that the tank has been used to store hazardous materials or radionuclides; however, the contents of the tank have not been analyzed. To date, there have been no documented releases from this unit. 


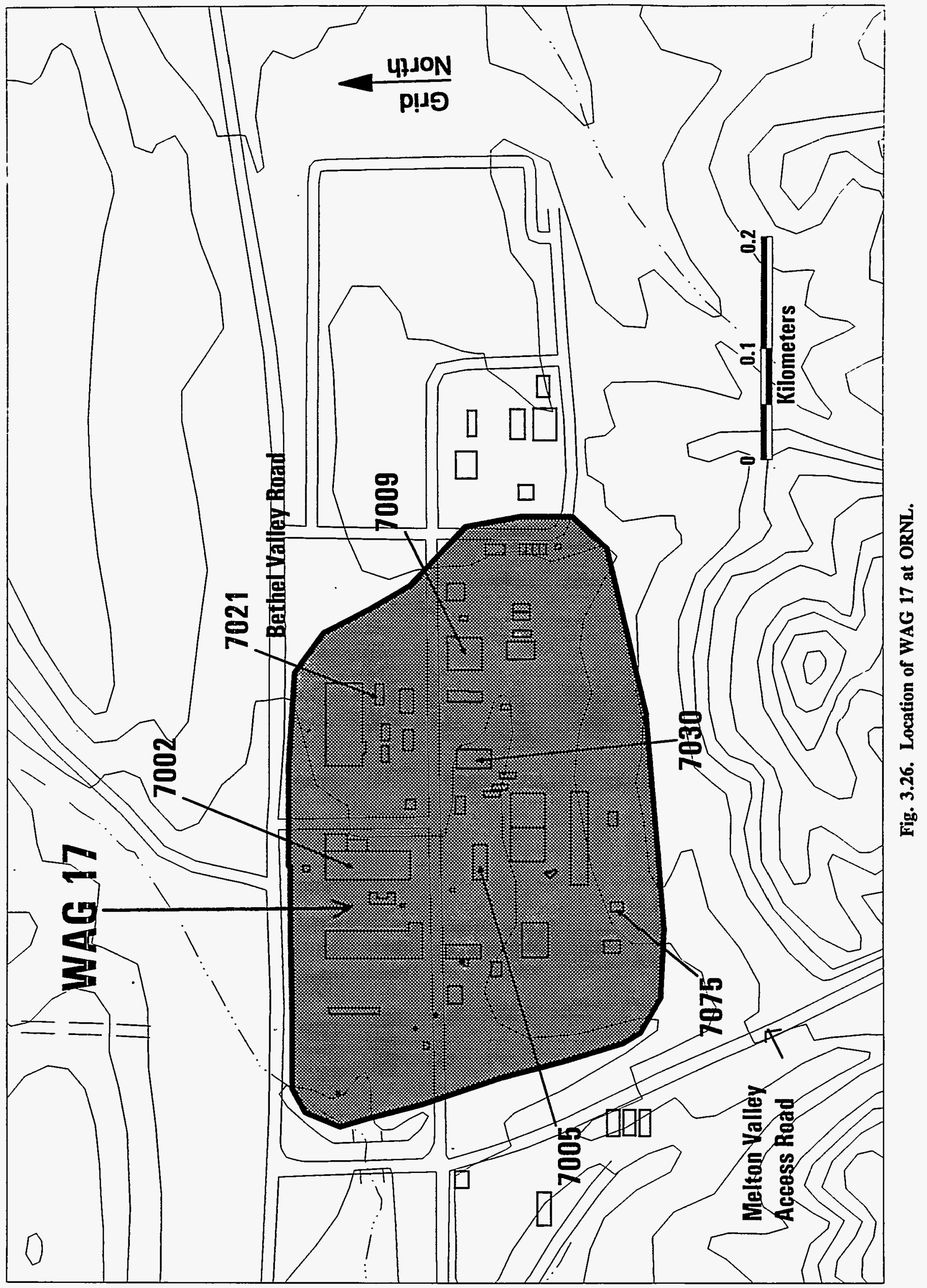




\subsubsection{7075 Waste Oil Storage Tank}

This tank is located below ground and is east of Building 7020. It has a capacity of $15,897 \mathrm{~L}$ (4200 gal) and was installed in 1982. It is presently used to store waste oil contaminated with tritium. No data are available regarding the presence of hazardous constituents. The tank is reportedly full, and no releases have been reported from this unit.

\subsubsection{7021W Waste Oil Storage Tank}

This tank is located above ground and is west of Building 7021. It is constructed of steel

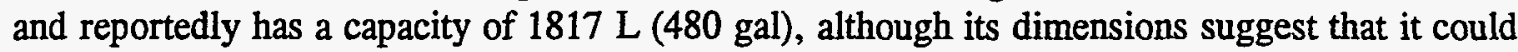
contain as much as $2884 \mathrm{~L}$ (752 gal). The tank was installed in 1983 and is currently being used to store waste oil. There are no records indicating that the tank has been used to store hazardous materials or radionuclides; however, the contents of the tank have not been analyzed. To date, there have been no documented releases from this unit.

\subsubsection{7030E Waste Oil Storage Tank}

This tank is located above ground at Building 7036. The tank is mounted on a vehicle and has a capacity of $4164 \mathrm{~L}$ (1100 gal). It began operating in 1975 and continues to be used to store waste fuel oil and reportedly PCBs. There are no reports indicating that radionuclides have been stored in this unit, and no releases have been reported from the unit.

\subsubsection{7075A and 7075B Photographic Reproduction Waste Storage Tanks}

These tanks are located above ground east of Building 7020 at the same site. Both tanks are constructed of fiberglass and are mounted on diked concrete pads. The 7075A tank has a capacity of $11,355 \mathrm{~L}(3000 \mathrm{gal})$, and the $7075 \mathrm{~B}$ tank has a capacity of $7570 \mathrm{~L}$ (2000 gal). Both tanks are presently active and used to store photographic waste, which is periodically transferred to the silver recovery facility in Melton Valley. The chemical composition of both tanks' contents is not known, but it is presumed to exceed the characteristic waste standard for silver in an aqueous phase. No leaks or spills from either of these units have been reported.

\subsubsection{Gasoline Leak Site at Underground Tank}

The underground leaking gasoline tank is located along the main access road to WAG 17 northeast of Building 7005. This tank has a capacity of $31,415 \mathrm{~L}$ (8300 gal) and was most recently used for the storage of unleaded gasoline. It was abandoned in August 1986 after leakage was detected in June 1986.

\subsubsection{Characterization of Groundwater Contamination}

\subsubsection{Groundwater monitoring system}

The groundwater monitoring system in and around WAG 17 includes 24 piezometers installed in 1986 or 1987 and 8 monitoring wells installed between 1989 and 1990. The piezometers were constructed of $5-\mathrm{cm}$ or 10 -cm (2-in. or 4-in.) ID PVC casing and screens. Sandpack was placed around the screens, and a bentonite seal was placed above the sandpack. 
The remaining annulus was grouted, and each piezometer was completed with a cap and protective cover.

The monitoring wells at WAG 17 were installed as part of a groundwater quality monitoring well installation program at ORNL. These wells were constructed of $5-\mathrm{cm}$ or $10-\mathrm{cm}$ (2-in. or 4-in.) ID stainless steel casing and screens. The remainder of the well construction was the same as described for the piezometers. Each well was completed with a steel protective casing, locking cap, steel guardposts, and a concrete pad. The locations of the monitoring wells or piezometers within WAG 17 for which groundwater quality data were evaluated for this summary are presented in Fig. 3.27, and a summary of the total depths for these installations is presented in Table 3.10 .

\subsubsection{Contamination nature and extent}

The principal source document used to develop an understanding of groundwater contamination at WAG 17 was the Oak Ridge Reservation Environmental Report for 1991 (Energy Systems 1992b). The environmental report summarized results for groundwater samples collected during April 1991 from the eight groundwater quality wells located along the east and west boundaries of the WAG. Several volatile organic contaminants were detected in samples collected from Well 1201: 1,1-dichloroethene, benzene, tetrachloroethene, trichloroethene, and vinyl chloride. Concentrations of these contaminants ranged from $21 \mu \mathrm{g} / \mathrm{L}$ for benzene to 1200 $\mu \mathrm{g} / \mathrm{L}$ for trichloroethene. Well 1202 was also found to contain trichloroethene contamination at a concentration of $13 \mu \mathrm{g} / \mathrm{L}$. Subsequent sampling conducted during April 1992 found similar concentrations of the same contaminants in Well 1201. However, trichloroethene contamination in Well 1202 was absent, and trichloroethene not previously detected in Well 1203 was encountered at $53 \mu \mathrm{g} / \mathrm{L}$.

Based on the historical information and analytical sampling results reported for WAG 17, the source and release mechanism for trichloroethene contamination within the WAG has not been identified, and the extent of groundwater contamination associated with trichloroethene and its degradation products has not been defined.

\subsection{WAG 19}

\subsubsection{Site Location, Description, and Background}

WAG 19 is located southeast of the main ORNL plant area in the vicinity of WAG 12 (Fig. 3.1). This WAG contains six SWMUs that represent ORNL's hazardous waste treatment and storage facilities. WAG 19 is broken up into two separate geographic clusters of facilities; the first cluster is located east of WAG 12 , and the second is located south of WAG 12 . The first cluster includes four permitted hazardous and mixed waste storage units; the second cluster includes two interim status units that treat and/or dispose of reactive or gaseous hazardous wastes. No releases of hazardous materials (chemical or radionuclide) have been reported at any of the SWMUs located in WAG 19. All of the facilities have been designed to contain any spills or leaks that occur from the waste containers handled or stored at the facilities. 


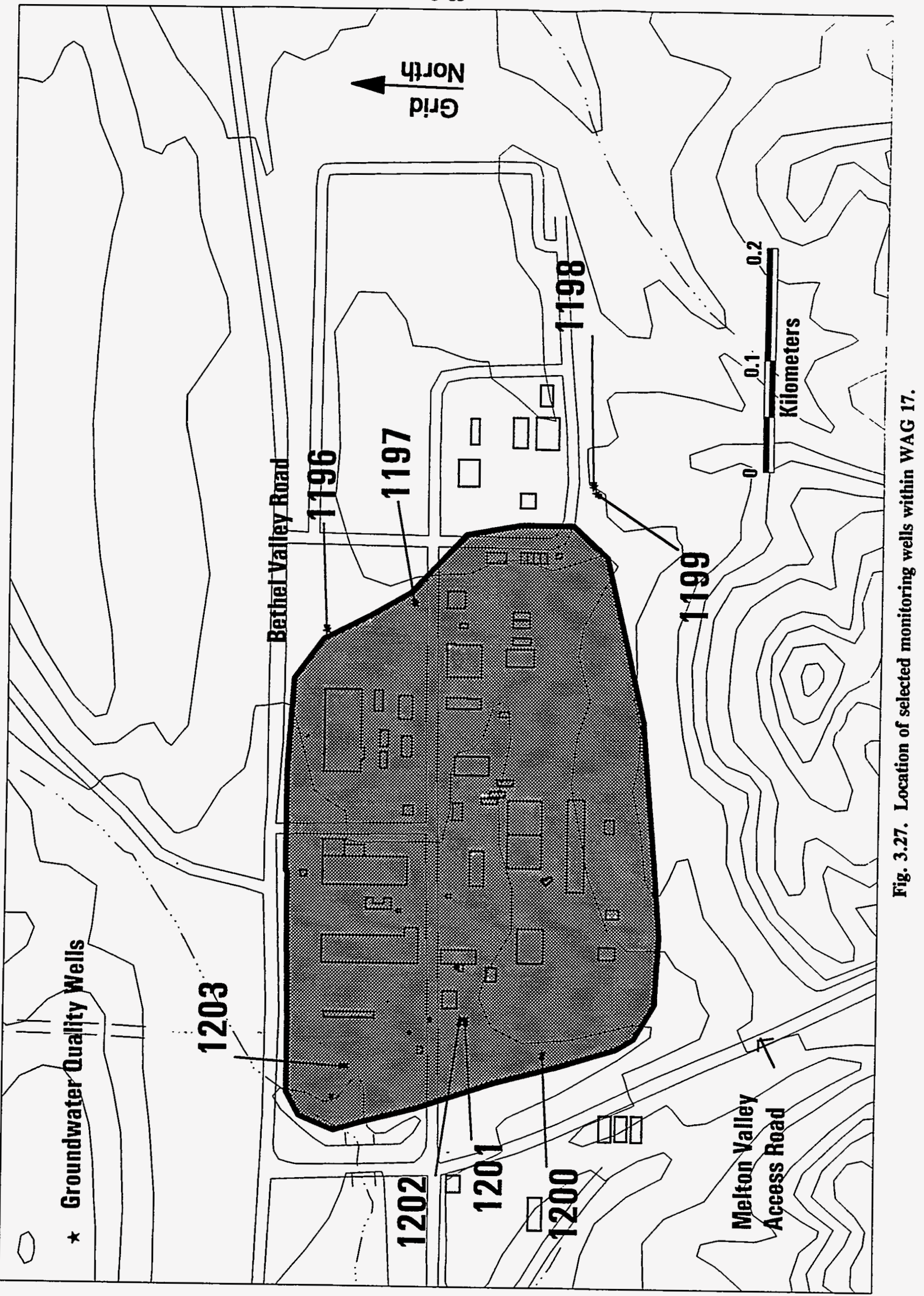


Table 3.10. Summary of WAG 17 groundwater monitoring system wells

\begin{tabular}{cc}
\hline Well no. & Total depth (ft) \\
\hline \multicolumn{3}{c}{ Groundwater quality wells } \\
1196 & 18.30 \\
1197 & 49.00 \\
1198 & 43.30 \\
1199 & 73.00 \\
1200 & 40.00 \\
1201 & 48.00 \\
1202 & 20.30 \\
1203 & 18.00 \\
\hline
\end{tabular}

\subsubsection{Characterization of Groundwater Contamination}

None of the available reference documents reviewed contained information concerning investigation of groundwater contamination related to WAG 19. 


\section{GROUNDWATER MODELING, AND CONTAMINANT FATE AND TRANSPORT INVESTIGATIONS}

Groundwater modeling and contaminant fate and transport investigations are related activities since both are used in tandem to analyze the migration of contaminants in the groundwater system, and both must be considered in proposing and designing any remedial actions for groundwater contamination. In this characterization plan groundwater modeling is addressed at two scales of resolution: a regional scale that for the ORNL site is defined as the Bethel Valley and Melton Valley portions of the total GWOU area, respectively, and a local scale that would be higher resolution for areas on the order of individual contaminant source WAGs.

\subsection{GROUNDWATER FLOW AND CONTAMINANT TRANSPORT MODELING}

It is expected the groundwater flow and contaminant transport modeling will play a key role in characterizing the GWOU. Model results will be used to aid investigators in their understanding of the site hydrologic regime, and will guide other remedial investigation activities. The models will be used to address the following overall objectives:

- resolve questions about the depth of the active flow system and the potential for off-site transport via the deep system;

- facilitate refinement of the site conceptual hydrologic model by testing current ideas against field data (history matching);

- improve our understanding of the relative importance of factors controlling fluid flow and contaminant migration (fracture flow, matrix diffusion, lithologic controls, etc.);

- determine the impact of scale on model applications (degree of detail required, boundary conditions, etc.);

- provide a means for evaluating the performance of remedial alternatives and support contaminant source WAG remedial alternatives selection;

- develop models which more accurately represent/account for known geometry, lithologic and structural properties, and flow and transport processes;

- $\quad$ provide a predictive capability for justifying well locations, based on what we expect to see from model output, and refinement of that capability through history matching;

- provide the front-end model to incorporate into cost-benefit decision analysis for optimizing monitoring and remedial activities; and

- provide combined groundwater flow and contaminant transport modeling capability to predict long-term migration of groundwater COPCs, to define the uncertainties inherent in such model predictions, and to quantify the uncertainties in such model predictions. 
Several modeling activities already planned by ORNL staff that are in progress address some of the key objectives identified for the GWOU modeling activities. The GWOU investigations will interface with other modeling groups and activities to allow maximum utilization of resources and to avoid duplication of effort. These group interfaces include data and resource sharing with the ORR Hydrologic and Geologic Studies (ORRHAGS), the High Performance Computing Center (HPCC), and focused local efforts within the GWOU and elsewhere on the ORR. The ORRHAGS team is currently supporting several modeling activities and investigations relevant to the GWOU objectives, such as geochemical modeling, analysis of the effects of density-driven flow, isotopic dating of groundwater, and comparison of fracture flow and porous media models. HPCC provides support for model development including generation of numerical codes capable of rapid model execution for the extremely large modal arrays required for regional scale problems being addressed at this site.

Modeling objectives will be addressed through the development and use of both regional and local scale models. Regional models will allow an examination of large scale processes, interactions between the shallow and deep flow systems, analysis of flow system boundary effects, and the impact of regional dynamics on local flow systems. Local-scale models (including contaminant source WAGs individually or in local combinations) will allow incorporation of greater detail for studying site-specific questions and testing remedial alternatives. Local-scale models will also allow examination of processes, such as the effects of fractures and lithologic controls on flow, which cannot be incorporated into regional models efficiently.

The following sections describe the specific objectives and modeling activities that will address those objectives for both scales of investigation. Model resources for both scales are identified and described in the final section.

\subsubsection{Regional Models}

\subsubsection{Objectives for regional models}

1. Determine the base of the active flow system and assess the potential for off-site transport of contaminants via the deep system.

Determination of the base of the active system will allow investigators to set an appropriate base for regional flow models and will be used to limit the depth of investigation for monitoring and remedial activities. Several studies are currently ongoing in the ORRHAGS group that will provide data for improved model calibration. These studies include an investigation of brine occurrence and chemistry throughout the ORR that will help delineate the base of active freshwater circulation. The GWOU investigations must utilize this information and support the completion of such characterization studies to achieve the objective of determining the base of active groundwater flow. Additionally, surface geophysical measurements may prove useful to locate the sharp salinity interface associated with the brine layer observed in parts of the ORNL GWOU. Use of the geophysical method for mapping the salinity interface requires method testing and calibration before areal mapping is feasible. Chapter 6 of this characterization plan includes discussion of the use of surface geophysical methods for brine zone mapping. As geophysical and direct measurements of the brine zone progress, flow models can be used to 
estimate flux rates and residence times for assessing the contaminant transport potential of the deep system.

2. Assess the impact of the regional flow system on local flow regimes to guide choice of appropriate boundary conditions in local models.

The development of local models usually involves establishing boundary conditions based on local surface divides with assumptions that the local flow regime is somehow isolated from regional effects. These assumptions may lead to poor calibration of local models and significant errors in flux and water balance calculations. Through development and calibration of regional models, boundary conditions can be chosen based on groundwater divides within a regional context, reducing the uncertainty associated with the assumption of isolated local systems. In addition, sensitivity analysis can be performed on regional models to test the sensitivity of local boundary conditions to uncertainties in input parameters.

3. Provide a means for testing scale differences through comparison with local scale models.

The use of numerical models requires assigning average parameter values over discrete regions that may include a single grid block or hundreds of grid blocks. The ability to distribute parameter values and incorporate heterogeneities is limited by the size of the grid, the density of data for calibration, computational time, memory allocation, and adequate field data for development of the conceptual model. Generally, a balance is struck between incorporating enough detail for the specific model application, while allowing enough generality to efficiently calibrate and apply the model. One means for testing the impact of scale in addition to the previously described objective is to compare regional and local scale models where they overlap. One such model comparison is currently being completed for WAG 6 and will provide information that can be applied to other local modeling activities within the GWOU.

4. Test and refine the site conceptual model.

At the site-wide or regional scale, the conceptual model of groundwater flow, as incorporated into computational models, incorporates large scale features such as major flow system boundaries, recharge and stormflow concepts, vertical hydraulic conductivity contrasts, and water budget. At the local scale, the conceptual model and computational implementation of groundwater modeling incorporating local geologic controls on groundwater flow (e.g., cavities and conduit flow) and hydrogeologic heterogeneity along with contaminant transport attenuating properties, such as matrix diffusion and $\mathrm{Kd}$, have significant application.

At the regional scale (Bethel Valley and Melton Valley scale), the conceptual model for groundwater flow and solute transport incorporates the components of:

- $\quad$ areal recharge with seasonal variations controlled by variations in precipitation patterns and seasonal variations in evapotranspiration;

- vadose processes that tend to damp or attenuate the flux of water that actually reaches the water table as recharge; and 
- groundwater flow from higher topographic areas toward lower topographic areas with flow pathways and flow- and transport-controlling parameters (hydraulic conductivity, dispersivity, retardation) modified by the general geologic structure and lithologic variations as defined at the geologic formation scale and by depth below the ground surface or elevation.

The site hydrologic and geologic conceptual model provides the basis for our understanding of contaminant transport processes and, therefore, drives the schemes for monitoring contaminants and mitigating their migration. As such, refinement of our understanding of the site hydrology must be an essential component in the characterization of ORNL groundwater. Regional models will provide a means for testing large scale processes and aquifer properties through calibration of steady-state and transient three-dimensional saturated models. These models will, in turn, help to identify data gaps to direct field measurements. In this way, the conceptual and computational models will be updated.

Regional groundwater models on the ORR have all indicated recharge occurs on the ridges only, which is an unrealistic distribution. Several explanations for this result will be considered in future modeling. Because the regional model only accounts for the saturated zone, it is possible that the model is showing recharge to the deep system only and that this does occur from the ridge tops. Smaller scale saturated/unsaturated models will be used to test this hypothesis. Alternatively, a more complex permeability distribution could change the modeled recharge pattern. This effect could be tested by regional fracture flow modeling.

Examples of how three-dimensional regional modeling is necessary for site-wide flow system delineation include:

- The need at ORNL to evaluate whether strike preferential flow could be caused by anisotropy or by discharge to cross-cutting streams. Anisotropy in all three dimensions must be considered to address this question.

- The need to address the question of whether or not the ridges (Haw Ridge and Copper Ridge) act as groundwater divides for the deep flow system, as suggested by the site conceptual model; or if there is significant underflow that would provide a means for groundwater transport of contaminants off site in presently unidentified and nonmonitored pathways.

5. Provide a front-end model to incorporate into cost-benefit decision analysis for optimizing monitoring and remedial activities.

With the high cost of implementing monitoring and remedial activities, it is increasingly important to analyze the cost of these activities against the anticipated benefit, as discussed earlier in this section. A regional groundwater flow model is an essential component of hydrogeologic decision analysis. At the regional scale, decision analysis could be used to evaluate the worth of existing data points for well plugging and abandoning activities and for locating new piezometers and water quality wells to address regional questions. 


\subsubsection{Activities for regional modeling}

In order to address these objectives, two broadly defined activities have been identified.

1. The first requirement is the development of regional-scale models that cover all of the GWOU. Efficient calibration and utilization will be achieved by the development of separate models for Melton and Bethel Valleys utilizing the same code. The three-dimensional saturated model developed for western Melton Valley (West and Toran 1992) has been expanded to incorporate the eastern portion of Melton Valley. This activity, supported by PICS on the ORNL massively parallel computer (supercomputer), is nearly complete. The regional-scale model for Bethel Valley must be created. The Bethel Valley model will utilize the same numerical code and gridding scheme as the Melton Valley model so that portions of these models can be tied together as needed. The Bethel Valley model will also require use of the supercomputer.

2. The second requirement is the preparation of transient data sets defining seasonal and event related variations in groundwater levels and head pressures for use in calibration of the regional-scale models to the dynamic character of the hydrologic cycle at the ORR. Calibration of the regional models will be improved by the development of three-dimensional saturated transient models and history-matching to time series water level and flux data. Development of the transient model for Melton Valley is planned for FY94. Calibration of these models will also be improved through the use of inverse modeling techniques that provide a better estimation of the values and distribution of aquifer properties.

These early models will utilize P-FEM, a version of 3DFEMWATER (Yeh 1987) that was optimized for use on the supercomputer. P-FEM is a porous media code and requires that the effects of fracture flow be simulated by anisotropy. The advantage of this code over a fracture flow code is that it is simpler to apply and is adequate for estimating regional flow characteristics. The disadvantage is that it will not simulate discrete fracture flow paths or transport times. The development of local scale fracture flow models, described later, will lead to the development of regional fracture flow models in the future.

\subsubsection{Local Models}

\subsubsection{Objectives for local models}

1. Determine the relative importance of controls on fluid flow and contaminant migration such as fracture flow, strata-bound flow, and matrix diffusion.

The greater detail afforded by local-scale models will allow a closer examination of the relative importance of geological and structural.controls on groundwater flow patterns and, ultimately, on the fate and transport of contaminants. These detailed models will provide the framework for developing and testing remedial alternatives. Of particular importance is the incorporation of fracture flow into these models to allow more accurate simulation of contaminant transport pathways and incorporation of matrix diffusion processes. 
2. Test and refine the site conceptual model.

At the local model scale (individual contaminant source WAG), the conceptual model of groundwater flow and contaminant transport incorporates:

- local recharge with variations related to vegetative cover type or presence of hydrologic caps and soil type, as well as seasonal variations described for the regional scale models;

- local scale stormflow and vadose processes related to the amount of site soil profile modification cause by waste disposal activities, capping, and vegetative patterns; and

- groundwater flow from upland recharge areas toward lowland discharge areas incorporating the effects of flow through waste disposal units, vadose materials, and within the groundwater zone including local detailed information on geologic structures, detailed lithologic distribution, matrix material characteristics, and conventional contaminant retardation mechanisms.

Detailed examination of the site conceptual model can be accomplished using local models. Shallow effects such as stormflow, and local heterogeneities such as waste disposal trenches, can be accommodated in these local models that will ultimately provide the tools for testing specific remedial alternatives. Determination of local controls on groundwater flow and contaminant transport and establishment and use of local-scale models are essential to successful remediation.

3. Provide a means for testing scale differences through comparison with regional models.

As described in the previous section, comparative studies between local and regional models will be performed to assess the effects of grid size and local boundary conditions on model output.

4. Provide front-end models to incorporate into cost-benefit decision analysis for optimizing monitoring and remedial activities.

Hydrogeologic decision analysis needs to be applied at both the local and regional scales. At the local scale, decision analysis can be applied to optimizing monitoring networks and to assessing the worth of remedial alternatives in terms of reduction of risk based on model predictions.

\subsubsection{Activities for local models}

Establishing a capability for consistent local-scale models within the ORNL GWOU requires testing and development of appropriate tools for detailed site modeling in the environment of the ORR, defining the input data requirements for the chosen model, determining the appropriate local model boundaries, and obtaining calibration data sets for the model area. A strong interface exists between the ORNL GWOU and the contaminant source WAGs in the areas of groundwater system characterization and data collection. This strong interaction will allow the GWOU modeling activities to dovetail with the overall ORNL ER Program priorities for RI/FSs at various contaminant source WAGs and OUs throughout the complex. 
The local-scale modeling activity for ORNL begins with the development of a generic site model using FRAC3D, a fracture flow and solute transport code developed by Therrien and Sudicky (1993) at the University of Waterloo. This generic model will serve as a training vehicle and starting point for development of site-specific models. The performance and usability of this model will be tested through application at an existing groundwater contaminant plume site at ORNL. Potential model test sites include the Trench 7 in WAG 7 and the Corehole 8 plume in WAG 1. These activities are envisioned as a cooperative effort involving both GWOU and ORRHAGS resources.

Depending on the success of the Beta test for FRAC3D, it is anticipated that many of the site-specific models will be developed utilizing this code due to its ability to incorporate many of the complexities inherent in the flow and transport system at the ORR.

Several initial tasks required for local-scale modeling have been identified and are described as follows:

- Evaluation of the role of stormflow on local water budgets and flow systems. To examine details of the shallow system, a two-dimensional stormflow model is currently under development and is scheduled to be completed in FY94. This model is being developed for a cross section through WAG 6 and will be further calibrated using field data that will be collected in FY94 as part of the WAG 6 environmental monitoring program. Output from this model will provide verification of the distribution of subsurface flow as proposed by the site conceptual model.

- Evaluation of the effect of model grid scaling and selection of boundary conditions within the regional model context. All local models will need to be compared to and developed in conjunction with regional models to assess the appropriateness of local boundary conditions. The impact of scale is currently being evaluated as part of the WAG 6 modeling activities for FY93 and FY94. A local model to support engineering design was developed by Environmental Consulting Engineers for the WAG 6 area using 3DFEMWATER. Water budgets, boundary fluxes, and calibrated heads are being compared with those from the Melton Valley regional model to identify differences. This effort will provide information critical to the development of other local models as part of the GWOU activities.

- Evaluation of the role of geologic structures on groundwater flow and modeling. An understanding of the relative importance of structural controls and media properties on flow characteristics will be accomplished by comparison of the output from porous media and fracture flow models. These comparisons will need to be made at the local level initially, as the fracture flow models will first be developed at that scale. The results of these comparisons will drive decisions about the need to incorporate fracture flow into regional models. Some of these comparative activities will be addressed as part of the ORRHAGS modeling activities for FY94.

Following development of the local models, their primary uses will be to support site characterization and to support development and testing of remedial alternatives. The development and calibration of local models for individual WAGs will support site characterization by providing information about local flow patterns and contaminant transport 
pathways. Additional data needs will be identified and model results will be incorporated into the development of site characterization and monitoring strategies.

As described above, greater detail can be incorporated into local models and it is anticipated that site-specific models will be used to develop and test remedial alternatives. In using these models for predictive purposes, it must be remembered that these predictions carry with them substantial uncertainty. Validation is an indication of the ability of the model to match historical data under historical conditions and should not be construed as the ability of the model to predict future behavior under future conditions. Nevertheless, well calibrated models can provide a means for first-order prediction of the response of the system to stresses, and iterative updating will improve the model's predictive capability.

A key component of both site characterization and development of remedial alternatives is the incorporation of hydrogeologic decision analysis. All strategies for monitoring and remediation must be determined within the framework of cost versus benefit.

\subsubsection{Resources}

Several groundwater models currently exist and will be applied to GWOU modeling objectives. Those that will be directly applied include a regional three-dimensional steady state saturated groundwater model for Melton Valley (West and Toran 1992) and a smaller scale steady state saturated groundwater model for WAG 6 (ESI 1993). In addition, two-dimensional saturated/unsaturated transient groundwater models have been developed for WAG 6 (ESI 1993; Gwo 1992). These models will provide the basis for development of a three-dimensional saturated transient model for Melton Valley and a three-dimensional saturated/unsaturated steady state model for WAG 6 during FY94, as well as providing a template for development of a regional model for Bethel Valley.

Numerous groundwater and solute transport codes are available at ORNL (Moore and Toran 1992, Table 6). Those proposed for use in support of the GWOU modeling objectives primarily include the following:

- 3DFEMWATER: a three-dimensional saturated/unsaturated finite difference groundwater flow code for porous media (Yeh 1987).

- P-FEM: a version of 3DFEMWATER adapted for massively parallel processing (Toran et al. 1992).

- FRAC3D: a three-dimensional saturated/unsaturated finite difference groundwater and solute transport code for porous and discretely-fractured porous media (Therrien and Sudicky 1993).

- HYDROGEOCHEM: coupled transport and geochemistry (Yeh and Tripathi 1990).

The computational resources available for support of the GWOU modeling objectives are considerable inciuding ORNL VAXs, various ORNL work stations, and the ORNL Center for Computational Science family of supercomputers. 


\subsection{CONTAMINANT FATE AND TRANSPORT INVESTIGATIONS}

\subsubsection{Introduction}

Risk assessments for groundwater contaminants require use of either assumptions of contaminant transport parameters or development of site-specific data that can be used to perform more realistic modeling of the groundwater flow and transport system. In characterizing the ORNL GWOU, the intention is to develop site-specific data concerning the behavior of the COPCs in the local hydrogeologic environment. Historically, contaminant transport models used on site have relied upon either published data for adsorption coefficients for specific contaminants or have utilized batch test results to derive bulk Kd values. Neither approach provides data that are compatible with current knowledge of the nature of the groundwater flow systems at the ORR. These systems are characterized as fractured media having variable porosity and hydraulic conductivity. The weakness of previous transport modeling efforts has been the use of hydrogeologic concepts and models that oversimplify the actual site conditions. Such oversimplification and use of crude estimates of contaminant sorption or retardation characteristics have often resulted in poor model calibration to observed contaminant plumes.

As a part of verifying and strengthening the conceptual model of groundwater flow and contaminant transport at ORNL, investigations will be performed leading to a broader understanding of the factors that control the mobility of COPCs in the subsurface. These factors include:

- Defining source concentrations for contaminant plumes that merit model analysis for longterm transport. At contaminant source WAGs that have site or remedial investigations, the source WAG groundwater investigations will perform these investigations. Sources in areas outside source WAG boundaries may be investigated directly by the GWOU.

- Developing retardation mechanism characterization data compatible with the input requirements of fractured material models that will be used in local-scale models (including matrix porosity, COPC adsorption or retention in the matrix, and fracture orientation data).

- Determining the variability and distribution of porosity in the subsurface.

- Characterizing the general mineralogical components of the major stratigraphic units within the ORNL GWOU to enable more reliable geochemical modeling.

Quantification of contaminant fate and transport mechanisms is an integral part of creating reliable groundwater contaminant transport models. Fate and transport investigations for ORNL groundwater characterization will be performed at the scale of the local groundwater models. Using the local approach for contaminant fate and transport investigations allows maximum interfacing of the GWOU investigations with those of the contaminant source WAGs where higher spatial resolution will be incorporated in the modeling. Figure 4.1 shows a conceptual flow chart for the integration of groundwater flow and contaminant transport modeling at the local model scale. This flow chart identifies the principal data requirements for a groundwater flow and contaminant transport modeling for the baseline risk assessment. The following sections describe the process that will be used to obtain the necessary fate and transport data in the ORNL GWOU. 


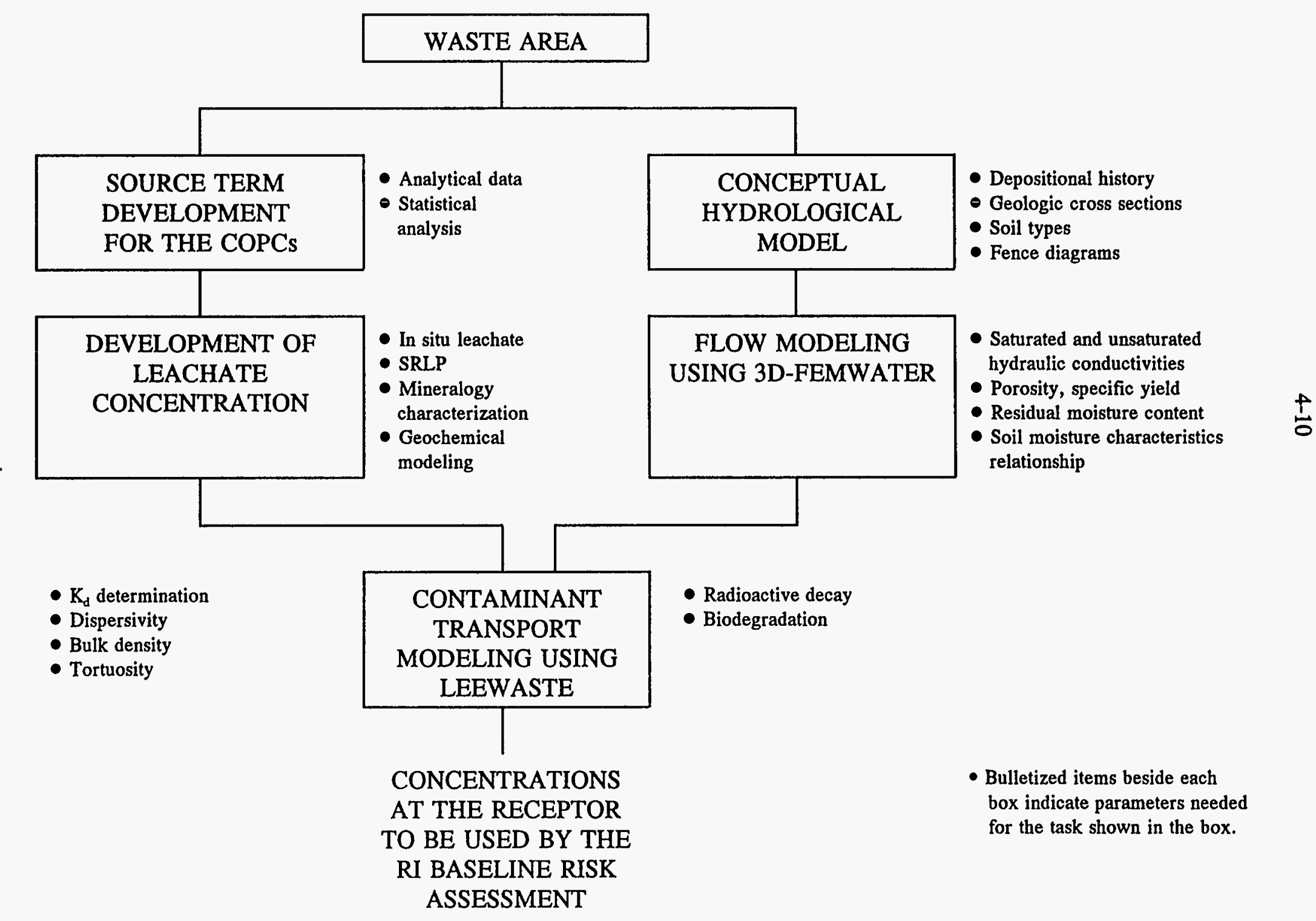

Fig. 4.1. Conceptual flow chart for conducting fate and transport modeling. 


\subsubsection{Contaminant Source Concentration}

Within the operating strategy in use at ORNL, the determination of contaminant source concentrations is a requirement for the principal contaminant source WAGs. The GWOU takes primary responsibility for modeling the long-term fate and transport of contaminants in the groundwater system and will use leachate composition derived from source WAG remedial investigations whenever available. The GWOU will characterize source concentrations for SWMUs not included in contaminant source WAGs and for secondary contaminant sources where needed.

Determination of contaminant source concentrations is required for any realistic contaminant transport effort. Approaches to source concentration determination include: sampling and direct analysis of waste, sampling of existing leachate in contact with the waste, and solubility-based modeling of leachate based on data or information concerning the waste form. Wastes disposed at ORNL have been quite heterogeneous in their radiochemical composition and waste form. Data are not available to adequately define the leachate composition using the solubility limited approach. In some instances at ORNL, waste is sampled and analyzed to determine the waste and leachate composition. To date, this approach has been used to characterize sludges contained in tanks and for contaminated soil characterization.

The volume and heterogeneity of solid low-level radioactive wastes disposed by shallow land burial at ORNL are large. The preferred method for determining contaminant source concentration for the groundwater pathway is by installation and sampling of drive point wells installed in saturated portions of waste disposal units. The advantages of this method over waste sampling and direct analysis include greater worker protection by limiting exposure to potentially highly contaminated material, and the ability to identify those contaminants that are chemically mobile. The assumption, which underlies this approach to source term definition, is that at least some of all contaminants present have been released from their disposal containers and would be available for detection.

\subsubsection{Retardation Mechanism Definition}

Solute or contaminant retardation is a broad term as applied here including the mechanisms of chemical adsorption, ion exchange, matrix diffusion, and biodegradation. The task of defining the retardation mechanisms for use in fate and transport modeling within the ORNL GWOU includes identifying which mechanism(s) affect the mobility of each of the major COPCs present in each of the local-scale model areas. Retardation mechanism investigations will emphasize the behavior of major COPCs and those with very long half-lives (typically the alpha particle emitting radionuclides) because the long-term fate and transport analysis for these radionuclides may constitute limiting cases for the baseline risk assessment. The principal components of these retardation mechanism investigations include:

- Perform a limited number of batch sorption/desorption tests on soil and bedrock materials to bracket batch Rd characteristics for the principal COPCs. Determination of the reversibility of these tests is important to create sorption/desorption isotherms to approximate the behavior of contaminant retardation as concentration fronts pass through the soil or rock material. 
- Perform column tests on soil or saprolite and bedrock materials to determine the retardation characteristics of contaminants passing through natural features in the most undisturbed condition possible. Again, determination of the passage of concentration fronts through the columns is important to quantify the concentration and time dependence of retardation.

\subsubsection{Soil and Bedrock Porosity Determinations}

Porosity is a parameter which is important both for the unsaturated groundwater flow modeling and for the contaminant transport modeling. Because it involves primarily laboratory testing, porosity testing is addressed in Chap. 6. Porosity measurement methods useful for bedrock tests include gravimetric and volumetric analysis using water as the saturating fluid or mercury poisimetry. American Society for Testing and Materials (ASTM) methods are available for porosity measurement in soils, and column tests used for retardation mechanism tests may provide effective porosity data.

The purpose for quantifying porosity as part of the fate and transport investigations is to provide the necessary data documenting the variability and distribution of porosity throughout local-scale model areas to allow realistic groundwater flow and contaminant transport modeling of specific contaminant plumes or flow paths. A significant contrast in porosity between soil and bedrock has profound effects on the mobility of contaminants and on the modeling required for realistic site analysis. This distinction is compounded by contrasts in the retardation characteristics for COPCs because of chemical and mineralogical differences between soil and bedrock.

A distribution of data will be obtained for each local-scale model area by testing soil samples obtained from well construction or from shallow test pits where appropriate and from rock core obtained from installation of additional multi-zone groundwater monitoring equipment. When feasible, existing bedrock core from the ORNL site will be utilized for porosity testing.

\subsubsection{Mineralogic Characterization}

Characterization of soil mineralogy will be necessary to assess the precipitation of contaminants from leachate that percolates through the soil column. To obtain data on the mineralogy long potential flow paths to the receptor, petrographic and X-ray diffraction studies will be conducted with selected uncontaminated samples obtained from the site.

The number of samples and duplicates will be chosen during the site characterization study representing all of the different types of materials present beneath the ORNL site. Petrographic

and $\mathrm{X}$-ray diffraction results must agree for all minerals identified in the samples, and the relative percent of each distinct mineral in the samples must agree within $\pm 20 \%$.

Petrographic studies will be conducted with oversized thin sections prepared for the site soil samples. All samples will be impregnated with an epoxy resin prior to the preparation of thin sections. Half of the area of all thin sections will be used to identify all mineral phases (e.g., clay, calcite, dolomite, quartz), and a point-counting technique will be used for quantification (e.g., $50 \%$ clay, $20 \%$ calcite, $10 \%$ dolomite, $8 \%$ quartz, trace zicron). 


\section{4-13}

$\mathrm{X}$-ray diffraction studies will be conducted to identify the clay minerals in the site soils. Samples used for X-ray diffraction studies will be sieved to separate the $<200$-mesh size fraction. This size fraction will be placed in deionized water that contains a deflocculating agent and ultrasonically agitated to desegregate the particles. Centrifugation or settling tube will be used to separate the silt fraction ( $>2$ microns); the remaining clay suspension will be decanted into a vacuum filtration system to collect the clay fraction and orient the crystallites parallel to their basal (001) d-spacing. The relative intensity of the principal d-spacing reflection of a clay mineral is used to semiquantify $( \pm 20 \%)$ the proportion of clay mineral in a sample. An appropriate calibration standard (e.g., NBS Silicon d-spacing SRM-640b) will be run before and after the analysis of the samples to ensure instrument calibration. 


\section{RISK ASSESSMENT}

\subsection{INTRODUCTION}

The ER program at ORNL has begun to develop a risk-based strategy for addressing environmental issues throughout the site. Major aspects of the strategy include:

- support rapid reduction of risks to human health and the environment;

- reduce contaminant releases off site;

- address the major sources of contaminant releases in a prioritized fashion, addressing sites of greatest concern (risk, regulatory, public) first;

- identify source control action that results in a significant reduction of risks or contaminant flux, or may prevent the spread of contamination that could lead to significant future risk; and

- collect data necessary to design, implement, and verify final remedies.

This basic strategy has been translated into specific risk assessment strategies for individual WAGs. Much of the strategy is being implemented through the WAG 2 site investigation. WAG 2 is the surface water integrator at ORNL and the focus for implementing the strategy because it is assumed that at least $90 \%$ of the water flowing through the waste units at ORNL resurfaces in the surface water system. WAG 2 risk assessment support uses an Integration Point (IP) assessment to address sources that are currently contributing the most to off-site contamination through White Oak Dam. This method assesses risk at points in the surface water system that are strategically located to illustrate contaminant migration from major sources that contribute to contaminant flux over the dam.

The conceptual model for the surface water flow system in the White Oak Creek watershed lends itself to the IP assessment. However, based on the definition of the GWOU and on the current conceptual model for the groundwater system, a different type of risk assessment support is required for the GWOU.

This section presents:

- the current conceptual risk framework for the GWOU;

- the outline of a general strategy for providing risk assessment support for decisions that will need to be made concerning the GWOU over an extended period of time; and

- a brief discussion of some general risk assessment methods that will be used during various stages of the GWOU. 


\subsection{CONCEPTUAL RISK MODEL}

A conceptual risk model has four major components:

1. a contaminant fate and transport model (based on the conceptual hydrogeological model and information on each individual contaminant's tendency to partition into surrounding environmental media);

2. a conceptual exposure model that describes current and future potential exposures to human and environmental receptors, and the point (geographical location) at which the exposure will occur (known as the exposure point);

3. an understanding of the contaminants and their concentrations currently present in sources and surrounding environmental media, especially at the presumed exposure points; and

4. a knowledge of the toxicity of the known contaminant, which is used to determine the major contributors to risk at the site.

\subsubsection{Fate and Transport}

It has been estimated that at least $90 \%$ of the subsurface water on the site exits by means of the stormflow and water table interval zones and can be captured at existing surface water weirs. The conceptual model is not complete on the contaminant transport pathways to off-site receptors via groundwater in the intermediate and deep groundwater intervals. Currently, the model does not identify off-site migration of contaminants by groundwater and a resultant exposure to potential receptors. Groundwater in these intervals may flow directly to the Clinch River. However, the rates of flow are slow in these zones $\left(10^{-5}\right.$ to $\left.10^{-7} \mathrm{~cm} / \mathrm{sec}\right)$, and significant contaminant movement is unlikely. The conceptual hydrological and geological models for the GWOU are presented in Chap. 2.

Section 4.2 describes the chemical-specific properties (e.g., decay, solubility, etc.) and mechanisms of contaminant fate and transport.

\subsubsection{Exposure Model}

The conceptual exposure model is presented in terms of land use with and without institutional controls. In general, one can equate current land use to land use with government controls. Future land use may or may not include institutional controls. Because the GWOU risk assessment will focus on groundwater that does not resurface on site, only two major types of exposures are possible: those that result from groundwater feeding directly into the Clinch River and those occurring from intrusive human activities, such as constructing a well.

It is too early in the CERCLA process in Oak Ridge to attempt to identify future land uses of the ORR. The strategic planning for future use of the government-owned property at ORNL is a continuing topic of discussion that likely will be resolved over time. It is probable that the results of several OU risk assessments and cost-benefit analyses performed during feasibility studies will help derive the decisions concerning future land use. In the meantime, to aid the 
future land-use decision process, it is assumed that multiple land use scenarios will be evaluated and that data collection activities should be directed under the assumption that future residential receptors could be either on or off site.

\subsubsection{Land use with institutional controls}

Currently, groundwater at the site is not being used as a potable or industrial water source. It is assumed that if institutional controls are maintained in the future, on-site groundwater will not be used. However, institutional controls cannot prevent on-site groundwater from migrating to off-site groundwater or to the Clinch River. Currently, nine public water supply systems serve $-91,500$ people within a 32-km (20-mile) radius of the ORR. The intake for Kingston is located on the Tennessee River at about 0.6 river $\mathrm{km}(0.37 \mathrm{mile})$ above the confluence of the Clinch and Tennessee rivers and about 34.1 river $\mathrm{km}$ ( 21.3 miles) below the White Oak Dam outfall. Sixteen public groundwater supplies are located within a $32-\mathrm{km}(20$-mile) radius of ORNL. Of these sources, the closest to ORNL is the Allen Fine Spring supplying the Dixie Lee Utility District in Loudon County, which serves 6700 people. Private single-family wells are common in adjacent rural areas not served by the public water supply. Most of the residential wells, other than those adjacent to the City of Oak Ridge, are south of the Clinch River. The nearest resident is $-3.7 \mathrm{~km}$ ( 2 miles) from the ORNL site.

Potential exposure pathways by which a receptor may come into contact with contaminated water include:

- ingestion;

- dermal contact while showering or bathing;

- inhalation from household (showering and other) water use (volatiles only);

- watering of livestock (with eventual uptake into meat and milk); and

- ingestion of vegetables, meat, and milk if groundwater is used to irrigate vegetation, with eventual uptake into the meat and milk of livestock if groundwater is used to water livestock feed.

\subsubsection{Land use without institutional controls}

If the government releases control of the land in the future, the potential for exposures could change. Two likely land use scenarios are industrial and residential. Under the residential land use scenario, it is assumed that the above-mentioned exposures could occur. Under the industrial scenario, it is likely that groundwater would not be used.

\subsubsection{Current COPCs and Associated Risk}

Historical analytical data are available for groundwater wells at ORNL that have been monitored for compliance with DOE Order 5400.1. Groundwater concentration data from these wells were summarized and subjected to well-screening techniques for the purposes of identifying preliminary contaminants of concern for the GWOU. In this chapter, the COPCs list for the 
compliance wells are summarized. In addition, Appendix A provides a comprehensive summary of the risk results for these compliance wells and for the groundwater data collected for RIs at WAGs 1,5 , and 6 . The wells can be identified according to WAGs, but the screening of chemicals was performed for each well individually. The risk results were generated in a series of steps:

- eliminating chemicals that were not detected in any well;

- identifying the oral carcinogens;

- assigning values to non-detects;

- calculating risk for COPCs; and

- identifying the high-priority wells and contaminants.

The first step screened the available data for each well by frequency of detection; chemicals that were never detected in any well were eliminated from further consideration in the quantitative risk evaluation. All of the remaining non-detects were assigned a value equal to the sample's quantitation limit.

For the concentration term, after non-detects are assigned the detection limit value, a test for normality and log-normality is performed using the Kolmogorov-Smirnov Test. If a normal distribution provides the better fit based on this test, then the upper $95 \%$ confidence limit on the mean is calculated based on a normal distribution. If the underlying distribution is not normal, as represented here for when a log-normal distribution provides a better fit based on the test, then replacing censored observations by proxy values is an inefficient method that can produce biased estimates. In this case the log-normal distribution is estimated through a maximum likelihood procedure that finds the mean and standard deviations of the distribution by methods in Beauchamp et al. (1992) to reduce the bias in proxy methods for the mean for small sample sizes. The upper $95 \%$ confidence limit on the mean is then calculated based on this estimated log-normal distribution. The minimum of the upper $95 \%$ confidence limit and the maximum detected concentration is used as the representative exposure concentration.

The residential groundwater risk was then calculated for each well using the cancer slope factors for the contaminant, the representative concentration of the contaminant, and the default residential assumptions for the drinking water, dermal contact, and indoor inhalation pathways (EPA 1989). The equations used to calculate the pathway risk are listed in Table 5.1 for the drinking water pathway, Table 5.2 for the dermal contact pathway, and Table 5.3 for the indoor inhalation pathway.

Table 5.4 provides a summary of the carcinogenic contaminants that exceed $1 \times 10^{-4}$ risk and the perimeter wells where the exceedance occurred. Contaminants most commonly encountered that exceed $1 \times 10^{-4}$ include vinyl chloride, ${ }^{90} \mathrm{Sr}$, tritium, and beryllium. In a few high-ranking wells, vinyl chloride contributed the majority of the risk. However, because of its volatility, vinyl chloride does not appear in the surface water at high risk levels. In general, organics are detected in pockets of groundwater and are not as prevalent site-wide as radionuclides. When a chlorinated organic is detected, the risk associated with them is often higher than $1 \times 10^{-4}$ due to their high detection limits. The contaminants that drive the surface water ingestion risk at White Oak Dam are radionuclides ${ }^{90} \mathrm{Sr}$ and tritium). Therefore, it is expected that these radionuclides would comprise the majority of the risk in a number of the perimeter wells. However, the prevalence of beryllium at high risk concentrations was 
Table 5.1. Residential parameters for the drinking water pathway

Equations:

$$
\begin{aligned}
& \text { Radionuclide Intake }(\mathrm{pCi})=\mathrm{A}_{\mathrm{w}} \times \mathrm{IR} \times \mathrm{FI} \times \mathrm{EF} \times \mathrm{ED} \\
& \text { Chemical Intake }(\mathrm{mg} / \mathrm{kg} \text {-day })=\frac{\mathrm{C}_{\mathrm{w}} \times \mathrm{IR} \times \mathrm{FI} \times \mathrm{EF} \times \mathrm{ED}}{\mathrm{BW} \times \mathrm{AT}}
\end{aligned}
$$

\begin{tabular}{|c|c|c|c|}
\hline Parameter & Units & Value used & References/justification \\
\hline $\begin{array}{l}\text { Radiological Activity / Chemical } \\
\text { Concentration in Water }=\mathbf{A}_{\mathbf{w}} / \mathbf{C}_{\mathbf{w}}\end{array}$ & $\begin{array}{l}\mathrm{pCi} / \mathrm{L} \text { or } \\
\mathrm{mg} / \mathrm{L}\end{array}$ & $\begin{array}{l}\text { chemical } \\
\text { specific }\end{array}$ & Measured value \\
\hline Ingestion Rate $=\mathbf{I R}$ & $\mathrm{L} / \mathrm{d}$ & 2 & EPA $1991^{a}$ \\
\hline Diet Fraction $=$ FI & unitless & 1 & EPA $1989^{b}$ \\
\hline Exposure Frequency $=\mathbf{E F}$ & $\mathrm{d} /$ year & 350 & EPA $1991^{a}$ \\
\hline Exposure Duration = ED & years & 30 & EPA $1991^{a}$ \\
\hline Body weight $=\mathbf{B W}$ & $\mathbf{k g}$ & 70 & $\begin{array}{l}\text { EPA } 1991^{a} \text { - Combined mean of } \\
\text { female and male body weight }\end{array}$ \\
\hline Carcinogen averaging time $=\mathbf{A T}$ & days & 25550 & $\begin{array}{l}\text { EPA } 1991^{a} \text { - Equivalent to } 70 \text {-year } \\
\text { lifetime exposure, } 365 \text { d/year }\end{array}$ \\
\hline
\end{tabular}

a EPA 1989. Superfund Exposure Assessment Manual, EPA/540/1-88/001, Office of Remedial Response.

b EPA 1991. Risk Assessment Guidance for Superfund: Volume 1 - Human Health Evaluation Manual (Part B, Development of Risk-Based Preliminary Remediation Goals), Office of Emergency and Remedial Response, Washington, D.C. 


\section{$5-6$}

Table 5.2. Residential parameters for dermal contact with groundwater

\begin{tabular}{|c|c|c|c|}
\hline \multicolumn{4}{|c|}{$g / k g-d)=\frac{\left(C_{w}\right)(S A)(P C)(C F)(E D)(E F)(E T)}{(B W)(A T)}$} \\
\hline Parameter & Units & Value used & References/justification \\
\hline Concentration in water $=\mathrm{C}_{\mathrm{w}}$ & $\mathrm{mg} / \mathrm{L}$ & $\begin{array}{l}\text { chemical } \\
\text { specific }\end{array}$ & Measured value \\
\hline Skin surface area exposed $=\mathbf{S A}$ & $\mathrm{cm}^{2}$ & 23000 & EPA $1992^{a}$ \\
\hline Skin permeability constant $=\mathbf{P C}$ & $\mathrm{cm} / \mathrm{h}$ & $\begin{array}{l}\text { chemical } \\
\text { specific }\end{array}$ & \\
\hline Exposure time $=\mathbf{E T}$ & $\mathrm{hrs} / \mathrm{bath}$ & 0.25 & EPA $1992^{a}$ \\
\hline Exposure frequency $=\mathbf{E F}$ & baths/yr & 350 & EPA $1992^{\circ}$ \\
\hline Exposure duration $=$ ED & years & 30 & EPA $1991^{b}$ \\
\hline Conversion Factor $=\mathbf{C F}$ & $\mathrm{L} / \mathrm{cm}^{3}$ & $1 / 1000$ & \\
\hline Body weight $=\mathbf{B W}$ & $\mathrm{kg}$ & 70 & $\begin{array}{l}\text { EPA } 1991^{b} \text { - Combined mean of } \\
\text { male and female body weight }\end{array}$ \\
\hline Carcinogen averaging time $=\mathbf{A T}$ & $\mathrm{d}$ & 25550 & $\begin{array}{l}\text { EPA } 1991^{b} \text { - Equivalent to } 70 \text {-year } \\
\text { lifetime exposure, } 365 \mathrm{~d} / \text { year }\end{array}$ \\
\hline
\end{tabular}

a EPA 1992. Human Health Evaluation Manual, Supplemental Guidance: Standard Default Exposure Factors, OSWER Directive 9285.6-03, Office of Emergency and Remedial Response, Washington, D.C.

${ }^{b}$ EPA 1991. Risk Assessment Guidance for Superfund: Volume 1 - Human Health Evaluation Manual (Part B, Development of Risk-Based Preliminary Remediation Goals, Office of Emergency and Remedial Response, Washington, D.C. 
Table 5.3. Residential parameters for indoor inhalation pathway

\begin{tabular}{|c|c|c|c|}
\hline \multicolumn{4}{|c|}{$/ \mathrm{kg}-\mathrm{d})=\frac{\left(\mathrm{C}_{\mathrm{w}}\right)(\mathrm{K})(\mathrm{IR})(\mathrm{CF})(\mathrm{EF})(\mathrm{ED})}{(\mathrm{BW})(\mathrm{AT})}$} \\
\hline Parameter & Units & Value used & References/justification \\
\hline Concentration in water $=\mathrm{C}_{\mathrm{w}}$ & $\mathrm{mg} / \mathrm{L}$ & $\begin{array}{l}\text { chemical } \\
\text { specific }\end{array}$ & Measured value \\
\hline Volatilization Factor $=\mathbf{K}$ & $\mathrm{L} / \mathrm{m}^{3}$ & 0.5 & Andelman $1990^{\circ}$ \\
\hline Inhalation Rate $=\mathbf{I R}$ & $\mathrm{m}^{3} / \mathrm{d}$ & 15 & EPA $1992^{b}$ \\
\hline Exposure frequency $=\mathbf{E F}$ & baths/yr & 350 & EPA $1992^{b}$ \\
\hline Exposure duration $=\mathbf{E D}$ & years & 30 & EPA $1991^{c}$ \\
\hline Body weight $=\mathbf{B W}$ & $\mathrm{kg}$ & 70 & $\begin{array}{l}\text { EPA } 1991^{c} \text { - Combined mean of male } \\
\text { and female body weight }\end{array}$ \\
\hline Carcinogen averaging time $=\mathbf{A T}$ & d & 25550 & $\begin{array}{l}\text { EPA } 1991^{c} \text { - Equivalent to } 70 \text {-year } \\
\text { lifetime exposure, } 365 \mathrm{~d} / \mathrm{year}\end{array}$ \\
\hline
\end{tabular}

a Andelman, J.B. 1990. Total Exposure to Volatile Organic Chemicals in Potable Water, N.M. Ram, R.F. Christman, and K.P. Cantor (eds.), Lewis Publishers.

b EPA 1992. Human Health Evaluation Manual, Supplemental Guidance: Standard Default Exposure Factors, OSWER Directive 9285.6-03, Office of Emergency and Remedial Response, Washington, D.C.

c EPA 1991. Risk Assessment Guidance for Superfund: Volume I-Human Health Evaluation Manual (Part B, Development of Risk-Based Preliminary Remediation Goals, Office of Emergency and Remedial Response, Washington, D.C. 
5-8

Table 5.4. Chemicals of concern in ORNL perimeter groundwater wells with risks $>1 \times 10^{-4}$

\begin{tabular}{|c|c|c|c|c|}
\hline Chemical of concern & $\begin{array}{l}\text { Number } \\
\text { of wells }\end{array}$ & Well & WAG & $\begin{array}{c}\text { Range of } \\
\text { concentrations } \\
\text { (mg/L; pCi/L) }\end{array}$ \\
\hline 1,1-Dichloroethene & 4 & $954,958,1190,1201$ & $2,4,17$ & $0.017-0.044$ \\
\hline 1,2,3-Trichloropropane & 2 & 818,819 & 1 & 0.005 \\
\hline 1,2-Dibromo-3-chloropropane & 2 & 818,819 & 1 & 0.01 \\
\hline 1,2-Dibromoethane & 2 & 818,819 & 1 & 0.005 \\
\hline 1,4-Dioxane & 2 & 818,819 & 1 & 5.0 \\
\hline 2-Propenenitrile & 2 & 818,819 & 1 & 0.01 \\
\hline 3,3'-Dimethyl-benzidine & 1 & 814 & 1 & 0.085 \\
\hline Aroclor- 1254 & 1 & 854 & 6 & 0.001 \\
\hline Beryllium & 58 & $\begin{array}{c}745,806,807,808,809, \\
810,811,812,813,814, \\
816,818,824,827,828, \\
829,830,831,832,833, \\
835,836,837,838,839, \\
840,841,842,843,844, \\
845,846,847,848,849, \\
850,851,852,853,854, \\
855,856,857,858,859, \\
860,986,992,1071 \\
1074,1076,1079,1084, \\
1145,1194,1195,1245, \\
1248\end{array}$ & $\begin{array}{l}1,2,3 \\
6,7,11\end{array}$ & $0.001-0.025$ \\
\hline Bis(2-ethylhexyl)phthalate & 1 & 977 & 1 & 3.1 \\
\hline Carbon tetrachloride & 1 & 842 & 6 & 0.0614 \\
\hline${ }^{60} \mathrm{Co}$ & 3 & $1078,1243,1244$ & $2,6,7$ & $432-915$ \\
\hline N-Nitroso-di-n-propylamine & 1 & 809 & 1 & 0.008 \\
\hline${ }^{228} \mathrm{Ra}$ & 1 & 973 & 5 & 77.4 \\
\hline${ }^{90} \mathrm{Sr}$ & 13 & $\begin{array}{c}806,812,956,969,973 \\
975,992,993,994 \\
1087,1096,1097,1191\end{array}$ & $\begin{array}{r}1,2,3 \\
4,5,8\end{array}$ & $140-7,900$ \\
\hline${ }^{99} \mathrm{Tc}$ & 1 & 1078 & 7 & 11,000 \\
\hline Tritium & 31 & $\begin{array}{c}841,842,843,847,848 \\
849,854,954,955,956, \\
957,958,968,969,970 \\
971,972,973,974,975 \\
976,977,978,981 \\
1076,1079,1084,1152 \\
1156,1191,1243\end{array}$ & $\begin{array}{c}2,4,5 \\
6,7\end{array}$ & $\begin{array}{c}93,800- \\
290,000,000\end{array}$ \\
\hline
\end{tabular}




\section{$5-9$}

Table 5.4 (continued)

\begin{tabular}{|c|c|c|c|c|}
\hline Chemical of concern & $\begin{array}{l}\text { Number } \\
\text { of wells }\end{array}$ & Well & WAG & $\begin{array}{c}\text { Range of } \\
\text { concentrations } \\
\text { (mg/L; pCi/L) }\end{array}$ \\
\hline${ }^{234} \mathrm{U}$ & 1 & 812 & 1 & 346 \\
\hline Vinyl chloride & 16 & $\begin{array}{c}818,819,825,830,849 \\
853,854,954,955,958 \\
969,973,975,978,981, \\
1201\end{array}$ & $\begin{array}{c}1,4,5 \\
6,17\end{array}$ & $0.005-5.5$ \\
\hline
\end{tabular}


unexpected. The oral slope factor for beryllium is high, suggesting it is a potent carcinogen; therefore, almost any detection would lead to a high risk. This high slope factor combined with the fact that the frequency of detection of beryllium in most wells is low, while the concentrations of beryllium have decreased over the monitoring period, may indicate that improvements in detection techniques may be driving the trends in the beryllium risk results. Adequate background data may also assist in determining whether beryllium is site-related.

Table 5.5 ranks all the perimeter wells according to the risk summed across all pathways and contaminants. Figure 5.1 provides a WAG-by-WAG risk ranking of all the perimeter wells. These results indicate that the majority of the groundwater wells with high risk results are located in WAGs 1 and 5, and to a lesser extent in WAGs 4 and 6. The spatial distribution of risk in the GWOU is summarized in Figure A.1. Each circle represents a well where risk was calculated, with the size of the circle indicates the magnitude of the risk.

The detailed risk results of the expanded data sets are presented in Appendix A. Table A.1 provides a summary of the risk results by class (organics, metals, transuranics, and other radionuclides) as well as other information regarding the alias name and the coordinates. The radionuclide and chemical-specific risk results are presented in Tables A.2 and A.3. The representative concentrations used to calculate the risk for the radionuclides and the chemicals are located in Tables A.4 and A.5. The frequency of detection is shown in Tables A.6 and A.7. Contaminants at wells that exceeded $1 \times 10^{-4}$ risk are bolded and outlined in Tables A.2 through A.7. Table A.8 is a compilation of the abbreviations used in the header rows and the full contaminant name.

\subsubsection{Uncertainties in the Conceptual Risk Model}

The current conceptual risk model is limited to understanding risk from the drinking water pathway and to the calculation of carcinogenic risk. The baseline risk assessment performed as part of any RI will look at other pathways as well as non-carcinogenic health effects. One important modifier for the development of the conceptual risk model is the assumed usage of groundwater as a drinking water source. This assumption is conservative for two primary reasons. First, no receptors are currently using the groundwater at ORNL as a drinking water source. In developing the conceptual model, it was assumed that a receptor could be exposed directly to contaminants in individual wells. If an exposure scenario that reflected current land use conditions at the site (for example, off-site exposure to chemicals in the Clinch River) had been used, the results of the screening would have been vastly different; e.g., none of the volatile organic compounds would have shown up as COPCs.

Second, it is questionable whether the shallow or deep aquifers underlying ORNL could be used as a potable water source based solely on the low yield rates in many of the wells. The yield rate of a well is proportional to the hydraulic conductivity measured for the well. Hydraulic conductivity data are available for all wells in the study and were thus used to perform a general screen of the aquifer's reliability as a potable water source. The conductivity values were generally related to aquifer potability using a table from Bear (1979) and were assigned values of good or poor. The results of this exercise indicated that, with some exceptions, the majority of the wells are located in areas with low hydraulic conductivities that most likely would not be potable water sources because of low well yield. 


\section{$5-11$}

Table 5.5. GWOU wells ranked by total risk with quality of aquifer denotations

\begin{tabular}{|c|c|c|c|c|c|c|c|c|c|c|c|}
\hline WAG & Well & $\begin{array}{l}\text { Total } \\
\text { risk }\end{array}$ & $\begin{array}{l}\text { Quality of } \\
\text { aquifer }\end{array}$ & WAG & Well & $\begin{array}{l}\text { Total } \\
\text { risk }\end{array}$ & $\begin{array}{l}\text { Quality of } \\
\text { aquifer }\end{array}$ & WAG & Well & $\begin{array}{l}\text { Total } \\
\text { risk }\end{array}$ & $\begin{array}{l}\text { Quality of } \\
\text { aquifer }\end{array}$ \\
\hline 5 & 973 & $2.8 \mathrm{E}-01$ & $\mathrm{P}$ & 5 & 972 & 5.3E-04 & $P$ & 8 & 1088 & $8.6 \mathrm{E}-05$ & $P$ \\
\hline 5 & 978 & $2.0 \mathrm{E}-01$ & $\mathbf{P}$ & 1 & 830 & $5.1 \mathrm{E}-04$ & $\mathrm{P}$ & 11 & 1246 & 8.6E-05 & $N A$ \\
\hline 5 & 974 & $9.1 \mathrm{E}-02$ & $\mathrm{P}$ & 6 & 847 & 4.7E-0.4 & $\mathrm{NA}$ & 5 & 983 & 8.5E-05 & $\mathrm{P}$ \\
\hline 4 & 958 & $6.4 \mathrm{E}-02$ & $\mathbf{P}$ & 1 & 808 & 4.7E-04 & $P$ & 1 & 820 & 8.3E-05 & $\mathrm{P}$ \\
\hline 5 & 969 & $2.2 \mathrm{E}-02$ & $\mathbf{P}$ & 1 & 813 & 4.5E-04 & $\mathrm{P}$ & 5 & 979 & $7.1 \mathrm{E}-05$ & $P$ \\
\hline 4 & 954 & $1.7 \mathrm{E}-02$ & $\mathbf{P}$ & 1 & 829 & $4.4 \mathrm{E}-04$ & $\mathbf{P}$ & 7 & 1073 & $7.1 \mathrm{E}-05$ & $P$ \\
\hline 1 & 814 & $1.6 \mathrm{E}-02$ & G & 6 & 833 & 4.4E-04 & $P$ & 1 & 822 & $6.9 E-05$ & G \\
\hline 1 & 818 & $1.2 \mathrm{E}-02$ & $\mathrm{P}$ & 6 & 745 & 4.2E-04 & $\mathbf{P}$ & 7 & 1075 & $6.1 \mathrm{E}-05$ & $\mathbf{P}$ \\
\hline 1 & 819 & $1.1 \mathrm{E}-02$ & $\mathbf{P}$ & 6 & 844 & 4.2E-04 & $\mathbf{P}$ & 8 & 1089 & $5.9 \mathrm{E}-05$ & $\mathbf{P}$ \\
\hline 5 & 975 & $1.1 \mathrm{E}-02$ & $\mathbf{P}$ & 1 & 824 & $4.0 \mathrm{E}-04$ & $\mathbf{P}$ & 4 & 949 & $5.1 E-05$ & $\mathbf{P}$ \\
\hline 5 & 977 & 8.7E-03 & $P$ & 6 & 839 & 3.7E-04 & $\mathbf{P}$ & 7 & 1072 & $5.1 E-05$ & $P$ \\
\hline 4 & 957 & $7.9 \mathrm{E}-03$ & $\mathbf{P}$ & 1 & 828 & $3.6 \mathrm{E}-04$ & $\mathrm{P}$ & 17 & 1198 & $4.9 \mathrm{E}-05$ & $P$ \\
\hline 5 & 976 & $6.9 \mathrm{E}-03$ & $\mathrm{P}$ & 2 & 1152 & 3.6E-04 & $\mathrm{P}$ & 5 & 965 & $4.8 \mathrm{E}-05$ & $\mathrm{P}$ \\
\hline 1 & 812 & $6.7 \mathrm{E}-03$ & G & 6 & 838 & 3.4E-04 & $P$ & 4 & 952 & 4.3E-05 & $\mathrm{P}$ \\
\hline 17 & 1201 & $6.6 \mathrm{E}-03$ & $\mathrm{P}$ & 1 & 827 & 3.4E-04 & $P$ & 5 & 963 & 4.3E-05 & $\mathrm{P}$ \\
\hline 6 & 843 & $3.1 \mathrm{E}-03$ & $\mathrm{P}$ & 5 & 968 & 3.3E-04 & $\mathrm{P}$ & 17 & 1196 & 4.1E-05 & $P$ \\
\hline 6 & 846 & $2.6 \mathrm{E}-03$ & $\mathbf{P}$ & 1 & 811 & 3.2E-04 & $\mathrm{P}$ & 2 & 1151 & 4.0E-05 & $\mathbf{P}$ \\
\hline 6 & 837 & $2.6 \mathrm{E}-03$ & NA & 2 & 1156 & $3.2 \mathrm{E}-04$ & $P$ & 8 & 1090 & $3.8 \mathrm{E}-05$ & $\mathrm{P}$ \\
\hline 1 & 809 & $2.4 \mathrm{E}-03$ & $\mathbf{P}$ & 1 & 810 & 3.1E-04 & $\mathrm{P}$ & 8 & 1091 & $3.8 \mathrm{E}-05$ & $\mathrm{P}$ \\
\hline 6 & 1243 & $2.3 E-03$ & NA & 7 & 1084 & $3.1 \mathrm{E}-04$ & $\mathrm{P}$ & 2 & 1192 & 3.7E-05 & G \\
\hline 5 & 981 & 1.7E-03 & $\mathbf{P}$ & 6 & 1244 & $2.9 \mathrm{E}-04$ & NA & 7 & 1081 & $3.5 \mathrm{E}-05$ & $P$ \\
\hline 6 & 842 & 1.7E-03 & $\mathbf{P}$ & 6 & 832 & 2.8E-04 & $\mathrm{P}$ & 7 & 1082 & $3.5 \mathrm{E}-05$ & G \\
\hline 6 & 831 & $1.5 \mathrm{E}-03$ & NA & 3 & 992 & $2.4 \mathrm{E}-04$ & NA & 4 & 961 & $3.4 \mathrm{E}-05$ & $\mathrm{P}$ \\
\hline 7 & 1076 & $1.5 \mathrm{E}-03$ & $P$ & 6 & 836 & 2.2E-04 & $\mathbf{P}$ & 2 & 1189 & $3.4 \mathrm{E}-05$ & $\mathbf{P}$ \\
\hline 6 & 840 & $1.4 \mathrm{E}-03$ & $\mathrm{P}$ & 6 & 859 & $2.2 \mathrm{E}-04$ & $\mathbf{P}$ & 8 & 1095 & 3.3E-05 & $\mathbf{P}$ \\
\hline 5 & 971 & $1.4 \mathrm{E}-03$ & $\mathrm{P}$ & 1 & 816 & $2.1 \mathrm{E}-04$ & $\mathbf{P}$ & 11 & 1149 & $3.3 E-05$ & $N A$ \\
\hline 5 & 970 & $1.3 \mathrm{E}-03$ & $\mathrm{P}$ & 6 & 835 & $1.8 \mathrm{E}-04$ & $\mathbf{P}$ & 11 & 1146 & $3.0 \mathrm{E}-05$ & $\mathrm{NA}$ \\
\hline 6 & 841 & $1.3 \mathrm{E}-03$ & $\mathrm{P}$ & 3 & 993 & $1.6 \mathrm{E}-04$ & $\mathrm{P}$ & 1 & 823 & $3.0 \mathrm{E}-05$ & $\mathrm{P}$ \\
\hline 6 & 858 & $1.2 \mathrm{E}-03$ & $\mathrm{P}$ & 6 & 860 & $1.6 \mathrm{E}-04$ & $\mathrm{P}$ & 2 & 1154 & $3.0 \mathrm{E}-05$ & $\mathrm{P}$ \\
\hline 1 & 825 & $1.0 \mathrm{E}-03$ & $\mathrm{P}$ & 3 & 1248 & $1.6 \mathrm{E}-04$ & $P$ & 5 & 964 & $2.9 \mathrm{E}-05$ & $P$ \\
\hline 6 & 856 & $9.9 \mathrm{E}-04$ & $\mathrm{P}$ & 2 & 1194 & $1.5 \mathrm{E}-04$ & $\mathrm{P}$ & 7 & 1083 & $2.8 \mathrm{E}-05$ & $P$ \\
\hline 6 & 857 & $9.6 \mathrm{E}-04$ & $\mathbf{P}$ & 6 & 1245 & $1.5 \mathrm{E}-04$ & NA & 1 & 821 & 2.TE-05 & $\mathrm{P}$ \\
\hline 2 & 1191 & $8.9 E-04$ & $\mathrm{P}$ & 3 & 986 & $1.3 \mathrm{E}-04$ & $P$ & 2 & 1193 & 2.TE-05 & $\mathrm{p}$ \\
\hline 4 & 955 & 8.4E-04 & $\mathrm{P}$ & 2 & 1195 & $1.2 \mathrm{E}-04$ & $\mathrm{P}$ & 4 & 959 & 2.TE-05 & $\mathrm{P}$ \\
\hline 7 & 1079 & 8.3E-04 & $\mathbf{P}$ & 5 & 984 & $1.2 \mathrm{E}-04$ & $\mathrm{P}$ & 2 & 1153 & $2.6 \mathrm{E}-05$ & $P$ \\
\hline 8 & 1097 & 8.0E-04 & $\mathbf{P}$ & 7 & 1071 & $1.2 E-04$ & $\mathrm{P}$ & 3 & 987 & $2.6 \mathrm{E}-05$ & $\mathrm{P}$ \\
\hline 6 & 855 & $7.9 \mathrm{E}-04$ & $\mathbf{P}$ & 7 & 1074 & 1.2E-04 & $\mathrm{P}$ & 8 & 1093 & $2.5 \mathrm{E}-05$ & $\mathrm{P}$ \\
\hline 4 & 956 & $7.4 \mathrm{E}-04$ & $\mathbf{G}$ & 1 & 815 & 1.1E-04 & $\mathrm{P}$ & 3 & 985 & $2.5 \mathrm{E}-05$ & $P$ \\
\hline 2 & 1190 & $7.2 \mathrm{E}-04$ & $\mathbf{P}$ & 4 & 960 & 1.1E-04 & $\mathrm{P}$ & 11 & 1143 & $2.4 \mathrm{E}-05$ & NA \\
\hline 8 & 1096 & $7.0 \mathrm{E}-04$ & $\mathbf{P}$ & 1 & 826 & $1.1 \mathrm{E}-04$ & G & 17 & 1199 & 2.4E-05 & $\mathrm{P}$ \\
\hline 1 & 806 & $6.6 \mathrm{E}-04$ & NA & 1 & 946 & 1.1E-04 & $\mathbf{P}$ & 5 & 980 & $2.2 E-05$ & $P$ \\
\hline 7 & 1078 & $6.2 \mathrm{E}-04$ & $P$ & 5 & 967 & $1.0 \mathrm{E}-04$ & $\mathbf{P}$ & 7 & 1085 & 2.1E-05 & G \\
\hline 8 & 1087 & 6.1E-04 & $\mathbf{P}$ & 1 & 947 & $1.0 \mathrm{E}-04$ & $\mathbf{P}$ & 4 & 962 & $2.1 E-05$ & $P$ \\
\hline 11 & 1145 & 5.7E-04 & NA & 5 & 982 & 9.3E-05 & $\mathrm{P}$ & 8 & 1092 & $2.0 \mathrm{E}-05$ & $\mathrm{P}$ \\
\hline 1 & 807 & 5.5E-04 & $P$ & 3 & 997 & 8.9E-05 & $\mathbf{P}$ & 17 & 1203 & $2.0 \mathrm{E}-05$ & $\mathbf{P}$ \\
\hline 3 & 994 & $5.5 E-04$ & $\mathbf{P}$ & 7 & 1077 & $8.8 \mathrm{E}-05$ & $\mathbf{P}$ & 3 & 990 & $2.0 \mathrm{E}-05$ & $P$ \\
\hline
\end{tabular}




\section{$5-12$}

Table 5.5 (continued)

\begin{tabular}{ccccccccccccc}
\hline WAG & Well & $\begin{array}{l}\text { Total } \\
\text { risk }\end{array}$ & $\begin{array}{l}\text { Quality of } \\
\text { aquifer }\end{array}$ & WAG & Well & $\begin{array}{l}\text { Total } \\
\text { risk }\end{array}$ & $\begin{array}{l}\text { Quality of } \\
\text { aquifer }\end{array}$ & WAG & Well & $\begin{array}{c}\text { Total } \\
\text { risk }\end{array}$ & $\begin{array}{l}\text { Quality of } \\
\text { aquifer }\end{array}$ \\
\hline 7 & 1086 & $1.9 \mathrm{E}-05$ & $\mathrm{G}$ & 7 & 1080 & $1.6 \mathrm{E}-05$ & $\mathrm{P}$ & 11 & 1140 & $8.8 \mathrm{E}-06$ & NA \\
17 & 1200 & $1.8 \mathrm{E}-05$ & $\mathrm{P}$ & 3 & 998 & $1.5 \mathrm{E}-05$ & $\mathrm{P}$ & 4 & 953 & $8.7 \mathrm{E}-06$ & $\mathrm{P}$ \\
2 & 1185 & $1.8 \mathrm{E}-05$ & $\mathrm{P}$ & 4 & 951 & $1.5 \mathrm{E}-05$ & $\mathrm{P}$ & 11 & 1139 & $8.5 \mathrm{E}-06$ & NA \\
11 & 1144 & $1.8 \mathrm{E}-05$ & NA & 8 & 1094 & $1.3 \mathrm{E}-05$ & $\mathrm{P}$ & 3 & 996 & $7.5 \mathrm{E}-06$ & $\mathrm{P}$ & \\
17 & 1202 & $1.7 \mathrm{E}-05$ & $\mathrm{G}$ & 2 & 1150 & $1.3 \mathrm{E}-05$ & $\mathrm{P}$ & 11 & 1147 & $6.3 \mathrm{E}-06$ & NA \\
2 & 1186 & $1.7 \mathrm{E}-05$ & $\mathrm{P}$ & 2 & 1188 & $1.3 \mathrm{E}-05$ & $\mathrm{P}$ & 11 & 1148 & $6.1 \mathrm{E}-06$ & NA \\
5 & 966 & $1.7 \mathrm{E}-05$ & $\mathrm{P}$ & 3 & 995 & $1.1 \mathrm{E}-05$ & $\mathrm{P}$ & 4 & 948 & $5.7 \mathrm{E}-06$ & $\mathrm{P}$ \\
2 & 1155 & $1.6 \mathrm{E}-05$ & $\mathrm{P}$ & 4 & 950 & $1.1 \mathrm{E}-05$ & $\mathrm{P}$ & 3 & 988 & $5.5 \mathrm{E}-06$ & $\mathrm{P}$ \\
17 & 1197 & $1.6 \mathrm{E}-05$ & $\mathrm{P}$ & 2 & 1187 & $1.0 \mathrm{E}-05$ & $\mathrm{P}$ & & & & & \\
3 & 991 & $1.6 \mathrm{E}-05$ & $\mathrm{P}$ & 2 & 1245 & $1.0 \mathrm{E}-05$ & $\mathrm{P}$ & & & & \\
\hline
\end{tabular}

${ }^{\circ}$ Quality of aquifer: $\mathrm{P}=$ poor, $\mathrm{G}=$ good, NA $=$ Not available 


\begin{tabular}{|c|c|c|c|c|c|c|c|c|c|c|c|c|c|c|c|c|c|}
\hline Risk & & $\overline{\text { AG I }}$ & & $\overline{A G 2}$ & & $\overline{A A G 3}$ & & AG 4 & & $\overline{A G 5}$ & & AG 6 & & $\overline{\mathrm{AG} 7}$ & WAG 8 & WAG II & WAG 17 \\
\hline & Well & Risk & Well & Risk & Well & Risk & Well & Risk & Well & Risk & Well & Risk & Well & Risk & Well & Well & Eell \\
\hline $\mid \mathbf{x} 10-1$ & & & & & & & & & $\begin{array}{l}973 \\
978 \\
\end{array}$ & $\begin{array}{l}2.8 \mathrm{E}-01 \\
2.0 \mathrm{E}-01\end{array}$ & & & & & & & \\
\hline $\mid 1 \times 10-2$ & $\begin{array}{l}814 \\
818 \\
819 \\
\end{array}$ & $\begin{array}{l}1.6 \mathrm{E}-02 \\
1.2 \mathrm{E}-02 \\
1.1 \mathrm{E}-02\end{array}$ & & & & & \begin{tabular}{|l|}
958 \\
954
\end{tabular} & $\begin{array}{l}6.4 \mathrm{E}-02 \\
1.7 \mathrm{E}-02\end{array}$ & $\begin{array}{l}974 \\
969 \\
975\end{array}$ & $\begin{array}{l}9.1 \mathrm{E}-02 \\
2.2 \mathrm{E}-02 \\
1.1 \mathrm{E}-02\end{array}$ & & & & & & & \\
\hline $\mid 1 \times 10-3$ & $\begin{array}{l}812 \\
809 \\
825\end{array}$ & $\begin{array}{l}6.7 \mathrm{E}-03 \\
2.4 \mathrm{E}-03 \\
1.0 \mathrm{E}-03\end{array}$ & & & & & 957 & $7.9 \mathrm{E}-03$ & $\begin{array}{l}977 \\
976 \\
981 \\
971 \\
970\end{array}$ & $\begin{array}{l}8.7 \mathrm{E}-03 \\
6.9 \mathrm{E}-03 \\
1.7 \mathrm{E}-03 \\
1.4 \mathrm{E}-03 \\
1.3 \mathrm{E}-03\end{array}$ & \begin{tabular}{|l|}
843 \\
846 \\
837 \\
1243 \\
842 \\
831 \\
840 \\
841 \\
858 \\
\end{tabular} & $\begin{array}{l}3.1 \mathrm{E}-03 \\
2.6 \mathrm{E}-03 \\
2.6 \mathrm{E}-03 \\
2.3 \mathrm{E}-03 \\
1.7 \mathrm{E}-03 \\
1.5 \mathrm{E}-03 \\
1.4 \mathrm{E}-03 \\
1.3 \mathrm{E}-03 \\
1.2 \mathrm{E}-03\end{array}$ & 1076 & $1.5 \mathrm{E}-03$ & & & $12016.6 E-03$ \\
\hline$|1 \times 10-4|$ & $\begin{array}{l}806 \\
807 \\
830 \\
808 \\
813 \\
829 \\
824 \\
828 \\
827 \\
811 \\
810 \\
816 \\
815 \\
826 \\
946 \\
947 \\
\end{array}$ & $\begin{array}{l}6.6 \mathrm{E}-04 \\
5.5 \mathrm{E}-04 \\
5.1 \mathrm{E}-04 \\
4.7 \mathrm{E}-04 \\
4.5 \mathrm{E}-04 \\
4.4 \mathrm{E}-04 \\
4.0 \mathrm{E}-04 \\
3.6 \mathrm{E}-04 \\
3.4 \mathrm{E}-04 \\
3.2 \mathrm{E}-04 \\
3.1 \mathrm{E}-04 \\
2.1 \mathrm{E}-04 \\
1.1 \mathrm{E}-04 \\
1.1 \mathrm{E}-04 \\
1.1 \mathrm{E}-04 \\
1.0 \mathrm{E}-04\end{array}$ & $\begin{array}{l}1191 \\
1190 \\
1152 \\
1156 \\
1194 \\
1195\end{array}$ & $\begin{array}{l}8.9 \mathrm{E}-04 \\
7.2 \mathrm{E}-04 \\
3.6 \mathrm{E}-04 \\
3.2 \mathrm{E}-04 \\
1.5 \mathrm{E}-04 \\
1.2 \mathrm{E}-04\end{array}$ & $\begin{array}{l}994 \\
992 \\
993 \\
1248 \\
986\end{array}$ & $\begin{array}{l}.5 \mathrm{E}-04 \\
2.4 \mathrm{E}-04 \\
1.6 \mathrm{E}-04 \\
1.6 \mathrm{E}-04 \\
1.3 \mathrm{E}-0.4\end{array}$ & $\begin{array}{l}955 \\
956 \\
960\end{array}$ & $\begin{array}{l}8.4 \mathrm{E}-04 \\
7.4 \mathrm{E}-04 \\
1.1 \mathrm{E}-04\end{array}$ & $\begin{array}{l}972 \\
968 \\
984 \\
967\end{array}$ & $\begin{array}{l}5.3 \mathrm{E}-04 \\
3.3 \mathrm{E}-04 \\
1.2 \mathrm{E}-04 \\
1.0 \mathrm{E}-04\end{array}$ & \begin{tabular}{|l|}
856 \\
857 \\
855 \\
847 \\
833 \\
745 \\
844 \\
839 \\
838 \\
1244 \\
832 \\
836 \\
859 \\
835 \\
860 \\
1245 \\
\end{tabular} & $\begin{array}{l}9.9 \mathrm{E}-04 \\
9.6 \mathrm{E}-04 \\
7.9 \mathrm{E}-04 \\
4.7 \mathrm{E}-04 \\
4.4 \mathrm{E}-04 \\
4.2 \mathrm{E}-04 \\
4.2 \mathrm{E}-04 \\
3.7 \mathrm{E}-04 \\
3.4 \mathrm{E}-04 \\
2.9 \mathrm{E}-04 \\
2.8 \mathrm{E}-04 \\
2.2 \mathrm{E}-04 \\
2.2 \mathrm{E}-04 \\
1.8 \mathrm{E}-04 \\
1.6 \mathrm{E}-04 \\
1.5 \mathrm{E}-04 \\
\end{array}$ & $\begin{array}{l}1079 \\
1078 \\
1084 \\
1071 \\
1074\end{array}$ & $\begin{array}{l}8.3 E-04 \\
6.2 E-04 \\
3.1 E-04 \\
1.2 E-04 \\
1.2 E-04\end{array}$ & $\mid \begin{array}{ll}1097 & 8.0 \mathrm{E}-04 \\
1096 & 7.0 \mathrm{E}-04 \\
1087 & 6.1 \mathrm{E}-04\end{array}$ & $\mid 1145 \quad 5.7 \mathrm{E}-04$ & \\
\hline $\mid 1 \times 10-5$ & $\begin{array}{l}820 \\
822 \\
823 \\
821\end{array}$ & $\begin{array}{l}8.3 \mathrm{E}-05 \\
6.9 \mathrm{E}-05 \\
3.0 \mathrm{E}-05 \\
2.7 \mathrm{E}-05\end{array}$ & \begin{tabular}{|l}
151 \\
1192 \\
1189 \\
1154 \\
1193 \\
1153 \\
1185 \\
1186 \\
1155 \\
1150 \\
1188 \\
1187 \\
\end{tabular} & $\begin{array}{l}4.0 \mathrm{E}-05 \\
3.7 \mathrm{E}-05 \\
3.4 \mathrm{E}-05 \\
3.0 \mathrm{E}-05 \\
2.7 \mathrm{E}-05 \\
2.6 \mathrm{E}-05 \\
1.8 \mathrm{E}-05 \\
1.7 \mathrm{E}-05 \\
1.6 \mathrm{E}-05 \\
1.3 \mathrm{E}-05 \\
1.3 \mathrm{E}-05 \\
1.0 \mathrm{E}-05\end{array}$ & \begin{tabular}{|ll}
997 & 8 \\
987 & 2 \\
985 & 2 \\
990 & 2 \\
991 & 1 \\
998 & 1 \\
995 & 1
\end{tabular} & $\begin{array}{l}.9 \mathrm{E}-05 \\
2.6 \mathrm{E}-05 \\
2.5 \mathrm{E}-05 \\
2.0 \mathrm{E}-05 \\
1.6 \mathrm{E}-05 \\
1.5 \mathrm{E}-05 \\
1.1 \mathrm{E}-05\end{array}$ & $\begin{array}{l}949 \\
952 \\
961 \\
959 \\
962 \\
951 \\
950\end{array}$ & $\begin{array}{l}5.1 E-05 \\
4.3 E-05 \\
3.4 E-05 \\
2.7 E-05 \\
2.1 E-05 \\
1.5 E-05 \\
1.1 E-05\end{array}$ & $\begin{array}{l}982 \\
983 \\
979 \\
965 \\
963 \\
964 \\
980 \\
966\end{array}$ & $\begin{array}{l}9.3 \mathrm{E}-05 \\
8.5 \mathrm{E}-05 \\
7.1 \mathrm{E}-05 \\
4.8 \mathrm{E}-05 \\
4.3 \mathrm{E}-05 \\
2.9 \mathrm{E}-05 \\
2.2 \mathrm{E}-05 \\
1.7 \mathrm{E}-05\end{array}$ & & & $\begin{array}{l}1077 \\
1073 \\
1075 \\
1072 \\
1081 \\
1082 \\
1083 \\
1085 \\
1086 \\
1080\end{array}$ & $\begin{array}{l}8.8 \mathrm{E}-05 \\
7.1 \mathrm{E}-05 \\
6.1 \mathrm{E}-05 \\
5.1 \mathrm{E}-05 \\
3.5 \mathrm{E}-05 \\
3.5 \mathrm{E}-05 \\
2.8 \mathrm{E}-05 \\
2.1 \mathrm{E}-05 \\
1.9 \mathrm{E}-05 \\
1.6 \mathrm{E}-05\end{array}$ & $\begin{array}{|ll|}1088 & 8.6 \mathrm{E}-05 \\
1089 & 5.9 \mathrm{E}-05 \\
1090 & 3.8 \mathrm{E}-05 \\
1091 & 3.8 \mathrm{E}-05 \\
1095 & 3.3 \mathrm{E}-05 \\
1093 & 2.5 \mathrm{E}-05 \\
1092 & 2.0 \mathrm{E}-05 \\
1094 & 1.3 \mathrm{E}-05 \\
\end{array}$ & $\begin{array}{|ll|}1246 & 8.6 \mathrm{E}-05 \\
1149 & 3.3 \mathrm{E}-05 \\
1146 & 3.0 \mathrm{E}-05 \\
1143 & 2.4 \mathrm{E}-05 \\
1144 & 1.8 \mathrm{E}-05\end{array}$ & $\begin{array}{|ll|}1198 & 4.9 \mathrm{E}-05 \\
1196 & 4.1 \mathrm{E}-05 \\
1199 & 2.4 \mathrm{E}-05 \\
1203 & 2.0 \mathrm{E}-05 \\
1200 & 1.8 \mathrm{E}-05 \\
1202 & 1.7 \mathrm{E}-05 \\
1197 & 1.6 \mathrm{E}-05\end{array}$ \\
\hline||$|x| 0-6 \mid$ & & & & & $\begin{array}{l}996 \\
988\end{array}$ & $\begin{array}{l}7.5 \mathrm{E}-06 \\
5.5 \mathrm{E}-06\end{array}$ & \begin{tabular}{|l|}
953 \\
948
\end{tabular} & $\begin{array}{l}8.7 \mathrm{E}-06 \\
5.7 \mathrm{E}-06\end{array}$ & & & & & & & & $\begin{array}{|ll|}1140 & 8.8 E-06 \\
1139 & 8.5 E-06 \\
1147 & 6.3 E-06 \\
1148 & 6.1 E-06 \\
\end{array}$ & \\
\hline
\end{tabular}

Fig. 5.1. WAG contributions to risk in the GWOU. 


\subsection{RISK ASSESSMENT STRATEGY FOR THE GWOU}

Based on the difference in the definitions between WAG 2 and the GWOU, and based on the conceptual models presented above, the following assumptions have been made regarding risk issues associated with the GWOU.

1. It is assumed that the risk associated with contaminants in groundwater that resurface to the surface water system will be addressed by WAG 2 and the source WAGs.

2. Most of the risk associated with current off-site releases from ORNL can be assessed by measuring contaminant flux over White Oak Dam. This risk is being addressed by WAG 2 and the source WAGs.

3. Most of the risk associated with current on-site releases at ORNL is associated not with the GWOU but rather with contact of soils at the source WAGs.

4. Based on assumptions 2 and 3, it is assumed that the GWOU does not have a current risk issue to address.

5. Most of the risk associated with future off-site releases from ORNL will likely occur because of contaminant migration from the source WAGs through the stormflow, vadose, and water table interval zones.

6. Future off-site releases through the intermediate and deep groundwater zones are expected to be minimal contributors to future off-site risks. However, the current conceptual model must be confirmed to support this assumption. Points where contaminants may exit the site through the intermediate and deep groundwater zones have not been identified, and the potential for existing plumes to migrate to these exit points has not been assessed.

7. The risk scenario of greatest concern to the GWOU is the future on-site resident farmer who uses a groundwater well for drinking water and irrigation.

Figure 5.2 shows how these assumptions tie into risk assessment decision support for the GWOU. On the basis of these assumptions, the following risk assessment strategy has been developed for the GWOU.

As indicated by the Fig. 5.2., risk assessment support for the GWOU can be divided into three components: near-term support, mid-phase support, and the final phase.

Near-term support will include DQO support to help identify data needs for refining the conceptual hydrogeological and conceptual risk models. The conceptual risk model will be updated continually as data become available. Near-term support will also include support to help identify the need for a CERCLA removal action and the selection of administrative or engineering controls for the removal action. 


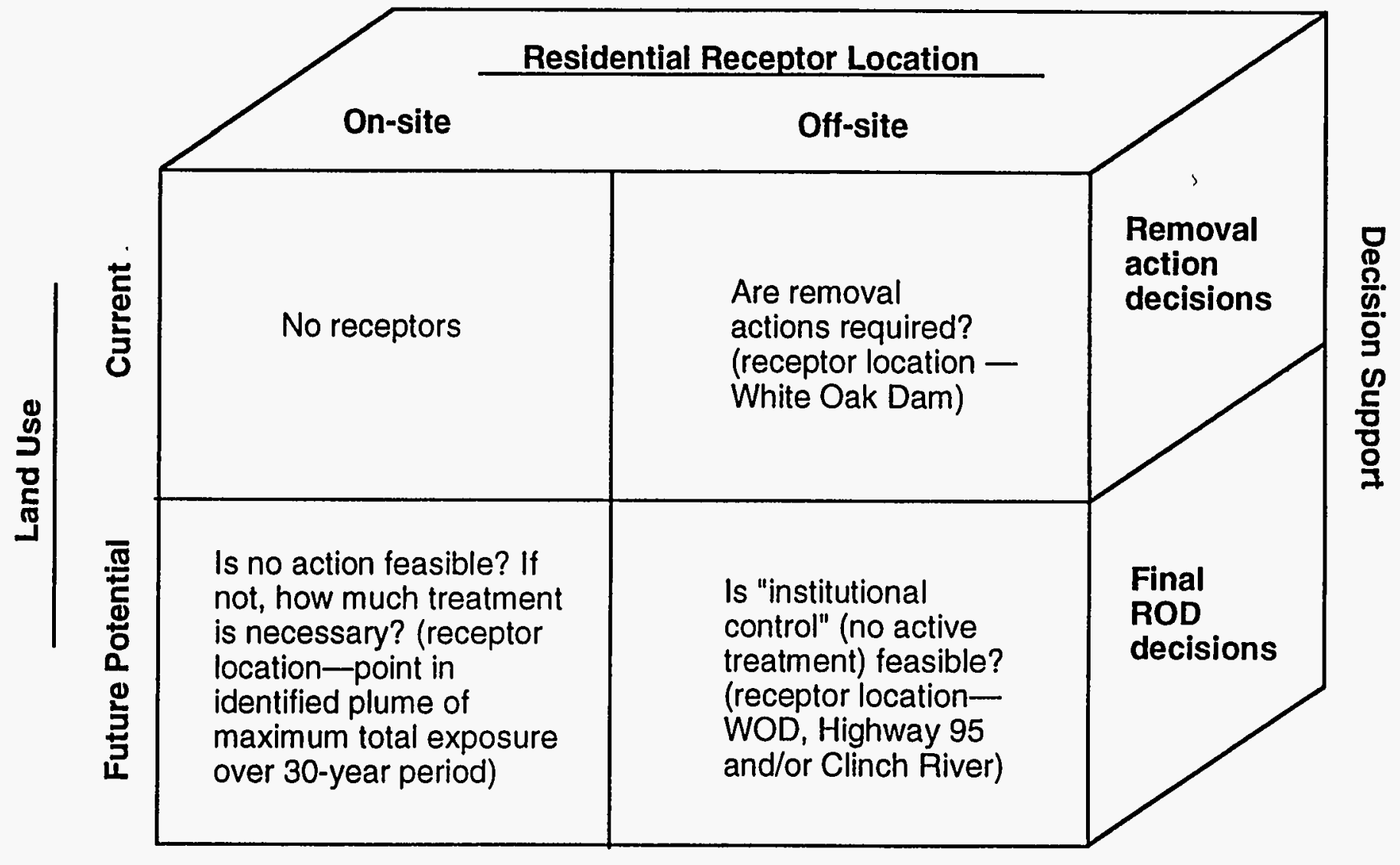

* "Institutional Controls Only" will be acceptable only if it is shown that long-term off-site migration will not cause unacceptable future risks to off-site receptors.

Fig. 5.2. Major decisions and likely receptor locations for risk assessment support. 


\section{$5-16$}

Mid-phase support is the projected period of time when most of the RI/FS work on the source WAGs will be occurring. During this time, the GWOU should provide to the source WAGs the conceptual and analytical models that the source WAGs need to evaluate the groundwater pathway as a source of future risk from within the source. This support may come in the form of chemical-specific dilution/attenuation factors (DAFs) (Sect. 5.4.1). During this phase, work will continue on refining the conceptual risk model and supporting removal actions. Efforts will begin to focus on identifying future potential potable water sources for the future land use scenario that will have to be addressed in the GWOU baseline risk assessment.

Final-phase support for the risk assessment for GWOU will consist primarily of performing the baseline risk assessment and risk evaluation of remedial alternatives for the GWOU RI/FS report. It is planned that this assessment will use the site-wide environmental situation postremediation decisions on the source WAGs as baseline conditions. Thus, the source of risks for the GWOU baseline will likely be contaminants in groundwater that are not addressed by source RODs and contaminant residuals remaining in the source WAGs. In this respect, the GWOU acts as a final integrator of risk for the ORNL site.

\subsection{RISK ASSESSMENT ACTIVITIES AND METHODS}

During the course of the GWOU activities, risk assessment and risk management issues must be addressed. Risk assessment issues pertain to performing the baseline risk assessment and the inputs into the calculation of risks. Risk management issues involve using risk assessment to heip make strategy and remediation decisions, such as development of risk-based cleanup levels and the allocation of site-wide remediation resources. This section discusses some of the methods that will be used to address these issues. Risk assessment is separate from the policy decisions that ultimately will be made by DOE, EPA, TDEC, and the public. To this end, it is assumed that the eventual baseline risk assessment for GWOU will not attempt to determine such things as "future land use" but will be comprehensive enough to provide the decision makers with risk estimates for multiple land use scenarios.

\subsubsection{Near-Term Support}

The following activities will take place in the early phases of the GWOU investigation.

1. Continue to compile toxicity data and chemical-specific data (such as Henry's Law Constants and decay rates) for updating preliminary remediation goals (PRGs).

PRGs have been developed for the worst-case residential land use scenario using default exposure equations for potable groundwater use presented in Risk Assessment Guidance for Superfund, Part B (EPA 1991). The PRGs are being and will continue to be used to:

- provide risk assessment input to the decision for the need for a CERCLA removal action according to the criteria described in the National Oil and Hazardous Substances Pollution Contingency Plan, $\$ 300.415$; 
- help assign priority to source WAGs by identifying those that may be actively contributing contaminants to the groundwater above PRG concentrations; and

- help assign priority to groundwater investigation activities.

2. Develop additional groundwater PRGs.

Groundwater PRGs based on current land use will need to quantitatively consider such factors as a point of compliance off site (likely near White Oak Dam), dilution, dispersion, and contaminant attention and decay between the groundwater problem and the point of compliance.

For alternative future land use scenarios, simple analytical models may be used early in the process to develop DAFs. DAFs incorporate what is known about how the chemical concentrations change over time and space. The PRG based on potable water use at a given receptor point (which is presumably the potential point of compliance) is multiplied by the DAF. The DAF allows the cleanup goal to account for the level of cleanup at the plume/source if the potential receptor remains off site, or if many years pass before a receptor moves on site. The DAF will be refined over time by incorporating data and by using and developing more sophisticated numerical fate and transport modeling tools.

3. Perform risk assessments to support CERCLA groundwater removal actions.

Removal actions, as defined by the NCP, occur if a detected problem could cause immediate threat to the human health or environment. A removal action may also occur if a problem can be dealt with expediently at a reasonable cost. The basic method that will be used to determine the need for a removal action will be to determine whether the contamination detected in the shallow groundwater is exiting to surface water via a seep. If it is, an IP assessment will be used to determine whether this groundwater contamination contributes significantly (e.g., 10\%) to the total risk at White Oak Dam.

The IP method has been devised primarily for near-term risk decision support for the White Oak Creek watershed. An IP is a point at which contaminant releases from multiple sources come together. The final IP for the White Oak Creek watershed at ORNL is White Oak Dam, which is the point where ORNL releases leave the site and thus could pose a risk to the public. However, several IPs upstream of White Oak Dam could be used for the assessment. The IP assessment produces a "relative risk" value for an individual source (or plume in this case) at White Oak Dam or any other identified IP. The IP assessment is designed to rank off-site risks associated with the various sources and thus helps determine where remediation resources should be spent.

The premise of the method is that risks associated with multiple contaminants at a source WAG are compared with risks associated with concentrations measured at the IP, after the difference in the total contaminant mass leaving the two points-referred to as contaminant flux-is accounted for. The exposure pathway, parameters, and toxicity data used calculate risk in the IP assessment are the same as those used to estimate risk at an individual well (Sect. 5.2.3); the governing equation for the assessment is: 
Relative $\operatorname{Risk}_{\mathrm{Well}}(\%)=\left(\left(\Sigma\left[\operatorname{Risk}_{\mathrm{i}, \mathrm{IP}}\left(\right.\right.\right.\right.$ Flux $_{\mathrm{i}, \text { Well }} /$ Flux $\left.\left.\left._{\mathrm{i}, \text { IP }}\right)\right]\right) /$ Risk $\left._{\text {toal IP }}\right) * 100$

where
Risk $_{\mathrm{IP}} \quad=$ risk associated with chemical $i$ at the IP,
Flux $_{\mathrm{i} \text { well }} \quad=$ flux of the $i^{\text {th }}$ substance originating at a well,
Flux $_{\mathrm{i} \text { IP }} \quad=$ flux of the $i^{\text {th }}$ substance identified at the IP,
Risk $_{\text {tooal IP }}=\Sigma$ Risk $_{\mathrm{i} \text { wOD }}$, or the sum of the risk estimates for the $i^{\text {th }}$ substances identified at the IP.

Contaminant flux is estimated by:

$$
\text { Flux }_{i, \text { well or IP }}=(C)(V)
$$

where

$$
\begin{array}{ll}
\text { Flux }_{\mathrm{i}} & =\text { contaminant flux, } i(\mathrm{pCi} / \text { time; mg/time), } \\
\mathrm{C} & =\text { concentration detected in groundwater (plume and } \mathrm{IP})(\mathrm{pCi} / \mathrm{L}),(\mathrm{mg} / \mathrm{L}), \\
\mathrm{V} & =\text { water discharge volume for the plume and IP }(\mathrm{L} / \mathrm{time}) .
\end{array}
$$

A tiered approach exists for calculating the water volume associated with a well or plume (Table 5.6). The Tier 1 method is the simple water balance model for a given area. The Tier 2 approach uses the regional scale Melton Valley groundwater model, which is described in Chap. 4. Tier 3 relies on more local models, which are under development, that will attempt to account for transient water flow conditions in the area of the plume (e.g., account for storm flow).

Table 5.6. Tiered approach for estimating plume water flow volumes

\begin{tabular}{llll}
\hline Flow component & Tier 1 approach & Tier 2 approach & \multicolumn{1}{c}{ Tier 3 approach } \\
\hline GW & $\begin{array}{l}\text { water balance model: } \\
\text { GW }=\text { P-ET-SW }\end{array}$ & groundwater model & $\begin{array}{l}\text { groundwater model } \\
\text { refinements and } \\
\text { expansions }\end{array}$ \\
\hline
\end{tabular}

On the basis of current knowledge about relative risk at WOD, a removal action has been initiated at groundwater seeps along WAG 5 . It is expected that no other removal actions will be performed to address contamination currently in the intermediate and deep groundwater zones. Removal actions are currently underway to address contaminants leaching from sources and flowing through the stormflow and water-table interval flow paths. WAG 2 has identified the need for these removal actions and will likely continue to support this effort.

\subsubsection{Mid-Phase Support}

During the middle phase of the investigation, the risk assessment needs of the source WAGs will require input from GWOU. Specifically, the source OUs will require tools for evaluating 
the current and future potential contaminant flux out of the sources. These tools will likely include the Melton Valley Aquifer Model, stormflow and vadose zone flow and transport models.

In its most simple form, GWOU can determine and provide chemical-specific DAFs to the source WAGs. The DAF concept was first introduced for developing toxicity characteristic leaching procedure regulatory limits. The DAF accounts for the dispersion and natural attenuation of the contaminant through time and space. These DAFs synthesize the information from flow models, site-specific and chemical-specific attenuation and retardation information [e.g., chemical-specific soil-water distribution coefficients $\left(\mathrm{K}_{\mathrm{d}} \mathrm{s}\right)$ ], radiological and biological decay information, and distance.

Using data collected during the early phases of the characterization, a focused effort will begin to identify the areas suspected to be potential potable water sources for the future land use scenario that will have to be evaluated in the GWOU baseline risk assessment. Data will be compiled on hydraulic conductivity and yield rates for wells in various areas and of varying depths to determine whether the aquifers could be relied on as future residential potable water sources.

In addition to developing the tools to support the source WAG RIs, risk assessors will continue to update and address PRGs and identify additional data needs for groundwater characterization.

\subsubsection{Final-Phase Support}

Risk assessment support in the final phase of the GWOU characterization will involve performing the baseline risk assessment. It is assumed for this document that by the time the baseline risk assessment is performed, risk assessment models and techniques for ORNL will change and be refined from those currently used. Much of the change will likely come from interaction with the regulatory agencies during source WAG RI reviews and through the development of advanced uncertainty analysis capabilities. Therefore, this characterization plan does not propose specific models and techniques that will be used to complete the GWOU baseline risk assessment; however, this plan provides some strategies for performing the baseline risk assessment, given that the GWOU RI must act as an integrator RI.

In addition to evaluating the risks associated with contamination in the groundwater, the GWOU baseline risk assessment must include a risk evaluation of post-source remediation residuals. As an integrator unit, this risk assessment must compile a post-remediation report of residual risk associated with "no-action" sources and post-remediation residual risks remaining after engineering controls have been implemented.

Residual risk from the source WAGs is expected because "zero risk" is not the goal of CERCLA. The FS report for each source OU will be required to present a discussion on the residual risks associated with the selected remediation alternative and to discuss the integratorwide impact of the residual.

The decisions made during the GWOU RI/FS process consolidate information gathered throughout the RI/FSs for the source and integrator units. The goal of the GWOU RI will be to determine the extent, if any, of remediation required in the surrounding environmental media 
when it is shown that releases from source OUs have been controlled. Three primary types of information will be used to support the groundwater OU risk assessment:

- the risk assessment results from contamination in the groundwater;

- post-remediation compliance monitoring data for the source operable units; and

- the results of the risk evaluation of remedial alternatives for the alternatives selected for each source OU (which address the risks associated with residuals).

\subsection{RISK MANAGEMENT SUPPORT}

Risk management support will be on going through each stage of the GWOU investigation. In addition to developing and providing PRGs and risk estimates, risk management tools will be developed to help systematically and clearly make decisions based on evaluation of the collected data.

\subsection{IDENTIFICATION OF CHEMICAL-SPECIFIC ARARS}

The CERCLA of 1980 was passed by Congress and signed into law on December 11, 1980 (Public Law 96-510). This act was intended to provide for "liability, compensation, cleanup, and emergency response for hazardous substances released into the environment and the cleanup of inactive waste disposal sites." The SARA, adopted on October 17, 1986 (Public Law 99-499), did not substantially alter the original structure of CERCLA but provided extensive amendments to it.

In particular, $\$ 121$ of CERCLA specifies that remedial actions for cleanup of hazardous substances must comply with requirements or standards under federal or more stringent state environmental laws that are applicable or relevant and appropriate to the hazardous substances or particular circumstances at a site. Inherent in the interpretation of ARARs is the assumption that protection of human health and the environmental is ensured.

As stated in the NCP (55 FR 8666, March 8, 1990), the goal of EPA's approach to cleanup of contaminated groundwater is to return usable groundwater to its beneficial use within a given time frame that is reasonable for the particular circumstances at a CERCLA site. The ORNL GWOU has not been given an EPA classification; however, the TDEC Underground Injection Control regulations classify all groundwater for domestic water supply except for certain exclusions. One of these exclusions is water that contains total dissolved solids (TDS) in excess of $3,000 \mathrm{mg} / \mathrm{L}$ and that is not reasonably expected to serve as a domestic water supply (TDEC 1200-4-6-.05).

The Ground Water Management Section of the Tennessee Division of Water Supply is developing a groundwater classification system for Tennessee groundwaters (TDEC Proposed Rule 1200-4-3-.04 to .08). A draft of the proposed rule, dated May 28, 1993, was issued for public comment in June, 1993; a final version is expected by late summer of 1994 . Chapter 1200-4-3-.07 of the proposed rule lists four classifications for groundwater: Class A-current or 
future source of water supply; Class B-current or future source of water supply but will not support all uses as a water supply because of contamination; Class $\mathrm{C}$-not a current or future source of water supply for drinking or other beneficial use; and Class D-groundwater that flows to the surface of the ground or mixes with surface water. Groundwater in Class D can also be identified as A, B, or C. The proposed rule recommends specific water quality criteria for each groundwater class, based on its intended use; however, it is unclear what the final proposed groundwater criteria will be. It appears from the proposed rule that this GWOU may be classified as Class D.

The ORNL GWOU encompasses all of Melton Valley, Bethel Valley, and Haw Ridge and extends down to the lowest depth where groundwater contains $10,000 \mathrm{mg} / \mathrm{L}$ of TDS (see Sect. 1.3). It is premature to develop chemical-specific or location-specific ARARs for remediation of the ORNL GWOU; determination of ARARs for this GWOU will depend on the chosen groundwater classification and will be addressed further in any subsequent RI. However, Safe Drinking Water Act MCLs for the groundwater contaminants of concern are listed in Table 5.7 for comparison with analytical detection limits.

Table 5.7. Safe Drinking Water Act maximum contaminant levels

\begin{tabular}{ll}
\hline Analyzed contaminants of concern & MCL $(\mu \mathrm{g} / \mathrm{L})$ \\
\hline 1.1-Dichloroethene & 7 \\
Beryllium & 4 \\
Bis(2-chloroethyl)ether & $\mathrm{NA}$ \\
Bis(2-chloroethylhexyl)phthalate & $\mathrm{NA}$ \\
Carbon tetrachloride & 5 \\
Chloroform & $100^{b}$ \\
N-nitroso-di-n-propylamine & $\mathrm{NA}$ \\
Trichloroethene & 5 \\
Vinyl chloride & 2 \\
${ }^{60}$ Co & 4 mrem/year \\
Total strontium & 4 mrem/year \\
Tritium & $20,000 \mathrm{pCi} / \mathrm{L}^{d}$ \\
${ }^{234} \mathrm{U}$ & $4 \mathrm{mrem} / \mathrm{year}$ \\
\hline
\end{tabular}

a TDEC 1200-5-1; 40 CFR 141.

$b$ The sum of the concentration of all the trihalomethanes present.

${ }^{c}$ If two or more radionuclides are present, the sum of their annual dose equivalents to the total body or to any organ shall not exceed 4 mrem/year.

$d$ The concentration that will result in the effective does equivalent of 4 mrem/year.

NA $=$ not available. 


\section{GWOU TEST METHODS}

\subsection{INTRODUCTION}

A number of test methods for gathering information related to the data gaps defined in Chap. 5 are proposed for the GWOU investigation. Both intrusive and nonintrusive methods must be used to resolve data gaps related to the characterization and identification of geologic units, stratigraphic correlations, fault and fracture properties, vertical head distribution, aquifer parameters, and GWOU boundary integrity. Definitions of karst development and water budgets are also key to the resolution of questions related to the GWOU. The following sections describe the methods to be used and the types of data to be obtained. Because the geophysical investigation is extremely important, a more detailed approach that delineates specific tests that will be conducted in the near future is included.

\subsection{AQUIFER PARAMETERS}

Aquifer parameters are key components in the evaluation of groundwater flow systems. The measurement of transmissivity or hydraulic conductivity is critical to modeling the rate and direction of flow within the system in order to address the data gaps defined in Sect. 2.4.6.2. This section summarizes the data gaps and describes the methods employed to derive hydrologic properties of the Knox aquifer along Copper Ridge, aquitard rocks of the Rome Formation, and Clinch River alluvial deposits.

\subsubsection{Slug Tests}

Single-well positive displacement tests-or slug tests, as they are commonly called-are a quick and inexpensive means of estimating the in situ hydraulic conductivity of an aquifer. Slug tests are often used in environmental investigations because they are fast and inexpensive, generate little waste for disposal, and work well in tight aquifers (where low hydraulic conductivities prohibit pumping tests).

Slug tests are conducted by stressing the aquifer by either inserting or removing a given volume of water from the well and then monitoring how quickly the well re-equilibrates. The response is monitored following either the insertion (slug-in) or removal (slug-out) of the slug. The slug-out, or rising head, test is recommended because of the harmonic oscillations or pressure waves, which are commonly observed in data collected from slug-in tests.

Slug tests are appropriate for many cases; however, they do have significant drawbacks that must .be considered... Slug tests provide only local estimates of hydraulic conductivity, are only accurate within one order of magnitude, will not provide reproducible values of aquifer storativity, and will not provide information about local aquifer boundaries.

\subsubsection{Pumping Tests}

Pumping tests represent perhaps the best method for estimating in situ aquifer parameters. Analysis of a properly designed pumping test can provide information about the hydraulic 
conductivity and storativity of the aquifer. Pumping tests can also be used to examine the effects of hydrogeologic boundaries (recharge and discharge) and the various anisotropic ratios of hydraulic conductivity within the aquifer.

Pumping tests are conducted by pumping water from the aquifer at a consistent rate and then monitoring the piezometric response with respect to time. The rate can be varied upward in steps, but detailed records must be kept of the flow rate and total amount of water pumped for any time during the test. The benefits of the test can be maximized by monitoring a number of local wells to evaluate the effects of aquifer depletion on each. Evaluation of the hydraulic conductivity, as determined from the monitoring wells, can be used to estimate the representative hydraulic conductivity tensors at the pumping wells.

Although pumping tests probably provide the best information for in situ tests, they do have significant drawbacks. Pumping tests are not feasible in aquifers with low hydraulic conductivity. Furthermore, pumping tests can be very expensive (especially as compared to slug tests) and time consuming. Because significant quantities of potentially contaminated groundwater are produced, pump tests can also create a waste management problem.

\subsubsection{Tracer Tests}

The most direct method of determining groundwater velocity and defining flow paths is to introduce a tracer at one point in a flow system and observe its arrival at other points. Flow velocities can be calculated from time and distance data after adjusting for dispersion and advection effects of the tracer and host material. Tracer substances used over the years have included fluorescent dyes, salts, radioisotopes, and nonreactive organic compounds. The test usually consists of injecting a tracer into a well bore or ground location directly connected to the subsurface flow system (such as a spring or swallow) and measuring the tracer concentration at various groundwater discharge points or groundwater monitoring wells. Because of the dispersivity of the tracer within the systems, the time of arrival is deduced using a breakthrough curve. This curve displays tracer concentration versus time at each monitoring point.

Tracer tests as described above require significant efforts to perform successfully. Long measurement periods are required at numerous locations to adequately monitor and detect the passage of a tracer through a flow field. The point-dilution method is a variation of the tracer test in which the horizontal average linear velocity is estimated. This method involves injecting the tracer into a packed-off section of a well bore and measuring the dilution effect of the lateral groundwater flow. The change in concentration over time is related to the lateral flow velocity. A disadvantage of the point-dilution test is that it cannot establish point-to-point flow paths.

One of the main problems regarding aquifer tests in fractured terrain, such as that at ORNL, is interpretation of the results. Currently, most interpretative models assume that flow in the aquifer is by way of intergranular flow. The results of aquifer tests in fractured terrain can be interpreted using these models where the predilection of flow along a preferred direction is dealt with by assuming an isotropic aquifer and a elementary volume such that no individual fracture dominates flow. However, this way of interpreting results cannot account for some of the very high apparent groundwater velocities that have been observed for tracer tests and does not take into account some of the fundamental differences between fracture flow and intergranular flow. Evaluation of aquifer tests based on stochastic modeling of fracture orientations may allow the 
prediction of preferred pathways and an understanding of flow paths and groundwater velocities. However, this interpretation method is complex and not fully proven.

\subsubsection{Pulse Train Tests}

Changes in pressure transmit through saturated aquifers very rapidly-in an open system with little or no storativity, a pressure pulse will propagate at approximately the speed of sound-and can be used to quickly test for discrete hydraulic connections in fractured rock or karst systems. Natural and artificial labels, such as isotopes and dyes, measure approximately the rate of flow of the water being traced; pressure pulses almost always exceed this by a significant value. Given an input pulse to a groundwater system, the output tracer record at wells surrounding the injection well should be a subdued replica of the output pulse response. However, this relationship may vary according to the transfer function of the system; it is therefore important to distinguish between the pulse-through-time measurement for a system (i.e., the hydraulic response) and the flow-through-time.

Puise train tests will be conducted at ORNL by injecting specified quantities of lowconductivity water, at 2 to $4^{\circ} \mathrm{C}\left(36\right.$ to $\left.39^{\circ} \mathrm{F}\right)$ above or below the temperature of the groundwater, into injection wells that are surrounded by a network of monitoring wells or monitored springs and seeps. The quantity of water to be injected will depend on the system being tested and will often be limited by the rate at which water can be injected into a formation. Poorly transmissive formations will require that less water be injected than karstic transmissive formation. The pressure pulse will be monitored in surrounding wells equipped with pressure transducers and data loggers or at springs and seeps equipped with automatic stage monitoring devices. The flowthrough-time pulse will be monitored by continually monitoring temperature and specific conductivity in the same wells, seeps, and springs. Where large distances are being tested, a chemical tracer may be added to the injected water as a label and the wells, seeps, and springs monitored for the tracer.

All monitoring locations will be monitored for 1 month before the injection test to record natural variations in pressure, temperature, specific conductivity, and the concentration of any chemical tracer being used. An optimum data logger sampling frequency for each test can be determined at this time and will depend on the rate of change in these parameters at each monitoring location. The sampling frequency will be increased during and immediately after injection so that rapid changes caused by the artificial pressure pulse can be accurately monitored. A data logger sampling frequency on the order of $1 \mathrm{~min}$ or $30 \mathrm{~s}$ may be used, and a chemical monitoring frequency of $30 \mathrm{~min}$ to $1 \mathrm{~h}$. The time period for monitoring after the injection test will depend on the areal extent of the test. Tests of large areas will be monitored for longer time periods than small localized tests. Pressure pulse monitoring need only continue for a short period of time (days), whereas monitoring of the flow-through-time data may need to be continued for weeks or months, depending on the size of the test.

\subsubsection{TVA Electromagnetic Borehole Flowmeter Tests}

The electromagnetic (EM) borehole flowmeter was designed and constructed by the Tennessee Valley Authority in 1987 to overcome the limitations of conventional impeller borehole flowmeters. The system consists of three primary components: a flow probe, a packer assembly, and an electronics package. The flow probe includes an electromagnet with two electrodes on 
opposite sides of the cylinder and an amplifier cemented in a watertight epoxy and covered with a stainless steel jacket. Water moving through the hollow core of the flowmeter in the presence of the electromagnet induces a voltage directly proportional to the flow rate, which is measured across the two electrodes. The probe transmits the flow-induced voltages through a waterproof cable to the electronics package at the surface. A portable computer converts the voltage into units of flow and records the raw and processed data. The entire system is compact and easily mounted in a van or truck.

In field tests, the flowmeter is progressively positioned at intervals down the well, and vertical flow is recorded while a constant and known flow rate is withdrawn from or injected into the well. After the rate of drawdown in the well has stabilized, the flowmeter is used to take flow measurements at selected depths. Changes in vertical flow with depth indicate water entering or leaving the well. Assuming initial conditions and aquifer physical properties, well hydraulic equations can be used to calculate the hydraulic conductivity profile (Young et al. 1992).

The sensitivity of the EM flowmeter does not depend on parts that move, corrode, or wear down. The EM flowmeter can measure within a few percent of flow rates as low as $10 \mathrm{~mL}$ $\mathrm{min}^{-1}$, making it very attractive for low-injection/pumping rate situations. The probe will fit into a 5 -cm (2-in.) diameter well. For wells 5 to $8.8 \mathrm{~cm}$ (2 to $3.5 \mathrm{in}$.) in diameter, a plexiglass collar is fitted to the probe to force flow through the hollow core. For uncased wells or $8.8-$ to $25-\mathrm{cm}$ (3.5- to 10-in.) diameter wells, an inflatable packer is used. The probe and packer assembly have no moving parts, so the probe is durable and rarely needs recalibration. The flowmeter has been operated successfully at a maximum depth of $170 \mathrm{~m}(558 \mathrm{ft})$. The threshold dissolved solids concentration needed for accurate electromagnetic readings is not known but is considerably low. In tests completed to date, tap water has been sufficient.

In most applications, a pump test is performed to estimate the total aquifer transmissivity and the EM borehole flowmeter is then used to determine the vertical distribution of conductivity. In most wells tested on the ORR, $>70 \%$ of the total discharge is from $<20 \%$ of the total screened interval (Nyquist et al. 1992). In the open holes tested to date, most of the flow enters and exits the well at one or two fractures over a several-hundred-foot interval. Over the same interval, conventional geophysical logging tools or geological mapping means show that many more fractures exist. Consequently, flow appears to be dominated by a small number of highly permeable fractures, and the Tennessee Valley Authority EM flowmeter can be used to map the fractures that are hydrogeologically significant.

\subsubsection{Rock and Soil Parameters}

\subsubsection{Bulk density}

The soil bulk density, $\rho_{b}$, is the ratio of the mass of the solid phase of the soil (i.e., dried soil) to its total volume (solid and pore volume together). The bulk density of a soil sample is evaluated on the basis of two measured values: (1) $M_{s}$, the oven dried mass of the sample, and (2) $V_{b}$, the bulk volume or the total volume of the sample. $M_{s}$ can be obtained by drying the soil sample (usually at $110 \pm 5^{\circ} \mathrm{C}$ ) until it reaches a constant weight. This laboratory technique directly determines the dry bulk density of a soil sample (DOA 1970, Appendix II). Possible direct methods for measuring bulk density include the core and excavation methods, which 
essentially consist of drying and weighing a known volume of sample. An indirect method of measuring the soil bulk density, applicable for in situ rather than laboratory determination, is the radiation method, or gamma-ray attenuation densitometry (Blake and Hartge 1986; ASTM 1992b,c).

\subsubsection{Core method}

In the core method (Blake and Hartge 1986; ASTM 1992d), a cylindrically shaped metal sampler is introduced into the soil, with care to avoid disturbing the sample. At the desired depth in the soil, a known bulk volume, $\mathrm{V}_{\mathrm{b}}$ of soil material is collected as it exists in situ. The sample is then oven-dried and weighed to obtain the mass, $M_{s}$. The value of the bulk density is calculated by dividing the mass by the volume. This method usually is unsatisfactory if more than an occasional stone is present in the soil.

\subsubsection{Excavation method}

In the excavation method (Blake and Hartge 1986), the bulk density of the soil is determined by excavating a hole in the ground, oven-drying and weighing the amount of soil removed from the ground to determine the mass, and measuring the volume of the excavation. The volume can be determined in different ways. One is the sand-funnel method (ASTM 1992e) in which a selected type of sand with known volume per unit mass is used to completely fill the hole. Then, by measuring the total mass of sand needed to fill the hole, the volume can be determined. Another way to measure volume is the rubber-balloon method (ASTM 1992f). In this technique, a balloon is placed within the hole and filled with water or other fluid until the hole is completely full; the volume of the excavated soil sample equals the volume of the fluid dispensed to fill the hole.

\subsubsection{Radiation method}

The radiation method (Blake and Hartge 1986; ASTM 1992b,c) is based on the principle that the amount of gamma radiation being attenuated and scattered in the soil depends on the soil properties, including the combined densities of the solid/liquid components of the medium. By measuring the radiation that is transmitted through the medium or scattered by soil components and reaches a detector placed at a distance from the source, and by using proper calibration, the wet density of the soil can be determined. To determine the bulk dry density, $\rho_{b}$, a correction of the result is needed to delete the contribution from the liquid phase of the soil.

The radiation method has several advantages over the laboratory methods: (1) it yields an in situ evaluation of soil density, (2) it causes minimum disturbance of the soil, (3) it requires a relatively short measurement time, (4) it is more applicable for deeper subsoil determinations because it requires minimal excavation, and (5) it is a nondestructive technique; continuous or repeated measurements can be performed at the same spot. The main disadvantage of this method is that, because it is a more sophisticated technique, it requires expensive equipment and highly trained operators. The operator should be able to handle the frequent calibration procedures, the electronics, and the sampling equipment, and must be trained in radiological protection procedures and the radiation aspects of the entire operation. 


\subsubsection{Porosity}

Porosity describes the relative pore volume in a soil. It refers to the volume fraction of pores and is expressed as follows:

$$
n_{s}=\frac{V_{v}}{V_{b}},
$$

where

$$
\begin{aligned}
& \mathrm{n}_{\mathrm{s}}=\text { porosity, } \\
& \mathrm{V}_{\mathrm{v}}=\text { volume of voids in a soil mass, } \\
& \mathrm{V}_{\mathrm{b}}=\text { bulk volume of the soil mass. }
\end{aligned}
$$

The fraction of the volume occupied by solid particles $\left(\eta_{\mathrm{s}}\right)$ can be expressed as:

$$
\eta_{s}=\frac{\rho_{b}}{\rho_{s}},
$$

where

$$
\begin{aligned}
& \rho_{\mathrm{b}} \quad=\text { bulk density of the soil, } \\
& \rho_{\mathrm{s}} \quad=\text { particle density of the soil. }
\end{aligned}
$$

The porosity can be defined as the percentage of the bulk volume not occupied by solids as follows:

$$
\mathrm{n}_{\mathrm{s}}=1-\eta_{\mathrm{s}} \text {. }
$$

Therefore, porosity can be calculated by determining bulk density and particle density of the soil. Total porosity was determined for the ORNL Engineered Test Facility site by assuming a value for particle density (Davis et al. 1984). Bulk density can be determined by the methods described in Sect. 6.2.5.1. The method for determining particle density is described below (ASTM 1992a).

Particle density of soil samples is measured by using a pycnometer (specific gravity flask). Two measured quantities, namely, mass and volume of the sample, are required to determine the particle density. The mass of the sample is determined by weighing, and the volume is determined by calculating the mass and density of water displaced by the soil sample.

A clean, dry pycnometer is weighed in air. A soil sample is poured into the pycnometer, and the weight of the pycnometer and soil sample is taken. The pycnometer is filled with water, and the pycnometer containing soil and water is also weighed. The soil sample is then removed from the pycnometer, which is filled with distilled water at room temperature and reweighed. 
The particle density is then calculated as:

$$
\rho_{p}=\frac{\rho_{w}\left(W_{s}-W_{2}\right)}{\left(W_{s}-W_{z}\right)-\left(W_{s w}-W_{w}\right)},
$$

where

$\rho_{\mathrm{p}} \quad=$ particle density,

$\rho_{\mathrm{w}}=$ density of water at observed temperature,

$\mathrm{W}_{\mathrm{s}}=$ weight of pycnometer and soil sample,

$\mathrm{W}_{\mathrm{a}}=$ weight of pycnometer filled with air,

$\mathrm{W}_{\mathrm{aw}}=$ weight of pycnometer filled with soil and water,

$\mathrm{W}_{\mathrm{w}}=$ weight of pycnometer filled with water at observed temperature.

Preparation of equipment, sampling procedures, and precision should be maintained as outlined in ASTM (1992a) and Methods of Soil Analysis, American Society of Agronomy (Klute 1986).

\subsubsection{Field capacity}

Field capacity is the water content at which internal drainage is assumed to cease. For practical purposes, it is defined as the amount of water content remaining in a soil $2 \mathrm{~d}$ after the soil has been saturated (Peters 1965). An initially saturated soil with a moisture profile, if drainage is allowed to continue, will reach a moisture content low enough to make change of the profile almost imperceptible (Childs 1969). This moisture content after the cessation of infiltration is stationary and is called the field capacity.

Many attempts have been made to establish the criteria for determining the field capacity (Jury et al. 1991; Morrison 1983; Peters 1965). Field capacity has been described in terms of the amount of water retention at a particular matrix potential. It has been suggested that the moisture content corresponding to $1 / 3$ bar represents the field capacity of a soil (Peters 1965). In this approach, soil moisture characteristic curves can be established for a particular soil, and the field capacity corresponding to $1 / 3$ bar can be determined. Field capacity can be determined in both laboratory and field by allowing drainage from an initially saturated soil. The laboratory and field methods are described below.

A column of soil sample is collected in a Plexiglas cylinder with porous plates at both ends. The soil water content is brought into complete saturation. Time-domain reflectometers and tensiometers are connected to the sample at different locations to determine the soil moisture content and suction head. The soil sample should be completely covered by plastic to prevent evaporation. Finally, the soil sample is allowed to drain, and the time-varying soil moisture data are recorded.

The soil moisture profile is plotted, and change in soil moisture distribution is observed. After complete drainage, the rate of change in the soil moisture profile will be almost imperceptible, and the corresponding moisture content can be interpreted as the field capacity (Childs 1969). 


\section{6-8}

The soil moisture content with respect to time can be plotted. The moisture content after cessation of drainage will reach a steady-state condition. The steady-state moisture content can be regarded as the field capacity of the soil (Bagerzadeh 1993). All the soil data can be subjected to statistical analysis to determine the representative and appropriate value for field capacity.

Field Method. The concept of the determination of the field capacity of a soil in the field is similar to the laboratory method. A field site is selected for sampling of the soil in its normal driest condition. A raised border should be placed around the plot at least $2.4 \times 2.4 \mathrm{~m}(8 \times$ $8 \mathrm{ft}$ ) (Peters 1965). Sufficient water should be added to wet the soil of the entire sampling area to the depth of interest.

The plot should be covered with polyethylene plastic to prevent evaporation. The soil is allowed to drain for $\sim 2 \mathrm{~d}$. Soil samples can be collected and analyzed, or time-domain reflectometers can be used to determine the soil moisture content, which should be determined by successive increments to the depth of wetting. The moisture content at the time of sampling is defined as the field capacity of the soil.

\subsubsection{Residual saturation}

van Genuchten (1978) has suggested measuring the residual saturation experimentally by determining the moisture content on very dry soil. The residual saturation can also be estimated by extrapolating soil moisture retention data of a soil. An estimate of residual saturation can be made by selecting a value of moisture content at which the curve of suction head versus moisture content appears to approach a vertical asymptote (Brooks and Corey 1964).

\subsubsection{Radioactive decay and biodegradation}

Nuclear, chemical, and biological processes play major roles in the fate of some contaminants and thus are important aspects of all fate and transport modeling. For example, concentrations of both radioactive isotopes and organic compounds remaining in the environment for long periods would be greatly overestimated without accounting for the effects of radioactive decay and biodegradation. Therefore, information about radioactive decay and environmental biodegradation will be used in the transport models.

\subsubsection{Radioactive decay}

The decrease in the quantity of a radioactive material over time is calculated by the exponential decay relationship:

$$
A=A_{0} e^{a t},
$$

where

A = Activity at time $\mathrm{t}$,

$\mathrm{A}_{0}=$ Activity at time $\mathrm{t}=0$,

a $=$ radioactive decay constant $\left(\right.$ day $\left.^{-1}\right)$, given by: 


$$
a=\ln (2) / T_{1 / 2}
$$

where

$$
\mathrm{T}_{12}=\text { radioactive half-life (day) }
$$

Equation 6 will be used to generate radioactive decay constants for the radiological constituents, that may be needed in support of the fate and transport modeling for the GWOU.

\subsubsection{Biodegradation}

The Handbook of Environmental Degradation Rates (Howard et al. 1991), prepared for EPA by the Syracuse Research Corporation to support the Superfund Amendments and Reauthorization Act Sect. 313, is an excellent source for determining degradation rates for organic chemicals. Reported half-lives reflect only the most important degradation process or processes. Biodegradation, and hydrolysis to a lesser extent, is the principal means of degradation in groundwater. The abiotic process of hydrolysis is important, but to a lesser extent. Other abiotic reactions, such as photolysis and oxidation/reduction, do not play an important role in degradation. A range of half-lives is available for most of the chemicals in each environmental compartment (e.g., air, soil, and water). 'In general, biodegradation rates for groundwater are slower than those for soil and surface water because groundwater is often limited in terms of microbial populations; rates are often one-half those of surface water.

To support the fate and transport modeling for the GWOU, the most conservative value (e.g., the longest half-life) will be used for determining the degradation coefficients. The following equation (Cember 1983) will be used to calculate the degradation coefficients:

$$
a_{c}=\ln (2) / T_{1 / 2}
$$

where

$\mathrm{a}_{\mathrm{c}} \quad=$ degradation coefficients $\left(\right.$ day $\left.^{-1}\right)$, given by:

$\mathrm{T}_{1 / 2}=$ degradation half-life (day).

\subsection{GROUNDWATER FLOW SYSTEM DEFINITION}

Hundreds of monitoring wells and piezometers are currently available within the GWOU boundaries for sampling groundwater or measuring hydraulic head. Most of these wells were installed as part of the following investigative programs:

- pre-RAP;

- hydrofracture monitoring;

- RAP;

- remedial investigations at individual WAGs;

- WAG perimeter water quality monitoring; and

- the hydrologic head monitoring stations (HHMS) task. 
A number of groundwater monitoring programs and investigations are underway at ORNL:

- groundwater monitoring at WAG perimeters;

- hydrochemical data assessment;

- groundwater level monitoring;

- $\quad$ shallow drive point investigation;

- shallow groundwater anomaly investigation in Melton Valley;

- HHMS activities;

- $\quad$ site-wide groundwater modeling; and

- groundwater investigations for individual WAG remedial investigations.

Most of these studies are being carried out by the WAG 2/SI program and will be transferred into the GWOU during the coming years (Clapp and Watts 1993).

A major initial effort in the GWOU investigation will be the review of existing data and the existing well network to decide the suitability of wells for use in fulfilling the data gaps identified in Chap. 5. When the existing wells network cannot be used to obtain data that address data gaps in the GWOU, new wells will be installed.

In addition to monitoring groundwater to fulfill some data gaps, it will be necessary as part of the GWOU characterization to monitor flow at seeps, springs, and surface water streams. Although surface water is not considered a medium to be addressed in this OU, it acts as an exit pathway for groundwater; therefore, surface water, seeps, and springs will be monitored to address exit pathways from the OU. Surface water monitoring will take a similar approach to that for groundwater in that the extensive existing surface water, spring, seep monitoring network in the GWOU will be evaluated for applicability to the data gaps before new monitoring points are established. Surface water, spring, and seep flow monitoring are described below in Sects. 6.3.1. through 6.3.4.

The data gaps related to the definition of the groundwater flow system within the GWOU are as follows:

- the degree of hydraulic head variability within the Knox aquifer along Chestnut and Copper Ridges;

- the hydrologic character of the water gap in Haw Ridge;

- the role of the topographic divide at the west end of Bethel Valley as a groundwater divide;

- groundwater underflow of west boundary;

- hydraulic head along the east boundary;

- the topography of the brine surface beneath the OU (in particular, the factors affecting the depth to brine in the Knox aquifer);

- the extent of flow over the Knox/Chickamauga and Knox/Nolichucky boundaries; 
- $\quad$ seep and spring input to the OU;

- streamflow of perennial streams entering the OU;

- streamflow in exit pathway streams including Raccoon Creek;

- seeps and springs west of the topographic divide at the west end of Bethel Valley;

- seeps and springs in the Clinch River; and

- the volume of water imported into the OU.

\subsubsection{Seep and Spring Monitoring}

This section outlines the procedures required to implement systematic monitoring of seeps and springs in the OU. Seeps and springs are the exit points for groundwater and groundwater contaminants on the ORR. They also provide significant input to the OU water budget by way of seeps and springs arising from the Knox aquifer on the north and south boundaries of the OU. Monitoring of seeps and springs, therefore, may allow quantitative assessments to be made regarding water budgets and changes in contaminant flux. In addition, seep and spring monitoring will yield information about contaminant releases, thus providing insight into contaminant transport processes.

\subsubsection{Seep and spring locations}

A seep and spring survey is an important component of this characterization plan. Numerous seeps and springs in the OU have been mapped (Fig. 6.1). Many undocumented seeps and springs probably are also located within the OU-especially seeps, which are not as apparent as springs.

Before initiating a seep and spring survey, the OU will be evaluated to determine which areas are most crucial to the goals outlined in this document. When these priority areas have been identified, a systematic survey of each will be conducted.

Seeps and springs in the ORR tend to occur in low-lying areas near drainages. Initially, a field reconnaissance will be conducted to identify visible seeps and springs throughout a priority area and along any drainages that might eventually pass through the area. The initial reconnaissance will be conducted during the dry season, concentrating on areas where groundwater discharge would be most probable (i.e., heads of drainages, along drainages, etc.). In this way, exit pathways for baseflow could be evaluated for rate of flow and contaminant flux. The locations of these seeps and springs will be numbered and recorded on maps and in log books. The identified locations either will be permanently monitored or revisited during wet season, wet weather, and conditions to characterize changes in contaminant flux and rate of baseflow.

An experimental program for identifying impalpable and camouflaged seeps and springs will run concurrently with the field reconnaissance. This program will involve measuring water temperatures at specific intervals along stream reaches. As envisioned, the procedure will be 


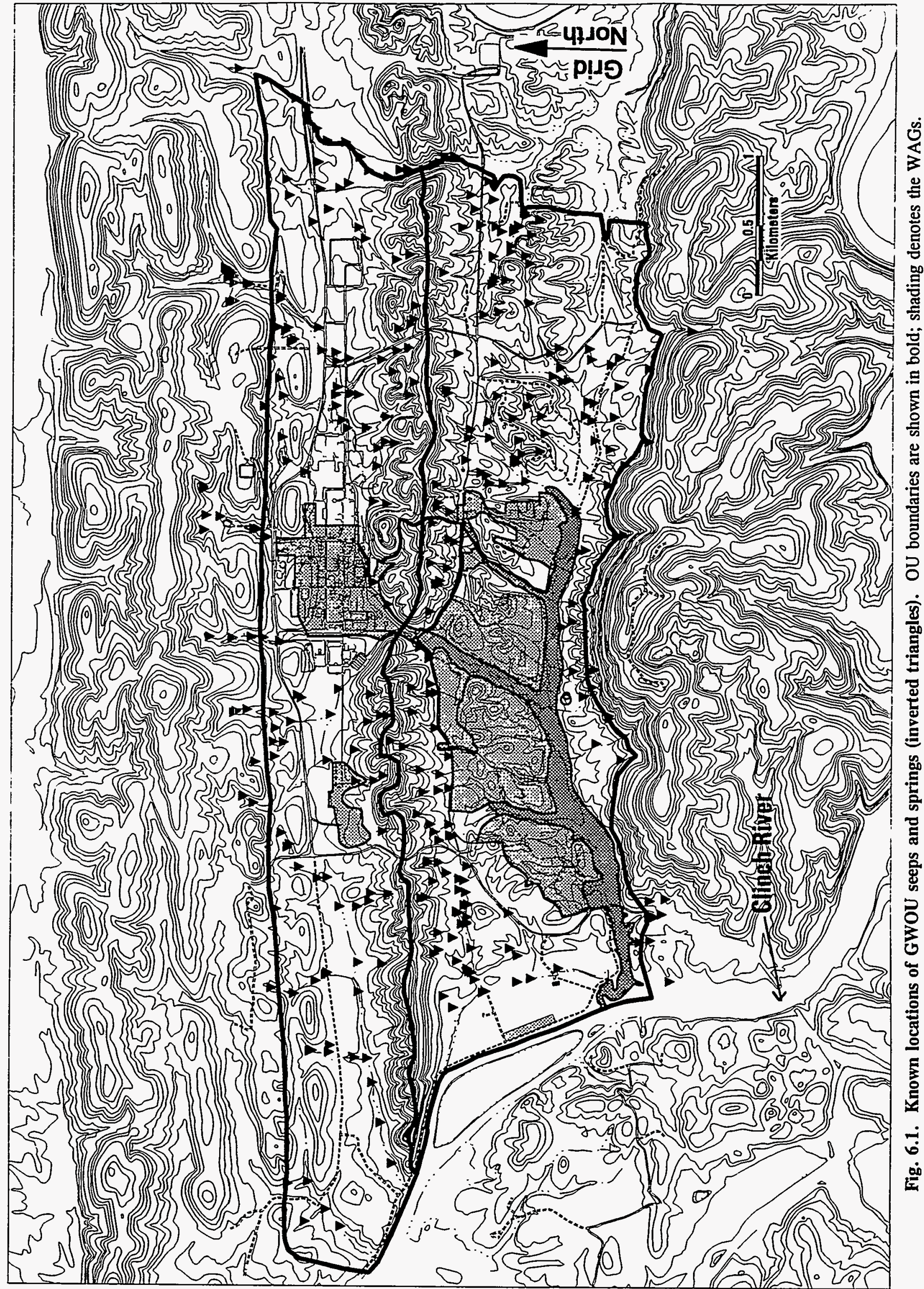


conducted in winter when the difference between air temperature and groundwater temperature is greatest and when the rate of heat loss from emerging groundwater is greatest. A particular stream reach of interest will be identified and a nylon cord, marked with numbered intervals

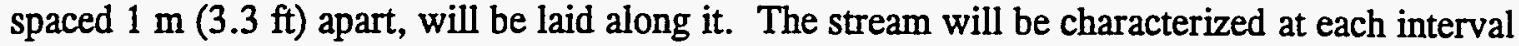
as either fast-flowing, slow-flowing, or pool. Water and air temperature measurements will be taken at each interval during the early morning hours when air temperature has been stable for $1 \mathrm{~h}$ or more. It is anticipated that a relatively steady decrease in temperature will be observed from the head of the stream reach to its end. However, because groundwater retains heat longer than surface water, seep and spring contributions to the stream will be marked by temperature increases.

\subsubsection{Seep and spring monitoring tasks}

Once identified, either in the records of former seep and spring surveys, during field surveys conducted specifically for the GWOU characterization or during the experimental program, the following specific monitoring tasks for selected seeps and springs will be conducted:

Measurement of Seep and Spring Flow. The resulting data will be essential for determining water balances in the OU. In addition, these data will be combined with measured contaminant concentrations to quantify contaminant flux.

Cold-weather Flyover. To help identify springs within the Clinch River that represent the discharge of submerged groundwater flow paths, a cold-weather flyover will be conducted using thermal infrared photography. The infrared photography will highlight areas of likely discharge by delineating waters of different temperatures. Once potential areas are identified, surface water measurement can be conducted to pinpoint and characterize submerged springs.

\subsubsection{Stream Flow Monitoring}

Monitoring stream flow within the GWOU boundaries will provide important information for understanding underflow of the OU boundaries, areas of groundwater recharge and discharge, and mechanisms of contaminant transport and migration. Additionally, the data derived from the measurements are necessary for calibrating groundwater models. Monitoring activities for the GWOU will focus on characterizing the locations of gaining and losing stream reaches (Fig. 6.2). Stream flow monitoring is already being conducted as part of WAG 2 activities, but not for all stream locations important to the GWOU including Bearden Creek (which is important for understanding groundwater underflow of GWOU boundaries), Raccoon Creek and its tributaries (for understanding underflow of the topographic divide at the west end of Bethel Valley), and the northwest tributary to White Oak Creek (for understanding contaminant transport in the subsurface).

\subsubsection{Piezometric Head Measurements}

Hydraulic head monitoring for the GWOU will be conducted in three ways: (1) conventional periodic water level monitoring, such as the monthly monitoring program currently operating for WAG 2; (2) monitoring of vertical head distribution using multiport sampling systems or nested piezometers; and (3) continuous monitoring of water levels in selected wells to produce well hydrographs. 
6-14

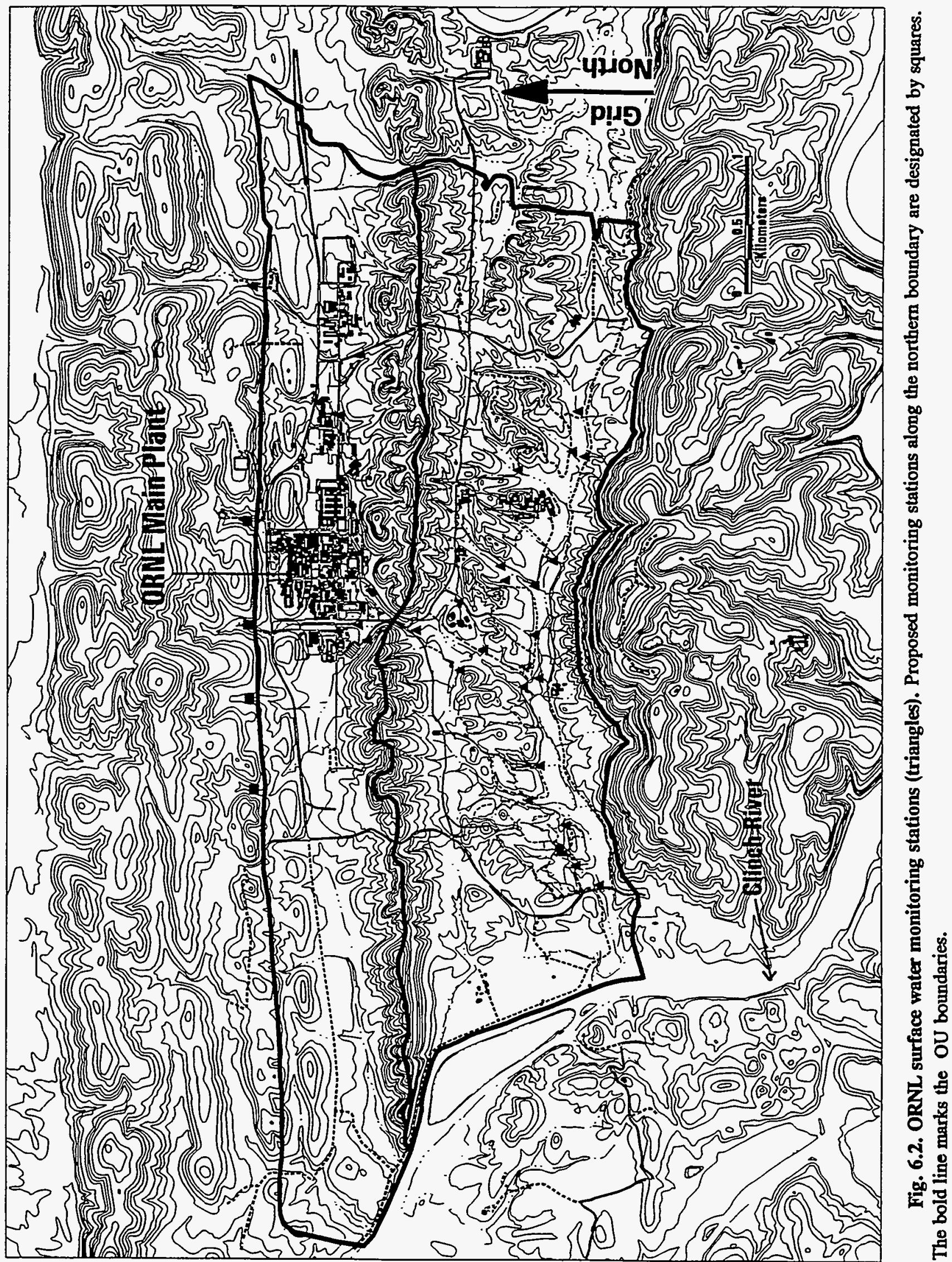




\subsubsection{Periodic groundwater monitoring}

Periodic groundwater level monitoring is a fundamental aspect of site monitoring that provides data used to determine hydraulic gradients and general groundwater flow directions and velocities. Figure 6.3 shows the location of monitoring wells that were sampled at monthly intervals during FY93 for the WAG 2 effort. It is currently envisioned that monitoring of these wells will continue for a long duration to establish a data base of consistent groundwater elevations for this site (Clapp and Watts 1993). Data from this monitoring network will be available to the GWOU and will form the majority of the periodic groundwater elevation database for characterizing the GWOU.

Where data gaps cannot be resolved using these monitoring well data, the need for additional monitoring wells will be identified. Additional monitoring points will be added to this network of wells to address specific data gaps, and their design will be such that the DQOs for that data gap will be satisfied. For example, the conceptual site model identifies the strong stratigraphic control on groundwater flow in the GWOU, and it follows that hydraulic head distribution is also strongly influenced by stratigraphy. To evaluate the ability of the current monitoring well network to identify variations in head distribution resulting from stratigraphic control of flow, each well in the existing monitoring well network will be reviewed for well depth, recorded or likely bottom formation, construction, and existing head monitoring data. Where strata-bound flow paths have been identified (i.e., in WAG 1 at $\mathrm{CH}-008$ ), additional monitoring wells may be needed to monitor head variations specifically at that stratigraphic interval. New wells may also be located at sites where flow paths are suspected or anticipated to evaluate flow directions and velocities.

\subsubsection{Multiport well sampling devices}

One of the key parameters in completing many of the data gaps in the GWOU investigation is the vertical head distribution at various points in Bethel and Melton Valleys. Analysis of vertical head distribution, combined with detailed geological information will be important in understanding stratigraphic controls on groundwater flow. Some of these data gaps may be filled by using the existing monitoring well network. However, in instances where a specific stratigraphic zone is being targeted, detailed geological information and accurate positioning of the well sample port or screen will be necessary. In such cases, new wells with either multiport sampling devices or short screen intervals will be installed. Each of these wells will be bored using core drilling techniques over enough of the hole to identify the target zone and to allow accurate positioning of the screen or port.

The choice of whether to install a multiport sampling device or a nest of monitoring wells will be driven by cost and will be site specific. Where a small number of stratigraphic horizons are targeted ( 2 or 3), a nest of piezometers may be less expensive to install and monitor than a multiport (MP) instrument. Where a greater number of zones are targeted, MP devices will be used.

An aquifer sampling and measurement system currently being considered for the GWOU investigation wells is the MP sampling system designed by Westbay Instruments, Ltd. The MP system consists of permanently installed well casing, couplings, and packers and portable pressure measurement and sampling probes. Details of the MP sampling system are provided in Westbay 


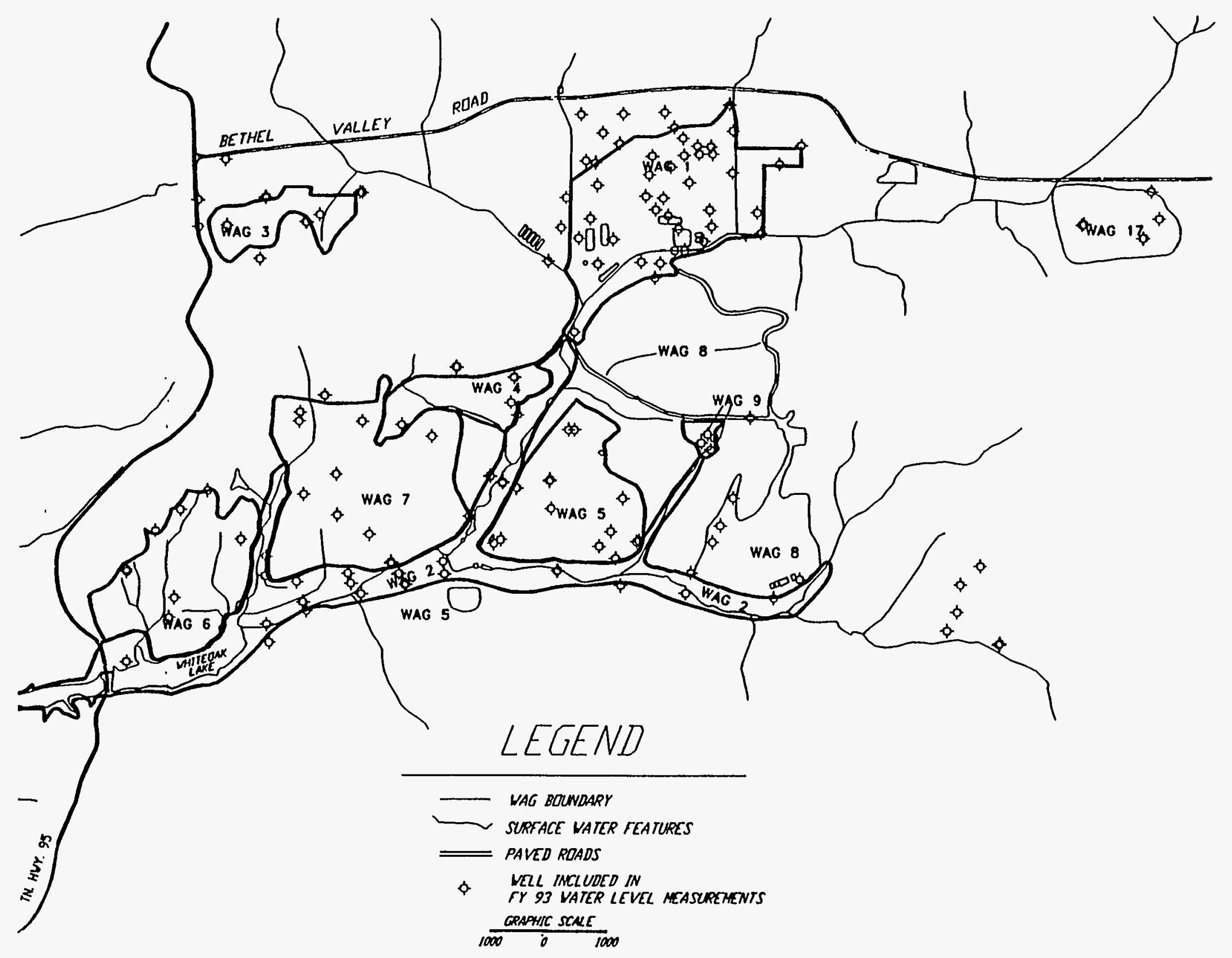

$\frac{9}{a}$

Fig. 6.3. Location of wells included in routine water level measurement programs at ORNL. 
Instruments (1993) and Black et al. (1986). Valved measurement port couplings are installed in the drill hole casing wherever measurements or samples are desired (Fig. 6.4). The MP system is a closed, single access tube monitoring system; pressure measurements can be calibrated and verified at any time. A probe is lowered into the casing, locates a measurement port coupling, and takes a reading or sample (Fig. 6.5). An unlimited number of measurement port couplings can be placed in a single well, and duplicate pressurized or unpressurized groundwater samples can be obtained.

The components selected depend on the purpose being served and the depth of the drill hole. In all cases, regular couplings and casing, and a means of sealing the drill hole with packers or backfilling, are required (Fig. 6.4). When packers are used, an inflation tool and pump are needed to inflate the packers with water. The number of monitoring ports required for pressure measurements and/or sampling determines the number of measurement port couplings, packers, and pumping port couplings. The type of probe used (pneumatic or electric) depends on the depth of the drill hole, the frequency of probe use, and the degree of accuracy required. Electric probes are needed for drill holes $>75 \mathrm{~m}(246 \mathrm{ft})$ in depth. The MP system has been used in many different geologic and climatic environments in drill holes ranging from a few meters to $1200 \mathrm{~m}(3937 \mathrm{ft})$ (Black et al. 1986).

Testing and sampling are isolated from the influence of water within the MP casing, which reduces time lag on fluid pressure measurements and eliminates changes in fluid chemistry that can occur in the casing of a conventional standpipe well or other open tube sampling system. Tracers can be injected and sampled through either measurement ports or pumping ports. Measurement ports together with a sampler probe offer a convenient way of taking samples for tracer tests with minimal disturbance to the groundwater environment.

Measurement port couplings can be installed wherever pressure measurements or water samples are required. The sample is drawn directly from the formation fluids outside the measurement port and the fluids inside the casing are unlikely to be a significant factor (Black et al. 1986). There is no need to pump a number of well volumes before each sampling period. Because the MP system is a discrete sampling system, the samples only characterize the groundwater within the sampling zone. The chemistry of these discrete samples may vary considerably from the water chemistry averaged over the entire saturated thickness. Pumping ports can be installed wherever it is necessary to pump water into or out of the formation. Using data from the sampling and measurement zones, it is possible to acquire a very detailed hydraulic head profile from each well, which will provide detailed information needed to define local groundwater conditions (Fig. 6.6).

\subsubsection{Continuous water level monitoring}

The conceptual site model highlights the need for information concerning the temporal variation in groundwater levels and how this relates to stormflow, baseflow, and contaminant migration in groundwater. Shallow groundwater flow at ORNL tends to have rapid temporal changes in the magnitude of flow. Although continuous head monitoring has been applied to stream and spring monitoring, relatively few wells have been installed in the GWOU to obtain this type of information for groundwater (mainly in WAG 6). 
PACKERS

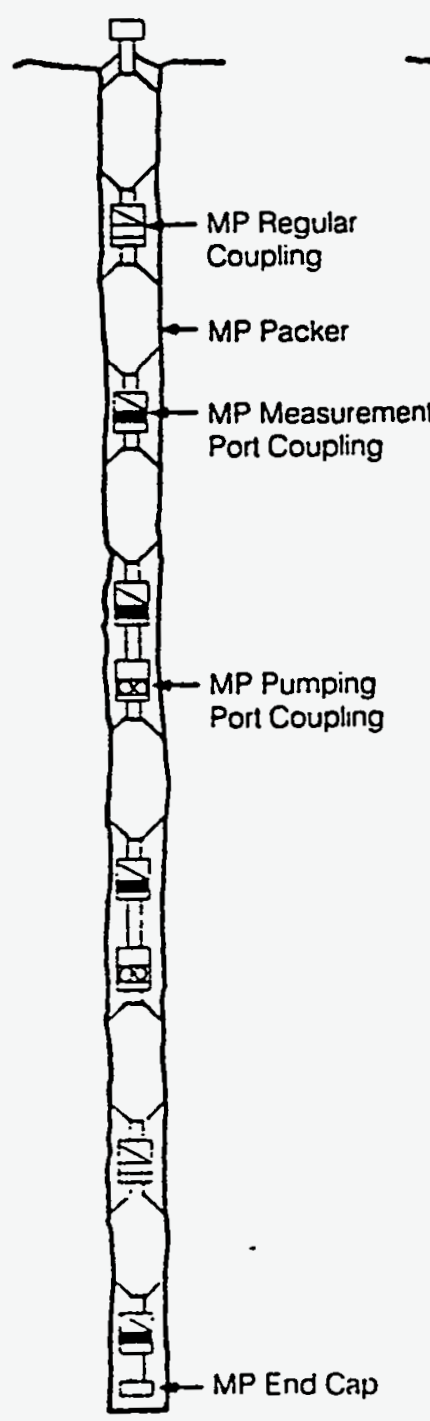

BACKFILLING

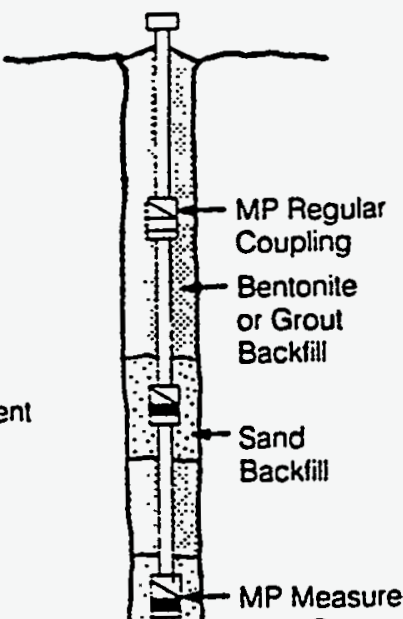

ment Port

Coupling

MP Pumping

Port

Coupling

Fig. 6.4 Westbay Multiport (MP) system showing packer/backfill and port setup. Packers are primarily used for: (1) small diameter drillholes (those too small for good quality backfilling), (2) deep drillholes, (3) protection against high or low fluid pressures in the drillhole, or (4) to reduce labor. Backfilling is used primarily for: (1) larger diameter drillholes, (2) shallow drillholes, or (3) hydrostatic pressure distribution. Source: Westbay Instruments, Ltd. 1993. 

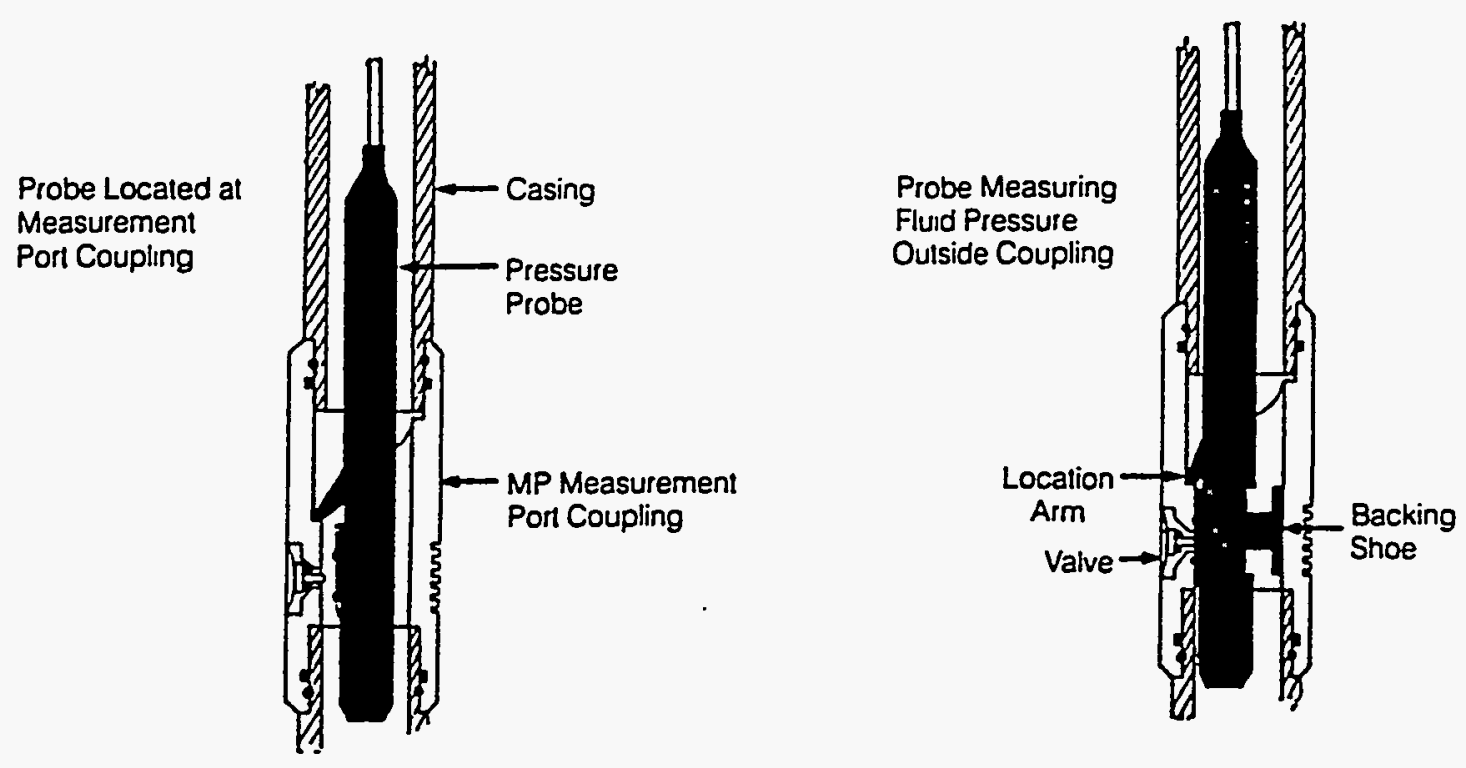

Fig. 6.5. Multiport pressure probe operation. Source: Westbay Instruments, Ltd. 1993. 


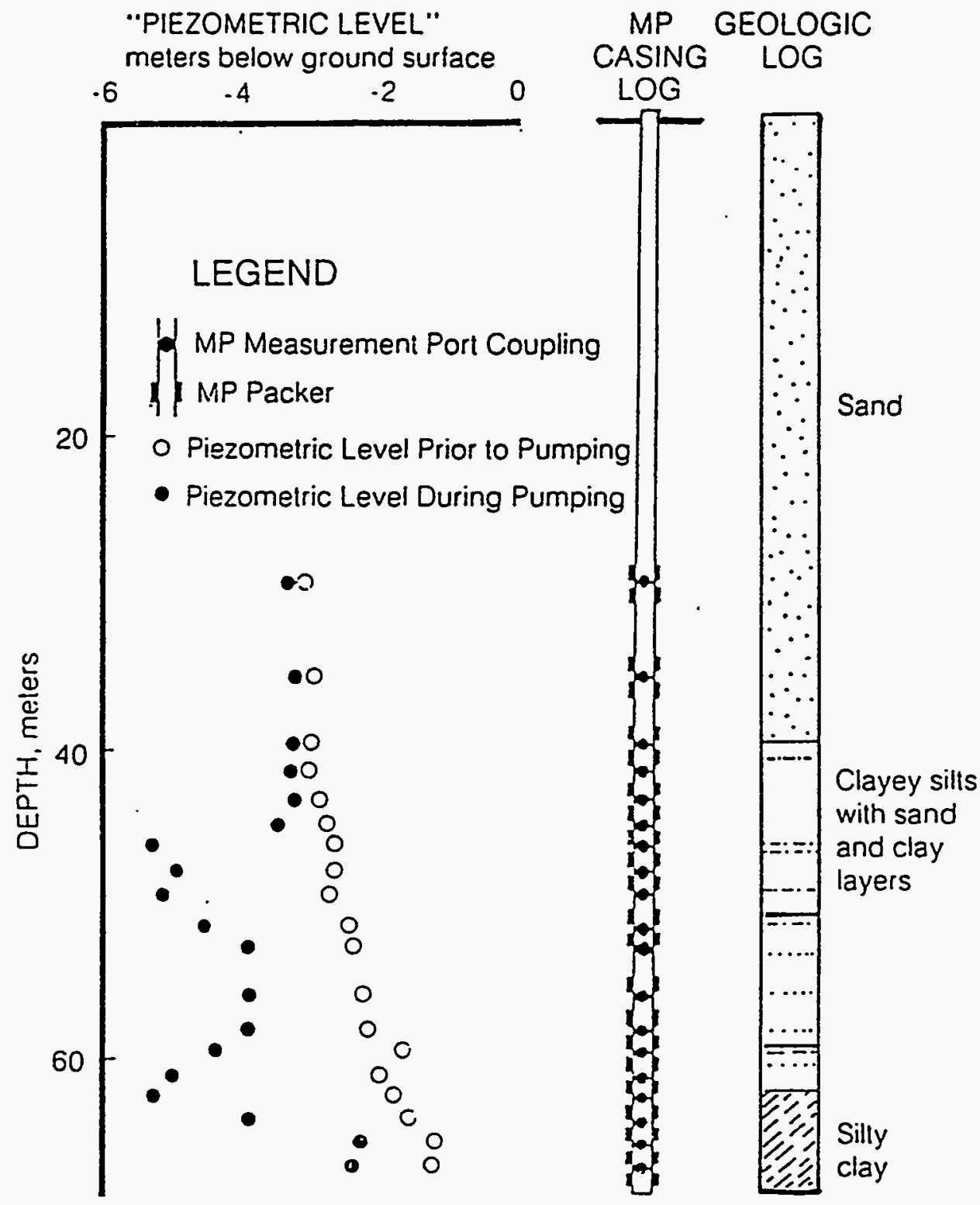

Fig. 6.6. Example of actual MP installation using 19 measurement port couplings isolated by 22 water inflated packers. A geologic log is beside the casing log. Piezometric level obtained from each pressure probe measurement is plotted versus the depth of the port. Piezometric levels recorded prior to the start of pumping are compared with readings taken several days later during the pumping test. Source: Westbay Instruments, Ltd. 1993. 
Pressure head will be monitored continuously in groups of selected wells that are chosen to carry out specific tests. For example, at the west end of Bethel Valley, preferential flow paths may exist with contaminant plumes moving both east and west away from WAG 3. The Witten formation has been identified as a potential stratigraphic horizon that could act as a preferred conduit. Monitoring a group of wells to test the dynamics of pressure head in this and surrounding formations near WAG 3 should help evaluate the mechanics of water flow in that area.

The continuous well group monitoring will have four main purposes: (1) to test specific hypotheses; (2) to understand the relationships between permanent monitoring wells and the regional groundwater flow system; (3) to select better locations for permanent monitoring wells; and (4) to identify likely preferential flow paths. Continuous pressure head monitoring data will be collected using pressure transducers, and data will be recorded using data loggers over time periods that depend upon specific data gap needs.

\subsubsection{Geochemical Monitoring}

Geochemical monitoring will be carried out in two broad categories: (1) sampling and laboratory analysis of groundwater and surface water for contaminants based on the COPC list, and (2) continuous monitoring of selected water quality parameters such as $\mathrm{pH}$, temperature, specific conductivity, or radioactivity using ion-specific electrodes or probes. Groundwater, seep, spring, and surface water monitoring will be performed. Although surface water is not considered part of this GWOU investigation, seeps and springs are exit pathways for groundwater and will therefore be sampled to allow identification of groundwater exit pathways. At least $10 \%$ of all samples collected for geochemical analysis for contaminants will be analyzed for the full target analyte and compound suite of analytes.

\subsubsection{Surface water}

Baseflow is the streamflow stage of most interest to the GWOU investigation. In recent source unit remedial investigation efforts, much emphasis has been placed on the effectiveness of stormflow for contaminant migration within the OU. In the GWOU, the need is to monitor streamflow for its groundwater contribution and, therefore, baseflow (not stormflow) must be the emphasis of sampling.

Sampling and analysis of groundwater and surface water will be performed at selected locations to determine the nature and extent of groundwater contamination, to monitor potential exit pathways for contamination, and to identify preferred flow paths where the contaminants act as a tracer. Monitoring wells will be selected for sampling based on water level monitoring data and the suitability of construction (e.g., open holes will not be selected). In addition, WAG perimeter wells will be sampled for compliance monitoring. Wells will be sampled during contrasting hydraulic conditions (i.e., low baseflow and high baseflow) to capture seasonal variability, and the period of sampling will be determined based on the water elevation monitoring data.

Concern has been expressed that in a flow system dominated by fracture flow such as that at ORNL, excessive purging of wells that tap preferred flow paths could increase the rate of contaminant migration toward that well. Therefore, purging rates need to be kept to a minimum, 
depending on the practicability of purging at low rates, which is well specific. In some cases, it may be possible to purge the well while maintaining a constant head. Where hydraulic head drawdown in a well during purging is such that the well runs dry, even at very low purge rates, the well will be considered unsuitable for geochemical sampling.

Constant monitoring of $\mathrm{pH}$, temperature, specific conductivity, and radioactivity will be carried out at selected surface water sites and monitoring wells. This monitoring will be conducted in combination with continuous pressure monitoring, as described above. Continuous monitoring data will be taken using ion-specific electrodes and/or probes. Data will be recorded using data loggers over time periods that depend on specific data gap needs.

Selected seeps and springs will be sampled on a periodic basis. Springs to be sampled will be selected based on the location of identified groundwater flow paths or contaminant plumes. Springs close to known plumes will be sampled to establish the likely exit pathway for that plume. Springs that issue from a formation known to contain a preferred flow path will also be sampled. Surface water will be sampled at selected monitoring points.

\subsection{SUBSURFACE CHARACTERIZATION}

A significant effort of the investigation will be devoted to defining the subsurface geology of the GWOU. It is critical to identify and characterize the hydrostratigraphic units that might act as exit pathways or aquicludes that confirm the integrity of the GWOU. The following is a summary of the data gaps related to the subsurface geology of the OU:

- the degree of connection between solution cavity systems in the Knox aquifer along the north and south boundaries;

- the geologic and hydrologic character of the dolostone aquifer in the Rome Formation, including understanding (along strike and to depth) the extent of solution features, the extent of permeability, and the hydraulic head;

- $\quad$ structures in Meiton Valley that create preferential flowpaths and new exit pathways;

- the depth to which solution phenomena provide enhanced permeability in the Knox aquifer;

- the extent of digenesis and annealing of the rocks of the Knox aquifer;

- the structure and general geology of the water gap in Haw Ridge;

- the distribution of fractures in the aquiclude; and

- the importance of solution cavities or solution widening of fractures in the aquiclude.

\subsubsection{Core Drilling}

Core drilling will be the intrusive test method that will provide definitive data for the GWOU investigation. Information obtained from coring will be used to calibrate the geophysical tools 
and to provide unambiguous data regarding fracture characteristics and stratigraphic information. In addition, core holes will be used most often to employ multiport sampling tools for vertical head distribution measurements and multizone sampling.

Recovered core is logged for two main characteristics: lithology and structure. Lithologic components are recorded as oolitic or intraclastic for limestones. Glauconite concentrations are also used to make correlations. Structure characteristics are defined as being any faults or fractures that could transmit water. Those fractures or faults that display staining, euhedral, anhedral, and granular crystals are noted as indicating groundwater flow. The orientations of fractures are noted with respect to core axis and strike of beds. Bedding dip is recorded on a per run basis.

\subsubsection{Geophysical Borehole Logs}

Geophysical logging will be used in the GWOU wells to obtain the required information about rock and fluid, properties' well construction or integrity, and the overall groundwater system. Geophysical logs can be quantitatively interpreted to determine values for some of the rock characteristics necessary for design and calibration of numerical groundwater models of the OU (Table 6.1). Parameters that can be estimated include lithology, geometry, resistivity, bulk density, porosity, permeability, moisture content, and specific yield of the groundwater units. Geophysical logging also provides a means to directly locate and measure areas of high porosity and permeability that would produce the most water, such as fracture or joint sets or karst solution features. Zones with high-salinity water and regional groundwater flow patterns can be identified.

Geophysical logs give a permanent record, based on repeatable measurements; thus data collected for one purpose are available for other, unanticipated, uses in the future. Many borehole geophysical logging techniques are applicable to groundwater investigations; only the methods that are appropriate and readily available through the ORNL geophysics staff are discussed here. In most borehole well logging applications to groundwater investigations, a suite of geophysical logs is made, rather than only a single type. The methods tend to be complementary; one may confirm the other. Likewise, certain interpretations are made on the basis of two or more logs. Figure 6.7 shows six different geophysical logs made on the same borehole, along with a lithologic log. It can readily be seen that the logs respond to the changes in lithology.

\subsubsection{Caliper logging}

A caliper log is used to measure the diameter of an uncased borehole in bedrock units. It can be used to identify solution-enlarged bedding planes and joints in carbonate aquifer units. It can also be used to find the casing depth in cased wells. The hole may also be enlarged by caving of the formations into the hole or by solution of minerals by the drilling fluid.

\subsubsection{Temperature logging}

A temperature $\log$ is a continuous vertical record of the temperature of the fluid in the borehole. This may or may not be indicative of the temperature of the fluid in the rocks opposite the borehole fluid. The temperature log can reveal zones of differing temperature in the well. 
Table 6.1. Borehole geophysical methods applicable to ORNL OU groundwater investigations

Required information on the properties of rocks, fluid, wells, or groundwater system

Bedrock lithology and stratigraphic correlation of aquifers and associated rocks

Total porosity or bulk density

Effective porosity

Permeability

Secondary permeability -fractures, solution openings

Clay or shale content

Specific yield of unconfined aquifers

Grain size

Moisture content

Direction, velocity, and path of groundwater flow

Cementing

Location of water level or saturated zone

Casing leaks and/or plugged screen

Dispersion, dilution, and movement of waste
Geophysical logging technique

Electric, sonic, or caliper logs made in open holes; nuclear logs made in open or cased holes

Calibrated sonic logs in open holes; calibrated neutron or gamma-gamma logs in open or cased holes

Calibrated long-normal resistivity logs

No direct measurement by geophysical logging; may be related to porosity or sonic amplitude.

Caliper, sonic, or borehole televiewer or television logs

Gamma logs

Calibrated neutron logs

Possible relation to formation factor derived from electric logs

Calibrated neutron logs

Single-well tracer studies

Caliper, temperature, gamma-gamma, acoustic

Electric, temperature, or fluid conductivity in open (uncased) boreholes or inside casing; neutron or gamma-gamma in open hole or outside casing

Tracer and flowmeter

Fluid conductivity and temperature logs, gamma logs for some radioactive wastes, fluid sampler

Source: Keys and MacCary 1971. 


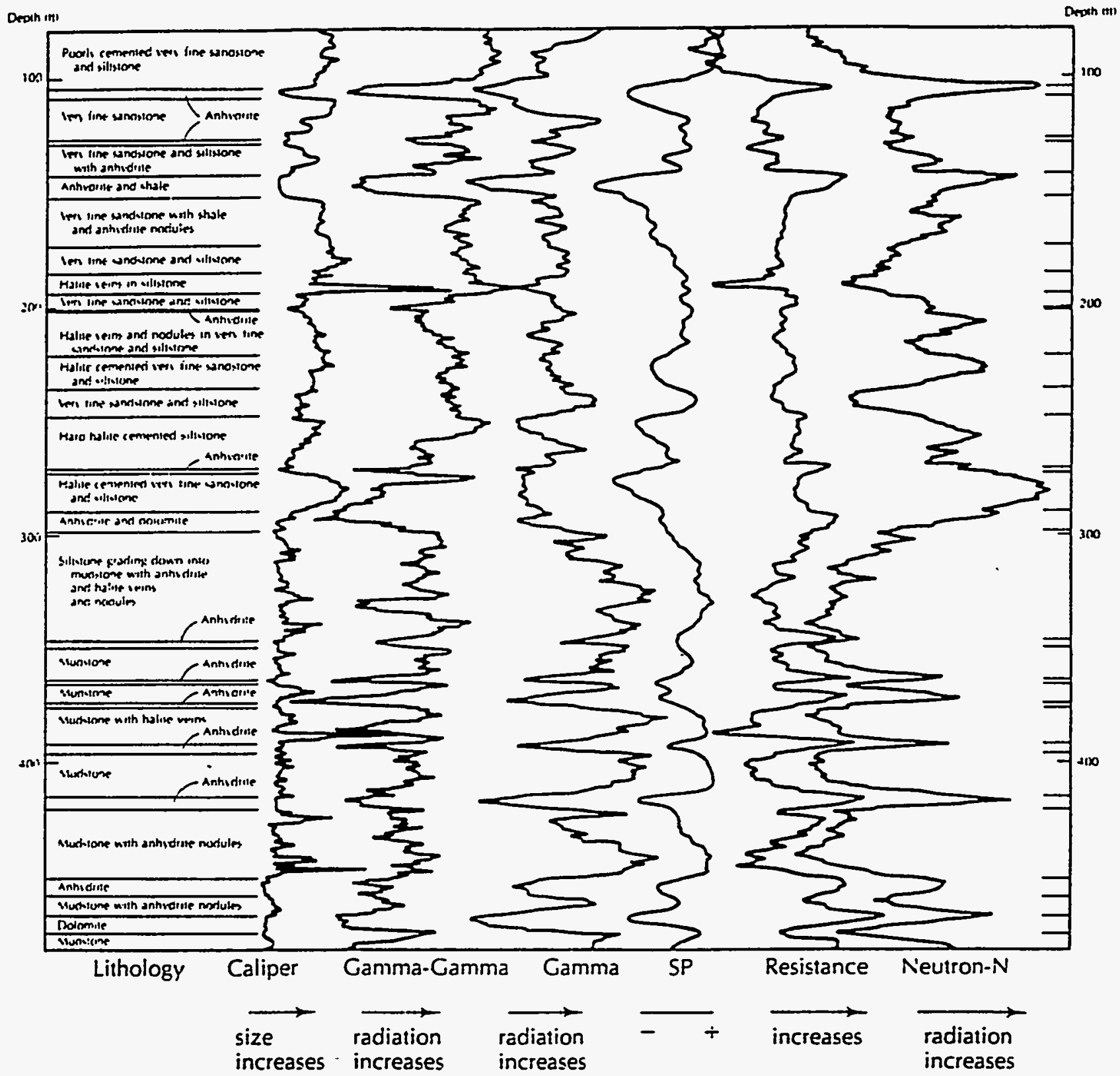

Fig. 6.7. Example of six different geophysical logs of a well in the upper Brazos River Basin. Source: Keys and MacCary 1971. 
There will be components of the geothermal gradient present; however, water in different aquifers may be at discrete temperatures, which may be detected in the log. Thermal logging can be used to trace the movement of water previously injected into an aquifer.

\subsubsection{Resistivity logging}

A resistivity $\log$ is a continuous measurement of the earth's resistivity. It is measured by lowering two electrodes into a borehole and measuring the resistivity between two additional electrodes. Resistivity is measured in units of ohm-meters. Depending on the electrode configuration, the resistivity of zones close to or far away from the borehole can be determined. For example, the $5.5-\mathrm{m} \times 20$-cm $(18-\mathrm{ft} \times 8$-in.) lateral log will be best for beds at least $12 \mathrm{~m}$ $(40 \mathrm{ft})$ thick. Resistivity logs are used to determine the formation resistivity, porosity, water saturation, and fluid resistivity.

\subsubsection{Spontaneous potential logging}

Spontaneous potential (SP) measures the natural electrical potential that develops between the formation and the borehole fluids. It is run only on an open hole filled with fluid. An SP device consists of a surface electrode and a borehole electrode with a voltmeter to measure potential. The SP curve can be used to determine bed thickness and geologic correlation and to delineate permeable rocks. One of the most common uses of the SP curve is distinguish shale from sandstone lithology. Shale has a positive SP response and sandstone a negative one, if the salinity of the formation fluid is greater than that of the borehole fluid.

\subsubsection{Nuclear logging}

Some of the most useful geophysical logging methods involve measuring either the natural radioactivity of the rock and fluids or their attenuation of induced radiation. Nuclear logging records the number of radioactive decay events over a fixed period of time. The longer the time constant, the less the likelihood that a variation in radiation intensity is due to random decay; instead the variation reflects different lithology. Consideration must therefore be given to the speed at which the probe is moved up or down the borehole. Selection of the proper time constant and logging speed is very important and depends on the equipment, logging technique, and lithology. Nuclear logging can be done in either a cased or an uncased hole, and the logs are not affected by the type of drilling mud. The use of radioactive isotopes involves special safety precautions. Nuclear logs do not have exact reproducibility, because of the statistical nature of the radioactive decay process. Repeat logging runs are necessary to determine whether an observed variation represents a lithologic change or a statistical fluctuation in the decay rate. The thickness of the individual strata can be determined from nuclear logs if there is a change in lithology or porosity from one unit to the next.

Three nuclear methods are generally used for composite identification:

Natural Gamma Radiation. This is the nuclear logging method most commonly employed in geophysical borehole. Natural gamma is a measure of the natural radiation of rocks, as determined by the emission of gamma activity by ${ }^{40} \mathrm{~K}$, the ${ }^{238} \mathrm{U}$ decay series, and the ${ }^{232} \mathrm{Th}$ decay series. These are constituent materials for some shales and clays with high gamma activity. 
Certain feldspars and micas are high in ${ }^{40} \mathrm{~K}$. A natural gamma log shows increasing radiation opposite sedimentary beds that contain potassium-rich shale, or clay, or phosphate rock.

The natural gamma radiation increases with increasing clay or shale content, as well as with increased phosphate and potassium feldspars, but has no direct relationship to porosity. The neutron count rate increases with decreasing porosity, while the gamma-gamma count rate decreases. A stratum with low natural gamma radiation and low neutron count (or high gammagamma count) could be interpreted as a porous sandstone. A low natural gamma radiation and high neutron count could be a dense quartz sandstone or quartzite. The natural gamma radiation log has an advantage in that it can be performed on an existing cased well.

Gamma-Gamma Radiation. In this type of logging, a source of gamma radiation, such as ${ }^{60} \mathrm{Co}$, is lowered into the borehole. Gamma photons are absorbed or scattered by all material with which the ${ }^{60} \mathrm{Co}$ comes in contact, including fluid, casing, and rock. The absorption is proportional to the bulk density of the earth material (the weight of the rock divided by the total volume). Bulk density can be determined from a calibrated gamma-gamma log, from which the formation porosity can be determined.

Neutron. A neutron probe contains a radioactive element, such as $\mathrm{PbBe}$, which is a source of neutrons and a detector. The emitted neutrons are slowed and scattered by collisions with nuclei of hydrogen atoms. An increase in the amount of water will result in an increase in the number of neutrons that are captured or moderated. As a result, saturated rocks with a high porosity will have a lower neutron count than low-porosity rocks. Above the water table, the neutron-logging equipment can be used to determine the moisture content, but not the porosity. Neutron logging can be used to determine the specific yield of unconfined aquifers.

\subsubsection{Surface Geophysical Investigations}

Surface geophysical methods will be integral to characterizing the GWOU in obtaining information regarding the conditions of groundwater quality and the constraints of groundwater flow within and adjacent to the ORNL GWOU. Geophysical studies will be conducted in two overlapping phases. The objective of the first phase is to investigate a variety of geophysical methods and to better develop their applications for specific GWOU problems. The second phase is the large scale application of the results of the methods development phase. These two phases will overlap since the initial phase will be addressing real problems with results of utility to the characterization. Also, there will be a need for continuing methods development during the second phase.

This section discusses:

- a brief discussion of each of the surface geophysical methods likely to be used during the characterization;

- current and ongoing geophysical methods testing and development efforts; and

- the plan for the initial phase of geophysical methods testing and development with respect to specific OU and WAG problems, including a discussion of the coordination with and use of current geophysical efforts. 


\section{Discussion of Geophysical Methods}

This section provides a brief discussion of a variety of geophysical methods. The primary surface geophysical methods of interest for the GWOU are: microgravity, self-potential, directcontrol (DC) resistivity, magnetic, frequency and time-domain electromagnetics, seismic refraction and reflection, and ground penetrating radar. A brief summary of each of the above geophysical methods, typical data analysis and interpretation techniques, and subsurface conditions that affect survey results follows.

\section{Microgravity}

Microgravity has been successfully used on the ORR in delineating karst features (Wilson 1991; Wilson and Ketelle 1992; Doll and Nyquist, unpublished study in Bear Creek Valley). Relative to karst characterization, microgravimetry can delineate subsurface cavities (depending on depth and size), map their areal extent, and is also sensitive to the weathered zone surrounding karst features.

Microgravimetry is a potential field geophysical method which uses measurements of the earth's gravitational field to delineate variations of the subsurface density structure. Geologic structure can be derived from the subsurface density data. Subsurface karst features such as solution cavities and zones of increased weathering are typical targets for microgravimetry surveys.

After standard data corrections have been applied, forward or inverse modeling is used for quantitative analysis. Nonuniqueness in microgravimetry, as with any potential field method, can only be reduced by incorporating site geologic constraints or other geophysical data. Geological logs from wells and borings as well as a site conceptual model are used to constrain the gravity modeling. Once the modeling has been completed, lithology and geological structure are then inferred from the density models.

Anomalous density structure is often related to karstification. Microgravimetry and the subsequent density modeling are capable of delineating zones of mass deficiency. In karstic environments, this mass deficiency is often due to not only to solution cavities but also to the reduced density of the altered zone surrounding solution features. Anomalous density structure may also be due to variations in regolith thickness, and it is critical that the extent of this influence be evaluated.

\section{Spontaneous Potential}

Spontaneous potential, also known as self potential, is a surface geophysical method that uses differences in the earth's ambient electric field to deduce geologic and hydrogeologic information. There are many processes including electrochemical interactions between groundwater and porous media, the movement of ions in groundwater, reduction-oxidation (redox) reactions, etc., which collectively comprise the earth's ambient electrical field or SP. Variations in the ambient electric field are termed SP anomalies and can be attributed to either subsurface geologic features or processes, anthropogenic features, or noise. Geologic phenomena that can produce SP anomalies include groundwater flow, seepage, or infiltration. Anthropogenic features such as drums, metal well casing, and buried utilities can produce SP anomalies. 
SP data can be quantitatively analyzed but is usually examined only in a qualitative sense. Quantitative analysis is difficult because of the large number of contributing factors that comprise the ambient electric field. It is often desirable to conduct some data processing to aid in the qualitative assessment. It is sometimes necessary to correct for electrode drift, although this is seldom a problem when using nonpolarizing electrodes. Also, regional trends and/or trends that correlate with topography can easily be removed to aid in interpretation. The qualitative analysis is generally performed graphically by plotting and contouring the SP values. Geological and hydrogeological interpretations are then based on the SP contour plots.

Although generalizations regarding SP anomalies are difficult because of the many factors which contribute to the ambient electrical field, several points regarding SP anomalies should be considered. First, nearly all anthropogenic features such as metal well casings, buried utilities, and buried drums will produce large SP anomalies. Anomalies associated with these anthropogenic features are usually negative (relative to adjacent and unaffected SP values). Zones of pronounced horizontal and downward groundwater flow typically produce negative anomalies. For example, negative SP anomalies are often associated with areas of enhanced seepage through landfill berms or earthen dams. Conversely, areas of upward groundwater movement are often associated with positive SP anomalies.

\section{Resistivity}

DC electrical resistivity is a surface geophysical method that uses an applied electrical current to delineate the subsurface electrical structure. Electrical resistivities are characteristically different in differing lithologies. Other factors such as the conductivity of pore fluids, weathering, fractures, and karst features can affect the electrical structure. DC resistivity surveys can be configured to either delineate vertical electrical structure or to map lateral variations in resistivity. Typically, a combination of both electrical depth soundings and lateral mapping is used.

Forward and/or inverse modeling techniques are usually used to analyze resistivity data. Modeling analysis attempts to produce a model of the subsurface electrical structure that will produce a resistivity signature similar to the observed data. Although seldom used because of the wide availability of computer technology, several quantitative and qualitative graphical analysis methods exist for electrical resistivity data. Geological and hydrogeological information is then inferred from the modeling/analysis results.

Although there are many possibilities, there are common geological phenomena that affect the electrical resistivity structure of the subsurface. Different lithologies often have significant electrical resistivity differences. Pore water, both the abundance of and electrical conductivity, greatly affects subsurface electrical resistivity structure. Increased pore water salinity decreases electrical resistivity values (by increasing conductivity). Weathering, faulting, and fractures also decrease electrical resistivity by increasing the volume of electrically conductive pore water.

\section{Magnetic}

Magnetic geophysical methods use the magnetic properties of the earth and buried materials to deduce information regarding subsurface conditions. Historically, magnetic surveys have been used in the mining industry to locate metallic ore bodies. With respect to environmental 
applications, magnetic surveys are typically associated with locating buried metallic objects such as underground storage tanks drums, and pipelines.

Analysis and interpretation of magnetic data are typically conducted in a qualitative or a semi-quantitative manner. Magnetic data are usually graphically plotted and contoured. After contouring, semi-quantitative assessment can be conducted by comparing the magnitude of observed anomalies to the magnitude of anomalies for known objects (such as drums). Quantitative forward or inverse modeling is possible but is not usually warranted. Usually the desired information is inferred directly from the contoured total field or gradient plots.

For environmental applications, magnetic geophysical data are usually used to locate and delineate buried metallic objects. Buried metallic objects are usually very obvious features on contour plots of magnetic total field and vertical gradient data.

\section{Frequency-Domain Electromagnetics}

Frequency-domain electromagnetic surface geophysical methods, generally referred to as EM methods, uses electromagnetic waves to deduce subsurface electrical properties. A wide variety of EM methods have been developed to use natural or artificial sources. The EM methods discussed in this section are limited to artificial source ground conductivity methods. Ground conductivity methods use electromagnetic induction for both transmitting and receiving signals. These types of EM methods are relatively fast, inexpensive, and can yield very useful results regarding lateral conductivity variations in the near subsurface. Unfortunately, EM methods are of little utility in identifying vertical variation in conductivity. Examples of subsurface features that can be delineated by EM methods are zones of high water content, karst features, preferential flow pathways, buried metallic objects such as drums, waste burial trench boundaries, landfill boundaries, and plumes of groundwater contamination.

Analysis and interpretation of EM data are typically conducted in a qualitative or a semiquantitative manner. EM data are usually graphically plotted and contoured. After contouring, semi-quantitative assessment can be conducted by comparing the magnitude of observed conductivity anomalies to the magnitude of anomalies for known objects (such as drums). Quantitative forward or inverse modeling is possible but is not usually warranted. Usually geological and/or hydrogeological information is inferred directly from contour plots of the electrical conductivity.

The types of information derived from EM data interpretation are based on phenomena that affect the electrical conductivity. As discussed in the $\mathrm{DC}$ resistivity section, water content greatly affects electrical conductivity. Areas of high water content are typically more electrically conductive than areas with less water content. For this reason, clay has a high conductivity (low resistivity) due to its high moisture content. Zones of weathering, solutioning, faulting, and fracturing that have a higher moisture content are typically more conductive than surrounding unaltered areas. Anthropogenic features that typically have easily detected electrical conductivity signatures are buried metallic objects such as drums, waste burial trench boundaries, landfill boundaries, and plumes of groundwater contamination. 


\section{Time-Domain Electromagnetics}

Time-domain electromagnetics or transient electromagnetics (TEM) use the transient decay of an induced electric field to determine the subsurface electrical structure. TEM can be used for both vertical electrical soundings and/or for lateral mapping of subsurface structure. TEM is typically used in determining subsurface geologic structure, determining the depth to the water table, and mapping ionic groundwater contaminant plumes or saline/freshwater interfaces. Field data acquisition is relatively fast as compared with resistivity surveys, although instrumentation is quite expensive.

Forward and/or inverse modeling is needed to analyze the apparent resistivity versus time curves generated from a single TEM sounding. This type of analysis results in either one-dimensional or two-dimensional resistivity models of the subsurface. The vertical electrical structure from several depth soundings can be used to generate two-dimensional cross sections or three-dimensional representations of the subsurface electrical structure. Geologic and/or hydrogeologic information is then inferred from the subsurface electrical structure.

Although there are many possibilities, there are common geological phenomena that affect the electrical resistivity structure of the subsurface. Different lithologies often have significant electrical resistivity differences. Pore water, both the abundance of and electrical conductivity, greatly affects subsurface electrical resistivity structure. Increased pore water salinity decreases electrical resistivity values (by increasing conductivity). Similarly, contaminant plumes can be mapped using the subsurface electrical structure. Weathering, faulting, and fractures also decrease electrical resistivity by increasing the volume of electrically conductive pore water.

\section{Seismic Refraction}

Seismic refraction is a surface geophysical method that uses the travel times of acoustic waves to deduce subsurface seismic velocity information. Geological properties are then inferred from the subsurface velocity information. Examples of geological factors that affect subsurface seismic velocities are lithology, weathering, faults, fractures, and karst processes.

A wide variety of analysis and interpretation methods exists for the seismic refraction method. Graphical interpretation, forward, and inverse modeling all are commonly used to deduce the subsurface seismic velocity structure. Geological information is inferred from the seismic velocity structure.

Seismic velocity structure yields information such as depths to the water table, depth to bedrock, and the location of faults, fractures, and karst features. The seismic structure also can be used to deduce geotechnical properties such as competency, density, and elastic moduli.

\section{Seismic Reflection}

Seismic reflection is a surface geophysical method that uses seismic energy reflected from subsurface interfaces to deduce subsurface geological structure. There is an extensive variety of data collection, data processing, analysis, and interpretation techniques available for the seismic reflection method. The typical end product of data processing and analysis is a seismic record section which consists of many seismic traces. Each trace represents the seismic response of the 
subsurface to a vertically traveling seismic wave. Subsurface geological structure is then interpreted directly on the "vertical incidence" seismic section. Examples of geological factors that can be imaged with the seismic reflection technique are lithologic boundaries, faults, fractures, and karst features.

Geological analysis and interpretation of seismic reflection data are primarily based on the results of data processing. Data processing is necessary to successfully image the subsurface. The large quantities of data generated with seismic reflection profiling require much sorting and gathering of data in a variety of formats. Filtering, sorting, muting unwanted portions of the seismic wave field, velocity analysis and correction, and surface static removal are examples of some of the many steps needed to arrive at a final seismic reflection section. Typically some form of forward and/or inverse modeling is employed during seismic data processing. Once the data have been processed, geological interpretation is conducted by inferring geological structure from the seismic section.

Lithological and structural information is derived from seismic reflection interpretation. With careful interpretation of seismic reflection data, it is common to delineate both vertical and lateral stratigraphic changes. Structural features such as faults, fractures, and karst are routinely delineated during seismic interpretation.

\section{Ground-Penetrating Radar}

Ground-penetrating radar (GPR) is a surface geophysical technique, similar to seismic reflection, that uses reflected electromagnetic waves to image the subsurface. As with seismic reflection, subsurface geological structure is the primary information derived from GPR surveys. Examples of geological structure that GPR surveys can delineate are bedrock topography, groundwater table topography, faults, fracture, karst features, and underground utilities.

Most GPR data are single fold and require little or no processing. GPR data analysis and interpretation are similar to seismic reflection analysis and interpretation in that geological structure is directly interpreted from the GPR section. Data processing with GPR is also similar to seismic reflection processing. In contrast to seismic reflection techniques, much less processing is usually required prior to geological interpretation.

Because of the potentially high resolution of GPR surveys, there are many geological and anthropogenic features that GPR can successfully image. Geological information such as depth to water, depth to bedrock, location of faults and fractures, and karst delineation can be obtained by interpretation of GPR data. GPR surveys can also image subsurface anthropogenic features such as culverts, buried utilities, underground storage tanks, pipelines, and drums. 


\section{FIELD SAMPLING/SURVEY PLAN}

\subsection{INTRODUCTION}

The Field Sampling/Survey Plan (FS/SP) outlines the approach for the first 18 months of work necessary to meet the objectives of the Characterization Plan for the ORNL Area-Wide Groundwater Program. During this period, the investigation will focus mainly on nonintrusive activities. A review of historical data will be conducted in an effort to optimize available resources and direct efforts in subsequent stages of the investigation. These data will be evaluated for their quality and applicability to attaining the goals of this characterization plan. Data collection during this 18-month period will involve field activities such as piezometric head measurements in existing wells, and seep and spring monitoring and analysis. Additionally, in preparation for subsequent data collection activities, existing well bores will be retrofitted during this time period for vertical head measurements and discrete zone sampling, and geophysical methods will be developed for karst delineation and subsurface structure interpretation. Figure 7.1 provides an approximate schedule of planned activities for the first 18 months of the GWOU investigation, and Fig. 7.2 displays the overall schedule for the initial 7-year period. The areas of investigation within the GWOU and the type of data to be obtained are shown in Fig. 7.3.

\subsection{OBSERVATIONAL APPROACH}

The Observational Approach is a step-wise method of investigation whereby the strategy for each successive step of the investigation is planned based upon evaluation of the information derived during the previous steps. The Observational Approach encompasses implementation of the $D Q O$ process while managing uncertainties inherent in the environmental investigation. In doing this, it combines stated objectives (e.g., defining the problem and ensuring data sufficiency) with contingency planning for unexpected developments. The characterization of the GWOU will employ the Observational Approach to foster a flexible investigation that will respond to new information.

As described below, the investigation of the GWOU consists of a number of staged investigations in which the activities in the later stages of each investigation will be contingent upon results in preceding stages. The initial step in each investigation described in this FS/SP will be to evaluate existing data for adequacy and applicability to the goals of the plan. This step is an opportunity to evaluate the goals of specific investigations in light of what is already known about the problems being addressed. It also helps focus any investigations toward these objectives by the most effective and efficient methods. Focusing each investigation will be an ongoing process throughout the duration of the GWOU investigations. As new data are derived, implementation of a particular investigation will be reevaluated in light of the new data so that . the next step in the investigation will be an effective and efficient continuation of the previous step. 


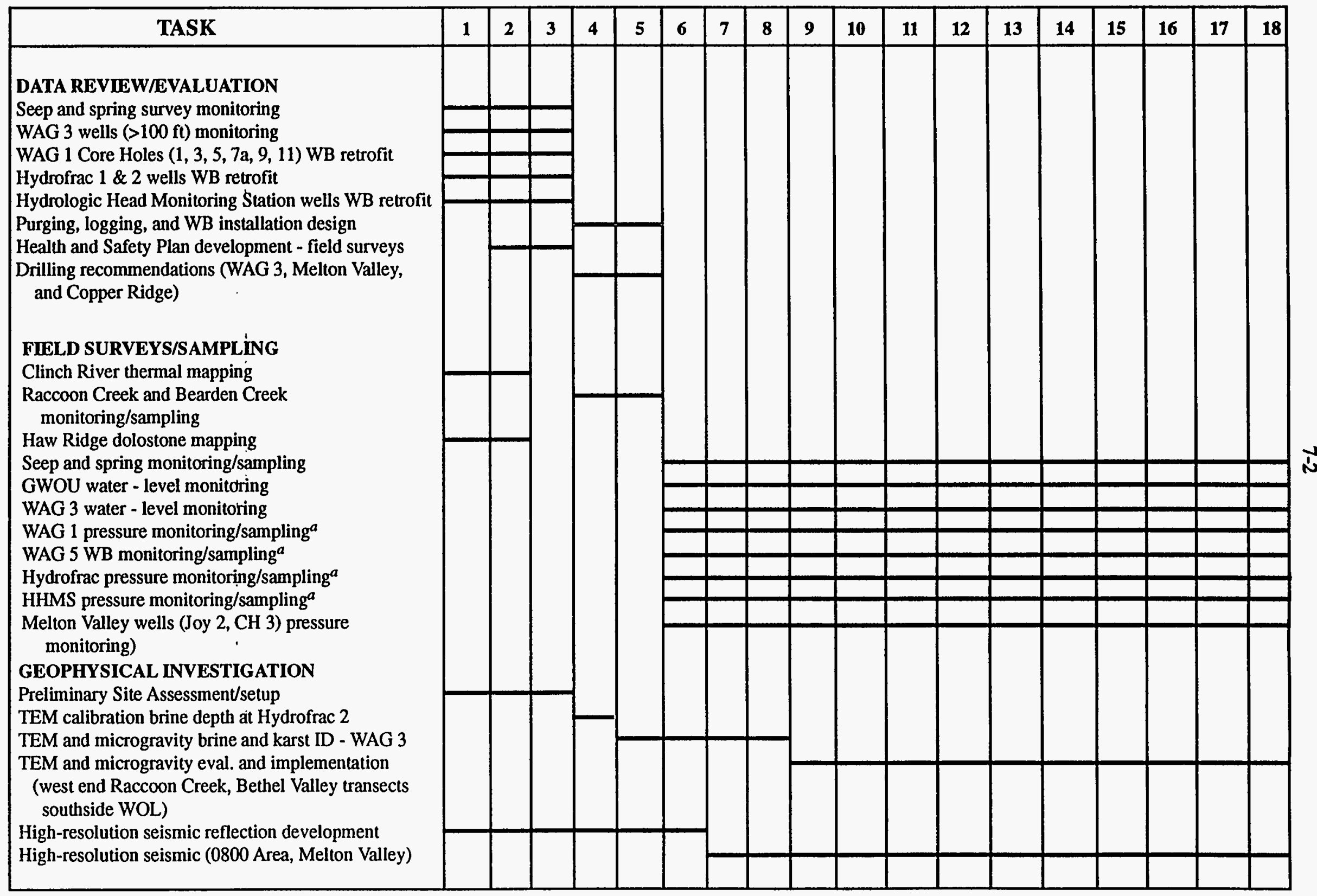

$a$ includes procurement time $\mathrm{WB}=$ Westbay

93.008MS/012294

Fig. 7.1. Timeline for proposed activities during the first 18 months of GWOU. 


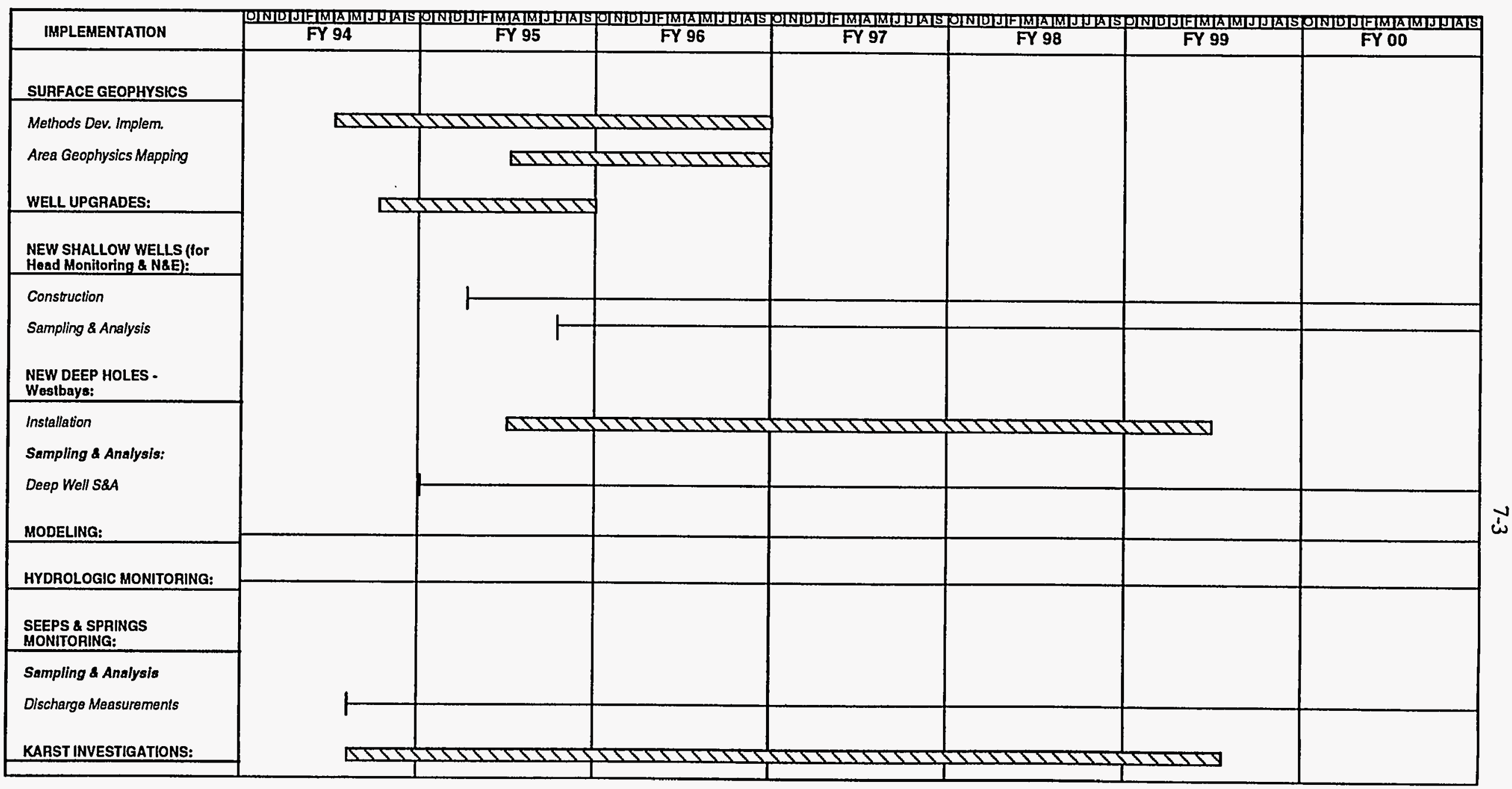

$$
\begin{aligned}
& 1 \text { Continuous Activity } \\
& \text { Discrete Task }
\end{aligned}
$$

Fig. 7.2. RI 7-Year Plan. 


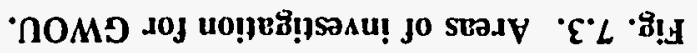

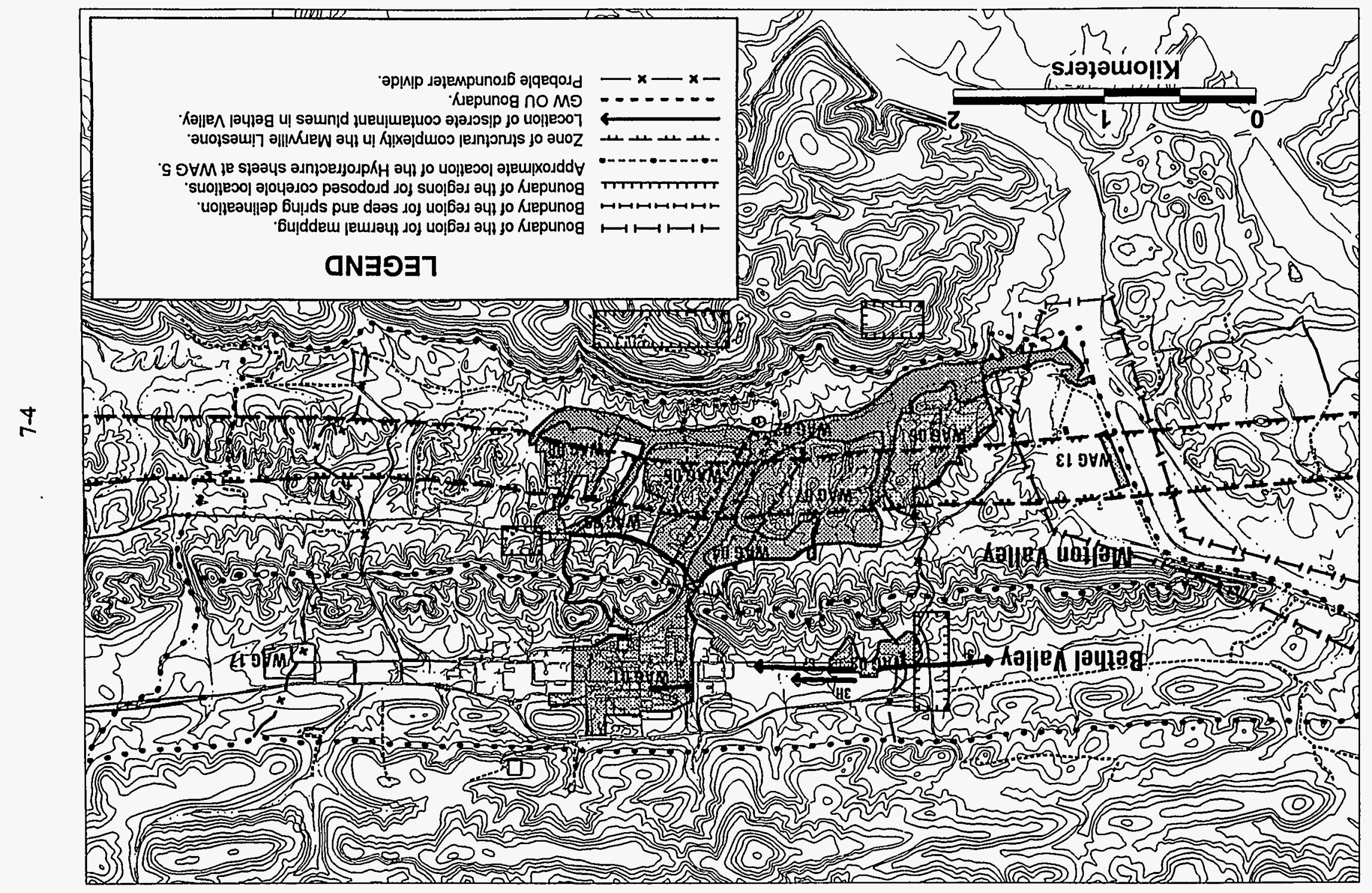




\subsection{DATA REVIEW}

Review of existing data as it pertains to the characterization plan will be one of the first steps in any investigation associated with this plan. The data that will have to be reviewed apply mainly to seeps and springs and groundwater wells. A general discussion of reviews of these data is described below and particular applications of the data are described throughout Sect. 7.5.

\subsubsection{Groundwater Well Review}

One of the primary efforts for data review will be examination of the ORNL groundwater well data base to select appropriate wells for piezometric head measurement with existing instrumentation and for retrofitting existing wells with new instrumentation including Westbay installation (vertical head measurement). The groundwater well review will evaluate existing wells by the following set of criteria:

- Location of the well with respect to the data needs of this FS/SP and subsequent work plans.

- Depth of the well with respect to the data needs of this FS/SP and subsequent work plans.

- Current instrumentation.

- Frequency at which head measurements are taken in wells currently fitted for these measurements.

- Feasibility, including a cost benefit analysis, of retrofitting the well if location and depth are appropriate for remedial investigation data needs.

General depths of wells to be employed during the 18 months covered by this FS/SP are described below.

\subsubsection{Deep wells}

A GWOU data gap/need identified in this plan is the extent of groundwater flow via deep pathways. This information is important for modeling contaminant transport because deep paths may underflow surface discharge points that, according to the current groundwater model, reside within the boundaries of the GWOU. Therefore, the review will evaluate existing deep core holes $>30.5 \mathrm{~m}(100 \mathrm{ft})$ according to the criteria outlined above and recommend suitable ones for retrofitting of multiport samplers. In particular, the WAG 1 coreholes in which deep contaminants have been noted (e.g., well 4005 in WAG 1) will be reviewed for monitoring and sampling suitability. Information acquired from these wells will help clarify not only the extent and mechanisms of deep flow and transport but also will help define the mechanism for stratabound flow. Another set of deep wells that are specifically targeted for evaluation of their data and instrumentation or for retrofitting are the hydrofracture monitoring wells. These are particularly deep wells that will provide information on the GWOU basal boundary and on contaminant migration from the injection grout sheets. Other deep wells that will be used are described in Sect. 7.5. 


\subsubsection{Shallow wells}

Two important goals of the characterization plan are to provide a three-dimensional characterization of GWOU groundwater and to understand the dynamics of shallow flow within the stormflow zone and the water table interval of the groundwater zone. Meeting these goals will enhance our understanding of the mechanisms for contaminant transport and retardation (i.e., Matrix Diffusion). Part of the process of attaining these goals will entail a review of any pertinent data derived from existing shallow wells. For the purposes of this plan, shallow wells are those wells that bottom at $30.5 \mathrm{~m}(<100 \mathrm{ft})$, or are screened for multiport sampling at intervals $<30.5 \mathrm{~m}(<100 \mathrm{ft})$ deep.

\subsubsection{Seeps and Springs Review}

Seeps and springs survey data compiled by the U.S. Geological Survey will be reviewed in order to develop a seep and spring sampling and monitoring deployment plan. The objective of the plan will be to evaluate groundwater discharge response to temporal changes and episodic storm events and to assess contaminant transport under the same conditions. The review will involve selection of existing data to be used during characterization and investigations and identification of seeps and springs for additional sampling and monitoring. The following criteria will be used for data and seep or spring selection:

- Existing data must directly address data gaps and needs identified in this plan.

- In order to be complete, data must include flow rate, conductivity, $\mathrm{pH}$, and temperature as well as contaminant information.

- Seeps and springs must be optimally located with respect to remedial investigation data needs to be selected for additional sampling and monitoring.

\subsection{SAMPLING AND SURVEY APPROACH AND RATIONALE}

\subsubsection{Overview}

The following major activities will constitute the bulk of the field sampling/survey effort to be implemented during the time period covered by this FS/SP:

- a Clinch River thermal mapping project to identify locations of springs in the Clinch River;

- geophysical investigations for characterizing karst;

- groundwater piezometric measurements and sampling for characterizing local hydraulic gradients and groundwater contaminant concentrations; and

- seep and spring monitoring and sampling to identify exit pathways. 


\subsubsection{Clinch River Thermal Mapping}

An important data gap identified in this plan is the integrity of the GWOU boundaries. A simple, cost-effective way to address this data gap at the western boundary of the GWOU is to obtain data from a thermal mapping project already planned for ORNL. The thermal mapping project involves an early morning flyover and infrared photography of ORNL. That part of the project, which will be of use to investigating the GWOU, is thermal mapping of the Clinch River. The utility of such information is that, given expected temperature differences between Clinch River water and GWOU groundwater, thermal mapping should indicate regions of the Clinch River where there are subsurface springs.

The Clinch River on the western boundary of the GWOU is fed by bottom water from Melton Hill Lake that has been passed through Melton Hill Dam and therefore is relatively cold. Spring water in the ORR, on the other hand, is maintained at a relatively warm temperature by its slow passage through the ground. The temperature contrast between the two waters should be sufficient to resolve plumes of spring water in the Clinch River during thermal mapping. To enhance the temperature contrast and therefore the resolution, mapping is planned for daybreak in early March 1994 when the air and the surface of the Clinch River are cold.

\subsubsection{Geophysical Investigations}

Because it resides mainly in the subsurface, the GWOU presents major technical challenges to characterization. There are two broad categories of activities that are used for subsurface characterization. The first, and more common, of these are wells and other types of intrusive borings that are directed toward point characterization. The second group is composed of geophysical techniques which are more effective at broad subsurface characterizations. This section discusses the uses of geophysical investigations in the GWOU characterization.

\subsubsection{Environmental Sciences Division geophysical programs and methods development activities}

There are several geophysical methods programs in various stages of development by ORNL Environmental Sciences Division (ESD) geophysicists. One of these is use of airborne geophysics in which high resolution, multi-spectral EM, magnetic, and radiation aerial data are collected over the entire ORR. Currently, the data from this effort are being processed and formatted for use in ER programs. The results of the aerial EM and magnetic mapping are readily available and of utility to other site characterizations and investigations on the ORR. Other methods of testing and development efforts currently being implemented by ESD geophysicists include:

- continued processing, application, and ground-based follow-up surveys of the airborne EM and magnetic data;

- TEM instrument procurement and method testing and development with emphasis on saline interface studies;

- GPR testing and development for karst applications; 
- seismic source testing to determine the best seismic source for the geologic environment on the ORR;

- Vertical Seismic Profiling testing and development;

- compilation of a comprehensive geophysical well log data base; and

- SP method testing and development for subsurface stormflow monitoring.

It would be of mutual benefit to both the ER and ESD programs to coordinate their geophysical efforts. The GWOU characterization program would benefit from data resulting from the ESD geophysical efforts. The ESD geophysical program would benefit by gaining methods development and testing opportunities while appiying them to GWOU problems, having detailed ground-based follow-up activities for the EM and magnetic aerial data assessment and development, and through GWOU support.

\subsubsection{GWOU strategy for geophysical investigations}

Effective and cost efficient employment of geophysical techniques requires careful planning. Therefore, a set of DQO guidelines has been developed that will be used to evaluate the use of specific geophysical techniques when problems are encountered. These guidelines are:

- identify the problem (e.g., karst believed to control contaminant movement);

- $\quad$ assess the objectives of the geophysical study;

- obtain any existing aerial and ground-based data;

- $\quad$ assess expected conditions (i.e., parameters of concern);

- determine the resolution required to solve the problem;

- $\quad$ select the appropriate geophysical techniques for the data needs; and

- $\quad$ plan the survey using the most time- and cost-effective technique first-use the more timeconsuming and expensive methods on an as-needed basis.

As presented in Chaps. 2 and 3, the primary geopnysical data needs of GWOU investigations are saline interface mapping, karst characterization, geologic structure, metal detection, and hydrogeological process assessment. A discussion of these data needs, including applicable geophysical techniques, follows.

\subsubsection{Saline interface mapping}

Because the transition from the deep groundwater interval to the brine that underlies the GWOU represents a change in groundwater composition, geophysical techniques employed to map the saline interface/transition zone must be responsive to the change in composition. Electrical conductivity is the primary physical characteristic affected by salinity and is best 
measured using DC resistivity, EM, and TEM techniques. However, EM techniques are not likely to be sensitive at the expected depth of the saline interface, thus leaving DC resistivity and EM as the techniques to measure electrical conductivity. Other physical characteristics that will be affected by the compositional change at the saline interface are Earth's ambient electrical field and the bulk density of the rock/groundwater system. SP techniques are most appropriate for electrical field measurements, but do not have the vertical resolution needed for mapping this interface. Microgravity, seismic, and GPR techniques are appropriate for measuring density changes in the earth. However, microgravity will not work because it will not resolve the small bulk density changes associated with increased salinity at the interface. Similarly, seismic velocities will not be affected by the density change thereby rendering both seismic refraction and reflection ineffective. Theoretically, GPR surveying could be sensitive to changes in salinity, but the target depths of investigation exceed the capability of the method.

The following was developed as a strategy for the saline interface mapping:

- Locate deep groundwater monitoring wells where the depths to the saline interface and transition zone are known. These wells will provide ground truth and should be logged for geologic control.

- Select initial test sites based upon proximity to selected deep groundwater monitoring wells and considerations such as verification of test results, ambient noise, and site access.

- The test site should be relativity free from sources of anthropogenic noise such as power lines and fences.

- Areas of steep topography should be avoided.

- $\quad$ TEM mapping should be attempted prior to DC resistivity because of its greater capabilities for lateral resolution.

\subsubsection{Karst characterization}

Karstification affects most physical parameters to some degree. Karst features can create observable changes in density, seismic velocity, electrical resistivity, and SP. Thus, potential techniques for karst characterization include microgravity, GPR, seismic, EM, TEM, and SP. Nearly all of these techniques have been employed to delineate karst on the ORR.

The following strategy was developed for characterizing karst-related features within the GWOU using geophysical methods. All of the potential methods for karst characterization are affected to varying degrees by site conditions as described in Sect. 6.4. Provided that site conditions do not preclude their use, expedient and inexpensive methods such as EM, SP, and GPR methods should be employed first. If site conditions such as suspected depth to karst, noise, or anthropogenic features preclude the use of these methods, other methods such as microgravity or seismic reflection should then be considered.

It is important to note that it is not cost effective to investigate the entire ORNL GWOU for karst. Only exit or significant pathways of groundwater flow and/or contaminant transport suspected of being controlled by karst should be investigated. 


\subsubsection{Geologic structure}

Geologic structure studies must consider the specific site and target before appropriate geophysical techniques can be selected. Initially, however, aerial EM and magnetic data should be obtained and analyzed. Following this, the survey objectives, desired resolution, affected physical parameters, etc., should be considered. Finally, an appropriate technique should then be selected. If more than one technique is deemed appropriate, the most expedient and cost effective one should be implemented first.

It is prudent to conduct geophysical investigations to evaluate potential locations for monitoring wells. Of primary concern is the location of deep monitoring wells. Depending on the particular well in question, it may or may not be advantageous to locate the well in anomalous geologic structure. Due to the deep nature of investigation, TEM and/or seismic reflection methods are likely to be appropriate geophysical methods. Vertical seismic profiling and other methods might be used to characterize a broader region surrounding the well.

\subsubsection{Metal detection}

Aerial geophysical information is of primary importance to metal detection. Aerial methods are sensitive to buried metal; however, resolution is not always sufficient for adequate characterization. If this is the case, then other techniques such as magnetic, EM, and SP must be employed. Typically, magnetic should be the technique of choice. Depending on survey objectives, it may be prudent to collect EM and/or SP data in conjunction with magnetic data. Although data collection, analysis, and interpretation of all of these methods are quick and inexpensive, magnetic surveys are probably the quickest and least expensive.

\subsubsection{Hydrogeologic process investigations}

The hydrogeologic processes that best lend themselves to investigation by geophysical techniques are subsurface stormflow and groundwater seepage processes. The geophysical characteristic that is affected by groundwater flow, and makes these hydrogeologic processes measurable, is the ambient electrical potential that results from the process of electrofiltration. Thus, the SP technique is the primary technique for subsurface groundwater flow. Appropriate geophysical techniques for other hydrogeologic processes will be developed when a particular data need is identified and an appropriate means of investigation identified.

\subsubsection{Piezometric Measurements and Well Sampling}

Measuring hydraulic head in the GWOU is critical to addressing many of the data needs identified in Chap. 2. For example, hydraulic head measurements in a series of well-spaced wells over a particular area can determine horizontal changes in hydraulic head and, from this, the hydraulic gradient of the area can be determined. Hydraulic gradient indicates the direction of groundwater flow that is important information for addressing data needs such as those associated with boundary integrity issues. Vertical hydraulic head measurements are accomplished using nested piezometers (closely spaced wells that bottom at different depths) or multiport sampling in a single well. Vertical head measurements are needed for addressing data needs related to deep groundwater flow, the effectiveness of the Knox aquifer pressure barrier at the north and 
south boundaries, and in characterizing the mechanisms of shallow groundwater flow in the GWOU.

Collecting water samples from wells is a critical step in characterizing contaminant flux and in defining flow systems in the GWOU. Understanding contaminant flux within and out of the GWOU is a necessary step in calculating risk to potential receptors. Defining flow systems is necessary for characterizing the mechanism of groundwater flow that is part of developing a model to serve as a predictive tool for fate and transport. The impact of collecting water samples on this process is that, often, contaminants are important tracers in the groundwater system. For example, the ${ }^{90} \mathrm{Sr}$ plumes at WAG 3 define a distinct flow system that would not have been apparent were it not for the presence of a contaminant. In other instances, parameters such as conductivity or temperature may relate wells to each other or wells to springs via the same flow system. The topographic divide at the west end of Bethel Valley, including WAG 3 , is an important location for these types of investigations because contaminants have been observed in surface waters of Raccoon Creek and its tributaries, which almost certainly have their origin in WAG 3. However, observations of these contaminants have raised questions about the nature and extent of contaminant flux out of Bethel Valley. That is, is the source for contaminants in the Raccoon Creek basin all of WAG 3 or only one part of it? Also, is there any other source of contaminant flux under the topographic divide such as WAG 1 ?

\subsubsection{Seep and Spring Sampling}

Section 6.3.1.1 described the procedure for seep and spring gauging to determine water balances. In addition to water balances, seeps and springs are important locations for sample collection. Data from chemical analysis of water samples will be used much like similar data from wells, i.e., to characterize contaminant flux and to define flow systems. A primary location for sample collection is in the seeps and springs of the Raccoon Creek drainage basin. Information obtained from analysis of these samples will be crucial for answering the questions raised in the preceding section about the nature and extent of contaminant flux under the topographic divide at the west end of Bethel Valley.

\subsection{FIELD SAMPLING/SURVEY PLAN}

This section describes the specific investigations that will be undertaken during the first 18 months of the GWOU RIs. As a brief outline, these investigations are:

- Clinch River thermal mapping (Sect. 7.5.1);

- Raccoon Creek and Bearden Creek monitoring/sampling (Sect. 7.5.2);

- Haw Ridge dolostone mapping (Sect. 7.5.3);

- GWOU water level monitoring (Sect. 7.5.4);

- WAG 3 water level monitoring (Sect.7.5.5);

- WAG 1 pressure monitoring and well sampling (Sect. 7.5.6);

- WAG 5 Westbay monitoring and sampling (Sect. 7.5.7);

- hydrofracture pressure monitoring and sampling (Sect. 7.5.8);

- Hydraulic Head Monitoring Station pressure monitoring and sampling (Sect. 7.5.9); and

- geophysical investigations (Sect. 7.5.10). 


\subsubsection{Clinch River Thermal Mapping}

One of the earliest surveys that will provide data for the GWOU investigations will be thermal mapping of the Clinch River. A goal of this effort, which is tentatively scheduled to occur in March 1994, is to identify springs in the Clinch River. Deep groundwater flow has been identified as a potentially major mechanism for off-site contaminant transport with the Clinch River a likely exit point for some of this flow (Chap. 2). The problem of identifying a spring within an actively flowing river using traditional field and mapping techniques is obvious. Therefore, a more innovative approach is necessary to attack this important boundary-related data gap, and thermal mapping has the potential to succeed. In order for thermal mapping to work, it will be necessary that the contrast between the temperatures of Clinch River water and spring water is at a maximum. Thus, the mapping mission is planned to occur in early March 1994 just after sunrise. It is anticipated that, at this date and time, air and surface water temperatures will be cold and interferences resulting from reflection of the sun off the Clinch River will be minimized.

\subsubsection{Raccoon Creek and Bearden Creek Monitoring/Sampling}

The Raccoon Creek and Bearden Creek drainages represent important locations for studying GWOU boundary conditions. Both locations are on boundaries that are orthogonal to the general direction of groundwater flow. The Raccoon Creek drainage is on the west boundary of the GWOU and is located on the western side of the topographic divide that separates Bethel Valley from the Clinch River. As such, the Raccoon Creek drainage is an important location for monitoring potential underflow of the divide. It is also an important location for ascertaining the origin of any contaminant fluxes under the divide as these might be either locally derived from WAG 3 or they might represent general groundwater contamination from Bethel Valley. The Bearden Creek drainage is on the east boundary of the GWOU and, as yet, little if any work has been done to characterize the integrity of this divide.

Investigations in the Raccoon Creek drainage will begin with a review of existing seep and spring data to locate known seeps and springs and to identify those for which there are analytical data as described in Sect. 7.3.2. The thrust of the seep and spring investigation in the Raccoon Creek basin will be to characterize contaminant exit points and water quality in order to understand the point(s) of origin of the contaminants. Thus, looking for contaminated seeps and springs is a high priority. However, other types of data, i.e., temperature, $\mathrm{pH}$, conductivity, also are important for characterizing flow systems. For example, seep and spring water in the Raccoon Creek drainage basin might be linked to specific strata identified in WAG 3 wells by these parameters when contaminant data are lacking or insufficient.

Existing information (seep and spring location, analytical data) will be evaluated in light of the DQOs for the GWOU investigations to determine if it is sufficient to fill data needs as described in Sect. 7.3.2. If the data do not adequately address the DQOs of a particular investigation, then new data will be obtained. The particular new data will depend on where the existing data are lacking. Two classes of new data are possible: (1) seep and spring locations; and (2) seep and spring analytical data. If it is warranted by gaps in the existing data, a seep and spring survey will be undertaken in the Raccoon Creek basin to identify perennial and ephemeral groundwater exit points. Also, water samples will be collected and analyzed from newly identified seeps and springs, and from those already identified, if analytical data are lacking or 
deemed inadequate. In addition to seep and spring sampling, it is anticipated that sampling of Raccoon Creek and its tributaries will be necessary to fully characterize contaminant flux into the Raccoon Creek Basin.

Identification of seeps and springs is often hindered by the fact that the water emerges within the channel of a perennial stream and therefore the seep or spring is not obvious. In order to identify such seeps and springs in the Raccoon Creek basin, water temperature surveys of Raccoon Creek and its tributaries will be undertaken as described in Sect. 6.3.1.1.

Beside contaminant and flow system information, Raccoon Creek is an important location for water flux information in order to attempt a Bethel Valley water balance. As described in Sect. 6.3.2, surface water leaving via exit pathways is an important parameter for water balances. In Bethel Valley, there are only two likely exit pathways for both surface and groundwater - the water gap in Haw Ridge and underflow of the topographic high that separates the Raccoon Creek basin from Bethel Valley. Water leaving Bethel Valley via the water gap is easily measured because, according to the conceptual model, all water leaves through the water gap as surface water in White Oak Creek. The Raccoon Creek exit pathway is not so easily measured or well understood. In order to determine how much Bethel Valley groundwater is underflowing the topographic divide, it will be necessary to determine a water balance for Raccoon Creek and see if any water unaccounted for by the input parameters is flowing in the creek. Water temperature surveys for identifying occult seeps and springs (Sect. 6.3.1.1) within stream channels will be important to this part of the investigation.

The Bearden Creek investigation will be conducted much like that for Raccoon Creek described above. A major difference between the two investigations is that there is no contaminant source nearby to Bearden Creek such as WAG 3 is to Raccoon Creek. Thus, using contaminants as tracers of groundwater flow systems probably will not be possible. The Bearden Creek investigation will be conducted according to the following chronology of events:

- Review historical seep and spring locations and analytical data for applicability and adequacy to the goals of the RI.

- Perform a seep and spring survey if the reviews indicate gaps in the historical data base.

- Collect and analyze water samples if existing data are insufficient or lacking.

- Perform water balance calculations.

\subsubsection{Haw Ridge Dolostone Mapping}

The Rome Formation at Haw Ridge, and its projection into the subsurface, probably constitutes an effective barrier to groundwater communication between Bethel and Melton Valleys. A major contributor to this barrier is the thin dolostone unit in the Rome Formation with high hydraulic head. Characterization of this dolostone unit is incomplete; therefore, understanding its role as a pressure barrier to groundwater and contaminant flux between the two valleys of the GWOU is also incomplete. In order to develop a better understanding of it, a mapping project of the dolostone unit will be undertaken for the RI. The project will fully 
characterize the unit's lithology, structure, and karstification where the unit is exposed on Haw Ridge and within the water gap.

\subsubsection{GWOU Water Level Monitoring}

The goal of the GWOU water level monitoring program will be to characterize GWOU hydraulic gradients in three dimensions. The importance of this goal lies in its ability to predict contaminant flow paths for their eventual interception and remediation. In order to attain this goal, it will be necessary to obtain hydraulic head data over the GWOU at different depths :nnd within the different rock units that constitute the GWOU. The program will, therefore, require water level data from both deep and shallow wells as well as multiport wells. Included in the three-dimensional characterization is understanding the mechanisms of deep and shallow flow in the GWOU and their implications for contaminant transport. For example, it was remarked in Sect. 2.4.6.2 that shallow flow, which dominates in the GWOU, is a new concept and, because it is new, contaminant transport by shallow flow is not well understood. An important consequence of the mechanism of shallow flow that bears on contaminant transport is Matrix Diffusion. It was also pointed out throughout Chap. 2 that deep groundwater : nw is largely a boundary condition problem. The likelihood of boundary violations by deep fi. along boundaries that are orthogonal to the direction of groundwater flow, i.e., the east and west boundaries of the GWOU. This is both a directional effect of groundwater flow and an effect of the relative permeabilities of the boundaries; i.e., the north and south boundaries are thought to pose effective pressure barriers to underflow that do not exist at the east and west boundaries. As a consequence of the greater potential for underflow of the east and west boundaries, deep wells on the east and west ends of Melton Valley will be the first to be appraised for monitoring and sampling. Included in the appraisal will be Well 2542 (JOY 2), a deep well at the east end of Melton Valley.

In general, hydraulic head monitoring for the GWOU water level monitoring program will be conducted on a periodic basis because this type of information will be sufficient to provide the data needs for this broad-scale program. However, selected wells will also be monitored continuously as part of this program. The goal for continuous monitoring will be to establish wells that are related to the same flow system by monitoring synchronal changes in response to storm events and other phenomena that would affect water levels.

A general chronology for the GWOU water level monitoring program is described below:

- evaluate locations and depths of wells throughout the GWOU relative to the needs of the water level monitoring program;

- evaluate existing wells and their data against the needs of the program;

- create a data base of existing hydraulic head data that will be used to meet the goals of the program;

- $\quad$ select those wells that are located and instrumented adequately to contribute additional data to the program; 
- select existing wells for retrofitting with instrumentation, including Westbay multiport instruments, that will satisfy the data needs of the program;

- $\quad$ select sites for new wells where there are no existing wells or where existing wells cannot be retrofitted to satisfy the data needs of the program;

- retrofit existing wells and drill new wells; and

- collect water level data from monitoring program wells.

\subsubsection{WAG 3 Water Level Monitoring}

A primary goal of GWOU investigations will be to establish an understanding of the nature and extent of contamination at WAG 3 in order to support development of alternatives. WAG 3 has been selected as a primary target of investigation in this FS/SP for two reasons: (1) it represents a location at which unmonitored contaminants are potentially escaping the GWOU by underflow of the topographic divide at the west end of Bethel Valley; and (2) there are sufficient monitoring wells within the WAG to determine the existence and locations of a significant component of strata-bound flow. This makes WAG 3 an excellent location for testing geophysical techniques as methods of subsurface investigation. Geophysical measurements at WAG 3 are described in Sect. 7.5.10.2.

In addition to its importance to this FS/SP, WAG 3 has also been selected as the site for the drilling of a deep well for investigation of hydrologic properties of the Knox aquifer at depth. Only site characterization for this well is part of this FS/SP; actual emplacement of the well is a future activity for the RI. Evaluation of a potential site for installation of the deep well is primarily a geophysical investigation that is described in Sect. 7.5.10.2.

Water level monitoring at WAG 3 will focus on obtaining data for verifying and characterizing groundwater and contaminant underflow of the topographic divide, which WAG 3 straddles at the west end of Bethel Valley. To do this, it will be necessary to construct a threedimensional map of the hydraulic gradient in the WAG 3 area. This map will provide information on horizontal and vertical characteristics of groundwater flow in order to address the following questions: (1) Is the source of contaminant flux under the topographic divide all or part of WAG 3? (2) Is any of the contaminant flux under the topographic divide contributed by sources other than WAG 3, such as WAG 1 ?

The chronology of activities for the WAG 3 water level monitoring program is as follows:

- review existing well data for their adequacy and applicability to the goals of the water level monitoring program;

- compile a data base of useful existing well data;

- evaluate existing wells for range of depths and instrumentation with the goal of satisfying the WAG 3 water level monitoring program data objectives; 
- evaluate existing wells for retrofitting instruments to satisfy the data objectives of the WAG 3 water level monitoring program;

- evaluate the grid of existing wells and retrofitted wells for data adequacy to meet the objectives of the water level monitoring program and site new wells as needed;

- drill the new wells; and

- $\quad$ collect water level data.

\subsubsection{WAG 1 Pressure Monitoring and Well Sampling}

The importance of WAG 1 to remedial investigation efforts is that WAG 1 is the primary contaminant source for Bethel Valley. In addition, previous characterizations of WAG 1 led to the development of the concept of strata-bound flow in the GWOU. There are three goals to the WAG 1 pressure monitoring and well sampling program: (1) a three-dimensional characterization of hydrostatic pressure throughout WAG 1 in order to understand the horizontal and vertical characteristics of groundwater flow and, in particular, to understand the relationships of horizontal and vertical pressure variations to strata; (2) obtain well water and/or pressure data to characterize flow systems in the groundwater of WAG 1; and (3) obtain groundwater contamination data to evaluate the risk of WAG 1 contaminants to potential receptors.

There are a number of existing wells that are potentially well-suited to address the three goals of the pressure monitoring and well sampling program. These wells are commonly referred to as Coreholes 1 through 9 and Coreholes 11 and 12. Their official designations are, respectively: Wells $2531,1802,2533,2534,2535,4003,4004,4005,4006,4008$, and 4009 . Pressure monitoring of these wells for three-dimensional characterization of WAG 1 hydrostatic pressure will require periodic monitoring. Characterizing flow systems beneath WAG 1 , on the other hand, requires continuous monitoring to observe synchronal responses to temporal changes in water levels. Pressure pulse testing is also an option for this second goal; but, because existing data indicate that cavities play an important role in the flow system beneath WAG 1 , pressure pulse tests may not be effective. The reason is that, during artificial pressure pulse tests, pressure disperses rapidly in response to the damping effect of the large storativity associated with cavity systems. In place of pressure pulse testing, analytical data such as conductivity, temperature, and $\mathrm{pH}$ may be used to link wells via a common flow system. These data will be collected during the sampling part of the pressure monitoring and well sampling program at WAG 1.

Another WAG 1 well that has been targeted for the WAG 1 pressure monitoring and sampling program is Well 0883. This is a well with low hydraulic head that fluctuates within only a narrow range. The characteristics of this well imply a direct connection to an exit pathway-that keeps water levels in the well similar to those of the Clinch River. Characterizing this well, and the aquifer around it, will require continuous monitoring to compare water level fluctuations to those in the Clinch River. Periodic sampling will also be included in monitoring this well to assess its contribution of risk to potential receptors.

The chronology of activities for the WAG 1 pressure monitoring and sampling program is as follows: 
- evaluate data from the existing corehole wells, and other wells in WAG 1, for their adequacy and applicability to the goals of the pressure monitoring and well sampling program;

- evaluate the instrumentation in the existing corehole wells, and other wells in WAG 1 , for their adequacy in addressing the goals of the pressure monitoring and well sampling program;

- evaluate the locations of existing wells for adequacy in addressing the goals of the pressure monitoring and well sampling program;

- retrofit existing wells with new instruments, including multiport sampling capabilities, where existing instrumentation is determined to be inadequate;

- drill new wells where the existing locations are lacking; and

- collect pressure and water quality data.

\subsubsection{WAG 5 Westbay Monitoring and Sampling}

Three deep wells are being drilled and installed with Westbay MP sampling capabilities as part of the WAG $5 \mathrm{RI}$, which is currently underway. The ORNL Area-Wide Groundwater Program will assume responsibility for monitoring and sampling these wells. There are three goals for this monitoring and sampling program that pertain to the GWOU: (1) to discriminate between shallow surface source contaminants at WAG 5 and those contaminants derived from the hydrofracture program; (2) to bridge the interface between the GWOU, WAG 5, and WAG 10; and (3) to be part of the GWOU-wide water level monitoring program.

\subsubsection{Hydrofracture Pressure Monitoring and Sampling}

The fundamental concern regarding deep groundwater flow is movement of contaminants from near-surface to deep levels where they might exit the GWOU and pose potential risk to receptors. The groundwater model for the ORR indicates that, under natural conditions, deep groundwater flow is negligible and therefore is not important as a contaminant pathway. The hydrofracture experiments represent instances where natural conditions were circumvented and contaminants were intentionally emplaced into the deep groundwater system. The experiments were designed to contain the contaminants within a solidified, cement-based grout injected into an impermeable shale. However, monitoring wells for the experiments indicate that all of the contaminants may not have been contained. Therefore, the hydrofracture facilities' wells will be evaluated for retrofitting with Westbay Multiport instrumentation to monitor the extent of contaminant release from the grout sheets and to determine the extent of vertical migration of the contaminants. As part of this, it will be necessary to monitor pressure variations at different depths within the hydrofracture wells. In addition, because of the depths of the injection wells and their proximities to the southern boundary, recommendations will be developed during this period for the locations and specifications for possibly two wells on Copper Ridge. The location of one well will be such that the integrity of the southern boundary is tested near the hydrofracture facility, and the other location will provide vertical head measurement near White Oak Lake. 


\subsubsection{HHMS Pressure Monitoring and Sampling}

As part of the HHMS program currently underway at ORNL, a number of deep wells have been and will be drilled and installed with Westbay MP instrumentation. The GWOU investigations will incorporate the data from the HHMS program with three goals in mind: (1) to determine the depth to which surface contaminants are moving in the GWOU; (2) to determine whether groundwater is rising as it approaches the Clinch River or whether pathways indicate that groundwater is underflowing the Clinch River; and (3) to incorporate water level data into the GWOU-wide three-dimensional hydraulic gradient characterization.

\subsubsection{Geophysical Investigations}

Following is a description of the geophysical investigations that will be conducted during the 18 months' activities described in this FS/SP. Subsequent to this first round of geophysical investigations will be a round of large-scale applications of geophysics to remedial investigation problems. It is premature to discuss these later geophysical applications because, consistent with the observational approach, plans for them will be developed as investigations proceed through work described in this FS/SP.

\subsubsection{TEM calibration of brine depth at the Hydrofracture 2 site}

One of the ultimate goals for characterizing the GWOU is to map the basal boundary of the GWOU. This is an important goal because the basal boundary defines the conceptual limit of contaminant migration. Mapping this boundary will involve determining the depth to the brine GWOU-wide and, for this, TEM is probably the most effective instrument. In order to obtain accurate information during mapping, it will be necessary to calibrate TEM measurements where the depth to the brine is known; this calibration activity is part of this FS/SP. The location selected for calibrating the TEM is the Hydrofracture 2 site in Melton Valley. The process will involve selecting and sampling one or more deep wells at the site to determine the brine's depth.

\subsubsection{WAG 3 investigations}

There are four areas of investigation at WAG 3 that will utilize geophysical techniques: (1) karstification within the thin zone of strata-bound contaminant transport that runs through WAG 3; (2) investigation of the surface water divide west of WAG 3 to determine mechanisms for underflow of the divide; (3) evaluation of potential sites for installation of a deep monitoring well to investigate the hydrologic properties of the Knox aquifer at depth; and (4) characterization of the brine surface beneath WAG 3 and the impact of its location on placement of the deep well. Approaches to these four areas of investigation are described below.

1. The following chronological approach will be used for the WAG 3 karst investigation:

- Existing aerial EM and magnetic data will be examined for any correlation between geophysical anomalies and the suspected location of the thin transmissive unit.

- Small-scale, surface EM and SP surveys will be conducted over the area of interest to determine how well these techniques perform. 
- If EM and SP provide acceptable results, more detailed and comprehensive surveys will be planned and instituted. However, if the initial EM and SP surveys indicate that more definitive information is required, microgravity, GPR, or seismic reflection methods will be evaluated and implemented.

2. A major GWOU question at WAG 3 is whether the surface water divide at the west end of Bethel Valley also acts as a groundwater divide. A geophysical investigation of this question will occur by the following steps:

- evaluate existing ESD aerial EM and magnetic data, and

- use appropriate geophysical techniques to investigate the water table beneath the divide.

Because the location of the water table is of prime importance in assessing the impact of the surface water divide on the groundwater system, geophysical methods with the capability of discerning the water table will be employed. Of the available methods, TEM, DC resistivity, and GPR are the most viable techniques. Because TEM will probably be used for siting of the deep well, it would be prudent to conduct several small scale test soundings to evaluate the effectiveness of TEM in addressing the groundwater divide problem as well. If it proves ineffective, the other methods will be evaluated and then employed. The area encompassed by this investigation will include both the area in and around WAG 3 in Bethel Valley and the Raccoon Creek drainage basin.

3. The WAG 3 karst investigation will be extended over the topographic divide at the west end of Bethel Valley into the Raccoon Creek drainage basin. The rationale for this is that a single karstified unit is thought to be most likely responsible for transporting contaminants from WAG 3 into the Raccoon Creek basin.

Siting of the deep well will occur by the following steps:

- $\quad$ select potential sites by evaluating ESD airborne EM and magnetic data, and

- $\quad$ select the site by evaluating potential sites using ground-based TEM or seismic techniques to gain information on subsurface structures.

TEM is the preferred method for final site selection because characterization of the brine surface beneath WAG 3 is also part of the well site evaluation and seismic techniques will not resolve this surface. TEM is best suited to measure both karst and brine information. Also, TEM data collection and interpretation are less costly, and the method is more time efficient than seismic reflection profiling.

4. Characterization of the brine surface under WAG 3 will proceed following TEM calibration described above in Sect. 7.4.10.1. TEM methods and procedures developed during the calibration will be used for the WAG 3 brine surface characterization.

\subsubsection{WAG 17 investigations}

As with WAG 3, WAG 17 geophysical investigations will be focused toward a thin, carbonate unit that controls strata-bound contaminant transport. The approach at WAG 17 will 
be identical to that at WAG 3. Existing aerial geophysical data will be evaluated initially followed by evaluation and implementation of an expedient and inexpensive technique such as EM or SP. Finally, the need for more intensive and quantitative investigations using microgravity, seismic reflection, or TEM will be evaluated.

\subsubsection{Copper Ridge well siting investigations}

Several deep monitoring wells may be installed on Copper Ridge to assess the hydrologic conditions along this southern boundary of the GWOU. Geophysical investigations of geologic structure and characterization of the brine surface will be conducted as part of the well siting efforts. Initially, existing airborne geophysical data will be used for well location evaluation. As discussed above for WAG 3 well siting efforts, the two best geophysical methods for evaluating deep structure are TEM and seismic reflection. However, considering that the brine surface is also an important aspect of well location, TEM's capabilities make it the preferable method.

\subsubsection{Bethel Valley transect}

In an effort to characterize the influence of subsurface structure on groundwater flow paths and, therefore, contaminant transport, TEM and microgravity transects of Bethel Valley are planned. Initially, this project will involve evaluation of the techniques over a small area. If the evaluation demonstrates that one or both techniques will adequately and accurately chara::size the subsurface geology, then a number of transects will be undertaken to develop a tnreedimensional model of the subsurface of Bethel Valley.

\subsubsection{Southside of White Oak Lake}

Presently, the only exit pathway for contaminated water in the GWOU is thought to be over White Oak Dam. Prior to leaving the GWOU all water resides in White Oak Lake for some, unspecified, period of time. An important point that will be addressed by a TEM and microgravity survey of the southside of White Oak Lake is the potential for underflow both of the Dam and of Copper Ridge. 


\section{QUALITY ASSURANCE PROJECT PLAN}

\subsection{QUALITY ASSURANCE OVERVIEW}

\subsubsection{Project Description}

Activities for the ORNL GWOU investigations will be preformed in accordance with the ER Program's QA Program, and with the Energy Systems' document, Environmental Restoration Quality Program Plan, ES/ER/TM-4/R3 (Energy Systems 1993d). This QAPjP has been prepared in accordance with ES/ER/TM-4/R3; DOE Order 5700.6C (DOE 1992); EPA Interim Guidelines and Specifications for Preparing Quality Assurance Project Plans, EPA-600/4-83-004 (QAMS-005/80) (EPA 1983a); and Quality Assurance Program Requirements for Nuclear Facilities, NQA-1 (ANSI/ASME 1989). EPA QAMS-005/80 contains EPA's guidance for project QA/QC plans. The American National Standards Institute/American Society of Mechanical Engineers (ANSI/ASME) NQA-1 has been adopted as the implementation standard for this QAPjP. Because this plan falls under CERCLA regulation, the ORNL GWOU QAPjP is subject to the Office of Solid Waste and Environmental Response Directive 9502.00-6C (EPA 1987a), Directive 9355.0-76 (EPA 1987a), and Directive 9355.3-01 (EPA 1988a).

This QAPjP supports the ORNL GWOU investigations and defines procedures to be followed in the collection and analysis of data used in the GWOU program. These procedures are intended to ensure that results achieve QA/QC goals established for the GWOU investigation program. They are also intended to minimize field measurement errors, analytical errors, and errors occurring in data transfer and management. The mechanisms employed to ensure quality are:

- prevention of defects in quality through planning and design, documented instructions and procedures, and performance-based training of personnel;

- assessment through regular audits and surveillances to supplement continual informal reviews; and

- permanent correction of conditions adverse to quality.

This plan describes the QA program and the QC procedures to be implemented during investigations of the GWOU. Data produced by these investigations will be used to meet the objectives described in the bullets presented above. The methods used to meet these objectives are detailed in the previous sections of the Characterization Plan for the ORNL Area-Wide Groundwater Program.

\subsubsection{Modular Profile}

The modular profile for the GWOU investigations (Table 8.1) shows the relationship between DOE Order 5700.6C, QAMS-005/80, NQA-1, and ORNL QA elements, and the elements of this QAPjP. Some of the regulating agencies' elements identified in the modular profile are not applicable to the GWOU project. These elements, which are excluded from this plan, are identified in the "Exclusion Rationale" section of this QAPjP. Many of the ORNL elements adequately describe GWOU project-specific procedures and have been adopted for 
Table 8.1. Modular profile for the GWOU project

\begin{tabular}{|c|c|c|c|c|c|c|c|c|c|}
\hline & 2A-1 Basic Element & & QAMS 005/80 & & $\begin{array}{c}\text { DOE ORDER } \\
5700.6 \mathrm{C} \text { Criteria } \\
\end{array}$ & $\begin{array}{c}\text { ORNL QA } \\
\text { Manual reference }\end{array}$ & $\begin{array}{l}\text { Implementing } \\
\text { procedures }\end{array}$ & $\begin{array}{l}\text { Location in } \\
\text { GWOU QAPjP }\end{array}$ & $\begin{array}{l}\text { Additions/ } \\
\text { Clarifications }\end{array}$ \\
\hline 1. & Organization & 5.4 & $\begin{array}{l}\text { Project Organization } \\
\text { and Responsibility }\end{array}$ & 1. & Program & QA-L-1-100 & QA-L-1-100 & Section 8.2 & YES \\
\hline 2. & $\begin{array}{l}\text { Quality Assurance } \\
\text { Program }\end{array}$ & $\begin{array}{l}5.3 \\
5.16\end{array}$ & $\begin{array}{l}\text { Project Description } \\
\text { QA Reports }\end{array}$ & 2. & $\begin{array}{l}\text { Personnel Training } \\
\text { and Qualification }\end{array}$ & $\begin{array}{l}\text { QA-L-2-100 } \\
\text { QA-L-2-101 } \\
\text { QA-L-2-103 }\end{array}$ & $\begin{array}{l}\text { ES-ADM-91-002 } \\
\text { SOP Training }{ }^{a}\end{array}$ & Section 8.3 & YES \\
\hline 3. & Design Control & $\begin{array}{l}5.5 \\
5.6 \\
5.10 \\
\\
\\
5.11 \\
5.14 \\
\\
5.9\end{array}$ & $\begin{array}{l}\text { QA Objectives for } \\
\text { Measuring Data } \\
\text { Sampling Procedures } \\
\text { Data Reduction, } \\
\text { Validation and } \\
\text { Reporting } \\
\text { Internal QC Checks } \\
\text { Specific Routine } \\
\text { Procedures } \\
\text { Analytical Procedures }\end{array}$ & 6. & Design & QA-L-3-100 & N/A & N/A & N/A \\
\hline 4. & $\begin{array}{l}\text { Procurement } \\
\text { Document Control }\end{array}$ & & & 7. & Procurement & QA-L-4-100 & QA-L-4-100 & Section 8.4 & No \\
\hline 5. & $\begin{array}{l}\text { Instructions, } \\
\text { Procedures, and } \\
\text { Drawings }\end{array}$ & $\begin{array}{l}5.9 \\
5.6\end{array}$ & $\begin{array}{l}\text { Analytical Procedures } \\
\text { Sampling Procedures }\end{array}$ & 5. & Work Processes & QA-L-5-100 & $\begin{array}{l}\text { SOP Procedure } \\
\text { development \& } \\
\text { control }^{a}\end{array}$ & Section 8.5 & YES \\
\hline 6. & Document Control & $\begin{array}{l}5.1 \\
5.2 \\
5.3 \\
5.6 \\
5.7 \\
5.9\end{array}$ & $\begin{array}{l}\text { Title Page } \\
\text { Table of Contents } \\
\text { Project Description } \\
\text { Sampling Procedures } \\
\text { Sample Custody } \\
\text { Analytical Procedures }\end{array}$ & 4. & $\begin{array}{l}\text { Documents and } \\
\text { Records }\end{array}$ & QA-L-6-100 & $\begin{array}{l}\text { SOP Tech } \\
\text { notebooks } \\
\text { SOP Document } \\
\text { mgmt. center } \\
\text { SOP Forms } \\
\text { development and } \\
\text { control }^{a}\end{array}$ & Section 8.6 & YES \\
\hline
\end{tabular}


Table 8.1 (continued)

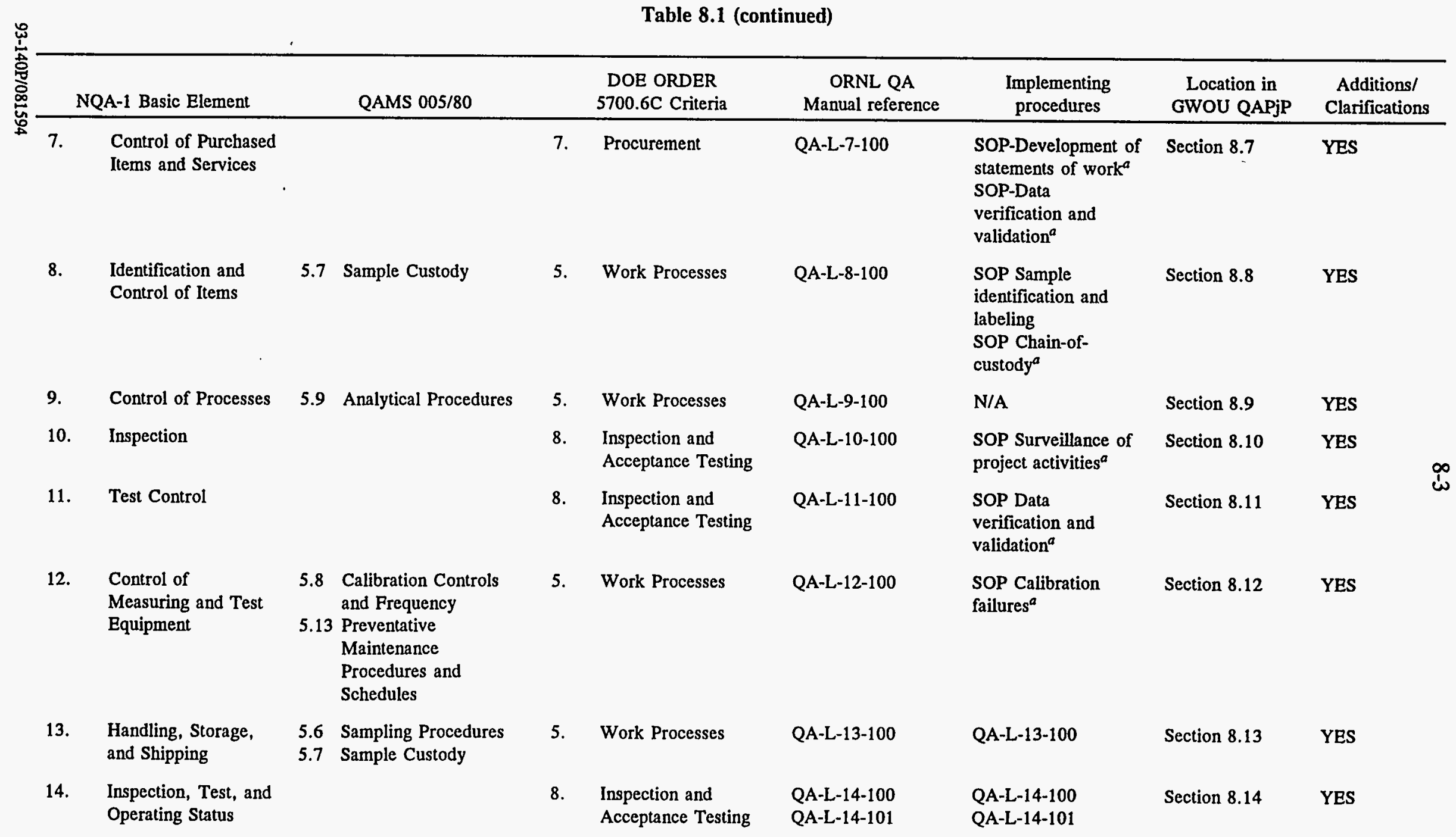


Table 8.1 (continued)

\begin{tabular}{|c|c|c|c|c|c|c|c|c|}
\hline & & & & & & & & \\
\hline \multicolumn{2}{|c|}{ NQA-1 Basic Element } & \multirow[t]{2}{*}{ QAMS 005/80 } & \multirow{2}{*}{\multicolumn{2}{|c|}{$\begin{array}{l}\text { DOE ORDER } \\
\text { 5700.6C Criteria } \\
\text { Quality Improvement }\end{array}$}} & \multirow{3}{*}{$\begin{array}{c}\text { ORNL QA } \\
\text { Manual reference } \\
\text { QA-L-15-100 } \\
\text { QA-L-16-102 }\end{array}$} & \multirow{2}{*}{\begin{tabular}{l}
\multicolumn{1}{c}{$\begin{array}{c}\text { Implementing } \\
\text { procedures }\end{array}$} \\
SOP Variance, \\
nonconformance, \\
occurrences and \\
corrective action $^{a}$
\end{tabular}} & \multirow{2}{*}{$\begin{array}{c}\text { Location in } \\
\text { GWOU QAPJP }\end{array}$} & \multirow{2}{*}{$\begin{array}{l}\text { Additions/ } \\
\text { Clarifications } \\
\text { YES }\end{array}$} \\
\hline 15. & Non-conformances & & & & & & & \\
\hline 16. & Corrective Action & $\begin{array}{l}\text { 5.15 Corrective Actions } \\
\text { 5.16 QA Reports }\end{array}$ & 3. & Quality Improvement & & SOP in above SOPa & Section 8.16 & YES \\
\hline 17. & $\begin{array}{l}\text { Quality Assurance } \\
\text { Records }\end{array}$ & & & & QA-L-17-100 & $\begin{array}{l}\text { ER/P-OS/ERP-DMC } \\
\text { SOP Document } \\
\text { mgmt. center }\end{array}$ & Section 8.17 & YES \\
\hline 18. & Audits & $\begin{array}{l}\text { 5.12 Performance and } \\
\text { System Audits and } \\
\text { Frequency }\end{array}$ & $\begin{array}{l}9 . \\
10 .\end{array}$ & $\begin{array}{l}\text { Management } \\
\text { Assessments } \\
\text { Independent } \\
\text { Assessments }\end{array}$ & $\begin{array}{l}\text { QA-L-18-100 } \\
\text { QA-L-18-101 } \\
\text { QA-L-18-102 }\end{array}$ & $\begin{array}{l}\text { QA-L-18-100 } \\
\text { QA-L-18-101 } \\
\text { QA-L-18-102 }\end{array}$ & Section 8.18 & YES \\
\hline 19. & Software & & & & QA-L-19-100 & QA-L-19-100 & Section 8.19 & YES \\
\hline 20. & $\begin{array}{l}\text { Program Specific } \\
\text { Procedures }\end{array}$ & & & & QA-L-20-102 & $\begin{array}{l}\text { SOP Document } \\
\text { review }^{a}\end{array}$ & Section 8.20 & YES \\
\hline
\end{tabular}

aStandard operating procedures (SOPs) to be developed or in development. 
GWOU use with referenced additions and/or clarifications. Where minor additions and/or clarifications to the ORNL QA plan are sufficient, no project-specific procedures have been developed. However, some of the ORNL elements require extensive elaboration to describe GWOU project-specific procedures. In these cases, project-specific standard operating procedures (SOPs) are referenced in the modular profile.

\subsubsection{Exclusion Rationale}

NQA-1 Element 3, "Design Control," is intended to control project interfaces with design organizations. The GWOU project has no current need to interface with the Engineering Division or other Energy Systems design organizations. If this need arises, the design control element will be addressed in a subsequent revision of this plan, or within project-specific QA plans. The QAMS 005/80 topics associated with NQA-1 Element 3 are addressed in various sections of the ORNL GWOU RI QAPjP.

\subsection{PROJECT ORGANIZATION}

The project organization and project participants are discussed below. The responsibilities defined within this section are those specific to the development, implementation, and assessment of the GWOU project QAPjP. Additional QA-related responsibilities are delineated in the Project Document Summary (Table 8.2).

All organizations performing tasks for the GWOU must have a QA plan that meets the GWOU investigation DQOs. Review of other organizations' QA plans is the responsibility of the Extra-Project Coordinator, the GWOU QA/QC Coordinator, and the Project Manager. If there is no approved QA plan for the task, then the organization will be required to develop an acceptable plan. It may be necessary to add project-specific attachments, such as organization charts, functional responsibility matrixes, and surveillance plans, to otherwise adequate plans.

Interface agreements will be developed with all organizations performing tasks for the GWOU. These interface agreements will provide configuration and change control statements between organizations.

\subsubsection{Responsibilities}

\subsubsection{Project manager}

In addition to those responsibilities outlined in the Program Management Plan (ORNL/ER 167), the responsibilities of the Project Manager include the following:

- ensures that the appropriate QA requirements of this document are included in planning, investigation, analysis, and reporting activities for the GWOU project;

- ensures that the QA Specialists are included in, or informed of, all project activities;

- consults with the QA Specialists on all quality-related matters; 
Table 8.2. GWOU project document summary

\begin{tabular}{|c|c|c|c|c|c|c|c|c|c|c|c|}
\hline Document title & $\begin{array}{c}\mathrm{QA} \\
\text { record? }\end{array}$ & $\begin{array}{l}\text { Controlled } \\
\text { document? }\end{array}$ & Prepare & & & & & & & rove & \\
\hline $\begin{array}{l}\text { Quality assurance } \\
\text { plan }\end{array}$ & YES & YES & QAC & PM & GWOU-QAS & ERD-QAS & HSC & $\mathrm{PM}$ & ERD-QAS & GWOU-QAS & \\
\hline $\begin{array}{l}\text { Personnel training } \\
\text { records }\end{array}$ & YES & No & QAC & PM & & & & PM & & & \\
\hline $\begin{array}{l}\text { Standard } \\
\text { operating } \\
\text { procedures and } \\
\text { instructions }\end{array}$ & YES & YES & PS & WAC & PM & & & $\mathrm{PM}$ & & & \\
\hline $\begin{array}{l}\text { Sampling and } \\
\text { analysis plan }\end{array}$ & No & YES & PM, PS & PR & & & & & & & \\
\hline $\begin{array}{l}\text { Remedial } \\
\text { investigations } \\
\text { plan }\end{array}$ & No & YES & PM, PS & PR & & & & & & & \\
\hline $\begin{array}{l}\text { Chain ' 'istody } \\
\text { formus }\end{array}$ & YES & No & FSC & DBM & QAC & & & & & & $\mathrm{QAC}, \mathrm{AO}$ \\
\hline $\begin{array}{l}\text { QA } \\
\text { audit/surveillance } \\
\text { reports }\end{array}$ & YES & No & QAC, AO & PM & QAC & ERD-QAS & GWOU-QAS & DD & PRM & & \\
\hline $\begin{array}{l}\text { External data } \\
\text { source QAPs }\end{array}$ & No & No & EDS & $\mathrm{EPC}$ & QAC & & & TSK & QAC & & \\
\hline $\begin{array}{l}\text { Statements of } \\
\text { work }\end{array}$ & YES & No & $\begin{array}{l}\text { ASC, } \\
\text { APO }\end{array}$ & PM & QAC & & & PM & & & \\
\hline $\begin{array}{l}\text { Standards } \\
\text { traceability } \\
\text { documents }\end{array}$ & YES & No & & STL & QAC & & & & & & \\
\hline Lab/field forms & YES & No & PS & FSC & QAC & & & & & & \\
\hline $\begin{array}{l}\text { Lab/field } \\
\text { notebooks }\end{array}$ & YES & No & PS & FSC & QAC & STL & & & & & \\
\hline
\end{tabular}


Table 8.2 (continued)

\begin{tabular}{|c|c|c|c|c|c|c|c|c|c|c|}
\hline Document title & $\begin{array}{l}\text { QA } \\
\text { record? }\end{array}$ & $\begin{array}{l}\text { Controlled } \\
\text { document? }\end{array}$ & Prepare & \multicolumn{4}{|c|}{ Review } & \multicolumn{2}{|c|}{ Approve } & \\
\hline $\begin{array}{l}\text { Data: } \\
\text { electronic/hard } \\
\text { copy }\end{array}$ & YES & No & DBM & QAC & STL & & & & & \\
\hline $\begin{array}{l}\text { Memoranda of } \\
\text { agreement }\end{array}$ & YES & No & PM & QAC & $\mathrm{DD}$ & PRM & & & & \\
\hline $\begin{array}{l}\text { Interface } \\
\text { agreements }\end{array}$ & YES & No & PM & QAC & DD & PRM & & & & \\
\hline Variance logbook & YES & No & FSC & QAC & GWOU-QAS & PM & PM & ERD-QAS & GWOU-QAS & \\
\hline $\begin{array}{l}\text { Deviation request } \\
\text { forms }\end{array}$ & YES & No & PS & QAC & GWOU-QAS & PM & PM & ERD-QAS & GWOU-QAS & PRM \\
\hline $\begin{array}{l}\text { Controlled } \\
\text { soflware }\end{array}$ & No & YES & $\begin{array}{l}\text { DBM, } \\
\text { STL }\end{array}$ & & & & & & & \\
\hline $\begin{array}{l}\text { QA summary } \\
\text { reports }\end{array}$ & YES & No & QAC & & & & PM & ERD-QAS & GWOU-QAS & PRM \\
\hline Inspection reports & YES & No & EI & LS & & & & & & \\
\hline $\begin{array}{l}\text { Lab operations } \\
\text { manual }\end{array}$ & No & YES & LS & QAC & & & PM & & & \\
\hline
\end{tabular}


Table 8.2 (continued)

\begin{tabular}{|c|c|c|c|c|c|c|c|c|c|}
\hline \multirow{2}{*}{$\begin{array}{l}\text { Document title } \\
\text { Corrective action } \\
\text { reports }\end{array}$} & \multirow{2}{*}{$\begin{array}{c}\text { QA } \\
\text { record? } \\
\text { YES }\end{array}$} & \multirow{2}{*}{$\begin{array}{c}\begin{array}{c}\text { Controlled } \\
\text { document? }\end{array} \\
\text { NO }\end{array}$} & \multirow{2}{*}{$\frac{\text { Prepare }}{\text { QAC }}$} & \multicolumn{3}{|c|}{ Review } & \multicolumn{3}{|c|}{ Approve } \\
\hline & & & & PM & GWOU-QAS & ERD-QAS & AO & PRM & $\mathrm{DD}$ \\
\hline $\begin{array}{l}\text { Health and safety } \\
\text { plan }\end{array}$ & YES & YES & HSC & ASC & & QAC & PM & & \\
\hline
\end{tabular}

Table Key

$\begin{array}{lll}\text { AD } & \text { agency/organization director/manager } & \text { FSC field sampling coordinator } \\ \text { AL } & \text { Analytical Laboratory } & \text { HSC health and safety coordinator } \\ \text { AO } & \text { auditing organization } & \text { LS laboratory steward } \\ \text { APO } & \text { analytical projects office } & \text { PM project manager } \\ \text { ASC } & \text { analytical services coordinator } & \text { PR peer reviews } \\ \text { DBM } & \text { data base manager } & \text { PRM ER program manager } \\ \text { DD } & \text { division director } & \text { PS project staff } \\ \text { EDS } & \text { external data source } & \text { QAC quality assurance/quality control } \\ \text { EI } & \text { equipment inspector } & \text { RM ER remediation manager } \\ \text { EPC } & \text { extra project coordinator } & \text { SH section head } \\ \text { ERD-QAS } & \text { ORNL Environmental Restoration } & \text { STL sampling team leader } \\ & \text { Program quality assurance specialist } & \text { TSK task leader }\end{array}$

Ground quality assur

assurance specialist 
- provides resolutions for quality problems and determines root-cause analysis, proposed solutions, and corrective actions, coordinating these activities with the QA/QC Coordinator;

- $\quad$ submits the appropriate documents to the QA Specialist for comment and approval; and

- ensures that the project personnel are qualified and trained to perform the assigned project activities.

\subsubsection{QA specialist}

The responsibilities of the QA Specialist include the following:

- provides assistance and approval of the QAPJP, procedures, and instructions;

- evaluates the effectiveness of project QA activities through scheduled audits and surveillances in cooperation with the GWOU QA/QC Coordinator; and

- provides guidance to resolve quality problems and ensures that corrective action is taken and is appropriately documented.

\subsubsection{QA/QC coordinator}

The responsibilities of the QA/QC Coordinator include the following:

- provides QA coordination between the Project Manager, QA Specialist, and project participants to ensure implementation and assessment of this plan;

- conducts field and laboratory evaluations of sampling methods and analytical procedures to ensure adherence to the QAPjP, SOPs, and instructions;

- oversees project-specific procedures and training development, implementation, and tracking;

- verifies that SOPs are in place and that appropriate personnel have been trained in the procedures; and

- conducts QAPjP orientation to all GWOU investigation staff.

\subsubsection{Task leaders}

Task leaders are responsible for integrating available information and collected data to meet the objectives and requirements of their specific tasks. Additional responsibilities of the task leaders include the following:

- assists the Project Manager in achieving the goals and objectives of the GWOU project;

- assists in project management and provides the Project Manager with project progress reports; 


\section{$8-10$}

- supervises and reviews subcontractor activities;

- maintains records in accordance with the GWOU QAPjP;

- provides final validation of field and analytical laboratory data and review of data for completeness, documentation, procedures, and consistency with known physical-chemical principles;

- resolves any technical questions concerning the data; and

- implements appropriate staff training and ensures that all project staff have been adequately trained and are in compliance with project QA/QC, health and safety, waste management, and data management requirements.

\subsubsection{Sampling team leaders}

Sampling team leaders are responsible for the management and coordination of specific field sampling teams. Additional responsibilities of the sampling team leaders include the following:

- coordinates and supervises field sampling activities and ensures that all sampling activities have been approved by the QA/QC Coordinator;

- coordinates activities with project management;

- provides orientation, hazard information, and training to technical staff, based on the requirements of the support plans;

- ensures that field-related activities are performed correctly and documented as required by the GWOU QAPjP;

- reviews and signs field logbooks and transfer copies of field logs to the ER Document Management Center (DMC) and the subcontractor's records center;

- $\quad$ performs initial validation of analytical data provided by internal GWOU laboratories prior to data transfer to the ER DMC and subcontractor's records center;

- provides field implementation of the health and safety (H\&S) plan, including communication of requirements to all personnel and field supervision, and ensures that site personnel have received required OSHA and GWOU training and that they adhere to the site safety requirements;

- informs the project H\&S-Coordinator of any directed or required changes in sampling plans so that they may be appropriately addressed; and

- ensures that Corrective Action and Nonconformance Reports are initiated if necessary. 


\subsubsection{Analytical services coordinator}

The Analytical Services Coordinator is responsible for the custody and transfer of samples and results among the sampling teams and analytical laboratories. The Analytical Services Coordinator is the main contact for the laboratories concerning chain of custody and requests for services forms. Additional responsibilities of the Analytical Services Coordinator include the following:

- coordinates all sampling analysis requirements with the Analytical Project Office per Requirements for Quality Control of Analytical Data for the Environmental Restoration Program, ES/ER/TM-16 (Energy Systems 1992c);

- establishes and maintains a chain-of-custody and request-for-services forms control system, in conjunction with the project QA/QC Coordinator;

- receives chain-of-custody samples from the field crews and transfers them to analytical laboratories;

- ensures that chain-of-custody and request-for-services forms are properly completed prior to transfer of sample custody;

- ensures that Corrective Action and Nonconformance Reports are initiated if necessary; and

- oversees final disposal of samples to ensure that proper procedures are followed.

\subsubsection{Health and safety coordinator}

The H\&S Coordinator is responsible for ensuring that site personnel adhere to the site H\&S requirements. Additional responsibilities of the H\&S Coordinator include the following:

- $\quad$ reviews the QAPjP;

- develops, coordinates, and implements the H\&S plan;

- revises the H\&S plan as warranted by changed site conditions; and

- ensures that all GWOU personnel adhere to H\&S requirements.

The Project Manager, with the assistance of the H\&S Coordinator, handles the agency liaison matters relating to health and safety. During field work, the sampling team leader will normally assume the responsibilities of the H\&S Coordinator in his or her absence.

\subsubsection{Extra-project coordinator}

The -Extra-Project Coordinator is responsible for establishing linkages, exchanging information, and generally cooperating with other research, investigation, and monitoring activities in and around the GWOU area. 


\subsubsection{Technical support staff}

The responsibilities of the technical support staff include the following:

- complies with all aspects of the GWOU QAPjP;

- performs project activities in accordance with approved SOPs; and

- identifies and documents variations to SOPs as described under Element 15 of the QAPjP modular profile.

The responsibilities of other key individuals with regard to specific QA issues are presented in subsequent "Responsibilities" sections of this QAPjP.

\subsection{QA PROGRAM}

\subsubsection{QA Program}

The Project Document Summary (Table 8.2) identifies responsibilities for the development, review, approval, and control of the QAPjP.

\subsubsection{QA Planning}

The development, review, approval, revision, and distribution of this QAPjP will follow guidelines set forth in Preparation, Division Approval, and Clearance of Environmental Restoration Documents, ER/C-P1103 (Energy Systems 1991b).

\subsubsection{DQOs}

DQOs are derived from the intended uses of the data. To develop DQOs, environmental variability and analytical quantitation requirements must be considered along with measures to evaluate the PARCC of both sample collection and analysis, and the level of documentation required to support the intended use of the data. Because initial GWOU sampling efforts emphasize scoping and screening activities, the sampling locations, number of samples, and methods of data collection are intended to:

1. provide information for locations, media, and/or analytes for which few data exist, and

2. estimate environmental variability.

Therefore, consideration of environmental variability has not been included in the development of DQOs for this stage of the GWOU activities.

To allow for flexibility in the GWOU program, the DQO process will incorporate three phases: 


\section{$8-13$}

1. Qualified individuals designated by the Project Manager will perform an evaluation to determine the logical use of the data and the definition of the parameters that must support the sampling and analysis process.

2. This group will then determine the enhancement of specific requirements such as sampling and analytical methodology resulting in detection limits and determine the QC documentation to support this process.

3. Finally, this group will make a determination of the most effective way to maximize the efficiency of the collection design. This involves, when applicable, the identification of acceptable levels of uncertainty and the inherent variability of environmental samples, while taking into consideration those factors that could account for variability of the data.

The analytical methods selected are based on quantitation limits (levels of concern) required to identify COPCs (e.g., the evaluation of applicable or relevant and appropriate requirements, the conducting of risk-based contaminant screening, the establishment of background conditions, etc.). Data meeting historic method quality control criteria therefore meet the analytical requirement of the DQO for this project.

Meeting project data-use requirements will require the use of a decision-making process by which measurement tasks are assigned the appropriate level of QC documentation to support the stated environmental problem. These levels will be designated I through IV, and are intended to be equivalent to the levels defined in Data Quality Objectives for Remedial Response Activities (EPA 1987a). The GWOU investigation risk assessment team, in consultation with the Project Manager and the ER Analytical Project Office, will determine the QA level required for all measurements and activities.

In general, if data are to be used directly for risk assessment, feasibility studies, or remedial design, QA Level III or higher will be required. Data of two different quality levels will be generated during field investigations. Field data such as the results of radiation monitoring will meet the requirements of QA Level I or Level II. Analytical laboratory data collected for surface water and groundwater will meet the requirements of QA Level III or Level IV. For example, Level I and Level II data is obtained from field screening exercises using portable instruments. Results may not be quantitative or compound specific, but are inexpensive and can be made available quickly. Level I and Level II data can be used for such scoping and screening activities as (1) initial delineation of contaminated zones, (2) crude presence or absence of contamination, and (3) gross determination of analytes in samples.

Level III and Level IV data requirements provide laboratory analyses using standard EPA methods such as those in SW-846 (EPA 1986), EPA 600/4-79-020 (EPA 1983b), and the CLP. Levels III and IV provide quantitative analytical results that require a level of QA/QC resulting in legally defensible data. -Data at both of these levels are produced under equally rigorous conditions. Level IV, however, has a deliverable that is provided in a legally defensible "package." Levels III and IV data are suitable for site characterizations and risk assessments. The QA requirements for Levels III and IV are (1) detection limits for each procedure will be consistent with EPA-approved methods, (2) laboratory QA/QC procedures will follow method-specific requirements, and (3) field QA/QC procedures will be assessed by reviewing data generated from the analysis of trip blanks, equipment rinsates, field blanks, and duplicate 


\section{$8-14$}

samples. Level III packages should also include analytical results for the QA/QC samples run, which aids in validation or verification. The determination of the appropriate QA level for data collection (field measurements or analytical methods) will depend on the intended use of the data.

The GWOU project will involve a long-term investigation and assessment effort, during which time analytical methods will likely change. Therefore, a minimum of $10 \%$ of the data collected for the GWOU investigation will meet the requirements of QA Level IV data. The Level IV, full CLP-like data packages will compare to current and future analytical methods, and will ensure the ongoing usability of data for the duration of the GWOU project.

\subsubsection{QA Program Status Reporting}

The active participation of management in the GWOU investigations is fundamental to the success of this QAPjP. Management will be aware of project activities and will participate in development, review, and operation of the project. Management will be informed of QA status and activities through the receipt, review, and approval of the following documentation:

- laboratory and project-specific QA/QC plans and procedures;

- post-audit reports and audit closures;

- surveillance reports;

- deviation request forms;

- corrective-action overdue notices;

- nonconformance reports; and

- self assessments.

The individuals responsible for providing management with the noted documentation are defined in Table 8.2. Copies of these reports will be distributed to appropriate Energy Systems and Oak Ridge Field Office management and regulatory agencies. In addition, bi-annual assessment of QA/QC activities and data PARCC will be conducted by the QA/QC Coordinator and reported to the GWOU Project Manager.

Project management will inform the ER Program and others, as appropriate, of the QA status of the project, especially with regard to any significant quality accomplishments. GWOU investigation personnel are required to inform the Project Manager or project support staff of all nonconformances or quality failures. The Project Manager will document and immediately report any nonconformances or quality failures to the QA Specialist. It is the responsibility of the QA Specialist to report all quality-associated activities to the ORNL ER Program QA Specialist.

\subsubsection{QA Training and Awareness}

All ORNL and subcontractor personnel working on the GWOU investigations will be properly trained, qualified individuals. $\mathrm{QA}$ awareness will be addressed at information sessions and though distribution of the project $\mathrm{QAPjP}$. The QA/QC Coordinator will be responsible for conducting the information sessions and distributing the plan. Receipt of information will be documented by attendance and document sign-out sheets. Prior to the commencement of work, all project and sampling team personnel will receive a training needs assessment specific to the investigation covering the following areas: 
- organization and lines of communication and authority;

- description of the GWOU system;

- overview of the Sampling and Analysis, QA/QC, H\&S, and Data Management Plans;

- documentation requirements;

- sampling related procedures;

- personnel protection procedures;

- waste management procedures;

- decontamination procedures; and

- emergency procedures.

Personnel will receive required training by qualified instructors prior to performing work related functions. Instructions will be qualified/certified and substantiating documentation will be provided. Documentation will be maintained as QA records. QA information sessions will be conducted annually or more frequently as needed. Training information is included in each applicable standard operating procedure or instruction.

\subsubsection{QC Samples}

\subsubsection{Field QC samples}

Field QC sampling will be conducted to establish bias inherent in field activities and will constitute 5\% to $10 \%$ of the total number of samples collected. All QC samples will be shipped according to the chain-of-custody procedures specified in Sect. 8.8 of this QAPjP. Field QC samples will include blanks and replicates as described below.

Field rinsate. A field rinsate consists of final rinse water from the decontamination of field sampling equipment. Analysis of the field rinsate determines whether the decontamination procedure is adequate to prevent carryover of contamination from one sampling location to another. A field rinsate will be collected as designated by the project-specific sampling plan for any given piece of sampling equipment.

Field blank. One field blank, consisting of source water (organic-free water) used for decontamination, will be collected once per sampling event or as designated by the project-specific sampling plan. Field blanks will also be used to detect airborne metal or organic contaminants present at the time of sample collection. One field blank container consisting of organic-free water will be opened during the collection of metal or organic samples as designated by the project-specific sampling plan.

Trip blank. A trip blank, consisting of a sealed container of organic-free water, will travel from the field to the laboratory with the samples to be analyzed for the contaminants of concern. The trip blank identifies contamination that may have been contributed to the field samples during transportation (receives the same treatment as sample containers). Trip blanks will be collected no less than once per week during field sampling activities, or as designated by the project-specific sampling plan.

Field duplicate. Field duplicates, which consist of a duplicate sample from one field sampling location, indicate whether the field sampling technique is reproducible. Duplicate samples will be obtained at an appropriate collection frequency for all sample matrices. 
Field QC samples will have discrete sample numbers and will be submitted as "blind" to the laboratories. Resuits of these samples will be included in the analytical data reports. Results for QC samples will not be used to adjust the results obtained for original samples. In the event that contaminants are found in the blank samples, attempts will be made to identify the source of contamination, and corrective action will be initiated.

\subsubsection{Laboratory QC samples}

Laboratory QC samples will be used to check sample preparation and analysis, and to monitor laboratory performance. Specific data deliverables will be approved by the ER Program Analytical Project Office. Specific requirements for groups of samples will be specified in SOWs for those samples. The laboratory QC documentation requested for delivery will be specified in the SOW and will be dependent upon the intended use of the data, as determined by DQOs, for a given sampling event. Requirements for quality control of analytical data will be implemented in accordance with Energy Systems document ES/ER/TM-16 (Energy Systems 1992c).

\subsection{PROCUREMENT DOCUMENT CONTROL}

The GWOU project procurement document control will follow ORNL procedure QA-L-4-100 (Energy Systems 1988c). Procurement of laboratory services will be in accordance with ES/ER/TM-16.

\subsection{INSTRUCTIONS, PROCEDURES, AND DRAWINGS}

\subsubsection{Responsibilities}

\subsubsection{ER procedures coordinator}

The ER procedures coordinator reviews the purpose and scope of GWOU procedures and task instructions for applicability to other environmental restoration activities.

\subsubsection{GWOU procedures coordinator}

The responsibilities of the GWOU procedures coordinator include the following:

- assigns numbers to GWOU procedural documents and interfaces with the ORNL ER Program-QA Specialist and editor;

- inputs into a data base tracking information on the documents created;

- ensures that the data base remains current;

- coordinates the development and issuance of GWOU procedures and instructions with ERORNL Site Document Manager; 
- facilitates the review of new and revised GWOU procedures and instructions with appropriate review staff and makes certain that required approvals are obtained for these documents;

- facilitates the revision of procedures and instructions;

- arranges for a classification review of procedural documents;

- develops appropriate distribution lists, along with the assistance of the author, for review copies and final copies of GWOU RI procedural documents;

- arranges for the distribution of these documents with the GWOU DMC;

- issues binders for storing procedural documents to individuals on a controlled distribution list;

- prepares and arranges the distribution of revised tables of contents and acknowledgment forms for the receipt of procedural documents;

- conducts routine yearly reviews of procedural documents (in conjunction with the principal author, and/or peer reviewers of the procedural documents) to determine any necessary revisions of these documents; and

- indicates approval of all procedures and instructions on an approval form before they are routed to the principal author and Project Manager for their approvals.

The GWOU investigations procedures coordinator's approval indicates that procedural documents have gone through all necessary reviews and that appropriate required changes have been incorporated into the documents. Procedures coordinator approval is not approval of the technical or administrative content of a document, and it is not approval from a quality assurance perspective.

\subsubsection{Principal author}

The author of a GWOU remedial investigation procedure or instruction is responsible for ensuring that the document addresses the following:

- complies with ER Procedure ERWM/C-P1100-Initiation, Review, Revision, Approval, and Issuance of ER Waste Management Programs Intersite Procedural Documents;

- adequately addresses its intended audience;

- communicates complete and accurate information on the process being described;

- complies with federal, state, and local laws and regulatory guidelines, and Martin Marietta corporate, Energy Systems, division, and site policies, procedures, and instructions; and

- shows an appropriate effective data on the last page of the document. 


\section{8-18}

Additional responsibilities of the author include the following:

- making certain the above noted requirements are accomplished;

- $\quad$ soliciting two peer reviews of the document (see definitions);

- working with the GWOU procedures coordinator, other authors who may need to be assigned to assist with the writing task, the peer reviewers, and the editor to follow the procedure or instruction from conception through management approval; and

- indicating his/her approval of a procedure or instruction before it is routed to the Project Manager for approval.

\subsubsection{Editor}

The editor of a GWOU-generated procedure or instruction is responsible for the following:

- ensuring that the document's style, format, and organization are consistent with the Document Preparation Guide (Energy Systems 1989) and that the document meets the quality guidelines specified in this QAPjP;

- editing the document to the level of edit specified by the author, which may include a substantive in-depth review of the document's content;

- ensuring that any changes required by the author and other reviewers of the document are made;

- providing a copy of the final document to the author for verbal approval; and

- sending the original document to the GWOU procedures coordinator for routing and project approval.

The editor of a GWOU procedural document does not indicate approval of the document on the form developed for project approval unless he/she is also the principal author of the document.

\subsubsection{QA/QC coordinator}

The QA/QC Coordinator is responsible for the following:

- reviewing technical and administrative procedural documents to ensure that appropriate QA program requirements have been addressed;

- providing written comments on all procedural documents reviewed and indicating approval of final documents; and

- updating the GWOU remedial investigation modular profile when procedures or instructions have been approved. 


\subsubsection{Peer reviewer}

The peer reviewer of any GWOU RI procedure or instruction is responsible for verifying that the document addresses the following:

- adequately addresses its intended audience;

- accurately describes the process being documented; and

- has an appropriate scope and execution.

Additional responsibilities of the peer reviewer include the following:

- provides written comments on all documents reviewed but is not required to indicate approval of a procedural document; and

- requests to see a copy of an approved procedure or instruction prior to its distribution to verify that all of the peer reviewers' concerns have been addressed.

Two peer reviewers are required for every administrative and technical procedure and instruction generated by the GWOU RI. One peer reviewer is required for every PCN issued by the GWOU RI.

\subsubsection{Project manager}

The GWOU RI Project Manager has ultimate responsibility for the following:

- ensuring the appropriateness of the scope and execution of technical and administrative procedural documents;

- ensuring that procedures and instructions conform to federal, state, and local laws and regulatory guidelines, and Martin Marietta corporate, Energy Systems, division, and site policies, procedures, and instructions;

- verifying that reviews appropriate for the type of procedural document (administrative or technical procedure or instruction) have taken place (as evidenced by the signatures on the approval form for procedures and instructions);

- $\quad$ signing the approval form for all procedures and instructions and signing and dating the last page of procedural documents to indicate approval; and

- ensuring that procedures and instructions are properly administered and implemented within the project.

\subsubsection{GWOU DMC information assistant}

The GWOU DMC information assistant works with the GWOU procedures coordinator to ensure that GWOU procedures and instructions are distributed to all appropriate parties. The information assistant is also responsible for the following: 
- prepares approval copies of procedural documents for mailing using distribution lists supplied by the GWOU procedures coordinator; and

- maintains the record copy and the original, approved copy of all procedural documents generated by the GWOU in accordance with the Energy Systems guidelines outlined in "Retention and Disposition of Records," GP-21, Policy, Standards, and Procedures Manual (Energy Systems 1991c).

\subsubsection{Standard Operating Procedures and Instructions}

Identification of the individuals involved with project procedures and instructions is presented in the Project Document Summary (Table 8.2). All project-specific SOPs and instructions are maintained in the GWOU RI Plan Procedures and Instructions Manual by the GWOU QA/QC Coordinator. Refer to Table 8.3 for a listing of GWOU RI standard operating procedures and instructions.

\subsection{DOCUMENT CONTROL}

This section applies to documents pertaining to the GWOU project and to the management of those quality-related documents that are in active use during the life of the project. The documents include, but are not limited to, the following:

- QA documents;

- sampling data;

- technical notebooks; and

- procedures.

Document control will be in accordance with Distribution of Controlled Documents by the Document Management Center for the ER Program, ER/C-P1113.

\subsubsection{Responsibilities}

Refer to the Project Document Summary (Table 8.2) for a list of project documents, and for identification of controlled documents.

\subsubsection{Project manager}

The Project Manager is responsible for the following:

- identifies project documents required to be controlled; and

- informs the QA/QC Coordinator of controlled document designations.

\subsubsection{QA/QC coordinator}

The QA/QC Coordinator oversees the control of designated project documents according to the procedures listed in the Modular Profile (Table 8.1). 


\section{$8-21$}

Table 83. Surveillance activities

\begin{tabular}{llll}
\hline \multicolumn{1}{c}{ Item or activity } & Responsible person & \multicolumn{1}{c}{ Frequency } & Date \\
\hline Field operations & QAC or QAS & Quarterly (initially) & TBD \\
Technical procedures & QAC or QAS & Annually & TBD \\
Training documentation & QAC or QAS & Annually & TBD \\
Chain-of-custody records & QAC & Quarterly & TBD \\
Instrument calibration & QAC or PS & Annually & TBD \\
documentation & & & \\
Sample identification \& storage & QAC or PS & Semi-Annually & TBD \\
Project QA plans & QAC & Annually & TBD \\
Laboratory operations manual & PS or QAC & Annually & TBD \\
\hline
\end{tabular}

${ }^{a}$ Quality assurance/quality control

${ }^{b}$ Quality assurance specialist

'Project staff

Note: Overview of surveillance activities will be performed by ER-QA Specialist quarterly, or as deemed necessary by same. 


\subsubsection{Procedures}

The QA/QC Coordinator ensures adequate document control by:

- developing and maintaining a distribution list of individuals requiring controlled project documents;

- distributing revisions to controlled documents; and

- tracking the receipt of revisions by project staff through the use of receipt forms and periodic document checks.

Record copies of all GWOU documents will be indexed and filed at the GWOU RI DMC and the ER DMC.

\subsection{CONTROL OF PURCHASED ITEMS AND SERVICES}

\subsubsection{Responsibilities}

Identification of organizations and GWOU investigation staff members responsible for the development, review, and approval of Analytical Laboratory SOWs is presented in the Project Document Summary (Table 8.2).

The laboratory steward is responsible for the following:

- monitors and schedules (when necessary) equipment inspections as designated in the laboratory operations manual for any internal laboratory performing services for the GWOU project;

- provides the Project Manager and the QA/QC Coordinator with inspection reports;

- develops and maintains the laboratory operations manual and calibration logbooks; and

- records calibration failures.

\subsubsection{Procedures}

\subsubsection{Laboratory scope of work}

Laboratory SOWs will comply with the following:

- be developed in conjunction with the ER Analytical Project Office and in accordance with ES/ER/TM-16; 
- $\quad$ specify QC requirements and QC sample deliverables; and

- be submitted to the laboratory for approval prior to sample shipment.

The analytical laboratory shall submit the results of requested control sample analyses and other QA/QC documentation to the GWOU RI Analytical Services Coordinator to ensure conformance with established control limits and other QA requirements. The QC requirements will be established based on project DQOs as they are developed for specific tasks over the course of the GWOU investigation. The data validation process will impose sufficient controls over the quality of analytical laboratory data and services. The laboratory will not perform data validation; rather, data will be validated by an organization independent of the laboratory. The data review process consists of data screening, checking, auditing, verification, certification, and review.

All GWOU laboratories shall develop, control, and maintain a laboratory operations manual in accordance with Procedure ES-ADM-92-003 (Energy Systems 1992d). Refer to Table 8.2 for the identification of individuals responsible for laboratory operations manuals.

Laboratory calibration standards, when commercially available, will be traceable to NIST, EPA, or other certified laboratories. Documents certifying traceability are considered QA records and shall be indexed and filed in the GWOU DMC and the ER DMC.

The format and content of hard copy and electronic data reports will adhere to project needs and will be specified in SOWs, which include contract requirements of DOE and regulatory agency reporting formats. The laboratory supervisors are responsible for the preparation of each technical report, including the process of data validation. The required hard copy format will be specified in the laboratory SOW. The following requirements regarding data will also be applied:

- final data presentation shall be checked according to data validation requirements and approval by the appropriate sampling team leader and laboratory steward;

- each page of data will be identified with the project number or project name, sample delivery group number, batch number, and data of issue; and

- electronic copies of the data must match the hard copy reports.

Electronic data contents in the report will include the following:

- sample identification number used by the laboratory and/or the sample identification provided to the laboratory if it is different from that used in the laboratory;

- sample delivery group number and batch number;

- chemical parameters analyzed, reported values, laboratory data qualifiers, and units of measurement;

- quantification limit of the analytical procedure; 
- results of QC sample analysis;

- achieved accuracy, precision, and completeness of data;

- references to specific data if required to explain reported values; and

- analytical methods used.

Analytical methods will be specifically refereri:ed on all laboratory reports. Any method modification will be included in the case narrative provided by the contract laboratory. Data for field QC samples will be reported in the same format as that used for actual samples.

\subsubsection{Equipment calibration}

A calibration information table for all laboratory and field equipment is located in the laboratory operations manual of the laboratory where the equipment is stored or operated. The calibration information table defines the calibration schedule, calibration procedure reference, measurement and test equipment category, and the individual responsible for calibration.

Calibration methods, when calibration is performed by the operator, are located in SOPs referenced in the laboratory operations manual calibration information table.

Registered calibration logbooks shall be maintained for each laboratory. The laboratory steward ensures that calibration records are kept current through periodic reviews.

Calibrated equipment shall be uniquely identified by either the manufacturer's serial number or an instrumentation and control number.

All equipment shall be categorized according to measurement and test equipment categories described in the laboratory operations manual of the laboratory where the equipment is stored or operated. The laboratory steward shall place calibration category decals on laboratory equipment.

Calibration failures can occur regardless of timely calibration checks. In the event that an individual suspects an equipment malfunction, that person should perform the following:

1. remove the device from service;

2. tag the device so that it is not inadvertently used; and

3. notify the laboratory steward or sampling team leader.

If equipment is found to be out of calibration, the sampling team leader or laboratory steward shall evaluate and document (in the calibration logbook) the validity of previous inspection or test results; and the acceptability of similar equipment previously inspected or tested. Devices that are out of calibration will be recalibrated prior to reuse. Any equipment found to be consistently out of calibration shall be repaired or replaced. Any such action shall be recorded in the calibration logbook. 


\subsection{IDENTIFICATION AND CONTROL OF ITEMS}

\subsubsection{Responsibilities}

\subsubsection{Field sampling coordinator}

The field sampling coordinator is responsible for the following:

- determines the method of identification of samples in conjunction with the QA/QC Coordinator and the Data Base Manager, and ensures that the items are identified in accordance with project SOPs;

- ensures that physical identification of equipment is provided to the maximum extent possible;

- ensures that when identification markings are used the identification materials and methods provide a clear and legible identification, that they do not detrimentally affect the function, integrity, or service life of the item, and that the markings will last for the time required; and

- $\quad$ ensures that identification markings are transferred to each part of an identified item when the item is subdivided and that the markings shall not be obliterated or hidden by surface treatments or coatings unless other means of identification are substituted.

\subsubsection{QA/QC coordinator}

The QA/QC Coordinator is responsible for the following:

- determines that sponsor requirements for identification and traceability of samples are met;

- ensures that chain-of-custody procedures are completely described through the issuance of, and training on, chain-of-custody procedures;

- ensures that procedures for the collection, handling, storage, and identification of samples are included in the GWOU SOPs; and

- ensures that procedures for control, identification, and cleaning and maintenance of sampling equipment and instruments are developed and implemented.

\subsubsection{Procedures}

Each environmental sample collected will have a unique identifier that will be physically associated with the sample; and maintained from the time of sample collection to sample disposal.

Sample chain-of-custody procedures require documented sample possession from the time of collection to disposal, in accordance with Energy Systems Procedure ESP-500 (Kimbrough et al. 1994). 
Shipping and handling procedures will be in accordance with technical SOPs developed for each sample medium and type of analysis.

\subsection{CONTROL OF PROCESSES}

For the purpose of this program, control of processes will be used to indicate the use of data/sampling collection through interface agreements. Data from several other projects will be utilized in the GWOU RI. The Extra-Project Coordinator will be the point of contact for interactions with these various groups (i.e., Clinch River RI, ORNL WAGs RI/FS, the Biological Monitoring and Abatement Program, the National Pollutant Discharge Elimination System, the Active Sites Environmental Monitoring Program, and the Environmental Surveillances Program). Data from these groups will be transferred to the Data Management and Integration Group. The QA plans developed for these groups will be reviewed and their status relative to GWOU data quality objectives will be documented. GWOU QA staff will review the data and data quality objectives to ensure that the data are appropriate for the proposed application in the GWOU investigation. GWOU staff will also review or participate in audits and surveillances to ensure that the data are being collected and handled in the manner prescribed in the QA plan of the group providing the data. Interaction between external data sources will be additionally controlled by the implementation of interface agreements.

\subsubsection{Responsibilities}

Identification of organizations and GWOU staff members responsible for the review and approval of QA plans of external data sources, and the development, review, and approval of interface agreement, are presented in the Project Document Summary (Table 8.2). In addition, the Project Manager is responsible for the following:

- identifies organizations and projects for which interface agreements shall be written; and

- implements and revises interface agreements as necessary.

\subsubsection{Procedures}

Interface agreements for projects or organizations that provide sample collection services, analytical services, and data to the GWOU investigations but do not receive funds for such services, will be written by the Project Manager and submitted to ER Management for distribution and approval. Because changes in the interface agreement may potentially affect GWOU data quality, the GWOU Project Manager will be notified by the external organization directly if any changes in the interface agreement have occurred. The Project Manager will then notify ER Management of the changes.

Interface agreements shall include, but are not restricted to, the following:

- identification of participating project or organization;

- identification of responsible person(s) within each project or organization;

- effective dates of Interface Agreement;

- responsibilities of each interacting organization;

- definition of and schedule for deliverables; 
- $\quad$ signature approval of both designated responsible persons; and

- quality assurance applicability.

\subsection{INSPECTION}

\subsubsection{Responsibilities of the Project Manager}

The Project Manager is responsible for the following:

- reviews inspection reports from inspections of field measuring devices and sampling equipment performed by inspecting and calibrating organizations to verify and track inspections on items important to the success of the project; and

- indicates his/her review and approval by signature on the inspection report.

\subsubsection{Responsibilities of the QA/QC Coordinator}

The QA/QC Coordinator is responsible for the following:

- maintains inspection report copies as QA records; and

- submits reports to the GWOU DMC and the ER DMC for indexing and filing.

\subsection{TEST CONTROL}

\subsubsection{Data Summarization, Validation, and Reporting}

The performance of laboratory equipment will be monitored through the analysis of QC samples and the verification and validation of QC sample data. In addition, the type and frequency of quality control tests shall be specified for different media and analyses in laboratory SOPs.

The data validation process compares the objective with the actual through the evaluation of the PARCC parameters. The laboratory will not perform data validation; laboratory and field QA/QC data will be validated by an independent contract organization or by GWOU staff as appropriate. An SOW describing data editing, screening, checking, auditing, verification, certification, and review (EPA 1988b) will be implemented prior to the initiation of data validation. All data for this project will be evaluated by QA/QC methods and internal peer review. Data reduction, verification, and reporting will be in accordance with the ongoing ORNL ER Program Data Base Management activities (Hook et al. 1990). Data will be entered into common, standardized formats. - In addition to following field sampling documentation and QA/QC procedures, data are verified using a variety of computerized checks for reasonableness. These procedures will ensure that data are entered, encoded, and manipulated consistently and are available to GWOU investigators in a usable format.

Data validation for QA/QC Levels I and II will follow the ER Program's requirements for quality control of analytical data. Functional guidelines will be developed for review of Level 
III QA/QC data packages according to the DQOs established for the project. Data validation for Level IV will be performed according to EPA's functional guidelines.

\subsubsection{Field Data Reduction and Evaluation}

Data collection during field activities will be evaluated by checking the procedures used and comparing the data to previous measurements. The QA/QC Coordinator and sampling team leaders will be responsible for checking field QC sample results to ensure that field measurement and sampling protocols have been observed. These reviews will check the following:

- data and time sampled;

- preservation;

- SOPs utilized;

- calibration method and frequency;

- chain-of-custody documentation; and

- nonconforming conditions and corrective actions.

Reviewers are responsible for ensuring that data reduction calculations are documented and checked by qualified personnel. Reviews will be indicated by signature on the sample results. Written reports, including reduced and summarized data, will include the raw data in appendices. Specific calculations used for data reduction will also be included.

\subsubsection{Analytical Laboratory Data Reduction and Evaluation}

Analytical data generated during the sampling and analysis phase will be evaluated for completeness as an ongoing and concurrent process. This will include, but is not limited to, review of completed custody logs, photocopied pages of laboratory notebooks and data forms completed by the technical staff, including sample weights, dilutions, concentrations, data reduction, instrument logs, and all raw data. Reviewers of materials will include the sampling team leader, GWOU QA/QC Coordinator, and the assigned contract laboratory program manager. In the data review process, the data are compared to information such as the sample history, sample preparation, and QC sample data to evaluate the validity of the results. Data validation includes the following:

- dated and signed entries by technical staff and supervisors on the worksheets and logbooks used for samples;

- sample tracking and numbering systems to track the progress of samples through the laboratory;

- quality control criteria to reject or accept specific data in accordance with EPA CLP protocols and laboratory data validation functional-guidelines for evaluating organic and inorganic data (EPA 1988b, EPA 1988c), and field QC versus laboratory QC as mandated by this QAPjP and those requested EPA procedures; and

- examination of all data for a sample and site by checking for consistency among replicate samples, sending split samples to other laboratories for analysis, and using frequency distributions and range checks to evaluate outliers. 
Where possible, other checks for internal consistency, such as evaluating ion balances, will be employed.

\subsection{CONTROL OF MEASURING- AND TESTING-EQUIPMENT CALIBRATION}

\subsubsection{Responsibilities}

\subsubsection{Project manager}

The Project Manager reviews and approves, in coordination with the Analytical Project Office, laboratory operations manuals for laboratories conducting analyses for the GWOU RI.

\subsubsection{Sampling team leader}

The sampling team leader is responsible for the following:

- maintains equipment field calibration logbooks; and

- records calibration failures.

\subsubsection{Procedures}

Procedures regarding calibration of equipment are discussed in the "Control of Purchased Items and Services" section of this QAPjP.

\subsection{HANDLING, STORAGE, AND SHIPPING}

\subsubsection{Responsibilities}

The identification of individuals responsible for the development, review, and approval of SOWs is presented in the Project Document Summary (Table 8.2).

\subsubsection{Procedures}

Requirements for controlling the handling, storage, cleaning, packaging, shipping, and preservation of items and samples to prevent damage or loss and to minimize deterioration are described in SOPs for each sample medium and analysis. In addition, SOWs shall be developed in conjunction with the ER Analytical Project Office for each analytical laboratory performing services for the GWOU RI. These SOWs shall describe specific shipping, handling, and preservation measures for each analysis and sample medium.

\subsection{INSPECTION, TESTING, AND OPERATING STATUS}

The inspection, testing, and operating status determinations of monitoring stations and associated equipment used to collect data used by GWOU investigation project management are the responsibility of the monitoring organization. Interface agreements between the GWOU 
management and the monitoring organizations ensure that the GWOU RI Project Manager will be notified when test failures or changes affecting data quality occur.

\subsection{NONCONFORMANCE}

\subsubsection{Responsibilities}

The identification of individuals responsible for the review and approval of nonconformance, variance, occurrence, and corrective action documents is presented in the Project Document Summary (Table 8.2).

\subsubsection{Procedures}

All variances from approved GWOU standard operating procedures will be documented in a deviation request form. Only GWOU personnel may initiate a variance. All variances must be reviewed by the GWOU RI Project Manager and the QA Specialist, and evaluated with regard to its possible impact on reportable data. Upon review, the Project Manager and the QA Specialist may initiate the following:

1. approve the variance and allow field procedures to resume; or

2. proceed with nonconformance, occurrence, and corrective action procedures.

If the issuance of a deviation request form indicates the need for a minor procedural change, the Project Manager, field sampling coordinator, or the field team leader may initiate a Procedural Change Notice.

Nonconforming equipment, items, activities, conditions, and unusual incidents that could affect compliance with project requirements will be identified, controlled, and reported in a timely manner. A nonconformance is defined as a malfunction, failure, deficiency, or deviation that renders the quality of an item unacceptable or indeterminate. The originator of a Nonconformance Report will describe the finding on the form provided for this purpose, and notify the GWOU RI Project Manager, QA Specialist, and QA/QC Coordinator. Each nonconformance will be reviewed and a disposition given for the item, activity, or condition. Evaluations also will determine if the event justifies the issuance of a Corrective Action Report and Status. The appropriate report will document the event, the findings of the evaluation, and the required corrective actions. The disposition of a nonconformance will be documented and approved by the GWOU RI Project Manager. The QA Specialist will concur with the disposition of the nonconformance.

The QA/QC Coordinator for a particular laboratory is responsible for the assessment of laboratory QC-sample information. If data fall outside accepted limits, established laboratory procedures for identifying the problem and taking appropriate corrective actions will be employed. Completion of corrective action should be evidenced by deviations returning to prescribed acceptable limits.

The modification, repair, rework, or replacement of nonconforming equipment, items, or activities will require the reverification of acceptability. In certain instances, as determined by 
project management (including the Project Manager, laboratory QA/QC Coordinator, or project QA Specialist), these activities may require that corrective action be completed and verified before work continues.

If, in the opinion of the Project Manager and the QA Specialist, the nonconformance does not significantly affect the technical quality or use of the work, the work may continue pending resolution of the nonconformance. The basis for such a decision will be documented on the nonconformance report and submitted to the QA Specialist for review and approval. The documentation will include the statement that the decision of no significant affect was made before continuing with the work. All nonconformances will be trended for the project-specific activities performed for the GWOU RI. The QA Specialist, in coordination with the QA/QC Coordinator, will determine the trending criteria and maintain the trending of the nonconformances.

\subsection{CORRECTIVE ACTIONS}

Information regarding corrective actions is discussed in the "Nonconformance" section of this QAPjP.

\subsection{QA RECORDS}

All project records, including QA records, will be managed by the GWOU DMC and ER DMC. The GWOU DMC is responsible for the processing, maintenance, reporting, and retrieving of all GWOU investigation record materials and for forwarding copies to the ER DMC.

SOP ER/P-OS/ERP-DMC establishes general responsibilities and guidelines for use of the GWOU DMC. Duplicate files will be maintained by the ER DMC. GWOU QA records include the following:

- data collection information (including electronic and paper forms);

- data verification and validation materials;

- $\quad$ surveillance and audit reports;

- deviation request forms, nonconformance reports, occurrence reports;

- corrective action documentation;

- $\quad$ project-specific training records;

- laboratory notebook, calibration notebook, and field notebook copies;

- chain-of-custody and QA sample forms;

- analytical laboratory SOWs;

- interface agreements;

- variance logbook copies;

- standards traceability documents;

- Memorandums of Understanding;

- SOPs;

- QA summary reports;

- inspection reports;

- calibration reports; 
- training needs assessment;

- sampling and analysis plans;

- H\&S plan; and

- data management plan.

\subsection{AUDITS}

This section describes the methods and policies for planning, performing, and reporting audits to verify compliance with all aspects of the QA program and to determine program effectiveness. The requirements of this section apply to internal audits or surveillances.

Audits will be performed in accordance with QA-L-18-100, and personnel performing these audits shall be qualified in accordance with QA-L-18-101.

\subsubsection{Responsibilities of the QA/QC Coordinator}

The responsibilities of the QA/QC Coordinator include the following:

- assigns, tracks, and ensures implementation of all corrective actions identified by formal audits and surveillances;

- together with the Project Manager, ensures that internal surveillances of field and laboratory operations are planned, executed, and documented;

- prepares a brief surveillance summary for review and follow-up determinations by the Project Manager; and

- designates, in conjunction with the Project Manager and QA Specialist, which project activities, if any, require surveillances and develops a plan for implementing surveillances and self-assessments.

\subsubsection{Procedures}

\subsubsection{Surveillances}

The ER-QA Specialist will provide oversight of all activities as he/she deems necessary. When deemed appropriate by the Project Manager, the QA/QC Coordinator will conduct surveillances of GWOU field and laboratory operations. The QA adequacy of these operations will be assessed according to the GWOU sampling and analysis plans and applicable GWOU SOPs. Management will be informed of QA status through the receipt of surveillance reports.

Project documents will be regularly surveilled for completion and clarity. Table 8.3 presents the surveillance frequency of project documents for the GWOU project. A surveillance schedule will be issued upon implementation of this QAPjP. 


\subsubsection{Audits}

Audits shall be performed utilizing project program documents, highlighting the items to be verified, and/or checklist questions. Audit results shall be documented in a report and issued promptly, providing the status of items reviewed and verified. Copies of audit reports shall be provided to the Section Head, Program Director, and QA Specialist for use in management assessment. Audits of GWOU field and laboratory activities will be conducted by the QA Specialist and the Central ER audit staff. External analytical laboratories audits shall be conducted by the ER Program's Analytical Project Office. Audits conducted by regulatory agencies shall also be performed at the discretion of the regulatory agencies.

\subsubsection{Frequency of audits}

The QA Specialist may perform internal audits according to a schedule that coincides with appropriate activities on the project schedule and sampling plans. These internal audits will be utilized in independent self-assessment. Such scheduled audits may be supplemented by additional audits for one or more of the following reasons:

- when significant changes are made in the QA/QC plan;

- when it is necessary to verify that corrective action has been taken on a nonconformance reported in a previous audit; or

- when requested by the Project Manager.

All other audits will be performed according to the discretion of the auditing organization.

\subsubsection{Self assessments}

Individuals will regularly assess that portion of GWOU project-specific elements for which they are responsible. These evaluations are to be done by the individuals responsible for performing or overseeing the work. The purpose of these assessments is to measure the effectiveness of the project with respect to documented specifications or objectives, in addition to procedural compliance.

Management shall also evaluate that portion of GWOU project-specific elements for which they are responsible. The purpose of management assessments is: (1) to verify that the strategic objectives of the project are being met, and (2) to identify, correct, and prevent management problems which hinder the objectives of the project. All self assessments will be documented and it will be the responsibility of management to review the self assessments. 


\section{8-34}

\subsection{SOFTWARE QA}

\subsubsection{Responsibilities of the Project Manager}

The Project Manager, in conjunction with the Data Base Manager and relevant project team leaders, determines the project-related automated data processing (ADP) software (software, computer programs, documentation, etc.) and assigns the ADP software category.

\subsubsection{Procedures}

ADP software shall be categorized according to the following:

Category 1: ADP software the failure of which can cause failure of a project or endanger personnel.

Category 2: ADP software the failure of which will not cause the failure of a project or endanger personnel, but the failure of which will have a serious effect on project deliverables, production schedules, and/or cost.

Category 3: ADP software the failure of which will neither endanger personnel nor have a serious effect on project deliverables, production schedules, and/or cost.

Category 4: ADP software subject to NQA-1 or similar standards by sponsor directive. This includes software that will be licensed or used in a licensed facility.

Category 5: ADP software, often with a short shelf-life, developed or modified in the course of continuing research or development activities and that is an integral part of the research or development project.

Category 6: Purchased ADP software that is a standard off-the-shelf item of proven application. If the purchased software is to be modified, the modified software will be categorized as $1,2,3,4$, or 5 , as described above.

Energy Systems Policy Standards and Procedures, Quality Vol. 4-ESS-QA-19.0, Software Quality Assurance, will provide QA guidance for the GWOU regarding ADP software control.

\subsection{TECHNICAL AND PEER REVIEWS}

\subsubsection{Responsibilities}

\subsubsection{Project manager}

Responsibilities of the Project Manager include the following:

- determines the need for technical or peer reviews of project documents;

- appoints qualified technical or peer reviewers for project procedures and documents; and 


\section{8-35}

- incorporates reviewers comments, as the Project Manager deems necessary, into reviewed documents or procedures.

\subsubsection{QA/QC coordinator}

Responsibilities of the QA/QC Coordinator include the following:

- enters documents or procedures tracking information into the data base;

- assists the author in developing distribution lists for review and final copies;

- obtains all required approvals;

- confirms that all necessary approvals have been obtained and that all required changes have been made before author and Project Manager final approval; and

- submits copies of reviewers comments to the GWOU DMC.

\subsubsection{Procedures}

The ER Program's procedure, Preparation, Division Approval, and Clearance of Environmental Restoration Documents (Energy Systems 1991b), will be followed with regard to GWOU RI documents and procedures. 


\section{HEALTH AND SAFETY PLAN}

\subsection{INTRODUCTION}

Accomplishment of this policy requires that operations for the ORNL GWOU investigation at ORNL be guided by an overall plan and consistent proactive approach to safety and health issues. All site activities related to the groundwater investigative effort shall be performed in accordance with all applicable DOE Orders, applicable Occupational Safety and Health Administration Standards 29 CFR 1910 and 1926, and applicable EPA requirements and consensus standards.

\subsection{PROPOSED PLAN}

An ER Programmatic H\&S Plan, which will be comprehensive for all ER activities, is in the process of completion. This document will contain all the required elements of $29 C F R$ 1910.120 for operating within a hazardous waste site and will be specific for the ER efforts at ORNL. A Site Specific Hazard Evaluation Addendum (SSHEA), which will be specific for the groundwater investigation effort, will be written to coincide with the ER Programmatic H\&S Plan. The programmatic plan and the SSHEAs for the GWOU will implement the policies and establish criteria for the day-to-day investigation of the GWOU to prevent or minimize adverse impacts to the environment and site personnel.

\subsection{PLAN SCOPE}

This plan, and any addendum addressing safety and health, shall be available for on-site inspection and review by all subcontractors, Energy Systems, and DOE personnel and shall be easily accessible in the field for on-site personnel. During on-site activities, all personnel, including subcontractors and visitors, are expected to comply fully with the requirements of this plan and other DOE policies and procedures.

It is understood that it may not be possible to determine actual working hazards in advance of the work. Therefore, the plan must allow the opportunity to provide a range of protection based on site history and actual working conditions that could be encountered during on-site activities. Site-specific information will be presented in SSHEAs to the extent possible. 
$10-1$

\section{WASTE MANAGEMENT PLAN}

\subsection{INTRODUCTION}

The main purpose of this Waste Management Plan (WMP) for the Characterization Plan for the ORNL Area-Wide Groundwater Program is to identify wastes that are expected to be generated in connection with the surface water and groundwater investigations and/or monitoring to be conducted within the GWOU. The WMP also identifies (1) the methods by which investigation-derived wastes (IDWs) are to be disposed of and (2) the organization, responsibilities, and administrative controls that will be followed to ensure that wastes are properly handled and meet applicable Waste Acceptance Criteria (WAC).

\subsection{GENERAL SITE INFORMATION}

The work will be performed within the ORNL GWOU, which is bound by Pine Ridge to the north, Clinch River to the west, Copper Ridge to the south, and Bearden Creek to the east.

\subsection{GENERAL PROJECT DESCRIPTION}

The purpose of this project is to fill gaps in data regarding (1) the conceptual model for the GWOU, (2) exit pathways through which contaminants may be migrating from source areas to the GWOU boundaries, and (3) the nature and extent of groundwater contamination within the GWOU. Activities that may be conducted to obtain the data include but may not be limited to:

- installing monitoring devices at seep and/or spring locations;

- sampling surface water at seep and/or spring locations;

- installing new groundwater monitoring wells/piezometers and retrofitting existing wells with monitoring devices;

- sampling groundwater at new and existing monitoring wells;

- drilling core holes and collecting rock and soil samples;

- measuring groundwater depth at new and existing monitoring wells; and

- $\quad$ sampling surface water at stream locations.

\subsection{ORGANIZATIONAL STRUCTURE AND RESPONSIBILITY}

Specific waste management responsibilities will be listed in Project WMP Checklists to be developed for each specific GWOU investigation activity. The overall project will be accomplished with the joint resources of the following participants:

- DOE;

- Energy Systems [the Facility Manager (FM)];

- Ebasco Services, Inc. (the Architect-Engineer);

- M-K Ferguson (the Construction Manager); and

- the Service Contractor to the FM or Fixed Price Subcontractor to the Construction Manager. 
A brief summary of the participants' responsibilities and duties are presented below.

\subsubsection{DOE}

DOE will furnish overall program management and provide project support as required through the DOE/ORNL site office. Additionally, all coordination with EPA and TDEC will be the responsibility of the DOE.

\subsubsection{Energy Systems}

As the FM, Energy Systems is responsible for managing and operating ORNL under prime contract to the DOE. Waste management aspects of GWOU investigation activities will be conducted and supervised by the Waste Management and Remedial Action Division (WMRAD) of Energy Systems for the ORNL ER program. Various groups within Energy Systems have specific responsibilities related to waste management:

- The Energy Systems ER Program will provide general oversight and will assume ultimate responsibility for Energy Systems.

- Energy Systems Engineering will manage the project, prepare standard project documentation, incorporate data into as-built drawings, and prepare a Certified for Construction Package.

- Energy Systems ESD will provide technical oversight.

- Energy Systems Plant Support will provide health physics (HP), industrial hygiene (IH), and environmental compliance oversight as well as environmental compliance support.

- Energy Systems WMRAD will provide FM support, a Generator Certification Official, and waste operations support.

- The ORNL Groundwater Coordinator will coordinate resolution of groundwater issues and will provide data concerning groundwater monitoring.

- The ORNL Surface Water Coordinator will coordinate resolution of surface water issues and will provide data concerning surface water monitoring.

\subsubsection{Ebasco Services, Inc.}

Ebasco Services, Inc., the Architect-Engineer, will provide (1) all project-specific engineering services except those specifically assigned to Energy Systems, (2) input for updating the as-built well data base, and (3) specifications for the fixed price contracts.

\subsubsection{M-K Ferguson}

As the Construction Manager, M-K Ferguson will (1) develop project-specific Site H\&S Plans and Comprehensive Work Plans, (2) purchase HP and IH equipment if required, (3) construct Temporary Staging and Steam Cleaning Areas, (4) create specifications for and 
administer new construction contracts, and (5) be responsible for all segregation, packaging, labeling, and transportation of waste to Temporary Staging Areas. In addition to also providing overall HP and IH support coverage, a Site H\&S Officer, and trailers and other required temporary equipment, $\mathrm{M}-\mathrm{K}$ Ferguson will install the latter.

\subsubsection{Service Contractor or Fixed Price Subcontractors}

Field activities will be performed by Fixed Price Subcontractors such as Highland Drilling Company under an existing service contract with Energy Systems. Fixed Price Subcontractors will perform any field activities not assigned to M-K Ferguson or Energy Systems. In addition, the subcontractor(s) will provide all field personnel, construction equipment (drill rigs, pumps, sampling devices, etc.) and associated maintenance and will segregate, package, label, and transport wastes to Temporary Staging Areas as required.

\subsubsection{Generator Certification Official}

The Generator Certification Official must be an Energy Systems employee (unless the ORNL Laboratory Certification Official waives this requirement) who has successfully completed waste generator training for Solid Low Level Waste (SLLW), Satellite Accumulation Area training, the Generator Certification Official training module, 90-day Accumulation Area training (required for only the generation of hazardous waste), 40-hour Occupational Safety and Health Act (OSHA) training, and Radiation Worker training. The Generator Certification Official's specific responsibilities include:

- interfacing among GWOU projects, the ORNL Laboratory Certification Official, and the ORNL Waste Management Organization to address generator problems and waste certification requirements;

- initiating and completing the Generator Certification Official section of the form used to replace UCN-2822, "Request for Storage or Disposal of Radioactive Solid Waste or Special Materials" (Beginning on September 13, 1993, a uniform set of request-for-disposal forms will be used at all three of the ORR sites; identification numbers for these forms may be obtained through Waste Management Operations.);

- certifying by signature that the waste was packaged in accordance with the ORNL WAC and the ORNL SLLW certification program plan;

- ensuring that each containerized waste item is identified with a properly completed Waste Item Description form and bar code label and verifying that the container is sealed, is labeled, and meets all applicable criteria for transfer to Waste Management;

- certifying that the information on the Container Packing List [TX-5749 V1.0 (Document Management Center-CP)] (Fig. 10.1) is complete and accurate and that the waste was packaged by personnel with appropriate training;

- $\quad$ ensuring that the generation of wastes follows a documented, Waste Management-approved certification program; 


\section{$10-4$}

MARTIN MARIETTA

\section{CONTAINER PACKING LIST}

CONTAINER DENTIFICATION

\begin{tabular}{|l|l|l|l|l|}
\hline C1. Conteiner ID. No. & C. Container Type & C. Holding Site & CA. Holding Fucility & C5. Holding Rocar/Area \\
\hline
\end{tabular}

CONTAINER PACKING LIST

\begin{tabular}{|c|c|c|c|}
\hline 11. WasteItem II Namber & II. Waste Item Wo Number: & In Waste Item m Number: & 11. Waste Item m Number \\
\hline & & & \\
\hline & & & \\
\hline & & & \\
\hline & & & \\
\hline & & & \\
\hline & & & \\
\hline & & & \\
\hline & & & \\
\hline & & & \\
\hline & & & \\
\hline & & & \\
\hline & & & \\
\hline & & & \\
\hline & & & \\
\hline & & & \\
\hline & & & \\
\hline & & & \\
\hline & & & \\
\hline & & & \\
\hline & & & \\
\hline & & & \\
\hline & & & \\
\hline & & & \\
\hline & & & \\
\hline & & & \\
\hline & & & \\
\hline & & & \\
\hline
\end{tabular}

HANDLING INFORMATION

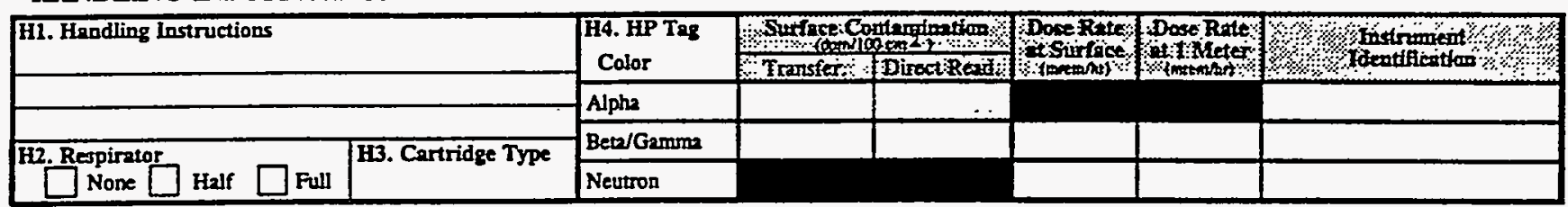

SIGNATURES and APPROVALS

\begin{tabular}{|l|l|l|l|l|l|}
\hline S1. Certification Oficer & Badge & Date Technician & Badge & Date \\
\hline S3. WhiO Oficer & Badge & Date & Sh. & Badge & Date \\
\hline
\end{tabular}


- periodically inspecting or auditing waste-generating and waste-managing activities to ensure that they meet the requirements of an approved certification program;

- ensuring that the Waste Pickup Request Form [TX-5753 V1.0 (Document Management Center-CP)] (Fig. 10.2) is completed properly and that Form UCN-1911, "Environmental Restoration Waste Management Program Total Generated Waste” (Fig. 10.3), is completed weekly;

- reviewing and approving nonconformance reports and trends, log-in sheets, training records, all project-specific.WMPs and WMP checklists, and facility-specific procedures for the proper packaging and handling of SLLW;

- ensuring that SLLW is properly classified, adequately characterized, and packaged in accordance with project-specific WMP criteria and applicable waste acceptance criteria; and

- making arrangements or having his/her designee make arrangements with Waste Management Operations for retrieval and transfer of waste packages to the designated. storage or treatment facility.

\subsubsection{Laboratory Certification Official}

The Laboratory Certification Official implements and manages the ORNL SLLW Certification Program. The Laboratory Certification Official's specific responsibilities include reviewing and approving project-specific WMPs and WMP checklists and approving all other applicable plans pertaining to the generation of transuranic wastes.

\subsubsection{Generator-Packager}

The generator-packager is the responsible Energy Systems organization, prime contractor, subcontractor, or person(s) that is physically generating the waste. The generator-packager's specific responsibilities include:

- properly containerizing, packaging, and segregating all waste generated as part of any specific project for the GWOU;

- completing and signing box $S 1$ on the new Waste Item Description Form, UCN-2109 (Fig. 10.4);

- completing new equivalent of UCN-13698 if hazardous waste is generated (Beginning on September 13, 1993, a uniform set of request-for-disposal forms will be used at all three ORR sites; identification numbers for these forms may be obtained through Waste Management Operations.);

- $\quad$ minimizing SLLW production;

- successfully completing current ORNL SLLW generator training and facility-specific training prior to generating SLLW; 


\section{MARTIN MARIETTA}

\section{WASTE PICKUP REQUEST}

\section{REQUEST}

P1. Requed Number

PS. Request Dite

P10. Comment
P2. Requestor's Name (print)

\begin{tabular}{|l|l|}
\hline P6. Pickop Site & P7. Prckup Facility \\
\hline
\end{tabular}

\section{P3. Badige No.}

P4. Requestor's Phooe No.

\begin{tabular}{|l|r|} 
Po. Plckup Roow/Ares & $\begin{array}{r}\text { P9. Uryency } \\
\square \text { Routine } \square \text { Urgex } \\
\square \text { Critical }\end{array}$
\end{tabular}

\section{PICINUP LIST}

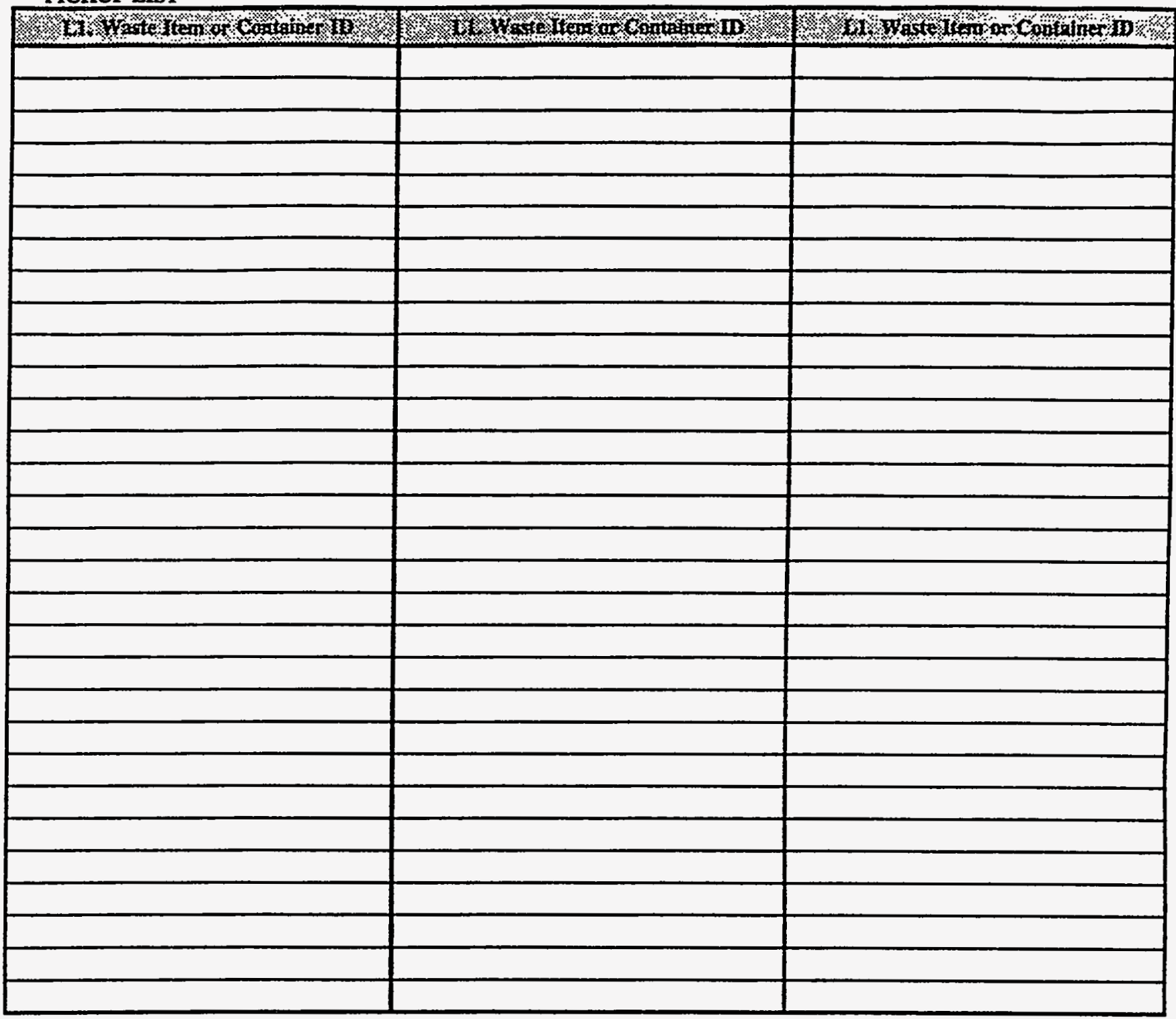

SIGNATURE and APPROVALS

\begin{tabular}{|l|l|l|}
\hline S1. Requestor & Badge & Date \\
\hline S3. WMO Oficer & Badge & Date \\
\hline
\end{tabular}

\begin{tabular}{|l|l|l|}
\hline S2. & Badge & Date \\
\hline S4. & Badge & Date \\
\hline
\end{tabular}

Fig. 10.2. Waste Pickup Request form (TX-5753 V1.0) 


\section{ENVIRONMENTAL RESTORATION WASTE MANAGEMENT PROGRAM TOTAL GENERATED WASTE}

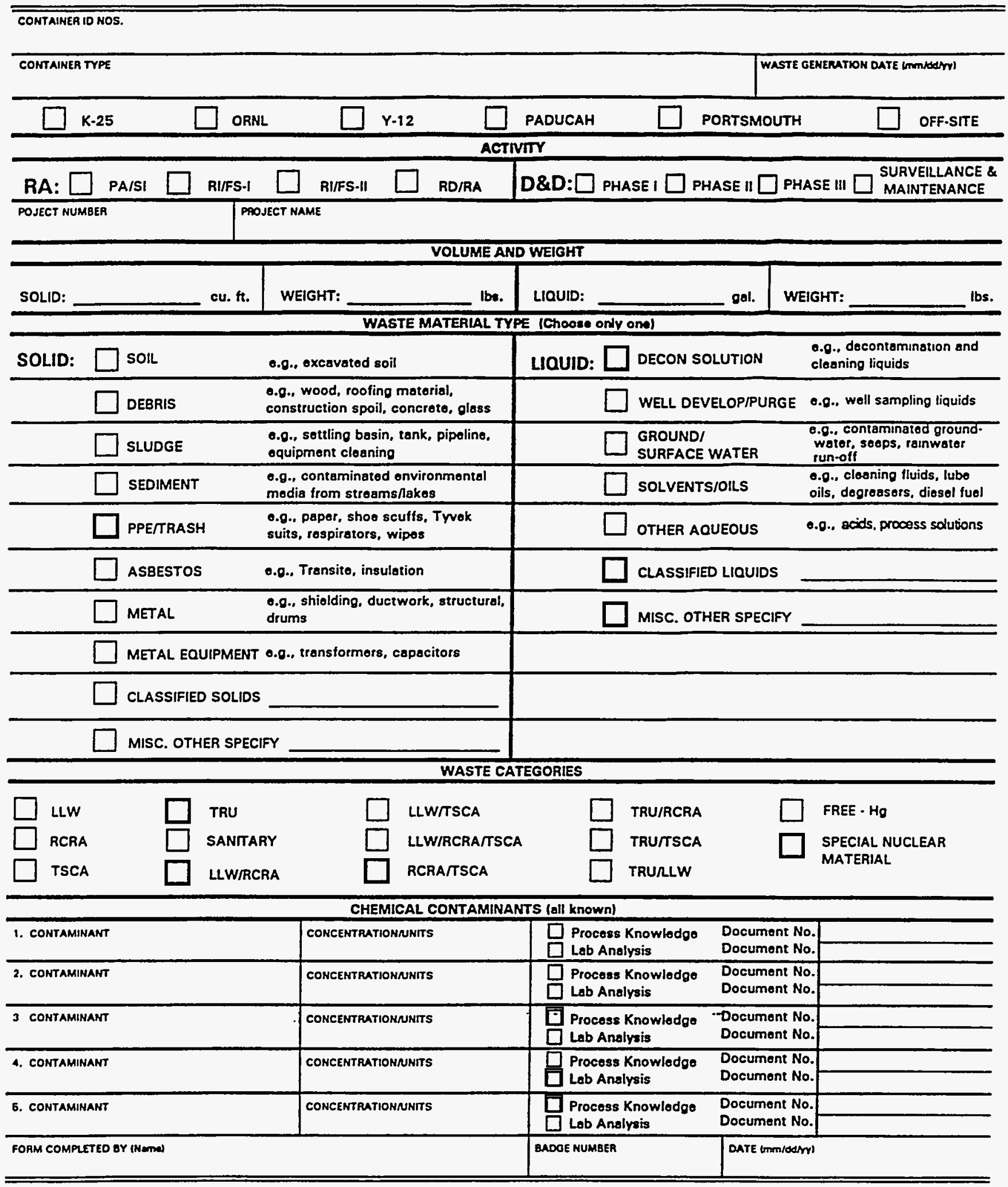

uCN.1881" Fig. 10.3. Environmental Restoration Waste Management Program Total Generated Waste form (UCN-1911). 
MATTIN MARIETTA

WASTE ITEM DESCRIPTION

WASTE ITEM TENTIFICATION

\begin{tabular}{|c|c|c|c|c|c|c|c|c|}
\hline \multicolumn{2}{|c|}{ 11. Waste Item ID Number } & \multicolumn{3}{|c|}{ 12. Geperator's Name (Print) } & 13. Badge No. & \multicolumn{2}{|c|}{\begin{tabular}{|l|l|} 
14. Generator's Phone No. I5. MS \\
\end{tabular}} & 16. Charge Nuraber/wo \\
\hline 17. Oripin Div. & 18. Oripin I & & 19. Origin Site & 110. Origin 1 & Faciltity & II1. Origin Rocem/A & & $\begin{array}{l}\text { I12. Radiological Area? } \\
\square \text { Yes } \square \text { No }\end{array}$ \\
\hline 113. Eat. Net Volume & \begin{tabular}{l|l} 
Jume & 114.1
\end{tabular} & 114. Units & \multicolumn{2}{|c|}{ I15. Est. Gross Weight } & I16. Units & \multicolumn{3}{|c|}{ (Reserved) } \\
\hline
\end{tabular}

CONTANNER INFORMATION ( 1 of ) If more than one attach Waste Container List (UCN-2109A)

\begin{tabular}{|c|c|c|c|c|c|c|c|c|}
\hline C1. Contsiner $\mathbf{D}$. No. & C2. Contpiner Type & C3. Holding Site & C4. Holding Facility & & \multicolumn{4}{|c|}{ C5. Holding Room/Ares } \\
\hline \multicolumn{9}{|c|}{ WASTE CATEGORY } \\
\hline W1. Process Stream DD & W2. Process Category & W3. Process Activity & \multicolumn{6}{|c|}{ W8. Waste Category (Check all) } \\
\hline \multirow{2}{*}{ W4. Physical Form } & W5. Material Type & W6. AWA N & & Yes & No & & Yes & No \\
\hline & & & Chemical & & & Biological & & \\
\hline \multirow{2}{*}{\multicolumn{3}{|c|}{ W7. Waste Description }} & Radiouctive & & & Accountable & & \\
\hline & & & Asbestos & & & Carcinogen & & \\
\hline \multirow{3}{*}{ 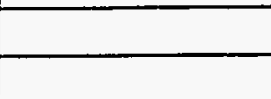 } & & & $\operatorname{San} / \operatorname{lnd}$ & & & Compactible & & \\
\hline & & & Const. Debris & & & Recyclable & & \\
\hline & & & Medical & & & Classified & & \\
\hline
\end{tabular}

CHEMICAL WASTE

\begin{tabular}{|c|c|c|c|c|c|c|}
\hline \begin{tabular}{|l|l} 
M1. RCRA? & M2. R \\
$\square$ Yes $\square$ No &
\end{tabular} & CRA 90-do & y Start I & $\begin{array}{l}\text { M13. PCB? } \\
\square \text { Yes } \square \text { No }\end{array}$ & M4. PCB Start Date & M5. PCB ConC. (PPM) & \\
\hline \multirow{2}{*}{\multicolumn{2}{|c|}{$\begin{array}{l}\text { M16. Determination Method } \\
\text { (Check ONE) } \\
\square \text { Process Knowledge } \square \text { Analysis } \\
\square \text { Reference }\end{array}$}} & \multicolumn{3}{|c|}{ M7. Determination Document Number(s) } & M8. Flosh P1. & M9. pH \\
\hline & & \multicolumn{5}{|c|}{ M10. EPA Waste Code Numbers } \\
\hline MIII. Substance $\mathbf{m}$ & \multicolumn{2}{|c|}{ M12.VoI:90. } & \multicolumn{4}{|c|}{ MI3:Substance Name $\cdots$} \\
\hline & & & & & & \\
\hline & & & & & & \\
\hline & & & & & & \\
\hline & & & & & & \\
\hline & & & & & & \\
\hline
\end{tabular}

RADIOACTIVE WASTE

RI. RAD Category (Check ONE)

$\square$ TRU $\square$ High-Level $\square$ Low-Level $\square$ Special $\square$ VLA $\square$ Contact $\square$ Remote

R4. Determinstion Method (Check ONE) R5. Determination Document Number(s)

$\square$ Process Knowledge $\square$ Reference R6. Chemical Form

(Reserved)

\begin{tabular}{|c|c|c|c|c|c|c|c|c|}
\hline R7/Isotope & R8. Est Qty & R9. Inits & XR7: Isotope: & R8. Bstoly & R9:Units & R7 Esotope & R8.:Bst. Qty & R9. Units \\
\hline & & & & & & & & \\
\hline & & & & & & & & \\
\hline & & & & & & & & \\
\hline
\end{tabular}

HANDLING INFORMATION

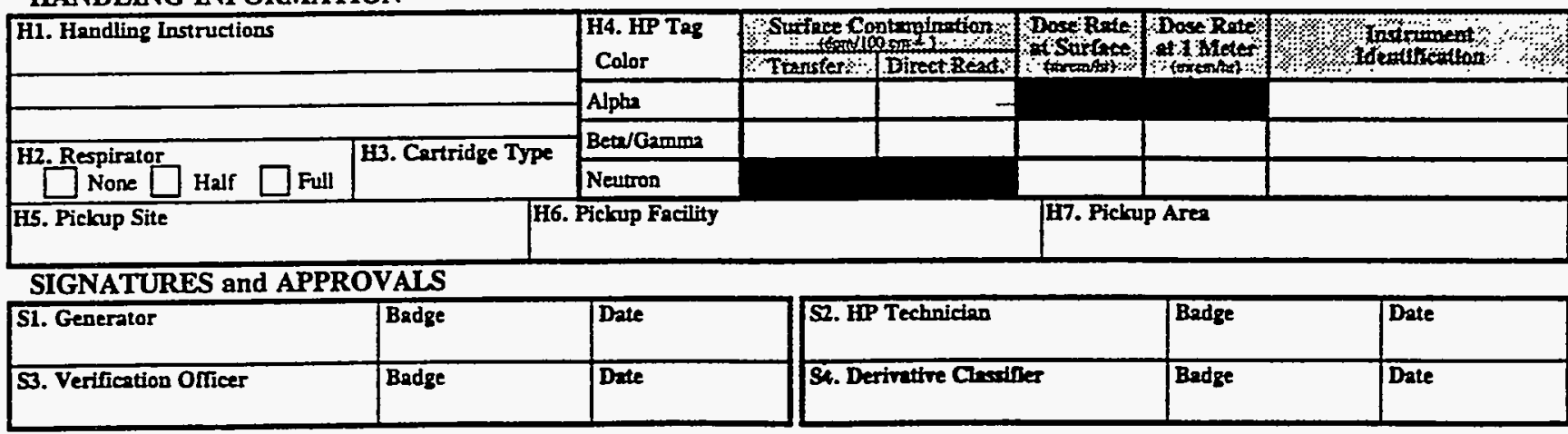

Fig. 10.4. Waste Item Description form (UCN-2109). 


\section{MARTIN MARIETTA}

\section{WASTE ITEM CONTINUATION}

\section{(Continuation Page 2 of 2 )}

\begin{tabular}{|c|c|c|}
\hline $\begin{array}{r}\text { Sequence } \\
\text { Number } \\
1\end{array}$ & \multicolumn{2}{|c|}{ Referenced from WD (UCN-2109) } \\
\cline { 2 - 3 } & I1. Waste Item ID Number & C1. Container D. No. \\
\hline
\end{tabular}

\section{CFEMICAL WASTE}

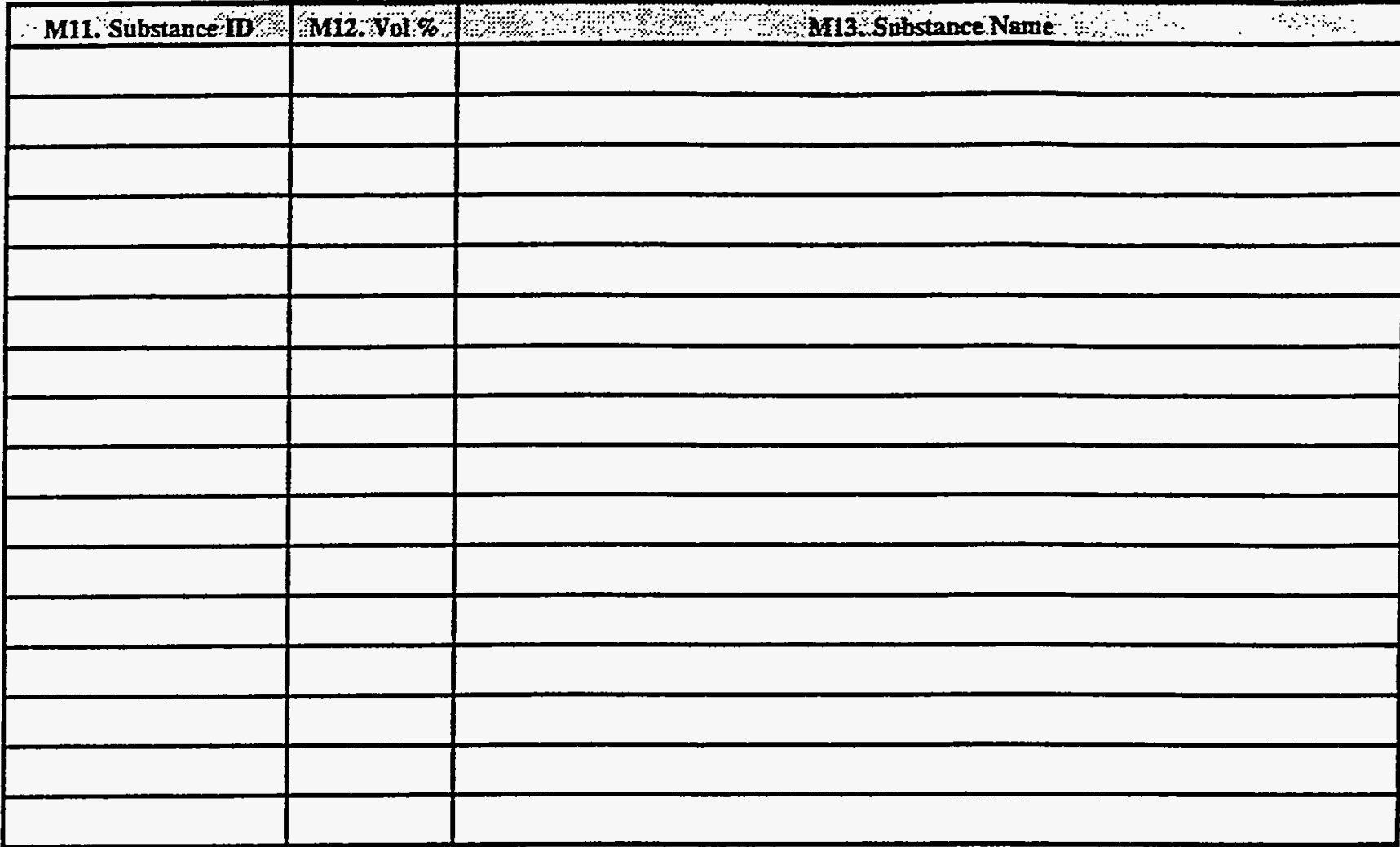

RADIOACTIVE WASTE

\begin{tabular}{|c|c|c|c|c|c|c|c|c|}
\hline R7 Isotope & R8.Est:QtY & R9: Units: & R7. S Sutope & IR8_Est_Qty & R9.Uñits & R7..Isotope: & R8. Ext. Oty & R9. Units \\
\hline & & & & & & & & \\
\hline & & & & & & & & \\
\hline & & & & & & & & \\
\hline
\end{tabular}

Fig. 10.4. (continued) 
- interfacing with the Generator Certification Official to ensure that any issues regarding SLLW characterization are promptly brought to the attention of the responsible individuals and that any new certification requirements or procedures are promptly instituted;

- providing as much data as possible for certification of SLLW and documenting the data on the required forms; and

- assisting the Generator Certification Official with the preparation of the new Waste Pickup Request and the Container Packing List.

\subsection{WASTE GENERATION}

\subsubsection{Waste-Generating Activities}

Types of waste that may be generated during the GWOU investigations include but are not limited to: development and purge water, soil cuttings, decontamination solutions, contaminated personal protective equipment (PPE), and miscellaneous contaminated and noncontaminated refuse.

During well installation and all other intrusive activities, HP personnel will use portable alpha and beta/gamma detectors to monitor for radioactivity in the material and samples removed. IH personnel will use portable ionization detectors to monitor for volatile organics in the material and samples removed. If screening indicates the presence of radioactive or volatile organics contamination above Category 2 limits as defined in Health, Safety, and Environmental Protection Procedure for Excavating Operations (ORNL/M-116/R1), or if previous analyses indicate the presence of RCRA materials, the waste generator shall ensure that appropriate analyses are performed on the generated waste.

The waste generators shall ensure the integrity of waste samples by following the chain-of-custody procedure described in Test Methods for Evaluating Solid Waste (EPA SW-846) (EPA 1986). This procedure includes the steps necessary to trace possession and handling of samples from the time of collection through analysis and final disposition.

Whenever possible, soil cuttings and/or rock material will be backfilled into drilled core holes if the cuttings and material are demonstrated to not pose a breathing or external radiation hazard. Any contaminated spoils excavated or generated during GWOU project-specific activities will be maintained in waste consolidation areas that are lined and covered with polyvinyl sheeting until disposal can be arranged. Contamination control will be maintained as defined in project-specific H\&S plans for GWOU activities.

\subsubsection{Possible Wastes Generated}

Table 10.1 summarizes types of wastes that may be generated during GWOU project-specific activities: noncontaminated, hazardous, mixed, low-level, TRU, and very low activity (VLA) solid wastes, and noncontaminated, process, nonradiological, and LLLW. Types of waste expected to be generated during the investigations may be further defined within project-specific WMPs developed for each activity. 


\section{$10-11$}

Table 10.1. Categories of solid and liquid wastes that may be generated during implementation of GWOU project-specific activities

\begin{tabular}{|c|c|}
\hline Waste categories & Components \\
\hline \multicolumn{2}{|r|}{ Solid } \\
\hline Noncontaminated & $\begin{array}{l}\text { Noncontaminated soil, rock, concrete, wood, cardboard, metal (e.g., } \\
\text { rebar, wire fence, steel scrap), and garbage refuse placed in a dumpster } \\
\text { (e.g., metal bands, plastics, paper products, silt, fence, wire scraps, } \\
\text { conduit scraps, glass, and personal protective equipment) }\end{array}$ \\
\hline Hazardous & $\begin{array}{l}\text { Nonradioactive but hazardous asbestos materials; and nonradioactive but } \\
\text { hazardous RCRA materials }\end{array}$ \\
\hline Mixed & $\begin{array}{l}\text { VLA, hazardous asbestos materials; VLA, hazardous RCRA materials; } \\
\text { radioactive, hazardous asbestos-contaminated materials; and radioactive, } \\
\text { hazardous RCRA materials }\end{array}$ \\
\hline Low level & $\begin{array}{l}\text { VLA, nonhazardous materials; radioactive, nonhazardous waste } \\
\text { ( }>200 \mathrm{mR} / \mathrm{hr} \text { ); radioactive, nonhazardous, noncompactible waste } \\
\text { ( }<10 \mathrm{mR} / \mathrm{hr}) ; \text { radioactive, nonhazardous, noncompactible waste } \\
\text { ( }>10,<200 \mathrm{mR} / \mathrm{hr} \text { ); radioactive, nonhazardous, compactible hard waste } \\
\text { ( }<10 \mathrm{mR} / \mathrm{hr}) ; \text { radioactive, nonhazardous, compactible hard waste } \\
\text { ( }>10,<200 \mathrm{mR} / \mathrm{hr} \text { ); radioactive, nonhazardous, compactible soft waste } \\
\text { ( }<10 \mathrm{mR} / \mathrm{hr}) ; \text { radioactive, nonhazardous, compactible soft waste } \\
\text { ( }>10,<200 \mathrm{mR} / \mathrm{hr} \text { ) }\end{array}$ \\
\hline TRU & $\begin{array}{l}\text { Radioactive, TRU-contaminated, nonhazardous waste; and radioactive, } \\
\text { TRU-contaminated, hazardous waste }\end{array}$ \\
\hline \multicolumn{2}{|r|}{ Liquid } \\
\hline \multicolumn{2}{|l|}{ Noncontaminated } \\
\hline \multicolumn{2}{|l|}{ Process } \\
\hline \multicolumn{2}{|l|}{ Nonradiological } \\
\hline Low level & \\
\hline
\end{tabular}


$10-12$

\subsection{WASTE PACKAGING AND HANDLING}

\subsubsection{Generating}

DOE and Energy Systems control programs that govern engineering, construction, and waste disposal activities will be implemented for all GWOU project-specific activities to ensure compliance with applicable state and federal regulatory requirements (including RCRA, CERCLA, SARA, OSHA, and Department of Transportation regulations) for handling and controlling of radioactive and hazardous wastes. The control programs include sampling and analysis, waste certification, hazardous-waste and radiation worker training, environmental compliance, quality assurance, environmental health and safety, health physics, and configuration management.

\subsubsection{Segregating}

HP personnel will use portable alpha and beta/gamma detectors to monitor for radioactivity in material and/or samples removed during field activities. IH personnel will use portable ionization detectors to monitor for volatile organics in material and/or samples removed during these activities. The results of this monitoring in combination with process knowledge and data generated from GWOU project-specific activity samples will be used to properly segregate all waste and determine the need for a Satellite or 90-day Accumulation Area.

\subsubsection{Packaging and Handling}

Wastes will be packaged under the guidance of the Generator Certification Official. The individual signing as waste generator shall be present during all waste packaging activities. SLLW will be packaged to comply with the WAC established for the GWOU project-specific activity being performed. For any SLLW or VLA waste, the Generator Certification Official and the generator shall complete the Waste Item Description form (UCN-2109), Container Packing List (TX-5749 V1.0), and the Waste Pickup Request (TX-5753 V1.0). The Generator Certification Official shall ensure that HP Form UCN-2785, "Radiation Tag," and a bar code label are attached to the waste container and shall request retrieval of the package after acceptance by Radioactive Solid Waste Operations.

Bar codes for noncompactible waste items shall be centered on the longest side of the waste item or on the side that has the greatest surface area, excluding the bottom. If a waste item is so small or uneven that the required bar code cannot be satisfactorily affixed after packaging, the bar code shall be affixed to a tag and the tag durably attached to the waste item. The tag must be attached such that it will not become dislodged or detached during normal handling, transportation, storage, and disposal operations. For remote-handled waste items (having surface dose rates greater than $1 \mathrm{R} / \mathrm{hr}$ ), the bar code shall be supplied with but not permanently attached to the waste package documentation. The waste item bar code for compactible waste items shall be placed on the lower-most right hand corner of the outer (second) clear polyethylene compactible waste bag.

Categories 1 and 2 soil (defined in ORNL/M-116/R1) will be stockpiled at a temporary storage area for reuse (soil with activity at background levels may be sent to the Y-12 Recontour Site). Soil or material that is stockpiled for reuse or relocation will be placed in a diked area 
lined with polyvinyl sheeting, and covered with this type sheeting. All waste soil will be handled according to ORNL/M-116/R1 unless the soil is deemed to be IDW.

Waste generated from environmental monitoring activities associated with the GWOU investigations may be considered to be IDW and may be handled according to the Management of Investigation-Derived Waste During Site Investigations (EPA/540/G-91/009). The IDWmanagement strategy is aimed at minimizing waste, particulariy in areas of minimal contamination. The general options for managing IDW are collection and either immediate disposal or some type of interim management. Interim management may include storage or other temporary measures.

Waste liquids will be collected in 55-gal drums or tanks, which will be monitored for radioactivity, volatile organics, and $\mathrm{pH}$. If a representative sample of the liquid waste has not been characterized, the generator will ensure that appropriate analyses (required by the ORNL Liquid Waste Treatment Systems WAC, WM-WMCO-201) are performed. Following analysis, the liquid waste will be released on site, or Waste Management Operations will transfer the liquid to a tanker truck and transport it to the Non-Radiological Wastewater Treatment Plant (NRWTP) or the PWTP. If any liquid waste meets RCRA criteria (as defined in 40 CFR 260 series), a Satellite or 90-day Accumulation Area will be established until control of the liquid is transferred to the Hazardous Waste Operations Group or the Liquid and Gaseous Waste Operations Group (the NRWTP and PWTP can accept low concentrations of some RCRA liquids as specified by WM-WMCO-201).

Following revision of the current National Pollutant Discharge Elimination System (NPDES) permit, regulations may permit disposal of noncontaminated purge water in nearby streams or water bodies. This option will be considered only following approval of the new NPDES permit. In addition, release criteria, release location, and permitting requirements will be evaluated following approval.

\subsubsection{Equipment Decontamination}

All drill rigs, nondedicated pumps, tools, and related sampling devices and equipment will be screened for radioactive contamination and volatile organics. Contaminated equipment and devices will be decontaminated as directed in project-specific H\&S plans for GWOU activities. All personnel will be required to read and sign the Criteria for the Well Drilling Steam Cleaning Area at ORNL before using this area for decontamination of equipment and devices. No contaminated equipment will be allowed in the steam cleaning area.

\subsection{WASTE MINIMIZATION}

All efforts will be made to minimize waste generation during the implementation of GWOU project-specific activities. At a minimum, the following actions will be taken.

- Site delivery of materials for well/piezometer installation activities will be properly planned and executed to minimize the delivery of excess materials. 
- As little water as possible will be used in decontamination operations. Whenever possible, water will be processed by the NRWTP or the PWTP, or released on site, instead of being disposed of in the LLLW System.

- Subcontractors will be required to remove all excess delivered materials from work sites.

- All generated wastes will be segregated to minimize the disposal of nonrecyclable, noncontaminated, and nonhazardous wastes.

- As appropriate, the IDW strategy will be implemented.

\subsection{CONTROL PROGRAMS}

\subsubsection{HP/IH Surveys}

HP and IH personnel will perform surveillances during GWOU project-specific activities to identify radioactive and volatile organic contamination. The Generator Certification Official, as designated by WMRAD, will be responsible for determining whether additional testing or sampling is required by Energy Systems. Excavated materials that cannot be placed either back into the boring from which they were generated or in the area of concern will be containerized or stockpiled. Excavated materials will be properly handled and stockpiled on polyvinyl sheeting in temporary storage areas to prevent the spread or loss of any material containing radioactive or organic contamination.

\subsubsection{Controls}

HP personnel will monitor field activities to ensure that wastes are handled in a manner that will prevent the spreading, mixing, or loss of any solid or liquid waste suspected of containing organic or radioactive contamination. IH personnel will monitor wastes for volatile organics.

\subsubsection{Personnel Exposure Control}

HP and IH personnel will perform surveillances during GWOU project-specific activities to identify radioactive contamination and organic vapors. If radioactively contaminated areas are encountered during the field activities, standard radiation protection measures defined in the project-specific H\&S plan for GWOU investigations will be followed to ensure worker safety. Work exposure times and other conditions will be established by the Health Physicist in charge. The Construction Manager will ensure that worker exposure is as low as reasonably achievable during all work in contaminated or radiological areas.

\subsubsection{Training}

Personnel involved in on-site activities will be required to have training and pre-employment medical assessments as required in the project-specific H\&S plan for the GWOU activity being performed. These personnel must also participate in the Hazardous Waste Operations Group Medical Surveillance Program and will be required to have hazardous-waste and radiation worker training. Personnel responsible for completing and signing waste tracking and disposal forms will 
be required to have 40-h SARA/OSHA and SLLW generator training, and must be present during waste packaging. All individuals packaging SLLW will be required to have SLLW generator training. The Generator Certification Official and the generator will be required to have the training described in Sects. 10.4.6 and 10.4.8, respectively, of this WMP. If hazardous waste is encountered, the generator must also have Waste Generator Training for Satellite and/or 90-day Accumulation Areas. Personnel engaged in excavation operations shall be trained in accordance with the requirements defined in ORNL/M-116/R1.

\subsubsection{QA Requirements}

As the FM, Energy Systems will track participant activities and consolidate records and reports to ensure that GWOU project-specific QA activities are performed and that required documentation is completed. Surveillances will be conducted as defined in the GWOU QAPjP.

\subsubsection{Spill Control}

If any spill of liquid waste occurs, the first responder will use a spill-control kit to contain it. Other requirements and procedures regarding the control of liquid-waste spills will be defined in project-specific WMPs developed for the GWOU activities.

\subsection{TEMPORARY STORAGE OF WASTE}

Polyvinyl sheeting will be used to isolate radioactively contaminated soil and solid material from the environment until the soil and material are properly packaged for disposal. Potentially contaminated wastewater will be placed in drums and staged at the work site in the temporary storage area until analytical results are available. When characterization is complete, waste water will be transported to the NRWTP or the PWTP or will be released on site. Waste water that does not meet the requirements of WM-WMCO-201 may also be stored by the Hazardous Waste Operations Group. 


\section{DATA MANAGEMENT PLAN}

\subsection{INTRODUCTION}

Because the DOE ORR is on EPA's National Priorities List, Energy Systems ER Program staff must abide by the regulatory requirements of CERCLA in performing work during the characterization of ORR sites. They must also comply with data-management and data-access requirements for environmental data as specified in the FFA and the Tennessee Oversight Agreement. During site and remedial investigations performed under CERCLA, Energy Systems or its subcontractors collect environmental samples, have the samples analyzed at analytical laboratories, and receive the resulting data. These data are used to evaluate whether the site under study is contaminated and, if so, to determine the nature and extent of contamination and to evaluate whether the contamination poses a threat to human health and the environment. The data must support any subsequent remedial selection decisions and will be an essential element in legal or cost-recovery actions.

To meet current regulations, the ERP must maintain a complete, traceable flow of information that is easily accessed. To fulfill the requirements of the FFA and Tennessee Oversight Agreement, DOE-ORO assigned Energy Systems the task of implementing a centralized data base, the Oak Ridge Environmental Information System (OREIS) (ES/ER/TM-39/RI) (Energy Systems 1993b), to consolidate all environmental data collected on the ORR. In addition, the ER Program staff maintain their own project data bases that have data structures compatible to those of OREIS. The project-specific data are copied and transferred to central OREIS after final data validation. Only electronic information that is required by the regulators and that meets central OREIS standards will be transferred.

\subsection{PURPOSE AND GOAL}

The primary purpose of data management is to support the environmental restoration and monitoring process by providing a system for generating technically and legally defensible data. To meet current regulatory requirements for environmental restoration, a complete audit trail of the information flow must be established. Each step in the data management process (planning, collection, handling and control, analysis, and storage) must be adequately planned, executed, and documented. To achieve these goals, qualified professional personnel must work together as a data management team. The primary goals of the data management team are to:

- provide data that will support environmental remediation decision-making and planning;

- ensure the accessibility of environmental data for regulatory. reports, environmental analyses, risk assessments, and other environmental needs;

- $\quad$ provide data that are complete, consistent, and fully qualified;

- facilitate the efficient access, reporting, analysis, display, and export of the data; 
- minimize the uncertainties associated with the data, data products, and interpretation of results; and

- ensure that data are adequately documented with descriptive information (metadata) to ensure the technical defensibility and legal admissibility of the data.

\subsection{SCOPE}

This data management plan (DMP) is targeted at the project level and describes activities to be performed for all remediation projects. This plan presents a four-phase, multi-step process model developed to achieve the outlined goals (Fig. 11.1). The plan describes a comprehensive methodology for acquiring and managing environmental data from the planning stage through presentation of data in reports, tables, maps, and graphs to final storage and archival. It expands the traditional concept of data management and integrates into the process model all activities relevant to ensuring technically sound and legally defensible data. This methodology requires that the following components be integrated:

1. The direction and approach of Data Management Plan for the Environmental Restoration Division, ES/ER/TM-88 Draft (Energy Systems 1993c) as established by the ER Program. This high level document provides the basis of data management for all ER projects.

2. A team of data management professionals consisting of program and project managers, statisticians, data managers, data-base administrators, data coordinators, programmer analysts, data-entry clerks, validators, QA specialists, spatial analysts, and records managers. The functional requirements of team members are defined in Sect. 11.4 .

3. The steps in the process model (Fig. 11.1) for planning, field preparation and sampling, data verification and validation, and data analysis and presentation. These steps are described in Sects. 11.5.1, 11.5.2, 11.5.3, and 11.5.4.

4. A set of written data management, validation, and analysis procedures. The steps and procedures are presented in Table 11.1 and correlate to the procedures in the ER Program data management plan.

5. A standardized data base structure to manage project characterization information. This structure should interface with the centralized data repository, OREIS.

\subsection{FUNCTIONAL RESPONSIBILITIES}

The functional responsibilities of project staff members are described below; the responsibilities are identified by titles but are not individual staff positions. 
Phase 1

11-3

PLANNING

- Acquisition of Currently Available Relevant Data

- Document Maintenance

- Planning Data Management Activities
Phase 2

FIELD PREPARATION AND SAMPLING

- Analytical Laboratory Interface

- Populating the Site Project Data Base with Sampling \& Analysis Plan Data

- Collection of Field Dati

- Data Entry of Field Information

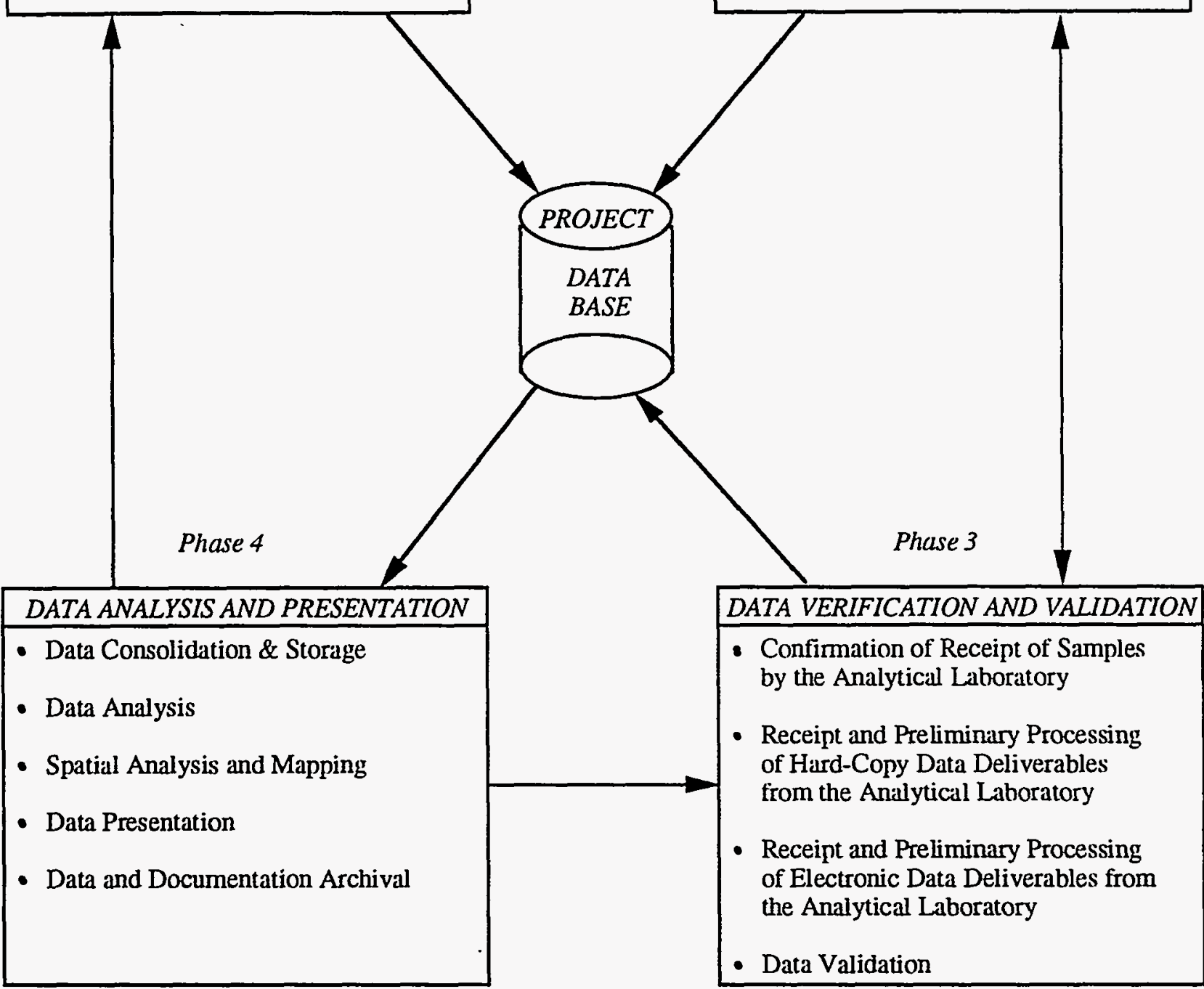

Fig. 11.1. Data management process model. 
$11-4$

Table 11.1 Mapping of data management activities to proposed set of data management procedures and suggested interim guidance documents

\begin{tabular}{|c|c|c|c|}
\hline Data management activities & $\begin{array}{l}\text { DMP } \\
\text { section }\end{array}$ & $\begin{array}{l}\text { Data management procedure } \\
\text { interim guidance }\end{array}$ & Status \\
\hline \multirow[t]{3}{*}{$\begin{array}{l}\text { Step 1: Acquisition of currently } \\
\text { available relevant data }\end{array}$} & \multirow[t]{3}{*}{ 11.5.1 } & $\begin{array}{l}\text { Identification and Acquisition of } \\
\text { Currently Available Relevant Data and } \\
\text { Documents }\end{array}$ & Proposed \\
\hline & & $\begin{array}{l}\text { Description and Assessment of Historical } \\
\text { Data }\end{array}$ & Proposed \\
\hline & & $\begin{array}{l}\text { Data Entry and Verification of } \\
\text { Environmental Data }\end{array}$ & Proposed \\
\hline \multirow[t]{5}{*}{ Step 2: Document maintenance } & \multirow[t]{5}{*}{ 11.5.1 } & $\begin{array}{l}\text { Receiving, Processing, and Maintaining } \\
\text { Environmental Restoration Program } \\
\text { Records ER/C-P1110 }\end{array}$ & Available \\
\hline & & $\begin{array}{l}\text { Document Classification of ER Program } \\
\text { Records }\end{array}$ & Proposed \\
\hline & & $\begin{array}{l}\text { Identifying and Acquiring Documents for } \\
\text { ER Project Files }\end{array}$ & Proposed \\
\hline & & Document Indexing Scheme & Proposed \\
\hline & & EPA $1990 b$ & Available \\
\hline \multirow[t]{5}{*}{ Step 3: Project planning } & \multirow[t]{5}{*}{11.5 .1} & $\begin{array}{l}\text { Description and Assessment of Historical } \\
\text { Data }\end{array}$ & Proposed \\
\hline & & $\begin{array}{l}\text { Development of Data Quality Objectives } \\
\text { ER/C-P2305 }\end{array}$ & Available \\
\hline & & $\begin{array}{l}\text { Development of ER Program Standard } \\
\text { Forms }\end{array}$ & Proposed \\
\hline & & $\begin{array}{l}\text { Environmental Restoration Quality } \\
\text { Program Plan ES/ER/TM-4/R3 } 3^{a}\end{array}$ & Available \\
\hline & & EPA 1980 & Available \\
\hline \multirow[t]{4}{*}{ Step 4: Analytical laboratory interface } & \multirow[t]{4}{*}{11.5 .2} & $\begin{array}{l}\text { Procurement of Analytical Services } \\
\text { ER/K-I2001 }\end{array}$ & Available \\
\hline & & $\begin{array}{l}\text { Manual Chain-of-Custody Procedures } \\
\text { ESP-500 }\end{array}$ & Available \\
\hline & & $\begin{array}{l}\text { Field Data Inventory and Validation } \\
\text { ER/CR-50P2020/R0 (IAD) }\end{array}$ & Available \\
\hline & & $\begin{array}{l}\text { Comprehensive Data Validation for the } \\
\text { Waste Area Grouping } 2 \text { Project } \\
\text { ER-WAG2-SOP-2009/R0 }\end{array}$ & Available \\
\hline
\end{tabular}


Table 11.1 (continued)

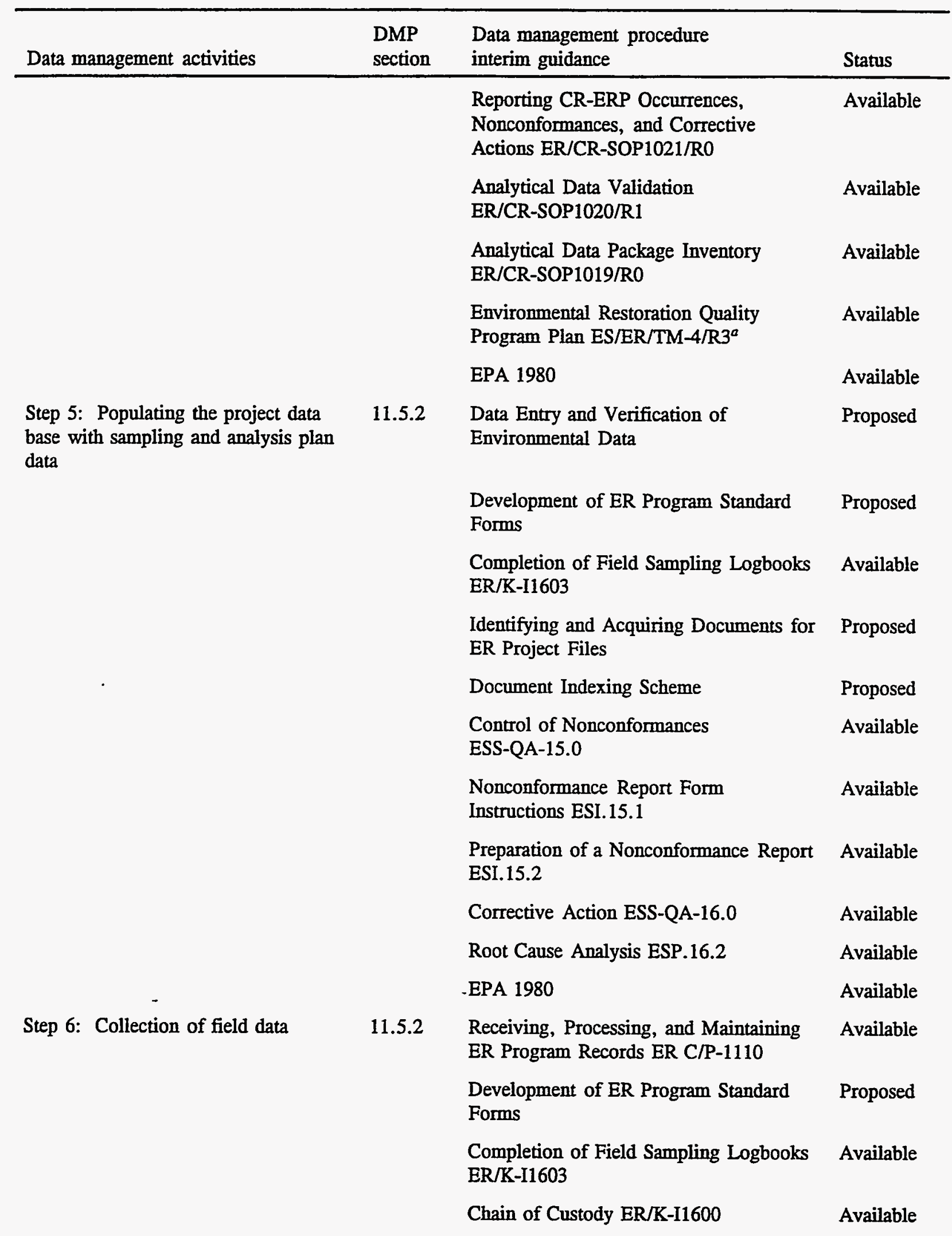


11-6

Table 11.1 (continued)

\begin{tabular}{|c|c|c|c|}
\hline Data management activities & $\begin{array}{l}\text { DMP } \\
\text { section }\end{array}$ & $\begin{array}{l}\text { Data management procedure } \\
\text { interim guidance }\end{array}$ & Status \\
\hline & & $\begin{array}{l}\text { Identifying and Acquiring Documents for } \\
\text { ER Project Files }\end{array}$ & Proposed \\
\hline & & $\begin{array}{l}\text { Control of Nonconformances } \\
\text { ESS-QA-15.0 }\end{array}$ & Available \\
\hline & & $\begin{array}{l}\text { Preparation of a Nonconformance Report } \\
\text { ESI.15.2 }\end{array}$ & Available \\
\hline & & $\begin{array}{l}\text { Policy Standards and Procedures Manual, } \\
\text { Energy Systems ESS-ENV.1 }\end{array}$ & Available \\
\hline & & EPA 1980 & Available \\
\hline & & EPA $1987 b$ & Available \\
\hline \multirow[t]{4}{*}{$\begin{array}{l}\text { Step 7: Data entry of field } \\
\text { information }\end{array}$} & 11.5 .2 & $\begin{array}{l}\text { Receiving, Processing, and Maintaining } \\
\text { ER Program Records ER C/P-1110 }\end{array}$ & Available \\
\hline & & $\begin{array}{l}\text { Handling and Control of Sampling } \\
\text { Documentation ER/K-I1607 }\end{array}$ & Available \\
\hline & & Field Data Validation ER/K-I1604 & Available \\
\hline & & Document Indexing Scheme & Proposed \\
\hline \multirow[t]{9}{*}{$\begin{array}{l}\text { Step 8: Confirmation of receipt of } \\
\text { samples by the analytical laboratory }\end{array}$} & 11.5 .3 & $\begin{array}{l}\text { Procurement of Analytical Services } \\
\text { ER/K-I2001 }\end{array}$ & Available \\
\hline & & $\begin{array}{l}\text { Completion of Field Sampling Logbooks } \\
\text { ER/K-I1603 }\end{array}$ & Available \\
\hline & & Chain of Custody ER K/I-1600 & Available \\
\hline & & $\begin{array}{l}\text { Handling and Control of Sampling } \\
\text { Documentation ER/K-I1607 }\end{array}$ & Available \\
\hline & & $\begin{array}{l}\text { Control of Nonconformances } \\
\text { ESS-QA-15.0 }\end{array}$ & Available \\
\hline & & $\begin{array}{l}\text { Preparation of a Nonconformance Report } \\
\text { ESS. } 15.2\end{array}$ & Available \\
\hline & & $\begin{array}{l}\text { Environmental Restoration Quality } \\
\text { Program Plan ES/ER/TM-4/R3 }\end{array}$ & Available \\
\hline & & $\begin{array}{l}\text { Policy Standards and Procedures Manual, } \\
\text { Energy Systems ESS-ENV.1 }\end{array}$ & Available \\
\hline & & EPA 1980 & Available \\
\hline $\begin{array}{l}\text { Step 9: Receipt and preliminary } \\
\text { processing of hard-copy data } \\
\text { deliverables from the analytical } \\
\text { laboratory }\end{array}$ & 11.5 .3 & $\begin{array}{l}\text { Data Entry and Verification of } \\
\text { Environmental Data }\end{array}$ & Proposed \\
\hline
\end{tabular}


Table 11.1 (continued)

\begin{tabular}{|c|c|c|c|}
\hline Data management activities & $\begin{array}{l}\text { DMP } \\
\text { section }\end{array}$ & $\begin{array}{l}\text { Data management procedure } \\
\text { interim guidance }\end{array}$ & Status \\
\hline & & Field Data Validation ER/K-I1604 & Available \\
\hline & & $\begin{array}{l}\text { Analytical Data Verification } \\
\text { ER/K-I1602 }\end{array}$ & Available \\
\hline & & $\begin{array}{l}\text { Nonconformance Reports for Analytical } \\
\text { Data Packages }\end{array}$ & Proposed \\
\hline & & $\begin{array}{l}\text { Evaluation of Field and Analytical Data } \\
\text { ER/K-12004 }\end{array}$ & Available \\
\hline & & Analytical Data Validation ER/K-I1606 & Available \\
\hline & & $\begin{array}{l}\text { Control of Nonconformances } \\
\text { ESS-QA-15.0 }\end{array}$ & Available \\
\hline & & $\begin{array}{l}\text { Preparation of a Nonconformance Report } \\
\text { ESI.15.2 }\end{array}$ & Available \\
\hline & & $\begin{array}{l}\text { Policy Standards and Procedures Manual, } \\
\text { Energy Systems ESS-ENV.1 }\end{array}$ & Available \\
\hline & & EPA 1980 & Available \\
\hline & & EPA 1987a & Available \\
\hline \multirow{11}{*}{$\begin{array}{l}\text { Step 10: Receipt and preliminary } \\
\text { processing of electronic data } \\
\text { deliverables from the analytical } \\
\text { laboratory }\end{array}$} & 11.5 .3 & $\begin{array}{l}\text { Analytical Data Verification } \\
\text { ER/K-I1602 }\end{array}$ & Available \\
\hline & & ANSI/ASME 1989 & \\
\hline & & $\begin{array}{l}\text { Nonconformance Reports for Analytical } \\
\text { Data Packages }\end{array}$ & Proposed \\
\hline & & $\begin{array}{l}\text { Evaluation of Field and Analytical Data } \\
\text { ER/K-I2004 }\end{array}$ & Available \\
\hline & & Analytical Data Validation ER/K-I1606 & Available \\
\hline & & $\begin{array}{l}\text { Control of Nonconformances } \\
\text { ESS-QA-15.0 }\end{array}$ & Available \\
\hline & & $\begin{array}{l}\text { Preparation of a Nonconformance Report } \\
\text { ESI. } 15.2\end{array}$ & Available \\
\hline & & $\begin{array}{l}\text { Policy and Standards Manual, Energy } \\
\text { Systems ESS-ENV.1 }\end{array}$ & Available \\
\hline & & EPA 1980 & Available \\
\hline & & EPA $1987 a$ & Available \\
\hline & & EPA 1990a & \\
\hline
\end{tabular}


Table 11.1 (continued)

\begin{tabular}{|c|c|c|c|}
\hline Data management activities & $\begin{array}{l}\text { DMP } \\
\text { section }\end{array}$ & $\begin{array}{l}\text { Data management procedure } \\
\text { interim guidance }\end{array}$ & Status \\
\hline \multirow[t]{12}{*}{ Step 11: Data validation } & 11.5.3 & $\begin{array}{l}\text { Data Entry and Verification of } \\
\text { Environmental Data }\end{array}$ & Proposed \\
\hline & & $\begin{array}{l}\text { Comprehensive Data Validation for the } \\
\text { WAG } 2 \text { Project ER-WAG2-SOP-2009/R0 }\end{array}$ & Available \\
\hline & & Field Data Validation ER/K-I1604 & Available \\
\hline & & Analytical Data Verification ER/K-I1602 & Available \\
\hline & & $\begin{array}{l}\text { Nonconformance Reports for Analytical } \\
\text { Data Packages }\end{array}$ & Proposed \\
\hline & & $\begin{array}{l}\text { Evaluation of Field and Analytical Data } \\
\text { ER/K-12004 }\end{array}$ & Available \\
\hline & & $\begin{array}{l}\text { Standardization of Spatial Data } \\
\text { ES/ER/TM-56 }\end{array}$ & Draft \\
\hline & & Analytical Data Validation ER/K-I1606 & Available \\
\hline & & EPA 1980 & Available \\
\hline & & EPA $1987 a$ & Available \\
\hline & & EPA $1988 a$ & \\
\hline & & EPA $1988 b$ & \\
\hline \multirow[t]{5}{*}{$\begin{array}{l}\text { Step 12: Data consolidation and } \\
\text { storage }\end{array}$} & 11.5 .4 & $\begin{array}{l}\text { Receiving, Processing, and Maintaining } \\
\text { ER Program Records ER/C-P1110 }\end{array}$ & Available \\
\hline & & $\begin{array}{l}\text { Identifying and Acquiring Documents for } \\
\text { ER Project Files }\end{array}$ & Proposed \\
\hline & & ADP Security Handbook & Available \\
\hline & & $\begin{array}{l}\text { Technical Software Configuration } \\
\text { Management (TSCM) Handbook }\end{array}$ & Available \\
\hline & & Operating Security (OPSEC) Plan & Available \\
\hline \multirow[t]{5}{*}{ Step 13: Data analysis } & 11.5.4 & Field Data Validation ER/K-I1604 & Available \\
\hline & & - Analytical-Data-Verification ER/K-I1602 & Available \\
\hline & & $\begin{array}{l}\text { Evaluation of Field and Analytical Data } \\
\text { ER/K-I2004 }\end{array}$ & Available \\
\hline & & Analytical Data Validation ER/K-I1606 & Available \\
\hline & & $\begin{array}{l}\text { Environmental Restoration Quality } \\
\text { Program Plan ES/ER/EM-4/R3 }\end{array}$ & Available \\
\hline
\end{tabular}


$11-9$

Table 11.1 (continued)

\begin{tabular}{|c|c|c|c|}
\hline Data management activities & $\begin{array}{l}\text { DMP } \\
\text { section }\end{array}$ & $\begin{array}{l}\text { Data management procedure } \\
\text { interim guidance }\end{array}$ & Status \\
\hline & & EPA 1980 & Available \\
\hline & & DOE 1987a & \\
\hline & & DOE 1987b & \\
\hline \multirow[t]{4}{*}{ Step 14: Spatial analysis and mapping } & 11.5.4 & Standardization of Spatial Data & Proposed \\
\hline & & $\begin{array}{l}\text { Development and Maintenance of the } \\
\text { Spatial Data Base }\end{array}$ & Proposed \\
\hline & & $\begin{array}{l}\text { Environmental Restoration Quality } \\
\text { Program Plan ES/ER/TM-4/R3 }\end{array}$ & Available \\
\hline & & EPA $1987 a$ & Available \\
\hline Step 15: Data presentation & 11.5.4 & $\begin{array}{l}\text { Evaluation of Field and Analytical Data } \\
\text { ER/K-I2004 }\end{array}$ & Available \\
\hline Data presentation & & Software Quality Assurance ER/K-P1601 & Available \\
\hline Data presentation & & Document Indexing Scheme & Proposed \\
\hline \multirow[t]{7}{*}{ Step 16: Data and document archival } & 11.5.4 & $\begin{array}{l}\text { Receiving, Processing, and Maintaining } \\
\text { ER Program Records ER/C-P1110 }\end{array}$ & Available \\
\hline & & $\begin{array}{l}\text { Transfer of Data from Site OREIS to } \\
\text { Central OREIS }\end{array}$ & Proposed \\
\hline & & $\begin{array}{l}\text { Identifying and Acquiring Documents for } \\
\text { ER Project Files }\end{array}$ & Proposed \\
\hline & & Document Indexing Scheme & Proposed \\
\hline & & $\begin{array}{l}\text { Environmental Restoration Quality } \\
\text { Program Plan ES/ER/TM-4/R3 }\end{array}$ & Available \\
\hline & & $\begin{array}{l}\text { Processing and Review Associated with } \\
\text { Data Transmitted to OREIS } \\
\text { (OREIS-I2801) }\end{array}$ & Available \\
\hline & & DOE 1988 & \\
\hline
\end{tabular}

${ }^{a}$ Energy Systems $1993 d$

TSCM = Technical Software Configuration Management.

OPSEC = Operating Security. 
The analytical laboratory coordinator oversees contracted analytical services, which may include pre-award auditing and review, coordination of the project/laboratory interface, and continuing performance review of the laboratory.

The data acquisition clerk helps acquire documents for project files, maintains the holdings and acquisitions lists, and prepares acquisition status reports.

The data analysts perform statistical summaries of physical and chemical data by medium, location, and sampling event, and present these summaries in tables, charts, graphs, or maps. The data are examined for consistency with the SAP. The analysts identify anomalies in the data and determine whether corrections or qualifiers are required, performing statistical analyses as needed, and preparing data for input to numerical models.

The data base administrator has overall responsibility for the design, operation, and maintenance of the data base.

The data coordinator participates in QA/QC activities including nonconformance investigations and reports and QA reviews; when coordinating data support for the multidisciplinary technical team, he/she prepares work agreements as necessary, reviews samplereceipt acknowledgements, and receives laboratory data packages.

The data entry clerk has responsibility for the entry of new or existing data generated by field activities or as a result of laboratory analyses and performs data-entry verification.

The data manager is responsible for identifying and acquiring all relevant data; ensures that data are complete and consistent; and resolves problems associated with data.

The data validator conducts data-validation activities following prescribed guidance documents to ensure that data are in compliance with DQOs and meet project needs; participates in QA/QC activities to resolve nonconformances as necessary; and assigns data qualifiers.

The data verifier, following validation of data, conducts data verification activities, and participates in QA/QC activities to resolve nonconformances as necessary.

The Energy Systems ER project manager oversees personnel and activities of ER Program site-characterization or site-remediation projects and is responsible for the successful completion of work assignments within budget and on schedule.

The field team leader helps prepare the SAP and implement it in the field, assigns staff members to sampling teams; assigns responsibilities to team members; prepares for and coordinates sampling activities; oversees field-data collection, recording, and documentation activities; and supervises the packing and shipping of samples.

The Geographic Information System applications specialist/cartographer/spatial analyst prepares maps illustrating geographical features and area characteristics such as topology, land use, ground cover, roads, buildings, and water; digitizes existing maps; edits and formats spatial data, combining them with attribute data from the project data base, and prepares topological 
overlays; and displays results through graphic outputs that include maps, color displays, and tabular information.

The QA Specialist prepares or helps prepare procedures and documents, evaluates the effectiveness of QA activities through scheduled audits and surveillances, and helps to resolve quality problems and to ensure that corrective action is taken and appropriately documented.

The records analyst specializes in the analysis and evaluation of systems and procedures involved in the creating, processing, and storing of records.

The records manager has responsibility for controlling the recorded information about project activities that is generated and/or received by project organizations.

\subsection{DATA MANAGEMENT ACTIVITIES AND RESPONSIBILITIES}

The range and complexity of the ER Program remediation and monitoring activities require a multidisciplinary staff working closely as an integrated data management team. This section of the plan introduces team staff members by describing their responsibilities and their interactions with each other as they perform the multistep process. The discussion of this process generally proceeds in chronological sequence; however, many activities occur simultaneously. The steps are organized and discussed below in four parts that reflect the four phases of the datamanagement process:

- $\quad$ Phase 1: Planning (Sect. 11.5.1);

- Phase 2: Field Preparation and Sampling (Sect. 11.5.2);

- Phase 3: Data Verification and Validation (Sect. 11.5.3); and

- Phase 4: Data Analysis and Presentation (Sect. 11.5.4).

\subsubsection{Phase 1: Planning}

Overview:

During the planning phase, the multidisciplinary team of records and data managers concentrate on the collection and review of existing documents and data. Any data contained in existing documents and/or standalone data bases are reviewed for applicability to the area under study. If data are applicable, they are entered either manually or electronically into the project data base for subsequent use in developing DQOs and detailed sampling and analysis work plans. All existing documents and hard-copy forms of data are indexed and stored in the project file.

\section{Step 1: Acquisition of currently available relevant data}

\section{General Information:}

This step includes the identification of relevant data held by the ER Program and other sources, the acquisition of these data with their associated metadata, and the evaluation of the quality of the data for the purpose of initiating an environmental site analysis. Data considered for review include all existing data (i.e., existing data in numeric, spatial, attribute, or textual 
form) that relate to the site. Potential sources of data include existing site environmental monitoring and compliance data; data from previous site groundwater and remedial studies; personal holdings of staff members; and spatial data from the site gathered by a fly-over, by the U.S. Geological Survey, by the U.S. Army Corps of Engineers, or by the Tennessee Valley Authority. Early in the process, the records analyst and the program manager review the records management plan to ensure that it meets all specific project requirements.

\section{Process Description:}

The records analyst meets with the project manager and other staff to discuss regulatory requirements for records management, an approach to the acquisition of existing data, the handling of acquired data, and current records management tools and practices.

The project manager, assisted by the records analyst and the data acquisition clerk, interviews project staff to identify relevant and available data sets and metadata. The metadata are found as comments and notes associated with data arrays, as descriptions and footnotes in reports, and especially as evaluative information that is the product of QA, verification, and validation analyses. The interviewer also requests names of experts who may provide leads to other relevant data and metadata. The staff conduct interviews until they have followed all possible leads.

On the basis of information obtained in interviews and subsequent research, the data acquisition clerk compiles an annotated and prioritized data acquisition list describing the desired data sets and their locations; the analyst then submits the list to the project manager for review and recommendations. Using the amended data acquisition list, the data acquisitions clerk acquires available data and then submits data sets to the data coordinator. Deliveries are made periodically and reflect priorities established by the project manager. The data coordinator tracks the data sets and accompanying metadata on a records management data base and transmits them for processing to the data manager, who reviews the data and identifies problems and questions that require resolution. The data acquisition clerk reports acquisitions, questions, and problems on an acquisition status report.

The project manager works with the data manager to answer questions and resolve problems about the data. When problems are resolved, the usable data are entered into the project data base by the data entry clerk under the supervision of the data manager. Unusable data are submitted to the records management staff and recorded in the project file.

\section{Step 2: Document maintenance}

\section{General Information:}

The team performs Steps 1 and 2 concurrently. The objectives of Step 2 are to ensure that the acquisition process minimizes the collection of unwanted documentation, to implement a system from which data and documents can be readily retrieved, and to ensure that appropriate document pointers will accompany analytical data in the project data base. 


\section{Process Description:}

Step 2 is closely associated with the collection of currently available data described in Step 1 and should be conducted concurrently with that activity and performed throughout the project. The records analyst and records manager meet with the project manager and jointly develop a project file guide and handbook and an indexing manual. The file guide and handbook describes the categories that will be used for filing and establishes the procedures for adding documents to and retrieving them from the project file. The indexing manual describes the descriptors to be used in indexing and how access to the index data base is to be obtained by project staff. Project staff submit documents during the entire term of the project. Records management staff implement the records classification scheme described in the handbook and index documents in accord with the indexing manual. In addition, records management staff access, retrieve, and reproduce requested records and documents for distribution to authorized individuals.

\section{Step 3: Project planning}

\section{General Information:}

This step involves the development of a work plan that presents an initial evaluation of the existing data, defines the scope and objectives of remedial activities, identifies the DQOs, and specifies the tasks to be performed. Detailed descriptions of the characterization tasks are found in the SAP. The SAP contains two parts: (1) the field sampling plan, which identifies the sample-collection, -handling and -analysis procedures to be used and the locations to be sampled, and (2) a QAPjP that describes the roles and responsibilities for the sampling and analysis activities and the QA/QC protocols to achieve the DQOs specified in the work plan.

\section{Process Description:}

To develop the DQOs, the project manager forms a multidisciplinary technical team. In the first stage of this activity, the types of decisions that should be made are identified. Data users are involved, availabie data are evaluated, a conceptual model is developed, and objectives and decisions are specified. In the next stage, data requirements and uses are identified. A concise statement of the data types needed is developed, data quality factors are defined, data quality requirements are identified, sampling and analysis options are evaluated, and sensitivity, precision, accuracy, representativeness, completeness, and comparability (SPARCC) parameters are reviewed. In stage three, the data collection program is designed by organizing the elements already identified in the first two stages. Data collection components are assembled, data collection documentation is developed, and the documentation is submitted for approval by the appropriate regulatory agencies.

During the development of the DQOs, specific concentration levels of concern for each analyte to be collected shall be determined and specific analytical methods and detection limits are identified. The existing data and documents collected earlier will be used to assist in the identification of COPCs and action levels, and to identify existing gaps in the data. Plans for the collection of field and laboratory QA/QC samples (e.g., field blanks, trip blanks, equipment rinsates, laboratory blanks, etc.) will also be finalized and reported in the SAP as part of the detail sampling design. This sampling design will be used to fill out and complete all required sample requisition forms. 
During the planning process, staff will review and finalize standardized field-data collection forms for field sampling, groundwater sampling, well construction, borehole logs, lithology, field measurements, instrument calibrations, and chains of custody (COC).

\subsubsection{Phase 2: Field Preparation and Sampling}

\section{Overview:}

During the field preparation and sampling phase, project chemists and data managers work closely with analytical laboratory staff to establish detailed procedures for processing samples and data, including scheduling the receipt of samples, COC handling, hard copy data package content, and electronic data deliverable content. The details of the work plan (sample identifications, location, depth, media, analysis types, containers, field QC samples, etc.) are entered into the project data base that is then used to output preprinted field logbooks and labels. As data are collected in the field, team data entry staff members manually enter field information (well construction data, lithology, borehole, water level, etc.) and COC data into the project data base for review against the original SAP. All field logbooks and COC forms are then indexed and stored in the project file.

\section{Step 4: Analytical laboratory interface}

The analytical laboratory coordinator and the QA Specialist conduct a pre-award audit of the analytical laboratory. During this review, procedures for data and document handling activities will be discussed. Specifically, the scheduling and receipt of samples will be established, the processing of COC and sample receipt forms will be detailed, the format and content of CLP and non-CLP data packages will be determined, electronic data deliverable contents and formats will be established, and procedures for processing nonconformance reports will be set. Findings and recommendations will be presented at the end of the project at a closeout meeting. An audit report will be prepared and sent to the laboratory for response. Recommendations and all decisions agreed on during the pre-award survey should be detailed.

The analytical laboratory coordinator and the QA Specialist, using the results of the preaward audit, prepare a standardized SOW package. Sample collection will not proceed until the findings in the audit have been resolved and the contract with the analytical laboratory has been executed.

\section{Step 5: Populating the project data base with SAP data}

\section{General Information:}

The project SAP specifies all sampling and analysis data. During this step, the data manager and the field sampling team-leader verify data specific to the SAP before loading it into the project data base. These data form the basis for the generation of preprinted labels and logbooks. 


\section{Process Description:}

The data manager creates a temporary SAP data base. Specific data items to be entered include sample identifications, sample survey locations and stations, sample depths, sample media, sample types, number of samples, sample container types and volumes, preservatives, types of analyses, and field QC data. The field team leader completes sample requisition forms based on sampling and analysis data specified in the project SAP and submits the forms to the data manager. Working under the technical supervision of the data manager, the data entry clerk manually enters data specified in the sample-requisition forms.

The data manager generates and reviews a report from the SAP data base to verify the data and makes any corrections necessary. A corrected report is reviewed by the field team leader; his or her corrections (if any) are incorporated by the data base administrator, who then integrates the verified data base into the project data base.

\section{Step 6: Collection of field data}

\section{General Information:}

The proper collection of samples and the proper completion, handling, and control of sampling documentation, such as logbooks, are crucial to the success of a project. Because information contained in the logbooks may be admitted as evidence in cost recovery or other litigation, the importance of activities that take place in this step in the process cannot be overstated. The purpose of this step is to ensure that samples are collected according to the SAP and QAPjP and that information about each sampling event is properly recorded and documented.

This step describes (1) preparatory activities for the collection of field sampling data and (2) sample- handling, -documentation, and -management activities conducted during field sampling events; it covers sampling activities from the point at which the data coordinator generates field logbooks, sample labels, and sample tags directly from the verified SAP data in the project data base to the point at which a QA review of entries on sampling documentation is conducted.

\section{Process Description:}

\section{First Stage}

During the first stage, the data coordinator prepares the preprinted logbooks, sample labels, sample tags, and other materials for the sampling team. Using copies of the sample requisition forms prepared by the field team leader, the data coordinator generates requested logbook sheets, sample labels, and sample tags on which data extracted from tables in the project data base are printed in the appropriate fields. These preprinted-logbook sheets and additional blank logbook sheets are arranged by medium, sampling event, or sampling team-whichever method of organization is most efficient for an actual sampling event. The logbooks are submitted unbound to the field team leader for QA review. Following this review, the data coordinator makes any needed corrections and submits the logbooks to the reproduction center, where they are bound. From this point on, all bound logbooks are kept in secure storage; access to them is controlled at all times. 


\section{$11-16$}

The data coordinator numbers the bound logbooks; delivers the bound logbooks, sample labels, sample tags, and COC forms to the field team leader for secure storage; and enters logbook titles and numbers in the project data base.

Before sampling begins, the data coordinator ensures that sampling team members are trained to follow procedures in completing logbooks, COC forms, labels, tags, and custody seals. The field team leader or QA Specialist ensures that sampling team members are trained to conduct sampling activities according to procedures and conducts a readiness surveillance during a trial sampling event to identify and correct problems. Trainers also submit documentation of successful completion of training and the readiness surveillance to the project file.

\section{Second Stage}

The field team collects samples as required by the SAP and QAPjP, carefully following relevant procedures. The team attaches a pressure-sensitive, gummed label to each sample container at the time of collection. The labels may be partially filled out and attached to the appropriate containers before samples are collected. The sampling team recorder will complete labels in indelible black ink during the sampling activity. In addition to the sample label, a sample container tag will be firmly attached with string, waterproof tape, or rubber bands to provide evidence and a permanent record of samples received by the analytical laboratory. If preprinted sample labels are not used, all information is recorded manually during field sample collection.

The field team also completes the COC during sampling. Each sample must be recorded on a COC form. Ultimately, each sample is accounted for by a custody transfer, although samples may be transferred as a group. The sampling team attaches seals to the containers when samples are collected to ensure that the samples are not tampered with between collection and analysis (the seals are affixed in such a way that it is necessary to break them to open the sample containers). All samples designated for shipment that leave the sampler's custody will have a seal affixed. Specific requirements for completing the logbooks will be detailed in the SAP, the QAPjP, and relevant procedures.

The field team leader completes the site logbook, a bound book with a hard cover and sequentially numbered pages, which is the master field-investigation document. Its primary purpose is to document each day's field activities; the personnel on each sampling team; and any administrative occurrences, conditions, or activities that may have affected the field work or data quality of any environmental samples for any given day. Each sampling team at the site has a field logbook for recording each day's sampling activities.

\section{Third Stage}

Following sampling, a different team member conducts־an independent QA review to verify whether the SAP has been followed, instruments calibrated, and procedures followed, and to ensure that logbook, COC, label, and tag entries are correct and legible. This review is dated and signed by the reviewer. Original entries may be corrected but not obliterated; the corrections are dated and signed. If the SAP has not been followed, the project manager evaluates the effect on the data and determines how to proceed, documents the decision in the logbook, and signs the logbook entry. If appropriate, field data are flagged. 
The sampling team members package samples for shipping, complete shipping documentation, and ship samples with the original COC form to the analytical laboratory for analysis. The field team leader retains copies of the COC form and shipping documentation and notifies appropriate project personnel that the samples have been shipped.

Backup copies of logbooks are made and submitted to the project file. The field team leader transfers the logbooks to a secure storage area and delivers a copy of the COC form to the data coordinator.

\section{Step 7: Data entry of field information}

\section{General Information:}

During this step in the process, the project data base is updated with field data and relevant metadata. Data entries are verified.

\section{Process Description:}

Within $72 \mathrm{~h}$ of sampling completion, the field team leader submits a copy of the COC to the data coordinator, who in turn enters the COC form number, sample identifications, and analyses requested into the project data base and verifies all information. If any samples were collected that were not planned in the SAP, their sample identification numbers, analyses requested, and all other relevant sampling information are entered to the data base. Any problems identified by the data coordinator during the review of the $\mathrm{COC}$ are resolved with the field sampling team leader; if necessary, a nonconformance report is generated, in which case the field team leader or data coordinator contacts the laboratory.

The data coordinator signs out the field logbooks and verifies their accuracy and completeness. Under the supervision of the data coordinator, the data entry clerk manually enters field data and any relevant metadata from logbooks and the COC into the project data base. Field data captured include field sample measures, well construction logs, lithologic descriptions, and field screening results. Data entry is verified, and a report is created and submitted to the project file.

\subsubsection{Phase 3: Data Verification and Validation}

\section{Overview:}

During the data verification and validation phase, the analytical laboratory submits a letter of receipt, data packages, and a set of diskette deliverables. The letter of receipt data are entered into the project data base and compared with the original plan by team data coordinators. The results data from diskette deliverables are stripped out and added to the project data base for preliminary analysis, interpretation, and SPARCC parameter estimation. The diskettes are also used for automated data verification and validation for CLP analyses and for some non-CLP analyses. After resolution of all nonconformance reports, the data packages and data quality summary reports and checklists are forwarded to the data validators for final assessment and assignment of data quality flags. The data quality flags are then uploaded into the project data 
base to create a final, validated, and centralized data base of both field and analytical information. All data packages, worksheets, and final data listings are indexed and stored in the project file.

\section{Step 8: Confirmation of receipt of samples by the analytical laboratory}

\section{General Information:}

During this step, interactions between project and analytical laboratory staff ensure that the laboratory understands and will meet project needs and that any problems will be addressed immediately. The analytical laboratory returns a copy of the COC with the letter of receipt that confirms the receipt of specific samples, reports what condition the samples were in when received, and documents any problems and resolutions. The letter of receipt also reports analyses scheduled by the laboratory and the expected turnaround time, and cross-references sample identification numbers with laboratory sample identification numbers. The data coordinator ensures that scheduled analyses concur with the requirements of the SAP and that expected turnaround will meet holding time requirements. The data coordinator updates the project data base with letter of receipt data.

\section{Process Description:}

When samples are received at the analytical laboratory, sample-receiving personnel sign and date the air bill. The laboratory staff members open the shipping container; record the date and time of receipt; document on the $\mathrm{COC}$ the presence or absence of custody seals, the condition of sample containers, the temperature, and the $\mathrm{pH}$ level; and sign and date the $\mathrm{COC}$. If there are problems, the laboratory contacts the field team leader for resolution.

Within three days of receiving the samples, the analytical laboratory sends an letter of receipt and a copy of the COC to the data coordinator. The letter of receipt documents the date and time of receipt of the samples, the condition of the samples on receipt, the analyses requested for samples, and the due date for results. It also cross-references the sample identification listed on the $\mathrm{COC}$ and printed on the sample label and sample tag with the laboratory sample identification number assigned by the laboratory. The letter of receipt also documents any problems and their resolutions.

The data coordinator reviews the letter of receipt and compares information to the data in the project data base to ensure that the proper chemical and radiological analyses are specified and understood by the laboratory. Any deviations from established procedures are documented in nonconformance reports. The data coordinator updates the project data base with laboratory identification numbers for each sample and any other information (e.g., loss of sample because of breakage) and generates a status report.

Step 9: Receipt and preliminary processing of hard-copy data deliverables from the analytical laboratory

\section{General Information:}

The results of the analyses of samples are reported by the analytical laboratory in a hardcopy data package; results may also be reported in electronic format on a diskette. This step 
discusses the handling of data packages, both CLP and non-CLP. Diskette deliverables are handled concurrently, as discussed in Step 10, "Receipt and preliminary processing of electronic data deliverables from the analytical laboratory."

The data coordinator receives and processes the data package and initiates tracking of analytical data. Verification is performed to ensure that data are accurately quantified, transcribed, and recorded and that prescribed procedures have been complied with. When verification is complete, summary reports are prepared, and any nonconformances are documented. Unvalidated data are entered into the project data base so that they are available for preliminary analysis while data validation is performed.

\section{Process Description:}

The analytical laboratory submits results of sample analyses to the data coordinator in a hard-copy data package. The data coordinator receives and processes the data package by stamping the date on it, assigning it an accession number, photocopying it, and submitting the original to the project file. A copy is retained for use in verification, validation, and data entry, and the data coordinator initiates tracking of analytical data by logging the sample delivery group information into the project data base, linking sample identifications with the sample delivery group number.

The data coordinator assigns data verification responsibilities, delivers to the data verifier the data package and checklists appropriate to the analytical method employed by the laboratory and tracks custody of data packages and the status of verification activities. The data verifier completes a Laboratory Data Package Summary Form to record sample delivery group information and a Laboratory Data Package Detail Form to record sample-specific information for each sample delivery group. These forms document receipt of results for specific samples.

If a CLP electronic diskette has been received, the verifier performs automated verification and validation using software discussed in Step 10. If results have not been submitted on a CLP electronic diskette, the verifier manually verifies the data to ensure that they are accurately quantified, transcribed, and recorded in accordance with prescribed procedures. If nonconformances are identified, a nonconformance report form is completed. All verification documentation, including checklists, any electronic summary reports, and any nonconformance reports, are signed and returned to the data coordinator for forwarding to the data validator.

The data entry clerk enters unvalidated information (e.g., analysis types, dates, and preliminary results) to the project data base, thus making data available for preliminary analysis while data validation is performed. Data entry is verified either by entering data twice and comparing the resultant files or by performing a total review. Changes are iterated until the correct file is produced. On completion of data entry, a report is created and submitted to the project file. 
Step 10: Receipt and preliminary processing of electronic data deliverables from the analytical laboratory

\section{General Information:}

This step encompasses the handling of analytic sampling results submitted by the analytical laboratory in electronic format on a diskette. Electronic deliverables are usually required for CLP analyses but are submitted on a case-by-case basis for non-CLP analyses, as required by the SOW. Activities described in this step are performed concurrently with activities described in Step 9, "Receipt and preliminary processing of hard-copy data deliverables from the analytical laboratory."

Unvalidated data are stripped and loaded to the project data bise for use in preliminary data analysis. Automated data verification and validation are conducted and summary reports are generated for review by the validator.

\section{Process Description:}

The data coordinator receives the electronic diskette from the analytical laboratory, copies it, and submits the original to the project file. The data are reviewed to ensure that sample identifications on the electronic diskette match those in the hard copy. Unvalidated data are stripped using verified programs and are loaded to the project data base for use in preliminary analysis of data while validation is completed. An error report is generated after data loading, and the data manager resolves any discrepancies. If appropriate, nonconformance reports are generated.

Automated verification of CLP data is performed using EPA's Contract Compliance Screening (CCS) software, and a summary report is generated. Automated validation of CLP data is performed using a validation software program (e.g., Computer Assisted Validation and Evaluation Assessment Tool), which generates a summary report. Any deficiencies are reported on a nonconformance report form. All summary reports are signed, and the data coordinator transmits them to the data validator for review.

On a case-by-case basis, the data manager builds a library of routines for stripping non-CLP data from diskette deliverables supplied by the laboratories. Automated verification and validation may then be performed.

When subsequent deliveries of corrected data are submitted in electronic format, printouts of changes in the data base are reviewed to ensure that any nonconformance reports are addressed. If nonconformance reports are resolved, the data are corrected in the data base.

\section{Step 11: Data validation -}

\section{General Information:}

The data validator uses a systematic process to review data against a defined set of criteria to evaluate whether the data are adequate for their intended uses. Data are reviewed following EPA or other functional guidelines for data validation to determine whether analyses were 
performed in accordance with required analytical methods and proper QC procedures. The level of validation required is stated in the SAP or the QAPjP. If necessary, the data validator flags the data with codes that signify usability.

\section{Process Description:}

The data coordinator distributes materials needed for validation to the data validator and tracks both the custody of the data package and the status of data validation efforts. These materials include the data package, validation worksheets appropriate for the analysis performed by the analytical laboratory, and reports completed during data verification (e.g., the Laboratory Data Package Summary Form, Laboratory Data Package Detail Form, CCS summary, automated validation summary, and nonconformance report form). The data validator evaluates the data verification and validation summary reports generated during data verification and reviews the data against criteria specified in the SAP. If required for the given level of validation, the validator completes a worksheet as part of the validation process.

When the SAP requires comprehensive validation, all data presented on standardized reporting forms are validated against guideline criteria in all data packages. However, when CLP diskettes are provided with the data package, the data are validated using CCS and validation software program summary reports. Validation criteria examined by those software programs determined to be in compliance are accepted; criteria identified as deficient in the reports are reviewed in detail. In addition, from the total group of data packages, the project manager or data manager may select a percentage on the basis of sample medium, analysis type, analysis time, and critical sample location to be subjected to a comprehensive data validation process, including examination of raw analytical data.

The data validator documents all discrepancies discovered during the validation process and also provides concurrence for reviews any nonconformance reports completed by the data verifier. If appropriate, he or she adds to or initiates a nonconformance report following standard procedures. The resolution of these nonconformance reports is handled by the QA Specialist and the analytical laboratory QA manager.

When the review is completed, the data validator must certify in writing that data have been validated and flagged in accordance with the process required in the SAP and must enter by hand any flags or qualifiers on copies of the results form (e.g., CLP Form 1). If required for the given level of review, the data validator also prepares a validation review package that contains a narrative summarizing the findings of the validation review, copies of the pages on which data flags and qualifiers are hand-entered, and the completed and signed validation worksheets. The data package and all documentation of the validation review are delivered to the data coordinator, who oversees manual entry of flags and qualifiers into the project data base by the data entry clerk; the data entered are verified either by double entry and comparison or by total review. The data coordinator also submits verification and validation documentation to the project file. 


\subsubsection{Phase 4: Data Analysis and Presentation}

\section{Overview:}

During the data analysis and presentation phase, team data analysts retrieve specific subsets of data from the project data base for determining contaminants of concern, comparing concentrations to background levels and regulatory limits, and performing risk assessments and modeling activities. By use of a Geographic Information System, spatial data are combined with validated attribute data to perform spatial analysis, plume modeling, land-use mapping, volume calculations, and contaminant-nature and -extent contouring. All data reports and listings presented in technical reports are generated by computer application programs (following software QA procedures) that access and summarize validated data contained in the project data base. The validity of application programs will be entered into the project files. If appropriate, validity will be demonstrated through successful performance of benchmark applications. Widely accepted commercial software (e.g., LOTUS) will not require validation; however, successful performance of derived applications such as spreadsheets or reports must be documented in the project file. All data summaries, maps, reports, application programs, and data base files are indexed and stored in the project file. As a result, reports and summaries can be successfully replicated.

\section{Step 12: Data consolidation and storage}

\section{General Information:}

This step focuses on ensuring the integrity of the data and the data base. Emphasis is placed on ensuring that the sources of all information and data are verified and documented and that all information and data collected are appropriately stored and indexed. Metadata are added to the project data base and linked to the corresponding data.

\section{Process Description:}

When the data for a given sample or group of samples are complete and have been entered into the data base, the data coordinator ensures that logbooks, other field records, and all analytical records are complete and properly stored in the project file. These records include the electronic forms, all the associated data packages, and documents that have been added to the data package file, such as the Laboratory Data Summary Form, Laboratory Data Detail Form, CCS summary report, automated validation summary report, validation review report, and closed nonconformance report. The source of each piece of information is documented. Hard-copy information is appropriately indexed and filed. Metadata are added to the project data base and linked to corresponding data.

After the data base is loaded, the data base administrator verifies and validates the security (per the Automated Data Processing Security Handbook)-and configuration control plan (per the Technical Software Configuration Management Handbook) to minimize the possibility of physical corruption (i.e., hardware or software failure) or unauthorized and illegal updating. Strict adherence to recovery procedures, time-stamping, and other related standard operating processes and controls ensure physical security. Any changes to the data base will be documented on a data base change request form. 


\section{Step 13: Data analysis}

\section{General Information:}

Subsets of the site characterization data are extracted from the project data base using quality-controlled retrieval programs; the data are then analyzed by use of standardized methods. All data analyses are generated from application programs accessing the validated data in the project data base. Data analysis may include activities such as determining COPCs, performing risk assessments, conducting transport modeling, estimating SPARCC parameters, and conducting statistical and spatial analyses that compare concentration values with background levels, regulatory limits, and ARARs. Analysis results are presented in such forms as tables, graphs, electronic files, or maps. A component of data analysis is data evaluation, in which spatial, temporal, content, and context analyses are performed on validated data in the project data base.

\section{Process Description:}

The project manager works with the data analysts and data base staff to determine which analyses need to be performed. Using standardized and quality-controlled retrieval programs, the data analyst extracts data base subsets for analysis, including combinations of site, location, station, sampling date, analysis type, analyte, data quality flag, and upper and lower data values from the project data base. These subsets are then passed to specific data analysis applications. All data analyses are generated from application programs accessing the validated project data base.

The data analyst documents critical aspects of the data-analysis process. The project manager completes a work request form to document data-selection criteria, analyses to be performed, and, if relevant, equations to be used. The data analyst prepares a calculation package that includes the listing of the data query, the listing of the program run log to ensure that the program ran correctly, and the product plus any additional output needed to check the accuracy of results. The analyst includes the name and version of the data set, the name and version of the program, and the date on all products. Before the product is delivered, a technical review is performed and documented by a second data analyst or other qualified technical staff member. Customized programs and all documentation are stored in the project file.

\section{Step 14: Spatial analysis and mapping}

\section{General Information:}

The Geographic Information System data base is composed of (1) spatial data files containing coordinate (map) data and (2) attribute files containing tabular descriptions of the map data. Creating the Geographic Information System data base involves manipulation and QA of coordinate data, input and $\mathrm{QA}$ of attribute data establishing a link between the spatial and attribute data, and importing of tabular data from other sources. The Geographic Information System data base is then used to further analyze the attribute or tabular data on the basis of its spatial content and to produce tabular and cartographic output of the analysis results. 


\section{Process Description:}

On the basis of outputs identified in the SAP, the project manager and Geographic Information System analyst identify and acquire early in the project data such as contours, land use, vegetation, and stream courses that will be needed to generate project deliverables. The data obtained are usually either electronic drawing files, survey data in electronic form, or hard-copy maps.

With the exception of points, all features in the coordinate data base are captured from a digital file. Thus, the cartographer must digitize hard-copy maps and import electronic data in spatial data base format. The project manager or technical team member performs QA reviews of the drawings produced, and iterations are generated until the drawings are approved. The spatial analyst then imports attribute data into the defined data files. The coordinate data files and attribute data files are stored in a spatial data base. A unique identification found in both files links attribute information (e.g., well number, street name, vegetation type) with entities (i.e., points, lines, polygons). Points may be loaded directly into the Geographic Information System from electronic data files. The spatial analyst performs a QA review of spatial data, querying the spatial data base, plotting the map features along with attribute information, and checking the plots against data source(s).

Attribute data files may be added to the spatial data base as they become available. The Geographic Information System analyst extracts from the project data base site characterization data associated with verified sampling points, in the form of one or more tables (which must include each point's unique identification), and imports the data directly into the Geographic Information System data base. All attribute records are linked to the entities by a unique identification assigned to every map entity.

\section{Step 15: Data presentation}

\section{General Information:}

The team generates customized data-reporting products that clearly indicate findings while using standardized annotation and precisely referenced data sources. All data listings, summaries, and reports containing graphics are generated by application programs accessing the validated data in the project data base.

\section{Process Description:}

The ER project manager and other project staff members collaborate in customizing data reporting products that will clearly present project findings while using standardized annotation and precisely-referenced data sources.

The data analyst extracts data subsets for reporting, including combinations of site, location, station, sampling date, analysis type, analyte, data quality flag, and upper and lower data values from the project data base with data retrieval tools. These subsets are passed to specific data reporting applications and reporting products (e.g., maps and spatial analyses, statistical analyses and models, risk assessments, graphics displays, tabular summaries, SPARCC reports, special application programs) are generated. 
Step 16: Data and document archival

\section{General Information:}

The process of data archival requires the updating of data from the project data base to the central OREIS data base, as well as retention of hardcopy records. The purpose of the transfer is to provide long-term secure storage and to assure maximum accessibility by the regulators and the environmental engineering community.

Sufficient documentation, including the associated metadata, must accompany archived data to describe the source, contents, and structure of the data to ensure its future usability. Computer programs used to manipulate or report the archived data must include references to the host software with its version identifiers. Hardcopies of all original field and analytical results, datareduction and data- summarization programs, data packages, and associated QA/QC forms must be classified, indexed, and stored into appropriate file groups and record series within the project files.

\section{Process Description:}

Over the course of the project, the records management staff acquires and processes project records and builds the project file. As the project nears completion, the Records Manager, using a checklist of documents required for comprehensive documentation of all project activities, checks for the completeness of the project file, and when satisfied that the file is complete, reports this to the Project Manager and provides the project manager and the QA specialist with a comprehensive listing of all documents in the index data base.

When the project manager and the QA specialist are satisfied that the project file is complete, the comprehensive listing of documents along with an electronic copy of the index data base is added to the project file. The project file is then boxed and delivered to permanent storage, e.g. the Central Record Facility or Document Management Center. A copy of the index data base is also delivered to the data base administrator.

The data base administrator is responsible for the completeness and final closeout of the project data base. After verifying that the processes described under Step 12, "data consolidation and storage," have been fully satisfied and the data base with the inclusion of metadata is complete, the data base administrator informs the project manager and QA Specialist. Upon approval, all files including the index data base, are archived. 


\section{REFERENCES}

Andelman, J.B. 1990. Total Exposure to Volatile Organic Chemicals in Potable Water, N.M. Ram, R.F. Christman, K.P. Cantor (eds), Lewis Publishers, Chelsea, Michigan.

ANSI/ASME (American National Standards Institute/American Society of Mechanical Engineers) 1989. Quality Assurance Program Requirements for Nuclear Facilities, ANSI/ASME NQA1-1989 (and current amendments).

ASTM (American Society for Testing and Materials) 1992a. Annual Book of ASTM Standards: - Soil and Rock; Dimension Stone; and Geosynthetics, Vol. 04.08, Philadelphia, Pennsylvania.

ASTM 1992b. "Standard Test Methods for Density of Soil and Soil-Aggregate in Place by Nuclear Methods (Shallow Depths) (D 2922-91), " in 1992 Annual Book of ASTM Standards, Sect. 4: Construction, Vol. 8: Soil and Rock; Dimension Stone; Geosynthetics; Philadelphia, Pennsylvania.

ASTM 1992c. "Standard Test Method for Density of Soil and Rock In-Place at Depth Below the Surface by Nuclear Methods (D 5195-91)," in 1992 Annual Book of ASTM Standards, Sect. 4: Construction, Vol. 8: Soil and Rock; Dimension Stone; Geosynthetics; Philadelphia, Pennsylvania.

ASTM 1992d. "Standard Test Method for Density of Soil in Place by the Drive-Cylinder Method (D 2937-83)," in 1992 Annual Book of ASTM Standards, Sect. 4: Construction, Vol. 8: Soil and Rock; Dimension Stone; Geosynthetics; Philadelphia, Pennsylvania.

ASTM 1992e. "Standard Test Method for Density and Unit Weight of Soil in Place by the SandCone Method (D 1556-90)," in 1992 Annual Book of ASTM Standards, Sect. 4: Construction, Vol. 8: Soil and Rock; Dimension Stone; Geosynthetics; Philadelphia, Pennsylvania.

ASTM 1992f. "Standard Test Method for Density and Unit Weight of Soil in Place by the Rubber Balloon Method (D 2167-84)," in 1992 Annual Book of ASTM Standards, Sect. 4: Construction, Vol. 8: Soil and Rock; Dimension Stone; Geosynthetics; Philadelphia, Pennsylvania.

Bagerzadeh, H. 1993. Personal communication from H. Bagerzadeh, Environmental Consulting Engineers, Inc., Knoxville, Tennessee, to S. Ahmed, Science Applications International Corporation, October 15.

Bear, J. 1979. Hydraulics of Groundwater, McGraw-Hill, New York, 569 pp.

Beauchamp, J.J., C.C. Brandt, and F.O. Hoffman, Jr. 1992. Risk and VMAP Multiple Pathways Assessment, Oak Ridge National Laboratory, Oak Ridge, Tennessee. 
Black, W.H., H.R. Smith, and F.D. Patton 1986. “Multiple-level Groundwater Monitoring with the MP System," in Proceedings of the NWWA Conference on Surface and Borehole Geophysical Methods and Groundwater Instrumentation, Denver, Colorado, October 15-17, 1986, pp. 41-61.

Blake, G.R. and K.H. Hartge 1986. "Bulk Density," in A. Klute (ed.) Methods of Soil Analysis, Part I: Physical and Mineralogical Methods, 2nd ed., American Society of Agronomy, Inc., and Soil Sciences Society of America, Madison, Wisconsin, pp. 363-376.

Brooks, R.H. and A.T. Corey 1964. Hydraulic Properties of Porous Media, Hydrology Paper No. 3, Colorado State University, Fort Collins, Colorado.

Cember, H. 1983. Introduction to Health Physics, Pergamon Press, Oxford.

Childs, E.C. 1969. An Introduction to the Physical Basis of Soil Water Phenomena, John Wiley and Sons, Ltd., London, $493 \mathrm{pp}$.

Clapp, R.B. and J.A. Watts (eds.) 1993. Second Annual Report of the Environmental Restoration Monitoring and Assessment Program at the Oak Ridge National Laboratory, ORNL/ER-180, Environmental Sciences Division, Oak Ridge National Laboratory, Oak Ridge, Tennessee, September.

Cooper, G.A. 1956. Chazyan and Related Brackiopods, Smithsonian Miscellaneous Collection 127, Part I.

Davis, E.C., W.J. Boegly, Jr., E.R. Rothschild, B.P. Spalding, N.D. Vaughan, C.S. Haase, D.D. Huff, S.Y. Lee, E.C. Walls, J.D. Newbold, and E.D. Smith 1984 . Site Characterization Techniques Used at a Low-Level Waste Shallow Land Burial Field Demonstration Facility, Publication No. 2306, Environmental Sciences Division, Oak Ridge National Laboratory, Oak Ridge, Tennessee.

deLaguna, W., T. Tamura, H.O. Weernen, E.G. Struxness, W.C. McClain, and R.C. Sexton 1968. Engineering Development of Hydraulic Fracturing as a Method for Permanent Disposal of Radioactive Wastes, ORNL/4259, Oak Ridge National Laboratory, Oak Ridge, Tennessee.

DOA (U.S. Department of the Army) 1970. Engineering and Design: Laboratory Soils Testing, EM 1110-2-1906. U.S. Army Corps of Engineers, Washington, D.C.

DOE (U.S. Department of Energy) 1987a. Environmental Survey Manual, Appendix A, "Criteria for Data Evaluation.” DOE/EH-0053, August.

DOE 1987b. Environmental Survey Manual, Appendix H. "Data Management and Analysis Guidance." DOE/EH-0053, August.

DOE 1988. Records Management. DOE Order 1324.2A, Office of Organization and Management Systems, September 13. 
DOE 1992. Quality Assurance, DOE Order 5700.6C, Office of Nuclear Energy and Office of Environment, Safety, and Health.

Domenico, P.A and F.W. Schwartz 1990. Physical and Chemical Hydrogeology, John Wiley and Sons, New York.

Dreier, R.B., D.K. Solomon, and C.M. Beaudoin 1987a. "Fracture Characterization in the Unsaturated Zone of a Shallow Land Burial Facility," in Flow and Transport Through Fractured Rock, American Geophysical Union Monograph 42, pp. 51-59.

Dreier, R.B., C.S. Haase, C.M. Beaudoin, H.L. King, and J. Switek 1987b. Summary of Geologic Data in the Vicinity of the Hydrofracture Facilities, ORNL/RAP/LTR-87/26, Oak Ridge National Laboratory, Oak Ridge, Tennessee.

Dreier, R.B. and L. E. Toran 1989. Hydrology of Melton Valley Determined from Hydraulic Head Measuring Station Data, ORNL/TM-11216, Oak Ridge National Laboratory, Oak Ridge, Tennessee.

DuBuchananne, G.D. and R.M. Richardson 1956. Groundwater Resources of East Tennessee, Bulletin 58, Part I, Division of Geology, State of Tennessee Department of Conservation.

ESI (Ebasco Services, Inc.) 1993. WAG 6 Interim Remediation Design Criteria Studies: Results of $3 D$ and $2 D$ Groundwater Flow Modeling, prepared for Department Of Energy - Oak Ridge Field Office, Environmental Restoration and Waste Management Program.

Energy Systems (Martin Marietta Energy Systems, Inc.) 1987a. Preliminary Geohydrologic Site Characterization and Proposed Water Quality Well Locations for WAG 4, WAG 5, WAG 3, and SWSA 1, ORNL/RAP/Sub-86/72139/1.

Energy Systems 1987b. Preliminary Geohydrologic Site Characterization and Proposed Water Quality Well Locations for WAG 7, WAG 8, WAG 9, ORNL/RAP/Sub-86/72139/2.

Energy Systems 1987c. RCRA Facilities Assessment (RFA) - Oak Ridge National Laboratory, ORNL/RAP-12/V1.

Energy Systems 1988a. Preliminary Geohydrologic Site Characterization and Proposed Water Quality Well Locations for WAG 11 and Upper WAG 2, ORNL/RAP/Sub-86/189/1.

Energy Systems 1988b. Preliminary Geohydrologic Site Characterization and Proposed Water Quality Well Locations for WAG 17 and Lower WAG 2, ORNL/RAP/Sub-86/189/2.

Energy Systems 1988c. Quality Assurance Manual, Oak Ridge National Laboratory.

Energy Systems 1989. Document Preparation Guide, ORNL/IRO-1, Oak Ridge National Laboratory.

Energy Systems 1990. ORNL Wag 6 Site Characterization Summary Volume I. Main Report, ORNL/RAP/Sub-87/99053/27/V1. 
Energy Systems 1991a. RCRA Facility Investigation Report for Waste Area Grouping 6 at Oak Ridge National Laboratory, Oak Ridge, Tennessee: Volume 1. Sections 1 through 3, ORNL/ER/Sub-87/99053/5/V1.

Energy Systems 1991b. Preparation, Division Approval, and Clearance of Environmental Restoration Documents, ER/C-P1103, Oak Ridge National Laboratory.

Energy Systems 1991c. Policy, Standards, and Procedures Manual, Vol. 4.

Energy Systems 1992a. Site Characterization Summary Report for Waste Area Grouping 1 at Oak Ridge National Laboratory, Oak Ridge, Tennessee: Volume 2. Sections 4 through 6 , DOE/OR-1043/V2\&D1.

Energy Systems 1992b. Oak Ridge Reservation Environmental Report for 1991, ES/ESH-22/V1 and ES/ESH-22/V2.

Energy Systems 1992c. Requirements for Quality Control of Analytical Data for the Environmental Restoration Program, ES/ER/TM-16.

Energy Systems 1992d. Developing and Maintaining Laboratory Operations Manuals, Environmental Sciences Division Administrative Procedures ESD-ADM-92-003.

Energy Systems 1993a. Phase II Remedial Investigation Work Plan for Groundwater at Waste Area Grouping 1 at Oak Ridge National Laboratory, Oak Ridge, Tennessee, DOE/OR/011194\&D0.

Energy Systems 1993b. Data Management Plan for the Oak Ridge Environmental Information System. ES/ER/TM-39/R1, Version 2.0. Oak Ridge Environmental Information System (OREIS) Team.

Energy Systems 1993c. Data Management Plan for the Environmental Restoration Division, ES/ER/TM-88, Draft, December 1993.

Energy Systems 1993d. Environmental Restoration Quality Program Plan, ES/ER/TM-4/R3.

Engelder, T. 1985. "Loading Paths to Joint Propagation During a Tectonic Cycle: An Example from the Appalachian Plateau, U.S.A.," J. Structural Geology, Vol. 7, No. 314, pp. 459476.

EPA (U.S. Environmental Protection Agency) 1980. Interim Guidelines for Preparing Quality Assurance Project Plans, .QAMS:005/80, December 29.

EPA 1983a. Interim Guidelines and Specifications for Preparing Quality Assurance Plans, EPA-600/4-83-004 (QAMS 005/80), Office of Monitoring Systems and Quality Assurance.

EPA 1983b. Methods for the Chemical Analysis of Water and Wastes, EPA 600/4-79-020. 
EPA 1986. Test Methods for Evaluating Solid Waste, SW-846, 3rd ed., Office of Solid Waste and Emergency Response.

EPA 1987a. Data Quality Objectives for Remedial Response Activities: Development Process, EPA540/G-87-003, Office of Emergency and Remedial Response, Washington, D.C., March. OSWER Directive 9355.0-7B.

EPA 1987b. Quality Criteria for Water, EPA 440/5-86-001 (May 1, 1987 update), OSWER Directive 9502.00-6C, EPA Office of Water Regulations and Standards.

EPA 1988a. Guidance for Conducting Remedial Investigations and Feasibility Studies under CERCLA, OSWER Directive 9335.3-01 (Draft), Office of Emergency and Remedial Response.

EPA 1988b. Laboratory Data Validation Functional Guidelines for Evaluating Organic Analyses, Hazardous Site Division.

EPA 1988c. Laboratory Data Validation Functional Guidelines for Evaluating Inorganic Analyses, Office of Emergency and Remedial Response.

EPA 1989. Superfund Exposure Assessment Manual, EPA/540/1-88/001, Office of Remedial Response.

EPA 1990a. Organic Contract Compliance Screening System (OCCSS) Software for the PC (Version 2/90) User Manual, EPA/SW/DK-90/025A, National Technical Information Service, February.

EPA 1990b. Final Guidance on Administrative Records for Selecting CERCLA Response Actions, OSWER Directive No. 9833.3A-1, Office of Solid Waste and Emergency Response, December 3.

EPA 1991. Risk Assessment Guidance for Superfund: Volume 1- Human Health Evaluation Manual (Part B, Development of Risk-Based Preliminary Remediation Goals), Office of Emergency and Remedial Response, Washington, D.C.

EPA 1992. Human Health Evaluation Manual, Supplemental Guidance: Standard Default Exposure Factors, OSWER Directive 9285.6-03. Office of Emergency and Remedial Response, Washington, D.C.

Foreman, J. L., K.R. Walker, L.J. Weber, S.L. Driese, and R.B. Dreier 1991. "Slope and Basinal Carbonate Deposition in the Nolichucky Shale (Upper Cambrian), East Tennessee: Effect of Carbonate Suppression by Silicilastic Deposition on Basin-Margin Morphology," in Mixed Carbonates-Silicilastic Sequences, SEPM Core Workshop, No. 15, Dallas, Texas.

Gregory, K.J. and D.E. Walling 1973. Drainage Basin Form and Process, John Wiley, New York. 
Gwo, J-P 1992. Multi-region Flow and Transport Modeling in Subsurface Media. Unpublished Ph.D. dissertation, Dept. of Civil and Environmental Engineering, Pennsylvania State University.

Haase, C.S., E.C. Walls, and C.D. Farmer 1985. Structural and Stratigraphic Data for the Conasauga Group and Rome Formation on the Copper Creek Thrust Sheet Near Oak Ridge, Tennessee: Preliminary Data from Test Borehole ORNL-Joy No. 2, ORNL/TM-9159, Oak Ridge National Laboratory, Oak Ridge, Tennessee.

Haase, C. S., J. Switek, and S.H. Stow 1987. Geochemistry of Formation Waters in the Lower Conasauga Group at the New Hydrofracture Facility: Preliminary Data form the Deep Monitoring (DM) Wells, ORNL/RAP-6, Oak Ridge National Laboratory, Oak Ridge, Tennessee.

Hatcher, R.D., P.J. Lemiszki, R.B. Dreier, R.H. Ketelle, R.R. Lee, D.A. Leitzke, W.M. McMaster, J.L. Foreman, and S.Y. Lee 1992. Status Report on the Geology of the Oak Ridge Reservation, ORNL/TM-12074, Oak Ridge National Laboratory, Oak Ridge, Tennessee.

Hook, L.A., L.D. Voorhees, M.J. Gentry, M.A. Faulkner, J.A. Shaakir-Ali, K.A. Newman, R.A. McChord, L.F. Goins, and P.T. Owen 1990. Database Management Activities for the Remedial Action Program at ORNL: Calendar Year 1989, ORNL ER-16, Oak Ridge National Laboratory, Oak Ridge, Tennessee.

Hoos, H.B. and Z.C. Bailey 1986. Reconnaissance of Surficial Geology, Regolith Thickness, and Configuration of the Bedrock Surface in Bear Creek and Union Valleys, Near Oak Ridge, Tennessee, Water Resources Investigations Report 86-4165, U.S. Geological Survey.

Howard, P.H., R.S. Boethling, W.F. Jarvis, W.M. Meylan, and E.M. Michalenko 1991. Handbook of Environmental Degradation Rates, Lewis Publishers, Chelsea, Michigan.

Jury, W.A., W.R. Gardner, and W.H. Gardner 1991. Soil Physics, Fifth Edition, John Wiley and Sons, Inc., New York, 328 pp.

Ketelle, R.H. and D.D. Huff 1984. Site Characterization of the West Chestnut Ridge Site, ORNL/TM-9229, Oak Ridge National Laboratory, Oak Ridge, Tennessee.

Ketelle, R.H. and R.R. Lee 1992. Migration of a Groundwater Contaminant Plume by Stratabound Flow in Waste Area Grouping 1 at Oak Ridge National Laboratory, Oak Ridge, Tennessee, ORNL/ER-126, Oak Ridge National Laboratory, Oak Ridge, Tennessee.

Keys, W.S. and L.M. MacCary 1971. "Application of Borehole Geophysics to Water-Resources Investigations," in Techniques of Water-Resources Investigations of the United States Geological Survey, Chapter E1, U.S. Geological Survey, 126 pp.

Kimbrough, C.W., L.W. Long, and L.W. McMahon 1994. Environmental Surveillance Procedures Quality Control Program, Rev. 4, ES/EH/INT-14 (Replaces 
ESH/SUB/8721706/1), Martin Marietta Energy Systems, Inc., Oak Ridge K-25 Site, Oak Ridge, Tennessee.

King, H.L. and C.S. Haase 1987. Subsurface-controlled Geological Maps for the Y-12 Plant and Adjacent Areas of Bear Creek Valley, ORNL/TM-10112, Oak Ridge National Laboratory, Oak Ridge, Tennessee.

Klute, A. 1986. "Laboratory Measurement of Hydraulic Conductivity of Unsaturated Soil," in Methods of Soil Analysis, American Society of Agronomy, Madison, Wisconsin.

Law Engineering (Law Engineering Testing Company) 1975. Preliminary Safety Analysis Report for Nuclear Fuel Recovery and Recycling Center, Prepared for Exxon Nuclear Company.

Lee, R.R. and R.H. Ketelle 1987. Stratigraphic Influence on Deep Groundwater Flow in the Knox Group Copper Ridge Dolomite on the West Chestnut Ridge Site, ORNL/TM-10479, Oak Ridge National Laboratory, Oak Ridge, Tennessee.

Lee, R.R and R.H. Ketelle 1988. Subsurface Geology of the Chickamauga Group at the Oak Ridge National Laboratory, ORNL/TM-10749, Oak Ridge National Laboratory, Oak Ridge, Tennessee.

Lomenick, T. F. and H. J. Wyrick 1965. Geohydrological Evaluation of Solid Waste Storage Area 6, ORNL/TM-1327, Oak Ridge National Laboratory, Oak Ridge, Tennessee.

McMaster, W.M. 1962. Geologic Map of the Oak Ridge Area, Tennessee, U.S. Atomic Energy Commission.

Moore, G.K. 1988. Concepts of Groundwater Occurrence and Flow Near Oak Ridge National Laboratory, Tennessee, ORNL/TM-10969, Oak Ridge National Laboratory, Oak Ridge, Tennessee.

Moore, G.K. 1989. Groundwater Parameters and Flow Systems Near Oak Ridge National Laboratory, Tennessee, ORNL/TM-11368, Oak Ridge National Laboratory, Oak Ridge, Tennessee.

Moore, G.K. and L.E. Toran 1992. Supplement to a Hydrologic Framework for the Oak Ridge Reservation, Oak Ridge, Tennessee, ORNL/TM-12191, Oak Ridge National Laboratory, Oak Ridge, Tennessee.

Morrison, R.D. 1983. Ground Water Monitoring Technology: Procedures, Equipment, and Applications, Timco Manufacturing, Inc., Prairie Du Sac, Wisconsin.

Myrick, T.E. and S.H. Stow 1987. Remedial Action Plan for ORNL Hydrofracture Operations, ORNL/RAP-9, Oak Ridge National Laboratory, Oak Ridge, Tennessee.

Nativ, R. and A.E. Hunley 1993. The Deep Hydrogeologic Flow System Underlying the Oak Ridge Reservation, ORNL/GWPO-003, Environmental Sciences Division, Oak Ridge National Laboratory, Oak Ridge, Tennessee. 
Nyquist, J.E., G.K. Moore, S.C. Young, and R.B. Clapp 1992. "Use of Electromagnetic Borehole Flowmeter to Delineate Groundwater Producing Fractures," in Fourth Tennessee Water Resources Symposium, pp. 26-28.

Olsen, C.R., P.D. Lowry, S.-Y. Lee, I. L. Larsen, and N.H. Cutshall 1983. Chemical Geological, and Hydrological Factors Governing Radionuclide Migration from a Formerly Used Seepage Trench, ORNL/TM-8839, Oak Ridge National Laboratory, Oak Ridge, Tennessee.

Olsen, C.R., P.D. Lowry, S.-Y. Lee, I. L. Larsen, and N.H. Cutshall 1986. “Geochemical and Environmental Processes Affecting Radionuclide Migration from a Formerly Used Seepage Trench," Geochim. at Cosmochim, Acta, Vol. 50, pp. 1-15.

Peters, D.B. 1965. "Water Availability," in C.A. Black (ed.), Methods of Soil Analysis, Monograph 9, American Society of Agronomy, Madison, Wisconsin.

Rothschild, E.R., R.R. Turner, S.H. Stow, M.A. Boyle, L.K. Hyder, O.M. Sealand, and J.H. Wyrick 1984. Investigation of Subsurface Mercury at the Oak Ridge Y-12 Plant, ORNL/TM-9092, Oak Ridge National Laboratory, Oak Ridge, Tennessee.

Shevenell, L.S., R.B. Dreier, and W.K. Jago 1992. Draft Summary of Fiscal Year 1991 and 1992 Construction, Hydrologic and Geologic Data Obtained from the Maynardville Limestone Exit Pathway Monitoring Program, Y/TS-814, Oak Ridge Y-12 Plant, Oak Ridge, Tennessee.

Sledz, J.J. and D.D. Huff 1981. Computer Model for Determining Fracture Porosity and Permeability in the Conasauga Group, ORNL/TM-7695, Oak Ridge National Laboratory, Oak Ridge, Tennessee.

Smith, E.D. and N.D. Vaughan 1985. "Aquifer test analysis in nonradial flow regimes: a case study," Groundwater, Vol. 23, pp. 167-175.

Solomon, D.K., G.K. Moore, L.E. Toran, R.B. Dreier, and W.M. McMaster 1992. Status Report: A Hydrologic Framework for the Oak Ridge Reservation, Publication No. 3815, Environmental Sciences Division, Oak Ridge National Laboratory, Oak Ridge, Tennessee.

Stockdale, P.B. 1951. Geologic Conditions at the Oak Ridge National Laboratory (X-10) Area Relevant to the Disposal of Radioactive Waste, ORO-38, U.S. Department of Energy, Oak Ridge, Tennessee.

Switek, J., C.S. Haase, and S.H. Stow 1987. Geochemistry of Formation Waters in the Lower Conasauga Group: Preliminary Data from the Rock Cover $(R C D)$ Wells, ORNL/RAP-5, Oak Ridge National Laboratory, Oak Ridge, Tennessee.

Therrien, R. and E.A. Sudicky 1993. User's Guide for FRAC3DVS: An Efficient Simulator for Three-dimensional, Saturated-Unsaturated Groundwater Flow and Chain-Decay Solute Transport in Porous or Discretely-fractured Porous Formations, University of Waterloo, Waterloo, Ontario, April. 
Toran, L.E., E. D'Azevedo, and O.M. Reyes 1992. Modification of FEMWATER for parallel computer. Annual Spring Meeting, American Geophysical Union; Montreal, May 12-15.

van Genuchten, M. T. 1978. Calculating the Unsaturated Hydraulic Conductivity with a New Closed-Form Analytical Model, U.S. Salinity Laboratory, Riverside, California.

Webster, D.A and M.W. Bradley 1987. Hydrology of the Melton Valley Radioactive-Waste Burial Grounds at Oak Ridge National Laboratory, Tennessee, U.S. Geological Survey Open File Report 87-686, Nashville, Tennessee.

West O. and L. Toran 1992. Development of a Three-Dimensional Groundwater Flow Model for Western Melton Valley: Application of P-FEM on a DOE Waste Site (Draft). ORNL-TM12474, Oak Ridge National Laboratory, Oak Ridge, Tennessee.

Westbay Instruments, Ltd. 1993. The MP System, Technical System Brochure, Westbay Instruments, Ltd., Vancouver, B.C., Canada, 12 pp.

Wilson, J.M. 1991. East Chestnut Ridge Hydrogeologic Characterization - A Geophysical Study of Two Karst Features, ECE-91-002. Environmental Consulting Engineers, Inc., Knoxville, Tennessee.

Wilson, J.M. and R.H. Ketelle 1992. K-1070-A Gravity Survey, MMHE 1.11-001, Environmental Consulting Engineers, Inc., Knoxville, Tennessee.

Yeh, G.T. 1987. 3DFEMWATER: A Three-dimensional Finite Element Model of Water Flow Through Saturated-Unsaturated Media. ORNL-6386, Oak Ridge National Laboratory, Oak Ridge, Tennessee.

Yeh, G.T. and V.S. Tripathi 1990. HYDROGEOCHEM: A Coupled Model of HYDROlogic Transport and GEOCHEMical Equilibria in Reactive Multicomponent Systems. ORNL-6371, Oak Ridge National Laboratory, Oak Ridge, Tennessee.

Young, S.C., H.S. Pearson, D.E. Warren, and J.W. Hamby 1992. "Demonstration of the Electromagnetic Flowmeter for Geohydrological Assessments," in Fourth Tennessee Water Resources Symposium, pp. 172-173. 


\section{APPENDIX A}

SUMMARY OF RISK RESULTS FOR COMPLIANCE WELLS AND GROUNDWATER DATA COLLECTED FOR REMEDIAL INVESTIGATIONS AT WAGS 1, 5, AND 6 



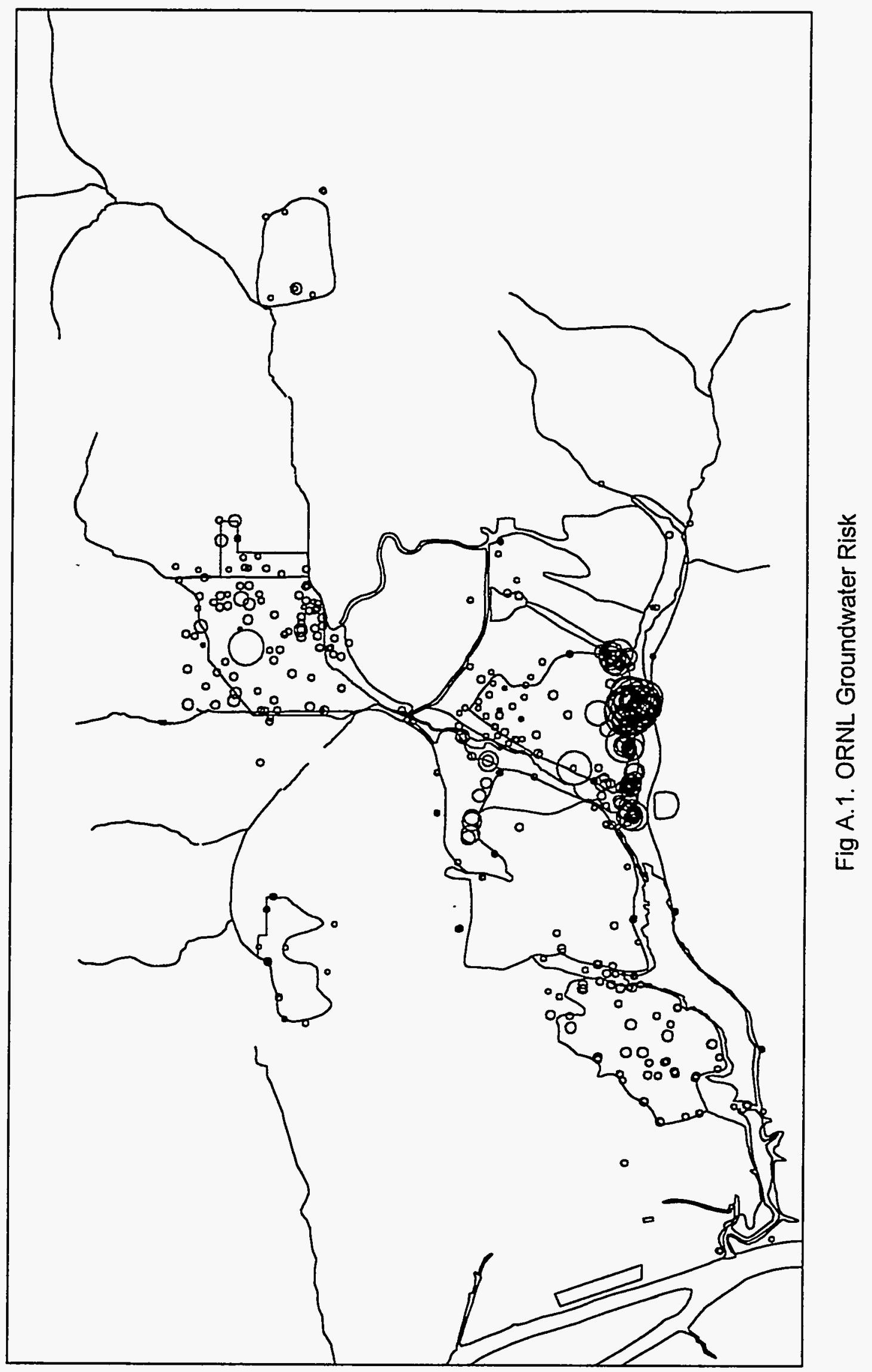


WELL_Metal Rsk Org_Rsk Rad_Rsk TRU_Rsk Total Rsk Rad_\% Met_\% TRU_\% Org_\% \begin{tabular}{llllllllll}
533 & $2.74 E-04$ & $0.00 E+00$ & $136 E-05$ & $303 E-05$ & $3.18 E-04$ & 4.28 & 86.2 \\
\hline
\end{tabular} \begin{tabular}{r|r|rrr|r|rrr|r|}
538 & $1.60 \mathrm{E}-03$ & $1.02 \mathrm{E}-06$ & $7.48 \mathrm{E}-05$ & $926 \mathrm{E}-06$ & $\mathbf{1 . 6 9 E - 0 3}$ & 4.71 & 94.64 & 0.58 & 0.06
\end{tabular} \begin{tabular}{|l|lllllllll}
539 & $0.00 E+00$ & $3.12 \mathrm{E}-06$ & $8.62 \mathrm{E}-03$ & $734 \mathrm{E}-05$ & $\mathbf{8 . 7 0 E - 0 3}$ & 9912 & 0 & 084 & 0.04 \\
\hline
\end{tabular} \begin{tabular}{llllllllll}
540 & $6.40 \mathrm{E}-04$ & $0.00 \mathrm{E}+00$ & $5.90 \mathrm{E}-06$ & $346 \mathrm{E}-07$ & $6.46 \mathrm{E}-04$ & 0.91 & 99.03 \\
\hline
\end{tabular}

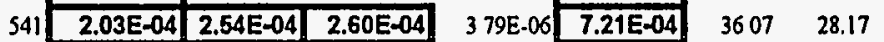

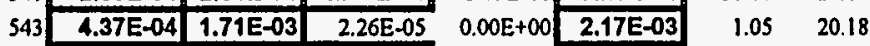

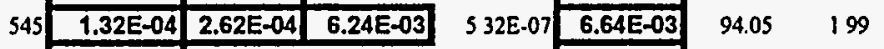
$\begin{array}{llllllllll}546 & 2.03 E-04 & 7.71 E-06 & 2.55 E-05 & 1.72 E-06 & 2.38 E-04 & 10.71 & 8533\end{array}$ \begin{tabular}{|l|l|lll|l|l|l|}
548 & $1.42 \mathrm{E}-04$ & $0.00 \mathrm{E}+00$ & $3.46 \mathrm{E}-06$ & $0.00 \mathrm{E}+00$ & $1.46 \mathrm{E}-04$ & 2.37 & 97.63 \\
\hline
\end{tabular}

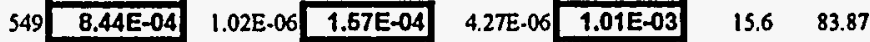
\begin{tabular}{|l|l|l|l|l|l|l|l|l|}
550 & $6.10 \mathrm{E}-04$ & $7.79 \mathrm{E}-07$ & $2.27 \mathrm{E}-04$ & $8.59 \mathrm{E}-06$ & $8.46 \mathrm{E}-04$ & 26.88 & 72.02 \\
\hline
\end{tabular} \begin{tabular}{l|r|r|r|r|rrr}
553 & $6.19 E-04$ & $6.97 E-04$ & $9.20 \mathrm{E}-06$ & $277 \mathrm{E} .06$ & $1.23 \mathrm{E}-03$ & 0.75 & 5045
\end{tabular} $\begin{array}{lllllllll}554 & 2.43 \mathrm{E}-04 & 1.60 \mathrm{E}-06 & 7.89 \mathrm{E}-06 & 131 \mathrm{E}-07 & 2.53 \mathrm{E}-04 & 3.12 & 9619\end{array}$ $\begin{array}{llllllrr}558 & 0.00 \mathrm{E}+00 & 3.90 \mathrm{E}-07 & 0.00 \mathrm{E}+00 & 000 \mathrm{E}+00 & 3.90 \mathrm{E}-07 & 0 & 0\end{array}$ $\begin{array}{lllllllll}563 & 000 E+\infty & 0.00 E+\infty & 1.02 E-04 & 303 E-06 & 1.05 E-04 & 97.11 & 0\end{array}$ \begin{tabular}{l|l|l|r|r|r|rr}
564 & $0.00 \mathrm{E}+00$ & $000 \mathrm{E}+00$ & $6.92 \mathrm{E}-04$ & $0.00 \mathrm{E}+00$ & $6.92 \mathrm{E}-04$ & 100 & 0 \\
\hline 566 & $2.67 \mathrm{E}-04$ & $1.07 \mathrm{E}-06$ & $3.63 \mathrm{E}-04$ & $210 \mathrm{E}-06$ & $6.33 \mathrm{E}-04$ & 57.36 & 42.13
\end{tabular}

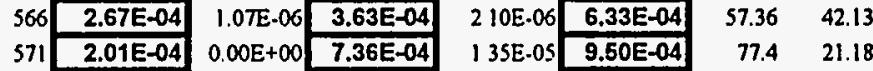

ALIAS EASTINO NORTHINO

28.22-5 $28818.67 \quad 22006.67$

$\begin{array}{llr}29.21 .5 & 29485.31 & 21889.9\end{array}$

29-22-53 $29736.18 \quad 22630.29$ 29.22. $5 \quad 29807.39 \quad 22379.31$

29-21-54 29644.32 21955.86

$\begin{array}{lll}29.21 .5 & 298161 & 21829.32\end{array}$

$\begin{array}{lllll}0 & 78.78 & 29.21 .5 & 297135 & 21335.57\end{array}$

$\begin{array}{lllll}0.01 & 3.95 & 29-23-54 & 29741.9 & 23004.53\end{array}$

$\begin{array}{lllll}0.72 & 324 & 30.22 .5 & 30034.16 & 22758.18\end{array}$

$\begin{array}{lllll}0 & 0 & 29-22-5 & 29960.92 & 22049.19\end{array}$

$\begin{array}{lllll}0.42 & 0.1 & 30.23 .5 & 30311.39 & 23013.09\end{array}$

$\begin{array}{lllll}1.02 & 009 & 30-22.5 & 30194.59 & 22379.43\end{array}$

$\begin{array}{lllll}0.23 & 4858 & 30-21.5 & 30243.72 & 21584.37\end{array}$

$\begin{array}{lllll}0.05 & 063 & 30.21 .5 & 30180.2 & 21319.13\end{array}$

$\begin{array}{lllll}0 & 100 & 30.22 .5 & 30699.55 & 22800.03\end{array}$

$\begin{array}{lllll}2.89 & 0 & 30-21-5 & 30615.41 & 21899.82\end{array}$

$\begin{array}{lllll}0 & 0 & 30-21.5 & 30459.19 & 21836.37\end{array}$

$\begin{array}{lllll}0.33 & 0.17 & 30.21 .5 & 30625.08 & 21755.47\end{array}$

$\begin{array}{lllll}1.42 & 0 & 30-20.5 & 30515.25 & 20920.68\end{array}$

$\begin{array}{lllll}025 & 0 & 30.23-5 & 30872.67 & 23037.69\end{array}$

$\begin{array}{rrrrr}0.34 & 0 & 30.21 .5 & 30919.87 & 21640.4\end{array}$

$\begin{array}{lllll}0 & 100 & 30-22-5 & 30954.85 & 22298.95\end{array}$

$\begin{array}{lllll}11.41 & 788 & 31.22 .5 & 31289.7 & 22874.82\end{array}$

$\begin{array}{llllll}0.35 & 8 & 31.22 .5 & 31308.45 & 22581.53\end{array}$

$\begin{array}{lllll}0.05 & 0.17 & 31-22.5 & 31331.72 & 22474.41\end{array}$

$\begin{array}{lllll}0.27 & 0 & 31-22.5 & 3111331 & 22191.37\end{array}$

$211 \quad 0 \quad 31.21 .5 \quad 31191.49 \quad 21833.08$

$\begin{array}{lllll}34.71 & 1372 & 31.22-5 & 31384.8 & 22660.72\end{array}$

$\begin{array}{lllll}0 & 9901 & 31.22 .5 & 31445.19 & 22288.21\end{array}$

$\begin{array}{lllll}0.01 & 9443 & 31.22 .5 & 31358.87 & 22175.01\end{array}$

$\begin{array}{lllll}0 & 664 & 31.22 .5 & 31417.95 & 22009.55\end{array}$

$\begin{array}{llllll}0.21 & 115 & 31.21 .6 & 31503.38 & 21497.54\end{array}$

$\begin{array}{lllll}0.07 & 191 & 31.22 .6 & 31482.03 & 2285619\end{array}$

$\begin{array}{rrrrr}0.45 & 0 & 31.22 .6 & 31490.62 & 2257523\end{array}$

$\begin{array}{lllll}1.66 & 0.45 & 31.22 .6 & 31521.98 & 2203986\end{array}$

$\begin{array}{lllll}5.18 & 0 & 31.22 .6 & 31512.47 & 22476.84\end{array}$

$\begin{array}{rrrrr}0.45 & 0 & 31-22-6 & 31660.1 & 22180\end{array}$

$\begin{array}{lllll}0.54 & 0.62 & 31.21 .6 & 31645.42 & 21410.13\end{array}$

$\begin{array}{lllll}0.33 & 0.05 & 31.22 .6 & 31790.15 & 22790.02\end{array}$

$\begin{array}{lllll}0 & 0 & 31.22-6 & 31656.13 & 2230548\end{array}$

$\begin{array}{lllll}0.42 & 164 & 31.21 .6 & 31855.7 & 21739.94\end{array}$

$\begin{array}{lllll}0 & 5731 & 31-22.6 & 31916.94 & 2287032\end{array}$

$\begin{array}{rrrrr}0 & 0 & 31.22 .6 & 3192445 & 22459.85\end{array}$

$241 \quad 1 \quad 31.22 .6 \quad 3196023 \quad 2223998$

2194564 
WELL_Metal Rsk Org_Rsk Rad_Rsk TRU_Rsk Total Rssk Rad_\% Met_\% TRU_\% OTB_\% $\begin{array}{lllllllll}634 & 2.13 E-04 & 0.00 E+00 & 1.31 E-05 & 0.00 E+00 & 2.26 E-04 & 5.8 & 94.2\end{array}$

$\begin{array}{llllllll}806 & 5.37 E-04 & 1.74 E-06 & 1.19 E-04 & 0.00 E+00 & 6.58 E-04 & 18.17 & 81.57\end{array}$

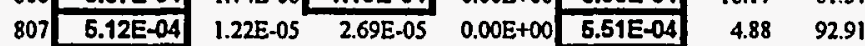

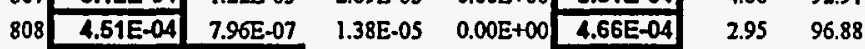
\begin{tabular}{ll|lllllll}
809 & $1.22 E-03$ & $1.17 E-03$ & $2.39 E-05$ & $0.00 E+00$ & 2.41E-03 & 0.99 & 5052 \\
\hline
\end{tabular} \begin{tabular}{l|llllllll}
810 & $2.91 \mathrm{E}-04$ & $1.07 \mathrm{E} .05$ & $1.24 \mathrm{E}-05$ & $0.00 \mathrm{E}+00$ & $3.14 \mathrm{E}-04$ & 3.93 & 9266 \\
\hline
\end{tabular}

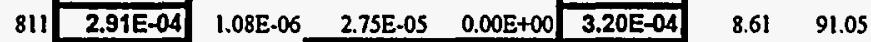
\begin{tabular}{l|l|l|l|l|l|l|l}
\hline 812 & $5.01 E-04$ & $3.26 E-06$ & $6.01 E-03$ & $1.34 E-04$ & $6.65 E-03$ & 90.39 & 7.54 \\
\hline
\end{tabular} \begin{tabular}{l|l|l|l|l|l|l|l|l}
813 & $3.68 \mathrm{E}-04$ & $5.58 \mathrm{E}-05$ & $220 \mathrm{E}-05$ & $0.00 \mathrm{E}+00$ & $4.46 \mathrm{E}-04$ & 4.93 & 82.55 \\
\hline
\end{tabular}

\begin{tabular}{l|l|lllllll}
\hline 814 & $2.82 E-04$ & $1.60 E-02$ & $255 E-05$ & $0.00 E+00$ & $1.63 E-02$ & 0.16 & 1.72
\end{tabular} \begin{tabular}{|l|lllll|l|l|}
\hline 815 & $8.80 \mathrm{E}-05$ & $7.69 \mathrm{E}-07$ & $181 \mathrm{E}-05$ & $0.00 \mathrm{E}+00$ & $1.07 \mathrm{E}-04$ & 16.92 & 8236 \\
\hline
\end{tabular} \begin{tabular}{l|llllllll}
\hline 816 & $1.89 E-04$ & $7.61 E-07$ & $232 E-05$ & $0.00 E+00$ & $2.13 E-04$ & 10.89 & 8875 \\
\hline
\end{tabular}

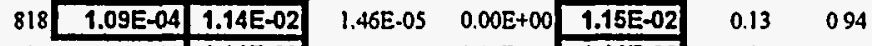
$\begin{array}{rrrrrrrrrr}819 & 0.00 \mathrm{E}+00 & 1.14 \mathrm{E}-02 & 179 \mathrm{E}-05 & 0.00 \mathrm{E}+00 & 1.14 \mathrm{E}-02 & 0.16 & 0 \\ 820 & 5.72 \mathrm{E}-05 & 4.71 \mathrm{E} .06 & 206 \mathrm{E}-05 & 0.00 \mathrm{E}+\infty & 8.25 \mathrm{E}-05 & 2492 & 6937\end{array}$ $\begin{array}{rrrrrrrrr}820 & 5.72 \mathrm{E}-05 & 4.71 \mathrm{E}-06 & 206 \mathrm{E}-05 & 0.00 \mathrm{E}+\infty & 8.25 \mathrm{E}-05 & 2492 & 6937 \\ 821 & 0.00 \mathrm{E}+00 & 8.42 \mathrm{E}-06 & 1.89 \mathrm{E}-05 & 0.00 \mathrm{E}+\infty & 2.73 \mathrm{E}-05 & 69.19 & 0\end{array}$ $\begin{array}{lllllll}822 & 3.25 \mathrm{E}-05 & 7.44 \mathrm{E} .06 & 292 \mathrm{E}-05 & 0.00 \mathrm{E}+00 & 6.92 \mathrm{E}-05 & 4225\end{array}$ $\begin{array}{llllllll}823 & 0.00 \mathrm{E}+00 & 7.17 \mathrm{E}-06 & 2.29 \mathrm{E}-05 & 0.00 \mathrm{E}+00 & 3.00 \mathrm{E}-05 & 76.12\end{array}$ $\begin{array}{llllllll}824 & 3.70 E-04 & 1.38 \mathrm{E}-05 & 169 \mathrm{E}-05 & 0.00 \mathrm{E}+00 & 4.01 E-04 & 421\end{array}$ \begin{tabular}{lllllllll}
\hline 825 & $7.62 \mathrm{E}-05$ & $9.00 \mathrm{E}-04$ & $504 \mathrm{E}-05$ & $0.00 \mathrm{E}+00$ & $1.03 \mathrm{E}-03$ & 491 \\
\hline
\end{tabular} \begin{tabular}{llllllllll}
826 & $7.90 \mathrm{E}-05$ & $8.83 \mathrm{E}-06$ & $186 \mathrm{E}-05$ & $0.00 \mathrm{E}+\infty$ & $\mathbf{1 . 0 6 E}-04$ & 17.49 & 74.21 \\
\hline
\end{tabular} $\begin{array}{llllllllll}827 & 3.06 E-04 & 113 E-05 & 193 E-05 & 0.00 E+00 & 3.36 E-04 & 5.75 & 90.9\end{array}$ $\begin{array}{lllllllllll}828 & 3.48 E-04 & 1 & 45 E-06 & 140 E-05 & 0.00 E+00 & 3.63 E-04 & 3.85 & 9575\end{array}$ \begin{tabular}{l|l|lll|l|l|l}
829 & $4.06 E-04$ & $2.82 \mathrm{E}-06$ & $3.08 \mathrm{E}-05$ & $000 \mathrm{E}+00$ & $4.40 \mathrm{E}-04$ & 7 & 9236
\end{tabular}

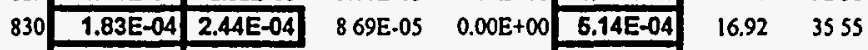
\begin{tabular}{llllllllll}
873 & $1.83 E-04$ & $6.83 E-07$ & $2.64 E-05$ & $7.06 E-07$ & $2.11 E-04$ & 12.52 & 86.82 \\
\hline
\end{tabular} \begin{tabular}{lll|l|l|l|l|l|l}
874 & $0.00 E+\infty$ & $2.52 E-04$ & $1.97 E-03$ & $5.61 E-07$ & $2.22 E-03$ & 88.62 \\
\hline
\end{tabular} $\begin{array}{lllllllll}875 & 0.00 E+00 & 1.59 E-03 & 1.39 E-02 & 4.99 E-06 & 1.56 E-02 & 89.74\end{array}$ \begin{tabular}{lllllllll}
876 & $0.00 E+\infty 0$ & $2.24 \mathrm{E}-07$ & $3.88 \mathrm{E}-04$ & $0.00 \mathrm{E}+00$ & $3.88 \mathrm{E}-04$ & 9994 \\
\hline
\end{tabular} $\begin{array}{lllllllll}877 & 0.00 E+00 & 2.66 E-04 & 4.33 E-05 & 5.47 E-07 & 3.09 E-04 & 13.99\end{array}$ $\begin{array}{llllllllll}878 & 0.00 E+\infty & 2.53 E-04 & 302 E-06 & 3.90 E-07 & 2.56 E-04 & 1.18\end{array}$ $\begin{array}{llllllll}879 & 0.00 \mathrm{E}+00 & 0.00 \mathrm{E}+00 & 610 \mathrm{E} .06 & 0.00 \mathrm{E}+00 & 6.10 \mathrm{E} .06 & 100\end{array}$ $\begin{array}{lllllll}880 & 0.00 \mathrm{E}+00 & 2.53 \mathrm{E}-04 & 4.63 \mathrm{E}-06 & 0.00 \mathrm{E}+\infty & 2.57 \mathrm{E}-04 & 1.8\end{array}$ $\begin{array}{lllllllll}881 & 0.00 E+00 & 8.75 E-04 & 508 E-06 & 4.17 E-07 & 8.81 E-04 & 0.58\end{array}$ $\begin{array}{lllllllll}882 & 0.00 \mathrm{E}+00 & 0.00 \mathrm{E}+00 & 3.50 \mathrm{E} \cdot 05 & 4.10 \mathrm{E}-07 & 3.54 \mathrm{E}-05 & 98.84\end{array}$ $\begin{array}{llllllll}884 & 0.00 E+00 & 2.52 E-04 & 2.00 E-04 & 0.00 E+00 & 1.53 E-04 & 44.27\end{array}$ \begin{tabular}{llllllll}
885 & $0.00 E+00$ & $2.02 E-04$ & $1.18 E-03$ & $0.00 E+00$ & $1.38 E-03$ & 8539 \\
\hline
\end{tabular} $\begin{array}{llllllll}886 & 0.00 \mathrm{E}+00 & 0.00 \mathrm{E}+00 & 1.55 \mathrm{E}-05 & 0.00 \mathrm{E}+00 & 1.55 \mathrm{E}-05 & 100\end{array}$ $\begin{array}{llllllll}946 & 6.71 \mathrm{E}-05 & 4.92 \mathrm{E}-06 & 3.32 \mathrm{E}-05 & 0.00 \mathrm{E}+00 & 1.05 \mathrm{E}-04 & 31.56\end{array}$ $\begin{array}{llllllll}947 & 6.81 \mathrm{E}-05 & 1.52 \mathrm{E}-06 & 3.30 \mathrm{E}-05 & 0.00 \mathrm{E}+00 & 1.03 \mathrm{E}-04 & 32.18\end{array}$ \begin{tabular}{lllllllll}
1100 & $0.00 E+00$ & $4.33 E-04$ & $2.43 E-04$ & $0.00 E+00$ & $6.77 E-04$ & 35.98 \\
\hline
\end{tabular} \begin{tabular}{llllllllll}
1101 & $0.00 E+00$ & $2.67 E-04$ & $6.39 E-04$ & $3.21 E-06$ & $9.09 E-04$ & 70.32 \\
\hline
\end{tabular} \begin{tabular}{lllllllll}
1102 & $0.00 E+00$ & $5.67 E-04$ & $1.47 E-03$ & $2.55 E-05$ & $2.04 E-03$ & 72.05 \\
\hline
\end{tabular} $\begin{array}{lllllllll}1103 & 000 E+\infty & 7.56 E-04 & 2.62 E-04 & 0.00 E+00 & 1.02 E-03 & 25.71\end{array}$ $\begin{array}{llllllll}1104 & 000 \mathrm{E}+00 & 927 \mathrm{E}-06 & 9.04 \mathrm{E}-04 & 000 \mathrm{E}+00 & 9.14 \mathrm{E}-04 \\ 9899\end{array}$$$
0 \quad 0
$$
$\begin{array}{ll}0 & 026 \\ 0 & 2.21\end{array}$ $\begin{array}{ll}0 & 2.21 \\ 0 & 0.17\end{array}$ $0 \quad 48.49$ 3.41 $\begin{array}{ll}0 & 3.41 \\ 0 & 0.34\end{array}$ $2.02 \quad 0.05$ $\begin{array}{lll}0 & 12.53 \\ & 0 & 98.12\end{array}$ $\begin{array}{ll}0 & 98.12\end{array}$ $\begin{array}{rr}0 & 98.12 \\ 0 & 0.72\end{array}$

ALIAS EASTING NORTHING $\begin{array}{lll}32-22.6 & 32722 & 22599.09\end{array}$

$\begin{array}{ll}29657.3 & 20082.9 \\ 30008.5 & 20909.3\end{array}$

$30018.6 \quad 20910.2$

$29652.5 \quad 21142.9$

$29539.2 \quad 21879.3$

$29652.3 \quad 22002.7$

$29931.4 \quad 22350.4$

22615

$\begin{array}{rr}30999.2 & 22831.8 \\ 31746.3 & 23144\end{array}$

$31746.7 \quad 23134.2$

$32390.3 \quad 22564.6$

$32714.9 \quad 22382.4$

$32422 \quad 22341.8$

$32436 \quad 22340.7$

$\begin{array}{ll}32116.7 & 22262.8 \\ 32141.8 & 22057.3\end{array}$

$31932 \quad 21399.2$

$31666.2 \quad 21388.3$

$316544 \quad 21387.3$

$30813.5 \quad 21012.5$

$30741.4 \quad 20815.2$

$30557.1 \quad 21026.1$

$\begin{array}{lll}31-002 & 30833.78 & 21692.62\end{array}$

$31.003 \quad 30943.46 \quad 21473.94$

$31.004 \quad 3105884 \quad 21465.27$

$\begin{array}{lll}31.005 & 31265.94 & 21276.72\end{array}$

$31.006 \quad 31295.73 \quad 21248.33$

$\begin{array}{lll}31.007 & 3130994 & 21430.25\end{array}$

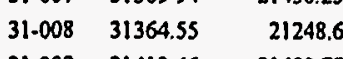

$31.009 \quad 31413.46 \quad 2140077$

$\begin{array}{lll}31.010 & 31397.07 & 21299.26\end{array}$

$\begin{array}{lll}31.012 & 3125519 & 21359.68\end{array}$

$\begin{array}{lll}31.013 & 30949.28 & 21468.07\end{array}$

$31.015 \quad 30884.43 \quad 21696.3$

$30646.76 \quad 21091.05$

$30666.93 \quad 21061.66$

3513_1 $3115739 \quad 21463.3$

3513_IA $3115527 \quad 2146219$

$3513 \_2 \quad 3114145 \quad 21180.43$

$3513_{3} 3 \quad 3100921 \quad 2118033$

$3513 \_3097003 \quad 21281.89$ 
WELL Metal_Rsk Org_Rsk Rad_Rsk TRU_Rsk Total_Rsk Rad_\% Met_\% TRU_\% Org_\% $\begin{array}{llllllllll}2531 & 0.00 \mathrm{E}+00 & 3.41 \mathrm{E}-06 & 6.74 \mathrm{E}-05 & 6.82 \mathrm{E}-07 & 7.15 \mathrm{E}-05 & 94.27 & 0 & 0.95 & 4.77\end{array}$ \begin{tabular}{llllllll}
2533 & $1.02 E-04$ & $0.00 E+00$ & $7.86 E-06$ & $0.00 E+00$ & $1.09 E-04$ & 7.18 \\
\hline
\end{tabular} \begin{tabular}{l|llllll|}
\hline 4003 & $2.87 E-04$ & $4.41 \mathrm{E}-06$ & $5.48 \mathrm{E}-06$ & $0.00 \mathrm{E}+00$ & $2.97 \mathrm{E}-04$ & 1.85 \\
\hline
\end{tabular} \begin{tabular}{llllllll}
4004 & $1.27 E-04$ & $3.90 E-07$ & $1.45 E-05$ & $0.00 E+00$ & $1.42 E-04$ & 10.21 \\
\hline
\end{tabular} \begin{tabular}{l|l|l|l|l|l|l|}
4005 & $1.05 E-04$ & $2.55 E-04$ & $2.11 E-01$ & $1.16 E-03$ & $2.12 E-01$ & 99.36 \\
\hline
\end{tabular} 92.82 \begin{tabular}{|l|l|l|l|l|l|l|}
\hline 4006 & $1.12 E-04$ & $7.08 E-04$ & $3.70 \mathrm{E}-05$ & $0.00 \mathrm{E}+00$ & $8.57 \mathrm{E}-04$ & 4.32 \\
\hline
\end{tabular} 96.67 $\begin{array}{llllllllll}4008 & 0.00 E+00 & 0.00 E+00 & 3.02 E-04 & 6.18 E-06 & 3.09 E-04 & 98\end{array}$ $\begin{array}{llllllll}4009 & 0.00 \mathrm{E}+\infty 0 & 3.90 \mathrm{E}-07 & 4.68 \mathrm{E}-06 & 0.00 \mathrm{E}+00 & 5.07 \mathrm{E}-06 & 92.32\end{array}$ $\begin{array}{lllllll}1150 & 0.00 \mathrm{E}+00 & 1.02 \mathrm{E}-06 & 1.21 \mathrm{E}-05 & 0.00 \mathrm{E}+00 & 1.31 \mathrm{E}-05 & 92.17\end{array}$

$\begin{array}{llllllll}1151 & 0.00 \mathrm{E}+00 & 0.00 \mathrm{E}+00 & 3.96 \mathrm{E}-05 & 0.00 \mathrm{E}+00 & 3.96 \mathrm{E}-05 & 100\end{array}$

$\begin{array}{llllllllll}1152 & 0.00 E+00 & 6.32 E-07 & 3.57 E-04 & 0.00 E+00 & 3.57 E-04 & 99.82\end{array}$

$\begin{array}{lllllllll}1153 & 0.00 E+\infty & 6.32 \mathrm{E}-07 & 2.54 \mathrm{E}-05 & 0.00 \mathrm{E}+00 & 2.61 \mathrm{E}-05 & 9757\end{array}$

$\begin{array}{lllllll}1154 & 0.00 \mathrm{E}+00 & 1.26 \mathrm{E}-06 & 2.86 \mathrm{E}-05 & 0.00 \mathrm{E}+00 & 2.99 \mathrm{E}-05 & 9577\end{array}$

$\begin{array}{lllllll}1155 & 0.00 \mathrm{E}+00 & 1.26 \mathrm{E}-06 & 1.51 \mathrm{E}-05 & 0.00 \mathrm{E}+\infty & 1.64 \mathrm{E}-05 & 9228\end{array}$

$\begin{array}{lllllllll}1156 & 0.00 \mathrm{E}+00 & 6.32 \mathrm{E}-07 & \mathbf{3 . 1 7 E}-04 & 0.00 \mathrm{E}+00 & \mathbf{3 . 1 7 E}-04 & 99.8\end{array}$

$\begin{array}{llllllll}1185 & 0.00 \mathrm{E}+\infty & 5.67 \mathrm{E} .06 & 1.25 \mathrm{E} .05 & 0.00 \mathrm{E}+\infty & 1.81 \mathrm{E}-05 & 687\end{array}$

$\begin{array}{lllllll}1186 & 0.00 \mathrm{E}+00 & 000 \mathrm{E}+00 & 165 \mathrm{E}-05 & 0.00 \mathrm{E}+\infty 0 & 1.65 \mathrm{E}-05 & 100\end{array}$

$\begin{array}{lllllll}1187 & 0.00 E+\infty & 000 E+00 & 104 E-05 & 000 E+\infty 0 & 1.04 E-05 & 100\end{array}$

$\begin{array}{lllllll}1188 & 0.00 \mathrm{E}+00 & 0.00 \mathrm{E}+00 & 128 \mathrm{E} .05 & 0.00 \mathrm{E}+00 & 1.28 \mathrm{E}-05 & 100\end{array}$

$\begin{array}{lllllll}1189 & 0.00 \mathrm{E}+00 & 2.73 \mathrm{E}-06 & 311 \mathrm{E}-05 & 0.00 \mathrm{E}+00 & 3.38 \mathrm{E}-05 & 9193\end{array}$

$\begin{array}{lllllllll}1190 & 000 \mathrm{E}+00 & 6.18 \mathrm{E}-04 & 9.80 \mathrm{E}-05 & 0.00 \mathrm{E}+00 & 7.16 \mathrm{E}-04 & 1368\end{array}$

$\begin{array}{llllllllll}1191 & 0.00 E+00 & 205 E-06 & 8.85 E-04 & 0.00 E+00 & 8.87 E-04 & 99.77\end{array}$

$\begin{array}{lllllll}1192 & 0.00 \mathrm{E}+00 & 239 \mathrm{E}-06 & 345 \mathrm{E}-05 & 0.00 \mathrm{E}+00 & 3.69 \mathrm{E}-05 & 93.52\end{array}$

$\begin{array}{lllllll}1193 & 0.00 \mathrm{E}+00 & 0.00 \mathrm{E}+00 & 273 \mathrm{E}-05 & 0.00 \mathrm{E}+00 & 2.73 \mathrm{E}-05 & 100\end{array}$

$\begin{array}{lllllllll}1194 & 1.40 E-04 & 0.00 E+00 & 903 \mathrm{E}-06 & 0.00 \mathrm{E}+00 & 1.49 \mathrm{E}-04 & 606 & 93.94\end{array}$

\begin{tabular}{llllllll}
1195 & $1.18 \mathrm{E}-04$ & $0.00 \mathrm{E}+00$ & $6.42 \mathrm{E}-06$ & $0.00 \mathrm{E}+00$ & $1.24 \mathrm{E}-04$ & 516 \\
\hline
\end{tabular}

$\begin{array}{llllllllllllll}1244 & 0.00 E+00 & 0.00 E+00 & 1.82 E-04 & 0.00 E+00 & 1.82 E-04 & 100\end{array}$

$\begin{array}{lllllllll}1245 & 0.00 \mathrm{E}+00 & 2.39 \mathrm{E}-06 & 800 \mathrm{E}-06 & 0.00 \mathrm{E}+00 & 1.04 \mathrm{E}-05 & 7699\end{array}$ $\begin{array}{lllllll}985 & 0.00 \mathrm{E}+00 & 000 \mathrm{E}+00 & 249 \mathrm{E}-05 & 000 \mathrm{E}+00 & 2.49 \mathrm{E}-05 & 100\end{array}$

$\begin{array}{lllllll}986 & 1.18 E-04 & 0.00 E+00 & 131 E-05 & 0.00 E+00 & 1.31 E-04 & 10.01\end{array}$

$\begin{array}{lllllllll}987 & 0.00 \mathrm{E}+00 & 0.00 \mathrm{E}+00 & 2.61 \mathrm{E} .05 & 0.00 \mathrm{E}+00 & 2.61 \mathrm{E}-05 & 100\end{array}$

$\begin{array}{lllllll}988 & 0.00 \mathrm{E}+00 & 0.00 \mathrm{E}+00 & 5.50 \mathrm{E}-06 & 0.00 \mathrm{E}+\infty & 5.50 \mathrm{E}-06 & 100\end{array}$

$\begin{array}{lllllll}990 & 0.00 \mathrm{E}+00 & 0.00 \mathrm{E}+00 & 195 \mathrm{E}-05 & 0.00 \mathrm{E}+00 & 1.95 \mathrm{E}-05 & 100\end{array}$

$\begin{array}{llllllll}991 & 0.00 E+00 & 341 \mathrm{E}-07 \quad 1.54 \mathrm{E}-05 & 0.00 \mathrm{E}+00 & 1.57 \mathrm{E}-05 & 9783\end{array}$

\begin{tabular}{l|c|c|c|c|c|c|}
992 & $1.24 E-04$ & $000 E+00$ & $1.20 E-04$ & $0.00 E+00$ & $2.44 E-04$ & 4929 \\
993 & $0.00 E+00$ & $1.90 E-06$ & $1.63 E-04$ & $0.00 E+00$ & $1.64 E-04$ & 98.85
\end{tabular}

\begin{tabular}{rrrr|r|r|r|r}
993 & $0.00 E+00$ & $1.90 E-06$ & $1.63 E-04$ & $0.00 E+00$ & $1.64 E-04$ & 98.85 \\
994 & $0.00 E+\infty$ & $0.00 E+00$ & $5.48 E-04$ & $0.00 E+00$ & $5.48 E-04$ & 100
\end{tabular}

$\begin{array}{llllllll}995 & 0.00 \mathrm{E}+00 & 224 \mathrm{E}-07 & 1.10 \mathrm{E}-05 & 0.00 \mathrm{E}+00 & 1.12 \mathrm{E}-05 & 98\end{array}$

$\begin{array}{llllllll}996 & 0.00 \mathrm{E}+00 & 224 \mathrm{E}-07 & 7.30 \mathrm{E}-06 & 0.00 \mathrm{E}+00 & 7.53 \mathrm{E}-06 & 97.02\end{array}$

$\begin{array}{llllllll}997 & 0.00 \mathrm{E}+00 & 2.24 \mathrm{E}-07 & 8.89 \mathrm{E}-05 & 0.00 \mathrm{E}+00 & 8.91 \mathrm{E}-05 & 99.75\end{array}$

$\begin{array}{llllllll}998 & 0.00 \mathrm{E}+00 & 323 \mathrm{E}-06 & 1.17 \mathrm{E}-05 & 0.00 \mathrm{E}+00 & 1.49 \mathrm{E}-05 & 7838\end{array}$

$\begin{array}{lllllll}1248 & 1.08 E-04 & 5.85 E-07 & 474 E-05 & 0.00 E+00 & 1.56 E-04 & 30.43\end{array}$

$\begin{array}{llllllll}948 & 0.00 \mathrm{E}+00 & 0.00 \mathrm{E}+00 & 569 \mathrm{E}-06 & 0.00 \mathrm{E}+00 & 5.69 \mathrm{E}-06 & 100\end{array}$

$\begin{array}{llllllll}949 & 0.00 E+00 & 116 \mathrm{E}-05 & 392 \mathrm{E}-05 & 0.00 \mathrm{E}+00 & 5.07 \mathrm{E}-05 & 77.19\end{array}$

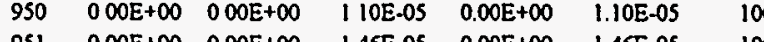

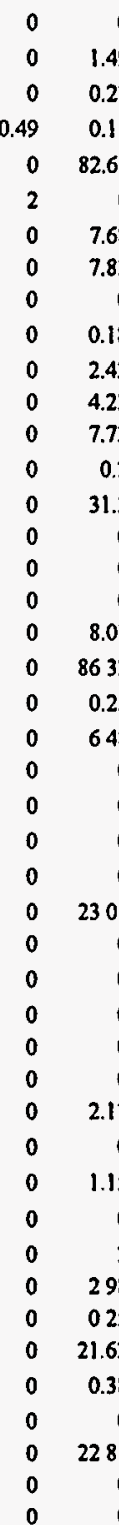

ALIAS EASTING NORTHING

$\begin{array}{lll}\text { CH.1 } & 31969.39 & 23184.76\end{array}$

$\begin{array}{lll}\mathrm{CH}-3 & 31954.89 & 22192.81\end{array}$

CH-6 $30839.76 \quad 22919.02$

$\begin{array}{lll}\text { CH-7A } \quad 30430.54 & 22499.98\end{array}$

$\begin{array}{lll}\text { CH.8 } & 30659.35 & 22211.96\end{array}$

$\begin{array}{lll}\text { CH-9 } & 30850.47 & 21244.27\end{array}$

$\begin{array}{lll}\text { CH-11A } & 29656.75 & 21784.79\end{array}$

CH.12 29651.05 21171.97

$29620.1 \quad 19298.55$

$31761.37 \quad 18531.44$

$32503.04 \quad 16470.82$

$33324.88 \quad 17395.67$

$32693.87 \quad 16191.49$

$30538.54 \quad 16676.57$

$27876.12 \quad 17001.93$

$26464.8 \quad 16343.85$

$\begin{array}{ll}2644378 & 16346.39\end{array}$

$24285.13 \quad 15183.27$

$24267.22 \quad 15170.51$

$23280.95 \quad 15146.78$

23387.36

$23358.39 \quad 1554238$

$2122591 \quad 15021.21$

$2104677 \quad 15736.11$

$21043.63 \quad 15716.88$

$25459.01 \quad 17155.45$

$25424.11 \quad 16900.21$

21833.81

$26674.67 \quad 21813.16$

$25857.89 \quad 21650.14$

$2547129 \quad 21075.73$

$24723.62 \quad 21657.34$

21736.64

$25069.69 \quad 21737.04$

$25619.08 \quad 21884.35$

$25639.92 \quad 21895.03$

$2586756 \quad 2201141$

$26458.18 \quad 21920.17$

$26467.5 \quad 21911.04$

$26235.94 \quad 20984.59$

$2465408 \quad 21366.92$

$2700143 \quad 18959.25$

$2700424 \quad 1897716$

28028.7
2859429 
WELL Metal_Rsk Org_Rsk Rad_Rsk TRU_Rsk Total_Rsk Rad_\% Met_\% TRU_\% ORB_\% $952 \quad 0.00 \bar{E}+00 \quad 4.49 \mathrm{E}-07 \quad 4.30 \mathrm{E}-05 \quad 0.00 \bar{E}+00 \quad 4.34 \mathrm{E}-05 \quad 98.97$ \begin{tabular}{lllllllll}
953 & $0.00 \mathrm{E}+00$ & $4.46 \mathrm{E}-07$ & $8.21 \mathrm{E}-06$ & $0.00 \mathrm{E}+00$ & $8.65 \mathrm{E}-06$ & 94.85 \\
\hline & $0.00 \mathrm{E}+0$ & $9.70 \mathrm{E}-02$ & $3.68 \mathrm{E}-04$ & $0.00 \mathrm{E}$ & $\mathbf{1 0 0}$ & $1.74 \mathrm{E}-02$ & 2.09
\end{tabular} $\begin{array}{llllllll}954 & 0.00 E+00 & 1.70 E-02 & 3.68 E-04 & 0.00 E+00 & 1.74 E-02 & 2.09\end{array}$ $\begin{array}{llllllllll}955 & 0.00 E+00 & 1.97 E-04 & 6.45 E-04 & 0.00 E+00 & 8.42 E-04 & 76.63\end{array}$ $\begin{array}{lllllllll}956 & 0.00 \mathrm{E}+00 & 8.57 \mathrm{E}-07 & \mathbf{7 . 4 1 E - 0 4} & 0.00 \mathrm{E}+00 & \mathbf{7 . 4 2 E - 0 4} & 99.88\end{array}$ $\begin{array}{llllllllll}957 & 0.00 E+\infty & 4.92 E-07 & 7.92 E-03 & 0.00 E+00 & 7.92 E-03 & 99.99\end{array}$

$\begin{array}{lllllllllll}958 & 0.00 \mathrm{E}+00 & 5.38 \mathrm{E}-02 & 1.05 \mathrm{E}-02 & 0.00 \mathrm{E}+00 & 6.37 \mathrm{E}-02 & 15.97\end{array}$ $9590.00 \mathrm{E}+00 \quad 0.00 \mathrm{E}+\infty 0^{2} \quad 266 \mathrm{E}-05 \quad 0.00 \mathrm{E}+00 \quad 2.66 \mathrm{E}-05 \quad 100$ $\begin{array}{lllllll}960 & 0.00 \mathrm{E}+00 & 6.46 \mathrm{E}-07 & 1.06 \mathrm{E}-04 & 0.00 \mathrm{E}+00 & 1.07 \mathrm{E}-04 & 99.4\end{array}$ $\begin{array}{llllllll}961 & 0.00 \mathrm{E}+00 & 0.00 \mathrm{E}+00 & 3.39 \mathrm{E}-05 & 0.00 \mathrm{E}+00 & 3.39 \mathrm{E}-05 & 100\end{array}$ $\begin{array}{llllllll}962 & 0.00 E+00 & 0.00 E+00 & 2.05 E-05 & 0.00 E+00 & 2.05 E-05 & 100\end{array}$ $\begin{array}{lllllll}440 & 2.54 E-04 & 0.00 E+00 & 3.11 E-02 & 7.92 E-05 & 3.15 E-02 & 98.96\end{array}$ \begin{tabular}{|llllllll}
441 & $0.00 \mathrm{E}+00$ & $0.00 \mathrm{E}+00$ & $6.08 \mathrm{E}-04$ & $7.48 \mathrm{E}-06$ & $6.15 E-04$ & 98.78 \\
\hline
\end{tabular} \begin{tabular}{llllllll}
468 & $1.63 E-04$ & $0.00 E+00$ & $3.40 E-05$ & $4.28 E-06$ & $2.01 E-04$ & 16.95 \\
\hline
\end{tabular}

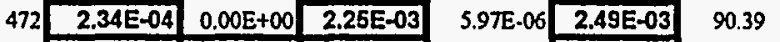
\begin{tabular}{l|l|l|l|l|l|l|}
\hline 476 & $1.83 E-04$ & $2.81 E-04$ & $1.69 E-02$ & $6.40 E-05$ & $1.74 E-02$ & 97
\end{tabular} $\begin{array}{llllllll}513 & 0.00 \mathrm{E}+00 & 0.00 \mathrm{E}+00 & 4.08 \mathrm{E}-05 & 9.90 \mathrm{E}-06 & 5.07 \mathrm{E}-05 & 80.48\end{array}$ $\begin{array}{llllllll}514 & 0.00 E+00 & 0.00 E+00 & 2.61 E-06 & 0.00 E+00 & 2.61 E-06 & 100\end{array}$ $\begin{array}{lllllll}516 & 7.42 \mathrm{E}-05 & 0.00 \mathrm{E}+00 & 6.09 \mathrm{E}-04 & 9.57 \mathrm{E}-06 & 6.93 \mathrm{E}-04 & 87.91\end{array}$ $\begin{array}{llllllll}518 & 0.00 \mathrm{E}+00 & 0.00 \mathrm{E}+00 & 2.51 \mathrm{E}-06 & 0.00 \mathrm{E}+00 & 2.51 \mathrm{E}-06 & 100 \\ 519 & 0.00 \mathrm{E}+00 & 0.00 \mathrm{E}+00 & 1.64 \mathrm{E}-04 & 1.45 \mathrm{E}-05 & \mathbf{1 . 7 8 E - 0 4} & 91.88\end{array}$ $\begin{array}{rrrrrrrrr}519 & 000 \mathrm{E}+00 & 0.00 \mathrm{E}+00 & 1.64 \mathrm{E}-04 & 1.45 \mathrm{E}-05 & 1.78 \mathrm{E}-04 & 91.88 \\ 520 & 0.00 \mathrm{E}+00 & 0.00 \mathrm{E}+0 & 9.08 \mathrm{E}-07 & 0.00 \mathrm{E}+00 & 9.08 \mathrm{E}-07 & 100\end{array}$ $\begin{array}{lllllllll}521 & 0.00 \mathrm{E}+00 & 0.00 \mathrm{E}+00 & 9.27 \mathrm{E}-07 & 1.88 \mathrm{E}-04 & 1.89 \mathrm{E}-04 & 0.49\end{array}$ \begin{tabular}{llllllll}
522 & $000 \mathrm{E}+00$ & $0.00 \mathrm{E}+00$ & $1.01 \mathrm{E}-04$ & $0.00 \mathrm{E}+00$ & $1.01 \mathrm{E}-0.4$ \\
\hline
\end{tabular} $\begin{array}{lllllllll}523 & 0.00 \mathrm{E}+00 & 0.00 \mathrm{E}+00 & 7.66 \mathrm{E} \cdot 05 & 8.57 \mathrm{E} .06 & 8.52 \mathrm{E}: 05 & 89.93\end{array}$

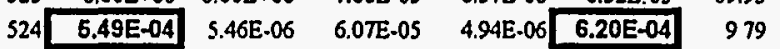
$\begin{array}{lllllll}525 & 0.00 \mathrm{E}+00 & 0.00 \mathrm{E}+00 & 1.45 \mathrm{E}-05 & 1.73 \mathrm{E} .06 & 1.62 \mathrm{E}-05 & 89.32\end{array}$ $\begin{array}{llllllll}526 & 0.00 \mathrm{E}+00 & 2.80 \mathrm{E}-05 & 2.31 \mathrm{E}-05 & 6.22 \mathrm{E}-07 & 5.17 \mathrm{E}-05 & 44.68\end{array}$ $\begin{array}{llllllll}708 & 0.00 \mathrm{E}+00 & 0.00 \mathrm{E}+00 & 4.77 \mathrm{E}-05 & 7.47 \mathrm{E}-06 & 5.52 \mathrm{E}-05 & 86.47\end{array}$ $\begin{array}{lllllll}715 & 0.00 E+00 & 000 E+00 & 2.87 E-04 & 9.18 E-06 & 2.96 E-04 & 969\end{array}$ \begin{tabular}{llllllll}
716 & $1.32 \mathrm{E}-04$ & $0.00 \mathrm{E}+\infty$ & $1.75 \mathrm{E}-05$ & $6.99 \mathrm{E}-07$ & $1.50 \mathrm{E}-04$ \\
\hline
\end{tabular} $\begin{array}{llllllll}963 & 3.25 \mathrm{E}-05 & 0.00 \mathrm{E}+00 & 9.71 \mathrm{E}-06 & 5.56 \mathrm{E}-07 & 4.28 \mathrm{E}-05 & 22.71\end{array}$ $\begin{array}{llllllll}964 & 0.00 \mathrm{E}+00 & 5.93 \mathrm{E}-06 & 2.19 \mathrm{E}-05 & 1.12 \mathrm{E}-06 & 2.90 \mathrm{E}-05 & 7566\end{array}$ $\begin{array}{lllllll}965 & 0.00 E+00 & 1.91 \mathrm{E}-05 & 2.80 \mathrm{E}-05 & 1.20 \mathrm{E}-06 & 4.84 \mathrm{E}-05 & 57.99\end{array}$ $966 \quad 000 \mathrm{E}+00 \quad 000 \mathrm{E}+00 \quad$ I.59E-05 $\quad 66 \mathrm{EE}-07 \quad$ 1.65E-05 95.97 $\begin{array}{llllllll}967 & 0.00 \mathrm{E}+00 & 0.00 \mathrm{E}+00 & 1.04 \mathrm{E}-04 & 8.36 \mathrm{E}-07 & 1.04 \mathrm{E}-04 & 99.2\end{array}$ \begin{tabular}{llll|l|l|l|l|l|l|l|l|l|l|l|}
968 & $0.00 \mathrm{E}+00$ & $0.00 \mathrm{E}+00$ & $3.30 \mathrm{E}-04$ & $1.49 \mathrm{E}-06$ & $3.32 \mathrm{E}-04$ & 99.55
\end{tabular}

\begin{tabular}{lll|l|l|l|l|l|l}
969 & $0.00 E+00$ & $4.00 E-04$ & $2.19 E-02$ & $6.62 \mathrm{E}-06$ & $2.23 \mathrm{E}-02$ & 98.2
\end{tabular}

$\begin{array}{llllllllll}970 & 0.00 E+00 & 0.00 E+00 & 1.32 E-03 & 1.14 E-06 & 1.32 E-03 & 99.91\end{array}$

$\begin{array}{llllllll}971 & 0.00 E+\infty 0 & 0.00 E+00 & 1.37 E-03 & 8.84 E-07 & 1.37 E-03 & 9994\end{array}$ $\begin{array}{llllllllll}972 & 0 & 00 \mathrm{E}+00 & 0.00 \mathrm{E}+00 & 6.25 \mathrm{E}-04 & 2.20 \mathrm{E}-06 & \mathbf{5 . 2 7 E}-04 & 99.58\end{array}$ $\begin{array}{llllllll}973 & 0 & 00 E+\infty & 1.30 E-03 & 2.80 E-01 & 1.05 E-05 & 2.81 E-01 & 996\end{array}$ $\begin{array}{llllllllll}974 & 0.00 E+\infty & 7.69 E-07 & 9.07 E-02 & 7.21 E-06 & 9.07 E-02 & 99.99\end{array}$ \begin{tabular}{|l|l|l|l|l|l|l|}
975 & $000 \mathrm{E}+00$ & $1.91 E-03$ & $9.33 E-03$ & $4.40 \mathrm{E}-06$ & $1.12 E-02$ & 8301 \\
\hline
\end{tabular}

\begin{tabular}{|c|c|c|}
\hline & & \\
\hline 0 & 0 & 1.03 \\
\hline 0 & 0 & 5.15 \\
\hline 0 & 0 & 97.9 \\
\hline 0 & 0 & 23.37 \\
\hline 0 & 0 & 0.12 \\
\hline 0 & 0 & 0.01 \\
\hline 0 & 0 & 84.03 \\
\hline 0 & 0 & 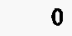 \\
\hline 0 & 0 & 0. \\
\hline 0 & 0 & \\
\hline 0 & 0 & \\
\hline 0.79 & 0.25 & \\
\hline 0 & 1.22 & \\
\hline 80.92 & 2.13 & \\
\hline 9.37 & 0.24 & \\
\hline 1.04 & 0.36 & 1.59 \\
\hline 0 & 19.52 & \\
\hline 0 & 0 & \\
\hline 10.71 & 1.38 & \\
\hline 0 & 61.65 & \\
\hline 0 & 0 & \\
\hline 0 & 8.12 & \\
\hline 0 & 0 & \\
\hline 0 & 99.51 & \\
\hline 0 & 0 & \\
\hline 0 & 10.07 & \\
\hline 88.53 & 0.8 & 0.88 \\
\hline 0 & 10.68 & \\
\hline 0 & 1.2 & 54.1 \\
\hline 0 & 13.53 & \\
\hline 0 & 3.1 & ( \\
\hline 87.88 & 0.47 & 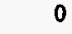 \\
\hline 75.99 & 1.3 & \\
\hline 0 & 3.86 & 20.4 \\
\hline 0 & 2.47 & 39.5 \\
\hline 0 & 4.03 & \\
\hline 0 & 0.8 & \\
\hline 0 & 0.45 & \\
\hline 0 & 0.03 & 1.7 \\
\hline 0 & 0.09 & \\
\hline 0 & 0.06 & \\
\hline 0 & 0.42 & \\
\hline 0 & 0 & 035 \\
\hline 0 & 001 & \\
\hline 0 & 004 & 169 \\
\hline
\end{tabular}

ALIAS EASTING NORTHING $28670.76 \quad 19597.79$ $28686.09 \quad 19594.13$

$29252.93 \quad 19252.06$

$29239.15 \quad 19243.54$

28935.51 19123.72

$28861 \quad 18908.93$

$28857.05 \quad 18900.37$

$28682.44 \quad 18729.07$

28674.37 18742.04

$27371.38 \quad 18799.18$

$29382 \quad 17280$

$29604 \quad 17822$

$28551 \quad 17457$

$29914 \quad 18026$

$30532 \quad 17265$

$29209 \quad 18440$

$29537 \quad 18452$

$29324-18679$

18937

18752

$30024 \quad 18681$

$29918 \quad 18896$

$29805 \quad 19040$

$29703 \quad 19220$

$30163 \quad 19012$

$30279 \quad 18871$

$\begin{array}{lll}29-18.7 & 29264.52 & 18778.57\end{array}$

29-18.7 $29589.45 \quad 18752.99$

$\begin{array}{lll}29.18 .7 & 29205.86 & 18535.72\end{array}$

$29700.02 \quad 19045.24$

$30100.95 \quad 18844.95$

$30072.06 \quad 18398.53$

$30202.04 \quad 18332.79$

30447.16 18179.87

$30573.52 \quad 17803.81$

$30610.4 \quad 17371.21$

$30614.63 \quad 17350.89$

$30380.97 \quad 16982.7$

$29852.63 \quad 16891.93$

$2984149 \quad 16897.75$

$29425.68 \quad 1697292$

$29013.7 \quad 16984.39$ 
WELL Meta__Rsk Org_Rsk Rad Rsk TRU_Rsk Total Rsk Rad_\% Met_\% TRU_\% Org_\%

\begin{tabular}{llllllll}
976 & $0.00 \mathrm{E}+\infty$ & $0.00 \mathrm{E}+\infty$ & $6.91 \mathrm{E}-03$ & $2.51 \mathrm{E}-06$ & $\mathbf{6 . 9 1 E - 0 3}$ & 99.96 \\
\hline
\end{tabular}

\begin{tabular}{lllllllll}
977 & $0.00 E+00$ & $1.06 E-03$ & $7.64 E-03$ & $5.40 E-07$ & $8.70 E-03$ & 87.83 \\
\hline
\end{tabular}

$\begin{array}{lllllllll}978 & 3.15 \mathrm{E}-05 & 1.95 \mathrm{E}-01 & 1.43 \mathrm{E}-03 & 1.29 \mathrm{E}-06 & 1.96 \mathrm{E}-01 & 0.66\end{array}$

$\begin{array}{lllllll}979 & 0.00 \mathrm{E}+00 & 6.32 \mathrm{E}-07 & 6.99 \mathrm{E}-05 & 8.53 \mathrm{E}-07 & 7.14 \mathrm{E}-05 & 9792\end{array}$

$\begin{array}{llllllll}980 & 0.00 \mathrm{E}+00 & 0.00 \mathrm{E}+00 & 2.02 \mathrm{E}-05 & 1.23 \mathrm{E}-06 & 2.15 \mathrm{E}-05 & 9429\end{array}$

$\begin{array}{llllllll}981 & 0.00 E+00 & 3.15 E-04 & 1.38 E-03 & 151 E-06 & 1.69 E-03 & 8132\end{array}$

$\begin{array}{llllllll}982 & 0.00 \mathrm{E}+00 & 3.41 \mathrm{E}-06 & 8.81 \mathrm{E}-05 & 1.73 \mathrm{E}-06 & 9.33 \mathrm{E}-05 & 9448\end{array}$

$\begin{array}{llllllll}983 & 3.25 \mathrm{E}-05 & 4.91 \mathrm{E}-06 & 4.58 \mathrm{E}-05 & 1.41 \mathrm{E}-06 & 8.46 \mathrm{E}-05 & 54.12\end{array}$

$\begin{array}{llllllll}984 & 9.47 \mathrm{E}-05 & 0.00 \mathrm{E}+00 & 2.21 \mathrm{E}-05 & 1.98 \mathrm{E}-06 & 1.19 \mathrm{E}-04 & 18.65\end{array}$

$\begin{array}{llllllllll}1105 & 0.00 \mathrm{E}+00 & 0.00 \mathrm{E}+00 & 2.38 \mathrm{E}-03 & 0.00 \mathrm{E}+00 & 2.38 \mathrm{E}-03 & 100\end{array}$

\begin{tabular}{lllllllll}
1106 & $0.00 \mathrm{E}+00$ & $3.62 \mathrm{E}-05$ & $2.08 \mathrm{E}-03$ & $2.51 \mathrm{E} \cdot 06$ & $2.12 \mathrm{E}-03$ & 98.17 \\
\hline
\end{tabular}

$\begin{array}{llllllll}1107 & 0.00 \mathrm{E}+00 & 0.00 \mathrm{E}+00 & 5.28 \mathrm{E}-03 & 0.00 \mathrm{E}+00 & 5.28 \mathrm{E}-03 & 100\end{array}$

\begin{tabular}{llllllll}
1108 & $0.00 E+00$ & $0.00 E+00$ & $3.31 E-02$ & $7.40 E-06$ & $3.31 E-02$ & 99.98 \\
\hline
\end{tabular}

\begin{tabular}{ll|l|l|l|l|l|}
4113 & $6.30 E-04$ & $0.00 E+00$ & $1.96 E-04$ & $2.82 E-06$ & $8.29 E-04$ & 23.69 \\
\hline
\end{tabular}

\begin{tabular}{l|l|l|l|l|l|l|}
4114 & $1.93 E-04$ & $6.39 E-04$ & $3.01 E-03$ & $1.02 E-01$ & $1.06 E-01$ & 2.69 \\
\hline
\end{tabular}

\begin{tabular}{ll|l|l|l|l|l|l}
4115 & $1.32 E-04$ & $1.71 E-06$ & $2.57 E-03$ & $9.53 E-08$ & $2.70 E-03$ & 95.05 \\
\hline
\end{tabular}

\begin{tabular}{llllllll}
4116 & $7.42 E-05$ & $2.74 E-05$ & $2.98 E-04$ & $4.61 E-06$ & $4.05 E-04$ & 73.75 \\
\hline
\end{tabular}

$\begin{array}{llllllll}4173 & 0.00 E+00 & 000 E+00 & 9.83 E-01 & 0.00 E+00 & 9.83 E-01 & 100\end{array}$

$\begin{array}{lllllll}4174 & 0.00 E+00 & 0.00 E+00 & 7.83 E-01 & 0.00 E+00 & 7.83 E-01 & 100\end{array}$

$4175 \quad 0.00 E+00 \quad 0.00 E+001.00 E+00 \quad 000 E+001.00 E+00$

\begin{tabular}{lllllll}
4176 & $000 \mathrm{E}+00$ & 0 & $00 \mathrm{E}+00$ & $6.84 \mathrm{E}-02$ & $0.00 \mathrm{E}+00$ & $6.84 \mathrm{E}-02$ \\
\hline
\end{tabular}

\begin{tabular}{llllllllll}
4177 & $0.00 E+00$ & $0.00 E+00$ & $3.12 E-02$ & $0.00 E+00$ & $3.12 E-02$ \\
\hline
\end{tabular}

\begin{tabular}{llllllll}
+178 & $0.00 E+00$ & $0.00 E+00$ & $2.32 E-01$ & $0.00 E+00$ & $2.32 E-01$ \\
\hline
\end{tabular}

\begin{tabular}{lllllll}
4179 & $0.00 E+00$ & $0.00 E+00$ & $2.34 E-03$ & $1.00 E+00$ & $1.00 E+00$ \\
\hline
\end{tabular}

\begin{tabular}{llllllll}
4179 & $0.00 \mathrm{E}+00$ & $0.00 \mathrm{E}+00$ & $1.00 \mathrm{E}+00$ & $0.00 \mathrm{E}+00$ & $1.00 \mathrm{E}+00$ \\
\hline
\end{tabular}

\begin{tabular}{lllllllll}
4180 & $0.00 E+\infty$ & $0.00 E+00$ & $1.19 E-01$ & $0.00 E+00$ & $1.19 E-01$ \\
\hline
\end{tabular}

\begin{tabular}{lllllll}
4185 & $0.00 E+00$ & $0.00 E+00$ & $1.17 E-01$ & $0.00 E+00$ & $1.17 E-01$ \\
\hline
\end{tabular}

\begin{tabular}{lllllll}
4188 & $0.00 E+00$ & $0.00 E+00$ & $1.11 E-01$ & $0.00 E+00$ & $1.11 E-01$ \\
\hline
\end{tabular}

\begin{tabular}{lllllll}
4189 & $0.00 \mathrm{E}+00$ & $0.00 \mathrm{E}+00$ & $2.17 \mathrm{E}-03$ & $0.00 \mathrm{E}+00$ & $2.17 \mathrm{E}-03$ \\
\hline
\end{tabular}

\begin{tabular}{lllllllll}
4190 & $0.00 E+00$ & $0.00 E+00$ & $7.97 E-02$ & $3.86 E-03$ & $8.32 E-02$ & 95.16 \\
\hline
\end{tabular}

$\begin{array}{llllllll}4191 & 0.00 \mathrm{E}+00 & 0.00 \mathrm{E}+00 & 2.95 \mathrm{E}-01 & 0.00 \mathrm{E}+00 & 2.95 \mathrm{E}-01 & 100\end{array}$

$41930.00 E+000.00 E+00$ 235E-01 $000 \mathrm{E}+00$ $435 \mathrm{E}-01$

\begin{tabular}{lllllll}
4195 & $0.00 E+00$ & $0.00 E+00$ & $5.12 E-01$ & $0.00 E+00$ & $5.12 E-01$ \\
\hline
\end{tabular}

\begin{tabular}{llllllll}
4198 & $0.00 E+00$ & $000 \mathrm{E}+00$ & $2.57 E-01$ & $0.00 E+00$ & $2.57 \mathrm{E}-01$ \\
\hline
\end{tabular}

$4199 \quad 0.00 E+00 \quad 0.00 E+00 \quad 1.57 E-01 \quad 0.00 E+00 \quad 1.57 E-01$

\begin{tabular}{llllllll}
4201 & $0.00 \mathrm{E}+00$ & $0.00 \mathrm{E}+00$ & $3.57 \mathrm{E}-01$ & $0.00 \mathrm{E}+00$ & $3.57 \mathrm{E}-01$ \\
\hline
\end{tabular}

$\begin{array}{llllllll}4202 & 0.00 E+\infty & 0.00 E+\infty & 2.45 E-01 & 0.00 E+00 & 2.45 E-01 & 100\end{array}$

$\begin{array}{lllllllll}4203 & 0.00 \mathrm{E}+00 & 0.00 \mathrm{E}+00 & 1.45 \mathrm{E}-01 & 1.49 \mathrm{E}-02 & 1.58 \mathrm{E}-01 & 91.26\end{array}$

$\begin{array}{lllllllll}4204 & 0.00 E+00 & 0.00 E+\infty & 3.35 E-01 & 1.80 E-02 & 3.47 E-01 & 95.74\end{array}$

$\begin{array}{lllllllll}4205 & 0.00 E+\infty & 0.00 E+\infty & 7.01 E-02 & 0.00 E+00 & 7.01 E-02 & 100\end{array}$

\begin{tabular}{llllllll}
4206 & $000 E+\infty$ & $000 E+00$ & $7.35 E-01$ & $6.75 E-04$ & $7.35 E-01$ \\
\hline
\end{tabular} 99.95

$\begin{array}{lllllllll}4207 & 0.00 E+00 & 0.00 E+00 & 9.71 E-01 & 0.00 E+00 & 9.71 E-01 & 100\end{array}$

$\begin{array}{llllllll}4208 & 0.00 E+00 & 0.00 E+\infty & 4.78 E-01 & 0.00 E+00 & 4.78 E-01\end{array}$

\begin{tabular}{llllllll}
4209 & 0 & $00 \mathrm{E}+00$ & 0 & $00 \mathrm{E}+00$ & $8.83 \mathrm{E}-02$ & $1.17 \mathrm{E}-01$ & $1.95 \mathrm{E}-01$ \\
\hline
\end{tabular} $42 \mathrm{S2}$

$\begin{array}{llllllll}4211 & 0.00 E+00 & 000 E+\infty 0 & 1.00 E+00 & 000 E+00 & 1.00 E+00 & 100\end{array}$

0
0
0.01
0
0
0
0
38.41
7969
0
0
0
0
75.97
0.17
4.88
1833
0
0
0
0
0
0
0
0
0
0
0
0
0
0
0
0
0
0
0
0
0
0
0
0
0
0
0
0

ALIAS EASTING NORTHING $28994.24 \quad 16978.44$ $28444.1 \quad 17084.35$

$28749.92 \quad 17729.8$

$28746.51 \quad 17740.81$

$28970.82 \quad 18204.96$

$28978.97 \quad 18225.49$

$29195.34 \quad 18513.55$

$29402.27 \quad 18803.88$

$29411.99 \quad 18819.93$

OHF_ $28600.38 \quad 17325.24$

$\begin{array}{lll}\mathrm{OHF}_{2} 2 & 28504.8 & 17236.06\end{array}$

OHF_3 $28496.78 \quad 17298.86$

OHF_4 $28519.01 \quad 17339.13$

$\begin{array}{llll}0 & 05 . M W 002 & 29280 & 18250\end{array}$

057 O5.MW005 $\quad 29630 \quad 17422$

006 05.MW006 $30103 \quad 17249$

$\begin{array}{llll}78 & 05 . S B 010 & 28753 & 17398\end{array}$

$\begin{array}{llll}0 & 05 . M W 015 & 29007.83 & 17077.57\end{array}$

$\begin{array}{llll}0 & 05 . M W 016 & 29039.48 & 17061.87\end{array}$

$\begin{array}{llll}0 & 05 . M W 017 & 29062.47 & 17064.4\end{array}$

$\begin{array}{llll}0 & 05 . M W 018 & 29105.15 & 17054.96\end{array}$

$\begin{array}{llll}0 & 05 . M W 019 & 29119.98 & 17052.12\end{array}$

$\begin{array}{llll}0 & \text { 05.MW020 } & 29145.88 & 17045.86\end{array}$

$\begin{array}{llll}0 & 05 . M W 021 & 29466.35 & 17051.83\end{array}$

$\begin{array}{lll}0 & 29466.35 & 1705183\end{array}$

$\begin{array}{llll}0 & 05 . M W 022 & 29485.75 & 17045.15\end{array}$

$\begin{array}{llll}0 & 05 . M W 024 & 29529.03 & 17053.8\end{array}$

$\begin{array}{llll}0 & 05 . M W 025 & 29554.02 & 17046.22\end{array}$

$\begin{array}{llll}0 & \text { 05.MW026 } & 29586.69 & 1704048\end{array}$

$\begin{array}{llll}0 & 05 . M W 027 & 29605.09 & 17025.73\end{array}$

$\begin{array}{llll}0 & \text { 05.MW028 } & 29636.96 & 1701891\end{array}$

$\begin{array}{llll}0 & 05 M W 029 & 29663.61 & 1701599\end{array}$

$\begin{array}{llll}0 & \text { 05.MW030 } & 29686.82 & 17012.81\end{array}$

$\begin{array}{llll}0 & 05 . M W 032 & 29725.54 & 17042.41\end{array}$

$\begin{array}{llll}0 & \text { 05.MW033 } 29743.82 & 17027.99\end{array}$

$\begin{array}{llll}0 & 05 . M W 034 & 29750.57 & 17004.27\end{array}$

$\begin{array}{llll}0 & 05 . M W 035 & 29770.4 & 1699856\end{array}$

$\begin{array}{llll}0 & 05 . M W 036 & 29787.71 & 1699801\end{array}$

$\begin{array}{llll}0 & 05 . M W 037 & 29805.36 & 1698622\end{array}$

$\begin{array}{llll}0 & 05 . M W 038 & 29827.3 & 16990.15\end{array}$

$\begin{array}{llll}0 & 05 . M W 039 & 29859.81 & 1701003\end{array}$

$\begin{array}{llll}0 & 05 . M N O 40 & 2987974 & 1699153\end{array}$

$\begin{array}{llll}0 & 05 . M W 041 & 2989468 & 16996.9\end{array}$

$\begin{array}{llll}0 & 05 \mathrm{MWO42} & 2992308 & 1701306\end{array}$

$\begin{array}{llll}0 & 05 \mathrm{MWNO43} & 29941.29 & 1701432\end{array}$ 


\begin{tabular}{|c|c|c|c|c|c|c|c|c|c|c|c|c|c|}
\hline$A G$ & WELL & Metal_Rsk & Org Rsk & Rad Rsk & TRU_Rsk & Total Rsk & Rad_\% & Met_\% & TRU_\% & Org_\% & ALIAS & EASTING & NORTHING \\
\hline 5 & 4212 & $0.00 \mathrm{E}+\infty$ & $0.00 E+00$ & $1.98 E-01$ & $0.00 \mathrm{E}+00$ & $1.98 E-01$ & 100 & 0 & 0 & 0 & 05.MW044 & 29955.19 & 17014.81 \\
\hline 5 & 4213 & $0.00 E+\infty 0$ & $0.00 E+\infty 0$ & $6.13 \mathrm{E}-05$ & $0.00 \mathrm{E}+00$ & $6.13 \mathrm{E}-05$ & 100 & 0 & 0 & 0 & 05.MWO45 & 29965.87 & 17026.46 \\
\hline 5 & 4214 & $0.00 E+00$ & $0.00 \mathrm{E}+\infty$ & $7.04 E-05$ & $0.00 E+00$ & 7.04E-05 & 100 & 0 & 0 & 0 & 05.MW045 & 29977.39 & 17025.91 \\
\hline 5 & 4216 & $0.00 \mathrm{E}+\infty$ & $0.00 \mathrm{E}+00$ & $1.59 \mathrm{E}-03$ & $0.00 \mathrm{E}+00$ & $1.59 E-03$ & 100 & 0 & 0 & 0 & 05.MW047 & 29957.46 & 17058.35 \\
\hline 5 & 4218 & $0.00 E+\infty 0$ & $0.00 \mathrm{E}+\infty$ & $1.99 E-03$ & $0.00 \mathrm{E}+\infty 0$ & 1.99E-03 & 100 & 0 & 0 & 0 & 05.MW048 & 30384.64 & 1711456 \\
\hline 5 & 4219 & $0.00 E+00$ & $0.00 E+00$ & $2.34 E-03$ & $0.00 \mathrm{E}+00$ & $2.34 \mathrm{E}-03$ & 100 & 0 & 0 & 0 & 05.MW049 & 30395.37 & 17129.31 \\
\hline 5 & 4221 & $0.00 E+00$ & $0.00 E+00$ & $3.43 \mathrm{E}-04$ & $0.00 \mathrm{E}+0$. & 3.43E-04 & 100 & 0 & 0 & 0 & OS.MWOSO & 30399.61 & 17143.29 \\
\hline 5 & 4224 & $0.00 \mathrm{E}+00$ & $0.00 \mathrm{E}+\infty$ & $2.03 E-04$ & $0.00 \mathrm{E}+00$ & $2.03 E-04$ & 100 & 0 & 0 & 0 & 05.MW05! & 30404.48 & 17151.19 \\
\hline 5 & 4225 & $0.00 \mathrm{E}+00$ & $0.00 \mathrm{E}+00$ & $1.48 E-03$ & $0.00 E+\infty$ & $1.48 \mathrm{E}-03$ & 100 & 0 & 0 & 0 & 05.MN0S2 & 30414.13 & 17133.19 \\
\hline 5 & 4226 & $0.00 E+00$ & $0.00 \mathrm{E}+00$ & $9.07 E-01$ & $0.00 E+00$ & 1.07E-01 & 100 & 0 & 0 & 0 & 05.MW053 & 30434.9 & 17149.45 \\
\hline 5 & 4227 & $0.00 \mathrm{E}+00$ & $0.00 \mathrm{E}+00$ & $1.08 \mathrm{E}-01$ & $0.00 E+00$ & $1.08 \mathrm{E}-01$ & 100 & 0 & 0 & 0 & 05.MW054 & 30427.64 & 17161.62 \\
\hline 5 & 4228 & $0.00 E+00$ & $0.00 E+00$ & $3.19 E-01$ & $0.00 E+\infty$ & 3.19E-01 & 100 & 0 & 0 & 0 & 05.MW05s & 30429.44 & 17180.15 \\
\hline 5 & 4230 & $0.00 E+00$ & $0.00 E+\infty$ & 3.79E-01 & $0.00 E+\infty$ & 3.79E-01 & 100 & 0 & 0 & 0 & 05.MW056 & 30441.06 & 17192.83 \\
\hline 5 & 4231 & $0.00 \mathrm{E}+00$ & $0.00 \mathrm{E}+00$ & 5.33E-02 & $5.15 \mathrm{E}-02$ & $1.02 E-01$ & 50.86 & 0 & 49.14 & 0 & 05.MW057 & 30448.82 & 17203.95 \\
\hline 5 & 4233 & $0.00 \mathrm{E}+00$ & $0.00 \mathrm{E}+00$ & 1.71E-03 & $0.00 E+\infty$ & 1.71E-03 & 100 & 0 & 0 & 0 & 05.MW058 & 30435.29 & 17266.11 \\
\hline 5 & 4235 & $0.00 \mathrm{E}+00$ & $0.00 E+00$ & $7.17 \mathrm{E}-04$ & $0.00 E+\infty$ & 7.17E-04 & 100 & 0 & 0 & 0 & 05.MN059 & 30455.08 & 17265.08 \\
\hline 5 & 4238 & $0.00 \mathrm{E}+00$ & $0.00 \mathrm{E}+00$ & $1.91 \mathrm{E}-03$ & $3.22 E-03$ & 5.13E-03 & 37.31 & 0 & 6269 & 0 & 05.MW061 & 30489.9 & 17251.38 \\
\hline 5 & 4239 & $0.00 \mathrm{E}+00$ & $0.00 E+00$ & $9.04 E-02$ & $4.13 E-03$ & $9.42 E-02$ & 95.83 & 0 & 4.17 & 0 & 05.MN062 & 30514.57 & 17247.29 \\
\hline 5 & 4240 & $0.00 E+00$ & $0.00 E+00$ & 1.17E-01 & 1.19E-03 & $1.18 \mathrm{E}-01$ & 99.05 & 0 & 0.95 & 0 & 05.MW063 & 29505.53 & 16900.22 \\
\hline 5 & 4241 & $0.00 \mathrm{E}+00$ & $0.00 E+00$ & 1.46E-01 & $0.00 \mathrm{E}+00$ & $1.46 E-01$ & 100 & 0 & 0 & 0 & 05.MNO64 & 29586.27 & 16849.55 \\
\hline 5 & 4242 & $0.00 \mathrm{E}+00$ & $0.00 E+00$ & 1.37E-01 & $0.00 \mathrm{E}+00$ & 1.37E-01 & 100 & 0 & 0 & 0 & 05.MW065 & 29623.04 & 16804.72 \\
\hline$\xi$ & 4243 & $0.00 E+\infty 0$ & $0.00 E+00$ & $1.10 E-01$ & $0.00 \mathrm{E}+00$ & 1.10E-01 & 100 & 0 & 0 & 0 & 05.MNVOG6 & 29726.42 & 16724.62 \\
\hline 5 & 4244 & $0.00 \mathrm{E}+00$ & $0.00 \mathrm{E}+00$ & $8.66 \mathrm{E}-02$ & $0.00 E+00$ & $8.66 E-02$ & 100 & 0 & 0 & 0 & 05.MW067 & 29768.07 & 16754.18 \\
\hline 5 & 4245 & $0.00 E+00$ & $0.00 \mathrm{E}+00$ & $1.46 \mathrm{E}-01$ & $0.00 \mathrm{E}+00$ & $1.46 E-01$ & 100 & 0 & 0 & 0 & 05.MW068 & 29703.74 & 16789.86 \\
\hline 5 & 4246 & $0.00 E+00$ & $0,00 \mathrm{E}+00$ & $1.34 \mathrm{E}-01$ & $0.00 E+\infty$ & $1.34 \mathrm{E}-01$ & 100 & 0 & 0 & 0 & 05.MW069 & 29644.97 & 16857.93 \\
\hline 5 & 4247 & $0.00 \mathrm{E}+00$ & $0.00 E+00$ & $9.12 E-02$ & $2.13 E-04$ & $9.14 E-02$ & 99.78 & 0 & 0.22 & 0 & 05.MW070 & 29716.1 & 16869.5 \\
\hline 5 & 4248 & $0.00 E+00$ & $0.00 E+00$ & 1.19E-01 & $0.00 \mathrm{E}+\infty$ & 1.19E-01 & 100 & 0 & 0 & 0 & 05.MW071 & 29781.43 & 16803.97 \\
\hline 5 & 4249 & $0.00 E+\infty 0$ & $0.00 \mathrm{E}+00$ & $1,47 E-01$ & $0.00 E+\infty$ & 1.47E-01 & 100 & 0 & 0 & 0 & OS.MW072 & 29831,3 & 16764.82 \\
\hline 5 & 4250 & $0.00 \mathrm{E}+00$ & $0.00 E+00$ & 2.43E-01 & $0.00 E+00$ & 2.43E-01 & 100 & 0 & 0 & 0 & 05.MW073 & 29850.49 & 16806.8 \\
\hline 5 & 4251 & $0.00 E+\infty 0$ & $0.00 \mathrm{E}+00$ & 2.16E-01 & $0.00 E+\infty$ & $2.16 E-01$ & 100 & 0 & 0 & 0 & 05.MW074 & 29790.05 & 16856.06 \\
\hline 5 & 4252 & $0.00 \mathrm{E}+\infty 0$ & $0.00 E+00$ & $1.40 E-02$ & $0.00 E+\infty$ & $1.40 E-02$ & 100 & 0 & 0 & 0 & 05.MW075 & 29978.55 & 16789.29 \\
\hline 5 & 4253 & $0.00 \mathrm{E}+\infty 0$ & $0.00 E+00$ & $3.91 E-02$ & $0.00 \mathrm{E}+\infty$ & $3.91 E-02$ & 100 & 0 & 0 & 0 & 05.MW076 & 29942.28 & 16842.86 \\
\hline 5 & 4254 & $0.00 \mathrm{E}+00$ & $0.00 \mathrm{E}+00$ & $8.12 E-03$ & $0.00 \mathrm{E}+00$ & $8.12 E-03$ & 100 & 0 & 0 & 0 & 05.MW077 & 28008.8 & 16887.1 \\
\hline 5 & 4255 & $0.00 \mathrm{E}+00$ & $0.00 \mathrm{E}+00$ & $1.26 E-02$ & $0.00 \mathrm{E}+00$ & $1.26 E-02$ & 100 & 0 & 0 & 0 & 05.MW078 & 27988.1 & 16922.3 \\
\hline 5 & 4256 & $0.00 \mathrm{E}+\infty 0$ & $0.00 \mathrm{E}+00$ & $3.76 E-04$ & $0.00 \mathrm{E}+\infty$ & $3.75 E-04$ & 100 & 0 & 0 & 0 & 05.MW079 & 27979.39 & 16996.05 \\
\hline 5 & 4257 & $0.00 \mathrm{E}+00$ & $0.00 \mathrm{E}+00$ & $2.40 E-03$ & $0.00 \mathrm{E}+00$ & $2,40 E-03$ & 100 & 0 & 0 & 0 & 05.MW080 & 28059.6 & 16951.1 \\
\hline 5 & 4258 & $0.00 \mathrm{E}+00$ & $0.00 \mathrm{E}+00$ & $3.07 E-04$ & $0.00 \mathrm{E}+00$ & 3.07E-04 & 100 & 0 & 0 & 0 & 05.MW081 & 28099.67 & 16895.24 \\
\hline 5 & 4259 & $0.00 \mathrm{E}+00$ & $0.00 \mathrm{E}+00$ & $4.59 E-03$ & $0.00 \mathrm{E}+\infty$ & 4.69E-03 & 100 & 0 & 0 & 0 & 05.MNO 082 & 28148.57 & 17006.46 \\
\hline 5 & 4260 & $0.00 E+00$ & $0.00 \mathrm{E}+00$ & $3.65 E-03$ & $0.00 \mathrm{E}+\infty 0$ & 3.65E-03 & 100 & 0 & 0 & 0 & 05.MN083 & 28173.27 & 1695061 \\
\hline 5 & 4261 & $0.00 E+00$ & $0.00 E+00$ & $7.66 E-03$ & $0.00 \mathrm{E}+00$ & $7.66 \mathrm{E}-03$ & 100 & 0 & 0 & 0 & 05.MW084 & 28168.05 & 17036.65 \\
\hline 5 & 4262 & $0.00 \mathrm{E}+00$ & $0.00 E+00$ & $8,45 E-03$ & $0.00 E+\infty$ & 8.45E-03 & 100 & 0 & 0 & 0 & 05.MW085 & 28265.99 & 16964.03 \\
\hline 5 & 4263 & $0.00 E+00$ & $0.00 E+00$ & 6.91E-03 & $0.00 E+\infty$ & 6.91E-03 & 100 & 0 & 0 & 0 & 05.MN087 & 2822543 & 171168 \\
\hline 5 & 4264 & $0.00 E+00$ & $0.00 E+00$ & $6.51 E-03$ & $0.00 E+00$ & 6.51E-03 & 100 & 0 & 0 & 0 & 05.MW088 & 28182.28 & 17107.55 \\
\hline 5 & 4265 & $0.00 \mathrm{E}+00$ & $000 \mathrm{E}+00$ & 1.68E-02 & $000 \mathrm{E}+\infty$ & $1,68 E-02$ & 100 & 0 & 0 & 0 & 05 MW089 & 28405.63 & 16957.0: \\
\hline
\end{tabular}




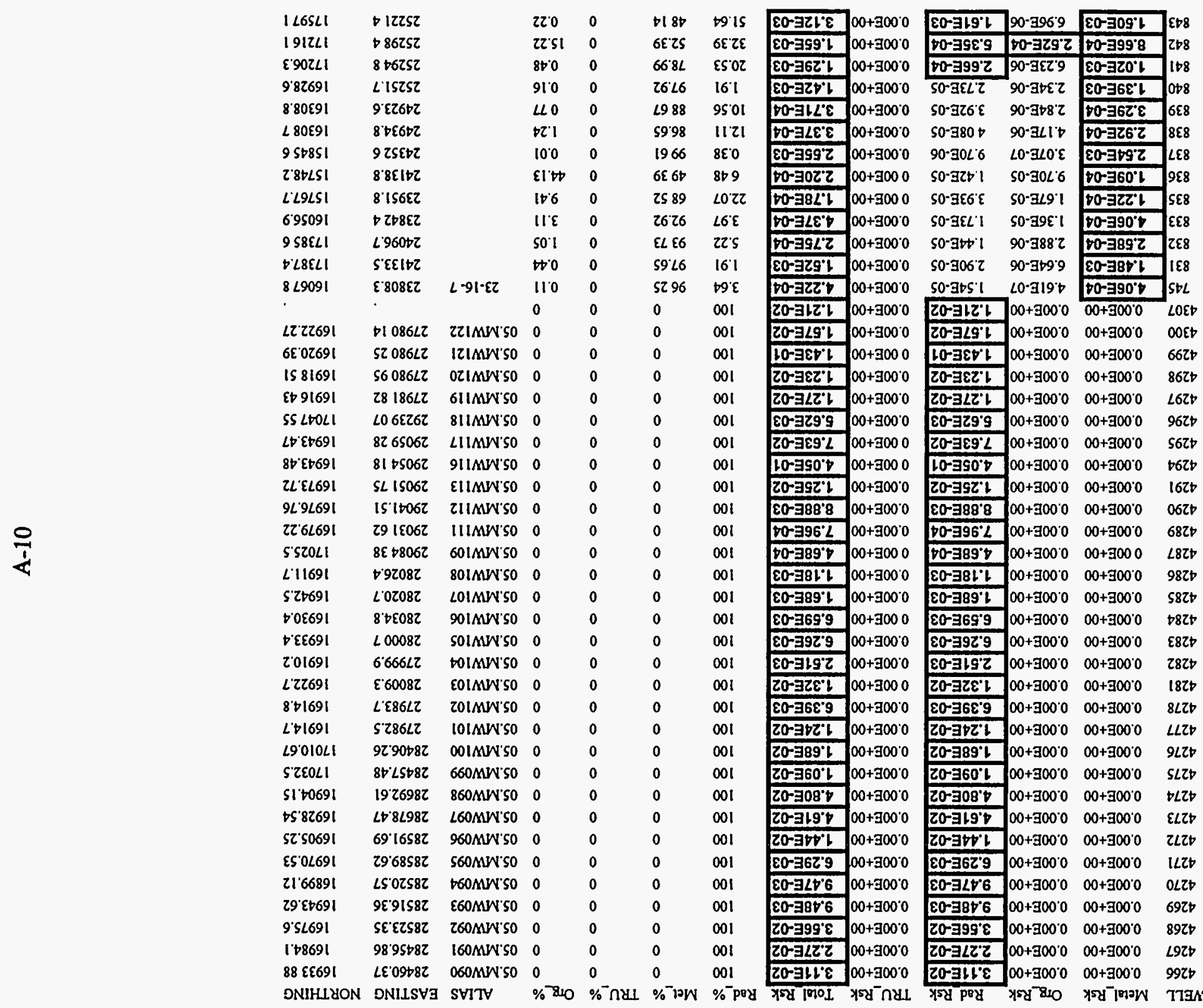




WAG
6
6
6
6
6
6
6
6
6
6
6
6
6
6
6
6
6
6
6
6
6
6
6
6
6
6
6
6
6
6
6
6
6
6
6
7
7
7
7
7
7
7
7
7
7
7

WELL Metal Rsk OTB_Rsk Rad Rsk TRU_Rsk Total Rsk Rad_\% Met_\% TRU_\% Org\%

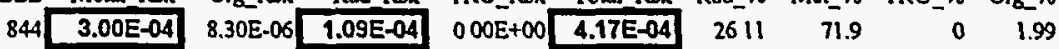
\begin{tabular}{l|l|l|l|l|lllll}
845 & $3.76 E-04$ & $4.29 E-06$ & $5.17 E-05$ & $0.00 E+00$ & $4.32 E-04$ & 11.98 & 87.03 & 0 & 0.99
\end{tabular} $\begin{array}{llllllllllll}846 & 2.54 E-03 & 3.04 E-06 & 2.15 E-05 & 0.00 E+00 & 2.56 E-03 & 0.84 & 99.04 & 0 & 0.12\end{array}$

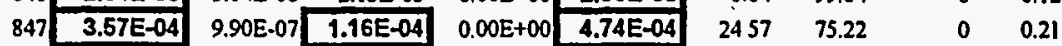
\begin{tabular}{l|l|l|l|l|l|llll}
848 & $2.85 E-04$ & $4.63 E-06$ & $4.95 E-03$ & $0.00 E+00$ & $5.24 E-03$ & 94.46 & 5.45 & 0 & 0.09
\end{tabular} \begin{tabular}{l|l|l|l|l|llllll}
849 & $2.93 E-04$ & $2.17 E-03$ & $3.08 E-03$ & $000 E+00$ & $5.55 E-03$ & 55.54 & 5.29 & 0 & 39.17
\end{tabular} \begin{tabular}{l|lllllllllll}
850 & $2.79 E-04$ & $3.24 E-05$ & $5.55 E-05$ & $000 E+00$ & $3.67 E-04$ & 15.1 & 76.07 & 0 & 8.83
\end{tabular} \begin{tabular}{r|rrrr|rrrrr}
851 & $3.29 E-04$ & $4.40 \mathrm{E}-05$ & $6.00 \mathrm{E}-05$ & $0.00 \mathrm{E}+00$ & $4.33 \mathrm{E}-04$ & 13.85 & 76 & 0 & 10.16
\end{tabular} \begin{tabular}{l|lllllllll}
\hline 852 & $4.57 E-04$ & $9.05 E-05$ & $6.91 E-05$ & $0.00 E+00$ & $6.17 E-04$ & 11.2 & 74.12 & 0 & 14.68
\end{tabular} \begin{tabular}{l|l|llllllll}
853 & $2.95 E-04$ & $2.41 E-04$ & $9.98 E-06$ & $000 E+00$ & $5.46 E-04$ & 1.83 & 54.04 & 0 & 44.13
\end{tabular} \begin{tabular}{l|l|l|l|l|lllll}
854 & $2.89 E-04$ & $4.27 E-04$ & $2.83 E-04$ & $0.00 E+00$ & $9.98 E-04$ & 28.35 & 28.91 & 0 & 42.75
\end{tabular} \begin{tabular}{l|l|lllllllll}
855 & $7.81 \mathrm{E}-04$ & $2.21 \mathrm{E}-06$ & $8.78 \mathrm{E}-06$ & $0.00 \mathrm{E}+00$ & $7.92 \mathrm{E}-04$ & 1.11 & 98.61 & 0 & 0.28
\end{tabular} \begin{tabular}{l|llllllllll}
856 & $9.46 E-04$ & $7.26 \mathrm{E}-06$ & $3.41 \mathrm{E}-05$ & $000 \mathrm{E}+00$ & $9.88 \mathrm{E}-04$ & 3.45 & 95.82 & 0 & 0.73
\end{tabular} \begin{tabular}{l|llll|l|l|l|l}
857 & $9.48 \mathrm{E}-04$ & $3.57 \mathrm{E}-06$ & $1.15 \mathrm{E}-05$ & $0.00 \mathrm{E}+00$ & $9.63 \mathrm{E}-04$ & 1.2 & 98.43
\end{tabular} $\begin{array}{lllllllll}858 & 1.20 \mathrm{E}-03 & 262 \mathrm{E}-06 & 7.67 \mathrm{E}-06 & 0.00 \mathrm{E}+00 & 1.21 \mathrm{E}-03 & 0.63 & 9915\end{array}$ \begin{tabular}{l|c|ccc|c|c|c|}
\hline 859 & $2.03 E-04$ & $307 E-07$ & $1.56 E-05$ & $000 E+00$ & $2.19 E-04$ & 7.1 & 92.76
\end{tabular} \begin{tabular}{|l|lll|l|r|r|r|}
8600 & $1.41 \mathrm{E}-04$ & $1.49 \mathrm{E}-06$ & $1.40 \mathrm{E}-05$ & $0.00 \mathrm{E}+00$ & $1.57 \mathrm{E}-04$ & 8.94 & 90.12 \\
\hline
\end{tabular} $25228.6 \quad 17602.5$

24988.3 17108.2

$24803.5 \quad 18030.7$

$24790.5 \quad 17769.9$

$24656.3 \quad 16942.4$

$24215.2 \quad 16781.8$

$24793.5 \quad 16595.4$

$24058.2 \quad 16485$

$23911.6 \quad 16346.9$

$24047.5 \quad 16695.1$

$23851.9 \quad 16711.9$

$23427.7 \quad 16755.3$

$23432.9 \quad 16764.4$

$23106.3 \quad 16538$

$23115.8 \quad 16542.1$

$23246.2 \quad 16009.4$

$23252.9 \quad 15999.6$

$\begin{array}{ll}24603.65 & 17754.77\end{array}$

$23763.29 \quad 17043.45$

$23838.21 \quad 16569.39$

$23878.8 \quad 16334.67$

$24072.69 \quad 16453.32$

$24659.86 \quad 16403.79$

$24211.9 \quad 17005.25$

$25249.05 \quad 16956.93$

$23195.49 \quad 16195.25$

$23868.74 \quad 17089.07$

$23862.43 \quad 17079$

$22449.09 \quad 17013.86$

$25183.89 \quad 18066.23$

$25097.59 \quad 17913.59$

$25344.78 \quad 17367.94$

$25239.04 \quad 17085.6$

$25459.01 \quad 17155.45$

$25424.11 \quad 16900.21$

$1234 \mathrm{~A} \quad 25244.09 \quad 16969.58$

$27233.93 \quad 19302.85$

19294.3

25707.53

$25697.46 \quad 18135.02$

$2585889 \quad 1788274$

25815.09

$25613.69 \quad 1740694$

$\begin{array}{ll}25612.66 & 17389.59\end{array}$ 


\begin{tabular}{|c|c|c|c|c|c|c|c|c|c|c|}
\hline WAG & WELL & Metal_Rsk & Org_Rsk & Rad_Rsk & TRU_Rsk & Total_Rsk & Rad_\% & Met_\% & TRU_\% & Org_\% \\
\hline 7 & 1080 & $0.00 E+00$ & $0.00 E+\infty$ & $157 \mathrm{E} .05$ & $000 \mathrm{E}+\infty 0$ & $1.57 \mathrm{E}-05$ & 100 & 0 & 0 & 0 \\
\hline 7 & 1081 & $0.00 E+00$ & $0.00 E+00$ & 3.51E-05 & $0.00 E+00$ & 3.51E-05 & 100 & 0 & 0 & 0 \\
\hline 7 & 1082 & $0.00 \mathrm{E}+00$ & $0.00 E+00$ & $347 \mathrm{E}-05$ & $0.00 \mathrm{E}+00$ & 3.47E.0S & 100 & 0 & 0 & 0 \\
\hline 7 & 1083 & $0.00 \mathrm{E}+\infty 0$ & $0.00 \mathrm{E}+00$ & 2.83E-05 & $0.00 \mathrm{E}+00$ & 2.83E-05 & 100 & 0 & 0 & 0 \\
\hline 7 & 1084[ & 1.03E-04 & $0.00 \mathrm{E}+00$ & 2.04E-04 & $0.00 E+\infty 0$ & $3.06 E-04$ & 66.52 & 33.48 & 0 & 0 \\
\hline 7 & 1085 & $0.00 \mathrm{E}+00$ & $0.00 E+\infty 0$ & 2.07E-05 & $0.00 E+\infty$ & $2.07 \mathrm{E}-05$ & 100 & 0 & 0 & 0 \\
\hline 7 & 1086 & $000 \mathrm{E}+00$ & $0.00 E+\infty$ & $1.89 \mathrm{E}-05$ & $000 \mathrm{E}+00$ & 1.89E.05 & 100 & 0 & 0 & 0 \\
\hline 8 & 1087 & $0.00 E+00$ & $0.00 E+00$ & $6.05 \mathrm{E}-04$ & $0.00 \mathrm{E}+00$ & $6.05 E-04$ & 100 & 0 & 0 & 0 \\
\hline 8 & 1088 & $000 E+00$ & $0.00 \mathrm{E}+00$ & $8.62 \mathrm{E} .05$ & $0.00 E+\infty$ & $8.62 \mathrm{E}-05$ & 100 & 0 & 0 & 0 \\
\hline 8 & 1089 & $0.00 E+00$ & $0.00 \mathrm{E}+00$ & 5.92E-05 & $0.00 \mathrm{E}+00$ & $5.92 \mathrm{E}-05$ & 100 & 0 & 0 & 0 \\
\hline 8 & 1090 & $0.00 E+00$ & $000 \mathrm{E}+\infty$ & 3.83E-05 & $0.00 E+00$ & 3.83E.05 & 100 & 0 & 0 & 0 \\
\hline 8 & 1091 & $000 E+00$ & $0.00 \mathrm{E}+\infty$ & .05 & $0.00 \mathrm{E}+00$ & E-05 & 100 & 0 & 0 & 0 \\
\hline 8 & 1092 & $000 E+00$ & $0.00 \mathrm{E}+\infty 0$ & 1.98E.05 & $0.00 \mathrm{E}+00$ & 1.98E-05 & 100 & 0 & 0 & 0 \\
\hline 8 & 1093 & $0.00 E+00$ & $0.00 \mathrm{E}+\infty$ & $2.54 \mathrm{E}-05$ & $0.00 E+00$ & 2.54E-0S & 100 & 0 & 0 & 0 \\
\hline 8 & 1094 & $000 \mathrm{E}+00$ & $0.00 \mathrm{E}+00$ & .05 & $0.00 \mathrm{E}+00$ & $1.32 \mathrm{E}-05$ & 100 & 0 & 0 & 0 \\
\hline 8 & 1095 & $000 E+00$ & $0.00 \mathrm{E}+00$ & $3.34 \mathrm{E}-05$ & $0.00 E+00$ & $3.34 \mathrm{E}-05$ & 100 & 0 & 0 & 0 \\
\hline 8 & 1096 & $000 E+00$ & $000 E+\infty$ & 6.95E-04 & $0.00 E+00$ & $6.95 \mathrm{E}-0.4$ & 100 & 0 & 0 & 0 \\
\hline 8 & 1097 & $000 E+00$ & $000 \mathrm{E}+\infty 0$ & $8.01 E-04$ & $000 E+00$ & 8.01E-04 & 100 & 0 & 0 & 0 \\
\hline 11 & 1139 & $000 E+00$ & $0.00 \mathrm{E}+\infty 0$ & $8.45 \mathrm{E}-06$ & $0.00 E+00$ & $8.45 \mathrm{E}-06$ & 100 & 0 & 0 & 0 \\
\hline 11 & 1140 & $000 E+00$ & $0.00 E+00$ & $8.76 \mathrm{E}-06$ & $0.00 E+00$ & 8.76E-06 & 100 & 0 & 0 & 0 \\
\hline 11 & 1141 & $000 \mathrm{E}+00$ & $000 E+\infty 0$ & $240 \mathrm{E}-05$ & $0.00 E+00$ & $240 \mathrm{E}-05$ & 100 & 0 & 0 & 0 \\
\hline 11 & 1143 & $000 E+00$ & $0.00 \mathrm{E}+00$ & .05 & $000 E+00$ & $2.43 \mathrm{E}-05$ & 100 & 0 & 0 & 0 \\
\hline 11 & 144 & $0.00 \mathrm{E}+00$ & $0.00 \mathrm{E}+\infty 0$ & 80E-05 & $=+\infty$ & $1.80 \mathrm{E}-05$ & 100 & 0 & 0 & 0 \\
\hline 11 & 1145 L & $5.35 E-04$ & $0.00 \mathrm{E}+00$ & 2.97E-0S & $0.00 E+00$ & $5.65 E-04$ & 526 & 94.74 & 0 & 0 \\
\hline 11 & 1146 & $000 \mathrm{E}+00$ & $000 E+00$ & 3.01E-05 & $000 E+00$ & -05 & 100 & 0 & 0 & 0 \\
\hline 11 & 1147 & $0.00 \mathrm{E}+00$ & $000 \mathrm{E}+00$ & $633 \mathrm{E}-06$ & $0.00 E+00$ & $6.33 \mathrm{E}-06$ & 100 & 0 & 0 & 0 \\
\hline 11 & 1148 & $0.00 \mathrm{E}+00$ & 3 OTE-07 & $5.76 \mathrm{E}-06$ & $0.00 E+00$ & $606 \mathrm{E}-06$ & 94.93 & 0 & 0 & 507 \\
\hline 11 & 1149 & $E+\infty$ & 3.07E.07 & & $0.00 E+00$ & 3.30E-05 & 99.07 & 0 & 0 & 093 \\
\hline 11 & 1246 & $000 E+00$ & $0.00 \mathrm{E}+\infty 0$ & 8.S5E-05 & $000 E+00$ & $8.55 \mathrm{E}-05$ & 100 & 0 & 0 & 0 \\
\hline 17 & 1196 & $0.00 \mathrm{E}+\infty$ & $0.00 \mathrm{E}+00$ & 4.05E-05 & $000 \mathrm{E}+00$ & 4.05E-05 & 100 & 0 & 0 & 0 \\
\hline 17 & 1197 & $000 E+00$ & $000 E+00$ & $1.59 \mathrm{E}-05$ & $000 \mathrm{E}+00$ & $1.59 \mathrm{E}-05$ & 100 & 0 & 0 & 0 \\
\hline 17 & 1198 & $000 \mathrm{E}+00$ & $000 \mathrm{E}+00$ & 05 & $0.00 \mathrm{E}+00$ & $4.86 \mathrm{E}-05$ & 100 & 0 & 0 & 0 \\
\hline 17 & 1199 & $000 \mathrm{E}+00$ & $000 \mathrm{E}+00$ & E.05 & $\infty$ & & 100 & 0 & 0 & 0 \\
\hline 17 & 1200 & $000 E+00$ & $0.00 \mathrm{E}+00$ & $182 \mathrm{E} .05$ & $000 \mathrm{E}+00$ & $1.82 \mathrm{E}-05$ & 100 & 0 & 0 & 0 \\
\hline 17 & 1201 & $000 \mathrm{E}+00$ & $6.56 E-03$ & $1.48 E .05$ & $000 E+00$ & $6.58 \mathrm{E}-03$ & 0.23 & 0 & 0 & 9977 \\
\hline 17 & 1202 & $000 E+00$ & $713 E \cdot 06$ & 9.47E-06 & $000 E+00$ & $1.66 \mathrm{E}-05$ & 5703 & 0 & 0 & 4297 \\
\hline 17 & 1203 & $000 E+00$ & $000 \mathrm{E}+\infty 0$ & $196 \mathrm{E}-05$ & $0.00 E+00$ & $1.96 \mathrm{E}-05$ & 100 & 0 & 0 & 0 \\
\hline Seep & NW. 1 & $5.08 \mathrm{E} \cdot 05$ & $000 \mathrm{E}+00$ & $1.81 E-05$ & $000 E+00$ & $6.89 \mathrm{E}-05$ & 2632 & 73.68 & 0 & 0 \\
\hline Seep & $5 N$ N.2 & $508 \mathrm{E}-05$ & $000 \mathrm{E}+\infty$ & $3.25 \mathrm{E}-05$ & $0.00 E+\infty$ & $8.33 \mathrm{E}-05$ & 39 & 61 & 0 & 0 \\
\hline Seep & BTT & $813 E .05$ & $307 E \cdot 08$ & $1.77 \mathrm{E}-02$ & $000 E+00$ & $1.78 E-02$ & 99.55 & 0.45 & 0 & 0 \\
\hline Seep & IDRA & $000 \mathrm{E}+00$ & $000 E+\infty$ & $6.62 \mathrm{E}-03$ & $0.00 E+\infty$ & 6.62E-03 & 100 & 0 & 0 & 0 \\
\hline Seep & RS.1 & $406 E-05$ & $461 \mathrm{E}-08$ & $1.71 E-04$ & $0.00 E+00$ & 2.11E-04 & 80.75 & 19.23 & 0 & 0.02 \\
\hline Seep & RS.3 & $406 E-05$ & $000 E+\infty 0$ & $1.11 E-03$ & $000 E+00$ & 1.16E-03 & 9648 & 3.52 & 0 & 0 \\
\hline Seep & sw2-1 & $406 \mathrm{E}-05$ & $\mid 54 \mathrm{E}-07$ & $2.90 \mathrm{E}-04$ & $000 E+00$ & $3.31 E-04$ & 8768 & 1227 & 0 & 005 \\
\hline Seep & Sw $2-2$ & $610 E-05$ & $\mid 54 \mathrm{E}-08$ & 5.69E-04 & $0.00 E+00$ & $6.30 E-04$ & 9032 & 9.68 & 0 & 0 \\
\hline Seep & $12-3$ & $508 \mathrm{E}-05$ & $000 E+\infty$ & 1.55E-05 & $0.00 E+00$ & $6.63 \mathrm{E}-05$ & 2338 & 7662 & 0 & 0 \\
\hline Seep & sw2-4 & $000 E+00$ & $138 \mathrm{E}-07$ & 1.66E-03 & $000 \mathrm{E}+00$ & $1.66 \mathrm{E}-03$ & 9999 & 0 & 0 & 001 \\
\hline
\end{tabular}

ALIAS EASTING NORTHINO

\begin{tabular}{rr}
25971.36 & 16854.85 \\
26322.67 & 16919.81 \\
26347.58 & 16911.04 \\
27175.92 & 16997.52 \\
27852.14 & 17282.35 \\
27858.72 & 17299.12 \\
28117.01 & 17454.77 \\
29497.73 & 19935.31 \\
30367.64 & 19155.72 \\
31431.76 & 19159.16 \\
31441.95 & 19157.68 \\
32186.4 & 18785.4 \\
32378.93 & 18752.79 \\
32402.19 & 18762.57 \\
31329.16 & 16682.85 \\
31325.24 & 16634.4 \\
31549.54 & 18657.31 \\
31506.26 & 18499.6 \\
28700.7 & 34507.97 \\
28111.21 & 34497.98 \\
28148.9 & 34488.64 \\
27569.56 & 35068.41 \\
27421.61 & 35339.33 \\
27674.96 & 35589.35 \\
28337.71 & 35704.2 \\
28354.41 & 35696.5 \\
29698.7 & 35000.42 \\
29702.28 & 34973.56 \\
27507.53 & 35090.06 \\
37553.85 & 21988.52 \\
37633.94 & 21732.7 \\
37984.98 & 21214.15 \\
37967.59 & 21206.57 \\
36317.79 & 21339.18 \\
36414.64 & 21566.89 \\
36414.77 & 21581.53 \\
36272.97 & 21916.39 \\
29142.11 & 18623.85 \\
29252.2 & 18935.78 \\
27633.71 & 19165.14 \\
244480.17 & 16445.01 \\
26107.92 & 17951.94 \\
2546598 & 1727523 \\
28149.05 & 17293.58 \\
29417.34 & 1930275 \\
28610 & 18275.23 \\
28309.71 & 17354.5 \\
\hline
\end{tabular}


WELL Metal_Rsk Org_Rsk Rad Rsk TRU_Rsk Total Rsk Rad_\% Met_\% TRU_\% OTg\% $\begin{array}{llllllllll}\text { SW2-5 } & 0.00 \mathrm{E}+00 & 0.00 \mathrm{E}+00 & 1.15 \mathrm{E}-01 & 0.00 \mathrm{E}+00 & 1.15 \mathrm{E}-01 & 100\end{array}$ \begin{tabular}{ll|l|l|l|l|l} 
SW4-1 & $8.13 \mathrm{E}-05$ & $5.88 E-04$ & $5.82 E-03$ & $0.00 E+00$ & $6.49 E-03$ & 89.68 \\
\hline
\end{tabular}

\begin{tabular}{lllllllll} 
SW4-2 & $813 \mathrm{E}-05$ & $2.51 E-03$ & $1.14 E-02$ & $0.00 \mathrm{E}+00$ & $1.39 \mathrm{E}-02$ & 81.56 \\
\hline
\end{tabular} $\begin{array}{lllllllll}\text { SWS-11 } & 4.06 E-05 & 0.00 E+00 & 6.33 E-01 & 0.00 E+00 & 6.33 E-01 & 100\end{array}$

\begin{tabular}{llllllll} 
SW5-3 & $4.06 \mathrm{E}-05$ & $0.00 \mathrm{E}+00$ & $1.18 \mathrm{E}-02$ & $0.00 \mathrm{E}+00$ & $1.18 \mathrm{E}-02$ & 99.66 \\
\hline
\end{tabular} $\begin{array}{lllllllll}\text { SWS-4 4.06E-05 } 0.00 E+\infty & 3.57 E-01 & 0.00 E+00 & 3.57 E-01 & 99.99\end{array}$

$\begin{array}{lllllllll}\text { SWVS-5 } & 0.00 E+00 & 0.00 E+00 & 1.37 E-02 & 0.00 E+00 & 1.37 E-02 & 100\end{array}$

$\begin{array}{lllllllll}\text { SW5.6 } & 3.05 E-05 & 0.00 E+00 & \text { 4.33E-02 } & 0.00 E+\infty & \text { 4.34E-02 } & 99.93\end{array}$

\begin{tabular}{llllllll} 
SW5-7 & $3.05 E-05$ & $0.00 E+00$ & $1.37 E-01$ & $0.00 E+00$ & $1.37 E-01$ & 99.98 \\
\hline
\end{tabular}

$\begin{array}{llllllll}\text { SW5-8 } & 0.00 \mathrm{E}+00 & 0.00 \mathrm{E}+00 & 3.99 \mathrm{E}-02 & 0.00 \mathrm{E}+00 & 3.99 \mathrm{E}-02 & 100\end{array}$

$\begin{array}{lllllllll}\text { STV5.9 } & 4.06 \mathrm{E}-05 & 0.00 \mathrm{E}+00 & 3.06 \mathrm{E}-02 & 0.00 \mathrm{E}+00 & 3.06 \mathrm{E}-02 & 99.87\end{array}$

$\begin{array}{lllllllll}\text { SWW6-1 } & 2.03 E-05 & 0.00 E+00 & 2.76 E-04 & 0.00 E+00 & 2.96 E-04 & 93.13\end{array}$

\begin{tabular}{llllll|r} 
SIV6-2 & $0.00 \mathrm{E}+00$ & $0.00 \mathrm{E}+00$ & $\mathbf{1 . 8 5 E - 0 3}$ & $0.00 \mathrm{E}+00$ & $1.85 \mathrm{E}-03$ & 100 \\
\hline
\end{tabular}

$\begin{array}{llllllllll}\text { SIV7.1 } & 4.06 \mathrm{E}-05 & 0.00 \mathrm{E}+00 & 4.46 \mathrm{E}-05 & 0.00 \mathrm{E}+00 & 8.52 \mathrm{E}-05 & 52.33\end{array}$

$\begin{array}{lllllllll}\text { SiV7.2 } & 406 E-05 & 0.00 E+00 & 6.04 E-04 & 0.00 E+00 & 6.45 E-04 & 93.7\end{array}$

$\begin{array}{lllllllll}\text { SW7.3 } & 508 E-05 & 1.54 E-08 & 2.86 E-04 & 0.00 E+00 & 3.36 E-04 & 84.9\end{array}$

\begin{tabular}{llllllll} 
Siv7.5 & $610 \mathrm{E} .05$ & $4.61 \mathrm{E}-06$ & $4.60 \mathrm{E}-04$ & $0.00 \mathrm{E}+00$ & $6.26 \mathrm{E}-04$ & 87.5 \\
\hline
\end{tabular}

$\begin{array}{lllllllll}\text { SiV7.6 203E-05 } & 0.00 E+00 & 9.72 E-04 & 0.00 E+00 & 9.92 E-04 & 97.95\end{array}$

$\begin{array}{lllllllll}\text { IV4TRIB-11 } & 000 \mathrm{E}+00 & 7.90 \mathrm{E}-06 & \mathbf{4 . 4 9 E}-02 & 0.00 \mathrm{E}+00 & \text { 4.49E-02 } & 99.98\end{array}$

$\begin{array}{lllllllll}\text { IV4TRIB-5 } & 0.00 E+00 & 0.00 E+00 & 2.63 E-02 & 0.00 E+\infty & 2.63 E-02 & 100\end{array}$

\begin{tabular}{lllllll} 
IV4TRIB-7 & $000 \mathrm{E}+00$ & $0.00 \mathrm{E}+00$ & $5.25 \mathrm{E}-02$ & $000 \mathrm{E}+00$ & $5.25 \mathrm{E}-02$ \\
\hline
\end{tabular}

0
1.25
0.58
0
0.34
0.01
0
0.07
0.02
0
0.13
6.87
0
47.67
6.3
15.1
11.59
2.05
0
0
0

\begin{tabular}{rr} 
& 0 \\
\hline & 9.07 \\
& 17.86 \\
0 & 0 \\
0 & 0 \\
& 0 \\
0 & 0 \\
& 0 \\
0 & 0 \\
0 & 0 \\
0 & 0 \\
0 & 0 \\
0 & 0 \\
0 & 0 \\
0 & 0 \\
0 & 0 \\
0 & 088 \\
0 & 0 \\
0 & 0.02 \\
0 & 0 \\
0 & 0
\end{tabular}

ALIAS EASTING NORTHING $\begin{array}{ll}27978.66 & 16972.89 \\ 28509.08 & 18926.61\end{array}$

$28304.05 \quad 19015.82$

$29932.54 \quad 16986.5$

$28490.73 \quad 16972.48$

$29004.49 \quad 16935.78$

$29371.47 \quad 17000$

30527.43 17018.35

$30591.65 \quad 17137.62$

$30619.17 \quad 17211.01$

$30655.87 \quad 17266.05$

$25298.07 \quad 16816.51$

$25296.84 \quad 17598.35$

$25518.26 \quad 17568.81$

$25582.48 \quad 17192.66$

$26233.85 \quad 17174.31$

$27845.12 \quad 17210.37$

$27802.66 \quad 1846789$

27692.94 19131.48

$27956.5 \quad 19114.96$ 
$\begin{array}{rrrrrrr}\text { WELL } & \text { CS_137 } & \text { RA_228 } & \text { SR_-90 } & \text { TH_228 } & \text { TH_230 } & \text { TRITIUM } \\ 533 & 0.00 E_{+00} & 0.00 E^{2}+00 & 2.20 E_{-06} & 4.03 E_{-06} & 161 E_{-06} & 244 E_{-} 06\end{array}$ $\begin{array}{lllllll}336 & 0.00 E+00 & 8.27 E-06 & 2.51 E-06 & 2.69 E-06 & 4.22 E-07 & 2.75 E-06\end{array}$ $\begin{array}{lllllll}538 & 0.00 \mathrm{E}+00 & 2.02 \mathrm{E}-05 & 1.64 \mathrm{E}-06 & 2.75 \mathrm{E}-05 & 464 \mathrm{E}-06 & 2.01 \mathrm{E}-06\end{array}$ $\begin{array}{llllllll}539 & 0.00 E+00 & 4.16 E-03 & \text { A.A5E-03 } & 2.41 \mathrm{E}-06 & 0.00 \mathrm{E}+\infty & 1.53 \mathrm{E}-05\end{array}$ $\begin{array}{lllllllll}540 & 0.00 \mathrm{E}+00 & 0.00 \mathrm{E}+00 & 1.31 \mathrm{E}-06 & 2.08 \mathrm{E}-06 & 292 \mathrm{E}-07 & 222 \mathrm{E}-06\end{array}$ $\begin{array}{lllllll}541 & 1.82 E-05 & 2.02 E-04 & 1.29 E-06 & 4.27 \mathrm{E}-06 & 116 \mathrm{E}-06 & 1.87 \mathrm{E}-06\end{array}$ $\begin{array}{llllllll}543 & 0.00 \mathrm{E}+00 & 0.00 \mathrm{E}+00 & 2.23 \mathrm{E}-06 & 0.00 \mathrm{E}+00 & 3.30 \mathrm{E}-07 & 2.01 \mathrm{E}-05\end{array}$ $\begin{array}{llllllll}545 & 0.00 E+00 & 8.96 E-05 & 2.81 E-06 & 2.06 E-06 & 0.00 E+00 & 4.13 E-06\end{array}$ $\begin{array}{lllllll}546 & 0.00 E+00 & 8.61 E-06 & 0.00 E+00 & 4.09 E-06 & 232 E-07 & 2.84 E-06\end{array}$ $548 \quad 0.00 \mathrm{E}+00 \quad$. 3.46E-06

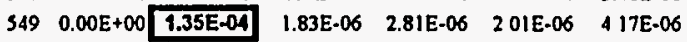
$530 \quad 0.00 \mathrm{E}+00 \quad 0.00 \mathrm{E}+00 \quad 1.81 \mathrm{E}-05 \quad 306 \mathrm{E}-06 \quad 3 \quad 32 \mathrm{E}-06$ $\begin{array}{lllllll}553 & 0.00 E+00 & 0.00 E+00 & 2.87 E-06 & 1.77 E-06 & 3.44 E-07 & 2.64 E-06\end{array}$ $\begin{array}{lllllll}554 & 000 E+\infty 0 & 0.00 E+00 & 2.45 E-06 & 2.38 E-06 & 371 E .07 & 2.67 E .06\end{array}$ 558

$\begin{array}{lllllll}563 & 0.00 \mathrm{E}+00 & 6.58 \mathrm{E}-05 & 2.44 \mathrm{E}-05 & 1.03 \mathrm{E}-06 & 000 \mathrm{E}+00 & 4.83 \mathrm{E}-06\end{array}$ \begin{tabular}{lllllll}
564 & $0.00 E+00$ & $1.84 E-04$ & $2.83 E-04$ & $1.87 E-06$ & $598 E-07$ & $1.22 E-04$ \\
\hline
\end{tabular} \begin{tabular}{lllllllll}
366 & $0.00 \mathrm{E}+00$ & $9.03 \mathrm{E}-05$ & $1.49 \mathrm{E}-05$ & $2.88 \mathrm{E}-06$ & $373 \mathrm{E}-07$ & 2.49E-04 \\
\hline
\end{tabular} S71 3.07E-05 4.47E-05 2.09E-05 2.15E-06 4.40E-07 $\begin{array}{llllllll}572 & 1.68 E-04 & 2.14 E-04 & 3.44 E-06 & 1.26 E-06 & 0.00 E+00 & 3.10 E-06\end{array}$

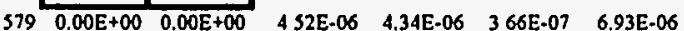

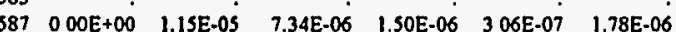
$588 \quad 0.00 E+004.05 E-04$ 4.65E-05 $4.38 E-06$ S S7E-07 $166 \mathrm{E}-06$ $\begin{array}{lllllllll}389 & 3.94 E-05 & 1.92 E-04 & 1.92 E-04 & 3.16 E-06 & 1 & 32 E-06 & 4 & 404 E-03\end{array}$ $\begin{array}{llllllll}590 & 2.32 E-05 & 1.97 E-03 & 6.37 E-04 & 3.40 E-06 & 606 E-07 & 25 S E-05\end{array}$ $\begin{array}{lllllllll}593 & 0.00 E+00 & 5.52 \mathrm{E}-05 & 2.98 \mathrm{E}-05 & 1.61 \mathrm{E}-05 & 239 \mathrm{E}-06 & 8.28 \mathrm{E}-07\end{array}$ $\begin{array}{llllllll}596 & 0 & 00 \mathrm{E}+00 & 9.45 \mathrm{E}-06 & 6.52 \mathrm{E}-06 & 3.40 \mathrm{E}-06 & 7.40 \mathrm{E}-07 & 1.29 \mathrm{E}-06\end{array}$ $\begin{array}{lllllllll}597 & 0.00 \mathrm{E}+00 & 2.16 \mathrm{E}-05 & 4.04 \mathrm{E}-05 & 1.66 \mathrm{E}-06 & 000 \mathrm{E}+00 & 5.65 \mathrm{E}-06\end{array}$ $398 \quad 000 \mathrm{E}+00$ 1.79E-04 $6.77 \mathrm{E}-05 \quad 0.00 \mathrm{E}+00 \quad 000 \mathrm{E}+00 \quad 8$ 10E-06 $\begin{array}{llllllllll}599 & 0 & 00 E+00 & 0.00 E+00 & 1.07 E-06 & 0.00 E+00 & 0.00 E+00 & 6.58 E .06\end{array}$ $\begin{array}{lllllllll}601 & 0.00 \mathrm{E}+00 & 2.67 \mathrm{E}-04 & 7.36 \mathrm{E}-04 & 2.08 \mathrm{E}-06 & 426 \mathrm{E}-07 & 399 \mathrm{E}-06\end{array}$ $\begin{array}{lllllll}602 & 0.00 \mathrm{E}+00 & 0.00 \mathrm{E}+00 & 2.77 \mathrm{E}-06 & 4.23 \mathrm{E}-06 & 688 \mathrm{E}-07 & 1.16 \mathrm{E}-05\end{array}$ $\begin{array}{lllllll}603 & 0.00 E+00 & 9.95 E-05 & 1.50 E-05 & 8.56 E-06 & 104 E-06 & 7.00 E-05\end{array}$ $604 \quad 0.00 E+00 \quad 1.03 E-05 \quad 1.23 E-06 \quad 2.91 E-06 \quad 5.19 E-07 \quad 5$ SOE-06 $\begin{array}{lllllll}607 & 0 & 00 E+00 & 2.31 E-05 & 2.65 E-06 & 2.89 E-07 & 0 \\ 000 E+00 & 4.03 E-06\end{array}$ \begin{tabular}{lllllll}
608 & $0.00 E+00$ & $5.02 E-05$ & $9.07 E-06$ & $1.00 E-05$ & $7.07 E-07$ & 2.06E-04 \\
\hline
\end{tabular} $\begin{array}{llllllll}610 & 0.00 E+00 & 0.00 E+00 & 3.35 E-06 & 0.00 E+00 & 0.00 E+00 & 1.95 E-06\end{array}$ $\begin{array}{llllllll}611 & 0.00 \mathrm{E}+00 & 1.28 \mathrm{E}-05 & 6.93 \mathrm{E}-06 & 4.48 \mathrm{E}-06 & 6 & 64 \mathrm{EE}-07 & 8.31 \mathrm{E}-06\end{array}$ $6130.00 E+00$ 2.65E-01 3.41E-05 $0.00 E+00$ S0SE-07 6.14E-05 $\begin{array}{lllllll}618 & 0.00 \mathrm{E}+00 & 4.83 \mathrm{E}-06 & 1.53 \mathrm{E}-06 & 1.70 \mathrm{E}-06 & 000 \mathrm{E}+00 & 3\end{array} \mathrm{35E}-06$ $\begin{array}{llllllll}620 & 0.00 E+00 & 0.00 E+00 & 4.88 E-06 & 0.00 E+00 & 0.00 E+00 & 4.91 E-06\end{array}$ (2.70E-06 $\begin{array}{lllllll}622 & 0.00 E+00 & 6.57 E-06 & 0.00 E+00 & 1.80 E-06 & 298 E-07 & 7.21 E-06\end{array}$ $\begin{array}{lllllll}623 & 0.00 E+00 & 0.00 E+00 & 9.22 E-07 & 1.17 E-06 & 3.41 E-07 & 5.85 E-06\end{array}$ $634 \quad 0.00 E+00 \quad 0.00 \mathrm{E}+00 \quad 9.83 \mathrm{E}-06$ $806 \quad 5.65 \mathrm{E}-06$

$807 \quad 8.16 \mathrm{E}-06$

$809 \quad 6.49 \mathrm{E}-06$

9.83E-06

$3.51 E-06$

$2.14 E-06$

7.02E-0.06

2.29E-06
$2.52 \mathrm{E}-06 \quad 2.84 \mathrm{E}-05$

$0.00 \mathrm{E}+00 \quad 4.43 \mathrm{E}-0$

$1.47 E-03 \quad 3.02 E-06$

$0.00 \mathrm{E}+00 \quad 6.82 \mathrm{E}-05$

$0.00 \mathrm{E}+00 \quad 3.46 \mathrm{E}-07$

$7.31 E-06 \quad 1.47 E-06$

$0.00 E+\infty 0 \quad 0.00 E+00$

$0.00 E+00 \quad 5.32 E-07$

8.92E-06 7.90E-07

$000 \mathrm{E}+\infty$

TC_99 PU_239 PB_210

$K_{-} 40 \quad C_{-} 244$

C.14

CO_60

SR_89 Total Rak

$\begin{array}{llllll}1.01 E-05 & 1.93 E-06 & 0.00 E+00 \quad 000 E+00 & 179 E-07 & 1.37 E-07\end{array}$ $2.88 \mathrm{E}-06$ $\begin{array}{lllll}0.00 E+\infty & 1.08 \mathrm{E}-06 & 0.00 \mathrm{E}+00 \quad 000 \mathrm{E}+\infty & 0.00 \mathrm{E}+\infty & 0.00 \mathrm{E}+\infty\end{array}$ $\begin{array}{lll}00 E+\infty & 131 \mathrm{E}-07 & 0.00 \mathrm{E}+\infty 0\end{array}$

$\begin{array}{lllll}5.29 \mathrm{E}-06 & 1.27 \mathrm{E}-06 & 0.00 \mathrm{E}+00 & 000 \mathrm{E}+00 & \text { 186E-07 }\end{array}$ $0.00 E+00 \quad 0.00 E+00$

4 84E-06 9.02E-07

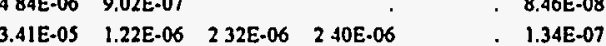

$0.00 \mathrm{E}+00 \quad 9.44 \mathrm{E}-07$

$0.00 E+00$

$0.00 \mathrm{E}+00 \quad 7.09 \mathrm{E}-07$

$000 E+\infty 0$

$0.00 E+00 \quad 1.55 \mathrm{E}-06$

5.29E-06 1.35E-06 000E+00 $000 \mathrm{E}+00 \quad 199 \mathrm{E}-07$

1.70E-05 $\quad$ 4.74E-07

$\begin{array}{llll}7.56 E-06 & 2.33 \mathrm{E}-06 & 0.00 \mathrm{E}+00 & 2.96 \mathrm{E}-06\end{array}$

2.24E-04

$9.32 \mathrm{E}-06 \quad 2.20 \mathrm{E}-06 \quad 8.52 \mathrm{E}-06 \quad 0.00 \mathrm{E}+00 \quad, \quad 1.06 \mathrm{E}-06$

$0.00 \mathrm{E}+00 \quad 1.21 \mathrm{E}-07$

$9.75 \mathrm{E}-08$

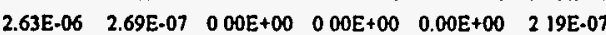
$0.00 E+00 \quad 000 \mathrm{E}+00$

$000 \mathrm{E}+00 \quad 1.16 \mathrm{E}-0.0$

$\begin{array}{llll}0.00 E+\infty & 4.17 \mathrm{E}-07 & 0.00 \mathrm{E}+00\end{array}$

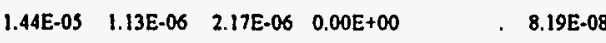

$7.71 \mathrm{E}-06 \quad 9.64 \mathrm{E}-07$

$\begin{array}{llllll}1.41 \mathrm{E}-06 & 3.39 \mathrm{E}-07 & 9.58 \mathrm{E}-07 & 0.00 \mathrm{E}+\infty & 0.00 \mathrm{E}+00\end{array}$

2.67E-06 $\quad 1.79 \mathrm{E}-06 \quad 146 \mathrm{E}-06 \quad 000 \mathrm{E}+00$

$0.00 \mathrm{E}+00 \quad 7.76 \mathrm{E}-07$

3.35E-06 8.97E-07 $\quad 0.00 E+00$

$4.28 \mathrm{E}-06 \quad 0.00 \mathrm{E}+00 \quad 0.00 \mathrm{E}+00 \quad 1.47 \mathrm{E}-07$

$2.97 \mathrm{E}-06 \quad 5.85 \mathrm{E}-07$

$0.00 E+00 \quad 0.00 E+00$

$0.00 E+00 \quad 0.00 E+00$

1.13E-06 2.20E-06

$0.00 E+00 \quad 0.00 E+00$

$0.00 E+00$

2.04E-06

3.81E-06

$1.91 E-06$

4.77E-06

$681 \mathrm{E}-08$

6.14E-03

2.00E-04

4. $10 \mathrm{E}-05 \quad 2.23 \mathrm{E}-06$

$0.00 E+00$ 


\begin{tabular}{|c|c|c|c|c|c|c|c|c|c|c|c|c|}
\hline VELL & $C S \_137$ & $\mathrm{RA}_{-} 228$ & SR_90 & TH_228 & TH_230 & TRITIUM & TOTAL_RA & $U_{-} 234$ & $A M_{-} 241$ & PU_238 & $P M_{-} 147$ & TC_99 \\
\hline 811 & $1.64 \bar{E}-05$ & & 2.87E-06 & & & 8.13E-07 & $3.41 E-06$ & & & & & \\
\hline 812 & $6.73 \mathrm{E}-06$ & & $5.97 E-03$ & $1.22 \mathrm{E}-06$ & $2.14 E-06$ & $1.00 \mathrm{E}-05$ & S.4SE-0S & 7.16E-04 & & $487 \mathrm{E}-07$ & & \\
\hline 813 & $2.63 E=06$ & & $5.75 E-06$ & & & $2.32 \mathrm{E}-06$ & 6 13E-06 & & & & & \\
\hline 814 & $3.50 \mathrm{E}-06$ & & $2.24 \mathrm{E}-06$ & & & 4.35E-06 & 5.45E.06 & . & $0.00 E+\infty$ & $000 E+00$ & $0.00 E+00$ & $0.00 E+00$ \\
\hline 815 & $9.88 \mathrm{E} \cdot 06$ & & 1.31E-06 & & & $1.12 E-06$ & 2.04E-06 & & & & & \\
\hline 816 & $5.79 \mathrm{E}-06$ & & $2.22 \mathrm{E}-06$ & & & $1.88 E-06$ & $6.06 \mathrm{E}-06$ & & & & & \\
\hline 818 & $2.66 \mathrm{E}-06$ & • & 1.38E-06 & & & $5.09 E-06$ & 2.25E-06 & & $0.00 E+00$ & $000 E+00$ & & $8.19 \mathrm{E}-07$ \\
\hline 819 & $7.49 \mathrm{E}-06$ & & $4.25 \mathrm{E}-06$ & & & $1.73 E-06$ & $204 E-06$ & & $0.00 E+00$ & $0.00 E+00$ & $0.00 E+00$ & $0.00 E+\infty 0$ \\
\hline 820 & 5.45E-06 & . & $2.74 \mathrm{E} .06$ & & & $9.18 \mathrm{E}-06$ & 9.54E-07 & & & . & & \\
\hline 821 & $827 E-06$ & . & $1.83 \mathrm{E}-06$ & & & $11 \mathrm{IIE}-06$ & $1.23 \mathrm{E}-06$ & & & . & & . \\
\hline 822 & 1.12E-05 & & $2.58 \mathrm{E}-06$ & . & & $7.62 E-06$ & 4.09E-06 & & & . & & . \\
\hline 823 & 5.59E-06 & & 3.65E-06 & & & 4.25E-06 & 3.4IE-06 & & & & & . \\
\hline 824 & $2.96 \mathrm{E}-06$ & & 2.32E-05 & & & $2.59 \mathrm{E}-06$ & 3.4IE-06 & & & . & & . \\
\hline 825 & $3.43 \mathrm{E}-06$ & & 3.02E.0S & & & 3.22E-06 & $2.04 E-06$ & & & . & & . \\
\hline 826 & 8.5SE-06 & & $3.46 \mathrm{E}-06$ & & & 2.34E-06 & & & & . & & . \\
\hline 827 & $7.11 \mathrm{E}-06$ & & $2.73 \mathrm{E}-06$ & & & $1.75 \mathrm{E}-06$ & $6.81 \mathrm{E}-07$ & & & . & & 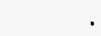 \\
\hline 828 & $4.10 E-06$ & . & 2.34E.06 & & & $2.44 \mathrm{E}-06$ & $2.72 \mathrm{E}-06$ & & & . & & \\
\hline 829 & $2.93 \mathrm{E}-06$ & & $1.59 \mathrm{E}-0 \mathrm{~S}$ & & & 2.03E-06 & $136 \mathrm{E}-06$ & & & . & & \\
\hline 830 & $7.06 E .06$ & & 3.14E-0S & & & 4.08E-05 & $2.72 E-06$ & & & . & & \\
\hline 873 & $0.00 E+00$ & $0.00 E+00$ & 1.39E-0s & $1.50 E-06$ & $000 E+00$ & 1.10E-05 & $0.00 E+00$ & 7.06E.07 & & & & \\
\hline 874 & $0.00 E+00[$ & 6.64 E-OA & 8.A7E-04 & $1.49 E .06$ & $000 E+\infty$ & $4.58 E-04$ & $000 E+00$ & $561 E-07$ & & & & \\
\hline 875 & $0.06 E-06[$ & \begin{tabular}{|l|}
$3.93 \mathrm{E}-03$ \\
\end{tabular} & $9.07 E-03$ & 1.S1E.06 & 2 S3E.06 & $9.39 E-04$ & $0.00 E+00$ & $343 \mathrm{E}-06$ & $000 E+00$ & $000 E+00$ & $288 \mathrm{E} \cdot 06$ & $000 E+\infty 0$ \\
\hline 876 & $0.00 E+00$ & & $3.33 \mathrm{E}-06$ & & & $3.84 E-04$ & & & & & & \\
\hline 877 & $0.00 E+00$ & $1.53 \mathrm{E}-05$ & $1.75 \mathrm{E}-03$ & 1.34E.06 & $000 E+00$ & $2.82 \mathrm{E}-06$ & $347 \mathrm{E}-06$ & $5.47 \mathrm{E} \cdot 07$ & & $000 \varepsilon+00$ & & \\
\hline 878 & $0.00 E+00$ & $0.00 E+\infty 0$ & $0.00 E+00$ & $000 E+00$ & $000 E+\infty 0$ & $3.02 \mathrm{E}-06$ & $0.00 E+\infty 0$ & $3.90 \mathrm{E} \cdot 07$ & & & & \\
\hline 879 & $0.00 E+00$ & $0.00 E+00$ & $8.24 E-07$ & 1.54E-06 & 3 IIE. 07 & 3.42E-06 & $000 E+00$ & $0.00 E+\infty 0$ & & & & \\
\hline 880 & $0.00 E+00$ & $0.00 E+00$ & $1.39 \mathrm{E} .06$ & $000 E+00$ & $000 E+00$ & $3.24 \mathrm{E} .06$ & $0.00 E+00$ & $0.00 E+00$ & & & & \\
\hline 881 & $000 E+00$ & $0.00 \mathrm{E}+00$ & $2.18 \mathrm{E} .06$ & $000 E+00$ & $000 E+\infty 0$ & $2.90 \mathrm{E}-06$ & $000 E+00$ & $4.17 \mathrm{E}-07$ & & & . & \\
\hline 882 & $0.00 E+00$ & 7.88E-06: & 1.53E-05 & $000 E+00$ & $000 \mathrm{E}+\infty$ & $1.18 \mathrm{E}-05$ & $000 E+00$ & $4.10 E-07$ & & & & \\
\hline 884 & $0.00 E+00[$ & $1.96 E-04$ & $0.00 E+\infty 0$ & $1.28 \mathrm{E}-06$ & $125 E .06$ & $1.94 \mathrm{E}-06$ & $000 \mathrm{E}+00$ & $000 E+00$ & & & . & \\
\hline 885 & $0.00 E+00^{2}$ & $2.73 \mathrm{E}-05$ & $2.33 E-05$ & $000 E+\infty$ & $000 E+\infty$ & $1.03 E-03$ & $0.00 E+00$ & $0.00 E+00$ & & & . & $126 \mathrm{E}-07$ \\
\hline 886 & $0.00 E+00$ & $0.00 E+00$ & 2.49E.06 & $000 E+00$ & $0,00 E+00$ & $1.30 \mathrm{E} \cdot 05$ & $0.00 E+00$ & $000 E+00$ & & & . & \\
\hline 946 & $6.94 \mathrm{E} .06$ & & $1.20 \mathrm{E}-0 \mathrm{~s}$ & & & $153 \mathrm{E}-06$ & & & & & & \\
\hline 947 & $5.16 \mathrm{E}-06$ & & $4.90 \mathrm{E} .06$ & & & $1.46 E-05$ & & & & & & \\
\hline 1100 & $0.00 E+00$ & 3.68E-05 & 8.39E-05 & $0.00 E+00$ & $000 E+\infty$ & 1.18E-04 & $0.00 E+00$ & $0.00 E+00$ & & & & \\
\hline 1101 & $0.00 E+00$ & & 8.67E-05 & $0.00 E+00$ & $000 E+\infty$ & 1.91E-04 & $3.53 E-04$ & $2.60 \mathrm{E}-06$ & & & & \\
\hline 1102 & $0.00 E+00[$ & 6.A7E-04 & 7.61E-OA & $000 \mathrm{E}+00$ & $000 E+00$ & $4.76 \mathrm{E}-05$ & $3.38 \mathrm{E}-06$ & $8.57 \mathrm{E} \cdot 07$ & & & & \\
\hline 1103 & $0.00 E+00$ & $3.61 \mathrm{E} \cdot 05$ & $2.84 \mathrm{E}-05$ & $0.00 E+\infty$ & $0.00 E+00$ & $226 \mathrm{E}-05$ [ & 1.75E-04 & $0.00 E+00$ & & & . & \\
\hline 1104 & $0.00 E+\infty 0$ & $3.21 E-05$ & $6.57 \mathrm{E}-05$ & $0.00 E+\infty$ & $7.15 E-04$ & $9.02 \mathrm{E}-05$ & $0.00 E+\infty 0$ & $0.00 E+00$ & $000 E+\infty 0$ & $000 E+\infty 0$ & $0.00 E+00$ & $0.00 E+\infty 0$ \\
\hline 2531 & $000 E+00$ & 5.96E-0S & & 7 0SE -07 & $000 \mathrm{E}+00$ & $1.87 \mathrm{E}-06$ & $5.04 \mathrm{E}-06$ & $1.65 \mathrm{E}-07$ & $000 E+00$ & $000 E+00$ & 1 18E-07 & $0.00 E+\infty$ \\
\hline 2533 & $0.00 E+\infty 0$ & & $5.66 \mathrm{E}-06$ & & & $2.20 \mathrm{E}-06$ & & & & & & \\
\hline 4003 & $0.00 E+00$ & & 3.17E-06 & & & 2.31E-06 & & & & & & \\
\hline 4004 & $0.00 E+00$ & & $3.87 E-06$ & & & 3.69E-06 & & & & & $2.02 E-07$ & $1.83 \mathrm{E}-07$ \\
\hline 4005 & $0.00 E+00$ & $0.00 E+00$ & $2.10 E-01$ & $367 E .06$ & $0.00 E+00$ & $4.02 \mathrm{E}-06$ & $1.99 \mathrm{E}-05$ & $1.13 E-03$ & $1.99 \mathrm{E}-05$ & $000 E+00$ & $2.66 E-04$ & $1.73 \mathrm{E} .06$ \\
\hline 4006 & $0.00 E+00$ & & $2.99 E-06$ & & & 3.40E-0s & & & & & & \\
\hline 4008 & $0.00 E+00[$ & $2.90 E-0.9$ & $1.32 \mathrm{E}-06$ & $7.28 \mathrm{E}-06$ & $000 E+\infty 0$ & $9.98 E-07$ & $227 \mathrm{E}-06$ & $2.59 \mathrm{E}-06$ & $0.00 E+00$ & $000 E+00$ & $7.23 \varepsilon-07$ & $0.00 E+\infty 0$ \\
\hline 4009 & $0.00 E+00^{2}$ & & & & & & & & & & & \\
\hline 1150 & $222 \mathrm{E}-06$ & & 4.8 & & & & & & & & & \\
\hline 1151 & & & & & & & & & & & & \\
\hline 1152 & 3.50E-0s & & $2.50 E-06$ & & & $3.06 E-04$ & & & & & & \\
\hline 1153 & $3.02 \mathrm{E}-06$ & & & & & $145 \mathrm{E}-06$ & & & & & & \\
\hline 1154 & $1.27 \mathrm{E}-0 \mathrm{~S}$ & & $286 E-06$ & & & $166 \mathrm{E}-06$ & & & & & & \\
\hline
\end{tabular}

\begin{tabular}{|c|c|c|c|c|c|}
\hline$K_{-} 40$ & CM_244 & C_14 & $\begin{array}{r}\text { CO_60 } \\
4.08 E-06\end{array}$ & $\mathrm{SR}_{-} 89$ & $\frac{\text { Total Rak }}{3.20 \mathrm{E}-0.4}$ \\
\hline . & " & . & $8.52 E-06$ & & $6.65 \mathrm{E}-03$ \\
\hline & & & 5.14E-06 & & $9,16 E-04$ \\
\hline & $0.00 \mathrm{E}+00$ & $0.00 E+\infty 0$ & $4.60 \mathrm{E}-06$ & & 1.63E-02 \\
\hline . & $\bullet$ & & $3.73 \mathrm{E}-06$ & & $1.07 E-04$ \\
\hline & & & $7.24 E-06$ & & $2.13 E-04$ \\
\hline . & . & $0.00 E+00$ & 2.44E-06 & & $1.15 E-02$ \\
\hline . & & $0.00 \mathrm{E}+00$ & $2.32 \mathrm{E}-06$ & & 1.14E-02 \\
\hline & ${ }^{\circ}$ & & $2.23 \mathrm{E}-06$ & & $8.25 \mathrm{E}-05$ \\
\hline & - & & $4.48 \mathrm{E}-06$ & & $2.73 \mathrm{E}-05$ \\
\hline & . & . & $3.70 \mathrm{E}-06$ & & $6.92 \mathrm{E}-05$ \\
\hline . & • & & $3.96 \mathrm{E}-06$ & & $3.00 \mathrm{E}-05$ \\
\hline . & ${ }^{\circ}$ & . & $5.61 E-06$ & & A.01E-04 \\
\hline • & • & . & 1.15E-0S & & $1.03 E-03$ \\
\hline . & - & . & $4.26 \mathrm{E}-06$ & & $9.06 E-04$ \\
\hline & . & . & $7.07 \mathrm{E}-06$ & & $3.36 E-04$ \\
\hline . & . & . & $2.38 \mathrm{E}-06$ & & $3.63 \mathrm{E}-04$ \\
\hline . & . & . & 8.57E-06 & & 4A0E-04 \\
\hline . & . & . & $4.98 \mathrm{E}-06$ & & $5.14 E-04$ \\
\hline & & & & & 2.11E-04 \\
\hline & & & & & $2.22 \mathrm{E}-03$ \\
\hline & $0.00 E+00$ & $5.88 \mathrm{E}-06$ & , & & $1.55 E-02$ \\
\hline . & & & & & $3.88 E-04$ \\
\hline . & 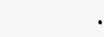 & . & $285 \mathrm{E}-06$ & & $3.09 E-04$ \\
\hline & . & e & & & $2.56 E-04$ \\
\hline & & & & & $6.10 \mathrm{E}-06$ \\
\hline . & & & & & $2.57 \mathrm{E}-0 \mathrm{~A}$ \\
\hline . & , & . & & & $8.81 E-04$ \\
\hline . & & . & & & $3.54 \mathrm{E}-05$ \\
\hline & & . & & & $4.53 \mathrm{E}-04$ \\
\hline$E-05$ & . & & $5.83 \mathrm{E}-06$ & & $1.38 E-03$ \\
\hline & . & ${ }^{\circ}$ & & & 1.55E.05 \\
\hline & . & . & $1.19 \mathrm{E}-0 \mathrm{~s}$ & & $1.05 E-04$ \\
\hline & . & . & $8.38 E-06$ & & 1.03E-04 \\
\hline & . & & & & $6.77 E-04$ \\
\hline . & . & . & & & $9.09 E-04$ \\
\hline$=$ & . & . & & & $2,04 E-03$ \\
\hline & . & . & & & $1.02 E-03$ \\
\hline & . & . & & & $9.14 \mathrm{E}-04$ \\
\hline $00 E+\infty 0$ & . & & & & $7.15 E-05$ \\
\hline $100 E+\infty 0$ & & & & & $1.09 E-04$ \\
\hline & . & . & 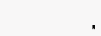 & & $2.97 E-04$ \\
\hline $100 E+\infty$ & & & & & $1,12 E-04$ \\
\hline $100 E+\infty$ & $2.94 E-04$ & " & & $4.21 \mathrm{E}-0$ & $2.12 E-01$ \\
\hline $.00 E+\infty 0$ & & . & & & $8.57 E-04$ \\
\hline $.00 E+00$ & . & . & & & $3.09 E-04$ \\
\hline $00 E+\infty$ & . & & & & $5.07 \mathrm{E} \cdot 06$ \\
\hline & & & 2.62E.06 & & $131 \mathrm{E}-05$ \\
\hline & . & & | 19E.0S & & $3.96 \mathrm{E}-05$ \\
\hline & & & I 30E.05 & & $3.57 E-04$ \\
\hline & & & $138 \mathrm{E}-0 \mathrm{~S}$ & & 261E-05 \\
\hline & & & $114 \mathrm{E}-05$ & & $299 \mathrm{E}-05$ \\
\hline
\end{tabular}




\begin{tabular}{|c|c|c|c|c|c|c|c|c|c|c|}
\hline WELL & CS_137 & RA_228 & SR_90 & TH_228 & $T H \_230$ & TRITIUM & TOTAL_RA & $U_{-} 234$ & AM_24I & PU_238 \\
\hline 1153 & $2.47 \mathrm{E}-06$ & & $1.69 \mathrm{E}-06$ & & & $3.98 \mathrm{E}-06$ & & & & \\
\hline 1156 & 2.38E-05 & . & $1.89 \mathrm{E} \cdot 06$ & & & 2.87E-04 & & . & i. & . \\
\hline 1185 & $7.95 \mathrm{E}-06$ & & 2.25E-06 & & & $1.35 \mathrm{E}-06$ & . & . & . & \\
\hline 1186 & $1.91 \mathrm{E}-06$ & . & $1.73 \mathrm{E}-06$ & & & $1.83 \mathrm{E}-06$ & . & . & . & . \\
\hline 1187 & $4.29 E-06$ & & 3.64E.06 & & & $14 \mathrm{IE}-06$ & & & 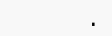 & \\
\hline 1188 & $7.20 E-06$ & . & $1.98 \mathrm{E}-06$ & & & 2.06E-06 & . & . & & . \\
\hline 1189 & 2.54E-05 & . & 1.168 .06 & & & $3.25 E-06$ & . & & . & . \\
\hline 1190 & $1.27 \mathrm{E}-06$ & & $3.63 \mathrm{E}-06$ & & & 8.47E-05 & . & . &. & . \\
\hline 1191 & $1.39 \mathrm{E}-0 \mathrm{~S}$ &. & $6.52 E-04$ & & & 2.18E-04 & . & . & . & . \\
\hline 1192 & $7.06 \mathrm{E}-06$ & & $4.40 \mathrm{E} \cdot 06$ & & & $4.30 \mathrm{E}-06$ & - & . & 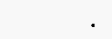 & . \\
\hline 1193 & $1.37 \mathrm{E}-05$ & . & 4.50E-06 & & & $5.52 \mathrm{E}-07$ & & . & 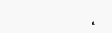 & \\
\hline 1194 & $1.63 \mathrm{E}-06$ & . & 3.09E-06 & & & $7.02 \mathrm{E}-07$ & & & & . \\
\hline 1195 & 7.95E-07 & . & $2.87 \mathrm{E} \cdot 06$ & & & $1.21 \mathrm{JE}-06$ & & & & . \\
\hline 12.44 & $1.43 \mathrm{E}-06$ & . & $2.62 \mathrm{E}-06$ & & & $4.19 \mathrm{E}-05$ & . & . & . & . \\
\hline 1245 & $2.22 \mathrm{E}-06$ & 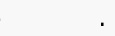 & 4.50E-06 & & & $0.00 E+\infty 0$ & . & & . & \\
\hline 985 & $1.11 \mathrm{E}-05$ & . & $2.66 \mathrm{E}-08$ & & & $1.73 E-06$ & . & . & & \\
\hline 986 & $6.76 \mathrm{E}-06$ & 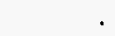 & $1.53 \mathrm{E}-06$ & & & $1.75 E-06$ & . & & . & \\
\hline 987 & $1.59 \mathrm{E}-05$ & . & $2.12 \mathrm{E} \cdot 06$ & & & $126 \mathrm{E}-06$ & . & & & \\
\hline 988 & $1.11 E-06$ & & $1.96 \mathrm{E} \cdot 06$ & & & | $41 \mathrm{E}-06$ & & . & & \\
\hline 990 & $6.36 E=07$ & & $1.98 \mathrm{E}-06$ & & & $1.53 \mathrm{E}-06$ & & & & \\
\hline 991 & $7.95 E-06$ & & $3.98 \mathrm{E}-06$ & & & $889 \mathrm{E}-07$ & & & & \\
\hline 992 & $9.54 \mathrm{E}-06$ & & $1.08 E-04$ & & & 9 SOE-07 & & & & \\
\hline 993 & $6.36 \mathrm{E}-07$ & & 1.59E-04 & & & $1.44 \mathrm{E}-06$ & & & & \\
\hline 994 & I 43E.05 & & $4.90 \mathrm{E}-04$ & & & $3.67 E-05$ & & & & \\
\hline 995 & $6.36 \mathrm{E}-06$ & & $1.63 \mathrm{E}-08$ & & & $1.31 E-06$ & & & . & \\
\hline 996 & 1.11E-06 & & 4.09E.06 & & & $1.68 \mathrm{E}-06$ & & & & \\
\hline 997 & 9.54E-06 & & $7.76 \mathrm{E}-0 \mathrm{~s}$ & & & $162 \mathrm{E}-06$ & & & & \\
\hline 998 & $7.95 E-07$ & & $1.78 \mathrm{E}-06$ & & & i $47 \mathrm{E} .06$ & & & . & \\
\hline 1248 & $2.22 \mathrm{E}-0 \mathrm{~S}$ & & 1.63E.0S & & & 2.4SE-07 & & & & \\
\hline 9.48 & 9.33E-07 & & $3.11 \mathrm{E} .06$ & & & $7.89 \mathrm{E}-07$ & & & & \\
\hline 949 & $1.20 \mathrm{E}-05$ & & 1.45E-06 & & & $222 \mathrm{E}-0 \mathrm{~S}$ & & & & \\
\hline 950 & $3.49 E-06$ & & $2.11 E .06$ & & & $9.13 E-07$ & & & & \\
\hline 951 & 4.44E-06 & & 3.84E-06 & & & $250 \mathrm{E}-07$ & & & & \\
\hline 952 & $9.25 \mathrm{E}-06$ & & $1.25 \mathrm{E} .06$ & & & 3.06E-05 & & & & \\
\hline 953 & $1.40 \mathrm{E}-06$ & & $5.30 \mathrm{E}-06$ & & & $4.88 \mathrm{E}-07$ & & & & \\
\hline 954 & $2.79 \mathrm{E}-06$ & & $2.98 \mathrm{E}-06$ & & & $3.45 E-04$ & & & & , \\
\hline 955 & $3.18 \mathrm{E}-05$ & & 3.06E-05 & & & \begin{tabular}{|l|}
$5.71 E-04$ \\
\end{tabular} & & & & \\
\hline 956 & $1.13 \mathrm{E}-05$ & & $5,48 E-04$ & & & $1.76 \mathrm{E}-04$ & & & & \\
\hline 957 & $1.42 \mathrm{E}-05$ & & $1.46 \mathrm{E} .06$ & & & $7.89 \mathrm{E}-03$ & & & & \\
\hline 958 & 2.46E-05 & & 2.84E-06 & & & 1.04E-02 & & & & \\
\hline 959 & $8.79 \mathrm{E}-06$ & & $3.10 E \cdot 06$ & & & T.15E-05 & & & & \\
\hline 960 & $1.21 \mathrm{E}-05$ & & 4.30E-06 & & & $8.23 \mathrm{E}-05$ & & & & \\
\hline $\begin{array}{l}961 \\
962\end{array}$ & $\begin{array}{l}1.43 \mathrm{E}-05 \\
2.38 \mathrm{E}-06\end{array}$ & & $\begin{array}{l}4.17 \mathrm{E}-06 \\
7.36 \mathrm{E}-06\end{array}$ & & & $\begin{array}{l}1.04 \mathrm{E}-06 \\
9.80 \mathrm{E}-06\end{array}$ & & & . & \\
\hline 440 & $0.00 E+00$ & $0.00 E+00$ & 4.34E-04 & $425 E .05$ & $4.42 E-06[$ & $3.04 E-02$ & $917 E-06$ & $625 \mathrm{E}-06$ & $3.91 \mathrm{E}-05$ & $2.66 \mathrm{E}-05$ \\
\hline 441 & 4.15E-06 & $2.02 E-04$ & $2.19 E-04$ & $700 \mathrm{E}-06$ & $196 \mathrm{E}-06$ & 1.13E-04 & $680 \mathrm{E}-06$ & $114 \mathrm{E}-06$ & $262 E-06$ & $2.54 \mathrm{E}-06$ \\
\hline 468 & $0.00 E+\infty$ & $3.57 E-06$ & $4.46 \mathrm{E}-06$ & 4 35E.06 & $106 \mathrm{E} .06$ & $7.71 \mathrm{E}-06$ & $8.32 E-06$ & $840 \mathrm{AO}-07$ & $1.56 \mathrm{E}-06$ & $8.78 E-07$ \\
\hline 472 & $0.00 E+00[$ & $1.85 E-04$ & $3.33 E-04$ & $2.00 E-06$ & $423 \mathrm{E}-07$ & 1.70E-03 & $34 S E-06$ & $282 E-06$ & $000 E+00$ & $0.00 E+00$ \\
\hline 476 & $000 E+\infty$ & $0.00 E+00$ & $1.10 E-02$ & $000 E+00$ & $6.80 \mathrm{E}-08$ & $5.85 \mathrm{E}-03$ & 1) 34E-05 & $470 E-06$ & $2.07 \mathrm{E}-0 \mathrm{~s}$ & $3.21 E-05$ \\
\hline $\begin{array}{l}513 \\
314\end{array}$ & $\begin{array}{l}0.00 E+\infty 0 \\
0.00 E+\infty 0\end{array}$ & $0.00 E+\infty 0$ & $\begin{array}{l}0.00 E+00 \\
0.00 E+00\end{array}$ & $\begin{array}{l}6.50 E-06 \\
0.00 E+00\end{array}$ & $\begin{array}{l}8.63 \mathrm{E}-07 \\
000 \mathrm{D}+00\end{array}$ & $\begin{array}{l}146 \mathrm{E}-06 \\
141 \mathrm{E}-06\end{array}$ & $\begin{array}{l}285 E-05 \\
117 E-06\end{array}$ & $\begin{array}{c}1.11 E-06 \\
000 E+00\end{array}$ & $\begin{array}{l}0.00 \mathrm{E}+\infty \\
0.00 \mathrm{E}+\infty\end{array}$ & $\begin{array}{r}6.84 \mathrm{E}-06 \\
0.00 \mathrm{E}+00\end{array}$ \\
\hline 316 & $000 E+\infty 0$ & $000 E+00$ & $0.00 E+\infty$ & $120 \mathrm{E}-06$ & $156 \mathrm{E}-07$ & $181 E-06$ & $849 E-07$ & $134 \mathrm{E}-07$ & S.64E-06 & $362 \mathrm{E}-06$ \\
\hline$\$ 17$ & $425 E-06$ & $000 E+00$ & $0.00 E+00$ & $252 E-06$ & $650 \mathrm{E} \cdot 07$ & $630 E-07$ & $781 \mathrm{E}-07$ & $+30 E-07$ & $338 E-06$ & $103 \mathrm{E}-05$ \\
\hline
\end{tabular}
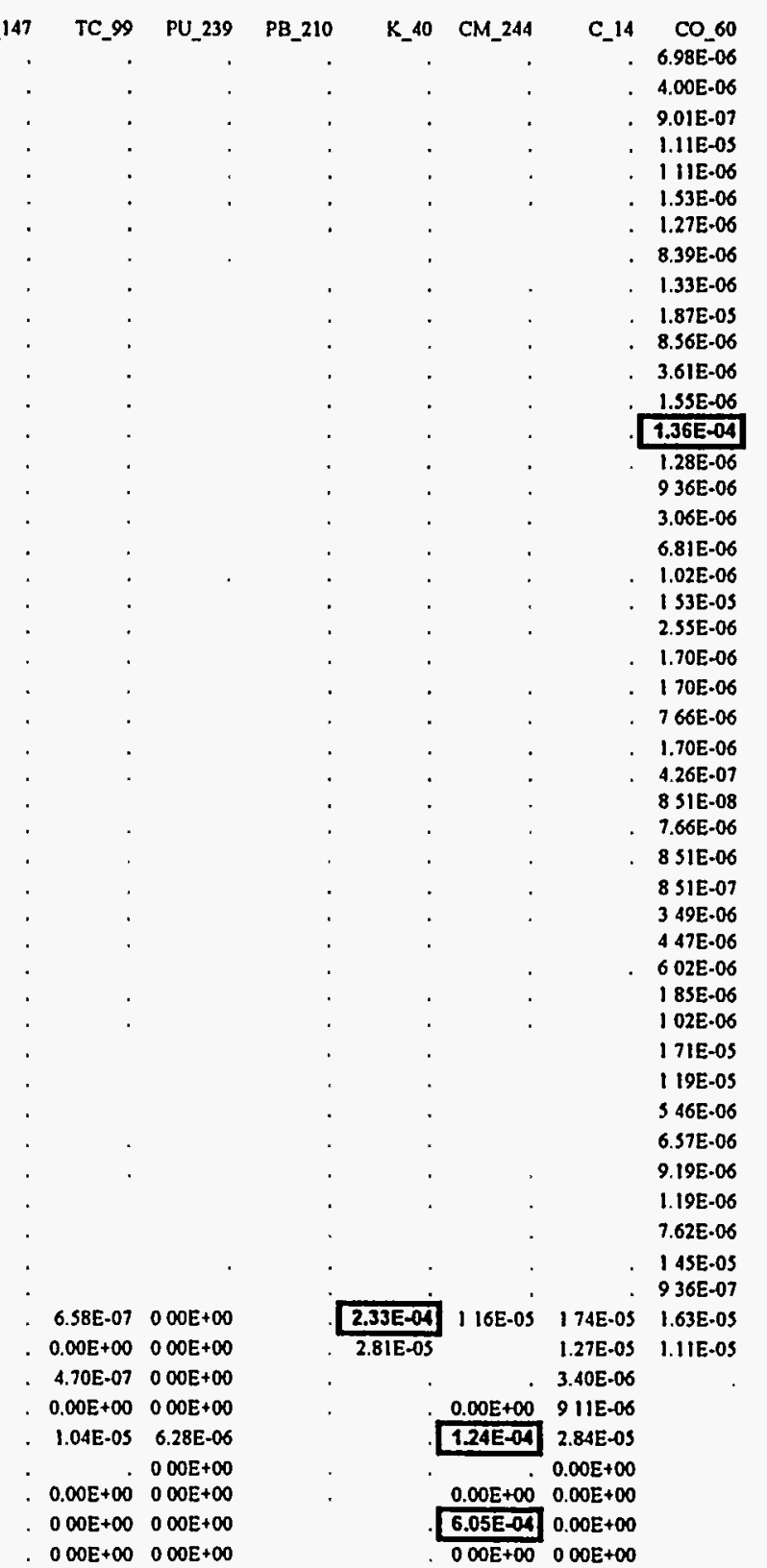

SR_89 Total_Rsk

$1.64 \mathrm{E}-0 \mathrm{~s}$

$3.17 E-04$

$1.81 \mathrm{E}-05$
$1.65 \mathrm{E}-05$

$1.04 \mathrm{E}-05$

$1.28 E-05$

3.38E-05

$\frac{8.87 E-04}{3.69 \mathrm{E}-05}$

\begin{tabular}{|c|}
$2.73 E-05$ \\
\hline $1.49 E-04$ \\
\hline $1.21 E-04$ \\
\hline $1.82 E-04$ \\
\hline
\end{tabular}

1.82E-04

.

\begin{tabular}{l}
$2.49 E-05$ \\
$1.31 E-04$ \\
\hline $2.6 E-05$
\end{tabular}

2.61E-05

5.SOE-06

1.95E-05

2.44E-04

1.64E-04

5.A8E-04

$7.53 \mathrm{E}-06$
$8.91 \mathrm{E}-05$

1.49E-05

5.69E-06

$1.10 \mathrm{E}-05$

1.46E-0s

4.34E-0s

8.65E-06

$\frac{1.74 E-02}{8.42 E-04}$

7A2E-04

7.92E-03

6.37E-02

2.66E-05

3.39E-05

2.05E-05

$0.00 E+\infty 0000+\infty$

$\frac{3.15 E-02}{6.15 E-04}$

6.15E-04

2A9E-03

2A9E-03

.07E-05

2.61E-06

$240 \mathrm{E}-0 \mathrm{~S}$ 
WELL CS_137 RA_228

SR 90 TH 228 TH 230 TRITIUM TOTAL_RA

U_234 AM 241

PM_147

TC_99 PU_239 PB_210

$518 \quad 0.00 \mathrm{E}+00$

$519 \quad 4.48 E-06 \quad 507 E-05 \quad 000 E+00 \quad 9.85 E-06 \quad 2.12 E-06 \quad 7.13 E-07$

$520 \quad 0.00 E+00$ $000 E+00 \quad 9.85 E-06 \quad 2.12 \mathrm{E}-06 \quad 7.13 \mathrm{E}-0$

$S 21 \quad 0.00 E+00$ $\begin{array}{llll}0.00 E+00 & 0.00 E+00 & 0.00 E+00 & 9.27 E-07\end{array}$

$\begin{array}{llllllllllll}522 & 0.00 E+00 & 9.70 E-05 & 0.00 E+00 & 0.00 E+\infty & 0.00 E+00 & 0.00 E+\infty 0\end{array}$

$523 \quad 0.00 E+00 \quad$. $0.00 E+\infty \quad$. $1.81 \mathrm{E}-06$

$\begin{array}{lllllll}524 & 0.00 E+00 & 126 E-05 & 0.00 E+00 & 6.47 E-06 & 7.64 E-07 & 8.91 E-06\end{array}$ S2S $0.00 E+00 \quad$. $0.00 E+00 \quad 8.32 E-07 \quad 4.91 E-08 \quad 4.65 E-07$ $526 \quad 0.00 E+00$ $\begin{array}{rrrr}0.00 \mathrm{E}+00 & 8.32 \mathrm{E}-07 & 4.91 \mathrm{E}-08 & 4.65 \mathrm{E}-07 \\ 3.63 \mathrm{E}-06 & . & . & 1.93 \mathrm{E}-05\end{array}$ $715 \quad 0.00 E+00$ 1.02E-04 $0.00 E+00$ S.S4E-06 $9.58 E-07 \quad 2.09 E-06$ $\begin{array}{llllllll}716 & 4.47 \mathrm{E}-06 & 4.41 \mathrm{E}-06 & 0.00 \mathrm{E}+00 & 1.73 \mathrm{E}-06 & 4.91 \mathrm{E}-07 & 4.65 \mathrm{E}-07\end{array}$ $963 \quad 7.28 \mathrm{E}-06 \quad 0.00 \mathrm{E}+00 \quad 9.18 \mathrm{E}-07 \quad 0.00 \mathrm{E}+00 \quad 2.68 \mathrm{E}-08 \quad 2.86 \mathrm{E}-0$ ?

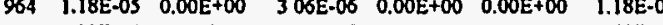
$\begin{array}{llllllll}965 & 6.39 E-06 & 2.37 E-06 & 2.49 E-07 & 4.65 E-07 & 0.00 E+00 & 1.59 E-06\end{array}$ $966 \quad 1.77 E-06 \quad 2.14 E-06 \quad 1.51 E-06 \quad 0.00 E+00 \quad 0.00 E+00 \quad 1.57 E-06$ $\begin{array}{llllllll}967 & 5.16 \mathrm{E}-06 & 0.00 \mathrm{E}+00, & 3.69 \mathrm{E}-06 & 0.00 \mathrm{E}+00 & 173 \mathrm{E}-07 & 1.45 \mathrm{E}-06 \\ 968 & 1.75 E-06 & 3.76 E-07 & 1.25 E-06 & 3.37 E-07 & 9.99 E-08 & 3.22 \mathrm{E}-04 & \end{array}$ \begin{tabular}{lllllllll}
968 & $1.73 E-06$ & $3.76 E-07$ & $1.25 E-06$ & $3.37 E-07$ & $9.99 E-08$ & $3.22 E-04$ \\
\hline
\end{tabular} \begin{tabular}{|lll|l|l|l|l|l|}
969 & $1.12 \mathrm{E}-06$ & $0.00 \mathrm{E}+00$ & $\mathbf{4 . 1 0 E}-04$ & $4.37 \mathrm{E}-07$ & $0.00 \mathrm{E}+00$ & $\mathbf{2 . 4 5 E - 0 2}$ \\
\hline 970 & $2.07 \mathrm{E}-06$ & $0.00 \mathrm{E}+00$ & $3.08 \mathrm{E}-06$ & $0.00 \mathrm{E}+00$ & $1.61 \mathrm{E}-05$ & $\mathbf{1 . 3 0 E - 0 3}$ \\
\hline
\end{tabular} \begin{tabular}{lllllll}
971 & $6.90 \mathrm{E}-06$ & $790 \mathrm{E}-07$ & $339 \mathrm{E}-05$ & $0.00 \mathrm{E}+00$ & $4.97 \mathrm{E}-08$ & $\mathbf{1 . 3 2 E - 0 3}$ \\
\hline
\end{tabular} \begin{tabular}{llllllll}
972 & $4.77 \mathrm{E}-07$ & $3.44 \mathrm{E}-06$ & $2.60 \mathrm{E}-05$ & $6.13 \mathrm{E}-07$ & $0.00 \mathrm{E}+00$ & $4.90 \mathrm{E}-04$ \\
\hline
\end{tabular} \begin{tabular}{|lll|l|l|l|l|l|}
973 & $7.80 E-06$ & $1.63 E-04$ & $1.07 E-04$ & $0.00 E+\infty$ & 0.00 & $0.00 E+\infty$ & $2.80 E-01$ \\
\hline
\end{tabular}

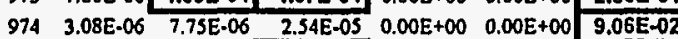

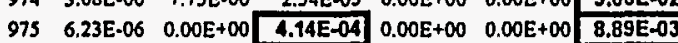
\begin{tabular}{llllllllll}
976 & $7.41 \mathrm{E}-06$ & $2.29 \mathrm{E}-06$ & $6.96 \mathrm{E}-06$ & $5.42 \mathrm{E}-07$ & $0.00 \mathrm{E}+00$ & $6.88 \mathrm{E}-0.03$ \\
\hline
\end{tabular} \begin{tabular}{lllllllll}
9 & 977 & $1.14 E-05$ & $0.00 E+00$ & $6.98 E-06$ & $0.00 E+00$ & $0.00 E+00$ & $7.61 E-03$ \\
\hline
\end{tabular}

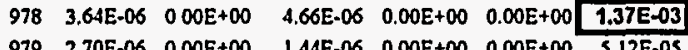
$\begin{array}{lllllllll}979 & 2.70 E-06 & 000 \mathrm{E}+00 & 1.44 \mathrm{E}-06 & 000 \mathrm{E}+00 & 0.00 \mathrm{E}+00 & 5.12 \mathrm{E}-05 \\ 980 & 4.15 \mathrm{E}-06 & 0.00 \mathrm{E}+00 & 3.62 \mathrm{E}-06 & 0.00 \mathrm{E}+00 & 0.00 \mathrm{E}+00 & 6.44 \mathrm{E}-07\end{array}$ \begin{tabular}{llllllll}
980 & $4.15 E-06$ & $0.00 E+00$ & $3.62 E-06$ & $0.00 E+00$ & $0.00 E+00$ & $6.44 E-07$ \\
981 & $636 E-07$ & $0.00 E+00$ & $1.47 E-05$ & $2.99 E-05$ & $8.79 E-08$ & $1.32 E-03$ \\
\hline
\end{tabular} $\begin{array}{llllllll}982 & 7.74 \mathrm{E}-06 & 0 & 00 \mathrm{E}+00 & 9.81 \mathrm{E}-07 & 0.00 \mathrm{E}+00 & 6.50 \mathrm{E}-08 & 1.27 \mathrm{E}-06\end{array}$ $\begin{array}{lllllll}983 & 4.93 E-06 & 0.00 E+00 & 395 E-05 & 0.00 E+00 & 0.00 E+00 & 7.30 E-06\end{array}$ $\begin{array}{llllllll}984 & 8.53 \mathrm{E}-06 & 2.52 \mathrm{E}-07 & 1.49 \mathrm{E}-06 & 0.00 \mathrm{E}+00 & 7.32 \mathrm{E}-08 & 1.17 \mathrm{E}-06\end{array}$ $\begin{array}{rrrrrrr}1105 & 0.00 E+00 & 0.00 E+00 & 3.42 E-05 & 0.00 E+00 & 0.00 E+00 & 2.34 E-03 \\ 1\end{array}$ \begin{tabular}{lllllllll}
11106 & $0.00 E+00$ & $0.00 E+001$ & $4.61 E-06$ & $0.00 E+00$ & $0.00 E+\infty 0$ & $2.04 E-03$ \\
\hline
\end{tabular} \begin{tabular}{llllllll|}
1106 & $0.00 E+00$ & $0.00 E+00$ & $4.61 E-06$ & $0.00 E+00$ & 0 & $00 E+\infty$ & $2.04 E-03$ \\
1107 & $0.00 E+\infty$ & $6.34 E-04$ & $3.36 E-03$ & $0.00 E+00$ & $0.00 E+\infty$ & $1.27 E-03$ \\
\hline
\end{tabular} \begin{tabular}{|l|l|l|l|l|l|l|}
11107 & $0.00 E+00$ & $6.34 E-04$ & $3.36 E-03$ & $0.00 E+00$ & $000 E+00$ & $1.27 E-03$ \\
\hline 1108 & $1.62 E-03$ & $0.00 E+00$ & $3.09 E-02$ & $0.00 E+00$ & $472 E-08$ & $6.23 E-04$ \\
\hline
\end{tabular} \begin{tabular}{l|l|l|l|l|l|l|l|}
1108 & $1.62 \mathrm{E}-0 \mathrm{j}$ & $0.00 \mathrm{E}+00$ & $3.09 \mathrm{E}-02$ & $0.00 \mathrm{E}+00$ & 4 & $42 \mathrm{E}-08$ & $6.23 \mathrm{E}-04$ \\
\hline 4113 & $0.00 \mathrm{E}+00$ & $9.03 \mathrm{E}-06$ & $1.89 \mathrm{E}-05$ & $3.70 \mathrm{E}-05$ & $6.55 \mathrm{E}-06$ & $1.25 \mathrm{E}-04$ \\
\hline
\end{tabular} \begin{tabular}{|llll|l|l|l|l|}
4113 & $0.00 E+00$ & $9.03 E-06$ & $1.89 E-06$ & $3.70 E-05$ & $6.55 E-06$ & $1.25 E-04$ \\
\hline 4114 & $0.00 E+00$ & $315 E-05$ & $9.68 E-04$ & $2.43 E-04$ & $0.00 E+00$ & $1.74 E-03$ \\
\hline
\end{tabular} 4lIS $0.00 \mathrm{E}+00 \quad 0.00 \mathrm{E}+00 \quad 1.36 \mathrm{E}-05 \quad 0.00 \mathrm{E}+00 \quad 0.00 \mathrm{E}+00 \quad 2.55 \mathrm{E}-03$ \begin{tabular}{llllllll}
4116 & $0.00 E+00$ & 0 & $00 E+\infty 0$ & $0.00 E+00$ & $297 E-06$ & $661 E-07$ & $2.86 E-04$ \\
\hline
\end{tabular} . $0.00 \mathrm{E}+00$

$2.28 E-05 \quad 2.88 E-06 \quad 7.01 E-06 \quad 0.00 E+00$ $\begin{array}{llllllllllll}0.00 E+\infty & 0.00 E+\infty & 0.00 E+\infty 00 & 0.00 E+\infty\end{array}$ $0.00 \mathrm{E}+\infty 00.00 \mathrm{E}+00 \quad 1.88 \mathrm{E}-0 \mathrm{~d}] 0.00 \mathrm{E}+\infty$ 3.53E-06 $0.00 \mathrm{E}+00 \quad 0.00 \mathrm{E}+00 \quad 0.00 \mathrm{E}+00$ $1.73 E-06 \quad 3.78 E-06 \quad 0.00 E+00$ 3.06E-06 $0.00 \mathrm{E}+00$ $0.00 E+00 \quad 0.00 E+00$ $0.00 E+00 \quad 0.00 E+00$ 3.52E-07 $0.00 E+\infty$ 4.56E-07 $0.00 \mathrm{E}+\infty$ $1.27 E-06 \quad 0.00 E+00$
$0.00 E$ 9.68E-06 1.51E-06 3.43E-06 $0.00 \mathrm{E}+00$ $\begin{array}{lll}1.30 E-05 & 0.00 E+00 \quad 0.00 E+00 & 1.57 E-06\end{array}$ 2.99E-07 $0.00 \mathrm{E}+00$

O.00E+00 1.75E-07 7.06E-06 $000 \mathrm{E}+00$ $\begin{array}{lllll}1.37 \mathrm{E}-05 & 3.37 \mathrm{E}-06 & 0.00 \mathrm{E}+00 \quad 0.00 \mathrm{E}+00\end{array}$ $\begin{array}{llll}3.65 E-06 & 3.70 E-07 & 0.00 E+\infty 0 & 0.00 E+00\end{array}$ $\begin{array}{llll}0.00 E+\infty & 1.76 E-07 & 0.00 E+00 & 2.62 E-07\end{array}$ $\begin{array}{lllll}0.00 \mathrm{E}+00 & 1.36 \mathrm{E}-07 & 2.86 \mathrm{E}-07 & 0.00 \mathrm{E}+00\end{array}$ $\begin{array}{llll}0.00 E+00 & 1.82 E-07 & 6.35 E-07 & 1.62 E-0\end{array}$ $\begin{array}{llll}5.59 E-07 & 2.00 E-07 & 3.54 E-07 & 0.00 E+00\end{array}$ $0.00 \mathrm{E}+00 \quad 2.30 \mathrm{E}-07 \quad 2.32 \mathrm{E}-07 \quad 2.34 \mathrm{E}-07$ $\begin{array}{lllll}000 E+00 & 2.04 E-07 & 5.49 E-07 & 0.00 E+00\end{array}$ $000 E+00 \quad 2.55 E-07 \quad 1.82 E-06 \quad 4.02 E-06$ $\begin{array}{lllll}0 & 00 \mathrm{E}+00 & 1.09 \mathrm{E}-07 \quad 5.97 \mathrm{E}-07 \quad 3.34 \mathrm{E}-07\end{array}$ 0 OOE +00 1.5SE-07 3.98E-07 2.12E.-07

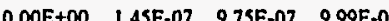
$\begin{array}{lllll}0.00 \mathrm{E}+00 & 8.99 \mathrm{E}-08 & 8.32 \mathrm{E}-06 & 1.99 \mathrm{E}-06\end{array}$ $\begin{array}{llll}0.00 E+\infty & 1.27 E-07 \quad 5.18 E-07 \quad 6.48 E-06\end{array}$ $\begin{array}{llll}0.00 E+00 & 1.18 E-07 & 1.36 E-06 & 2.41 E-06\end{array}$ $\begin{array}{llll}5.64 \mathrm{E}-07 & 1.16 \mathrm{E}-07 & 1.83 \mathrm{E}-06 & 4.00 \mathrm{E}-07\end{array}$ $\begin{array}{llll}0.00 E+00 & 2.55 E-07 & 1.77 E-07 & 2.50 E-08\end{array}$ $\begin{array}{llll}8.24 E-07 & 3.73 E-07 & 5.43 E-07 & 0.00 E+\infty\end{array}$ $\begin{array}{lllll}000 \mathrm{E}+00 & 3.09 \mathrm{E}-07 & 3.13 \mathrm{E}-07 & 1.25 \mathrm{E}-08\end{array}$ $\begin{array}{lllll}0 & 00 E+00 & 2.91 E-07 & 4.77 E-07 & 1.04 E-07\end{array}$ $000 E+00 \quad 4.18 E-07 \quad 0.00 E+00 \quad 250 E-08$ $000 \mathrm{E}+00 \quad 2.22 \mathrm{E}-07 \quad 1.06 \mathrm{E}-06 \quad 1.83 \mathrm{E}-07$ $\begin{array}{lllll}0.00 E+00 & 4.54 \mathrm{E}-07 & 0.00 \mathrm{E}+00 & 6.87 \mathrm{E} \cdot 07\end{array}$ $\begin{array}{lllll}5.64 \mathrm{E}-07 & 2.28 \mathrm{E}-07 & 1.77 \mathrm{E}-07 & 8.69 \mathrm{E}-07\end{array}$ $0.00 E+00 \quad 0.00 E+00 \quad 0.00 E+00 \quad 0.00 E+\infty 0$

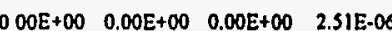
$\begin{array}{llll}0.00 E+\infty 0 & 0.00 E+\infty 0 & 0.00 E+\infty 0 & 0.00 E+\infty\end{array}$ $\begin{array}{llll}138 \mathrm{E}-06 & 4.74 \mathrm{E}-06 & 9.88 \mathrm{E}-07 & 1.08 \mathrm{E}-06\end{array}$ $764 \mathrm{E} .06 \quad 7.06 \mathrm{E}-07 \quad 2.12 \mathrm{E}-06 \quad 0.00 \mathrm{E}+00$ \begin{tabular}{|l|l|l|l|}
\hline 1 73E-06 & $1.28 E-03$ & $1.09 E-0.9$ & $1.01 E-01$ \\
\hline
\end{tabular}

$0.00 E+\infty 000 E+00 \quad 0.00 E+\infty) 0.00 E+C$

4173

4175 3.58E-04

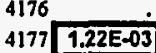

$4 1 7 8 \longdiv { 3 . 7 8 E - 0 2 }$

9.83E-01

\begin{tabular}{|l|l|}
\hline 6.11E-03 \\
\hline $9.25 E-03$ \\
\hline $1.07 E-02$
\end{tabular}

$882 \mathrm{E}-06 \quad 1.98 \mathrm{E}-07 \quad 2.62 \mathrm{E}-06 \quad 1.57 \mathrm{E}-06$

$0.00 E+\infty 00.00 E+00$

$9.25 \mathrm{E}-07 \quad 0.00 \mathrm{E}+00$

3.28E-07 $0.00 \mathrm{E}+0.0$

$0.00 E+\infty 0.00 E+00$

$0.00 E+00$ 4.31E-07

$000 \mathrm{E}+00 \quad 2.87 \mathrm{E}-08$

$0.00 \mathrm{E}+\infty \quad 5.22 \mathrm{E}-08$

$0.00 \mathrm{E}+\infty \quad 0.00 \mathrm{E}+00$

$000 \mathrm{E}+\infty 00 \quad 3.41 \mathrm{E} \cdot 07$

$0.00 \mathrm{E}+00 \quad 2.74 \mathrm{E}-07$

$000 \mathrm{E}+00 \quad 0.00 \mathrm{E}+00$

$0.00 \mathrm{E}+\infty \quad$ 1.31E-08

$0.00 \mathrm{E}+00 \quad 0.00 \mathrm{E}+00$

$0.00 \mathrm{E}+00 \quad 0.00 \mathrm{E}+00$

$0.00 E+\infty 00.00 E+00$

$0.00 \mathrm{E}+00 \quad 4.41 \mathrm{E}-07$

$0.00 \mathrm{E}+00 \quad 3.92 \mathrm{E}-08$

$0.00 \mathrm{E}+00 \quad 0.00 \mathrm{E}+00$

$0.00 \mathrm{E}+00 \quad 1.70 \mathrm{E}-0$

$0.00 \mathrm{E}+00 \quad 0.00 \mathrm{E}+00$

$0.00 E+00 \quad$ 1.31E-08

$0.00 \mathrm{E}+00 \quad 9.75 \mathrm{E}-07$

$0.00 \mathrm{E}+\infty 00 \quad 7.83 \mathrm{E}-08$

$000 \mathrm{E}+00 \quad 6.14 \mathrm{E}-07$

$0.000+00$ O.,00E+00

$472 \mathrm{E}-07 \quad 0.00 \mathrm{E}+00$

I $47 \mathrm{E}-00 \quad 0.00 \mathrm{E}+00$

$846 \mathrm{E}-07 \quad 0.00 \mathrm{E}+00$

3.82E-07 $0.00 E+00$

$\begin{array}{lll}140 E-05 & 2.75 E-04 \\ 3.84 E-07 & 0.00 E+00\end{array}$

$0.00 E+00 \quad 0.00 E+00$

$1.00 E+00$

$\frac{9.25 E-03}{1.07 E-02}$

$2.96 \mathrm{E}-0$.

2.91E-04

\begin{tabular}{l}
$1.93 E-01$ \\
\hline $2.27 E-03$ \\
\hline $1.00 E+00$
\end{tabular}

$4180 \quad 3.25 E-05$

$\frac{1.00 \mathrm{E}+00}{5.87 \mathrm{E}-02}$

$000 E+00 \quad 000 E+00$ 9.97E-01 $9.72 E-01$ $0.00 \mathrm{E}+00$

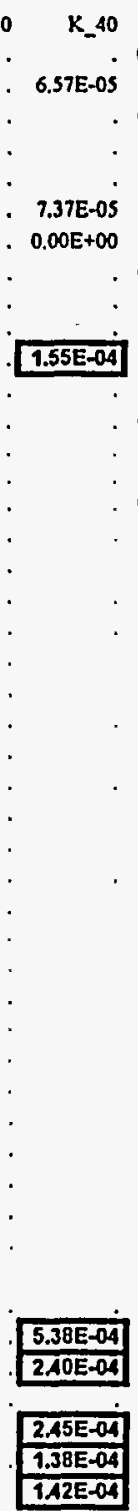

6.37E-02

$6.35 E-02$

$\begin{array}{r}\hline 6.35 E-02 \\ \hline 1.13 E-01 \\ \hline\end{array}$

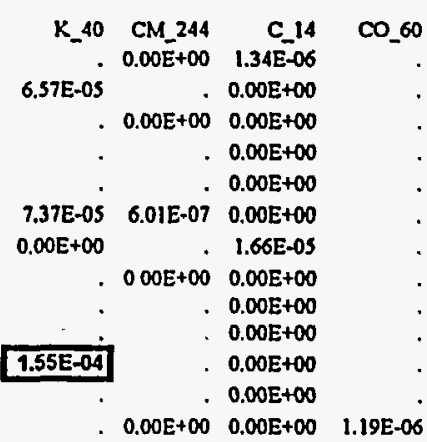

$6.72 E-07 \quad 1.74 E-06 \quad 3.51 E-06$

6.63E-07 5.62E-07 1.57E-05

$0.00 \mathrm{E}+00 \quad 1.74 \mathrm{E}-06 \quad 6.58 \mathrm{E}-06$

7.26E-08 2.04E-06 7.03E-06

$0.00 E+00 \quad 0.00 E+00 \quad 4.95 E-06$

1.41E-05 3.06E-06 7.58E-07

$0.00 E+00 \quad 0.00 E+00 \quad 9.36 E-06$

$1.62 \mathrm{E}-06 \quad 0.00 \mathrm{E}+00 \quad 7.26 \mathrm{E}-06$

$4.49 E-07 \quad 0.00 E+00 \quad 3.39 E-05$

$4.36 E-05$ 2.96E-05 $3.32 E-07$

1.25E-06 2.09E-05 1.19E-0S

6.01E-06 1.53E-05 3.09E-06

2.25E-06 8.70E-07 3.49E-06

6.36E-08 1.12E-05 2.20E-05

6.36E-08 3.47E-0S 1.35E-0s

9.08E-09 8.17E-06 6.37E-06

2.43E-07 3.06E-06 8.51E-06

$0.00 \mathrm{E}+00 \quad 5.11 \mathrm{E}-05 \quad 3.03 \mathrm{E}-06$

6.08E-05 8.69E-06 8.51E-06

$\begin{array}{lll}6.08 E-05 & 8.69 E-06 & 8.51 E-06 \\ 3.01 E-06 & 6.89 E-05\end{array}$

4.4SE-08 2.09E-06 $7.03 E-06$

$0.00 E+00 \quad 0.00 E+\infty 0$

$0.00 E+00$ 3.19E-0s

$0.00 E+00 \quad 1.25 \mathrm{E}-05 \quad 7.62 \mathrm{E}-06$

2.38E-05 3.76E-06 2.79E-0s $0.00 E+\infty 0$

3.56E-07 1.26E-05

$000 E+00 \quad$ 4.31E-06

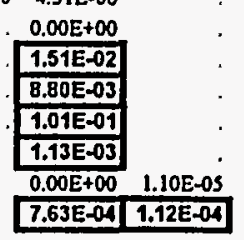

$000 \mathrm{E}+\infty 0$

$000 \mathrm{E}+00$

$\begin{aligned} & 000 E+\infty \\ & 2.17 E-04\end{aligned} \quad .000 E+\infty$

SR_89 Total_Rsk 2.51E-06

9.08E-

$1.89 \mathrm{E}-04$

$6.20 \mathrm{E}-04$

$1.62 \mathrm{E}-05$

$3.17 \mathrm{E}-05$

2.96E-04

$4.28 \mathrm{E}-0.5$

2.90E-05

4.84E-05

$1.65 \mathrm{E}-05$

1.04E-04

2.23E-02

1.37E-03

5.27E-04

9.07E-02

1.12E-02

6.91E-03

$8.70 E-03$

1.96E-01

7.14E-0S

2.15E-05

9.33E-05

8.46E-0S

2.38E-03

$\frac{2.12 E-03}{5.28 E-03}$

\begin{tabular}{l}
\hline 3.31E-02 \\
\hline $8.29 E-04$
\end{tabular}

$1.06 E-01$

2.70E-03

9.05E-04

7.83E-01

$\frac{1.00 E+00}{6.84 E-02}$

3.12E-02

$\frac{2.32 E-01}{1.00 E+00}$

$\frac{1.00 E+00}{1.00 E+00}$ 


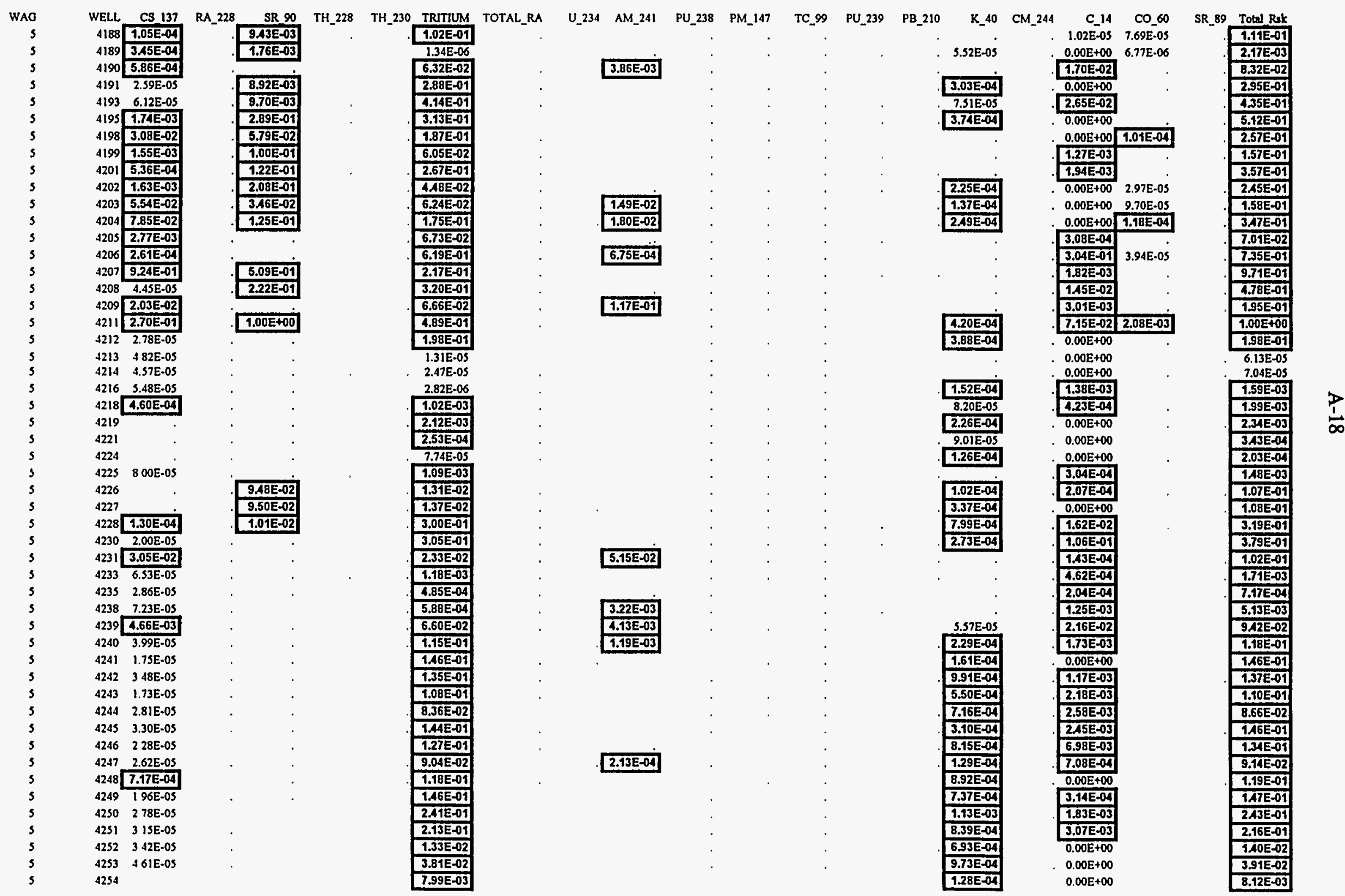


WELL CS 137 RA_228 SR_90 TH_228 TH_230 TRITIM TOTAL_RA

\begin{tabular}{|c|c|c|c|c|c|c|}
\hline $\begin{array}{l}\text { NELL } \\
\text { N25s }\end{array}$ & $\frac{\text { CS } 137}{1.18 E-04}$ & RA_228 & SR_90 & TH_228 & $\begin{array}{c}\text { TH_230 TRITIUM } \\
1.23 \mathrm{E}^{-02} \\
\end{array}$ & TOTAL_F \\
\hline $4256^{\circ}$ & & - & & & 3.75E-04 & \\
\hline 4257 & 7.41E-05 & . & & & $2.33 E-03$ & \\
\hline 4258 & & . & . & & $1.33 \mathrm{E}-04$ & \\
\hline 4259 & $1.34 E-05$ & • & . & " & 4.,95E-03 & \\
\hline 4260 & & . & 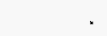 & & 3.54E-03 & \\
\hline 4261 & $6.47 E-05$ & & . & & $7.59 \mathrm{E}-03$ & \\
\hline 4262 & & & & & $8.01 E-03$ & \\
\hline 4263 [ & 2.52E-0.9 & & . & & $6.66 \mathrm{E}-03$ & \\
\hline $4264^{\circ}$ & $8.94 \mathrm{E}-05$ & & & & $6.33 \mathrm{E}-03$ & \\
\hline 4265 & & & & & 1.64E-02 & \\
\hline 4266 & $2.15 E-0 S$ & . & & & $3.07 E-02$ & \\
\hline 4267 & & . & & & $2.22 \mathrm{E}-02$ & \\
\hline 4268 & $4.28 E-05$ & . & & & $3.50 \mathrm{E}-02$ & \\
\hline 4269 & $1.98 \mathrm{E}-05$ & . & & & $9.18 \mathrm{E}-03$ & \\
\hline$\$ 270$ & $8.23 \mathrm{E}-05$ & . & & & $9.18 E-03$ & \\
\hline 4271 & 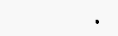 & - & & & $6.02 E-03$ & \\
\hline 4272 & . & . & & & $1.10 E-02$ & \\
\hline 4273 & . & & & & $4.60 E-02$ & \\
\hline 4274 & . & . & . & & $4.76 E-02$ & \\
\hline 4275 & & . & . & & $1.07 E-02$ & \\
\hline 4276 & & & & & $1.64 E-02$ & \\
\hline 4277 & 7.64E-05 & . & $r$ & & $1.22 E-02$ & \\
\hline 4278 & & & & & $6.39 \mathrm{E}-03$ & \\
\hline 4281 & 1.65E-05 & & & & 1.31E-02 & \\
\hline 4282 & $1.33 \mathrm{E}-0 \mathrm{~S}$ & - & r & & $2.50 \mathrm{E}-03$ & \\
\hline 4283[ & $2.11 E-04$ & & & & 5.84E-03 & \\
\hline 4284 & 1.13E-04 & & & & $6.36 \mathrm{E}-03$ & \\
\hline 4285[ & 1.35E-04 & . & & & $1.46 E-03$ & \\
\hline 4286 & 9.41E-05 & " & & & $8.06 E-04$ & \\
\hline 4287[ & 1A2E-04 & & & & 1,A0E-04 & \\
\hline $4289^{\circ}$ & & & & & $7.96 E-04$ & \\
\hline 4290 & 4.77E-05 & & & & $7.07 E-03$ & \\
\hline 4291[ & $1.66 E-03$ & & & & $6.70 E-03$ & \\
\hline $4294^{-}$ & & & $4.00 E-01$ & & A.57E-03 & \\
\hline 4295 & & & 6.94E-02 & & QA4AE-03 & \\
\hline 4296 & $9.88 \mathrm{E}-05$ & & & & $5.53 \mathrm{E}-03$ & \\
\hline 4297 & & . & & & $1.25 \mathrm{E}-02$ & \\
\hline 4298 & & & & & $1.23 \mathrm{E}-02$ & \\
\hline 4299 [ & 2.32E-04 & & 1.30E-01 & & $1.37 E-02$ & \\
\hline $4300^{\circ}$ & & & $2.69 \mathrm{E}-03$ & & $1.29 \mathrm{E}-02$ & \\
\hline 4307[ & 5.94E-04 & & & & $1.05 E-02$ & \\
\hline $745^{\circ}$ & $1.37 \mathrm{E}-0.06$ & & 3.57E-06 & & $4.95 E-06$ & $4.09 \mathrm{E}$ \\
\hline 831 & $1.37 \mathrm{E}-0 \mathrm{~S}$ & & $3.24 \mathrm{E}-06$ & & $8.78 \mathrm{E}-07$ & $3.88 \mathrm{E}$ \\
\hline 832 & 3.25E-06 & & $2.21 \mathrm{E}-06$ & & $7.80 E-07$ & $4.09 \mathrm{E}$ \\
\hline 833 & $1.92 \mathrm{E}-06$ & & $5.62 \mathrm{E}-06$ & & $5.21 \mathrm{E}-05$ & 4.09E- \\
\hline 835 & 1.86E-06 & & $1.37 \mathrm{E}-06$ & & $3.16 \mathrm{E}-0 \mathrm{~s}$ & 3.4IE-C \\
\hline 836 & $6.65 \mathrm{E}-06$ & & $2.51 \mathrm{E}-06$ & & $460 E-06$ & $0.00 E+$ \\
\hline 837 & 1.64E-06 & & 2.45E-06 & & $256 \mathrm{E}-06$ & $1.77 \mathrm{E}-06$ \\
\hline 838 & 2.83E-06 & & 3.04E-06 & & $2.77 \mathrm{E}-0 \mathrm{~S}$ & $681 E-06$ \\
\hline 839 & $2.54 E-06$ & & $170 E-06$ & & 2.97E-05 & $4.56 \mathrm{E}-\mathrm{C}$ \\
\hline
\end{tabular}

U 234 241 PU 238

TC_99 PU_239 PB_210

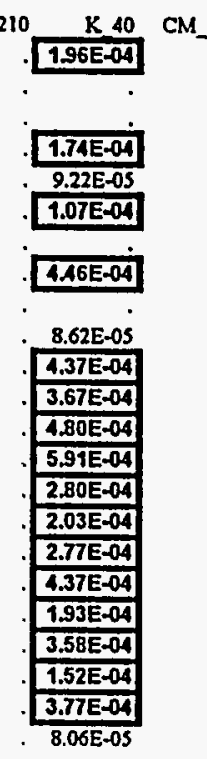

$244 \quad C_{-14}$

- $0.00 \mathrm{E}+00$

$0.00 E++00$

$0.00 \mathrm{E}+00$

$0.00 E+00$

$0.00 E+00$

$0.00 E+00$

$0.00 E+00$

$0.00 \mathrm{E}+00$

$0.00 \mathrm{E}+\infty 0$

$0.00 \mathrm{E}+00$

$6.90 \mathrm{E}-06$

$0.00 E+00$

$0.00 E+00$

.

$0.00 E+00$

$0.00 E+00$

$0.00 \mathrm{E}+00$

$0.00 \mathrm{E}+00$

$0.00 \mathrm{E}+\infty$

$0.00 E+00$

$0.00 E+00$

$0.00 E+00$

$0.00 E+\infty 0$

$7.46 \mathrm{E}-05$

$0.00 E+\infty$

209E-CI $\quad 0.00 E+00$

\begin{tabular}{|l|l|}
\hline $2.09 E-04$ & $0.00 E$ \\
\hline $1.23 E-04$ & $.0 .00 E$ \\
\hline
\end{tabular}

$0.00 E+00$

. $0.00 E+\infty 0$

$1.87 E-04$

$0.00 E+00$

$0.00 E+\infty 0$

\begin{tabular}{|l|}
\hline $3.00 E-04$ \\
\hline $5.98 E-04$ \\
\hline $3.72 E-04$ \\
\hline
\end{tabular}

. $3.85 \mathrm{E}-03$

2.66E-03

2.66E-03

9.06E-05

$0.00 \mathrm{E}+00$

$1.67 \mathrm{E}-0 \mathrm{~A}$

2.11E-04
CO_60 SR_89 Total Rik

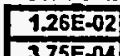

$3.70 E-003$

$3.07 E-04$

4.59E-03

3.65E-03

8.A5E-03

6.91E-03

1.68E-02

$3.11 E-02$

3.56E-02

$9, A 8 E-03$

9.A7E-03

1.A1E-02

4.61E-02

$\frac{4.80 E-02}{1.09 E-02}$

$1.68 E-02$

$1.24 E-02$

6.39E-03

$\frac{p}{6}$ 
WELL CS 137 RA 228 SR_90 TH_228 TH_230 TRTTUM TOTAL_RA U_234 AM_241 PU_238 PM_14

$840 \quad 3.46 \mathrm{E}-06 \quad 3.92 \mathrm{E}-06$

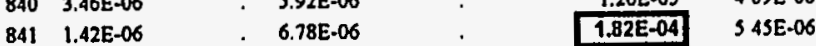

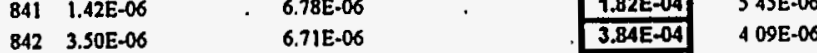

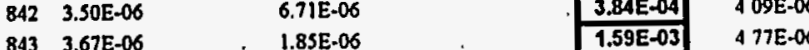

$8433.67 \mathrm{E}-06 \quad \cdot 1.85 \mathrm{E}-06 \quad \cdot 1.59 \mathrm{E}-03$ 4 $47 \mathrm{E}-06$

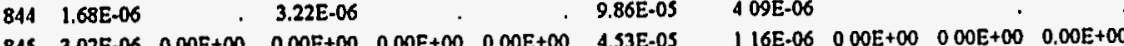

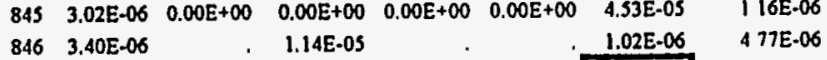

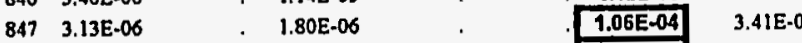

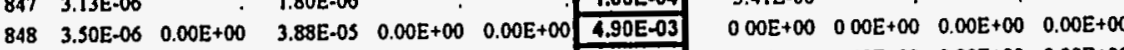

$\begin{array}{lllllllllllllllll}849 & 0.00 E+00 & 0.00 E+00 & 0.00 E+00 & 0.00 E+00 & 0.00 E+00 & 3.08 E-03 & 0.00 E+00 & 0.00 E+00 & 0.00 E+00 & 0.00 E+00\end{array}$

$\begin{array}{lllllllllllllll}850 & 2.70 \mathrm{E}-06 & 0.00 \mathrm{E}+00 & 6.49 \mathrm{E}-05 & 0.00 \mathrm{E}+00 & 0.00 \mathrm{E}+00 & 4.30 \mathrm{E}-05 & 3.31 \mathrm{E}-06 & 0.00 \mathrm{E}+\infty 0 & 0.00 \mathrm{E}+00 & 0.00 \mathrm{E}+00\end{array}$

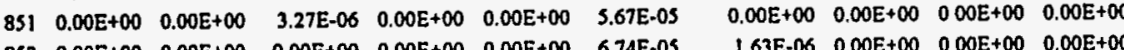

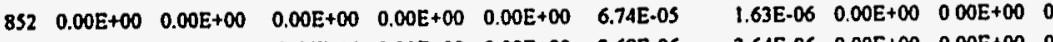

$\begin{array}{lllllllllll}853 & 0.00 E+\infty 0 & 0.00 E+00 & 2.66 E-06 & 0.00 E+00 & 0.00 E+00 & 3.68 E-06 & 3.64 E-06 & 000 E+\infty & 0.00 E+\infty & 0.00 E+\infty\end{array}$

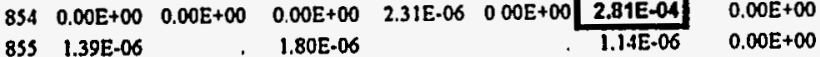

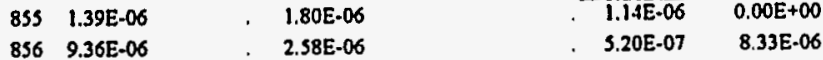

$857 \quad 4.67 \mathrm{E}-06 \quad 2.83 \mathrm{E}-06 \quad 7.88 \mathrm{E}-07 \quad 211 \mathrm{E}-06$

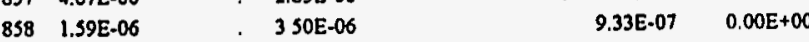

$859 \quad 1.22 \mathrm{E}-06 \quad$ 3.51E-06 $\quad$ - $4.48 \mathrm{E}-06 \quad 2.38 \mathrm{E}-06$

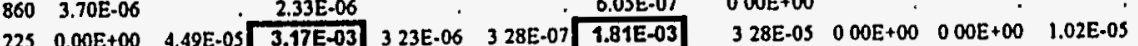

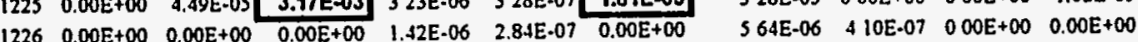

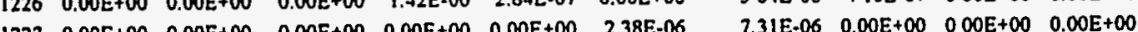

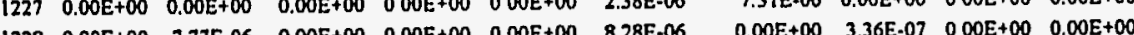

$\begin{array}{llllllllllll}1228 & 0.00 E+00 & 7.77 E-06 & 0.00 E+\infty 0 & 0.00 E+00 & 0.00 E+\infty & 8.28 E-06 & 0.00 E+00 & 3.36 E-07 & 000 E+\infty & 0.00 E+\infty\end{array}$

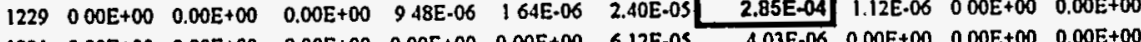

$\begin{array}{llllllllllllll}1231 & 0.00 E+00 & 0.00 E+00 & 0.00 E+00 & 0.00 E+00 & 0.00 E+00 & 6.12 E-05 & 4.03 E-06 & 0.00 E+00 & 0.00 E+00 & 0.00 E+00\end{array}$

\begin{tabular}{llllllll}
1233 & $0.00 E+00$ & $0.00 E+00$ & $0.00 E+00$ & 3 & $37 \mathrm{E}-06$ & $437 \mathrm{E}-07$ & $7.14 E-04$ \\
\hline
\end{tabular}

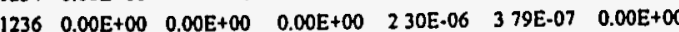

$1237 \quad 0.005+00 \quad 0.00 E+00 \quad 6,27 E-06 \quad 0,00 E+00 \quad 203 E-06 \quad 0.00 E+\infty 00$

$12380.00 E+000.00 E+00 \quad 0.00 E+00 \quad 119 E-06 \quad 0.00 E+00 \quad 0.00 E+00$

$1239 \quad 0.00 \mathrm{E}+000.00 \mathrm{E}+00 \quad 0.00 \mathrm{E}+00 \quad 586 \mathrm{E}-06 \quad 1.34 \mathrm{E}-06 \quad 0.00 \mathrm{E}+00$

$3.91 \mathrm{E}-06$ 3. $3.66 \mathrm{E}-07 \quad 000 \mathrm{E}+00 \quad 0.00 \mathrm{E}+00$

$340 \mathrm{E}-06 \quad 360 \mathrm{E}-07 \quad 6.00 \mathrm{E}-06 \quad 0.00 \mathrm{E}+00$

$287 \mathrm{E}-06 \quad 000 \mathrm{E}+00 \quad 000 \mathrm{E}+00 \quad 0.00 \mathrm{E}+00$

$\begin{array}{lllll}2800+00 & 169 \mathrm{E}-06 \quad 000 \mathrm{E}+00 \quad 000 \mathrm{E}+00\end{array}$

$1240 \quad 0.00 E+00 \quad 0.00 E+00 \quad 0.00 E+00 \quad 270 E-06 \quad 0.00 E+00 \quad 9.08 E-07$

$512 \mathrm{E}-06 \quad 7.06 \mathrm{E}-07 \quad 0.00 \mathrm{E}+00 \quad 0.00 \mathrm{E}+00$

1242 .

1242 1.71E-06 $0.00 E+00$ 2.40E.06 1

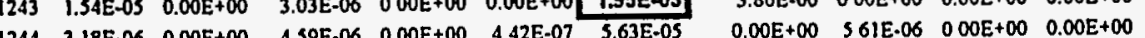

$0.00 E+00 \quad 561 E .06 \quad 000 E+00 \quad 0.00 E+00$

TC 99 PU $239 \quad \mathrm{~PB} 210$

\subsection{E.05}

3.63E-05

C.14 CO_60

$1.22 \mathrm{E}-06$
$3.60 \mathrm{E}-06$

$3.60 \mathrm{E}-06$
$6.80 \mathrm{E}-05$

$7.67 \mathrm{E}-06$

$1.29 \mathrm{E}-06$

2.21E-06

$8.47 \mathrm{E}-07$

$8.47 \mathrm{E}-07$

$1.78 \mathrm{E}-06$

$0.00 E+00$

$0.00 E+00$

$0.00 E+00$

$0.00 E+00$

$0.00 E+00$

$0.00 E+00$

$0.00 E+00$

4.45E.06

$1.70 \mathrm{E}-06$

$1.70 \mathrm{E}-06$

$113 E-06$

$165 \mathrm{E}-06$

$7.37 E .06$

$1.88 \mathrm{E}-05 \quad 6.62 \mathrm{E}-05$

7.06E-06

5.94E-05

S.82E-05

4.16E.0S $0.00 E+00$

S.OIE-0S

6.13E-06 $0.00 E+00 \quad 371 \mathrm{E}-06 \quad 3.52 \mathrm{E}-07$

$849 E-06 \quad 000 E+00 \quad 000 E+00 \quad 0.00 E+\infty 0$ $6.13 E-060.00 E+00$ 3 31 E- 06 $5.52 E-07$

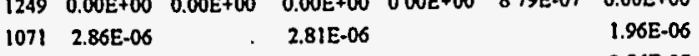

1072 2.07E-06 $\quad \cdot \quad 179 \mathrm{E}-06 \quad 3.76 \mathrm{E}-07$

1073 1 48E-05 $\quad 399 \mathrm{E}-06 \quad 1.02 \mathrm{E}-06$

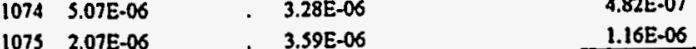

\begin{tabular}{llll}
1075 & $2.07 E-05$ & $3.59 E-06$ & $1.16 \mathrm{E}-06$ \\
1076 & $1.99 \mathrm{E}-05$ &. & $4.50 \mathrm{E}-06$ \\
1077 & $7.95 E-06$ & $5.93 \mathrm{E}-06$ & $1.34 \mathrm{E}-03$ \\
\hline $2.36 \mathrm{E}-06$
\end{tabular}

$\begin{array}{llll}1077 & 7.95 E-06 & \text {. } & 5.93 \mathrm{E}-06 \\ & 1.95 \mathrm{E} & \end{array}$

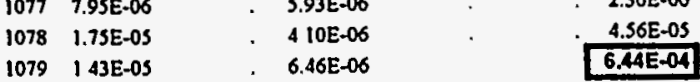

$1080732 E-06 \quad$ TS2E-06

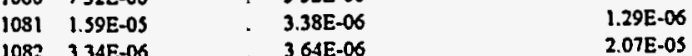

$4.48 \mathrm{E}-05$ 


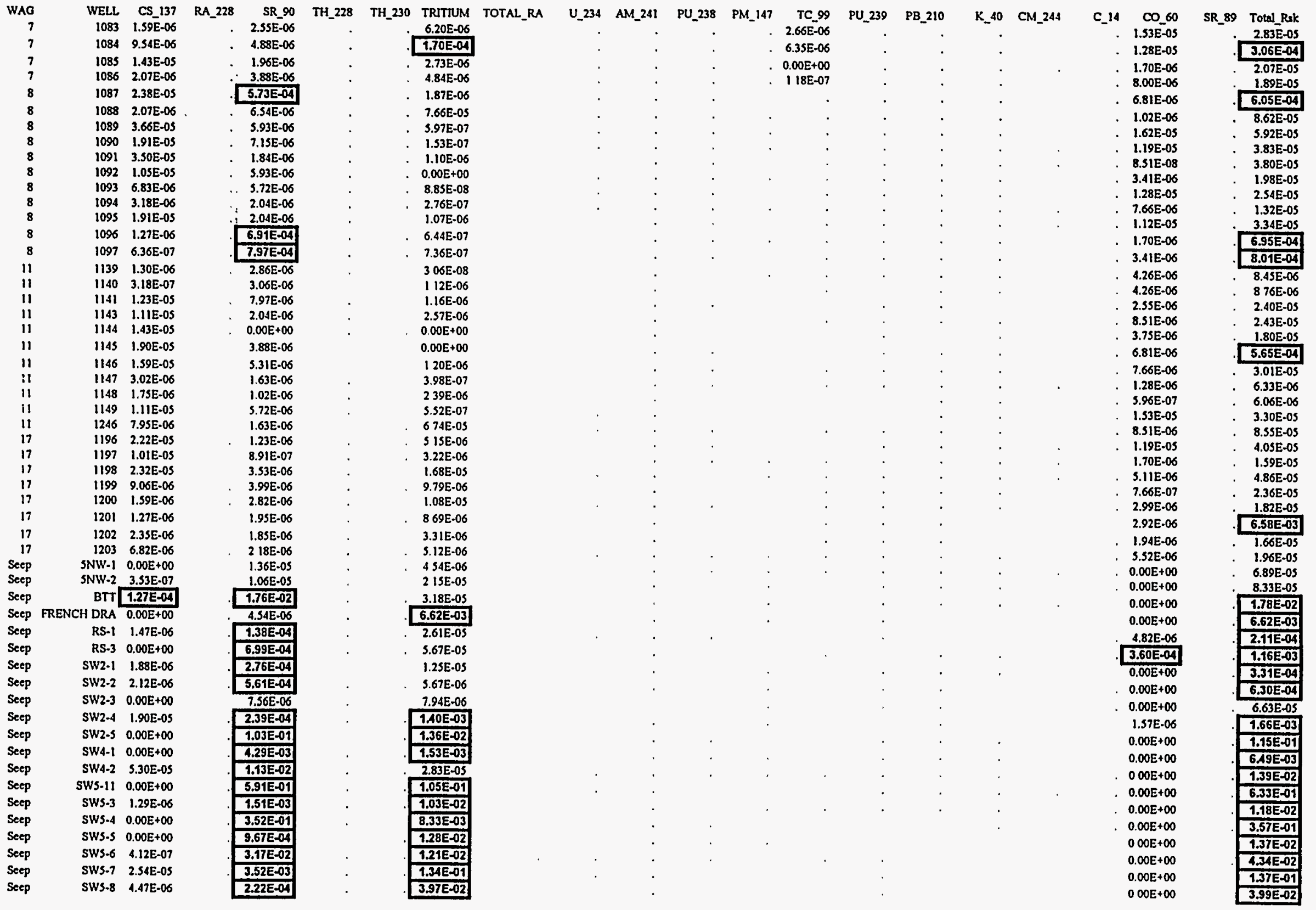



WELL CS_137 RA 228 SR 90 TH 228 TH 230 TRITIUM TOTAL_RA

Seep SWS.9 $1.23 \mathrm{E} .06$

SW6-1 $8.06 \mathrm{E}-06$ $5.30 \mathrm{E}-04$

The

\begin{tabular}{|l|}
\hline TRITIUM \\
\hline $3.00 E-02$ \\
\hline $2.51 E-04$ \\
\hline
\end{tabular}

C_14 $\quad \mathrm{CO}_{-} 60$

$0.00 E+\infty 0$

$6.80 E-06$

$1.85 E-03$

$\begin{array}{llll}S W 7-1 & 0.00 \mathrm{E}+00 & \text { 3.33E-05 } & 1.13 \mathrm{E} .05\end{array}$

SW7-2 $0.00 \mathrm{E}+00 \quad 3.02 \mathrm{E}-05 \quad 9.07 \mathrm{E}-06$

SW7-3 $0.00 \mathrm{E}+00 \quad$. 4.76E-05 3 S2E-05

SW7.5 $0.00 \mathrm{E}+00$

$-6.05 E-06$

2 9SE-0S

sW7.6[1.80E-04

$7.89 E-07$

$3.40 \mathrm{E}-06$

Seep W4TRIB- 11

Seep WATRIB-7

7.81E-03

1.94E-02

3.81E-02

9.29E-06

$0.00 E+\infty 00$

$0.00 E+00$

5.65E-04

2.03E-04

$\frac{4.37 E-04}{0.00 E+00}$

${ }^{\text {SR_89 Total Ruk }}$

3.06E-02

1.85E-03

8.52E-05

$\begin{array}{lll} & \\ & \end{array}$ 
EELL BE B2CEE TETII22 DCEEII METHYLI METHYL2 DIC33 PCBI2S4 BIS_2_ET BENZBFLU BENZENE BENZAANT BENZAPYR CARBON_T DIBENZ_A HCBE

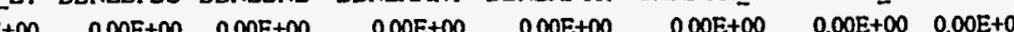

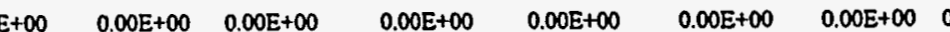
$\begin{array}{llllllllll}0.00 \mathrm{E}+00 & 0.00 \mathrm{E}+\infty & 0.00 \mathrm{E}+00 & 0.00 \mathrm{E}+00 & 0.00 \mathrm{E}+00 & 0.00 \mathrm{E}+00 & 0.00 \mathrm{E}+\infty & 1.02 \mathrm{E}-06\end{array}$

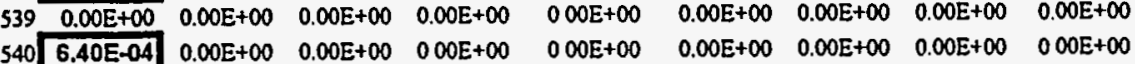

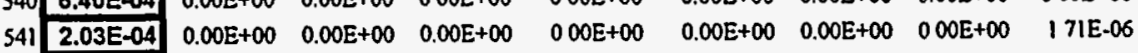

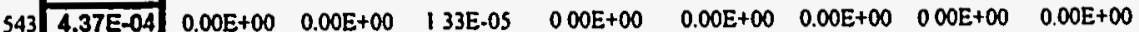

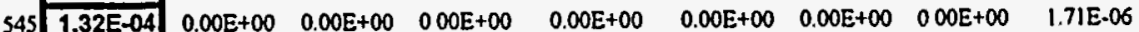

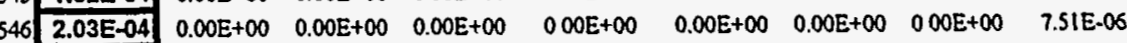
$\begin{array}{llllllllll}548 & 1.42 E-04 & 0.00 E+00 & 0.00 E+\infty & 0.00 E+00 & 0.00 E+\infty & 0.00 E+\infty & 0.00 E+\infty & 0.00 E+\infty 0 & 0.00 E+\infty\end{array}$ 549 \begin{tabular}{lllllllll}
\hline $.44 E-04$ & $0.00 E+\infty$ & $0.00 E+\infty$ & $0.00 E+00$ & $0.00 E+00$ & $0.00 E+\infty$ & $0.00 E+\infty 0$ & $0.00 E+\infty 0$ & $1.02 E-06$
\end{tabular}

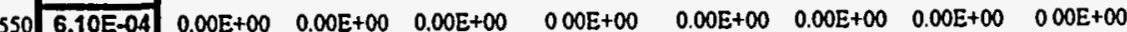

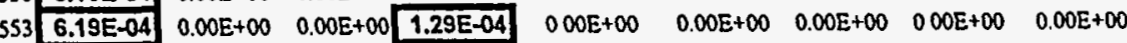

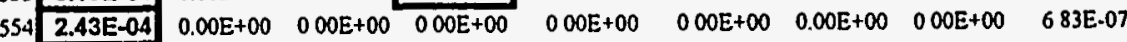
$558 \quad . \quad 0.00 \mathrm{E}+00 \quad 000 \mathrm{E}+00$

$563 \quad 0.00 E+00 \quad 0.00 E+00 \quad 0.00 E+00 \quad 0.00 E+00 \quad 0.00 E+00 \quad 0.00 E+00 \quad 000 E+00 \quad 000 E+00 \quad 000 E+00$ $\begin{array}{llllllllll}0.00 E+00 & 0.00 E+00 & 0.00 E+\infty 0 & 0.00 E+00 & 0.00 E+00 & 0.00 E+\infty 0 & 0.00 E+00 & 0.00 E+00\end{array}$

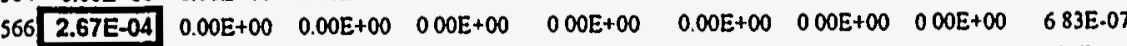
571 2.01E-04 $0.00 \mathrm{E}+00 \quad 0.00 \mathrm{E}+00 \quad 000 \mathrm{E}+00 \quad 000 \mathrm{E}+00 \quad 0.00 \mathrm{E}+00 \quad 0.00 \mathrm{E}+00 \quad 000 \mathrm{E}+00 \quad 000 \mathrm{E}+00$

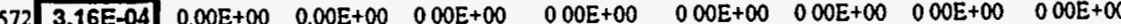

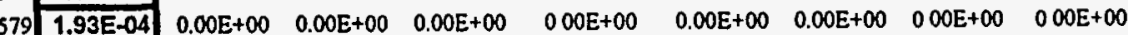
$\begin{array}{ll}0.00 \mathrm{E}+00 & 0.00 \mathrm{E}+\infty \\ 0.00 \mathrm{E}+00 & 0.00 \mathrm{E}+00 \\ 0.00 \mathrm{E}+00 & 0.00 \mathrm{E}+00\end{array}$ $0.00 \mathrm{E}+00 \quad 0.00 \mathrm{E}+00$

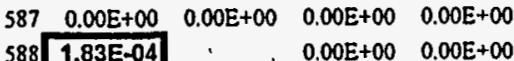
$0.00 \mathrm{E}+00 \quad 0.00 \mathrm{E}+00$ $0.00 E+00 \quad 0.00 E+\infty$ $0.00 \mathrm{E}+\infty \quad 0.00 \mathrm{E}+\infty 0$ $0.00 \mathrm{E}+00 \quad 0.00 \mathrm{E}+00$ $0.00 E+00 \quad 0.00 E+00$ $0.00 E+00 \quad 0.00 E+00$ $0.00 \mathrm{E}+00 \quad 0.00 \mathrm{E}+00$ $0.00 E+\infty 00.00 E+\infty 0$ $0.00 \mathrm{E}+\infty 00.00 \mathrm{E}+\infty 0$ $0.00 \mathrm{E}+00 \quad 0.00 \mathrm{E}+\infty 0$ $0.00 E+00 \quad 0.00 E+00$ $0.00 E+00 \quad 1.09 E-04$ $0.00 \mathrm{E}+00 \quad 0.00 \mathrm{E}+00$ $0.00 \mathrm{E}+00$

$0.00 E+00 \quad 0.00 E+00$

$0.00 \mathrm{E}+00 \quad 0.00 \mathrm{E}+00$

$0.00 \mathrm{E}+\infty 00 \quad 0.00 \mathrm{E}+\infty 00$

$0.00 \mathrm{E}+00 \quad 0.00 \mathrm{E}+00$

$0.00 \mathrm{E}+00 \quad 0.00 \mathrm{E}+00$

$0.00 \mathrm{E}+00 \quad 0.00 \mathrm{E}+00$

$0.00 \mathrm{E}+00 \quad 0.00 \mathrm{E}+00 \quad 0.00 \mathrm{E}+00 \quad 0.00 \mathrm{E}+00 \quad 683 \mathrm{E}-07$ $0.00 \mathrm{E}+00$

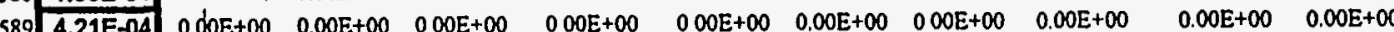
$590 \quad 1.83 E-04$ $5 9 3 \longdiv { 3 . 6 6 E - 0 4 }$

$5 9 6 \longdiv { 1 . 1 2 \mathrm { E } - 0 4 }$ $0.00 E+\infty 000.00 E+00$

$0.00 E+\infty$ $597 \quad 1.76 E-04 \quad 2.33 E-04 \quad 0.00 E+00 \quad 000 E+00$ \begin{tabular}{llllllllll}
\hline & $0.00 E+\infty$ \\
\hline
\end{tabular} 599 \begin{tabular}{lllllllllll}
\hline $.52 E-04$ & $0.00 \mathrm{E}+00$ & $0.00 \mathrm{E}+00$ & $0.00 \mathrm{E}+\infty$ & $0.00 \mathrm{E}+00$ & $0.00 \mathrm{E}+00$ & $0.00 \mathrm{E}+\infty$ & $0.00 \mathrm{E}+00$ & $0.00 \mathrm{E}+\infty 0$ & $0.00 \mathrm{E}+00$ & $0.00 \mathrm{E}+00$
\end{tabular} $\begin{array}{llllllllllll}601 & 0.00 E+00 & 0.00 E+00 & 0.00 E+00 & 0.00 E+00 & 0.00 E+00 & 0.00 E+00 & 0.00 E+00 & 0.00 E+00 & 116 \mathrm{E}-05 & 0.00 \mathrm{E}+00 & 0.00 \mathrm{E}+00\end{array}$ $\begin{array}{llllllllll} & 0.00 \mathrm{E}+00 & 0.00 \mathrm{E}+\infty\end{array}$ $6 0 3 \longdiv { 1 . 0 9 E - 0 3 }$

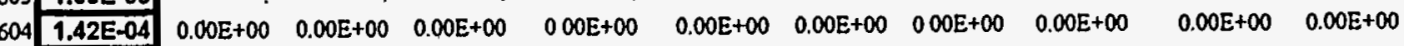
$607 \quad 0.00 \mathrm{E}+00$

$6 0 8 \longdiv { 6 . 2 0 E - 0 4 }$

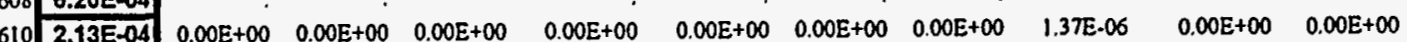

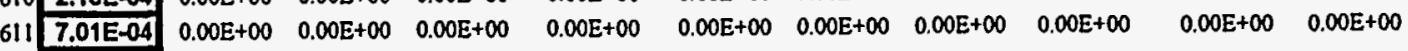

$6 1 8 \longdiv { 2 . 7 7 E - 0 4 } \quad 0 . 0 0 E + 0 0 \quad 0 . 0 0 E + 0 0 \quad 0 . 0 0 E + 0 0 \quad 0 . 0 0 E + 0 0 \quad 0 . 0 0 E + 0 0 \quad 0 . 0 0 E + 0 0 \quad 0 . 0 0 E + 0 0 \quad 0 . 0 0 E + 0 0$

$0.00 \mathrm{E}+00 \quad 0.00 \mathrm{E}+00$ $\begin{array}{llllllllll}0.00 \mathrm{E}+00 & 0.00 \mathrm{E}+00 & 0.00 \mathrm{E}+00 & 0.00 \mathrm{E}+00 & 0.00 \mathrm{E}+00 & 0.00 \mathrm{E}+\infty & 0.00 \mathrm{E}+\infty & 0.00 \mathrm{E}+\infty & 1.31 \mathrm{E}-0 \mathrm{~S}\end{array}$ $\begin{array}{llllllllll}621 & 0.00 E+00 & 0.00 E+00 & 0.00 E+00 & 0.00 E+00 & 0.00 E+00 & 0.00 E+00 & 0.00 E+00 & 0.00 E+00 & 0.00 E+00\end{array}$

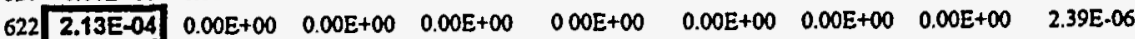
$0.00 \mathrm{E}+00 \quad 0.00 \mathrm{E}+00$ $0.00 \mathrm{E}+00 \quad 000 \mathrm{E}+\infty 0$

$0.00 \mathrm{E}+\infty 0$

$0.00 E+\infty 0$

$0.00 \mathrm{E}+\infty 0$

$0.00 E+\infty 0$

$0.00 \mathrm{E}+00$

$0.00 \mathrm{E}+\infty$

$0.00 \mathrm{E}+\infty$

$0.00 \mathrm{E}+\infty 0$

$0.00 \mathrm{E}+00$

$0.00 \mathrm{E}+00$

$0.00 \mathrm{E}+00$

$0.00 \mathrm{E}+00$

$0.00 E+00$

$0.00 \mathrm{E}+\infty$

$0.00 \mathrm{E}+00$

$0.00 \mathrm{E}+00$

$0.00 \mathrm{E}+00$

$0.00 \mathrm{E}+00$

0.00

$0.00 E+\infty$

$0.00 \mathrm{E}+\infty$

$0.00 E+\infty$

$0.00 E+00$

$0.00 E+\infty$

$0.00 \mathrm{E}+00$

$0.00 E+00$

$0.00 \mathrm{E}+\infty$

$0.00 E+\infty 0$

$0.00 \mathrm{E}+\infty$

$0.00 \mathrm{E}+\infty 0$

$0.00 \mathrm{E}+\infty$

$0.00 \mathrm{E}+\infty$

$0.00 E+00$

$0.00 E+00$

$0.00 \mathrm{E}+00$

$0.00 \mathrm{E}+00$

$0.00 \mathrm{E}+00$

$0.00 \mathrm{E}+\infty$

$0.00 \mathrm{E}+00$

$0.00 \mathrm{E}+00$

$0.00 \mathrm{E}+00$

$0.00 \mathrm{E}+\infty 0$

$0.00 E+\infty 0$

$0.00 \mathrm{E}+00$

$8.49 \mathrm{E}-06$

$0.00 E+00$

$0.00 \mathrm{E}+\infty$

$0.00 \mathrm{E}+00$

$0.00 \mathrm{E}+\infty$

$0.00 E+\infty 0$

$0.00 E+\infty 0$

$0.00 \mathrm{E}+00$

$0.00 E+00$

$0.00 \mathrm{E}+00$

$0.00 \mathrm{E}+00$

$0.00 E+00$

$0.00 \mathrm{E}+\infty$

$0.00 \mathrm{E}+\infty 0$

$0.00 \mathrm{E}+00$

S.38E.0S

$0.00 \mathrm{E}+00$

$0.00 E+\infty 00.00 E+00$

$0.00 \mathrm{E}+00 \quad 0.00 \mathrm{E}+00$

$0.00 E+00 \quad 0.00 E+00$

$0.00 E+00 \quad 0.00 E+\infty 0$

$0.00 \mathrm{E}+00 \quad 0.00 \mathrm{E}+\infty 0$

$0.00 \mathrm{E}+00 \quad 0.00 \mathrm{E}+00$

$0.00 \mathrm{E}+00 \quad 0.00 \mathrm{E}+00$

$0.00 \mathrm{E}+00 \quad 0.00 \mathrm{E}+00$

$0.00 E+00 \quad 0.00 E+00$ $0.00 \mathrm{E}+00 \quad 0.00 \mathrm{E}+00$

$0.00 E+00 \quad 0.00 E+00$ $0.00 E+00 \quad 0.00 E+00$

$0.00 E+00 \quad 0.00 E+00$ $0.00 E+00 \quad 0.00 E+00$ $0.00 E+00 \quad 0.00 E+00$ $000 \mathrm{E}+00 \quad 000 \mathrm{E}+00$ $0.00 \mathrm{E}+00 \quad 000 \mathrm{E}+\infty 0$ $0.00 E+00 \quad 000 E+00$

$0.00 E+00 \quad 000 E+00$

$0.00 E+00 \quad 0.00 E+00$

$3.68 \mathrm{E}-05$

$0.00 \mathrm{E}+00$ 7.94E-03 $4.36 \mathrm{E}-04$

$0.00 \mathrm{E}+00 \quad 0.00 \mathrm{E}+00 \quad 0.00 \mathrm{E}+00$

$\begin{array}{llll}0.00 E+00 & 0.00 E+00 & 0.00 E+00\end{array}$

$0.00 \mathrm{E}+00 \quad 0.00 \mathrm{E}+00 \quad 0.00 \mathrm{E}+00$

$0.0 \mathrm{E}+00 \quad 0.00 \mathrm{E}+00$

$000 \mathrm{E}+\infty 00 \quad 0.00 \mathrm{E}+\infty$

$0.00 E+\infty$

$0.00 E+00 \quad 0.00 E+\infty 0$

$0.00 E+\infty 00 \quad 0.00 E+\infty$

$0.00 E+00 \quad 0.00 E+\infty 0 \quad 0.00 E+\infty 0$

$0.00 \mathrm{E}+\infty 00 \quad 0.00 \mathrm{E}+\infty 0$

$0.00 \mathrm{E}+\infty \quad 0.00 \mathrm{E}+\infty$

$0.00 \mathrm{E}+\infty 00 \quad 0.00 \mathrm{E}+00 \quad 0.00 \mathrm{E}+\infty 0$ $0.00 E+\infty \quad 0.00 E+\infty 0 \quad 000 E+\infty 0$

$000 E+\infty 0000 E+00$

$000 \mathrm{E}+\infty$

$000 E+\infty 0$

$000 \mathrm{E}+\infty 0 \quad 0.00 \mathrm{E}+00$

$000 E+00 \quad 000 E+\infty 0$

$0.00 E+00 \quad 0.00 E+00 \quad 0.00 E+00$

$0.00 E+\infty 0000 E+\infty 00000+\infty$

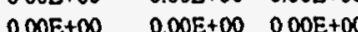
$0.00 E+\infty 0 \quad 0.00 E+00 \quad 000 E+\infty 0$ $0.00 E+00 \quad 000 E+\infty 0 \quad 000 E+00$ 
INDENO_1 NNDNPA PENTACHL VINYL_CH $\begin{array}{llll}0.00 \mathrm{E}+00 & 0.00 \mathrm{E}+00 & 0.00 \mathrm{E}+00 & 0.00 \mathrm{E}+00\end{array}$ $0.00 E+00 \quad 0.00 E+00 \quad 2.50 E-04 \quad 0.00 E+\infty$

$0.00 E+00 \quad 0.00 E+\infty \quad 0.00 E+00 \quad 000 E+00$

$\begin{array}{llll}0.00 \mathrm{E}+00 & 0.00 \mathrm{E}+00 & 0.00 \mathrm{E}+00 & 0.00 \mathrm{E}+00\end{array}$

$0.00 E+\infty \quad 0.00 E+\infty \quad 0.00 E+\infty \quad 0.00 E+\infty$

\begin{tabular}{llll}
$0.00 E+00$ & $0.00 E+00$ & $2.50 E-04$ & $0.00 E+\infty$ \\
\hline
\end{tabular}

\begin{tabular}{lllll}
$000 \mathrm{E}+00$ & $000 \mathrm{E}+\infty$ & $0.00 \mathrm{E}+00$ & $1.69 \mathrm{E}-03$ \\
\hline
\end{tabular}

\begin{tabular}{lllll}
$0.00 E+00$ & $000 \mathrm{E}+00$ & $2.50 \mathrm{E}-04$ & $0.00 \mathrm{E}+00$ \\
\hline
\end{tabular}

$0.00 \mathrm{E}+00 \quad 0.00 \mathrm{E}+00 \quad 0.00 \mathrm{E}+00 \quad 0.00 \mathrm{E}+00$

$\begin{array}{llll}0.00 \mathrm{E}+00 & 0.00 \mathrm{E}+00 & 0.00 \mathrm{E}+\infty & 0.00 \mathrm{E}+00\end{array}$

$0.00 \mathrm{E}+00 \quad 0.00 \mathrm{E}+00 \quad 0.00 \mathrm{E}+00 \quad 0.00 \mathrm{E}+00$

$\begin{array}{llll}0.00 E+\infty 0 & 0.00 E+\infty 0 & 0.00 E+\infty & 0.00 E+00\end{array}$

$\begin{array}{lllllll}0.00 E+00 & 0.00 E+00 & 0.00 E+00 & 2.75 E-04 & 0.00 E+\infty & 0.00\end{array}$

$0.00 E+00 \quad 0.00 E+\infty 0 \quad 0.00 E+\infty 0 \quad 0.00 E+\infty 0$

$000 \mathrm{E}+00$

$000 \mathrm{E}+00 \quad 000 \mathrm{E}+00 \quad 0.00 \mathrm{E}+00 \quad 0.00 \mathrm{E}+00$

$\begin{array}{llll}0.00 \mathrm{E}+00 & 0.00 \mathrm{E}+00 & 0.00 \mathrm{E}+00 & 0.00 \mathrm{E}+00\end{array}$

$0.00 E+00 \quad 0.00 E+00 \quad 0.00 E+\infty 00 \quad 0.00 E+00$

$0.00 E+00 \quad 0.00 E+00 \quad 0.00 E+00 \quad 0.00 E+00$

$\begin{array}{llll}0.00 E+\infty 0 & 0.00 E+\infty 0 & 0.00 E+\infty & 0.00 E+\infty 0\end{array}$

$0.00 \mathrm{E}+00 \quad 0.00 \mathrm{E}+\infty 0 \quad 000 \mathrm{E}+\infty 0 \quad 000 \mathrm{E}+00$

. $0.00 \mathrm{E}+00$

$0.00 \mathrm{E}+00$
.

$0.00 E+00 \quad 0.00 E+00 \quad 0.00 E+00 \quad 0.00 E+00$

TRI123 D12CHL3 DBE12 DIOXAN14 PROPENE2 _3_3_DI Total Rask WAG

WELL

\begin{tabular}{lll}
\hline $3.18 \mathrm{E}-04$ & 1 \\
\hline $6.12 \mathrm{E}-04$ & 1
\end{tabular}

$0.00 \mathrm{E}+00$

\section{\begin{tabular}{ll|l|l|l|}
\hline $1.61 E-03$ & $1.45 E-03$ & $2.50 E-04$ & $0.00 E+\infty$ \\
\hline
\end{tabular}}

$0.00 \mathrm{E}+00 \quad 0.00 \mathrm{E}+00 \quad 000 \mathrm{E}+00 \quad 000 \mathrm{E}+00$

$0.00 E+00 \quad 0.00 E+00 \quad 0.00 E+00 \quad 000 E+00$

$0.00 \mathrm{E}+00 \quad 0.00 \mathrm{E}+00 \quad 0.00 \mathrm{E}+00 \quad 0.00 \mathrm{E}+00$

$0.00 \mathrm{E}+\infty 000 \mathrm{E}+\infty 000 \mathrm{E}+\infty 01.18 \mathrm{E}-04$

$0.00 E+00 \quad 0.00 E+00 \quad 000 E+00 \quad 000 E+00$

2.99E-04

2.46E-02

9.45E-03

$1.71 E-04$

1.02E-03

6.28E-04

$1.75 \mathrm{E}-04$

$0.00 \mathrm{E}+00 \quad 000 \mathrm{E}+00 \quad 000 \mathrm{E}+\infty 0000 \mathrm{E}+00$

$0.00 E+\infty 0 \quad 000 E+\infty 0 \quad 000 E+\infty 0 \quad 000 E+\infty$

$0.00 \mathrm{E}+00 \quad 0.00 \mathrm{E}+00 \quad 000 \mathrm{E}+\infty 00 \quad 0.00 \mathrm{E}+00$

$000 E+00 \quad 000 \mathrm{E}+\infty 0 \quad 000 \mathrm{E}+\infty 0 \quad 000 \mathrm{E}+\infty 0$

$000 \mathrm{E}+\infty 0000 \mathrm{E}+\infty 0 \quad 000 \mathrm{E}+00 \quad 000 \mathrm{E}+00$

$000 E+\infty O \quad 000 E+\infty O \quad 000 E+\infty O \quad 000 E+\infty O$

$000 \mathrm{E}+\infty 0 \quad 000 \mathrm{E}+\infty 0 \quad 000 \mathrm{E}+\infty 0 \quad 000 \mathrm{E}+\infty$ 
DIC33 PCB1254 BIS 2 ET

\begin{tabular}{|c|c|c|c|c|c|c|c|c|c|c|c|c|c|c|c|c|}
\hline & 2.13E-04 & $0.00 \mathrm{E}+\infty 0$ & $00 E+00$ & $00 E+00$ & $0.00 E+\infty 0$ & $0.00 E+\infty 0$ & $0.00 E+00$ & $00 \mathrm{E}+\infty$ & $0.00 E+\infty$ & $\begin{array}{r}\text { ENLEFLU } \\
0.00 \mathrm{E}\end{array}$ & $0.00 E+00$ & $0.00 E+\infty 0$ & $0.00 E+00$ & $0.00 E+\infty 0$ & $0.00 E+\infty$ & $0.00 E+00$ \\
\hline & $5.37 E-04$ & $00 \mathrm{E}+\infty$ & $00 E+\infty 0$ & $20 E+00$ & $0.00 E+\infty 0$ & $0.00 \mathrm{E}+00$ & $00 E+00$ & $00 E+00$ & $0.00 \mathrm{E}+00$ & $0.00 E+00$ & $.00 E+00$ & $00 E+\infty$ & $0.00 E+\infty 0$ & $0.00 E+00$ & $0.00 \mathrm{E}+\infty 0$ & $0.00 E+00$ \\
\hline & $5.12 E-04$ & $10 E+00$ & $D 0 E+\infty$ & $10 E+\infty$ & $00 E+\infty$ & $.00 E+00$ & $00 E+00$ & $00 E+00$ & $00 E+00$ & $00 E+\infty 0$ & 90E-06 & $0 E+\infty$ & $00 E+\infty 0$ & $.00 E+\infty$ & $0 \mathrm{E}+\infty$ & $.00 E+\infty$ \\
\hline & 4.51E-04 & $00 E+\infty 0$ & $00 E+\infty 00$ & $00 E+00$ & $00 E+\infty 0$ & $.00 E+\infty 0$ & $00 E+00$ & $00 E+00$ & $00 E+00$ & $00 E+\infty$ & $90 \mathrm{E}-07$ & $0 E+\infty$ & $\infty O E+\infty$ & $00 E+\infty$ & $0 E+\infty$ & $00 E+\infty 0$ \\
\hline & 1.22E-03 & $00 E+\infty 0$ & $00 \mathrm{E}+00$ & $0 E+\infty 0$ & $00 E+\infty$ & $.00 E+\infty 0$ & $0.00 E+00$ & $00 E+00$ & $8.13 E-06$ & $D O E+\infty O$ & $0.00 E+\infty$ & $0 E+\infty$ & $.00 E+00$ & $00 E+\infty$ & $00 E+\infty$ & $00 E+\infty$ \\
\hline & $2.91 E-04$ & $00 E+00$ & $00 \mathrm{E}+\infty$ & $0 E+00$ & $.00 E+00$ & $00 E+\infty 0$ & $00 E+00$ & $00 E+\infty$ & $5.6 \pi E-06$ & $00 E+\infty$ & $.00 E+\infty$ & $0 E+\infty$ & $00 E+\infty$ & $00 E+00$ & $00 E+\infty$ & $00 E+00$ \\
\hline & 2.91E-04 & $0 E+\infty$ & $00 \mathrm{E}+00$ & $00 \mathrm{E}+00$ & $00 E+\infty 0$ & $00 E+00$ & $00 E+00$ & $20 \mathrm{E}+00$ & $0.00 E+\infty$ & $20 E+\infty$ & $16 \mathrm{E}-07$ & $0 E+\infty$ & $00 E+\infty$ & $00 E+\infty 0$ & $00 E+\infty$ & $00 E+\infty 0$ \\
\hline & 5.01E-04 & $00 E+00$ & $00 E+00$ & $00+\infty$ & $00 \mathrm{E}+\infty 0$ & $00 \mathrm{E}+00$ & $00 \mathrm{E}+00$ & $0 E+00$ & $.00 \mathrm{E}+\infty 0$ & $00 E+\infty 0$ & $0.00 E+00$ & $0 E+\infty$ & $00 E+\infty$ & $00 E+\infty$ & $00 E+\infty$ & $00 E+00$ \\
\hline & $3.68 \mathrm{E}-04$ & $00 \mathrm{E}+00$ & $00 \mathrm{E}+\infty$ & $0 E+\infty$ & $00 E+\infty 0$ & $00 E+\infty 0$ & $00 E+00$ & $.07 \mathrm{E} .05$ & $.00 E+\infty 0$ & $00 E+\infty$ & $30 \mathrm{E}-06$ & $0 E+\infty$ & $30 E+\infty$ & 49E-06 & $00 E+\infty$ & $20 E+00$ \\
\hline & 2.82E-04 & $00 E+\infty$ & $.00 E+\infty$ & $00 E+\infty 0$ & $.00 E+\infty 0$ & $00 \mathrm{E}+00$ & $00 \mathrm{E}+00$ & $0.00 \mathrm{E}+00$ & $1.37 E .06$ & $20 E+\infty 0$ & $6.32 \mathrm{E}-07$ & $\mathrm{E}+00$ & $00 E+\infty 0$ & $.00 E+\infty$ & $00 E+\infty 0$ & $00 E+00$ \\
\hline & $8.80 \mathrm{E}-05$ & $0 E+\infty$ & $00 \mathrm{E}+00$ & $0 E+00$ & $00 E+\infty 0$ & $00 E+\infty$ & $20 \mathrm{E}+\infty 0$ & $00 E+00$ & $00 E+\infty$ & $20 E+\infty 0$ & $0.00 E+00$ & $\mathrm{E}+\infty$ & $20 E+00$ & $00 E+\infty$ & $00 E+00$ & $10 \mathrm{E}+\infty$ \\
\hline & 1.89E-04 & $0 E+00$ & $0.00 \mathrm{E}+00$ & $0 E+\infty$ & $00 \mathrm{E}+\infty$ & $00 E+\infty 0$ & $00 E+00$ & $00 E+\infty 0$ & $.00 \mathrm{E}+00$ & $00 E+\infty$ & $.00 E+00$ & $0 \mathrm{E}+\infty$ & $00 E+00$ & $0 E+\infty$ & $.00 \mathrm{E}+\infty 0$ & $00 E+00$ \\
\hline & 1.09E-04 & $00 E+00$ & $2.15 E-05$ & 6SE.0S & $00 E+\infty 0$ & $00 \mathrm{E}+\infty 0$ & $00 \mathrm{E}+\infty 0$ & $00 E+\infty$ & $100 E+00$ & $00 E+\infty 0$ & $.16 \mathrm{E}-06$ & $E+\infty$ & $0 \mathrm{E}+\infty$ & 42E-05 & $00 E+\infty$ & $00 \mathrm{E}+00$ \\
\hline & $0.00 \mathrm{E}+00$ & $00 E+00$ & ISE.0S & 6.65E.05 & $00 E+\infty 0$ & $0 E+\infty$ & $00 E+00$ & $00 E+00$ & $0.00 E+00$ & $0 E+\infty$ & 8.06 & $8+\infty$ & $E+\infty$ & $42 \mathrm{E}-05$ & $00 E+\infty$ & $0 E+\infty$ \\
\hline & .05 & $10 \mathrm{E}+\infty$ & $00 E+00$ & $0 E+00$ & $00 \mathrm{E}+\infty$ & $+\infty$ & $\$+\infty$ & $E+\infty$ & .06 & $+\infty$ & $+\infty$ & $+\infty$ & $+\infty$ & $8+\infty$ & $D E+\infty$ & $E+00$ \\
\hline & $0.00 \mathrm{E}+00$ & $10 E+\infty$ & $00 E+\infty$ & $0 E+\infty$ & & $+\infty$ & $0 E+\infty$ & $\$+\infty$ & -06 & $+\infty$ & & $+\infty$ & & & $E+\infty$ & $\varepsilon+\infty 0$ \\
\hline & & $E+\infty$ & 00 & $0 \mathrm{E}+00$ & & $+\infty$ & $20 E+\infty 0$ & $+\infty$ & & $+\infty$ & & & & & & \\
\hline & $0.00 \mathrm{E}+00$ & $10 E+\infty$ & $000 E+00$ & $00 E+00$ & $000 E+\infty$ & $00 E+\infty$ & $00 E+00$ & $00 E+00$ & E.06 & $\infty 0 E+\infty$ & $00 E+\infty$ & $E+\infty$ & $+\infty$ & $E+\infty$ & $E+\infty$ & $E+\infty$ \\
\hline & -04 & $00 E+\infty 0$ & $0.00 \mathrm{E}+00$ & $00 \mathrm{E}+00$ & $00 E+\infty 0$ & $000 E+\infty 0$ & $00 E+\infty$ & $00 E+\infty$ & 921 E.06 & $00 E+\infty$ & $1.26 \mathrm{E}-06$ & $0 E+\infty$ & $00 E+\infty$ & $.00 E+\infty 0$ & $0 \mathrm{E}+\infty 0$ & $00 \mathrm{E}+00$ \\
\hline 25 & $7.62 \mathrm{E}-05$ & $0.00 \mathrm{E}+00$ & $00 \mathrm{E}+00$ & $00 E+\infty$ & $00 E+00$ & $000 E+\infty 0$ & $00 E+\infty$ & $00 E+\infty$ & $171 \mathrm{E}-06$ & $00 \mathrm{E}+\infty$ & $000 \mathrm{E}+00$ & $O E+\infty 0$ & $E+\infty$ & $00 E+00$ & $0 \mathrm{E}+\infty$ & $00 E+00$ \\
\hline 6 & 7.90E-05 & $00 \mathrm{E}+\infty$ & $0.00 \mathrm{E}+00$ & $0 E+\infty$ & $0.00 E+00$ & $0.00 E+00$ & $00 E+\infty 0$ & $00 E+00$ & $76 \pi-06$ & $00 E+00$ & $632 \mathrm{E}-07$ & $D E+\infty$ & $E+\infty$ & $00 \mathrm{E}+\infty 0$ & $0 E+00$ & $00 \mathrm{E}+\infty$ \\
\hline . & 3.06E-04 & $00 E+\infty$ & $0.00 E+00$ & $00 E+\infty$ & $000 \mathrm{E}+00$ & $000 \mathrm{E}+\infty$ & $000 \mathrm{E}+00$ & $00 E+00$ & $137 \mathrm{E}-06$ & $00 E+\infty$ & 3.96E-06 & $0 \mathrm{E}+\infty$ & $E+\infty$ & $.00 E+\infty$ & $00 E+\infty$ & $.00 E+\infty 0$ \\
\hline 28 & $3.48 \mathrm{E}-04$ & $0.00 E+00$ & $.00 E+00$ & $00 E+00$ & $00 E+\infty 0$ & $00 E+00$ & $00 \mathrm{E}+\infty 0$ & $00 E+\infty$ & $683 \mathrm{E}-07$ & $20 E+00$ & $0.00 \mathrm{E}+00$ & $D E+\infty$ & $0 E+00$ & $00 E+\infty$ & $0 E+\infty$ & $00 \mathrm{E}+00$ \\
\hline 9 & $4.06 \mathrm{E}-04$ & $0.00 \mathrm{E}+00$ & $.00 \mathrm{E}+00$ & $00 E+\infty$ & $00 E+\infty$ & $00 E+\infty$ & $00 E+\infty$ & $00 E+\infty$ & $205 \mathrm{E}-06$ & $00 E+\infty 0$ & $0.00 \mathrm{E}+00$ & $0 E+00$ & $20 E+\infty 0$ & $00 \mathrm{E}+00$ & $00 E+00$ & $00 \mathrm{E}+00$ \\
\hline 0 & $1.83 \mathrm{E}-04$ & $0 . \dot{00} \mathrm{E}+00$ & $.00 \mathrm{E}+00$ & $20 E+\infty 0$ & $00 E+00$ & $00 E+00$ & $00 E+\infty 0$ & $00 \mathrm{E}+00$ & $171 \mathrm{E}-06$ & $00 E+00$ & $000 E+\infty 0$ & $0 E+\infty$ & $20 \mathrm{E}+\infty 0$ & $00 \mathrm{E}+00$ & $10 E+\infty$ & $00 E+00$ \\
\hline I & 1.83E-04 & $0.00 \mathrm{E}+00$ & $00 E+00$ & $20 E+\infty 0$ & $00 E+00$ & $00 E+00$ & $00 E+\infty$ & $00 \mathrm{E}+00$ & $6.83 \mathrm{E} \cdot 07$ & $10 E+\infty$ & $000 E+00$ & $0 E+\infty$ & $E+\infty$ & $.00 \mathrm{E}+00$ & $0 E+\infty 0$ & $00 \mathrm{E}+\infty 0$ \\
\hline 74 & $0.00 \mathrm{E}+\infty 0$ & $0.00 \mathrm{E}+00$ & $00 E+00$ & $00 E+00$ & $0.00 E+\infty$ & $00 E+00$ & $000 E+00$ & $00 \mathrm{E}+00$ & $000 E+00$ & $20 E+\infty$ & $0.00 \mathrm{E}+00$ & $0 E+\infty$ & $00 E+\infty 0$ & $.00 \mathrm{E}+\infty 0$ & $00 E+00$ & $00 \mathrm{E}+00$ \\
\hline 75 & $0.00 E+00$ & $0.00 \mathrm{E}+00$ & $00 \mathrm{E}+00$ & $0 \mathrm{E}+\infty 0$ & $00 E+\infty[$ & SEE-04 & $00 E+\infty$ & $00 \mathrm{E}+00$ & $0.00 E+00$ & $20 E+\infty 0$ & $.00 \mathrm{E}+00$ & $E+00$ & $0 E+\infty$ & $00 \mathrm{E}+00$ & $00 E+\infty 0$ & $00 E+\infty 0$ \\
\hline 6 & $000 E+00$ & $0.00 E+00$ & $00 E+00$ & $0 E+\infty$ & $00 E+\infty$ & $0 E+\infty$ & $00 \mathrm{E}+\infty 0$ & $00 \mathrm{E}+00$ & $000 E+00$ & $00 E+00$ & $000 E+00$ & $E+\infty 0$ & $0 E+\infty$ & $00 \mathrm{E}+\infty$ & $10 E+00$ & $00 \mathrm{E}+00$ \\
\hline 7 & $0.00 E+\infty 0$ & $0.00 E+00$ & $00 E+\infty$ & $10 E+\infty$ & $00 \mathrm{E}+00$ & $0 E+\infty$ & $00 \mathrm{E}+00$ & $00 E+\infty$ & $133 \mathrm{E}-05$ & $10 E+\infty$ & $.00 E+\infty 0$ & $E+00$ & $E+\infty$ & $00 E+00$ & $0 E+\infty 0$ & $00 \mathrm{E}+00$ \\
\hline 18 & $000 E+00$ & $0.00 \mathrm{E}+00$ & $00 \mathrm{E}+00$ & $20 E+\infty 0$ & $00 E+\infty 0$ & $0 E+00$ & $00 E+00$ & $00 \mathrm{E}+00$ & $000 E+00$ & $0 \mathrm{E}+\infty$ & $.00 \mathrm{E}+\infty 0$ & $E+\infty 0$ & $0 E+\infty$ & $00 \mathrm{E}+00$ & $00 \mathrm{E}+\infty 0$ & $00 E+00$ \\
\hline 19 & $0.00 E+00$ & $0.00 E+00$ & $00 E+00$ & $00 E+\infty$ & $00 E+\infty 0$ & $00 E+00$ & $20 \mathrm{E}+\infty 0$ & $00 \mathrm{E}+00$ & $00 E+\infty 0$ & $0 E+\infty$ & $0.00 E+00$ & $E+\infty$ & $0 E+\infty 0$ & $00 \mathrm{E}+00$ & $0 E+00$ & $00 E+\infty 0$ \\
\hline 80 & $0.00 \mathrm{E}+00$ & $0.00 \mathrm{E}+00$ & $0.00 E+\infty 0$ & $0.00 \mathrm{E}+00$ & $0 E+\infty$ & $0 E+\infty$ & $00 \mathrm{E}+\infty$ & $00 \mathrm{E}+\infty$ & $00 E+00$ & $0 \mathrm{E}+00$ & $0.00 E+00$ & $E+00$ & $0 E+\infty 0$ & $00 \mathrm{E}+00$ & $0 E+\infty 0$ & $00 \mathrm{E}+\infty 0$ \\
\hline 81 & $000 \mathrm{E}+00$ & $0 . \dot{00} \mathrm{E}+00$ & 2.15E-05 & 6.65E.05 & $0 E+00$ & $0 \mathrm{E}+\infty 0$ & $00 \mathrm{E}+00$ & $00 \mathrm{E}+\infty$ & $00 \mathrm{E}+00$ & $0 \mathrm{E}+\infty 0$ & $3.16 \mathrm{E}-06$ & $E+\infty$ & $E+00$ & 2E-05 & $0 E+\infty$ & $00 E+00$ \\
\hline 32 & $0.00 E+00$ & $0.00 E+00$ & $000 E+\infty 0$ & $20 E+\infty 0$ & $10 \mathrm{E}+\infty$ & $0 E+00$ & $30 E+\infty 0$ & $00 \mathrm{E}+00$ & $00 E+00$ & $0 \mathrm{E}+00$ & $0.00 E+00$ & $E+00$ & $0 E+\infty$ & $00 E+\infty$ & $E+\infty$ & $00 E+\infty$ \\
\hline 84 & $000 \mathrm{E}+\infty 0$ & $0.00 E+\infty 0$ & $0.00 E+\infty 0$ & $000 E+00$ & $10 \mathrm{E}+\infty$ & $0 E+\infty 0$ & $00 \mathrm{E}+\infty$ & $00 \mathrm{E}+\infty$ & $000 E+00$ & $0 \mathrm{E}+\infty$ & $000 E+\infty$ & $E+\infty$ & $+\infty$ & $10 \mathrm{E}+\infty$ & $E+\infty$ & $\infty$ \\
\hline 85 & $000 \mathrm{E}+00$ & $0.00 E+00$ & $0.00 E+00$ & $00 E+\infty$ & $E+\infty$ & $0 E+\infty 0$ & $00 \mathrm{E}+00$ & $0 \mathrm{E}+00$ & E-06 & $E+\infty$ & $\pm+\infty$ & $+\infty$ & 00 & $+\infty$ & $i+\infty$ & $0 E+\infty$ \\
\hline 36 & $0.00 \mathrm{E}+00$ & $0.00 E+\infty 0$ & $000 E+00$ & $0 \mathrm{E}+\infty$ & $0 E+\infty$ & $E+\infty$ & $00 E+\infty$ & $E+\infty$ & $000 E+\infty$ & $+\infty$ & $+\infty$ & $+\infty$ & $\infty$ & $+\infty$ & $+\infty$ & $0 E+\infty$ \\
\hline 46 & 671 .05 & $0 E+\infty 0$ & $000 E+00$ & $0 \mathrm{E}+\infty$ & $E+\infty$ & $E+\infty$ & $00 \mathrm{E}+\infty 0$ & $E+\infty$ & 8.06 & $+\infty$ & $+\infty$ & $+\infty$ & 100 & $+\infty$ & $E+\infty$ & $20 \mathrm{E}+00$ \\
\hline 47 & $6.81 \mathrm{E}-05$ & $0 E+\infty$ & $0.00 E+00$ & $0 E+\infty 0$ & $E+\infty$ & $\varepsilon+\infty$ & $10 \mathrm{E}+\infty$ & $E+\infty$ & .06 & 100 & $+\infty$ & & 100 & 100 & $E+\infty$ & $00 E+00$ \\
\hline & $+\infty$ & $0 E+\infty$ & $\infty 0 E+\infty$ & $0 E+\infty$ & $+\infty$ & $E+\infty$ & $0 \mathrm{E}+\infty$ & $\varepsilon+\infty 0$ & $+\infty$ & 00 & $+\infty$ & & & $+\infty$ & $+\infty$ & $20 E+\infty$ \\
\hline & $\pm+\infty$ & $0.00 E+00$ & $0 \mathrm{E}+\infty$ & $0 E+\infty$ & & $=+\infty$ & $0 \mathrm{E}+\infty$ & $E+\infty 0$ & $+\infty$ & & .00 & & $\infty$ & $+\infty$ & $E+\infty$ & $0 E+\infty$ \\
\hline & $+\infty$ & $0.00 E+\infty$ & $000 E+\infty 0$ & $\mathrm{DE}+\infty$ & & +00 & $0 E+\infty$ & & & & & & & $\mathrm{E}+\infty$ & $+\infty$ & $00 E+\infty$ \\
\hline & & 00 & 00 & $E+\infty$ & $E+\infty$ & +00 & $E+00$ & $E+\infty$ & & & $+\infty$ & & $+\infty$ & $00 E+00$ & $000 E+\infty$ & \\
\hline
\end{tabular}




\begin{tabular}{|c|c|c|c|c|c|c|c|c|c|c|c|c|}
\hline $\begin{array}{r}\text { INDENO_1 } \\
0.00 E+00\end{array}$ & $\begin{array}{r}\text { NNDNPA } \\
0.00 E+\infty 0\end{array}$ & $\begin{array}{r}\text { PENTACHL } \\
0 \text { OOE }+\infty 0\end{array}$ & VINYL_CH & TRI123 & D12CHL3 & DBE 12 & DIOXANI4 & PROPENE2 & -3_3_-DI & Total Rsk & WAG & $\begin{array}{r}\text { WELL } \\
634\end{array}$ \\
\hline & & & $0.00 \mathrm{E}+00$ & - & & & . & & & 2.26E-04 & 1 & 634 \\
\hline $0.00 \mathrm{E}+\infty 0$ & $0.00 E+00$ & $0.00 \mathrm{E}+\infty$ & $0.00 E+00$ & . & & & . & & & $6.58 \mathrm{E}-04$ & 1 & 806 \\
\hline $0.00 E+\infty$ & $0.00 E+\infty$ & $0.00 \mathrm{E}+\infty 0$ & $0.00 E+00$ & . & & & . & - & & 5.51E-04 & 1 & 807 \\
\hline $0.00 \mathrm{E}+00$ & $0.00 E+00$ & $0.00 E+00$ & $000 \mathrm{E}+00$ & . & & & . & F & & $4.66 \mathrm{E}-04$ & 1 & 808 \\
\hline $0.00 \mathrm{E}+00$ & $1.16 E-03$ & $0.00 \mathrm{E}+00$ & $000 \mathrm{E}+00$ & . & & & & . & & 2.41E-03 & 1 & 809 \\
\hline $000 \mathrm{E}+\infty 0$ & $0.00 \mathrm{E}+00$ & $0.00 \mathrm{E}+00$ & $000 E+00$ & . & & & . & & & $3.14 E-04$ & 1 & 810 \\
\hline $0.00 E+00$ & $0.00 E+\infty 0$ & $0.00 E+\infty 0$ & $000 E+00$ & . & & & . & & & $3.20 E-04$ & 1 & 811 \\
\hline $0.00 \mathrm{E}+00$ & $000 E+00$ & $0.00 E+00$ & $0.00 E+00$ & . & & & . & & & $6.65 \mathrm{E}-03$ & 1 & 812 \\
\hline $0.00 \dot{E}+\infty$ & $0.00 E+\infty 0$ & $0.00 E+00$ & $0.00 \mathrm{E}+00$ & . & & & . & & & 4.46E-04 & 1 & 813 \\
\hline $0.00 E+00$ & $0.00 E+\infty 0$ & $000 E+00$ & $000 E+00$ & $0.00 \mathrm{E}+\infty 0$ & $000 \mathrm{E}+00$ & $0.00 E+00$ & $0.00 \mathrm{E}+00$ & $0.00 E+00$ & 1.59E-02 & 1.63E-02 & 1 & 814 \\
\hline $0.00 E+\infty$ & $0.00 E+00$ & $0.00 \mathrm{E}+00$ & $0.00 E+00$ & & & & & & & $1.07 E-04$ & 1 & 815 \\
\hline $0.00 \mathrm{E}+\infty$ & $0.00 E+00$ & $0.00 E+00$ & $0.00 E+00$ & & & & & & & $2.13 \mathrm{E}-04$ & 1 & 816 \\
\hline $0.00 E+00$ & $0.00 E+00$ & $0.00 E+00$ & $3.94 E-04$ & $7.12 E-04$ & 2.85E-04 & $8.70 \mathrm{E}-03$ & 1.12E-03 & 1.12E-04 & $0.00 E+00$ & 1.15E-02 & 1 & 818 \\
\hline $0.00 \mathrm{E}+\infty$ & $0.00 E+00$ & $000 E+00$ & 3.94E-04 & 7.12E-04 & $2.85 E-04$ & $8.70 E-03$ & 1.12E-03 & $1.12 E-04$ & $0.00 \mathrm{E}+00$ & 1.14E-02 & 1 & 819 \\
\hline $0.00 \mathrm{E}+00$ & $000 E+\infty$ & $000 E+00$ & $0.00 \mathrm{E}+00$ & . & 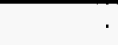 & & 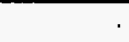 & 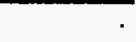 & & $8.25 \mathrm{E}-05$ & 1 & 820 \\
\hline $0.00 E+00$ & $0.00 E+\infty 0$ & $0.00 E+00$ & $000 E+00$ & . & & & & . & & $2.73 \mathrm{E}-05$ & 1 & 821 \\
\hline $0.00 E+\infty$ & $0.00 E+00$ & $000 E+00$ & $0.00 \mathrm{E}+00$ & & & & & . & & $6.92 \mathrm{E}-05$ & 1 & 822 \\
\hline $0.00 E+\infty$ & $0.00 \mathrm{E}+\infty$ & $000 E+00$ & $000 \mathrm{E}+00$ & & & & & . & & $3.00 \mathrm{E}-05$ & 1 & 823 \\
\hline $0.00 \mathrm{E}+00$ & $0.00 E+\infty 0$ & $0.00 \mathrm{E}+00$ & $0.00 \mathrm{E}+00$ & & & & , & & & 4.01E-04 & 1 & 824 \\
\hline $0.00 \mathrm{E}+\infty$ & $000 \mathrm{E}+00$ & $000 E+00$ & $8.90 \mathrm{E}-04$ & & & & & . & & $1.03 E-03$ & 1 & 825 \\
\hline $0.00 E+00$ & $000 \mathrm{E}+00$ & $000 \mathrm{E}+00$ & $000 E+00$ & & & & & . & & $1.06 E-04$ & 1 & 826 \\
\hline $0.00 E+00$ & $0.00 \mathrm{E}+\infty$ & $000 E+00$ & $000 \mathrm{E}+00$ & & & & & . & & $3.36 \mathrm{E}-04$ & 1 & 827 \\
\hline $0.00 E+\infty$ & $0.00 E+00$ & $0.00 \mathrm{E}+00$ & $000 \mathrm{E}+00$ & & & & & • & & $3.63 \mathrm{E}-04$ & 1 & 828 \\
\hline $0.00 \mathrm{E}+00$ & $0.00 \mathrm{E}+00$ & $000 \mathrm{E}+\infty 0$ & $0.00 E+00$ & , & & & & & & $4.40 E-04$ & 1 & 829 \\
\hline $0.00 \mathrm{E}+00$ & $000 \mathrm{E}+00$ & $000 \mathrm{E}+00$ & $2.36 E-04$ & & . & & & . & & $6.14 \mathrm{E}-04$ & 1 & 830 \\
\hline $0.00 \mathrm{E}+00$ & $000 \mathrm{E}+00$ & $0.00 E+00$ & $000 E+00$ & . & & & & . & & $2.11 E-04$ & 1 & 873 \\
\hline $0.00 \mathrm{E}+00$ & $0.00 \mathrm{E}+00$ & $2.50 E-04$ & $000 \mathrm{E}+00$ & & & & & . & & $2.22 E-03$ & 1 & 874 \\
\hline $0.00 \mathrm{E}+00$ & 1.45E-03 & $0.00 \mathrm{E}+00$ & $000 E+\infty 0$ & $0.00 E+00$ & $0.00 \mathrm{E}+00$ & $000 E+00$ & $000 E+00$ & $0.00 \mathrm{E}+00$ & $0.00 E+00$ & 1.65E-02 & 1 & 875 \\
\hline $0.00 \mathrm{E}+00$ & $0.00 \mathrm{E}+\infty 0$ & $0.00 E+00$ & $000 E+00$ & & & & & & & $3.88 E-04$ & 1 & 876 \\
\hline $0.00 \mathrm{E}+00$ & $000 \mathrm{E}+00$ & $2.50 E-04$ & $000 \mathrm{E}+00$ & & & & & & & $3.09 E-04$ & 1 & 877 \\
\hline $0.00 \mathrm{E}+\infty 0$ & $0.00 \mathrm{E}+00$ & $2.60 \mathrm{E}-0.4$ & $000 \mathrm{E}+00$ & ? & & & & & & $2.56 E-04$ & 1 & 878 \\
\hline $0.00 E+\infty$ & $0.00 \mathrm{E}+00$ & $0.00 \mathrm{E}+00$ & $0.00 E+00$ & & & & & & & $6.10 \mathrm{E}-06$ & 1 & 879 \\
\hline $0.00 \mathrm{E}+00$ & $0.00 \mathrm{E}+\infty$ & $2.50 \mathrm{E}-04$ & $0.00 \mathrm{E}+00$ & & & & & & & 2.67E-04 & 1 & 880 \\
\hline $0.00 \mathrm{E}+00$ & $0.00 \mathrm{E}+\infty 0$ & 2.50E-04 & 4.72E-04 & - & & & & - & & 8.81E-0. & 1 & 881 \\
\hline $0.00 \mathrm{E}+00$ & $0.00 E+00$ & $0.00 \mathrm{E}+00$ & $0.00 E+00$ & & & & & & & $3.54 \mathrm{E}-05$ & 1 & 882 \\
\hline $0.00 E+00$ & $0.00 E+00$ & $2.50 E-0.4$ & $0.00 E+00$ & & & & & & & 4.53E-04 & 1 & 884 \\
\hline $0.00 E+00$ & $0.00 \mathrm{E}+00$ & $0.00 \mathrm{E}+00$ & 1.97E-04 & . & & & & & & $1.38 E-03$ & 1 & 885 \\
\hline $0.00 \mathrm{E}+\infty 0$ & $0.00 E+00$ & $0.00 \mathrm{E}+00$ & $000 E+00$ & & & & & & & $1.55 \mathrm{E}-05$ & 1 & 886 \\
\hline $0.00 \mathrm{E}+00$ & $0.00 \mathrm{E}+00$ & $000 \mathrm{E}+00$ & $0.00 E+00$ & * & & & & • & & $1.05 \mathrm{E}-0.4$ & 1 & 946 \\
\hline $0.00 \mathrm{E}+00$ & $0.00 E+00$ & $0.00 \mathrm{E}+00$ & $0.00 \mathrm{E}+00$ & & & & & & & $1.03 E-04$ & 1 & 947 \\
\hline $0.00 \mathrm{E}+00$ & $0.00 \mathrm{E}+\infty 0$ & $0.00 \mathrm{E}+00$ & 4.33E-04 & & & & & & & 6.77E-04 & 1 & 1100 \\
\hline $0.00 \mathrm{E}+00$ & $0.00 E+\infty$ & $2.50 E-04$ & $0.00 \mathrm{E}+00$ & & . & & & & & $9.09 E-04$ & 1 & 1101 \\
\hline $0.00 E+00$ & $0.00 \mathrm{E}+00$ & $2.50 \mathrm{E}-04$ & 3.15E-04 & & & & . & & & $2.04 E-03$ & 1 & 1102 \\
\hline $0.00 \mathrm{E}+00$ & $0.00 E+00$ & $0.00 \mathrm{E}+00$ & $7.48 E-04$ & & & & . & & & $1.02 E-03$ & 1 & 1103 \\
\hline $0.00 E+\infty 0$ & $0.00 \mathrm{E}+00$ & $0.00 E+00$ & $000 E+00$ & & & & & & & $9.14 E-04$ & 1 & 1104 \\
\hline
\end{tabular}


WELL BE B2CEE TETI122 DCEEII METHYLI METHYL2 DIC33 PCB1254 BIS_2_ET BENZBFLU BENZENE BENZAANT BENZAPYR CARBON_T DIRENZ_A HCBE $\begin{array}{llllllll}2533 & 1.02 \mathrm{E}-24 & 0.00 \mathrm{E}+00 & 0.00 \mathrm{E}+\infty & 0.00 \mathrm{E}+00 & 0.00 \mathrm{E}+\infty & 0.00 \mathrm{E}+\infty 0 & 0.00 \mathrm{E}+\infty\end{array}$ $\begin{array}{lllllllll}4003 & 2.87 E-04 & 0.00 E+00 & 0.00 E+00 & 0.00 E+00 & 0.00 E+00 & 0.00 E+00 & 0.00 E+\infty\end{array}$

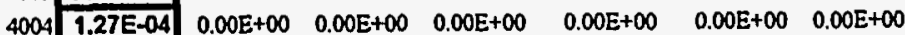

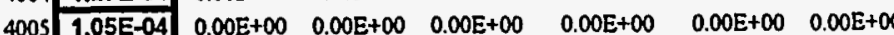

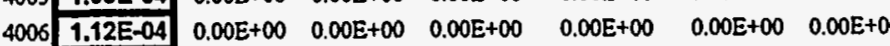
$\begin{array}{llllllll}4008 & 0.00 \mathrm{E}+\infty & 0.00 \mathrm{E}+00 & 0.00 \mathrm{E}+00 & 0.00 \mathrm{E}+00 & 0.00 \mathrm{E}+00 & 0.00 \mathrm{E}+00 & 0.00 \mathrm{E}+00\end{array}$

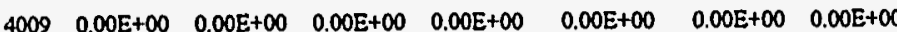
$\begin{array}{lllllllll}1150 & 0.00 \mathrm{E}+\infty & 0.00 \mathrm{E}+\infty & 0.00 \mathrm{E}+\infty & 0.00 \mathrm{E}+\infty & 0.00 \mathrm{E}+\infty & 0.00 \mathrm{E}+\infty & 0.00 \mathrm{E}+\infty\end{array}$

$\begin{array}{lllllllll}1151 & 0.00 E+00 & 0.00 E+00 & 0.00 E+00 & 0.00 E+\infty & 0.00 E+\infty & 0.00 E+\infty 0 & 0.00 E+\infty\end{array}$

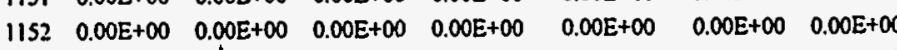
$\begin{array}{lllllllll}1153 & 0.00 \mathrm{E}+00 & 0.00 \mathrm{E}+00 & 0.00 \mathrm{E}+00 & 0.00 \mathrm{E}+00 & 0.00 \mathrm{E}+00 & 0.00 \mathrm{E}+00 & 0.00 \mathrm{E}+00\end{array}$

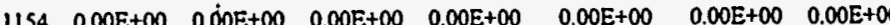
IISS $0.00 \mathrm{E}+00$ 0.00E+00 $0.00 \mathrm{E}+00 \quad 0.00 \mathrm{E}+00$ O.00E+00 $0.00 \mathrm{E}+00$ OCOE+ $\begin{array}{llllllll}1156 & 0.00 \mathrm{E}+00 & 0.00 \mathrm{E}+00 & 0.00 \mathrm{E}+00 & 0.00 \mathrm{E}+00 & 0.00 \mathrm{E}+00 & 0.00 \mathrm{E}+00 & 0.00 \mathrm{E}+00\end{array}$

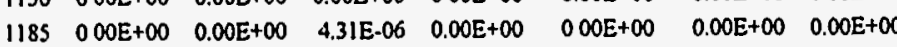
$\begin{array}{lllllllll}1186 & 0.00 \mathrm{E}+00 & 0.00 \mathrm{E}+00 & 0.00 \mathrm{E}+00 & 0.00 \mathrm{E}+00 & 0.00 \mathrm{E}+00 & 0.00 \mathrm{E}+00 & 0.00 \mathrm{E}+\infty\end{array}$ $\begin{array}{lllllllll}1187 & 0.00 E+\infty & 0.00 E+00 & 0.00 E+00 & 0.00 E+00 & 0.00 E+00 & 0.00 E+00 & 0.00 E+00\end{array}$ $1188 \quad 0.00 \mathrm{E}+00 \quad 0.00 \mathrm{E}+00 \quad 0.00 \mathrm{E}+00 \quad 0.00 \mathrm{E}+00 \quad 000 \mathrm{E}+00 \quad 000 \mathrm{E}+00 \quad 000 \mathrm{E}+00$ $1189 \quad 0.00 E+00 \quad 0.00 E+00 \quad 0.00 E+00 \quad 0.00 E+00 \quad 000 E+00 \quad 000 E+00 \quad 000 E+00$

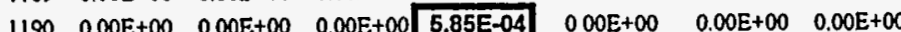
$\begin{array}{llllllllll}1191 & 0.00 \mathrm{E}+00 & 0.00 \mathrm{E}+00 & 0.00 \mathrm{E}+00 & 0.00 \mathrm{E}+00 & 0.00 \mathrm{E}+00 & 0.00 \mathrm{E}+00 & 0.00 \mathrm{E}+00\end{array}$ $\begin{array}{lllllllll}1192 & 0.00 \mathrm{E}+00 & 0.00 \mathrm{E}+00 & 0.00 \mathrm{E}+00 & 0.00 \mathrm{E}+00 & 0.00 \mathrm{E}+00 & 0.00 \mathrm{E}+00 & 0.00 \mathrm{E}+00\end{array}$ $\begin{array}{llllllll}1193 & 0.00 E+\infty 0 & 0.00 E+00 & 0.00 E+00 & 0.00 E+00 & 0.00 E+00 & 0.00 E+00 & 0.00 E+00\end{array}$ $1194 \quad 1.40 E-04 \quad 0.00 E+\infty 000.00 E+00 \quad 0.00 E+00 \quad 0.00 E+00 \quad 0.00 E+00 \quad 0.00 E+\infty$

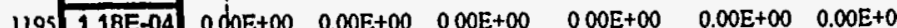
$\begin{array}{llllllll}1244 & 0.00 \mathrm{E}+00 & 0.00 \mathrm{E}+00 & 0.00 \mathrm{E}+00 & 0.00 \mathrm{E}+00 & 0.00 \mathrm{E}+\infty 0 & 0.00 \mathrm{E}+00 & 0.00 \mathrm{E}+00\end{array}$ $\begin{array}{lllllllll}1245 & 0.00 \mathrm{E}+\infty & 0.00 \mathrm{E}+\infty & 0.00 \mathrm{E}+00 & 0.00 \mathrm{E}+00 & 0.00 \mathrm{E}+\infty & 0.00 \mathrm{E}+00 & 0.00 \mathrm{E}+\infty\end{array}$

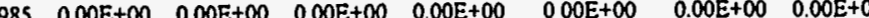

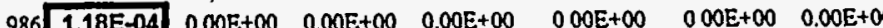
$\begin{array}{llllllll}987 & 0.00 \mathrm{E}+\infty 0 & 0.00 \mathrm{E}+00 & 0.00 \mathrm{E}+\infty & 0.00 \mathrm{E}+\infty & 0.00 \mathrm{E}+\infty & 0.00 \mathrm{E}+\infty & 0.00 \mathrm{E}+\infty\end{array}$ $\begin{array}{llllllll}988 & 0.00 \mathrm{E}+00 & 0.00 \mathrm{E}+00 & 0.00 \mathrm{E}+00 & 0.00 \mathrm{E}+\infty & 0.00 \mathrm{E}+\infty 0 & 0.00 \mathrm{E}+00 & 0.00 \mathrm{E}+\infty\end{array}$ $\begin{array}{lllllllll}990 & 0.00 \mathrm{E}+00 & 0.00 \mathrm{E}+00 & 0.00 \mathrm{E}+00 & 0.00 \mathrm{E}+\infty & 0.00 \mathrm{E}+\infty & 0.00 \mathrm{E}+\infty & 0.00 \mathrm{E}+\infty\end{array}$

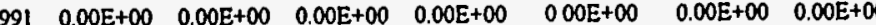
$9920.000-0.00 E+00 \quad 0.00 E+\infty 0$

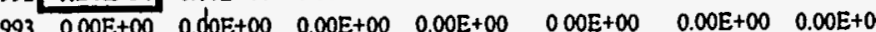
$\begin{array}{llllllll}994 & 0.00 \mathrm{E}+\infty & 0.00 \mathrm{E}+00 & 0.00 \mathrm{E}+00 & 0.00 \mathrm{E}+00 & 0.00 \mathrm{E}+00 & 0.00 \mathrm{E}+00 & 0.00 \mathrm{E}+00\end{array}$ $\begin{array}{lllllllll}995 & 0.00 \mathrm{E}+\infty & 0.00 \mathrm{E}+00 & 0.00 \mathrm{E}+00 & 0.00 \mathrm{E}+00 & 0.00 \mathrm{E}+00 & 0.00 \mathrm{E}+00 & 0.00 \mathrm{E}+00\end{array}$

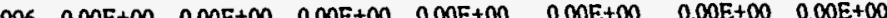
DE $1248 \begin{array}{lllllll}1.08 E-04 & 0.00 E+\infty & 0.00 E+\infty & 0.00 E+\infty 0 & 0.00 E+\infty 0 & 0.00 E+\infty & 0.00 E+\infty\end{array}$ $\begin{array}{lllllllll}948 & 0.00 E+\infty & 0.00 E+\infty & 0.00 E+00 & 0.00 E+\infty 0 & 0.00 E+\infty 0 & 0.00 E+\infty 0 & 0.00 E+\infty\end{array}$ $\begin{array}{lllllllll}949 & 0.00 \mathrm{E}+00 & 0.00 \mathrm{E}+00 & 0.00 \mathrm{E}+00 & 0.00 E+\infty 0 & 0.00 \mathrm{E}+00 & 0.00 \mathrm{E}+\infty 0 & 0.00 \mathrm{E}+\infty 0\end{array}$ $950 \quad 0.00 E+\infty 000.00 E+00 \quad 000 E+00 \quad 0.00 E+00 \quad 0.00 E+00 \quad 0.00 E+00 \quad 0.00 E+\infty 0$

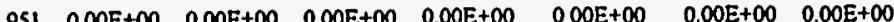
052 .

\begin{tabular}{|c|c|c|}
\hline $.07 E-06$ & $0.00 \mathrm{E}+\infty$ & $0.00 \mathrm{E}+\infty 0$ \\
\hline $1.00 E+\infty 0$ & $0.00 \mathrm{E}+00$ & $0.00 E+00$ \\
\hline 2.05E-06 & $0.00 \mathrm{E}+\infty 0$ & $0.00 \mathrm{E}+\infty 0$ \\
\hline $000 E+00$ & $0.00 \mathrm{E}+00$ & $0.00 E+00$ \\
\hline $000 \mathrm{E}+00$ & $0.00 \mathrm{E}+00$ & $0.00 \mathrm{E}+00$ \\
\hline $0.00 \mathrm{E}+00$ & $0.00 \mathrm{E}+00$ & $0.00 E+\infty 0$ \\
\hline $0.00 E+\infty 0$ & $0.00 \mathrm{E}+00$ & $0.00 E+\infty 0$ \\
\hline $0.00 E+00$ & $0.00 \mathrm{E}+00$ & $0.00 E+\infty 0$ \\
\hline $1.02 \mathrm{E}-06$ & $0.00 \mathrm{E}+00$ & $0.00 E+00$ \\
\hline $0.00 E+00$ & $0.00 \mathrm{E}+\infty 0$ & $0.00 E+\infty$ \\
\hline $0.00 E+00$ & $0.00 \mathrm{E}+\infty 0$ & $6.32 \mathrm{E}-07$ \\
\hline $000 E+\infty$ & $0.00 E+00$ & $6.32 \mathrm{E}-07$ \\
\hline $000 E+00$ & $0.00 E+\infty 0$ & $1.26 \mathrm{E}-06$ \\
\hline $000 E+\infty 0$ & $0.00 \mathrm{E}+\infty$ & $1.26 \mathrm{E} .06$ \\
\hline $0.00 \mathrm{E}+00$ & $0.00 \mathrm{E}+00$ & $6.32 \mathrm{E} \cdot 07$ \\
\hline $137 \mathrm{TE}-06$ & $0.00 \mathrm{E}+00$ & $0.00 E+\infty 0$ \\
\hline $0.00 E+00$ & $0.00 \mathrm{E}+00$ & $0.00 \mathrm{E}+00$ \\
\hline $000 E+\infty 0$ & $0.00 E+\infty 0$ & $0.00 \mathrm{E}+00$ \\
\hline $0.00 E+00$ & $0.00 \mathrm{E}+00$ & $0.00 E+00$ \\
\hline $273 \mathrm{E}-06$ & $0.00 E+00$ & $0.00 E+00$ \\
\hline 205E.06 & $0.00 E+00$ & 3.10E-05 \\
\hline $205 \mathrm{E} .06$ & $0.00 E+00$ & $0.00 \mathrm{E}+00$ \\
\hline $239 \mathrm{E} .06$ & $0.00 \mathrm{E}+00$ & $0.00 E+00$ \\
\hline $000 E+00$ & $0.00 \mathrm{E}+00$ & $0.00 E+00$ \\
\hline $000 E+00$ & $0.00 E+00$ & $0.00 \mathrm{E}+00$ \\
\hline $000 E+\infty 0$ & $0.00 \mathrm{E}+\infty$ & $0.00 E+\infty 0$ \\
\hline $0.00 E+\infty 0$ & $0.00 \mathrm{E}+00$ & $0.00 \mathrm{E}+\infty 0$ \\
\hline $239 \mathrm{E}-06$ & $0.00 E+\infty$ & $0.00 E+00$ \\
\hline $000 E+00$ & $\infty$ & $0.00 E+\infty 0$ \\
\hline $000 E+00$ & $0.00 E+00$ & $0.00 E+\infty$ \\
\hline $000 E+00$ & $0.00 E+00$ & $0.00 E+00$ \\
\hline $0.00 E+00$ & $0.00 \mathrm{E}+00$ & $0.00 E+00$ \\
\hline $000 E+\infty 0$ & $0.00 \mathrm{E}+00$ & $0.00 E+\infty 0$ \\
\hline $3.41 E .07$ & $0.00 E+\infty$ & $0.00 E+00$ \\
\hline $000 E+\infty$ & $0.00 \mathrm{E}+00$ & $0.00 E+\infty$ \\
\hline $000 E+00$ & $0.00 E+00$ & $1.90 \mathrm{E}-06$ \\
\hline $000 \mathrm{E}+00$ & $0.00 E+00$ & $0.00 E+\infty$ \\
\hline $000 E+00$ & $0.00 \mathrm{E}+\infty 0$ & $0.00 E+\infty$ \\
\hline $000 E+00$ & $0.00 E+00$ & $000 E+\infty$ \\
\hline $0.00 E+00$ & $0.00 E+00$ & $0.00 E+\infty 0$ \\
\hline $000 \mathrm{E}+00$ & $0.00 \mathrm{E}+\infty$ & $0.00 E+00$ \\
\hline $000 E+\infty 0$ & $0.00 E+00$ & $0.00 E+00$ \\
\hline $000 E+\infty 0$ & $0.00 \mathrm{E}+00$ & $0.00 E+\infty$ \\
\hline $000 E+\infty$ & $0.00 E+\infty 0$ & $0.00 E+00$ \\
\hline $000 E+\infty$ & $0.00 \mathrm{E}+\infty$ & $0.00 E+\infty$ \\
\hline $000 E+\infty 0$ & $000 E+\infty 0$ & $000 E+00$ \\
\hline $0.00 E+\infty$ & $000 E+00$ & $000 E+00$ \\
\hline
\end{tabular}
0.00E+00 0.00E+00 0.00E+00 0.00E+00 0.00E+00 $\begin{array}{llllll}0.00 E+00 & 0.00 E+00 & 0.00 E+00 & 0.00 E+00 & 0.00 E+00\end{array}$ $\begin{array}{llllll}0.00 E+\infty 0 & 0.00 E+00 & 0.00 E+\infty & 0.00 E+\infty 0 & 0.00 E+00\end{array}$ $\begin{array}{llllll}0.00 E+\infty 0 & 0.00 E+\infty & 0.00 E+\infty & 0.00 E+\infty 0 & 0.00 E+\infty\end{array}$

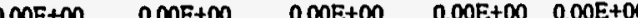
$\begin{array}{lllllllll}0.00 \mathrm{E}+00 & 0.00 \mathrm{E}+00 & 0.00 \mathrm{E}+00 & 0.00 \mathrm{E}+00 & 0.00 \mathrm{E}+00\end{array}$ $\begin{array}{llllll}0.00 E+00 & 0.00 E+00 & 0.00 E+00 & 0.00 E+00 & 0.00 E+00\end{array}$ $\begin{array}{lllllll}0.00 \mathrm{E}+\infty & 0.00 \mathrm{E}+00 & 0.00 \mathrm{E}+00 & 0.00 \mathrm{E}+00 & 0.00 \mathrm{E}+\infty\end{array}$ $\begin{array}{lllllll}0.00 \mathrm{E}+\infty 0 & 0.00 \mathrm{E}+00 & 0.00 \mathrm{E}+00 & 0.00 \mathrm{E}+00 & 0.00 \mathrm{E}+00\end{array}$ $0.00 \mathrm{E}+00 \quad 0.00 \mathrm{E}+\infty 00 \quad 0.00 \mathrm{E}+\infty 00 \quad 0.00 \mathrm{E}+00 \quad 0.00 \mathrm{E}+\infty 0$ $\begin{array}{llllll}0.00 E+\infty 0 & 0.00 E+\infty & 0.00 E+\infty & 0.00 E+\infty 0 & 0.00 E+\infty\end{array}$ $\begin{array}{llllll}0.00 E+00 & 0.00 E+\infty 0 & 0.00 E+00 & 0.00 E+00 & 0.00 E+\infty 0\end{array}$ $\begin{array}{llllll}0.00 \mathrm{E}+00 & 0.00 \mathrm{E}+00 & 0.00 \mathrm{E}+00 & 0.00 \mathrm{E}+00 & 0.00 \mathrm{E}+00\end{array}$ $\begin{array}{llllll}0.00 \mathrm{E}+00 & 0.00 \mathrm{E}+00 & 0.00 \mathrm{E}+00 & 0.00 \mathrm{E}+00 & 0.00 \mathrm{E}+00\end{array}$ $0.00 E+00 \quad 0.00 E+00 \quad 0.00 E+\infty 000.00 E+00 \quad 0.00 E+00$ $\begin{array}{llllll}0.00 E+00 & 0.00 E+00 & 0.00 E+\infty 0 & 0.00 E+00 & 0.00 E+00\end{array}$ $\begin{array}{lllll}0.00 E+00 & 0.00 E+00 & 0.00 E+00 & 0.00 E+00 & 0.00 E+00\end{array}$ $\begin{array}{llllll}0.00 E+\infty 0 & 0.00 E+\infty 0 & 0.00 E+\infty 0 & 0.00 E+\infty & 0.00 E+00\end{array}$ $\begin{array}{lllllll}0.00 E+\infty & 0.00 E+\infty 0 & 0.00 E+\infty & 0.00 E+\infty & 0.00 E+\infty 0\end{array}$ $\begin{array}{llllll}0.00 E+\infty 0 & 0.00 E+00 & 0.00 E+\infty 0 & 0.00 E+\infty 0 & 0.00 E+\infty\end{array}$ $0.00 E+\infty 00 \quad 0.00 E+00 \quad 0.00 E+\infty \quad 0.00 E+\infty 00.00 E+\infty 0$ $0.00 \mathrm{E}+\infty 00.00 \mathrm{E}+\infty 00 \quad 0.00 \mathrm{E}+\infty 000.00 \mathrm{E}+\infty 0000 \mathrm{E}+00$ $\begin{array}{lllll}0.00 E+00 & 0.00 E+00 & 0.00 E+\infty & 0.00 E+\infty & 0.00 E+00\end{array}$ $\begin{array}{lllllllll}0.00 \mathrm{E}+\infty & 0.00 \mathrm{E}+\infty 0 & 0.00 \mathrm{E}+\infty & 0.00 \mathrm{E}+\infty & 0.00 \mathrm{E}+\infty\end{array}$ $\begin{array}{llllll}0.00 E+\infty 0 & 0.00 E+\infty 0 & 0.00 E+\infty & 0.00 E+\infty 0 & 0.00 E+\infty 0\end{array}$ $\begin{array}{llllll}0.00 E+00 & 0.00 E+00 & 0.00 E+\infty & 0.00 E+\infty & 0.00 E+00\end{array}$ $\begin{array}{lllllll}0.00 E+00 & 0.00 E+00 & 0.00 E+\infty & 0.00 E+\infty 0 & 0.00 E+\infty 0\end{array}$ $\begin{array}{llllll}0.00 E+\infty 0 & 0.00 E+\infty 0 & 0.00 E+\infty & 0.00 E+00 & 0.00 E+\infty 0\end{array}$ $\begin{array}{llllll}0.00 \mathrm{E}+00 & 0.00 \mathrm{E}+00 & 0.00 \mathrm{E}+00 & 0.00 \mathrm{E}+00 & 0.00 \mathrm{E}+00\end{array}$ $\begin{array}{llllll}0.00 E+00 & 0.00 E+00 & 0.00 E+00 & 0.00 E+00 & 0.00 E+00\end{array}$ $0.00 \mathrm{E}+\infty \quad 0,00 \mathrm{E}+00 \quad 0,00 \mathrm{E}+\infty 00$ $\begin{array}{llllll}0.00 E+00 & 0.00 E+00 & 0.00 E+\infty & 0.00 E+\infty 0 & 0.00 E+\infty 0\end{array}$ $\begin{array}{llllll}0.00 E+\infty & 0.00 E+00 & 0.00 E+\infty 0 & 0.00 E+\infty 0 & 0.00 E+00\end{array}$ $\begin{array}{llllll}0.00 E+\infty 0 & 0.00 E+\infty 0 & 0.00 E+\infty & 0.00 E+\infty 0 & 0.00 E+\infty\end{array}$ $\begin{array}{llllll}0.00 E+\infty 0 & 0.00 E+\infty 0 & 0.00 E+\infty 0 & 0.00 E+\infty 0 & 0.00 E+\infty 0\end{array}$ $\begin{array}{llllll}0.00 E+\infty 0 & 0.00 E+\infty 0 & 0.00 E+\infty 0 & 0.00 E+00 & 0.00 E+\infty\end{array}$ $\begin{array}{llllll}0.00 \mathrm{E}+00 & 0.00 \mathrm{E}+00 & 0.00 \mathrm{E}+00 & 0.00 \mathrm{E}+00 & 0.00 \mathrm{E}+00\end{array}$ $0.00 E+\infty 0 \quad 0.00 E+\infty 0 \quad 0.00 E+\infty 0 \quad 0.00 E+00 \quad 0.00 E+00$ $0.00 \mathrm{E}+00 \quad 0.00 \mathrm{E}+\infty 0 \quad 0.00 \mathrm{E}+00 \quad 0.00 \mathrm{E}+00 \quad 0.00 \mathrm{E}+00$ $0.00 \mathrm{E}+\infty 0 \quad 0.00 \mathrm{E}+00 \quad 0.00 \mathrm{E}+\infty 00.00 \mathrm{E}+00 \quad 0.00 \mathrm{E}+\infty 0$ $\begin{array}{llllll}0.00 E+00 & 0.00 E+00 & 0.00 E+00 & 0.00 E+00 & 0.00 E+\infty 0\end{array}$ $\begin{array}{llllll}0.00 E+00 & 0.00 E+\infty 0 & 0.00 E+00 & 0.00 E+00 & 0.00 E+00\end{array}$ $\begin{array}{llllll}0.00 E+\infty 0 & 0.00 E+\infty & 0.00 E+\infty & 0.00 E+\infty 0 & 0.00 E+\infty 0\end{array}$ $0.00 E+\infty 0 \quad 0.00 E+\infty 0 \quad 0.00 E+\infty 00000+00 \quad 000 E+\infty 0$ $\begin{array}{lllllll}0.00 \mathrm{E}+\infty 0 & 0.00 \mathrm{E}+00 & 0.00 \mathrm{E}+\infty 0 & 0.00 \mathrm{E}+00 & 0.00 \mathrm{E}+00\end{array}$ $000 \mathrm{E}+\infty 0 \quad 000 \mathrm{E}+\infty 0000 \mathrm{E}+\infty 0 \quad 000 \mathrm{E}+00 \quad 000 \mathrm{E}+00$ $\begin{array}{lllll}0.00 E+00 & 0.00 E+00 & 0.00 E+00 & 0.00 E+00 & 0.00 E+00\end{array}$ 
INDENO_I NNDNPA PENTACHL VINYL_CH

$\begin{array}{llll}0.00 \mathrm{E}+00 & 0.00 \mathrm{E}+00 & 0.00 \mathrm{E}+00 & 0.00 \mathrm{E}+00\end{array}$

$\begin{array}{llll}0.00 E+\infty 0 & 0.00 E+00 & 0.00 E+\infty 0 & 0.00 E+00\end{array}$

$\begin{array}{llll}0.00 \mathrm{E}+\infty 0 & 0.00 \mathrm{E}+00 & 0.00 \mathrm{E}+00 & 0.00 \mathrm{E}+00\end{array}$

$0.00 E+\infty 0 \quad 0.00 E+\infty 0 \quad 0.00 E+\infty \quad 0.00 E+\infty 0$

$0.00 \mathrm{E}+00 \quad 0.00 \mathrm{E}+00 \quad 2.50 \mathrm{E}-040.00 \mathrm{E}+00$

\begin{tabular}{lllll}
$0.00 \mathrm{E}+00$ & $0.00 \mathrm{E}+00$ & $0.00 \mathrm{E}+00$ & $\mathbf{7 . 0 8 E}-0.4$ \\
\hline
\end{tabular}

$0.00 E+00 \quad 0.00 E+00 \quad 000 E+00 \quad 0.00 E+00$

$\begin{array}{llll}0.00 E+00 & 0.00 E+00 & 0.00 E+00 & 0.00 E+\infty 0\end{array}$

$0.00 \mathrm{E}+\infty 0000 \mathrm{E}+\infty 00 \quad 0.00 \mathrm{E}+\infty 0 \quad 000 \mathrm{E}+00$

$0.00 E+\infty 0000 E+\infty 000.00 E+\infty \quad 0.00 E+\infty 0$

$0.00 \mathrm{E}+00 \quad 0.00 \mathrm{E}+\infty 0 \quad 0.00 \mathrm{E}+00 \quad 0.00 \mathrm{E}+\infty 0$

$0.00 \mathrm{E}+00 \quad 0.00 \mathrm{E}+\infty \quad 0.00 \mathrm{E}+00 \quad 0.00 \mathrm{E}+00$

$0.00 \mathrm{E}+00 \quad 0.00 \mathrm{E}+00 \quad 0.00 \mathrm{E}+00 \quad 0.00 \mathrm{E}+00$

$0.00 \mathrm{E}+00 \quad 0.00 \mathrm{E}+00 \quad 0.00 \mathrm{E}+00 \quad 0.00 \mathrm{E}+00$

$0.00 \mathrm{E}+00 \quad 0.00 \mathrm{E}+00 \quad 0.00 \mathrm{E}+00 \quad 0.00 \mathrm{E}+00$

$\begin{array}{llll}0.00 \mathrm{E}+00 & 0.00 \mathrm{E}+00 & 0.00 \mathrm{E}+00 & 0.00 \mathrm{E}+00\end{array}$

$0.00 \mathrm{E}+00 \quad 0.00 \mathrm{E}+00 \quad 0.00 \mathrm{E}+00 \quad 0.00 \mathrm{E}+00$

$0.00 \mathrm{E}+00 \quad 0.00 \mathrm{E}+00 \quad 0.00 \mathrm{E}+00 \quad 0.00 \mathrm{E}+00$

$0.00 \mathrm{E}+00 \quad 0.00 \mathrm{E}+00 \quad 0.00 \mathrm{E}+00 \quad 0.00 \mathrm{E}+00$

$0.00 E+00 \quad 0.00 E+00 \quad 0.00 E+\infty 00 \quad 0.00 E+\infty 0$

$0.00 \mathrm{E}+00 \quad 0.00 \mathrm{E}+00 \quad 0.00 \mathrm{E}+00 \quad 0.00 \mathrm{E}+00$

$\begin{array}{llll}0.00 \mathrm{E}+00 & 0.00 \mathrm{E}+00 & 0.00 \mathrm{E}+00 & 0.00 \mathrm{E}+00\end{array}$

$0.00 \mathrm{E}+00 \quad 000 \mathrm{E}+00 \quad 0.00 \mathrm{E}+00 \quad 0.00 \mathrm{E}+00$

$0.00 \mathrm{E}+00 \quad 0.00 \mathrm{E}+00 \quad 0.00 \mathrm{E}+\infty 0 \quad 0.00 \mathrm{E}+\infty 0$

$0.00 \mathrm{E}+00 \quad 0.00 \mathrm{E}+00 \quad 0.00 \mathrm{E}+00 \quad 0.00 \mathrm{E}+00$

$\begin{array}{llll}0.00 \mathrm{E}+00 & 0.00 \mathrm{E}+00 & 0.00 \mathrm{E}+00 & 0.00 \mathrm{E}+00\end{array}$

$0.00 E+00 \quad 0.00 E+00 \quad 0.00 E+\infty 0 \quad 0.00 E+00$

$0.00 \mathrm{E}+00 \quad 0.00 \mathrm{E}+00 \quad 0.00 \mathrm{E}+00 \quad 0.00 \mathrm{E}+00$

$0.00 E+00 \quad 000 E+00 \quad 000 E+00 \quad 0.00 E+00$

$0.00 \mathrm{E}+00 \quad 0.00 \mathrm{E}+00 \quad 0.00 \mathrm{E}+00 \quad 0.00 \mathrm{E}+00$

$\begin{array}{llll}0.00 \mathrm{E}+00 & 0.00 \mathrm{E}+00 & 0.00 \mathrm{E}+00 & 0.00 \mathrm{E}+00\end{array}$

$0.00 E+00 \quad 0.00 E+00 \quad 0.00 E+00 \quad 0.00 E+00$

$000 \mathrm{E}+00 \quad 000 \mathrm{E}+00 \quad 000 \mathrm{E}+00 \quad 000 \mathrm{E}+00$

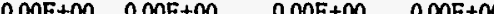

$0.00 E+\infty 0 \quad 0.00 E+00 \quad 000 E+00 \quad 0.00 E+00$

$0.00 E+00 \quad 000 E+00 \quad 000 E+\infty 0 \quad 000 E+00$

$000 \mathrm{E}+00 \quad 000 \mathrm{E}+00 \quad 000 \mathrm{E}+\infty 0 \quad 000 \mathrm{E}+\infty 0$

$0.00 E+00 \quad 0.00 E+00 \quad 000 E+00 \quad 0.00 E+00$

$0.00 \mathrm{E}+00 \quad 0.00 \mathrm{E}+\infty 00 \quad 0.00 \mathrm{E}+00 \quad 0.00 \mathrm{E}+\infty 0$

$0.00 E+00 \quad 0.00 E+\infty 00 \quad 0.00 E+\infty 00 \quad 000 E+00$

$000 \mathrm{E}+00 \quad 000 \mathrm{E}+\infty 0 \quad 000 \mathrm{E}+\infty 0 \quad 000 \mathrm{E}+\infty 0$

$0.00 E+00 \quad 0.00 E+\infty 0 \quad 000 E+00 \quad 000 E+\infty 0$

$0,00 E+\infty 0 \quad 0,00 E+\infty 0 \quad 0,00 E+00 \quad 0,00 E+\infty 0$

$000 E+00 \quad 0.00 E+00 \quad 0,00 E+00 \quad 0.00 E+00$

DOEE $0.00 E+00$ OODE

$000 \mathrm{E}+00 \quad 0.00 \mathrm{E}+\infty 0 \quad 000 \mathrm{E}+\infty 0 \quad 000 \mathrm{E}+00$

$\begin{array}{llll}0.00 E+\infty 0 & 0.00 E+\infty 0 & 000 E+\infty 0 & 0.00 E+\infty \\ 0.00 E+\infty 0 & 0.00 E+\infty 0 & 0.00 E+\infty 0 & 0.00 E+\infty 0\end{array}$

TRI123 DI2CHL3 DBE12 DIOXAN14 PROPENE2 _3_3_DI Total_Rsk WAG

WELL

7.15E-05 1 253

2.09E-04 1 -04 1

$1.42 E-04 \quad 1 \quad 4004$

2.12E-01 $1 \quad 4005$

\begin{tabular}{lll}
\hline 8.67E-04 & 1 \\
\hline $3.09 E-04$ & 4006
\end{tabular}

4009

$3.96 \mathrm{E}-05 \quad 2 \quad 1151$

$\begin{array}{lll}3.57 E-04 & 2 & 1152 \\ 2.61 E-05 & 2 & 1153\end{array}$

1153

1154

$\begin{array}{rrr}1.64 E-05 & 2 & 1155 \\ 3.17 E-04 & 2 & 1156\end{array}$

$\begin{array}{lll}1.81 \mathrm{E}-05 & 2 & 1185\end{array}$

$\begin{array}{lll}1.65 E-05 & 2 & 1186\end{array}$

$2040-1188$

$\begin{array}{lll}3.38 E-05 & 2 & 1189\end{array}$

7.16E-04 2

$8.87 E-04$
$3.69 E-05$ $2 \quad 119$

1192

$\begin{array}{lll}2 & 1193\end{array}$

1.49E-04 2

\begin{tabular}{lll}
$1.24 E-04$ & 2 & 1195 \\
\hline $1.82 E-04$ & 2 & 1244
\end{tabular}

$\begin{array}{lll}2.49 \mathrm{E}-05 & 3 & 985\end{array}$

1.31E-04 $3 \quad 986$

$\begin{array}{lll}2.61 \mathrm{E} .05 & 3 & 987 \\ 5.50 E-06 & 3 & 988\end{array}$

$1.95 E-05 \quad 3$

1.5TE-05 $3 \quad 991$

2.44E-04 3

\begin{tabular}{rl}
\hline $1.64 E-04$ & 993
\end{tabular}

3994

$1.12 E-05 \quad 3 \quad 995$

$\begin{array}{lll}7.53 E-06 & 3 & 996 \\ 8.91 E-05 & 3 & 997\end{array}$

1.49E-05 $3 \quad 998$

$\begin{array}{lll}1.56 E-04 & 3 & 1248\end{array}$

$\begin{array}{lll}5.69 \mathrm{E}-06 & 4 & 948\end{array}$

SOTE-OS $4 \quad 949$

$\begin{array}{lll}110 \mathrm{E}-05 & 4 & 950 \\ 146 \mathrm{E}-05 & 4 & 951\end{array}$ 
BE B2CEE TETI122 DCEEII METHYLI METHYL 2

$\begin{array}{lllllllll}954 & 0.00 E+\infty & 0.00 E+\infty 0 & 0.00 E+\infty & 2.72 E-04 & 0.00 E+\infty & 0.00 E+\infty 0 & 0.00 E+\infty\end{array}$

$\begin{array}{lllllllll}955 & 0.00 E+\infty 0 & 0.00 E+\infty 0 & 0.00 E+00 & 0.00 E+\infty 0 & 0.00 E+\infty 0 & 0.00 E+\infty 0 & 0.00 E+\infty\end{array}$

$0.00 \mathrm{E}+\infty 00.00 \mathrm{E}+\infty 00000$

$\begin{array}{rr}0.00 \mathrm{E}+\infty 0 & 0.00 \mathrm{E}+\infty \\ 0.00 \mathrm{E}+\infty & 1.26 \mathrm{E}-06\end{array}$

$\begin{array}{rrr}0.00 E+\infty 0 & 0.00 E+\infty 0 & 1.26 E-06 \\ 0.00 E+\infty 0 & 0.00 E+\infty 0 & 0.00 E+\infty\end{array}$

$0.00 E+\infty 0 \quad 0.00 E+\infty 0 \quad 0.00 E+\infty 0$

$\begin{array}{lllllllll}956 & 0.00 \mathrm{E}+00 & 0.00 \mathrm{E}+00 & 0.00 \mathrm{E}+00 & 0.00 \mathrm{E}+00 & 0.00 \mathrm{E}+00 & 0.00 \mathrm{E}+00 & 0.00 \mathrm{E}+00\end{array}$

$0.00 \mathrm{E}+\infty$

$\begin{array}{lllllllll}957 & 0.00 \mathrm{E}+00 & 0.00 \mathrm{E}+00 & 0.00 \mathrm{E}+00 & 0.00 \mathrm{E}+00 & 0.00 \mathrm{E}+00 & 0.00 \mathrm{E}+00 & 0.00 \mathrm{E}+00\end{array}$

$\begin{array}{lll}0.00 E+\infty 0 & 0.00 E+00 & 0.00 E+\infty 0\end{array}$

$\begin{array}{lllllllllll}958 & 0.00 \mathrm{E}+\infty & 0.00 \mathrm{E}+00 & 0.00 \mathrm{E}+00 & 2.26 \mathrm{E}-0.4 & 0.00 \mathrm{E}+00 & 0.00 \mathrm{E}+00 & 0.00 \mathrm{E}+00\end{array}$

$000 \mathrm{E}+\infty 0 \quad 0.00 \mathrm{E}+\infty 0 \quad 1.26 \mathrm{E}-06$

$0.00 \mathrm{E}+00 \quad 0.00 \mathrm{E}+00 \quad 0.00 \mathrm{E}+00$

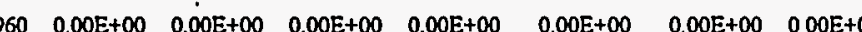

$0.00 \mathrm{E}+00 \quad 0.00 \mathrm{E}+00 \quad 0.00 \mathrm{E}+00$

$9610.00 \mathrm{E}+00 \quad 0.00 \mathrm{E}+00 \quad 0.00 \mathrm{E}+00 \quad 0.00 \mathrm{E}+\infty \quad 0000 \mathrm{E}+\infty \quad 0.00 \mathrm{E}+\infty 000.00 \mathrm{E}+00$

$0.00 \mathrm{E}+00 \quad 0.00 \mathrm{E}+00 \quad 0.00 \mathrm{E}+\infty 0$

$\begin{array}{llllllll}962 & 0.00 E+\infty 0 & 0.00 E+\infty 0 & 0.00 E+\infty & 0.00 E+\infty 0 & 0.00 E+\infty 0 & 0.00 E+00 & 0.00 E+\infty\end{array}$

$\begin{array}{lll}0.00 \mathrm{E}+\infty & 0.00 \mathrm{E}+\infty & 0.00 \mathrm{E}+\infty\end{array}$

$\begin{array}{lll}0.00 \mathrm{E}+\infty & 0.00 \mathrm{E}+\infty\end{array}$

$441 \frac{0.00 E+00}{2.002}+0.00 E+00$

$000 E+\infty$

$000 E+\infty 0$

$\begin{array}{llll}468 & 1.63 E-04 & \cdot & \cdot \\ 472 & 2.34 E-04 & \cdot & 0.00 E+00 \\ 476 & 1.03 E-04 & 0.00 E+00\end{array}$

$476 \frac{1.83 E-04}{1} \quad 000 E+00$

$0.00 E+00$

$\begin{array}{rrll}514 & 0.00 \mathrm{E}+00 & . & 000 \mathrm{E}+00 \\ 516 & 7.42 \mathrm{E}-05 & . & 000 \mathrm{E}+00\end{array}$

$000 \mathrm{E}+00$

$000 \mathrm{E}+00$

- $0.00 \mathrm{E}+\infty 0$

517

518

519

520

521

522

523

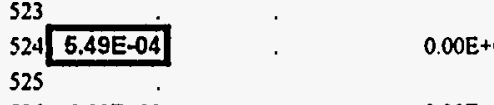

$526 \quad 000 \mathrm{E}+00 \quad 0.00 \mathrm{E}+00$

$0.00 \mathrm{E}+00$

$546 \mathrm{E}-06$

BENZAPYR CARBON T DIBENZ A HCBE $\begin{array}{lllll}0.00 E+\infty 0 & 0.00 E+\infty 0 & 0.00 E+\infty 0 & 0.00 E+\infty 0 & 0.00 E+\infty\end{array}$ $\begin{array}{llllll}0.00 \mathrm{E}+\infty 0 & 0.00 \mathrm{E}+\infty & 0.00 \mathrm{E}+\infty & 0.00 \mathrm{E}+\infty & 0.00 \mathrm{E}+\infty\end{array}$ $\begin{array}{llllll}0.00 E+\infty 0 & 0.00 E+\infty 0 & 0.00 E+\infty 0 & 0.00 E+\infty & 0.00 E+\infty 0\end{array}$ $0.00 E+00 \quad 0.00 E+00 \quad 0.00 E+00 \quad 0.00 E+00 \quad 0.00 E+\infty 0$ $\begin{array}{llllll}0.00 E+00 & 0.00 E+00 & 0.00 E+\infty 0 & 0.00 E+00 & 0.00 E+00\end{array}$ $\begin{array}{llllll}0.00 \mathrm{E}+00 & 0.00 \mathrm{E}+\infty 0 & 0.00 \mathrm{E}+00 & 0.00 \mathrm{E}+\infty & 0.00 \mathrm{E}+\infty\end{array}$ $\begin{array}{lllllll}0.00 \mathrm{E}+00 & 0.00 \mathrm{E}+00 & 0.00 \mathrm{E}+\infty & 0.00 \mathrm{E}+\infty & 0.00 \mathrm{E}+\infty\end{array}$ $\begin{array}{llllll}0.00 \mathrm{E}+00 & 0.00 \mathrm{E}+00 & 0.00 \mathrm{E}+00 & 0.00 \mathrm{E}+00 & 0.00 \mathrm{E}+00\end{array}$ $\begin{array}{lllllll}0.00 \mathrm{E}+00 & 0.00 \mathrm{E}+00 & 0.00 \mathrm{E}+\infty 0 & 0.00 \mathrm{E}+\infty 0 & 0.00 \mathrm{E}+\infty\end{array}$ $\begin{array}{lllllll}0.00 \mathrm{E}+\infty & 0.00 \mathrm{E}+\infty & 0.00 \mathrm{E}+\infty 0 & 0.00 \mathrm{E}+\infty & 0.00 \mathrm{E}+\infty\end{array}$ $0.00 \mathrm{E}+\infty$

$0.00 \mathrm{E}+00$

$0.00 \mathrm{E}+00$

$0.00 \mathrm{E}+00$

$0.00 \mathrm{E}+00$

$0.00 \mathrm{E}+00$

$0.00 \mathrm{E}+00$

$7 1 6 \longdiv { 1 . 3 2 E - 0 4 } \quad$. $\quad 0.00 E+\infty 0$

$\begin{array}{llllllllll}963 & 3.25 \mathrm{E}-05 & 0.00 \mathrm{E}+00 & 0.00 \mathrm{E}+00 & 0.00 \mathrm{E}+00 & 0.00 \mathrm{E}+00 & 0.00 \mathrm{E}+00 & 0.00 \mathrm{E}+00 & 0.00 \mathrm{E}+00 & 0.00 \mathrm{E}+\infty 0\end{array}$ $\begin{array}{lllllllllll}964 & 0.00 \mathrm{E}+00 & 0.00 \mathrm{E}+00 & 0.00 \mathrm{E}+00 & 0.00 \mathrm{E}+00 & 0.00 \mathrm{E}+00 & 0.00 \mathrm{E}+00 & 0.00 \mathrm{E}+00 & 0.00 \mathrm{E}+00 & 593 \mathrm{E}-06\end{array}$ $\begin{array}{lllllllllll}965 & 0.00 \mathrm{E}+00 & 0.00 \mathrm{E}+00 & 0.00 \mathrm{E}+00 & 0.00 \mathrm{E}+00 & 0.00 \mathrm{E}+00 & 0.00 \mathrm{E}+00 & 0.00 \mathrm{E}+00 & 0.00 \mathrm{E}+00 & 1 \text { 9IE } 05\end{array}$ $\begin{array}{llllllllll}966 & 0.00 \mathrm{E}+00 & 0.00 \mathrm{E}+00 & 0.00 \mathrm{E}+00 & 0.00 \mathrm{E}+00 & 0.00 \mathrm{E}+00 & 0.00 \mathrm{E}+00 & 0.00 \mathrm{E}+00 & 0.00 \mathrm{E}+\infty 0 & 0.00 \mathrm{E}+00\end{array}$ $\begin{array}{llllllllll}967 & 0.00 \mathrm{E}+00 & 0.00 \mathrm{E}+00 & 0.00 \mathrm{E}+00 & 0.00 \mathrm{E}+00 & 0.00 \mathrm{E}+00 & 0.00 \mathrm{E}+00 & 0.00 \mathrm{E}+00 & 0.00 \mathrm{E}+00 & 0.00 \mathrm{E}+00\end{array}$ $\begin{array}{llllllllll}968 & 0.00 \mathrm{E}+00 & 0.00 \mathrm{E}+00 & 0.00 \mathrm{E}+00 & 0.00 \mathrm{E}+00 & 0.00 \mathrm{E}+00 & 0.00 \mathrm{E}+00 & 0.00 \mathrm{E}+00 & 0.00 \mathrm{E}+00 & 0.00 \mathrm{E}+00\end{array}$ $\begin{array}{lllllllllll}969 & 0.00 \mathrm{E}+00 & 0.00 \mathrm{E}+00 & 0.00 \mathrm{E}+00 & 0.00 \mathrm{E}+00 & 0.00 \mathrm{E}+00 & 0.00 \mathrm{E}+00 & 0.00 \mathrm{E}+0 & 0.00 \mathrm{E}+00 & 341 \mathrm{E}-06\end{array}$ $\begin{array}{llllllllll}970 & 0.00 \mathrm{E}+00 & 0.00 \mathrm{E}+00 & 0.00 \mathrm{E}+00 & 0.00 \mathrm{E}+00 & 0.00 \mathrm{E}+00 & 0.00 \mathrm{E}+00 & 0.00 \mathrm{E}+00 & 0.00 \mathrm{E}+00 & 0.00 \mathrm{E}+00\end{array}$

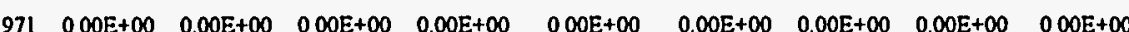
$\begin{array}{llllllllll}972 & 0.00 \mathrm{E}+00 & 0.00 \mathrm{E}+\infty 0 & 0.00 \mathrm{E}+00 & 0.00 \mathrm{E}+00 & 0.00 \mathrm{E}+00 & 0.00 \mathrm{E}+00 & 0.00 \mathrm{E}+00 & 0.00 \mathrm{E}+00 & 0.00 \mathrm{E}+00\end{array}$ $\begin{array}{lllllllllll}973 & 0.00 E+00 & 0.00 E+00 & 0.00 E+\infty & 0.00 E+00 & 0.00 E+00 & 0.00 E+00 & 0.00 E+00 & 0.00 E+00 & 0.00 E+00\end{array}$ $\begin{array}{lllllllllll}974 & 0.00 E+00 & 0.00 E+00 & 0.00 E+00 & 0.00 E+00 & 0.00 E+00 & 0.00 E+00 & 0.00 E+00 & 0.00 E+00 & 0.00 E+00\end{array}$ $\begin{array}{llllllllll}975 & 0.00 \mathrm{E}+00 & 4.66 \mathrm{E}-05 & 0.00 \mathrm{E}+\infty & 0.00 \mathrm{E}+00 & 0.00 \mathrm{E}+00 & 0.00 \mathrm{E}+\infty 0 & 0.00 \mathrm{E}+00 & 0.00 \mathrm{E}+\infty & 0.00 \mathrm{E}+\infty\end{array}$ $\begin{array}{llllllllll}976 & 0.00 E+\infty 0 & 0.00 E+\infty 0 & 0.00 E+\infty 0 & 0.00 E+\infty 0 & 0.00 E+\infty & 0.00 E+\infty 0 & 0.00 E+\infty & 0.00 E+\infty & 0.00 E+\infty 0\end{array}$ $977 \quad 0.00 E+00 \quad 0.00 E+00 \quad 0.00 E+00 \quad 0.00 E+00 \quad 0.00 E+00 \quad 0.00 E+\infty 0 \quad 0.00 E+00 \quad 000 E+00 \quad 1.06 E-03$
$0.00 \mathrm{E}+00$

$1.26 \mathrm{E}-06$

$0.00 E+00$ $0.00 \mathrm{E}+00$

$0.00 E+00$

$0.00 \mathrm{E}+\infty 0$

$0.00 \mathrm{E}+00 \quad 0.00 \mathrm{E}+00$ $0.00 E+00 \quad 0.00 E+00$ $0.00 \mathrm{E}+\infty 00.00 \mathrm{E}+00$ $0.00 \mathrm{E}+\infty 00 \quad 0.00 \mathrm{E}+\infty$ $0.00 E+00 \quad 0.00 E+00$ $0.00 \mathrm{E}+\infty \quad 0.00 \mathrm{E}+\infty$ $0.00 \mathrm{E}+00 \quad 0.00 \mathrm{E}+\infty 0$

$0.00 \mathrm{E}+00 \quad 0.00 \mathrm{E}+00$ $0.00 E+00 \quad 0.00 E+\infty 0$ $0.00 \mathrm{E}+00 \quad 0.00 \mathrm{E}+\infty 0$ $0.00 \mathrm{E}+00 \quad 6.32 \mathrm{E}-07$

$0.00 \mathrm{E}+00 \quad 0.00 \mathrm{E}+00$ $0.00 \mathrm{E}+00 \quad 6.32 \mathrm{E}-07$ $000 \mathrm{E}+00 \quad 000 \mathrm{E}+00$ $0.00 \mathrm{E}+00 \quad 000 \mathrm{E}+\infty 0$
$0.00 \mathrm{E}+00$ $0.00 \mathrm{E}+00$ $0.00 \mathrm{E}+00$ $0.00 E+00$ $0.00 E+\infty 0$ $000 \mathrm{E}+00$ $000 \mathrm{E}+00$

$0.00 E+00$ $0.00 \mathrm{E}+\infty 0$ $0.00 \mathrm{E}+00$ $0.00 \mathrm{E}+00$

$000 \mathrm{E}+00$

$000 E+\infty$

$000 \mathrm{E}+\infty 0$

$000 E+\infty 0$

.




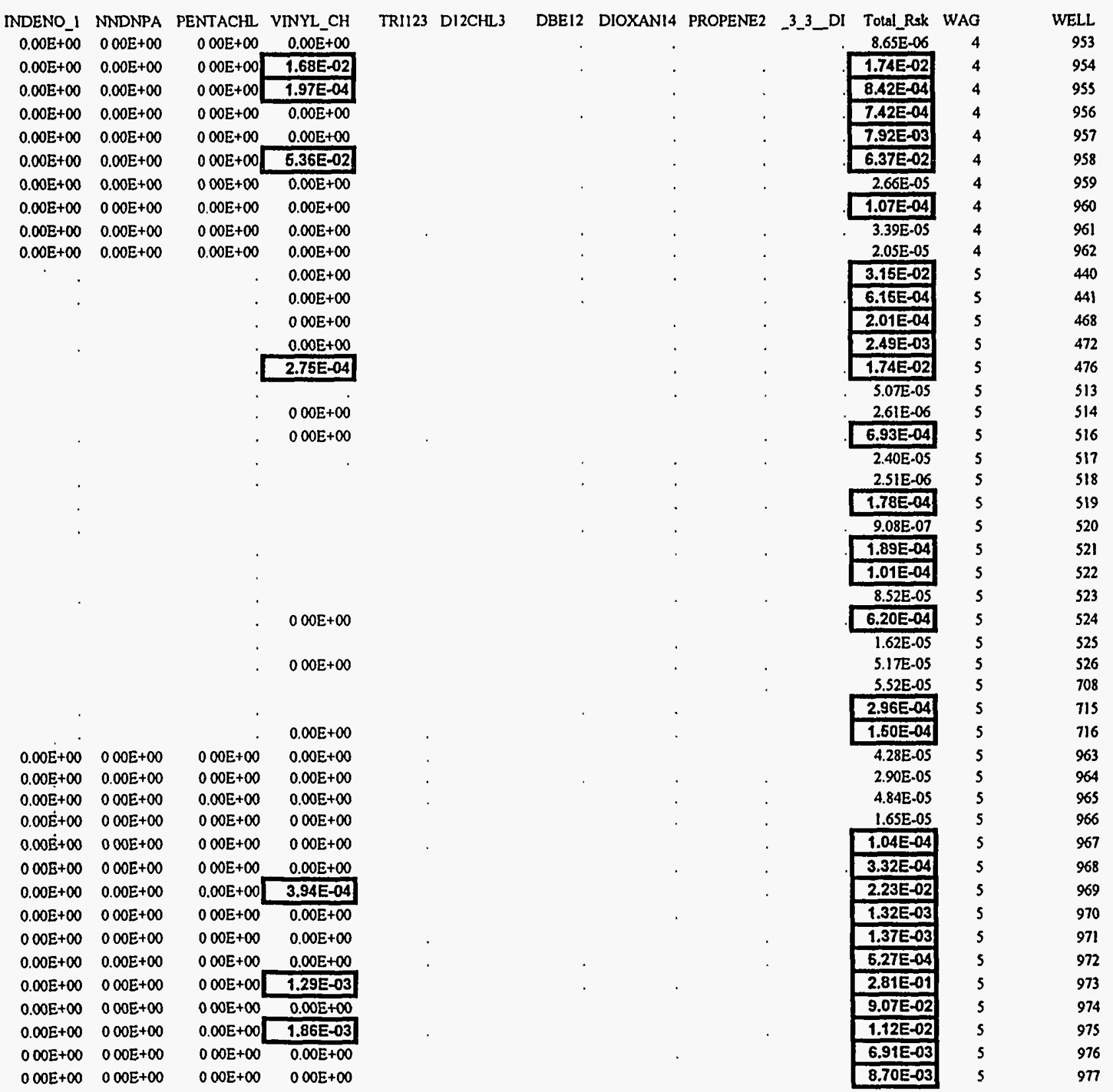


BE B2CEE TETI122

DCEEII METHYLI METHYL

DIC33 PCB1254 BIS_2

BENZBFLU BENZENE BE

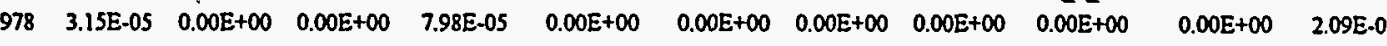
$\begin{array}{llllllllllll}979 & 0.00 E+00 & 0.00 E+00 & 0.00 E+\infty & 0.00 E+00 & 0.00 E+\infty & 0.00 E+00 & 0.00 E+\infty 0 & 0.00 E+\infty & 0.00 E+\infty\end{array}$

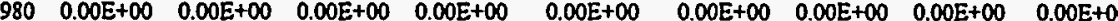

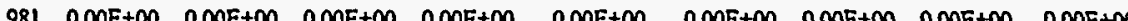

$0.00 E+00 \quad 6.32 E-07$

$0.00 \mathrm{E}+00 \quad 0.00 \mathrm{E}+00$

$\begin{array}{ll}0.00 E+00 & 0.00 E+00 \\ 0.00 E+00 & 0.00 E+00\end{array}$

BENZAANT BENZAPYR CARBON_T DIBENZ_A HCBE $0.00 \mathrm{E}+00 \quad 0.00 \mathrm{E}+\infty 0$

$0.00 \mathrm{E}+00$

$0.00 \mathrm{E}+\infty$

$0.00 E+\infty 0 \quad 0.00 E+\infty \quad 0.00 E+\infty$

$\begin{array}{lllllllllll}982 & 0.00 E+\infty 0 & 0.00 E+\infty & 0.00 E+\infty 0 & 0.00 E+00 & 0.00 E+\infty 0 & 0.00 E+\infty 0 & 0.00 E+\infty & 0.00 E+\infty & 3.41 E-06\end{array}$

$0.00 E+00$

$0.00 \mathrm{E}+00$

$0.00 E+\infty 0$

$0.00 \mathrm{E}+00$

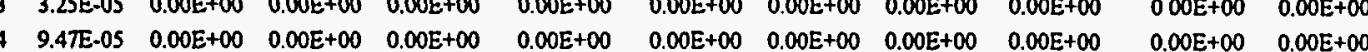

$0.00 E+\infty 0000+00$

$0.005+\infty$

$0.00 E+\infty$

$0.00 \mathrm{E}+00$

$0.00 \mathrm{E}+\infty 0 \quad 0.00 \mathrm{E}+\infty 00.00 \mathrm{E}+\infty 0$

$0.00 \mathrm{E}+00 \quad 0.00 \mathrm{E}+00 \quad 0.00 \mathrm{E}+\infty$

$1106 \quad 0.00 \mathrm{E}+00$

$0.00 \mathrm{E}+00$

$0.00 \mathrm{E}+00$

$0.00 E+00$

1107

1108

$4 1 1 3 \longdiv { 6 . 3 0 E - 0 4 }$

$41141.93 E-04$

$0.00 \mathrm{E}+00$

$\begin{array}{ll}4115 & 1.32 E-04 \\ 4116 & 7.42 \mathrm{E}-05\end{array}$

$0.00 E+00$

$0.00 \mathrm{E}+00$

$0.00 \mathrm{E}+00$

4173

$1.02 \mathrm{E}-05$

$0.00 E+00$

$0.00 \mathrm{E}+\infty$

4174

4175

4176

417

4178

4179
4179

4180

4180
4185

4188

4189

4190

4191

4193

4195

4199

4201

4202

4204

4205

4206

4208

4211

4212

4213 


\begin{tabular}{|c|c|c|c|c|c|c|c|c|c|c|c|c|}
\hline $\begin{array}{r}\text { INDENO_I } \\
0.00 E+\infty 0\end{array}$ & $\begin{array}{r}\text { NNDNPA } \\
000 E+\infty 0\end{array}$ & $\begin{array}{l}\text { PENTACHL } \\
000 \mathrm{E}+\infty 01\end{array}$ & $\frac{\text { VINYL_CH }}{1.95 E-01}$ & TRI123 & DI2CHL3 & DBE12 & DIOXANI4 & PROPENE2 & $-^{3}{ }^{3}-\mathrm{DI}$ & $\frac{\text { Total Rsk }}{1,96 E-01}$ & $\begin{array}{r}\text { WAG } \\
5\end{array}$ & $\begin{array}{r}\text { WELL } \\
978\end{array}$ \\
\hline & $000 \mathrm{E}+00$ & & & & & & · & & & & & 978 \\
\hline $0.00 E+\infty 0$ & $0.00 E+\infty$ & $000 E+00$ & $000 \mathrm{E}+00$ & & & & . & & & $7.14 \mathrm{E}-05$ & 5 & 979 \\
\hline $0.00 \mathrm{E}+00$ & $000 \mathrm{E}+00$ & $000 \mathrm{E}+00$ & $0.00 \mathrm{E}+00$ & r & . & & . & & & 2.15E-05 & $s$ & 980 \\
\hline $0.00 E+00$ & $0.00 E+00$ & $000 E+00$ & $3.15 E-04$ & & . & & . & . & & 1.69E-03 & 5 & 981 \\
\hline $0.00 E+00$ & $0.00 E+00$ & $000 E+00$ & $0.00 \mathrm{E}+\infty$ & 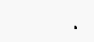 & . & & . & . & & $9.33 \mathrm{E}-05$ & 5 & 982 \\
\hline $0.00 \mathrm{E}+\infty$ & $0.00 \mathrm{E}+00$ & $000 E+00$ & $000 E+\infty 0$ & & ' & & . & . & & $8.46 \mathrm{E}-05$ & 5 & 983 \\
\hline \multirow[t]{39}{*}{$0.00 \mathrm{E}+00$} & $0.00 E+\infty 0$ & $000 E+00$ & $0.00 E+\infty$ & . & & & & . & & 1.19E-04 & 5 & 984 \\
\hline & . & & & $\cdot$ & & & . & . & & $2.38 E-03$ & 5 & 1105 \\
\hline & . & & $0.00 E+00$ & . & . & & . & . & & $2.12 E-03$ & 5 & 1106 \\
\hline & . & & & . & & & . & . & & $5.28 E-03$ & 5 & 1107 \\
\hline & & & & . & t & & . & . & & 3.31E-02 & 5 & 1108 \\
\hline & & & $0.00 E+\infty 0$ & . & . & & . & . & & 8.29E-04 & 5 & 4113 \\
\hline & & & 6.51E-04 & . & & & . & . & & $1.06 E-01$ & 5 & 4114 \\
\hline & & & $000 \mathrm{E}+00$ & . & : & & . & & & $2.70 E-03$ & 5 & 4115 \\
\hline & & & $000 E+00$ & . & . & & . & . & & $4.05 E-04$ & 5 & 4116 \\
\hline & & & & . & & & & . & & 9.83E-01 & 5 & 4173 \\
\hline & & & & & & & . & • & & $7.83 \mathrm{E}-01$ & 5 & 4174 \\
\hline & & & & 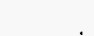 & & & . & & & $1.00 E+00$ & 5 & 4175 \\
\hline & & & & . & & & . & & & $6.84 E-02$ & 5 & 4176 \\
\hline & & & & . & & & . & . & & $3.12 E-02$ & 5 & 4177 \\
\hline & & & & & & & . & & & $2.32 E-01$ & 5 & 4178 \\
\hline & . & & & & " & & . & . & & $1.00 \mathrm{E}+00$ & 5 & 4179 \\
\hline & & & & . & & & . & . & & $1.00 E+00$ & 5 & 4179 \\
\hline & & & & & r & & . & . & & 1.19E-01 & 5 & 4180 \\
\hline & & & & . & & & & . & & 1.17E-01 & 5 & 4185 \\
\hline & & & & & & & & & & 1.11E-01 & 5 & 4188 \\
\hline & & & & & & & . & & & 2.17E-03 & 5 & 4189 \\
\hline & & & & , & & & . & & & $8.32 E-02$ & 5 & 4190 \\
\hline & & & & • & & & . & & & 2.95E-01 & 5 & 4191 \\
\hline & & & & 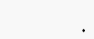 & & & & & & $4.35 E-01$ & 5 & 4193 \\
\hline & & & & & & & . & & & 5.12E-01 & 5 & 4195 \\
\hline & & & & & & & . & & & $2.57 E-01$ & 5 & 4198 \\
\hline & & & & . & & & & . & & 1.67E-01 & 5 & 4199 \\
\hline & & . & & - & & & . & . & & $3.67 E-01$ & 5 & 4201 \\
\hline & & & & & & & . & . & & $2.45 E-01$ & 5 & 4202 \\
\hline & . & . & & . & & & . & - & & $1.58 \mathrm{E}-01$ & 5 & 4203 \\
\hline & & & & " & & & & . & & $3.47 E-01$ & 5 & 4204 \\
\hline & & & & • & & & & . & & $7.01 E-02$ & 5 & 4205 \\
\hline & . & & & . & . & & . & . & & $7.35 \mathrm{E}-01$ & 5 & 4206 \\
\hline & & & & व & $\therefore$ & & & & & $9.71 E-01$ & 5 & 4207 \\
\hline & & & & . & & & 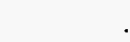 & & & $4.78 E-01$ & 5 & 4208 \\
\hline & & & & & & & . & & & $1.95 \mathrm{E}-01$ & 5 & 4209 \\
\hline & & & & & & & . & . & & $1.00 E+00$ & 5 & 4211 \\
\hline & & & & & & & . & 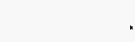 & & 1.98E-01 & 5 & 4212 \\
\hline & & & & & & & & & & $613 \mathrm{E}-05$ & 5 & 4213 \\
\hline
\end{tabular}


WAG WELL

4214

4216

4218

4219

4221

4224

4225

4226

4227

4228

4230

4231

4233

4235

4238

4239

4240

4241

4242

4243

424

4245

4246

4247

4248

4249

4250

4251

4252

4253

425

4255

4256

4257

4258

4259

4260

4261

4262

4263

4264

4265

4266

4267

4268
DIC33 PCB1254 BIS_2_ET BENZBFLU BENZENE BENZAANT BENZAPYR CARBON_T DIBENZ_A

HCBE 

WAG WELL BE B2CEE TETI122 DCEEII METHYLI METHYL2 DIC33 PCB1254 BIS_2_ET BENZBFLU BENZENE BENZAANT BENZAPYR CARBON_T DIBENZ_A HCBE

4270

4271

4272

4273

4274

4275

4276
4277

4278

4281

4282

4283

4284

4285

4286
4287

4289

4290

429

4294

4296

4297

4298
4299

4300

4307

$745 \quad 4.06 \mathrm{E}-04 \quad 000 \mathrm{E}+00 \quad 000 \mathrm{E}+00 \quad 000 \mathrm{E}+00 \quad 000 \mathrm{E}+00 \quad 000 \mathrm{E}+00 \quad 000 \mathrm{E}+00 \quad 000 \mathrm{E}+00 \quad 0.00 \mathrm{E}+00$

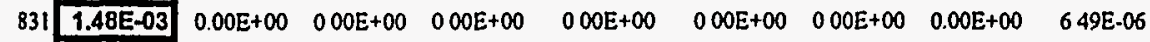

$0.00 \mathrm{E}+00 \quad 0.00 \mathrm{E}+00$

$0.00 \mathrm{E}+00 \quad 0.00 \mathrm{E}+00$

$0.00 E+\infty$

$0.00 E+00 \quad 0.00 E+00$

332 2.5BE-04 $0.00 E+00 \quad 000 E+00 \quad 0.00 E+00$

$0.00 \mathrm{E}+00 \quad 0.00 \mathrm{E}+00 \quad 000 \mathrm{E}+00 \quad 0.00 \mathrm{E}+00 \quad 2.73 \mathrm{E} .06$

$833 \quad$ 4.06E-04 $0.00 \mathrm{E}+00 \quad 000 \mathrm{E}+00 \quad 133 \mathrm{E}-05$

$\begin{array}{lllll}0.00 E+00 & 0.00 E+00 & 0.00 E+00 & 0.00 E+00 & 0.00 E+00\end{array}$

$0.00 \mathrm{E}+00 \quad 000 \mathrm{E}+00$

$0.00 \mathrm{E}+\infty$

$0.00 \mathrm{E}+00$

$0.00 \mathrm{E}+00$

$0.00 \mathrm{E}+\infty$

$0.00 \mathrm{E}+00$

$0.00 \mathrm{E}+00$

$0.00 \mathrm{E}+00$

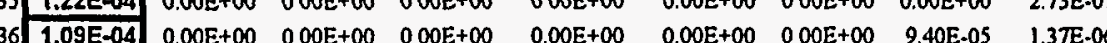

$0,00 E+\infty 00000+00$

$0.00 \mathrm{E}+\infty 0$

$0.00 E+\infty$

837 2.54E-03 $0.00 E+00 \quad 000 E+00 \quad 0.00 E+00$

$0.00 \mathrm{E}+\infty$

$0.00 \mathrm{E}+\infty 0$

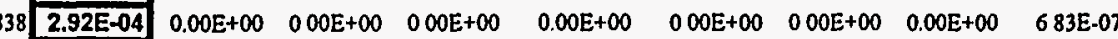

$0.00 \mathrm{E}+00 \quad 000 \mathrm{E}+\infty 0$

$0.00 \mathrm{E}+\infty 0$

$0.00 \mathrm{E}+\infty$

$\begin{array}{llllllll}0.00 E+00 & 0.00 E+00 & 0.00 E+\infty 0 & 0.00 E+\infty 0 & 0.00 E+\infty & 000 E+\infty & 0.00 E+\infty & 1.02 E-06\end{array}$

$000 E+\infty 0000 E+\infty$

$0.00 \mathrm{E}+\infty 0$

$0,00 E+00$

$0.00 \mathrm{E}+00 \quad 0.00 \mathrm{E}+00$

$\begin{array}{llllll}841 & 1.02 E-03 & 0.00 E+\infty & 0.00 E+\infty & 0.00 E+\infty\end{array}$

$0.00 \mathrm{E}+00 \quad 0.00 \mathrm{E}+00$

$\begin{array}{llllllllll}842 & 8.66 E-04 & 0.00 E+00 & 0.00 E+00 & 1.33 E-05 & 0.00 E+00 & 0.00 E+\infty 0 & 0.00 E+00 & 0.00 E+00 & 3.41 E-06\end{array}$

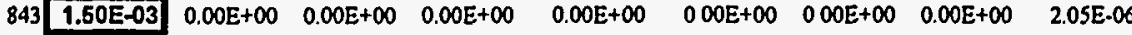

$0.00 \mathrm{E}+00 \quad 0.00 \mathrm{E}+00$

$0.00 \mathrm{E}+\infty$

$0.00 \mathrm{E}+\infty$

$0.00 \mathrm{E}+00$

$0.00 \mathrm{E}+\infty$

$0.00 E+00 \quad 126 \mathrm{E}-06$

$0.00 \mathrm{E}+\infty 0$

$000 \mathrm{E}+\infty$

-

$\begin{array}{llllllll}0.00 \mathrm{E}+\infty & 0.00 \mathrm{E}+00 & 0.00 \mathrm{E}+00 & 0.00 \mathrm{E}+\infty & 5.19 \mathrm{E}-06 & 0.00 \mathrm{E}+\infty 0 & 190 \mathrm{E}-06\end{array}$

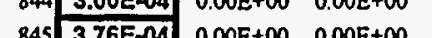

$0.00 \mathrm{E}+\infty \quad 000 \mathrm{E}+\infty 0$

$000 \mathrm{E}+00$

$000 \mathrm{E}+00$

1.74E-04

$0.00 \mathrm{E}+00$

$0.00 \mathrm{E}+00$

$0.00 \mathrm{E}+00$

$000 E+00$

$0.00 E+00$

$0.00 \mathrm{E}+00$

$0.00 \mathrm{E}+00$

$0.00 \mathrm{E}+00$

$0.00 E+\infty$

$000 \mathrm{E}+00$

$0.00 E+00 \quad 0.00 E+00$

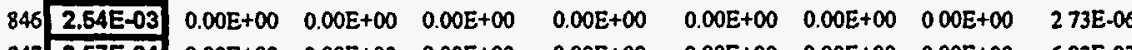

$0.00 \mathrm{E}+00 \quad 0.00 \mathrm{E}+00$

$000 E+\infty$

$000 E+00$

$000 \mathrm{E}+00$

$000 \mathrm{E}+\infty$

$0.00 \mathrm{E}+\infty$

$000 \mathrm{E}+00$

$0.00 E+00$

$000 \mathrm{E}+00$

$0.00 E+00 \quad 0.00 E+00$ $0.00 \mathrm{E}+\infty 00 \quad 0.00 \mathrm{E}+\infty$ $0.00 E+00 \quad 0.00 E+00$ $000 E+00 \quad 0.00 E+00$ $000 E+00 \quad 0.00 E+00$ $0.00 \mathrm{E}+00 \quad 0.00 \mathrm{E}+00$ $000 \mathrm{E}+00 \quad 0.00 \mathrm{E}+00$ $0.00 E+00 \quad 0.00 E+00$ $0.00 \mathrm{E}+00 \quad 0.00 \mathrm{E}+00$ $000 \mathrm{E}+\infty 0.00 \mathrm{E}+\infty 0$ $0.00 E+\infty 00.00 E+\infty 0$ $0.00 E+00 \quad 0.00 E+\infty 0$ $000 E+00 \quad 0.00 E+\infty 0$ $0.00 E+\infty 0 \quad 0.00 E+\infty 0$ 0 OOE $+00 \quad 0$ OOE +00 $000 E+00 \quad 000 E+00$ $000 E+\infty 0 \quad 000 E+00$ 
INDENO_I NNDNPA PENTACHL VINYL_CH TRI123 DI2CHL3 DBE12 DIOXAN14 PROPENE2 _3_3_DI Tolal Rsk WAG

WELL

$\frac{9.48 E-03}{9.47 E-03}$

6.29E-03

1.44E-02

$\begin{array}{r}4.61 \mathrm{E}-02 \\ \hline .80 \mathrm{E}-02\end{array}$

1.09E-02

$1.68 \mathrm{E}-02$

$1.24 \mathrm{E}-02$

6.39E-03

1.32E-02

2.51E-03

6.26E-03

6.69E-03

1.68E-03

1.18E-03

7.96E-04

\begin{tabular}{|c|}
\hline $8.88 E-03$ \\
\hline $1.25 E-02$ \\
\hline
\end{tabular}

4.05E-01

7.63E-02

5.62E-03

$1.23 \mathrm{E}-02$

$\frac{1.43 E-01}{1.57 E-02}$

\begin{tabular}{|c|}
\hline $1.57 E-02$ \\
\hline $1.21 E-02$ \\
\hline $4.22 E-04$
\end{tabular}

4.22E-04

1.52E-03

2.75E-04

4.37E-04

$1.78 \mathrm{E}-04$

\begin{tabular}{l}
$2.20 E-04$ \\
\hline $2.55 E-03$
\end{tabular}

3.37E-04

3.71E-04

1.42E-03

$1.29 \mathrm{E}-03$

$1.65 E-03$

3.12E-03

4.17E-0.

4.32E-04

2.56E-03

4.74E-04 
WELL BE B2CEE TETI122 DCEEII METHYLI METHYL2 DIC33 PCB1254 BIS_2_ET BENZBFLU BENZENE BENZAANT BENZAPYR CARBON_T DIBENZ_A HCBE

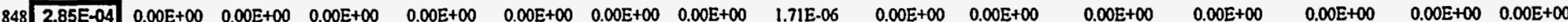
$\begin{array}{llllllllll}2.93 E-04 & 0.00 E+00 & 0.00 E+00 & 1.33 E-05 & 0.00 E+\infty 0 & 0.00 E+\infty 0 & 0.00 E+\infty & 0.00 E+\infty 0 & 3.41 E-06\end{array}$

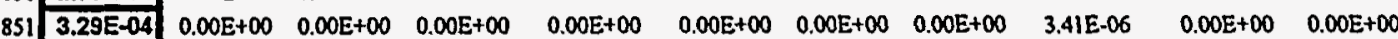
$852 \quad \begin{array}{llllllllllll}4.57 E-04 & 0.00 E+00 & 0.00 E+00 & 0.00 E+00 & 0.00 E+00 & 0.00 E+00 & 0.00 E+00 & 0.00 E+00 & 3.41 E-06 & 000 E+00 & 6.96 E-05\end{array}$

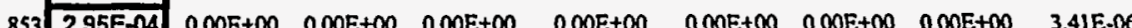

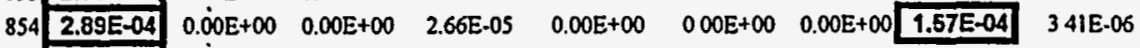

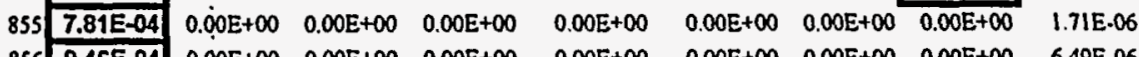
$\begin{array}{llllllllll}856 & 9.46 E-04 & 0.00 \mathrm{E}+00 & 0.00 \mathrm{E}+00 & 0.00 \mathrm{E}+\infty & 0.00 \mathrm{E}+00 & 0.00 \mathrm{E}+00 & 0.00 \mathrm{E}+00 & 0.00 \mathrm{E}+00 & 6.49 \mathrm{E}-06\end{array}$ $857 \begin{array}{lllllllll}9.48 E-04 & 0.0 \dot{0} \mathrm{E}+00 & 0.00 \mathrm{E}+00 & 0.00 \mathrm{E}+00 & 0.00 \mathrm{E}+00 & 0.00 \mathrm{E}+00 & 0.00 \mathrm{E}+00 & 0.00 \mathrm{E}+00 & 3.41 \mathrm{E}-06\end{array}$

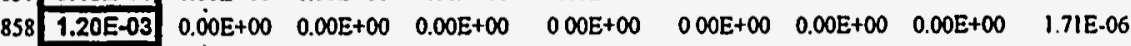
$859 \begin{array}{lllllllll}8.03 E-04 & 0.00 E+\infty & 0.00 E+\infty 0 & 0.00 E+\infty 0 & 0.00 E+\infty 0 & 0.00 E+\infty 0 & 0.00 E+\infty 0 & 0.00 E+\infty & 0.00 E+\infty\end{array}$ $\begin{array}{lllllllllll}860 & 1.41 E-04 & 0.00 E+00 & 0.00 E+00 & 0.00 E+\infty & 0.00 E+00 & 0.00 E+\infty & 0.00 E+\infty 0 & 0.00 E+\infty 0 & 1.02 E-06\end{array}$

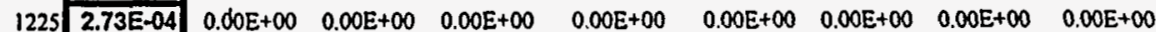

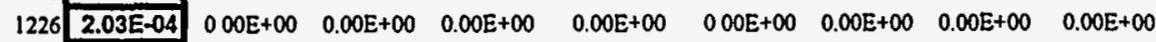
$\begin{array}{llllllllll}1227 & 0.00 E+00 & 0.00 E+00 & 0.00 E+00 & 0.00 E+00 & 0.00 E+00 & 000 E+\infty 0 & 0.00 E+00 & 0.00 E+00 & 0.00 E+00\end{array}$

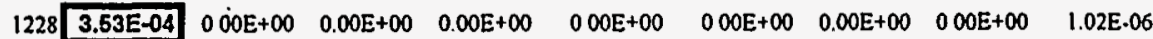

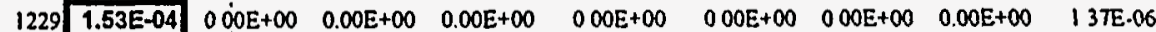

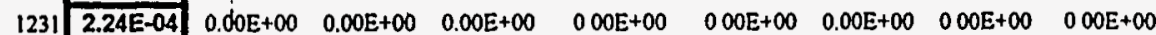
$\begin{array}{llllllllll}1233 & 4.83 E-04 & 0.00 E+00 & 1.90 E-04 & 7.98 E-05 & 0.00 E+00 & 0.00 E+00 & 0.00 E+00 & 0.00 E+00 & 0.00 E+00\end{array}$ $\begin{array}{llllllllll}1234 & 0.00 E+00 & 0.00 E+00 & 0.00 E+\infty 0 & 0.00 E+00 & 0.00 E+00 & 0.00 E+\infty 0 & 0.00 E+\infty 0 & 0.00 E+\infty 0 & 0.00 E+00\end{array}$

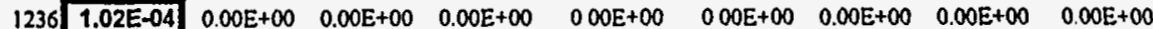

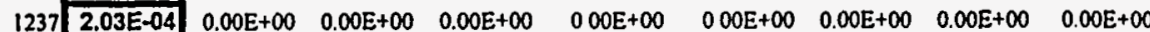
$1238 \begin{array}{lllllllll}1.02 E-04 & 0.00 E+\infty & 0.00 E+00 & 0.00 E+00 & 0.00 E+00 & 0.00 E+\infty 0 & 0.00 E+00 & 0.00 E+00 & 0.00 E+00\end{array}$ 1239 2.03E-04 $\quad . \quad 0.00 \mathrm{E}+\infty \quad 0.00 \mathrm{E}+00$ $0.00 E+00$

$0.00 E+\infty 0.00 E+\infty$

$\begin{array}{llllll}0.00 E+\infty 0 & 0.00 E+\infty 0 & 0.00 E+\infty 0 & 0.00 E+\infty & 0.00 E+\infty 0\end{array}$ $\begin{array}{llllll}0.00 E+\infty 0 & 0.00 E+\infty 0 & 0.00 E+\infty & 0.00 E+\infty & 0.00 E+\infty\end{array}$ $\begin{array}{lllll}0.00 E+\infty & 0.00 E+\infty 0 & 2.83 E-06 & 0.00 E+\infty 0 & 0.00 E+\infty\end{array}$ $\begin{array}{llllll}0.00 \mathrm{E}+\infty & 0.00 \mathrm{E}+\infty & 0.00 \mathrm{E}+\infty & 0.00 \mathrm{E}+\infty & 0.00 \mathrm{E}+00\end{array}$ $\begin{array}{lllllllllllllllll}0.00 E+\infty 0 & 0.00 E+\infty 0 & 0.00 E+00 & 0.00 E+\infty 0 & 0.00 E+\infty 0 & 0.00 E+\infty & 0.00 E+\infty\end{array}$ $\begin{array}{llllllll}0.00 E+\infty 0 & 1.26 \mathrm{E}-06 & 0.00 \mathrm{E}+00 & 0.00 \mathrm{E}+00 & 0.00 \mathrm{E}+00 & 0.00 \mathrm{E}+00 & 0.00 \mathrm{E}+\infty\end{array}$ $\begin{array}{lllllll}0.00 E+00 & 0.00 E+00 & 0.00 E+00 & 0.00 E+00 & 0.00 E+00 & 0.00 E+00 & 0.00 E+00\end{array}$ $\begin{array}{llllllll}0.00 \mathrm{E}+\infty & 0.00 \mathrm{E}+\infty 0 & 0.00 \mathrm{E}+\infty & 0.00 \mathrm{E}+\infty 0 & 0.00 \mathrm{E}+\infty & 0.00 \mathrm{E}+\infty & 0.00 \mathrm{E}+\infty\end{array}$ $\begin{array}{lllllllll}0.00 E+\infty 00 & 0.00 E+00 & 0.00 E+00 & 0.00 E+\infty & 0.00 E+\infty & 0.00 E+\infty & 0.00 E+\infty\end{array}$ $\begin{array}{lllllll}0.00 E+00 & 6.32 E-07 & 0.00 E+00 & 0.00 E+00 & 0.00 E+00 & 0.00 E+00 & 0.00 E+00\end{array}$ $\begin{array}{lllllll}0.00 E+00 & 0.00 E+00 & 0.00 E+00 & 0.00 E+\infty 0 & 0.00 E+00 & 0.00 E+\infty & 0.00 E+\infty\end{array}$ $\begin{array}{llllllll}0.00 E+\infty 0 & 0.00 E+00 & 0.00 E+\infty 0 & 0.00 E+\infty 0 & 0.00 E+\infty 0 & 0.00 E+\infty 0 & 0.00 E+\infty\end{array}$ $\begin{array}{lllllllll}0.00 E+00 & 0.00 E+00 & 0.00 E+\infty 0 & 0.00 E+00 & 0.00 E+00 & 0.00 E+00 & 0.00 E+00\end{array}$ $\begin{array}{lllllll}0.00 E+00 & 0.00 E+00 & 0.00 E+00 & 0.00 E+00 & 0.00 E+00 & 0.00 E+00 & 0.00 E+\infty 0\end{array}$ $\begin{array}{lllllll}0.00 \mathrm{E}+\infty & 0.00 \mathrm{E}+\infty 0 & 0.00 \mathrm{E}+00 & 0.00 \mathrm{E}+00 & 0.00 \mathrm{E}+\infty & 0.00 \mathrm{E}+\infty & 0.00 \mathrm{E}+\infty\end{array}$ $\begin{array}{llllllll}000 E+00 & 632 E-07 & 0.00 E+00 & 0.00 E+00 & 0.00 E+00 & 0.00 E+00 & 0.00 E+00\end{array}$ $\begin{array}{llllllll}0.00 \mathrm{E}+\infty & 0.00 \mathrm{E}+00 & 0.00 \mathrm{E}+00 & 0.00 \mathrm{E}+00 & 0.00 \mathrm{E}+\infty 0 & 0.00 \mathrm{E}+\infty 0 & 0.00 \mathrm{E}+00\end{array}$

$\begin{array}{llllllll}0.00 \mathrm{E}+00 & 0.00 \mathrm{E}+00 & 0.00 \mathrm{E}+\infty & 0.00 \mathrm{E}+\infty 0 & 0.00 \mathrm{E}+00 & 0.00 \mathrm{E}+00 & 0.00 \mathrm{E}+\infty\end{array}$ $0.00 \mathrm{E}+00 \quad 0.00 \mathrm{E}+00$ $0.00 E+\infty 00 \quad 0.00 E+\infty$

$0.00 E+00 \quad 0.00 E+\infty 0$ $0.00 E+00 \quad 0.00 E+00$ $0.00 \mathrm{E}+\infty 00$ $\begin{array}{llllllllllll}1240 & 0.00 E+00 & 0.00 E+00 & 0.00 E+00 & 0.00 E+00 & 0.00 E+00 & 0.00 E+\infty 0 & 0.00 E+00 & 0.00 E+\infty 0 & 0.00 E+\infty 0 & 0.00 E+\infty 0 & 0.00 E+\infty\end{array}$

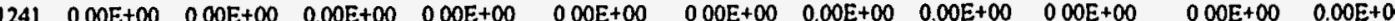

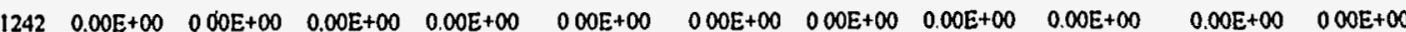

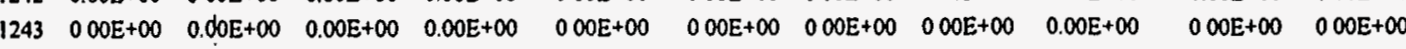
$\begin{array}{lllllllllllll}1244 & 0.00 \mathrm{E}+00 & 0.00 \mathrm{E}+\infty & 0.00 \mathrm{E}+00 & 0.00 \mathrm{E}+00 & 0.00 \mathrm{E}+00 & 0.00 \mathrm{E}+00 & 0.00 \mathrm{E}+00 & 0.00 \mathrm{E}+\infty 0 & 0.00 \mathrm{E}+00 & 0.00 \mathrm{E}+00 & 0.00 \mathrm{E}+\infty\end{array}$ $1245 \quad \begin{array}{llllllllllll}1.22 E-04 & 0.00 E+00 & 0.00 E+00 & 0.00 E+00 & 0.00 E+00 & 0.00 E+\infty & 0.00 E+00 & 0.00 E+\infty 0 & 0.00 E+00 & 0.00 E+\infty 0 & 6.32 E-07\end{array}$

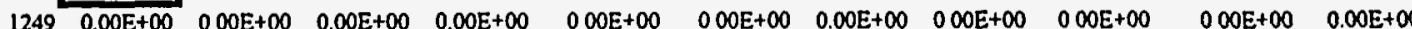

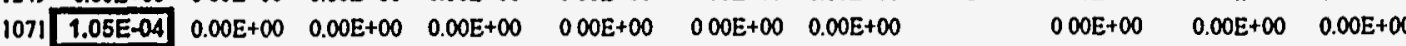

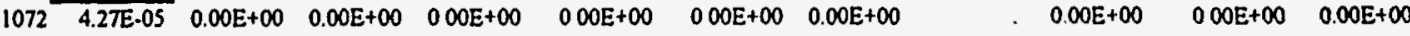
$\begin{array}{llllllllllll}1073 & 3.86 \mathrm{E}-05 & 0.00 \mathrm{E}+00 & 0.00 \mathrm{E}+00 & 0.00 \mathrm{E}+00 & 0.00 \mathrm{E}+00 & 0.00 \mathrm{E}+00 & 0.00 \mathrm{E}+00 & .000 \mathrm{E}+00 & 000 \mathrm{E}+00 & 0.00 \mathrm{E}+\infty\end{array}$

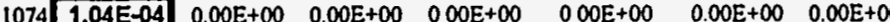
1075 4.37E-05 $0.00 \mathrm{E}+00 \quad 0.00 \mathrm{E}+00 \quad 0.00 \mathrm{E}+00 \quad 0.00 \mathrm{E}+\infty 0 \quad 000 \mathrm{E}+\infty 0 \quad 0.00 \mathrm{E}+\infty 0$ $1076 \quad 1.25 E-04 \quad 0.00 E+\infty 0 \quad 0.00 E+\infty 00 \quad 000 E+\infty 0000 E+\infty 0 \quad 000 E+\infty 0 \quad 000 E+\infty$ $1077 \quad 5.69 \mathrm{E}-05 \quad 0.00 \mathrm{E}+00 \quad 0.00 \mathrm{E}+00 \quad 000 \mathrm{E}+00 \quad 000 \mathrm{E}+00 \quad 0.00 \mathrm{E}+00 \quad 0.00 \mathrm{E}+\infty$ $1078 \quad 0.00 \mathrm{E}+00 \quad 0.00 \mathrm{E}+00 \quad 0.00 \mathrm{E}+00 \quad 0.00 \mathrm{E}+00 \quad 0.00 \mathrm{E}+00 \quad 0.00 \mathrm{E}+00 \quad 0.00 \mathrm{E}+00$

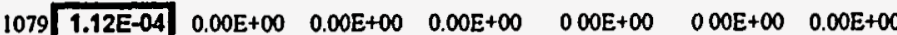
$1080 \quad 0.00 E+\infty 0 \quad 0.00 E+\infty 00.00 E+\infty 0 \quad 0.00 E+\infty 0 \quad 0.00 E+\infty 0 \quad 0.00 E+\infty 0 \quad 0.00 E+\infty 0$ $\begin{array}{llllllllll}1081 & 0.00 E+\infty & 0.00 E+\infty 0 & 0.00 E+00 & 0.00 E+\infty 0 & 0.00 E+\infty 0 & 0.00 E+\infty 0 & 0.00 E+\infty\end{array}$ $\begin{array}{lllllllll}1082 & 0.00 E+\infty 0 & 0.00 E+\infty 0 & 0.00 E+\infty 0 & 0.00 E+\infty 0 & 0.00 E+\infty 0 & 0.00 E+\infty & 0.00 E+\infty\end{array}$ $\begin{array}{lllllllll}1083 & 0.00 E+\infty & 0.00 E+\infty & 0.00 E+\infty & 0.00 E+\infty & 0.00 E+00 & 0.00 E+00 & 0.00 E+00\end{array}$

$0.00 \mathrm{E}+00$

$0.00 E+\infty$

$0.00 \mathrm{E}+\infty 0$

$0.00 \mathrm{E}+00 \quad 0.00 \mathrm{E}+00$

$0.00 \mathrm{E}+\infty 00 \quad 0.00 \mathrm{E}+\infty$

$0.00 E+00 \quad 0.00 E+00$

$0.00 \mathrm{E}+\infty 00 \quad 0.00 \mathrm{E}+00$

$0.00 E+00 \quad 0.00 E+00$

$0.00 \mathrm{E}+\infty 0 \quad 0.00 \mathrm{E}+\infty 0$

$0.00 E+\infty \quad 0.00 E+\infty$

$0.00 \mathrm{E}+\infty 00 \quad 0.00 \mathrm{E}+\infty 0$

$0.00 \mathrm{E}+00 \quad 0.00 \mathrm{E}+00$

$0.00 \mathrm{E}+00 \quad 0.00 \mathrm{E}+00$

$0.00 \mathrm{E}+\infty 0 \quad 0.00 \mathrm{E}+\infty 0$

$0.00 \mathrm{E}+00 \quad 0.00 \mathrm{E}+00$

$0.00 E+00$

$0.00 \mathrm{E}+00 \quad 0.00 \mathrm{E}+00$

$0.00 \mathrm{E}+00 \quad 0.00 \mathrm{E}+00$

$0.00 E+00 \quad 0.00 E+00$

$0.00 E+\infty$

$0.00 E+\infty \quad 0.00 E+\infty$

$0.00 E+\infty 0 \quad 0.00 E+\infty 0$

$000 E+00 \quad 000 E+\infty 0$

$0.00 E+\infty 0 \quad 000 E+\infty$

$0.00 \mathrm{E}+00 \quad 0.00 \mathrm{E}+\infty 00.00 \mathrm{E}+00$

$\begin{array}{lll}0.00 \mathrm{E}+\infty 0 & 0.00 \mathrm{E}+00 \quad 0.00 \mathrm{E}+\infty\end{array}$

$0.00 \mathrm{E}+00 \quad 0.00 \mathrm{E}+00 \quad 0.00 \mathrm{E}+00$ 


\begin{tabular}{|c|c|c|c|c|c|c|c|c|c|c|c|c|}
\hline INDENO_1 & NNDNPA & PENTACHL & VINYL_CH & TRII23 & D12CHL3 & DBE 12 & DIOXAN14 & PROPENE2 & $-{ }^{3}-^{3}-\mathrm{DI}$ & Total Rak & WAO & WELL \\
\hline $0.00 E+\infty 0$ & $0.00 E+00$ & $0.00 E+00$ & $0.00 \mathrm{E}+\infty$ & & & & $1.12 E-06$ & & & 5.24E-03 & 6 & 848 \\
\hline $0.00 E+\infty 0$ & $0.00 \mathrm{E}+00$ & $0.00 \mathrm{E}+00$ & $2.16 \mathrm{E}-03$ & & & & $6.72 E-07$ & . & & 5.55E-03 & 6 & 849 \\
\hline $0.00 \mathrm{E}+00$ & $0.00 \mathrm{E}+00$ & $0.00 \mathrm{E}+00$ & $0.00 \mathrm{E}+00$ & & & & $1.34 \mathrm{E}-06$ & . & & $3.67 \mathrm{E}-04$ & 6 & 850 \\
\hline $0.00 E+\infty$ & $0.00 E+00$ & $000 E+00$ & $0.00 \mathrm{E}+00$ & & & . & $3.58 \mathrm{E}-05$ & . & & 4.33E-04 & 6 & 851 \\
\hline $0.00 E+\infty$ & $0.00 \mathrm{E}+00$ & $0.00 E+00$ & $0.00 E+00$ & & & . & $1.68 \mathrm{E}-05$ & . & & 6.17E-04 & 6 & 852 \\
\hline $0.00 \mathrm{E}+00$ & $0.00 E+00$ & $0.00 E+00$ & $2.36 \mathrm{E}-04$ & & & & & & & 5.46E-04 & 6 & 853 \\
\hline $0.00 \mathrm{E}+\infty$ & $0.00 E+00$ & $0.00 E+00$ & $2.36 E-04$ & & & & & & & $9.98 \mathrm{E}-04$ & 6 & 854 \\
\hline $0.00 E+00$ & $0.00 \mathrm{E}+\infty$ & $0.00 E+00$ & $0.00 \mathrm{E}+00$ & & & & & & & $7.92 E-04$ & 6 & 855 \\
\hline $0.00 E+\infty$ & $0.00 E+00$ & $0.00 E+00$ & $0.00 \mathrm{E}+\infty$ & & & & & & & 9.88E-04 & 6 & 856 \\
\hline $0.00 \mathrm{E}+00$ & $0.00 \mathrm{E}+00$ & $0.00 E+00$ & $0.00 E+\infty$ & & & . & & . & & 9.63E-04 & 6 & 857 \\
\hline $0.00 £+00$ & $0.00 E+00$ & $0.00 E+00$ & $0.00 E+\infty$ & & & & & . & & $1.21 E-03$ & 6 & 858 \\
\hline $0.00 \mathrm{E}+00$ & $0.00 \mathrm{E}+00$ & $0.00 E+00$ & $0.00 E+\infty$ & & & . & & 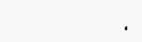 & & $2.19 E-04$ & 6 & 859 \\
\hline $0.00 \mathrm{E}+00$ & $0.00 \mathrm{E}+00$ & $0.00 \mathrm{E}+00$ & $0.00 \mathrm{E}+\infty 0$ & & & . & & & & $1.57 E-04$ & 6 & 860 \\
\hline $0.00 \mathrm{E}+00$ & $0.00 \mathrm{E}+00$ & $0.00 E+00[$ & $4.50 \mathrm{E}-04$ & & & & . & , & & 5.90E-03 & 6 & 1225 \\
\hline $0.00 \dot{\mathrm{E}}+00$ & $0.00 \mathrm{E}+00$ & $000 \mathrm{E}+00$ & $0.00 \mathrm{E}+00$ & & & $=$ & . & & & $2.23 E-04$ & 6 & 1226 \\
\hline $0.00 \mathrm{E}+00$ & $0.00 \mathrm{E}+00$ & $000 \mathrm{E}+00$ & $3.94 E-04$ & & & 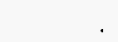 & & & & $4.04 E-04$ & 6 & 1227 \\
\hline $0.00 E+00$ & $0.00 \mathrm{E}+00$ & $000 E+00$ & 4.58E-04 & & & & $=$ & & & B.91E-04 & 6 & 1228 \\
\hline $0.00 E+00$ & $0.00 E+00$ & $000 E+00$ & $0.00 \mathrm{E}+00$ & & & & . & r & & $4.82 \mathrm{E}-04$ & 6 & 1229 \\
\hline $0.00 E+00$ & $000 E+\infty$ & $000 E+00$ & $0.00 \mathrm{E}+\infty$ & & & & . & & & $3.48 E-04$ & 6 & 1231 \\
\hline $0.00 E+\infty$ & $0.00 E+00$ & $000 \mathrm{E}+00$ & $2.37 E-03$ & & & & & . & & $3.93 E-03$ & 6 & 1233 \\
\hline $0.00 \dot{\mathrm{E}}+\infty$ & $0.00 \mathrm{E}+00$ & $000 E+00$ & $000 \mathrm{E}+00$ & $0.00 \mathrm{E}+00$ & $000 \mathrm{E}+00$ & $0.00 \mathrm{E}+00$ & $0.00 E+00$ & $000 E+00$ & $000 \mathrm{E}+00$ & $3.64 \mathrm{E}-05$ & 6 & 1234 \\
\hline $0.00 E+00$ & $0.00 \mathrm{E}+00$ & 0 OOE +00 & $000 \mathrm{E}+00$ & & & & . & & & 1.27E-04 & 6 & 1236 \\
\hline $0.00 E+00$ & $0.00 E+00$ & $0.00 E+00$ & $000 \mathrm{E}+00$ & & & & . & & & $2.23 E-04$ & 6 & 1237 \\
\hline \multirow[t]{2}{*}{$0.00 E+00$} & $0.00 E+00$ & $000 \mathrm{E}+00$ & $000 E+00$ & & & & . & . & & $1.73 E-04$ & 6 & 1238 \\
\hline & & & $0.00 \mathrm{E}+\infty 0$ & & & & & & & $2.29 E-04$ & 6 & 1239 \\
\hline $0.00 \mathrm{E}+00$ & $0.00 \mathrm{E}+00$ & $000 E+00$ & $000 \mathrm{E}+\infty$ & & & & & & & $2.85 \mathrm{E}-05$ & 6 & 1240 \\
\hline $0.00 \mathrm{E}+00$ & $0.00 \mathrm{E}+\infty$ & $000 E+00$ & $0.00 E+\infty 0$ & & & & & , & & 9.13E-05 & 6 & 1241 \\
\hline $0.00 E+\infty 0$ & $0.00 E+00$ & $000 E+00$ & $0.00 \mathrm{E}+\infty 0$ & & & & & & & 5.13E-04 & 6 & 1242 \\
\hline $0.00 E+00$ & $000 E+00$ & $000 \mathrm{E}+00$ & $000 E+\infty 0$ & & & & 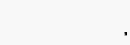 & & & $2.32 E-03$ & 6 & 1243 \\
\hline $0.00 E+00$ & $000 E+00$ & $000 \mathrm{E}+00$ & $000 E+00$ & & & . & . & & & 2.93E-04 & 6 & 1244 \\
\hline $0.00 E+00$ & $0.00 \mathrm{E}+00$ & $000 \mathrm{E}+00$ & $000 \mathrm{E}+00$ & $0.00 \mathrm{E}+\infty$ & $000 E+00$ & $000 E+\infty 0$ & $0.00 E+\infty$ & $0.00 E+00$ & $0.00 E+00$ & $1.46 \mathrm{E}-04$ & 6 & 1245 \\
\hline $0.00 \mathrm{E}+00$ & $000 \mathrm{E}+00$ & $000 \mathrm{E}+00$ & $000 \mathrm{E}+00$ & & & & . & & & 1.91E.05 & 6 & 1249 \\
\hline $0.00 E+00$ & $0.00 E+00$ & $000 E+00$ & $000 \mathrm{E}+00$ & & & & . & & & 1.18E-04 & 7 & 1071 \\
\hline $0.00 \mathrm{E}+\infty 0$ & $0.00 \mathrm{E}+\infty$ & $000 \mathrm{E}+00$ & $000 \mathrm{E}+00$ & & & . & & . & & $5.06 \mathrm{E}-05$ & 7 & 1072 \\
\hline $000 \mathrm{E}+00$ & $0.00 \mathrm{E}+00$ & $000 \mathrm{E}+00$ & $000 E+00$ & & & & & & & $7.12 \mathrm{E}-05$ & 7 & 1073 \\
\hline $0.00 E+00$ & $0.00 E+00$ & $000 E+00$ & $000 \mathrm{E}+00$ & & & & . & . & & $1.17 E-04$ & 7 & 1074 \\
\hline $0.00 E+00$ & $0.00 E+00$ & $000 E+00$ & $000 \mathrm{E}+00$ & & & & 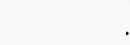 & & & $6.13 \mathrm{E}-05$ & 7 & 1075 \\
\hline $0.00 E+\infty 0$ & $0.00 \mathrm{E}+00$ & $000 E+00$ & $000 \mathrm{E}+\infty 0$ & & & & . & . & & 1.51E-03 & 7 & 1076 \\
\hline $0.00 E+\infty$ & $000 \mathrm{E}+\infty$ & $000 E+00$ & $000 \mathrm{E}+\infty 0$ & & & & . & & & $8.79 \mathrm{E}-05$ & 7 & 1077 \\
\hline $0.00 E+\infty$ & $000 E+\infty 0$ & $0.00 \mathrm{E}+00$ & $0.00 E+\infty$ & & & & . & . & & $6.20 E-04$ & 7 & 1078 \\
\hline $0.00 E+00$ & $0.00 E+00$ & $000 \mathrm{E}+00$ & $000 E+\infty 0$ & & & & & . & & $8.25 E-04$ & 7 & 1079 \\
\hline $0.00 E+\infty 0$ & $0.00 \mathrm{E}+00$ & $000 E+\infty$ & $000 E+00$ & & & & & & & $15 T E .05$ & 7 & 1080 \\
\hline $0.00 E+\infty$ & $000 \mathrm{E}+\infty$ & $000 E+\infty 0$ & $000 E+\infty 0$ & & & & & & & 3 SIE-OS & 7 & 1081 \\
\hline $0.00 E+\infty$ & $0.00 \mathrm{E}+\infty$ & $000 \mathrm{E}+\infty$ & $000 E+\infty$ & & & & & & & $347 E-05$ & 7 & 1082 \\
\hline $0.00 E+\infty 0$ & $0.00 E+\infty 0$ & $000 E+\infty 0$ & $000 E+00$ & & & & & & & $283 \mathrm{E}-05$ & 7 & 1083 \\
\hline
\end{tabular}


WELL BE B2CEE TETI122 DCEE11 METHYL1 METHYL2 DIC33 PCB1254 BIS 2 ET $\begin{array}{lllllllll}1085 & 0.00 E+\infty 0 & 0.00 E+00 & 0.00 E+00 & 0.00 E+\infty 0 & 0.00 E+\infty & 0.00 E+\infty & 0.00 E+\infty\end{array}$

$\begin{array}{llllllll}1086 & 0.00 E+\infty 0 & 0.00 E+\infty & 0.00 E+\infty & 0.00 E+00 & 0.00 E+\infty 0 & 0.00 E+\infty 0 & 0.00 E+\infty 0\end{array}$

$\begin{array}{llllllll}1087 & 0.00 E+\infty & 0.60 E+\infty & 0.00 E+\infty & 0.00 E+\infty & 0.00 E+\infty 0 & 0.00 E+\infty & 0.00 E+\infty\end{array}$

$\begin{array}{llllllll}1088 & 0.00 \mathrm{E}+00 & 0.00 \mathrm{E}+00 & 0.00 \mathrm{E}+00 & 0.00 \mathrm{E}+\infty 0 & 0.00 \mathrm{E}+00 & 0.00 \mathrm{E}+00 & 0.00 \mathrm{E}+\infty\end{array}$

$\begin{array}{llllllll}1089 & 0.00 E+00 & 0.00 E+00 & 0.00 E+\infty 0 & 0.00 E+\infty 0 & 0.00 E+\infty & 0.00 E+\infty 0 & 0.00 E+\infty\end{array}$

$\begin{array}{llllllll}1090 & 0.00 E+\infty 0 & 0.00 E+00 & 0.00 E+00 & 0.00 E+\infty 0 & 0.00 E+00 & 0.00 E+\infty 0 & 0.00 E+\infty\end{array}$

$\begin{array}{lllllllll}1091 & 0.00 \mathrm{E}+00 & 0.00 \mathrm{E}+00 & 0.00 \mathrm{E}+00 & 0.00 \mathrm{E}+00 & 0.00 \mathrm{E}+00 & 0.00 \mathrm{E}+00 & 0.00 \mathrm{E}+00\end{array}$

$\begin{array}{lllllllll}1092 & 0.00 E+00 & 0.00 E+\infty 0 & 0.00 E+\infty 0 & 0.00 E+\infty 0 & 0.00 E+\infty 0 & 0.00 E+\infty 0 & 0.00 E+\infty\end{array}$

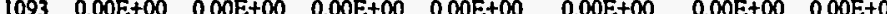

$\begin{array}{llllllll}1094 & 0.00 E+00 & 0.00 E+00 & 0.00 E+\infty 0 & 0.00 E+\infty 0 & 0.00 E+\infty 0 & 0.00 E+00 & 0.00 E+\infty 0\end{array}$

$\begin{array}{llllllll}1095 & 0.00 E+00 & 0.00 E+\infty & 0.00 E+\infty 0 & 0.00 E+\infty & 0.00 E+\infty & 0.00 E+00 & 0.00 E+\infty\end{array}$

$\begin{array}{llllllll}1096 & 0.00 E+00 & 0.00 E+\infty & 0.00 E+00 & 0.00 E+\infty 0 & 0.00 E+\infty & 0.00 E+\infty 0 & 0.00 E+\infty\end{array}$

$\begin{array}{lllllllll}1097 & 0.00 E+\infty 0 & 0.00 E+00 & 0.00 E+00 & 0.00 E+00 & 0.00 E+\infty 0 & 0.00 E+00 & 0.00 E+\infty\end{array}$

$\begin{array}{lllllllll}1139 & 0.00 E+00 & 0.00 E+00 & 0.00 E+00 & 0.00 E+\infty 0 & 0.00 E+\infty & 0.00 E+\infty & 0.00 E+\infty\end{array}$

$\begin{array}{llllllll}1140 & 0.00 E+00 & 0.00 E+\infty & 0.00 E+00 & 0.00 E+00 & 0.00 E+\infty 0 & 0.00 E+00 & 0.00 E+00\end{array}$

$\begin{array}{lllllllll}1141 & 0.00 E+00 & 0.00 \mathrm{E}+00 & 0.00 \mathrm{E}+00 & 0.00 \mathrm{E}+00 & 0.00 \mathrm{E}+00 & 0.00 \mathrm{E}+00 & 0.00 \mathrm{E}+00\end{array}$

$\begin{array}{llllllll}1143 & 0.00 E+00 & 0.00 E+00 & 0.00 E+00 & 0.00 E+00 & 0.00 E+00 & 0.00 E+00 & 0.00 E+00\end{array}$

$\begin{array}{llllllll}1144 & 0.00 \mathrm{E}+\infty & 0.60 \mathrm{E}+\infty & 0.00 \mathrm{E}+\infty & 0.00 \mathrm{E}+\infty 0 & 0.00 \mathrm{E}+\infty & 0.00 \mathrm{E}+\infty 0 & 0.00 \mathrm{E}+\infty\end{array}$

$1145 \quad 5.35 E-04 \quad 0.00 E+00 \quad 0.00 E+00 \quad 0.00 E+00 \quad 0.00 E+00 \quad 0.00 E+00 \quad 000 E+00$

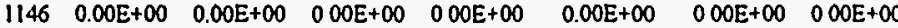

$1147 \quad 0.00 E+00 \quad 0.00 E+00 \quad 000 E+00 \quad 000 E+00 \quad 000 E+00 \quad 000 E+00 \quad 000 E+00$

$\begin{array}{llllllll}1148 & 0.00 \mathrm{E}+00 & 0.00 \mathrm{E}+00 & 0.00 \mathrm{E}+00 & 0.00 \mathrm{E}+00 & 0.00 \mathrm{E}+\infty & 0.00 \mathrm{E}+00 & 0.00 \mathrm{E}+00\end{array}$

$1149 \quad 0.00 E+00 \quad 0.00 E+00 \quad 0.00 E+00 \quad 000 E+00 \quad 0.00 E+00 \quad 000 E+00 \quad 000 E+00$

$\begin{array}{llllllll}1246 & 0.00 \mathrm{E}+00 & 0.00 \mathrm{E}+00 & 0.00 \mathrm{E}+00 & 0.00 \mathrm{E}+00 & 0.00 \mathrm{E}+00 & 0.00 \mathrm{E}+\infty & 0.00 \mathrm{E}+00\end{array}$

$\begin{array}{lllllllll}1196 & 0.00 E+00 & 0.00 E+00 & 0.00 E+\infty & 0.00 E+\infty 0 & 0.00 E+\infty 0 & 0.00 E+\infty 0 & 0.00 E+\infty\end{array}$

$1197 \quad 0.00 \mathrm{E}+00 \quad 0.00 \mathrm{E}+00 \quad 000 \mathrm{E}+00 \quad 000 \mathrm{E}+00 \quad 000 \mathrm{E}+00 \quad 000 \mathrm{E}+\infty 0000 \mathrm{E}+\infty 0$

$\begin{array}{llllllll}1198 & 0.00 E+00 & 0.00 E+00 & 0.00 E+\infty 0 & 0.00 E+\infty 0 & 0.00 E+\infty 0 & 0.00 E+00 & 0.00 E+00\end{array}$

$\begin{array}{llllllll}1199 & 0.00 E+00 & 0.00 E+00 & 0.00 E+00 & 0.00 E+00 & 0.00 E+\infty 0 & 0.00 E+\infty 0 & 0.00 E+00\end{array}$

$\begin{array}{llllllllll}1200 & 0.00 E+00 & 0.00 E+00 & 0.00 E+00 & 0.00 E+00 & 0.00 E+00 & 0.00 E+00 & 0.00 E+\infty 0\end{array}$

$\begin{array}{llllllll}1201 & 0.00 E+00 & 0.00 E+00 & 0.00 E+00 & 3.31 E-04 & 0.00 E+00 & 0.00 E+00 & 0.00 E+\infty\end{array}$

$1202 \quad 0.00 \mathrm{E}+00 \quad 0.00 \mathrm{E}+00 \quad 000 \mathrm{E}+00 \quad 0.00 \mathrm{E}+00 \quad 0.00 \mathrm{E}+00 \quad 0.00 \mathrm{E}+00 \quad 0.00 \mathrm{E}+00$

$1203 \quad 0.00 \mathrm{E}+00 \quad 0.00 \mathrm{E}+00 \quad 0.00 \mathrm{E}+00 \quad 0.00 \mathrm{E}+\infty 0000 \mathrm{E} \quad 0.00 \quad 0.00 \mathrm{E}+00 \quad 0.00 \mathrm{E}+\infty 0$ $5 \mathrm{NWV}-1 \quad 5.08 \mathrm{E} \cdot 05$

5 NWV-2 5.08E-05

BTT 8.13E.05

FRENCH DRA $0.00 E+00$

RS-1 $4.06 E-05$

$0.00 \mathrm{E}+00 \quad 0.00 \mathrm{E}+00$

\section{$0.00 \mathrm{E}+00$}

BENZBFLU BENZENE
$0.00 E+00 \quad 0.00 E+00$

$0.00 E+00$

$0.00 \mathrm{E}+\infty \quad 0.00 \mathrm{E}+00$

$0.00 \mathrm{E}+\infty 00.00 \mathrm{E}+\infty$

$0.00 \mathrm{E}+00$

$0.00 \mathrm{E}+00 \quad 0.00 \mathrm{E}+\infty$

$0.00 \mathrm{E}+\infty 0$

$0.00 \mathrm{E}+00 \quad 0.00 \mathrm{E}+00$

$0.00 E+00 \quad 0.00 E+00 \quad 0.00 E+\infty 0$

$0.00 \mathrm{E}+00 \quad 0.00 \mathrm{E}+\infty 0 \quad 0.00 \mathrm{E}+00$

$0.00 E+00 \quad 0.00 E+00 \quad 0.00 E+\infty 0$

$0.00 \mathrm{E}+00 \quad 0.00 \mathrm{E}+\infty 0$

$0.00 \mathrm{E}+\infty 0 \quad 0.00 \mathrm{E}+\infty 00.00 \mathrm{E}+00$

$0.00 \mathrm{E}+00 \quad 0.00 \mathrm{E}+00 \quad 0.00 \mathrm{E}+00$

$\begin{array}{lll}0.00 \mathrm{E}+00 & 0.00 \mathrm{E}+00 \quad 0.00 \mathrm{E}+00\end{array}$

$0.00 E+00 \quad 0.00 E+00 \quad 0.00 E+\infty 0$

$0.00 E+00 \quad 0.00 E+00 \quad 0.00 E+00$

$0.00 \mathrm{E}+00 \quad 0.00 \mathrm{E}+00 \quad 0.00 \mathrm{E}+00$

$0.00 E+\infty 0 \quad 0.00 E+\infty 0 \quad 0.00 E+\infty 0$

$0.00 E+00 \quad 0.00 E+00 \quad 0.00 E+00$

$0.00 E+00 \quad 0.00 E+00 \quad 0.00 E+00$

$0.00 E+00 \quad 0.00 E+00 \quad 000 E+00$

$0.00 \mathrm{E}+00 \quad 0.00 \mathrm{E}+00 \quad 0.00 \mathrm{E}+00$

$0.00 \mathrm{E}+00 \quad 0.00 \mathrm{E}+00 \quad 0.00 \mathrm{E}+00$

$0.00 E+00 \quad 0.00 E+00 \quad 0.00 E+00$

$\begin{array}{lll}0.00 E+00 & 0.00 E+00 & 0.00 E+00\end{array}$

$0.00 E+00 \quad 0.00 E+00 \quad 0.00 E+00$

$0.00 \mathrm{E}+00 \quad 0.00 \mathrm{E}+00 \quad 0.00 \mathrm{E}+00$

$000 \mathrm{E}+00 \quad 0.00 \mathrm{E}+00 \quad 000 \mathrm{E}+00$

$000 \mathrm{E}+00 \quad 0.00 \mathrm{E}+00 \quad 000 \mathrm{E}+00$

$0.00 \mathrm{E}+00 \quad 0.00 \mathrm{E}+00 \quad 0.00 \mathrm{E}+00$

$0.00 \mathrm{E}+00 \quad 0.00 \mathrm{E}+00 \quad 0.00 \mathrm{E}+00$

$000 \mathrm{E}+00 \quad 0.00 \mathrm{E}+00 \quad 1.32 \mathrm{E}-05$

$0.00 E+00 \quad 0.00 E+00 \quad 0.00 E+00$

$0.00 \mathrm{E}+00$

$0.00 \mathrm{E}+00 \quad 0.00 \mathrm{E}+00$

BENZAANT BENZAPYR CARBON_T DIBENZ_A HCBE

$\begin{array}{llllll}0.00 \mathrm{E}+00 & 0.00 \mathrm{E}+\infty 0 & 0.00 \mathrm{E}+\infty 0 & 0.00 \mathrm{E}+\infty 0 & 0.00 \mathrm{E}+\infty 0\end{array}$

$\begin{array}{llllll}0.00 E+\infty 0 & 0.00 E+\infty 0 & 0.00 E+\infty 0 & 0.00 E+\infty 0 & 0.00 E+\infty\end{array}$

$\begin{array}{llllll}0.00 E+\infty 0 & 0.00 E+\infty 0 & 0.00 E+\infty 0 & 0.00 E+\infty & 0.00 E+\infty 0\end{array}$

$\begin{array}{llllll}0.00 \mathrm{E}+00 & 0.00 \mathrm{E}+00 & 0.00 \mathrm{E}+\infty 0 & 0.00 \mathrm{E}+00 & 0.00 \mathrm{E}+\infty\end{array}$

$\begin{array}{llllll}0.00 E+00 & 0.00 E+\infty 0 & 0.00 E+\infty 0 & 0.00 E+00 & 0.00 E+\infty 0\end{array}$

$\begin{array}{llllll}0.00 E+00 & 0.00 E+00 & 0.00 E+00 & 0.00 E+00 & 0.00 E+00\end{array}$

$\begin{array}{llllll}0.00 \mathrm{E}+00 & 0.00 \mathrm{E}+00 & 0.00 \mathrm{E}+00 & 0.00 \mathrm{E}+00 & 0.00 \mathrm{E}+\infty\end{array}$

$\begin{array}{llllll}0.00 E+\infty & 0.00 E+\infty 0 & 0.00 E+\infty 0 & 0.00 E+\infty 0 & 0.00 E+\infty 0\end{array}$

$\begin{array}{llllll}0.00 E+00 & 0.00 E+00 & 0.00 E+\infty 0 & 0.00 E+00 & 0.00 E+00\end{array}$

$0.00 E+00-0.00 E+00 \quad 0.00 E+00 \quad 0.00 E+00 \quad 0.00 E+00$

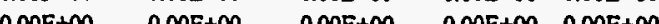

$\begin{array}{llllll}0.00 E+00 & 0.00 E+\infty 0 & 0.00 E+\infty 0 & 0.00 E+00 & 0.00 E+00\end{array}$

$\begin{array}{llllll}0.00 \mathrm{E}+00 & 0.00 \mathrm{E}+00 & 0.00 \mathrm{E}+\infty 0 & 0.00 \mathrm{E}+00 & 0.00 \mathrm{E}+00\end{array}$

$\begin{array}{llllll}0.00 \mathrm{E}+00 & 0.00 \mathrm{E}+00 & 0.00 \mathrm{E}+00 & 0.00 \mathrm{E}+00 & 0.00 \mathrm{E}+00\end{array}$

$0.00 E+\infty 0 \quad 0.00 E+\infty 000.00 E+\infty 000.00 E+\infty 00.00 E+00$

$\begin{array}{lllll}0.00 E+00 & 0.00 E+\infty 0 & 0.00 E+00 & 0.00 E+\infty & 0.00 E+\infty 0\end{array}$

$\begin{array}{llllll}0.00 E+\infty 0 & 0.00 E+\infty 0 & 0.00 E+\infty & 0.00 E+00 & 0.00 E+\infty 0\end{array}$

$\begin{array}{llllll}0.00 \mathrm{E}+\infty & 0.00 \mathrm{E}+\infty & 0.00 \mathrm{E}+\infty 0 & 0.00 \mathrm{E}+\infty & 0.00 \mathrm{E}+\infty\end{array}$

$\begin{array}{llllll}0.00 \mathrm{E}+\infty 0 & 0.00 \mathrm{E}+\infty & 0.00 \mathrm{E}+\infty 0 & 0.00 \mathrm{E}+\infty 0 & 0.00 \mathrm{E}+\infty\end{array}$

$\begin{array}{lllll}0.00 \mathrm{E}+00 & 0.00 \mathrm{E}+00 & 0.00 \mathrm{E}+00 & 0.00 \mathrm{E}+00 & 0.00 \mathrm{E}+00\end{array}$

$\begin{array}{llllll}0.00 E+\infty & 0.00 E+00 & 0.00 E+\infty & 0.00 E+\infty & 0.00 E+\infty 0\end{array}$

$\begin{array}{lllllll}0.00 E+\infty 0 & 0.00 E+\infty 0 & 0.00 E+\infty & 0.00 E+\infty & 0.00 E+\infty\end{array}$

$\begin{array}{lllll}0.00 \mathrm{E}+\infty & 0.00 \mathrm{E}+\infty & 0.00 \mathrm{E}+\infty & 0.00 \mathrm{E}+00 & 0.00 \mathrm{E}+00\end{array}$

$\begin{array}{llllll}0.00 E+\infty & 0.00 E+\infty & 0.00 E+\infty & 0.00 E+\infty 0 & 0.00 E+\infty\end{array}$

$\begin{array}{llllll}0.00 \mathrm{E}+\infty 0 & 0.00 \mathrm{E}+00 & 0.00 \mathrm{E}+\infty 0 & 0.00 \mathrm{E}+00 & 0.00 \mathrm{E}+00\end{array}$

$\begin{array}{lllllllll}0.00 \mathrm{E}+00 & 0.00 \mathrm{E}+00 & 0.00 \mathrm{E}+00 & 0.00 \mathrm{E}+00 & 0.00 \mathrm{E}+00\end{array}$

$\begin{array}{lllllll}0.00 \mathrm{E}+\infty & 0.00 \mathrm{E}+00 & 0.00 \mathrm{E}+00 & 0.00 \mathrm{E}+\infty & 0.00 \mathrm{E}+\infty\end{array}$

$\begin{array}{llllll}0.00 \mathrm{E}+00 & 0.00 \mathrm{E}+\infty & 0.00 \mathrm{E}+00 & 0.00 \mathrm{E}+00 & 0.00 \mathrm{E}+\infty\end{array}$

$0.00 E+00 \quad 0.00 E+\infty 0 \quad 0.00 E+00 \quad 0.00 E+00 \quad 0.00 E+\infty 0$

$\begin{array}{lllllll}0.00 E+00 & 0.00 E+00 & 0.00 E+00 & 0.00 E+00 & 0.00 E+00\end{array}$

$\begin{array}{llllll}0.00 \mathrm{E}+\infty 0 & 0.00 \mathrm{E}+00 & 0.00 \mathrm{E}+\infty 0 & 0.00 \mathrm{E}+00 & 0.00 \mathrm{E}+00\end{array}$

$\begin{array}{lllllll}0.00 E+\infty 0 & 0.00 E+\infty 0 & 0.00 E+\infty & 0.00 E+\infty & 0.00 E+\infty\end{array}$

$0.00 \mathrm{E}+00 \quad 0.00 \mathrm{E}+00 \quad 0.00 \mathrm{E}+00$

$0.00 E+\infty 0$

$000 E+\infty$

$0.00 \mathrm{E}+\infty$

$000 \mathrm{E}+00$

$0.00 E+\infty$

$000 \mathrm{E}+\infty 0$

$0.00 \mathrm{E}+\infty 00$

$0.00 \mathrm{E}+\infty$

$0.00 \mathrm{E}+\infty 00.00 \mathrm{E}+00$

$0.00 \mathrm{E}+00 \quad 0.00 \mathrm{E}+00$

$000 \mathrm{E}+00 \quad 6.65 \mathrm{E}-06$

SW2-5 $0.00 E+00$

$000 E+\infty 0$

SIV4-2 8.13E-0S

$000 \mathrm{E}+\infty 00 \quad 2.66 \mathrm{E}-05$

$1.90 \mathrm{E}-06$

$0.00 \mathrm{E}+00$

$000 \mathrm{E}+00$

$0.00 E+00$

$0.00 \mathrm{E}+00$

$000 \mathrm{E}+00$

$0.00 \mathrm{E}+\infty 0$

$0.00 \mathrm{E}+00$ 


\begin{tabular}{|c|c|c|c|c|c|c|c|c|c|c|c|}
\hline $\begin{array}{r}\text { [NDENO_1 } \\
0.00 \mathrm{E}+00\end{array}$ & $\begin{array}{r}\text { NNDNPA } \\
0.00 \mathrm{E}+00\end{array}$ & $\begin{array}{r}\text { PENTACHL } \\
0.00 E+\infty\end{array}$ & $\begin{array}{r}\text { VINYL_CH } \\
000 \mathrm{E}+\infty\end{array}$ & TRII23 & D12CHL.3 & $\mathrm{DBE} 12$ & DIOXANI4 & PROPENE2 & $\begin{array}{l}\text { 3-33_DI Total Rsk } \\
\text { 3.06E-04 }\end{array}$ & $\begin{array}{r}\text { WAO } \\
7\end{array}$ & $\begin{array}{r}\text { WELL } \\
1084\end{array}$ \\
\hline $0.00 \mathrm{E}+00$ & $000 \mathrm{E}+00$ & $0.00 \mathrm{E}+\infty 0$ & $000 \mathrm{E}+00$ & & & & , & . & 2.07E-05 & 7 & 1085 \\
\hline $0.00 E+\infty 0$ & $0.00 E+00$ & $0.00 \mathrm{E}+\infty 0$ & $000 \mathrm{E}+00$ & & & & & . & $1.89 \mathrm{E}-05$ & 7 & 1086 \\
\hline $0.00 \mathrm{E}+00$ & $0.00 E+00$ & $000 \mathrm{E}+00$ & $000 E+\infty 0$ & & & & & & 6.05E-04 & 8 & 1087 \\
\hline $0.00 \mathrm{E}+00$ & $0.00 E+00$ & $0.00 E+00$ & $000 \mathrm{E}+00$ & & & & & & 8.62E-05 & 8 & 1088 \\
\hline $0.00 \mathrm{E}+00$ & $0.00 \mathrm{E}+00$ & $000 \mathrm{E}+00$ & $000 \mathrm{E}+00$ & & & & & . & $5.92 \mathrm{E}-05$ & 8 & 1089 \\
\hline $0.00 \mathrm{E}+00$ & $0.00 E+\infty 0$ & $000 \mathrm{E}+00$ & $000 E+00$ & & & & . & . & 3.83E.05 & 8 & 1090 \\
\hline $0.00 \mathrm{E}+\infty 0$ & $0.00 \mathrm{E}+\infty$ & $000 E+00$ & $000 E+00$ & & & & . & . & $3.80 \mathrm{E}-05$ & 8 & 1091 \\
\hline $0.00 \mathrm{E}+00$ & $0.00 E+\infty 0$ & $0.00 \mathrm{E}+00$ & $000 E+00$ & & & & & . & $1.98 \mathrm{E}-05$ & 8 & 1092 \\
\hline $0.00 \mathrm{E}+\infty 0$ & $0.00 \mathrm{E}+\infty$ & $000 E+00$ & $0.00 E+00$ & & & & & . & 2.54E-05 & 8 & 1093 \\
\hline $0.00 \mathrm{E}+\infty$ & $0.00 \mathrm{E}+00$ & $000 E+\infty 0$ & $0.00 \mathrm{E}+00$ & . & & & & . & $1.32 \mathrm{E}-05$ & 8 & 1094 \\
\hline $0.00 \mathrm{E}+00$ & $0.00 \mathrm{E}+\infty 0$ & $0.00 \mathrm{E}+00$ & $0.00 E+00$ & & & & & . & 3.34E-05 & 8 & 1095 \\
\hline $0.00 \mathrm{E}+\infty$ & $0.00 \mathrm{E}+\infty$ & $0.00 \mathrm{E}+\infty 0$ & $0.00 E+\infty 0$ & & & & & . & 6.95E-04 & 8 & 1096 \\
\hline $0.00 \hat{E}+\infty$ & $0.00 E+\infty$ & $0.00 E+00$ & $000 E+00$ & & & & & . & 8.01E-04 & 8 & 1097 \\
\hline $0.00 \mathrm{E}+\infty$ & $0.00 \mathrm{E}+00$ & $0.00 E+00$ & $000 E+00$ & & & & & . & $8.45 \mathrm{E} .06$ & 11 & 1139 \\
\hline $000 \mathrm{~B}+00$ & $0.00 \mathrm{E}+00$ & $0.00 \mathrm{E}+00$ & $000 \mathrm{E}+00$ & & & & . & . & $8.76 \mathrm{E}-06$ & 11 & 1140 \\
\hline $0.00 \mathrm{E}+00$ & $000 E+00$ & $000 E+\infty$ & $000 E+00$ & & & & & . & $2.40 \mathrm{E}-05$ & 11 & 1141 \\
\hline $0.00 \mathrm{E}^{1}+\infty 0$ & $0.00 E+00$ & $000 E+\infty 0$ & $000 E+00$ & & & & & . & 2.43E-05 & 11 & 1143 \\
\hline $0 \dot{00} \dot{E}+\infty$ & $000 E+00$ & $000 E+00$ & $000 E+00$ & . & & & & & $1.80 \mathrm{E}-05$ & 11 & 1144 \\
\hline $0.00 E+\infty$ & $000 E+00$ & $000 E+00$ & $000 \mathrm{E}+00$ & . & & & , & . & 6.65E-0.4 & 11 & 1145 \\
\hline $0.00 E+\infty 0$ & $0.00 E+00$ & $000 E+00$ & $000 \mathrm{E}+00$ & . & . & & & . & 3.01E-05 & 11 & 1146 \\
\hline $000 \dot{0}+\infty$ & $0.00 E+00$ & $000 E+00$ & $000 \mathrm{E}+00$ & . & & & & . & $6.33 \mathrm{E}-06$ & 11 & 1147 \\
\hline $0.00 \mathrm{E}+00$ & $0.00 \mathrm{E}+00$ & $000 E+00$ & $0.00 E+00$ & . & & & . & . & $6.06 \mathrm{E}-06$ & 11 & 1148 \\
\hline $000 E+\infty$ & $0.00 E+\infty 0$ & $000 \mathrm{E}+00$ & $000 E+00$ & . & & & . & . & 3.30E-05 & 11 & 1149 \\
\hline $0.00 \mathrm{E}+\infty$ & $0.00 E+00$ & $000 \mathrm{E}+00$ & $000 E+00$ & . & & & & . & $8.55 \mathrm{E}-05$ & 11 & 1246 \\
\hline $0.00 E+00$ & $0.00 \mathrm{E}+00$ & $000 \mathrm{E}+00$ & $000 \mathrm{E}+00$ & . & & & . & . & 4.05E-05 & 17 & 1196 \\
\hline $0.00 \mathrm{E}+00$ & $0.00 E+00$ & $000 \mathrm{E}+00$ & $000 E+00$ & . & . & & . & . & 1.59E-05 & 17 & 1197 \\
\hline $0.00 \mathrm{E}+00$ & $0.00 \mathrm{E}+00$ & $000 \mathrm{E}+00$ & $0.00 E+00$ & . & & & . & . & $4.86 \mathrm{E}-05$ & 17 & 1198 \\
\hline $0.00 \mathrm{E}+00$ & $000 \mathrm{E}+00$ & $000 E+00$ & $0.00 \mathrm{E}+00$ & . & & & & . & $2.36 \mathrm{E} \cdot 05$ & 17 & 1199 \\
\hline $0.00 \mathrm{E}+00$ & $0.00 E+00$ & $000 \mathrm{E}+00$ & $0.00 E+00$ & . & & & & . & $1.82 \mathrm{E}-05$ & 17 & 1200 \\
\hline $0.00 \dot{E}+00$ & $000 E+00$ & $000 \mathrm{E}+00$ & $6.22 \mathrm{E}-03$ & . & & & & . & $6.68 E-03$ & 17 & 1201 \\
\hline $0.00 \mathrm{E}+00$ & $0.00 \mathrm{E}+\infty$ & $0.00 \mathrm{E}+\infty 0$ & $0.00 \mathrm{E}+00$ & . & & & & . & $1.66 \mathrm{E}-05$ & 17 & 1202 \\
\hline \multirow[t]{15}{*}{$0.00 \mathrm{E}+00$} & $0.00 \mathrm{E}+00$ & $000 E+00$ & $000 E+00$ & & & & & . & 196E.05 & 17 & 1203 \\
\hline & & & & . & & & & . & $6.89 \mathrm{E} \cdot 05$ & Seep & $5 N W-1$ \\
\hline & & & & & & & & & 8.33E.05 & Seep & $5 \mathrm{NW}-2$ \\
\hline & & & $000 E+00$ & & $0.00 \mathrm{E}+00$ & $000 \mathrm{E}+00$ & & . & $1.78 \mathrm{E}-02$ & Seep & BTT \\
\hline & & & & & & & & & $6.62 E-03$ & Seep & FRENCH DRA \\
\hline & & & $000 E+00$ & & $000 E+\infty$ & $000 E+00$ & & . & 2.11E-04 & Seep & RS -1 \\
\hline & & & & & & & & & $1.16 \mathrm{E}-03$ & Seep & RS.3 \\
\hline & & & $000 E+00$ & & $000 E+00$ & $000 \mathrm{E}+00$ & & . & $3,31 E-04$ & Seep & sw2-1 \\
\hline & & & $000 E+00$ & & $000 E+00$ & $000 \mathrm{E}+\infty 0$ & & & 6.30E-04 & Seep & Sw2.2 \\
\hline & & & $000 \mathrm{E}+00$ & & $000 \mathrm{E}+\infty 0$ & $000 \mathrm{E}+00$ & & & $6.63 \mathrm{E}-05$ & Seep & Sw2.3 \\
\hline & & & $0.00 E+00$ & & $000 E+\infty$ & $0.00 E+\infty$ & & . & $1.66 \mathrm{E}-03$ & Seep & sw2-4 \\
\hline & & & $0.00 E+00$ & & $000 E+\infty$ & $000 \mathrm{E}+00$ & & . & $1.15 \mathrm{E}-01$ & Seep & sw2.5 \\
\hline & & & 5.82E-04 & & $0.00 \mathrm{E}+00$ & $000 E+\infty 0$ & & . & $6.49 E-03$ & Seep & SW4-1 \\
\hline & & & $2.48 E-03$ & & $000 \mathrm{E}+00$ & $000 E+\infty$ & & . & $1.39 \mathrm{E}-02$ & Seep & sw4-2 \\
\hline & & & & & & & & & $6.33 E-01$ & Seep & sw5.11 \\
\hline
\end{tabular}


Table A.3

WAG

Seep

Seep

Seep

Seep

Seep

Seep

Seep

Seep

Seep

Seep

Seep

Seep

Seep

Seep

Seep
WELL BE SWW-3 4.06E-05

SWW-4 4.06E-05

SWS.5 $0.00 E+\infty 0$

SW5-6 3.05E-05

SWS.7 3.05E.05

SW5-8 $0.00 E+00$

SIVS.9 4.06E-05

SW6-1 2.03E-05

SW6-2 $0.00 E+00$

SW7-1 4.06E-05

SW7.2 4.06E-0S

SWV7.3 5.08E-05

SWV7.5 6.10E.0S

SW7.6 2.03E-05

IV4TRIB-1I

IV4TRIB-5

IV4TRIB-7
B2CEE TETII22 DCEEII METHYL1 METHYL2

Chemical Risk Results by Well

DIC33 PCB1254 BIS_2ET BENZBFLU BENZENE BENZAANT BENZAPYR CARBON_T DIBENZ_A

$0.00 E+\infty 0 \quad 0.00 E+\infty 0$

$0.00 \mathrm{E}+00 \quad 0.00 \mathrm{E}+00$

$0.00 \mathrm{E}+00 \quad 0.00 \mathrm{E}+00$

$0.00 \mathrm{E}+00 \quad 0.00 \mathrm{E}+00$

$0.00 E+00 \quad 0.00 E+00$

$0.00 \mathrm{E}+00 \quad 000 \mathrm{E}+00$

$000 \mathrm{E}+00 \quad 000 \mathrm{E}+00$

$000 E+00 \quad 000 E+00$

$0.00 E+\infty 0000 E+\infty 0$

$000 \mathrm{E}+00 \quad 000 \mathrm{E}+00$
$0.00 \mathrm{E}+\infty$

$000 \mathrm{E}+00$

$0.00 \mathrm{E}+\infty$

$0.00 \mathrm{E}+00$

$000 \mathrm{E}+00$

$000 \mathrm{E}+00$

$0.00 \mathrm{E}+00$

$000 E+\infty$

$000 \mathrm{E}+00$

$000 \mathrm{E}+00$ 
INDENO I NNDNPA PENTACHL VINYL CH TRI123 DI2CHL3 DBE12 DIOXAN14 PROPENE2 333 DI TOtal Rek WAO

WEL

sws.

SW5-4

SW5.5

SW5.6

SW5.7

SW5.8

SWV5-9

SW6-1

SW6-2

SW7.1

SW7.2

SW7.3

Sw7-5

SW7.6

W4TRIB.1]

W4TRIB-

W4TRIB-7 
U 234 AM_241 PU_238 PM_147 $1.00 E+00 \quad 8.45 E+01$ $536-0.00 E+00339100$ 3.3.0.

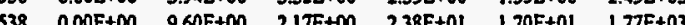

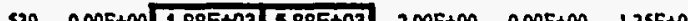

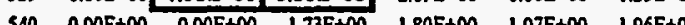
$\begin{array}{lllllll}541 & 3.09 E+01 & 9.61 \mathrm{E}+01 & 1.71 \mathrm{E}+00 & 3.70 \mathrm{E}+00 & 4.24 \mathrm{E}+00 & 1.65 \mathrm{E}+03\end{array}$ $\begin{array}{lllllll}543 & 0.00 E+00 & 0.00 E+00 & 2.95 E+00 & 0.00 E+00 & 1.21 E+00 & 1.77 E+04\end{array}$ $\begin{array}{llllllll}545 & 0.00 E+00 & 4.27 E+01 & 3.71 E+00 & 1.79 E+00 & 0.00 E+00 & 364 E+03\end{array}$ $\begin{array}{lllllll}546 & 0.00 E+00 & 4.10 E+D 0 & 0.00 E+00 & 3.54 E+00 & 8.50 E-01 & 2.50 E+03 \\ 548 & & & 0.00 E+00 & & & 3.5 E+03\end{array}$ $548 \quad 0.00 E+00$. $305 E+03$ $3490.00 E+006.45 E+012.42 E+\infty 0$

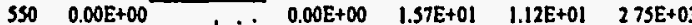
$\begin{array}{lllllll}553 & 0.00 E+\infty 0 & 0.00 E+\infty & 3.79 E+\infty & 1.54 E+\infty & 1.26 E+\infty & 2.33 E+03\end{array}$ $\begin{array}{lllllll}554 & 0.00 E+00 & 0.00 E+00 & 3.24 E+00 & 2.06 E+00 & 1.36 E+\infty 0 & 2.35 E+03\end{array}$

$563 \quad 0.00 E+00 \quad 3.13 E+01 \quad 3.23 E+0 i \quad 9.10 E-01 \quad 0.00 E+00 \quad 4.26 E+03$

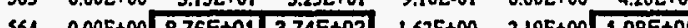

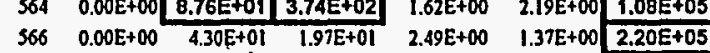
$\begin{array}{lllllll}566 & 0.00 E+00 & 4.30 E+01 & 1.97 E+01 & 2.49 E+00 & 1.37 E+\infty 0 & 2.20 E+05 \\ 571 & 5.23 E+01 & 2.13 \mathrm{E}+01 & 2.77 E+01 & 1.86 \mathrm{E}+00 & 1.61 \mathrm{E}+00 & 17 \mathrm{EE}+03\end{array}$ \begin{tabular}{ll|l|l|l|l|l}
\hline 572 & $2.86 E+02$ & $1.02 E+02$ & $455 E+00$ & $1.09 E+00$ & $0.00 E+00$ & $2.73 E+03$
\end{tabular} $\begin{array}{lllllll}579 & 0.00 E+00 & 000 E+00 & 3.98 E+00 & 3.76 E+00 & 1.34 E+00 & 611 E+03\end{array}$

$\begin{array}{llllllll}587 & 0.00 E+00 & 5.47 \mathrm{E}^{\circ}+00^{\circ} & 971 \mathrm{E}+00^{\circ} & 1.30 \mathrm{E}+00 & 1.12 \mathrm{E}+00 & 157 \mathrm{E}+03\end{array}$ $\begin{array}{llllllll}588 & 0.00 E+00 & 1.93 E+02 & 6.13 E+01 & 3.79 E+00 & 2.04 E+00 & 146 E+03\end{array}$ $\begin{array}{llllllll}589 & 6.70 E+01 & 9.15 E+01 & 2.55 E+02 & 2.74 E+00 & 5.55 E+00 & 356 E+04\end{array}$ $\begin{array}{lllllllll}390 & 3.94 E+01 & 9.38 E+02 & 8.42 E+02 & 2.94 E+00 & 2.22 E+00 & 2.25 E+04\end{array}$ $\begin{array}{llllllll}593 & 0.00 E+00 & 2.63 E+01 & 3.94 E+01 & 1.39 E+01 & 9.50 E+00 & 130 E+02\end{array}$ $596 \quad 0,00 E+00 \quad 450 E+60 \quad 8,63 E+00 \quad 201 E+00 \quad 2.71 E+00 \quad 114 E+03$

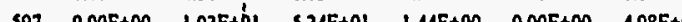

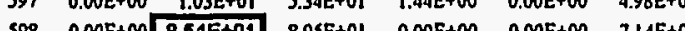

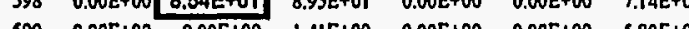
S99 $0.00 E+00 \quad 0.00 E+00 \quad 1.41 E+00 \quad 0.00 E+00 \quad 0.00 E+00$ S.80E+03 $\begin{array}{llllllll}601 & 0.00 \mathrm{E}+00 & 1.27 \mathrm{E}+02 & 9.73 \mathrm{E}+02 & 1.80 \mathrm{E}+00 & 1.56 \mathrm{E}+00 & 3.52 \mathrm{E}+03\end{array}$ $\begin{array}{llllllll}602 & 0.00 \mathrm{E}+00 & 0.00 \mathrm{E}+00 & 3.66 \mathrm{E}+00 & 3.66 \mathrm{E}+00 & 2.52 \mathrm{E}+00 & 1.03 \mathrm{E}+04\end{array}$ $\begin{array}{lllllll}603 & 0.00 E+00 & 4.74 E+01 & 1.99 E+01 & 7.41 E+00 & 3.80 E+00 & 618 E+0.4\end{array}$ $\begin{array}{lllllll}604 & 0.00 \mathrm{E}+00 & 4.90 \mathrm{E}+00 & 1.63 \mathrm{E}+00 & 2.52 \mathrm{E}+00 & 1.90 \mathrm{E}+00 & 48 \mathrm{SE}+03\end{array}$ $3.55 E+03$ $\begin{array}{llllll}608 & 000 E+00 & 2.39 E+01 & 1.20 E+01 & 8.67 E+00 & 2.59 E+00 \\ 1.82 E+05\end{array}$ $\begin{array}{lllllll}610 & 0.00 E+00 & 0.00 E+\infty 0 & 4.43 E+\infty & 0.00 E+00 & 0.00 E+\infty 0 & 1.72 E+03 \\ 611 & 0.00 E+\infty 0 & 6.09 E+60 & 9.17 E+\infty & 3.88 E+\infty 0 & 2.36 E+\infty 0 & 7.33 E+03\end{array}$ $\begin{array}{lllllll}613 & 0.00 E+00 & 1.26 E+02 & 4.51 E+01 & 0.00 E+00 & 1.85 E+00 & 542 E+04\end{array}$ $618 \quad 0.00 E+00 \quad 230 E+00 \quad 2.03 E+00 \quad 1.47 E+00 \quad 0.00 E+00 \quad 331 E+03$

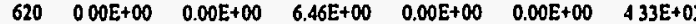
$621 \quad 0.00 \mathrm{E}+00 \quad 0.00 \mathrm{E}+00 \quad 0.00 \mathrm{E}+00 \quad 0.00 \mathrm{E}+00 \quad 0.00 \mathrm{E}+00 \quad 503 \mathrm{E}+03$ $\begin{array}{llllllll}622 & 0.00 E+00 & 3.13 E+00 & 0.00 E+00 & 1.56 E+00 & 1.09 E+00 & 636 E+03\end{array}$

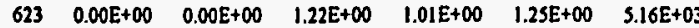
$\begin{array}{lllll}634 & 0.00 E+00 & 0.00 E+00 & 1.30 E+01 & 1.01\end{array}$ $805 \quad 9.60 \mathrm{E}+00$

$807 \quad 139 E+01$ $\frac{1.30 E+01}{1.40 E+02}$ $\frac{1.40 E+02}{4.65 E+00}$

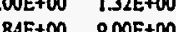
$0.00 E+\infty 00 \quad 2.03 E+02$ $0.00 \mathrm{E}+00 \quad 1.03 \mathrm{E}+00$ $2.90 \mathrm{E}+\infty 00 \quad 4.37 \mathrm{E}+\infty 0$ $0.00 E+\infty \quad 0.00 E+\infty$ $0.00 E+00 \quad 1.58 E+00$ $354 E+00 \quad 2.35 E+00$ $T C_{-} 99$ PU_239 PB_210

$\begin{array}{llllll}4.02 E+00 & 5.73 E+00 & 0.00 E+00 & 0.00 E+00 & 2.75 E+01 & 5.00 E+00\end{array}$ $8.56 \mathrm{E}+00 \quad-0.00 \mathrm{E}+\infty$ $\begin{array}{lllll}0.00 E+\infty 0 & 3.22 \mathrm{E}+\infty 00 & 0.00 E+\infty & 0.00 \mathrm{E}+\infty & 0.00 \mathrm{E}+00 \quad 0.00 \mathrm{E}+\infty\end{array}$ 3.90E-01 $0.00 \mathrm{E}+00$ (1) $0.00 \mathrm{E}+00$

$2.10 \mathrm{E}+00^{\circ} \quad 3.78 \mathrm{E}+00^{\circ} \quad 0.00 \mathrm{E}+00^{\circ} \quad 0.00 \mathrm{E}+\infty 0^{\circ}$ $0.00 \mathrm{E}+00 \quad 0.00 \mathrm{E}+00$ $\begin{array}{lll}1.92 \mathrm{E}+00 & 2.68 \mathrm{E}+00 & .\end{array}$ $\begin{array}{lllll}135 E+01 & 362 \mathrm{E}+00 & 4.60 \mathrm{E}-01 & 5.20 \mathrm{E}-01 & \end{array}$ $000 \mathrm{E}+\infty 00 \quad 2.81 \mathrm{E}+00$ $000 E+\infty \quad 211 E+00 \quad 0.00 E+00$

$000 \mathrm{E}+00^{\circ} \quad 4.62 \mathrm{E}+00^{\circ}$ $210 E+00 \quad 4.03 E+00 \quad 0.00 E+00 \quad 000 E+00 \quad 7.30 E+00$ $675 E+00 \quad 1.41 E+00$

$\begin{array}{lllll}300 E+\infty & 6.93 E+00 & 0.00 E+\infty 00 & 6.40 E-01 & 0.21 E+03\end{array}$ $\begin{array}{lllll}3.70 \mathrm{E}+00 & 6.54 \mathrm{E}+00 & 1.69 \mathrm{E}+00 & 000 \mathrm{E}+00 & 3.87 \mathrm{E}+01\end{array}$ $\begin{array}{llllll}3.70 E+\infty 00 & 9.70 E-01 & 2.04 E+01 & 0.00 E+\infty & 7.80 E+\infty\end{array}$ $0.00 \mathrm{E}+\infty 00 \quad 3.60 \mathrm{E}-01$ 3.57 $\begin{array}{llllll}104 \mathrm{E}+00 & 8.00 \mathrm{E}-01 & 0.00 \mathrm{E}+00 & 0.00 \mathrm{E}+\infty & 0.00 \mathrm{E}+00 & 8.01 \mathrm{E}+00\end{array}$ $000 \mathrm{E}+\infty 00 \quad 0.00 \mathrm{E}+\infty 0$ $0.00 E+\infty 0 \quad 3.45 E+00$ $0.00 \mathrm{E}+00 \quad 1.24 \mathrm{E}+00$ S.70E $+00 \quad 3.33 E+00$ $3.06 \mathrm{E}+00 \quad 2.87 \mathrm{E}+00$ $5.60 \mathrm{E}-01 \quad 1.01 \mathrm{E}+00$ $1.06 \mathrm{E}+00 \quad 5.33 \mathrm{E}+00$ $\begin{array}{ll}0.00 E+00 & 231 \mathrm{E}+00 \\ 133 \mathrm{E}+00 & 267 \mathrm{E}+00\end{array}$

$1.70 E+\infty 0$ $4.30 E-0 i \quad 0.00 E+00$ 1.90E-01 $000 \mathrm{E}+00$

$5.90 \mathrm{E}+00$ $0.00 E+00 \quad 000 E+00$

$000 E+00$

$118 \mathrm{E}+00 \quad 1.74 \mathrm{E}+\infty 00$

$0.00 E+00 \quad 0.00 E+00$

$0.00 \mathrm{E}+\infty 00 \quad 000 \mathrm{E}+00$

$\begin{array}{ll}4.50 E-01 & 6.55 E+00 \\ 0.00 E+\infty 0 & 0.00 E+\infty\end{array}$

$540 E+00$

$000 E+00$

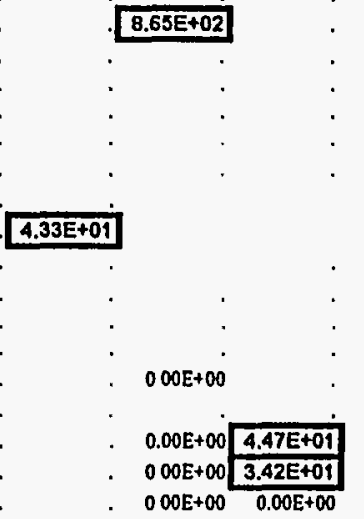




\begin{tabular}{|c|c|c|c|c|c|c|c|c|c|c|c|c|}
\hline $\begin{array}{r}\text { WELLL } \\
814\end{array}$ & $\begin{array}{r}\text { CS_137 } \\
3.95 E+00\end{array}$ & RA_228 & $\begin{array}{r}\text { SR_90 } \\
2.97 \mathrm{E}+00\end{array}$ & TH_228 & $T H_{-} 230$ & $\begin{array}{l}\text { TRMIUM } \\
3.84 E+03\end{array}$ & $\begin{array}{r}\text { TOTAL_RA } \\
2.16 \mathrm{E}+00\end{array}$ & U_234 & $\begin{array}{r}A M_{1} 241 \\
0.00 E+\infty\end{array}$ & $\begin{array}{r}\text { PU_238 } \\
0.00 E+00\end{array}$ & $\begin{array}{r}P M_{-147} 147 \\
0,00 \mathrm{E}+00\end{array}$ & $\begin{array}{r}\text { TC_99 } \\
0.00 E+00\end{array}$ \\
\hline 815 & $1.68 \mathrm{E}+01$ & & $1,73 \mathrm{E}+00$ & : & & $9.92 E+02$ & $8.11 E .01$ & & & & & \\
\hline 816 & $9.85 \mathrm{E}+00$ & & $2.94 E+00$ & . & & $1.66 E+03$ & $2.41 \mathrm{E}+00$ & & & & . & \\
\hline 818 & $4.52 \mathrm{E}+00$ & & $182 E+00$ & . & & $4.48 \mathrm{E}+03$ & $892 \mathrm{E}-01$ & & $000 E+\infty$ & $0.00 E+00$ & & $3.00 E+01$ \\
\hline 819 & $1.27 \mathrm{E}+01$ & & $5.63 \mathrm{E}+00$ & & & I $54 E+03$ & $8.11 \mathrm{E}-01$ & & $000 E+\infty 0$ & $000 E+00$ & $000 E+00$ & $0.00 \mathrm{E}+00$ \\
\hline 820 & $9.27 \mathrm{E}+00$ & & $3.63 E+00$ & & & $810 E+03$ & $3.78 \mathrm{E}-01$ & & & & & \\
\hline 821 & | $41 E+0 \mid$ & & $2.42 E+00$ & & & $2.74 E+03$ & $4.86 \mathrm{E}-01$ & & & & & \\
\hline 822 & $1.91 E+01$ & & $3.41 E+00$ & & & $6.72 E+03$ & $1.62 \mathrm{E}+00$ & & & & . & . \\
\hline 823 & $9.51 E+00$ & & $483 E+00$ & & & $374 E+03$ & $135 E+\infty 0$ & & & & . & \\
\hline 824 & $5.03 E+00$ & & $3.07 E+00$ & & & $2.28 \mathrm{E}+03$ & $1.35 \mathrm{E}+\infty 0$ & & & & & \\
\hline 825 & $5.84 E+00$ & & $3.99 E+01$ & . & & $2.84 E+03$ & 8.1IE-01 & & & & . & \\
\hline 826 & $1.45 E+01$ & & $4.57 E+\infty 0$ & & & $2.07 \mathrm{E}+03$ & & & & & & \\
\hline 827 & $1.21 E+01$ & & $3.61 \mathrm{E}+\infty 0$ & & & $1.54 E+03$ & $2.70 \mathrm{E}-01$ & & & . & $r$ & \\
\hline 828 & $698 E+00$ & & $3.10 E+00$ & & & $2.15 E+03$ & $1.08 E+00$ & & & . & . & \\
\hline 829 & $498 E+00$ & & $2.10 E+01$ & & & $1.79 E+03$ & $3.41 E-01$ & & & & . & \\
\hline 830 & $120 E+01$ & & $4.15 E+01$ & & & $360 E+04$ & $1.08 E+00$ & & & & & \\
\hline 873 & $000 E+\infty$ & $0.00 E+100$ & $1.83 E+01$ & $1.30 \mathrm{E}+00$ & $0.00 E+00$ & $9.71 E+03$ & $0.00 E+00$ & $210 E+\infty 0$ & & . & . & \\
\hline 874 & $000 E+\infty$ & $3.16 E+02$ & $1.12 E+03$ & $1.29 E+\infty 0$ & $0.00 E+0$. & $4.04 E+05$ & $0.00 E+00$ & $167 E+\infty 0$ & & . & . & \\
\hline 873 & $103 E+01$ & 1.87E+03 & $1.20 \mathrm{E}+04$ & $1.31 E+\infty 0$ & $927 E+00$ & $8.28 E+05$ & $0.00 E+\infty 0$ & $102 E+01$ & $0.00 E+\infty$ & $0.00 E+\infty 0$ & $4.43 \mathrm{E}+02$ & $0.00 E+00$ \\
\hline 876 & $000 E+00$ & & $4.40 E+\infty 0$ & & & $3.39 \mathrm{E}+05$ & & & & & & \\
\hline 877 & $0.00 E+\infty$ & $7.28 E+\infty$ & $232 \mathrm{E}+01$ & $1.16 \mathrm{E}+00$ & $000 E+00$ & $2.49 E+03$ & $1.38 E+00$ & $163 E+\infty 0$ & . & $0.00 E+00$ & & \\
\hline 878 & $000 E+\infty$ & $0.00 \mathrm{E}+00$ & $0.00 \mathrm{E}+00$ & $0.00 E+\infty 0$ & $000 E+00$ & $2.66 \mathrm{E}+03$ & $0.00 E+00$ & $116 E+\infty 00$ & & . & - & \\
\hline 879 & $0.00 E+\infty$ & $0.00 E+00$ & $1.09 \mathrm{E}+\infty 0$ & $133 E+\infty 0$ & $114 E+00$ & $3.02 E+03$ & $0.00 E+00$ & $0.00 E+00$ & & & & \\
\hline 880 & $000 E+\infty$ & $0.00 E+\infty$ & $1.84 E+00$ & $000 E+\infty 0$ & $0.00 E+00$ & $2.86 \mathrm{E}+03$ & $0.00 E+00$ & $0.00 E+00$ & & . & & \\
\hline 881 & $000 E+\infty$ & $0.00 E+00$ & $2.88 \mathrm{E}+00$ & $000 E+00$ & $000 E+00$ & $256 \mathrm{E}+03$ & $0.00 E+00$ & $1.24 E+00$ & & & & \\
\hline 882 & $0.00 E+00$ & $3.75 E+00$ & $2.03 E+01$ & $0.00 E+\infty$ & $0.00 E+00$ & $10.4 E+04$ & $0.00 E+00$ & $1.22 \mathrm{E}+00$ & & & & \\
\hline 884 & $000 E+00$ & $9.33 E+01$ & $0.00 E+00$ & $1.11 E+\infty 0$ & $4.59 \mathrm{E}+00$ & $1.71 E+03$ & $0.00 E+00$ & $0.00 E+\infty 0$ & & . & & \\
\hline 885 & $000 E+\infty$ & $1.30 \mathrm{E}+01$ & $3.08 \mathrm{E}+01$ & $0.00 E+00$ & $0.00 E+00$ & $9.12 E+05$ & $0.00 E+00$ & $000 E+00$ & & & & $4.60 E+00$ \\
\hline 886 & $0.00 E+\infty 0$ & $0.00 E+00$ & $330 E+00$ & $0.00 E+\infty 0$ & $000 E+00$ & $.1 .14 E+04$ & $0.00 \mathrm{E}+00$ & $000 E+00$ & & & & \\
\hline 946 & $1.18 E+01$ & & $1.59 \mathrm{E}+01$ & & & $1.35 E+03$ & & & . & & & 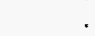 \\
\hline 947 & $8.77 E+\infty 0$ & & $6.49 \mathrm{E}+00$ & & & $1.29 \mathrm{E}+04$ & & & & & & \\
\hline 1100 & $0.00 E+00$ & $1.75 E+01$ & $1.11 \mathrm{E}+02$ & $0.00 E+\infty 0$ & $000 E+00$ & $1.04 E+03$ & $0.00 E+00$ & $0.00 E+\infty$ & & & . & \\
\hline 1101 & $000 E+\infty 0$ & & $1.15 E+02$ & $0.00 E+00$ & $0.00 E+00$ & $1.6 \mathrm{gE}+05$ & $1.40 E+02$ & $7.74 E+\infty 0$ & & & . & \\
\hline 1102 & $000 E+00$ & $3.08 E+02$ & $1.01 E+03$ & $0.00 \mathrm{E}+00$ & $0.00 E+00$ & $4.20 E+04$ & $1.34 E+00$ & $2.59 E+00$ & & & . & \\
\hline 1103 & $000 E+\infty 0^{\circ}$ & $1.72 \mathrm{E}+01$ & $376 \mathrm{E}+01$ & $0.00 E+00$ & $0.00 E+00$ & $1.99 E+0.4[$ & $6.93 E+01$ & $0.00 E+\infty 0$ & & & & \\
\hline 1104 & $0.00 E+00$ & $1.53 E+01$ & $8.69 E+01$ & $0.00 E+00$ & $2.62 E+03$ & $7.95 E+04$ & $0.00 E+00$ & $0.00 \mathrm{E}+00$ & $0.00 \mathrm{E}+00$ & $000 \mathrm{E}+00$ & $0.00 E+00$ & $0.00 E+00$ \\
\hline 2531 & $0.00 E+00$ & $2.84 E+01$ & & $610 \mathrm{E}-01$ & $0.00 E+00$ & $1.65 E+03$ & $2.00 E+\infty 0$ & 4.90E.01 & $0.00 E+\infty 0$ & $000 \mathrm{E}+\infty 0$ & $181 E+01$ & $0.00 E+00$ \\
\hline 2533 & $0.00 E+\infty$ & & $7.49 E+00$ & & & $1.94 E+03$ & & & & & & \\
\hline 4003 & $000 E+00$ & & $419 E+00$ & & & $2.04 E+03$ & & & & & & \\
\hline 4004 & $0.00 E+\infty 0$ & & $5.12 \mathrm{E}+00$ & & & $3.25 \mathrm{E}+03$ & & & & & $3.10 E+01$ & $6.70 E+00$ \\
\hline 4005 & $0.00 E+00$ & $0.00 E+0$. & $3.12 \mathrm{E}+05$ & $3.18 E+\infty 0$ & $000 E+00$ & $3.54 E+03$ & $7.88 \mathrm{E}+00[$ & $3.35 E+03$ & $3.95 E+\infty 0$ & $000 E+\infty 0$ & $4.08 E+04$ & $6.34 E+01$ \\
\hline 4006 & $000 E+00$ & & $3.95 \mathrm{E}+00$ & & & $300 E+04$ & & & & & & \\
\hline 4008 & $000 \mathrm{E}+\infty$ & $1.38 E+02$ & $1.74 E+00$ & $630 E+00$ & $000 E+00$ & $880 E+02$ & $9.00 E-01$ & $7.72 \mathrm{E}+00$ & $0.00 E+00$ & $000 \mathrm{E}+00$ & 1. $.11 E+02$ & $0.00 E+00$ \\
\hline 4009 & $0.00 E+00$ & & $0.00 E+00$ & & & $3.10 E+02$ & & & & & 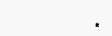 & \\
\hline 1150 & $3.78 E+\infty 0$ & & & & & & & & & & ' & \\
\hline 1151 & $3.51 \mathrm{E}+01$ & & $6.62 \mathrm{E}+00$ & & & $1.75 E+03$ & . & & & & 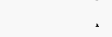 & \\
\hline 1152 & $5.95 E+01$ & & $3.30 E+00$ & & & $2.70 E+05$ & . & & & & . & \\
\hline 1153 & $5.14 E+00$ & & $9.46 \mathrm{E}+00$ & & & $1.28 E+03$ & . & & & & . & \\
\hline 1154 & $216 E+01$ & & $3.78 E+00$ & & & $1.46 \mathrm{E}$ & . & & & & . & \\
\hline $115 s$ & $420 \mathrm{E}+\infty 0$ & & $223 \mathrm{E}+\infty 0$ & & & $3.51 E+03$ & & & & & . & \\
\hline 1156 & 4.05E +01 & & $250 \mathrm{E}+00$ & & & $2.53 E+05$ & . & & & & . & \\
\hline 1183 & $135 E+01$ & & $2.98 E+00$ & & & $1.19 E+03$ & & & & & . & \\
\hline 1186 & $324 E+00$ & & 2.2 & & & $162 \mathrm{E}$ & & & & & . & \\
\hline 1187 & $7.30 E+00$ & & $482 E+00$ & & & 103 & & & & & & \\
\hline 1188 & $122 \mathrm{E}+01$ & & $262 \mathrm{E}+00$ & & & $182 E+03$ & & & & & & \\
\hline
\end{tabular}

K_40 CM_244 C_ $14 \quad$ CO 60 $0.00 \mathrm{E}+00 \quad 0.00 \mathrm{E}+00 \quad 1 \quad 16 \mathrm{E}+01$

$0.00 \mathrm{E}+00 \quad 3.11 \mathrm{E}+02$

$9.06 \mathrm{E}+00$

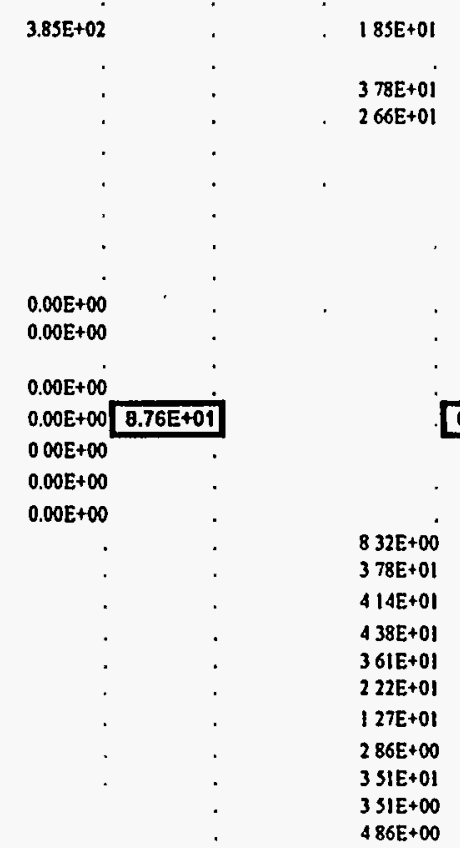




\begin{tabular}{|c|c|c|c|c|c|c|c|c|c|c|c|c|c|}
\hline $\begin{array}{r}\text { WELL } \\
1189\end{array}$ & $\begin{array}{r}\text { CS_137 } \\
4.32 E+01\end{array}$ & RA_228 & $\begin{array}{r}\text { SR_90 } \\
1.53 E_{+}+\infty\end{array}$ & TH_228 & $\mathrm{TH}_{-} 230$ & $\begin{array}{l}\text { TRTTUM } \\
2.86 \mathrm{E}+03\end{array}$ & TOTAL_RA & U_234 & $A M_{-} 241$ & PU_238. & PM_147 & TC_99 & $\mathrm{PU}_{-} 239$ \\
\hline 1190 & $2.16 E+00$ & & $4.80 E+00$ & . & & $7.47 \mathrm{E}+04$ & & & . & . & & & \\
\hline 1191 & $2.37 E+01$ & & $8.62 E+02$ & . & & $1.92 \mathrm{E}+05$ & & . & . & • & & & . \\
\hline 1192 & $1.20 E+01$ & & $5.81 E+\infty$ & . & & $3.79 E+03$ & & . & . & . & . & & \\
\hline 1193 & $2.33 E+01$ & & $5.95 E+00$ & . & & $4.86 \mathrm{E}+02$ & & • & . & : & : & : & : \\
\hline 1194 & $2.77 E+00$ & & . $4.08 E+\infty 0$ & & & $6.19 E+02$ & & $\cdot$ & . & . & & & \\
\hline 1195 & 1.3SE +00 & 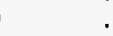 & $3.79 \mathrm{E}+\infty$ & . & & $1.06 \mathrm{E}+03$ & & 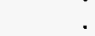 & 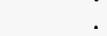 & . & . & . & \\
\hline 1244 & $2.43 \mathrm{E}+00$ & & $3.46 E+\infty$ & . & & $3.70 E+04$ & & & & . & - & & \\
\hline 1245 & 3.78E +00 & & $5.95 E+\infty 0$ & . & & $0.00 E+00$ & & . & . & . & 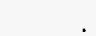 & & \\
\hline 985 & $1.89 E+01$ & & $3.51 E+\infty$ & & & $1.53 \mathrm{E}+03$ & & 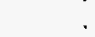 & . & . & & & \\
\hline 986 & 1.15E +01 & & $2.03 \mathrm{E}+00$ & . & & $1.55 E+03$ & & & & . & . & & \\
\hline 987 & $2.70 E+01$ & & $2.80 \mathrm{E}+\infty 0$ & . & & $1.11 E+03$ & & & . & : & & & \\
\hline 988 & $1.89 E+00$ & & $2.59 E+00$ & . & & $1.24 E+03$ & & & . & . & . & & \\
\hline 990 & $1.08 E+00$ & & $2.62 \mathrm{E}+00$ & . & & $1.35 E+03$ & & & & & & & \\
\hline 991 & $1.35 \mathrm{E}+01$ & & $5.27 \mathrm{E}+\infty$ & . & & $7.84 \mathrm{E}+02$ & & . & . & : & . & , & \\
\hline 992 & $1.62 E+01$ & & $1.43 E+02$ & . & & $8.38 E+02$ & & . & . & . & & & \\
\hline 993 & $1.08 E+00$ & & $2.10 E+02$ & . & & $1.27 E+03$ & & & . & & . & & \\
\hline 994 & $2.43 E+01$ & & $6.48 \mathrm{E}+02$ & . & & $3.24 E+04$ & & & . & . & & & . \\
\hline 995 & $1.08 E+01$ & & $2.16 \mathrm{E}+\infty$ & & & $1.16 \mathrm{E}+03$ & & & . & & & & \\
\hline 996 & $1.89 E+00$ & & $5.41 E+\infty 0$ & . & & $1.48 \mathrm{E}+03$ & & & . & & & & \\
\hline 997 & $1.62 E+01$ & & $103 E+02$ & . & & $1.43 \mathrm{E}+03$ & & & . & & . & & \\
\hline 998 & $1.35 \mathrm{E}+00$ & & $2.35 \mathrm{E}+00$ & : & & $1.30 \mathrm{E}+03$ & & & . & & & & \\
\hline 1248 & $3.78 E+01$ & & $216 \mathrm{E}+01$ & . & & $2.16 \mathrm{E}+02$ & & . & . & : & & . & $\cdot$ \\
\hline 948 & $1.59 E+00$ & & $412 E+00$ & . & & $6.95 E+02$ & & & . & & & & \\
\hline 949 & 2.0SE +01 & & $192 \mathrm{E}+00$ & . & & $1.95 E+04$ & & & . & . & & & \\
\hline 950 & $5.94 E+00$ & & $280 \mathrm{E}+00$ & . & & $8.05 E+02$ & & & . & : & . & & : \\
\hline 931 & $7.56 \mathrm{E}+00$ & & $5.08 E+\infty$ & . & & $2.21 E+02$ & & & e & . & - & & \\
\hline 952 & $1.57 \mathrm{E}+01$ & & $1.65 E+\infty$ & . & & $2.70 \mathrm{E}+04$ & & . & . & . & . & & \\
\hline 953 & $2.3 \mathrm{BE}+\infty 0$ & & $7.01 E+\infty$ & . & & $4.30 \mathrm{E}+02$ & & & ; & & & & \\
\hline 954 & $4.75 E+00$ & & $3.95 E+00$ & & & $3.04 E+05$ & & . & ' & & . & & . \\
\hline 9ss & $5.41 E+01$ & & $4.05 E+01$ & & & $5.03 E+05$ & & & . & & e & . & \\
\hline 986 & $1.92 E+01$ & & $7.25 E+02$ & . & & $1.55 E+05$ & & & . & & & & . \\
\hline 957 & $2.41 E+01$ & & $1.94 \mathrm{E}+00$ & . & & $6.96 E+06$ & & & . & & . & & \\
\hline 958 & $419 E+01$ & & $3.25 E+00$ & . & & $9.24 E+06$ & & & . & & e & & \\
\hline 959 & $1.49 E+01$ & & $6.74 E+00$ & & & $1.02 E+04$ & . & & . & . & & . & \\
\hline 960 & $2.05 E+01$ & & $369 E+00$ & . & & $7.26 \mathrm{E}+04$ & & . & 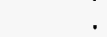 & & & & \\
\hline 961 & $2.43 E+01$ & & $5 . S 1 E+\infty 0$ & . & & $9.14 E+02$ & & & . & & & & \\
\hline 962 & $4.05 E+00$ & & $9.73 E+00$ & & & $8.64 E+03$ & & & & & & & \\
\hline 440 & $0.00 E+00$ & $0.00 E+00$ & $5.74 E+02$ & $3.68 \mathrm{E}+01$ & $1.62 E+01$ & $2.72 E+07$ & $364 E+00$ & $1.86 \mathrm{E}+01$ & $7.75 E+\infty 0$ & $5.75 E+00$ & & $2.41 E+01$ & $0.00 E+00$ \\
\hline 441 & $7.06 \mathrm{E}+00$ & $9.62 E+01$ & $2.90 E+02$ & $6.06 E+\infty 00$ & $7.18 E+00$ & $3.00 E+05$ & $270 E+00$ & $3.40 E+00$ & $5.20 \mathrm{E}-01$ & 5.50E-01 & & $0.00 E+\infty 0$ & $0.00 E+\infty 0$ \\
\hline 468 & $0.00 E+00$ & $1.70 \mathrm{E}+00$ & $3.90 \mathrm{E}+00$ & $3.77 \mathrm{E}+00$ & $3.88 E+\infty 0$ & $6.80 \mathrm{E}+03$ & $330 E+00$ & $2.50 E+00$ & 3.10 E. 01 & $1.90 \mathrm{E}-01$ & & $1.72 E+01$ & $0.00 E+\infty 0$ \\
\hline 472 & $0.00 E+00$ & $8.80 E+01$ & $4.40 E+02$ & $1.73 E+00$ & $1.55 E+\infty$ & $1.50 E+06$ & $137 E+00$ & $840 E+00$ & $0.00 E+\infty 0$ & $000 E+\infty 0$ & & $000 E+00$ & $0.00 E+00$ \\
\hline 476 & $0.00 E+00$ & $0.00 E+00$ & $1.46 E+04$ & $000 E+00$ & 2.49E-01 & $5.16 E+06$ & $530 E+\infty 00$ & $1.40 E+01$ & $4.10 \mathrm{E}+\infty 0$ & $695 \mathrm{SE}+00$ & & $3.82 E+02$ & $1.30 E+00$ \\
\hline $\begin{array}{l}513 \\
514\end{array}$ & $\begin{array}{l}0.00 E+\infty 0 \\
0.00 E+00\end{array}$ & & $\begin{array}{l}0.00 E+00 \\
0.00 E+00\end{array}$ & $\begin{array}{l}5.63 \mathrm{E}+\infty 0 \\
0.00 \mathrm{E}+00\end{array}$ & $\begin{array}{l}3.16 E+00 \\
0.00 E+00\end{array}$ & $\begin{array}{l}1.29 \mathrm{E}+03 \\
1.24 \mathrm{E}+03\end{array}$ & $\begin{array}{l}1.13 \mathrm{E}+01 \\
4.66 \mathrm{E}-01\end{array}$ & $330 \mathrm{E}+00$ & $0.00 E+00$ & $1.48 E+00$ & & & $\begin{array}{l}0.00 E+00 \\
0.00 E+00\end{array}$ \\
\hline 514 & $0.00 E+00$ & $0.00 E+00$ & $0.00 E+00$ & $0.00 E+00$ & $0.00 \mathrm{E}+00$ & $1.24 E+03$ & $4.66 \mathrm{E}-01$ & $0.00 E+00$ & $0.00 E+\infty 0$ & $0.00 E+00$ & & $0.00 E+\infty 0$ & $0.00 E+\infty 0$ \\
\hline$\$ 16$ & $0.00 E+00$ & $0.00 E+00$ & $0.00 E+00$ & $1.04 E+00$ & S.71E-01 & $160 E+03$ & $337 E-01$ & $3.99 \mathrm{E} \cdot 01$ & $1.12 \mathrm{E}+\infty$ & $7.84 \mathrm{E}-01$ & & $000 E+00$ & $0.00 E+\infty 0$ \\
\hline $\begin{array}{l}517 \\
518\end{array}$ & $\begin{array}{l}7.22 E+00 \\
0.00 E+00\end{array}$ & $0.00 E+00$ & $\begin{array}{l}0.00 E+00 \\
0.00 E+\infty\end{array}$ & $\begin{array}{l}2.18 E+00 \\
0.00 E+00\end{array}$ & $\begin{array}{l}2.38 E+\infty \\
0.00 E+\infty 0\end{array}$ & $\begin{array}{l}5.56 E+02 \\
1.03 E+03\end{array}$ & $\begin{array}{r}3.10 E-01 \\
0.00 E+00\end{array}$ & $1.28 E+00$ & $\begin{array}{l}6.70 \mathrm{E}-01 \\
0.00 \mathrm{E}+00\end{array}$ & $2.24 E+\infty 0$ & . & $0.00 E+00$ & $0.00 E+00$ \\
\hline 519 & $7.62 E+00$ & $2.41 \mathrm{E}+01$ & $000 E+\infty 0$ & $8.53 \mathrm{E}+00$ & $7.77 E+00$ & $6.29 E+02$ & $905 E+00$ & $856 E+00$ & $1.39 E+00$ & $0.00 E+00$ & . & $112 E+02$ & $000 E+\infty 0$ \\
\hline 520 & $0.00 E+00$ & & $0.00 E+00$ & $0.00 E+00$ & $0.00 E+00$ & $8.01 E+02$ & $0.00 E+00$ & $0.00 E+00$ & $0.00 E+00$ & $0.00 E+00$ & & $000 E+\infty$ & $0.00 E+\infty 0$ \\
\hline 521 & $0.00 E+00$ & & $0.00 E+00$ & $000 E+00$ & $0.00 E+\infty$ & $8.17 E+02$ & $000 E+00$ & $000 E+00$ & $3.73 E+01$ & $0.00 E+\infty$ & & $0.00 E+\infty 0$ & $000 E+\infty$ \\
\hline 522 & $0.00 E+00$ & $4.62 E+01$ & $000 E+00$ & $0.00 E+00$ & $0.00 E+00$ & $000 \mathrm{E}+00$ & $140 E+00$ & $000 E+00$ & $0.00 E+00$ & $0.00 E+\infty 0$ & & $1.29 \mathrm{E}+01$ & $0.00 E+\infty 0$ \\
\hline 523 & OOOE +00 & & $0.00 E+\infty$ & & & $1.60 E+03$ & & S.1SE +00 & $7.50 E-01$ & $0.00 E+\infty 0$ & & $1.67 E+01$ & $000 E+\infty 0$ \\
\hline 524 & $000 E+00$ & $600 E+00$ & $0.00 E+00$ & $5.60 E+\infty 0$ & $280 E+\infty 0$ & $786 \mathrm{E}+03$ & $384 E+00$ & $450 E+00$ & $6.80 E-01$ & $0.00 \mathrm{E}+00$ & & $464 E+01$ & $000 E+00$ \\
\hline 525 & OOOE +00 & & $0.00 E+00$ & $7.20 \mathrm{E}-01$ & $180 \mathrm{E}-01$ & $410 E+02$ & $S 17 E+\infty 0$ & $000 E+00$ & $0.00 E+00$ & $3.40 \mathrm{E}-01$ & & $000 E+\infty$ & $000 E+00$ \\
\hline
\end{tabular}




\begin{tabular}{|c|c|c|c|c|c|c|c|c|c|c|c|c|c|c|c|c|c|c|c|}
\hline $\begin{array}{r}\text { WAG } \\
3 \\
3\end{array}$ & $\begin{array}{r}\text { WELL } \\
526 \\
708\end{array}$ & $\begin{array}{r}C S \_137 \\
0.00 E+00 \\
0.00 E+00\end{array}$ & RA_228 & $\begin{array}{r}\text { SR_90 } \\
480 E+00 \\
0.00 E+00\end{array}$ & $\begin{array}{l}\text { TH_228 } \\
2.80 E \cdot 01\end{array}$ & $\begin{array}{r}T_{-} 230 \\
000 E+00\end{array}$ & $\begin{array}{l}\text { TRMUUM } \\
1.70 E+04 \\
106 E+03\end{array}$ & $\begin{array}{r}\text { TOTAL_RA } \\
000 E+\infty\end{array}$ & $\begin{array}{r}U-234 \\
890 E \cdot 01 \\
5.20 E-01\end{array}$ & $\begin{array}{l}A M_{2} 241 \\
0.00 E+\infty 0 \\
1.40 E+\infty 0\end{array}$ & $\begin{array}{l}\text { PU_238 } \\
0.00 E+\infty 0^{\circ}\end{array}$ & PM__147 & $\begin{array}{r}\text { TC_99 } \\
0.00 E+00 \\
339 E+01\end{array}$ & $\begin{array}{l}P U_{-} 239 \\
0.00 E+00\end{array}$ & PB_210 & $\mathrm{CM}_{-} 244$ & $\begin{array}{r}C_{-} 14 \\
000 E+00 \\
0.00 E+00\end{array}$ & $\mathrm{CO}_{-} 6 \mathrm{O}$ & SR_89 \\
\hline 3 & 715 & $0.00 E+00$ & $4.86 \mathrm{E}+01$ & $000 E+00$ & $480 \mathrm{E}+00$ & $3.51 \mathrm{E}+\infty 0$ & $184 E+03$ & $S 44 E+00$ & $100 E+01$ & $0.00 \mathrm{E}+00$ & $0.00 E+00$ & & & $0.00 E+00$ & $6.72 E+02$ & & $0.00 E+\infty 0$ & & . \\
\hline$s$ & 716 & $7.60 E+00$ & $2.10 E+\infty 0$ & $000 E+00$ & $1.50 \mathrm{E}+\infty 0$ & $1.80 E+\infty 0$ & $4.10 E+02$ & $14 S E+\infty 0$ & $1.10 E+00$ & $0.00 E+\infty 0$ & $0.00 E+00$ & & $120 E+01$ & $0.00 E+00$ & & & $0.00 E+\infty 0$ & & \\
\hline$s$ & 963 & $1.24 E+01$ & $000 E+00$ & $1.21 E+00$ & $0.00 \mathrm{E}+00$ & $9.83 \mathrm{E} \cdot 02$ & $253 E+02$ & $000 E+00$ & S24E.01 & $0.00 E+00$ & $5.68 \mathrm{E} \cdot 02$ & & $0.00 E+00$ & $0.00 E+00$ & & $0.00 E+00$ & $0.00 E+00$ & $3.78 E+00$ & \\
\hline s & 964 & $2.00 E+01$ & $0.00 E+00$ & $4.05 E+00$ & $0.00 \mathrm{E}+00$ & $0.00 \mathrm{E}+\infty 0$ & $1.04 E+03$ & $000 E+00$ & 4 OSE.01 & $568 \mathrm{E}-02$ & $0.00 E+00$ & & $0.00 E+\infty$ & $8.92 E-02$ & $\cdot$ & $2.00 E \cdot 01$ & $9.19 \mathrm{E}+01$ & $1.12 \mathrm{E}+01$ & \\
\hline 5 & 965 & $1.09 E+01$ & $1.13 E+00$ & $3.29 \mathrm{E}-01$ & $4.03 \mathrm{E}-01$ & $000 E+\infty 0$ & $1.41 \mathrm{E}+03$ & $000 E+00$ & SAIE.0I & $1.26 \mathrm{E} \cdot 01$ & 3.51E-02 & & $000 E+00$ & $5.95 E .03$ & . & $1.97 E .01$ & $2.97 \mathrm{E}+01$ & $4.99 E+01$ & \\
\hline 5 & 966 & $3.00 E+00$ & $1.02 E+00$ & $2.00 E+00$ & $0.00 E+00$ & $0.00 E+\infty$ & $1.38 E+03$ & $2.22 \mathrm{E}-01$ & 595E-01 & $7.03 E-02$ & $0.00 E+\infty 0$ & & $000 E+\infty$ & $1.08 E-02$ & . & $0.00 E+00$ & $9.19 E+01$ & $2.09 E+01$ & \\
\hline 3 & 967 & $8.78 E+00$ & $0.00 E+00$ & $489 E+00$ & $0.00 \mathrm{E}+00$ & $6.32 \mathrm{E}-01$ & $1.28 E+03$ & $000 E+00$ & $686 \mathrm{E} .01$ & 4.59E-02 & S.07E.02 & & $0.00 \mathrm{E}+00$ & $0.00 E+00$ & . & $2.16 E-02$ & $1.08 E+02$ & $2.23 E+01$ & \\
\hline s & 968 & $2.97 E+00$ & $1.79 \mathrm{E}-01$ & $1.65 E+00$ & $2.92 \mathrm{E}-01$ & $3.66 \mathrm{E}-01$ & $2.84 E+05$ & $000 E+00$ & $608 \mathrm{E}-01$ & $1.09 \mathrm{E}-01$ & $0.00 E+00$ & & $000 E+00$ & $1.12 \mathrm{E}-01$ & . & $0.00 E+00$ & $0.00 E+00$ & $1.57 E+01$ & \\
\hline$s$ & 969 & $1.90 E+00$ & $0.00 E+00$ & $5.42 E+02$ & $3.78 \mathrm{E}-01$ & $000 E+00$ & $1.92 E+07$ & $000 E+00$ & $760 \mathrm{E}-01$ & $3.62 \mathrm{E}-01$ & 8.71E-01 & & $000 E+00$ & $3.68 \mathrm{E}-02$ & & $4.21 E+00$ & $1.62 E+02$ & $2.41 E+00$ & \\
\hline 3 & 970 & $3.51 E+00$ & $0.00 E+00$ & $407 \mathrm{E}+00$ & $0.00 E+\infty 0$ & $5.88 \mathrm{E}+\infty 0$ & $1.15 E+06$ & $000 E+00$ & $324 \mathrm{E} .01$ & $1.18 \mathrm{E}-01$ & $7.23 \mathrm{E}-02$ & & $000 E+00$ & $0.00 E+\infty 0$ & . & $0.00 E+00$ & $0.00 E+\infty 0$ & $2.97 E+01$ & \\
\hline s & 971 & $1.17 E+01$ & $3.76 \mathrm{E}-01$ & $448 E+01$ & $0.00 \mathrm{E}+00$ & $1.82 \mathrm{E}-01$ & $1.16 E+06$ & $0.00 E+00$ & $460 E-01$ & $7.89 \mathrm{E} \cdot 02$ & 4 59E.02 & & $0.00 E+00$ & $2.70 \mathrm{E}-03$ & . & $482 E-01$ & $0.00 E+\infty$ & $2.30 \mathrm{E}+0 \mathrm{I}$ & \\
\hline$s$ & 972 & $8.11 E .01$ & $1.64 E+00$ & $3.44 E+01$ & $5.31 \mathrm{E} \cdot 01$ & $0.00 \mathrm{E}+00$ & $4.32 E+05$ & $000 E+00$ & $432 \mathrm{E}-01$ & $1.93 \mathrm{E}-01$ & $2.16 \mathrm{E}-01$ & & $000 E+00$ & $000 E+00$ & . & $1.34 E-01$ & $0.00 E+00$ & $1.08 E+01$ & r \\
\hline s & 973 & $1.33 \mathrm{E}+0 \mathrm{t}$ & $7.74 E+01$ & $1.42 E+02$ & $0.00 E+\infty$ & $000 \mathrm{E}+00$ & $2.90 E+08$ & $000 E+00$ & $268 \mathrm{E} .01$ & $165 E+00$ & 4.31E-01 & & $000 E+00$ & $0.00 E+00$ & & $1.30 E+01$ & $1.57 E+03$ & $1.69 \mathrm{E}+00$ & . \\
\hline$s$ & 974 & $5.24 E+00$ & $3.69 \mathrm{E}+00$ & $3.37 E+01$ & $000 E+00$ & $000 E+00$ & \begin{tabular}{|l|}
$8.38 E+07$ \\
\end{tabular} & $000 E+00$ & $3.78 \mathrm{E} \cdot 01$ & $1.03 \mathrm{E} \cdot 01$ & $1.40 E+00$ & & $000 E+00$ & $0.00 \mathrm{E}+00$ & . & $3.71 \mathrm{E}-01$ & $111 \mathrm{E}+03$ & $3.78 \mathrm{E}+0 \mathrm{t}$ & \\
\hline$s$ & 975 & $106 E+01$ & $000 E+00$ & $5.47 E+02$ & $0.00 E+00$ & $000 E+00$ & $7.84 E+06$ & $000 E+00$ & 3 SIE-0I & $2.70 \mathrm{E}-01$ & $5.22 \mathrm{E}-01$ & & $000 E+00$ & $9.14 E-02$ & . & $179 E+00$ & $811 \mathrm{E}+02$ & $981 E+\infty 0$ & \\
\hline s & 976 & $|26 E+0|$ & $109 E+00$ & $920 \mathrm{E}+00$ & $4.69 \mathrm{E}-01$ & $000 \mathrm{E}+00$ & $6.07 E+06$ & $224 E .01$ & $346 \mathrm{E} .01$ & $3.63 \mathrm{E}-01$ & 8.65E-02 & & $000 E+00$ & $8.11 E-03$ & . & $6.71 \mathrm{E}-01$ & $4.61 E+01$ & $1.11 E+01$ & . \\
\hline 5 & 977 & $1.94 E+01$ & $000 E+00$ & $923 E+00$ & $000 E+00$ & $000 E+00$ & $6.71 E+06$ & $000 E+00$ & $760 E .01$ & 3 SIE.02 & S.41E.03 & & $000 E+00$ & $0.00 E+00$ & x & $1.89 E-02$ & $9.93 E+02$ & $6.97 \mathrm{E}+\infty 0$ & . \\
\hline 5 & 978 & $620 E+00$ & $000 E+00$ & $616 E+00$ & $000 E+\infty$ & $000 \mathrm{E}+00$ & $1.21 E+06$ & $327 \mathrm{E} .01$ & $111 \mathrm{E}+\infty 0$ & | 08E-01 & $000 E+\infty 0$ & & $000 E+\infty$ & 3.5IE-02 & . & 189E.02 & $184 E+03$ & $428 E+01$ & \\
\hline$s$ & 979 & 4.59E +00 & O OOE +00 & $191 E+00$ & $000 E+00$ & $000 E+\infty 0$ & $4.51 E+0.4$ & $000 E+00$ & $9 \mid 9 E-01$ & $6.22 \mathrm{E}-02$ & $2.70 \mathrm{E}-03$ & & $000 E+00$ & $0.00 E+00$ & . & $270 E \cdot 03$ & $4.32 \mathrm{E}+02$ & $202 E+01$ & \\
\hline 5 & 980 & $7.05 E+00$ & $000 E+00$ & $479 E+00$ & $0.00 E+00$ & $000 \mathrm{E}+\infty 0$ & $5.68 \mathrm{E}+02$ & $000 E+00$ & $865 E .01$ & $9.46 \mathrm{E}-02$ & $2.26 \mathrm{E} \cdot 02$ & & $000 E+00$ & $2.70 \mathrm{E} \cdot 03$ & 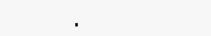 & $7,23 E-02$ & $1.62 E+02$ & $2.70 \mathrm{E}+01$ & \\
\hline 3 & 981 & $108 E+00$ & $000 E+00$ & $195 E+00$ & $259 E+\infty 0$ & $322 \mathrm{E}-01$ & $1.16 E+06$ & $000 E+00$ & $12.4 E+00$ & $0.00 E+00$ & S $4 I E-03$ & & $000 E+00$ & $2.02 \mathrm{E}-01$ & . & $0.00 E+00$ & $270 E+03$ & $9.61 \mathrm{E}+\infty 0$ & \\
\hline s & 982 & $132 E+01$ & $000 E+00$ & $130 E+\infty 00$ & $0.00 E+00$ & $238 \mathrm{E}-01$ & $1.12 E+03$ & $000 E+00$ & $661 E .01$ & $2.10 \mathrm{E}-01$ & $397 \mathrm{E}-02$ & & $000 E+00$ & $1.62 \mathrm{E}-02$ & & $1.81 \varepsilon+01$ & $460 E+02$ & $2.70 E+01$ & \\
\hline s & 983 & $8.38 \mathrm{E}+00$ & OOOE +00 & $322 E+00$ & $0.00 \mathrm{E}+00$ & $0.00 \mathrm{E}+00$ & $6.44 E+03$ & $000 E+00$ & $135 E+00$ & $0.00 E+00$ & | 49E.01 & & $0.00 E+00$ & $1.08 E-02$ & & $1.04 E-01$ & $265 \mathrm{E}+02$ & $219 E+01$ & . \\
\hline$s$ & 984 & $1.45 E+01$ & $120 \mathrm{E}-0 \mid$ & $197 \mathrm{E}+00$ & $000 E+00$ & $268 \mathrm{E}-01$ & $1.03 E+03$ & $224 \mathrm{E}-01$ & $680 \mathrm{E}-01$ & 3.SIE -02 & $1.88 \mathrm{E}-01$ & & $000 \mathrm{E}+00$ & $1.27 \mathrm{E}-01$ & . & $1.32 E-02$ & $1.11 E+02$ & $252 E+01$ & . \\
\hline$s$ & 1105 & $000 E+00$ & $000 E+00$ & $453 E+01$ & $0.00 E+00$ & $000 E+00$ & $2.06 E+06$ & $000 E+00$ & $000 E+00$ & $000 E+\infty 0$ & $0.00 E+00$ & & $000 E+\infty 0$ & $0.00 \mathrm{E}+\infty 0$ & . & $000 E+00$ & $0.00 E+\infty 0$ & & . \\
\hline 5 & 1106 & $0.00 E+\infty 0$ & $0.00 E+00$ & $6.10 E+00$ & $0.00 \mathrm{E}+00$ & $000 E+\infty$ & $1.80 E+06$ & $000 E+00$ & $000 E+\infty$ & $000 E+00$ & S.4AE.01 & & $1.73 E+0 t$ & $0.00 E+\infty 0$ & . & $000 \mathrm{E}+00$ & $169 E+03$ & & \\
\hline$s$ & 1107 & $0.00 E+\infty$ & $3.02 E+02$ & $4.44 E+03$ & $0.00 \mathrm{E}+00$ & $0.00 E+\infty 0$ & $1.12 E+06$ & $000 E+00$ & $000 E+00$ & $0.00 E+00$ & $000 E+00$ & & $537 E+01$ & $0.00 E+00$ & & $0.00 E+00$ & $6.60 E+02$ & $242 E+01$ & . \\
\hline 3 & 1108 & $2.75 E+03$ & $0.00 E+00$ & $4.15 E+04$ & $0.00 E+00$ & $173 \mathrm{E}-01$ & $5.49 E+05$ & $548 \mathrm{E}-01$ & $14|E+0|$ & $1.96 \mathrm{E}-01$ & 2.3HE-01 & & $310 E+01$ & $0.00 \mathrm{E}+00$ & & $708 E+\infty 0$ & $1.99 E+02$ & $885 E+01$ & \\
\hline 5 & 4113 & $0.00 E+00$ & $430 E+00$ & $2.50 E+00$ & $3.20 E+01$ & $240 E+01$ & $1.10 \mathrm{E}+05$ & $303 E+\infty 0$ & $2.10 E+00$ & $4.20 \mathrm{E}-01$ & $0.00 E+00$ & & $140 E+01$ & $0.00 E+\infty 0$ & . & & $000 E+\infty$ & & \\
\hline 5 & 4114 & $0.00 E+00$ & $|S O E+0|$ & $1.28 \mathrm{E}+03$ & $2.10 E+02$ & $0.00 \mathrm{E}+\infty 0$ & $1.53 E+06$ & $687 E-01$ & $3.80 E+03$ & $2.17 E+01$ & $2.30 E+04$ & & $512 E+02$ & $5.70 E+01$ & & $1.06 \mathrm{E} .01$ & $6.66 \mathrm{E}+02$ & & \\
\hline 5 & 4115 & $0.00 E+00$ & $0.00 E+00$ & $1.80 \mathrm{E}+01$ & $0.00 \mathrm{E}+00$ & $000 E+00$ & $2.25 E+06$ & $000 E+00$ & $000 E+00$ & $0.00 E+00$ & $0.00 E+00$ & & $2.14 E+01$ & $0.00 E+00$ & & $0.00 \mathrm{E}+00$ & $2.28 \mathrm{E}+02$ & & . \\
\hline s & 4116 & $0.00 E+00$ & $000 E+00$ & $0.00 E+00$ & $257 \mathrm{E}+\infty 0$ & $242 E+\infty 0$ & $2.52 E+05$ & $350 E+00$ & $590 \mathrm{E} .01$ & $5.20 \mathrm{E}-01$ & $340 \mathrm{E} .01$ & & $000 E+00$ & $0.00 E+\infty 0$ & & & $0.00 E+\infty 0$ & & . \\
\hline 3 & 4173 & & & $5.38 E+06$ & & & $3.39 \mathrm{E}+06$ & & & & & & & & $2.33 E+03$ & & $8.05 E+05$ & & \\
\hline s & 4174 & & & $2.00 E+06$ & & & $8.15 E+06$ & & & & & & & & $1.04 E+03$ & & $4.66 E+05$ & & \\
\hline 3 & 4175 & $6.08 \mathrm{E}+02$ & & $1.96 \mathrm{E}+07$ & & & $9.49 \mathrm{E}+06$ & & & & & & & & & & $3.66 E+06$ & & \\
\hline s & 4176 & & & $8.39 E+04$ & & & $3.29 \mathrm{E}+06$ & & & & & & & . & $1.06 E+03$ & & $5.96 \mathrm{E}+04$ & & \\
\hline 3 & 4177 & $2.08 E+03$ & & $3.85 E+02$ & & & $2.65 E+07$ & & & & & & & 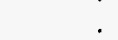 & $5.99 \mathrm{E}+02$ & & $0.00 E+00$ & $3.50 E+01$ & \\
\hline$s$ & 4178 & $6.53 E+04$ & & $2.64 E+05$ & & & $8.99 E+06$ & & & & & & & & \begin{tabular}{|c|}
$6.16 E+02$ \\
\end{tabular} & & $4.04 E+04$ & $3.54 E+02$ & \\
\hline 3 & 4179 & $8.74 E+00$ & & $3.00 E+03$ & & & & $0.00 E+00$ & $000 E+\infty 0[$ & $1.15 E+06$ & $7.77 E+05$ & & & $1.36 E+04$ & & & & & \\
\hline 5 & 4179 & & & $1.20 E+07$ & & & $1.00 \mathrm{E}+08$ & & & & & & & & & & $000 E+00$ & & \\
\hline 3 & 4180 & $5.52 E+01$ & & $8.01 E+04$ & & & $5.79 E+07$ & & & & & & & . & $8.54 E+02$ & & $000 E+\infty 0$ & & \\
\hline 5 & 4185 & & & $5.68 E+03$ & & & $1.06 \mathrm{E}+08$ & & & & & & & . & $9.41 \varepsilon+02$ & & $000 E+\infty$ & & \\
\hline 3 & 4188 & $1.78 E+02$ & & $1.25 E+04$ & & & $9.51 E+07$ & & & & & & & . & & & $S 41 E+02$ & $2.44 E+02$ & \\
\hline 5 & 4189 & $5.87 E+02$ & & $2.33 E+03$ & & & $1.18 \mathrm{E}+03$ & & & & & & & . & $239 E+02$ & & $0.00 E+\infty$ & $215 E+01$ & \\
\hline 3 & 4190 & $9.96 E+02$ & & & & & $5.76 E+07$ & & & $7.65 E+02$ & & & & . & & & $9.09 E+05$ & & \\
\hline 3 & 4191 & $4.40 \mathrm{E}+01$ & & $1.18 E+04$ & & & $2.99 E+08$ & & & & & & & . & $1.31 \mathrm{E}+03$ & & $0.00 E+00$ & & \\
\hline s & 4193 & $1.04 E+02$ & & $1.20 E+04$ & & & $4.71 E+00$ & & & & & & & . & $3.25 \mathrm{E}+02$ & & $1.12 E+06$ & & \\
\hline s & 4195 & $2.96 \mathrm{E}+03$ & & $4.51 E+05$ & & & $3.31 \mathrm{E}+08$ & & & & & & & & $1.62 \mathrm{E}+03$ & & $0.00 E+00$ & & \\
\hline s & 4198 & $5.32 E+04$ & & $7.88 E+04$ & . & & $1.82 \mathrm{E}+08$ & & & & & & & . & & & $0.00 E+00$ & $3.22 \mathrm{E}+02$ & \\
\hline 5 & 4199 & $2.64 E+03$ & & $1.40 E+03$ & & & $5.50 E+07$ & & & & & & & & & & 6.69E+04 & & \\
\hline
\end{tabular}




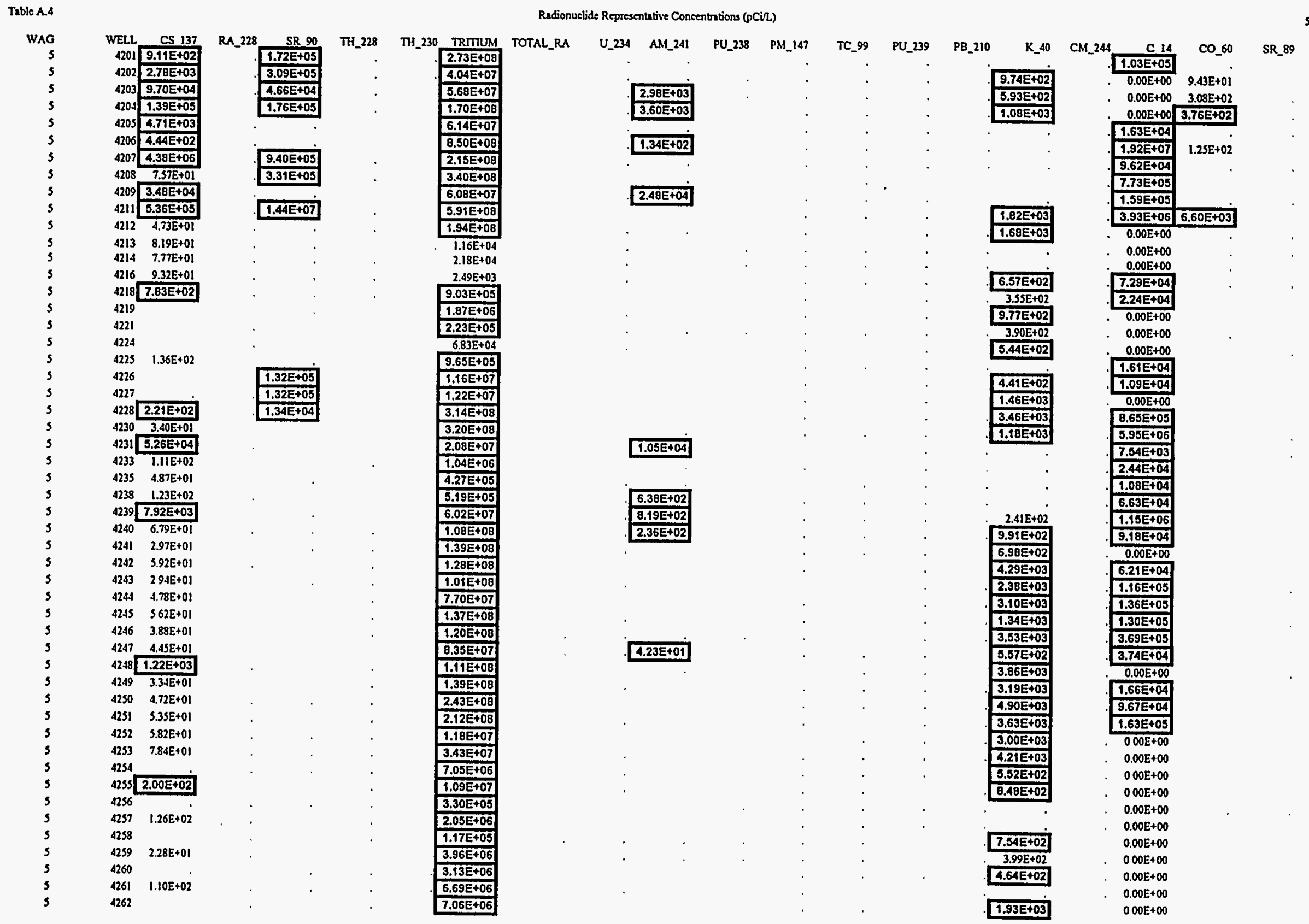




\begin{tabular}{|c|c|c|c|c|c|c|c|c|c|c|c|c|c|}
\hline WELL & $\begin{array}{r}\text { CS 137 } \\
4.29 E+02\end{array}$ & RA_228 & SR_90 & TH_228 & TH_230 & $\begin{array}{r}\text { TRITIUM } \\
5.87 E+06\end{array}$ & TOTAL_RA & $U_{-} 234$ & $\mathrm{AM}_{-} 241$ & PU_238 & PM_147 & TC_99 & PU_239 \\
\hline $4264^{\circ}$ & $1.52 E+02$ & . & & & & $3.59 E+06$ & & & . & & . & & \\
\hline 4265 & & & & & & $1.46 E+07$ & & . & . & & & & \\
\hline 4266 & $3.66 \mathrm{E}+01$ & . & & . & & $2.75 E+07$ & & . & . & . & & & \\
\hline 4267 & & . & & . & & $1.98 \mathrm{E}+07$ & & & . & & & & \\
\hline 4268 & $7.28 \mathrm{E}+01$ & . & & & & $3.14 E+07$ & & & . & & & & \\
\hline 4269 & $3.37 \mathrm{E}+01$ & . & & . & & $8.10 \mathrm{E}+06$ & & & 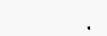 & & & & \\
\hline 4270 & $1.40 \mathrm{E}+02$ & & & & & $8.10 E+06$ & & . & & & & & \\
\hline 4271 & & . & & & & $5.30 E+06$ & & r. & . & & & & \\
\hline 4272 & . & . & & & & $1.24 E+07$ & & . & 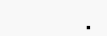 & & & & \\
\hline 4273 & . & . & & & & $4.15 E+07$ & & & & & & & \\
\hline 4274 & . & . & & & & A.30E+07 & & & & & & & \\
\hline 4275 & . & . & & & & $9.51 E+06$ & & . & & & & & \\
\hline 4276 & & & & & & $1.46 E+07$ & & . & . & & & & \\
\hline 4277 & $1.30 \mathrm{E}+02$ & . & & & & $1.09 E+07$ & & & . & & & & \\
\hline 4278 & & . & & & & $5.63 E+06$ & & & . & & & & \\
\hline 4281 & $2.80 E+01$ & . & & & & $1.16 E+07$ & & & . & & & & \\
\hline 4282 & $2.26 E+01$ & & & & & $2.20 E+06$ & & & . & . & & & \\
\hline 4283[ & $3.59 \mathrm{E}+02$ & & & & & $5.15 E+06$ & & & & & & & \\
\hline 4284 & $1.93 E+02$ & & & & & $5.61 E+06$ & & & . & & & & . \\
\hline 4285 & $2.30 E+02$ & & & & & $1.29 E+06$ & & & . & & & & \\
\hline 4286 & $1.60 E+02$ & & & & & $7.11 E+05$ & & & . & & & & \\
\hline 4287[ & $2.41 E+02$ & . & & & & $1.23 E+05$ & & & & & & & . \\
\hline $4289^{\circ}$ & & & & & & $7.02 E+05$ & & & & & & & . \\
\hline 4290 & $8.12 \mathrm{E}+01$ & & & & & $6.24 E+06$ & & . & . & & & & \\
\hline 4291 & $2.82 E+03$ & & & & & $5.91 E+06$ & & & & & & & \\
\hline 4294 & & & $6.76 E+05$ & & & $4.03 E+06$ & & & & & & & . \\
\hline 4295 & & & $9.51 E+04$ & & & $3.92 E+06$ & & & & & & & . \\
\hline 4296 & $1.68 E+02$ & & & & & $4.87 E+06$ & & & & & & & 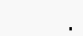 \\
\hline 4297 & & & & & & $1.11 E+07$ & & & & . & & & \\
\hline 4298 & & & & & & $1.09 E+07$ & & & & & & & \\
\hline 4299[ & $3.94 \mathrm{E}+02$ & & $1.84 \mathrm{E}+05$ & & & $1.21 E+07$ & & & & . & & & \\
\hline 4300 & & & $3.56 E+03$ & & & $1.14 E+07$ & & & & & & & \\
\hline 4307[ & $1.01 E+03$ & & & & & \begin{tabular}{|l|}
$9.29 E+06$ \\
\end{tabular} & & & & & & & \\
\hline $745^{2}$ & $2.33 \mathrm{E}+00$ & & $\$ 72 E+00$ & & & $4.36 \mathrm{E}+03$ & $162 E+\infty 0$ & & & & & & \\
\hline 831 & $2.34 E+01$ & & $429 E+\infty 0$ & & & $7.74 E+02$ & I $5.4 \mathrm{E}+00$ & & & . & & & \\
\hline 832 & $5.54 E+\infty 0$ & & $292 E+00$ & & & $687 E+02$ & $162 E+\infty 0$ & & & . & & & \\
\hline 833 & $3.26 E+00$ & & $7.44 E+\infty 0$ & & & $459 E+03$ & $162 E+\infty 0$ & & & & & & \\
\hline 835 & $3.16 E+00$ & & $1.81 E+00$ & & & $2.78 E+04$ & $135 E+00$ & & & & & & \\
\hline 836 & $1.13 E+01$ & & $332 E+00$ & & & $4.06 E+03$ & $000 E+00$ & & & & & & \\
\hline 837 & $2.79 E+00$ & & $3.24 \mathrm{E}+\infty 0$ & & & $226 \mathrm{E}+03$ & $703 \mathrm{E}-01$ & & & & & & \\
\hline 838 & $481 E+00$ & & $402 E+00$ & & & $2.44 E+04$ & $270 E+\infty 0$ & & & & & & \\
\hline 839 & $4.33 E+00$ & & $225 \mathrm{E}+00$ & & & $262 E+04$ & $181 E+\infty$ & & & & & & \\
\hline 840 & $5.88 E+00$ & & $7.83 \mathrm{E}+\infty 0$ & & & $1.11 E+04$ & $162 E+\infty 0$ & & & & & & \\
\hline 841 & $242 E+00$ & & $8.96 E+\infty 00$ & & & $1.60 \mathrm{E}+03$ & $216 E+\infty 0$ & & & & & & \\
\hline $\mathbf{8 4 2}$ & $5.95 E+00$ & & $8.88 E+00$ & & & $3.38 E+05$ & $162 E+\infty 0$ & & & & & & \\
\hline 843 & $6.24 E+00$ & & $2.44 E+\infty 0$ & & & $1.41 E+06$ & $189 \mathrm{E}+00$ & & & & & & \\
\hline & $286 E+00$ & & $426 E+\infty 0$ & & & $869 E+04$ & $162 E+00$ & & & & & & \\
\hline $\begin{array}{l}845 \\
846\end{array}$ & $\begin{array}{l}514 E+00 \\
\text { S } 78 E+00\end{array}$ & $000 E+00$ & $\begin{array}{l}000 E+00 \\
1 \text { SIE+01 }\end{array}$ & $000 E+\infty$ & $000 E+\infty$ & $\begin{array}{l}400 E+04 \\
9.03 E+02\end{array}$ & $\begin{array}{l}460 E-01 \\
189 E+\infty 0\end{array}$ & $000 E+\infty$ & $000 E+\infty 0$ & $000 E+\infty 0$ & & & \\
\hline 847 & $533 \mathrm{E}+00$ & & $238 E+\infty 0$ & & & $9.38 E+04$ & $135 E+\infty$ & . & & & & & \\
\hline 848 & $5.95 E+00$ & $000 E+00$ & $S 14 E+01$ & $000 E+00$ & $000 E+\infty$ & $4.32 E+06$ & $000 E+\infty 0$ & $000 E+\infty$ & $0.00 E+00$ & $000 E+00$ & & & \\
\hline
\end{tabular}

\begin{tabular}{|c|c|}
\hline & \\
\hline $1.47 E+03$ & $2.04 E+03$ \\
\hline $2.59 E+03$ & $1.41 E+03$ \\
\hline $1.61 E+03$ & $1,42 \mathrm{E}+05$ \\
\hline & $0.00 E+00$ \\
\hline $3.92 \mathrm{E}+02$ & $8.83 E+03$ \\
\hline & $2.37 E+03$ \\
\hline & $7.31 E+04$ \\
\hline & $6.96 \mathrm{E}+03$ \\
\hline $9.15 E+02$ & $4.58 E+04$ \\
\hline
\end{tabular}

$4.47 E+00$ $2.31 \mathrm{E}+01$ $1.29 \mathrm{E}+01$ $1.62 E+\infty 0$ $3.41 E+\infty 0$ 1 SIE +00 $4.05 E+\infty 0$ $127 \mathrm{E}+00$ 2.31E+ +00 $3.87 E+00$ 1.78E+01 $2.16 \mathrm{E}+02$ $244 E+0 I$ $411 \mathrm{E}+00$ $703 E+00$ $269 \mathrm{E}+00$ $364 E+00$ $000 E+\infty 0$ 


\begin{tabular}{|c|c|c|c|c|c|c|c|c|c|c|c|c|c|c|c|c|c|c|c|}
\hline $\begin{array}{r}\text { WAG } \\
6\end{array}$ & $\begin{array}{r}\text { WELL } \\
849\end{array}$ & $\begin{array}{r}C S_{1} 137 \\
0.00 E+\infty\end{array}$ & $\begin{array}{r}\text { RA_228 } \\
000 \bar{E}+00\end{array}$ & $\begin{array}{r}\text { SR_90 } \\
0.00 E+00\end{array}$ & $\begin{array}{r}7 H_{2}^{2228} \\
0.00 E+00\end{array}$ & $\begin{array}{c}T H \_230 \\
0.00 E+00\end{array}$ & $\begin{array}{r}\text { TRMTMM } \\
2.72 E+06\end{array}$ & $\begin{array}{r}\text { TOTAL_RA } \\
0.00 \mathrm{E}+\infty\end{array}$ & $\begin{array}{r}U_{u} 234 \\
0.00 E+00\end{array}$ & $\begin{array}{l}\mathrm{AM}_{0} 241 \\
0.00 \mathrm{E}+00\end{array}$ & $\begin{array}{r}P U 238 \\
0.00 E+00\end{array}$ & PM_147 & $\pi C_{-} 99$ & PU_239 & PB_210 & $\begin{array}{r}K_{2} 40 \\
0.00 E+\infty\end{array}$ & $\mathrm{CM}_{-} 244$ & $C_{-} 14$ & $\begin{array}{r}C O \_60 \\
0.00 E+\infty 0\end{array}$ \\
\hline 6 & 850 & $4.60 \mathrm{E}+00$ & $0.00 E+00$ & $8.58 \mathrm{E}+00$ & $0.00 E+00$ & $0.00 E+00$ & $3.79 E+04$ & $1.31 E+00$ & $0.00 E+\infty$ & $0.00 E+00$ & $0.00 E+\infty$ & . & $\cdot$ & . & . & . & . & & $0.00 E+00$ \\
\hline 6 & 851 & $0.00 E+00$ & $0.00 E+00$ & $4.32 E+00$ & $0.00 E+\infty 0$ & $0.00 E+00$ & $5.00 E+04$ & $0.00 E+00$ & $0.00 E+00$ & $000 E+00$ & $0.00 E+00$ & . & . & . & . & . & . & . & $0.00 E+00$ \\
\hline 6 & 852 & $0.00 E+00$ & $0.00 E+00$ & $0.00 E+\infty 0$ & $0.00 E+\infty 0$ & $0.00 E+00$ & $5.95 E+04$ & $6.49 \mathrm{E}-01$ & $0.00 E+\infty 0$ & $0.00 E+00$ & $0.00 E+00$ & . & . & . & . & . & . & & $000 E+00$ \\
\hline 6 & 853 & $0.00 E+\infty 0$ & $0.00 E+00$ & $3.51 E+00$ & $0.00 E+00$ & $0.00 E+\infty$ & $3.24 E+03$ & $1.45 E+00$ & $0.00 E+00$ & $0.00 E+00$ & $0.00 E+00$ & . & . & . & 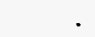 & . & . & & $0.00 E+\infty 0$ \\
\hline 6 & 854 & $0.00 E+00$ & $000 E+00$ & $0.00 E+00$ & $2.00 E+\infty 0$ & $0.00 E+00$ & $2.47 E+05$ & $0.00 E+00$ & $0.00 E+\infty$ & $0.00 E+00$ & $0.00 E+00$ & $\cdot$ & . & . & r & 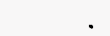 & . & . & $0.00 E+00$ \\
\hline 6 & 855 & $2.37 E+\infty 00$ & & $2.38 E+\infty 0$ & & & $1.01 E+03$ & $0.00 E+00$ & & & & . & . & . & v & $\cdot$ & . & & $1.41 E+01$ \\
\hline 6 & 856 & $1.59 E+01$ & & $3.42 E+00$ & 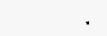 & & $4.58 \mathrm{E}+02$ & $3.31 \mathrm{E}+\infty 0$ & r & . & & . & . & . & . & . & . & & $5.41 E+00$ \\
\hline 6 & 857 & $7.94 E+00$ & & $3.74 E+00$ & . & & $6.95 \mathrm{E}+02$ & $8.38 \mathrm{E}-01$ & r & . & & . & & . & . & . & 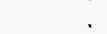 & . & $358 E+\infty 0$ \\
\hline 6 & 858 & $2.70 \mathrm{E}+00$ & & $4.63 E+00$ & . & & $8.22 \mathrm{E}+02$ & $0.00 \mathrm{E}+00$ & . & & & & 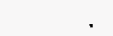 & 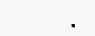 & r. & 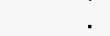 & . & . & $5.25 E+00$ \\
\hline 6 & 859 & $2.08 E+\infty 0$ & & $4.64 E+00$ & & & $3.95 E+03$ & $9.46 \mathrm{E} \cdot 01$ & & & & . & . & . & . & $\cdot$ & 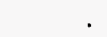 & & $1.26 \mathrm{E}+01$ \\
\hline 6 & 860 & $6.30 \mathrm{E}+00$ & & $3.08 \mathrm{E}+00$ & & & $3.34 E+02$ & $0.00 \mathrm{E}+00$ & & & & & . & . & . & 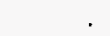 & . & . & $2.34 E+01$ \\
\hline 6 & 1225 & $0.00 E+00$ & $2.14 E+011$ & $4.20 E+03$ & $280 E+\infty 0$ & $1.20 \varepsilon+00$ & $1.60 E+06$ & $1.30 \mathrm{E}+01$ & $000 E+00$ & $000 \mathrm{E}+00$ & $2.21 E+\infty 0$ & & . & . & . & $8.15 E+01$ & $1.97 E+01$ & . & $2.24 E+01$ \\
\hline 6 & 1226 & $0.00 E+00$ & $0.00 E+00$ & $0.00 E+00$ & $1.23 E+\infty 0$ & $1.04 E+00$ & $0.00 E+00$ & $2.24 \mathrm{E}+00$ & $1.22 E+00$ & $0.00 E+00$ & $0.00 E+\infty 0$ & & & . & . & & r & . & • \\
\hline 6 & 1227 & $0.00 E+\infty$ & $000 E+00$ & $0.00 E+\infty 0$ & $0.00 E+\infty 0$ & $0.00 \mathrm{E}+00$ & $2.10 E+03$ & $2.90 \mathrm{E}+00$ & $000 E+00$ & $0.00 E+00$ & $0.00 E+00$ & & & . & 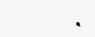 & & & & \\
\hline 6 & 1228 & $0.00 E+\infty 0$ & $3.70 \varepsilon+b 0$ & $0.00 \mathrm{E}+00$ & $0.00 \mathrm{E}+00$ & $0.00 E+00$ & $7.30 E+03$ & $0.00 E+00$ & $100 E+\infty 0$ & $0.00 \mathrm{E}+00$ & $0.00 E+00$ & & . & . & . & $2.57 E+02$ & r & . & \\
\hline 6 & 1229 & $0.00 E+00$ & $0.00 E+00$ & $0.00 E+\infty 0$ & $821 E+\infty 0$ & $5.99 E+00$ & $2.12 E+0.5[$ & $1.13 E+02$ & $334 E+\infty 0$ & $0.00 E+00$ & $0.00 E+00$ & & . & . & v & & . & . & \\
\hline 6 & 1231 & $0.00 E+00$ & $000 E+00$ & $000 E+00$ & $0.00 E+00$ & $0.00 E+00$ & $5.40 E+04$ & $1.60 E+\infty 00$ & $000 E+\infty$ & $0.00 E+00$ & $0.00 E+00$ & & & . & . & $2.52 E+02$ & . & . & . \\
\hline 6 & 1233 & $0.00 E+00$ & $0.00 E+00$ & $0.00 E+00$ & $300 E+\infty 0$ & $160 \varepsilon+00$ & $6.30 \mathrm{E}+05$ & $130 \mathrm{E}+\infty 0$ & $150 E+00$ & $000 E+00$ & $000 E+00$ & & & . & . & $1.80 E+02$ & $000 E+00$ & r. & \\
\hline 6 & 1234 & $0.00 E+00$ & & & $000 E+\infty$ & $214 E+00$ & $0.00 E+00$ & & & & & & & . & . & & & . & . \\
\hline 6 & 1236 & $0.00 E+00$ & $0.00 E+60$ & $0.00 E+00$ & $199 E+\infty 0$ & $139 E+00$ & $000 E+00$ & $155 E+00$ & $109 E+00$ & $0.00 E+00$ & $000 E+00$ & & & 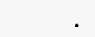 & & & & 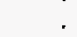 & \\
\hline 6 & 1237 & $0.00 E+00$ & $0.00 \varepsilon+00$ & $8.30 \mathrm{E}+00$ & $0.00 E+00$ & $7.45 E+00$ & $0.00 E+00$ & $135 E+\infty 0$ & $107 E+00$ & $1.19 E+\infty 0$ & $000 E+\infty 0$ & & . & . & . & & . & . & r. \\
\hline 6 & 1238 & $0.00 E+00$ & $0.00 E+00$ & $000 E+00$ & $103 E+00$ & $0.00 E+00$ & $0.00 E+00$ & $114 E+00$ & $000 E+00$ & $0.00 E+00$ & $0.00 E+00$ & & & . & . & $2.17 E+02$ & . & . & . \\
\hline 6 & 1239 & $0.00 E+00$ & $000 E+00$ & $000 E+\infty$ & $307 E+00$ & $491 \varepsilon+00$ & $0.00 E+00$ & $000 E+00$ & $30.4 E+\infty 0$ & $0.00 \mathrm{E}+00$ & $0.00 \varepsilon+00$ & & & 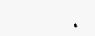 & & & & & \\
\hline 6 & 1240 & $0.00 E+\infty 0$ & $0.00 E+b 0$ & $000 E+\infty$ & $234 E+00$ & $000 E+\infty 0$ & $801 E+02$ & $203 E+00$ & $210 E+00$ & $000 E+\infty 0$ & $0.00 E+00$ & & . & . & . & & & $=$ & . \\
\hline 6 & 1241 & $0.00 E+\infty 00$ & $0.00 E+00$ & $0.00 E+\infty$ & $778 E+00$ & $556 \mathrm{E}+00$ & $2.80 E+03$ & $173 E+01$ & $856 E+00$ & $000 \mathrm{E}+\infty 0$ & $0.00 E+00$ & & & . & . & & . & & \\
\hline 6 & 1242 & $2.90 E+00$ & $0.00 E+00$ & $318 \mathrm{E}+00$ & $1.30 \mathrm{E}+\infty 0$ & $3.84 E+\infty 0$ & $4.30 E+05$ & $000 E+00$ & $194 E+00$ & $2.39 E+00$ & $000 E+00$ & & & . & . & & & & 1.16E+01 \\
\hline 6 & 1243 & $261 E+01$ & $000 E+00$ & $+01 E+\infty$ & $0.00 E+00$ & $000 E+00$ & $1.72 E+06$ & $153 E+00$ & $000 E+00$ & $0.00 E+00$ & $0.00 E+\infty$ & . & & 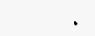 & . & $1.94 \mathrm{E}+02$ & . & & $9.15 E+02$ \\
\hline 6 & 1244 & $5.4 \mathrm{tE}+00$ & $000 E+00$ & $6.08 E+00$ & $000 E+\infty$ & $162 E+00$ & $496 \mathrm{E}+04$ & $000 E+00$ & $167 E+01$ & $000 E+00$ & $000 E+\infty 0$ & & $\therefore$ & . & . & & & & $6.49 \mathrm{E}+02$ \\
\hline 6 & 1245 & $1.89 \mathrm{E}+01$ & & $811 E+\infty$ & $000 E+\infty$ & $136 E+0 \mid$ & $4.86 \mathrm{E}+02$ & & & & & & & $\cdot$ & $\cdot$ & & & & $2.16 \mathrm{E}+\infty$ \\
\hline 6 & 1249 & $0.00 E+00$ & $000 E+00$ & $000 E+00$ & $000 E+\infty$ & $322 \mathrm{E}+00$ & $0.00 E+00$ & $337 E+00$ & $000 E+00$ & $0.00 E+00$ & $000 E+00$ & & & . & & & & & \\
\hline 7 & 1071 & $486 E+\infty 0$ & & $371 E+\infty$ & & & $173 E+03$ & & & & & & $811 E \cdot 0 !$ & . & r & . & & & $1.79 E+01$ \\
\hline 7 & 1072 & $3.51 E+\infty 0$ & & $236 \mathrm{E}+\infty 0$ & & & $332 E+02$ & & & . & & & $0.00 E+00$ & . & . & & & & $1.19 E+01$ \\
\hline 7 & 1073 & $2.52 \mathrm{E}+01$ & & $327 \mathrm{E}+\infty 0$ & & & $9.01 E+02$ & & & . & & & $8.11 \mathrm{E}-01$ & . & . & & . & & $405 E+01$ \\
\hline 7 & 1074 & $8.62 E+00$ & & $43+E+\infty 0$ & & & $42 S E+02$ & & & . & & & $108 E+00$ & . & . & & & & $13 S E+0 \mid$ \\
\hline 7 & 1073 & $3.51 E+00$ & & $475 E+\infty 0$ & & & $1.03 \mathrm{E}+03$ & & & . & & & $000 E+00$ & . & . & & & & $3.43 \mathrm{E}+01$ \\
\hline 7 & 1076 & $3.39 E+01$ & & $595 E+\infty 0$ & & & $1.18 \mathrm{BE}+06$ & & & . & & & $124 E+01$ & 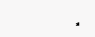 & $\cdot$ & & & & $5.68 \mathrm{E}+01$ \\
\hline 1 & 1077 & $1.35 \mathrm{E}+01$ & & $784 E+\infty 0$ & & & $2.08 E+03$ & & & . & & & $1.08 E+\infty 0$ & . & & & & & $4.08 E+01$ \\
\hline 7 & 1078 & $2.97 \mathrm{E}+01$ & & $542 \mathrm{E}+\infty 0$ & & & $4.02 E+04$ & & & & & & $1.11 E+04$ & . & & & & & $7.96 E+02$ \\
\hline 1 & 1079 & $2.43 \mathrm{E}+01$ & & $854 \mathrm{E}+\infty 0$ & & & $5.68 \mathrm{E}+03$ & & & , & & & $622 \mathrm{E}+01$ & $\cdot$ & . & & . & & $1.48 \varepsilon+02$ \\
\hline 7 & 1080 & $1.24 \mathrm{E}+01$ & & $730 \mathrm{E}+\infty 0$ & & & $1.54 E+03$ & & & . & & & $4.05 E+00$ & . & & & & & $3.24 E+00$ \\
\hline 7 & 1081 & $2.70 E+01$ & & $447 E+\infty 0$ & & & $1.14 E+03$ & & & . & & & $8 \| E .01$ & . & & & & & $4.59 \mathrm{E}+01$ \\
\hline 7 & 1082 & $3.68 \mathrm{E}+\infty 0$ & & $481 E+00$ & & & $182 E+04$ & & & & & & $703 E+\infty 0$ & & & & & & $2.19 E+01$ \\
\hline 7 & 1083 & $2.70 \mathrm{E}+00$ & & $3.37 E+00$ & & & $5.46 \mathrm{E}+03$ & & & & & & $973 \mathrm{E}+01$ & . & & & & & $486 \mathrm{E}+01$ \\
\hline 7 & 1084 & $1.62 \mathrm{E}+01$ & & $645 E+00$ & & & $1.30 E+05$ & & & & & & $232 E+02$ & & & & & & 4.05E+0I \\
\hline 7 & 1085 & $2.44 E+01$ & & $2.59 \mathrm{E}+\infty 0$ & & & $2.41 E+03$ & & & & & & $0.00 E+00$ & . & & & & & $5.41 E+\infty 0$ \\
\hline 7 & 1086 & $3.51 E+\infty$ & & $5.14 E+\infty 0$ & & & $4.27 \mathrm{E}+03$ & & & & & & $432 E+\infty 0$ & . & & & & & $2.54 \mathrm{E}+01$ \\
\hline 8 & 1087 & $4.05 E+01$ & & $7.58 E+02$ & & & $1.65 \mathrm{E}+03$ & & . & . & & & & . & & & r. & & $2.16 \mathrm{E}+01$ \\
\hline 8 & 1088 & $3.51 E+\infty 0$ & & $865 E+00$ & & & $676 \mathrm{E}+04$ & & . & . & & & & - & & & & & $324 E+00$ \\
\hline 8 & 1089 & $6.22 \mathrm{E}+01$ & & $7.84 E+00$ & & . & $526 E+02$ & & $\cdot$ & . & . & & & . & & & & & $514 E+01$ \\
\hline 8 & 1090 & $3.24 E+01$ & & $9.46 \mathrm{E}+00$ & & & $1.35 E+02$ & & . & & & & & & & & & & $3.78 E+01$ \\
\hline 8 & 1091 & $5.95 E+01$ & & $243 E+00$ & & & $9.69 E+02$ & & . & & & & & & & & & & $2.70 E-01$ \\
\hline 8 & 1092 & $1.79 E+01$ & & $7.84 E+\infty 0$ & & & $0.00 E+\infty 0$ & & 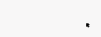 & & & & & & & & & & $1.08 E+01$ \\
\hline 8 & 1093 & $1.16 \mathrm{E}+01$ & & $7.57 E+\infty 0$ & & & $7.80 E+01$ & & . & & & & & & & & & & $40 S E+01$ \\
\hline & & & & $270 E+\infty 0$ & & & & & & & & & & & & & & & $243 \mathrm{E}+01$ \\
\hline
\end{tabular}




\begin{tabular}{|c|c|c|c|c|c|c|c|c|c|c|c|c|c|c|c|c|c|c|c|c|}
\hline $\begin{array}{r}\text { WAG } \\
8\end{array}$ & $\begin{array}{l}\text { WELL } \\
1095\end{array}$ & $\begin{array}{r}C S \_137 \\
3.24 E+01\end{array}$ & RA_228 & $\begin{array}{r}\text { SR_90 } \\
2.70 E+\infty 0 \\
\end{array}$ & TH_228 & $\mathrm{TH}_{-} 230$ & $\begin{array}{l}\text { TRMUUM } \\
9.46 \mathrm{E}+02\end{array}$ & TOTAL_RA & $U_{-} 234$. & $A_{2} 24 !$ & PU_238 & PM_l 147 & TC_99 & PU_239 & $\mathrm{PB}_{-} 210$ & $K_{-} 40$ & $\mathrm{CM}_{-} 244$ & $C_{-} 14$ & $\begin{array}{r}\text { CO.60 } \\
3.55 E+01\end{array}$ & $\mathrm{SR}_{-} 89$ \\
\hline 8 & 1096 & $2.16 \mathrm{E}+\infty 0$ & & $9.15 E+02$ & & & $568 E+02$ & & & . & & & & . & . & . & . & . & $5.41 E+00$ & \\
\hline 8 & 1097 & $1.08 E+00$ & & $1.05 E+03$ & & . & $649 \mathrm{E}+02$ & & & . & & & & . & . & . & . & $\cdot$ & $1.08 E+01$ & \\
\hline II & 1139 & $2.22 \mathrm{E}+00$ & & $3.78 E+00$ & & . & $270 E+01$ & . & . & . & & & . & . & . & . & 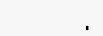 & . & $1.35 E+01$ & \\
\hline 11 & 1140 & 5.41E-01 & & $4.05 E+00$ & & & $991 \mathrm{E}+02$ & . & & . & & & & . & & & & & $1.35 E+01$ & \\
\hline "I & 1141 & $2.10 E+01$ & & $1.05 E+01$ & & & $102 E+03$ & & . & & & & & . & . & . & . & . & 8. $11 \mathrm{E}+00$ & \\
\hline 11 & 1143 & $1.89 E+01$ & & $2.70 E+00$ & & & $227 \mathrm{E}+03$ & . & . & . & & & & . & & . & . & r & $2.70 E+01$ & \\
\hline II & 1144 & 2.43E+01 & . & $0.00 E+\infty 0$ & & . & $000 E+00$ & . & . & . & & & & . & . & & . & . & $1.19 E+01$ & \\
\hline II & 1145 & $3.23 \mathrm{E}+01$ & & $5.14 E+00$ & & - & $000 E+00$ & & & . & & & r. & . & . & . & . & . & $2.16 \mathrm{E}+01$ & \\
\hline II & 1146 & $2.70 E+01$ & . & $7.03 E+00$ & & . & $1.05 E+03$ & & . & & & & . & . & . & . & . & & $2.43 E+01$ & \\
\hline II & 1147 & $5.14 E+00$ & . & $2.16 \mathrm{E}+00$ & & & $3.51 E+02$ & . & & . & & & & . & . & . & . & . & $4.05 E+00$ & \\
\hline 11 & 1148 & $2.97 E+00$ & . & $1.35 E+00$ & & & $211 E+03$ & & . & . & & & & . & . & & : & & $1.89 \mathrm{E}+00$ & \\
\hline "I & 1149 & $1.89 E+01$ & & $7.57 E+00$ & & . & $4.86 \mathrm{E}+02$ & . & . & . & & & . & . & . & , & . & . & $4.86 \mathrm{E}+01$ & \\
\hline 11 & 1246 & $1.35 E+01$ & & $2.16 \mathrm{E}+\infty 0$ & & & $395 E+04$ & . & r & . & & & & r. & . & . & . & . & $2.70 E+01$ & \\
\hline 17 & 1196 & $3.78 E+01$ & & $1.62 E+00$ & & & $454 E+03$ & . & . & . & & & & . & . & & . & . & $3.78 E+01$ & \\
\hline 17 & 1197 & $1.71 E+01$ & & $118 E+00$ & & & $284 E+03$ & . & . & . & & & & & . & & . & . & $3.41 E+\infty 0$ & \\
\hline 17 & 1198 & $3.94 E+0 I$ & & $467 \mathrm{E}+00$ & & & I 48E+04 & . & . & . & & & . & . & . & . & . & . & $1.62 E+01$ & \\
\hline 17 & 1199 & $|S 4 E+0|$ & & $5.27 \mathrm{E}+00$ & & & $863 E+03$ & & . & . & & & & 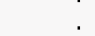 & . & & . & . & $2.43 E+\infty 0$ & \\
\hline 17 & 1200 & $2.70 E+\infty 00$ & & $3.73 \mathrm{E}+\infty 0$ & & & $953 E+03$ & & . & . & & & & . & . & & . & . & $9.48 E+00$ & \\
\hline 17 & 1201 & $2.16 E+\infty 0$ & & $2.58 \mathrm{E}+00$ & & & $766 \mathrm{E}+03$ & & & . & & & . & . & . & & . & : & $9.26 \mathrm{E}+00$ & \\
\hline 17 & 1202 & $4.00 E+00$ & & $24 S E+00$ & & & $292 \mathrm{E}+03$ & & . & . & & & . & . & . & & . & . & $6.17 E+00$ & \\
\hline 17 & 1203 & $116 E+0\}$ & & $289 E+00$ & & & $431 E+03$ & & & . & & & . & & & & . & & $1.75 E+01$ & \\
\hline Seep & SNW-1 & $0.00 E+00$ & & $180 E+01$ & & & $400 E+03$ & . & . & . & & & : & . & . & & . & : & $0.00 E+00$ & \\
\hline Seep & SNW-2 & $6.00 E-01$ & & $1.40 \mathrm{E}+01$ & & & $190 \mathrm{E}+04$ & - & . & . & & & . & . & . & & . & . & $0.00 E+00$ & \\
\hline Seep & BTT & $2.16 E+02$ & & $2.35 E+04$ & & & $2.80 \mathrm{E}+0.4$ & . & . & . & & & . & . & & & . & . & $0.00 E+00$ & \\
\hline Seep & FRENCH DRA & $0.00 E+00$ & & $6.00 \mathrm{E}+00$ & . & & $5.84 E+06$ & . & . & . & & & . & . & $\cdot$ & r. & $\cdot$ & & $0.00 E+00$ & \\
\hline Seep & RS.1 & $2.50 E+\infty 0$ & & $1.83 E+02$ & & & $230 \mathrm{E}+04$ & . & . & . & & & . & . & & . & . & & $1.53 E+01$ & \\
\hline S:ep & RS.3 & $0.00 E+00$ & & $9.24 E+02$ & & & $500 E+04$ & & . & . & & & & . & . & &. & & $1.14 E+03$ & \\
\hline Seep & sw2.1 & $3.20 E+00$ & & $3.65 E+02$ & . & & $110 E+04$ & & . & . & & & & . & . & & & & $0.00 E+00$ & \\
\hline Seep & sw2-2 & $3.60 E+00$ & & $7.42 \mathrm{E}+02$ & & & $300 \mathrm{E}+03$ & & . & . & & & . & . & . & & . & & $0.00 \varepsilon+\infty$ & \\
\hline Seep & SW2.3 & $0.00 E+00$ & & $1.00 E+01$ & & & $7.00 E+03$ & . & . & . & & & . & . & . & & & . & $0.00 E+00$ & \\
\hline Seep & SW2-4 & $3.23 \mathrm{E}+01$ & & $3.16 E+02$ & & & $1.24 E+06$ & . & . & . & & & . & . & & & & & $5.00 E+00$ & \\
\hline Seep & sw2.5 & $0.00 E+00$ & & $1.43 E+05$ & . & & \begin{tabular}{|l|}
$1.20 E+07$ \\
\end{tabular} & . & . & . & & & & & . & & & & $0.00 E+00$ & \\
\hline Seep & SW4.1 & $0.00 E+00$ & & $5.68 \mathrm{E}+03$ & & & \begin{tabular}{|l|}
$1.34 E+06$ \\
\end{tabular} & . & & . & & & . & . & & & & & $0.00 E+00$ & \\
\hline Seep & SW4.2 & $9.01 E+01$ & & $1.50 E+04$ & & & $2.50 E+04$ & & . & . & & & . & . & . & & & & $000 E+00$ & \\
\hline Seep & sws-11 & $0.00 E+00$ & & $1.18 E+06$ & & & $9.73 \mathrm{E}+07$ & & . & . & & & & & . & & & & $0.00 E+\infty 0$ & \\
\hline Seep & SW5.3 & $2.20 E+00$ & & $2.00 E+03$ & . & & $9.14 E+06$ & & . & . & & & . & . & . & & & & $0.00 E+00$ & \\
\hline Seep & SWS-4 & $000 E+00$ & & $5.73 E+05$ & & & $7.35 \mathrm{E}+06$ & & . & . & & & . & . & . & & & & $0.00 E+00$ & \\
\hline Seep & sws.5 & $0.00 E+\infty 0$ & & $1.28 \mathrm{E}+03$ & & & $1.13 E+07$ & . & & . & & & . & & . & & & & $0.00 E+00$ & \\
\hline Seep & SWS-6 & $7.00 \mathrm{E}-01$ & & $4.26 E+04$ & & & $1.07 E+07$ & . & . & . & & & . & . & & & & & $0.00 E+00$ & \\
\hline Seep & sw5.7 & $4.32 \mathrm{E}+01$ & & $4.66 \mathrm{E}+03$ & & & $1.27 E+08$ & & & & & & . & & & & & & $0.00 E+00$ & \\
\hline Seep & SW5.8 & $7.60 \mathrm{E}+00$ & & $2.94 E+02$ & & & $3.57 E+07$ & & . & & & & . & & & & & & $0.00 E+\infty 00$ & \\
\hline Seep & SWS-9 & $2.10 \mathrm{E}+00$ & & $7.01 E+02$ & & & $2.69 E+07$ & & . & . & & & & & & & & & $0.00 E+00$ & \\
\hline seep & SW6-1 & $137 \mathrm{E}+01$ & & $1.00 E+01$ & & & $2.21 E+05$ & & & & & & . & & & & & & $2.95 E+01$ & \\
\hline Seep & SW6.2 & $0.00 E+00$ & & $9.00 E+00$ & & & \begin{tabular}{|l|}
$1.63 E+06$ \\
\end{tabular} & & & . & & & . & & & & & & $0.00 E+00$ & \\
\hline Seep & SW7.1 & $0.00 E+00$ & & $440 E+01$ & & & $100 E+04$ & & 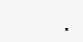 & & & & & & & & & & $0.00 E+00$ & \\
\hline Seep & SW7.2 & $0.00 E+00$ & & $4.00 E+01$ & & & $800 E+03$ & & . & & & & . & & & & & & 1.79E+03 & \\
\hline Seep & SW7.3 & $0.00 E+00$ & & $6.30 E+01$ & & & $310 E+04$ & & & & . & & . & & & & & & $6.44 E+02$ & \\
\hline seep & SW7.5 & $0.00 E+00$ & & $-8.00 E+\infty 0$ & & & $260 E+04$ & & & . & . & & . & & & & & & $1.39 \mathrm{E}+03$ & \\
\hline Seep & SW7-6 & $3.03 E+02$ & & $1.04 \mathrm{E}+03$ & & & $3.00 E+03$ & . & & & & & & & & & & & $0.00 E+00$ & \\
\hline Seep & WATRIB-II & & & $1.16 \mathrm{E}+0.4$ & & & $3.28 E+07$ & 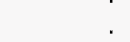 & & & & & . & & & & & & & \\
\hline Seep & WATRIB-S & & & $9.39 \mathrm{E}+03$ & & & $1.72 E+07$ &. & & . & & & & & & & & & & \\
\hline Seep & WoTRIB-? & & & $2.00 E+04$ & & & $3.43 E+07$ & & & & & & . & & & & & & & \\
\hline
\end{tabular}


B2CEE TET1122 DCEEII METHYLI METHYL $\begin{array}{lllllllll}0.00 E+00 & 0.00 E+00 & 0.00 E+00 & 0.00 E+\infty 0 & 0.00 E+00 & 0.00 E+00 & 0.00 E+\infty & 0.00 E+\infty 0 & 0.00\end{array}$ $\begin{array}{llllllllll}538 & 1.18 \mathrm{BE}-02 & 0.00 E+00 & 0.00 E+00 & 0.00 E+00 & 0.00 E+00 & 0.00 E+00 & 0.00 E+00 & 0.00 E+00 & 3.00 E-03\end{array}$

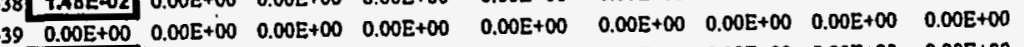
$340 \begin{array}{lllllllll}6.30 E-03 & 0.00 E+\infty 0 & 0.00 E+\infty & 0.00 E+00 & 0.00 E+00 & 0.00 E+\infty 0 & 0.00 E+\infty & 0.00 E+\infty & 0.00 E+\infty\end{array}$ $\begin{array}{llllllllll}541 & 2.00 E-03 & 0.00 E+\infty 0 & 0.00 E+\infty 0 & 0.00 E+\infty 0 & 0.00 E+\infty 0 & 0.00 E+\infty & 0.00 E+00 & 0.00 E+\infty 0 & 5.00 E-03\end{array}$

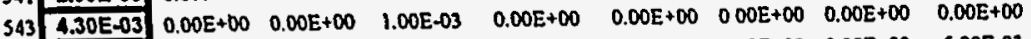

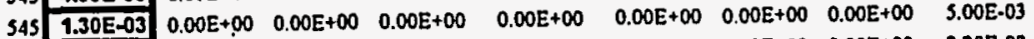

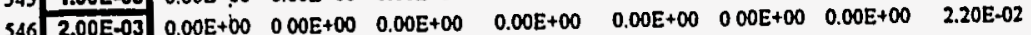
$\begin{array}{llllllll}5480.00 & 0.00 E+\infty & 0.00 E+\infty 0\end{array}$

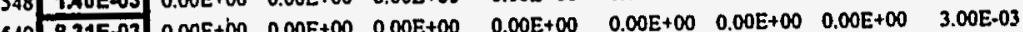
$3498.31 E-03$ O. $00 E+60$ 0.00E

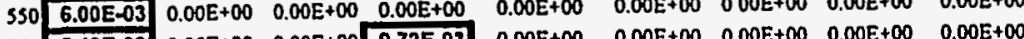

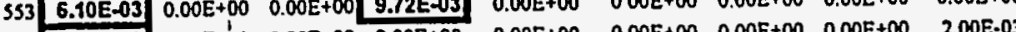
$\begin{array}{llllllllll}554 & 2.39 E-03 & 0.00 E+00 & 0.00 E+00 & 0.00 E+00 & 0.00 E+00 & 0.00 E+\infty 0 & 0.00 E+00 & 0.00 E+00 & 2.00 E-03\end{array}$ $558 \quad \therefore \quad 0.00 \mathrm{E}+00 \quad 0.00 \mathrm{E}+00$

$\begin{array}{lllllllllll}563 & 0.00 E+00 & 0.00 E+00 & 0.00 E+00 & 0.00 E+00 & 0.00 E+00 & 0.00 E+00 & 0.00 E+00 & 0.00 E+00 & 0.00 E+00\end{array}$ $\begin{array}{llllllllll}564 & 0.00 E+00 & 0.00 E+00 & 0.00 E+00 & 0.00 E+00 & 0.00 E+00 & 0.00 E+00 & 0.00 E+00 & 0.00 E+00 & 0.00 E+00\end{array}$

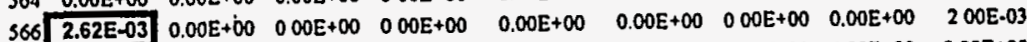
$\begin{array}{llllllllll}371 & 1.98 E-03 & 0.00 E+00 & 0.00 E+00 & 0.00 E+00 & 0.00 E+\infty & 0.00 E+00 & 0.00 E+00 & 0.00 E+00 & 0.00 E+\infty 0\end{array}$

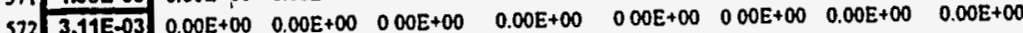
$\begin{array}{lllllllll}372 & 0.00 E+00 & 0.00 E+00 & 0.00 E+00 & 0.00 E+00\end{array}$ 379

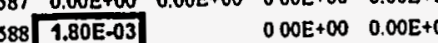

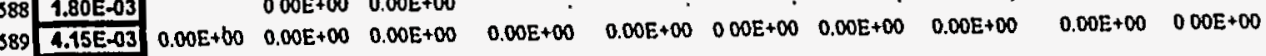
$390 \frac{1.15 E-03}{1.80 \mathrm{E}-03}$

$5 9 3 \longdiv { 3 . 6 0 E - 0 3 }$

$5 9 6 \longdiv { 1 . 1 0 E - 0 3 }$

$1996 \quad 1.10 \mathrm{E}-03 \quad 0.00 \mathrm{E}+00 \quad 0.00 \mathrm{E}+00$

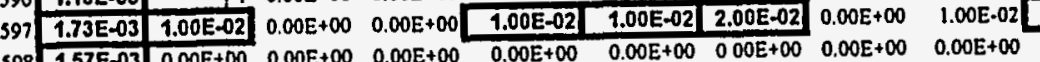
$150 E-03 \quad 0.00 E+00 \quad 0.00 E+000.00 E+00 \quad 0.00 E+00 \quad 0.00 E+00 \quad 000 E+00 \quad 0.00 E+00 \quad 0.00 E+00$

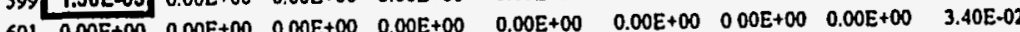

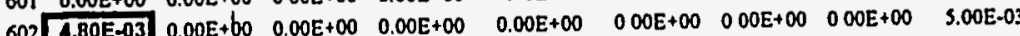

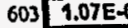
$604 \quad 1.40 E-03 \quad 000 E+60 \quad 000 E+\infty 0000 E+\infty 00.00 E+\infty 0 \quad 0.00 E+00 \quad 0.00 E+00 \quad 000 E+\infty 0 \quad 0.00 E+\infty 0$ $6070.00 E+00$

$6 0 8 \longdiv { 6 . 1 0 E - 0 3 }$

$\begin{array}{llllllllllllllllllll}0.00 E & 0.00 E+00 & 4.00 E-03 & 0.00 E+00 & 0.00 E+00\end{array}$ $\begin{array}{llllllllllllll}2.00 & 0.00 E+\infty & 0.00 E+\infty & 0.00 E+\infty\end{array}$ 611 613

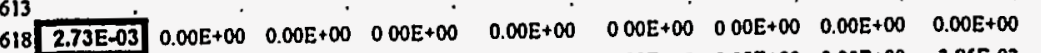
$\begin{array}{llllllllll}620 & 0.00 E+00 & 0.00 E+\infty 0 & 0.00 E+00 & 0.00 E+00 & 0.00 E+00 & 0.00 E+00 & 0.00 E+\infty 0 & 0.00 E+\infty 0 & 3.85 E-02\end{array}$

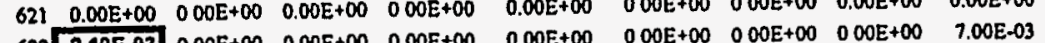

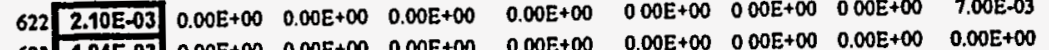

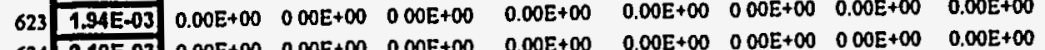
$\begin{array}{lllllllllll}032.00 & 2.00 E & 0.00 E+00 & 0.00 E+00\end{array}$

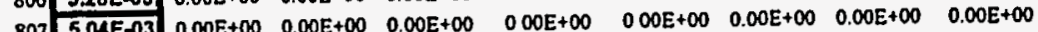
SOI

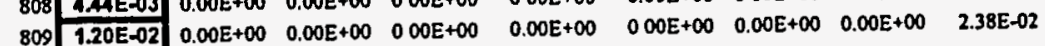

$0.00 E+00 \quad 0.00 E+00$ $0.00 E+00$ 0.00E+00 $0.00 E+00 \quad 0.00 E+00$ $0.00 E+\infty 00 \quad 0.00 E+\infty$ $0.00 E+00 \quad 0.00 E+00$ $0.00 E+\infty 00 \quad 000 E+00$ $000 \mathrm{E}+00 \quad 300 \mathrm{E}-03$ $0.00 E+00 \quad 3.00 E-04$ $0.00 E+00 \quad 000 E+\infty 0$
DENZANT BENZAPYR CAPBON T DIBENZ A HCBE INDENO I NNDNPA $\begin{array}{lllllllll}0.00 E+00 & 0.00 E+\infty & 0.00 E+00 & 0.00 E+00 & 0.00 E+\infty 0 & 0.00 E+00 & 0.00 E+\infty 0\end{array}$

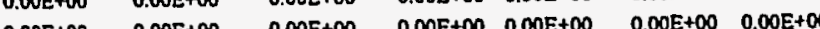
$\begin{array}{lllllllll}0.00 E+00 & 0.00 E+00 & 0.00 E+00 & 0.00 E+00 & 0.00 E+00 & 0.00 E+\infty 0 & 0.00 E+\infty\end{array}$ $\begin{array}{llllllll}0.00 E+00 & 0.00 E+00 & 0.00 E+\infty 0 & 0.00 E+00 & 0.00 E+00 & 0.00 E+00 & 0.00 E+\infty\end{array}$ $\begin{array}{llllllll}0.00 E+00 & 0.00 E+\infty 0 & 0.00 E+\infty 0 & 0.00 E+00 & 0.00 E+\infty 0 & 0.00 E+\infty 0 & 0.00 E+\infty 0\end{array}$ $\begin{array}{llllllllllllll}0.00 E+00 & 0.00 E+\infty 0 & 0.00 E+00 & 0.00 E+00 & 0.00 E+\infty & 0.00 E+\infty 0 & 0.00 E+\infty\end{array}$ $\begin{array}{llllllll}0.00 E+00 & 0.00 E+00 & 0.00 E+00 & 0.00 E+00 & 0.00 E+00 & 0.00 E+00 & 0.00 E+00\end{array}$ $0.00 E+00$ O. C. $0.00 \mathrm{E}$ 3.00E

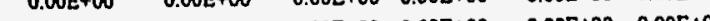
$\begin{array}{lllllllllllllll}0.00 E+\infty & 0.00 E+\infty & 0.00 E+\infty & 0.00 E+\infty 0 & 0.00 E+\infty & 0.00 E+\infty 0 & 0.00 E+\infty\end{array}$ $\begin{array}{lllllllll}0.00 E+\infty 0 & 0.00 E+00 & 0.00 E+00 & 0.00 E+00 & 0.00 E+00 & 0.00 E+00 & 0.00 E+00\end{array}$ $\begin{array}{lllllllll}0.00 E+00 & 0.00 E+00 & 0.00 E+00 & 0.00 E+00 & 0.00 E+00 & 0.00 E+00 & 0.00 E+00\end{array}$ $\begin{array}{llllllll}0.00 E+00 & 0.00 E+00 & 0.00 E+00 & 0.00 E+00 & 0.00 E+00 & 0.00 E+00 & 0.00 E+00\end{array}$ $\begin{array}{llllllll}0.00 E+00 & 0.00 E+\infty 0 & 0.00 E+00 & 0.00 E+00 & 0.00 E+00 & 0.00 E+00 & 0.00 E+\infty 0\end{array}$ $0.00 \mathrm{E}+\infty 0$

$0.00 E+00 \quad 0.00 E+00$ $0.00 E+00 \quad 0.00 E+00$ $0.00 E+00 \quad 0.00 E+00$ $0.00 E+\infty 00.00 E+\infty$ $0.00 E+00 \quad 0.00 E+\infty 0$ $0.00 E+\infty 00 \quad 0.00 E+\infty 0$

$0.00 \mathrm{E}+00 \quad 0.00 \mathrm{E}+00$ $0.00 E+00 \quad 0.00 E+00 \quad 0.00 E+00 \quad 0.00 E+00 \quad 0.00 E+00$ $\begin{array}{lllll}0.00 E+00 & 0.00 E+00 & 0.00 E+00 & 0.00 E+00 & 0.00 E+00\end{array}$ $0.00 E+\infty \quad 0.00 E+00 \quad 0.00 E+00 \quad 0.00 E+\infty 00 \quad 0.00 E+\infty 0$ $\begin{array}{llllll}0.00 E+\infty 0 & 0.00 E+00 & 0.00 E+00 & 0.00 E+\infty & 0.00 E+\infty 0\end{array}$ $\begin{array}{llllll}0.00 E+00 & 0.00 E+00 & 0.00 E+00 & 0.00 E+00 & 0.00 E+00\end{array}$ $\begin{array}{lllllll}0.00 E+\infty 0 & 0.00 E+00 & 0.00 E+\infty 0 & 0.00 E+00 & 0.00 E+\infty 0\end{array}$ $0.00 E+\infty 0$ $\begin{array}{llllll}0.00 E+00 & 0.00 E+00 & 0.00 E+00 & 0.00 E+00 & 0.00 E+00\end{array}$ $1.90 \mathrm{E}-02$ $0.00 E+00 \quad 0.00 E+00 \quad 0.00 E+00 \quad 0.00 E+\infty 00.00 E+\infty 0$

$1.30 \mathrm{E}-02$

\begin{tabular}{llllll}
$0.00 E+00$ & $1.00 E-02$ & $1.00 E-02$ & $1.00 E-02$ & $1.00 E-02$ \\
\hline
\end{tabular}
$0.00 E+\infty 00.00 E+000.00 E+00 \quad 0.00 E+00 \quad 0.00 E+00$ $\begin{array}{lllll}0.00 E+00 & 0.00 E+00 & 0.00 E+00 & 0.00 E+00 & 0.00 E+00\end{array}$ $\begin{array}{llllll}0.00 E+\infty 0 & 0.00 E+\infty 0 & 0.00 E+00 & 0.00 E+00 & 0.00 E+00\end{array}$ $000 E+\infty 0 \quad 0.00 E+\infty 0 \quad 0.00 E+00 \quad 0.00 E+00 \quad 0.00 E+00$ $0.00 E+00 \quad 0.00 E+\infty 0$ $0.00 \mathrm{E}+00 \quad 0.00 \mathrm{E}+00$ $000 E+00 \quad 0.00 E+00$ $\begin{array}{lllll}0.00 E+00 & 0.00 E+00 & 0.00 E+00 & 0.00 E+00 & 0.00 E+\infty 0\end{array}$

$000 E+\infty \quad 0.00 E+\infty$ $0.00 E+\infty \quad 0.00 E+\infty 0$ $0.00 E+00 \quad 0.00 E+00$ $0.00 E+00 \quad 0.00 E+00$ $0.00 E+\infty 00 \quad 0.00 E+\infty$ $0.00 E+00 \quad 0.00 E+00$ $0.00 E+\infty 0 \quad 0.00 E+\infty$ $0.00 E+00 \quad 0.00 E+\infty 0$ $0.00 E+00 \quad 0.00 E+00$ $0.00 E+00 \quad 0.00 E+00$ $0.00 E+\infty 00.00 E+\infty 0$
$0000+00 \quad 000 E+\infty 0000+00 \quad 000 E+\infty 00000+\infty$ $0.00 E+\infty \quad 0.00 E+\infty 0 \quad 0.00 E+00 \quad 0.00 E+\infty 0 \quad 0.00 E+\infty 0$

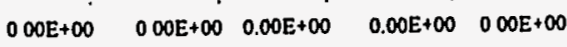
$\begin{array}{llllll}0.00 E+00 & 0.00 E+\infty 0 & 0.00 E+00 & 0.00 E+00 & 0.00 E+00\end{array}$ $\begin{array}{llllll}0.00 E+00 & 0.00 E+00 & 0.00 E+00 & 0.00 E+00 & 0.00 E+00\end{array}$ $\begin{array}{llllll}0.00 E+00 & 0.00 E+00 & 0.00 E+00 & 0.00 E+00 & 0.00 E+00\end{array}$ $0.00 E+\infty \quad 0.00 E+00 \quad 0.00 E+00 \quad 0.00 E+\infty 000.00 E+\infty$

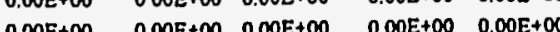
DOOE 00 OCOE

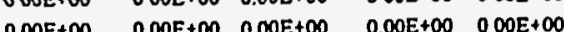
$\begin{array}{lllll}0.00 E+00 & 0.00 E+\infty 0 & 0.00 E+00 & 0.00 E+\infty 0 & 0.00 E+00 \\ 0.00 E+\infty & 0.00 E+\infty 0 & 0.00 E+00 & 0.00 E+00 & 8.00 E-03\end{array}$ 
$N$

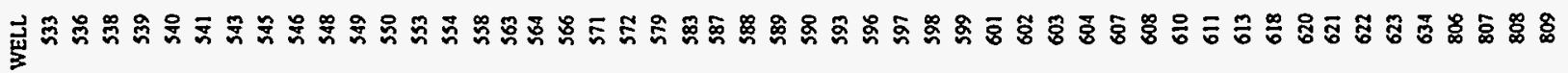

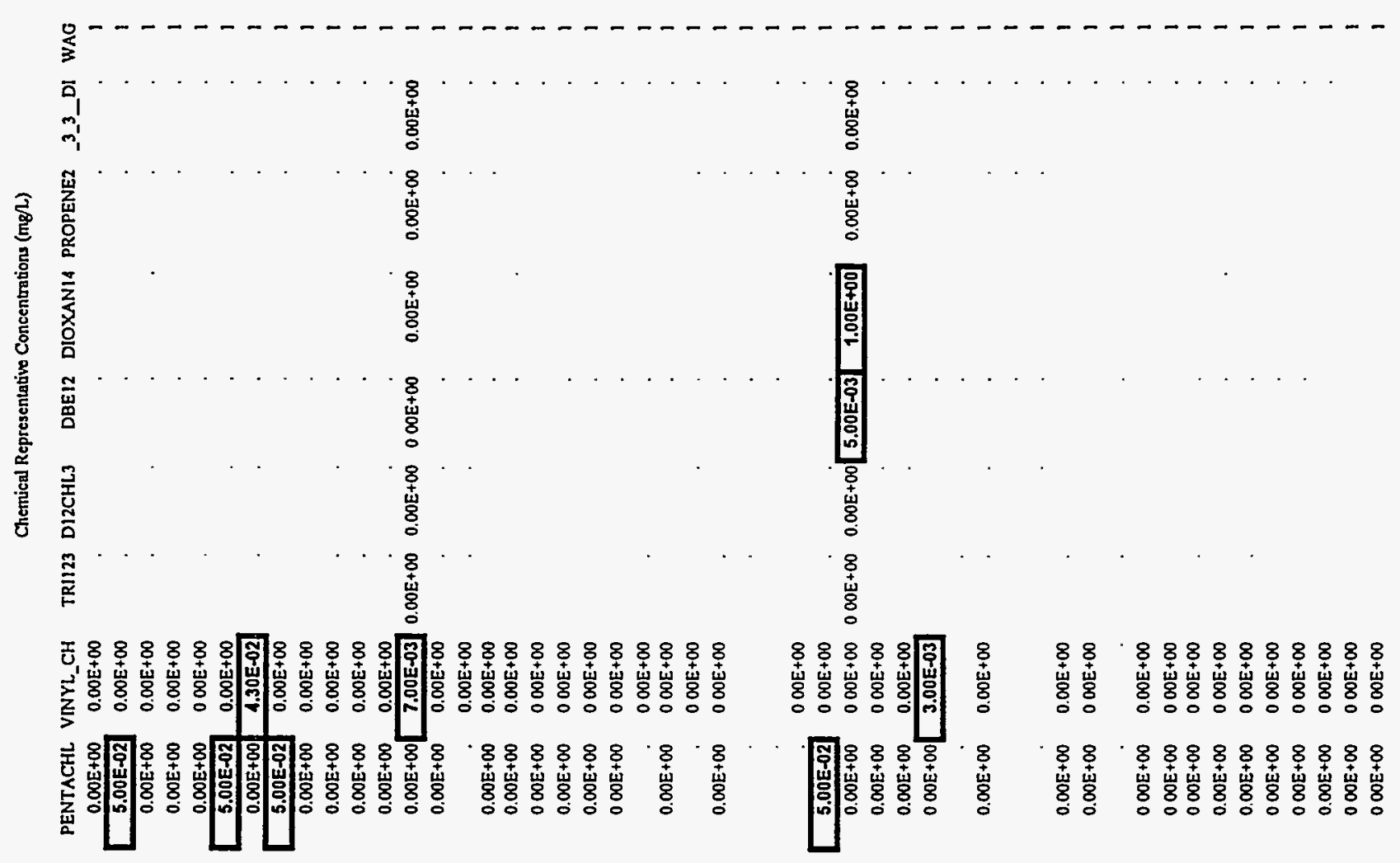




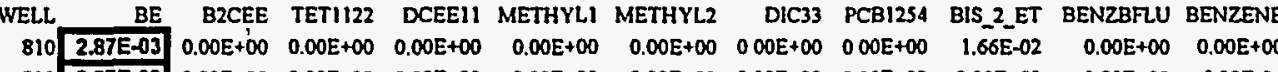

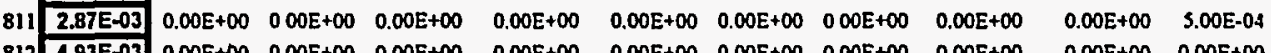

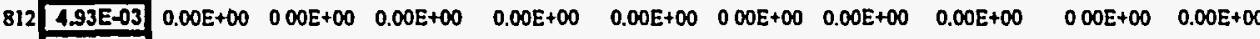

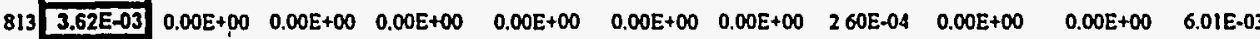

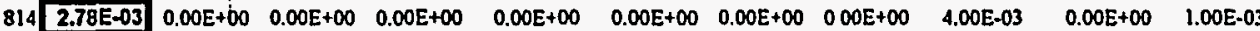
$\begin{array}{lllllllllllll}815 & 8.67 E-04 & 0.00 E+00 & 0.00 E+00 & 0.00 E+00 & 0.00 E+00 & 0.00 E+00 & 0.00 E+00 & 0.00 E+00 & 0.00 E+00 & 0.00 E+00 & 0.00 E+00\end{array}$

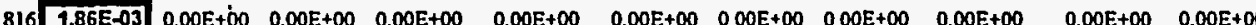

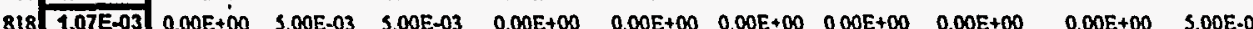
$8190.00 E+00$ O.

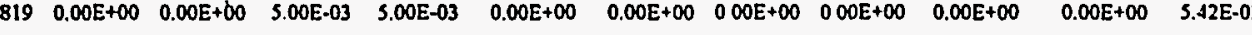
$\begin{array}{lllllllllllll}820 & 5.63 \mathrm{E}-04 & 0.00 \mathrm{E}+00 & 0.00 E+00 & 0.00 \mathrm{E}+00 & 0.00 \mathrm{E}+00 & 0.00 \mathrm{E}+00 & 0.00 \mathrm{E}+00 & 0.00 \mathrm{E}+00 & 1.16 \mathrm{E}-02 & 0.00 \mathrm{E}+00 & 0.00 \mathrm{E}+00\end{array}$ $\begin{array}{llllllllllll}821 & 0.00 E+00 & 0.00 E+00 & 0.00 E+00 & 0.00 E+00 & 0.00 E+00 & 0.00 E+00 & 0.00 E+00 & 0.00 E+00 & 2.24 E-02 & 0.00 E+00 & 0.00 E+00\end{array}$

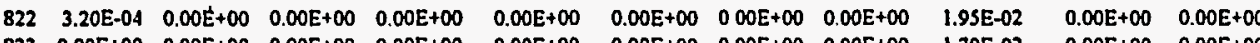
$\begin{array}{llllllllllll}823 & 0.00 E+00 & 0.00 E+00 & 0.00 E+00 & 0.00 E+\infty 0 & 0.00 E+\infty 0 & 0.00 E+\infty 0 & 0.00 E+00 & 0.00 E+00 & 1.70 E-02 & 0.00 E+\infty 0 & 0.00 E+00\end{array}$

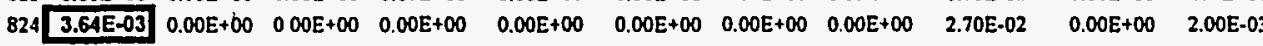

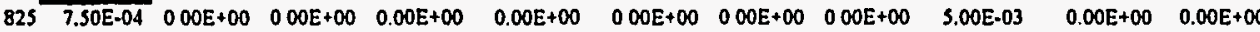
$\begin{array}{lllllllllllll}826 & 7.77 \mathrm{E}-04 & 0.00 \mathrm{E}+00 & 0.00 \mathrm{E}+00 & 0.00 \mathrm{E}+00 & 0.00 \mathrm{E}+00 & 0.00 \mathrm{E}+00 & 0.00 \mathrm{E}+00 & 0.00 \mathrm{E}+00 & 2.23 \mathrm{E}-02 & 000 \mathrm{E}+\infty 0 & 1.00 \mathrm{E}-03\end{array}$

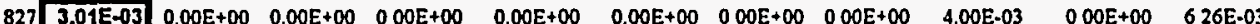

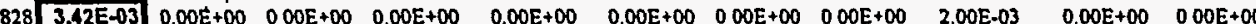

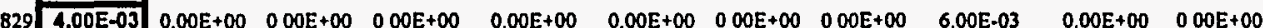

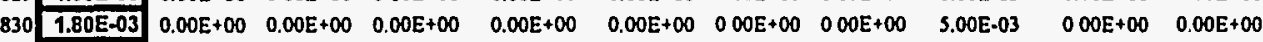

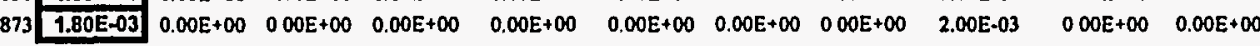
$\begin{array}{llllllllllll}874 & 0.00 E+00 & 0.00 E+00 & 0.00 E+00 & 0.00 E+00 & 0.00 E+00 & 0.00 E+00 & 0.00 E+00 & 0.00 E+00 & 0.00 E+00 & 0.00 E+00 & 0.00 E+00\end{array}$ $\begin{array}{lllllllllllll}875 & 0.00 E+00 & 0.00 E+00 & 0.00 E+00 & 0.00 E+00 & 0.00 E+00 & 1.00 E-02 & 0.00 E+00 & 0.00 E+\infty 0 & 0.00 E+00 & 0.00 E+00 & 0.00 E+00\end{array}$ $\begin{array}{lllllllllllll}876 & 0.00 E+\infty & 0.00 E+00 & 0.00 E+\infty 0 & 0.00 E+00 & 0.00 E+00 & 0.00 E+\infty & 0.00 E+00 & 0.00 E+\infty 0 & 0.00 E+00 & 0.00 E+00 & 0.00 E+00\end{array}$

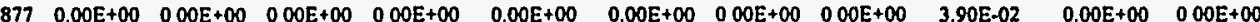

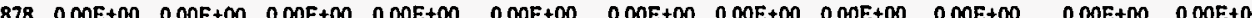

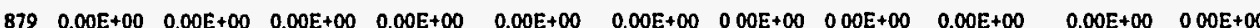
$\begin{array}{llllllllllll}880 & 0.00 E+00 & 0.00 E+00 & 0.00 E+00 & 0.00 E+00 & 0.00 E+00 & 0.00 E+00 & 0.00 E+00 & 0.00 E+00 & 0.00 E+00 & 0.00 E+00 & 0.00 E+00\end{array}$

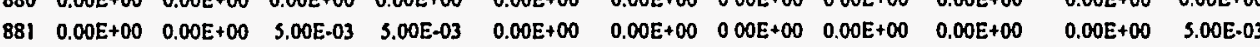

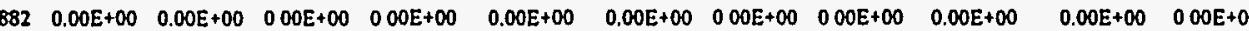
$\begin{array}{lllllllllllll}884 & 0.00 E+00 & 0.00 E+00 & 0.00 E+\infty 0 & 0.00 E+00 & 0.00 E+\infty 0 & 0.00 E+00 & 0.00 E+00 & 0.00 E+\infty & 0.00 E+00 & 0.00 E+00 & 0.00 E+00\end{array}$ $\begin{array}{lllllllllllll}885 & 0.00 \mathrm{E}+00 & 0.00 \mathrm{E}+00 & 0.00 \mathrm{E}+00 & 0.00 \mathrm{E}+00 & 0.00 \mathrm{E}+00 & 0.00 \mathrm{E}+00 & 0.00 \mathrm{E}+00 & 0.00 \mathrm{E}+00 & 1.48 \mathrm{E}-02 & 0.00 \mathrm{E}+00 & 0.00 \mathrm{E}+00\end{array}$ $\begin{array}{lllllllllllll}886 & 0.00 E+00 & 0.00 E+\infty 0 & 0.00 E+00 & 0.00 E+00 & 0.00 E+00 & 0.00 E+00 & 0.00 E+00 & 0.00 E+\infty & 0.00 E+00 & 0.00 E+00 & 0.00 E+00\end{array}$

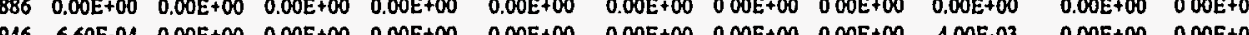
947 6.70E-04 $0.00 \mathrm{E}+00$ 0.00E+00 $0.00 \mathrm{E}+00$ 0.00E +00 0.00E $1100 \quad 0.00 E+00 \quad 0.00 E+00 \quad 0.00 E+00 \quad 0.00 E+00 \quad 0.00 E+\infty 000.00 E+\infty 00 \quad 0.00 E+00 \quad 0.00 E+\infty 000.00 E+00 \quad 0.00 E+00 \quad 0.00 E+00$

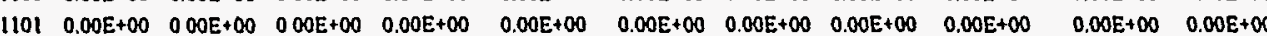
$\begin{array}{llllllllllll}1102 & 0.00 E+\infty 0 & 0.00 E+\infty & 0.00 E+\infty 0 & 0.00 E+\infty & 0.00 E+\infty 0 & 0.00 E+\infty & 0.00 E+\infty 0 & 0.00 E+\infty 0 & 0.00 E+\infty 0 & 0.00 E+\infty 0 & 0.00 E+00\end{array}$ $\begin{array}{llllllllllll}1103 & 0.00 E+00 & 0.00 E+00 & 0.00 E+00 & 0.00 E+00 & 0.00 E+00 & 0.00 E+00 & 0.00 E+00 & 0.00 E+00 & 0.00 E+00 & 0.00 E+00 & 0.00 E+00\end{array}$ $\begin{array}{lllllllllllll}1104 & 0.00 E+00 & 0.00 E+00 & 0.00 E+00 & 0.00 E+00 & 0.00 E+00 & 0.00 E+00 & 0.00 E+\infty 0 & 0.00 E+00 & 3.00 E-03 & 0.00 E+00 & 0.00 E+00\end{array}$

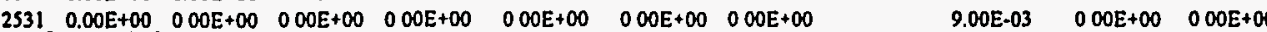
$2333 \quad 1.00 E-03 \quad 0.00 E+\infty 00 \quad 0.00 E+00 \quad 0.00 E+00 \quad 0.00 E+00 \quad 0.00 E+00 \quad 000 E+00$

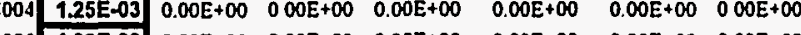
E. $+00 E+\infty$ $4006\left[\begin{array}{lllllll}1.10 E-03 & 0.00 E+00 & 0.00 E+00 & 0.00 E+00 & 0.00 E+00 & 0.00 E+00 & 0.00 E+00\end{array}\right.$ $\begin{array}{llllllllll}4008 & 0.00 E+00 & 0.00 E+00 & 0.00 E+00 & 0.00 E+00 & 0.00 E+00 & 0.00 E+\infty 0 & 0.00 E+\infty 0\end{array}$

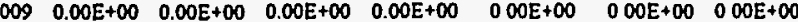
$\begin{array}{llllllllllll}150 & 0.00 E+\infty & 0.00 E+\infty & 0.00 E+\infty 0 & 0.00 E+\infty & 0.00 E+\infty 0 & 0.00 E+\infty 0 & 0.00 E+\infty\end{array}$ $\begin{array}{llllllllll}1151 & 0.00 E+\infty & 0.00 E+\infty & 0.00 E+00 & 0.00 E+\infty 0 & 0.00 E+\infty 0 & 0.00 E+\infty 0 & 0.00 E+\infty\end{array}$ $\begin{array}{llllllll}1152 & 0.00 E+00 & 0.00 E+\infty & 0.00 E+00 & 0.00 E+\infty 0 & 0.00 E+00 & 0.00 E+\infty 0 & 0.00 E+\infty\end{array}$
$0.00 E+00 \quad 0.00 E+00 \quad 0.00 E+00$

$6.00 E-03 \quad 0.00 E+00 \quad 0.00 E+00$ $0.00 E+00 \quad 0.00 E+00 \quad 0.00 E+00$ $0.00 E+\infty \quad 000 E+00 \quad 0.00 E+\infty 0$ $0.00 E+00 \quad 0.00 E+00 \quad 0.00 E+00$ $0.00 E+\infty \quad 0.00 E+00 \quad 0.00 E+00$ $0.00 E+00 \quad 0.00 E+00 \quad 0.00 E+00$ 3.00E-03 $000 \mathrm{E}+00 \quad 0.00 \mathrm{E}+00$ $0.00 E+\infty 00 \quad 0.00 E+00 \quad 000 E+\infty 0$ $0.00 E+00 \quad 0.00 E+\infty 0 \quad 100 E-03$

\begin{tabular}{|c|c|c|c|c|c|c|}
\hline $0 E+\infty 0$ & $0.00 E+\infty 0$ & $0.00 E+00$ & $\begin{array}{r}\text { DIBENZ_A } \\
0.00 E+00\end{array}$ & $\begin{array}{r}\text { HCBE } \\
0.00 E+00\end{array}$ & $\begin{array}{r}\text { DNDENO_1 } \\
0.00 E+00\end{array}$ & $0.00 E+00$ \\
\hline $10 E+\infty$ & $0.00 E+00$ & $0.00 E+00$ & $0.00 E+\infty$ & $0.00 E+00$ & $0.00 E+\infty 0$ & $0.00 E+\infty 0$ \\
\hline$D E+00$ & $0.00 E+00$ & $0.00 E+00$ & $0.00 E+00$ & $0.00 E+00$ & $00 E+\infty$ & $0.00 E+\infty 0$ \\
\hline $0 E+00$ & $0.00 E+\infty$ & $0 E-03$ & $0.00 E+\infty$ & $0.00 E+00$ & $00 E+\infty 0$ & $0.00 E+00$ \\
\hline $.00 \mathrm{E}+\infty 0$ & $0.00 \mathrm{E}+00$ & $10 \mathrm{E}+00$ & $0.00 E+\infty$ & $0.00 E+\infty 0$ & $00 E+00$ & $0.00 \mathrm{E}+00$ \\
\hline $00 \mathrm{E}+00$ & $0.00 E+\infty$ & $00 E+\infty 0$ & $0.00 \mathrm{E}+00$ & $0.00 E+00$ & $0.00 E+00$ & $0.00 E+\infty 0$ \\
\hline $00 \mathrm{E}+00$ & $00 E+00$ & $00 E+\infty$ & $0.00 E+00$ & $0.00 E+00$ & $.00 \mathrm{E}+\infty 0$ & $0.00 E+00$ \\
\hline $0 E+\infty$ & $00 E+\infty 0$ & $0 E-03$ & $0.00 E+00$ & $0.00 E+00$ & $.00 E+00$ & $0.00 E+\infty 0$ \\
\hline $0.00 E+00$ & $0.00 E+00$ & $0 E-03$ & $0.00 E+00$ & $0.00 E+00$ & $00 E+\infty 0$ & $0.00 E+\infty 0$ \\
\hline $.00 E+\infty 0$ & $0.00 E+\infty 0$ & $00 E+\infty 0$ & $0.00 E+\infty$ & $0.00 E+00$ & $00 E+00$ & $0.00 E+\infty 0$ \\
\hline $10 E+00$ & $F+\infty$ & $E+\infty$ & $0.00 E+\infty 0$ & $0.00 E+00$ & $10 E+\infty 0$ & $0.00 \mathrm{E}+00$ \\
\hline & & & $0.00 E+00$ & $0.00 E+00$ & $00 E+00$ & $.00 E+00$ \\
\hline & & & & & & \\
\hline $000 E+00$ & $00 E+\infty 0$ & $00 \mathrm{E}+00$ & $0.00 E+00$ & $0.00 E+\infty 0$ & $.00 E+00$ & $0.00 E+00$ \\
\hline $00 E+\infty 0$ & $10 E+\infty 0$ & $10 E+00$ & $0.00 E+00$ & $0.00 \mathrm{E}+\infty 0$ & $000 E+00$ & $0.00 E+00$ \\
\hline $.00 E+\infty 0$ & $20 E+00$ & $.00 E+00$ & $0.00 E+\infty 0$ & $0.00 E+00$ & $.00 E+00$ & $0.00 E+\infty 0$ \\
\hline $0.00 E+00$ & $00 E+00$ & $00 E+00$ & $0.00 E+00$ & $0.00 E+00$ & $.00 E+00$ & $0.00 E+00$ \\
\hline $000 E+00$ & $0 E+\infty 0$ & $0 E+\infty$ & $00 E+00$ & $0.00 E+00$ & $.00 E+00$ & $0.00 E+00$ \\
\hline $000 E+00$ & $00 E+00$ & $.00 E+\infty$ & $0.00 E+00$ & $0.00 E+00$ & $0.00 E+00$ & $0.00 E+00$ \\
\hline $00 E+\infty$ & $0.00 E+00$ & $0.00 E+00$ & $0.00 E+00$ & $0,00 E+\infty$ & $0.00 E+\infty$ & $0.00 E+00$ \\
\hline $0.00 E+00$ & $0.00 E+00$ & $0.00 E+00$ & $0.00 E+00$ & $0.00 E+00$ & $.00 E+00$ & $0.00 E+00$ \\
\hline $0.00 E+00$ & $0.00 E+\infty 0$ & $0.00 E+\infty 0$ & $0.00 E+00$ & $0.00 E+00$ & $0.00 E+00$ & $0.00 \mathrm{E}+00$ \\
\hline $000 E+00$ & $0.00 E+00$ & $.00 E+00$ & $0.00 E+00$ & $0.00 E+\infty 0$ & $00 E+00$ & $1.00 \mathrm{E}-02$ \\
\hline $0.00 E+00$ & $0.00 E+00$ & $0 E+00$ & $0.00 E+00$ & $0.00 E+\infty$ & $0.00 E+00$ & $0.00 E+00$ \\
\hline $0.00 E+00$ & $0.00 E+00$ & $00 E+\infty$ & $0.00 E+00$ & $0.00 E+\infty$ & $.00 E+\infty 0$ & $0.00 E+\infty 0$ \\
\hline $0.00 \mathrm{E}+00$ & $0.00 E+00$ & $0.00 E+00$ & $0.00 E+00$ & $0.00 E+\infty$ & $0.00 E+00$ & $0.00 E+00$ \\
\hline $000 E+00$ & $0.00 E+00$ & $00 E+\infty$ & $0.00 E+00$ & $0.00 E+00$ & $0.00 E+00$ & $0.00 E+00$ \\
\hline $0.00 E+\infty 0$ & $E+\infty 0$ & & & $0.00 E+\infty$ & $E+00$ & $10 E+00$ \\
\hline $0.00 E+00$ & $0.00 E+00$ & OE-03 & $0.00 E+00$ & $0.00 E+\infty$ & $0,00 E+00$ & $0.00 \varepsilon+00$ \\
\hline $0.00 E+00$ & $0.00 E+00$ & $00 E+\infty 0$ & $000 E+00$ & $0.00 E+\infty 0$ & $0.00 E+00$ & $0.00 E+00$ \\
\hline $0.00 E+00$ & $0.00 E+00$ & $0.00 E+00$ & $.00 E+00$ & $0.00 E+\infty$ & $.00 E+00$ & $0.00 E+00$ \\
\hline $0.00 E+\infty$ & 30 & & $00 E+00$ & & $+\infty$ & $+\infty$ \\
\hline$\varepsilon+\infty$ & $0.00 E+00$ & $E+\infty$ & 100 & $0.00 E+\infty 0$ & $+\infty 0$ & +00 \\
\hline & & & & $8+\infty 0$ & & 400 \\
\hline 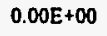 & 0 & 00 & 100 & & 00 & $+\infty$ \\
\hline $0.00 E+00$ & $0.00 E+00$ & $00 E+00$ & $0.00 E+00$ & $0.00 E+00$ & $.00 E+00$ & $0.00 E+00$ \\
\hline $000 E+00$ & $00 E+\infty 0$ & $0 E+00$ & $00 E+00$ & $000 E+00$ & $00 E+00$ & $0.00 E+00$ \\
\hline $00 E+00$ & $0.00 E+00$ & $10 E+00$ & $000 \mathrm{E}+00$ & $0.00 E+00$ & $.00 E+\infty 0$ & $000 E+\infty 0$ \\
\hline $000 E+00$ & $0.00 E+00$ & $00 E+\infty 0$ & $000 E+00$ & $0.00 E+00$ & $.00 E+00$ & $000 E+00$ \\
\hline $\begin{array}{l}0.00 E+00 \\
0.00 E+00\end{array}$ & $\begin{array}{l}0.00 E+00 \\
0.00 E+00\end{array}$ & $\begin{array}{l}00 E+00 \\
00 E+00\end{array}$ & $\begin{array}{l}000 E+00 \\
000 E+00\end{array}$ & $\begin{array}{l}0.00 E+00 \\
0.00 E+00\end{array}$ & $\begin{array}{l}.00 E+\infty \\
.00 E+\infty 0\end{array}$ & $\begin{array}{l}0.00 E+00 \\
0.00 E+00\end{array}$ \\
\hline $000 E+00$ & $000 \mathrm{E}+00$ & $00 E+00$ & $000 E+\infty 0$ & $0.00 E+00$ & $0.00 E+00$ & $0.00 E+00$ \\
\hline $0.00 E+00$ & $0.00 E+00$ & $00 E+00$ & $000 E+00$ & $0.00 E+00$ & $.00 E+\infty 0$ & $000 E+00$ \\
\hline $0.00 E+\infty 0$ & $0.00 E+00$ & $0 E+\infty$ & $0.00 E+00$ & $0.00 E+00$ & $0.00 E+00$ & $0.00 E+\infty 0$ \\
\hline$\$+\infty$ & w & $0 \mathrm{E}+\infty 0$ & $000 E+00$ & $0.00 E+\infty 0$ & $.00 E+\infty 0$ & $.00 E+\infty 0$ \\
\hline $000 E+00$ & $0.00 E+00$ & $0 E+\infty$ & $000 E+00$ & $0.00 E+00$ & $0.00 E+00$ & $0.00 E+00$ \\
\hline $0.00 E+00$ & & & $000 E+\infty 0$ & $0.00 E+00$ & $0.00 E+00$ & \\
\hline & & & & & & \\
\hline 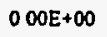 & & $E+00$ & $8+\infty$ & $000 E+00$ & $000 E+00$ & 0 OOE +00 \\
\hline & & & & & & \\
\hline $000 E+00$ & $+\infty$ & $10 E+\infty 0$ & 000 & & $0.00 \mathrm{E}+10$ & $000 E+00$ \\
\hline
\end{tabular}




\begin{tabular}{|c|c|c|c|c|c|c|c|c|c|}
\hline PENTACHL & VINYL_CH & TRI123 & D12CHL3 & DBE12 & DIOXANIA & PROPENE2 & ${ }_{-3}^{3}{ }^{3}-D I$ & WAO & WELL \\
\hline $0.00 \mathrm{E}+00$ & $0.00 E+00$ & . & . & . & - & . & 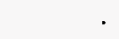 & 1 & 810 \\
\hline $0.00 E+\infty$ & $0.00 E+00$ & . & . & . & & . & . & 1 & 811 \\
\hline $0.00 E+\infty 0$ & $0.00 E+\infty 0$ & . & . & . & . & . & & 1 & 812 \\
\hline $0.00 E+00$ & $0.00 E+00$ & . & 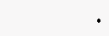 & . & . & & & 1 & 813 \\
\hline $0.00 E+\infty$ & $0.00 E+00$ & $0.00 \varepsilon+00$ & $0.00 E+00$ & $0.00 E+00$ & $0.00 E+00$ & $0.00 E+00$ & B.50E-02 & 1 & 814 \\
\hline $0.00 \mathrm{E}+00$ & $0.00 E+00$ & & & & & & & 1 & 815 \\
\hline $0.00 E+00$ & $0.00 E+00$ & & & & & & & 1 & 816 \\
\hline $0.00 E+\infty$ & $1,00 E-02$ & $5.00 E-03$ & $1.00 E-02$ & $5.00 E-03$ & $5.00 E+00$ & $1.00 E-02$ & $000 E+\infty$ & 1 & 818 \\
\hline $0.00 E+00$ & $1.00 E-02$ & $5.00 E-03$ & $1.00 E-02$ & $5.00 E-03$ & $5.00 E+00$ & 1.00E-02 & $0.00 E+\infty 0$ & 1 & 819 \\
\hline $0.00 E+00$ & $0.00 E+00$ & & & & & & - & 1 & 820 \\
\hline $0.00 E+00$ & $0.00 E+00$ & & . & & & . & . & 1 & 821 \\
\hline $0.00 E+00$ & $0.00 E+00$ & . & & & . & 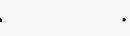 & . & 1 & 822 \\
\hline $0.00 E+\infty 0$ & $0.00 E+00$ & & & & & & - & 1 & 823 \\
\hline $0.00 E+\infty$ & $0.00 E+00$ & & & . & . & . & . & 1 & 824 \\
\hline $0.00 E+\infty$ & $2.26 E-02$ & & . & . & & . & . & 1 & 825 \\
\hline $0.00 E+00$ & $0.00 \mathrm{E}+00$ & & & . & . & . & . & 1 & 826 \\
\hline $0.00 E+00$ & $0.00 E+00$ & & . & . & . & . & . & 1 & 827 \\
\hline $0.00 E+00$ & $0.00 E+\infty$ & & . & . & & . & . & 1 & 828 \\
\hline $0.00 E+00$ & $0.00 E+00$ & & & . & . & & & 1 & 829 \\
\hline $000 E+00$ & $6.00 E-03$ & & & . & . & & & 1 & 830 \\
\hline $0.00 E+00$ & $0.00 E+00$ & . & & . & . & . & & 1 & 873 \\
\hline $5.00 E-02$ & $0.00 E+00$ & & & . & & & & 1 & 874 \\
\hline $0.00 E+00$ & $0.00 E+00$ & $000 E+00$ & $000 \mathrm{E}+00$ & $000 E+00$ & $0.00 E+00$ & $000 E+\infty$ & $000 E+00$ & 1 & 875 \\
\hline $0.00 E+00$ & $0.00 \mathrm{E}+00$ & 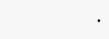 & t & . & & & & 1 & 876 \\
\hline $5.00 E-02$ & $0.00 E+00$ & & & . & & & & 1 & 877 \\
\hline $5.00 E-02$ & $0.00 E+00$ & . & . & . & & & . & 1 & 878 \\
\hline $0.00 \mathrm{E}+00$ & $0.00 E+\infty 0$ & & . & . & . & & & 1 & 879 \\
\hline $5.00 E-02$ & $0.00 E+00$ & . & . & . & 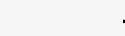 & & . & 1 & 880 \\
\hline $5.00 E-02$ & 1.20E-02 & & & . & & & & 1 & 881 \\
\hline $0.00 \mathrm{E}+00$ & $0.00 E+00$ & & & . & & & $\cdot$ & 1 & 882 \\
\hline $5.00 E-02$ & $0.00 E+00$ & . & & . & . & . & & 1 & 884 \\
\hline $0.00 E+00$ & $5.00 E-03$ & & & . & & . & & 1 & 885 \\
\hline $0.00 E+00$ & $0.00 \mathrm{E}+00$ & & & . & & & & 1 & 886 \\
\hline $0.00 E+00$ & $0.00 E+00$ & & & . & . & . & & 1 & 946 \\
\hline $0.00 E+00$ & $0.00 E+00$ & & . & . & . & . & . & 1 & 947 \\
\hline $0.00 E+00$ & 1.10E-02 & & & . & 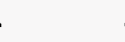 & . & . & 1 & 1100 \\
\hline $5.00 E-02$ & $0.00 E+00$ & & & . & 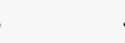 & . & . & 1 & 1101 \\
\hline $5.00 E-02$ & $8.00 E-03$ & & & . & - & . & . & 1 & 1102 \\
\hline $0.00 \mathrm{E}+\infty 0$ & 1.90E-02 & . & , & . & & 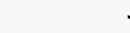 & . & 1 & 1103 \\
\hline $0.00 \mathrm{E}+00$ & $0.00 E+00$ & . & & & & & & 1 & 1104 \\
\hline $0.00 E+00$ & $0.00 E+00$ & . & & . & . & . & . & 1 & 2531 \\
\hline $0.00 E+\infty 0$ & $0.00 E+00$ & & . & . & . & . & . & 1 & 2533 \\
\hline $0.00 E+00$ & $0.00 E+00$ & . & & . & . & . & . & $t$ & 4003 \\
\hline $0.00 E+\infty 0$ & $0.00 E+\infty 0$ & . & & . & & . & . & 1 & 4004 \\
\hline $5.00 E-02$ & $0.00 E+00$ & . & . & & & & & 1 & 4005 \\
\hline $0.00 E+\infty 0$ & $1,80 E-02$ & & . & & & & & 1 & 4006 \\
\hline $0.00 \mathrm{E}+\infty 0^{\circ}$ & $0.00 \mathrm{E}+00$ & . & & & & . & . & 1 & 4008 \\
\hline $0.00 E+\infty 0$ & $0.00 E+\infty 0$ & & & & & & & 1 & 4009 \\
\hline $000 \mathrm{E}+00$ & $0.00 E+00$ & . & & . & & . & & 2 & 1150 \\
\hline $000 \mathrm{E}+00$ & $000 E+\infty 0$ & & & & & & & 2 & $\mid 151$ \\
\hline $000 E+\infty$ & $000 E+\infty 0$ & & & & & & & 2 & 1152 \\
\hline
\end{tabular}


WELL BE BZCEE TETIIZ2 DCEEII METHYLI METHYL2 DIC33 PCBI2SA BIS_2_ET BENZBFLU BENZENE BENZAMNT BENZAPYR CARBONTT DIBENZ A HCBE NNDENO 1 NNDNPA

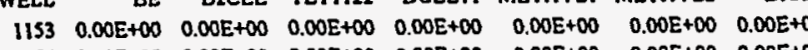

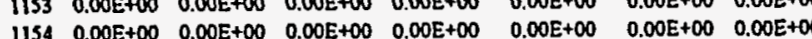

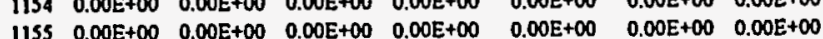

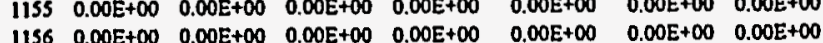
$\begin{array}{llllllllllll}1136 & 0.00 E+\infty & 0.00 E+\infty & 0.00 E+\infty & 0.00 E+\infty & 0.00 E+\infty & 0.00 E+\infty & 0.00 E+\infty\end{array}$

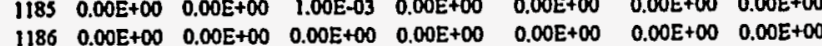

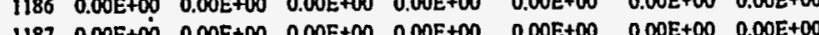
$\begin{array}{llllllll}1187 & 0.00 E+\infty 0 & 0.00 E+\infty 0 & 0.00 E+00 & 0.00 E+00 & 0.00 E+00 & 0.00 E+00 & 0.00 E+\infty 0\end{array}$ $\begin{array}{llllllll}1188 & 0.00 E+00 & 0.00 E+\infty & 0.00 E+\infty 0 & 0.00 E+\infty 0 & 0.00 E+00 & 0.00 E+00 & 0.00 E+\infty \\ 1189 & 0.00 E+00 & 0.00 E+\infty 0 & 0.00 E+00 & 0.00 E+\infty 0 & 0.00 E+00 & 0.00 E+00 & 0.00 E+\infty 0\end{array}$ $\begin{array}{lllllllll}1190 & 0.00 E+00 & 0.00 E+00 & 0.00 E+00 & 4.40 E-02 & 0.00 E+00 & 0.00 E+00 & 0.00 E+00\end{array}$ $\begin{array}{llllllllll}1191 & 0.00 E+00 & 0.00 E+00 & 0.00 E+00 & 0.00 E+00 & 0.00 E+00 & 0.00 E+\infty 0 & 0.00 E+00\end{array}$ $1192 \quad 0.00 E+00 \quad 0.00 E+\infty 000.00 E+\infty 000.00 E+\infty 000.00 E+\infty 0 \quad 0.00 E+\infty 00.00 E+\infty 0$ $\begin{array}{lllllllll}1193 & 0.00 E+\infty 0 & 0.00 E+\infty & 0.00 E+00 & 0.00 E+00 & 0.00 E+00 & 0.00 E+00 & 0.00 E+00\end{array}$

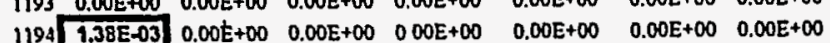

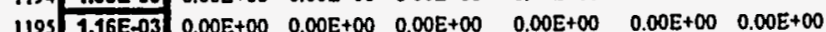
1195 1.16E-03 $0.00 E+00$ 0.00E+00 $0.00 E$ (1) $\begin{array}{llllllllllllllll}1244 & 0.00 E+\infty 0 & 0.00 E+\infty 0 & 0.00 E+\infty & 0.00 E+\infty 0 & 0.00 E+\infty 0 & 0.00 E+\infty 0 & 0.00 E+\infty 00\end{array}$

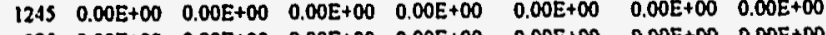

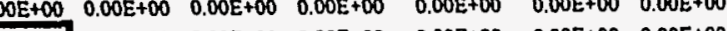
0.000 (a) $\begin{array}{llllllllll}987 & 0.00 E+00 & 0.00 E+00 & 0.00 E+00 & 0.00 E+00 & 0.00 E+\infty & 0.00 E+00 & 0.00 E+\infty 0\end{array}$ $988 \quad 0.00 E+00 \quad 0.00 E+00 \quad 0.00 E+00 \quad 0.00 E+00 \quad 0.00 E+00 \quad 0.00 E+00 \quad 0.00 E+00$ $\begin{array}{llllllll}990 & 0.00 E+00 & 0.00 E+00 & 0.00 E+00 & 0.00 E+\infty 0 & 0.00 E+00 & 0.00 E+\infty 0 & 0.00 E+00\end{array}$

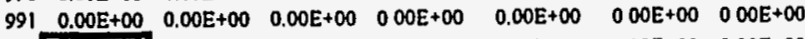
$992\left[\begin{array}{lllllll}1.22 E-03 & 0.00 E+00 & 0.00 E+00 & 0.00 E+\infty 0 & 0.00 E+00 & 0.00 E+00 & 0.00 E+\infty 0\end{array}\right.$ $\begin{array}{lllllllll}993 & 0.00 E+00 & 0.00 E+00 & 0.00 E+00 & 0.00 E+00 & 0.00 E+00 & 0.00 E+00 & 0.00 E+\infty 0\end{array}$ $\begin{array}{lllllllll}994 & 0.00 E+00 & 0.00 E+00 & 0.00 E+00 & 0.00 E+\infty 0 & 0.00 E+\infty 0 & 0.00 E+\infty 0 & 0.00 E+\infty 0\end{array}$ $\begin{array}{lllllllll}995 & 0.00 E+00 & 0.00 E+00 & 0.00 E+00 & 0.00 E+00 & 0.00 E+00 & 0.00 E+\infty 0 & 0.00 E+\infty 0\end{array}$ $\begin{array}{lllllllll}996 & 0.00 E+00 & 0.00 E+\infty & 0.00 E+\infty & 0.00 E+\infty & 0.00 E+\infty & 0.00 E+\infty & 0.00 E+\infty\end{array}$ $\begin{array}{lllllllll}997 & 0.00 E+\infty 0 & 0.00 E+00 & 0.00 E+00 & 0.00 E+\infty 0 & 0.00 E+\infty 0 & 0.00 E+\infty 0 & 0.00 E+\infty 0\end{array}$ $\begin{array}{lllllllll}998 & 0.00 E+00 & 0.00 E+60 & 0.00 E+00 & 0.00 E+00 & 0.00 E+00 & 0.00 E+00 & 0.00 E+00\end{array}$ $\begin{array}{llllllll}1248 & 1.06 E-03 & 0.00 E+00 & 0.00 E+00 & 0.00 E+\infty 0 & 0.00 E+\infty 0 & 0.00 E+00 & 0.00 E+00\end{array}$ $\begin{array}{lllllllll}948 & 0.00 E+00 & 0.00 E+00 & 0.00 E+00 & 0.00 E+00 & 0.00 E+\infty 0 & 0.00 E+\infty 0 & 0.00 E+\infty 0\end{array}$ $\begin{array}{lllllllll}949 & 0.00 E+00 & 0.00 E+60 & 0.00 E+00 & 0.00 E+00 & 0.00 E+00 & 0.00 E+00 & 0.00 E+\infty 0\end{array}$ $950 \quad 0.00 E+00 \quad 0.00 E+60 \quad 0.00 E+00 \quad 0.00 E+00 \quad 0.00 E+00 \quad 0.00 E+00 \quad 0.00 E+00$

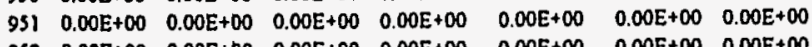

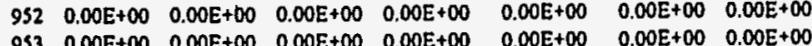
. 2.05E-02 $0.00 E+\infty 000.000+4$

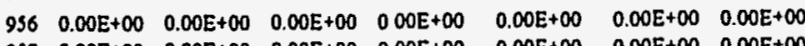
$957 \quad 0.00 E+00 \quad 0.00 E+00 \quad 0.00 E+00 \quad 0.00 E+00 \quad 0.00 E+\infty 0 \quad 000 E+\infty 0,0.0$ $\begin{array}{llllllllllllll}998 & 0.00 E+00 & 0.00 E+00 & 0.00 E+00 & 1.70 E-02 & 0.00 E+00 & 0.00 E+\infty 0 & 0.00 E+\infty 0\end{array}$ $\begin{array}{llllllllll}959 & 0.00 E+\infty 0 & 0.00 E+00 & 0.00 E+00 & 0.00 E+\infty 0 & 0.00 E+\infty 0 & 0.00 E+\infty 0 & 0.00 E+\infty\end{array}$ $\begin{array}{llllllll}960 & 0.00 E+\infty & 0.00 E+00 & 0.00 E+00 & 0.00 E+\infty 0 & 0.00 E+\infty & 0.00 E+\infty & 0.00 E+\infty\end{array}$ $\begin{array}{llllllll}961 & 0.00 E+\infty & 0.00 E+\infty & 0.00 E+\infty & 0.00 E+\infty 0 & 0.00 E+\infty & 0.00 E+\infty & 0.00 E+\infty\end{array}$ $\begin{array}{lllllllll}962 & 0.00 E+00 & 0.00 E+00 & 0.00 E+00 & 0.00 E+00 & 0.00 E+\infty 0 & 0.00 E+\infty 0 & 0.00 E+\infty\end{array}$ $4402.50 \mathrm{E}-03$

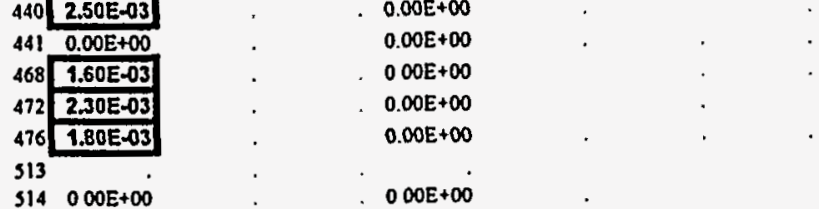

$0.005+00$ $\begin{array}{ll}0.00 E+00 \quad 0.00 E+00 & 1.00 E-03\end{array}$ 0.000 .000 .003

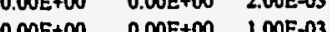
$4.00 E-03 \quad 0.00 E+00 \quad 0.00 E+00$ $\begin{array}{lll}0.00 E+\infty 0 & 0.00 E+\infty 0 & 0.00 E+\infty\end{array}$ $\begin{array}{lll}0.00 E+\infty 0 & 0.00 E+00 & 0.00 E+\infty 0\end{array}$ $\begin{array}{lll}0.00 E+\infty & 0.00 E+00 & 0.00 E+00\end{array}$ $\begin{array}{lll}8.00 E-03 & 0.00 E+00 & 0.00 E+00\end{array}$ $\begin{array}{lll}6.00 E-03 & 0.00 E+00 & 4.90 E-02\end{array}$ $6.00 E-03 \quad 0.00 E+00 \quad 0.00 E+00$ $\begin{array}{lll}7.00 E-03 & 0.00 E+\infty & 0.00 E+00 \\ 0.00 E+\infty 0 & 0.00 E+\infty 0 & 0.00 E+\infty 0\end{array}$ $\begin{array}{lll}0.00 E+\infty 0 & 0.00 E+\infty 0 & 0.00 E+\infty\end{array}$ $\begin{array}{lll}0.00 E+\infty 0 & 0.00 E+\infty & 0.00 E+\infty 0\end{array}$ $0.005+00 \quad 0.008+\infty 000.008+\infty 0$ $7.00 E-03 \quad 0.00 E+\infty \quad 0.00 E+\infty$ $0.00 E+00 \quad 0.00 E+\infty 000.00 E+00$ $0.00 E+00$ $0.00 E+00 \quad 0.00 E+00 \quad 0.00 E+00$ $\begin{array}{lll}0.00 E+00 & 0.00 E+00 & 0.00 E+00\end{array}$ $0.00 E+\infty \quad 0.00 E+\infty 0 \quad 0.00 E+\infty 0$ $1.00 E-03 \quad 0.00 E+\infty 00000$ $0.00 E+00 \quad 0.00 E+00 \quad 0.00 E+00$

$0.00 E+00 \quad 0.00 E+00 \quad 3.00 E-03$

$0.00 E+\infty 0 \quad 0.00 E+\infty 0 \quad 0.00 E+\infty 0$

$000 E+00 \quad 0.00 E+00 \quad 0.00 E+00$

$000 E+\infty 00 \quad 0.00 E+\infty 00.00 E+00$

$0.00 E+00 \quad 0.00 E+00 \quad 0.00 E+00$

$0.00 E+00 \quad 0.00 E+00 \quad 0.00 E+00$

$0.00 E+00 \quad 0.00 E+00 \quad 0.00 E+00$

$0.00 E+00 \quad 0.00 E+00 \quad 0.00 E+\infty 0$

$\begin{array}{lll}0.00 E+00 & 0.00 \mathrm{E}+00 \quad 0.00 \mathrm{E}+00\end{array}$

$\begin{array}{lll}0.00 E+00 & 0.00 E+\infty 0 & 0.00 E+\infty 0\end{array}$ $0.00 E+00 \quad 0.00 E+00 \quad 0.00 E+00$ $\begin{array}{lll}0.00 E+00 & 0.00 E+00 & 0.00 E+\infty 0\end{array}$ $0.00 E+00 \quad 0.00 E+00 \quad 0.00 E+00$

$0.00 E+00 \quad 0.00 E+00 \quad 2.00 E-03$

$\begin{array}{lll}0.00 E+00 & 0.00 E+00 & 0.00 E+00\end{array}$

$0.00 E+00 \quad 000 E+00 \quad 1.00 E-03$

$0.00 E+00 \quad 0.00 E+00 \quad 2.00 E-03$

$\begin{array}{lll}0.00 E+00 & 0.00 E+00 & 2.00 E-03 \\ 0.00 E+\infty 0 & 0.00 E+00 & 0.00 E+00\end{array}$

$\begin{array}{lll}0.00 E+00 & 0.00 E+00 & 0.00 E+00 \\ 0.00 E+00 & 0.00 E+00 & 0.00 E+00\end{array}$

$\begin{array}{lll}0.00 E+00 & 0.00 E+00 & 0.00 E+\infty 0 \\ 0.00 E+00 & 0.00 E+\infty 0 & 0.00 E+00\end{array}$

$0.00 E+00 \quad 0.00 E+00 \quad 0.00 E+00$

$0.00 E+\infty \quad \cdot 0.00 E+\infty$

$0.00 E+\infty \quad \cdot 0.00 E+00$

$0.00 E+00 \quad 0.00 E+00$

$0.00 E+00$
$2.00 E-03$

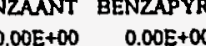
$0.00 E+\infty$

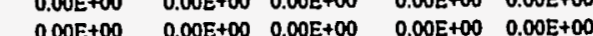
$\begin{array}{llllllll} & 0.00 E+\infty & 0.00 E+\infty & 0.00 E+\infty & 0.00 E+\infty & 0.00 E+\infty 0 & 0.00 E+\infty 0\end{array}$ $\begin{array}{lllllll}0.000 & 0.00 E+00 & 0.00 E+00 & 0.00 E+00\end{array}$ $\begin{array}{lllllllll}0.00 E+\infty 0 & 0.00 E+00 & 0.00 E+\infty 0 & 0.00 E+00 & 0.00 E+00 & 0.00 E+00 & 0.00 E+00\end{array}$

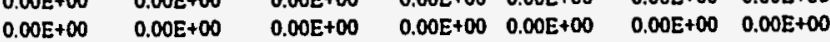

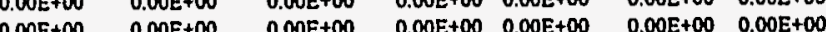
$\begin{array}{llllllll}0.00 E+\infty 0 & 0.00 E+\infty 0 & 0.00 E+00 & 0.00 E+00 & 0.00 E+\infty 0 & 0.00 E+00 & 0.00 E+\infty 0\end{array}$ $\begin{array}{llllllll}0.00 E+00 & 0.00 E+\infty & 0.00 E+00 & 0.00 E+00 & 0.00 E+00 & 0.00 E+\infty 0 & 0.00 E+00\end{array}$ $\begin{array}{llllllll}0.00 E+\infty 0 & 0.00 E+\infty 0 & 0.00 E+\infty 0 & 0.00 E+00 & 0.00 E+00 & 0.00 E+\infty 0 & 0.00 E+\infty\end{array}$ $\begin{array}{llllllll}0.00 E+00 & 0.00 E+\infty 0 & 0.00 E+00 & 0.00 E+00 & 0.00 E+00 & 0.00 E+00 & 0.00 E+00\end{array}$ $\begin{array}{llllllll}0.00 E+\infty 0 & 0.00 E+\infty 0 & 0.00 E+\infty 0 & 0.00 E+00 & 0.00 E+00 & 0.00 E+00 & 0.00 E+\infty 0\end{array}$ $\begin{array}{llllllll}0.00 E+\infty 0 & 0.00 E+\infty 0 & 0.00 E+\infty 0 & 0.00 E+\infty 0 & 0.00 E+00 & 0.00 E+00 & 0.00 E+\infty 0\end{array}$ $\begin{array}{llllllll}0.00 E+00 & 0.00 E+00 & 0.00 E+00 & 0.00 E+00 & 0.00 E+00 & 0.00 E+00 & 0.00 E+\infty 0\end{array}$ $\begin{array}{llllllll}0 & 00 E+\infty 0 & 0.00 E+\infty 0 & 0.00 E+\infty 0 & 0.00 E+\infty 0 & 0.00 E+00 & 0.00 E+\infty 0 & 0.00 E+\infty 0\end{array}$ $\begin{array}{lllllll}0.00 \mathrm{E}+00 & 0.00 \mathrm{E}+00 & 0.00 \mathrm{E}+\infty & 0.00 \mathrm{E}+\infty 0 & 0.00 \mathrm{E}+00 & 0.00 \mathrm{E}+00 & 0.00 \mathrm{E}+\infty 0\end{array}$

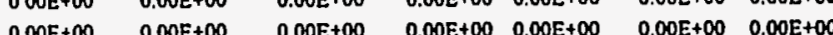
$\begin{array}{llllllll}0.00 E+00 & 0.00 E+00 & 0.00 E+\infty 0 & 0.00 E+00 & 0.00 E+00 & 0.00 E+00 & 0.00 E+\infty 0\end{array}$ $\begin{array}{llllllll}0.00 E+00 & 0.00 E+00 & 0.00 E+00 & 0.00 E+00 & 0.00 E+00 & 0.00 E+00 & 0.00 E+\infty\end{array}$ $\begin{array}{llllllll}0.00 E+00 & 0.00 E+00 & 0.00 E+\infty 0 & 0.00 E+00 & 0.00 E+\infty 0 & 0.00 E+00 & 0.00 E+\infty\end{array}$ $\begin{array}{llllllll}0.00 E+\infty 0 & 0.00 E+\infty 0 & 0.00 E+\infty & 0.00 E+\infty & 0.00 E+\infty & 0.00 E+\infty & 0.00 E+\infty\end{array}$ $\begin{array}{llllllll}0.00 E+\infty 0 & 0.00 E+\infty & 0.00 E+\infty & 0.00 E+\infty 0 & 0.00 E+\infty & 0.00 E+\infty 0 & 0.00 E+\infty\end{array}$ $\begin{array}{llllllll}0.00 E+00 & 0.00 E+00 & 0.00 E+\infty 0 & 0.00 E+\infty 0 & 0.00 E+\infty 0 & 0.00 E+\infty 0 & 0.00 E+\infty\end{array}$ $\begin{array}{llllllll}0.00 E+\infty 0 & 0.00 E+\infty 0 & 0.00 E+\infty & 0.00 E+\infty 0 & 0.00 E+\infty 0 & 0.00 E+00 & 0.00 E+\infty\end{array}$ $\begin{array}{llllllll}0.00 E+00 & 0.00 E+00 & 0.00 E+00 & 0.00 E+00 & 0.00 E+00 & 0.00 E+\infty 0 & 0.00 E+\infty 0\end{array}$ $\begin{array}{llllllll}0.00 E+00 & 0.00 E+00 & 0.00 E+00 & 0.00 E+00 & 0.00 E+\infty 0 & 0.00 E+\infty 0 & 0.00 E+\infty\end{array}$ $\begin{array}{llllllll}0.00 E+00 & 0.00 E+00 & 0.00 E+00 & 0.00 E+00 & 0.00 E+00 & 0.00 E+00 & 0.00 E+\infty 0\end{array}$ $\begin{array}{llllllllll}0.00 E+\infty 0 & 0.00 E+00 & 0.00 E+00 & 0.00 E+00 & 0.00 E+00 & 0.00 E+\infty 0 & 0.00 E+\infty 0\end{array}$ $\begin{array}{llllllll}0.00 E+00 & 0.00 E+00 & 0.00 E+00 & 0.00 E+00 & 0.00 E+00 & 0.00 E+00 & 0.00 E+\infty\end{array}$ $\begin{array}{llllllll}0.00 E+00 & 0.00 E+00 & 0.00 E+00 & 0.00 E+00 & 0.00 E+00 & 0.00 E+00 & 0.00 E+00\end{array}$ $\begin{array}{lllllllll}0.00 E+00 & 0.00 E+00 & 0.00 E+00 & 0.00 E+00 & 0.00 E+00 & 0.00 E+00 & 0.00 E+00\end{array}$ $\begin{array}{llllllll}0.00 E+00 & 0.00 E+00 & 0.00 E+00 & 0.00 E+00 & 0.00 E+00 & 0.00 E+00 & 0.00 E+\infty\end{array}$ $\begin{array}{lllllllll}0.00 E+00 & 0.00 E+00 & 0.00 E+00 & 0.00 E+00 & 0.00 E+00 & 0.00 E+00 & 0.00 E+00\end{array}$ $\begin{array}{llllllllllllllll}0.00 E+00 & 0.00 E+00 & 0.00 E+00 & 0.00 E+00 & 0.00 E+00 & 0.00 E+00 & 0.00 E+00\end{array}$ $\begin{array}{llllllll}0.00 E+00 & 0.00 E+00 & 0.00 E+00 & 0.00 E+00 & 0.00 E+00 & 0.00 E+00 & 0.00 E+00\end{array}$ $\begin{array}{llllllll}0.00 E+00 & 0.00 E+00 & 0.00 E+00 & 0.00 E+00 & 0.00 E+00 & 0.00 E+00 & 0.00 E+00\end{array}$ $\begin{array}{llllllll}0.00 E+00 & 0.00 E+00 & 0.00 E+00 & 0.00 E+00 & 0.00 E+00 & 0.00 E+00 & 0.00 E+00\end{array}$ $\begin{array}{lllllllll}0.00 E+\infty 0 & 0.00 E+\infty 0 & 0.00 E+00 & 0.00 E+00 & 0.00 E+00 & 0.00 E+00 & 0.00 E+\infty 0\end{array}$ $\begin{array}{llllllll}0.00 E+\infty 0 & 0.00 E+\infty 0 & 0.00 E+00 & 0.00 E+\infty 0 & 0.00 E+00 & 0.00 E+00 & 0.00 E+\infty 0\end{array}$ $\begin{array}{llllllll}0.00 E+\infty 0 & 0.00 E+\infty 0 & 0.00 E+00 & 0.00 E+\infty 0 & 0.00 E+00 & 0.00 E+00 & 0.00 E+\infty\end{array}$ $\begin{array}{llllllll}0.00 E+00 & 0.00 E+00 & 0.00 E+00 & 0.00 E+00 & 0.00 E+00 & 0.00 E+00 & 0.00 E+\infty\end{array}$ $\begin{array}{lllllllllll}0.00 E+\infty & 0.00 E+\infty 0 & 0.00 E+\infty & 0.00 E+00 & 0.00 E+\infty 0 & 0.00 E+\infty 0 & 0.00 E+\infty\end{array}$ $\begin{array}{llllllll}0.00 E+\infty & 0.00 E+\infty & 0.00 E+\infty & 0.00 E+00 & 000 E+\infty 0 & 0.00 E+\infty & 0.00 E+\infty\end{array}$

$0.00 E+00$

$000 E+00$ 


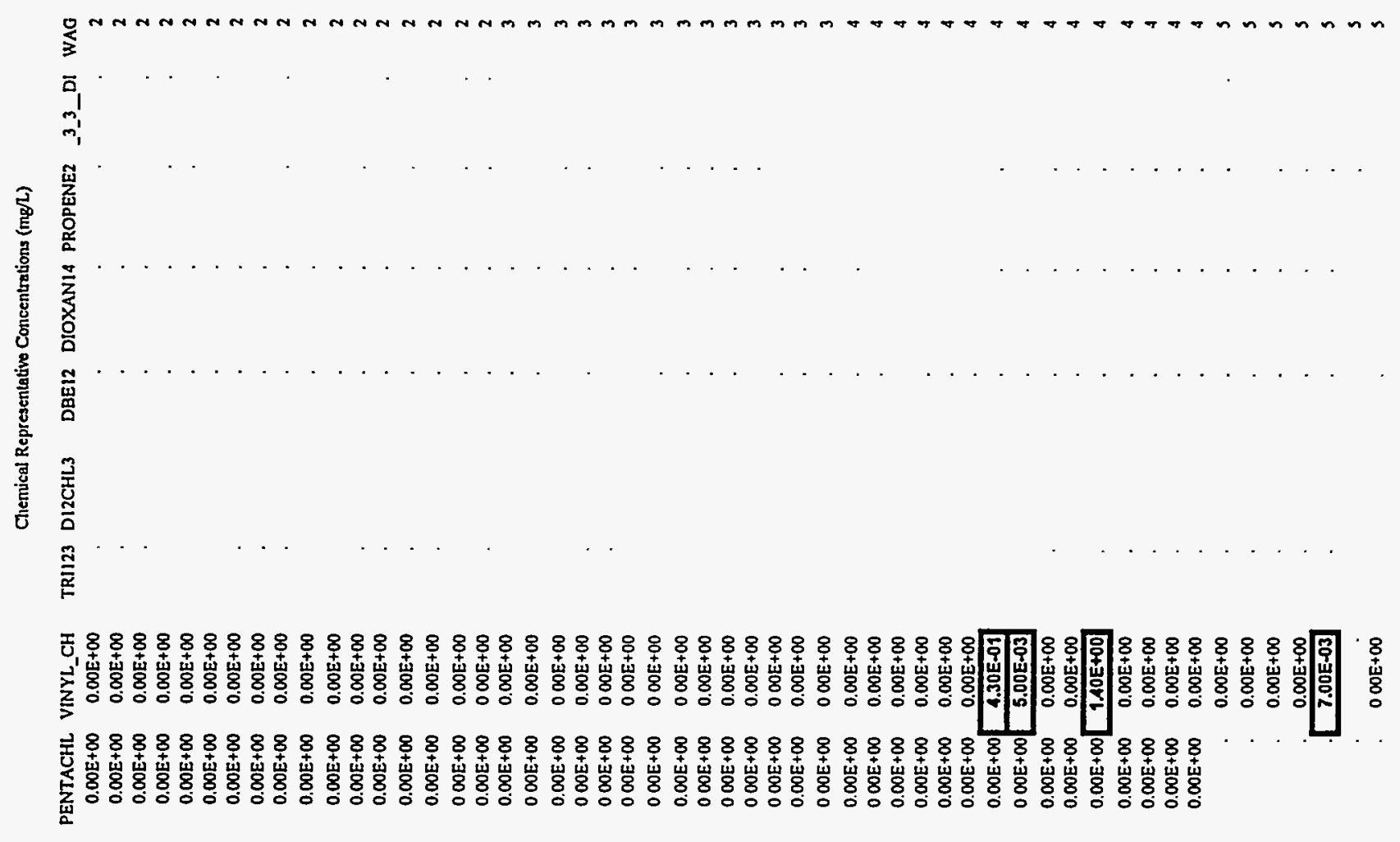


$0.00 E+00$

\section{$0.00 \mathrm{E}+00$}

$0.00 E+00$

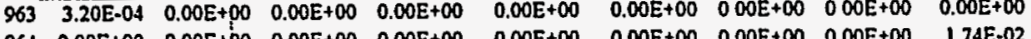
g6S $0.00 E+00$ O.00E

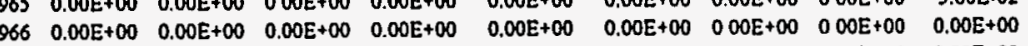
$\begin{array}{llllllllll}967 & 0.00 E+00 & 0.00 E+00 & 0.00 E+00 & 0.00 E+00 & 0.00 E+00 & 0.00 E+00 & 0.00 E+00 & 0.00 E+00 & 0.00 E+00\end{array}$ 968 . $969 \quad 000 E+00 \quad 0.00 E+\infty 0000 E+\infty 0000 E+\infty 00.00 E+\infty 0 \quad 0.00 E+00 \quad 000+\infty 0 \quad 000 E+\infty 0-1.00 E-02$ $\begin{array}{lllllllllll}970 & 0.00 E+00 & 0.00 E+\infty & 0.00 E+00 & 0.00 E+00 & 0.00 E+\infty 0 & 0.00 E+00 & 0.00 E+\infty 0 & 0.00 E+\infty 0 & 0.00 E+\infty 0\end{array}$ $\begin{array}{llllllllll}971 & 0.00 E+00 & 0.00 E+00 & 0.00 E+00 & 0.00 E+00 & 0.00 E+\infty 0 & 0.00 E+00 & 0.00 E+00 & 0.00 E+00 & 0.00 E+00 \\ 972 & 0.00 E+00 & 0.00 E+00 & 0.00 E+00 & 0.00 E+00 & 0.00 E+00 & 0.00 E+00 & 0.00 E+00 & 0.00 E+00 & 0.00 E+00\end{array}$ $\begin{array}{llllllllll}973 & 0.00 E+00 & 0.00 E+00 & 0.00 E+00 & 0.00 E+00 & 0.00 E+00 & 0.00 E+00 & 0.00 E+00 & 0.00 E+00 & 0.00 E+00\end{array}$ $\begin{array}{lllllllllll}974 & 0.00 E+00 & 0.00 E+00 & 0.00 E+00 & 0.00 E+00 & 0.00 E+00 & 0.00 E+00 & 0.00 E+00 & 0.00 E+00 & 0.00 E+00\end{array}$ $\begin{array}{lllllllllll}975 & 0.00 E+00 & 2.00 E-03 & 0.00 E+00 & 0.00 E+\infty 0 & 0.00 E+00 & 0.00 E+00 & 0.00 E+\infty 0 & 000 E+00 & 0.00 E+00\end{array}$ $\begin{array}{lllllllllll}976 & 0.00 E+00 & 0.00 E+00 & 0.00 E+00 & 0.00 E+00 & 0.00 E+00 & 0.00 E+00 & 0.00 E+00 & 0.00 E+00 & 0.00 E+00\end{array}$

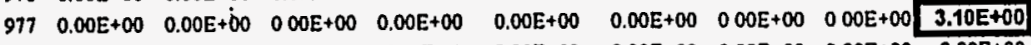

$\begin{array}{llllllllllll}978 & 3.10 \mathrm{E}-04 & 0.00 \mathrm{E}+00 & 0.00 \mathrm{E}+\infty 0 & 6.00 \mathrm{E}-03 & 0.00 \mathrm{E}+00 & 0.00 \mathrm{E}+00 & 0.00 \mathrm{E}+00 & 0.00 \mathrm{E}+00 & 0.00 \mathrm{E}+00\end{array}$ $\begin{array}{llllllllll}979 & 0.00 E+\infty 0 & 0.00 E+60 & 0.00 E+\infty 0 & 0.00 E+\infty 0 & 0.00 E+00 & 0.00 E+00 & 0.00 E+00 & 000 E+00 & 0.00 E+00 \\ 980 & 0.00 E+00 & 0.00 E+b 0 & 0.00 E+00 & 0.00 E+\infty 0 & 0.00 E+00 & 0.00 E+00 & 0.00 E+00 & 000 E+00 & 0.00 E+00\end{array}$

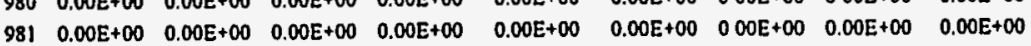
$\begin{array}{lllllllllll}982 & 0.00 E+00 & 0.00 E+00 & 0.00 E+00 & 0.00 E+00 & 0.00 E+00 & 0.00 E+00 & 0.00 E+00 & 0.00 E+00 & 1.00 E-02\end{array}$ $\begin{array}{llllllllll}983 & 3.20 E-04 & 0.00 E+00 & 0.00 E+00 & 0.00 E+00 & 0.00 E+00 & 0.00 E+00 & 0.00 E+00 & 0.00 E+00 & 0.00 E+00\end{array}$ $\begin{array}{llllllllll}984 & 9.32 \mathrm{E}-04 & 0.00 E+00 & 0.00 E+00 & 0.00 E+00 & 0.00 E+00 & 0.00 E+00 & 0.00 E+00 & 0.00 E+00 & 0.00 E+00\end{array}$ 984
1105

$1106 \quad 0.00 E+00$ 1107

\section{$4 1 1 3 \longdiv { 6 . 2 0 E - 0 3 }$}

$1114.90 E-03$

$4 1 1 6 \longdiv { 1 . 3 0 E - 0 3 }$

4173

4174

4174

4176

4177

4178

4179

4179
4180
1.60E-02

$0.00 \mathrm{E}+00^{\circ}$

.

$0.00 \mathrm{E}+00$

$0.00 E+\infty 0$

- $0.00 E+00$

$0.00 E+00 \quad 0.00 E+00$ $0.00 E+\infty \quad 0.00 E+\infty 0$ $0.00 E+\infty 0 \quad 0.00 E+00$ $0.00 \mathrm{E}+\infty 0000 \mathrm{E}+00$ $0.00 E+\infty 0 \quad 000 E+00$ $0.00 E+\infty 0000 E+00$ $0.00 E+00 \quad 000 E+00$ $0.00 E+00 \quad 0.00 E+00$ $0.00 E+\infty 0 \quad 0.00 E+00$ $0.00 \mathrm{E}+00 \quad 000 \mathrm{E}+00$ $0.00 E+\infty 0 \quad 100 E-03$ $0.00 \mathrm{E}+00 \quad 0.00 \mathrm{E}+00$ $0.00 E+00 \quad 1.00 E-03$ $0.00 \mathrm{E}+00 \quad 0.00 \mathrm{E}+00$ $0.00 E+00 \quad 0.00 E+00$ $0.00 E+00 \quad 330 \mathrm{E}-02$ $0.00 \mathrm{E}+00 \quad 1.00 \mathrm{E}-03$ $0.00 E+00 \quad 0.00 E+00$ $0.00 E+00 \quad 0.00 E+00$ $0.00 E+00 \quad 0.00 E+00$ $0.00 E+00 \quad 0.00 E+00$ $0.00 E+00 \quad 0.00 E+00$

$0.00 E+0$

$0.00 \mathrm{E}+00$

$0.00 \mathrm{E}+00$

$5.00 \mathrm{E}-03$

$6.00 \mathrm{E}-03$

$0.00 E+00$

3.00E-02
$000 E+00$

$0.00 E+00$

$0.00 E+00$

$0.00 E+00$
$0.00 E+\infty 0$
$0.00 \mathrm{E}+00$

$0,00 E+00$

$0.00 E+00$

$0.00 E+00 \quad 0.00 E+00$ $0.00 E+00 \quad 0.00 E+00$ $0.00 E+00 \quad 0.00 E+00$ $0.00 E+00 \quad 0.00 E+00$ $0.00 \mathrm{E}+0.0$ $0.00 E+00 \quad 0.00 E+00$ $0.00 E+00 \quad 0.00 E+00$ $0.00 E+00 \quad 0.00 E+00$ $000+00$ $0.00 \mathrm{E}+00$ $0.00 \mathrm{E}+00$ $0.00 E+00$ $0.00 E+00$

$0,00 E+00$

$0.00 E+00$

$000 \mathrm{E}+00$ $0.00 E+\infty 0$ 0 O0E+00 $0.00 E+\infty 0$ $0.00 E+00$
$0.00 E+\infty 0$ $0.00 E+00$ $0,00 E+00$ $0.00 E+\infty 0$ $0.00 E+00$ $0.00 E+00$ $0.00 E+00$ $0.00 E+\infty 0$ $0.00 E+\infty$ $0.00 E+00$
$0.00 E+00$ $0.00 \mathrm{E}+00$ $0.00 E+00$ $\begin{array}{lllll}0.00 E+\infty 0 & 0.00 E+\infty 0 & 0.00 E+\infty & 0.00 E+\infty & 0.00 E+\infty\end{array}$ $0.00 E+\infty 00 \quad 0.00 E+\infty 00.00 E+00 \quad 0.00 E+\infty 000.00 E+\infty 0$ $0.00 \mathrm{E}+\infty 00 \quad 0.00 \mathrm{E}+\infty 0000 \mathrm{E}+\infty \quad 0.00 \mathrm{E}+00 \quad 0.00 \mathrm{E}+\infty 0$ $\begin{array}{lllllllllll}0.00 E+\infty & 0.00 E+\infty & 0.00 E+\infty & 0.00 E+\infty & 0.00 E+\infty\end{array}$ $\begin{array}{llllll}0.00 E+00 & 0.00 E+00 & 0.00 E+00 & 0.00 E+\infty 0 & 0.00 E+\infty 0\end{array}$ $\begin{array}{llllll}0.00 E+00 & 0.00 E+\infty 0 & 0.00 E+00 & 0.00 E+00 & 0.00 E+00\end{array}$ $\begin{array}{llllll}0.00 E+00 & 0.00 E+00 & 0.00 E+00 & 0.00 E+00 & 0.00 E+00\end{array}$ $\begin{array}{lllll}0.00 E+00 & 0.00 E+00 & 0.00 E+00 & 0.00 E+00 & 0.00 E+00 \\ 0.00 E+00 & 0.00 E+00 & 0.00 E+\infty 0 & 0.00 E+\infty 0 & 0.00 E+00\end{array}$ $\begin{array}{llllll}0.00 E+00 & 0.00 E+00 & 0.00 E+00 & 0.00 E+00 & 0.00 E+00 \\ 0.00 E+00 & 0.00 E+00 & 0.00 E+00 & 0.00 E+00 & 0.00 E+00\end{array}$ $\begin{array}{llllll}0.00 E+00 & 0.00 E+00 & 0.00 E+00 & 0.00 E+00 & 0.00 E+00\end{array}$ $\begin{array}{llllll}0.00 E+00 & 0.00 E+00 & 0.00 E+00 & 0.00 E+00 & 0.00 E+00\end{array}$ $\begin{array}{llllll}0.00 E+00 & 0.00 E+\infty & 0.00 E+00 & 0.00 E+00 & 0.00 E+00\end{array}$ $\begin{array}{llllll}0.00 E+00 & 0.00 E+\infty 0 & 0.00 E+00 & 0.00 E+00 & 0.00 E+00\end{array}$ $\begin{array}{llllll}0.00 E+00 & 0.00 E+00 & 0.00 E+00 & 0.00 E+00 & 0.00 E+00\end{array}$ $\begin{array}{lllll}0.00 E+00 & 0.00 E+\infty 0 & 0.00 E+\infty & 0.00 E+00 & 0.00 E+\infty 0\end{array}$ $\begin{array}{llllll}0.00 E+00 & 0.00 E+00 & 0.00 E+00 & 0.00 E+00 & 0.00 E+00\end{array}$ $\begin{array}{llllll}0.00 E+00 & 0.00 E+00 & 0.00 E+00 & 0.00 E+00 & 0.00 E+00\end{array}$ $\begin{array}{llllllll}0.00 E+00 & 0.00 E+00 & 0.00 E+00 & 0.00 E+00 & 0.00 E+00\end{array}$ $\begin{array}{llllllll}0.00 E+00 & 0.00 E+00 & 0.00 E+\infty 0 & 0.00 E+00 & 0.00 E+0.0\end{array}$

9.00E-03

$0.00 E+00$

$0.00 \mathrm{E}+00$

$0.00 \mathrm{E}+00$

$6.00 \mathrm{E}-03$ 


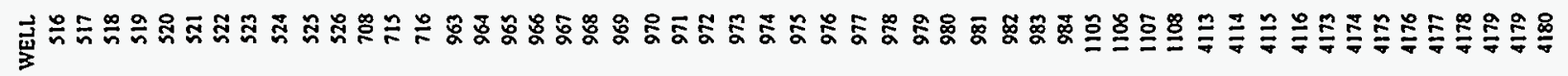

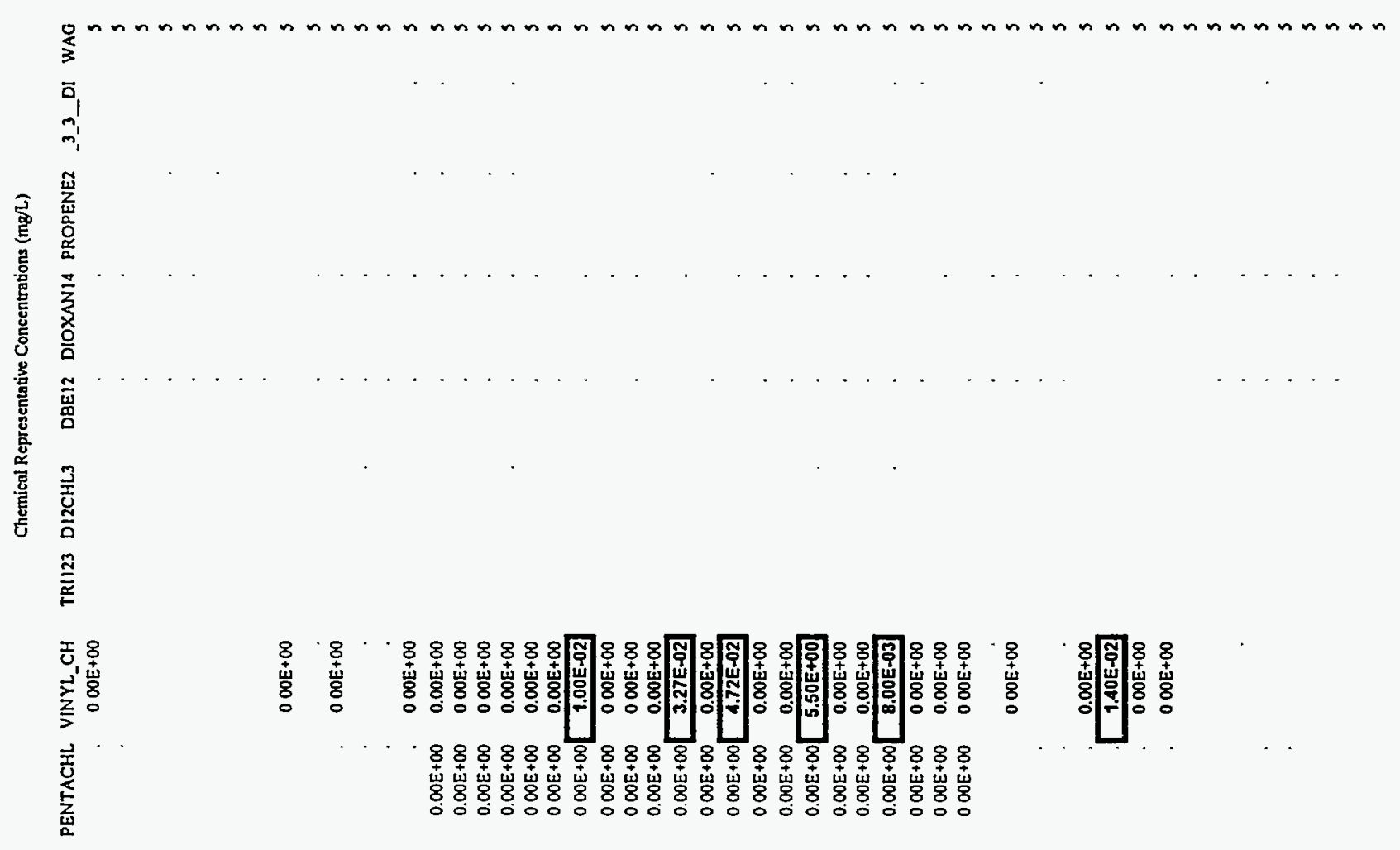


Table A.S

WELL

BE

4185

4188

4189

4190

4191
4193

4195

4198

4199

4201

4202

4203

4204

4205

4206

4207

4208

4209

4211

4212

4213

4214

4216

4218

4219

4221
4224

4225

4226

4227

4228

4230

4231

4233

4238

$\$ 239$

4241

4242

4243

42.44

4245

4246

4247

4248

4249

4250

4251

4232

4233

4254

4255

4256
4257
Chemical Representutive Concentrations (me/)

DIC33 PCB12S4 BIS_2_ET BENZBFLU BENZENE BENZAANT BENZAPYR CARBON_T DIBENZ_A

HCBE INDENO_I NNDNPA 
PENTACHL VINYL_CH TRI23 DI2CHL3 DBE12 DIOXANI4 PROPENE2 333_DI WAG WELL 
$7454.00 E-03 \quad 0.00 E+00 \quad 000 E+00 \quad 0.00 E+00 \quad 000 E+00 \quad 000 E+00 \quad 000 E+00 \quad 000 E+00 \quad 000 E+00 \quad 000 E+00 \quad 0.00 E+00$ 831 1.AGE-02 $0.00 E+00 \quad 000 E+00 \quad 000 E+00 \quad 000 E+00 \quad 000 E+00 \quad 000 E+00 \quad 000 E+00 \quad 190 E-02 \quad 000 E+00 \quad 0.00 E+00$

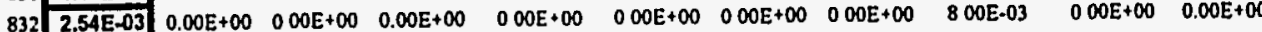
L 4. $36 \quad 1.07 E-03 \quad 0.00 E+00 \quad 000 E+00 \quad 0.00 E+00 \quad 000 E+00 \quad 000 E+00 \quad 000 E+00 \quad 600 E-04 \quad 400 E-03 \quad 000 E+00 \quad 0.00 E+00$

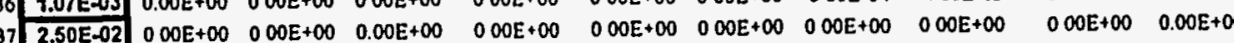
$\begin{array}{lllllllllll}2.87 E-03 & 0.00 E+00 & 0.00 E+00 & 000 \mathrm{E}+00 & 0.00 \mathrm{E}+00 & 0.00 \mathrm{E}+00 & 000 \mathrm{E}+00 & 000 \mathrm{E}+00 & 200 \mathrm{E}-03 & 0.00 \mathrm{E}+00 & 0.00 \mathrm{E}+\infty\end{array}$ $\begin{array}{lllllllllllll}3.24 E-03 & 0.00 E+00 & 000 E+00 & 0.00 E+00 & 0.00 E+00 & 0.00 E+00 & 000 E+\infty 0 & 000 E+\infty 0 & 3.00 E-03 & 0.00 E+00 & 0.00 E+\infty 0\end{array}$ $\begin{array}{llllllllllll}1.37 E-02 & 0.00 E+00 & 000 E+00 & 0.00 E+00 & 0.00 E+00 & 0.00 E+00 & 000 E+00 & 0.00 E+00 & 4.00 E-03 & 0.00 E+00 & 0.00 E+00\end{array}$ $\begin{array}{lllllllllll}1.01 E-02 & 0.00 E+00 & 0.00 E+00 & 0.00 E+00 & 0.00 E+00 & 0.00 E+00 & 000 E+00 & 0.00 E+00 & 1.60 E-02 & 0.00 E+00 & 0.00 E+\infty 0\end{array}$

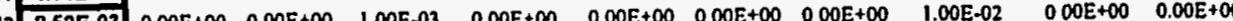

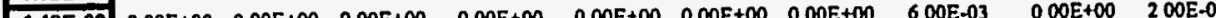
1 2 ESE

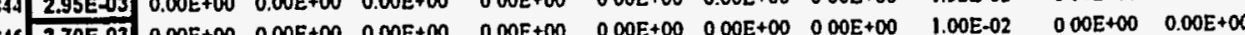

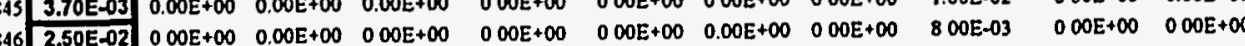

$0.00 E+00$
$0.00 E+00$
$0.00 E+00$
$0.00 E+\infty 0$
$0.00 E+00$
$0.00 E+00$
$0.00 E+00$
$0.00 E+00$
$0.00 E+00$
$0.00 E+00$
$0.00 E+00$
$0.00 E+00$
$0.00 E+\infty 0$
$0.00 E+\infty 0$
$0.00 E+00$
$0.00 E+00$

\begin{tabular}{|c|c|c|c|c|c|}
\hline$E+00$ & $0 E+00$ & $30 E+\infty 0$ & $0.00 E+00$ & $0.00 E+00$ & $0.00 E+0$ \\
\hline 0.00 & $0.00 E+00$ & $0.00 E+00$ & $0.00 E+\infty 0$ & $0.00 \mathrm{E}+00$ & $0.00 \mathrm{E}+00$ \\
\hline $0 E+\infty$ & $00 E+\infty 0$ & $0.00 E+00$ & $0.00 E+00$ & $0.00 E+00$ & $0.00 E+00$ \\
\hline $0 E+00$ & $00 E+00$ & $0.00 E+00$ & $0.00 E+00$ & $.00 E+00$ & $0.00 E+00$ \\
\hline$E+00$ & $00 \varepsilon+00$ & $00 E+\infty 0$ & $000 E+00$ & $0.00 E+\infty 0$ & $0.00 E+\infty$ \\
\hline & $10 E+00$ & $.00 E+\infty 0$ & $0.00 E+00$ & $0.00 E+00$ & $000 E+00$ \\
\hline$E+00$ & $30 E+00$ & $.00 E+00$ & $0.00 E+00$ & $00 E+\infty 0$ & $0.00 E+\infty 0$ \\
\hline $0 E+00$ & $.00 E+00$ & $00 E+\infty$ & $0.00 E+00$ & $0.00 \mathrm{E}+00$ & $0.00 E+\infty$ \\
\hline $20 E+\infty 0$ & $20 E+\infty 0$ & $00 E+00$ & $000 E+00$ & $0 E+\infty 0$ & $0.00 E+00$ \\
\hline $0.00 E+00$ & & $10 E+00$ & $0.00 E+00$ & $0.00 E+00$ & $0.00 E+\infty$ \\
\hline $10 E+\infty$ & 0.008 & $00 E+00$ & $0.00 E+00$ & $0.00 E+00$ & $0.00 E+\infty 0$ \\
\hline$\varepsilon+\infty$ & 6.1AE-02 & $0.00 E+00$ & $000 E+00$ & $000 E+00$ & $0.00 E+\infty 0$ \\
\hline $0.00 E+00$ & 0 & $000 E+\infty 0$ & $0.00 E+\infty 0$ & $0.00 E+00$ & $000 E+00$ \\
\hline & & $10 E+\infty 0$ & $0.00 E+00$ & $000 E+00$ & $000 E+\infty 0$ \\
\hline & 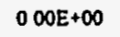 & $0 E+\infty$ & $000 E+00$ & $000 E+00$ & 000 \\
\hline & & & & 00 & \\
\hline
\end{tabular}


PENTACHL VINYL_CH TRI123 DI2CHL3 DBE12 DIOXANI4 PROPENE2 33_DI WAO WELL

4281

4282

4283

4284
4285

4286

4287

4289

4290

4291
4294

4295

4296

4297

4298

4299

4300
4307

$000 \mathrm{E}+00 \quad 000 \mathrm{E}+00$

$000 E+\infty 0 \quad 000 E+\infty 0$

$000 \mathrm{E}+00 \quad 000 \mathrm{E}+00$

$000 E+00 \quad 000 E+\infty 0$

$000 \mathrm{E}+00 \quad 000 \mathrm{E}+00$

$6.30 \mathrm{E}-02$

$00 E+00 \quad 0.00 E+\infty 0$

$6.30 \mathrm{E} \cdot 02$

$000 \mathrm{E}+00 \quad 000 \mathrm{E}+00$

$000 E+00 \quad 000 E+00$

$0.00 E+00 \quad 0.00 E+00$

$0.00 E+00 \quad 000 E+00$

$000 E+00 \quad 000 E+00$

$000 E+00 \quad 000 E+00$

$000 E+\infty 0 \quad 000 E+00$

$000 E+00 \quad 000 E+00$

O OOE $+00 \quad 0$ OOE +00 


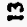

영 88 8

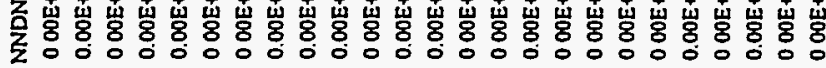

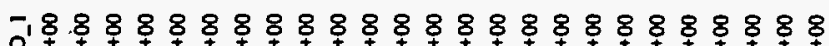

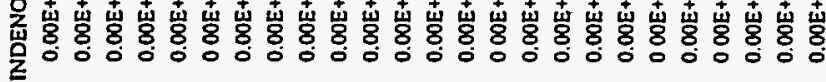

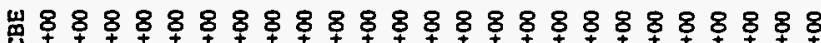

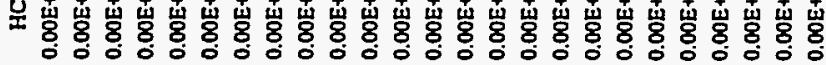

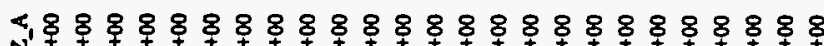

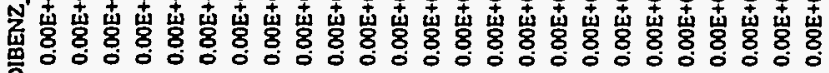

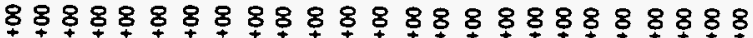

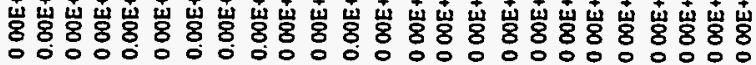

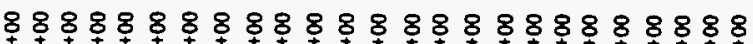

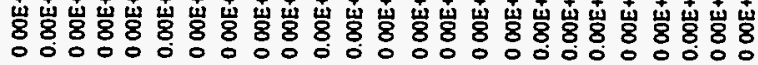

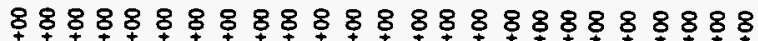

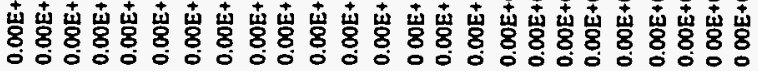

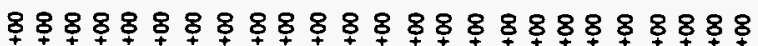

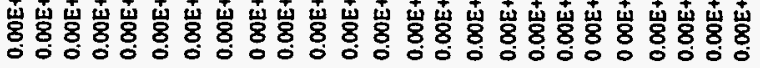

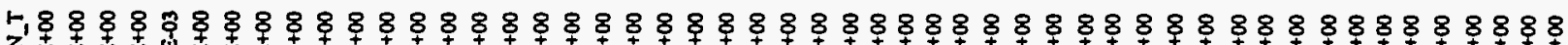

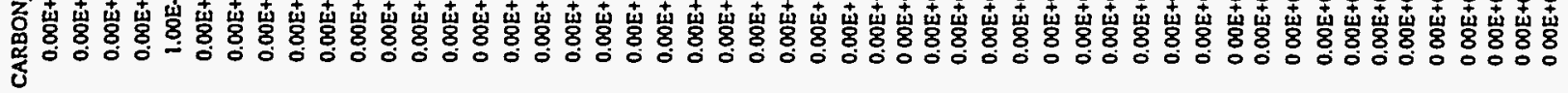

운 8

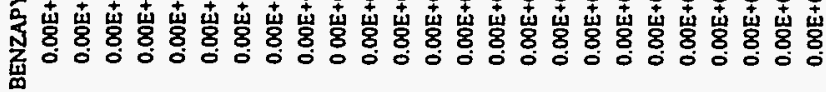

5888888888888888888888888

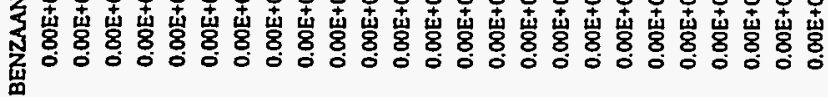

8888888888888888888888888

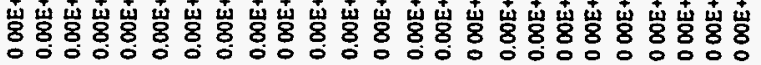

888888888888888888888888

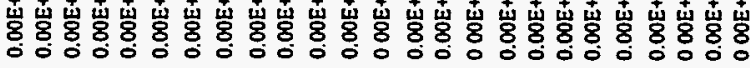

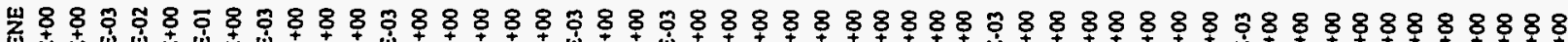

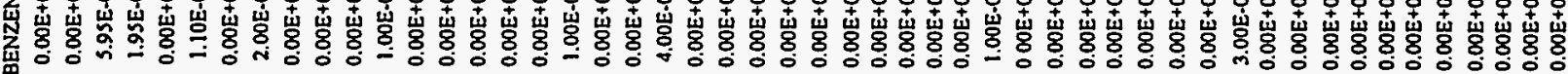

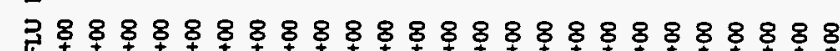

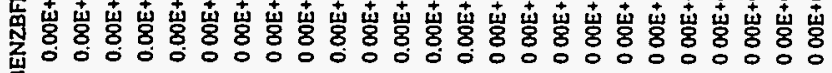

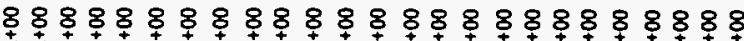

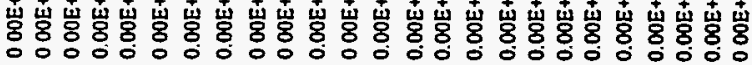

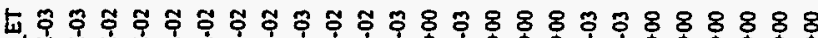

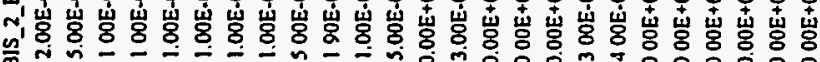

8888888888888888888888888

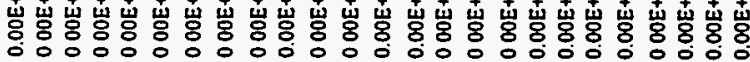

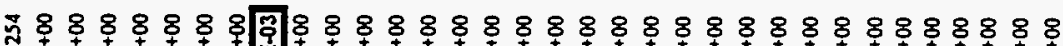

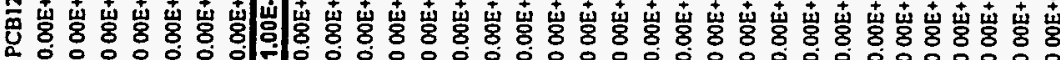

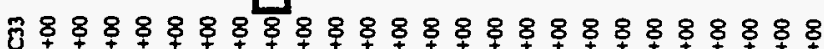

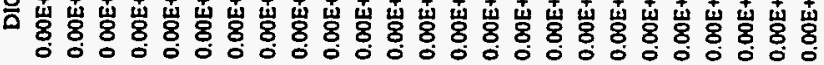

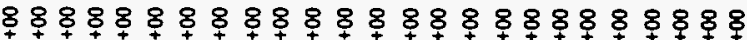

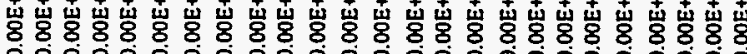
교요888888888888888888888

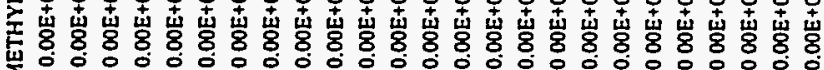
8888888888888888888888888

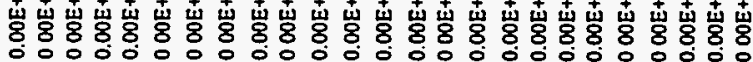

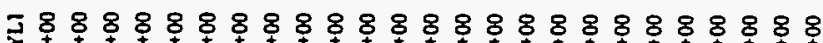

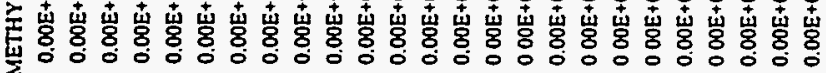

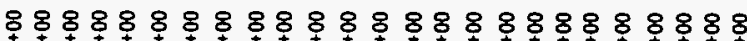

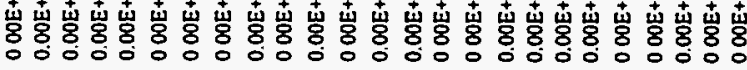

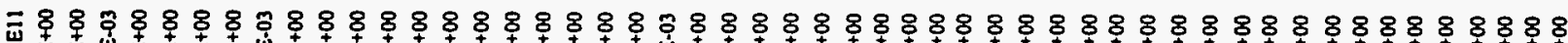

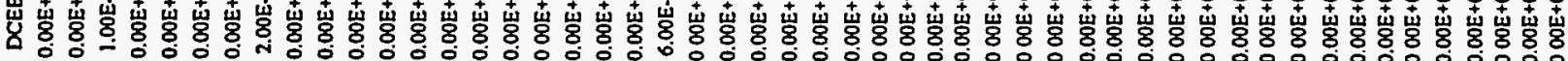

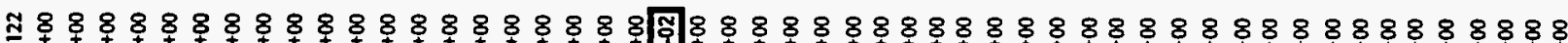

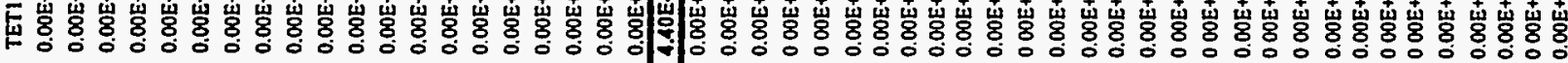
嵌 888888888888888888888.888

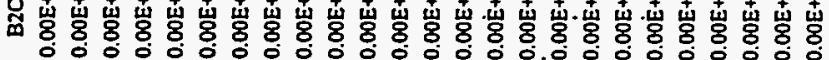

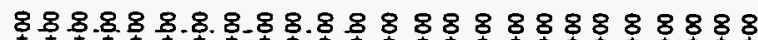

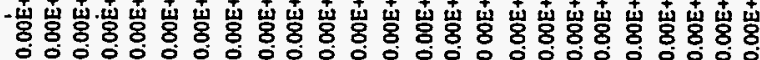

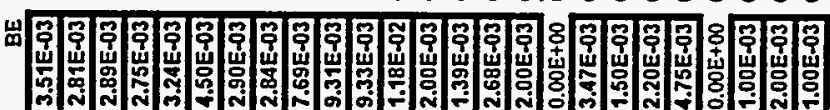

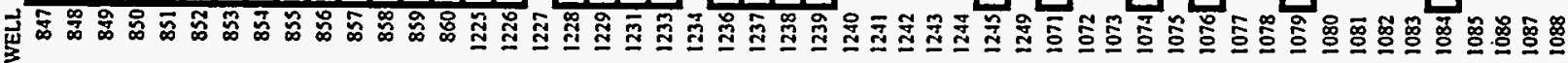




\begin{tabular}{|c|c|c|c|c|c|c|c|c|c|}
\hline PENTACHL & VINYL_CH & TRI123 & DI2CHL3 & DBEI2 & DIOXAN14 & PROPENE2 & -3_3_DI & WAG & WELL \\
\hline $0.00 E+00$ & $0.00 \mathrm{E}+00$ & . & & . & & & & 6 & 847 \\
\hline $0.00 E+00$ & $0.00 \mathrm{E}+00$ & . & & & $5.00 \mathrm{E}-03$ & 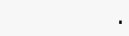 & $\cdot$ & 6 & 848 \\
\hline $0.00 E+\infty$ & $5,46 E-02$ & & & & $300 \mathrm{E}-03$ & . & 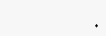 & 6 & 849 \\
\hline $0.00 \mathrm{E}+\infty$ & $0.00 E+00$ & . & & . & $6.00 \mathrm{E}-03$ & . & . & 6 & 850 \\
\hline $000 E+00$ & $0.00 E+00$ & & & . & $160 \mathrm{E}-01$ & & & 6 & 851 \\
\hline $000 E+\infty$ & $0.00 \mathrm{E}+00$ & . & & & $750 \mathrm{E}-02$ & . & & 6 & 852 \\
\hline $0.00 E+00$ & $6.00 E-03$ & & & & & & & 6 & 853 \\
\hline $000 E+00$ & $6.00 \mathrm{E}-03$ & . & & & & & & 6 & 854 \\
\hline $000 E+\infty$ & $0.00 E+00$ & . & & & & . & & 6 & 855 \\
\hline $0.00 E+\infty 0$ & $0.00 E+\infty 0$ & . & & . & & & . & 6 & 856 \\
\hline $0.00 E+00$ & $000 E+00$ & . & & & & & 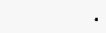 & 6 & 857 \\
\hline $0.00 E+\infty$ & $0.00 E+\infty 0$ & . & & & & & . & 6 & 858 \\
\hline $0.00 E+00$ & $0.00 E+00$ & . & & . & & . & & 6 & 859 \\
\hline $000 \mathrm{E}+00$ & $0.00 \mathrm{E}+00$ & . & & . & & . & . & 6 & 860 \\
\hline $000 E+00$ & 1.14E-02 & . & & & & & . & 6 & 1225 \\
\hline $0.00 E+00$ & $0.00 E+00$ & & & & & . & . & 6 & 1226 \\
\hline $000 E+00$ & $1.00 E-02$ & . & & . & & & . & 6 & 1227 \\
\hline $0.00 E+00$ & $1.16 E-02$ & . & & & & & & 6 & 1228 \\
\hline $0.00 E+00$ & $000 E+00$ & & & & & & & 6 & 1229 \\
\hline $000 E+00$ & $0.00 E+00$ & & & . & & & & 6 & 1231 \\
\hline $0.00 E+00[$ & $6.01 E-02$ & . & & & & & . & 6 & 1233 \\
\hline $000 E+00$ & $0.00 E+00$ & $0.00 E+00$ & $000 \mathrm{E}+00$ & $000 E+00$ & $0.00 E+\infty$ & $0.00 E+00$ & $0.00 E+\infty 0$ & 6 & 1234 \\
\hline $000 E+00$ & $000 E+00$ & . & & & & & & 6 & 1236 \\
\hline $000 E+00$ & $000 E+00$ & . & & & & & & 6 & 1237 \\
\hline \multirow[t]{2}{*}{$0.00 E+\infty$} & $000 E+00$ & . & & . & & & . & 6 & 1238 \\
\hline & $000 E+00$ & & & & & & r. & 6 & 1239 \\
\hline $000 E+00$ & $000 E+00$ & . & & & & & . & 6 & 1240 \\
\hline $000 E+00$ & $000 E+00$ & . & & & & & & 6 & 1241 \\
\hline $000 E+00$ & $000 E+00$ & . & & & & & & 6 & 1242 \\
\hline $000 E+00$ & $0.00 E+00$ & . & & & & & & 6 & 1243 \\
\hline $0.00 E+00$ & $000 E+00$ & & & & & & & 6 & 1244 \\
\hline $0.00 E+00$ & $000 E+00$ & $000 E+\infty 0$ & $0.00 E+00$ & $000 E+00$ & $000 E+\infty 0$ & $0.00 E+00$ & $0.00 E+00$ & 6 & 1245 \\
\hline $0.00 E+00$ & $000 E+00$ & , & & & & & . & 6 & 1249 \\
\hline $000 E+00$ & $000 E+00$ & . & & & & & . & 7 & 1071 \\
\hline $000 E+00$ & $000 E+00$ & . & & & & & & 7 & 1072 \\
\hline $0.00 E+00$ & $000 \mathrm{E}+00$ & . & & & & & & 7 & 1073 \\
\hline $000 E+00$ & $000 E+00$ & & & & & & & 7 & 1074 \\
\hline $0.00 E+00$ & $0.00 E+00$ & . & & . & & . & & 7 & 1075 \\
\hline $000 E+00$ & $000 E+00$ & . & & & & . & & 7 & 1076 \\
\hline $000 E+00$ & $000 E+00$ & . & & & & & & 7 & 1077 \\
\hline $0.00 E+\infty 0$ & $0.00 E+00$ & & & & & . & & 7 & 1078 \\
\hline $0.00 E+00$ & $0.00 E+00$ & & & & & & & 7 & 1079 \\
\hline $000 \mathrm{E}+00$ & $000 E+00$ & & & & & & & 7 & 1080 \\
\hline $0.00 E+00$ & $000 E+00$ & . & & & & & & 7 & 1081 \\
\hline $0.00 E+\infty 0$ & $000 E+00$ & . & & & & & & 7 & 1082 \\
\hline $0.00 E+\infty 0$ & $000 E+00$ & . & & & & & & 7 & 1083 \\
\hline $000 E+\infty$ & $000 E+00$ & & & & & & & 7 & 1084 \\
\hline $000 E+00$ & $0.00 E+00$ & & & & & & & 7 & 1085 \\
\hline $000 E+\infty$ & $0.00 E+00$ & & & & & & & 7 & 1086 \\
\hline $000 E+\infty$ & $000 E+00$ & & & & & & & 8 & 1087 \\
\hline $000 E+00$ & $000 E+00$ & & & & & & & 8 & 1088 \\
\hline
\end{tabular}


WELL BE BZCEE TETII22 DCEEII METHYLI METHYLL DIC33 PCB1254 BIS_2_ET BENZBFU BENZENE

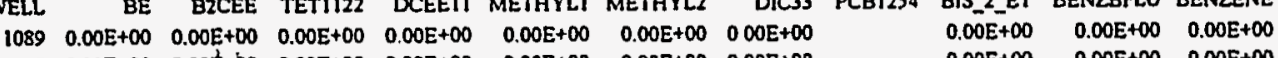
1090 .

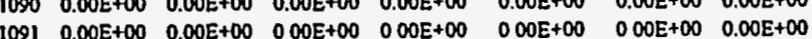

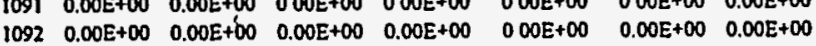
$\begin{array}{lll}0.00 E+\infty 0 & 0.00 E+00 \quad 0.00 E+00\end{array}$ $\begin{array}{lllllllll}1094 & 0.00 E+\infty 0 & 0.00 E+00 & 0.00 E+00 & 0.00 E+00 & 0.00 E+00 & 0.00 E+00 & 0.00 E+\infty 0\end{array}$ $\begin{array}{llllllllll}1095 & 0.00 E+\infty 0 & 0.00 E+00 & 0.00 E+00 & 0.00 E+\infty & 0.00 E+00 & 0.00 E+\infty 0 & 0.00 E+\infty 0\end{array}$ $\begin{array}{lllllllll}1096 & 0.00 E+\infty 0 & 0.00 E+\infty 0 & 0.00 E+00 & 0.00 E+00 & 0.00 E+\infty 0 & 0.00 E+\infty 0 & 0.00 E+\infty 00\end{array}$ \begin{tabular}{lll}
$0.00 E+00$ \\
\hline
\end{tabular} $\begin{array}{lllllllll}1140 & 0.00 E+00 & 0.00 E+60 & 0.00 E+00 & 0.00 E+\infty 0 & 0.00 E+\infty 0 & 0.00 E+\infty 0 & 0.00 E+\infty 0\end{array}$ $\begin{array}{llllllllll}1141 & 0.00 E+\infty 0 & 0.00 E+\infty 0 & 0.00 E+\infty & 0.00 E+\infty 0 & 0.00 E+\infty 0 & 0.00 E+\infty & 0.00 E+\infty 0\end{array}$ $\begin{array}{lllllllllll}1143 & 0.00 E+\infty & 0.00 E+\infty 0 & 0.00 E+00 & 0.00 E+\infty 0 & 0.0 E E+00 & 0.00 E+\infty 0 & 0.00 E+\infty 0\end{array}$ $\begin{array}{llllllllll}1144 & 0.00 E+00 & 0.00 E+00 & 0.00 E+00 & 0.00 E+00 & 0.00 E+00 & 0.00 E+00 & 0.00 E+00\end{array}$

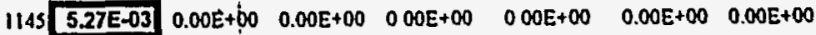
$\begin{array}{llllllllll}1146 & 0.00 E+\infty 0 & 0.00 E+00 & 0.00 E+00 & 0.00 E+\infty 0 & 0.00 E+\infty 0 & 0.00 E+\infty 0 & 0.00 E+\infty 0\end{array}$ $\begin{array}{lllllllll}1147 & 0.00 E+00 & 0.00 E+00 & 0.00 E+00 & 0.00 E+\infty 0 & 0.00 E+00 & 0.00 E+\infty 0 & 0.00 E+00\end{array}$ $\begin{array}{lllllllll}1148 & 0.00 E+\infty & 0.00 E+00 & 0.00 E+00 & 0.00 E+\infty 0 & 0.00 E+00 & 0.00 E+00 & 0.00 E+00\end{array}$ $\begin{array}{llllllll}1149 & 0.00 E+00 & 0.00 E+00 & 0.00 E+00 & 0.00 E+\infty 0 & 0.00 E+00 & 0.00 E+\infty 0 & 0.00 E+\infty 0\end{array}$ $1246 \quad 0.00 E+00 \quad 0.00 E+00 \quad 0.00 E+00 \quad 000 E+00 \quad 000 E+00 \quad 000 E+00 \quad 000 E+00$ $\begin{array}{lllllllll}1196 & 0.00 E+\infty & 0.00 E+00 & 0.00 E+00 & 0.00 E+\infty 0 & 0.00 E+00 & 0.00 E+00 & 0.00 E+\infty 0\end{array}$ $\begin{array}{llllllll}1197 & 0.00 E+\infty & 0.00 E+00 & 0.00 E+00 & 0.00 E+00 & 0.00 E+00 & 0.00 E+\infty 0 & 0.00 E+\infty 0\end{array}$ $\begin{array}{llllllll}1198 & 0.00 E+\infty & 0.00 E+\infty 0 & 0.00 E+00 & 0.00 E+\infty & 0.00 E+00 & 0.00 E+00 & 0.00 E+\infty 0\end{array}$ $\begin{array}{lllllllll}1199 & 0.00 E+00 & 0.00 E+00 & 0.00 E+00 & 0.00 E+00 & 0.00 E+00 & 0.00 E+00 & 0.00 E+00\end{array}$ $\begin{array}{llllllll}1200 & 0.00 E+\infty 0 & 0.00 E+\infty 0 & 0.00 E+00 & 0.00 E+00 & 0.00 E+00 & 0.00 E+00 & 0.00 E+\infty 0\end{array}$ $\begin{array}{llllllllllll}1201 & 0.00 E+00 & 0.00 E+00 & 0.00 E+00 & 2.49 E-02 & 0.00 E+00 & 0.00 E+00 & 0.00 E+00\end{array}$

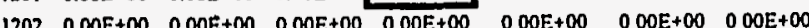
$12030.00 E+\infty 0 \quad 0.00 E+\infty 00 \quad 0.00 E+00 \quad 000 E+\infty 0000 E+00 \quad 000 E+00 \quad 000 E+00$ SNW-1 $5.00 \mathrm{E}-04$

BTT $8.00 E 04$

$0.00 E+00 \quad 000 E+00$ $\begin{array}{lll}0.00 E+\infty & 0.00 E+\infty & 0.00 E+\infty \\ 0.00 E+\infty & 0.00\end{array}$ $\begin{array}{lll}0.00 E+\infty & 0.00 E+\infty 0 & 0.00 E+\infty\end{array}$ $\begin{array}{lll}0.00 E+\infty 0 & 0.00 E+\infty & 0.00 E+\infty \\ 0.00 E+\infty 0 & 0.00 E+\infty & 0.00 E+\infty 0\end{array}$ $\begin{array}{lll}0.00 E+\infty 0 & 0.00 E+\infty & 0.00 E+\infty 0 \\ 0.00 E+\infty 0 & 0.00 E+\infty 0 & 0.00 E+\infty\end{array}$ $\begin{array}{lll}0.00 E+\infty & 0.00 E+\infty 0 & 0.00 E+\infty \\ 0.00 E+\infty & 0.00 E+\infty 0 & 0.00 E+\infty\end{array}$ $\begin{array}{lll}0.00 E+\infty 0 & 0.00 E+\infty 0 & 0.00 E+\infty \\ 0.00 E+\infty & 0.00 E+\infty & 0.00 E+\infty\end{array}$ $\begin{array}{lll}0.00 E+\infty & 0.00 E+\infty 0 & 0.00 E+\infty 0 \\ 0.00 E+\infty & 0.00 E+\infty 0 & 0.00 E+\infty 0\end{array}$ $\begin{array}{lll}0.00 E+\infty 0 & 0.00 E+00 & 0.00 E+\infty 0 \\ 0.00 E+\infty & 0.00 E+\infty 0 & 0.00 E+\infty 0\end{array}$ $0.00 E+\infty 00.00 E+00 \quad 0.00 E+00$ $\begin{array}{rrr}0.00 E+\infty 0 & 0.00 E+\infty 0 & 0.00 E+\infty 0 \\ 0.00 E+\infty & 0.00 E+\infty & 0.00 E+\infty\end{array}$ $\begin{array}{lll}0.00 E+\infty & 0.00 E+\infty & 0.00 E+\infty \\ 0.00 E+\infty & 0.00 E+\infty & 0.00 E+\infty 0\end{array}$ $\begin{array}{lll}0.00 E+\infty 0 & 0.00 E+00 & 0.00 E+\infty 0 \\ 0.00 E+\infty & 0.00 E+\infty & 0.00 E+\infty 0\end{array}$

$\begin{array}{lll}0.00 E+\infty 0 & 0.00 E+00 & 0.00 E+\infty 0 \\ 0.00 E+\infty & 0.00 E+\infty 0 & 0.00 E+\infty 0\end{array}$

$\begin{array}{lll}0.00 E+\infty & 0.00 E+00 & 0.00 E+\infty 0\end{array}$

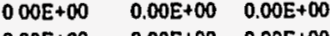

$0.00 E+\infty 00.00 E+00 \quad 0.00 E+00$

$0.00 E+\infty 00.00 E+00 \quad 0.00 E+00$

$0.00 E+00 \quad 0.00 E+00 \quad 0.00 E+\infty 0$

$0.00 E+\infty 0 \quad 0.00 E+\infty 0 \quad 000 E+\infty$

$0.00 E+\infty \quad 0.00 E+\infty 0 \quad 0.00 E+\infty$

$0.00 E+00 \quad 0.00 E+00 \quad 0.00 E+\infty$

$\begin{array}{llll}0.00 E+\infty & 0.00 E+00 & 0.00 E+\infty\end{array}$

$0.00 E+00$ O. $00 E+00$ O. $00 E+\infty 0$

$000 E+00 \quad 0.00 E+00 \quad 2.09 E-02$

$0.00 E+00 \quad 0.00 E+00 \quad 0.00 E+00$

$\begin{array}{lll}0.00 E+00 & 0.00 E+00 & 0.00 E+00\end{array}$

ENZAANT BENZAPYR CARBON_T DIBENZ_A HCBE INDENO_I NNDNPA $\begin{array}{llllllll}0.00 E+\infty 0 & 0.00 E+00 & 0.00 E+00 & 0.00 E+00 & 0.00 E+00 & 0.00 E+00 & 0.00 E+00\end{array}$ $\begin{array}{llllllll}0.00 E+00 & 0.00 E+00 & 0.00 E+00 & 0.00 E+\infty 0 & 0.00 E+00 & 0.00 E+00 & 0.00 E+00\end{array}$

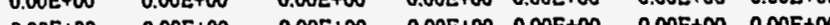

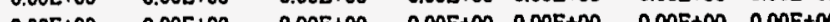
$0.00 E+00$ O. 00 E $0.00 \mathrm{E}$. $0.00 E+\infty O \quad 0.00 E+O O$ O.

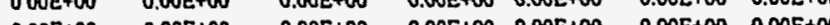
$0.00 E+\infty O \quad 0.00 E+\infty O \quad 0.00 E+\infty \quad 0.00 E+\infty 00.00 E+\infty O \quad 0.00 E+\infty 00.00 E+\infty 0$

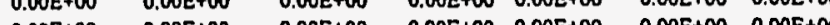
$\begin{array}{llllllllllllll}0.00 E+00 & 0.00 E+00 & 0.00 E+\infty & 0.00 E+00 & 0.00 E+\infty 0 & 0.00 E+\infty 0 & 0.00 E+\infty\end{array}$ $\begin{array}{llllllll}0.00 E+\infty 0 & 0.00 E+\infty 0 & 0.00 E+\infty & 0.00 E+\infty & 0.00 E+\infty & 0.00 E+\infty 0 & 0.00 E+\infty\end{array}$

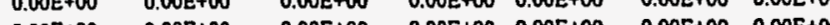
$\begin{array}{lllllllllllllll}0.00 E+\infty & 0.00 E+00 & 0.00 E+\infty & 0.00 E+\infty & 0.00 E+\infty & 0.00 E+\infty & 0.00 E+\infty\end{array}$

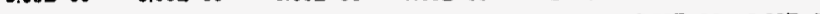
$\begin{array}{llllllll}0.00 E+\infty 0 & 0.00 E+00 & 0.00 E+\infty 0 & 0.00 E+\infty 0 & 0.00 E+00 & 0.00 E+00 & 0.00 E+00\end{array}$ $\begin{array}{lllllllll}0.00 E+\infty 0 & 0.00 E+\infty & 0.00 E+\infty 0 & 0.00 E+\infty & 0.00 E+\infty 0 & 0.00 E+\infty 0 & 0.00 E+\infty\end{array}$ $\begin{array}{llllllll}0.00 E+00 & 0.00 E+00 & 0.00 E+00 & 0.00 E+00 & 0.00 E+\infty 0 & 0.00 E+00 & 0.00 E+\infty\end{array}$ $\begin{array}{llllllll}0.00 E+00 & 0.00 E+00 & 0.00 E+\infty 0 & 0.00 E+00 & 0.00 E+\infty & 0.00 E+\infty 0 & 0.00 E+\infty\end{array}$ $\begin{array}{llllllll}0.00 E+00 & 0.00 E+00 & 0.00 E+00 & 0.00 E+00 & 0.00 E+00 & 0.00 E+00 & 0.00 E+00\end{array}$ $\begin{array}{llllllll}0.00 E+00 & 0.00 E+00 & 0.00 E+00 & 0.00 E+00 & 0.00 E+\infty 0 & 0.00 E+00 & 0.00 E+\infty 0\end{array}$ $\begin{array}{llllllll}0 & 00 E+00 & 0.00 E+\infty 0 & 0.00 E+00 & 0.00 E+00 & 0.00 E+00 & 0.00 E+00 & 0.00 E+00\end{array}$ $\begin{array}{llllllll}0.00 E+00 & 0.00 E+00 & 0.00 E+00 & 0.00 E+00 & 0.00 E+\infty 0 & 0.00 E+00 & 0.00 E+\infty 0\end{array}$ $\begin{array}{llllllll}0.00 \mathrm{E}+\infty 0 & 0.00 \mathrm{E}+00 & 0.00 \mathrm{E}+\infty 0 & 0.00 \mathrm{E}+00 & 0.00 \mathrm{E}+\infty & 0.00 \mathrm{E}+00 & 0.00 \mathrm{E}+00\end{array}$ $\begin{array}{llllllll}0.00 E+00 & 0.00 E+00 & 0.00 E+00 & 0.00 E+00 & 0.00 E+00 & 0.00 E+00 & 0.00 E+00\end{array}$ $\begin{array}{llllllll}0.00 E+00 & 0.00 E+00 & 0.00 E+00 & 0.00 E+00 & 0.00 E+00 & 0.00 E+00 & 0.00 E+00\end{array}$ $\begin{array}{llllllll}0.00 E+00 & 0.00 E+\infty 0 & 0.00 E+\infty 0 & 0.00 E+00 & 0.00 E+\infty 0 & 0.00 E+\infty 0 & 0.00 E+\infty\end{array}$ $\begin{array}{lllll}0.00 E+\infty 0 & 0.00 E+00 \quad 0.00 E+\infty 00 & 0.00 E+\infty 0 & 0.00 E+\infty\end{array}$ $\begin{array}{llllllll}0.00 E+00 & 0.00 E+\infty 0 & 0.00 E+00 & 0.00 E+00 & 0.00 E+00 & 0.00 E+00 & 0.00 E+00\end{array}$

$0.00 \mathrm{E}+00$

$0.00 \mathrm{E}+00$

$0.00 \mathrm{E}+00$

SWS-11 4.00E-04

$0.00 E+\infty 0$

SWT-3 $4.000-1$

SWS $0,5,00 E-04$

SWS.6 3.00E-04

SWS.7 3.00E-04

SWS-8 $0.00 E+00$

SWS.9 4.00E.04

SW6-1 2.00E-04

$0.00 E+00 \quad 0.00 E+00$

$0.00 E+00 \quad 0$ OOE +00

$0.00 E+00 \quad 0.00 E+00$

SW7-1 4.00E-04

$0.00 E+00 \quad 0.00 E+00$

SW7.2 $400 E-04$

$0.00 E+00 \quad 0.00 E+00$

0 OOE +00 


\begin{tabular}{|c|c|c|c|c|c|c|}
\hline PENTACHL & VINYL_CH & TRJ123 D12CHL3 & DBE 12 & DIOXAN14 PROPENE2 & 3.3_DI WAG & WELL \\
\hline $0.00 E+\infty 0$ & $0.00 E+00$ & . & & & 8 & 1089 \\
\hline $0.00 E+00$ & $0.00 E+\infty 0$ & . & & . & 8 & 1090 \\
\hline $0.00 E+\infty 0$ & $0.00 E+\infty$ & & & . & 8 & 1091 \\
\hline $000 E+00$ & $000 E+00$ & . & & . & 8 & 1092 \\
\hline $0.00 E+00$ & $000 E+00$ & . & . & . & 8 & 1093 \\
\hline $000 \mathrm{E}+00$ & $0.00 E+00$ & & & . & 8 & 1094 \\
\hline $0.00 E+00$ & $000 E+\infty$ & . & & . & 8 & 1095 \\
\hline $0.00 E+\infty 0$ & $000 E+00$ & & . & . & 8 & 1096 \\
\hline $0.00 E+00$ & $0.00 E+00$ & . & . & . & 8 & 1097 \\
\hline $0.00 \mathrm{E}+00$ & $0.00 E+00$ & & ${ }^{\circ}$ & . & 11 & 1139 \\
\hline $0.00 E+\infty 0$ & $0.00 E+00$ & . & 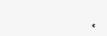 & . & 11 & 1140 \\
\hline $0.00 E+00$ & $0.00 E+00$ & . & . & . & 11 & 1141 \\
\hline $0.00 E+\infty$ & $0.00 E+\infty$ & . & & . & 11 & 1143 \\
\hline $0.00 E+00$ & $000 E+00$ & . & . & . & 11 & 1144 \\
\hline $0.00 E+00$ & $0.00 E+00$ & & & . & 11 & 1145 \\
\hline $0.00 E+00$ & $0.00 E+\infty 0$ & . & & . & 11 & 1146 \\
\hline $000 E+00$ & $0.00 E+\infty 0$ & & & . & II & 1147 \\
\hline $000 E+\infty 0$ & $0.00 E+00$ & & & . & "I & 1148 \\
\hline $000 E+00$ & $0.00 E+\infty$ & & & . & 11 & 1149 \\
\hline $000 \mathrm{E}+00$ & $000 E+\infty$ & & & . & 11 & 1246 \\
\hline $000 E+00$ & $0.00 \varepsilon+00$ & & & . & 17 & 1196 \\
\hline $000 E+00$ & $000 E+00$ & & & . & 17 & 1197 \\
\hline $0.00 E+00$ & $000 E+00$ & . & & . & 17 & 1198 \\
\hline $000 \mathrm{E}+00$ & $0.00 \varepsilon+00$ & & & . & 17 & 1199 \\
\hline $0.00 E+00$ & $0.00 E+00$ & & & . & 17 & 1200 \\
\hline $000 E+00$ & $1.58 \mathrm{E}-01$ & & & . & 17 & 1201 \\
\hline $000 E+00$ & $0.00 E+00$ & . & & . & 17 & 1202 \\
\hline \multirow[t]{28}{*}{$000 E+00$} & $000 E+00$ & & & 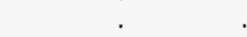 & 17 & 1203 \\
\hline & & & & & Seep & SNW-1 \\
\hline & & & & . & Seep & $5 \mathrm{NW}-2$ \\
\hline & $000 E+00$ & $000 E+00$ & $000 E+00$ & . & Seep & BTT \\
\hline & & & & & Seep & FRENCH DRA \\
\hline & $000 E+00$ & $000 E+00$ & $000 E+00$ & . & Seep & RS-1 \\
\hline & & & & . & Seep & RS-3 \\
\hline & $000 E+00$ & $000 E+00$ & $000 E+00$ & . & Seep & SW2-1 \\
\hline & $0.00 E+00$ & $000 E+00$ & $0.00 E+\infty 0$ & . & Seep & SW2-2 \\
\hline & $000 \varepsilon+00$ & $0.00 E+00$ & $000 E+\infty$ & . & Seep & SW2-3 \\
\hline & $0.00 E+\infty 0$ & 0 OOE +00 & $000 E+00$ & . & Seep & SW2-4 \\
\hline & $0.00 E+00$ & $0.00 E+00$ & $000 E+00$ & . & Seep & SW2-S \\
\hline & $1.48 E-02$ & $000 E+00$ & $000 E+00$ & . & Seep & SW4-1 \\
\hline & $6.30 \mathrm{E}-02$ & $0.00 E+00$ & $0.00 E+00$ & . & Seep & SW4-2 \\
\hline & & & & 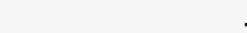 & Seep & sws-11 \\
\hline & & & & . & Seep & sws-3 \\
\hline & . & & & . & Seep & SWS.4 \\
\hline & 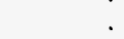 & . & - & . & Seep & sws-s \\
\hline & . & & & & Seep & SWS-6 \\
\hline & . & & & . & Seep & SWS-7 \\
\hline & . & & & . & Seep & SW5-8 \\
\hline & & & & & Seep & sws-9 \\
\hline & $0.00 E+\infty 0$ & $0.00 E+00$ & $000 E+00$ & . & Seep & SWG-1 \\
\hline & $0.00 E+00$ & $0.00 E+\infty 0$ & $0.00 E+00$ & & Seep & SW6-2 \\
\hline & $000 E+\infty 0$ & $000 E+00$ & $0.00 E+00$ & . & Seep & sw7-1 \\
\hline & $000 E+00$ & $0.00 E+00$ & $0.00 E+00$ & . & Seep & SW7.2 \\
\hline & $000 E+00$ & $000 E+00$ & $0.00 E+\infty$ & 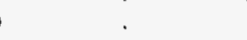 & Seep & SW7-3 \\
\hline & $000 E+\infty 0$ & $000 \mathrm{E}+00$ & $000 E+00$ & & Seep & sw7-s \\
\hline
\end{tabular}


Table A.S

WAG$$
\begin{aligned}
& \text { Seep } \\
& \text { Seep } \\
& \text { Seep } \\
& \text { Seep }
\end{aligned}
$$

Chemical Representative Concentrations (mg $/$ )

DIC33 PCBI254 BIS_2_ET BENZBFU BENZENE BENZAANT BENZAPYR CARBON_T DIBENZ_A HCBE INDENO_1 NNDNPA WELL BE B2CEE TETI122 DCEEII METHYLI METHYL2 DIC33 PCB1254 BIS 2 ET BENZBFU BENZENE

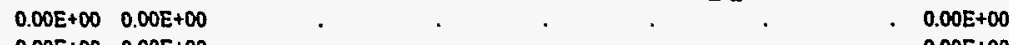
$0.00 E+\infty 00.00 E+00$

$0.00 \mathrm{E}+00$ $0.00 \mathrm{E}+00$
$0.00 \mathrm{E}+00$ 


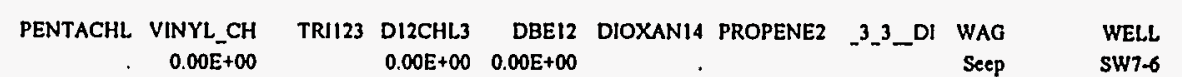

$\begin{array}{rrrrrr}0.00 \mathrm{E}+00 & 0.00 \mathrm{E}+00 & 0.00 \mathrm{E}+00 & . & \text { Seep } & \text { SW7-6 } \\ 200 \mathrm{E}-04 & 0.00 \mathrm{E}+00 & 0.00 \mathrm{E}+00 & . & \text { Seep } & \text { W4TRIB-11 }\end{array}$

$\begin{array}{llll}0.00 E+00 & 0.00 E+00 & 0.00 E+00 & \text { Seep WATRIB-5 }\end{array}$

$0.00 E+00$

$0.00 E+\infty 0.00 E+\infty$

Seep

WATRIB-7 
WELL CS_137 RA_228 SR_90 TH_228 TH_230 TRITIUM TOTAL_RA U_234 AM_241 PU_238 PM_147 TC_99 PU_239 PB_210 K_40 CM_244 C_14 CO_60 SR_89

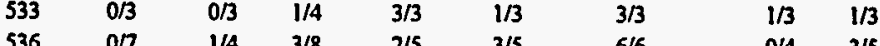

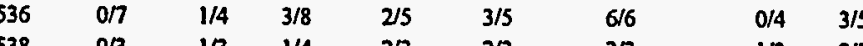

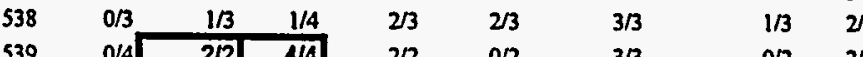

$\begin{array}{lllllll}539 & 0 / 4 & 2 / 2 & 4 / 4 & 2 / 2 & 0 / 2 & 3 / 3\end{array}$

$541 \quad 0 / 3 \quad 0 / 2 \quad 1 / 4 \quad 2 / 2 \quad 0 / 2 \quad 3 / 3$

$543 \quad 0 / 4 \quad 012 \quad 2 / 4 \quad 0 / 2 \quad 0 / 2$

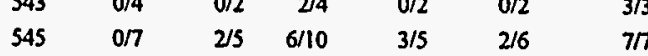

$546 \quad 0 / 2 \quad 1 / 1 \quad 0 / 2 \quad 1 / 1 \quad 1 / 1 \quad 1 / 1$

$548 \quad 0 / 2 \quad 1 / 1$

$\begin{array}{lllllll}549 & 0 / 5 & 2 / 4 & 2 / 6 & 1 / 3 & 0 / 3 & 4 / 4\end{array}$

$550 \quad 0 / 1 \quad 0 / 2 \quad 1 / 1 \quad 1 / 1 \quad 1 / 1$

$\begin{array}{rrrrrrr}553 & 0 / 10 & 0 / 4 & 2 / 8 & 1 / 4 & 1 / 4 & 6 / 6 \\ 554 & 0 / 7 & 0 / 2 & 6 / 8 & 2 / 3 & 0 / 3 & 5 / 5\end{array}$

558

\begin{tabular}{lllll}
564 & $0 / 3$ & $2 / 2$ & $2 / 2$ & $2 / 2$ \\
\hline
\end{tabular}

$\begin{array}{llllll}566 & 0 / 8 & 3 / 4 & 8 / 8 & 5 / 5\end{array}$

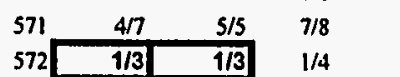

$\begin{array}{llll}572 & 1 / 3 & 1 / 3 & 1 / 4 \\ 579 & 0 / 5 & 0 / 2 & 4 / 6\end{array}$

587

588

589

590

593
596

596
597

598

599

601

602

603

604
607

607

610

611

613

618
620

620
621

$622 \quad 0 / 4$

$623 \quad 0 / 6$

$\begin{array}{ll}634 & 0 / 4 \\ 806 & 9 / 1\end{array}$
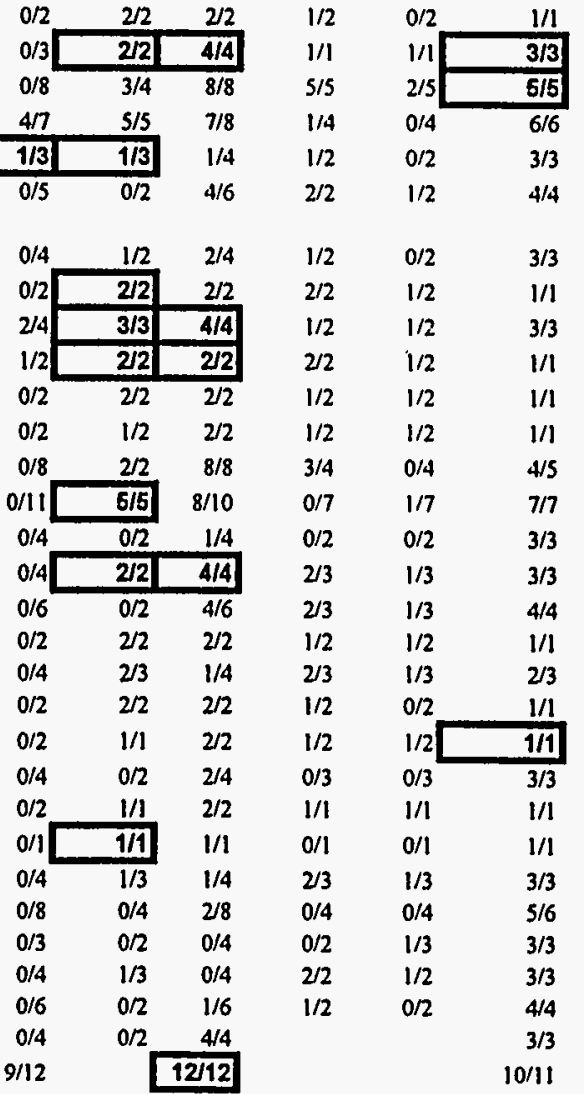

$\begin{array}{ll}1 / 2 & 3 / 3 \\ & 4 / 4\end{array}$

$0 / 2 \quad 3 / 3$

$1 / 2 \quad 1 / 1$

$1 / 2$

$1 / 2$
$1 / 2$

$1 / 2$

$1 / 7 \quad 7 / 7$

$0 / 2 \quad 3 / 3$

$1 / 3 \quad 3 / 3$

$\begin{array}{ll}1 / 3 & 4 / 4 \\ 1 / 2 & 1 / 1\end{array}$

$1 / 2 \quad 1 / 1$$$
0 / 2
$$

$0 / 2$
$1 / 2$
$0 / 3$
$1 / 1$

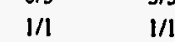

$\begin{array}{ll}1 / 1 & 1 / 1 \\ 0 / 1 & 1 / 1\end{array}$

$1 / 3 \quad 3 / 3$

$0 / 4 \quad 5 / 6$

$1 / 3 \quad 3 / 3$

$\begin{array}{ll}0 / 2 & 4 / 4 \\ & 3 / 3\end{array}$

$10 / 11$
$0 / 1$

$O / 2 \quad 1 / 2$

$1 / 3 \quad 2 / 3$

$0 / 2 \quad 0 / 2$

$0 / 4 \quad 3 / 5$

1/1 $1 / 1$

$1 / 3 \quad 2$

$0 / 4 \quad 2 / 5$

$0 / 2 \quad 1 / 3$

$2 / 2 \quad 2 / 2$

$0 / 2 \quad 0 / 2$

$3 / 7 \quad 5 / 6$

$0 / 2 \quad 2 / 2$

$0 / 2 \quad 2 / 3$

$0 / 2 \quad 1 / 2$

2/2 $\quad 1 /$

$1 / 3 \quad 2 / 3$

$2 / 2$

$2 / 2$

$0 / 2 \quad 1$

1/5

$0 / 2 \quad 0 / 2$

$0 / 2 \quad 2 / 3$

$0 / 2 \quad 1 / 3$

$\begin{array}{ll}2 / 2 & 1 / 2 \\ 1 / 3 & 2 / 3\end{array}$

$1 / 3$

$2 / 2 \quad 2$

$0 / 2 \quad 2 / 3$

1/1 $1 / 1$

$1 / 1$
$1 / 3$

$\begin{array}{ll}1 / 3 & 1 / 3 \\ 0 / 4 & 0 / 4\end{array}$

$0 / 2 \quad 0 / 2$

$0 / 2 \quad 0 / 2$

$0 / 2 \quad 0 / 2$

3

$0 / 1 \quad 0$

$0 / 2$

o/ $\quad 0 / 1$

$2 / 2 \quad 2 / 2$

$0 / 2 \quad 0 / 2$

$0 / 2 \quad 2 / 2$

$0 / 4 \quad 0 / 4$

$2 / 2 \quad 0 / 2$

$0 / 2$

$0 / 1$

o/I

$2 / 2$ 
WAG WELL CS_137 RA_228 SR_90 TH_228 TH_230 TRITIUM TOTAL_RA U_234 AM_241 PU_238 PM_147 TC_99 PU_239 PB_210 K_40 CM_244 C_14 CO_60 SR_89

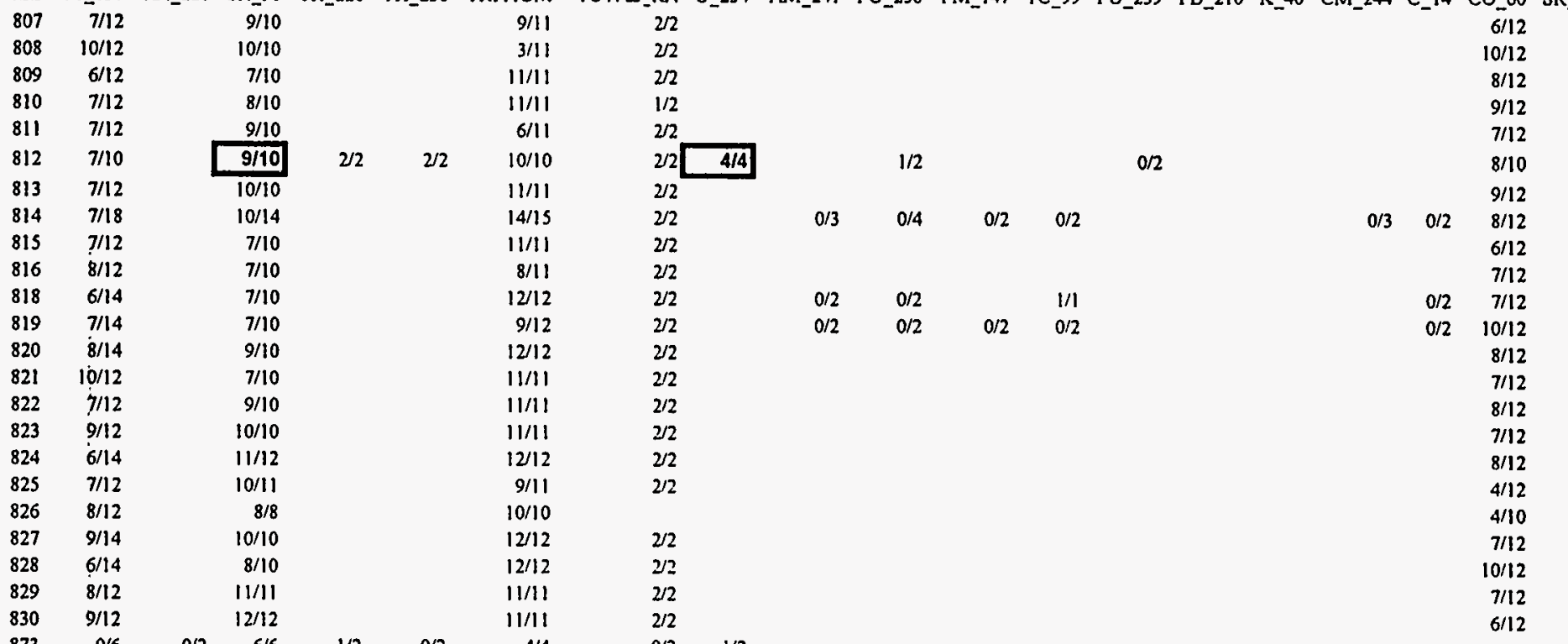

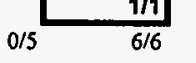

$1 / 5 \quad 3 / 4$
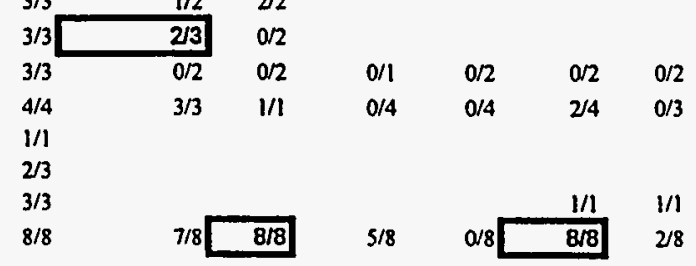
WAG WELL CS_137 RA_228 SR_90 TH_228 TH_230 TRTIUM TOTAL_RA U_234 AM_241 PU_238 PM_147 TC_99 PU_239 PB_210 K_40 CM_244 C_14 CO_60 SR_89

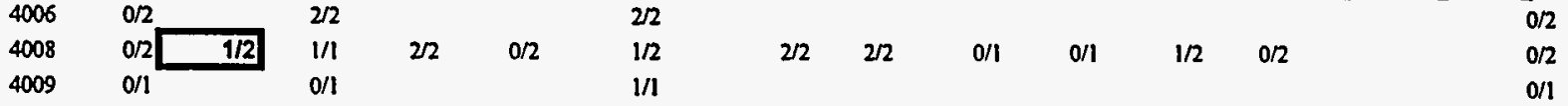

$1150 \quad 3 / 6$

$6 / 6$

$1151 \quad 4 / 6 \quad 6 / 6$

$1152 \quad 3 / 6 \quad 6 / 6$

$1153 \quad 3 / 6 \quad 6 / 6$

$1154 \quad 3 / 6 \quad 4 / 6$

$1156 \quad 4 / 6 \quad 5 / 6$

$1185 \quad 6 / 6$

$1186 \quad 316$

$1187 \quad 5 / 6$

$1188 \quad 4 / 6$

$1189 \quad 5 / 6$

$1190 \quad 2 / 6$

$1191 \quad 4 / 6$

$1192 \quad 5 / 6$

$\begin{array}{ll}1193 & 4 / 6 \\ 1194 & 5 / 6\end{array}$

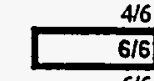

$6 / 6$

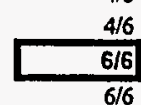

$6 / 6$

$5 / 6$

$5 / 6$
$4 / 6$

$6 / 6$

$5 / 6$

6/6

$4 / 6$
$5 / 6$

6/6

$2 / 6$

$4 / 6$

$4 / 6$

$4 / 4$

$4 / 4$

$2 / 4$

$3 / 4$
$4 / 4$

$3 / 4$

$3 / 4$ 
Radionuclide Frequency of Detect by Well

WAG WELL CS_137 RA_228 SR_90 TH_228 TH_230 TRITIUM TOTAL_RA U_234 AM_241 PU_238 PM_147 TC_99 PU_239 PB_210 K_40 CM_244 C_14 CO_60 SR_89

\begin{tabular}{|c|c|c|c|c|c|c|c|c|c|c|}
\hline 959 & $6 / 9$ & & $7 / 9$ & & & $5 / 9$ & & & & \\
\hline 960 & $6 / 8$ & & $7 / 8$ & & & $8 / 8$ & & & & \\
\hline 961 & $5 / 8$ & & $6 / 8$ & & & $4 / 8$ & & & & \\
\hline 962 & $3 / 8$ & & $6 / 8$ & & & $8 / 8$ & & & & \\
\hline 440 & $0 / 2$ & $0 / 1$ & $1 / 2$ & $2 / 2$ & $2 / 2$ & $2 / 2$ & $2 / 2$ & $2 / 2$ & $1 / 1$ & $1 / 2$ \\
\hline 441 & $1 / 2[$ & $1 / 1$ & $2 / 2$ & $1 / 1$ & $1 / 1$ & $2 / 2$ & $1 / 1$ & $1 / 1$ & $1 / 1$ & $1 / 1$ \\
\hline 468 & $0 / 2$ & $1 / 2$ & $2 / 2$ & $1 / 1$ & $1 / 1$ & $2 / 2$ & $1 / 2$ & $2 / 2$ & $1 / 1$ & $1 / 2$ \\
\hline 472 & $0 / 2$ & $1 / 2$ & $2 / 2$ & $1 / 2$ & $1 / 2$ & $2 / 2$ & $2 / 2$ & $2 / 2$ & $0 / 2$ & $0 / 2$ \\
\hline 476 & $0 / 2$ & $0 / 1$ & $2 / 2$ & $0 / 2$ & $0 / 2$ & $2 / 2$ & $2 / 2$ & $2 / 2$ & $2 / 2$ & $1 / 2$ \\
\hline 513 & $0 / 1$ & & $0 / 1$ & $1 / 1$ & $1 / 1$ & $1 / 1$ & $1 / 1$ & $1 / 1$ & $0 / 1$ & $1 / 1$ \\
\hline 514 & $0 / 2$ & $0 / 1$ & $0 / 2$ & $0 / 1$ & $1 / 1$ & $2 / 2$ & $1 / 1$ & $0 / 1$ & $0 / 2$ & $0 / 1$ \\
\hline 516 & $0 / 2$ & $0 / 1$ & $0 / 2$ & $1 / 2$ & $1 / 2$ & $2 / 2$ & $1 / 1$ & $1 / 2$ & $1 / 2$ & $1 / 2$ \\
\hline 517 & $1 / 1$ & $0 / 1$ & $0 / 1$ & $1 / 1$ & $1 / 1$ & $1 / 1$ & $1 / 1$ & $1 / 1$ & $1 / 2$ & $1 / 1$ \\
\hline 518 & $0 / 1$ & & $0 / 1$ & on & $0 / 1$ & $1 / 1$ & $0 / 1$ & & $0 / 1$ & \\
\hline 519 & $1 / 1$ & $1 / 1$ & $0 / 1$ & $t / 1$ & $1 / 1$ & $1 / 1$ & $1 / 1$ & $1 / 1$ & $1 / 2$ & $0 / 1$ \\
\hline 520 & $0 / 1$ & & $0 / 1$ & $0 / 1$ & $0 / 1$ & $1 / 1$ & $0 / 2$ & $0 / 1$ & $0 / 1$ & $0 / 1$ \\
\hline 521 & $0 / 1$ & & $0 / 1$ & $0 / 1$ & $0 / 1$ & $1 / 1$ & $0 / 1$ & $0 / 1[$ & $1 / 3$ & $0 / 1$ \\
\hline 522 & $0 / 1$ & $1 / 2$ & $0 / 1$ & $0 / 1$ & $0 / 1$ & $0 / 1$ & $1 / 1$ & $0 / 1$ & $0 / 2$ & $0 / 1$ \\
\hline$\$ 23$ & $0 / 1$ & & $0 / 1$ & & & $1 / 1$ & & $1 / 1$ & $1 / 2$ & $0 / 1$ \\
\hline 524 & $0 / 2$ & $1 / 2$ & $0 / 2$ & $2 / 2$ & $2 / 3$ & $2 / 2$ & $2 / 2$ & $1 / 2$ & $1 / 2$ & $0 / 2$ \\
\hline 525 & $0 / 1$ & & $0 / 1$ & $1 / 1$ & $1 / 1$ & $1 / 1$ & $1 / 1$ & $0 / 1$ & $0 / 1$ & $1 / 1$ \\
\hline 526 & $0 / 2$ & & $2 / 2$ & & & $2 / 2$ & & $1 / 1$ & $0 / 1$ & \\
\hline 708 & $0 / 1$ & & $0 / 1$ & $1 / 1$ & $0 / 1$ & $1 / 1$ & $0 / 1$ & $1 / 1$ & $2 / 2$ & $0 / 1$ \\
\hline 715 & $0 / 1[$ & $1 / 1$ & $0 / 1$ & $1 / 1$ & $1 / 1$ & $1 / 1$ & $1 / 1$ & $1 / 1$ & $0 / 1$ & $0 / 1$ \\
\hline 716 & $1 / 2$ & 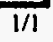 & $0 / 2$ & $1 / 1$ & $1 / 1$ & $1 / 2$ & $1 / 1$ & $1 / 1$ & $0 / 1$ & $0 / 2$ \\
\hline 963 & $4 / 9$ & $0 / 1$ & $4 / 9$ & $0 / 1$ & $1 / 1$ & $4 / 9$ & $0 / 1$ & $3 / 4$ & $0 / 4$ & $2 / 4$ \\
\hline 964 & $6 / 9$ & $0 / 1$ & $5 / 9$ & $0 / 1$ & $0 / 1$ & $9 / 9$ & $0 / 1$ & $3 / 3$ & $1 / 4$ & $0 / 4$ \\
\hline 965 & $7 / 9$ & $1 / 1$ & $4 / 8$ & $1 / 1$ & $1 / 1$ & $9 / 9$ & $0 / 1$ & $4 / 4$ & $3 / 4$ & $2 / 4$ \\
\hline 966 & $5 / 9$ & $1 / 1$ & $5 / 9$ & $0 / 1$ & $0 / 1$ & $9 / 9$ & $1 / 1$ & $3 / 4$ & $2 / 4$ & $0 / 4$ \\
\hline 967 & $5 / 9$ & $0 / 1$ & $\$ / 9$ & $0 / 1$ & 0/1 & $9 / 9$ & $0 / 1$ & $3 / 4$ & $1 / 4$ & $2 / 4$ \\
\hline 968 & $4 / 9$ & $1 / 1$ & $S / 9$ & $1 / 1$ & $0 / 1[$ & $9 / 9$ & $0 / 1$ & $4 / 4$ & $1 / 4$ & $0 / 4$ \\
\hline 969 & $S / 9$ & $0 / 1$ & $9 / 9$ & $1 / 1$ & $0 / 1$ & $9 / 9$ & $0 / 1$ & $4 / 4$ & $3 / 4$ & $3 / 4$ \\
\hline 970 & $4 / 9$ & $0 / 1$ & $7 / 9$ & 0/1 & $0 / 1$ & $9 / 9$ & $0 / 1$ & $3 / 4$ & $2 / 4$ & $2 / 4$ \\
\hline 971 & $7 / 9$ & $1 / 1$ & $9 / 9$ & $0 / 1$ & $0 / 1$ & $9 / 9$ & $0 / 1$ & $3 / 4$ & $3 / 4$ & $1 / 4$ \\
\hline 972 & $2 / 9$ & $1 / 1$ & $6 / 8$ & $1 / 1$ & $0 / 1$ & $9 / 9$ & $0 / 1$ & $3 / 4$ & $3 / 4$ & $1 / 4$ \\
\hline 973 & $6 / 9[$ & $1 / 1$ & $9 / 9$ & $0 / 1$ & $1 / 1$ & $9 / 3$ & $0 / 1$ & $2 / 4$ & $3 / 4$ & $4 / 4$ \\
\hline 974 & $3 / 9$ & $1 / 1$ & $9 / 9$ & $0 / 1$ & $0 / 1[$ & $9 / 9$ & $0 / 1$ & $3 / 4$ & $2 / 4$ & $4 / 4$ \\
\hline 975 & $3 / 9$ & $0 / 1$ & $9 / 9$ & $0 / 1$ & $0 / 1$ & $9 / 9$ & $0 / 1$ & $3 / 4$ & $3 / 4$ & $4 / 4$ \\
\hline 976 & $4 / 9$ & $1 / 1$ & $8 / 8$ & $1 / 1$ & $0 / 1$ & $9 / 9$ & $1 / 1$ & $4 / 4$ & $2 / 4$ & $2 / 4$ \\
\hline 977 & $4 / 9$ & $0 / 1$ & $9 / 9$ & $0 / 1$ & $1 / 1$ & $9 / 9$ & $0 / 1$ & $3 / 4$ & $2 / 4$ & $1 / 4$ \\
\hline 978 & $5 / 9$ & $0 / 1$ & $4 / 9$ & $0 / 1$ & $0 / 1$ & $9 / 9$ & $1 / 1$ & $3 / 4$ & $2 / 4$ & $0 / 4$ \\
\hline 979 & $3 / 9$ & $0 / 1$ & $5 / 9$ & 0/1 & $0 / 1$ & $9 / 9$ & $0 / 1$ & $3 / 4$ & $2 / 4$ & $1 / 4$ \\
\hline 980 & $6 / 9$ & $0 / 1$ & $4 / 9$ & $0 / 1$ & $0 / 1$ & $5 / 9$ & $0 / 1$ & $4 / 4$ & $2 / 4$ & $1 / 4$ \\
\hline 981 & $1 / 9$ & $0 / 1$ & $4 / 9$ & $1 / 1$ & $0 / 1[$ & $9 / 9$ & $0 / 1$ & $3 / 4$ & $0 / 4$ & $1 / 4$ \\
\hline 982 & $4 / 9$ & $0 / 1$ & $2 / 9$ & $0 / 1$ & $0 / 1$ & $8 / 9$ & $0 / 1$ & $3 / 4$ & $3 / 4$ & $1 / 4$ \\
\hline 983 & $3 / 9$ & $0 / 1$ & $6 / 9$ & $0 / 1$ & $0 / 1$ & $9 / 9$ & $0 / 1$ & $3 / 3$ & $0 / 4$ & , \\
\hline 984 & $6 / 9$ & $1 / 1$ & $7 / 9$ & $0 / 1$ & $0 / 1$ & $7 / 9$ & $1 / 1$ & $4 / 4$ & $2 / 4$ & $2 / 4$ \\
\hline
\end{tabular}

\begin{tabular}{|c|c|c|c|c|c|}
\hline & & & & & $\begin{array}{l}6 / 9 \\
5 / 8\end{array}$ \\
\hline & & & & & $5 / 8$ \\
\hline & & & & & $3 / 8$ \\
\hline $1 / 1$ & $O / 2$ & $1 / 1$ & $1 / 1$ & $2 / 2$ & $1 / 1$ \\
\hline $0 / 1$ & $0 / 1$ & $1 / 1$ & & $2 / 2$ & $1 / 1$ \\
\hline $1 / 1$ & $0 / 2$ & & & $1 / 2$ & \\
\hline $0 / 1$ & $0 / 2$ & & $0 / 2$ & $2 / 2$ & \\
\hline \multirow[t]{2}{*}{$2 / 2$} & $1 / 2$ & & $2 / 2$ & $2 / 2$ & \\
\hline & $0 / 1$ & & & $0 / 1$ & \\
\hline $0 / 1$ & $0 / 1$ & & $0 / 2$ & $0 / 2$ & \\
\hline $0 / 2$ & $0 / 2$ & & $2 / 2$ & $0 / 2$ & \\
\hline \multirow[t]{2}{*}{$0 / 1$} & $0 / 1$ & & $0 / 1$ & $0 / 1$ & \\
\hline & & & $0 / 1$ & $1 / 1$ & \\
\hline $1 / 1$ & $0 / 1$ & $1 / 1$ & & $0 / 1$ & \\
\hline $0 / 1$ & $0 / 1$ & & $0 / 1$ & $0 / 1$ & \\
\hline $0 / 1$ & $0 / 1$ & & & $0 / 1$ & \\
\hline $1 / 1$ & $0 / 1$ & & & $0 / 1$ & \\
\hline $1 / 1$ & $0 / 1$ & $1 / 1$ & $1 / 1$ & $0 / 1$ & \\
\hline $2 / 2$ & $0 / 2$ & $0 / 1$ & & $1 / 2$ & \\
\hline $0 / 1$ & $0 / 1$ & & $0 / 1$ & $0 / 1$ & \\
\hline $0 / 1$ & & & & $0 / 2$ & \\
\hline \multirow[t]{2}{*}{$1 / 1$} & $0 / 1$ & & & $0 / 1$ & \\
\hline & $0 / 1$ & $1 / 1$ & & $0 / 1$ & \\
\hline $1 / 2$ & $0 / 2$ & & & $0 / 2$ & \\
\hline $0 / 1$ & $0 / 4$ & & $0 / 4$ & $0 / 2$ & $2 / 8$ \\
\hline $0 / 1$ & $1 / 4$ & & $3 / 4$ & $1 / 1$ & $4 / 8$ \\
\hline $0 / 1$ & $1 / 4$ & & $2 / 4$ & $1 / 2$ & $8 / 8$ \\
\hline $0 / 1$ & $1 / 4$ & & $0 / 4$ & $1 / 1$ & $6 / 8$ \\
\hline $0 / 1$ & $0 / 4$ & & $1 / 4$ & $1 / 2$ & $5 / 8$ \\
\hline $0 / 1$ & $2 / 4$ & & $0 / 4$ & $0 / 4$ & $6 / 8$ \\
\hline $0 / 1$ & $2 / 4$ & & $4 / 4$ & $2 / 4$ & $3 / 8$ \\
\hline $0 / 1$ & $0 / 4$ & & $0 / 4$ & $0 / 4$ & $3 / 8$ \\
\hline $0 / 1$ & $1 / 4$ & & $4 / 4$ & $0 / 4$ & $5 / 8$ \\
\hline $0 / 1$ & $0 / 4$ & & $1 / 4$ & $0 / 4$ & $5 / 8$ \\
\hline $0 / 1$ & $0 / 4$ & & $4 / 4$ & $3 / 4$ & $4 / 8$ \\
\hline $0 / 1$ & $0 / 4$ & & $4 / 4$ & $4 / 4$ & $3 / 8$ \\
\hline $0 / 1$ & $1 / 4$ & & $4 / 4$ & $4 / 4$ & $4 / 8$ \\
\hline $0 / 1$ & $1 / 4$ & & $3 / 4$ & $2 / 4$ & $6 / 8$ \\
\hline $0 / 1$ & $0 / 4$ & & $1 / 4$ & $4 / 4$ & $6 / 8$ \\
\hline $0 / 1$ & $1 / 4$ & & $1 / 4$ & $3 / 4$ & $9 / 9$ \\
\hline $0 / 1$ & $0 / 4$ & & $1 / 4$ & $4 / 4$ & 9/9 \\
\hline $0 / 1$ & $1 / 4$ & & $2 / 4$ & $2 / 4$ & $2 / 8$ \\
\hline $0 / 1$ & $1 / 4$ & & $0 / 4$ & $3 / 4$ & $5 / 8$ \\
\hline $0 / 1$ & $1 / 4$ & & $3 / 4$ & $3 / 4$ & $5 / 8$ \\
\hline $0 / 1$ & $2 / 4$ & & $1 / 4$ & $1 / 1$ & $4 / 8$ \\
\hline $0 / 1$ & $1 / 4$ & & $1 / 4$ & $1 / 3$ & $5 / 8$ \\
\hline
\end{tabular}


WELL CS 137 RA 228 SR 90 TH 228 TH 230 TRITIM TOTAL RA U 234 AM 241 PU 238

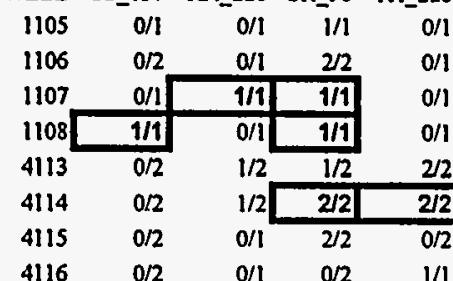

$4116 \quad 0 / 2$

4173

$\begin{array}{ll}4174 & \\ 4179\end{array}$

4176

\begin{tabular}{ll|l}
4177 & $1 / 1$ \\
\hline
\end{tabular}

\begin{tabular}{|l|l|}
4178 & $1 / 1$ \\
\hline 4179 & $1 / 1$
\end{tabular}

4179

$4180 \quad 1 / 1$

$4 1 8 8 \longdiv { 1 / 1 }$

$4 1 8 9 \longdiv { 1 / 1 }$

$4190 \square 111$

$4191 \quad 1 / 1$

4193

4195 III

$4198 \quad .1 / 1$

\begin{tabular}{l|l|}
4199 & $1 / 1$ \\
\hline 4201 & $1 / 1$ \\
\hline
\end{tabular}

$4202 \quad 1 / 1$

$4203 \quad 1 / 1$

\begin{tabular}{l|l|}
4204 & $1 / 1$ \\
\hline 4205 & $1 / 1 / 1$
\end{tabular}

$4206 \quad 1 / 1$

4207 1/1

\begin{tabular}{|l|l|}
4208 & $1 / 1$ \\
\hline 4209 & $1 / 1$
\end{tabular}

$4211 \quad 1 / 1$

$4212-1 / 1$

$4213 \quad 1 / 1$

$4214 \quad 1 / 1$

$\begin{array}{ll}4216 & 1 / 1 \\ 4218 & 1 / 1\end{array}$

$4218 \square$
4219

4221

$4225 \quad$ I/I

\begin{tabular}{|l|}
\hline $1 / 1$ \\
\hline $1 / 1$ \\
\hline
\end{tabular}

\begin{tabular}{|r|}
\hline $1 / 1$ \\
\hline $1 / 1$ \\
\hline $1 / 1$
\end{tabular}

\begin{tabular}{|l|}
\hline $1 / 1$ \\
\hline $2 / 2$ \\
\hline $1 / 1$
\end{tabular}

\begin{tabular}{l}
$1 / 1$ \\
\hline $1 / 1$ \\
\hline $1 / 1$ \\
\hline
\end{tabular}

\begin{tabular}{|l|}
\hline $1 / 1$ \\
\hline $1 / 1$ \\
\hline
\end{tabular}

$1 / 1$

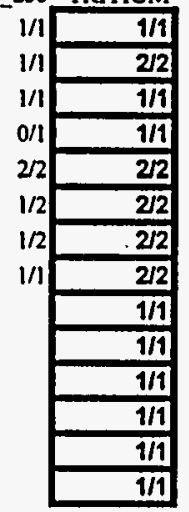

$0 / 1$

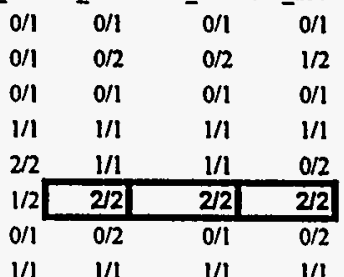

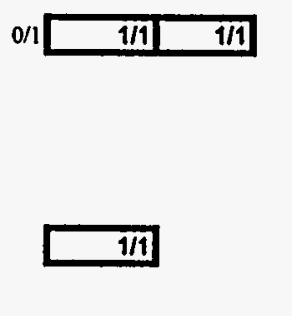
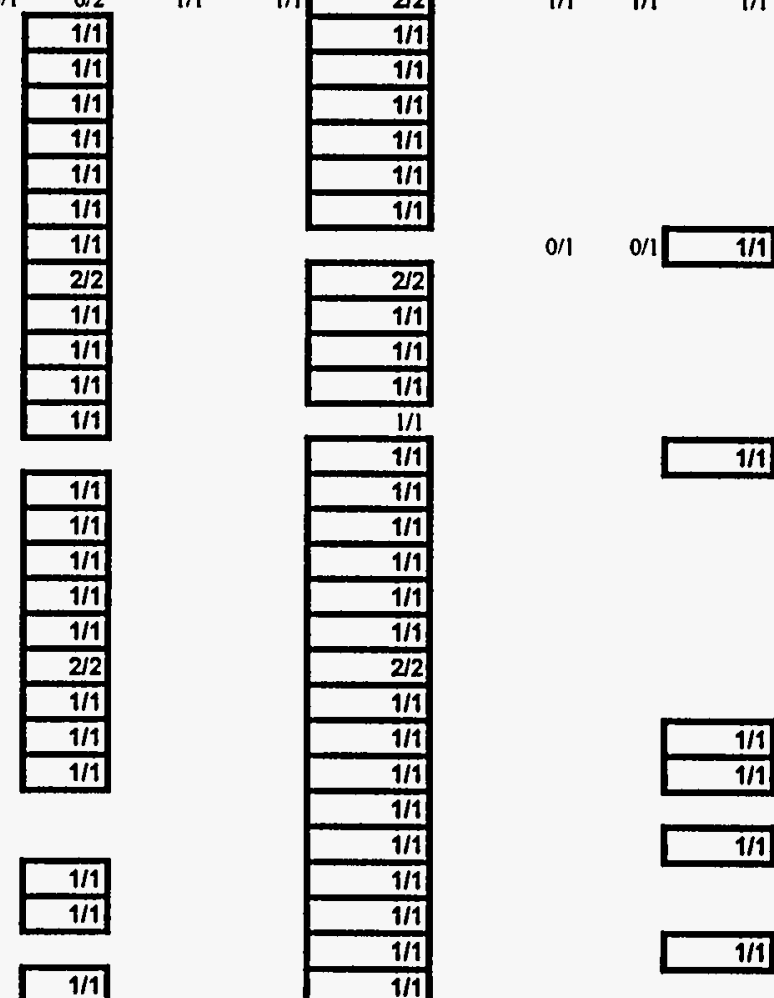

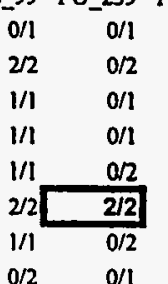

$0 / 2 \quad 0 / 1$

$1 / 1$

$1 / 11$

111
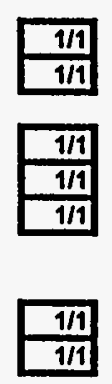

\begin{tabular}{l}
$1 / 1$ \\
\hline $1 / 1$ \\
\hline $1 / 1$ \\
\hline $1 / 1$
\end{tabular}

\begin{tabular}{|l|}
\hline $1 / 1$ \\
\hline $1 / 1$ \\
\hline $1 / 1$ \\
\hline
\end{tabular}

14 CO 60 SR 89

$0 / 1 \quad 0 / 1$

$0 / 2 \quad 2 / 2$

$0 / 1 \quad 1 / 1 \quad 1 / 1$

$\begin{array}{llllll}1 / 1 & 1 / 1 & 1 / 1\end{array}$

in $1 / 2$

o/1 $2 / 2$

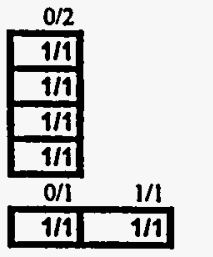

$0 / 2$

0/1

$1 / 1 \quad 1 / 1$

$\begin{array}{ll}0 / 1 & 1 / 1\end{array}$

ol1

111

0/1 $1 / 1$

$1 / 11$

o/1 $\quad 1 / 1$

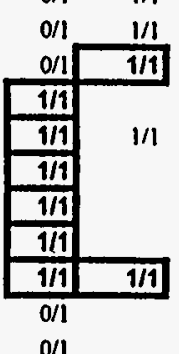

\begin{tabular}{|l|}
\hline $1 / 1$ \\
\hline $1 / 1$ \\
\hline
\end{tabular}

$\frac{1 / 17}{1 / 1}$
$\frac{1 / 17}{1 / 1}$
$\frac{1 / 1}{1}$ 
WELL CS 137 RA_228 SR 90 TH_228 TH_230 TRITIUM TOTAL_RA U_234 AM 241 PU_238 PM_147 TC 99 PU 239 PB_210 K 40 CM 244 C 14 CO 60 SR 89

WELL

4226
4227

\begin{tabular}{ll|}
4228 & $1 / 1$ \\
\hline $1 / 1$ \\
\hline $1 / 1$
\end{tabular}

$4230 \quad 1 / 1$

$4233-\frac{1 / 1}{1 / 1}$

$4235 \quad 1 / 1$

$4 2 3 9 \longdiv { 2 / 2 }$

$4240 \quad 1 / 1$

$4241 \quad 1 / 1$

$4242 \quad 1 / 1$

$4243 \quad 1 / 1$

$4244 \quad 1 / 1$

$4245 \quad 1 / 1$

$1 / 1$

$4247 \quad \frac{1 / 1}{\square}$

$4249 \quad 1 / 1$

$4250 \quad 1 / 1$

$4251 \quad \mathrm{l} / \mathrm{l}$

$4252 \quad 1 / 1$

$4 2 5 5 \longdiv { 4 2 5 4 }$

4256

4258

$4259 \quad 1 / !$

4260

\begin{tabular}{ll|}
4262 & \\
4264 & $1 / 1$ \\
\hline
\end{tabular}

$4266 \quad$ l/l

$\begin{array}{ll}4266 & 1 / 1\end{array}$

$4268 \quad 1 / 1$

$4269 \quad 1 / 1$

$4270 \quad 1 / 1$

4271

4273

4274
4275

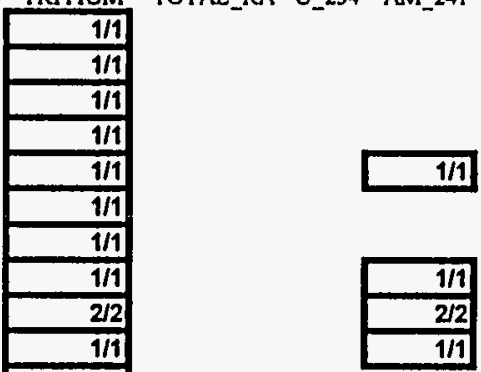

$1 / 1$

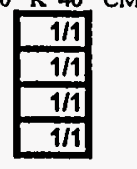

C 141

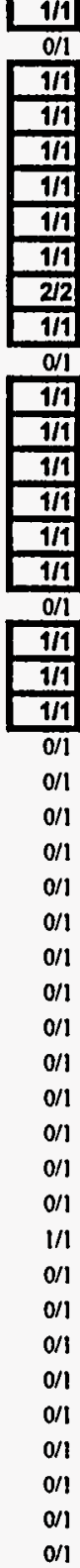


WAG WELL CS_137 RA_228 SR_90 TH_228 TH_230 TRITIUM TOTAL_RA U_234 AM_241 PU_238 PM_147 TC_99 PU_239 PB_210_K 40 CM_244 C_14 CO_60 SR_89
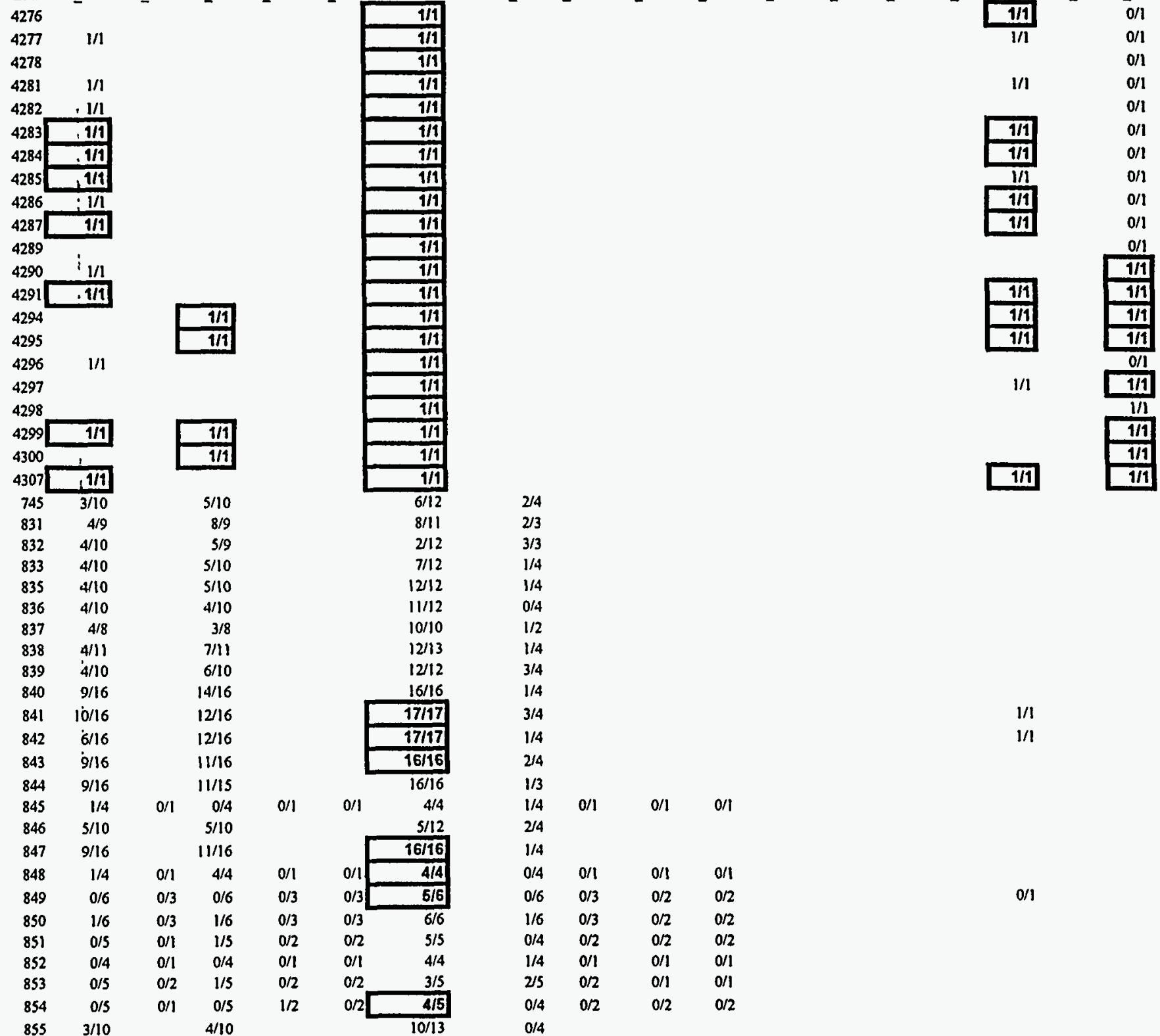
WELL CS 137 RA_228 SR 90 TH_228 TH_230 TRITIUM TOTAL_RA U_234 AM_241 PU_238 PM_147 TC_99 PU 239 PB 210 K 40 CM_244 C 14 CO_60 SR_89

\begin{tabular}{|c|c|c|c|c|c|c|}
\hline 856 & $4 / 10$ & & $6 / 10$ & & & $6 / 13$ \\
\hline 857 & $5 / 10$ & & $6 / 10$ & & & $8 / 12$ \\
\hline 858 & $2 / 10$ & & $7 / 10$ & & & $s / 12$ \\
\hline 859 & $3 / 8$ & & $5 / 8$ & & & $9 / 10$ \\
\hline 860 & $7 / 11$ & & $6 / 10$ & & & $7 / 13$ \\
\hline 1225 & $0 / 4$ & $1 / 1$ & $3 / 4$ & $3 / 3$ & $0 / 3$ & $3 / 4$ \\
\hline 1226 & $0 / 1$ & $0 / 1$ & $0 / 1$ & $1 / 1$ & $1 / 1$ & $0 / 1$ \\
\hline 1227 & $0 / 3$ & $0 / 3$ & $0 / 3$ & $0 / 3$ & $0 / 3$ & $2 / 3$ \\
\hline 1228 & $0 / 3$ & $1 / 2$ & $0 / 2$ & $0 / 2$ & $0 / 2$ & $1 / 2$ \\
\hline 1229 & $0 / 2$ & $0 / 2$ & $0 / 2$ & $1 / 2$ & $1 / 2$ & $2 / 2$ \\
\hline 1231 & $0 / 2$ & $0 / 2$ & $0 / 2$ & $0 / 2$ & $0 / 2$ & $2 / 2$ \\
\hline
\end{tabular}

314

$0 / 4$

$1 / 2$

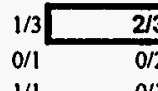

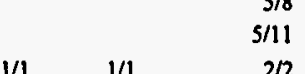

$1 / 1$

!/1

$1 / 1 \quad 1 / 1 \quad 0 / 1$

$1 / 1$

1/1 $0 / 1$

$0 / 1 \quad 1 / 1$

$1 / 1$

$1 / 1 \quad 1 / 1$

$1 / 1 \quad 0 / 1$

$0 / 2 \quad 2$

!/ $0 / 1$

$\begin{array}{r}5 / 5 \\ 4 / 5 \\ 5 / 5 \\ 3 / 5 \\ 3 / 5 \\ \hline 5 / 5 \\ \hline 4 / 5 \\ 5 / 5 \\ \hline\end{array}$

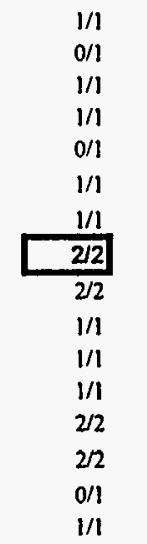


WAG WELL CS_137 RA_228 SR_90 TH_228 TH_230 TRITUM TOTAL_RA U_234 AM_241 PU_238 PM_147 TC_99 PU_239 PB_210 K_40 CM_244 C_14 CO_60 SR_89

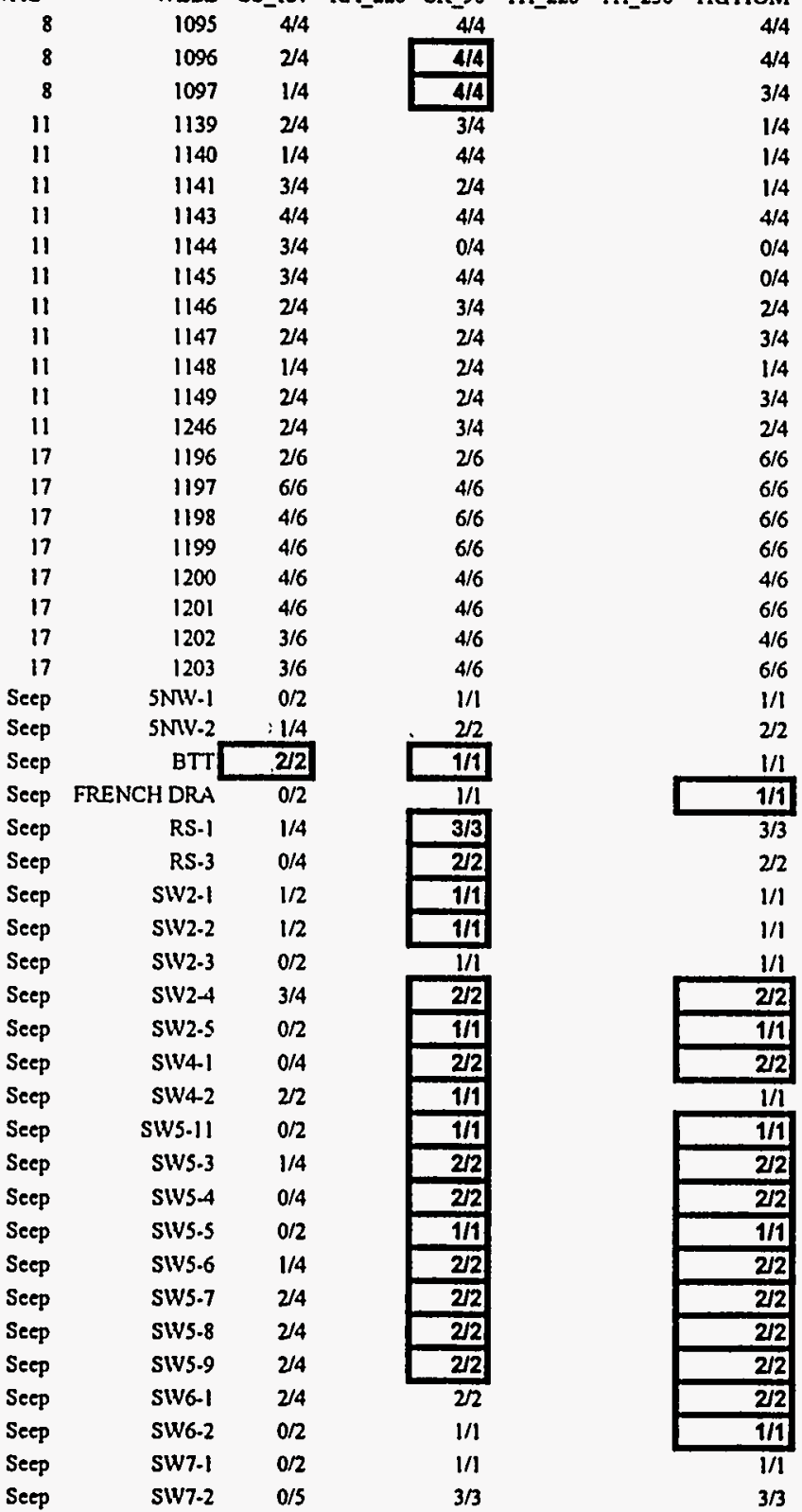


WAG WELL CS_137 RA_228 SR_90 TH_228 TH_230 TRITIUM TOTAL_RA U_234 AM_241 PU_238 PM_147 TC_99 PU_239 PB_210 K_40 CM_244 C_14 CO 60 SR_89

$\begin{array}{llrrr}\text { Seep } & \text { SW7.3 } & 0 / 4 & -2 / 2 & 2 / 2 \\ \text { Seep } & \text { SW7.5 } & 0 / 2 & 1 / 1 & 1 / 1\end{array}$

SW7.5

Seep

Seep

SW7.6 $1 / 2$

W4TRIB-11

$1 / 1$

W4TRIB.5

\begin{tabular}{|c|}
\hline $1 / 1$ \\
\hline $2 / 2$ \\
\hline $1 / 1$ \\
\hline $1 / 1$ \\
\hline
\end{tabular}

Seep W4TRIB-7

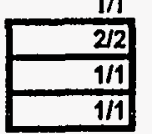



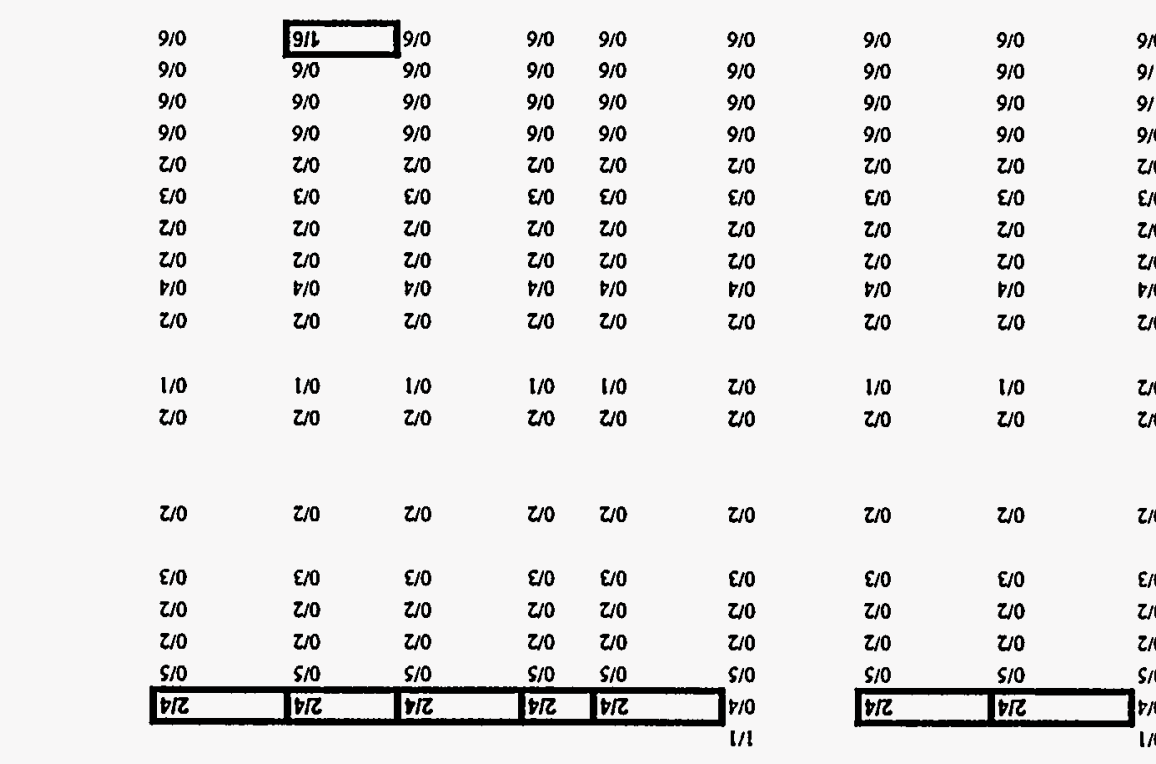

\begin{tabular}{|c|c|c|c|c|c|c|}
\hline $9 / 0$ & $9 / 1$ & 20 & $9 / 0$ & $9 / 0$ & 910 & $9 / 0$ \\
\hline $9 / 0$ & 910 & 210 & $9 / 0$ & $9 / 0$ & 910 & 910 \\
\hline 910 & 910 & 20 & $9 / 0$ & $9 / 0$ & $9 / 0$ & $9 / 0$ \\
\hline $9 / 0$ & $9 / 0$ & 20 & $9 / 0$ & $9 / 0$ & $9 / 0$ & $9 / 0$ \\
\hline $2 / 0$ & $2 / 0$ & 210 & $2 / 0$ & $2 / 0$ & 210 & 200 \\
\hline E/0 & $\varepsilon / 0$ & ย/ & $\varepsilon / 0$ & $\varepsilon / 0$ & $\varepsilon / 0$ & $\varepsilon / 0$ \\
\hline 210 & $2 / 1$ & 20 & $2 / 0$ & $2 / 0$ & $2 / 0$ & 210 \\
\hline $2 / 0$ & $2 / 0$ & 210 & $2 / 0$ & $2 / 0$ & $2 / 0$ & 210 \\
\hline$\nabla / 0$ & $p / 1$ & 670 & 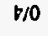 & $\forall / 0$ & p/0 & $t / 0$ \\
\hline $2 / 0$ & 210 & $z_{10}$ & $2 / 0$ & $2 / 0$ & 200 & 210 \\
\hline $1 / 0$ & $1 / 0$ & $1 / 0$ & $t / 0$ & $1 / 0$ & $1 / 0$ & $2 / 0$ \\
\hline
\end{tabular}
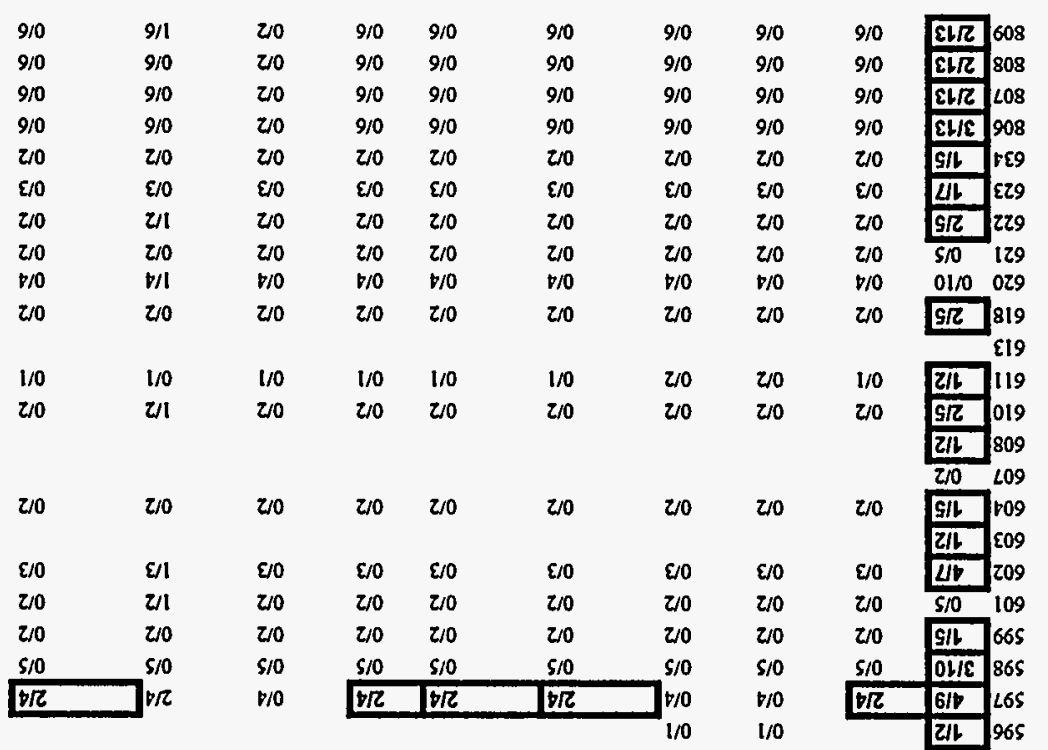

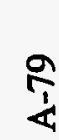

\begin{tabular}{|c|c|c|c|c|c|c|c|}
\hline$z / 0$ & 210 & 210 & $2 / 0$ & $2 / 0$ & $\begin{array}{l}z / 0 \\
u t\end{array}$ & z/o & $z / 0$ \\
\hline $1 / 0$ & t/o & $1 / 0$ & $t / 0$ & $1 / 0$ & $\begin{array}{l}z / 0 \\
\text { vo }\end{array}$ & $1 / 0$ & $1 / 0$ \\
\hline E/0 & $\varepsilon / 0$ & ย/O & $\varepsilon / 0$ & $\varepsilon / 0$ & $\varepsilon / 0$ & $\varepsilon / 0$ & $\mathfrak{E} / 0$ \\
\hline $1 / 0$ & $1 / 0$ & $1 / 0$ & t/o & $1 / 0$ & z/0 & L/0 & $1 / 0$ \\
\hline $8 / 0$ & $B / 0$ & $\nabla / 0$ & t/o & $\forall / 0$ & b/0 & $\forall / 0$ & $\$ / 0$ \\
\hline$\nabla / 0$ & $t / 0$ & $\nabla / 0$ & $t / 0$ & $\forall / 0$ & B/0 & D10 & $\nabla 10$ \\
\hline 2/0 & 210 & 210 & 210 & 210 & zo & 20 & $2 / 0$ \\
\hline $1 / 0$ & $1 / 0$ & $1 / 0$ & t/o & $1 / 0$ & $\begin{array}{l}1 / 0 \\
1 / 0\end{array}$ & $1 / 0$ & t/o \\
\hline 810 & $t / 0$ & $\nabla 10$ & $\$ / 0$ & $\nabla / 0$ & $B / 0$ & $\$ 10$ & $\nabla / 0$ \\
\hline S/O & $S / O$ & $s / 0$ & $S / 0$ & $s / 0$ & sio & SiO & S/0 \\
\hline $1 / 0$ & .10 & $1 / 0$ & $1 / 0$ & 1/0 & $1 / 0$ & $1 / 0$ & $t / 0$ \\
\hline \&/O & \&o & $\varepsilon / 0$ & $\varepsilon_{0}$ & ઘ/0 & घ/O & ع/ & $\varepsilon / 0$ \\
\hline $1 / 0$ & t/0 & $1 / 0$ & $1 / 0$ & $1 / 0$ & t/o & $1 / 0$ & t/0 \\
\hline $1 / 0$ & $1 / 0$ & $1 / 0$ & $\mathrm{t} / 0$ & $1 / 0$ & t/o & $1 / 0$ & t/o \\
\hline GIl & | s/o & $5 / 0$ & $S / 0$ & $S / 0$ & $S R$ & S:O & $5 / 0$ \\
\hline 270 & 200 & zio & $2 / 0$ & $z 10$ & zo & z/O & $2 / 0$ \\
\hline $2 \mathrm{IL}$ & 1210 & $z_{10}$ & $z_{10}$ & 210 & 20 & zjo & 210 \\
\hline 210 & 210 & 210 & 20 & zo & zo & 210 & z/0 \\
\hline $2 / 0$ & $2 / 0$ & 210 & 210 & 210 & 210 & 210 & 210 \\
\hline $2 / 0$ & 210 & 210 & 200 & z/o & 20 & 20 & $z / 0$ \\
\hline Ell & | & ENO & $\varepsilon / 0$ & ש/0 & $\nabla / 0$ & Ejo & \&/O \\
\hline $2 \pi 0$ & 20 & zo & 210 & $2 / 0$ & zio & 210 & 210 \\
\hline
\end{tabular}

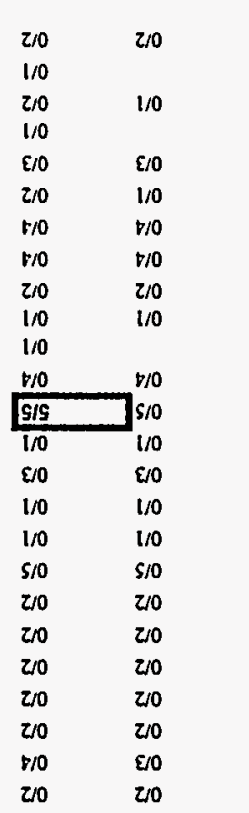

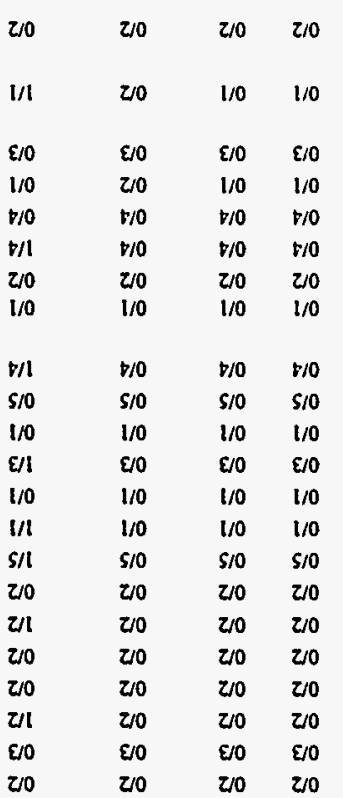
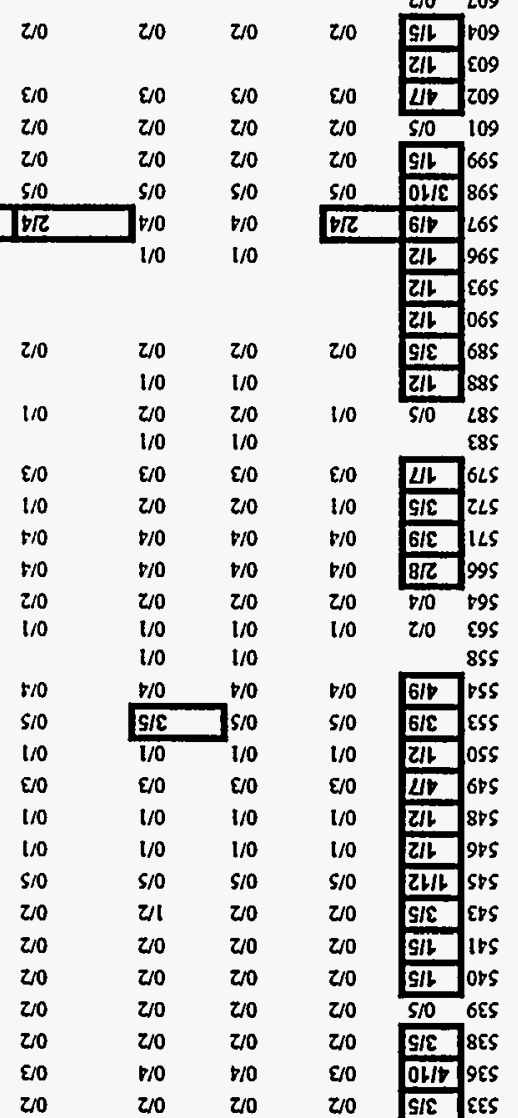

라. 965

$210 \quad$\begin{tabular}{lll}
\hline LIL & 065 \\
\hline ZIL & 685 \\
\hline 885
\end{tabular}

1/0 S/0 L8S

E/0 ULL 615

D/0 GIE ILS

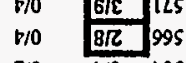

$\begin{array}{lll}210 & 510 & 795 \\ 1 / 0 & 210 & 295\end{array}$

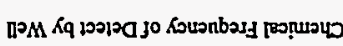


VINYL_CH TRI123 D12CHL3 DBEI2 DIOXAN14 PROPENE2 _333_DI WAG

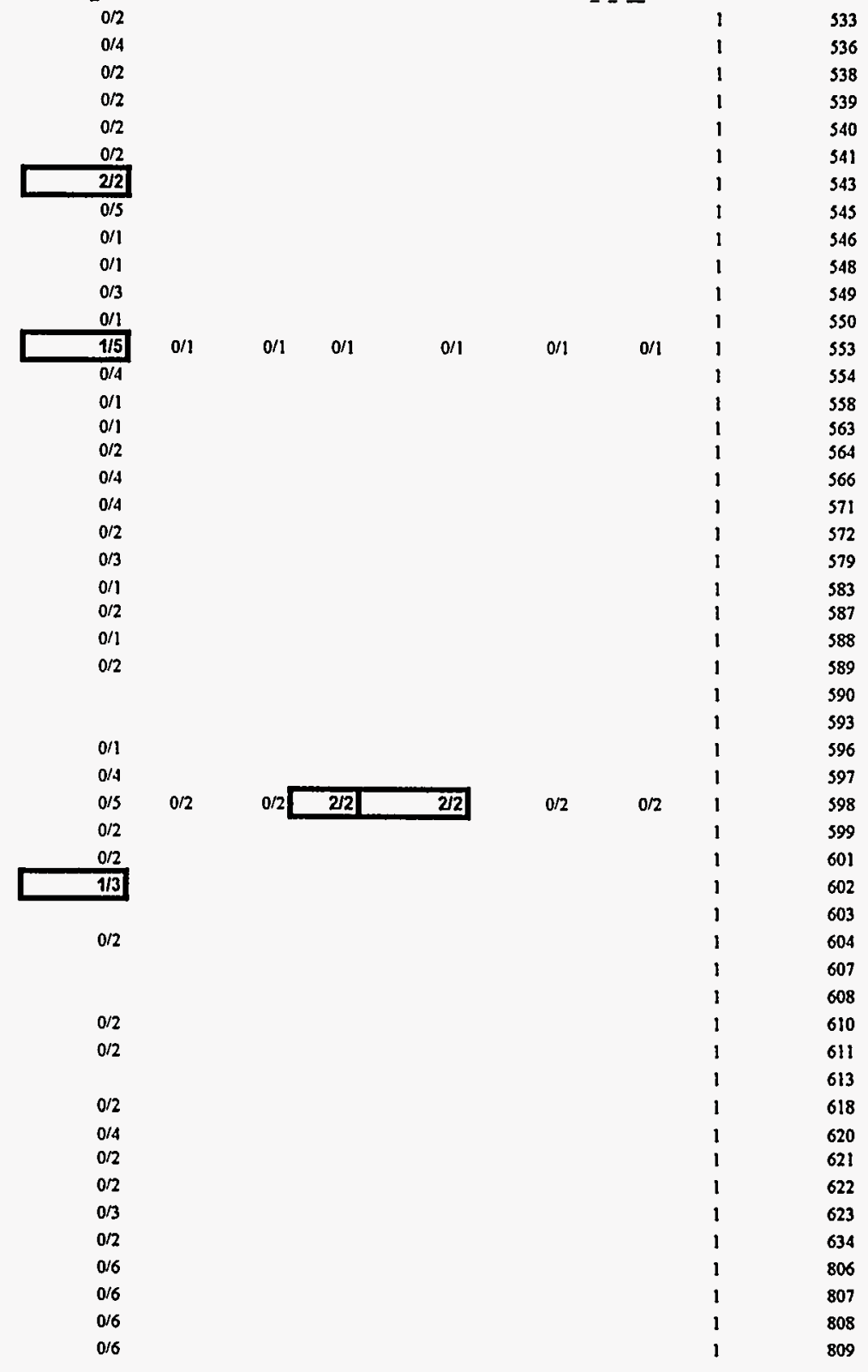




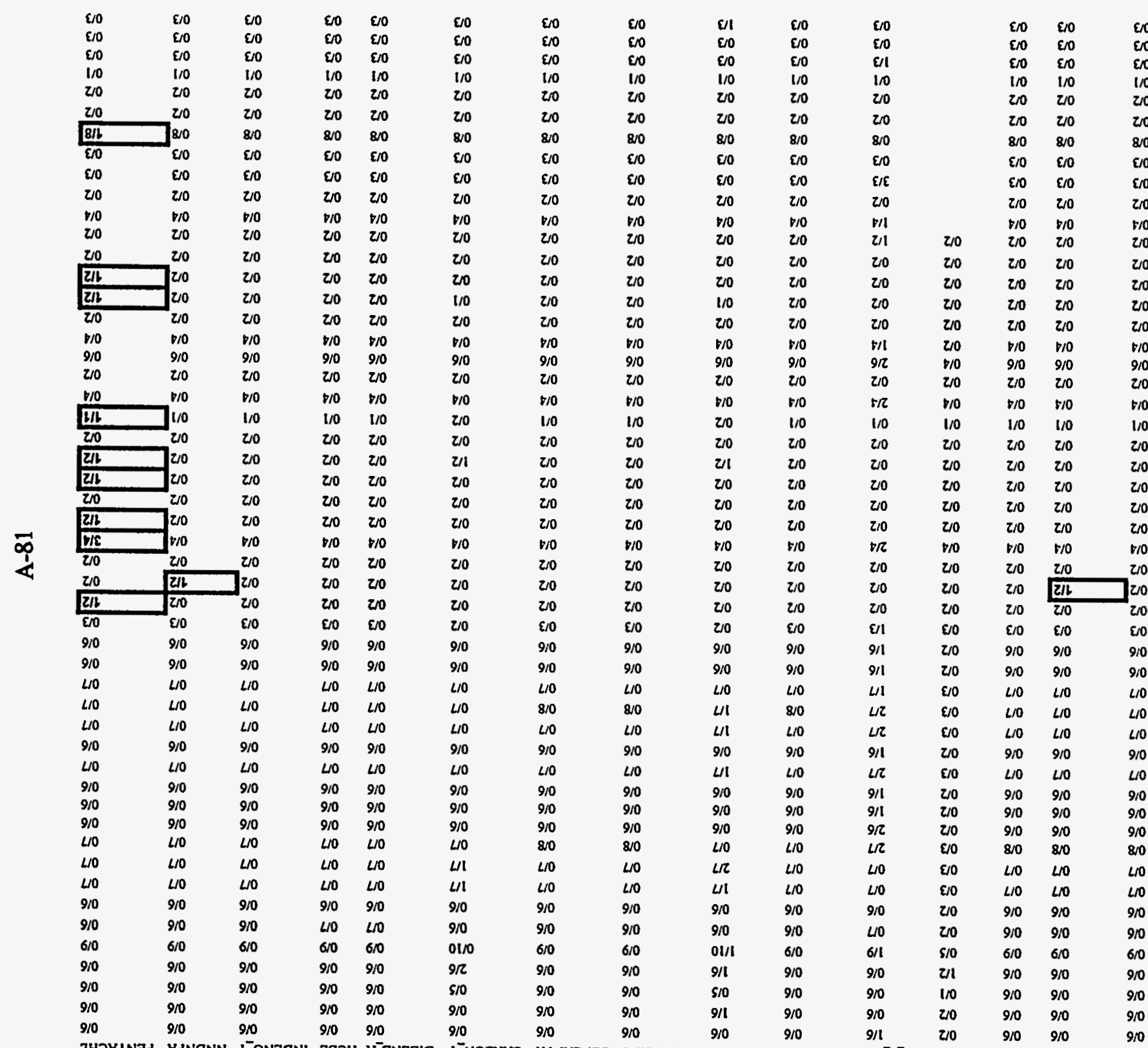

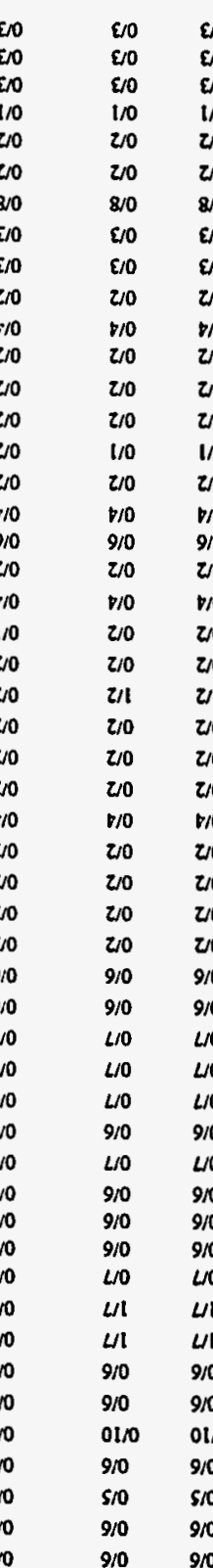

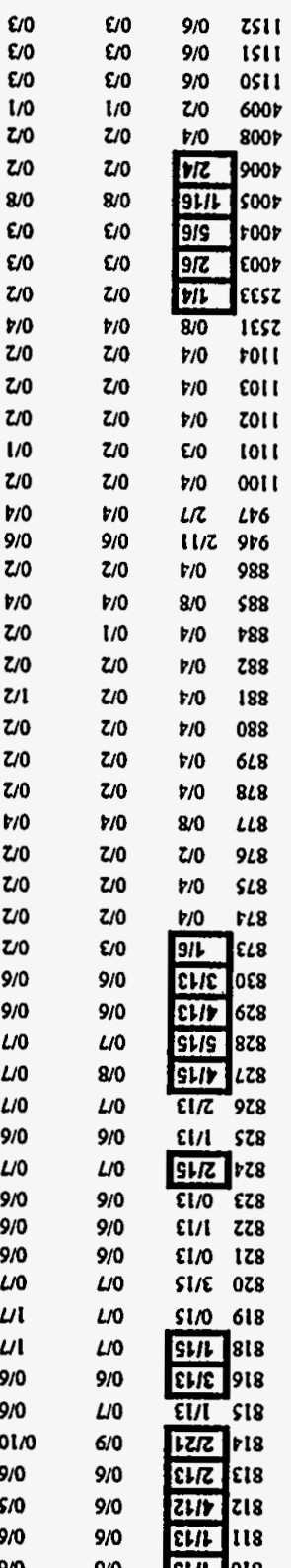


Chemical Frequency of Detect by Well

VINYL_CH TRI123 DI2CHL3 DBE12 DIOXAN14 PROPENE2 _3_3_DI WAG

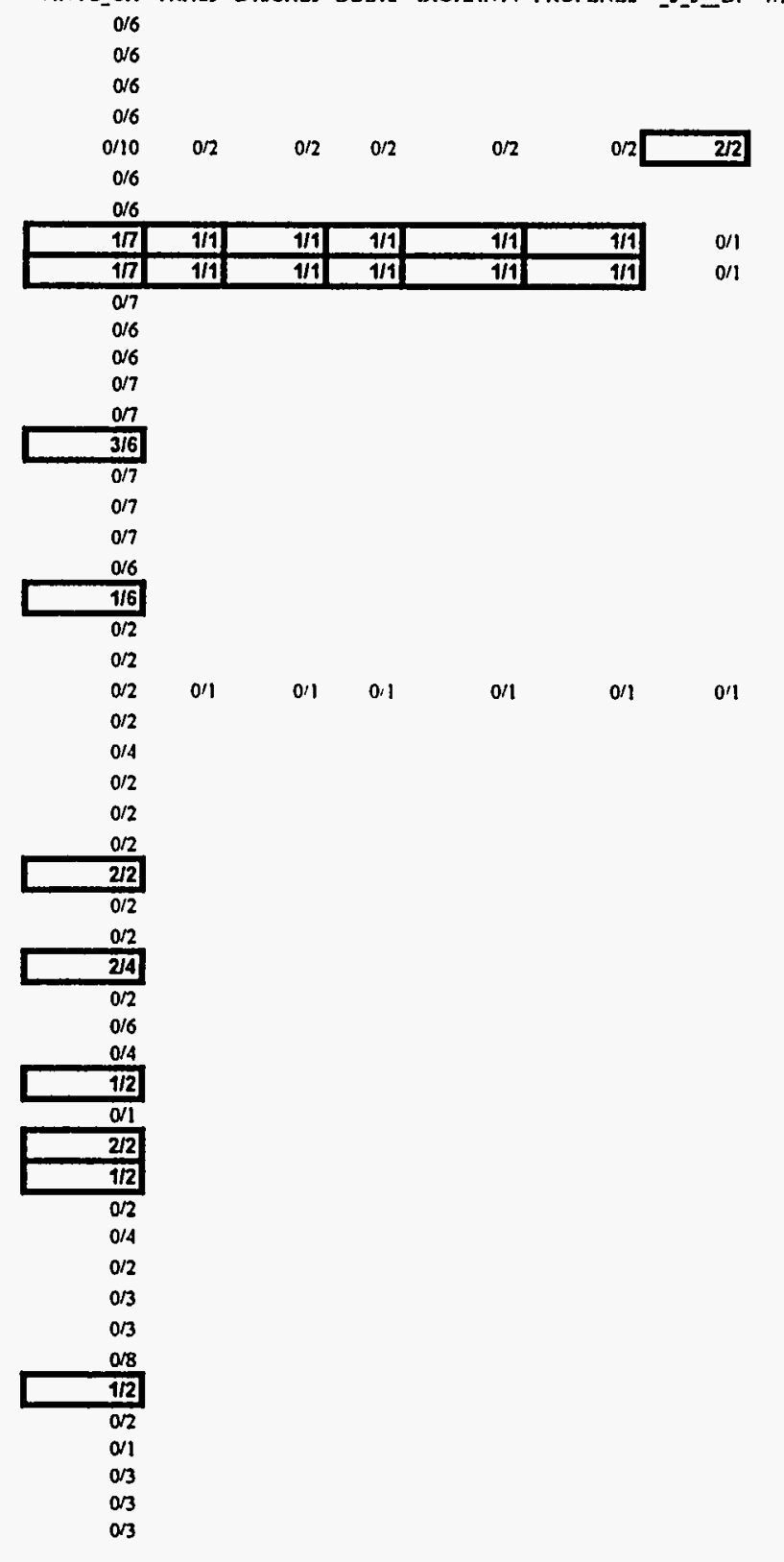


$n$

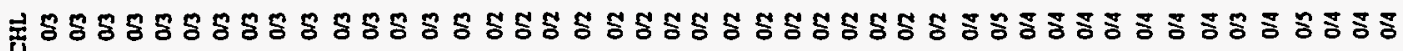
竞

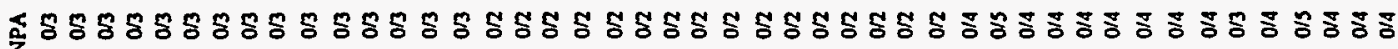
z

0.828 䓛

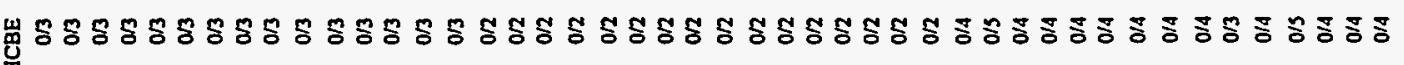

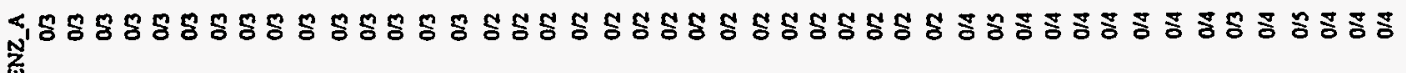
兽 完

$$
\text { 章 }
$$

$$
\text { 点 }
$$

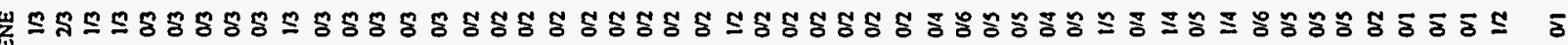
兽

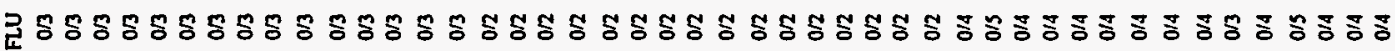

惫

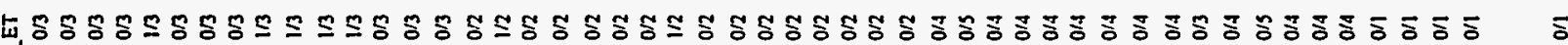
$\frac{\mathrm{c}}{\mathrm{m}}$

商

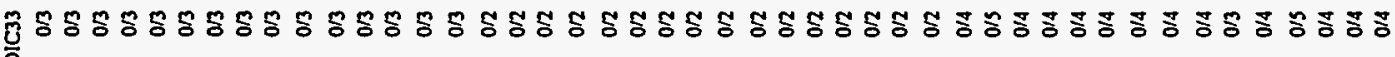

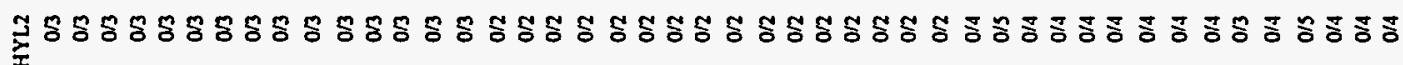
率

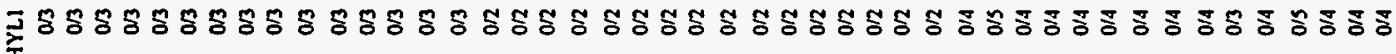

产

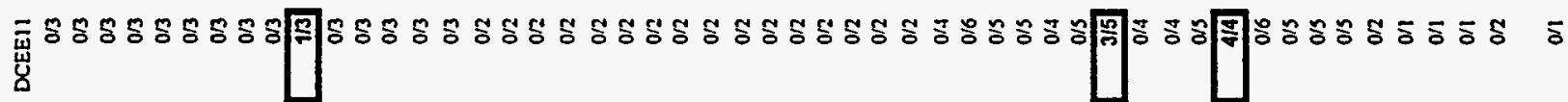

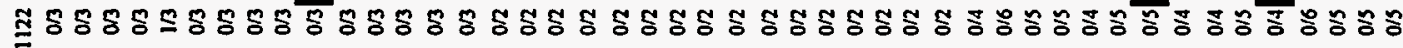
兽

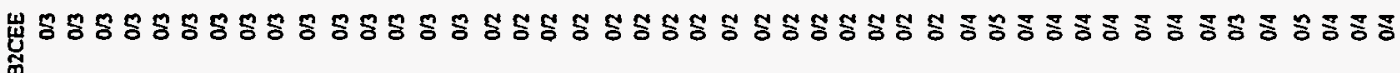

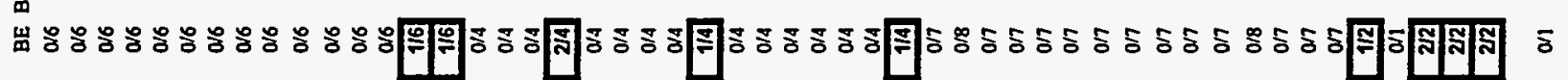

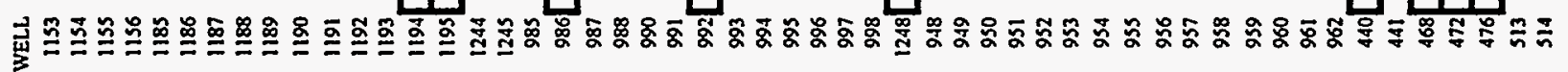


Chemical Frequency of Detect by Well

VINYL_CH TRI123 DI2CHL3 DBE12 DIOXAN14 PROPENE2 _3_3_DI WAG $0 / 3$

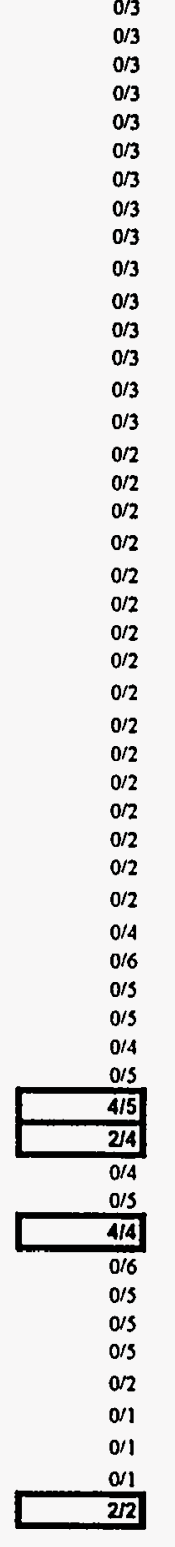

WELL

IIS3

IISs

1156
1185

1185

1186

1188

1189

1191
1192

1193

1194

1195

1244
1245

985

986

987

988

990

992

993

994

993

996

997

998

1248

948

950

951

953

954

955

956

957
958

959

960

961

962

441

468

472

476
513

514 


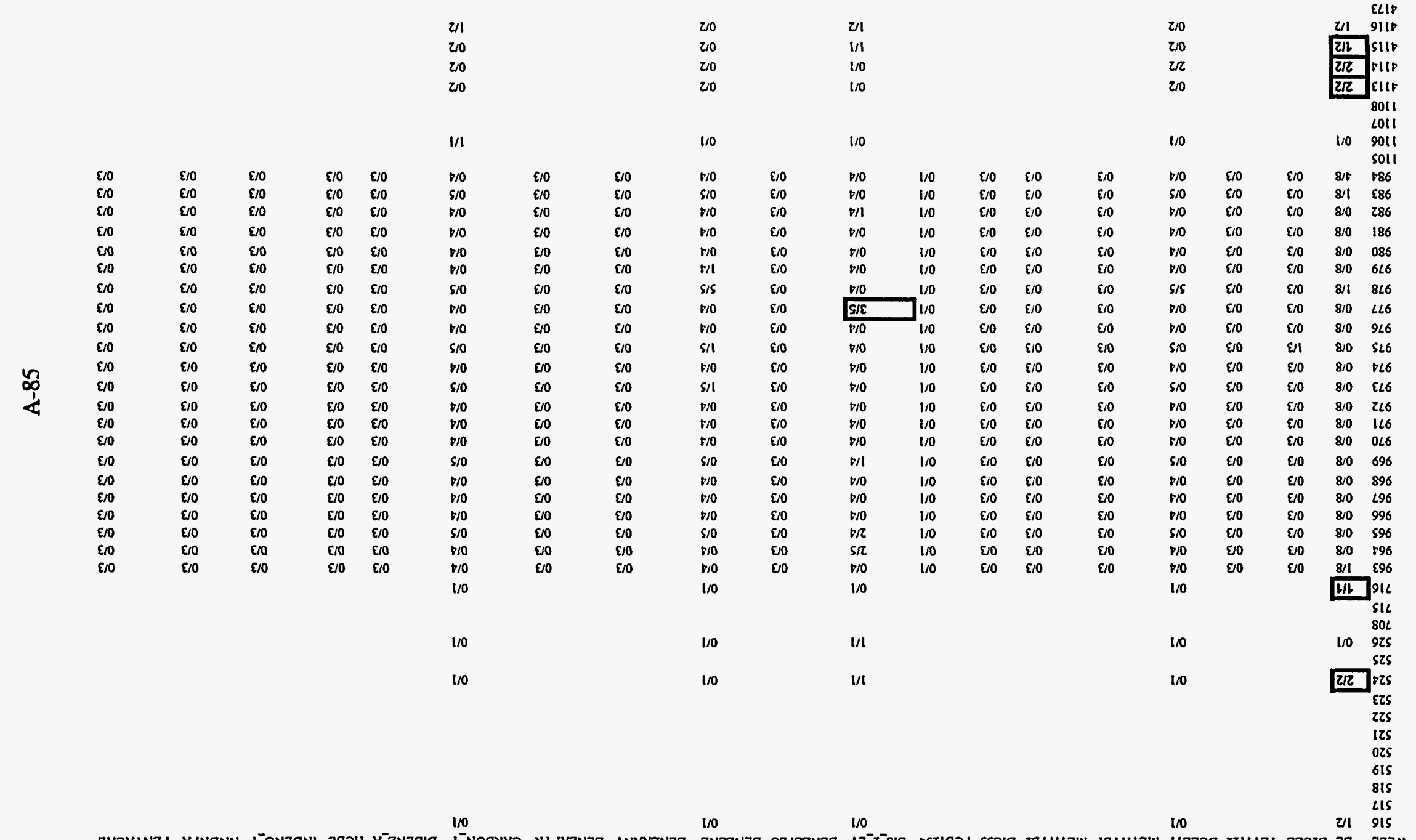

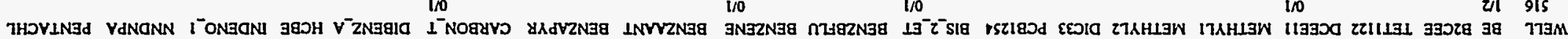

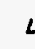


VINYL_CH TRI123 DI2CHL3 DBE12 DIOXAN14 PROPENE2 333_DI WAG

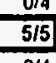

$0 / 4$
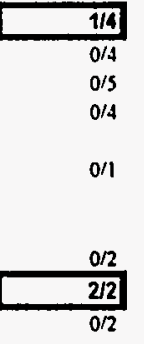
WAG WELL BE B2CEE TETI122 DCEEII METHYLI METHYL2 DIC33 PCB1254 BIS_2_ET BENZBFLU BeNZENE BENZAANT BENZAPYR CARBON_T DIBENZ_A HCBE INDENO_1 NNDNPA PENTACHL 
WAG WELL BE B2CEE TETII22 DCEE11 METHYLI METHYL2 DIC33 PCBI254 BIS_2_ET BENZBFLU BENZENE BENZAANT BENZAPYR CARBON_T DIBENZ_A HCBE INDENO_1 NNDNPA PENTACHL 4259 4260 4261 4262 4263
4264 4265 4266 4267

4268
4269

4269
4270

4271

4272

4273

4274

4275

4276

4277
4278

4281

4282

4283
4284

4285

4286

4287
4289

4289
4290

4291
4294

4295

4296
4297

4297
4298
4299

4299
4300
4307

\begin{tabular}{|c|c|c|c|c|}
\hline 07 & & & & \\
\hline 745 & 216 & $0 / 3$ & $0 / 11$ & $0 / 1$ \\
\hline 831 & $3 / 5$ & $0 / 2$ & $0 / 10$ & $0 / 1$ \\
\hline & 416 & $0 / 4$ & $0 / 11$ & $0 / 1$ \\
\hline 33 & 216 & $0 / 3$ & $0 / 11$ & $1 / 1$ \\
\hline & 24 & $0 / 3$ & $0 / 10$ & 1 \\
\hline 16 & 24 & $0 / 3$ & $0 / 111$ & 3 \\
\hline 77 & $1 / 2$ & $0 / 1$ & $0 / 9$ & $0 /$ \\
\hline 8 & 216 & $0 / 3$ & $0 / 12$ & $0 / 1$ \\
\hline 9 & 26 & $0 / 3$ & $0 / 11$ & 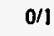 \\
\hline 40 & $3 / 6$ & $0 / 3$ & $0 / 17$ & $0 / 1$ \\
\hline 841 & $3 \pi$ & $0 / 3$ & $0 / 19$ & \\
\hline 842 & 47 & $0 / 3$ & $0 / 18$ & $2 / 1$ \\
\hline & $3 / 6$ & $0 / 3$ & $0 / 17$ & $0 / 1$ \\
\hline & 214 & $0 / 4$ & $0 / 17$ & $\mu$ \\
\hline & 215 & $0 / 4$ & $0 / 5$ & \\
\hline & 4.14 & $0 / 3$ & $0 / 11$ & \\
\hline
\end{tabular}

$\begin{array}{cc}0 / 3 & 0 / 11 \\ 0 / 2 & 0 / 10 \\ 0 / 4 & 0 / 11 \\ 0 / 3 & 0 / 11 \\ 0 / 3 & 4 / 10 \\ 0 / 3 & 0 / 11 \\ 0 / 1 & 0 / 9 \\ 0 / 3 & 0 / 12 \\ 0 / 3 & 0 / 11 \\ 0 / 3 & 0 / 17 \\ 0 / 3 & 0 / 19 \\ 0 / 3 & 0 / 18 \\ 0 / 3 & 1 / 17 \\ 0 / 4 & 2 / 17 \\ 0 / 4 & 0 / 5 \\ 0 / 3 & 0 / 11\end{array}$

$\begin{array}{rr}0 / 11 & 0 / 3 \\ 0 / 10 & 0 / 2 \\ 0 / 11 & 0 / 4 \\ 0 / 11 & 0 / 3 \\ 4 / 10 & 0 / 3 \\ 0 / 11 & 0 / 3 \\ 0 / 9 & 0 / 1 \\ 0 / 12 & 0 / 3 \\ 0 / 11 & 0 / 3 \\ 0 / 17 & 0 / 3 \\ 0 / 19 & 0 / 3 \\ 0 / 18 & 0 / 3 \\ 1 / 17 & 0 / 3 \\ 2 / 17 & 0 / 4 \\ 0 / 5 & 0 / 4 \\ 0 / 11 & 0 / 3\end{array}$

$\begin{array}{ll}0 / 3 & 0 / 11 \\ 0 / 2 & 0 / 10 \\ 0 / 4 & 0 / 11 \\ 0 / 3 & 0 / 11 \\ 0 / 3 & 0 / 10 \\ 0 / 3 & 0 / 11 \\ 0 / 1 & 0 / 9 \\ 0 / 3 & 0 / 12 \\ 0 / 3 & 0 / 11 \\ 0 / 3 & 0 / 17 \\ 0 / 3 & 0 / 19 \\ 0 / 3 & 17 / 18 \\ 0 / 3 & 1 / 17 \\ 0 / 4 & 0 / 17 \\ 0 / 4 & 0 / 3 \\ 0 / 3 & 0 / 11\end{array}$

$\begin{array}{ll}0 / 3 & 0 / 3 \\ 0 / 2 & 0 / 2 \\ 0 / 4 & 0 / 4 \\ 0 / 3 & 0 / 3 \\ 0 / 3 & 0 / 3 \\ 0 / 3 & 0 / 3 \\ 0 / 1 & 0 / 1 \\ 0 / 3 & 0 / 3 \\ 0 / 3 & 0 / 3 \\ 0 / 3 & 0 / 3 \\ 0 / 3 & 0 / 3 \\ 0 / 3 & 0 / 3 \\ 0 / 3 & 0 / 3 \\ 0 / 4 & 0 / 4 \\ 0 / 4 & 0 / 4 \\ 0 / 3 & 0 / 3\end{array}$

$\begin{array}{ll}0 / 3 & 0 / 3 \\ 0 / 2 & 0 / 2 \\ 0 / 4 & 0 / 4 \\ 0 / 3 & 0 / 3 \\ 0 / 3 & 0 / 3 \\ 0 / 3 & 0 / 3 \\ 0 / 1 & 0 / 1 \\ 0 / 3 & 0 / 3 \\ 0 / 3 & 0 / 3 \\ 0 / 3 & 0 / 3 \\ 0 / 3 & 0 / 3 \\ 0 / 3 & 0 / 3 \\ 0 / 3 & 0 / 3 \\ 0 / 4 & 0 / 4 \\ 0 / 4 & 0 / 4 \\ 0 / 3 & 0 / 3\end{array}$


WELL BE B2CEE TETII22 DCEEII METHYLI METHYL2 DIC33 PCB1254 BIS_2_ET BENZBFLU BENZENE BENZAANT BENZAPYR CARBON_T DIBENZ_A HCBE INDENO_1 NNDNPA PENTACHL

\begin{tabular}{|c|c|c|c|c|}
\hline 847 & 24 & $0 / 3$ & $0 / 17$ & $0 / 17$ \\
\hline 848 & $3 / 5$ & $0 / 4$ & $0 / 4$ & $0 / 4$ \\
\hline 849 & का & $0 / 6$ & $0 / 6$ & $1 / 6$ \\
\hline 850 & 319 & $0 / 6$ & 077 & $0 / 7$ \\
\hline 851 & $5 n$ & $0 / 5$ & $0 / 7$ & $0 / 7$ \\
\hline 852 & 45 & $0 / 4$ & $0 / 5$ & $0 / 5$ \\
\hline 853 & 47 & $0 / 6$ & $0 / 5$ & o/s \\
\hline 854 & 27 & $0 / 5$ & $0 / 6$ & $1 / 6$ \\
\hline 855 & 47 & $0 / 3$ & $0 / 13$ & $0 / 13$ \\
\hline 856 & 3n & $0 / 3$ & $0 / 13$ & $0 / 13$ \\
\hline 857 & $3 / 6$ & $0 / 3$ & $0 / 11$ & $0 / 11$ \\
\hline 858 & $3 / 6$ & $0 / 3$ & $0 / 11$ & $0 / 11$ \\
\hline 859 & 1/4 & $0 / 1$ & $0 / 9$ & $0 / 9$ \\
\hline 860 & 26 & $0 / 4$ & $0 / 12$ & $0 / 12$ \\
\hline 1225 & 48 & $0 / 4$ & $0 / 8$ & $0 / 8$ \\
\hline 1226 & 113 & $0 / 1$ & $0 / 2$ & $0 / 2$ \\
\hline 1227 & 016 & $0 / 4$ & $0 / 4$ & $0 / 4$ \\
\hline 1228 & 215 & $0 / 4$ & $0 / 7$ & 0/7 \\
\hline 1229 & 114 & $0 / 3$ & $0 / 5$ & $0 / 5$ \\
\hline 1231 & $2 / 4$ & $0 / 1$ & $0 / 3$ & $0 / 3$ \\
\hline 1233 & 216 & $0 / 4$ & 17 & $3 / 7$ \\
\hline $1234^{\circ}$ & $0 / 4$ & $0 / 2$ & $0 / 1$ & $0 / 4$ \\
\hline 1236 & 113 & $0 / 1$ & $0 / 2$ & $0 / 2$ \\
\hline 1237 & 912 & $0 / 1$ & $0 / 2$ & $0 / 2$ \\
\hline 1238 & 224 & $0 / 2$ & $0 / 2$ & $0 / 2$ \\
\hline 1239 & 214 & & $0 / 2$ & $0 / 2$ \\
\hline $1240^{\circ}$ & $0 / 2$ & $0 / 1$ & $0 / 2$ & $0 / 2$ \\
\hline 1241 & $0 / 2$ & oll & $0 / 2$ & $0 / 2$ \\
\hline 1242 & $0 / 2$ & o/1 & $0 / 12$ & $0 / 12$ \\
\hline 1243 & $0 / 2$ & o/1 & $0 / 12$ & $0 / 12$ \\
\hline 1244 & $0 / 4$ & $0 / 2$ & $0 / 8$ & $0 / 8$ \\
\hline 1245 & $1 / 3$ & $0 / 1$ & $0 / 6$ & $0 / 6$ \\
\hline 1249 & 012 & $0 / 1$ & $0 / 2$ & $0 / 2$ \\
\hline 1071 & 215 & $0 / 2$ & $0 / 2$ & $0 / 2$ \\
\hline 1072 & $1 / 5$ & $0 / 2$ & $0 / 2$ & $0 / 2$ \\
\hline 1073 & $1 / 5$ & $0 / 2$ & $0 / 2$ & $0 / 2$ \\
\hline 1074 & 215 & $0 / 2$ & $0 / 2$ & $0 / 2$ \\
\hline 1075 & $1 / 5$ & $0 / 2$ & $0 / 2$ & $0 / 2$ \\
\hline 1076 & $1 / 5$ & $0 / 2$ & $0 / 2$ & $0 / 2$ \\
\hline 1077 & $1 / 5$ & $0 / 2$ & $0 / 2$ & $0 / 2$ \\
\hline 1078 & $0 / 5$ & $0 / 2$ & $0 / 2$ & $0 / 2$ \\
\hline 1079 & $1 / 5$ & $0 / 2$ & $0 / 2$ & $0 / 2$ \\
\hline $1080^{\circ}$ & $0 / 5$ & $0 / 2$ & $0 / 2$ & $0 / 2$ \\
\hline 1081 & $0 / 5$ & $0 / 2$ & $0 / 2$ & $0 / 2$ \\
\hline 1082 & $0 / 5$ & $0 / 2$ & $0 / 2$ & $a / 2$ \\
\hline 1083 & $0 / 5$ & $0 / 2$ & $0 / 2$ & $0 / 2$ \\
\hline 1084 & 1/5 & $0 / 2$ & $0 / 2$ & $0 / 2$ \\
\hline 1085 & $\overline{a / 5}$ & $0 / 2$ & $0 / 2$ & $0 / 2$ \\
\hline 1086 & $0 / 5$ & $O / 2$ & $0 / 2$ & $0 / 2$ \\
\hline 1087 & $0 / 4$ & $0 / 2$ & $0 / 2$ & $a / 2$ \\
\hline 1088 & $0 / 4$ & 017 & 02 & $0 / 2$ \\
\hline
\end{tabular}

\begin{tabular}{|c|c|c|c|}
\hline $0 / 3$ & $0 / 3$ & $0 / 3$ & $0 / 4$ \\
\hline $0 / 4$ & $0 / 4$ & $0 / 4$ & $0 / 4$ \\
\hline $0 / 6$ & $0 / 6$ & $0 / 6$ & $0 / 5$ \\
\hline $0 / 6$ & $0 / 6$ & $0 / 6$ & or \\
\hline $0 / 5$ & $0 / 5$ & $0 / 5$ & $0 / 4$ \\
\hline $0 / 4$ & $0 / 4$ & $0 / 4$ & $0 / 4$ \\
\hline $0 / 6$ & $0 / 6$ & $0 / 6$ & $0 / 4$ \\
\hline $0 / 5$ & $0 / 5$ & $0 / 5$ & $1 / 4$ \\
\hline $0 / 3$ & $0 / 3$ & $0 / 3$ & $0 / 4$ \\
\hline $0 / 3$ & $0 / 3$ & $0 / 3$ & $0 / 4$ \\
\hline $0 / 3$ & $0 / 3$ & $0 / 3$ & $0 / 4$ \\
\hline $0 / 3$ & $0 / 3$ & $0 / 3$ & $0 / 4$ \\
\hline 0/1 & $0 / 1$ & $0 / 1$ & $0 / 2$ \\
\hline $0 / 4$ & $0 / 4$ & $0 / 4$ & $0 / 4$ \\
\hline $0 / 4$ & $0 / 4$ & $0 / 4$ & $0: 1$ \\
\hline on & $0 / 1$ & $0 / 1$ & $0 / 1$ \\
\hline $0 / 4$ & $0 / 4$ & $0 / 4$ & $0 / 2$ \\
\hline $0 / 4$ & $0 / 4$ & $0 / 4$ & $0 / 3$ \\
\hline $0 / 3$ & $0 / 3$ & $0 / 3$ & $0 / 3$ \\
\hline $0 / 1$ & $0 / 1$ & $0 / 1$ & $0: 1$ \\
\hline $0 / 4$ & $0 / 4$ & $0 / 4$ & $0 / 2$ \\
\hline $0 / 2$ & $0 / 2$ & $0 / 2$ & $0 / 4$ \\
\hline $0 / 1$ & $0 / 1$ & $0 / 1$ & $0: 1$ \\
\hline $0 / 1$ & $0 / 1$ & $0 / 1$ & $0 / 1$ \\
\hline \multirow[t]{2}{*}{$0 / 2$} & $0 / 2$ & $0 / 2$ & $0 / 1$ \\
\hline & & & $0^{\prime \prime}$ \\
\hline $0 / 1$ & $0 / 1$ & $0 / 1$ & $0 / 1$ \\
\hline $0 / 1$ & $0 / 1$ & 0/1 & 011 \\
\hline $0 / 1$ & $0 / 1$ & $0 / 1$ & $0 / 1$ \\
\hline $0 / 1$ & $0 / 1$ & $0 / 1$ & $0 / 1$ \\
\hline $0 / 2$ & $0 / 2$ & $0 / 2$ & $0 / 4$ \\
\hline $0 / 1$ & $0 / 1$ & $0 / 1$ & $0 / 1$ \\
\hline $0 / 1$ & $0 / 1$ & $0 / 1$ & on \\
\hline $0 / 2$ & $0 / 2$ & $0 / 2$ & \\
\hline $0 / 2$ & $0 / 2$ & $0 / 2$ & \\
\hline $0 / 2$ & $0 / 2$ & $0 / 2$ & \\
\hline $0 / 2$ & $0 / 2$ & $0 / 2$ & \\
\hline $0 / 2$ & $0 / 2$ & $0 / 2$ & \\
\hline $0 / 2$ & $0 / 2$ & $0 / 2$ & \\
\hline $0 / 2$ & $0 / 2$ & $0 / 2$ & \\
\hline $0 / 2$ & $0 / 2$ & $0 / 2$ & \\
\hline $0 / 2$ & $0 / 2$ & $0 / 2$ & \\
\hline $0 / 2$ & $0 / 2$ & $0 / 2$ & \\
\hline $0 / 2$ & $0 / 2$ & $0 / 2$ & \\
\hline $0 / 2$ & $0 / 2$ & $0 / 2$ & \\
\hline $0 / 2$ & $0 / 2$ & $0 / 2$ & \\
\hline $0 / 2$ & $0 / 2$ & $0 / 2$ & \\
\hline $0 / 2$ & $0 / 2$ & $0 / 2$ & \\
\hline $0 / 2$ & $0 / 2$ & $0 / 2$ & \\
\hline $0 / 2$ & $0 / 2$ & $0 / 2$ & \\
\hline $0 / 2$ & $0 / 2$ & $a / 2$ & \\
\hline
\end{tabular}

$1 / 3$
$2 / 4$
$3 / 6$
$4 / 6$
$3 / 5$
$2 / 4$
$3 / 6$
$4 / 5$
$1 / 3$
$1 / 3$
$1 / 3$
$1 / 3$
$0 / 1$
$2 / 4$
$0 / 4$
$0 / 1$
$0 / 4$
$1 / 4$
$1 / 3$
$0 / 1$
$0 / 4$
$0 / 2$
$0 / 1$
$0 / 1$
$0 / 2$
$0 / 1$
011
$0 / 1$
$0 / 1$
$0 / 2$
$0 / 1$
$0 / 1$
$0 / 2$
$0 / 2$
$0 / 2$
$0 / 2$
$0 / 2$
$0 / 2$
$0 / 2$
$0 / 2$
$0 / 2$
$0 / 2$
$0 / 2$
$0 / 2$
$0 / 2$
$0 / 2$
$0 / 2$
$0 / 2$
$0 / 2$
$0 / 2$

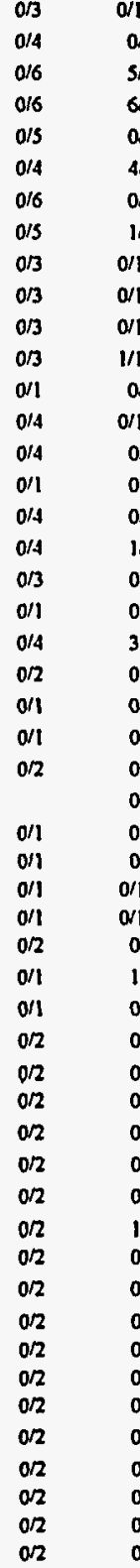

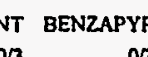

O/3 CARBON_T

$5 / 6$

$0 / 4$
$0 / 6$
$0 / 6$

O/4 016

$0 / 4$

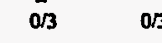

O/3

$0 / 3$

$4 / 5$

$0 / 5$

o/s

$0 / 4 \quad 0 / 4$

$\begin{array}{ll}0 / 6 & 0 / 6 \\ 0 / 5 & 0 / 5\end{array}$

$\begin{array}{ll}0 / 5 & 0 / 5 \\ 0 / 3 & 0 / 3\end{array}$

$\begin{array}{ll}0 / 3 & 0 / 3 \\ 0 / 3 & 0 / 3\end{array}$

$\begin{array}{ll}0 / 3 & 0 / 3 \\ 0 / 3 & 0 / 3\end{array}$

o/11

$0 / 4 \quad 0 / 4$

$0 / 4 \quad 0 / 4$

o/1 $0 / 1$

$\begin{array}{ll}0 / 4 & 0 / 4 \\ 0 / 4 & 0 / 4\end{array}$

$0 / 3 \quad 0 / 3$

o/1 $0 / 1$

$\begin{array}{ll}0 / 4 & 0 / 4 \\ 0 / 2 & 0 / 2\end{array}$

o/1 011

o/1 $0 / 1$

$0 / 2$

$\begin{array}{ll}0 / 1 & 0 / 1 \\ 0 / 1 & 0 / 1\end{array}$

o/1 $0 / 1$

o/l $0 / 1$

$\begin{array}{ll}0 / 2 & 0 / 2 \\ 0 / 1 & 0 / 1\end{array}$

o/1 $0 / 1$

$0 / 2 \quad 0 / 2$

$0 / 2 \quad 0 / 2$

$\begin{array}{ll}0 / 2 & 0 / 2 \\ 0 / 2 & 0 / 2\end{array}$

o/2 $\quad 0 / 2$

o/2 $0 / 2$

o/2 $0 / 2$

$0 / 2 \quad 0 / 2$

$0 / 2 \quad 0 / 2$

$0 / 2 \quad 0 / 2$

$\begin{array}{ll}0 / 2 & 0 / 2 \\ 0 / 2 & 0 / 2\end{array}$

$\begin{array}{ll}0 / 2 & 0 / 2 \\ 0 / 2 & 0 / 2\end{array}$

o/2 $\quad 0 / 2$

o/2 $0 / 2$

$\begin{array}{ll}a / 2 & a / 2 \\ 0 / 2 & a / 2\end{array}$

$\begin{array}{lll}0 / 4 & 0 / 4 & 0 / 4 \\ 0 / 6 & 0 / 6 & 0 / 6\end{array}$ 
VINYL_CH TRI123 DI2CHL3 DBE12 DIOXAN14 PROPENE2 _3_3_-DI WAO

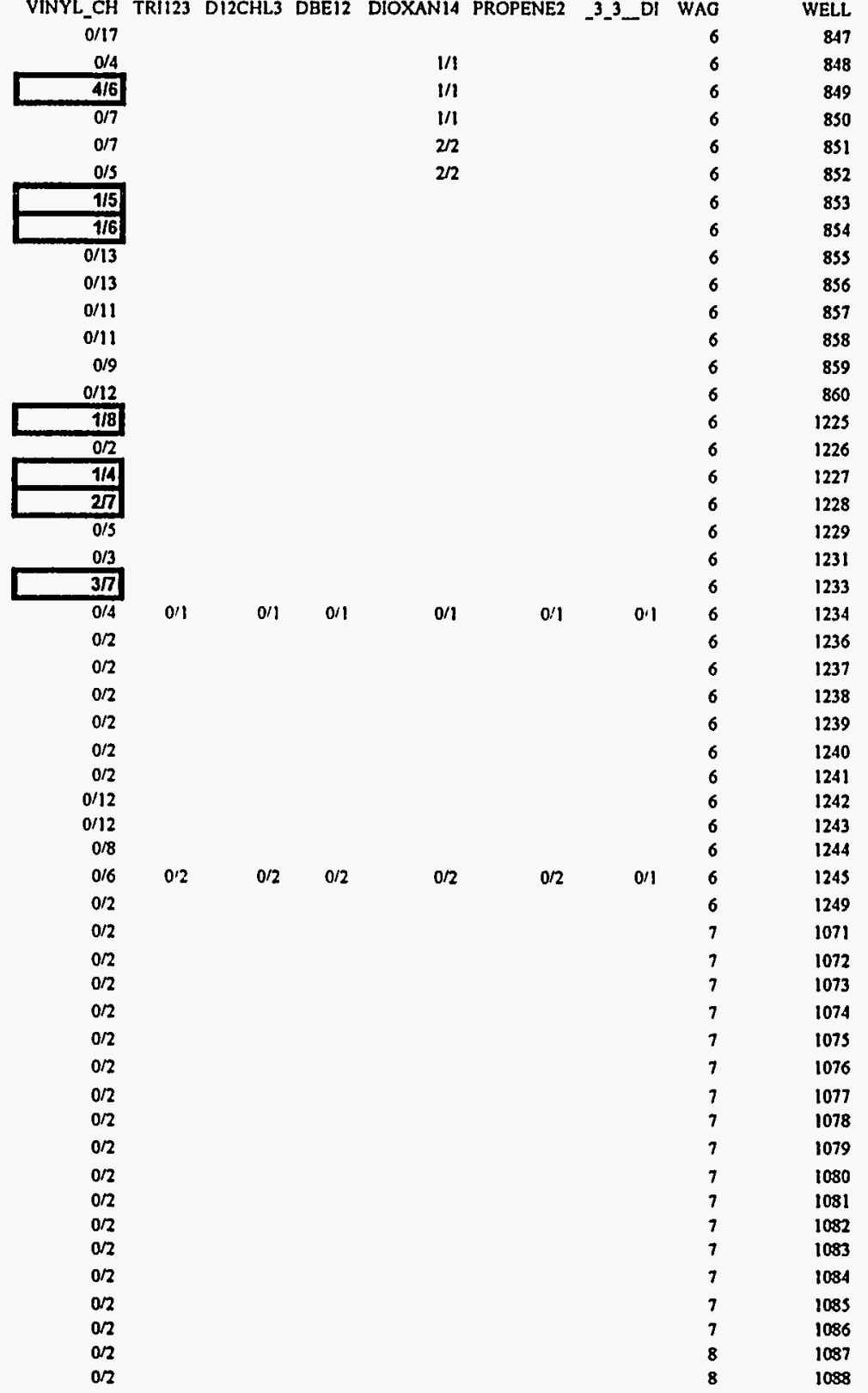




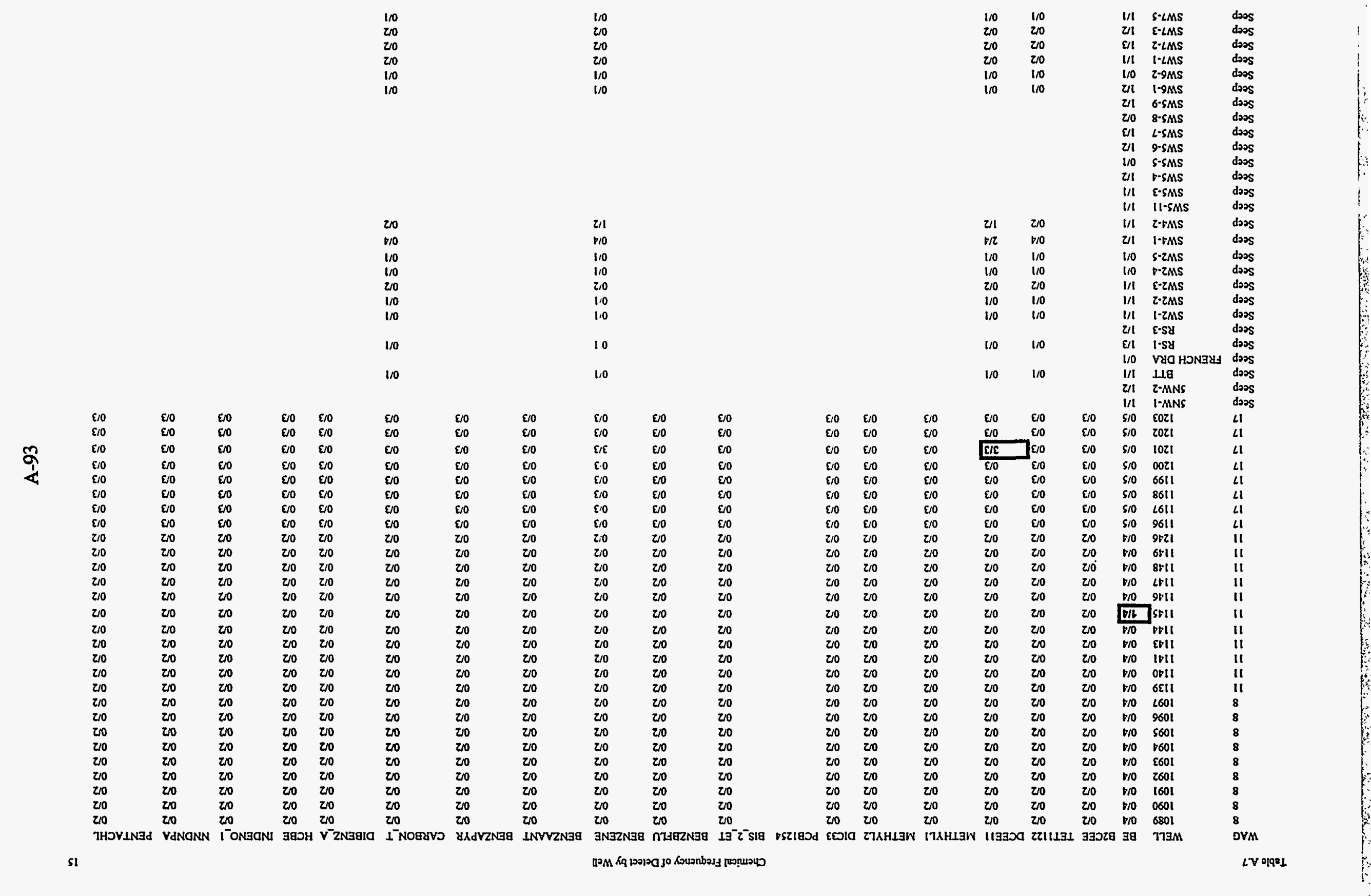




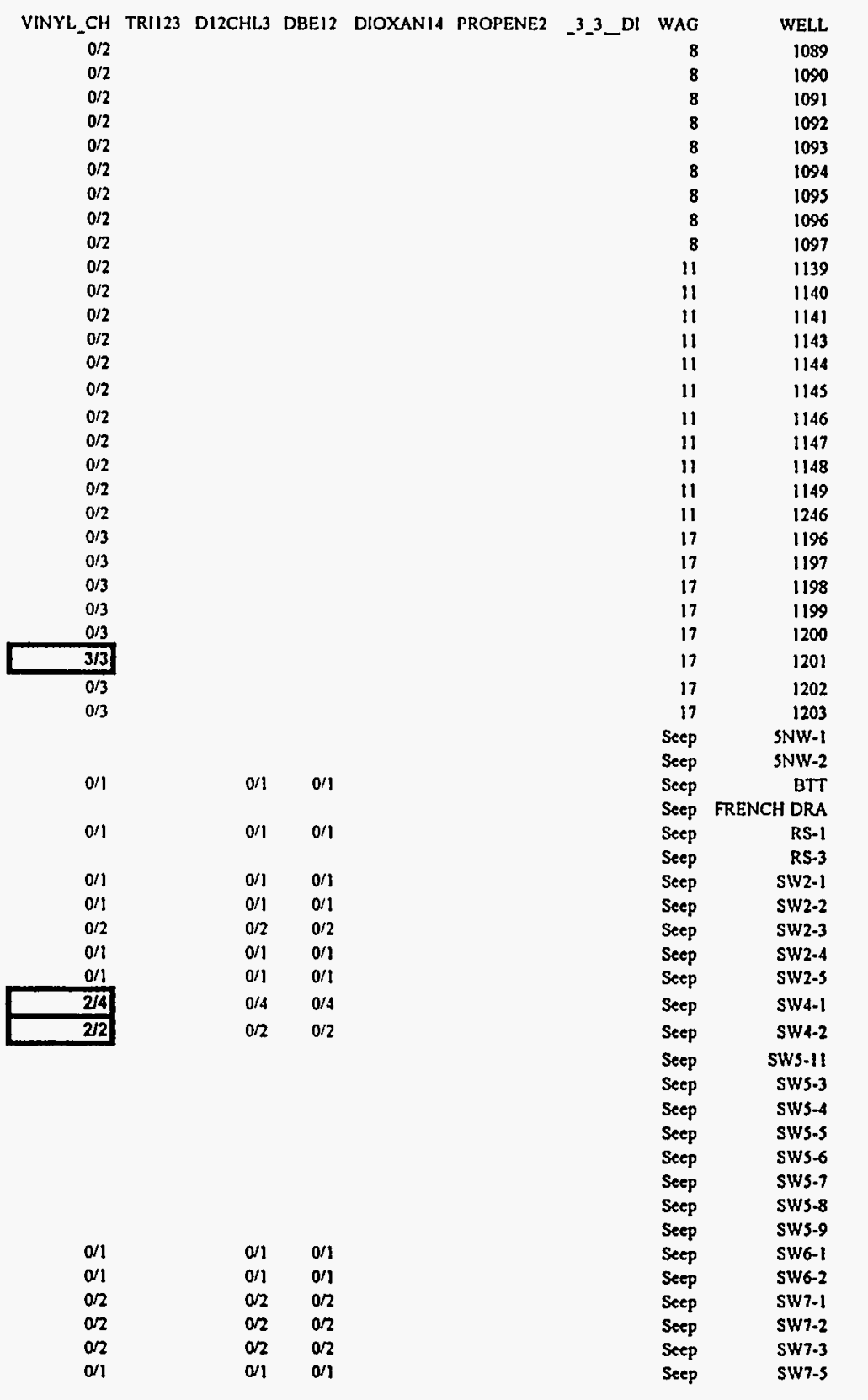




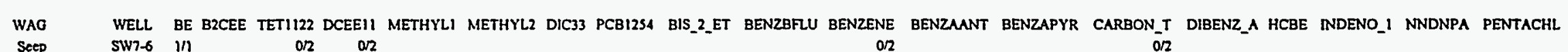
SW7-6 II $\quad 0 / 2$ O/2

$\begin{array}{llll}\text { Seep } & \text { W4TRIB-11 } & 0 / 1 & 0 / 1 \\ \text { Seep } & \text { W4TRIB-S } & 0 / 1 & 0 / 1 \\ \text { Seep } & \text { W4TRIB-7 } & 0 / 1 & 0 / 1\end{array}$

$0 / 2$
$0 / 1$
$0 / 1$

Seep WaTr

o/1 o/1

$0 / 2$
$0 / 1$
$0 / 1$
$o / 1$ 


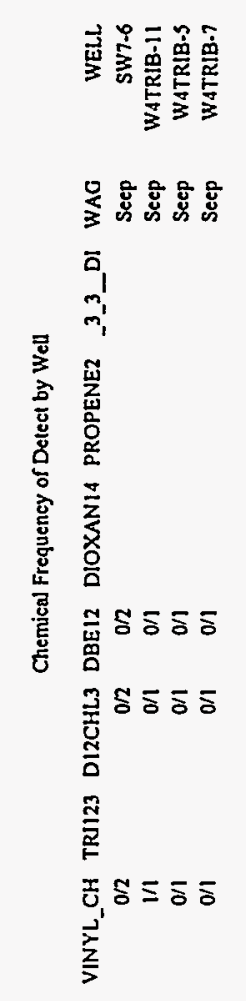


Table A.8. Table of Chemical and Radiological Abbreviations

\begin{tabular}{|c|c|}
\hline \multicolumn{2}{|l|}{ Chemicals } \\
\hline 3_3_DI & 3,3'-Dimethylbenzidine \\
\hline B2CEE & 1,1'-Oxybis[2-chloro]-ethane $\{$ Bis(2-chloroethyl)ether $\}$ \\
\hline $\mathrm{BE}$ & Beryllium \\
\hline BENZAANT & Benz[a]anthracene \\
\hline BENZAPYR & Benzo[a]pyrene \\
\hline BENZBFLU & Benz[e]acephenanthrylene $\{$ Benzo[b]fluoranthene $\}$ \\
\hline BENZENE & Benzene \\
\hline BIS_2_ET & Bis-2-ethylhexyl phthalate \\
\hline CARBON_T & Carbon tetrachloride \\
\hline $\mathrm{D} 12 \mathrm{CHL} 3^{-}$ & 1,2-Dibromo-3-chloropropane \\
\hline DBE12 & 1,2-Dibromoethane \\
\hline DCEEll & 1,1-Dichloroethene \\
\hline DIBENZ_A & Dibenz $[a, h]$ anthracene \\
\hline DIC33 & 3,3'-Dichlorobenzidine \\
\hline DIOXAN14 & 1,4-Dioxane \\
\hline HCBE & Hexachlorobenzene \\
\hline INDENO 1 & Indeno[1,2,3-cd]pyrene \\
\hline METHYL1 & 1-Methyl-2,4-dinitrobenzene $\{2,4-D i n i t r o t o l u e n e\}$ \\
\hline METHYL2 & 2-Methyl-1,3-dinitrobenzene $\{2,6-D$ initrotoluene $\}$ \\
\hline NNDNPA & N-Nitroso-Di-N-propylamine \\
\hline PCB1254 & Arochlor 1254 \\
\hline PENTACHL & Pentachlorophenol \\
\hline PROPENE2 & 2-Propenenitrile \{Acrylonitrile\} \\
\hline TET 1112 & 1,1,1,2-Tetrachloroethane \\
\hline TRII23 & 1,2,3-Trichloropropane \\
\hline VINYL CH & Vinyl chloride \\
\hline \multicolumn{2}{|c|}{ 'Commoniy used synonyms of chemical names are shown in braces \{\} . } \\
\hline \multicolumn{2}{|c|}{ Radionuclides } \\
\hline CS_137 & Cesium-137 \\
\hline RA_228 & Radium-228 \\
\hline SR_90 & Strontium-90 \\
\hline $\mathrm{TH}_{-} 228$ & Thorium-228 \\
\hline TH_230 & Thorium-230 \\
\hline TRITIUM & Tritium (H-3) \\
\hline TOTAL_RA & Total Radium \\
\hline U_234 & Uranium-234 \\
\hline AM_241 & Americium-24l \\
\hline PU_238 & Plutonium-238 \\
\hline PM_147 & Promethium-147 \\
\hline TC_99 & Technetium-99 \\
\hline PU_239 & Plutonium-239 \\
\hline PB_210 & Lead-210 \\
\hline K_- 40 & Potassium- 40 \\
\hline$\overline{C M} \_244$ & Curium-244 \\
\hline$C_{-} 14$ & Carbon-14 \\
\hline CO__60 & Cobalt- 60 \\
\hline SR_ 89 & Strontium-89 \\
\hline
\end{tabular}




\section{DISTRIBUTION}

1. F.P. Baxter

2-7. G.W. Bodenstein, DOE-ORO

8. T.O. Early

9-13. R.H. Ketelle

14. A.J. Kuhaida

15-16. D.M. Matteo

17-18. P.T. Owen

19. T.S. Purucker

20. P.A. Schrandt

21. M.F. Tardiff

22. A.S. Will

23. P.S. Wood

24. S.D. Van Hoesen

25. Central Research Library

26-28. ORNL ER Document Management Center

29. Central ER Document Management Center

30. Laboratory Records Dept.

31. ORNL Patent Section

32. Office of Assistant Manager for Energy Research and Development, DOE Oak Ridge Operations Office, P.O. Box 2001, Oak Ridge, TN 37831-8600

33. J.T. Sweeney, DOE Oak Ridge Operations Office, P.O. Box 2001, Oak Ridge, TN 37831-8541

34. Office of Scientific and Technical Information, P.O. Box 62, Oak Ridge, TN 37831 